\title{
300 Area Building Retention Evaluation Mitigation Plan
}

\section{July 2007}

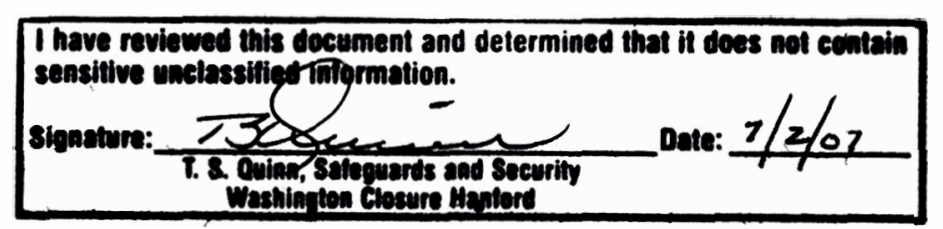

Washington Closure Hanford

Prepared for the U.S. Department of Energy, Richland Operations Office

Office of Assistant Manager for River Corridor

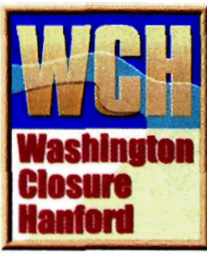


TRADEMARK DISCLAIMER

Reference herein to any specific commercial product, process, or service by trade name, trademark, manufacturer, or otherwise, does not necessarily constitute or imply its endorsement, recommendation, or favoring by the United States Government or any agency thereof or its contractors or subcontractors.

This report has been reproduced from the best available copy. Available in paper copy and microfiche.

Available for a processing fee to U.S. Department of Energy and its contractors from:

U.S. Department of Energy

Office of Scientific and Technical Information

P.O. Box 62

Oak Ridge, TN 37831-0062

(865) $576-8401$

fax: (865) 576-5728

email: reports@adonis.osti.gov

online ordering: http://www.doe.gov/bridge

Available for sale to the public, in paper, from:

U.S. Department of Commerce

National Technical Information Service

5285 Port Royal Road

Springfield, VA 22161

(800) 553-6847

fax: (703) 605.6900

email: orders@ntis.fedworld.gov

online ordering: http://www.ntis.gov/ordering.htm

Printed in the United States of America

DISCLM-5.CHP (11/99) 


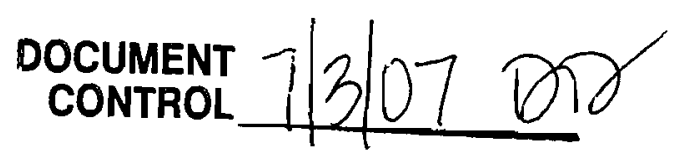

WCH-181

Rev. 0

\section{STANDARD APPROVAL PAGE}

Title:

300 Area Building Retention Evaluation Mitigation Plan

Author Name: D. J. McBride

Approval: $\quad$ M. B. Fox, WCH Project Integration
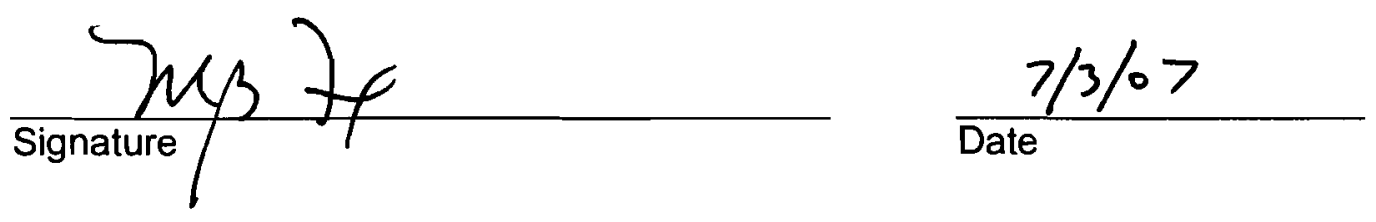

Approval: $\quad$ K. L. Kehler, D4/ISS Closure Director

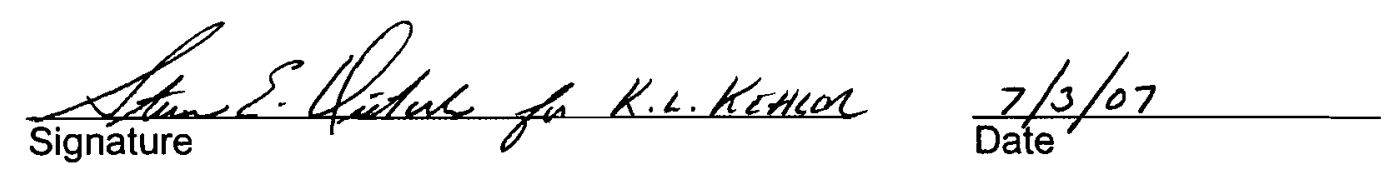

The approval signatures on this page indicate that this document has been authorized for information release to the public through appropriate channels. No other forms or signatures are required to document this information release. 

WCH-181

Rev. 0

\title{
River Corridor Closure Contract
}

\section{Area Building Retention Evaluation Mitigation Plan}

July 2007

\author{
Author: \\ D. J. McBride
}





\section{EXECUTIVE SUMMARY}

The referenced letters direct $\mathrm{WCH}$ to evaluate the long-term retention of several facilities associated with the PNNL Capability Replacement Laboratory and other Hanford mission needs. In accordance with RL direction, $\mathrm{WCH}$ prepared a mitigation plan for three scenarios with different release dates for specific buildings. The evaluations present a proposed plan for providing utility services to retained facilities in support of a long-term (+20 year) lifespan in addition to temporary services to buildings with specified delayed release dates.

The following assumptions are used for all three scenarios:

The following 300 Area facilities and underlying waste sites are retained long term (removed from the $\mathrm{WCH}$ contract):

- 318 Complex (318, 318B, 318C, MO-226)

- 325 Complex $(325,325 \mathrm{~A}, 325 \mathrm{~B}, 325 \mathrm{C}, 325 \mathrm{D}, 325 \mathrm{E})$

- 331 Building (331)

- 350 Complex (350, 350A, 350B, 350C, 350D)

- 339-A hLAN hub

- 3220 Telecommunications Hub

- 3709-A\&B Fire Station

- 312 River Pumphouse

- 3507 Microwave Tower

- 318-BA Boiler Annex

- 325-BA Boiler Annex

- 331-BA Boiler Annex

- 3508-T1, -T2, -T3 Sirens

- JCI Trailers (MO-258, MO-262, MO-263)

- 3906B Lift Station

- 3906C Monitoring Station

- 352F Electrical Substation

- 351, 351A, 351B Electrical Substation

- 3614A Monitoring Station 
Several additional facilities, not in the $\mathrm{WCH}$ contract, were identified for long-term retention and utility service:

- Subcontractor trailers (MO-675, 676, 677)

- Emergency preparedness sirens (3508-T1, -T2, -T3)

- $\quad$ Building 361

The following facilities are provided with the specified release dates for D4:

- 323

- 3730

- $3718-\mathrm{P}$

- 336

- 338

- 3760 (and 323-BA)

- 331C, 331D, 331G, 331H

- 329

- 320 (and 320-BA)
October 2007

October 2007

October 2007

October 2008

October 2008

October 2009

February 2011

February 2011

July 2011

In addition to removing the costs associated with Deactivation, Decommissioning, Decontamination and Demolition (D4) and field remediation (FR) of the retained sites, waste quantities associated with the deleted D4 facilities and waste sites were removed from the Environmental Restoration Disposal Facility (ERDF) disposal costs.

In accordance with RL direction, $\mathrm{WCH}$ worked with other contractors to identify functional requirements for utility systems to meet the operational needs of the retained and delayed release facilities. Conceptual designs and cost estimates were prepared for the necessary utility relocations. The cost estimate, $\$ 12 \mathrm{M}$ (Appendix A), was consistent with rough order of magnitude estimates prepared in support of the October 2006 submittal (Reference 2.)

The 100K Area D4, Interim Safe Storage (ISS) and FR activities (with the exception of sites already completed and the 118-K-1 Burial Ground) were removed from WCH scope in all mitigation plan scenarios per RL direction (Reference 9). Deletions included 106 D4 buildings, 
2 reactor ISS, and 87 waste sites. Waste quantities associated with these reductions were also removed from the ERDF disposal costs.

All scenarios assumed a 2.0X multiplier on the excavation quantity and cost for Contract Line Item 1 (CLIN 1) FR burial grounds remaining to go, based on observed scope increases in burial grounds remediated to date. Waste disposition costs to the ERDF were also adjusted to reflect the increased excavation quantities. Non-Site Specific Support costs for the remaining FR areas were increased by a multiplier of 1.5X. No changes were made to CLIN3 scope. Scope increases in FR and associated ERDF costs were offset by contingency reductions in the Integrated Project Baseline for this mitigation plan.

An increase to the Mission and General Support costs was also included to reflect current operational experience. These costs were included to account for added funding needs in the performance years, but they were not included in contingency and fee calculations or the final scope calculations because they do not represent an increase to the approved baseline scope.

Several ongoing Tri-Party Agreement (TPA) milestone negotiations or changes were incorporated as part of the plan assumptions. The milestones for $100 \mathrm{H}$ area remediation were assumed to change to a start milestone of October 2008, approximately a fourteen month delay. Milestones associated with IU-2 and IU-6 were assumed to be delayed to complete December 2012. Milestones associated with $100 \mathrm{~K}$ area were not considered because the scope was assumed to be removed from the RCC in this mitigation plan. The $100 \mathrm{~B} / \mathrm{C}$ waste sites were assumed to complete in December 2008. Several 300 Area milestones are affected by the building retention and were the same between the three scenarios analyzed and are discussed in the impact section below. One additional 300 Area milestone, related to the 618-7 burial ground, has been identified as at-risk due to delays in starting the high-risk excavation. The delayed completion of this site was not affected by the 300 Area mitigation plan but the delayed status is reflected in the scenarios and the TPA milestone is not met in the resulting schedules.

A funding profile of $\$ 209.5 \mathrm{M}$ for $\mathrm{FY} 2008$ and $\$ 242 \mathrm{M}$ for $\mathrm{FY} 2009$ was assumed per RL guidance (Ref. 7). 100\% funding per the RCC contract baseline was assumed for outyears. No reduction in the funding profile was assumed for the deletion of 100K or 300 Area scope. 


\section{Summary of Impacts:}

The variations between the three evaluated scenarios are the release dates for Buildings 326 and 326-BA, and the delay or retention of Building 3790:

Scenario 1. 326 and 326-BA Released October 2009 and 3790 Released February 2011 Scenario 2. 326 and 326-BA Released February 2011 and 3790 Released February 2011 Scenario 3. 326 and 326-BA Released February 2011 and 3790 Retained Long-Term.

The majority of the impacts are the same between Scenarios 1, 2, and 3 and will be discussed as a group. The specific differences between the scenario impacts are limited to the total cost and schedule impact and are described separately for each scenario. A detailed discussion of the impacts is provided in Sections 5, 6, and 7.

- Removal of the 300 Area facilities and waste sites from the $\mathrm{WCH}$ contract resulted in a direct reduction to the Baseline Target Cost of $\$ 65$ million (\$89 million including contingency and escalation.)

- Removal of the $100 \mathrm{~K}$ Area facilities and waste sites from the WCH contract resulted in a direct reduction to the Baseline Target Cost of $\$ 93$ million (\$125 million including contingency and escalation).

- A conceptual design and cost estimate were prepared for utility relocations in support of the retained and delayed facilities. The total cost for the utility relocations was estimated at approximately $\$ 12 \mathrm{M}$ including contingency (Appendix $\mathrm{A}$ ). The escalated cost estimate is \$12.7M. The utility relocation costs were spread from FY 2008 through FY 2011 as described in Section 4 to optimize the construction schedule since no added funding was provided by $\mathrm{RL}$ in the mitigation planning.

- Tri-Party Agreement (TPA) milestone impacts from the mitigation plan were limited to those sites already identified for changes as discussed above for the100 areas, and 300 area milestones directly affected by the retention of waste sites or buildings identified in milestones. The following 300 Area milestones are affected: 
M-016-00: Complete Remedial Actions for all non-Tank Farms Operable Units by 9/30/2024.

Impact: Waste sites underlying the retained facilities or retained active utility systems will not be completed as part of the RCC scope. They will be deferred until the retained facilities are vacated (20+ years).

M-016-00B: Complete all interim 300 Area remedial actions including the 618-10 and 618-11 burial grounds by 9/30/2018.

Impact: Waste sites underlying the retained facilities or retained active utility systems will not be completed as part of the RCC scope. They will be deferred until the retained facilities are vacated (20+ years).

M-016-69: Complete all interim 300 Area remedial actions to include confirmatory sampling of all candidate sites listed in the 300-FF-2 ROD (except 618-10 and 618-11 burial grounds) by 9/30/2015.

Impact: Waste sites underlying the retained facilities or retained active utility systems will not be completed as part of the RCC scope. They will be deferred until the retained facilities are vacated (20+ years).

M-016-74: Complete interim remediation(to include excavation, loadout, closeout sampling, backfill and revegetation), for all 300 Area "inside the fence" waste sites north of Apple Street, except for the 300-RLWS, 300-15, 300-4, 300-268 and 300-123 waste sites remediation need only be completed through excavation and loadout by 9/30/2012. Impact: Waste site 300-4 and portions of 300-RLWS and 300-15 are retained and should be removed from the milestone.

M-094-00: Complete disposition of 300 Area surplus facilities to be defined as the 220 facilities listed in the Hanford River Corridor Closure Contract Solicitation \#DE-RP0604RL14655 by 9/30/2015.

Impact: Milestone reference to 220 facilities and reference to \#DE-RP06-04RL14655 are outdated. By updating the references the existing milestone for "surplus" facilities (excluding the retained facilities) can be met. 
M-094-06, -07, -08, 09: Complete the selected removal and/or remedial actions that are selected for XX of the following 19 high priority facilities: 305B, 306E, 306W, 307 Retention Basins, 308, 309, 321, 323, 324, 324B, 325, 326, 327, 329, 333, 340, 3706, 307 Trench and 3720. (Multiple dates for different numbers of buildings completed) Impact: Editorial impact, 325 building should be deleted and total number of facilities reduced. Each of the specific milestones can be met with no impact.

Scenario-specific Impacts: Scenario 1. 326 and 326-BA Released October 2009 and 3790 Released February 2011

- $\mathrm{WCH}$ was able to mitigate the impacts of the delayed release facilities and added scope to avoid a critical path impact to the end date of the RCC contract. This avoids a "hotel load" (time-related cost) impact to the scenario. However, this mitigation plan does not reflect an equitable adjustment to performance fee to account for the favorable variance status (ahead of schedule and under budget) through 2007 that enabled the successful mitigation.

- Total impact of Scenario 1 resulted in a net Baseline Target Cost decrease of $\$ 220$ million (including contingency, escalation, fee, pension, and added utility scope) and no change to the RCC completion date of August 29, 2013.

Scenario -specific Impacts: Scenario 2. 326 and 326-BA Released February 2011 and 3790 Released February 2011

- $\mathrm{WCH}$ was able to mitigate the impacts of the delayed release facilities and reduce the impact from the 17 months delayed release of Building 326 to a critical path impact of 6 weeks to the end date of the RCC contract. This minimized the "hotel load" (time-related cost) impact to the scenario. However, this mitigation plan does not reflect an equitable adjustment to performance fee to account for the favorable variance status (ahead of schedule and under budget) through 2007 that enabled the successful mitigation.

- Total impact of Scenario 2 resulted in a net Baseline Target Cost decrease of \$205 million (including contingency, escalation, fee, pension, utility scope, and hotel loads) and a change to the RCC completion date from August 29, 2013 to October 15, 2013. 


\section{Scenario-specific Impacts: Scenario 3. 326 and 326-BA Released February 2011 and} 3790 Retained Long-Term

- $\mathrm{WCH}$ was able to mitigate the impacts of the delayed release facilities and reduce the impact from the 17 months delayed release of Building 326 to a critical path impact of 6 weeks to the end date of the RCC contract. This minimized the "hotel load" (time-related cost) impact to the scenario. However, this mitigation plan does not reflect an equitable adjustment to performance fee to account for the favorable variance status (ahead of schedule and under budget) through 2007 that enabled the successful mitigation.

- Total impact of Scenario 3 resulted in a net Baseline Target Cost decrease of \$206 million (including contingency, escalation, fee, pension, utility scope, and hotel loads) and a change to the RCC completion date from August 29, 2013 to October 15, 2013.

\section{Conclusion}

Figure ES-1 provides a summary of the evaluations for the identified scenarios. $\mathrm{WCH}$ recommends proceeding with the definitive design and construction phase of the utility relocation project. Any of the three mitigation scenarios appear to be viable depending on the Government's needs regarding facilities 326 and 3790 .

All scenarios result in impacts to the long-term configuration of waste sites remaining in the 300 Area, since there are waste sites associated with the retained facilities and utility systems that will be inaccessible for the assumed 20-year duration of facility occupancy. TPA milestones associated with the retained 300 Area facilities and waste sites will require renegotiation to reflect the changed scope.

Figure ES-2 provides a map of the planned configuration of the 300 area utility systems and the retained and delayed release facilities. 
Figure ES-1. Mitigation Plan Results Summary.

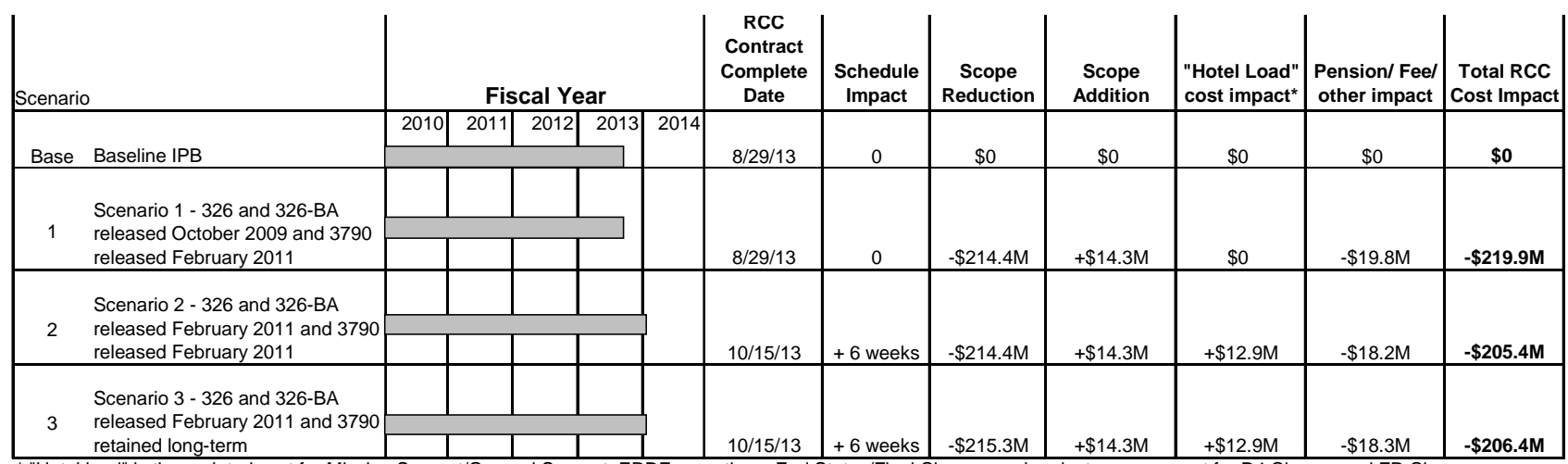

* "Hotel load" is time-related cost for Mission Support/General Support, ERDF operations, End States/Final Closure, and project management for D4 Closure and FR Closure. 
Figure ES-2. 300 Area Building Retention Evaluation.

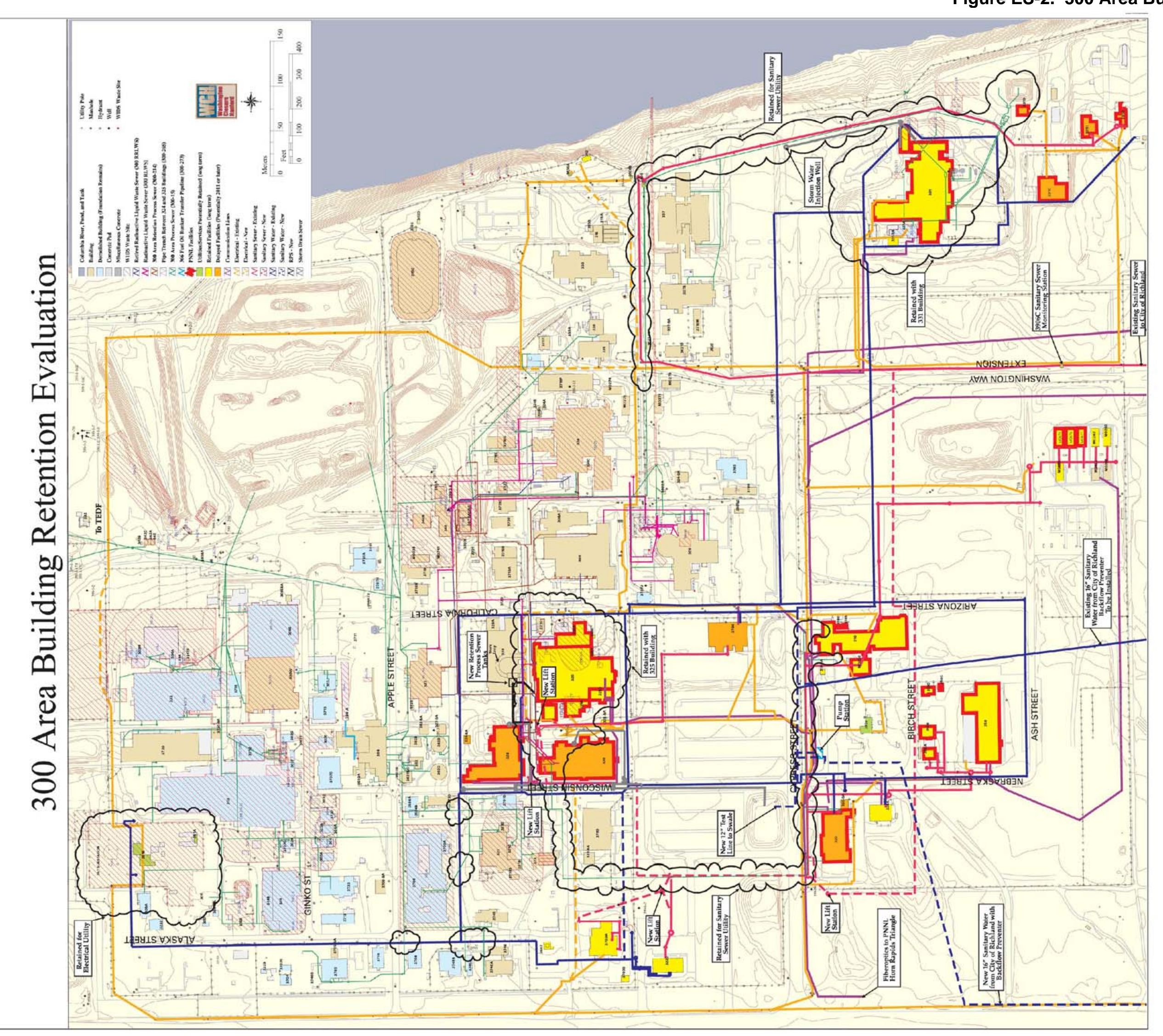




\section{TABLE OF CONTENTS}

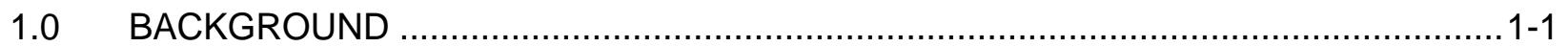

2.0 SCHEDULE ASSUMPTIONS/RL GUIDANCE ................................................... $2-1$

3.0 MITIGATION PLAN METHODOLOGYIAPPROACH .........................................

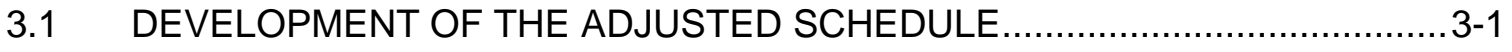

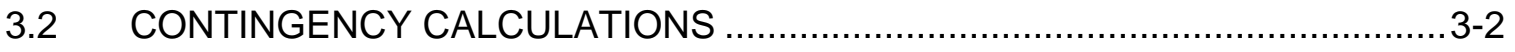

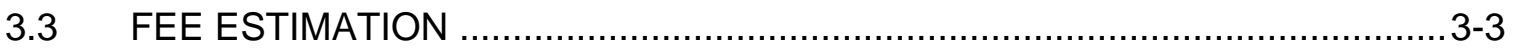

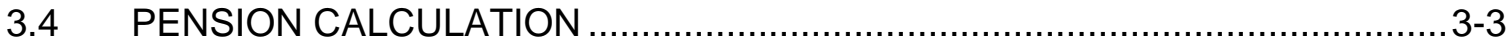

4.0 UTILITY RELOCATION PROJECT SUMMARY .............................................

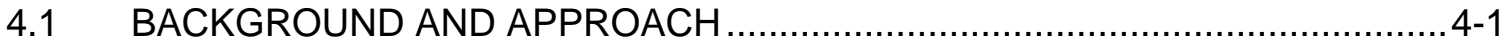

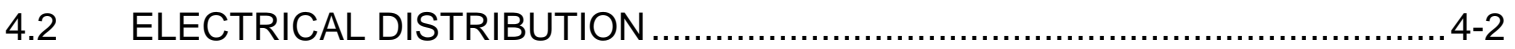

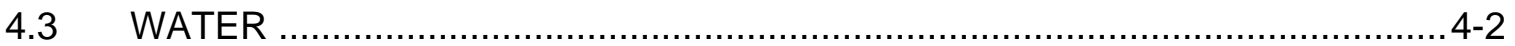

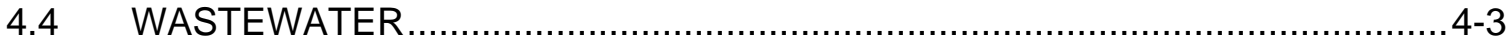

4.4.1 Sanitary Sewer ........................................................................ 4

4.4.2 Process Sewer............................................................................

4.4.3 Retention Process Sewer .......................................................... 4

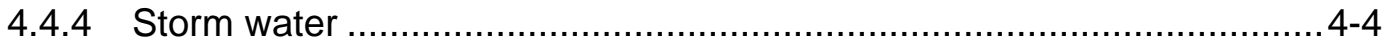

4.5 INFORMATION TECHNOLOGY ........................................................... $4-4$

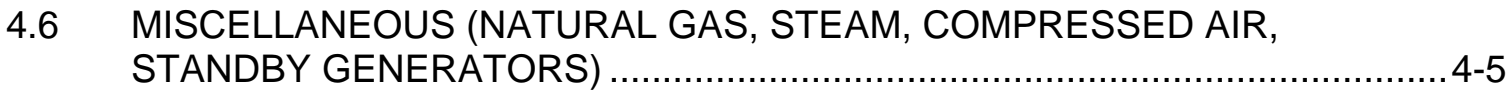

4.7 CONSTRUCTION SCHEDULE/PRIORITIZATION ..................................... $4-5$

5.0 SCENARIO 1: RETENTION AND RELEASE DATES AS SPECIFIED

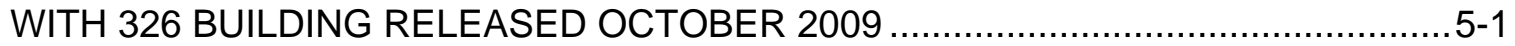

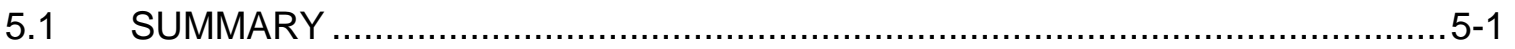

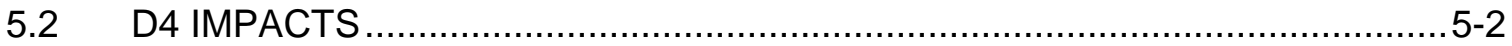

5.3 FIELD REMEDIATION IMPACTS ….....................................................

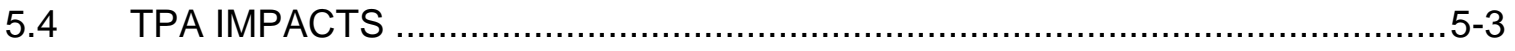

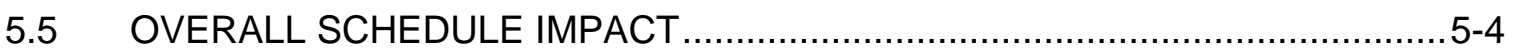

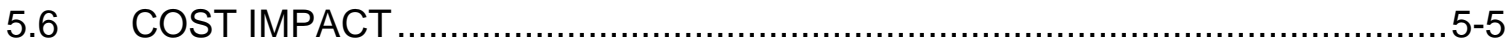


6.0 SCENARIO 2: RETENTION AND RELEASE DATES AS SPECIFIED WITH 326 BUILDING RELEASED FEBRUARY 2011

6.1 SUMMARY

6.2 D4 IMPACTS

6.3 FIELD REMEDIATION IMPACTS

6.4 TPA IMPACTS

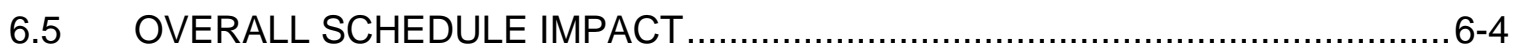

6.6 COST IMPACT.

7.0 SCENARIO 3: SAME AS SCENARIO 2 WITH LONG-TERM RETENTION OF BUILDING 3790

7.1 SUMMARY

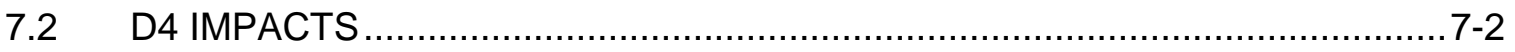

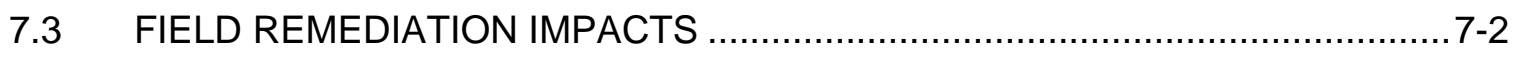

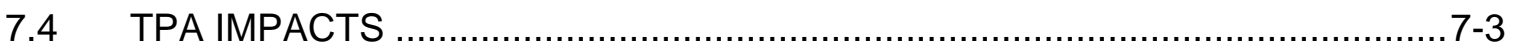

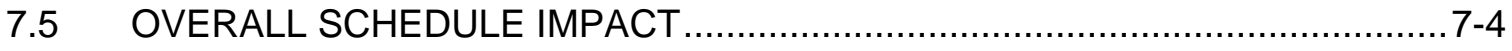

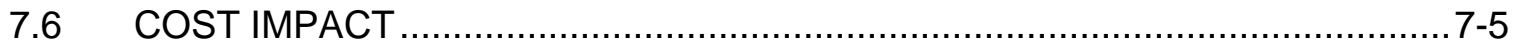

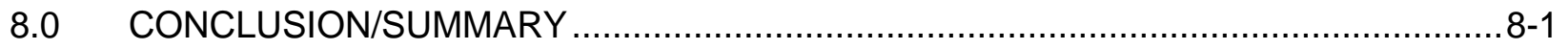

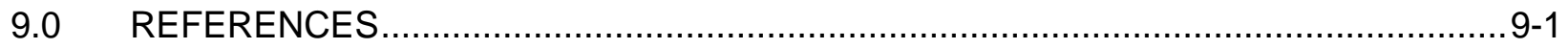

\section{APPENDICES}

A $\quad 300$ AREA UTILITY RELOCATION PROJECT COST ESTIMATE ................................A-i

B 300 AREA ELECTRICAL UTILITY RELOCATION PROPOSALS AND COST

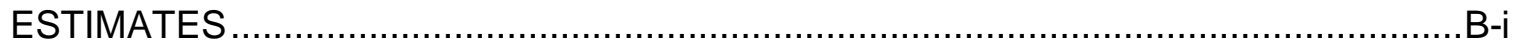

C $\quad 300$ AREA ELECTRICAL UTILITY DECISION MEETING .................................... C-i

D 300 AREA SANITARY AND FIRE PROTECTION WATER DECISION MEETING ....... D-i

E 300 AREA SANITARY AND FIRE PROTECTION WATER CONCEPTUAL DESIGN....E-i

F $\quad 300$ AREA WASTEWATER SUMMARY …...................................................... F-i

G $\quad 300$ AREA SANITARY SEWER DECISION MEETING ........................................ G-i

$\mathrm{H} \quad 300$ AREA SANITARY SEWER CONCEPTUAL DESIGN $\ldots \ldots \ldots \ldots \ldots \ldots \ldots \ldots \ldots \ldots \ldots \ldots . . . \mathrm{H}-\mathrm{i}$

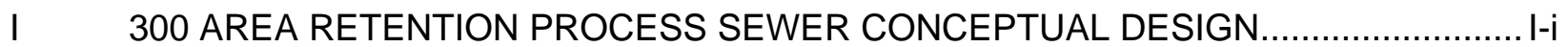

$\mathrm{j} \quad 300$ AREA STORM WATER CONCEPTUAL DESIGN …........................................... J-i

$\mathrm{K} \quad 300$ AREA INFORMATION TECHNOLOGY DECISION MEETING ...........................

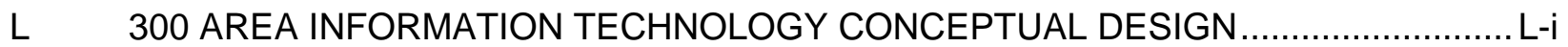

M FIELD REMEDIATION IMPACT FROM RETAINED UTILITIES ................................

$\mathrm{N} \quad \mathrm{SCENARIO} 1$ VARIANCE SCHEDULE...........................................................

O SCENARIO 2 VARIANCE SCHEDULE

P SCENARIO 3 VARIANCE SCHEDULE.......................................................... 


\section{FIGURES}

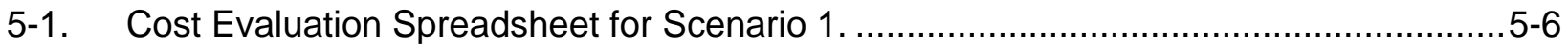

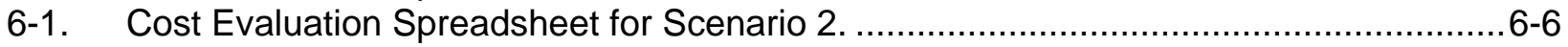

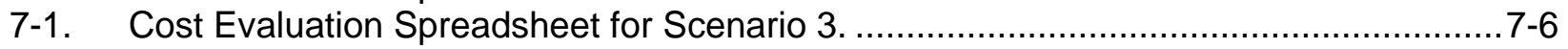


WHC-181

Table of Contents

Rev. 0 


\subsection{BACKGROUND}

The Washington Closure Hanford (WCH) River Corridor Closure (RCC) scope includes the deactivation, decommissioning, decontamination and demolition (D4) of 210 buildings located in the Hanford 300 Area, followed by field remediation of waste sites in the affected areas. Thirteen facility complexes in this area are currently occupied by the Pacific Northwest National Laboratory (PNNL) and have a delayed release to $\mathrm{WCH}$. The RCC contract specifies a release date of October 1, 2009 for turnover of these facilities. However, the U.S. Department of Energy, Richland Operations Office $(\mathrm{RL})$ has informed $\mathrm{WCH}$ that the replacement laboratory facilities that will be used to relocate PNNL's activities will not be ready for occupancy by the 2009 release date and changes to the $\mathrm{WCH}$ contract will be necessary. Several of the facilities will be retained by PNNL long-term (assumed $>20$ years) and several support facilities will be retained by other Hanford contractors such as the Project Hanford Management Contractor (PHMC), future Mission Support Contractor (MSC), or Johnson Controls, Inc. (JCI).

WCH and PNNL have jointly identified opportunities for the early release of several of the PNNL facilities that could reduce the impact of delays for the remaining facilities.

Several scenarios have been specified by RL for evaluation in a mitigation plan. The scenarios vary in defining transfer dates for several of the facilities. In all scenarios, RL directed WCH to proceed with activities necessary to reroute utilities for the long-term retention facilities identified by RL. This document provides the mitigation plan to identify and reduce impacts to the RCC Contract from integration of the utility relocation scope with the RCC scope for facilities and waste sites that will still undergo remediation in the 300 Area. The plan also provides a summary of the conceptual designs and cost estimates prepared for the utility relocation project.

Existing utility services or components will be used provided they do not require removal, relocation or replacement due to planned remediation or demolition activities, and that they provide a reasonable expectation of service life compatible with the planned 20-year occupancy of several of the identified facilities. The utility system requirements include Electrical; Potable/Fire Protection Water; Wastewater (Sanitary, Process, Retention Process, and Storm water); Information Technology (IT)/Telecommunications; and other miscellaneous services such as natural gas, steam, and compressed air. No changes are required for natural gas, steam, and compressed air services (utility needs for the steam boilers themselves are provided as part of the utility relocations for the buildings served by the steam boilers) so the four main utility categories discussed in this plan will be electrical, water, wastewater, and IT. 
WCH-181

Background

Rev. 0 


\subsection{SCHEDULE ASSUMPTIONS/RL GUIDANCE}

$\mathrm{RL}$ has provided multiple letters of direction to $\mathrm{WCH}$ identifying assumptions or direction for this mitigation plan.

Reference 1 requested a precursor evaluation of the cost impacts and mitigation opportunities for the proposed long-term retention of the 318, 325, 331 and 350 complexes, along with 3220, 339A, and 3709A\&B and several other structures. WCH provided the requested evaluation (Reference 2) and recommended proceeding with a more comprehensive conceptual design and mitigation planning effort.

Reference 3 directed $\mathrm{WCH}$ to prepare a mitigation plan with three scenarios. All scenarios would include a list of buildings for long-term retention and several facilities with specified release dates. The differences between the three scenarios were the release dates for buildings $326,326-\mathrm{BA}$, and 3790 , as follows:

Scenario 1. 326, 326-BA released October 2009; 3790 released February 2011 Scenario 2. 326, 326-BA released February 2011; 3790 released February 2011 Scenario 3. 326, 326-BA released February 2011; 3790 retained long term

Reference 4 provided supplemental guidance clarifying RL's expectations for utility systems, directing the completion of utility relocations by the end of fiscal year 2009 and the preparation of additional mitigation plan scenarios where RL would provide additional funding (\$3M per year) for the utility relocation scope. Reference 4 also provided a draft functional requirements document from PNNL for the utility needs of the retained facilities. $\mathrm{WCH}$ was directed to work with the other contractors to validate and revise the functional requirements document as appropriate. WCH subsequently prepared a combined functional requirements document (Reference 6) working with PNNL, Fluor Hanford, and Johnson Controls, Inc.

Reference 5 notified $\mathrm{WCH}$ that the long-term retention of ancillary facilities at the 331 Complex (331-C. 331-D. 331-G, 331-H, and 331-P) is not planned by the Pacific Northwest Site Office (PNSO) and that the mitigation plan should assume their turnover in February 2011. It should be noted that 331-P is not currently in the RCC contract and a minor contract change will be needed to add it at a later date. (There is no impact to the utility relocations or mitigation sequencing from the addition although the demolition cost for 331-P is not included in the mitigation plan.)

Reference 7 provided guidance for $\mathrm{WCH}$ to assume a reduced funding level for FY 2008 $(\$ 209,527 \mathrm{~K})$, lower than the level identified in the RCC contract. The letter identified a funding level of $\$ 242,000 \mathrm{~K}$ for FY09, equal to the $100 \%$ funding level identified in the RCC contract.

Reference 8 rescinded the direction to prepare additional scenarios that assumed added funding for utility relocations, and provided an extension to the assumed completion date for utility relocations to the end of fiscal year 2011 or the date of transfer for the last delayed release PNNL facility, whichever comes first.

Reference 9 directed WCH to remove facilities and waste sites at the $100 \mathrm{~K}$ area from the baseline in the mitigation planning scenarios. 
Reference 10 directed $\mathrm{WCH}$ to assume a further delay in the release date of Building 320 , to approximately July 2011 instead of February 2011.

The combination of References 1 through 10 resulted in the following set of assumptions used in this mitigation plan.

The following 300 Area facilities and underlying waste sites are retained long term (removed from the $\mathrm{WCH}$ contract):

- 318 Complex $(318,318 \mathrm{~B}, 318 \mathrm{C}, \mathrm{MO}-226)$

- 325 Complex (325, 325A, 325B, 325C, 325D, 325E)

- 331 Building (331)

- 350 Complex (350, 350A, 350B, 350C, 350D)

- 339-A hLAN hub

- 3220 Telecommunications Hub

- 3709-A\&B Fire Station

- 312 River Pump house

- 3507 Microwave Tower

- 318-BA Boiler Annex

- 325-BA Boiler Annex

- 331-BA Boiler Annex

- 3508-T1, -T2, -T3 Sirens

- $\mathrm{JCl}$ Trailers (MO-258, MO-262, MO-263)

- 3906B Lift Station

- 3906C Monitoring Station

- 352F Electrical Substation

- 351, 351A, 351B Electrical Substation

- 3614A Monitoring Station

Several additional facilities, not in the $\mathrm{WCH}$ contract, were identified for long-term retention and utility service:

- Subcontractor trailers (MO-675, 676, 677)

- Emergency preparedness sirens (3508-T1, -T2, -T3)

- Building 361

The following facilities are provided with the specified release dates for D4:

- 323

- 3730

- 3718-P

- 336

- 338

- 3760 (and 323-BA)

- 331C, 331D, 331G, 331H

- 329

- 320 (and 320-BA)
October 2007

October 2007

October 2007

October 2008

October 2008

October 2009

February 2011

February 2011

July 2011 
106 D4 buildings, 2 Reactor ISS, and 87 waste sites at the $100 \mathrm{~K}$ area are removed from the WCH contract.

Utilities will be provided to the retained facilities with completion of utility relocations not later than July 2011 (date of release of Building 320).

A funding level of $\$ 209,527 \mathrm{~K}$ is assumed for FY 2008 and $100 \%$ funding levels per the RCC contract are assumed for subsequent years.

Using these summarized assumptions, three separate scenarios are evaluated:

Scenario 1. 326, 326-BA released October 2009; 3790 released February 2011 Scenario 2. 326, 326-BA released February 2011; 3790 released February 2011

Scenario 3. 326, 326-BA released February 2011; 3790 retained long term

The results of the scenario evaluations are provided in Sections 5, 6, and 7 of this plan. 


\subsection{MITIGATION PLAN METHODOLOGYIAPPROACH}

\subsection{DEVELOPMENT OF THE ADJUSTED SCHEDULE}

The mitigation plan was prepared by first developing a conceptual design for each of the four main utility systems needed in accordance with the functional requirements and design criteria for retained facilities (Reference 5). Appendices B through $L$ provide the conceptual design development background and summaries for the selected utility relocation options. Cost estimates for the recommended utility options were prepared (Appendix A) and time-phased to match the necessary sequence of activities in support of facility and waste site remediation. The time-phasing of the utility cost estimate is described in Section 4.

A copy of the Integrated Project Baseline (IPB), statused through March 2007, was used as the basis for the mitigation planning effort. The statused IPB was used to reflect project progress and account for the ahead-of-schedule demolition of numerous structures, particularly in the 300 Area, that has been accomplished to date. The majority of the facilities that were originally planned in the IPB for completion in FY07-FY09 have already been completed, leaving some opportunity for the movement of additional scope such as utility relocations into the IPB while reducing the impact on the project funding profile. The statused IPB reflects some logic and sequencing changes from the provisionally approved IPB caused by work being started or completed early, or uncompleted work being pushed by the data date in the Primavera P3 schedule.

Adjustments were made to the Primavera P3 schedules in the IPB to delete facilities and waste sites being removed from the RCC baseline as discussed in Section 3. In addition, constraint dates were introduced or adjusted for the specified delayed release facilities.

Additional adjustments were made to reflect observed scope increases in field remediation of burial ground waste sites. Consistent with performance to date, a 2.0 times increase was assumed for both the cost and quantity of excavation, loadout and waste disposal for burial grounds remaining "to go" in Contract Line Item (CLIN) 1 above assumed quantities provided in Table B.2 of the RCC contract. These adjustments were then offset by reducing the contingency work scope identified in the IPB. No adjustments were made for CLIN 3 scope.

A separate $25 \%$ increase was assumed for both the duration and the cost (but not the excavated quantity) for sixteen waste sites in the 300 Area that were evaluated as having added complexity due to the presence of active utility systems in the 300 Area beyond the timeframes assumed in the IPB (Appendix M). The affected sites did not include any burial grounds so there were no sites that received both a $2 X$ increase and a $25 \%$ increase.

An increase to the Mission and General Support costs was also included to reflect current operational experience. These costs were included to account for added funding needs in the performance years, but they were not included in contingency and fee calculations or the final scope calculations because they do not represent an increase to the approved baseline scope.

A cost loading report was generated from the adjusted P3 schedules and compared against the funding profiles specified in the RCC contract. Funding levels of $\$ 209.5 \mathrm{M}$ for FY 2008 and \$242M for FY 2009 were assumed per Reference 7 and 100\% funding per the RCC contract was assumed for outyears. No reduction in the funding profile was assumed for the deletion of $100 \mathrm{~K}$ or 300 Area scope. Where the initial cost loading reports resulted in a funding shortfall, 
scope was moved in the adjusted P3 file to balance the funding profile including the added utility scope and the cost loading report was regenerated. Multiple iterations were performed until an acceptable balanced profile was obtained and overall impacts to the RCC schedule and TPA milestones were minimized.

Contingency, fee and pension were calculated for each scenario as described in sections 3.2 through 3.4 .

The process was repeated for each of the evaluation scenarios.

Results of the mitigation evaluations are provided in Sections 5 through 7.

\subsection{CONTINGENCY CALCULATIONS}

Contingency was calculated as follows:

- Burial Grounds and Non-Site Specific Support Estimate At Completion (EAC) and Waste Operations - Assumes quantity growth (2X) on the excavation scope for CLIN1 FR burial grounds remaining to go. The cost of the increased excavation scope (and ERDF disposal) was offset by a corresponding reduction (drawdown) of the contingency pool. However, because up to $15 \%$ of this growth falls within the contractual definition of Differing Site Conditions, and the other would become consideration for a Request for Equitable Adjustment (REA), 5\% contingency has been calculated on the scope for the increased quantities (compared to the average 10.9\% from the Integrated Project Baseline).

- FR Impact from Retained Utilities - Adjustments made to Field Remediation excavation estimates due to utility isolations, etc., impacting the complexity of sixteen 300 Area waste sites that would have otherwise been unimpeded by active utilities in the baseline. The Integrated Project Baseline average of $10.9 \%$ was applied to the increased excavation cost.

- Mission Support/General Support EAC - No contingency was applied to the Mission Support/General Support EAC because it does not represent added scope.

- Hotel Load for Schedule Extension - The Integrated Project Baseline average of 10.9\% was applied.

- Remove K Area ISS, D4, FR and Waste Operations - The Integrated Project Baseline average of $10.9 \%$ was applied (deleted) for the reduced scope.

- Remove PNNL Buildings, Ancillary Facilities, Waste Sites and Waste Operations - The Integrated Project Baseline average of $10.9 \%$ was applied (deleted) for the reduced scope.

- Utility Relocation Project - A contingency value of $30 \%$ was applied to the estimate (Appendix A). 


\subsection{FEE ESTIMATION}

Fee was estimated as follows:

- In the Integrated Project Baseline fee was calculated at $7 \%$ of direct cost, contingency, and escalation (Target Cost). The same methodology was applied to develop a fee reduction estimate for this Mitigation Plan. The resulting reduction in fee was then subtracted from the fee assumed in the IPB, \$142.8M.

- This calculation was performed to estimate the appropriate annualized spread of fee to represent the annual funding needs of the project. However, the resulting fee does not include equitable adjustment for ahead-of-schedule project status through March 2007 (the data date used in the IPB for the mitigation plan exercise) which enabled the mitigation of additional scope being inserted in the IPB. This mitigation plan does not constitute a Request for Equitable Adjustment.

An example of the fee estimate calculation for Scenario 2 is demonstrated below:

Scope Adjustments:

Reductions:

Removal of K Area, ISS, D4, FR and Waste Operations component

Removal of PNNL Buildings, Ancillary Facilities, Waste Sites and

Waste Operations Component

Additions:

FR Impacts from Retained Facilities

Hotel Load on Schedule Extension

Utility Relocation Project

Contingency \& Escalation

Delta Target Cost

Delta Fee $(0.07 * \$ 182.1 \mathrm{M})$

Total Fee (\$142.8M - \$12.8M)

$\$ 130 \mathrm{M}$

\subsection{PENSION CALCULATION}

Pension was calculated as follows:

A factor of 0.01460136148373137 times the net change in direct cost after all additions and deletions of scope was calculated for each fiscal year. Each year's change in pension was escalated and summed to represent an overall pension change. The change in pension was then subtracted from the pension assumed in the original IPB (\$27.6M). 


\subsection{UTILITY RELOCATION PROJECT SUMMARY}

\subsection{BACKGROUND AND APPROACH}

Development of an effective mitigation plan for long-term retention of selected 300 Area facilities required $\mathrm{WCH}$ to develop conceptual designs and cost estimates for the utility systems needed to serve the retained and delayed-release facilities. Pre-conceptual designs and rough order of magnitude cost estimates were developed in support of the October 2006 evaluation (Reference 2), and a draft functional requirements document from PNNL was provided by RL in Reference 4.

In late February through March 2007, WCH kicked off the design effort and conducted a workshop with participation from PNNL, Fluor Hanford, Lockheed Martin, JCl, RL, and PNSO to establish agreed-upon requirements and design criteria for the utility relocation project. A "core team" of key representatives of the responsible organizations was identified, and "functional teams" of technical staff were assigned including staff from the affected facilities, $\mathrm{WCH}$, and subcontracted engineering support staff. Functional teams were established for each of four areas: Electrical, Water, Wastewater, and IT/Miscellaneous. The functional teams used the initial PNNL functional requirements document (Reference 4) as a starting point, and worked to identify a requirements-based set of criteria for use in the design phase. The Project Manager synthesized the inputs from each of the design teams into a combined Functional Requirements and Design Criteria document, 0300X-DC-G0001 which was reviewed by the Core Team, issued in the WCH document control system and transmitted to RL (Reference 5).

With support from subcontracted engineering staff, each of the functional teams developed preconceptual designs for the utility systems in their area of responsibility. In some cases multiple design options were identified because the RL guidance in Reference 3 was different than some of the assumptions used in the October 2006 evaluation, including the need to evaluate use of existing systems as an alternative to replacement. The WCH estimating department developed cost estimates for each of the design options. The Core Team and functional teams then reviewed each of the design options and cost estimates to select a recommended option for each utility system. Conceptual designs were developed for each of the selected options and a summary cost estimate was prepared for the utility relocation project (Appendices A-L).

The recommended utility system modifications identified during the conceptual design phase of the utility relocation project include the following systems which will be discussed further in this section:

- Electrical distribution (currently provided by the 351 substation)

- Potable water/fire water (currently provided by the 382 Water Complex)

- Wastewater systems including sanitary wastewater, process sewer, retention process sewer, and storm water

- Information Technology/telecommunications systems.

For each of the utility systems, a description of the planned approach and associated assumptions are provided below. 
The cost estimate for providing the necessary utility service modifications for the retained facilities is $\$ 12$ million as detailed in Appendix $A$.

\subsection{ELECTRICAL DISTRIBUTION}

Electrical power is currently distributed to the 300 Area facilities from the 351 substation in the northwest corner of the 300 Area. The primary distribution system uses $13.8 \mathrm{kV}$ and a backup $2400 \mathrm{~V}$ system provides service to several facilities. Three of the retained facilities require a dual source of electrical power: the 325 building (currently served by $13.8 \mathrm{kV}$ and $2400 \mathrm{~V}$ ), the 312 pump house (currently served by $13.8 \mathrm{kV}$ and 2400V), and the 331 Building (currently served by two $13.8 \mathrm{kV}$ sources). The recommended option is to retain the existing 351 substation and the majority of the distribution infrastructure. (Appendices B and C). However, several modifications are required to support reconfiguration of the electrical distribution system to a smaller footprint, elimination of several features scheduled for demolition as part of the RCC contract, and elimination of interferences with planned remediation activities. Four main modification activities are identified: North power feed, 325 feed, 312 Bio Pump feed, and West secondary feed. The North power feed modification consists of moving an overhead power line at the northeast corner of the 300 area slightly farther north and raising it using higher elevation power poles. This reduces interference with planned excavation of the 618-1 burial grounds in that area. The 325 feed consists of modifications to provide a secondary power feed to replace the function of the 3621-BC 2400V backup power distribution system with a second source of $13.8 \mathrm{kV}$ feed. The 312 Bio Pump feed similarly replaces the $2400 \mathrm{~V}$ backup power source for the 312 pump system. The West secondary feed reroutes underground power lines on the west side of the 300 area to overhead lines to avoid the potential for waste site excavation impacts. The electrical distribution system modifications are described in more detail in Appendix B.

\subsection{WATER}

The existing water supply to the 300 Area consists of a 16" main from the City of Richland feeding a pressure boosting and water distribution facility identified as the 382 Complex. The 382 Complex boosts the water pressure from the City of Richland's 50-60 psi supply pressure to approximately 115 psi and distributes the water via looped underground piping systems throughout the 300 Area for potable (domestic) requirements as well as fire protection and process water uses. Modifications to the 300 Area water system are needed to accommodate the demolition of old 300 Area buildings and remediation of waste sites and to assure a reasonable expectation of service life to the facilities planned for extended operation (> 20 years).

Because of the fire protection role of the water supply system, the 300 Area water system needs to have built in redundancy so that a single failure of the water supply, pumps, or mains will not prevent water from being supplied to the system for fire suppression. DOE standards require a looped fire protection water distribution system and the National Fire Protection Association requires a reliable water source. DOE standards also require "significant" facilities, such as facilities with a maximum possible fire loss in excess of $\$ 1 \mathrm{M}$ or those which could cause unacceptable off-site consequences to health and safety, to be protected by an automatic fire suppression system (usually a Wet Pipe Sprinkler System). 
Recommended Option: As described in Appendices D and E, a new pumping station, consisting of two sanitary booster pumps, an electric fire water pump and a diesel driven fire water pump will be installed west of the 318 Building to replace the 382 Complex which will be demolished. The new pump station will be supplied by the existing 16" water main that currently serves the 300 Area. In order to eliminate the requirement for water storage, a second source of water is needed. A new 16" water main will be extended from the vicinity of Stevens Drive and Horn Rapids Road. This new main will then feed into the new pump station. The pump station will connect into the existing 300 Area underground water distribution system for the most part. Some new main distribution piping will be installed to facilitate the installation of the pump station and to ensure fire flow requirements are met. In addition, a 12" test discharge line will be installed from the pump station to the Cypress Street parking lot storm drainage swale located northwest of the proposed pump station location. This will provide for a means of collecting the water when the fire pumps are tested. Power for the new pump station will be provided by a new service supplied from the existing $13.8 \mathrm{kV} 300$ Area electrical infrastructure.

In addition to the replacement of the 382 Complex functionality, repairs are needed to ensure the required function of the water distribution system in the 300 Area and respond to regulator concerns regarding the presence of potentially leaking pressurized water mains in areas where waste sites are being left in place pending disposition of the retained facilities. Several 8" water distribution mains will be repaired using a scraping and mortar-lining process that has been used successfully at other Hanford site locations.

\subsection{WASTEWATER}

There are several wastewater streams currently generated by the retained and delayed release facilities as described in Appendix F. Sanitary (domestic) wastewater is collected in a sanitary sewer system that discharges through a series of gravity drains and lift stations and is routed through a monitoring station at the south end of the 300 Area before discharging to the City of Richland Publicly Owned Treatment Works (POTW). Process wastewater is collected in two streams, the Process Sewer (PS) and the Retention Process Sewer (RPS), both of which ultimately discharge to the 300 Area Treated Effluent Disposal Facility (310 TEDF). Storm water is collected in a variety of systems including surface discharges, injection wells, a storm water collection swale, and the process and retention process sewer systems.

\subsubsection{Sanitary Sewer}

The City of Richland POTW will continue to receive the sanitary sewer discharge from the retained facilities. A series of new lift stations and force mains will be used to reroute the sanitary sewer systems away from areas that will be impacted by excavation as part of remediation activities. Three main branches of sanitary sewer will be addressed: facilities near Cypress Street, facilities near the 325 Building, and facilities near the 331 Building. Facilities near Cypress Street will be served by lift stations near the 3709A fire station and near the 320 Building. Facilities near the 325 Building will be served by lift stations near the northwest corner of the 325 Building along Spruce Street, discharging to the same line serving the Cypress Street facilities. Sanitary sewer systems from the 331 Building area will continue to be served by the existing sanitary sewer line and the 3906B lift station. Appendix $\mathrm{G}$ documents a decision meeting held to determine the recommended route for the sanitary wastewater from the 325 Building area. A sketch of the sanitary sewer design is provided in Appendix $\mathrm{H}$. 


\subsubsection{Process Sewer}

Current contributors to the process sewer will be split into three disposition pathways and discharges to the 310 TEDF will be discontinued. Storm water contributors will be addressed as described in Section 4.4.4. Process sewer discharges from Buildings 326 and 329 will be combined with the Retention Process Sewer stream as described in Section 4.4.3. Remaining process contributors in the 318,320 , and 331 buildings will be permitted using the City of Richland Municipal Pretreatment Permit process and tied into the sanitary sewer system.

\subsubsection{Retention Process Sewer}

Retention process sewer discharges are currently collected from the $324,325,326,327$, and 329 buildings and flow by gravity to the 307 Retention Basins near the 340 Building. The discharges from 324 and 327 will be terminated as part of ongoing deactivation activities. Remaining contributors from 325, 326 and 329 will be collected from a retention process sewer manhole and transferred to a new effluent containment/pumping system located north of the 325 Building atop the slab from the 328 Building. The system will consist of four storage tanks, pumps and sampling capabilities. The system will be capable of discharging the effluent to the sanitary sewer system or pumping into a tanker truck for disposal. Process sewer contributors from the 326 and 329 buildings would also be tied into the RPS discharge and collected in the new tank system. The RPS conceptual design is provided in Appendix I.

\subsubsection{Storm water}

Two existing storm drain catch basins, which are located near the southeast corner of the 329 Building, are currently routed to the RPS system. In order to eliminate this flow potential to the new 325 Building RPS system, the outflow from these two catch basins will be rerouted to the existing Cypress Street parking lot drainage system. This system discharges into a grassy swale located in the southwest corner of the lot.

Additional storm water discharges have been identified that are cross-connected to either the process sewer or sanitary sewer systems. These cross-connections will be eliminated prior to the tie-in of remaining process sewer contributors to the City of Richland POTW. Examples include the rerouting of roof drains at the 3709A fire station, plugging catch basins near the 3790 parking lot, and rerouting equipment room drains and storm drains at the 331 Building. Appendix $\mathrm{J}$ provides sketches of the proposed storm water modifications.

\subsection{INFORMATION TECHNOLOGY}

The current fiber optic and copper network providing data and voice telecommunications service to the 300 Area will be impacted by planned remediation activities near the 309 Building. The majority of the existing systems are routed along New Mexico Street through the 3506-C building. As described in Appendix $\mathrm{K}$, the recommended option is to convert the majority of the data systems to a PNNL-based switch system based in the 318 Building, and provide voice over data service to replace the existing telephone services. Appendix $L$ provides a sketch of the final proposed configuration of the IT systems.

Short-term occupied buildings will remain on the existing services until demolition of the buildings. Temporary services will be routed to delayed release facilities such as 320, 326 and 
329. Telephone services in these buildings will remain on the Hanford IVDTS service unless the copper cabling feeding these buildings is also impacted by the remediation activities.

\subsection{MISCELLANEOUS (NATURAL GAS, STEAM, COMPRESSED AIR, STANDBY GENERATORS)}

The boiler annexes serving the retained facilities are operated and maintained by $\mathrm{JCl}$. Services for the boiler annexes come from retained facilities. The air compressors, which are located inside PNNL facilities, are owned and maintained by $\mathrm{JCl}$, but are operated by PNNL. Standby generators are operated and maintained by $\mathrm{JCl}$ for the 325 and 331 Buildings. No changes to the configuration of these services at retained facilities are planned. Natural gas lines serving the boilers will be left in place.

\subsection{CONSTRUCTION SCHEDULE/PRIORITIZATION}

The following constraints were used for the time phasing of utility relocations.

Sanitary sewer modifications for the 318, 320, 3709A\&B, 339A, and 3220 facilities were prioritized for completion ahead of the excavation of waste site 618-1 due to interference between an active sanitary sewer line and the waste site excavation. Due to funding constraints the 618-1 waste site was rescheduled to start in late fiscal year 2008.

Electrical utility modifications for the northeast corner of the 300 area fence line were prioritized for completion ahead of the excavation of waste site 618-1 due to interference between the overhead electrical lines and the movement of heavy equipment into the waste site, and the potential need for the excavation to undermine several power poles.

Retention process sewer modifications at 325, 326, and 329 are needed prior to September 2009 to support shutdown of the 307 Basins and turnover of the 340 Complex from the PHMC to $\mathrm{WCH}$ for demolition.

Storm water modifications to eliminate cross-connections between storm water and process sewer are needed prior to September 2009 to allow the transition of remaining process sewer contributors to sanitary sewer and shutdown of the 300 Area Treated Effluent Disposal Facility at the end of FY 2009.

Water system modifications (replacement of the 382 complex) were planned for FY10 because of funding constraints.

The majority of the contingency portion of the utility cost estimates was loaded in FY10-FY11.

A summary of the utility cost estimate time-phasing is provided below. 


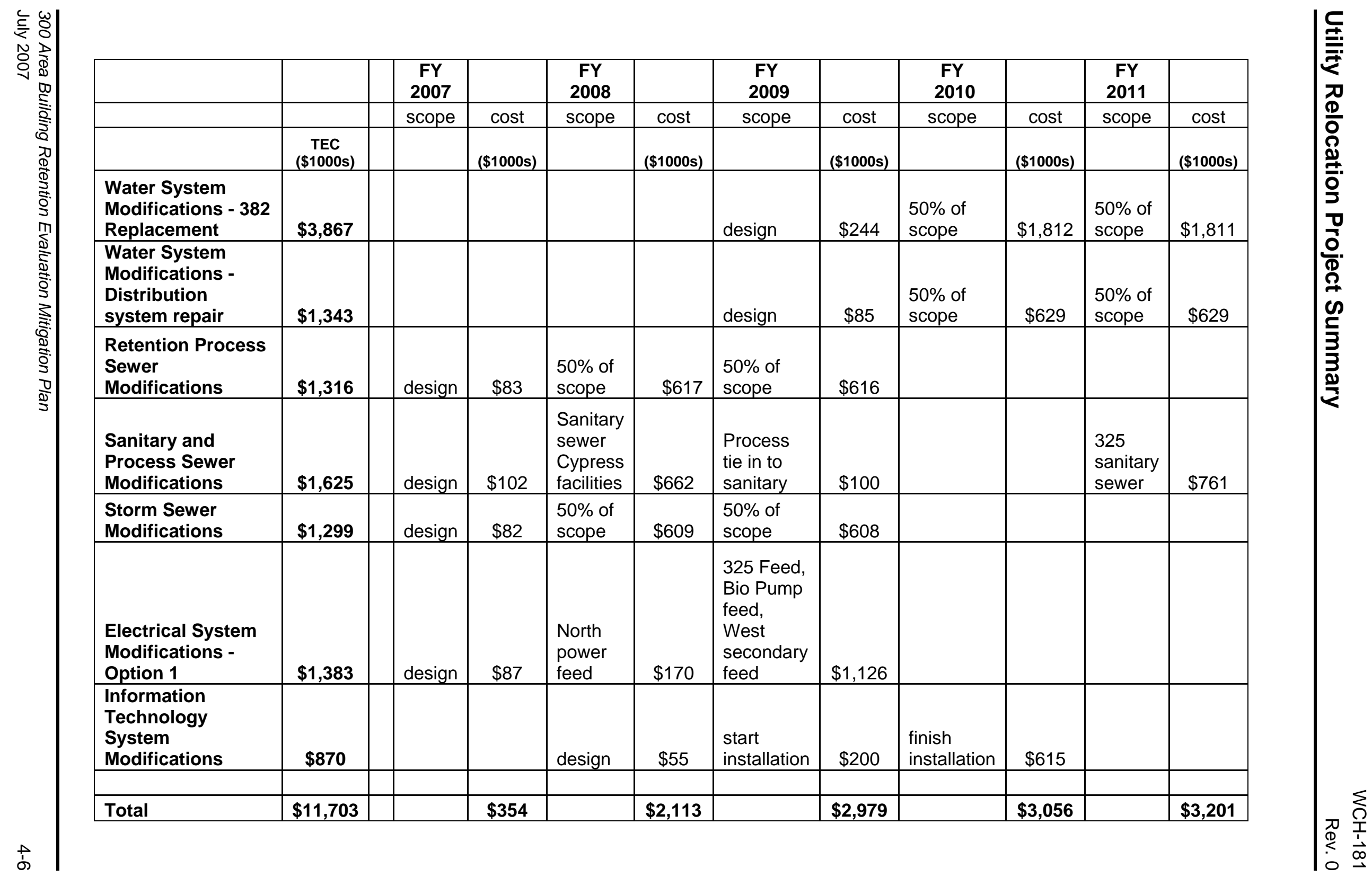




\subsection{SCENARIO 1: RETENTION AND RELEASE DATES AS SPECIFIED WITH 326 BUILDING RELEASED OCTOBER 2009}

\subsection{SUMMARY}

Scenario 1 is the release of Buildings 326 and 326-BA in October 2009 and the release of Building 3790 in February 2011. D4 buildings (106), ISS reactors (2), and FR waste sites (87) in the $100 \mathrm{~K}$ area are deleted from scope. Retained facilities in the 300 Area are deleted from scope and release dates for selected 300 Area facilities are assigned as specified. The scenario assumptions are summarized below.

The following 300 Area facilities and underlying waste sites are retained long term (removed from the WCH contract):

- 318 Complex (318, 318B, 318C, MO-226)

- 325 Complex (325, 325A, 325B, 325C, 325D, 325E)

- 331 Building (331)

- 350 Complex (350, 350A, 350B, 350C, 350D)

- 339-A HLAN hub

- 3220 Telecommunications Hub

- 3709-A\&B Fire Station

- 312 River Pumphouse

- 3507 Microwave Tower

- 318-BA Boiler Annex

- 325-BA Boiler Annex

- 331-BA Boiler Annex

- 3508-T1, -T2, -T3 Sirens

- JCl Trailers (MO-258, MO-262, MO-263)

- 3906B Lift Station

- 3906C Monitoring Station

- 352F Electrical Substation

- $351,351 \mathrm{~A}, 351 \mathrm{~B}$ Electrical Substation

- 3614A Monitoring Station

Several additional facilities, not in the $\mathrm{WCH}$ contract, were identified for long-term retention and utility service:

- Subcontractor trailers (MO-675, 676, 677)

- Emergency preparedness sirens (3508-T1, -T2, -T3)

- Building 361

The following facilities are provided with the specified release dates for D4:

- 323

- 3730

- 3718-P
October 2007

October 2007

October 2007 
- 336

- 338

- 3760 (and 323-BA)

- 326 (and 326-BA)

- 331C, 331D, 331G, 331H

- 329

- 3790

- 320 (and 320-BA)
October 2008

October 2008

October 2009

October 2009

February 2011

February 2011

February 2011

July 2011

The following 300 Area waste sites are removed from RCC scope:

- Confirmatory sites 331 LSLT1 and 331 LSLT2

- Remediation sites 300-175, 300-4, 300-269, 325 WTF, UPR-300-10, UPR-300-12, and UPR-300-48

ERDF waste disposal costs associated with waste quantities from the deleted buildings and waste sites were eliminated.

The 100K Area D4, Interim Safe Storage (ISS) and FR activities (with the exception of sites already completed and the 118-K-1 Burial Ground) were removed from WCH scope in all mitigation plan scenarios per RL direction (Reference 9). Deletions included 106 D4 buildings, 2 reactor ISS, and 87 waste sites. Waste quantities associated with these reductions were also removed from the ERDF disposal costs.

\section{$5.2 \quad$ D4 IMPACTS}

The majority of D4 impacts from the delayed release of identified facilities and insertion of additional scope into the baseline are mitigated by the deletion of $100 \mathrm{~K}$ and 300 area scope and the ahead-of-schedule status of D4 activities. Additional mitigation was accomplished by assuming an early start of the Planning and Documentation phase of D4 activities for the 329 Building (ahead of the February 2011 release date) and by accelerating the release of several PNNL buildings as stated in the scenario assumptions. The resulting schedule avoided a critical path impact from the 17-21 month delays in release of specified PNNL facilities.

The below-grade demolition portion of several D4 facilities was removed from scope because of the proximity of the buildings to long-term retained facilities. The 326, 329, 328, and 328-A buildings will be demolished to grade level only.

\subsection{FIELD REMEDIATION IMPACTS}

Field Remediation impacts from the 300 Area building retention include the long-term retention (removal from the RCC contract) of waste sites underlying or immediately adjacent to the retained facilities, and increased complexity and cost for waste sites in proximity to active utility systems that will remain to serve the retained facilities. 
The following waste sites were retained (deleted):

- $\quad$ Confirmatory sites 331 LSLT1 and 331 LSLT2

- Remediation sites 300-175, 300-4, 300-269, 325 WTF, UPR-300-10, UPR-300-12, and UPR-300-48

The following waste sites were determined to have the potential for increased excavation complexity and cost due to their proximity to active utility systems as described in Appendix M:

- $300-5$

- $300-15$

- 300-95

- 300-121

- 300-214

- 300-255

- 300-257

- 300-264

- 300-265

- 300-RLWS

- 300-RRLWS

- 309-TW-1

- $309-T W-2$

- 309-TW-3

- 316-3

- UPR-300-4

For these sites, the excavation duration and cost were increased by a factor of $25 \%$ to account for the added complexity.

\section{$5.4 \quad$ TPA IMPACTS}

- $\quad$ Tri-Party Agreement (TPA) milestone impacts from the mitigation plan were limited to those sites already identified for changes as discussed above for the100 areas, and 300 area milestones directly affected by the retention of waste sites or buildings identified in milestones. The following 300 Area milestones are affected:

M-016-00: Complete Remedial Actions for all non-Tank Farms Operable Units by 9/30/2024. Impact: Waste sites underlying the retained facilities or retained active utility systems will not be completed as part of the RCC scope. They will be deferred until the retained facilities are vacated (20+ years).

M-016-00B: Complete all interim 300 Area remedial actions including the 618-10 and 61811 burial grounds by $9 / 30 / 2018$.

Impact: Waste sites underlying the retained facilities or retained active utility systems will not be completed as part of the RCC scope. They will be deferred until the retained facilities are vacated (20+ years). 
M-016-69: Complete all interim 300 Area remedial actions to include confirmatory sampling of all candidate sites listed in the 300-FF-2 ROD (except 618-10 and 618-11 burial grounds) by $9 / 30 / 2015$.

Impact: Waste sites underlying the retained facilities or retained active utility systems will not be completed as part of the RCC scope. They will be deferred until the retained facilities are vacated (20+ years).

M-016-74: Complete interim remediation(to include excavation, loadout, closeout sampling, backfill and revegetation), for all 300 Area "inside the fence" waste sites north of Apple Street, except for the 300-RLWS, 300-15, 300-4, 300-268 and 300-123 waste sites remediation need only be completed through excavation and loadout by 9/30/2012. Impact: Waste site 300-4 and portions of 300-RLWS and 300-15 are retained and should be removed from the milestone.

M-094-00: Complete disposition of 300 Area surplus facilities to be defined as the 220 facilities listed in the Hanford River Corridor Closure Contract Solicitation \#DE-RP0604RL14655 by $9 / 30 / 2015$. Impact: Milestone reference to 220 facilities and reference to \#DE-RP06-04RL14655 are outdated. By updating the references the existing milestone for "surplus" facilities (excluding the retained facilities) can be met.

M-094-06, -07, -08, 09: Complete the selected removal and/or remedial actions that are selected for $\mathrm{XX}$ of the following 19 high priority facilities: 305B, 306E, 306W, 307 Retention Basins, 308, 309, 321, 323, 324, 324B, 325, 326, 327, 329, 333, 340, 3706, 307 Trench and 3720. (Multiple dates)

Impact: Editorial impact, 325 building should be deleted and total number of facilities reduced. Each of the specific milestones can be met with no impact.

In addition to the listed impacts from the 300 Area Building Retention Scenario itself, there are several TPA impacts shown in the adjusted schedule. These are not caused by the 300 area mitigation activities but reflect conditions of waste sites and remediation status in the 100 and 300 areas. One waste site near the 300 area, 618-7, is currently behind schedule for starting excavation because it is a high risk activity and is being deferred until completion of the project's Integrated Safety Management System (ISMS) verification and readiness evaluations. The schedule shows completion of the site later than the TPA milestone. Several 100 area milestones are also under negotiation such as milestones for $100 \mathrm{~B} / \mathrm{C}, 100 \mathrm{H}$, and IU-2 and IU6. Again these milestone impacts are not related to the 300 area mitigation plan activities but the schedule reflects the current and planned status of the sites.

\subsection{OVERALL SCHEDULE IMPACT}

Due to the mitigation activities described in Section 5.2, there was no overall change to the RCC end date of August 29, 2013 in this mitigation scenario. Note that this does not reflect an adjustment to the target date for the RCC Contract for use in calculating the schedule acceleration performance fee which would be addressed in a separate Request for Equitable Adjustment. 


\subsection{COST IMPACT}

This scenario resulted in a net decrease to the total project cost of approximately $\$ 220 \mathrm{M}$ as shown in the cost spreadsheet (Figure 5-1). Scope deletions from the $100 \mathrm{~K}$ area totaled $\$ 125 \mathrm{M}$ (\$110M including contingency and escalation and \$15M for ERDF disposal costs). Scope deletions from the 300 Area totaled $\$ 89 \mathrm{M}$ (\$85M including contingency and escalation and \$4M for ERDF disposal costs). Scope additions included $\$ 1.6 \mathrm{M}$ for added complexity of sixteen waste sites in the 300 Area, and $\$ 12.7 \mathrm{M}$ for the utility relocation project including escalation and contingency. The net change in scope was a reduction of $\$ 200.1 \mathrm{M}$. An additional $\$ 19.8 \mathrm{M}$ of reductions in fee, pension and miscellaneous were deleted based on the scope reductions. 


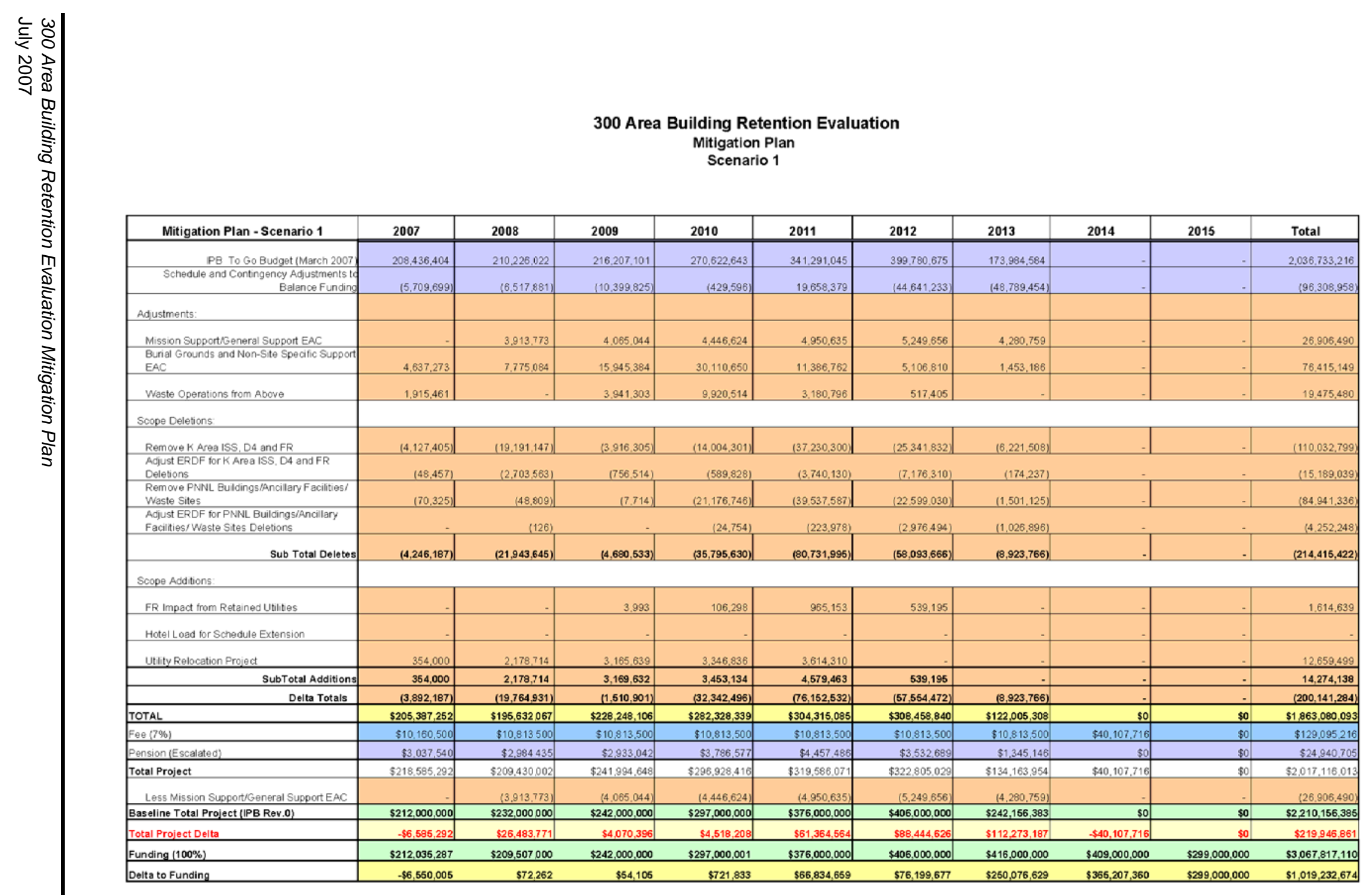




\subsection{SCENARIO 2: RETENTION AND RELEASE DATES AS SPECIFIED WITH 326 BUILDING RELEASED FEBRUARY 2011}

\subsection{SUMMARY}

Scenario 2 is the release of Buildings 326 and 326-BA in February 2011 and the release of Building 3790 in February 2011. D4 buildings (106), ISS reactors (2), and FR waste sites (87) in the $100 \mathrm{~K}$ area are deleted from scope. Retained facilities in the 300 Area are deleted from scope and release dates for selected 300 Area facilities are assigned as specified. The scenario assumptions are summarized below.

The following 300 Area facilities and underlying waste sites are retained long term (removed from the WCH contract):

- 318 Complex $(318,318 \mathrm{~B}, 318 \mathrm{C}, \mathrm{MO}-226)$

- 325 Complex (325, 325A, 325B, 325C, 325D, 325E)

- 331 Building (331)

- 350 Complex (350, 350A, 350B, 350C, 350D)

- 339-A HLAN hub

- 3220 Telecommunications Hub

- 3709-A\&B Fire Station

- 312 River Pumphouse

- 3507 Microwave Tower

- 318-BA Boiler Annex

- 325-BA Boiler Annex

- 331-BA Boiler Annex

- 3508-T1, -T2, -T3 Sirens

- JCl Trailers (MO-258, MO-262, MO-263)

- 3906B Lift Station

- 3906C Monitoring Station

- 352F Electrical Substation

- 351, 351A, 351B Electrical Substation

- 3614A Monitoring Station

Several additional facilities, not in the $\mathrm{WCH}$ contract, were identified for long-term retention and utility service:

- Subcontractor trailers (MO-675, 676, 677)

- Emergency preparedness sirens (3508-T1, -T2, -T3)

- $\quad$ Building 361

The following facilities are provided with the specified release dates for D4:

- 323

- 3730

- 3718-P

- 336

- 338
October 2007

October 2007

October 2007

October 2008

October 2008 
- 3760 (and 323-BA)

- 326 (and 326-BA)

- 331C, 331D, 331G, 331H

- 329

- 3790

- 320 (and 320-BA)
October 2009

February 2011

February 2011

February 2011

February 2011

July 2011

The following 300 Area waste sites are removed from RCC scope:

- $\quad$ Confirmatory sites 331 LSLT1 and 331 LSLT2

- Remediation sites 300-175, 300-4, 300-269, 325 WTF, UPR-300-10, UPR-300-12, and UPR-300-48

ERDF waste disposal costs associated with waste quantities from the deleted buildings and waste sites were eliminated.

The 100K Area D4, Interim Safe Storage (ISS) and FR activities (with the exception of sites already completed and the 118-K-1 Burial Ground) were removed from WCH scope in all mitigation plan scenarios per RL direction (Reference 9). Deletions included 106 D4 buildings, 2 reactor ISS, and 87 waste sites. Waste quantities associated with these reductions were also removed from the ERDF disposal costs.

\subsection{D4 IMPACTS}

The majority of D4 impacts from the delayed release of identified facilities and insertion of additional scope into the baseline are mitigated by the deletion of $100 \mathrm{~K}$ and 300 area scope and the ahead-of-schedule status of D4 activities. Additional mitigation was accomplished by assuming an early start of the Planning and Documentation phase of D4 activities for the 326 and 329 Buildings (ahead of the February 2011 release date) and by accelerating the release of several PNNL buildings as stated in the scenario assumptions. The resulting schedule significantly reduced the critical path impact from the 17-21 month delays in release of specified PNNL facilities. The 326 Building caused a critical path delay of six weeks, impacting the completion of the RCC contract as described in Section 6.5.

The below-grade demolition portion of several D4 facilities was removed from scope because of the proximity of the buildings to long-term retained facilities. The 326, 329, 328, and 328-A buildings will be demolished to grade level only.

\subsection{FIELD REMEDIATION IMPACTS}

Field Remediation impacts from the 300 Area building retention include the long-term retention (removal from the RCC contract) of waste sites underlying or immediately adjacent to the retained facilities, and increased complexity and cost for waste sites in proximity to active utility systems that will remain to serve the retained facilities. 
The following waste sites were retained (deleted):

- Confirmatory sites 331 LSLT1 and 331 LSLT2

- Remediation sites 300-175, 300-4, 300-269, 325 WTF, UPR-300-10, UPR-300-12, and UPR-300-48

The following waste sites were determined to have the potential for increased excavation complexity and cost due to their proximity to active utility systems as described in Appendix M:

- 300-5

- 300-15

- 300-95

- 300-121

- 300-214

- 300-255

- 300-257

- 300-264

- 300-265

- 300-RLWS

- 300-RRLWS

- 309-TW-1

- $309-T W-2$

- 309-TW-3

- 316-3

- UPR-300-4

For these sites, the excavation duration and cost were increased by a factor of $25 \%$ to account for the added complexity.

\subsection{TPA IMPACTS}

- $\quad$ Tri-Party Agreement (TPA) milestone impacts from the mitigation plan were limited to those sites already identified for changes as discussed above for the100 areas, and 300 area milestones directly affected by the retention of waste sites or buildings identified in milestones. The following 300 Area milestones are affected:

M-016-00: Complete Remedial Actions for all non-Tank Farms Operable Units by 9/30/2024. Impact: Waste sites underlying the retained facilities or retained active utility systems will not be completed as part of the RCC scope. They will be deferred until the retained facilities are vacated (20+ years).

M-016-00B: Complete all interim 300 Area remedial actions including the 618-10 and 618-11 burial grounds by $9 / 30 / 2018$.

Impact: Waste sites underlying the retained facilities or retained active utility systems will not be completed as part of the RCC scope. They will be deferred until the retained facilities are vacated (20+ years). 
M-016-69: Complete all interim 300 Area remedial actions to include confirmatory sampling of all candidate sites listed in the 300-FF-2 ROD (except 618-10 and 618-11 burial grounds) by $9 / 30 / 2015$.

Impact: Waste sites underlying the retained facilities or retained active utility systems will not be completed as part of the RCC scope. They will be deferred until the retained facilities are vacated (20+ years).

M-016-74: Complete interim remediation(to include excavation, loadout, closeout sampling, backfill and revegetation), for all 300 Area "inside the fence" waste sites north of Apple Street, except for the 300-RLWS, 300-15, 300-4, 300-268 and 300-123 waste sites remediation need only be completed through excavation and loadout by 9/30/2012. Impact: Waste site 300-4 and portions of 300-RLWS and 300-15 are retained and should be removed from the milestone.

M-094-00: Complete disposition of 300 Area surplus facilities to be defined as the 220 facilities listed in the Hanford River Corridor Closure Contract Solicitation \#DE-RP0604RL14655 by 9/30/2015.

Impact: Milestone reference to 220 facilities and reference to \#DE-RP06-04RL14655 are outdated. By updating the references the existing milestone for "surplus" facilities (excluding the retained facilities) can be met.

M-094-06, -07, -08, 09: Complete the selected removal and/or remedial actions that are selected for $\mathrm{XX}$ of the following 19 high priority facilities: 305B, 306E, 306W, 307 Retention Basins, 308, 309, 321, 323, 324, 324B, 325, 326, 327, 329, 333, 340, 3706, 307 Trench and 3720. (Multiple dates)

Impact: Editorial impact, 325 building should be deleted and total number of facilities reduced. Each of the specific milestones can be met with no impact.

In addition to the listed impacts from the 300 Area Building Retention Scenario itself, there are several TPA impacts shown in the adjusted schedule. These are not caused by the 300 area mitigation activities but reflect conditions of waste sites and remediation status in the 100 and 300 areas. One waste site near the 300 area, 618-7, is currently behind schedule for starting excavation because it is a high risk activity and is being deferred until completion of the project's Integrated Safety Management System (ISMS) verification and readiness evaluations. The schedule shows completion of the site later than the TPA milestone. Several 100 area milestones are also under negotiation such as milestones for $100 \mathrm{~B} / \mathrm{C}, 100 \mathrm{H}$, and IU-2 and IU6. Again these milestone impacts are not related to the 300 area mitigation plan activities but the schedule reflects the current and planned status of the sites.

\subsection{OVERALL SCHEDULE IMPACT}

Due to the mitigation activities described in Section 6.2, there was a significantly reduced impact to the RCC end date of August 29, 2013 in this mitigation scenario. The 326 building is on the critical path for 300 Area D4 activities in the IPB. Although this scenario introduces a 17-month delay in the 326 building release date, the scenario results in a mitigation of all but a six week extension in the completion date, from August 29, 2013 to October 15, 2013. Note that this does not reflect an adjustment to the target date for the RCC Contract for use in calculating the schedule acceleration performance fee which would be addressed in a separate Request for Equitable Adjustment. 


\subsection{COST IMPACT}

This scenario resulted in a net decrease to the total project cost of approximately $\$ 205 \mathrm{M}$ as shown in the cost spreadsheet (Figure 6-1). Scope deletions from the $100 \mathrm{~K}$ area totaled $\$ 125 \mathrm{M}$ (\$110M including contingency and escalation and \$15M for ERDF disposal costs). Scope deletions from the 300 Area totaled $\$ 89 \mathrm{M}$ (\$85M including contingency and escalation and \$4M for ERDF disposal costs). Scope additions included $\$ 1.6 \mathrm{M}$ for added complexity of sixteen waste sites in the 300 Area, $\$ 12.7 \mathrm{M}$ for the utility relocation project including escalation and contingency, and $\$ 12.9 \mathrm{M}$ in time-related costs (hotel load) for the six week contract extension. The net change in scope was a reduction of $\$ 187.2 \mathrm{M}$. An additional $\$ 18.2 \mathrm{M}$ of reductions in fee, pension and miscellaneous were deleted based on the scope reductions. 


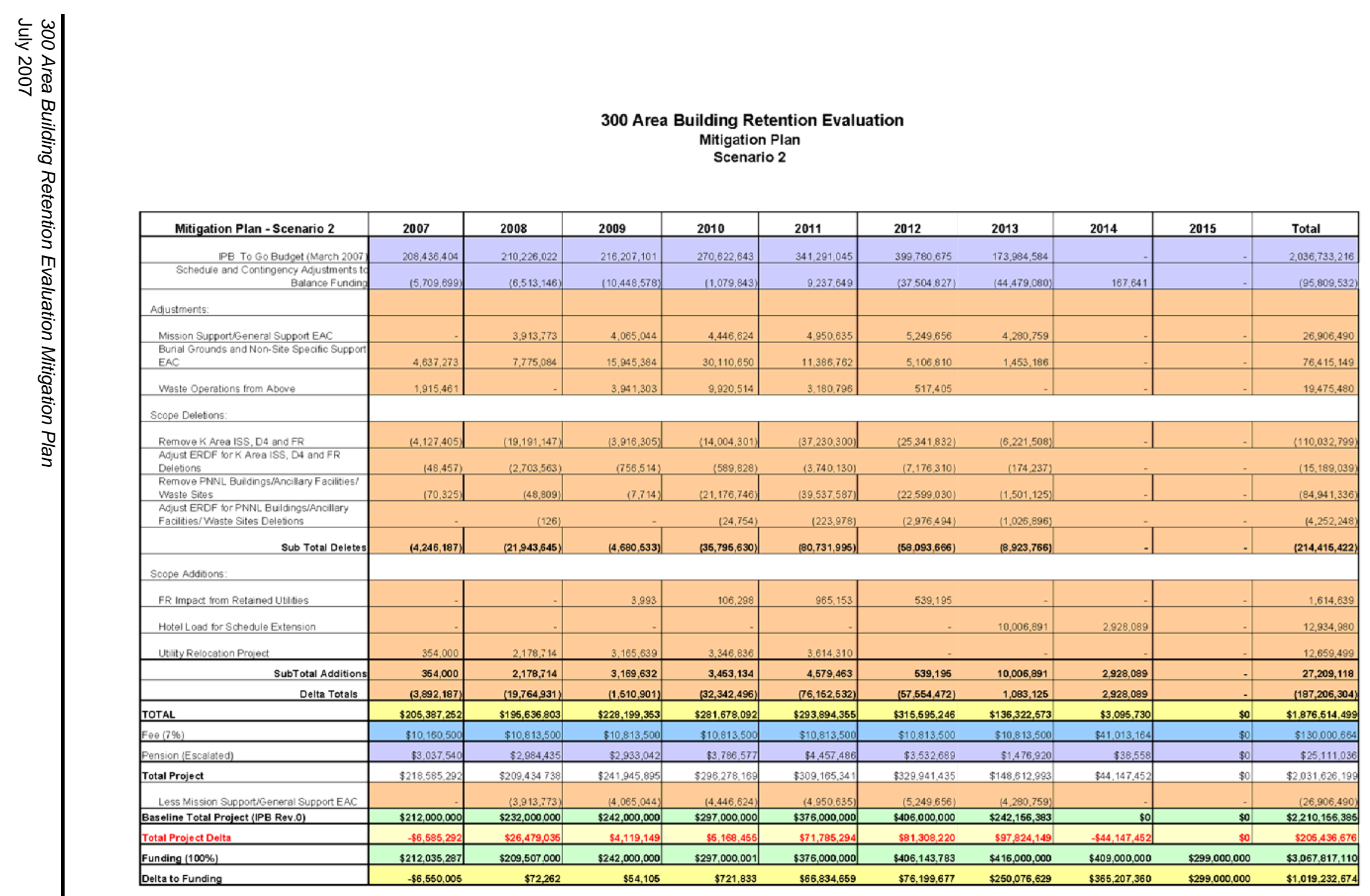




\subsection{SCENARIO 3: SAME AS SCENARIO 2 WITH LONG-TERM RETENTION OF BUILDING 3790}

\subsection{SUMMARY}

Scenario 3 is the release of Buildings 326 and 326-BA in February 2011 and the long-term retention of Building 3790. D4 buildings (106), ISS reactors (2), and FR waste sites (87) in the $100 \mathrm{~K}$ area are deleted from scope. Retained facilities in the 300 Area are deleted from scope and release dates for selected 300 Area facilities are assigned as specified. The scenario assumptions are summarized below.

The following 300 Area facilities and underlying waste sites are retained long term (removed from the WCH contract):

- 318 Complex $(318,318 \mathrm{~B}, 318 \mathrm{C}, \mathrm{MO}-226)$

- 325 Complex (325, 325A, 325B, 325C, 325D, 325E)

- 331 Building (331)

- 350 Complex (350, 350A, 350B, 350C, 350D)

- 339-A HLAN hub

- 3220 Telecommunications Hub

- 3709-A\&B Fire Station

- 312 River Pumphouse

- 3507 Microwave Tower

- 3790 Building

- 318-BA Boiler Annex

- 325-BA Boiler Annex

- 331-BA Boiler Annex

- 3508-T1, -T2, -T3 Sirens

- JCl Trailers (MO-258, MO-262, MO-263)

- 3906B Lift Station

- 3906C Monitoring Station

- 352F Electrical Substation

- 351, 351A, 351B Electrical Substation

- 3614A Monitoring Station

Several additional facilities, not in the WCH contract, were identified for long-term retention and utility service:

- Subcontractor trailers (MO-675, 676, 677)

- Emergency preparedness sirens (3508-T1, -T2, -T3)

- $\quad$ Building 361

The following facilities are provided with the specified release dates for D4:

- 323

- 3730

- $3718-\mathrm{P}$
October 2007

October 2007

October 2007 
- 336

- 338

- 3760 (and 323-BA)

- 326 (and 326-BA)

- 331C, 331D, 331G, 331H

- 329

- 320 (and 320-BA)
October 2008

October 2008

October 2009

February 2011

February 2011

February 2011

July 2011

The following 300 Area waste sites are removed from RCC scope:

- $\quad$ Confirmatory sites 331 LSLT1 and 331 LSLT2

- Remediation sites 300-175, 300-4, 300-269, 325 WTF, UPR-300-10, UPR-300-12, and UPR-300-48

ERDF waste disposal costs associated with waste quantities from the deleted buildings and waste sites were eliminated.

The 100K Area D4, Interim Safe Storage (ISS) and FR activities (with the exception of sites already completed and the 118-K-1 Burial Ground) were removed from WCH scope in all mitigation plan scenarios per RL direction (Reference 9). Deletions included 106 D4 buildings, 2 reactor ISS, and 87 waste sites. Waste quantities associated with these reductions were also removed from the ERDF disposal costs.

\subsection{D4 IMPACTS}

The majority of D4 impacts from the delayed release of identified facilities and insertion of additional scope into the baseline are mitigated by the deletion of $100 \mathrm{~K}$ and 300 area scope and the ahead-of-schedule status of D4 activities. Additional mitigation was accomplished by assuming an early start of the Planning and Documentation phase of D4 activities for the 326 and 329 Buildings (ahead of the February 2011 release date) and by accelerating the release of several PNNL buildings as stated in the scenario assumptions. The resulting schedule significantly reduced the critical path impact from the 17-21 month delays in release of specified PNNL facilities. The 326 Building caused a critical path delay of six weeks, impacting the completion of the RCC contract as described in Section 7.5.

The below-grade demolition portion of several D4 facilities was removed from scope because of the proximity of the buildings to long-term retained facilities. The 326, 329, 328, and 328-A buildings will be demolished to grade level only.

\subsection{FIELD REMEDIATION IMPACTS}

Field Remediation impacts from the 300 Area building retention include the long-term retention (removal from the RCC contract) of waste sites underlying or immediately adjacent to the retained facilities, and increased complexity and cost for waste sites in proximity to active utility systems that will remain to serve the retained facilities. 
The following waste sites were retained (deleted):

- $\quad$ Confirmatory sites 331 LSLT1 and 331 LSLT2

- Remediation sites 300-175, 300-4, 300-269, 325 WTF, UPR-300-10, UPR-300-12, and UPR-300-48

The following waste sites were determined to have the potential for increased excavation complexity and cost due to their proximity to active utility systems as described in Appendix M:

- $300-5$

- $300-15$

- 300-95

- 300-121

- $300-214$

- $300-255$

- $300-257$

- 300-264

- 300-265

- 300-RLWS

- 300-RRLWS

- 309-TW-1

- 309-TW-2

- $309-T W-3$

- 316-3

- UPR-300-4

For these sites, the excavation duration and cost were increased by a factor of $25 \%$ to account for the added complexity.

\section{$7.4 \quad$ TPA IMPACTS}

- Tri-Party Agreement (TPA) milestone impacts from the mitigation plan were limited to those sites already identified for changes as discussed above for the100 areas, and 300 area milestones directly affected by the retention of waste sites or buildings identified in milestones. The following 300 Area milestones are affected:

M-016-00: Complete Remedial Actions for all non-Tank Farms Operable Units by 9/30/2024. Impact: Waste sites underlying the retained facilities or retained active utility systems will not be completed as part of the RCC scope. They will be deferred until the retained facilities are vacated (20+ years).

M-016-00B: Complete all interim 300 Area remedial actions including the 618-10 and 61811 burial grounds by 9/30/2018.

Impact: Waste sites underlying the retained facilities or retained active utility systems will not be completed as part of the RCC scope. They will be deferred until the retained facilities are vacated (20+ years). 
M-016-69: Complete all interim 300 Area remedial actions to include confirmatory sampling of all candidate sites listed in the 300-FF-2 ROD (except 618-10 and 618-11 burial grounds) by $9 / 30 / 2015$.

Impact: Waste sites underlying the retained facilities or retained active utility systems will not be completed as part of the RCC scope. They will be deferred until the retained facilities are vacated (20+ years).

M-016-74: Complete interim remediation(to include excavation, loadout, closeout sampling, backfill and revegetation), for all 300 Area "inside the fence" waste sites north of Apple Street, except for the 300-RLWS, 300-15, 300-4, 300-268 and 300-123 waste sites remediation need only be completed through excavation and loadout by 9/30/2012. Impact: Waste site 300-4 and portions of 300-RLWS and 300-15 are retained and should be removed from the milestone.

M-094-00: Complete disposition of 300 Area surplus facilities to be defined as the 220 facilities listed in the Hanford River Corridor Closure Contract Solicitation \#DE-RP0604RL14655 by $9 / 30 / 2015$.

Impact: Milestone reference to 220 facilities and reference to \#DE-RP06-04RL14655 are outdated. By updating the references the existing milestone for "surplus" facilities (excluding the retained facilities) can be met.

M-094-06, -07, -08, 09: Complete the selected removal and/or remedial actions that are selected for $\mathrm{XX}$ of the following 19 high priority facilities: 305B, 306E, 306W, 307 Retention Basins, 308, 309, 321, 323, 324, 324B, 325, 326, 327, 329, 333, 340, 3706, 307 Trench and 3720. (Multiple dates)

Impact: Editorial impact, 325 building should be deleted and total number of facilities reduced. Each of the specific milestones can be met with no impact.

In addition to the listed impacts from the 300 Area Building Retention Scenario itself, there are several TPA impacts shown in the adjusted schedule. These are not caused by the 300 area mitigation activities but reflect conditions of waste sites and remediation status in the 100 and 300 areas. One waste site near the 300 area, 618-7, is currently behind schedule for starting excavation because it is a high risk activity and is being deferred until completion of the project's Integrated Safety Management System (ISMS) verification and readiness evaluations. The schedule shows completion of the site later than the TPA milestone. Several 100 area milestones are also under negotiation such as milestones for $100 \mathrm{~B} / \mathrm{C}, 100 \mathrm{H}$, and IU-2 and IU-6. Again these milestone impacts are not related to the 300 area mitigation plan activities but the schedule reflects the current and planned status of the sites.

\subsection{OVERALL SCHEDULE IMPACT}

Due to the mitigation activities described in Section 7.2, there was a significantly reduced impact to the RCC end date of August 29, 2013 in this mitigation scenario. The 326 building is on the critical path for 300 Area D4 activities in the IPB. Although this scenario introduces a 17-month delay in the 326 building release date, the scenario results in a mitigation of all but a six week extension in the completion date, from August 29, 2013 to October 15, 2013. Note that this does not reflect an adjustment to the target date for the RCC Contract for use in calculating the schedule acceleration performance fee which would be addressed in a separate Request for Equitable Adjustment. 


\subsection{COST IMPACT}

This scenario resulted in a net decrease to the total project cost of approximately $\$ 206 \mathrm{M}$ as shown in the cost spreadsheet (Figure 7-1). Scope deletions from the $100 \mathrm{~K}$ area totaled $\$ 125 \mathrm{M}$ (\$110M including contingency and escalation and \$15M for ERDF disposal costs). Scope deletions from the 300 Area totaled $\$ 90 \mathrm{M}$ (\$85.7M including contingency and escalation and $\$ 4 \mathrm{M}$ for ERDF disposal costs). Scope additions included $\$ 1.6 \mathrm{M}$ for added complexity of sixteen waste sites in the 300 Area, $\$ 12.7 \mathrm{M}$ for the utility relocation project including escalation and contingency, and $\$ 12.9 \mathrm{M}$ in time-related costs (hotel load) for the six week contract extension. The net change in scope was a reduction of $\$ 188 \mathrm{M}$. An additional $\$ 18.3 \mathrm{M}$ of reductions in fee, pension and miscellaneous were deleted based on the scope reductions. 


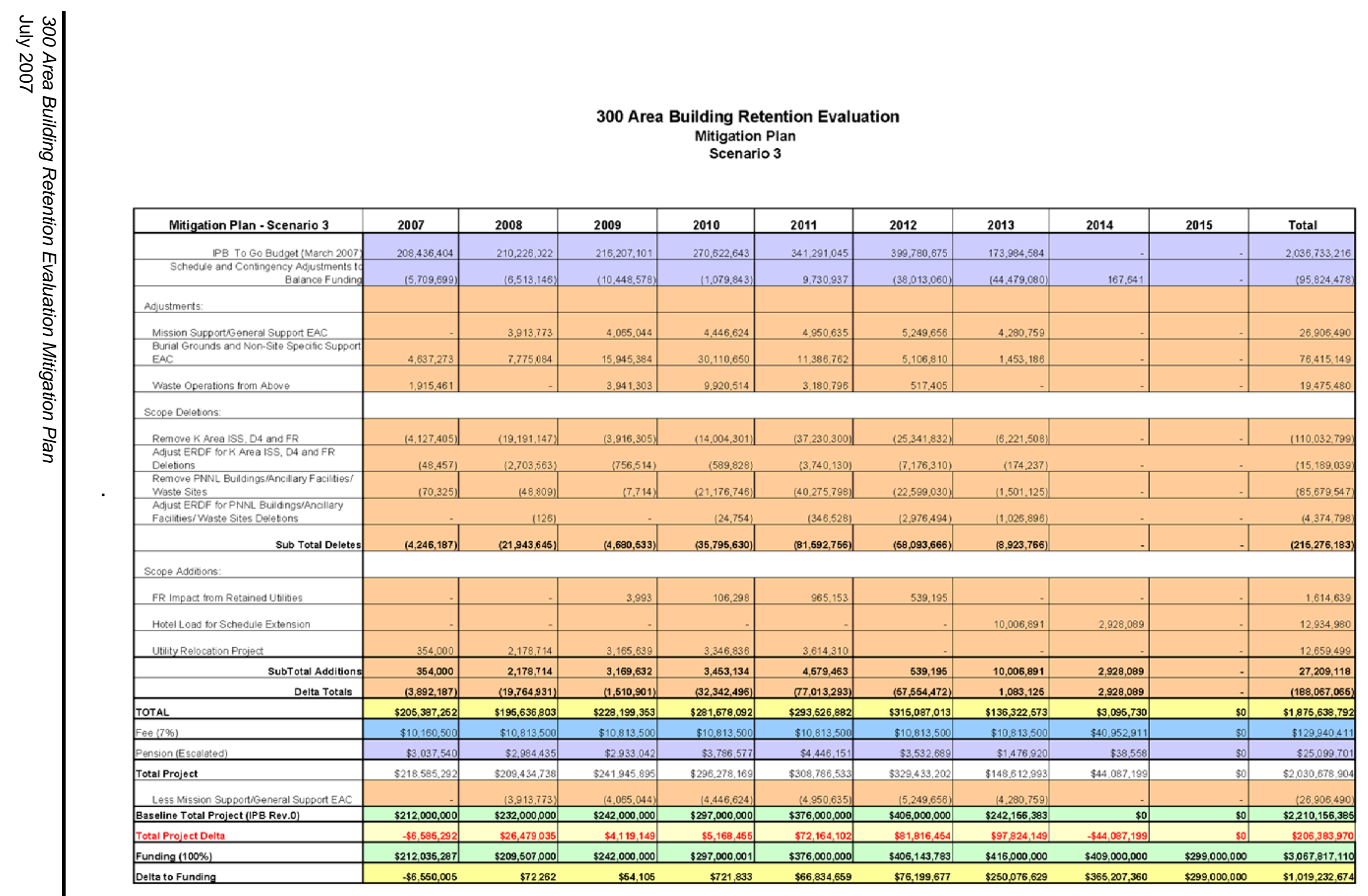




\subsection{CONCLUSION/SUMMARY}

This mitigation plan identifies a plan and approach for mitigating the impacts of the long-term retention of four laboratory complexes and multiple support facilities in the 300 Area to a minimal effect on the cost and schedule of the River Corridor Closure Contract. When integrated with the effect of removing $100 \mathrm{~K}$ area facilities, reactors and waste sites from the RCC scope, a net reduction in the cost of the RCC of between $\$ 205 \mathrm{M}$ and $\$ 220 \mathrm{M}$ resulted for the three release scenarios evaluated.

The majority of the impacts are the same between Scenarios 1, 2, and 3 and will be discussed as a group. The specific differences between the scenario impacts are limited to the total cost and schedule impact and are described separately for each scenario. A detailed discussion of the impacts is provided in Sections 5, 6, and 7.

- Removal of the 300 Area facilities and waste sites from the WCH contract resulted in a direct reduction to the Baseline Target Cost of \$65 million (\$89 million including contingency and escalation.)

- Removal of the 100K Area facilities and waste sites from the WCH contract resulted in a direct reduction to the Baseline Target Cost of $\$ 93$ million ( $\$ 125$ million including contingency and escalation).

- A conceptual design and cost estimate were prepared for utility relocations in support of the retained and delayed facilities. The total cost for the utility relocations was estimated at approximately $\$ 12 \mathrm{M}$ including contingency (Appendix $\mathrm{A}$ ). The escalated cost estimate is $\$ 12.7 \mathrm{M}$. The utility relocation costs were spread from FY 2008 through FY 2011 as described in Section 4 to optimize the construction schedule since no added funding was provided by $\mathrm{RL}$ in the mitigation planning.

- $\quad$ Tri-Party Agreement (TPA) milestone impacts from the mitigation plan were limited to those sites already identified for changes as discussed above for the100 areas, and 300 area milestones directly affected by the retention of waste sites or buildings identified in milestones. The following 300 Area milestones are affected:

M-016-00: Complete Remedial Actions for all non-Tank Farms Operable Units by 9/30/2024. Impact: Waste sites underlying the retained facilities or retained active utility systems will not be completed as part of the RCC scope. They will be deferred until the retained facilities are vacated (20+ years).

M-016-00B: Complete all interim 300 Area remedial actions including the 618-10 and 618-11 burial grounds by 9/30/2018.

Impact: Waste sites underlying the retained facilities or retained active utility systems will not be completed as part of the RCC scope. They will be deferred until the retained facilities are vacated (20+ years).

M-016-69: Complete all interim 300 Area remedial actions to include confirmatory sampling of all candidate sites listed in the 300-FF-2 ROD (except 618-10 and 618-11 burial grounds) by $9 / 30 / 2015$. 
Impact: Waste sites underlying the retained facilities or retained active utility systems will not be completed as part of the RCC scope. They will be deferred until the retained facilities are vacated (20+ years).

M-016-74: Complete interim remediation(to include excavation, loadout, closeout sampling, backfill and revegetation), for all 300 Area "inside the fence" waste sites north of Apple Street, except for the 300-RLWS, 300-15, 300-4, 300-268 and 300-123 waste sites remediation need only be completed through excavation and loadout by 9/30/2012. Impact: Waste site 300-4 and portions of 300-RLWS and 300-15 are retained and should be removed from the milestone.

M-094-00: Complete disposition of 300 Area surplus facilities to be defined as the 220 facilities listed in the Hanford River Corridor Closure Contract Solicitation \#DE-RP0604RL14655 by 9/30/2015.

Impact: Milestone reference to 220 facilities and reference to \#DE-RP06-04RL14655 are outdated. By updating the references the existing milestone for "surplus" facilities (excluding the retained facilities) can be met.

M-094-06, -07, -08, 09: Complete the selected removal and/or remedial actions that are selected for XX of the following 19 high priority facilities: 305B, 306E, 306W, 307 Retention Basins, 308, 309, 321, 323, 324, 324B, 325, 326, 327, 329, 333, 340, 3706, 307 Trench and 3720. (Multiple dates)

Impact: Editorial impact, 325 building should be deleted and total number of facilities reduced. Each of the specific milestones can be met with no impact.

- For Scenario 1 (release of 326 and 326-BA in October 2009 and 3790 in February 2011) WCH was able to mitigate the impacts of the delayed release facilities and added scope to avoid a critical path impact to the end date of the RCC contract. This avoids a "hotel load" (time-related cost) impact to the scenario. Total impact of Scenario 1 resulted in a net Baseline Target Cost decrease of $\$ 220$ million (including contingency, escalation, fee, pension, and added utility scope) and no change to the RCC completion date of August 29, 2013.

- For Scenario 2 (326, 326-BA, and 3790 released February 2011) WCH was able to mitigate the impacts of the delayed release facilities and reduce the impact from the 17 months delayed release of Building 326 to a critical path impact of 6 weeks to the end date of the RCC contract. This minimized the "hotel load" (time-related cost) impact to the scenario. However, this mitigation plan does not reflect an equitable adjustment to performance fee to account for the favorable variance status (ahead of schedule and under budget) through 2007 that enabled the successful mitigation. Total impact of Scenario 2 resulted in a net Baseline Target Cost decrease of $\$ 205$ million (including contingency, escalation, fee, pension, utility scope, and hotel loads) and a change to the RCC completion date from August 29, 2013 to October 15, 2013.

- For Scenario 3 (326 and 326-BA released February 2011 and 3790 retained long-term) WCH was able to mitigate the impacts of the delayed release facilities and reduce the impact from the 17 months delayed release of Building 326 to a critical path impact of 6 weeks to the end date of the RCC contract. This minimized the "hotel load" (time-related cost) impact to the scenario. However, this mitigation plan does not reflect an equitable adjustment to performance fee to account for the favorable variance status (ahead of 
schedule and under budget) through 2007 that enabled the successful mitigation. Total impact of Scenario 3 resulted in a net Baseline Target Cost decrease of \$206 million (including contingency, escalation, fee, pension, utility scope, and hotel loads) and a change to the RCC completion date from August 29, 2013 to October 15, 2013.

In summary, there appear to be minimal differences between the three scenarios evaluated. The two options for delayed release of the 326 Building (October 2009 or February 2011) result in a six week difference in the end date of the RCC contract, either August 29, 2013 (as in the current WCH contract) or October 15, 2013. The delay causes an increased time-related cost ("hotel load") of approximately \$12.9M The options for either delayed release or long-term retention of Building 3790 result in essentially no difference in RCC schedule, and the cost difference is simply the deletion of approximately $\$ 0.7 \mathrm{M}$ scope associated with the demolition of Building 3790.

All scenarios result in impacts to the long-term configuration of waste sites remaining in the 300 Area, since there are waste sites associated with the retained facilities and utility systems that will be inaccessible for the assumed 20-year duration of facility occupancy. TPA milestones associated with the retained 300 Area facilities and waste sites will require renegotiation to reflect the changed scope. In addition, any facilities or sites deleted from the current RCC contract for long-term retention will at some point require remediation at a presumably higher cost due to escalation.

WCH recommends proceeding with the definitive design and construction phase of the utility relocation project. Any of the three mitigation scenarios appear to be viable depending on the Government's needs regarding facilities 326 and 3790. 


\subsection{REFERENCES}

1. Letter 06-AMRC-0300, S. L. Sedgwick, RL, to P. L. Pettiette, WCH, "CONTRACT NO. DE-AC06-05RL14655 - BUILDING RETENTION EVALUATION," dated September 20, 2006.

2. Letter 130269, S. L. Feaster, WCH, to S. L. Sedgwick, RL, "CONTRACT NO. DE-AC06-05RL14655 - BUILDING RETENTION EVALUATION," dated October 17, 2006.

3. Letter 07-AMRC-0062, S. L. Sedgwick, RL to P. L. Pettiette, WCH, "CONTRACT NO. DE-AC06-05RL14655 - 300 AREA MITIGATION PLANNING," dated January 17, 2007.

4. Letter 07-AMRC-0107, J. Osso, RL, to C. G. Spencer, WCH, "CONTRACT NO. DE-AC06-05RL14655 - 300 AREA MITIGATION PLANNING," dated February 16, 2007.

5. Letter 07-AMRC-0141, S. L. Sedgwick, RL, to C. G. Spencer, WCH, "CONTRACT NO. DE-AC06-05RL14655 - 300 AREA MITIGATION PLANNING," dated April 19, 2007

6. Letter 133508, S. L. Feaster, WCH, to S. L. Sedgwick, RL, "CONTRACT NO. DE-AC06-05RL14655 - 300 AREA MITIGATION PLANNING," dated April 30, 2007.

7. Letter 07-FMD-0077, S. L. Sedgwick, RL, to C. G. Spencer, WCH, "CONTRACT NO. DE-AC06-05RL14655 - FISCAL YEAR (FY) 2007 FUNDING ESTIMATE AND FY 2008/2009 FUNDING GUIDANCE," dated May 11, 2007.

8. Letter 07-AMRC-0202, S. L. Sedgwick, RL, to C. G. Spencer, WCH, "CONTRACT NO. DE-AC06-05RL14655 - 300 AREA MITIGATION PLANNING," dated June 5, 2007.

9. Letter 07-AMRC-0216, S. L. Sedgwick, RL, to C. G. Spencer, WCH, "CONTRACT NO. DE-AC06-05RL14655 - 300 AREA MITIGATION PLANNING," dated June 8, 2007

10. Letter 07-AMRC-0218, R. L. Dawson, RL, to C. G. Spencer, WCH, "CONTRACT NO. DE-AC06-05RL14655 - 300 AREA PLANNING ASSUMPTIONS RELATED TO 300 AREA MITIGATION PLANNING," dated June 12, 2007. 
WCH-181

References

Rev. 0 


\section{APPENDIX A}

300 AREA UTILITY RELOCATION PROJECT COST ESTIMATE 
WCH-181

Rev. 0 


\title{
COST ESTIMATE REPORT
}

Closure

Hantord

\author{
Cost Estimate 1004 \\ 300 Area Utility Relocation Project \\ Status: \\ Est Type: \\ Pre-Conceptual Design \\ ROM \\ Task Manager: \\ Estimating Manager: \\ Project Estimator: \\ Don McBride \\ Doug Ahmer \\ Bruce Wilcox \\ Project Estimator: \\ Dan Jakubek
}




\begin{tabular}{|c|c|c|c|c|}
\hline 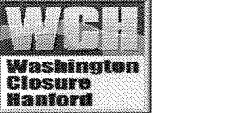 & Cost Estimat & & & 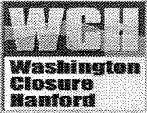 \\
\hline $\begin{array}{r}\text { TITLE: } \\
\text { AREA: } \\
\text { Estimate Requestor: } \\
\text { Prepared By: }\end{array}$ & $\begin{array}{l}300 \text { AREA UTILITY RELOCATION PROJECT } \\
300 \text { Area } \\
\text { D. McBride } \\
\text { bwwilcox/djiakubek/dwahmer }\end{array}$ & $\begin{array}{cc}\text { Date Prepared: } & 04 / 30 / 06 \\
\text { Date Revised: } & 06 / 05 / 07\end{array}$ & $\begin{array}{l}\text { Estimate Number: } \\
\text { Revision: } \\
\text { WBS Number: } \\
\text { Estimate Type: }\end{array}$ & $\begin{array}{l}1004 \\
\text { Rev 0 } \\
1.04 \\
\text { ROM }\end{array}$ \\
\hline
\end{tabular}

1.0 Purpose / Scope Description:

Provide ROM estimates for new, relocated and reused systems needed to provide utility services (Water, Sewer, Electrical and infromation Technology) to facilities planned for long tern retention in the Hanford the 300 Area.

2.0 Scope of Estimate

The Washington Closure Hanford (WCH) River Corridor Closure (RCC) scope includes the deactivation, decommissioning, decontamination and demolition (D4) of 210 buildings located in the Hanford 300 Area, followed by field remediation of waste sites in the affected areas.

Thirteen facility complexes in this area are currently occupied by the Pacific Northwest National Laboratory (PNNL) and have a delayed release to WCH for D4. The RCC contract specifies a release date of October 1, 2009 for turnover of these facilities.

The Department of Energy, Richland Operations Office (RL) has informed WCH that the replacement laboratory facilities that will be used to relocate PNNL's activities will not be ready for occupancy by the 2009 release date and changes to the WCH contract will be necessary.

Several of the facilities will be retained by PNNL long-term (assumed $>20$ years) and several support facilities will be retained by other Hanford contractors such as the Project Hanford Management Contractor (PHMC) or Johnson Controls, Inc. (JCI).

WCH and PNNL have jointly identified opportunities for the early release of several of the PNNL facilities that could reduce the impact of delays for the remaining facilities

Several scenarios have been specified by RL for evaluation in a mitigation plan. The scenarios vary in defining transfer dates for several of the facilities. In all scenarios, RL directed WCH to proceed with activities necessary to reroute utilities for the long-term retention facilities identified by RL to ensure their completion by September 2009.

Existing utility services or components will be used provided they do not require relocation or replacement due to planned remediation or demolition activities, and that they provide a reasonable expectation of service life compatible with the planned 20-year occupancy of several of the identified facilities.

The utility system requirements include Potable/Fire Protection Water; Wastewater (Sanitary, Process, Retention Process, and Stormwater); Electrical; Information Technology/Telecommunications; and other miscellaneous services such as natural gas, steam, and compressed air.

Attached are Rough Order of Magnitude (ROM) estimates including scope descriptions, bases and assumptions for the following utility systems: Potable/Fire Protection Water; Wastewater (Sanitary, Retention process, and Stormwater); Electrical; Information Technology/Telecommunications. Estimates for other miscellaneous services such as natural gas, steam, and compressed air are not include in this document.

Also included are costs for WCH Project Management for a duration of 18 months to provide coordination and oversight of all utility modifications.

\subsection{Basis and Assumptions:}

1. Individual Scopes Of Work (SOW) are estimated to be performed by a Subcontractor. Costs for SubK OH\&P are included in each estimate.

2. All estimates assumes SOW does not include work with radioactive or hazardous materials. Assumes Personal Protection Equipment (PPE) beyond hard hat, steel toes \& protective eye wear will not be required by OEM or Subcontractor personnel.

3. Engineering and design basis is conceptual. $10 \%$ of total estimated direct cost is added for ROM engineering costs.

4. In most cases, labor pricing based on FY07 Hanford Site Stabilization Agreement (HSSA) rates.

5. Equipment priced using $80 \%$ of current Blue Book rates.

6. Bulk material pricing and labor unit rates from RS Means Estimating Guide are used where applicable. Local and national vendor pricing is used for major equipment and sub-tier Subcontractors work,

\subsection{Exclusions:}

1. Costs for Contractor management \& oversight are included with each SOW. PM costs are based on an overall duration of 18 months to complete all 300 Area Utility Relocation work as performed by Subcontractors performing work for WCH. Costs for other Hanford Contractors for project support or oversight ARE NOT included in this estimate. Contingency percentages shown below are based on the conceptual nature of the design.

2. Long term operating (lifecycle) costs ARE NOT included in the estimates.

3. Costs are in current dollars. Costs for escalation of materials or services ARE NOT included in the estimates.

\begin{tabular}{|c|c|c|c|c|c|c|c|}
\hline \multicolumn{8}{|l|}{ 5.0 Estimated Cost } \\
\hline \multicolumn{2}{|c|}{ Total estimated cost $(\$ 1,000$ s) } & Estimated Cast & $\begin{array}{l}\text { 10\% Design } \\
\text { Engineering }\end{array}$ & Contingency \% & $\begin{array}{r}\text { Contingency } \\
\$ \$ \$ \$\end{array}$ & $\begin{array}{l}\text { WCH Project } \\
\text { Management }\end{array}$ & TEC \\
\hline \multicolumn{2}{|c|}{ Water Systems Modifications - 382 Replacement } & 2,436 & 244 & $30 \%$ & 804 & 384 & $\$ 3,867$ \\
\hline \multicolumn{2}{|c|}{ Water Systems Modifications - Distribution Sys Maintenance \& Repair } & 846 & 85 & $30 \%$ & 279 & 133 & $\$ 1,343$ \\
\hline \multicolumn{2}{|c|}{ Retention Process Sewer Modifications } & 829 & 83 & $30 \%$ & 274 & 131 & $\$ 1,316$ \\
\hline \multicolumn{2}{|c|}{ Sanitary \& Process Sewer Modifications } & 1,024 & 102 & $30 \%$ & 338 & 161 & $\$ 1,625$ \\
\hline \multicolumn{2}{|c|}{ Storm Sewer Modifications } & 818 & 82 & $30 \%$ & 270 & 129 & $\$ 1,299$ \\
\hline \multicolumn{2}{|c|}{ Electrical Systems Modifications } & 871 & 87 & $30 \%$ & 287 & 137 & $\$ 1,383$ \\
\hline \multicolumn{2}{|c|}{ Information Technology Modifications } & 548 & 55 & $30 \%$ & 181 & 86 & $\$ 870$ \\
\hline \multicolumn{8}{|l|}{ 6.0 Estimate Review } \\
\hline \multicolumn{8}{|l|}{ Estimator } \\
\hline \multicolumn{8}{|l|}{$\begin{array}{l}\text { Estimator } \\
\text { Estimating Manager }\end{array}$} \\
\hline \multicolumn{8}{|l|}{ Task Manager } \\
\hline \multicolumn{8}{|l|}{ Project Controls Lead } \\
\hline
\end{tabular}


WASHINGTON CLOSURE HANFORD

300 AREA UITLITIES - ROM R1 - Est 1004 - 300 Area Utility Relocation Project

Cost Estimate 1004

\section{Water Systems Modifications - 382 Replacement}




\begin{tabular}{|c|c|c|c|c|c|}
\hline 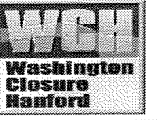 & & Cost Estimate & & & 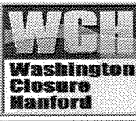 \\
\hline $\begin{array}{r}4 \\
\text { Estimate Re } \\
\text { Prep }\end{array}$ & $\begin{array}{l}\text { TITLE: } \\
\text { AREA: } \\
\text { questor: } \\
\text { ared By: }\end{array}$ & $\begin{array}{l}300 \text { AREA UTILITY RELOCATION PROJECT } \\
\text { WATER SYSTEMS MODIFICATIONS - } 382 \text { REPLACEMENT } \\
300 \text { Area } \\
\text { D. McBride } \\
\text { bwwilcox }\end{array}$ & $\begin{array}{rr}\text { Date Prepared: } & 04 / 12 / 07 \\
\text { Date Revised: } & 06 / 04 / 07 \\
\end{array}$ & $\begin{array}{l}\text { Estimate Number: } \\
\text { Revision: } \\
\text { WBS Number: } \\
\text { Estimate Type: }\end{array}$ & $\begin{array}{l}1004 \text { Water } 1 \\
\text { Rev } 0 \\
1.04 \\
\text { ROM }\end{array}$ \\
\hline
\end{tabular}

1.0 Purpose / Scope Description:

Provide ROM estimate for modifications to the 300 Area water systems. Replacement of the 382 Complex tanks, pumps and related facilities.

\subsection{Scope of Estimate}

The existing water supply to the 300 Area consists of a $16^{n}$ main from the City of Richland feeding a pressure boosting and water distribution facility identified as the 382 Complex that distributes water via looped underground piping systems throughout the 300 Area for potable (domestic) requirements as well as fire protection and process water uses. Modifications to the 300 Area water system are needed to accommodate the demolition of old 300 Area buildings, remediation of waste sites and to assure a reasonable expectation of service life to facilities that are planned for extended operation ( $>20$ years).

Because of the fire protection role, the system is required by DOE orders to have built in redundancy so that a single failure of the water supply, pumps, or mains will not prevent water from being supplied to the system for fire suppression. A looped system is required wherever practicable.

382 Replacement: Install a new pumping station on Cypress St. near Bldg 318 and abandon the 382 Complex of pump houses and storage tanks:

* Abandon 382 complex including tanks \& fire pumping station (382-B) and replace with new skid mounted pumping facility.

* Install new skid mounted pumping station consisting of 4 new pumps including one diesel firewater pump. Equipment will be provided and installed by Original Equipment Manufacturer (OEM)

* Tie new skid into existing 16 " water line from the City of Richland.

* Install a new second 16 " water line from the city and tie into the new pump station providing redundancy.

* Install 2 Reduced Pressure Back Flow Preventers (BFP) instalted in above-ground heated enclosures (Hot Box). One installed on new 16" water line and one on existing $16^{\prime \prime}$ water line.

* Install two new $12^{\prime \prime}$ water lines at Cypress St and from Wisconsin Ave to the existing Fire Station.

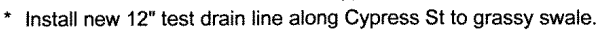

\subsection{Basis and Assumptions:}

1. Options are estimated to be performed by a Subcontractor. Costs for SubK OH\&P are included in the estimate.

2. Assumes scope does not include work with radioactive or hazardous materials. Assume Personal Protection Equipment (PPE) beyond hard hat, steel toes \& protective eye wear will not be required by OEM or Subcontractor personnel.

3. Engineering and design basis is conceptual. $10 \%$ of total estimated direct cost is added for ROM engineering costs.

4. Labor pricing based on FY07 Hanford Site Stabilization Agreement (HSSA) rates.

5. Equipment priced using $80 \%$ of current Blue Book rates.

6. Bulk material pricing and labor unit rates from RS Means Estimating Guide are used where applicable. Local and national vendor pricing is used for major equipment and sub-tier Subcontractors work

7. Pipe for new 16 " line will be ductile iron from connection point at the new Horn Rapids complex to Stevens Dr. From Stevens to new pump station, line will be $16^{\prime \prime}$ Blue Brute PVC pressure pipe.

8. See individual estimate sheets for additional scope and assumptions

\subsection{Exclusions}

1. Costs for Contractor management \& oversight are included below as WCH Project Management. Costs are based on an overall duration of 18 months to complete all 300 Area Utility Relocation work as performed by Subcontractors performing work for WCH. Costs for other Hanford Contractors for project support or oversight ARE NOT included in this estimate. Contingency percentages shown below are based on the conceptual nature of the design.

2. Long term operating (lifecycle) costs ARE NOT included in the estimates.

3. Costs are in current doilars. Costs for escalation of materials or services ARE NOT included in the estimates.

\subsection{Estimated Cost}

Total estimated cost ( $\$ 1,000$ s)

WATER SYSTEMS MODIFICATIONS - 382 REPLACEMENT

Direct Cost

Design Engineering

Contingency

WCH Project Management

6.0 Estimate Review
Estimator
Estimating Manager
Task Manager
Project Controls Lead


Washington Closure Hanford

W. 10.UTLITY OPTIONS: W1 - WATER- 382 REPLACEMENT

300 AREA UITLITIES - ROM R1 - Est 1004 - 300 Area Utility Relocation Project

02 - Direct Cost

\begin{tabular}{|c|c|c|c|c|c|c|c|c|c|c|c|}
\hline & WW1MOB01 * SubK Work Planning \& Preparation & 120.000 & & 630 & 36,429 & & & & & 6,303 & 42,732 \\
\hline & WW1MOB02 - * On-Site Requried Training \& Badging & 0.500 & LS & 186 & 9,460 & & & & 4,942 & 2,492 & 16,894 \\
\hline & WWIMOB03 - * Baseline Physical For Hanford Workers & 1.000 & LS & 40 & 1,828 & & & & & 316 & 2,144 \\
\hline & WW1MOB04 - * SubK Mob Equip, Tools, Materials & 1.000 & LS & 100 & 3,651 & & 1,290 & 1,618 & & 1,135 & 7,693 \\
\hline & WWIMOBOS - * Portable Toilets & 8.000 & Mo & & & & & & 3,504 & 606 & 4,110 \\
\hline & WW1MOB06 -*Two Way Radios & 12.000 & EA & & & & & 5,415 & & 937. & 6,352 \\
\hline & WWIMOB07 * * SubK Field Ofice Facilities Setup & 1.000 & LS & 120 & 5,232 & & & 11,754 & 9,150 & 4,522 & 30,659 \\
\hline & WWIMOPS1 - * Monthly Operations \& Overthead & 8.000 & Mo & 4,980 & 270,009 & & & 650 & 21,904 & 50,620 & 343,183 \\
\hline & WWINEW01 - "New 16" Main - Asphatt Cutting \& Removal & 266.000 & SY & 20 & 726 & & 410 & 496 & 360 & 345 & 2,337 \\
\hline & WW1NEW02 - "New 16" Main - Excavation \& Sand Bedding. & $6,700.000$ & $\mathrm{BCY}$ & 258 & 9,273 & 13,538 & 6,403 & 5,797 & 10,000 & 7,788 & 52,798 \\
\hline & WWINEW03 - * New 16 "Main - Blue Brute Pipe \& Valve Installat & $5,600.000$ & $L F$ & 2,328 & 95,864 & 227,933 & 8,825 & 17,751 & & 60,622 & 410,994 \\
\hline & WWINEW04 - *New 16" Main - Ductile Iron Pipe Installation & $1,100.000$ & LF & 1,100 & 46,083 & 116,554 & 6,688 & 9,950 & & 31,019 & 210,293 \\
\hline & WWINEW05 - * New $16 "$ Main - Recuced Pressure BFP Installation & 2.000 & EA & 330 & 13,575 & 79,893 & 2,111 & 3,211 & & 17,093 & 115,884 \\
\hline & WWINEW06 - "New 16" Main - Electrical Service to BFPs & 2.000 & EA & 220 & 8,656 & 4,874 & 329 & 723 & & 2,523 & 17,105 \\
\hline & WWINEW07 - * New 16" Main - Backfill \& Compaction & $7,370.000$ & LCY & 524 & 18,627 & 16,307 & 7,491 & 6,981 & & 8,548 & 57,954 \\
\hline & WW1NEW08 - *New $16 "$ Main - Pipeline Bridge at Heavy Haul Roa & 1.000 & EA & 200 & 7,203 & 3,812 & 85 & 589 & & 2,022 & 13,712 \\
\hline & WW1NEW09 - *New 16"Main-Road Repair & 108.000 & SY & & & & & & 905 & 156 & 1,061 \\
\hline & WW1NEW10 - "New 16" Main - Flush \& Test New Line & 1.000 & LS & 160 & 7,234 & & 136 & 223 & & 1,314 & 8,907 \\
\hline & WWINEW11 - * i2" Cypress Main - Asphalt Cutting \& Removal & 1.000 & LS & 20. & 726 & & 410 & 496 & 600 & 386 & 2,618 \\
\hline & WW1NEW12 - * 12" Cypress Main - Excavation \& Sand Bedding. & 650.000 & $\mathrm{BCY}$ & 125 & 4,473 & 1,354 & 3,278 & 2,937 & 10,000 & 3,814 & 25,855 \\
\hline & WW 1 NEW13 - * 12 "Cypress Main - Pipe \& Valve Installation & 650.000 & LF & 388 & 15,887 & 35,185 & 3,837 & 4,722 & & 10,317 & 69,948 \\
\hline & WW1NEW14 - * 12" Cypress Main - Backfill \& Compaction & 715.000 & LCY & 113 & 3,978 & 1,745 & 717 & 672 & & 1,231 & 8,344 \\
\hline & WW1NEW16 - " 12" Cypress Main - Road Repair & 108.000 & SY & & & & & & 838 & 145 & 982 \\
\hline & WW1NEW21 - *12" Fire Station Main - Asphatt Cutting \& Remova & 1.000 & LS & 20. & 726 & & 410 & 496 & 600 & 386 & 2,618 \\
\hline & WWINEW22 - "12" Fire Station Main - Excavation \& Sand Beddi & 650.000 & $\mathrm{BCY}$ & 125 & 4,473 & 1,354 & 3,278 & 2,937 & 10,000 & 3,814 & 25,855 \\
\hline & WW1NEW23 - *12" Fire Station Main - Pipe \& Valve Installatatio & 650.000 & LF & 388 & 15,887 & 30,574 & 3,837 & 4,722 & & 9,520 & 64,539 \\
\hline & WW1NEW24 - *12" Fire Station Main - Backill \& Compaction & 715.000 & LCY & 113 & 3,978 & 1,745 & 717 & 672 & & 1,231 & 8,344 \\
\hline & WW1NEW26* "12" Fire Station Main - Road Repair & 0.010 & LS & & & & & -4 & 838 & 145 & 982 \\
\hline & WW1NEW27 - *12" Fire Station Main - Flush \& Test New Line & 1.000 & LS & 80[ & 3,617 & & 68 & 112 & & 657 & 4,453 \\
\hline & WW1NEW31 - * 12" Test Drain - Asphalt Cutting \& Removal & 1.000 & LS & 10 & 363 & & 80 & 129 & 600 & 203 & 1,374 \\
\hline & WWINEW32 - "12" Test Drain - Excavation \& Backiill. & 650.000 & $\mathrm{BCY}$ & 30 & 1,028 & & 165 & 182 & & 238 & 1,613 \\
\hline & WWINEW33 - * 12" Test Drain - Pipe \& Valve Installation & 390.000 & $L F$ & 218 & 9,194 & 13,705 & 197 & 839 & & 4,141 & 28,076 \\
\hline & WWINEW36 - * i2" Test Drain - Road Repair & 0.010 & LS & & & & & & 168 & 29 & 196 \\
\hline & WWIPMP01 - * New Pump Station - Excavation \& Backfill & 100.000 & $\mathrm{BCY}$ & 10 & 366 & & 212 & 199 & 2,000 & 481 & 3,258 \\
\hline & WW1PMPO2 - * New Pump Station - Modular Bldg Foundation & 30.000 & CY & 200 & 7,310 & 3,899 & 714 & 1,208 & & 2,272 & 15,403 \\
\hline & WW1PMPO3 - " New Punp Station - Pump Station Installation & 1.000 & LS & 240 . & 9,740 & 434,283 & 1,779 & 2,057 & 10,000 & 79,220 & 537,077 \\
\hline & WWIPMP04 - * New Pump Station - New Electrical Service & 1.000 & LS & 220 & \begin{tabular}{ll|l}
9,528 \\
\end{tabular} & 30,866 & 320 & 834 & & 7,189 & 48,737 \\
\hline & WW1PMPO5 - * New Pump Station - Chlorination System & 1.000 & LS & 120 & 6,291 & 6,498 & & 341 & & 2,272 & 15,401 \\
\hline & WWIPMPO6 - *New Pump Station - Main LIne Connections & 1.000 & LS & 720 & 33,448 & 59,203 & 1,918 & 3,722 & & 17,007 & 115,298 \\
\hline & WW1PMP07 - * New Pump Station - Test Operating Systems & 1.000 & LS & 480 & 24,075 & & & 1,304 & & 4,391 & 29,770 \\
\hline & WW1WNDO1 - * Flush \& Test Entire System & 1.000 & LS & 640 & 28,934 & & 273 & 446 & & 5,131 & 34,784 \\
\hline & WW1 1WND02 - * Site Cleanup & 60.000 & $\mathrm{HR}$ & 360 & 12,529 & & 1,172 & 2,278 & & 2,765 & 18,743 \\
\hline & WW1 WND03 - * SubK DeMob Equip, Tools, Materials & 20.000 & HR & 100 & 3,651 & & 1,290 & 1,618 & & 1,135 & 7,693 \\
\hline & WW1WND04 - * Close Out & 1.000 & LS & 225 & 12,941 & & & & & 2,239 & 15,180 \\
\hline & W1 - WATER - 382 REPLACEMENT & & & 16,218 & 750,608 & $1,083,319$ & 58,509 & 98,192 & 86,407 & 359,373 & $2,436,408$ \\
\hline
\end{tabular}


WASHINGTON CLOSURE HANFORD

300 AREA UITLITIES - ROM R1 - Est 1004 - 300 Area Utility Relocation Project

Cost Estimate 1004

\section{Water Systems Modifications - Distribution Sys Maintenance \& Repair}




\begin{tabular}{|c|c|c|c|c|}
\hline 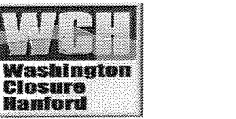 & \multicolumn{3}{|l|}{ Cost Estimate Summary } & 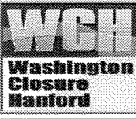 \\
\hline $\begin{array}{l}\text { TITL: } \\
\text { AREA: } \\
\text { Estimate Requestor: } \\
\text { Prepared By: }\end{array}$ & $\begin{array}{l}300 \text { AREA UTILITY RELOCATION PROJECT } \\
\text { WATER SYSTEMS MODIFICATIONS - DISTRIBUTION MAINTENANCE \& REPAIR } \\
300 \text { Area } \\
\begin{array}{l}\text { D. McBride } \\
\text { bwwilcox }\end{array} \\
\end{array}$ & $\begin{array}{l}04 / 12 / 107 \\
06 / 04 / 07\end{array}$ & $\begin{array}{r}\text { Estimate Number: } \\
\text { Revision: } \\
\text { WBS Number: } \\
\text { Estimate Type: }\end{array}$ & $\begin{array}{l}1004 \text { Water } 2 \\
\text { Rev } 0 \\
1.04 \\
\text { ROM }\end{array}$ \\
\hline
\end{tabular}

1.0 Purpose I Scope Description:

Provide ROM estimate for Option 1 modifications to the 300 Area water systems. Cleaning and relining water distribution systems.

2.0 Scope of Estimate

The existing water supply to the 300 Area consists of a $16^{\prime \prime}$ main from the City of Richland feeding a pressure boosting and water distribution facility identified as the 382 Complex that distributes water via looped underground piping systems throughout the 300 Area for potable (domestic) requirements as well as fire protection and process water uses. Modifications to the 300 Area water system are needed to accommodate the demolition of old 300 Area buildings, remediation of waste sites and to assure a reasonable expectation of service life to facilities that are planned for extended operation ( $>20$ years).

Because of the fire protection role, the system is required by DOE orders to have built in redundancy so that a single failure of the water supply, pumps, or mains will not prevent water from being supplied to the system for fire suppression. A looped system is required wherever practicable.

Distribution Maintenance \& Repair: Clean \& reline $\sim 3,500$ If and clean only $\sim 1,240$ If of existing ungerground water distribution piping throughout the 300 Area. Scope includes:

* Clean \& Re-line $~-3,500$ LF of existing 8 " underground water lines. Install new valves as required.

* Requies excavation to depth at major intersections of distribution systems piping to allow cleaning access at two ends of maixmim 600-700 if runs.

* Scrape and clean existing pipe lines using mechanical tools pulted through lines with cables. Flush line following cleaning.

* Refurbish pipe interiors using cement slurry lining pressure applied and trowled using mechanical tools pulled from one end of open line.

* Replace pipe spool removed for cleaning, install new valves as required, backfill \& compact excavations, repair concrete or asphalt roadways.

* Pig clean only 1,240 LF of existing 8 " underground water lines from Wisconsin at Hemlock to 6 " line near Fire Hydrant 80 . Requires installation of launch and retrieval spools in existing lines.

* Requies excavation to depth at major intersections of distribution systems piping to allow cleaning access at two ends of maixmim 2,000-2,400 if runs.

* Install permanent launch \& retrieval ports near intersections. Assumes access excavations and backfill will be smaller than with Clean \& Reline.

* Pig existing pipe lines using consecutively more aggressive honing tools pulled through lines with cables. Flush line following cleaning.

\subsection{Basis and Assumptions:}

1. Options are estimated to be performed by a Subcontractor. Costs for SubK OH\&P are included in the estimate.

2. Assumes scope does not include work with radioactive or hazardous materials. Assume Personal Protection Equipment (PPE) beyond hard hat, steel toes \& protective eye wear will not be required by OEM or Subcontractor personnel.

3. Engineering and design basis is conceptual. $10 \%$ of total estimated direct cost is added for ROM engineering costs.

4. Labor pricing based on FY07 Hanford Site Stabilization Agreement (HSSA) rates.

5. Equipment priced using $80 \%$ of current Blue Book rates.

6. Bulk material pricing and labor unit rates from RS Means Estimating Guide are used where applicable. Local and national vendor pricing is used for major equipment and sub-tier Subcontractors work,

7. See individual estimate sheets for additional scope and assumptions .

\subsection{Exclusions:}

1. Costs for Contractor management \& oversight are included below as WCH Project Management. Costs are based on an overall duration of 18 months to complete all 300 Area Utility Relocation work as performed by Subcontractors performing work for WCH. Costs for other Hanford Contractors for project support or oversight ARE NOT included in this estimate. Contingency percentages shown below are based on the conceptual nature of the design.

2. Long term operating (ilfecycle) costs ARE NOT included in the estimates

3. Costs are in current dollars. Costs for escalation of materials or services ARE NOT included in the estimates.

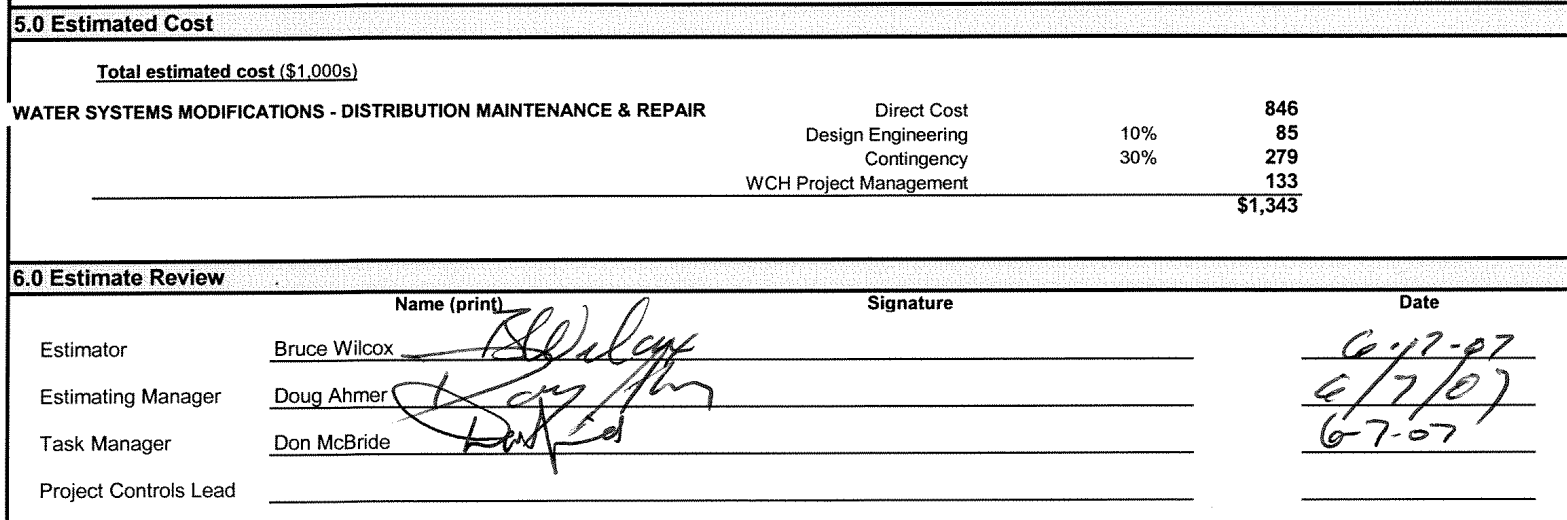


$\sum_{\underline{\Sigma}}^{\infty}$

ㄱㅇㅇ

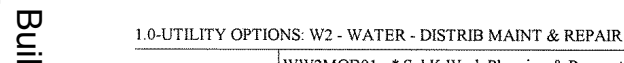

WW2MOBO1 - * SubK Work Plamning \& Prepration

ํㅡㄹ

D

$\stackrel{\Phi}{\Phi}$

$\stackrel{\mathbb{1}}{\stackrel{0}{*}}$

은

m

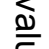

$\stackrel{\text { D. }}{\stackrel{2}{*}}$

운

ঔ

$\stackrel{0 \overline{0}}{\frac{0}{0}}$

후

$\stackrel{0}{\frac{0}{2}}$

Washington Closure Hanford

300 AREA UITLITIES - ROM R1 - Est 1004 - 300 Area Utility Relocation Project 02 - Direct Cost

\begin{tabular}{|c|c|c|c|c|c|c|c|c|c|c|c|}
\hline & WW2MOBO1 - * SubK Work Planning \& Preparation & 80.000 & & 420 & 24,286 & & & & & 4,202 & 28,488 \\
\hline & WW2MOB04 -* SubK Mob Equip, Tools, Materials & 1.000 & LS & 100 & 3,651 & & 1,290 & 1,618 & & 1,135 & 7,693 \\
\hline & WW2MOBOS - * Portable Toilets & 4.000 & MO & & & & & & 1,752 & 303 & 2,055 \\
\hline & WW2MOB06-*Two Way Radios & 6.000 & EA & & & & & 2,708 & & 468 & 3,176 \\
\hline & WW2MOB07 - * SubK Fíeld Office Facilities Setup & 1.000 & LS & 120 & 5,232 & & & 11,754 & 9,150 & 4,522 & 30,659 \\
\hline & WW2MOPS1 - * Monthly Operations \& Overhead & 4.000 & Mo & 2,490 & 135,004 & & & 650 & 10,952 & 25,366 & 171,972 \\
\hline & WW2PIG01 - * Install Pig Launcher & 1.000 & EA & 60 & 3,030 & 3,791 & 395 & 413 & 2,120 & 1,687 & 11,435 \\
\hline & WW2P1G02 - * Construct End of Line Pig Retrieval & 1.000 & $\mathrm{EA}$ & 48 & 2,591 & 1,083 & 190 & 165 & 2,000 & 1,043 & 7,071 \\
\hline & WW2PIG03 - * Clean (Pig Only) 8" Water Line & $1,240.000$ & LF & 30 & 1,233 & 1,083 & & 67. & & 412 & 2,795 \\
\hline & WW2PIG04 - * Backfili, Compaction \& Road Repair & 1.000 & Is & 30 & 1,047 & & 707 & 632 & 838 & 558 & 3,781 \\
\hline & WW2WLNO1 - * Water Main Clean \& Line - Excavation Scan & 9.000 & $\mathrm{EA}$ & & & & & & 18,000 & 3,114 & 21,114 \\
\hline & WW2WLNO2 -* Water Main Clean \& Line - Asphalt Cutting \& Remo & 9.000 & EA & 180 & 6,531 & & 3,691 & 4,466 & 5,400 & 3,476 & 23,563 \\
\hline & WW2WLN03 - * Water Main Clean \& Line - Site Excavation & 9.000 & $\mathrm{EA}$ & 1,584 & 57,652 & 2,112 & 22,366 & 21,862 & & 17,993 & 121,985 \\
\hline & WW2WLN04 - * Water Main Clean \& Line - Pipe Cleaning & $3,480.000$ & LF & 259 & 9,024 & & 2,060 & 2,880 & 95,489 & 18,938 & 128,391 \\
\hline & WW2WLN05 -* Water Main Clean \& Line - Spool \& Valve Replacem & 9.000 & EA & 1,080 & 47,119 & 45,161 & 1,817 & 5,705 & & 17,268 & 117,069 \\
\hline & WW2WLNO6 - * Water Main Clean \& Line - Backfill \& Compaction & 9.000 & EA & 810 & 28,460 & 4,057 & 9,812 & 8,995 & & 8,880 & 60,203 \\
\hline & WW2WLN07 - Water Main Clean \& Line - Road Repair & 9.000 & EA & & & & & & 7,538 & 1,304 & 8,842 \\
\hline & WW2WNDO1 - * Flush \& Test Entire System & 1.000 & Ls & 640 & 28,934 & & 273 & 446 & & 5,131 & 34,784 \\
\hline & WW2WND02 - S Site Cleanup & 60.000 & HR & 360 & 12,529 & & 1,172 & 2,278 & & 2,765 & 18,743 \\
\hline & WW2WND03 - * SubK DeMob Equip, Tools, Materials & 20.000 & HR & 100 & 3,651 & & 1,290 & 1,618 & & 1,135 & 7,693 \\
\hline & WW2WNDO4 - "Close Out & 1.000 & LS & 225 & 12,941 & & & & & 2,239 & 15,180 \\
\hline & wW3MOB02 - * On-Site Requried Training \& Badging & 0.500 & Ls & 186 & 9,460 & & & & 4,942 & 2,492 & 16,894 \\
\hline & WW3MOB03 - * Baseline Physical For Hanford Workers & 1.000 & LS & 40 & 1,828 & & & & & 316 & 2,144 \\
\hline Report Totals: & & & & 66,057 & $3,794,689$ & $1,918,110$ & 268,913 & 365,374 & $1,094,402$ & $1,089,835$ & $8,531,324$ \\
\hline
\end{tabular}


WASHINGTON CLOSURE HANFORD

300 AREA UITLITIES - ROM R1 - Est 1004 - 300 Area Utility Relocation Project

Cost Estimate 1004

\section{Retention Process Sewer Modifications}




\begin{tabular}{|c|c|c|c|c|c|}
\hline $\begin{array}{r}\text { TITLE: } \\
\text { Estimate Requestor: } \\
\text { Prepared By: }\end{array}$ & $\begin{array}{l}300 \text { AREA UTILITY RELOCATION PROJECT } \\
\text { RETENTION PROCESS SEWER MODIFICATIONS } \\
300 \text { Area } \\
\text { D. McBride / John Huber } \\
\text { bwwilcox }\end{array}$ & $\begin{array}{l}\text { Date Prepared: } \\
\text { Date Revised: }\end{array}$ & $\begin{array}{l}04 / 30 / 06 \\
06 / 04 / 07\end{array}$ & $\begin{array}{r}\text { Estimate Number: } \\
\text { Revision: } \\
\text { WBS Number: } \\
\text { Estimate Type: }\end{array}$ & $\begin{array}{l}1004 \text { RPS } \\
\text { Rev } 0 \\
1.04 \\
\text { ROM }\end{array}$ \\
\hline
\end{tabular}

1.0 Purpose / Scope Description:

Provide ROM estimate for modifications to the 300 Area Retention Process Sewer systems.

2.0 Scope of Estimate

The current and future Retention Process Sewer (RPS) system flows at the 300 Area Bldgs 325,326 and 329 will require rerouting to eliminate discharge into the sanitary sewer lines that currently run to the City of Richland. Proposed modifications include:

ITEM 1.1: Install two new discharge sump pumps into manhole RPS-3. Run new pressurized discharge line from manhole to new Load-Out facility. Includes:

* Core drill wall of existing manhole to accept new pressurized discharge line and power source conduit. Grouting openings on completion.

* Cut \& cap 8" gravity discharge lines to sanitary sewer at exterior of manhole structure. Requires excavation to -13 below finished grade

* Install new electrical service to the pumps. Assume power is available within 100 feet of the manhole.

* Excavate $50 \mathrm{ft}$ long, $4 \mathrm{ft}$ deep trench from manhole to new Load Out facility and install $1.5^{\prime \prime}$ pressurized PVC line.

ITEM 1.2: Construct new RPS Load-Out Facility at the current Bidg 328 site. Assumes Bidg 328 will be gone. Includes:

* Construct $30^{\prime} \times 30^{\prime} \times 8^{\prime \prime}$ thick concrete tank pad with $9^{\prime \prime}$ spill containment curb around perimeter. Slab will have $3^{\prime} \times 3^{\prime} \times 3^{\prime}$ deep closed sump below grade to collect potential spills and rainwater.

* Construct $12^{\prime} \times 50^{\prime} \times 6^{\prime \prime}$ thick concrete truck pad with 6" spill containment curb around perimeter. Install gravity drain from truck pad to sump at tank pad.

* Construct $36^{\prime} \times 50^{\prime} \times 20^{\prime}$ high open sided steel shelter over tank slab and truck pad to protect facility from collecting rainwater.

* Install 4 ea 1,000 gal tanks and associated piping, valves and controls on slab. Install submersible pump in $3 \times 3$ sump.

* Provide new electrical service to facility equipment. Assume power is available within 100 yards of the new structure.

* Install 6" drain from the new Load-Out facility to SS-38 sewer manhole.

ITEM 1.3: Modifications to various RPS sewer lines. Includes:

* Storm water isolation: Cut \& cap 4" PVC RPS sewer line as it exits the East side of Bldg 329. Requires asphalt cutting \& removal and excavation to $-4 \mathrm{ft}$ below finished grade.

* 329 PS to RPS Tie-In: Cut \& cap 3" PS line to small collection tank. Reroute line and tie into existing $2^{n}$ RPS line.

* 326 PS to RPS Tie-In: Cut concrete floor and install $20^{\prime \prime} \times 20^{\prime \prime} \times 36^{\prime}$ deep sump below floor level. Cut, cap and reroute $8^{\prime \prime}, 2^{\prime \prime}$ and $1.5^{\prime \prime}$ pipes to sump. Install 15 GPM sump pump including new power service. Install 125 If of new $1.5^{\prime \prime}$ CS line from pump to tie-in to existing $2^{\prime \prime}$ RPS line.

3.0 Basis and Assumptions

1. Options are estimated to be performed by a Subcontractor. Costs for SubK OH\&P are included in the estimate.

2. Assumes scope does not include work with radioactive or hazardous materials. Assume Personal Protection Equipment (PPE) beyond hard hat, steel toes \& protective eye wear will not be required by OEM or Subcontractor personnel.

3. Engineering and design basis is conceptual. $10 \%$ of total estimated direct cost is added for ROM engineering costs.

4. Labor pricing based on FY07 Hanford Site Stabilization Agreement (HSSA) rates.

5. Equipment priced using $80 \%$ of current Blue Book rates.

6. Bulk material pricing and labor unit rates from RS Means Estimating Guide are used where applicable. Local and national vendor pricing is used for major equipment and sub-tier Subcontractors work,

7. See individual estimate sheets for additional scope and assumptions

\subsection{Exclusions:}

1. Costs for Contractor management \& oversight are included below as WCH Project Management. Costs are based on an overall duration of 18 months to complete all 300 Area Utility Relocation work as performed by Subcontractors performing work for WCH. Costs for other Hanford Contractors for project support or oversight ARE NOT included in this estimate. Contingency percentages shown below are based on the conceptual nature of the design.

2. Long term operating (lifecycle) costs ARE NOT included in the estimates.

3. Costs are in current dollars. Costs for escalation of materials or services ARE NOT included in the estimates.

5.0 Estimated Cost

Total estimated cost ( $\$ 1,000$ s)

RETENTION PROCESS SEWER MODIFICATIONS

Direct Cost

Design Engineering Contingency

WCH Project Management

$10 \%$

$\begin{array}{ll}30 \% & 274 \\ & 131\end{array}$

829

$\frac{131}{316}$

6.0 Estimate Review
Estimator
$\begin{aligned} & \text { Estimating Manager } \\ & \text { Task Manager }\end{aligned}$


气

1.0-UTILITY OPTYNS: S2 - RETENTION PROCESS SEWER

\begin{tabular}{l|l}
\hline ㄹ. & WRPAMOB1 - SubK Work Planning \& Preparation \\
\hline
\end{tabular}

亏ิ

D

$\stackrel{\text { D. }}{\vec{D}}$

궁

药

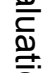

후

कृष्ठ

300 AREA UITLITIES - ROM R1 - Est 1004 - 300 Area Utility Relocation Project 02 - Direct Cost

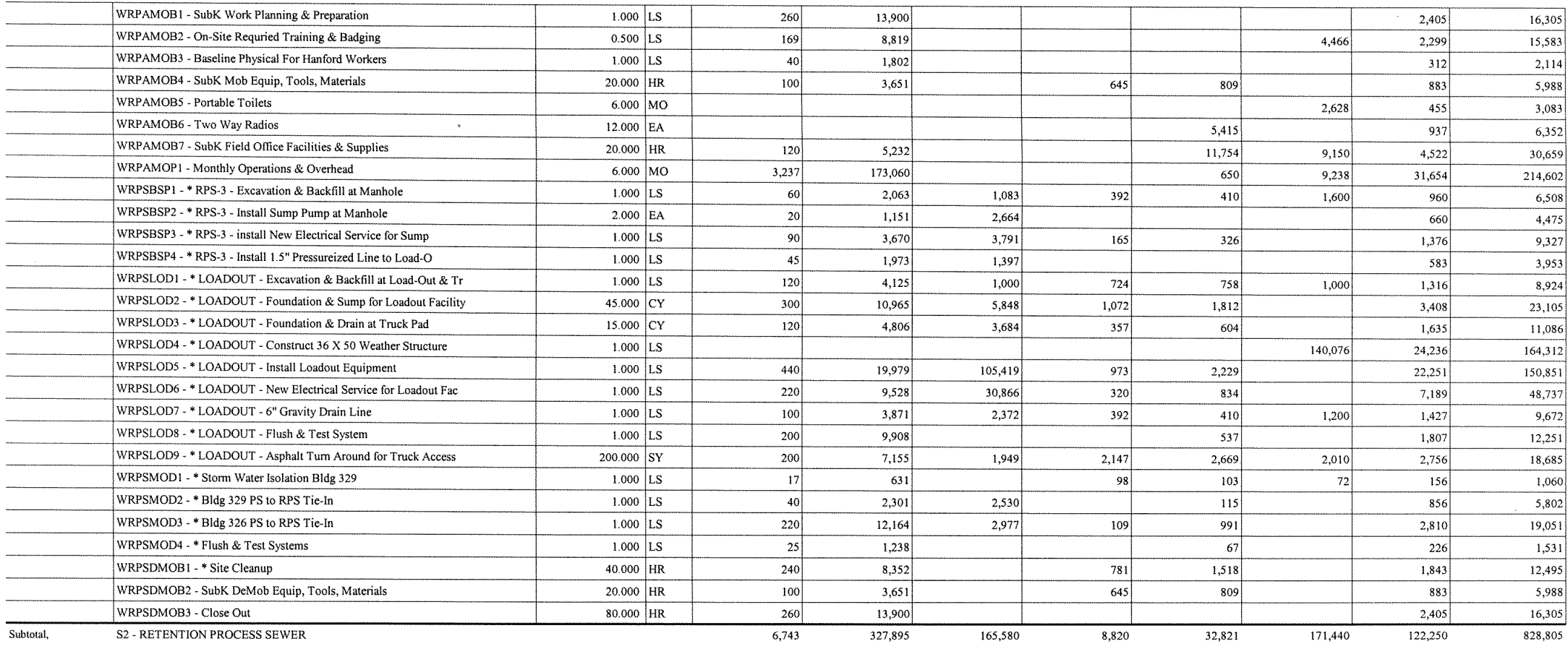


WASHINGTON CLOSURE HANFORD

300 AREA UITLITIES - ROM R1 - Est 1004 - 300 Area Utility Relocation Project

Cost Estimate 1004

\section{Sanitary \& Process Sewer Modifications}




\begin{tabular}{|c|c|c|c|c|c|}
\hline $\begin{array}{c}\text { TITLE: } \\
\text { Astimate Requestor: } \\
\text { Prepared By: }\end{array}$ & $\begin{array}{l}300 \text { AREA UTILITY RELOCATION PROJECT } \\
\text { SANITARY \& PROCESS SEWER MODIFICATIONS } \\
300 \text { Area } \\
\text { D. McBride / Tom Ambalam } \\
\text { bwwilcox }\end{array}$ & $\begin{array}{l}\text { Date Prepared: } \\
\text { Date Revised: }\end{array}$ & $\begin{array}{l}04 / 30 / 06 \\
06 / 04 / 07 \\
\end{array}$ & $\begin{array}{r}\text { Estimate Number: } \\
\text { Revision: } \\
\text { wBS Number: } \\
\text { Estimate Type: }\end{array}$ & $\begin{array}{l}1004 \text { SS } \\
\text { Rev O } \\
1.04 \\
\text { ROM } \\
\end{array}$ \\
\hline
\end{tabular}

1.0 Purpose/ Scope Description:

Estimate modifications to Sanitary Sewer systems for the remaining facilities at the 300 Area.

\subsection{Scope of Estimate}

Existing Sanitary Sewer systems for the 300 Area retained facilities will remain connected and in some cases modified to allow discharge of the total flow to a trunk line connected to the City Of Richland (COR). Current gravity flows will be reversed requiring 4 new lift stations and new sewer lines in several locations.

NEW LIFT STATIONS: Install 4 new lift stations (manholes) at strategic locations to collect sanitary sewer flows and pump through force main lines to a connection point with the COR $8^{\prime \prime}$ sewer at the George Washington Way extension. Scope includes:

* Excavate and install new concrete manholes including weather proof hatch and internal access ladder.

* Install duel submersible pumps, valves, floats, pipe, guide rails, lift chain, etc in concrete manholes.

* Provide controls panel (including remote alarm and telemetry systems) and new electrical service for each lift station.

* Core drill manholes as required to accept electric conduits, upstream and downstream flow piping.

* Shoring at excavations as required for UG utility support and safety

NEW FORCE MAIN LINES: Install $2^{\prime \prime}$ and $3^{\prime \prime}$ lines in shallow excavations between lift stations and existing manholes. Scope includes:

* New lines to be 2" or 3" PVC 100 PSI sectional or PE continuous piping. Check valves and gate valves as required.

* Includes hot tap into COR 8" force main line at GW Way Extension.

NEW GRAVITY SEWER LINES: Install 6" and 8 "lines in deep excavations for gravity flows between lift stations and existing manholes. Scope includes:

* New lines to be 6 " or 8 " PVC sectional piping. No check valves or gate valves required.

* Includes asphalt cutting and repair following roadway or parking lot crossings.

* Shoring at excavations as required for UG utility support and safety

SLEEVED FORCE MAIN: Install 2" PE force main line inside existing 8" gravity sewer line 450 LF between two existing manholes. Scope includes:

* Drain, "pig" and clean existing 8" line between manholes and install 2" 100 PSI PE line.

* Includes video record of 8 " line interior following cleaning.

* Seal both ends of 8" at manholes to prevent backflow.

\subsection{Basis and Assumptions:}

1. Options are estimated to be performed by a Subcontractor. Costs for SubK OH\&P are included in the estimate.

2. Assumes scope does not include work with radioactive or hazardous materials. Assume Personal Protection Equipment (PPE) beyond hard hat, steel toes \& protective eye wear will not be required by OEM or Subcontractor personnel.

3. Engineering and design basis is conceptual. $10 \%$ of total estimated direct cost is added for ROM engineering costs.

4. Labor pricing based on FY07 Hanford Site Stabilization Agreement (HSSA) rates.

5. Equipment priced using $80 \%$ of current Blue Book rates.

6. Bulk material pricing and labor unit rates from RS Means Estimating Guide are used where applicable. Local and national vendor pricing is used for major equipment and sub-tier Subcontractors work,

7. Costs for Personal Protection Equipment (PPE) and monitoring by Rad Con Techs (RCT) are included as a precautionary measure for some areas where radionuclide may be encountered. However, remediation of impacted materials or soils is not included in this estimate and is not considered as part of this scope.

8. See individual estimate sheets for additional scope and assumptions

\subsection{Exclusions:}

1. Costs for Contractor management \& oversight are included below as WCH Project Management. Costs are based on an overall duration of 18 months to complete all 300 Area Utility Relocation work as performed by Subcontractors performing work for WCH. Costs for other Hanford Contractors for project support or oversight ARE NOT included in this estimate. Contingency percentages shown below are based on the conceptual nature of the design.

2. Long term operating (lifecycle) costs ARE NOT included in the estimates.

3. Costs are in current dollars. Costs for escalation of materials or services ARE NOT included in the estimates.

5.0 Estimated Cost

Total estimated cost $(\$ 1,000 \mathrm{~s})$

SANITARY \& PROCESS SEWER MODIFICATIONS

Direct Cost

Design Engineering Contingency

WCH Project Management

\begin{tabular}{rr} 
& 1,024 \\
$10 \%$ & 102 \\
$30 \%$ & 338 \\
& 161 \\
\hline
\end{tabular}

\subsection{Estimate Review}

$\begin{array}{lll}\text { 6.0 Estimate Review } & \\ \text { Estimator } \\ \text { Estimating Manager } \\ \text { Task Manager } \\ \text { Project Controls Lead }\end{array}$



02 - Direct Cost

300 AREA UITLITIES - ROM

Quantity voM

1.0-UTILITY OPTIONS: S4 - SANITARY \& PROCESS SEWER

Labor Perm Materia

Equipmen

Supplos

Subentracts

Other

\begin{tabular}{|c|c|c|}
\hline W2SNIMOB1 - SubK Work Planning \& Preparation & 1.000 & \\
\hline W2SNIMOB2 - On-Site Requried Training \& Badging & 0.500 & LS \\
\hline W2SNIMOB3- Baseline Physical For Hanford Workers & 1.000 & LS \\
\hline W2SNIMOB4 - SubK Mob Equip, Tools, Materials & 20.000 & HR \\
\hline W2SNIMOBS - Portable Toilets & 6.000 & Mo \\
\hline W2SNIMOB6-Two Way Radios & 12.000 & EA \\
\hline W2SNIMOB7 - SubK Field Ofice Facilities \& Supplies & 20.000 & HR \\
\hline W2SNIMOP1 - Monthly Operations \& Overtiead & 6.000 & MO \\
\hline W2SNELC10 - Electrical Service to LS10 & 1.000 & LS \\
\hline W2SNELC11 * * Electrical Service to LS11 & 1.000 & LS \\
\hline W2SNELC13 -* Electrical Service to LS13 & 1.000 & LS \\
\hline W2SNELC14 * Electrical Service to LS14 & 1.000 & LS \\
\hline W2SNFM001 - * 2" Forec Main LS13 to LS14-240 LF & 240.000 & LF \\
\hline W2SNFM002 - *3" Forec Main LS14 to Wisconsin - 210 LF & 210.000 & LF \\
\hline W2SNFM003 - " 3" Forec Main Sprtuce to Vate - 680 LF & 680.000 & $L F$ \\
\hline W2SNFM004 - * 3" Forec Main Inside 8" GS - 430 LF & 430.000 & LF \\
\hline W2SNFM005 - * 3" Forec Main LS11 to GW Way - 2510 LF & $2,510.000$ & LF \\
\hline W2SNGSO01 - * 6" Gravity Sewer to LS10 - 450 LF & 450.000 & LF \\
\hline W2SNGS002 -* 6"Gravily Sewer Tie-in To LS10 - 70 LF & 70.000 & LF \\
\hline W2SNGS003 - * 8" Gravity Sewer to LS11 - 120 LF & 120.000 & LF \\
\hline W2SNGS004 - " 6" Gravity Sewer From Cypress to LS11 - 120 LF N & 120.000 & LF \\
\hline W2SNGS006 - * 6" Gravity Sewer Tie-in to LS14-85 LF & 85.000 & LF \\
\hline W2SNGS007 - * 6" Gravity Sewer to LS14 - 40 LF & 40.000 & LF \\
\hline W2SNGS008 - * 6 "Gravity Sewer to LSI3 - 40 LF & 40.000 & LF \\
\hline W2SNGS009 - * Divert 8" Gravity Sewer at Bldg 331 & 1.000 & LS \\
\hline W2SNLS101 - *LS-10 Manhole installation, Excavation \& Backfil & 1.000 & EA \\
\hline W2SNLS102 - " LS-10 Lif Station Equip Installation & 1.000 & $\mathrm{EA}$ \\
\hline W2SNLS111 - * LS-11 Manhole Installation, Excavation \& Backfil & 1.000 & EA \\
\hline W2SNLS1 12 - *LS-11 Lia Station Equip Installation & 1.000 & EA \\
\hline W2SNLS131 - *LS-13 Manhole Instalatation, Excavation \& Backfil & 1.000 & EA \\
\hline W2SNLS132 - "LS-13Lif Station Equip Installation & 1.000 & EA \\
\hline W2SNLS141 - *LS-14 Manhole Instalatation, Excavation \& Backil & 1.000 & EA \\
\hline W2SNLS142 - *LS-14 Lifi Station Equip Installation & 1.000 & EA \\
\hline W2SNXMOBO - - Site Cleanup & 40.000 & HR \\
\hline W2SNXMOB02 - SubK DeMob Equip, Tools, Materials & 20.000 & HR \\
\hline W2SNXI & 80.00 & \\
\hline
\end{tabular}

\begin{tabular}{r|r|r|}
\hline 260 & \\
\hline 160 & \\
\hline 100 & \\
\hline 3.237 & \\
\hline 110 & \\
\hline 110 & \\
\hline 110 & \\
\hline 344 & \\
\hline 422 & \\
\hline 110 & \\
\hline 476 & \\
\hline 400 & \\
\hline 165 & \\
\hline 180 & \\
\hline 542 & \\
\hline 412 & \\
\hline 135 & \\
\hline 155 & \\
\hline 80 & \\
\hline 155 & \\
\hline 80 & \\
\hline 155 & \\
\hline 80 & \\
\hline 350 & \\
\hline 80 & \\
\hline 240 & \\
\hline 260 & \\
\hline 9710 & \\
\hline
\end{tabular}

\begin{tabular}{|r|r|}
\hline 13,900 & \\
\hline 8,819 & \\
\hline 1,802 & \\
\hline 3,651 & \\
\hline 5,232 & \\
\hline 173,060 & \\
\hline 4,328 & \\
\hline 4,328 & \\
\hline 4,328 & \\
\hline 4,328 & \\
\hline 14,410 & \\
\hline 1,808 & \\
\hline 8,640 & \\
\hline 4,603 & \\
\hline 19,177 & \\
\hline 14,967 & \\
\hline 6,152 & \\
\hline 6,675 & \\
\hline 6,675 & \\
\hline 21,212 & \\
\hline 16,384 & \\
\hline 16,384 & \\
\hline 4,449 & \\
\hline 5,478 & \\
\hline 3,617 & \\
\hline 5,478 & \\
\hline 3,617 & \\
\hline 5,478 & \\
\hline 3,617 & \\
\hline 13,871 & \\
\hline 3,617 & \\
\hline 8,352 & \\
\hline 3,651 & \\
\hline 13,900 & \\
\hline $4,46,46$ & \\
\hline
\end{tabular}

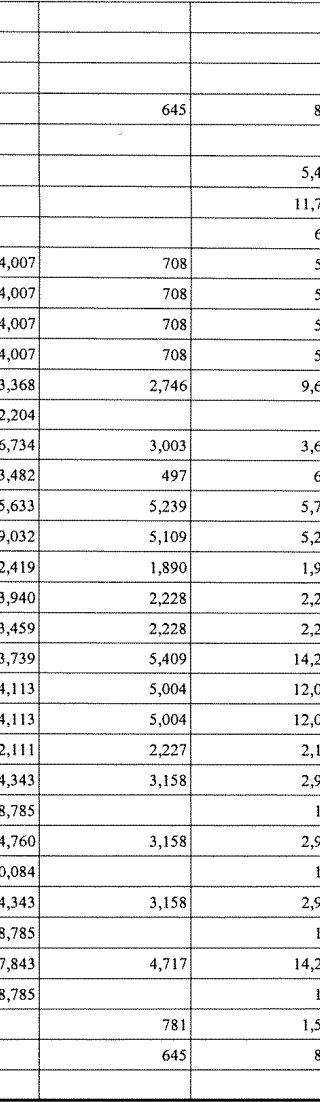

\begin{tabular}{|r|r|r}
\hline & 4,466 & \\
\hline 809 & & \\
\hline & 2,628 & \\
\hline
\end{tabular}
\begin{tabular}{|l|r|}
\hline 405 & 16,305 \\
\hline 299 & 15,583 \\
\hline 312 & 2,114 \\
\hline
\end{tabular} 
WASHINGTON CLOSURE HANFORD

300 AREA UITLITIES - ROM R1 - Est 1004 - 300 Area Utility Relocation Project

Cost Estimate 1004

\section{Storm Sewer Modifications}




\section{Cost Estimate Summary}

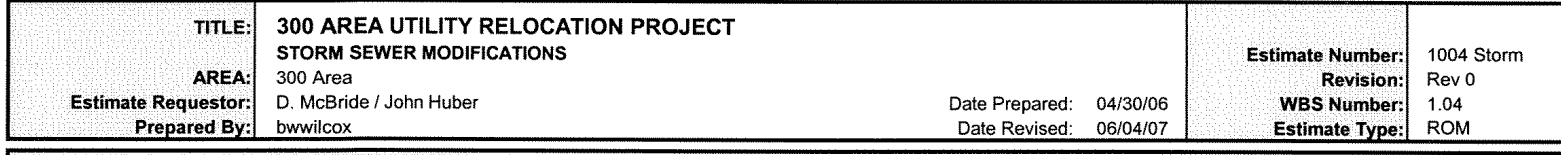

1.0 Purpose/ Scope Description:

Estimate modifications to the Storm Water Sewer systems for the remaining facilities at the 300 Area.

2.0 Scope of Estimate

Existing Storm Water Sewer systems for the 300 Area retained facilities will require modifications to divert flows from Sanitary and Process Sewer lines. Mods to some buildings include re-routing flows from current drain lines to disposal at ground. Lift stations (including new electrical service connections) are required at several locations to move Storm Water to existing catch basins or to ground. Modifications per facility include:

BLDG 318: A (-14) EL below grade loading dock at 318 has a drain in the floor flowing storm water through a 2" pipe into the basement of the building. Install $2 \times 2 \times 2$ sump and force drain line in the floor and an above grade sump pump to re-route storm water to ground at elevation. Scope includes:

* Cut and remove a $3 \times 3$ section of concrete floor, install external lift pump and associated piping to carry storm water from sump to ground at elevation.

BLDG 329: Storm water catch basins at the SE corner of 329 are connected to the Retention Process Sewer system. Cut existing lines and divert flow through new lift station to existing catch basin flowing to grassy swale. Scope includes:

* Cut \& cap existing RPS line from catch. Install new lift station and 4" force main from lift station to catch basin connected to the grassy swale.

BLDG 326: Storm water catch basins at the East corner of 326 are connected to the Sanitary Sewer system. Cut existing lines and divert flow through a new lift station to lift station at Bldg 329. Scope includes:

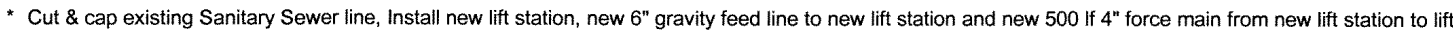
station at Bldg 329.

BLDG 3709A: Re-route 4 ea roof drains from sanitary sewer connection to ground. Scope includes:

" Cut 4 ea. 6" CS internal roof drains near ceiling inside building 379A and re-route through 8 " CMU wall to lower tier roof or to new downspouts to ground.

BLDG 3790: Isolate \& cap 4 ea Catch Basins NE of building 3709 that currently flow to the Process Sewer system. Scope includes:

* Cap the flow to the process sewer by partially filling Catch Basin 1 with concrete.

BLDG 331: Divert Storm Water collections from roof drains to sanitary sewer and to ground. Scope includes:

* Re-route to internal roof storm drains to exterior down spouts.

* Install North Side underground gravity lines from 6 of the down spouts through new lift station to an existing catch basin.

* Re-route 6 Process Sewer lines at the North side of 331 from old Storm Sewer header to new Sanitary Sewer header then $500 \mathrm{ft}$ gravity flow to existing Sanitary Sewer interconnection North of parking area. Includes flow from condensate lines at mechanical rooms

* Re-route Storm Water from Process Sewer 150 if to new underground injection well (2' dia $\times 10^{\prime}$ tall corrugated pipe filed with washed gravel)

\subsection{Basis and Assumptions}

1. Options are estimated to be performed by a Subcontractor. Costs for SubK OH\&P are included in the estimate.

2. Assumes scope does not include work with radioactive or hazardous materials. Assume Personal Protection Equipment (PPE) beyond hard hat, steel toes \& protective eye wear will not be required by OEM or Subcontractor personnel.

3. Engineering and design basis is conceptual. $10 \%$ of total estimated direct cost is added for ROM engineering costs.

4. Labor pricing based on FY07 Hanford Site Stabilization Agreement (HSSA) rates.

5. Equipment priced using $80 \%$ of current Blue Book rates.

6. Bułk material pricing and labor unit rates from RS Means Estimating Guide are used where applicable. Local and national vendor pricing is used for major equipment and sub-tier Subcontractors work,

7. See individual estimate sheets for additional scope and assumptions

\subsection{Exclusions:}

1. Costs for Contractor management \& oversight are included below as WCH Project Management. Costs are based on an overall duration of 18 months to complete all 300 Area Utility Relocation work as performed by Subcontractors performing work for WCH. Costs for other Hanford Contractors for project suppor or oversight ARE NOT included in this estimate. Contingency percentages shown below are based on the conceptual nature of the design.

2. Long term operating (lifecycle) costs ARE NOT included in the estimates.

3. Costs are in current dollars. Costs for escalation of materials or services ARE NOT included in the estimates.

\subsection{Estimated Cost}

Total estimated cost $(\$ 1,000 \mathrm{~s})$

STORM SEWER MODIFICATIONS
Direct Cost

Design Engineering

Contingency

WCH Project Management
$10 \%$
$30 \%$
818

270

129

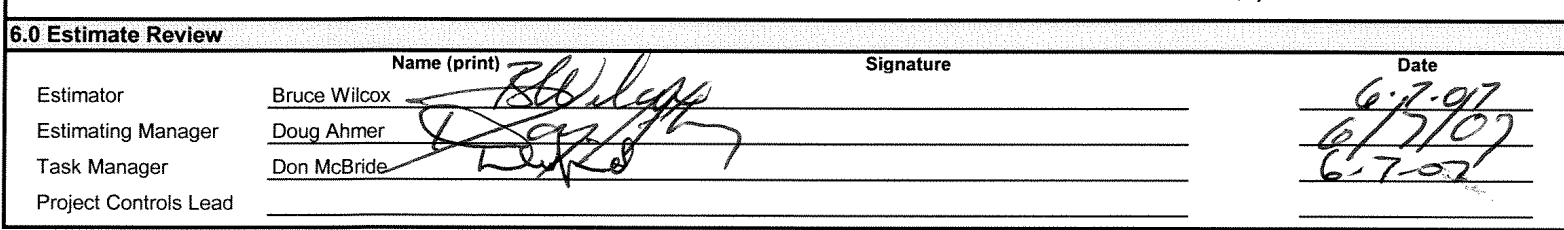


LO.UTLITY OPTIONS: S3-STORMWATER

osure Hanford

300 AREA UITLITIES - ROM R1 - Est 1004 - 300 Area Utility Relocation Project

02 - Direct Cost

Qunativ von

Labor Perm Mater

Equipmen

Supplies

Subcontracts

Other

WSTIMOB001 - SubK Work Planning \& Preparation

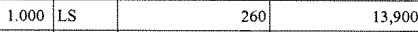

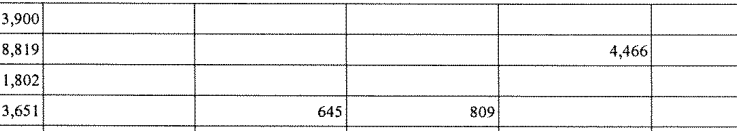

\begin{tabular}{l|l|l}
\hline & WSTIMOBO02 - On-Sile Requried Traning \& Badging & \\
\hline & WSTIMOBO03 - Baseline Physical For Han Ford Workers & \\
\hline & WSTI MOBO04 - SubK Mob Equip, Tools, Materials & \\
\hline
\end{tabular}

WSTIMOBO0S - Portable Toikts

\begin{tabular}{l|l|l}
\hline & WSTIMOBD06- Two Way Radios \\
\hline & WSTIMOB007 - * SubK Field Office Facilities \& Supplies & \\
\hline WSTIMOPDO1 * Monthly Operations \& Overhead &
\end{tabular}

\begin{aligned} & 1.000 LS \\ & 20.000 HR \\ & \hline\end{aligned}

6.000 MO

WSTIMOP001 * * Monthly Operations \& Overhead

WST3180001 * BIdg 318 Lifl Station Sump Construction

\begin{tabular}{r|l}
\hline & WST3180002 * Bldg 318 Lift Station Equip Installation \\
\hline
\end{tabular}

WST3180003 - * Bldg 318 Lif Station Elec Service

\begin{tabular}{l|l}
\hline WST3260001 - * Bldg 326 Lit Station Excavtion \& Backfil \\
\hline
\end{tabular}

\begin{tabular}{c|c|c}
\hline WST3260002**Bddg 326 Lif Station Equip installation \\
\hline
\end{tabular}

\begin{tabular}{|l|l|l}
\hline WST3260003 - *Bldg 326 Lit Station Elec Sevvice \\
\hline
\end{tabular}

WST 3260005 * * Bidg 326 6" Gravity Sewer to New Lif Station

WST3260006 * * Bdidg 326 4" Force Main Lif Station to Catch

\begin{tabular}{r|r|r|r|}
\hline & WST3290001 * * Bdg 329 Lit Station Excavation \& Backfill & 1.000 & EA \\
\hline
\end{tabular}

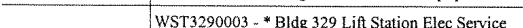

\begin{tabular}{l|l}
\hline WST $32900005 ~_{*}^{*}$ BIdg $3296^{\prime \prime}$ Gravity Sewer to New Lin Station \\
\hline WST3290006 * * Bldg $3294^{4}$ Force Main Lif Station to Catch B
\end{tabular}

WST33 10001 - Bldg 331 Cut Existing Roof Storm Drains

WST3310002 * Bldg 331 Install 6" PVC

\begin{tabular}{|l|l}
\hline WST33 10003 **Bldg 331 North Side Drain Line \& Lit Station \\
\hline
\end{tabular}

WST3310005 **Bdd 331 Lin Station Equip installation

WST3310006 * BIdg 331 Electrical Service to Lift Station

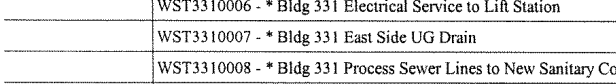

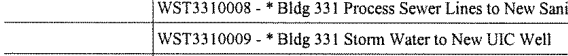

WST3310009 - * Bddg 331 Storm Water to New

WST3790002 - * Bldg 3790 Isolate 4 Catch Basins

WSTDMOBO01 - Site Cleanup

WSTDMOB002 - SubK DeMob Equip, Tools, Materials

WSTDMOB003- Close O

\begin{tabular}{|r|l|}
\hline 20.000 & HR \\
\hline 6.000 & MO
\end{tabular}

\begin{tabular}{l|l}
6.000 & MO \\
\hline 1.000 & EA \\
\hline
\end{tabular}

1.000 EA

\begin{tabular}{r|r|r|}
20 & 1,304 \\
\hline
\end{tabular}

$1.000 \mathrm{EA}$

1.000 EA

\begin{tabular}{rl|l|}
1.000 & EA \\
\hline 1.000 & LS \\
\hline
\end{tabular}

\begin{tabular}{r|r|}
100.000 & LF \\
\hline
\end{tabular}

175.000 LF

\begin{tabular}{|r|r|}
31.000 & EA \\
\hline 1680.000 & ELF \\
\hline 1.000 & LS
\end{tabular}

\begin{tabular}{r|r|}
\hline 1.080 .000 & ELF \\
\hline 1.000 & LS
\end{tabular}

1.000 LS

1000 is

135.000

800.000 FT

$150.000 \mathrm{FT}$

$1.000 \mathrm{LS}$

40.000 HR

$20.000 \mathrm{HR}$

80.000 HR

\begin{tabular}{r|r|r|}
\hline 260 & $\mid 69$ \\
\hline 40 & \\
\hline 100 & \\
\hline 3223 & \\
\hline 49 & \\
\hline 20 & \\
\hline 101 & \\
\hline 80 & \\
\hline 110 & \\
\hline 93 & \\
\hline 801 & \\
\hline 80 & \\
\hline 110 & \\
\hline 188 & \\
342 & \\
4419 & \\
836 & \\
\hline 165 & \\
\hline 80 & \\
\hline 64 & \\
\hline 86 & \\
\hline 378 & \\
\hline 152 & \\
\hline 124 & \\
\hline 8 & \\
\hline 240 & \\
\hline 100 & \\
260 & \\
\hline 892 &
\end{tabular}

8,982

407,150

29,988

49,182

49,572

\begin{tabular}{|r|r|}
\hline, 405 & 16,305 \\
\hline, 299 & 15,583 \\
\hline 312 & 2,114 \\
\hline 883 & 5,988 \\
\hline 455 & 3,083 \\
\hline 937 & 6,352 \\
\hline, 522 & 30,659 \\
\hline, 654 & 214,602 \\
\hline 411 & 2,789 \\
\hline, 699 & 11,517 \\
\hline 757 & 5,134 \\
\hline, 210 & 14,981 \\
\hline, 910 & 26,507 \\
\hline, 659 & 11,244 \\
\hline, 681 & 11,394 \\
\hline, 237 & 69,402 \\
\hline, 210 & 14,981 \\
\hline, 910 & 26,507 \\
\hline, 659 & 11,244 \\
\hline, 085 & 20,917 \\
\hline, .841 & 32,822 \\
\hline, 521 & 23,871 \\
\hline, 710 & 79,391 \\
\hline, 543 & 24,022 \\
\hline 3,433 & 23,278 \\
\hline, 067 & 7,233 \\
\hline, 292 & 8,758 \\
\hline, 869 & 39,790 \\
\hline, 099 & 14,227 \\
\hline 1,094 & 7,415 \\
\hline 111 & 754 \\
\hline 1,843 & 12,495 \\
\hline 883 & 5,988 \\
\hline 2,405 & 16,305 \\
\hline 0,605 & 817,654 \\
\hline
\end{tabular}


WASHINGTON CLOSURE HANFORD

300 AREA UITLITIES - ROM R1 - Est 1004 - 300 Area Utility Relocation Project

Cost Estimate 1004

\section{Electrical Systems Modifications Retain 315 Substation}




\begin{tabular}{|c|c|c|c|}
\hline 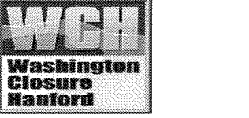 & ost Estimate Summary & & 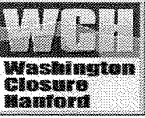 \\
\hline $\begin{array}{r}\text { TITLE: } \\
\text { AREA: } \\
\text { Estimate Requestor: } \\
\text { Prepared By: }\end{array}$ & $\begin{array}{l}300 \text { AREA UTILITY RELOCATION PROJECT } \\
\text { ELECTRICAL SYSTEMS MODIFICATIONS - RETAIN } 351 \text { SUBSTATION } \\
300 \text { Area } \\
\begin{array}{l}\text { Don McBride } \\
\text { dijakubek }\end{array} \\
\end{array}$ & $\begin{array}{r}\text { Estimate Number: } \\
\text { Revision: } \\
\text { WBS Number: } \\
\text { Estimate Type: }\end{array}$ & $\begin{array}{l}1004 \text { Elect } \\
\text { Rev } 0 \\
1.04 \\
\text { Pre-Concept }\end{array}$ \\
\hline
\end{tabular}

1.0 Purpose / Scope Description:

Provide cost for incorporating modifications and/or upgrades to the 300 Area electrical systems. Retain 351 substation.

\subsection{Scope of Estimate}

Modify 300 Area electrical systems to accommodate the demolition of portions of 300 Area buildings and continuation of remediation of waste sites while retaining electrical feed to certain 300 Area facilities and equipment extending their operations service life ( $>20$ years). Therefore the existing electrical systems providing services to remaining 300 Area buildings and equipment require electrical feed alterations allowing decommissioning and continued PNNL operations to be performed simultaneously.

- Estimate includes: Subcontractor construction costs: Flour Hanford support and alterations of 300 Area electrical system alterations and Bonneville Power support and alterations of electrical feed systems. For design and written scope see WCH Design Engineering reference documents.

- Meets DOE orders requiring a two feed system (primary and secondary) identified as a looped system to continue feeding power to the retained 300 Area buildings and systems eliminating the possibility of a single feed failure.

Retain 351 Substation

* Perform Constructability Discussions \& Permitting Process

* Provide Project Support for Duration

* Install North End Power Feed Circuits L6, L4, \& L1

* Install Bio-Pump Feed Service

* Install 325 Secondary Feed Service

* Install West Side Secondary Feed Service

* Rework Existing Fire Protection System Feeding 351 Sub-Station

* Clean Up Area, Demobe, \& Close-out Project

\subsection{Basis and Assumptions:}

1. Options are estimated to be performed by a Subcontractor, WCH, Flour Hanford, and Bonneville Power with associated cost adders

2. Scope does not include work with radioactive or hazardous materials. Assume Personal Protection Equipment (PPE) beyond hard hat, steel toes \& protective eye wear will not be required by OEM or Subcontractor personnel.

3. Engineering and design support used for developing the estimate were pre-conceptual capacity with less than $1 \%$ design complete.

4. Labor pricing based on FY07 Hanford Site Stabilization Agreement (HSSA) rates.

5. Equipment priced was taken from Blue Book rates.

6. Bulk material pricing, labor unit rates, equipment, and subcontractor pricing were estimated from discussions with WCH Engineers, Flour Hanford support personnel, other project support personnel, RS Means Estimating Guide, and Estimator's experience as applicable. Vendor pricing was used for a small portion of equipment and sub-tier Subcontractors costs.

7. See individual estimate sheets for scope details and further assumptions applied to Option segments.

\subsection{Exclusions:}

1. Costs for Contractor management \& oversight are included below as WCH Project Management. Costs are based on an overall duration of 18 months to complete all 300 Area Utility Relocation work as performed by Subcontractors performing work for WCH. Costs for other Hanford Contractors for project support or oversight ARE NOT included in this estimate. Contingency percentages shown below are based on the pre-conceptual nature of the design

2. Long term operating (lifecycle) costs ARE NOT included in the estimates.

3. Costs are in current dollars. Costs for escalation of materials or services ARE NOT included in the estimates.

\subsection{Estimated Cost}

Total estimated cost $(\$ 1,000 \mathrm{~s})$

ELECTRICAL SYSTEMS MODIFICATIONS - RETAIN 351 SUBSTATION

\begin{tabular}{rrr} 
Direct Cost & & $\mathbf{8 7 1}$ \\
Design Engineering & $10 \%$ & $\mathbf{8 7}$ \\
Contingency & $30 \%$ & $\mathbf{2 8 7}$ \\
WCH Project Management & & $\mathbf{1 3 7}$ \\
\hline
\end{tabular}

6.0 Estimate Review

Estimator

Project Controls Lead

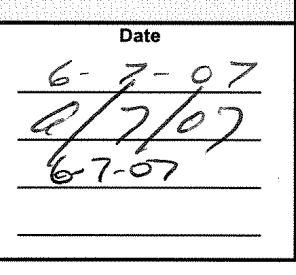

$6 / 7 / 2007$ 
Project: Est 1004 - 300 Area UtiIity Re_ocation Pro Sheet No: JEOP1001, Page 1.00 Number: 300 AREA UITLITIES - ROM R1

Sheet No: JEOP1001

\begin{tabular}{|lllllll|}
\hline Operation: & Retain 351 Sub Station & & & & \\
Quantity: & 1.000 & LS & parameters & Durations & & \\
Sheet Type: & Standard & Hours/Shift: & 10.00 & Hrs: & 0.00 \\
Estimator: & Dan Jakubek & Shifts/Day: & 1.00 & Shft: & 0.00 \\
Createdate: & $06 / 06 / 2007$ & Days/Week: & 4.00 & Days: & 0.00 \\
Revision: & & Days/Mo: & & Week: & 0.00 \\
Status: & Active & Critica1: & No & Months: & 0.00 \\
\hline
\end{tabular}

Modifications to the 300 Area electrical systems are needed to accommodate sites. At the same time certain 300 Area facilities and equipment are to remain in service for extended operation (>20 years). Therefore the equipment require re-work to enable decomnissioning and continued operation to be performed simultaneously.

This estimate retains 351 Sub Station. See Excel spread sheets for
activities.

\begin{tabular}{l} 
Estimate Codes \\
\hline 1.0 UTILTTY OPTIONS \\
\hline
\end{tabular}

\begin{tabular}{|c|c|c|c|c|c|c|c|c|c|c|c|c|c|}
\hline Line - & - Type & Set/Group/Code/Descrip & ciption & Quantity & & Manhours & Labor & $\begin{array}{l}\text { Perm, } \\
\text { Mat' is }\end{array}$ & Equip, & Supplies & $\begin{array}{l}\text { Sub- } \\
\text { Contracts }\end{array}$ & & $\begin{array}{l}\text { Total } \\
\text { Cost }\end{array}$ \\
\hline 1.00 & U.c. & 300E/351SUB/CON 2.1 & .1 - Constructability \& Permits & 1.00 & LS & 240 & 16,771 & 1,050 & 0 & 0 & 0 & 0 & 17,821 \\
\hline 2.00 & u.c. & 300E/351SUB/MOB 2.2 & 2 Subcontractor Mobilization & 1.00 & LS & 401 & 27,885 & 2,000 & 3,585 & 0 & 3,000 & 0 & 36,470 \\
\hline 3.00 & u.c. & 300 E $/ 351$ SUB $/$ PRO $\quad 2.3$ & .3 - SubK Project Support & 1.00 & LS & 1,210 & 67,040 & 2,500 & 55,315 & 0 & 683 & 0 & 125,538 \\
\hline 4.00 & u.c. & 3008/351SUB/NOR $\quad 2.4$ & 4 - North Power Feed & 1.00 & LS & 132 & 60,343 & 27,648 & 0 & 0 & 0 & 0 & 87,991 \\
\hline 5.00 & U.c. & $300 E / 351$ SUB $/$ BIO $\quad 2.5$ & .5 - Bio Pump Feed Service & 1.00 & LSS & 191 & 80,466 & 97,122 & 0 & 0 & 0 & 0 & 177,588 \\
\hline 6.00 & u.c. & $300 \mathrm{E} / 351 \mathrm{SUB} / 325 \quad 2.6$ & $6-325$ Feed Service & 1.00 & LS & 205 & 85,209 & 102,846 & 0 & 0 & 0 & 0 & 188,055 \\
\hline 7.00 & v.c. & 300E/351SUB/WES 2.7 & .7 - Install West side 2ndary Feed & 1.00 & LS & 104 & 48,825 & 18,102 & 0 & 0 & 0 & 0 & 66,927 \\
\hline 8.00 & U.C. & $\begin{array}{rl}300 E / 351 \text { SUB } / \mathrm{REN} & 2.8 \\
\text { OPS }\end{array}$ & $\begin{array}{l}8 \text { - Fire Sys - Deleted Cost Due to Part of } \\
\text { PS Scope }\end{array}$ & 0.00 & LS & 0 & 0 & 0 & 0 & 0 & 0 & 0 & \\
\hline 9.00 & u.c. & $300 \mathrm{E} / 351 \mathrm{SUB} / \mathrm{DEM} \quad 2.9$ & .9 - Subk Demobilization \& Clean-up & 1.00 & LS & 240 & 12,181 & 500 & 2,835 & 0 & 0 & 0 & 15,516 \\
\hline 10.00 & Grand $s / 3$ & & Grand Subtotal & & & 2,723 & 398,720 & 251,768 & 61,735 & 0 & 3,683 & 0 & 715,906 \\
\hline 11.00 & Add-On & ADD/TAX/SALES2 & State Sales \& Use $\operatorname{Tax} \& 8.3 \%$ & & & 0 & 0 & 20,897 & 5,124 & 0 & 306 & 0 & 26,326 \\
\hline 12.00 & Grand $\mathrm{S} / \mathrm{z}$ & Ti (Primar & Grard subtotal & & & 2,723 & 398,720 & 272,665 & 66,859 & 0 & 3,989 & 0 & 742,232 \\
\hline 13.00 & Add-on & ADD/SUBCON/SUBOH\&P & Subcontractor overhead \& Profit.t & & & 0 & 0 & 0 & 0 & 0 & 0 & 111,335 & 111,335 \\
\hline 14.00 & Add-on & ADD/SUBCON/SUBBOND & Subcontractor Bond & & & 0 & 0 & 0 & 0 & 0 & 0 & 12,989 & 12,989 \\
\hline 15.00 & Grand $\mathrm{S} / \mathrm{z}$ & & Grard subtotal & & & 2,723 & 398,720 & 272,665 & 66,859 & 0 & 3,989 & 124,324 & 866,556 \\
\hline 16.00 & Add-On & $\mathrm{ADD} / \mathrm{SUBCON} / \mathrm{SUBB} B \mathrm{O}$ & Subcontractor $B \notin O$ Tax & & & 0 & 0 & 0 & 0 & 0 & 0 & 4,099 & 4,099 \\
\hline 17.00 & Grand $s / 2$ & & Grard Subtota1 & & & 2,723 & 398,720 & 272,665 & 66,859 & 0 & 3,989 & 128,423 & 870,655 \\
\hline
\end{tabular}


WASHINGTON CLOSURE HANFORD

300 AREA UITLITIES - ROM R1 - Est 1004 - 300 Area Utility Relocation Project

Cost Estimate 1004

\section{Information Technology Modifications}




\section{Cost Estimate Summary}

TITLE: 300 AREA UTILITY RELOCATION PROJECT

AREA: 300 Area

Estimate Requestor D. McBride

Prepared Bya dwahmer

$\begin{array}{cc} & \\ \text { Date Prepared: } & 04 / 30 / 06 \\ \text { Date Revised: } & 06 / 04 / 07\end{array}$

Estimate Number: 1004 IT

Revision: Rev 0

WBS Number: 1.04

Estimate Type: ROM

\subsection{Purpose/ Scope Description:}

Provide ROM estimate for modifications to the 300 Area Information Technology systems.

\subsection{Scope of Estimate}

The majority of the existing IT and telecommunications cabling that supports PNNL activities in the 300 Area is served out of Building 3506C (a.k.a. "Bundy Hut") and/or through the fiber optic and copper cables that are routed along New Mexico Avenue in the vicinity of Building 309 . The associated infrastructure and cable routes are expected to be impacted by the D4 and Field Remediation activities in and around 309 and underlying waste sites and will require rerouting. The waste sites are scheduled for remediation starting in 2009. Proposed modifications include:

ITEM L1 - Long Term PNNUPHMC Facilities: Install new optical fiber for PNNL facilities, except 622R. Use existing cabling for PHMC facilities with exception of fiber route to 3790 . - Per functional requirements. The cable to $622 \mathrm{R}$ will need to be re-routed to ISB2.

* Allows for new infrastructure that can be installed away from D4 locations.

* Lowest risk installation, does not interfere with existing operational infrastructure.

* Supports retained facilities planned life of 20 years or more, i.e., meets lifecycle requirements.

* Presents best overall value to the DOE - investing in new infrastructure rather than reworking old infrastructure in support of PNNL's science mission in the 300 area.

ITEM 11- Interim/Short Term PNNL/PHMC Facilities: Install new optical fiber for PNNL facilities: 318 to $320 ; 325$ to $326 ; 325$ to 329 . Install new optical fiber cabling for PHMC facility 339A to 3790

* Allows for new infrastructure that can be installed away from D4 locations.

* Lowest risk installation, does not interfere with existing operational infrastructure. Work can be completed during business hours.

* Schedule flexibility - work can be completed anytime - this FY through FY09.

ITEM M2 - Modular Offices: Reuse existing optical fiber cabling that runs from 350 to 2 of the trailers. Wireless links for the remaining trailers that require connectivity.

* Consistent with the Site services architecture for PNNL to service it's supporting organizations.

\subsection{Basis and Assumptions:}

1. Options are estimated to be performed by a Subcontractor. Costs for SubK OH\&P are included in the estimate.

2. Assumes scope does not include work with radioactive or hazardous materials. Assume Personal Protection Equipment (PPE) beyond hard hat, steel toes \& protective eye wear will not be required by OEM or Subcontractor personnel.

3. Engineering and design basis is conceptual. $10 \%$ of total estimated direct cost is added for ROM engineering costs.

\subsection{Exclusions:}

1. Costs for Contractor management \& oversight are included below as WCH Project Management. Costs are based on an overall duration of 18 months to complete all 300 Area Utility Relocation work as performed by Subcontractors performing work for WCH. Costs for other Hanford Contractors for project support or oversight ARE NOT included in this estimate. Contingency percentages shown below are based on the conceptual nature of the design.

2. Long term operating (lifecycle) costs ARE NOT included in the estimates.

3. Costs are in current dollars. Costs for escalation of materials or services ARE NOT included in the estimates.

\subsection{Estimated Cost}

Total estimated cost ( $\$ 1,000$ s)

INFORMATION TECHNOLOGY MODIFICATIONS

Design Engineering

Contingency

WCH Project Managemen

$10 \%$

$30 \%$

548

181

86
$\$ 870$

$\begin{array}{lll}\text { 6.0 Estimate Review } & \\ \text { Estimator } \\ \text { Estimating Manager } \\ \text { Task Manager } \\ \text { Project Controls Lead }\end{array}$


Washinaton Groud Intexnationa1. Inc.

Pxoject: Est 1004 - 300 Area Utilitv Relocation Pro Sheet No: AIT000001, Page 1.00

Sheet No: AIT000001, Page 1.00

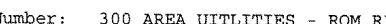

Printed: $6 / 7 / 2007 @ 6: 17: 30 \mathrm{AM}$

\begin{tabular}{|lllllll}
\hline operation: & Information Technology & & & & \\
Quantity: & 1.000 & Parameters & Durations & \\
Sheet Type: & Standard & Calculated & \\
Estimator: & Dan Jakubek & Hours/Shift: & 10.00 & Hrs: & 0.00 \\
CreateDate: & $06 / 06 / 2007$ & Shifts/Day: & 1.00 & ShFt: & 0.00 \\
Revision: & & Days/Week: & 4.00 & Days: & 0.00 \\
Status: & Active & Days/Mo: & & Week: & 0.00 \\
\end{tabular}

\section{Estimate Codes}

1.0 UTILITY OPTIONS

I1

INFORMATION TECHNOLOGY

Notes

sased on functionaI requirements, the following options were chosen by the
00 AREA UTILITY RELOCATION PROJECT - IT OPTIONS STUPY TTEAM tO Drovide service to the 300 Area retained facilities. opt L1: Install new optical fiber cabling as the recommended long term
option for retained facilities $318,325,331 \& 350$. Includes fiber reroute for $622 \mathrm{R}$. Opt I1: Install new optical fiber cabling as the recommended interim
option for retained facilities $320,326 \& 329$. Install new optical fiber cabling between buildings $339 \mathrm{~A} \& 3790$.

Opt M2: Re-use existing optical fiber cabling from 350 to trailers.
Deploy wireless network to provide interconnections between trailers.

\begin{tabular}{|c|c|c|c|c|c|c|c|c|c|c|c|c|c|}
\hline Line $-x$ & Type & Set/Group/Code/Desc & cription: & Quantity & & Manhours & Labor & $\begin{array}{l}\text { Perm: } \\
\text { Mat' } 1 \mathrm{~s}\end{array}$ & Equip. & Supplies & $\begin{array}{l}\text { Sub- } \\
\text { contracts }\end{array}$ & & $\begin{array}{l}\text { Total } \\
\text { Cost }\end{array}$ \\
\hline \multirow{2}{*}{$\begin{array}{l}1.00 \\
2.00\end{array}$} & v.c. & $300 \mathrm{~T} / 300 \mathrm{IT} / \mathrm{L1} \mathrm{L} \mathrm{I}$ & L,1 - Long Term PNNL/PHMC Facility option & 1.00 & LS & 0 & 0 & $\overline{0}$ & $\overline{0}$ & 0 & 350,000 & $\overline{0}$ & 350,000 \\
\hline & v.c. & $300 \mathrm{I} / 300 \mathrm{rT} / \mathrm{II} I$ & $\begin{array}{l}\text { I1 - Interim/Short Term PNNL/PYMC Facility } \\
\text { Option }\end{array}$ & 1.00 & LS & 0 & 0 & 0 & 0 & 0 & 145,000 & 0 & 145,000 \\
\hline \multirow{2}{*}{$\frac{3.00}{4.00}$} & u.c. & $300 I / 300 I T / M 2 M$ & M2 - Modular office Option & 1.00 & LS & 0 & 0 & 0 & 0 & 0 & 50,000 & 0 & 50,000 \\
\hline & Grand $S$ & S/T (Primar & Grand Subtotal & & & 0 & 0 & 0 & 0 & 0 & 545,000 & 0 & 545,000 \\
\hline $5.00=2$ & Add-On & ADD/SUBCON/SUBBEC & Subcontractor $\mathrm{B} \& \mathrm{O}$ Tax & & & 0 & 0 & 0 & 。 & 0 & 0 & 2,578 & 2,578 \\
\hline 6.000 & Grand & & Grand Subtotal & & & 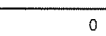 & 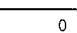 & 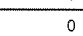 & 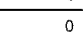 & 0 & 545,000 & 2,578 & \\
\hline
\end{tabular}

Totals for Sheet No. AIT000001

1.000

LS

0

545,000

$2,578 \quad 547,578$ 
WASHINGTON CLOSURE HANFORD

300 AREA UITLITIES - ROM R1 - Est 1004 - 300 Area Utility Relocation Project

Cost Estimate 1004

\section{WCH Project Management}




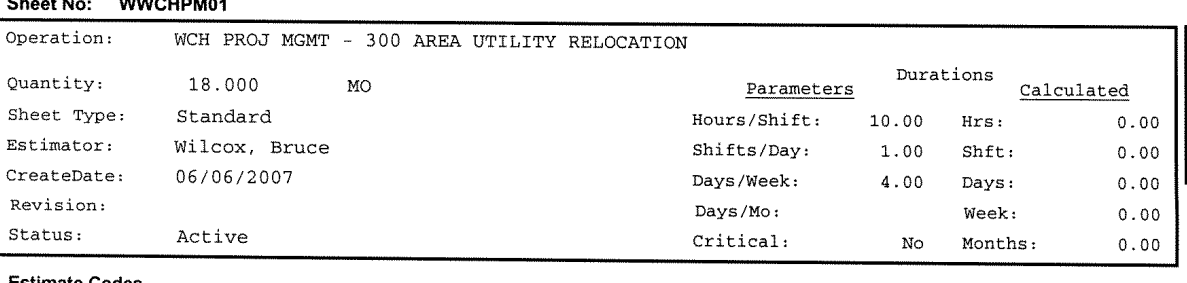

\section{Notes}

WCH Key personnel support for 300 Area Utility Relocation project.

Costs are based on 18 month duration for Water, Retention Process Sewer,
Sanitary Sewer, Storm Sewer, Information Technology and Electical projects.

costs to be pro-rated based on individual project costs.

Status:

Months:

\section{Estimate Codes}

1.0 UTILITY OPTIONS

A1

WCH PROJ MANAGEMENT

18.00

\begin{tabular}{|c|c|c|c|c|c|c|c|c|c|c|c|c|}
\hline Line Type & \multicolumn{2}{|c|}{ Set/Group/Code/Description } & \multicolumn{2}{|l|}{ Quantity } & \multirow[t]{2}{*}{ Manhours } & \multirow[t]{2}{*}{ Labor } & \multirow[t]{2}{*}{$\begin{array}{l}\text { Perm. } \\
\text { Mat' } 1 \mathrm{~s}\end{array}$} & \multirow[t]{2}{*}{ Equip. } & \multirow[t]{2}{*}{ Supplies } & \multirow[t]{2}{*}{$\begin{array}{l}\text { sub- } \\
\text { contracts }\end{array}$} & \multicolumn{2}{|r|}{$\begin{array}{l}\text { Total } \\
\text { Cost: }\end{array}$} \\
\hline 1.00 Note & **WCH PROJECT M & ANACEMENT \& SUPPORT** & & & & & & & & & & \\
\hline $2.00 \mathrm{crew}$ & LH07/NONMAN/51700 & Eroject Management & 1.00 & Ea & 1.00 & 115.79 & 0.00 & 0.00 & 0.00 & 0.00 & & 115.79 \\
\hline $3.00 \mathrm{crew}$ & L.HO7/NONMAN/58700 & Safety \& Health - Management & 0.25 & Ea & 0.25 & 27.20 & 0.00 & 0.00 & 0.00 & 0.00 & & 27.20 \\
\hline $4.00 \mathrm{crew}$ & LHO7/NONMAN/58731 & safety \& HeaIth - Industrial Hygiene & 0.25 & Ea & 0.25 & 16.00 & 0.00 & 0.00 & 0.00 & 0.00 & & 16.00 \\
\hline $5.00 \mathrm{crew}$ & LH07/NONMAN/21700 & Flanning and Controls & 0.50 & $\mathrm{Ea}$ & 0.50 & 31.13 & 0.00 & 0.00 & 0.00 & 0.00 & & 31.13 \\
\hline $6.00 \mathrm{Crew}$ & LH07/NONMAN/32711 & Project Engineer & 0.25 & Ea & 0.25 & 26.13 & 0.00 & 0.00 & 0.00 & 0.00 & & 26.13 \\
\hline 7.00 Crew & LH07/NONMAN/58723 & $\begin{array}{l}\text { Safety \& Heal.th - RadCon H.P./Support } \\
\text { Serv }\end{array}$ & 0.25 & Ea & 0.25 & 17.03 & 0.00 & 0.00 & 0.00 & 0.00 & & 17.03 \\
\hline $8.00 \mathrm{Crew}$ & LH07/NONMAN/53740 & Field support - Subcontract STR & 1.00 & Ea & 1.00 & 59.16 & 0.00 & 0.00 & 0.00 & 0.00 & & 59.16 \\
\hline $9.00 \mathrm{Crew}$ & LH07/NONMAN/53700 & Field Support - Management & 1.00 & Ea & 1.00 & 90.50 & 0.00 & 0.00 & 0.00 & 0.00 & & 90.50 \\
\hline $10.00 \mathrm{Crew}$ & LH07/NONMAN/41700 & Frocurement & 0.25 & Ea & 0.25 & 14.28 & 0.00 & 0.00 & 0.00 & 0.00 & & 14.28 \\
\hline 11.00 Crew S/T & Begins on $2.00 \mathrm{cr}$ & ew Subtotal & $2,713.00$ & Hrs & 4.75 & 397.22 & 0.00 & 0.00 & 0.00 & 0.00 & & 397.22 \\
\hline & Production Rates: & $\begin{aligned} 0.0066 & \text { Mo / Crew Hour } \\
0.0014 & \text { Mo / Manhour } \\
151.0000 & \text { Crew Hours / Mo <- } \\
717.2500 & \text { Manhours / Mo }\end{aligned}$ & & & 12,911 & $1,079,630$ & 0 & 0 & 0 & 0 & & $1,079,630$ \\
\hline \multicolumn{2}{|l|}{12.00 Grand $\mathrm{S} / \mathrm{T}$} & Grand Subtotal & & & 12,911 & $1,079,630$ & 0 & 0 & 0 & 0 & 0 & $\overline{1,079,630}$ \\
\hline 13.00 Add $-0 n$ & ADD/TAX/SALES & State Sales \& Use Tax \& 8.38 & & & 0 & 0 & 0 & 0 & 0 & 0 & 0 & 0 \\
\hline 14.00 Grand $S / T$ & T (Primax & Grand Subtotal & & & 12,911 & $1,079,630$ & 0 & 0 & 0 & 0 & 0 & $1,079,630$ \\
\hline 15.00 Add-On & $\mathrm{ADD} / \mathrm{SUBCON} / \mathrm{WCHFEE}$ & WCH FEE \& 78 & & & 0 & 0 & 0 & 0 & 0 & 0 & 75,574 & 75,574 \\
\hline 16.00 Grand $S / T$ & & Grard Subtotal & & & 12,911 & $1,079,630$ & 0 & 0 & 0 & 0 & 75,574 & $1,155,204$ \\
\hline 17.00 Add-On & $\mathrm{ADD} / \mathrm{SUBCON} / \mathrm{SUBB \& O}$ & Subcontractor B\&O Tax & & & 0 & 0 & 0 & 0 & 0 & 0 & 5,464 & 5,464 \\
\hline 18.00 Grand $\mathrm{S} / \mathrm{T}$ & & Grard Subtotal & & & 12,911 & $1,079,630$ & 0 & 0 & 0 & 0 & 81,038 & $1,160,669$ \\
\hline
\end{tabular}

motals for sheet

18.000

$12,911 \quad 1,079,630$ 
Wilcox 6/5/2007

UTILITY RELOCATION PROJECT - WCH Project Management Costs

\begin{tabular}{l|r|r|r} 
& \multicolumn{1}{|c|}{ TEC } & \% of ST & \% of PM \\
\hline \hline RPS & 828,805 & $11 \%$ & 130,513 \\
\hline SAN & $1,023,826$ & $14 \%$ & 161,224 \\
\hline STORM & 817,654 & $11 \%$ & 128,757 \\
\hline WATER 1 & $2,436,408$ & $33 \%$ & 383,665 \\
\hline WATER 2 & 845,729 & $11 \%$ & 133,178 \\
\hline ELEC & 870,655 & $12 \%$ & 137,103 \\
\hline IT & 547,578 & $7 \%$ & 86,228 \\
\hline ST & $\mathbf{7 , 3 7 0 , 6 5 5}$ & $\mathbf{1 0 0 \%}$ & $\mathbf{1 , 1 6 0 , 6 6 9}$ \\
PM & $1,160,669$ & & \\
\hline GT & $8,531,324$
\end{tabular}

Methodology for spreading Project Management costs across Utility Relo Projects 


\section{APPENDIX B}

\section{AREA ELECTRICAL UTILITY RELOCATION PROPOSALS AND COST ESTIMATES}


WCH-181

Rev. 0 


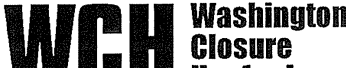 \\ Manford \\ Interoffice Memorandum}

To:

COPIES:
Steve E. Dieterle, L1-04

Don J. McBride, H4-15

See Below
DATE: $\quad$ May 22. 2007

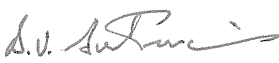

from: Arnold V. Gutmanis

Chair Person, Electrical Discipline Team for 300 Area Utility Relocation Project

L1-01/ 376-9108

SUBJECT: 300 AREA ELECTRICAL UTILITY RELOCATION PROPOSALS AND COST ESTIMATES

REF: Functional Requirements and Design Criteria for the 300 Area Utility Relocation Project, 0300X-DC-G0001, dated April 17, 2007.

Submitted for management review is the Electrical Discipline Team option proposals and preconceptual cost estimates to provide reliable electrical service to the retained facilities in the 300 Area. Considerations by Management, the regulators, and U.S. Department of Energy (DOE) may influence the final option chosen for implementation. This letter requests Washington Closure Hanford (WCH) management recommend one of the five proposed options presented for design preparation and implementation.

The 300 area electrical discipline team consisted of WCH, PNNL, FH, DOE-RL and other organizations staff members as needed to evaluate and determine options for the 300 Area electric utility relocation. The proposals set forth are broken down by the following options and cost analysis. The proposals are based on scenarios to reroute utilities for the long-term retention facilities identified by DOE-RL and functional requirements and design criteria in the above referenced document.

Option 1 Utilize the existing 351 Substation and distribution networks with modifications only to support demolition activities.

Option 2 Relocate the 351 substation to the west side of Stevens Drive and utilize the existing distribution networks with modifications only to support demolition activities.

Option 3 Use the City of Richland to provide one (1) new feeder and install one new substation with autotransformer to change the City of Richland's utility voltage from $12.5 \mathrm{kV}$ to match the 300 area's existing $13.8 \mathrm{kV}$ utility voltage, and convert the 400 Area "maintenance line" into a feeder as the other electrical service provider to the 300 area.

Option 4 Use the City of Richland to provide two (2) new feeders as the electrical service provider to the 300 area and install two new substations with autotransformers to change the City of Richland's utility voltage from $12.5 \mathrm{kV}$ to match the 300 area's existing $13.8 \mathrm{kV}$ utility voltage. 
Page 2

Option 5 Use the City of Richland to provide two (2) new feeders as the electrical service provider to the 300 Area and change the existing 300 Area's $13.8 \mathrm{kV}$ utility voltage to match the City of Richland's utility voltage $12.5 \mathrm{kV}$. Each retained building's transformers will required to be changed.

The Electrical Discipline Team is willing to convene at your earliest convince to discuss these proposals.

\section{AVG:la}

Attachments:

- Option Study for 300 Area Utility Relocation Project, Case 1, 2, 3, 4, and 5

- Cost Estimate Summary

- Detailed Cost Estimate Summary

Copies:

D. W. Ahmer, H4-15

S. M. Baker, S4-15

C. E. Carlson, S4-12

S. E. Dieterle, L1-04

G. A. Edwards, E6-27

R. G. Egge, X5-50

A. V Gutmanis, L1-01

D. J. Jakubek, H4-15

R. N. Krekel, A3-04

D. A. Larson, J2-09

T. H. Leone, L1-04

J. B. Logan, P7-28

G. M. MacFarlan, L6-06

D. J. McBride, H4-15

A. L. Minton, J2-09

M. E. Olson, J2-09

S. K Sanan, P7-08

D. J. Tollefson, E6-29

J. N. Winters, H4-20

Document Control, H4-11

\begin{tabular}{|c|c|c|c|}
\hline \multicolumn{4}{|l|}{ Concurrence } \\
\hline $5=22-67$ & $5-22.07$ & $5-22-0]$ & $3-22-07$ \\
\hline RGE NYE & DWA $X V D$ & MEO NLO & CEC lEe \\
\hline
\end{tabular}




\section{Option Study for 300 Area Utility Relocation Project Case 1, 2, 3, 4 and 5 Electrical Service for 300 Area}

\subsection{Introduction and Background}

The Department of Energy, Richland Operations Office (RL) has notified Washington Closure Hanford (WCH) of upcoming changes to the buildings previously planned for demolition as part of the River Corridor Closure Contract (RCCC). Several facilities occupied by the Pacific Northwest National Laboratory (PNNL) as well as utility and service facilities associated with both PNNL and other Hanford site missions will be retained. The utilities, which are currently serving the 300 Area facilities, will be modified to support these facilities and to allow the cleanup effort by WCH to continue. The PNNL buildings to be retained long-term include the 318 , 325,331 and 350 Building complexes. Other facilities will remain on an interim basis and may require utility modifications. Thus the 300 Area electrical distribution systems will require modifications and upgrades to continue to provide reliable electrical power for the retained facilities in the 300 Area. The 351 substation, which currently provides electrical power for the 300 Area, is planned in the RCCC baseline for demolition. Electrical services for these retained 300 Area facilities will be required and this paper presents the five (5) options proposed to support this need. Drawings of these options are attached. These options are as follows:

1. Utilize the existing 351 substation and distribution networks with modifications only to support demolition activities.

2. Relocate the 351 substation to the west side of Stevens Drive and utilize the existing distribution networks with modifications only to support demolition activities.

3. Use the City of Richland to provide one (1) new feeder and install one (1) new substation with autotransformer to change the City of Richland's utility voltage from $12.5 \mathrm{kV}$ to match the 300 Area's existing $13.8 \mathrm{kV}$ utility voltage, and convert the 400 Area "maintenance line" into a feeder as the other electrical power provider to the 300 Area.

4. Use the City of Richland to provide two (2) new feeders as the electrical power provider to the 300 Area and install two (2) new substations with autotransformers to change the City of Richland's utility voltage from $12.5 \mathrm{kV}$ to match the 300 Area's existing $13.8 \mathrm{kV}$ utility voltage.

5. Use the City of Richland to provide two (2) new feeders as the electrical power provider to the 300 Area and change the existing 300 Area's $13.8 \mathrm{kV}$ utility voltage to match the City of Richland's utility voltage of $12.5 \mathrm{kV}$. The identified transformers and equipment will be replaced.

The electrical utility replacement evaluation assumes the following scenario for ownership of the system. However, DOE could decide on alternate ownership scenarios. Similarly each of the options makes assumptions about the system ownership which would be subject to DOE determination of the final responsibility. The long-term retained facilities will be assigned to the Office of Science (SC) for a period of 20 years and reassigned after that time to the Office of Environmental Management (EM) for decontamination, decommissioning, deactivation and 
demolition (D4). The utilities support equipment and distribution systems will remain assigned to the RCCC until the end of that contract and then be assigned to the SC or another entity as determined by DOE for the balance of the 20 year period and then finally being reassigned to EM for $\mathrm{D} 4$ activities.

\subsection{Codes and Standards}

- National Electrical Safety Code, 2007(NESC)

- NFPA 70, National Electrical Code, 2005 (NEC)

- National Fire Protection Association (NFPA): NFPA 1, 2006; NFPA 101, 2006; NFPA 110, 2005; NFPA 20, 2007; NFPA 70E, 2004.

\subsection{Related Electrical Drawings:}

- H-3-404 ( 300 Area Switching Diagram)

- H-3-305155 (RPL One Line Diagram)

- H-3-25051 (318 One Line Diagram)

- H-3-28186 (331 One Line Diagram)

- H-3-70832 (326 One Line Diagram)

- H-3-49816 (329 One Line Diagram)

- H-3-21513 (320 One Line Diagram)

- H-3-308838 (338 One Line Diagram)

- H-3-308020 (3760 One Line Diagram)

- H-4-63000 (Single Line Diagram Standby Power System)

- H-2-65589 (400 Area Electrical Distribution One Line Diagram)

- H-4-151806 (451-B Substation Modifications)

- H-13-00261 (300 Area Electrical Distribution Map) and

- H-13-00262 (300 Area Pole and Underground Duct System Map).

\subsection{Functional Requirements}

1.3.1 Normal Power Utility Voltage Level: 13,800 VAC (Options 1-4), 12,500 VAC (Option 5).

1.3.2 Standby Power Utility Voltage: 2,400 VAC. The standby power system, as it exists today, will be deenergized when $3621 \mathrm{~B} / \mathrm{C}$ is decommissioned. There is a $1500 \mathrm{kVA}$, $13.8 \mathrm{kV}-2.4 \mathrm{kV}$ transformer located at $3621 \mathrm{~B} / \mathrm{C}$, which provides a connection between the normal and standby power system. Due to the planned demolition of $3621 \mathrm{~B} / \mathrm{C}$, a replacement transformer is required to provide standby power for the 325 Building.

1.3.3 Typical Facility Supply Voltage: 480VAC; Phase: 3 Phase; Frequency: $60 \mathrm{~Hz}$ or 120/240 VAC; Frequency: $60 \mathrm{~Hz}$.

1.3.4 Three retained facilities $(312,325$, and 331$)$ require electrical power from two independent sources. The RPL (325 Building) safety basis documents require a standby electrical power system which automatically provides an alternate supply of electrical power to RPL upon failure of the normal source. It provides a reliable 
source of power to RPL safety-significant structures, systems, and components (SSCs) under normal and emergency conditions. The two independent utility supply feeders for 331 and 312 Buildings are driven by critical research requirements.

1.3.5 Utility Service Transformers: Should remain the same or equivalent to existing in $\mathrm{kVA}$ and impedance rating.

1.3.6 Underground Duct banks: Use existing underground duct banks as much as possible for power distribution.

1.3.7 The 352F substation should remain in service to maintain power to the south 300 Area. A condition assessment should be performed to ensure the substation can provide service for 20 years.

1.3.8 The 352E substation may be required to provide an independent power source to the 331 Building (to be determined during design).

1.3.9 Any replacement transformers will be based on load evaluation.

1.3.10 When the utility electrical distribution system uses a different voltage level, the building service and equipment transformers will be replaced or autotransformers will be used.

1.3.11 Outage Requirements:

1.3.11.1 Electric service must be highly reliable. Unplanned power outages are not acceptable, and those that occur must be responded to rapidly.

1.3.11.2 Planned Power Outage Duration: The number and duration of planned outages must be kept to a minimum. Duration may vary depending upon the affected facility. Outages shall be negotiated with the affected building management.

1.3.11.3 Outages should be planned for weekends and off-shift hours.

1.3.11.4 Outage Notification: Major outages require 60 day advanced notification.

1.3.11.5 Standby generators presently at the $325,331,339 \mathrm{~A}, 3709 \mathrm{~A}$, and $331 \mathrm{H}$

Buildings will be retained with the facilities. Additional generators may be required for temporary power during planned outages.

1.3.12 Ownership: The building owner is responsible for electrical distribution from the secondary of the service transformer into the building. Under the RCCC the Surveillance and Maintenance/Utilities (S\&M/U) group will maintain ownership of the utility voltage distribution systems in the 300 Area and appropriately transition ownership once the RCCC is fulfilled.

1.3.13 All retained facilities in the 300 Area require electrical power equivalent to the existing supply.

1.3.14 The $3621 \mathrm{~B} / \mathrm{C}$ Building will be eliminated and the 312 and 325 retained facilities interface transformers (currently $2400 \mathrm{VAC}$ to $480 \mathrm{VAC}$ ) will be upgraded to match the new utility voltage.

1.3.15 Overhead Utility Lines: Use existing overhead utility lines where possible. New overhead electrical utility may be used if necessary.

1.3.16 Any new connections will tie into existing infrastructure where feasible and should not interfere with the proposed demolition work scope. 


\subsection{Option \#1}

This option would continue to utilize the 351 substation in its current configuration and only perform modification to the existing equipment on as-needed basis to support demolition and remediation activities.

\subsection{Introduction}

This option would utilize the electrical distribution system as it is currently configured and delay the eventual demolition of the 351 substation and remediation of the underlying 300-4 waste site. The 351 substation and distribution systems will remain assigned to the RCCC until the end of that contract and then be assigned to SC (or other entity determined by DOE) for the balance of the 20 year period and then finally being reassigned to EM for D4 activities. The current configuration of the substation and distribution networks would be adapted in order to accommodate the demolition schedule of the RCCC and maintain the two independent sources of electrical power to the 300 Area facilities. In addition, the 400 Area "maintenance line" would remain as currently configured.

Overall, this option minimizes the cost for adapting the existing distribution system but defers the eventual cleanup of the 300-4 waste site and demolition of the substation. This option is technically the most feasible option with the least costs but it has an unclear regulatory path forward for the un-remediated waste site that lies underneath the 351 substation.

\subsection{Scope of Work/System Description}

The existing 351 substation and $13.8 \mathrm{kV}$ lines which run north and south along Stevens and George Washington Way would remain. The existing 352F substation and associated electrical utility equipment would be maintained. In addition, the multiple drops from the existing overhead lines down to the existing underground electrical vaults in the 300 Area along Stevens and George Washington Way would also provide possible locations to access the 300 Area underground electrical distribution systems. The existing underground electrical distribution system should be maintained in the 300 Area south of Cypress street and along two pathways to 325 Building.

When the existing underground duct banks interferes with remediation or demolition activities, these systems would be modified to above ground aerial networks until the demolition of the building or remediation of the waste site was complete. Once the demolition or remediation has been accomplished then the undamaged, underground portion could be re-utilized.

Due to the removal of a portion of the fire water loop, it will be required to rework an existing 8 " radial water line to maintain the fire hydrants at the existing 351 substation. 


\subsection{Option \#2}

This option would replace the 351 substation with new switchgear and relocate the existing primary transformers to the west side of Stevens Drive and only perform modification to the existing distribution equipment on as-needed basis to support demolition and remediation activities. To accomplish this option, a new substation pad and switch yard would be constructed at the new location to provide connection to the existing Bonneville Power Administration Benton-White Bluffs Number One $115 \mathrm{kV}$ transmission line. In addition, currently there are concrete encased lines that run under the road at the northwest corner of the 300 Area that would be utilized to connect the relocated substation to the existing 300 Area overhead distribution network

\subsection{Introduction}

This option would allow the demolition of the existing 351 substation structure and the remediation of the 300-4 waste site. The new substation will use all new outdoor components except the existing power transformers at the existing substation would be relocated to the new location. The new substation would be located on the west side of Stevens Drive and the transformers would be relocated on a sequenced basis, thus minimizing to the greatest extent possible any single feed configuration to the 300 Area power distribution network. The relocated substation and distribution systems will remain assigned to the RCCC until the end of that contract and then be assigned to SC (or other entity determined by DOE) for the balance of the 20 year period and then finally being reassigned to EM for D4 activities. The current configuration of the substation and distribution networks would be adapted in order to accommodate the demolition schedule of the RCCC and maintain the two independent sources of electrical power to the 300 Area facilities.

This option provides the same functional operations criteria as Option 1 but will involve additional costs to relocate the substation on the west side of Stevens Drive. In addition, this option clears up the regulatory path forward for the 300-4 waste site that lies underneath the 351 substation. In addition, the 400 Area "maintenance line" would be reconnected to the new substation and thus remain as configured.

\subsection{Scope of Work/System Description}

The existing 351 substation will be replaced, with the exception of the relocated power transformers, to the west side of Stevens Drive. The existing encased concrete ducts would be utilized to connect the new substation to the existing $13.8 \mathrm{kV}$ lines which run north and south along Stevens and George Washington Way. The existing 352F substation and associated electrical utility equipment would be maintained. In addition, the multiple drops from the existing overhead lines down to the existing underground electrical vaults in the 300 Area along Stevens and George Washington Way would also provide possible locations to access the 300 Area underground electrical distribution systems. The existing underground electrical distribution system should be maintained in the 300 Area south of Cypress street and along two 
pathways to 325 Building. The existing underground ducts are relatively new and should have sufficient life for another 20 years.

When the existing underground duct banks interferes with remediation or demolition activities, these systems would be modified to above ground aerial networks until the demolition of the building or remediation of the waste site was complete. Once the demolition or remediation has been accomplished then the undamaged, underground portion could be re-utilized. The Bonneville Power Administration Benton-White Bluffs Number One $115 \mathrm{kV}$ transmission line would require modification at its existing service to the 351 substation, and it would also require modification at the new substation.

\subsection{Option 3}

This option describes a proposal to request the City of Richland to provide one (1) of the new feeders and convert the existing 400 Area "maintenance line" into the other feeder as the electrical service providers to the 300 Area.

\subsection{Introduction}

This option supports the eventual demolition of the 351 substation and underlying 300-4 waste site but will require the electrical distribution system to be substantially modified in order to continue to provide two independent, reliable electrical power sources for the retained facilities in the 300 Area. In order to minimize the cost for converting the 300 Area distribution system under this option and maintain the requirements for two independent sources of electrical power, the 400 Area "maintenance line" would be converted to a supply line configuration from the 400 Area to the 300 Area. The other source of electrical power would come from the City of Richland's Sandhill Crane Substation. The substation and distribution systems will remain assigned to the RCCC until the end of that contract and then be assigned to SC (or other entity determined by DOE) for the balance of the 20 year period and then finally being reassigned to EM for D4 activities. The interface point with the City of Richland has not been established but will be addressed in the future.

\subsection{Scope of Work/System Description}

The 400 Area "maintenance line" is a $13.8 \mathrm{kV}, 3$ MVA line that is utilized to provide maintenance outage power to circuits $\mathrm{H} 4$ and $\mathrm{H} 5$ in the 4721 Turbine Building located at the FFTF site, as well as the 4622 meteorology tower and several air samplers in the 400 Area. Representatives from WCH and Fluor Hanford discussed changing this line from a 400 Area maintenance outage line to a supplier of electrical power providing a second source of power for the 300 Area facilities. The line would have enough capacity to provide the electrical services needed to support an independent electrical source (less than 3 MVA). The 400 Area will require changes to circuits $\mathrm{H} 4$ and $\mathrm{H} 5$ within the 4721 turbine building, an additional distribution circuit breaker installed in the 451B substation. A new 1200 foot overhead line between the 451B substation and the 4721 turbine building and a sectionalizing switch near the 4721 turbine building will be installed. 
The City of Richland plans to upgrade the Sandhill Crane substation to support new facilities in the Horn Rapids Triangle (HRT) area. They expect to add a transformer bank which will increase the capacity of the Sandhill Crane substation to 58 MVA, in 2008. This would make it possible to route a single utility line from the Sandhill Crane substation to the 300 Areas to support the retained facilities. A new substation consisting of distribution breakers, autotransformer circuit breakers, and an autotransformer to adjust the City of Richland's utility voltage level from $12.5 \mathrm{kV}$ to the existing 300 Area's utility voltage of $13.8 \mathrm{kV}$, will be required. The existing $13.8 \mathrm{kV}$ overhead lines in the south end of the 300 Area which run north and south along Stevens would become an extension of the 400 Area "maintenance line" connecting the $352 \mathrm{~F}$ substation to the $451 \mathrm{~B}$ substation. The existing $352 \mathrm{~F}$ substation and associated electrical utility equipment would be maintained. Electrical power could be delivered to the 325 Building using the existing underground duct lines that run from the west side of 325 Building, around the 329 Building, and west over to the overhead lines along Stevens Drive. A second route for electrical supply to the 325 Building would be the existing underground duct lines coming from existing electrical vaults by the 318 Building, under Cypress St, and north along California Ave, and over to the 325 Building.

To maintain power to the retained facilities during demolition and remediation activities, some reconfiguration and electrical work will be required at some of the utility switches and vaults. This task will be coordinated by the S\&M/U group in order to minimize any impacts to these facilities.

The Bonneville Power Administration Benton-White Bluffs Number One $115 \mathrm{kV}$ transmission line would require modification at its existing service to the 351 substation to maintain continuity of the line.

\subsection{Option 4}

\subsection{Introduction}

This option describes a proposal to request the City of Richland become the provider for new electrical utilities to the 300 Area and maintain the 300 Area's utility voltage at $13.8 \mathrm{kV}$. The electrical power would be extended to the 300 Area from the City of Richland, Sandhill Crane Substation. The $352 \mathrm{~F}$ substation and on site distribution systems will remain assigned to the RCCC until the end of that contract and then be assigned to SC (or other entity determined by $\mathrm{DOE}$ ) for the balance of the 20 year period and then finally being reassigned to the EM for D4 activities. The interface point with the City of Richland has not been established but will be addressed in the future.

\subsection{Scope of Work/System Description}

The City of Richland plans to upgrade the Sandhill Crane substation to support new facilities in the HRT area. The substation is currently configured as two independent primary sources of power from the Bonneville Power Administration White-Bluffs substation and the Richland 
Switch (near Fred Meyer on Thayer Dr.) which meets the requirements for the retained 300 Area facilities. They expect to add a transformer bank which will increase the capacity of the Sandhill Crane substation to $58 \mathrm{MVA}$, in 2008. This would make it possible to route two separate utility lines from the Sandhill Crane substation to the HRT and 300 Area to support the retained facilities. WCH has conceptual City of Richland drawings which show how the City could provide the necessary electrical utilities to the 300 Area. After the City of Richland upgrades are completed for the support of the HRT area, it will be extended to the 300 Area.

The two new $12.5 \mathrm{kV}$ feeds will originate from the Sandhill Crane substation in underground duct banks and cross under Stevens into the corner of the HRT area. Each line will transition to open wire overhead distribution construction and one $12.5 \mathrm{kV}$ line will be routed north along the east side of Stevens and connect to the new substation at the south west corner of the 300 Area. The second overhead $12.5 \mathrm{kV}$ line will be routed north from the corner of George Washington Way and Horn Rapids Road along George Washington Way and connect to the new substation at the southeast corner of the 300 Area near trailer MO-265.

The two new substations will consist of distribution breakers, an autotransformer with circuit breakers for adjusting the City of Richland's utility voltage level from $12.5 \mathrm{kV}$ to the existing 300 Area's utility voltage of $13.8 \mathrm{kV}$. The existing $13.8 \mathrm{kV}$ lines in the south end of the 300 Area, which run north and south along Stevens, and the underground lines that parallel George Washington Way will connect to the new substations. The overhead $13.8 \mathrm{kV}$ line that runs west to east between George Washington Way and Stevens will be upgraded to become a maintenance line between the two new substations. There are multiple drops existing from these overhead lines down to the existing 300 Area underground electrical distribution system. Existing underground electrical vaults in the 300 Area along Stevens and George Washington Way also provide possible locations to access the 300 Area underground electrical distribution system.

The existing underground electrical distribution system should be maintained in the 300 Area south of Cypress Street and along two pathways to the 325 Building. This existing underground utility system should have sufficient life for another 20 years. The existing $352 \mathrm{~F}$ substation and associated electrical utility equipment should be maintained. Reuse of the existing utility infrastructure will minimize required modification costs.

The 400 Area $13.8 \mathrm{kV}$ "maintenance line" will be powered from the 400 Area 451B substation which will supply power to the 4622 meteorology tower and several air samplers in the 400 Area. Feeding the maintenance line from the 400 Area will require changes to circuits $\mathrm{H} 4$ and H5 within the 4721 turbine building, an additional distribution circuit breaker installed in the 451B substation. A new 1200 foot overhead line between the 451B substation and the 4721 turbine building and a sectionalizing switch near the 4721 turbine building will be installed.

Electrical power could be delivered to 325 Building using the existing underground duct lines that run from west side of the 325 Building, around the 329 Building, and west over to the overhead lines along Stevens Drive. A second route for electrical supply to the 325 Building 
would be the existing underground duct lines coming from existing electrical vaults by the 318 Building, under Cypress St, and north along California Ave, and over to the 325 Building.

To maintain power to the retained facilities during demolition and remediation activities some reconfiguration and electrical work will be required at some of the utility switches and vaults to maintain power to the retained facilities.

The Bonneville Power Administration Benton-White Bluffs Number One $115 \mathrm{kV}$ transmission line would require modification at its existing service to the 351 substation to maintain continuity of the line.

\subsection{Option 5}

\subsection{Introduction}

This option describes a proposal to request the City of Richland become the supplier for new electrical power to the 300 Area and change the utility voltage to $12.5 \mathrm{kV}$ to match the City of Richland. The electrical power would be extended to the 300 Area from the City of Richland, Sandhill Crane Substation. The 352F substation and on site distribution systems will remain assigned to the RCCC until the end of that contract and then be assigned to SC (or other entity determined by DOE) for the balance of the 20 year period and then finally being reassigned to the EM for D4 activities. The interface point with the City of Richland has not been established but will be addressed in the future.

\subsection{Scope of Work/System Description}

The City of Richland plans to upgrade the Sandhill Crane substation to support new facilities in the HRT area. The substation is currently configured as two independent primary sources of power from the Bonneville Power Administration White-Bluffs substation and the Richland Switch (near Fred Meyer on Thayer Dr.) which meets the requirements for the retained 300 Area facilities. The City expects to add a transformer bank which will increase the capacity of Sandhill Crane substation to $58 \mathrm{MVA}$, in 2008. This would make it possible to route two separate utility lines from the Sandhill Crane substation to the HRT and 300 Areas to support the retained facilities. WCH has conceptual City of Richland drawings which show how the City could provide the necessary electrical utilities to the 300 Area. After the City of Richland upgrades are completed for the support of the HRT area, it will be extended to the 300 Area.

The two new $12.5 \mathrm{kV}$ feeds will originate from the Sandhill Crane substation in underground duct banks and cross under Stevens into the corner of the HRT area. Each line will transition to open wire overhead distribution construction and one $12.5 \mathrm{kV}$ line will be routed north along the east side of Stevens and connect to the existing overhead lines at the south west corner of the 300 Area. The second overhead $12.5 \mathrm{kV}$ line will be routed north from the corner of George Washington Way and Horn Rapids Road along George Washington Way and connect to the underground lines at to the south east corner of the 300 Area near trailer MO-265. 
All the existing 300 Area utility distribution system that will be reused is currently rated and designed using $15 \mathrm{kV}$ equipment; therefore any changes to the distribution system will be minor except the utility transformers for the retained buildings. The existing utility transformers for each building or equipment will have to be changed to match the new distribution voltage of $12.5 \mathrm{kV}$. The $\mathrm{kVA}$ ratings will remain the same and the impedance ratings will be calculated so the existing buildings will have no significant increase of available fault current. There are multiple drops existing from these overhead lines down to the existing 300 Area underground electrical distribution system. Existing underground electrical vaults in the 300 Area along Stevens and George Washington Way also provide possible locations to access the 300 Area underground electrical distribution system. The existing underground electrical distribution system should be maintained in the 300 Area south of Cypress Street and along two pathways to the 325 Building. This existing underground utility system should have sufficient life for another 20 years. The existing $352 \mathrm{~F}$ facility and associated electrical utility equipment should be maintained. Reuse of the existing utility infrastructure will minimize required modification costs.

The 400 Area $13.8 \mathrm{kV}$ "maintenance line" will be powered from the 400 Area 451B substation which will supply power to the 4622 meteorology tower and several air samplers in the 400 Area. Feeding the maintenance line from the 400 Area will require changes to circuits $\mathrm{H} 4$ and H5 within the 4721 turbine building, an additional distribution circuit breaker installed in the 451B substation. A new 1200 foot overhead line between the 451B substation and the 4721 turbine building and a sectionalizing switch near the 4721 turbine building will be installed.

Electrical power could be delivered to 325 Building using the existing underground duct lines that run from west side of the 325 Building, around the 329 Building, and west over to the overhead lines along Stevens Drive. A second route for electrical supply to the 325 Building would be the existing underground duct lines coming from existing electrical vaults by the 318 Building, under Cypress St, and north along California Ave, and over to the 325 Building.

To maintain power to the retained facilities during demolition and remediation activities some reconfiguration and electrical work will be required at some of the utility switches and vaults to maintain power to the retained facilities.

The Bonneville Power Administration Benton-White Bluffs Number One $115 \mathrm{kV}$ transmission line would require modification at its existing service to the 351 substation to maintain continuity of the line. 
Option 1 Map

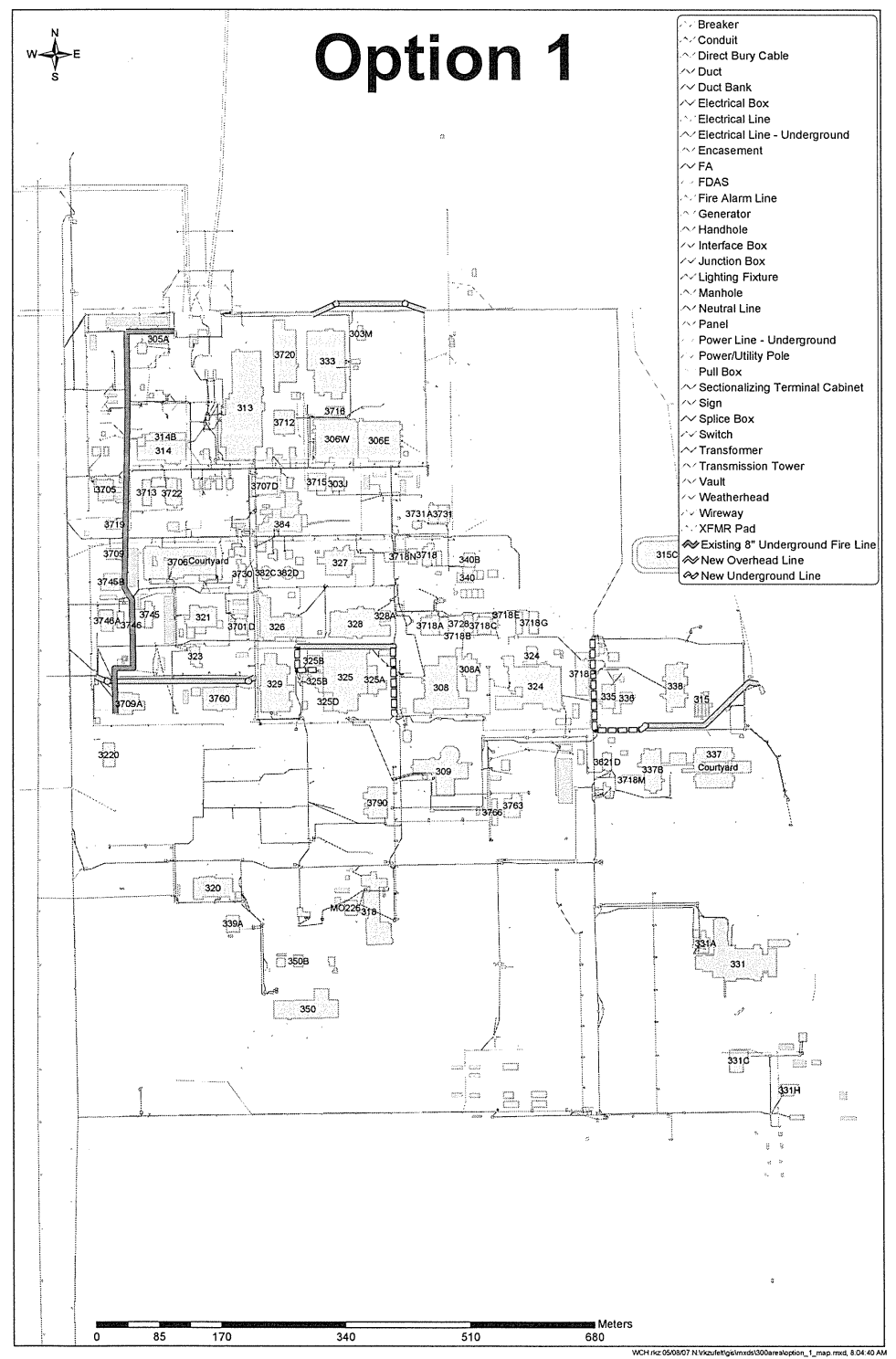


Option 2 Map

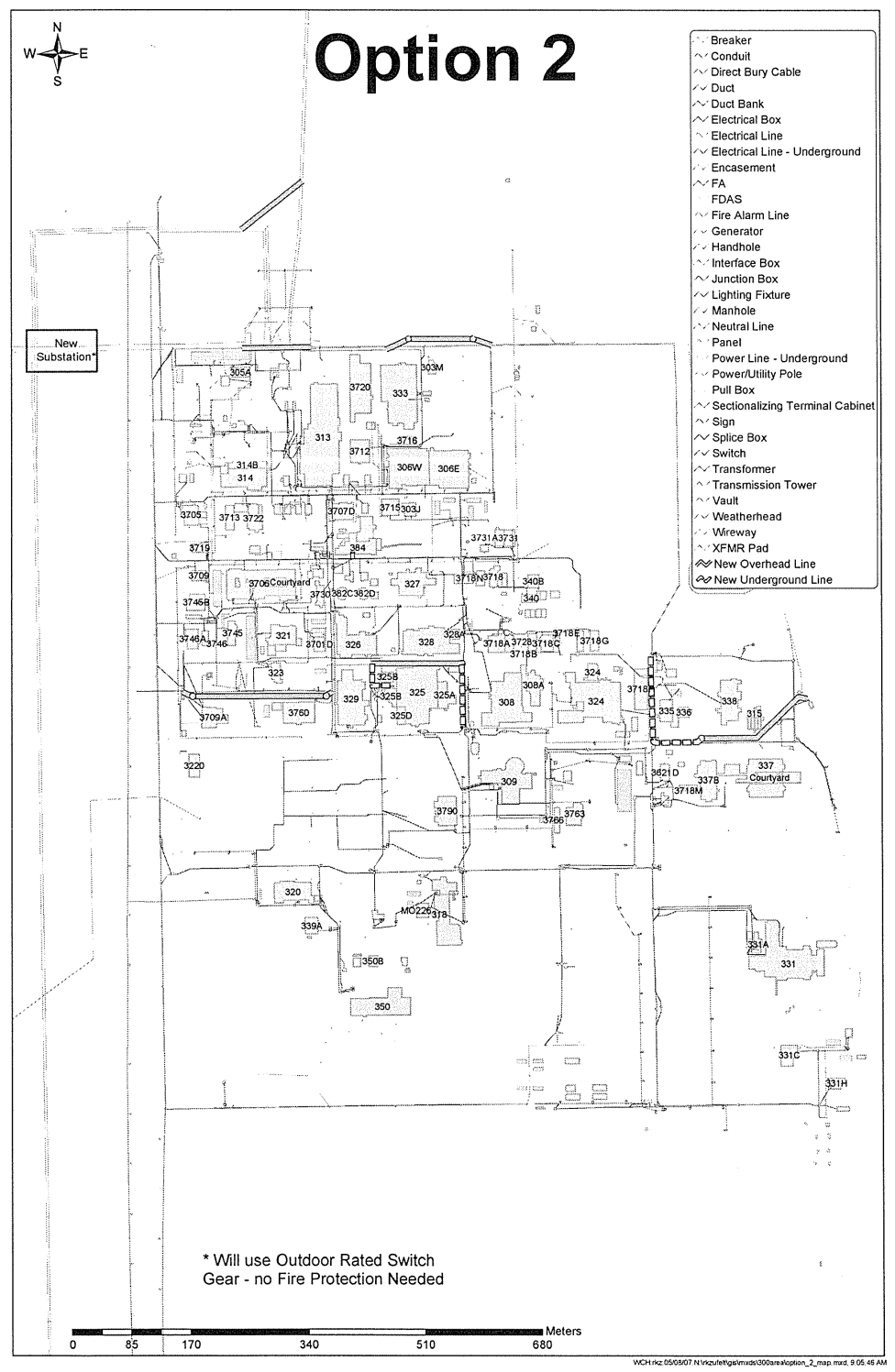


Option 3 Map

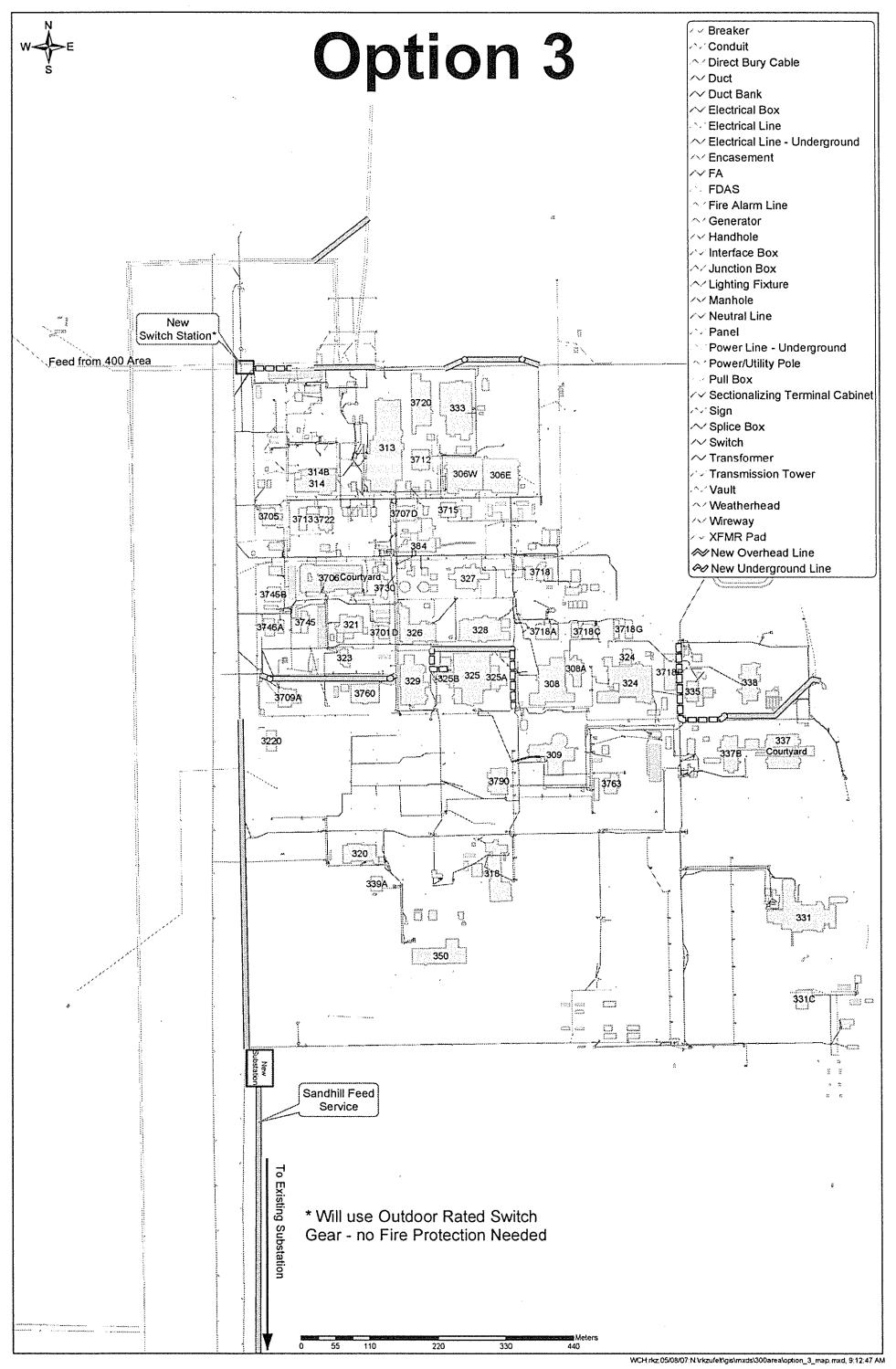


Option 4 Map

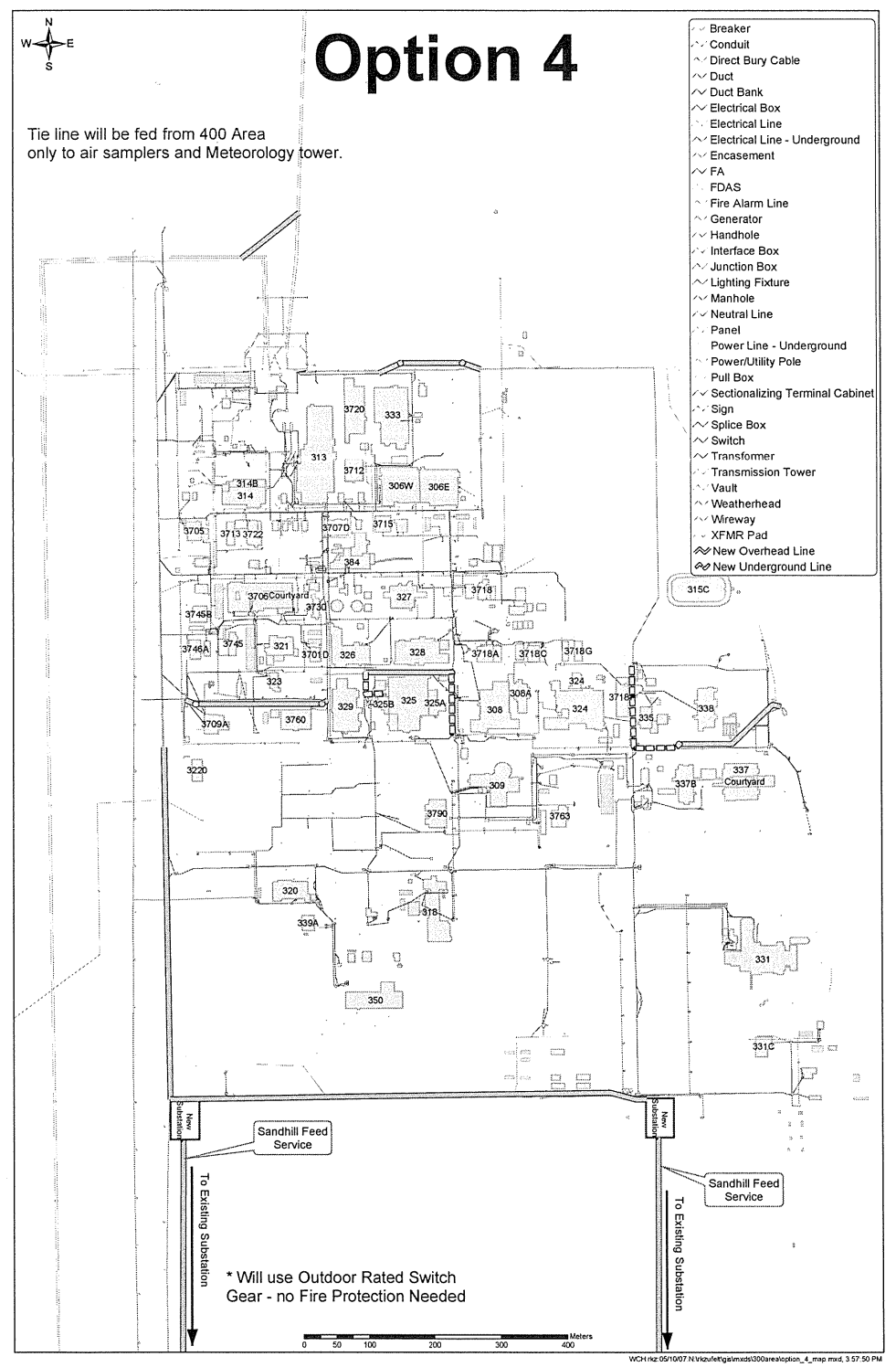


Option 5 Map

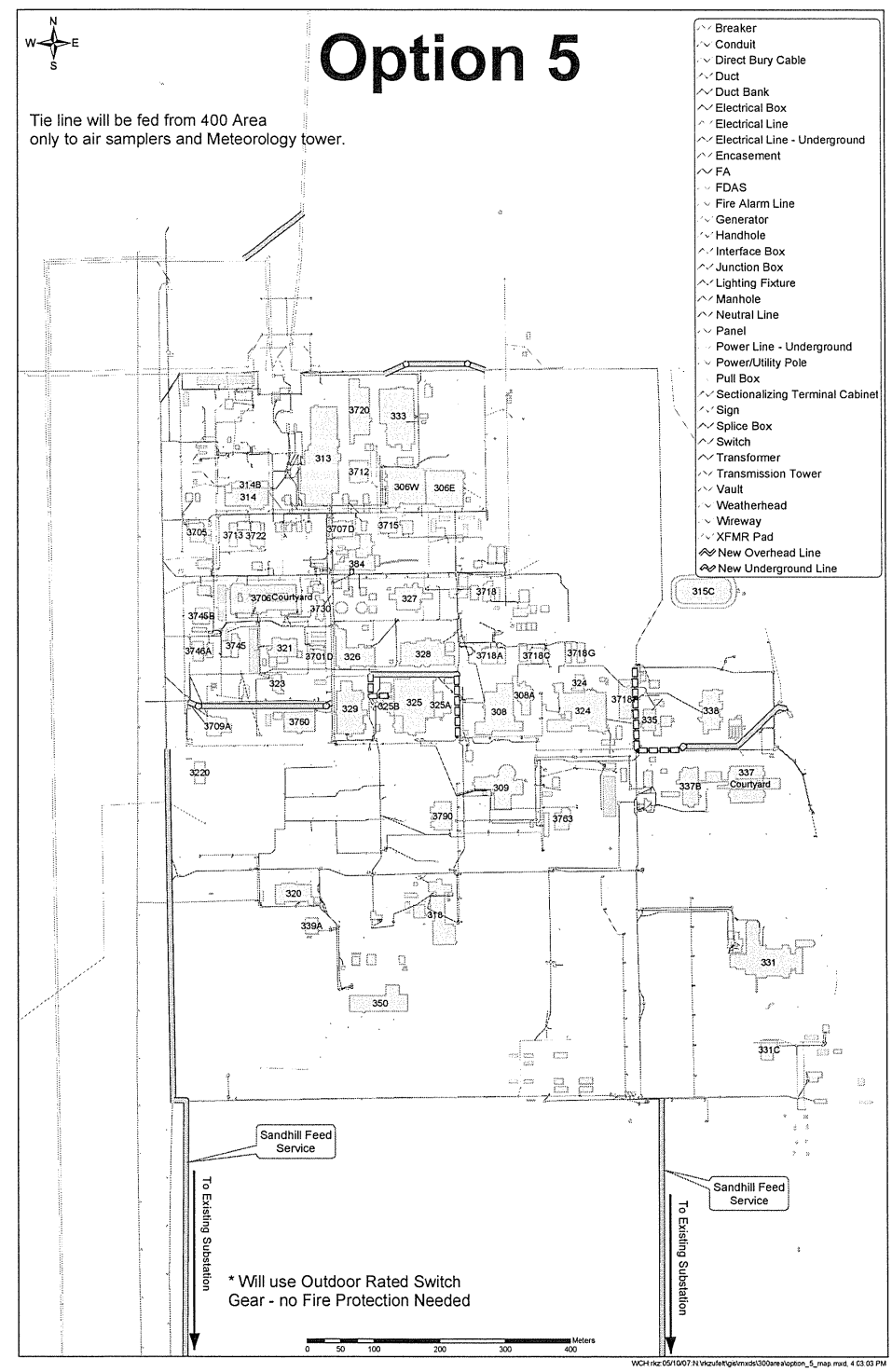


WCH-181

Rev. 0

\begin{tabular}{|c|c|c|c|c|c|c|}
\hline 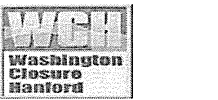 & \multicolumn{5}{|c|}{ Cost Estimate Summary } & \multirow{2}{*}{ 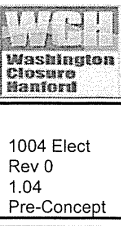 } \\
\hline $\begin{array}{r}\text { TITLE: } \\
\text { AREA: } \\
\text { Estimate Requestor: } \\
\text { Prepared By: }\end{array}$ & $\begin{array}{l}300 \text { AREA UTILITY RELOCATION PROJECT } \\
\text { ELECTRICAL SYSTEMS MODIFICATIONS } \\
300 \text { Area } \\
\text { Don McBride } \\
\text { dijakubek }\end{array}$ & $\begin{array}{c}\text { Date Prepared: } \\
\text { Date Revised: }\end{array}$ & $\begin{array}{l}04 / 18 / 07 \\
05 / 16 / 07 \\
\end{array}$ & \multicolumn{2}{|c|}{$\begin{array}{r}\text { Estimate Number: } \\
\text { Revision: } \\
\text { WBS Number: } \\
\text { Estimate Type: } \\
\end{array}$} & \\
\hline \multicolumn{7}{|l|}{ 5.0 Estimated Cost } \\
\hline \multicolumn{2}{|c|}{ Total estimated cost $(\$ 1,000 \mathrm{~s})$} & $\begin{array}{l}\text { Estimated } \\
\text { Cost }\end{array}$ & $\begin{array}{l}\text { Contingency } \\
\%\end{array}$ & $\begin{array}{c}\text { Contingency } \\
\text { sss }\end{array}$ & $T E C$ & \\
\hline \multicolumn{2}{|c|}{ Option 1: Retain 351 Substation } & $\$ 954$ & $30 \%$ & $\$ 286$ & $\$ 1,240$ & \\
\hline \multicolumn{2}{|c|}{ Option 2: Relocate 351 Substation } & $\$ 2,029$ & $40 \%$ & $\$ 812$ & $\$ 2,841$ & \\
\hline \multicolumn{2}{|c|}{ Option 3: Feed From Richland \& 400 Area } & $\$ 3,375$ & $35 \%$ & $\$ 1,181$ & $\$ 4,556$ & \\
\hline \multicolumn{2}{|c|}{ Option 4: Two Lines From Richland / Auto Transformers } & $\$ 5,118$ & $35 \%$ & $\$ 1,791$ & $\$ 6,909$ & \\
\hline \multicolumn{2}{|c|}{ Option 5: Two Lines From Richland / Buildings Transformers } & $\$ 4,712$ & $40 \%$ & $\$ 1,885$ & $\$ 6,597$ & \\
\hline \multicolumn{7}{|l|}{ 6.0 Estimate Review } \\
\hline \multirow[t]{2}{*}{$\begin{array}{l}\text { Estimator } \\
\text { Estimating Manager } \\
\text { Task Manager } \\
\text { Project Controls Lead }\end{array}$} & Dan Jakubek & & & & $\frac{5-2}{5-2} \frac{5-22}{5}$ & $\frac{2-07}{2-02}$ \\
\hline & & & & & & \\
\hline
\end{tabular}


WCH-181

Rev. 0

300 Area Building Retention Evaluation Mitigation Plan 
PROPRIETARY INFORMATION
Data furnished in connection with this proposal shall not be disclosed outside WCH approval, and shall not be duppicated, used, or discussed for any purpose other than to evaluate the proposal.

WASHINGTON CLOSURE HANFORD, INC. ESTIMATE PRICING SHEET

RIVER CORRIDOR CLEAN UP PROJECT RICHLAND, WASHINGTON
TITLE: 300 Area Utility Repacement Project - Electrical - Option \#1 SUBJECT: 20 Retain 351 Substation

* Rework Power Feeds At 5 Loc. Inside 300 Are
Estimate No: 1004-Elect-Opt\#1

Date: $04 / 18 / 07$

By: Dan Jakubek

Rev No: 0

\begin{tabular}{|c|c|c|c|c|c|c|c|c|c|c|c|c|c|c|}
\hline \multirow[b]{2}{*}{$\begin{array}{l}\text { Item } \\
\text { No. }\end{array}$} & \multirow[b]{2}{*}{ DESCRIPTION } & \multirow[b]{2}{*}{ Qty } & \multirow[b]{2}{*}{ Unit } & \multicolumn{4}{|c|}{$\angle A B O R$} & \multicolumn{2}{|c|}{ MATERIAL } & \multicolumn{2}{|c|}{$\begin{array}{c}\text { CONST. } \\
\text { EQUIPMENT }\end{array}$} & \multicolumn{2}{|c|}{$\begin{array}{l}\text { SUB } \\
\text { CONT }\end{array}$} & \multirow[b]{2}{*}{ TOTAL } \\
\hline & & & & $\begin{array}{l}\text { MHR } \\
\text { Rate }\end{array}$ & MHRS & $\begin{array}{l}\text { Rate } \\
\text { \$MHR }\end{array}$ & $\begin{array}{c}\text { Subtotal } \\
\text { Labor }\end{array}$ & $\begin{array}{l}\text { Unit } \\
\text { Cost }\end{array}$ & $\begin{array}{c}\text { Subtotal } \\
\text { Mat'l }\end{array}$ & $\begin{array}{l}\text { Unit } \\
\text { Cost }\end{array}$ & $\begin{array}{l}\text { Subtotal } \\
\text { Equip. }\end{array}$ & $\begin{array}{l}\text { Unit } \\
\text { Cost } \\
\end{array}$ & $\begin{array}{l}\text { Subtotal } \\
\text { Sub }\end{array}$ & \\
\hline
\end{tabular}

\begin{tabular}{|l|l|l|l|l|l|l|l|l|l|}
\hline 2.1. Perform Constructability Discussions \& Permitting Process & & & & & & & & & \\
\hline
\end{tabular} Includes activities such as: SubK perform constructability reviews for each system segment with approval organizations (Flour Hanford, PNNL, \& DOE; SubK perform construction start-up approval documentation \& work packages; \& develop procurement contracts.

SubK Meetings w/WCH, Flour Hanford, Others \& Discus Constrablablich

for discussing scope; prepare/review construction permitting docs. - Est 3 Design/Mgr personnel $\times 2$ wks \& mat'l allowance. Subtotal

\section{2-Mobe Site}

Includes personnel training, set up equipment, layout and survey area, \& prepare for construction activities. Est majority of equipment owned by SubK w/other pcs available in surrounding area with in 100 miles.

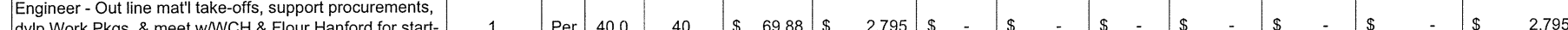

2 dvlp Work Pkgs, \& meet w/WCH \& Flour Hanford for start-

Superintendent - Support mat'l take-offs, procurements, dvlp Work Pkgs, \& meet w/WCH \& Flour Hanford for stat-

4 Surveyors - Used Fld Support Eng rate - 2 man crew

5 Training Budget - Estimated amount for Subcontractor training expenses. Allowance - $\$ 250$ per person

6 Training Labor - Estimated 8hrs per person to go thru site training. See Training wk shis for Labor costs.

8 Lineman - 4 man crew - Mobe

Lineman 4 man crew - Mober Mo

Storage on Sides, $6 \times 4,400 \mathrm{Hp}, 70000 \mathrm{lbs}$ max, Diesel, Lineman Pole Auger Truck - w/Man Boom, Pole Auger, \& $10 \begin{aligned} & \text { Tool Storage on Sides, } 6 \times 4,400 \mathrm{Hp}, 70000 \text { lbs max, } \\ & \text { Diesel, Yr/04 }\end{aligned}$

\begin{tabular}{|c|c|c|c|c|c|c|c|c|c|c|c|c|c|c|c|c|c|c|}
\hline 1 & Per & 40.0 & 40 & $\$$ & 69.88 & $\$$ & 2,795 & $\$$ & $\$$ & - & $\$-$ & $\$$ & - & $\$$ & $\$$ & - & $\$$ & 2,795 \\
\hline 1 & Per & 40.0 & 40 & $\$$ & 59.53 & $\$$ & 2,381 & $\$$ & $\$$ & - & $\$-$ & $\$$ & - & $\$$ & $\$$ & - & $\$$ & 2,381 \\
\hline 2 & $\mathrm{Ea}$ & 40.0 & 80 & $\$$ & 59.14 & $\$$ & 4,731 & $\$$ & $\$$ & - & $\$-$ & $\$$ & - & $\$$ & $\$$ & - & $\$$ & 4,731 \\
\hline 12 & $\mathrm{Ea}$ & 0.0 & 0 & $\$$ & - & $\$$ & - & $\$$ & $\$$ & - & $\$-$ & $\$$ & - & $\$ 250.00$ & $\$$ & 3,000 & $\$$ & 3,000 \\
\hline 1 & Ls & 0.0 & 1 & $\$$ & 6,451 & $\$$ & 6,451 & $\$$ & $\$$ & - & $\$-$ & $\$$ & - & $\$$ & $\$$ & - & $\$$ & 6,451 \\
\hline 1 & Crft & 20.0 & 20 & $\$$ & 61.04 & $\$$ & 1,221 & $\$$ & $\$$ & - & $\$$ & $\$$ & - & $\$$ & $\$$ & - & $\$$ & 1,221 \\
\hline 4 & Crrt & 20.0 & 80 & $\$$ & 55.79 & $\$$ & 4,463 & $\$$ & $\$$ & - & $\$$ & $\$$ & - & $\$$ & $\$$ & - & $\$$ & 4,463 \\
\hline 5 & Hrs & 0.0 & 0 & $\$$ & - & $\$$ & - & $\$$ & $\$$ & - & $\$ 59.04$ & $\$$ & 295 & $\$$ & $\$$ & - & $\$$ & 295 \\
\hline 5 & Hrs & 0.0 & 0 & $\$$ & - & $\$$ & - & $\$$ & $\$$ & - & $\$ 59.04$ & $\$$ & 295 & $\$$ & $\$$ & - & $\$$ & 295 \\
\hline
\end{tabular}


PROPRIETARY INFORMATION

WD WASHINGTON CLOSUREHANFORD

WASHINGTON CLOSURE HANFORD, INC ESTIMATE PRICING SHEET

EAN UP PROJECT RICHLAND, WASHINGTON
TITLE: 300 Area Utility Repacement Project - Electrical - Option \#1 20 Retain 351 Substation

* Rework Power Feeds At 5 Loc. Inside 300 Area
Estimate No: 1004-Elect-Opt\#1

Date: $04 / 18 / 07$

By: Dan Jakubek

RevNo: 0

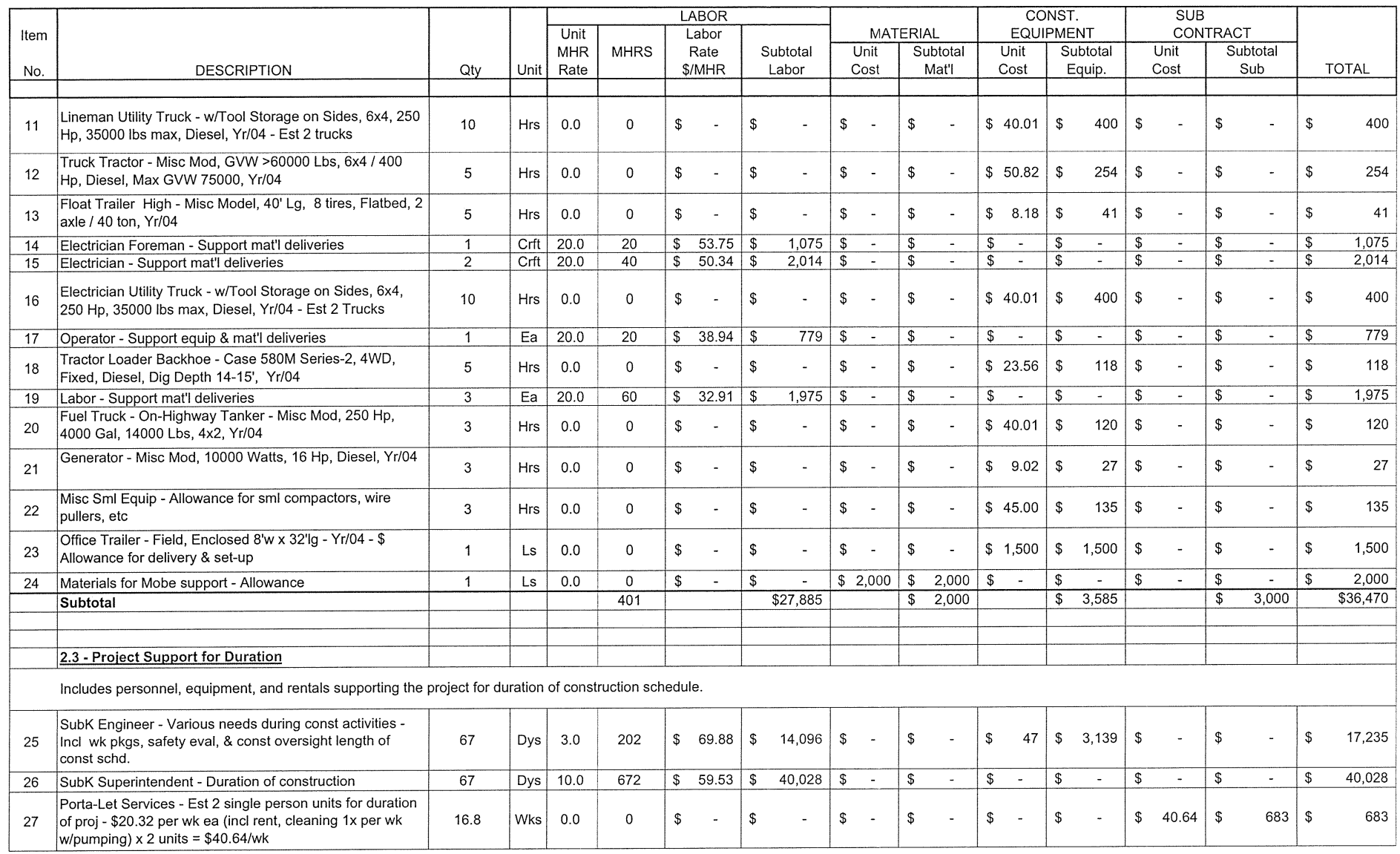

Page 3 of 12

$5 / 16 / 2007$ 
PROPRIETARY INFORMATION

Data furnished in connection with this proposal shall not be disclosed outside WRCPR

WASHINGTON CLOSURE HANFORD, INC. ESTIMATE PRICING SHEET RIVER CORRIDOR CLEAN UP PROJECT RICHLAND, WASHINGTON
TITLE: 300 Area Utility Repacement Project - Electrical - Option \#1 UBJECT: 2.0 Retain 351 Substation

t Rework Power Feeds At 5 Loc. Inside 300 Area
Estimate No: 1004-Elect-Optt1

Date: $04 / 18 / 07$

By: Dan Jakube

RevNo: 0

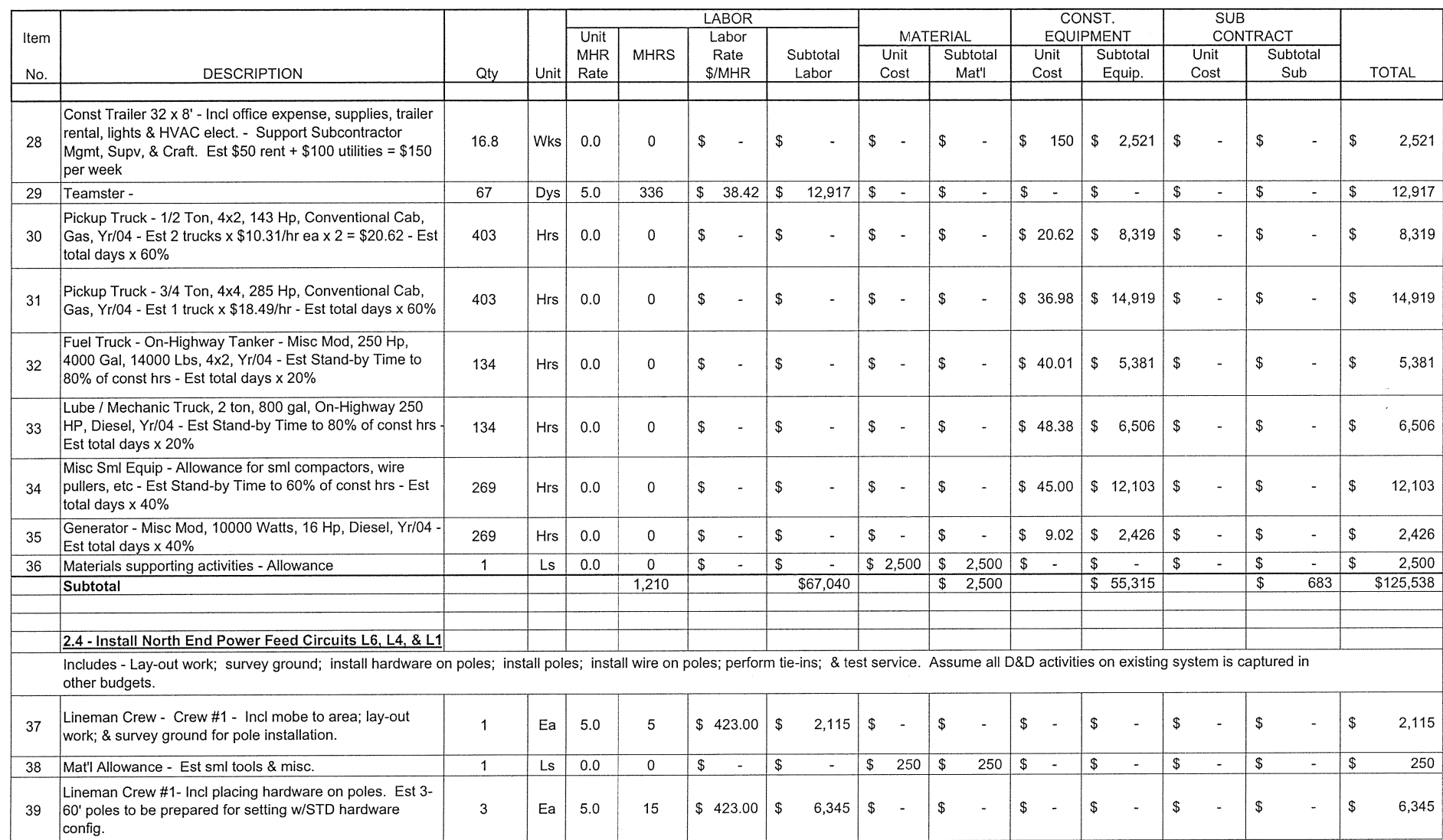


PROPRIETARY INFORMATION
Data furnished in connection with this proposal shall not be disclosed outside WCH approval, and shall not be duplicated, used, or discussed for any purpose other than to evaluate the proposal.

WASHINGTON CLOSURE HANFORD, INC. ESTIMATE PRICING SHEET

EAN UP PROJECT RICHLAND, WASHINGTON
TITLE: 300 Area Utility Repacement Project - Electrical - Option \#1 20 Retain 351 Substation

* Rework Power Feeds At 5 Loc. Inside 300 Area
Estimate No: 1004-Elect-Opt\#1

Date : $04 / 18 / 07$

By: Dan Jakubek

Date: $05 / 16107$

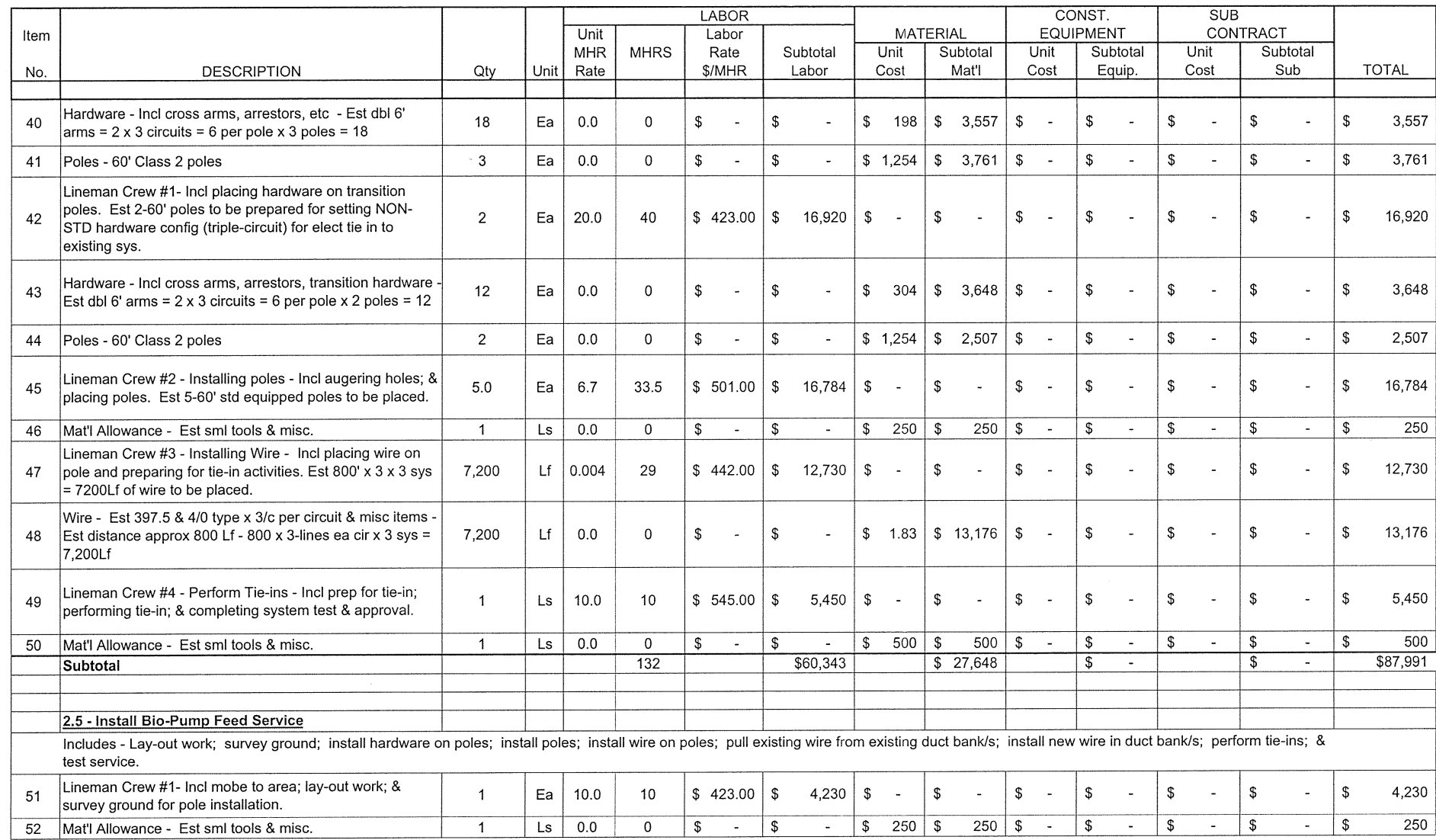


PROPRIETARY INFORMATION
Data furnished in connection with this proposal shall not be disclosed outside WCH approval, and shall not be duplicated, used, or discussed for any purpose other than to evaluate the proposal.

WASHINGTON CLOSURE HANFORD, INC ESTIMATE PRICING SHEET

RIVER CORRIDOR CLEAN UP PROJECT RICHLAND, WASHINGTON
TITLE: 300 Area Utility Repacement Project - Electrical - Option \#1 SUBJECT: 2.0 Retain 351 Substation Retain 351 Substation
Estimate No : 1004-Elect-Opt\#1

Date: $04 / 18 / 07$

By: Dan Jakubek

Rev No:

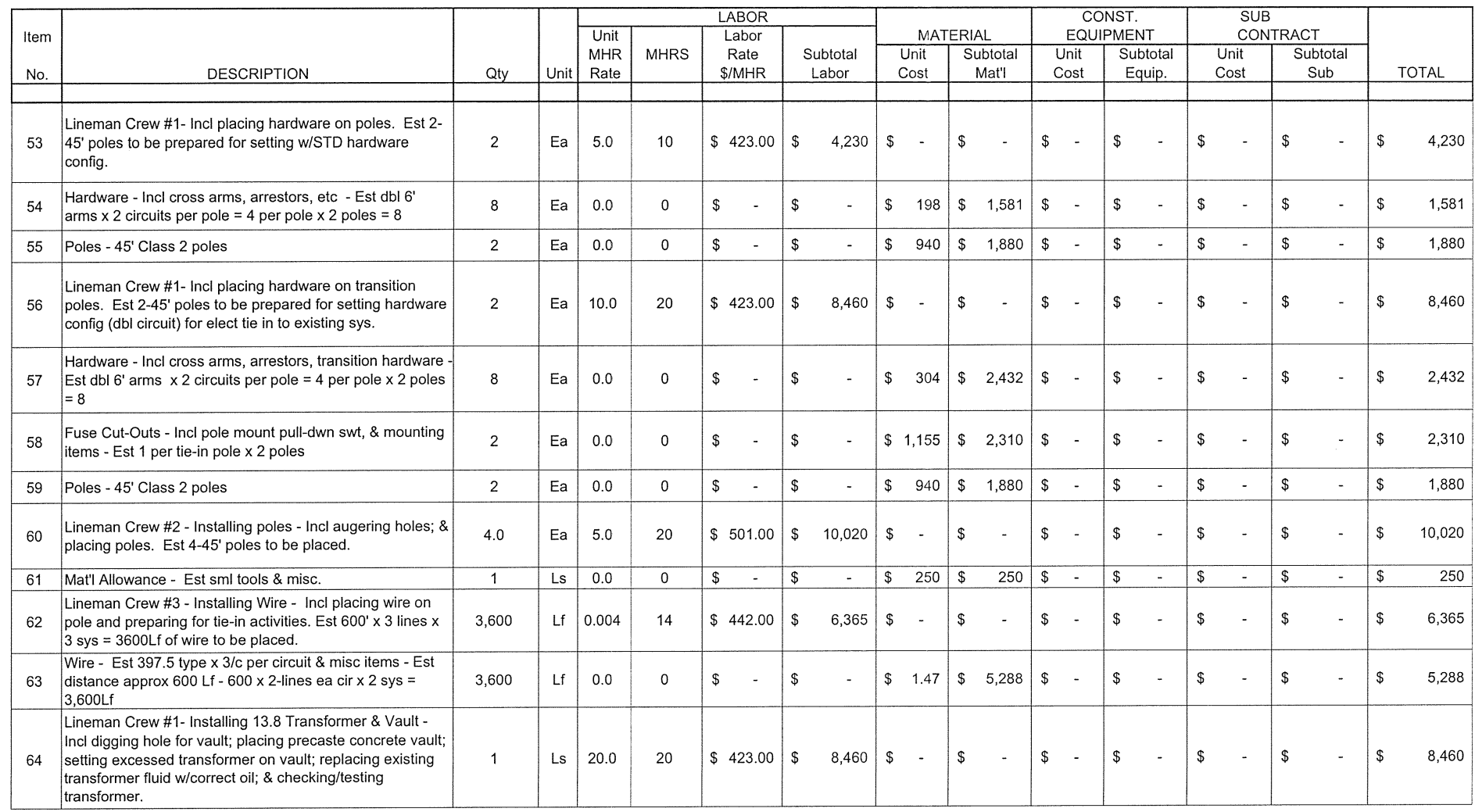


PROPRIETARY INFORMATION
Data furnished in connection with this proposal shall not be disclosed outside WCH approval, and shall not be dupicated, used, or discussed for any purpose other than to evaluate the proposal.

WASHINGTON CLOSURE HANFORD, INC. ESTIMATE PRICING SHEET

PROJECT RICHLAND, WASHINGTON
TITLE: 300 Area Utility Repacement Project - Electrical - Option \#1 SUBJECT: 20 Retain 351 Substation

* Rework Power Feeds At 5 Loc. Inside 300 Area
Estimate No: 1004-Elect-Opt\#1

Date: $04 / 18 / 07$

By: Dan Jakubek

Rev No: 0

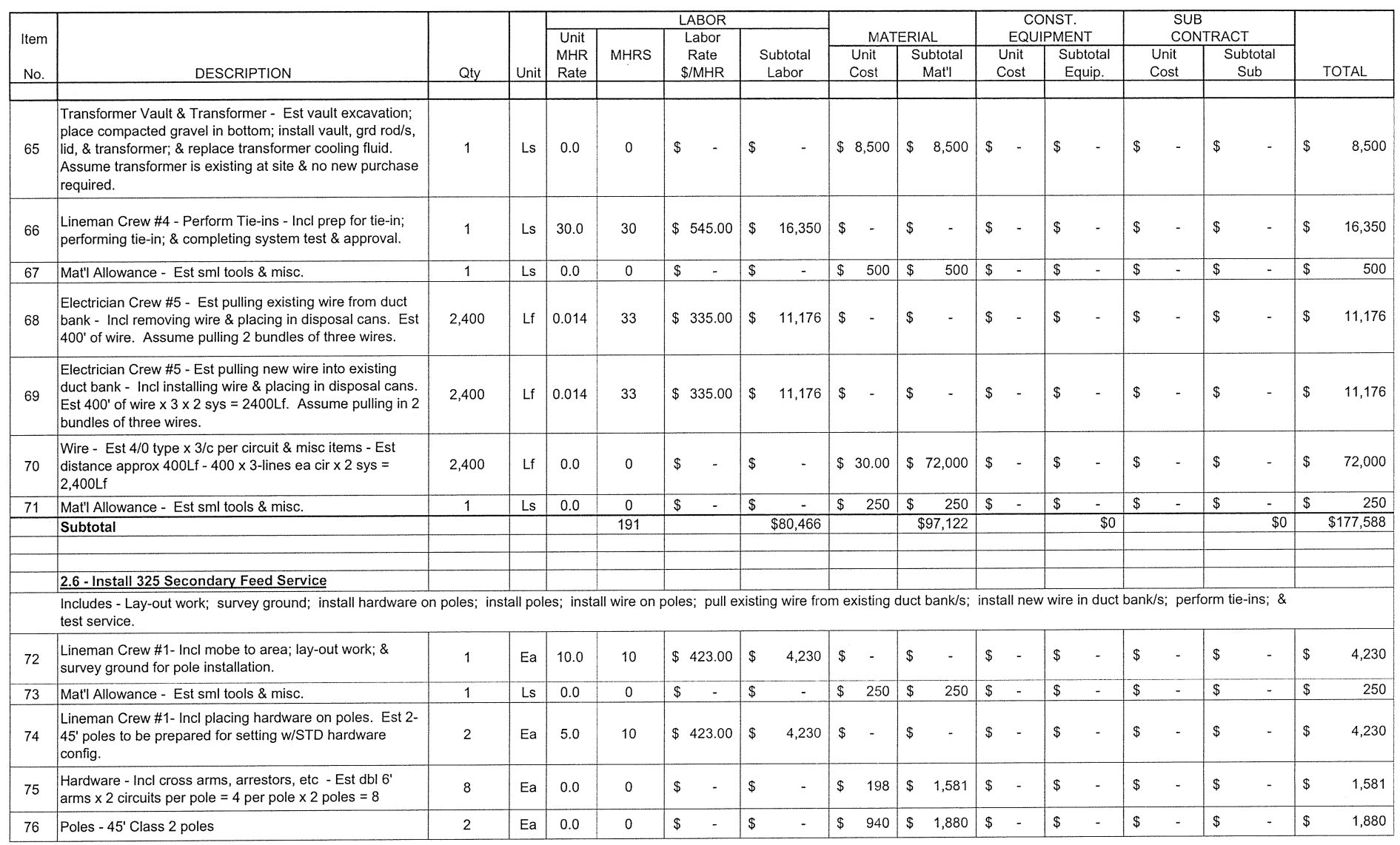


PROPRIETARY INFFRMATION
Data furnished in connection with this proposal shall not be disclosed outside WCH approval, and shall not be duplicated, used, or discussed for any purpose other than to evaluate the proposal.

WASHINGTON CLOSURE HANFORD, INC. ESTIMATE PRICING SHEET

PROJEC RICHLAND, WASHINGTON
TITLE: 300 Area Utility Repacement Project - Electrical - Option \#1 SUBJECT: 2.0 Retain 351 Substation

Rework Power Feeds At 5 Loc. Inside 300 Area
Estimate No: 1004-Elect-Op\#1

Date : $04 / 18 / 07$

By: Dan Jakubek

RevNo: 0

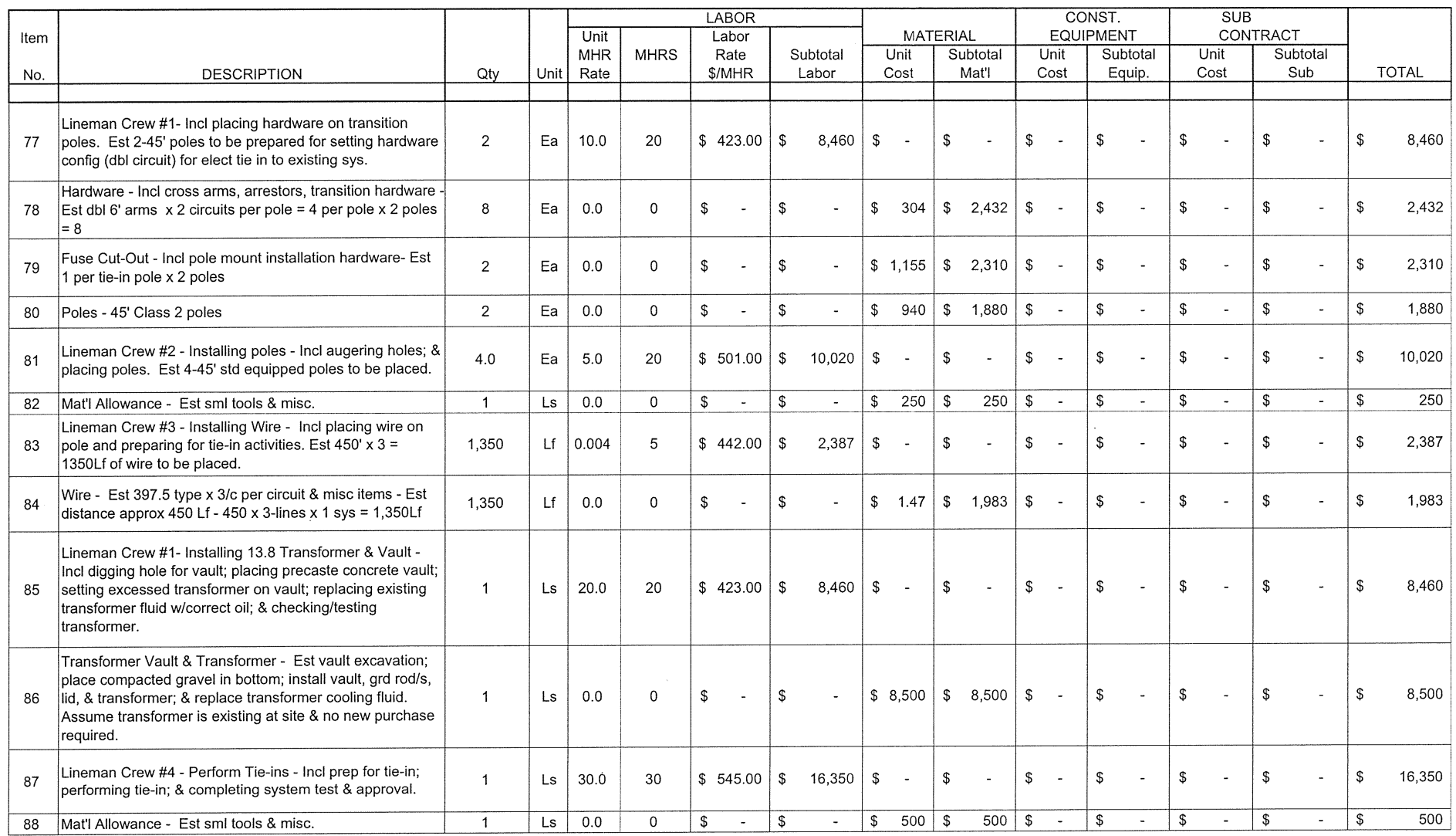


PROPRIETARY INFORMATION
Data furnished in connection with this proposal shall not be disclosed outside WCH approval, and shall not be duplicated, used, or discussed for any purpose other than to evaluate the proposal.

WASHINGTON CLOSURE HANFORD, INC. ESTIMATE PRICING SHEET EAN UP PROJECT RICHLAND, WASHINGTON
TITLE: 300 Area Utility Repacement Project - Electrical - Option \#1 SUBJECT: 2.0 Retain 351 Substation

* Rework Power Feeds At 5 Loc. Inside 300 Area
Estimate No: 1004-Elect-Optt1

Date: $04 / 18 / 07$

By: Dan Jakubek

Rev No: 0

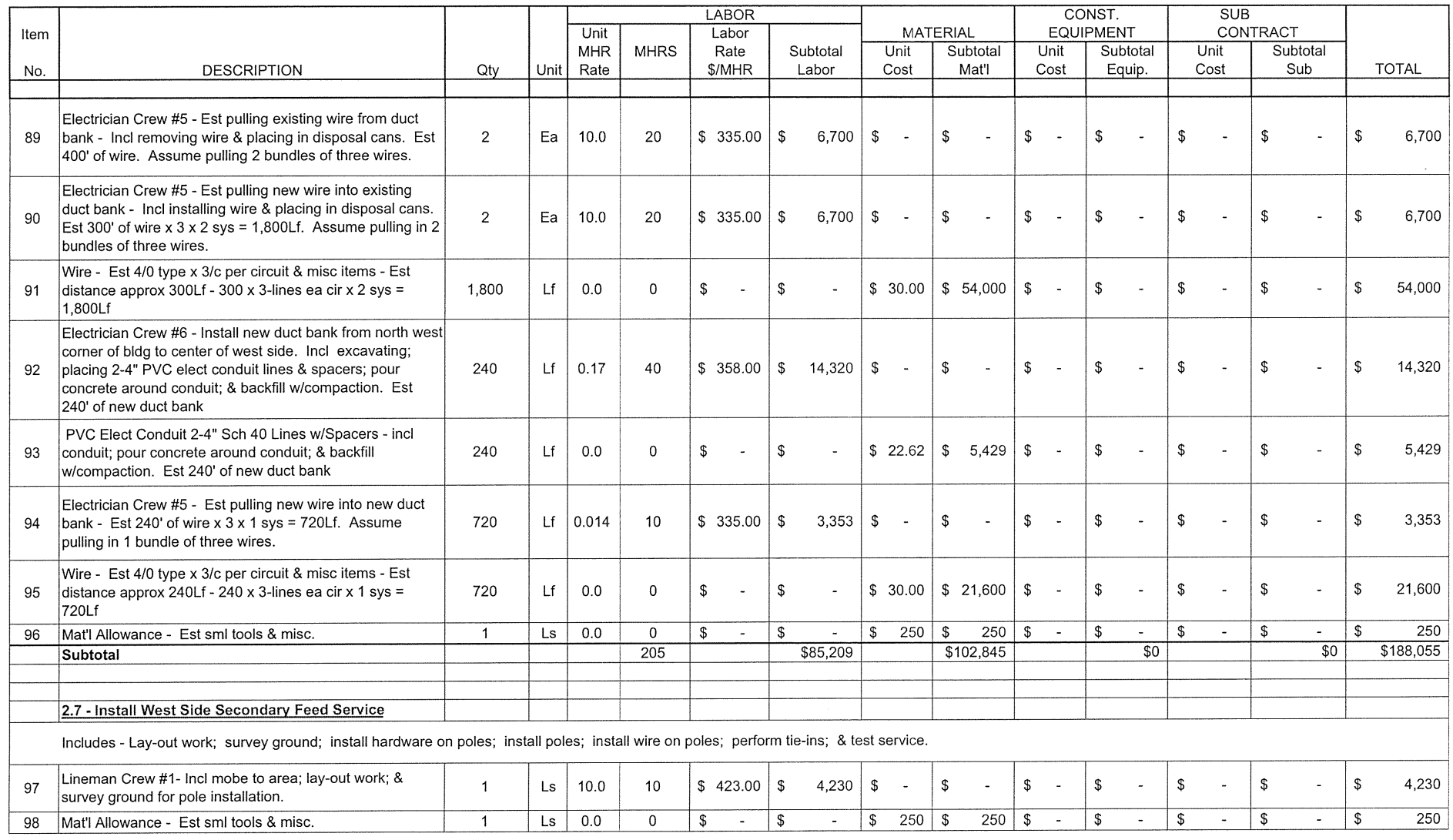




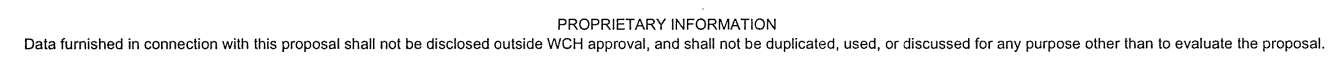

WASHINGTON CLOSURE HANFORD, INC. ESTIMATE PRICING SHEET RIVER CORRIDOR CLEAN UP PROJECT RICHLAND, WASHINGTON
TITLE: 300 Area Utility Repacement Project - Electrical - Option \#1 SUBJECT: 2.0 Retain 351 Substation

* Rework Power Feeds At 5 Loc. Inside 300 Area
Estimate No: 1004-Elect-Opt\#1

Date: $04 / 18 / 07$

By: Dan Jakubek

Rev No: 0

Date: $05 / 16 / 07$

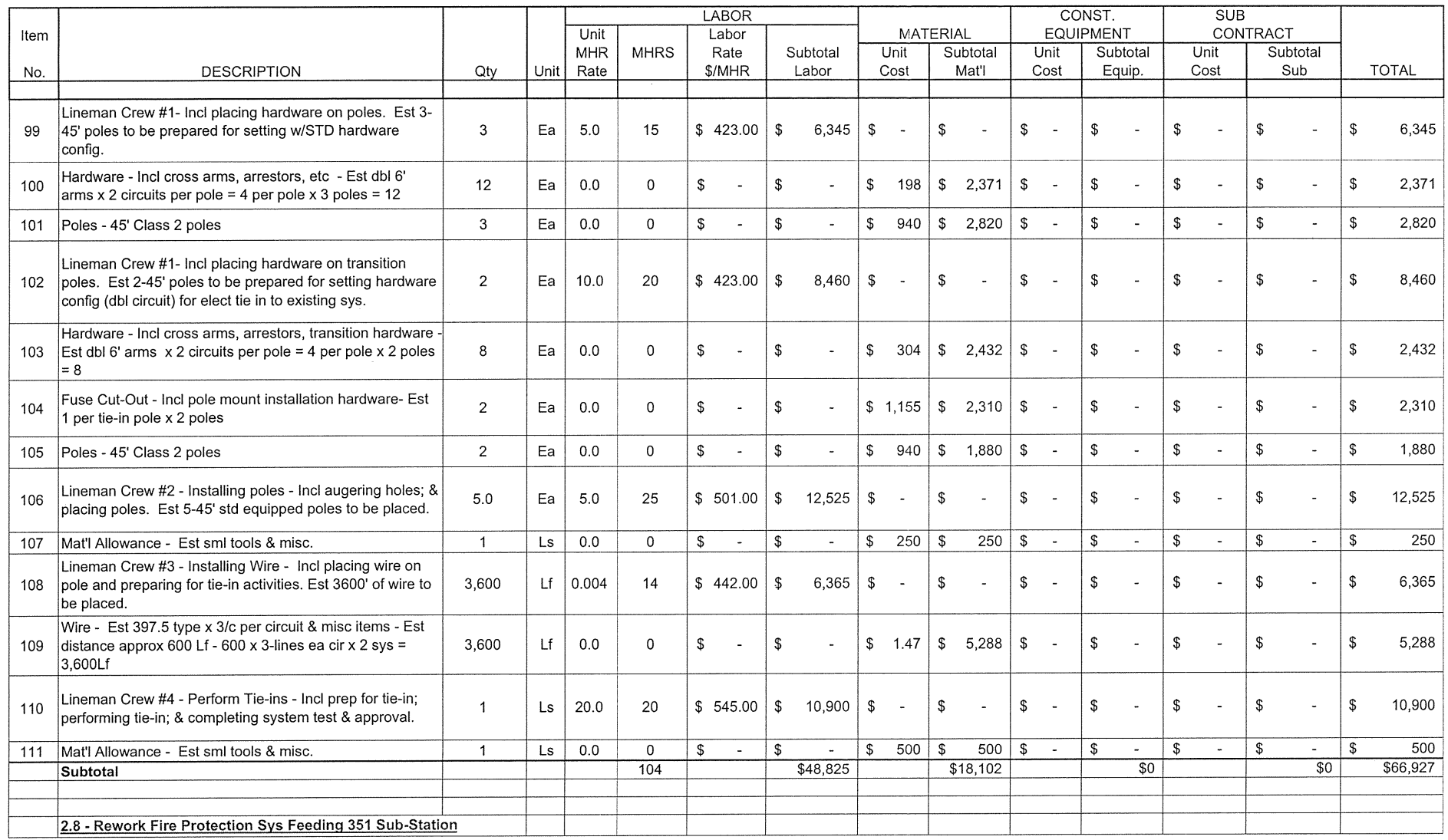


PROPRIETARY INFORMATION
Data furnished in connection with this proposal shall not be disclosed outside WCH approval, and shall not be duplicated, used, or discussed for any purpose other than to evaluate the proposal.

WASHINGTON CLOSURE HANFORD, INC. ESTIMATE PRICING SHEET EAN UP PROJECT RICHLAND, WASHINGTON
TITLE: 300 Area Utility Repacement Project - Electrical - Option \#1 SUBJECT: 20 Retain 351 Substation
Estimate No : 1004-Elect-Opt\#1

Date: $04 / 18 / 07$

By: Dan Jakubek

No:

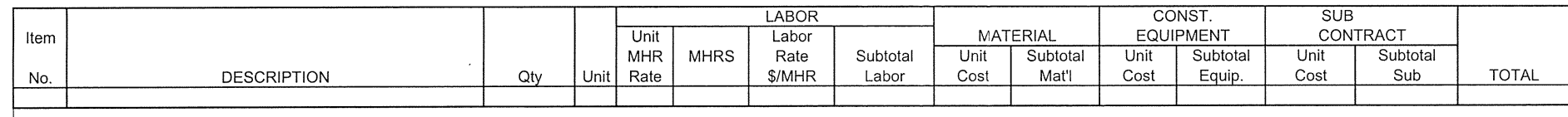

Includes - Lay-out work \& survey ground; Excavate at 2 locations of existing line for egressing fire protection line feeding the 351 sub-station. Est excavation to be approx $10^{\prime} \times 10^{\prime} \times 6^{\prime}$ deep. Caution due to possible ground contamination; use shoring; drain piping; cut or un-bolt existing line \& remove approx 10 of piping, clean line using router \& llushing practices, re-install new compact; and re-install gravel \& asphalt for road egress as needed. Est 2000' of 8" piping is in scope. Perform system turn-over evaluation w/pressure test \& sign off documentation.

SubK Meetings w/WCH, Flour Hanford, Others \& Discus

Constructability Activities - Incl initial in-house review,

112 develop schedule, procurements, etc; meet w/WCH

lor discussing scope; prepare/review construction permitting docs. - Est 1 Design/Mgr personnel x 2wks \& mat'l allowance.

Training Budget - Estimated amount for Subcontractor training expenses. Allowance - $\$ 250$ per person

114 Training Labor - Estimated 8hrs per person to go thru site

training. See Training wk shts for Labor costs.

Sprinkler Fitter Crew \#1 - Incl clean line using various size

15 cleaning pig \& followed by flushing practices. Est 2000' of Subtotal

2.9 - Clean Up Area, Demobe, \& Close-out Projec

Includes - Cleaning up area; demobe equipment; \& close-out proj at site.

\begin{tabular}{|c|c|c|c|c|c|c|c|c|c|c|c|c|c|c|c|c|c|}
\hline 116 & $\begin{array}{l}\text { Engineer - Close-out various items, incl paper wk, \& meet } \\
\text { w/WCH \& Flour Hanford for site close-out. }\end{array}$ & 1 & Per & 20.0 & 20 & $\$ \quad 69.88$ & 1,398 & $\$$ & $\$$ & - & $\$-$ & $\$$ & - & $\$$ & - & $\$$ & 1,398 \\
\hline 17 & $\begin{array}{l}\text { Superintendent - Close-out various items, incl paper wk, } \\
\text { \& meet w/WCH \& Flour Hanford for site close-out. }\end{array}$ & 1 & Per & 20.0 & 20 & $\$ 59.53$ & 1,191 & $\$-$ & $\$$ & - & $\$-$ & $\$$ & - & $\$$ & - & $\$$ & 1,19 \\
\hline 118 & $\begin{array}{l}\text { Lineman Foreman - Support Demobe activities - Est 5hrs } \\
\text { ea site }\end{array}$ & 1 & Crft & 20.0 & 20 & $\$ \quad 61.04$ & 1,221 & $\$$ & $\$$ & - & $\$-$ & $\$$ & - & $\$$ & - & $\$$ & 1,221 \\
\hline 9 & Lineman - 4 man crew - Demob & 4 & Crft & 20.0 & 80 & $\$ \quad 55.79$ & 4,463 & $\$$ & $\$$ & - & $\$$ & $\$$ & - & $\$$ & & $\$$ & 4,463 \\
\hline 0 & $\begin{array}{l}\text { Lineman Bucket Truck - w/Man Bucket Boom, \& Tool } \\
\text { Storage on Sides, } 6 \times 4,400 \mathrm{Hp}, 70000 \text { lbs max, Diesel, } \\
\text { Yr/04 }\end{array}$ & 5 & Hrs & 0.0 & 0 & $\$$ & $\$$ & $\$$ & $\$$ & - & $\$ 59.04$ & & 295 & $\$$ & & $\$$ & \\
\hline
\end{tabular}


PROPRIETARY INFORMATION
Data furnished in connection with this proposal shall not be disclosed outside WCH approval, and shall not be duf

-Data furnished in connection with this proposal shall not be disclosed outside WCH approval, and shall not be duplicated, used, or discussed for any purpose other than to evaluate the proposal.

WASHINGTON CLOSURE HANFORD, INC ESTIMATE PRICING SHEET

CLEAN UP PROJECT RICHLAND, WASHINGTON
TITLE: 300 Area Utility Repacement Project - Electrical - Option \#1 20 Retain 351 Substation

Rework Power Feeds At 5 Loc. Inside 300 Area
Estimate No: 1004-Elect-Opt\#1

Date : $04 / 18 / 07$

By: Dan Jakubek

Revno. 0

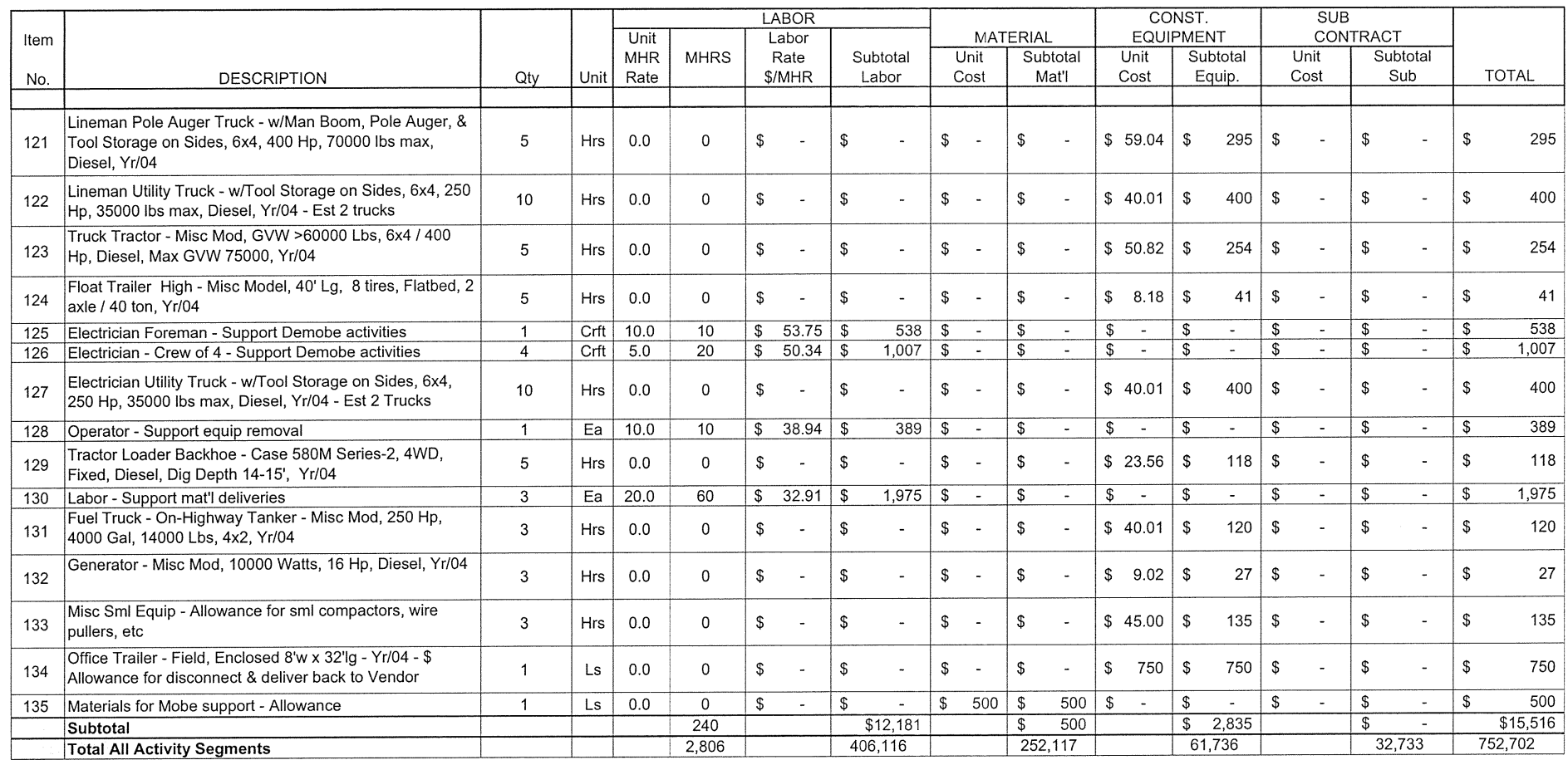


PROPRIETARY INFORMATION
Data furnished in connection with this proposal shall not be disclosed outside WCH approval, and shall not be duplicated, used, or discussed for any purpose other than to evaluate the proposal.

WASHINGTON CLOSURE HANFORD, INC ESTIMATE PRICING SHEET

RIVER CORRIDOR CLEAN UP PROJECT RICHLAND, WASHINGTON
TITLE: 300 Area Utility Repacement Project - Electrical - Option \#2 SUBJECT: 2.0 Relocate 351 Substation

* Rework Power Feeds At 5 Loc. Inside 300 Are

* Relocate Portions of 351 Substation West of Stevens Dr
Estimate No: 1004-Elect-Optt2

Date : $04 / 18 / 07$

By: Dan Jakubek

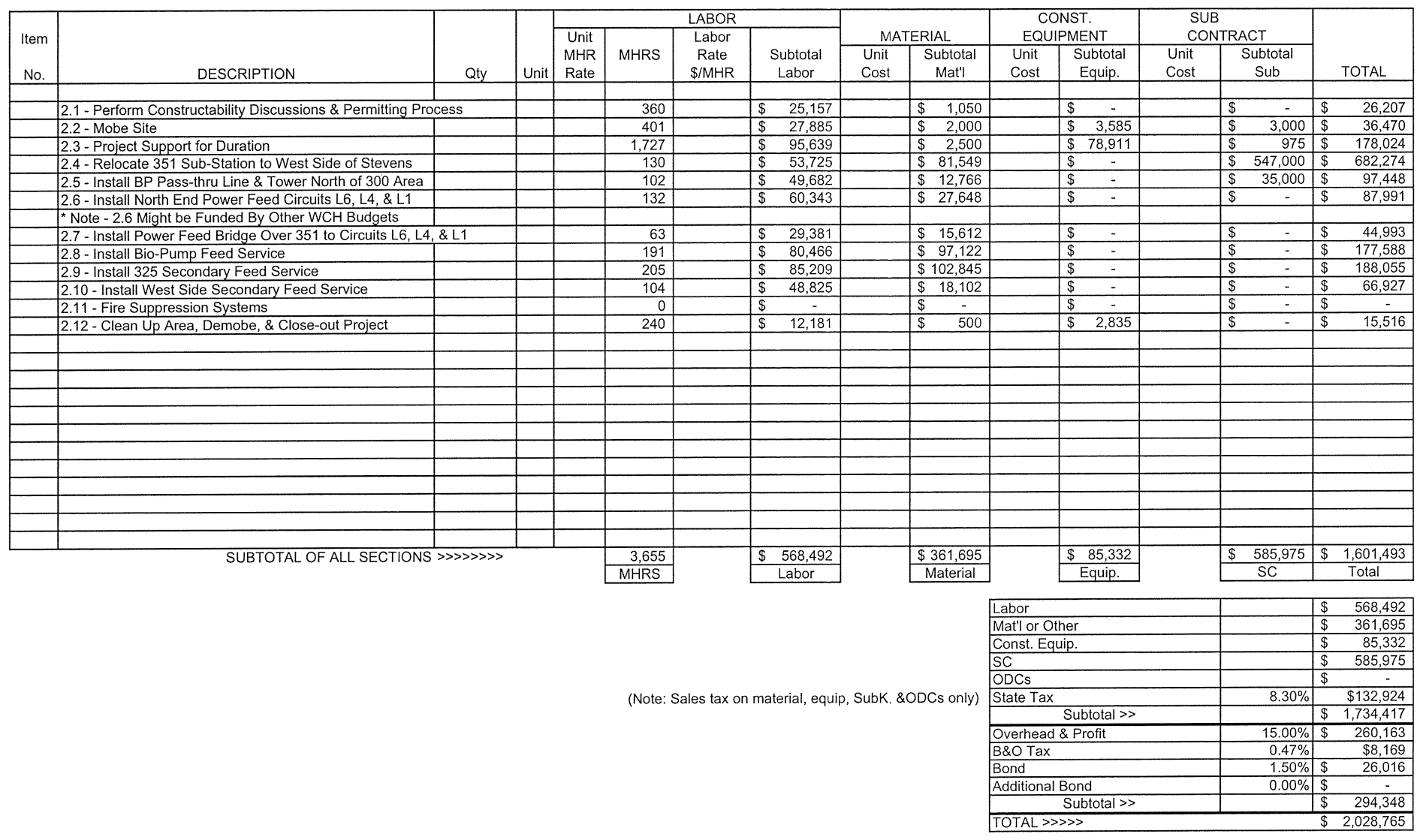

Page 1 of 16

$5 / 16 / 2007$ 
PROPRIETARY INFORMATION
Data funnished in connection with this proposal shall not be disclosed outside WCH approval, and shall not be duplicated, used, or discussed for any purpose other than to evaluate the proposal.

WASHINGTON CLOSURE HANFORD, INC ESTIMATE PRICING SHEET RIVER CORRIDOR CLEAN UP PROJECT RICHLAND, WASHINGTON
TITLE: 300 Area Utility Repacement Project - Electrical - Option \#2 SUBJECT: 2.0 Relocate 351 Substation

* Rework Power Feeds At 5 Loc. Inside 300 Area

* Relocate Portions of 351 Substation West of Stevens Dr
Estimate No: 1004-Elect-Ontt2

Date : $04 / 18 / 07$

By: Dan Jakubek

Date : $05 / 16 / 07$

\begin{tabular}{|c|c|c|c|c|c|c|c|c|c|c|c|c|c|c|}
\hline Item & DESCRIPTION & Qty & Unit & \multicolumn{4}{|c|}{ LABOR } & \multicolumn{2}{|c|}{ MATERIAL } & \multicolumn{2}{|c|}{$\begin{array}{c}\text { CONST. } \\
\text { EQUIPMENT }\end{array}$} & \multicolumn{2}{|c|}{$\begin{array}{l}\text { SUB } \\
\text { CONTRACT }\end{array}$} & TOTAL \\
\hline
\end{tabular}

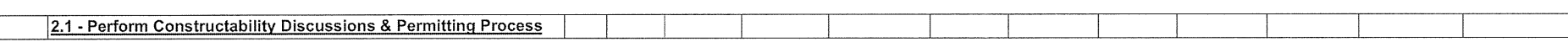
Includes activities such as: SubK perform constructability reviews for each system segment with approval organizations (Flour Hanford, PNNL, \& DOE, ; SubK perform construction start-up approval documentation \& work packages; \& develop procurement contracts.

SubK Meetings w/WCH, Flour Hanford, Others \& Discus

Constructability Activities - Incl initial in-house review,

1 develop schedule, procurements, etc; meet W/WCH \& FH

permitting docs. - Est 3 Design/Mgr personnel $\times$ 2wks \&

\section{(20)}

- Mobe Site

in 100 miles.

Engineer - Out line mat'l take-offs, support procurements,

dvlp Work Pkgs, \& meet w/WCH \& Flour Hanford for start-

Superintendent - Support mat'l take-offs, procurements, dvip Work Pkgs, \& meet w/WCH \& Flour Hanford for starup. Est 40/hrs

Surveyors - Used Fld Support Eng rate - 2 man crew

Training Budget - Estimated amount for Subcontractor training expenses. Allowance - $\$ 250$ per person

Training Labor - Estimated 8hrs per person to go thru site

training. See Training wk shts for Labor costs.

Lineman Foreman - Support Mor

Lineman - 4 man crew -Mobe

Storage on Sides, 6x4, $400 \mathrm{Hp}, 70000 \mathrm{lb}$ max, Diesel,

Yr/04

Lineman Pole Auger Truck - w/Man Boom, Pole Auger, 8

Tool Storage
Diesel, Yr/04

\begin{tabular}{|c|c|c|c|c|c|c|c|}
\hline Per & 120.0 & 360 & $\$ \quad 69.88$ & $\$$ & 25,157 & $\$ \quad 350$ & $\$$ \\
\hline & & 360 & & & $\$ 25,157$ & & $\$$ \\
\hline & & & & & & & \\
\hline & & & & & & & \\
\hline
\end{tabular}

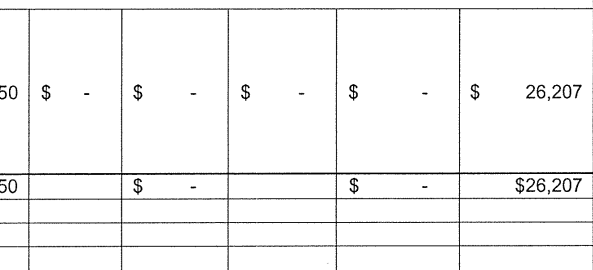

d survey area, \& prepare for construction activities. Est majority of equipment owned by SubK w/other pcs available in surrounding area with

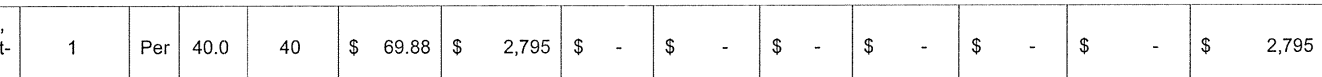

|ris,

\begin{tabular}{|l|l|l|l|ll|lll|ll|ll|ll|lll|ll|lll|ll}
1 & Per & 40.0 & 40 & $\$$ & 59.53 & $\$$ & 2,381 & $\$$ & - & $\$$ & - & $\$$ & - & $\$$ & - & $\$$ & - & $\$$ & - & $\$$ & 2,381
\end{tabular}

\begin{tabular}{|l|l|l|l|l|l}
\hline & Ea & 40.0 & & \\
\hline
\end{tabular}

\begin{tabular}{|l|l|l|l|l}
12 & Ea \\
\hline
\end{tabular}

\begin{tabular}{|l|l|l|l|l|l|l}
\hline 1 & Ls & 0.0 & 1 \\
\hline
\end{tabular}

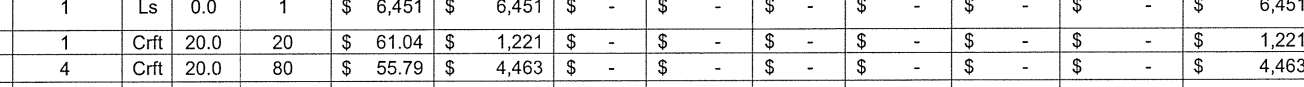

, \&

\begin{tabular}{l|l|l}
5 & Hrs & 0.0
\end{tabular}

Hrs 0.0

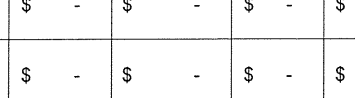

Page 2 of 16

$5 / 16 / 2007$ 
PROPRIETARY INFORMATION
Data furnished in connection with this proposal shall not be disclosed outside WCH approval, and shall not be duption

W. WASHINGTON CLOSURE HANFORD, INC.

WASHINGTON CLOSURE HANFORD, INC. ESTMATE RRCING SHEET PROJECT RICHLAND, WASHINGTON

TITLE: 300 Area Utility Repacement Project - Electrical - Option \#2 SUBJECT: 2.0 Relocate 351 Substation

* Rework Power Feeds At 5 Loc. Inside 300 Area

* Relocate Portions of 351 Substation West of Stevens Dr
Estimate No: 1004-Elect-Opt\#2

Date: $04 / 18 / 07$

By: Dan Jakubek

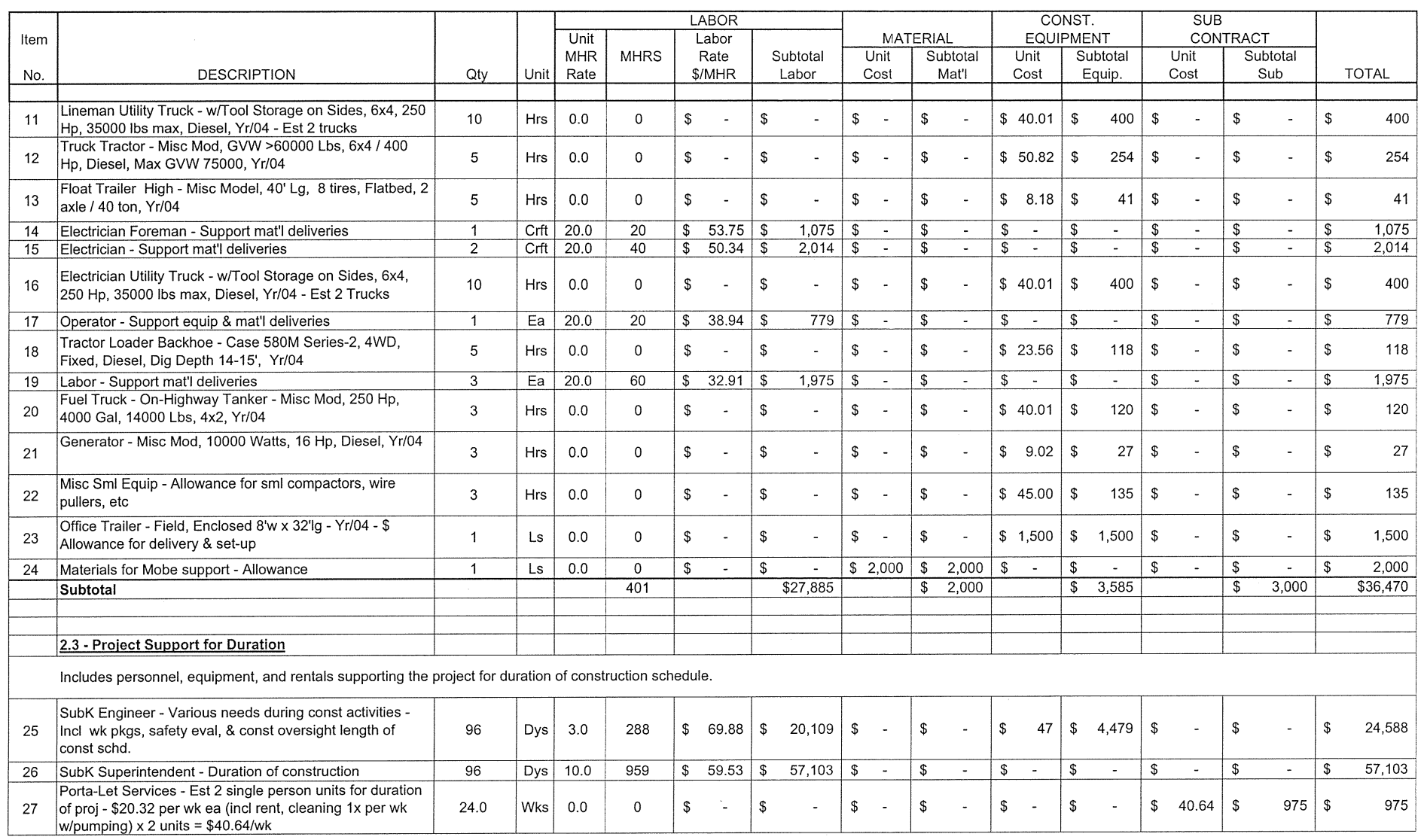


PROPRIETARY INFORMATION
Data furnished in connection with this proposal shall not be disclosed outside WCH approval, and shall not be duplicated, used, or discussed for any purpose other than to evaluate the proposal.

WASHINGTON CLOSURE HANFORD, INC ESTIMATE PRICING SHEET UP PROJECT RICHLAND, WASHINGTON
TITLE: 300 Area Utility Repacement Project - Electrical - Option \#2 SUBJECT: 2.0 Relocate 351 Substation

* Rework Power Feeds At 5 Loc. Inside 300 Area

* Relocate Portions of 351 Substation West of Stevens D
Estimate No : 1004-Elect-Opt\#2

Date: $04 / 18 / 07$

By: Dan Jakubek

Date: $05 / 16107$

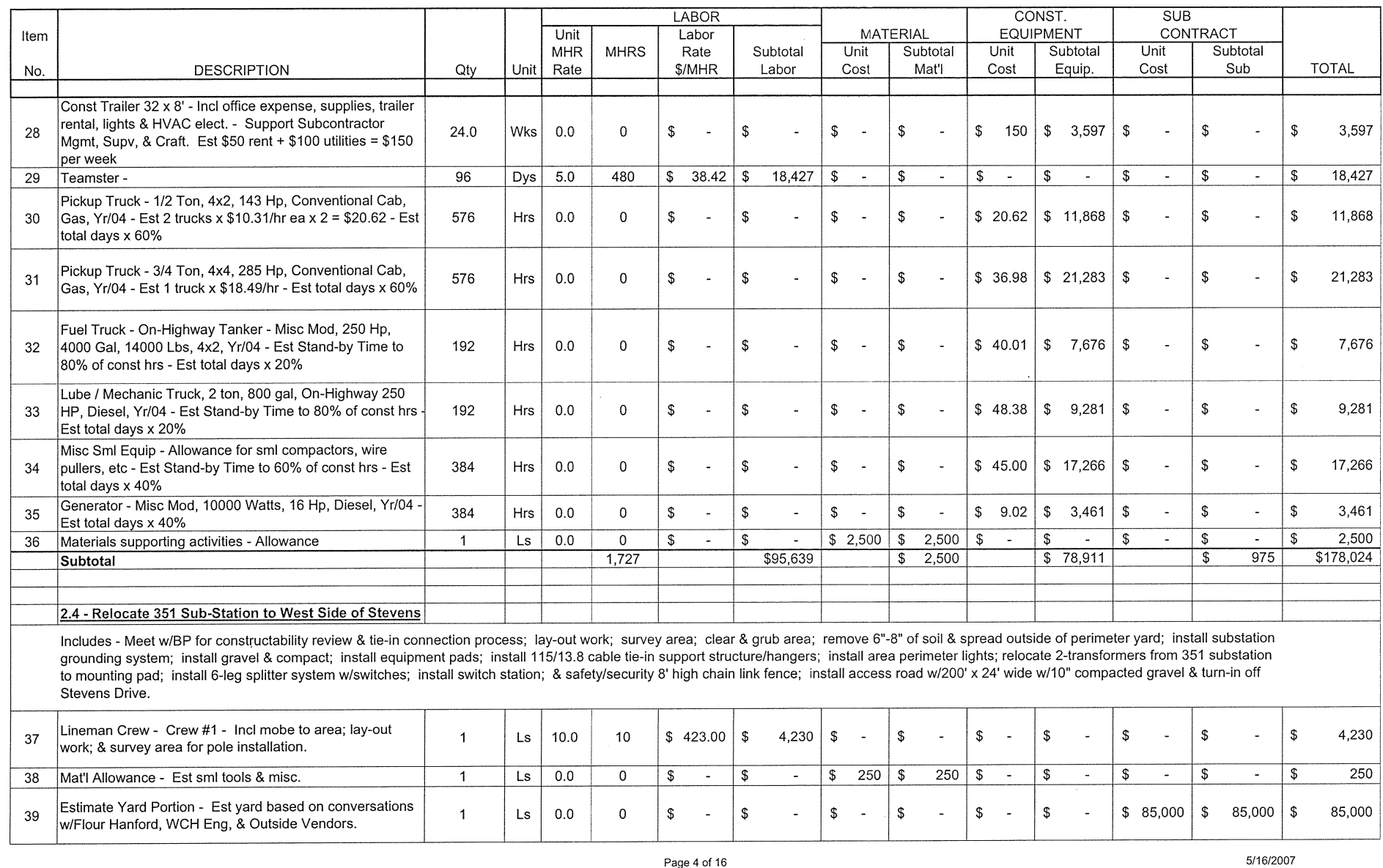




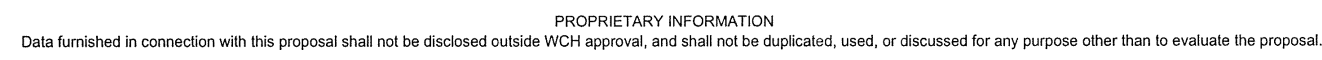

WASHINGTON CLOSURE HANFORD, INC. ESTIMATE PRICING SHEET

PROJECT RICHLAND, WASHINGTON
TITLE: 300 Area Utility Repacement Project - Electrical - Option \#2 SUBJECT: 2.0 Relocate 351 Substation

* Rework Power Feeds At 5 Loc. Inside 300 Area

* Relocate Portions of 351 Substation West of Stevens Dr
Estimate No: 1004-Elect-Opt\#2

Date: $04 / 18 / 07$

By: Dan Jakubek

\begin{tabular}{|c|c|c|c|c|c|c|c|c|c|c|c|c|c|c|c|c|c|c|}
\hline $\begin{array}{l}\text { Item } \\
\text { No. }\end{array}$ & DESCRIPTION & Qty & Unit & \multicolumn{4}{|c|}{$\angle A B O R$} & \multicolumn{2}{|c|}{ MATERIAL } & \multicolumn{4}{|c|}{$\begin{array}{c}\text { CONST. } \\
\text { EQUIPMENT }\end{array}$} & \multicolumn{3}{|c|}{$\begin{array}{l}\text { SUB } \\
\text { CONTRACT }\end{array}$} & & TOTAL \\
\hline 40 & $\begin{array}{l}\text { Estimate Elect BP Tie-in Stanchions w/Wire \& Tubing to } \\
\text { Transformer - Est based on conversations w/Flour } \\
\text { Hanford, WCH Eng, \& Outside Vendors. }\end{array}$ & 1 & Ls & 0.0 & 0 & $\$$ & $\$$ & $\$$ & $\$$ & $\$$ & & $\$$ & - & $\$ 75,000$ & $\$$ & 75,000 & $\$$ & 75,000 \\
\hline 41 & $\begin{array}{l}\text { Estimate Installation of Transformers - Est based on } \\
\text { conversations w/Flour Hanford, WCH Eng, \& Outside } \\
\text { Vendors. }\end{array}$ & 2 & Ea & 0.0 & 0 & $\$$ & $\$$ & $\$-$ & $\$$ & $\$$ & & $\$$ & - & $\$ 50,000$ & $\$$ & 100,000 & $\$$ & 100,000 \\
\hline 43 & $\begin{array}{l}\text { Estimate Switch Station Using Out-Door Rated Equip - Est } \\
\text { based on conversations w/Flour Hanford, WCH Eng, \& } \\
\text { Outside Vendors. }\end{array}$ & 1 & Ls & 0.0 & 0 & $\$$ & $\$$ & $\$$ & $\$$ & $\$$ & & $\$$ & - & $\$ 162,000$ & $\$$ & 162,000 & $\$$ & 162,000 \\
\hline 44 & $\begin{array}{l}\text { Estimate Road Extension \& Turn-in - Est based on } \\
\text { conversations w/Flour Hanford, WCH Eng, \& Outside } \\
\text { Vendors. }\end{array}$ & 1 & Ls & 0.0 & 0 & $\$$ & $\$$ & $\$$ & $\$$ & $\$$ & & $\$$ & - & $\$ 25,000$ & $\$$ & 25,000 & $\$$ & 25,000 \\
\hline 45 & $\begin{array}{l}\text { Electrician Crew \#6 - Install new duct bank from Sub- } \\
\text { station to Stevens Drive Connection point. Incl } \\
\text { excavating; placing 4-4" PVC elect conduit lines \& } \\
\text { spacers; pour concrete around conduit; \& backfill } \\
\text { w/compaction. Est 100' of new duct bank }\end{array}$ & 100 & Lf & 0.34 & 34 & $\$ 358.00$ & $\$ \quad 12,172$ & $\$$ & $\$$ & $\$$ & - & $\$$ & - & $\$$ & $\$$ & - & $\$$ & 12,172 \\
\hline 47 & $\begin{array}{l}\text { Electrician Crew } \# 4 \text { - Est pulling new wire into new duct } \\
\text { bank - Est } 100^{\prime} \text { of wire } \times 3 \times 3 \text { sys }=900 \text { Lf. Assume } \\
\text { pulling in } 3 \text { bundles of three wires. }\end{array}$ & 3.0 & Ea & 3.5 & 11 & $\$ 335.00$ & 3,518 & $\$-$ & $\$$ & $\$$ & - & $\$$ & - & $\$$ & $\$$ & - & $\$$ & 3,518 \\
\hline 48 & $\begin{array}{l}\text { Wire - Est } 4 / 0 \text { type } \times 3 / c \text { per circuit \& misc items - Est } \\
\text { distance approx } 100 \text { Lf - } 100 \times 3 \text {-lines ea cir } \times 3 \text { sys }= \\
900 L f\end{array}$ & 900 & Lf & 0.0 & 0 & $\$$ & $\$$ & $\$ 30.00$ & $\$ 27,000$ & $\$$ & - & $\$$ & - & $\$$ & $\$$ & - & $\$$ & 27,000 \\
\hline 49 & $\begin{array}{l}\text { Electrician Crew \#6 - Install Pull Box on West Side of } \\
\text { Stevens Dr Connecting to Existing Under Road Conduit - } \\
\left.\text { Est excavation \& installation of box (est } 44^{\prime} \times 6^{\prime} \times 4^{4}\right) \text {. }\end{array}$ & 1 & Ea & 10.0 & 10 & $\$ 358.00$ & 3,580 & $\$$ - & $\$$ & $\$$ & & $\$$ & - & $\$$ & $\$$ & - & $\$$ & 3,580 \\
\hline 50 & Precaste Concrete Pull Box- & 1 & Ls & 0.0 & 0 & $\$-$ & $\$$ & $\$ 1,600$ & $\$ 1,600$ & $\$$ & - & $\$$ & - & $\$$ & $\$$ & - & $\$$ & 1,600 \\
\hline
\end{tabular}


Data furnished in connection with this proposal shall not be disclosed outside WROPH approval, and shall not be duplicated, used, or discussed for any purpose other than to evaluate the proposal.

WASHINGTON CLOSURE HANFORD, INC. ESTIMATE PRICING SHEET

RIVER CORRIDOR CLEAN UP PROJECT RICHLAND, WASHINGTON
TITLE: 300 Area Utility Repacement Project - Electrical - Option \#2 SUBJECT: 2.0 Relocate 351 Substation

$*$ Rework Power Feeds At 5 Loc. Inside 300 Area

* Relocate Portions of 351 Substation West of Stevens Dr
Estimate No: 1004-Elect-Optt2

Date : $04 / 18 / 07$

By: Dan Jakubek

\begin{tabular}{|c|c|c|c|c|c|c|c|c|c|c|c|c|c|c|c|c|c|}
\hline $\begin{array}{l}\text { Item } \\
\text { No. }\end{array}$ & DESCRIPTION & Qty & Unit & \multicolumn{4}{|c|}{ LABOR } & \multicolumn{2}{|c|}{ MATERIAL } & \multicolumn{3}{|c|}{$\begin{array}{c}\text { CONST. } \\
\text { EQUIPMENT }\end{array}$} & \multicolumn{3}{|c|}{$\begin{array}{l}\text { SUB } \\
\text { CONTRACT }\end{array}$} & & TOTAL \\
\hline 51 & $\begin{array}{l}\text { Lineman Crew \#1- Incl placing hardware on transition pole } \\
\text { on east side of Stevens Dr. Est 1-45' pole to be prepared } \\
\text { for setting hardware config (dbl circuit) for elect tie in to } \\
\text { existing sys. }\end{array}$ & 3 & $\mathrm{Ea}$ & 5.0 & 15 & $\$ 423.00$ & $\$ \quad 6,345$ & $\$$. & $\$$ & $\$-$ & $\$$ & - & $\$$ & & $\$$ & $\$$ & 6,345 \\
\hline 52 & $\begin{array}{l}\text { Hardware - Incl cross arms, arrestors, transition hardware } \\
\text { Est dbl } 6 \text { arms } \times 3 \text { circuits per pole }=6 \text { arms per pole } \times 1 \\
\text { pole }=6\end{array}$ & 6 & $\mathrm{Ea}$ & 0.0 & 0 & $\$$ & $\$$ & $\begin{array}{ll}\$ & 304\end{array}$ & $\$ \quad 1,824$ & $\$$ & $\$$ & - & $\$$ & - & $\$$ & $\$$ & 1,824 \\
\hline 54 & Poles - $45^{\prime}$ Class \#2 pole & 1 & $\mathrm{Ea}$ & 0.0 & 0 & $\$$ & $\$$ & $\$ 940$ & 940 & $\$-$ & $\$$ & - & $\$$ & - & $\$$ & $\$$ & 940 \\
\hline 55 & \begin{tabular}{|l|} 
Lineman Crew \#2 - Installing poles - Incl augering holes; \& \\
placing poles. Est $1-45$ 'std equipped pole to be placed.
\end{tabular} & 1.0 & $\mathrm{Ea}$ & 5.0 & 5 & $\$ 501.00$ & $\$ \quad 2,505$ & $\$$. & $\$$ & $\$$ & $\$$ & - & $\$$ & & $\$$ & $\$$ & 2,505 \\
\hline 56 & Matl' Allowance - Est sml tools \& misc. & 1 & Ls & 0.0 & 0 & $\$$ & $\$$ & $\$ 250$ & $\$ \quad 250$ & $\$-$ & $\$$ & - & $\$$ & - & $\$$ & $\$$ & 250 \\
\hline 57 & $\begin{array}{l}\text { Electrician Crew \#5- Est pulling from new pull box into } \\
\text { existing under road conduit to new transition pole on east } \\
\text { side of Stevens D } \mathrm{Dr} \text { - Est } 150^{\prime} \text { of wire } \times 3 \times 3 \text { sys }=1,350 \mathrm{Lf} \text {. } \\
\text { Assume pulling in } 3 \text { bundles of three wires. }\end{array}$ & 3 & $\mathrm{Ea}$ & 5.0 & 15 & $\$ 335.00$ & 5,025 & $\$$ - & $\$$ & $\$-$ & $\$$ & - & $\$$ & - & $\$$ & $\$$ & 5,025 \\
\hline 59 & $\begin{array}{l}\text { Lineman Crew \#4 - Support BP Tie-ins - Allowance for } \\
\text { performing tie-in; \& completing system test \& approval. }\end{array}$ & 1 & Ls & 30.0 & 30 & $\$ 545.00$ & $\$ \quad 16,350$ & $\$$ & $\$$ & $\$-$ & $\$$ & - & $\$$ & - & $\$$ & $\$$ & 16,350 \\
\hline 60 & $\begin{array}{l}\text { Matl' Allowance - Est sml tools \& misc. } \\
\text { Subtotal }\end{array}$ & 1 & Ls & \begin{tabular}{|l|l|} 
& 0.0 \\
\end{tabular} & $\frac{0}{130}$ & $\$-$ & 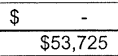 & $\$ \quad 500$ & $\begin{array}{|lr|}\$ & 500 \\
\$ & 81,549 \\
\end{array}$ & $\$-$ & \begin{tabular}{|l|}
$\$$ \\
$\$$
\end{tabular} & - & $\$$ & & 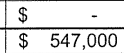 & $\$$ & $\begin{array}{r}500 \\
682,274\end{array}$ \\
\hline & & & & & & & & & & & & & & & & & \\
\hline & 2.5 - Install BP Pass-thru Line \& Tower North of 300 Are & & & & & & & & & & & & & & & & \\
\hline & $\begin{array}{l}\text { Includes - Meet w/BP for constructability review \& tie-in conn } \\
\text { w/concrete, \& place } 4 \text {-j-bolt leg fasteners in ea pier; pre-fab } \\
\text { install } 4 \text { new } 80^{\prime} \text { poles for west leg tie-in tying into BP systen }\end{array}$ & & & uppo & & $\begin{array}{l}\text { area; cle } \\
\text { End Pas } \\
\text { n-in to th }\end{array}$ & $\begin{array}{l}\text { \& grub are } \\
\text { Thru \& } 90 \text { c } \\
\text { system. }\end{array}$ & drill 3 'di & $\begin{array}{l}8 \text {-deep } \\
\text { westat si }\end{array}$ & & & & & & $\begin{array}{l}\text {; rebar, fill } \\
\text { hion; }\end{array}$ & & \\
\hline 61 & $\begin{array}{l}\text { Lineman Crew \#1- Incl mobe to area; lay-out work; \& } \\
\text { survey area for pole installation. }\end{array}$ & 1 & Ls & 10.0 & 10 & $\$ 423.00$ & 4,230 & $\$-$ & $\$$ & $\$-$ & $\$$ & - & $\$$ & & $\$$ & $\$$ & 4,230 \\
\hline 62 & Mat' Allowance - Est sml tools \& misc. & 1 & Ls & 0.0 & 0 & $\$ \quad-$ & $\$$ & $\$ \quad 250$ & $\$ \quad 250$ & $\$-$ & $\$$ & - & $\$$ & - & $\$$ & $\$$ & 250 \\
\hline
\end{tabular}


PROPRIETARY INFORMATION
Data furnished in connection with this proposal shall not be disclosed outside WCH approval, and shall not be duplicated, used, or discussed for any purpose other than to evaluate the proposal.

WASHINGTON CLOSURE HANFORD, INC. ESTIMATE PRICING SHEET RIVER CORRIDOR CLEAN UP PROJECT RICHLAND, WASHINGTON
TITLE: 300 Area Utility Repacement Project - Electrical - Option \#2 SUBJECT: 20 Relocate 351 Substation

* Rocat

* Relocate Portions of 351 Substation West of Stevens Dr

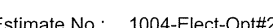

Date : $04 / 18 / 07$

By: Dan Jakubek

Date: $05 / 16 / 07$

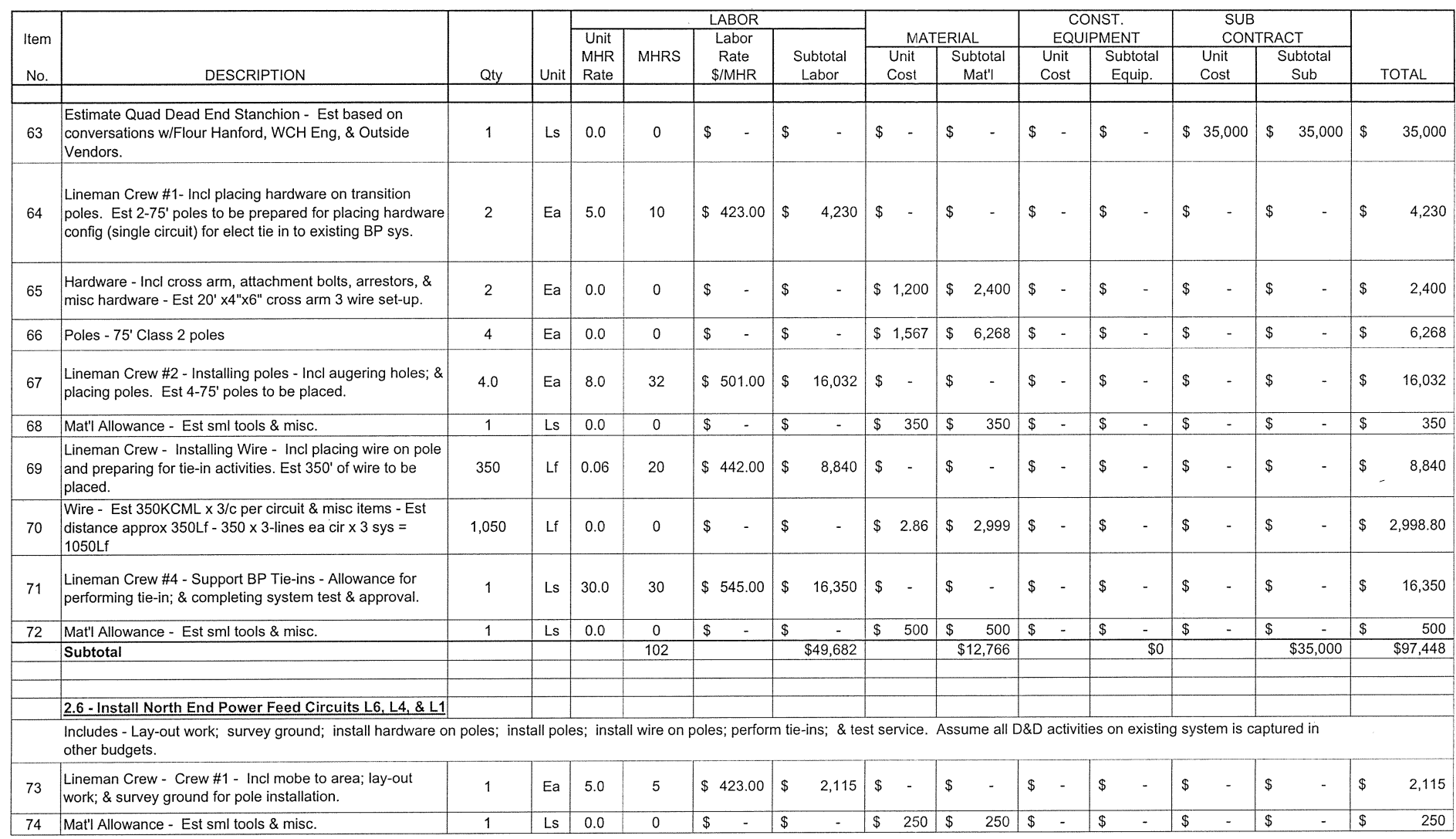


PROPRIETARY INFORMATION
Data furnished in connection with this proposal shall not be disclosed outside WCH approval, and shall not be duplicated, used, or discussed for any purpose other than to evaluate the proposal.

WASHINGTON CLOSURE HANFORD, INC. ESTIMATE PRICING SHEET

AN UP PROJECT RICHLAND, WASHINGTON
TITLE: 300 Area Utility Repacement Project - Electrical - Option \#2 SUBJECT: 2.0 Relocate 351 Substation

* Rework Power Feeds At 5 Loc. Inside 300 Are

* Relocate Portions of 351 Substation West of Stevens Dr
Estimate No: 1004-Elect-Opt\#2

Date : $04 / 18 / 07$

By: Dan Jakubek

Date: $05 / 16 / 07$

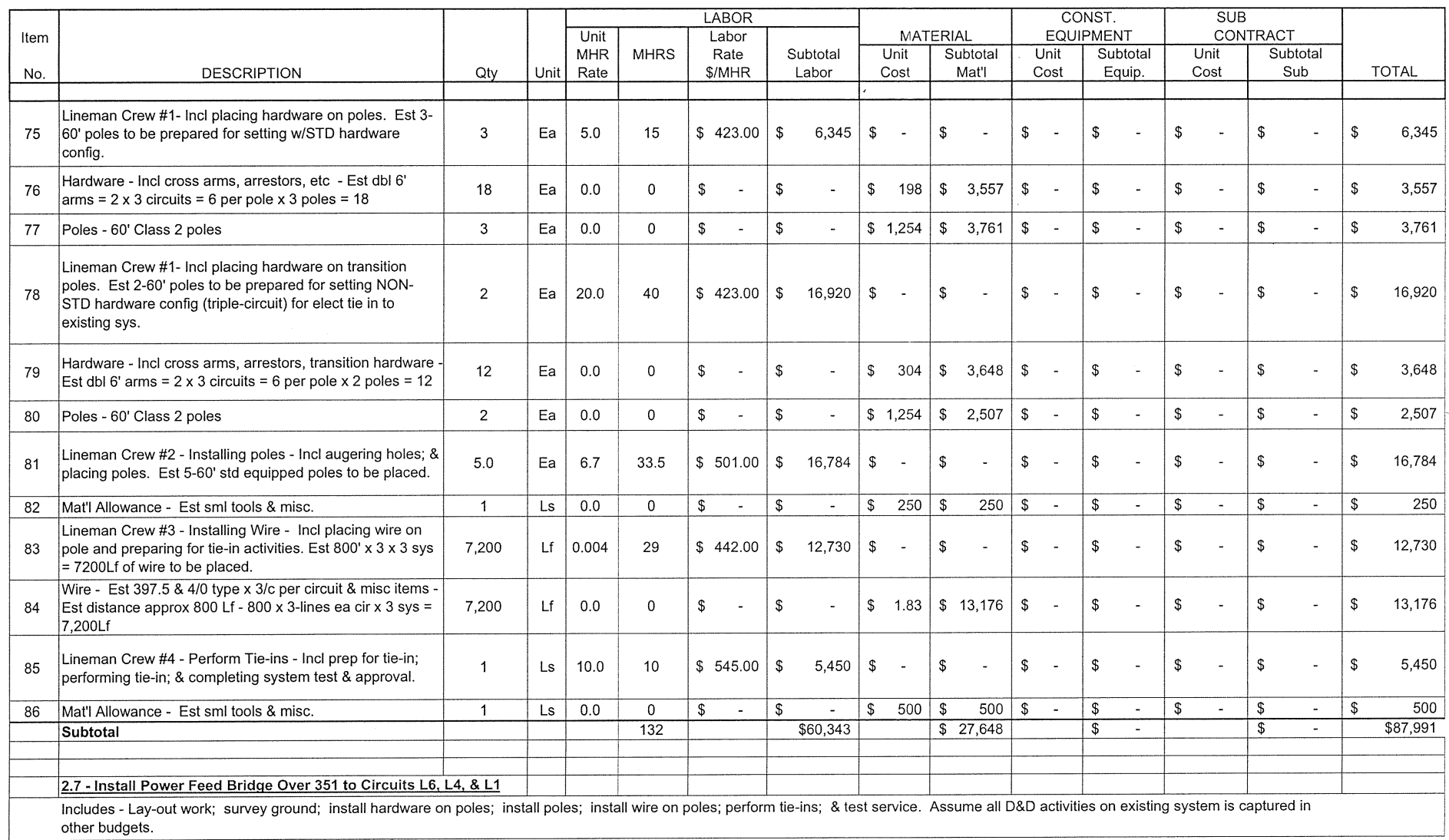


PROPRIETARY INFORMATION
Data funished in connection with this proposal shall not be disclosed outside WCH approval, and shall not be duplicated, used, or discussed for any purpose other than to evaluate the proposal.

WASHINGTON CLOSURE HANFORD, INC. ESTIMATE PRICING SHEET EAN UP PROJECT RICHLAND, WASHINGTON
TITLE: 300 Area Utility Repacement Project - Electrical - Option \#2 SUBJECT: 2.0 Relocate 351 Substation

$*$ Rework Power Feeds At 5 Loc. Inside 300 Area

* Relocate Portions of 351 Substation West of Stevens D
Estimate No: 1004-Elect-OpHtH2

Date : $04 / 18 / 07$

By: Dan Jakubek

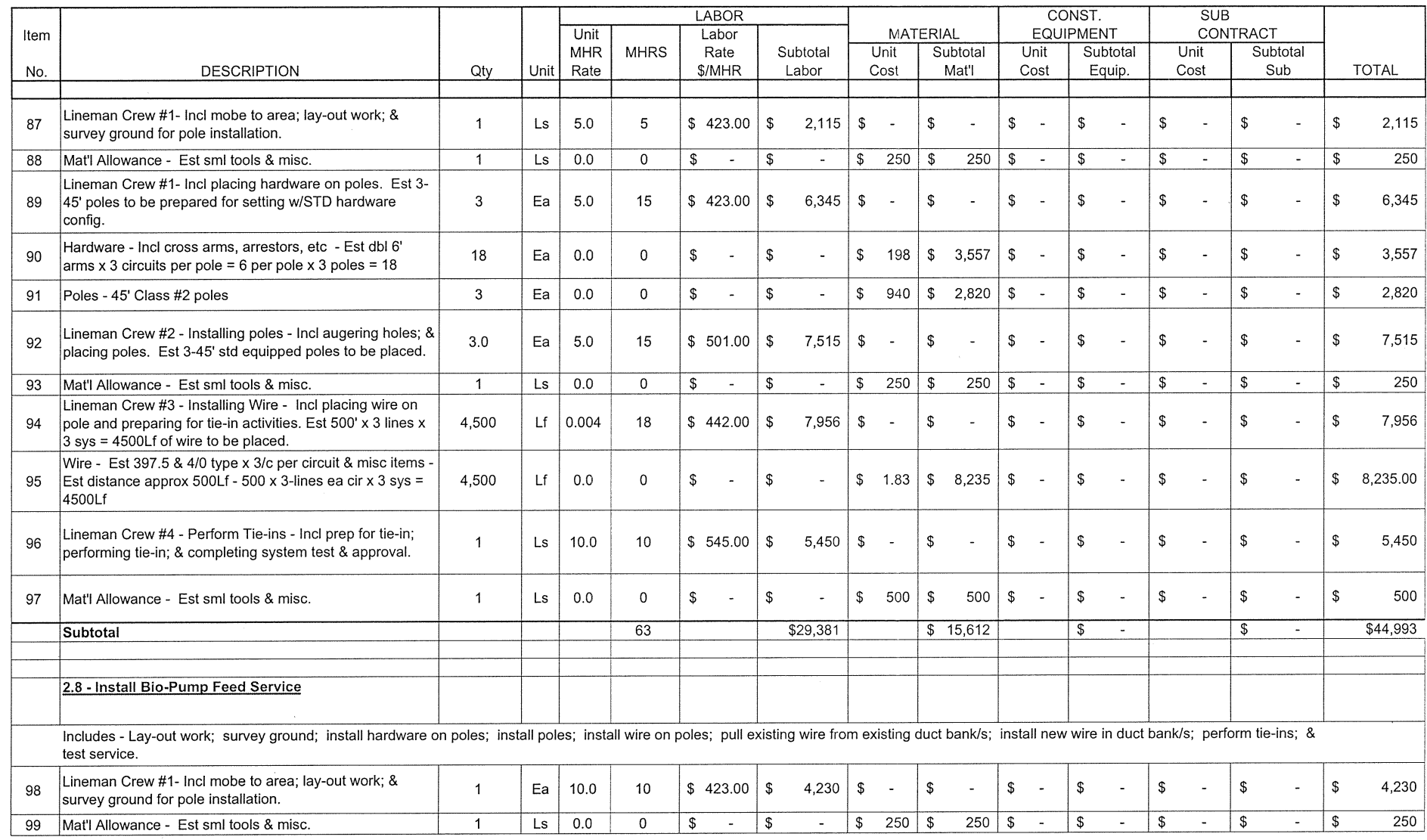




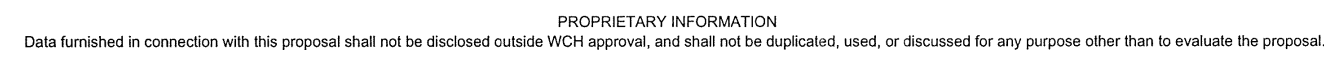

WASHINGTON CLOSURE HANFORD, INC. ESTIMATE PRICING SHEET

PROJECT RICHLAND, WASHINGTON
TITLE: 300 Area Utility Repacement Project - Electrical - Option \#2 SUBJECT: 2.0 Relocate 351 Substation

* Rework Power Feeds At 5 Loc. Inside 300 Area

* Relocate Portions of 351 Substation West of Stevens Dr
Estimate No: 1004-Elect-Opt\#2

Date: $04 / 18 / 07$

By: Dan Jakubek

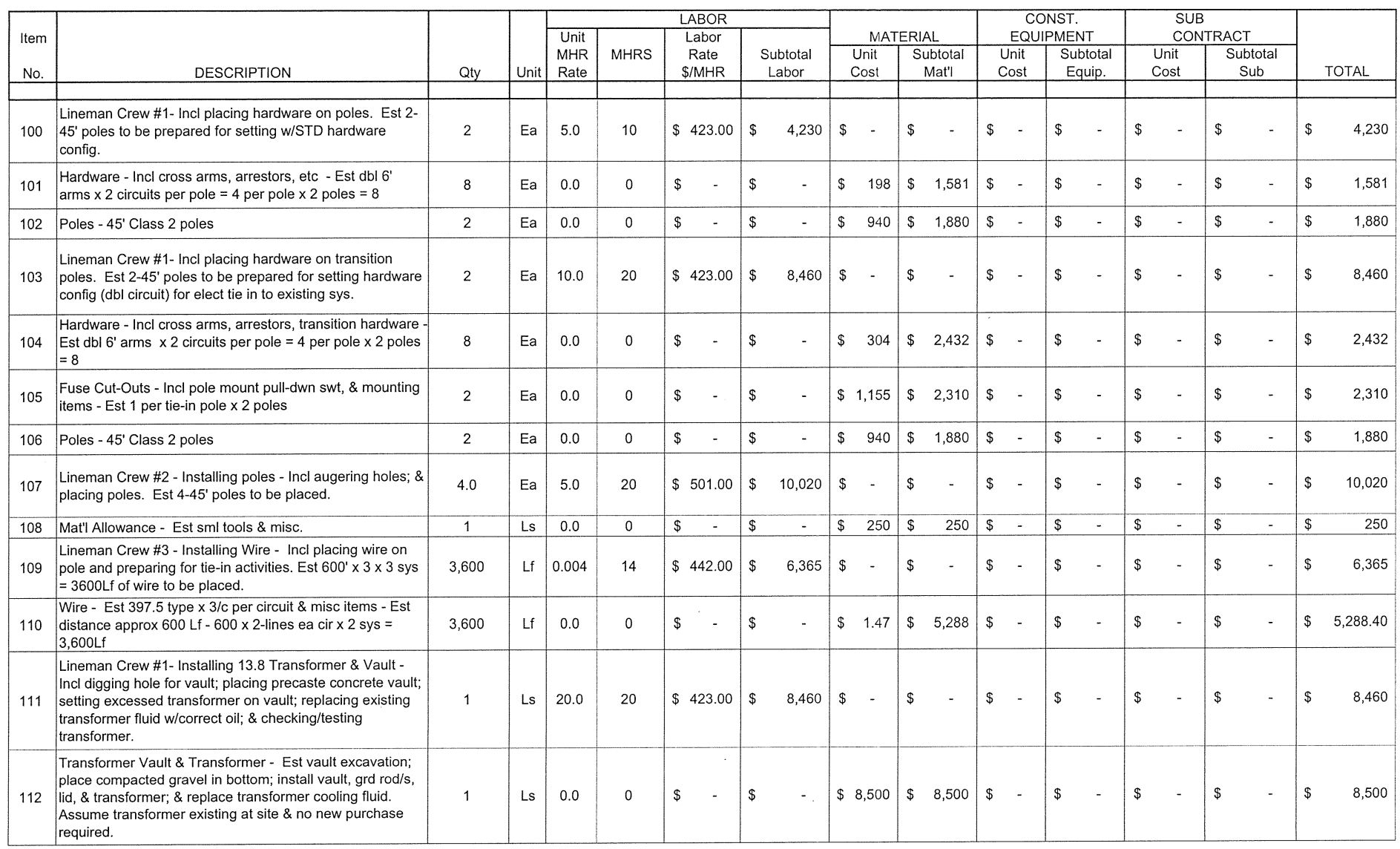


PROPRIETARY INFORMATION
Data furnished in connection with this proposal shall not be disclosed outside WCH approval, and shall not be dupicated, used, or discussed for any purpose other than to evaluate the proposal.

WASHINGTON CLOSURE HANFORD, INC. ESTIMATE PRICING SHEET

RIVER CORRIDOR CLEAN UP PROJECT RICHLAND, WASHINGTON
TITLE: 300 Area Utility Repacement Project - Electrical - Option \#2 SUBJECT: 2.0 Relocate 351 Substation

* Rework Power Feeds At 5 Loc. Inside 300 Are

* Relocate Portions of 351 Substation West of Stevens
Estimate No: 1004-Elect-Opt\#2

Date: $04 / 18 / 07$

By: Dan Jakubek

Date: $05 / 16 / 07$

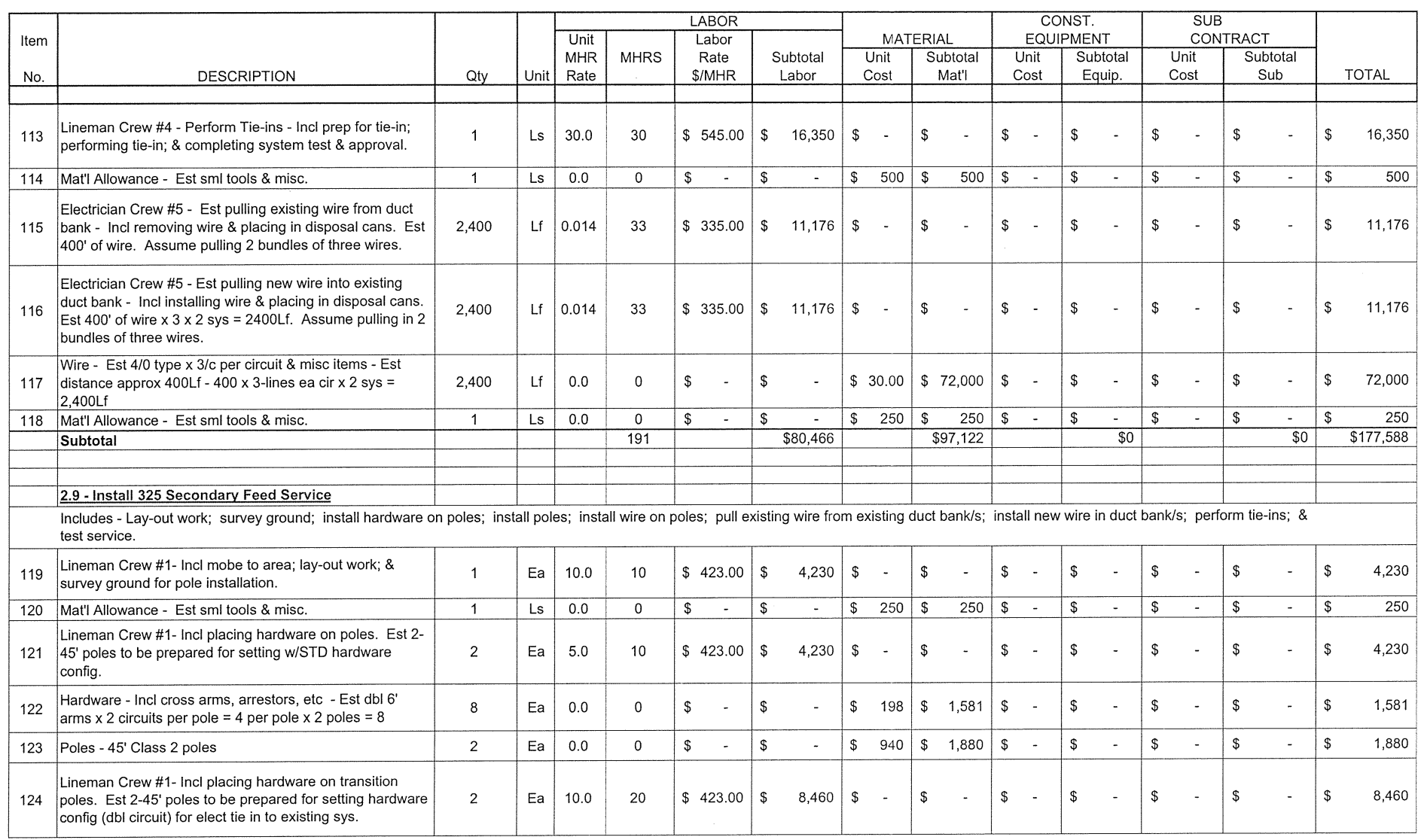

Page 11 of 16

$5 / 16 / 2007$ 
PROPRIETARY INFORMATION

Data furnished in connection with this proposal shall not be disclosed outside WROH

WASHINGTON CLOSURE HANFORD, INC. ESTIMATE PRICING SHEET

RIVER CORRIDOR CLEAN UP PROJECT RICHLAND, WASHINGTON
TITLE: 300 Area Utility Repacement Project - Electrical - Option \#2 UBJECT: 20 Relocate 351 Substation

* Rework Power Feeds At 5 Loc. Inside 300 Area

* Relocate Portions of 351 Substation West of Stevens
Estimate No: 1004-Elect-Opt\#2

Date: $04 / 18 / 07$

By: Dan Jakubek

Date: $05 / 16 / 07$

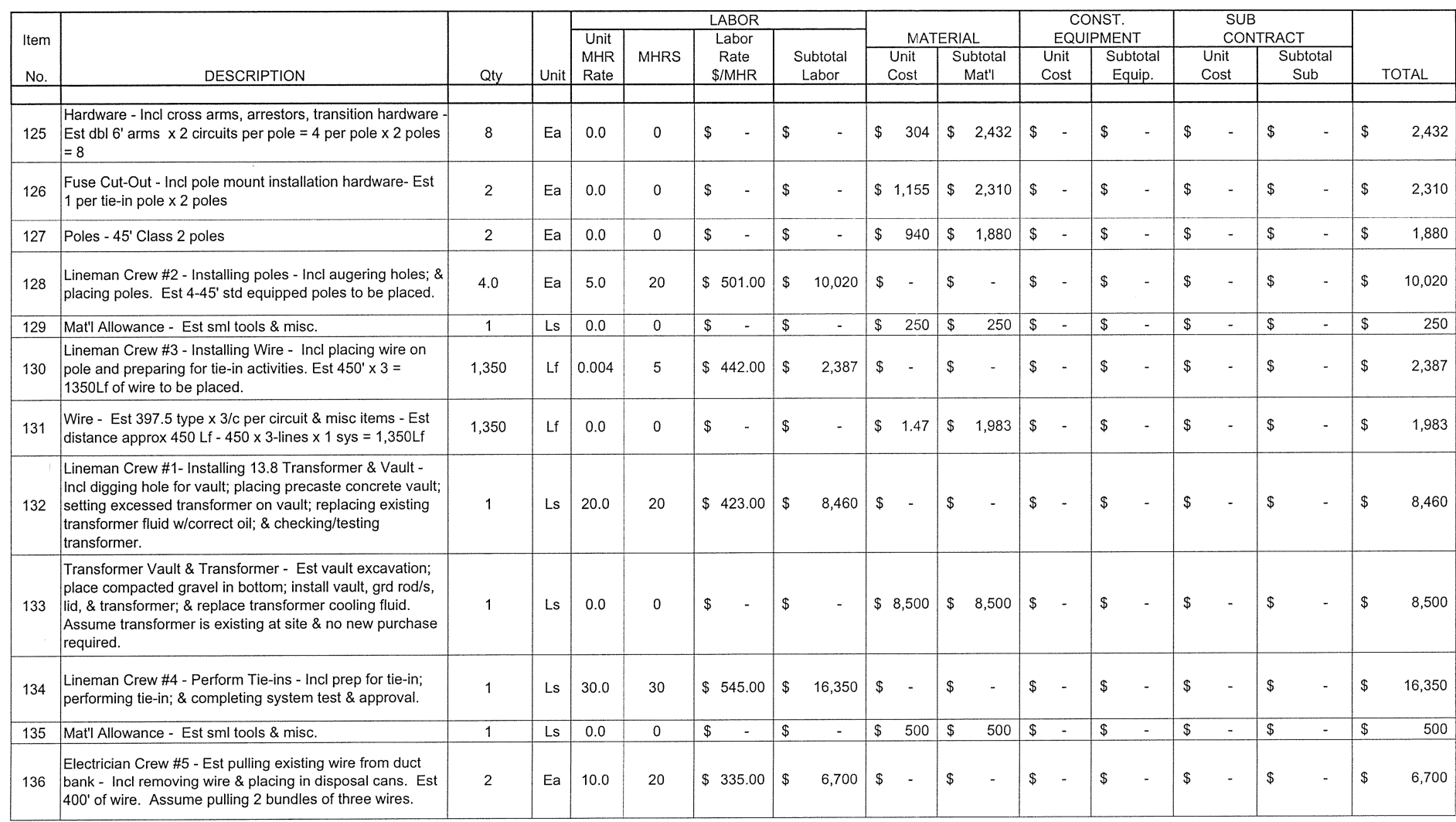


PROPRIETARY INFORMATION
Data funnished in connection with this proposal shall not be disclosed outside WCH approval, and shall not be dupicated, used, or discussed for any purpose other than to evaluate the proposal.

WASHINGTON CLOSURE HANFORD, INC. ESTIMATE PRICING SHEET

WDOR CLEAN UP PROJECT RICHLAND, WASHINGTON
TITLE: 300 Area Utility Repacement Project - Electrical - Option \#2 SUB 20 Relocate 351 Substalion

* Rework Power Feeds At 5 Loc. Inside 300 Area

* Relocate Portions of 351 Substation West of Stevens Dr
Estimate No: 1004-Elect-Opt\#2

Date : $04 / 18 / 07$

By: Dan Jakubek

Rev No: 0

Date: $05 / 16 / 07$

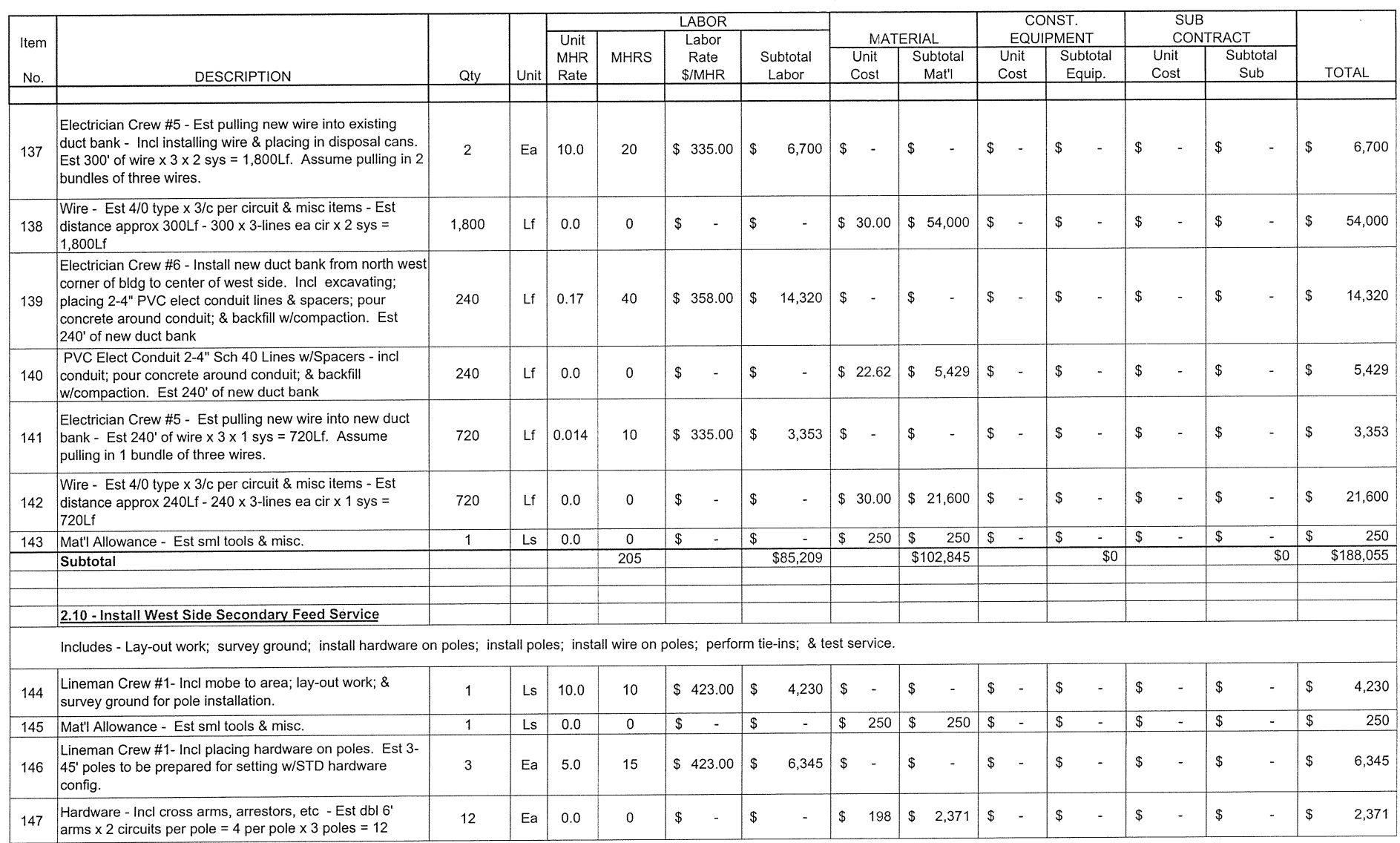


PROPRIETARY INFORMATION
Data furnished in connection with this proposal shall not be disclosed outside WCH approval, and shall not be duplicated, used, or discussed for any purpose other than to evaluate the proposal.

WASHINGTON CLOSURE HANFORD, INC. ESTIMATE PRICING SHEET

PROJECT RICHLAND, WASHINGTON
TITLE: 300 Area Utility Repacement Project - Electrical - Option \#2 SUBJECT: 20 Relocate 351 Substation

* Rework Power Feeds At 5 Loc. Inside 300 Are

* Relocate Portions of 351 Substation West of Stevens Dr
Estimate No: 1004-Elect-Opt\#2

Date: $04 / 18 / 07$

By: Dan Jakubek

Rev No: 0

Date: $05 / 16 / 07$

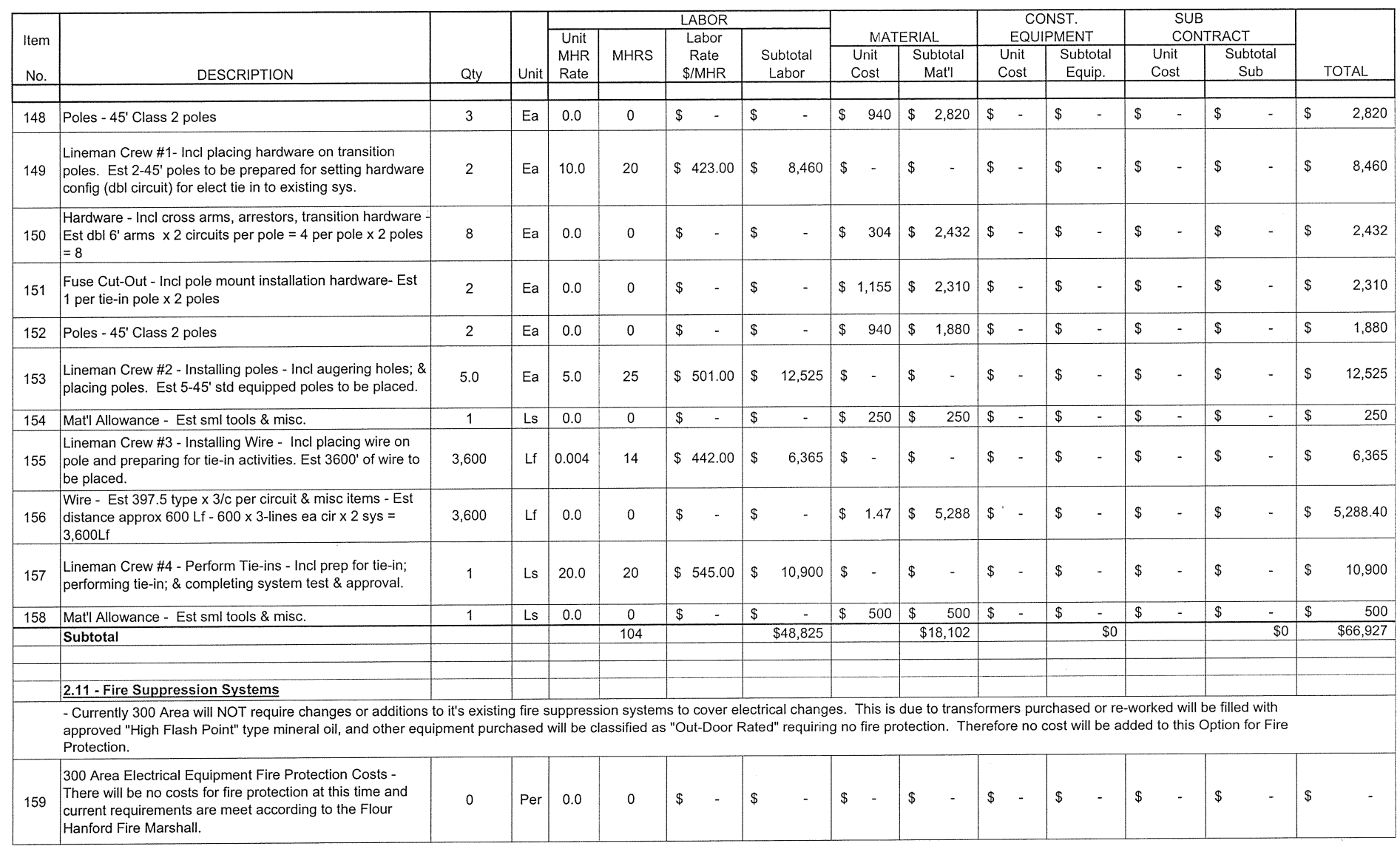


TITLE: 300 Area Utility Repacement Project - Electrical - Option \#2 SUBJECT: 20 Relocate 351 Substation

* Rework Power Feeds At 5 Loc. Inside 300 Area

* Relocate Portions of 351 Substation West of Stevens Dr
Estimate No: 1004-Elect-Opt\#2

Date : $04 / 18 / 07$

By: Dan Jakubek

Date: $05 / 16107$

\begin{tabular}{|c|c|c|c|c|c|c|c|c|c|c|c|c|c|c|}
\hline \multirow[b]{2}{*}{$\begin{array}{l}\text { Item } \\
\text { No. }\end{array}$} & \multirow[b]{2}{*}{ DESCRIPTION } & \multirow[b]{2}{*}{ Qty } & \multirow[b]{2}{*}{ Unit } & \multicolumn{4}{|c|}{$\angle A B O R$} & \multicolumn{2}{|c|}{ MATERIAL } & \multicolumn{2}{|c|}{$\begin{array}{c}\text { CONST. } \\
\text { EQUIPMENT }\end{array}$} & \multicolumn{2}{|c|}{$\begin{array}{l}\text { SUB } \\
\text { CONTRACT }\end{array}$} & \multirow[b]{2}{*}{ TOTAL } \\
\hline & & & & $\begin{array}{l}\text { Unit } \\
\text { MHR } \\
\text { Rate }\end{array}$ & MHRS & $\begin{array}{l}\text { Labor } \\
\text { Rate } \\
\text { \$MHR } \\
\end{array}$ & $\begin{array}{c}\text { Subtotal } \\
\text { Labor }\end{array}$ & $\begin{array}{l}\text { MA } \\
\text { Unit } \\
\text { Cost }\end{array}$ & \begin{tabular}{|c|} 
ShlA \\
Subtotal \\
Mat'I
\end{tabular} & $\begin{array}{l}\text { Unit } \\
\text { Cost } \\
\end{array}$ & \begin{tabular}{|c|} 
Subtotal \\
Equip. \\
\end{tabular} & $\begin{array}{l}\text { Unit } \\
\text { Cost } \\
\end{array}$ & $\begin{array}{c}\text { Subtotal } \\
\text { Sub }\end{array}$ & \\
\hline & Subtotal & & & & 0 & & $\$$ & & $\$$ & & $\$$ & & - & $\$$ \\
\hline & 2.12 - Clean Up Area, Demobe, \& Close-out Project & & & & & & & & & & & & & \\
\hline
\end{tabular}

12. Clem Up Aree Demobe \& Close-out Project

Includes - Cleaning up area; demobe equipment; \& close-out proj at site. $160 \begin{aligned} & \begin{array}{l}\text { Engineer - Close-out various items, incl paper wk, \& meet } \\ \text { w/WCH \& Flour Hanford for site close-out. }\end{array} \\ & 1\end{aligned}$

161 Superintendent - Close-out various items, incl paper wk, \& meet w/WCH \& Flour Hanford for site close-out. Lineman Foreman - Support Demobe activities - Est 5hrs

63 Lineman - 4 man crew - Demobe - Est 5hrs ea site Lineman Bucket Truck - w/Man Bucket Boom, \& Too Storage on Sides, 6x4, $400 \mathrm{Hp}, 70000$ lbs max, Diesel, Lineman Pole Auger Truck - w/Man Boom, Pole Auger, \&

65 Tool Storage on Sides, $6 \times 4,400 \mathrm{Hp}$, 70000 lbs max, Diesel, Yr/04 66 Lineman Utility Truck - w/Tool Storage on Sides, $6 \times 4,250$ Hp, 35000 lbs max, Diesel, Yr/04 - Est 2 trucks
Truck Tractor - Misc Mod, GVW $>60000$ Lbs, $6 \times 4 / 400$ Hp. Diesel, Max GVW 75000, Yr/04

Float Trailer High - Misc Model, $40^{\prime} \mathrm{Lg}, 8$ tires, Flatbed, 68 axle / 40 ton, Yr/04

169 Electrician Foreman - Support Demobe activities

(7) activities

171 Electrician Utility Truck - w/Tool Storage on Sides, $6 \times 4$ 172 Operator - Suppor

173 Tractor Loader Backhoe - Case 580M Series-2, 4WD 173 Fixed, Diesel, Dig Depth 14-15', Yr/04

174 Labor - Support mat'l deliveries

$175 \begin{aligned} & \text { Fuel Truck - On-Highway Tanker } \\ & 4000 \text { Gal, } 14000 \text { Lbs, } 4 \times 2, \text { Yrlo4 }\end{aligned}$

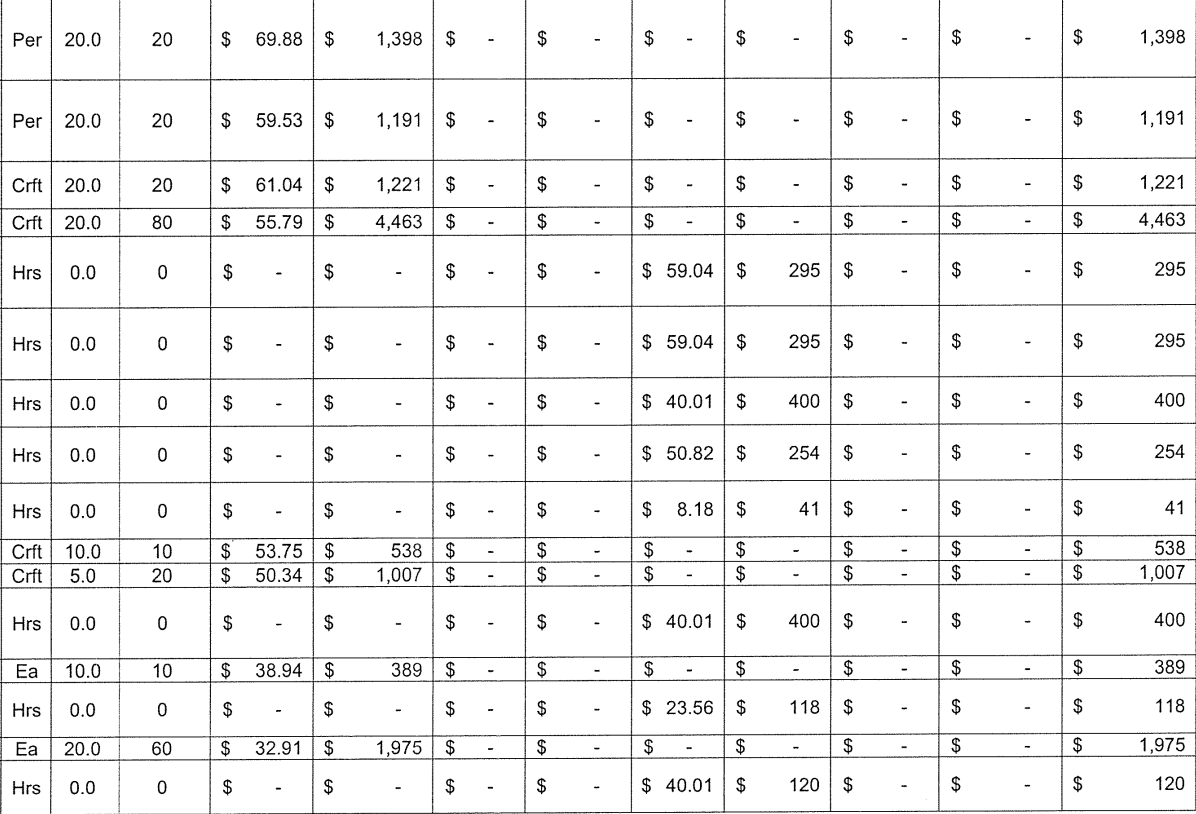


PROPRIETARY INFORMATION
Data furnished in connection with this proposal shall not be disclosed outside WCH approval, and shall not be dupicated, used, or discussed for any purpose other than to evaluate the proposal.

WASHINGTON CLOSURE HANFORD, INC ESTIMATE PRICING SHEET

RIVER CORRIDOR CLEAN UP PROJECT

RICHLAND, WASHINGTON
TITLE. 300 Area Utility Repacement Project - Electrical - Option \#2 SUBJECT: 2.0 Relocate 351 Substation

* Rework Power Feeds At 5 Loc. Inside 300 Area

* Relocate Portions of 351 Substation West of Stevens Dr
Estimate No: 1004-Elect-Opt\#2

Date: $04 / 18 / 07$

By: Dan Jakubek

Date: $05 / 16 / 07$

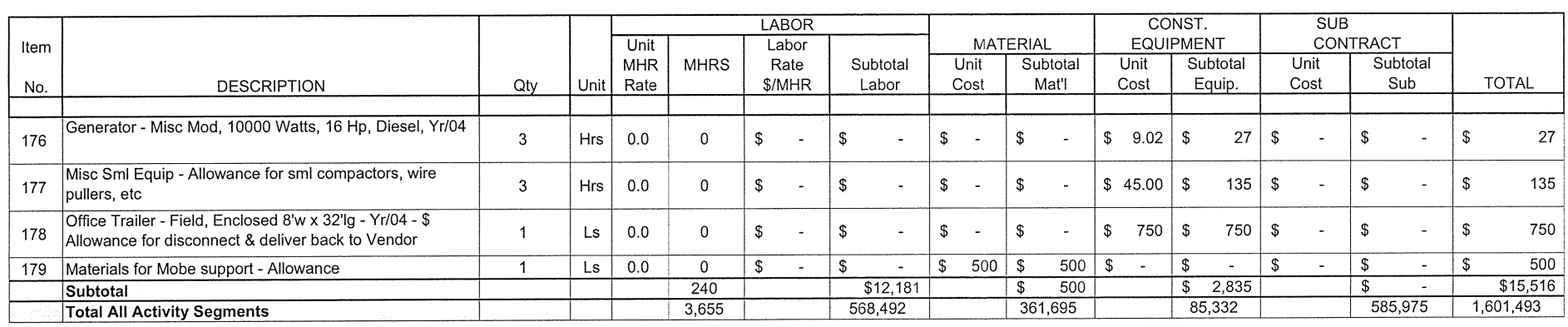


PROPRIETARY INFORMATION
Data funished in connection with this proposal shall not be disclosed outside WCH approval, and shall not be duplicated, used, or discussed for any purpose other than to evaluate the proposal.

WASHINGTON CLOSURE HANFORD, INC. ESTIMATE PRICING SHEET

RIVER CORRIDOR CLEAN UP PROJECT RICHLAND, WASHINGTON

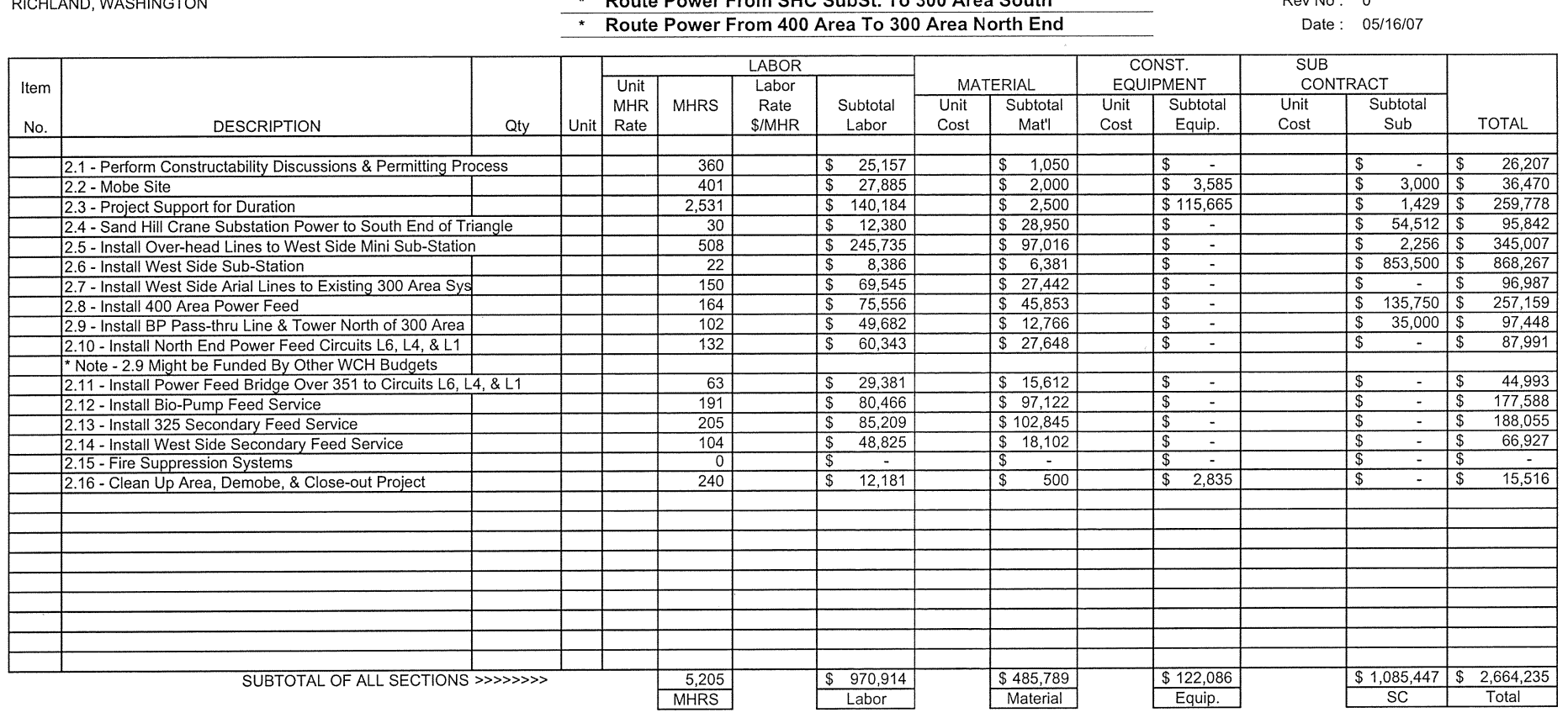

MHRS Labor

(Note: Sales tax on material, equip, SubK, \&ODCs only)

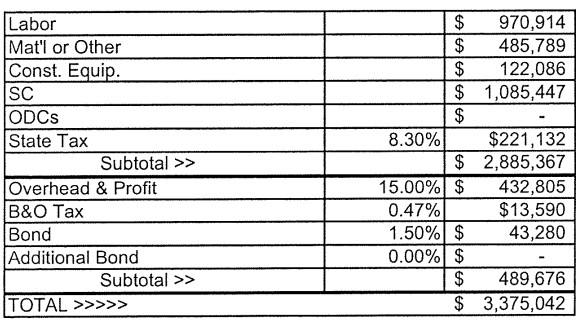

Estimate No: 1004-Elect-Optt3 Date: $04 / 24 / 07$ Jakubek TITLE: 300 Area Utility Repacement Project - Electrical - Option * Rework Power Feeds At 5 Loc. Inside 300 Area

Routh 
PROPRIETARY INFORMATION
Data funished in connection with this proposal shall not be disclosed outside WCH approval, and shall not be duplicated, used, or ciscussed for any purpose other than to evaluate the proposal.

WASHINGTON CLOSURE HANFORD, INC ESTIMATE PRICING SHEET

RIVER CORRIDOR CLEAN UP PROJECT RICHLAND, WASHINGTON
TITLE: 300 Area Utility Repacement Project - Electrical - Option \#3 SUBJECT: 2.0 Feed Fron Richland \& 400 Area

* Rework Power Feeds At 5 Loc. Inside 300 Area

* Rework Power Feeds At 5 Loc. Inside 300 Area

* Route Power From SHC SubSt. To 300 Area South
Estimate No: $1004-E l e c t-O p t \# 3$

Date: $04 / 24 / 07$

By: Dan Jakubek

Date: $05 / 16107$

\begin{tabular}{|c|c|c|c|c|c|c|c|c|c|c|c|c|c|c|}
\hline \multirow{3}{*}{$\begin{array}{l}\text { Item } \\
\text { No. }\end{array}$} & \multirow[b]{3}{*}{ DESCRIPTION } & \multirow[b]{3}{*}{ Qty } & \multirow[b]{3}{*}{ Unit } & \multicolumn{4}{|c|}{$\angle A B O R$} & \multirow{2}{*}{\multicolumn{2}{|c|}{ MATERIAL }} & \multicolumn{2}{|c|}{$\begin{array}{c}\text { CONST. } \\
\text { EQUIPMENT }\end{array}$} & \multicolumn{2}{|c|}{$\begin{array}{l}\text { SUB } \\
\text { CONTRACT }\end{array}$} & \multirow{3}{*}{ TOTAL } \\
\hline & & & & $\begin{array}{l}\text { Unit } \\
\text { MHR } \\
\text { Rate }\end{array}$ & MHRS & $\begin{array}{l}\text { Labor } \\
\text { Rate } \\
\text { \$MHR }\end{array}$ & $\begin{array}{c}\text { Subtotal } \\
\text { Labor }\end{array}$ & & & $\begin{array}{c}\frac{E Q}{} \\
\text { Unit }\end{array}$ & $\begin{array}{l}\text { PMENT } \\
\text { Subtotal }\end{array}$ & $\begin{array}{cc}\text { CC } \\
\text { Unit }\end{array}$ & $\begin{array}{l}\text { ACT } \\
\text { Subtotal }\end{array}$ & \\
\hline & & & & Rate & & $\$ / M H R$ & Labor & Cost & Mat'l & Cost & Equip. & & & \\
\hline
\end{tabular}

\begin{tabular}{|l|l|l|l|l|l|l|l|l|l|}
\hline 2.1 - Perform Constructability Discussions \& Permitting Process & $\mid$ & & & & & & & & \\
\hline
\end{tabular} Includes activities such as: SubK perform constructability reviews for each system segment with approval organizations (Flour Hanford, PNNL, \& DOE, ; SubK perform construction start-up approval documentation \& work packages; \& develop procurement contracts.

SubK Meetings w/WCH, Flour Hanford, Others \& Discuss

Constructability Activities - Incl initial in-house review,

FH for discussing scope; prepare/review construction permitting docs. - Est 3 Design/Mgr personnel $\times 3$ wks \& mat' allowance.

Subtotal

2.2- Mobe Site 100 miles.

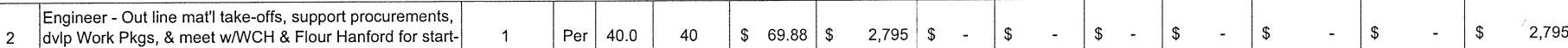

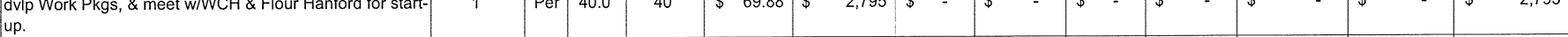

Superintendent - Support mat'l take-offs, procurements,

Surveyors - Used Fld Support Eng rate -2 man crew

40hrs

Training Budget - Estimated amount for Subcontractor

Training Labor - Estimated 8hrs per person to go thru site

Lineman - 4 man crew - Mobe

neman Bucket Truck - W/Man Bucket Boom, \& Tool

Storage on Sides, $6 \times 4,400 \mathrm{Hp}, 70000$ lbs max, Diesel,

Lineman Pole Auger Truck - w/Man Boom, Pole Auger,

Tool Strage on Sides, $6 \times 4,400 \mathrm{Hp}, 70000$ lbs max

Diesel, Yr/04

Lineman Utility Truck - w/Tool Storage on Sides, 6x4, 250

Hp, 35000 lbs max, Diesel, Yr/04 - Est 2 trucks

3

Per

$\operatorname{Per} 120.0 \quad 360$

$\$ 69.88$

\begin{tabular}{ll|ll|ll} 
& 25,157 & $\$$ & 350 & $\$$ & 1,050
\end{tabular}

$\$$

\begin{tabular}{l|l|l|l|}
\hline & & & 360 \\
\hline
\end{tabular}

$\$ 25,157$

\begin{tabular}{|l|l|l|}
\hline & $\$ 1,050$ \\
\hline
\end{tabular}

\begin{tabular}{|l|l|ll|l}
\hline & $\$$ & $\$$ & - & $\$ 26,207$ \\
\hline
\end{tabular}

\begin{tabular}{|l|l|l|l|l|l|l|l|l|l|l|l|l|}
\hline & & & &
\end{tabular}

\begin{tabular}{|c|c|c|c|cc|cc|cc|cc|cc|cc|cc|cc|cc|}
\hline & $\operatorname{Per}$ & 40.0 & 40 & $\$$ & 69.88 & $\$$ & 2,795 & $\$$ & - & $\$$ & - & $\$$ & - & $\$$ & - & $\$$ & - & $\$$ & - & $\$$ & 2,795 \\
\hline 1 & $\operatorname{Per}$ & 40.0 & 40 & $\$ 59.53$ & $\$$ & 2,381 & $\$$ & - & $\$$ & - & $\$$ & - & $\$$ & - & $\$$ & - & $\$$ & - & $\$$ & 2,381 \\
\hline
\end{tabular}

2

\begin{tabular}{|c|c|c|}
12 & Ea \\
\hline te & 1 & Ls
\end{tabular}

\begin{tabular}{|l|l|lllllllllll|ll|lllll|ll|}
40.0 & 80 & $\$$ & 59.14 & $\$$ & 4,731 & $\$$ & - & $\$$ & - & $\$$ & - & $\$$ & - & $\$$ & - & $\$$ & - & $\$$ & 4,731 \\
\hline
\end{tabular}

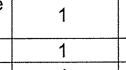

\begin{tabular}{|c|c|c|}
\hline 0.0 & 0 \\
\hline 0.0 & 1 \\
\hline & 20.0 & 20 \\
\hline
\end{tabular}

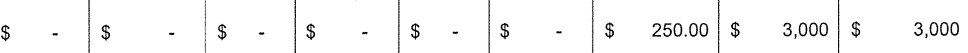

\begin{tabular}{l|l|l|l|l|l}
4 & Crtt & 20.0 \\
\hline & & &
\end{tabular}

\begin{tabular}{l|l|l}
5 & Hrs & 0.0
\end{tabular}

\begin{tabular}{|l|l|l|l|l|l|l}
\hline 5 & Hrs & 0.0
\end{tabular}

\begin{tabular}{|l|l|}
\hline 0 & 0 \\
\hline
\end{tabular}

\begin{tabular}{ll|ll|ll|ll|ll|ll|lll|lll|ll}
$\$$ & 6,451 & $\$$ & 6,451 & $\$$ & - & $\$$ & - & $\$$ & - & $\$$ & - & $\$$ & - & $\$$ & - & $\$$ & 6,451 \\
\hline
\end{tabular}

\begin{tabular}{llllllllll|ll|ll|ll|ll}
$\$$ & 61.04 & $\$$ & 1,221 & $\$$ & - & $\$$ & - & $\$$ & - & $\$$ & - & $\$$ & - & $\$$ & - & $\$$ & 1,221 \\
\hline & 55.79 & $\$$ & 4,463 & $\$$ & - & $\$$ & - & $\$$ & - & $\$$ & - & $\$$ & - & $\$$ & - & $\$$ & 4,463
\end{tabular}

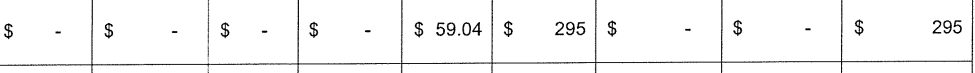

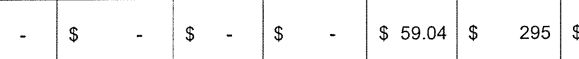

2 of 21 
PROPRIETARY INFORMATION
Data funished in connection with this propossal shall not be disclosed outside WCH approval, and shall not be du

WASHINGTON CLOSURE HANFORD, INC ESTIMATE PRICING SHEET

RIVER CORRIDOR CLEAN UP PROJECT RICHLAND, WASHINGTON
TITLE: 300 Area Utility Repacement Project - Electrical - Option \#3 SUBJECT: 20 Feed Fron Richland \& 400 A

* Rework Power Feeds At 5 Loc. Inside 300 Area

* Rework Power Feeds At 5 Loc. Inside 300 Area

* Route Power From SHC SubSt. To 300 Area South
Estimate No : 1004-Elect-Opt\#3

Date: $04 / 24 / 07$

By: Dan Jakubek

Rev No: 0

Date: $05 / 16 / 07$

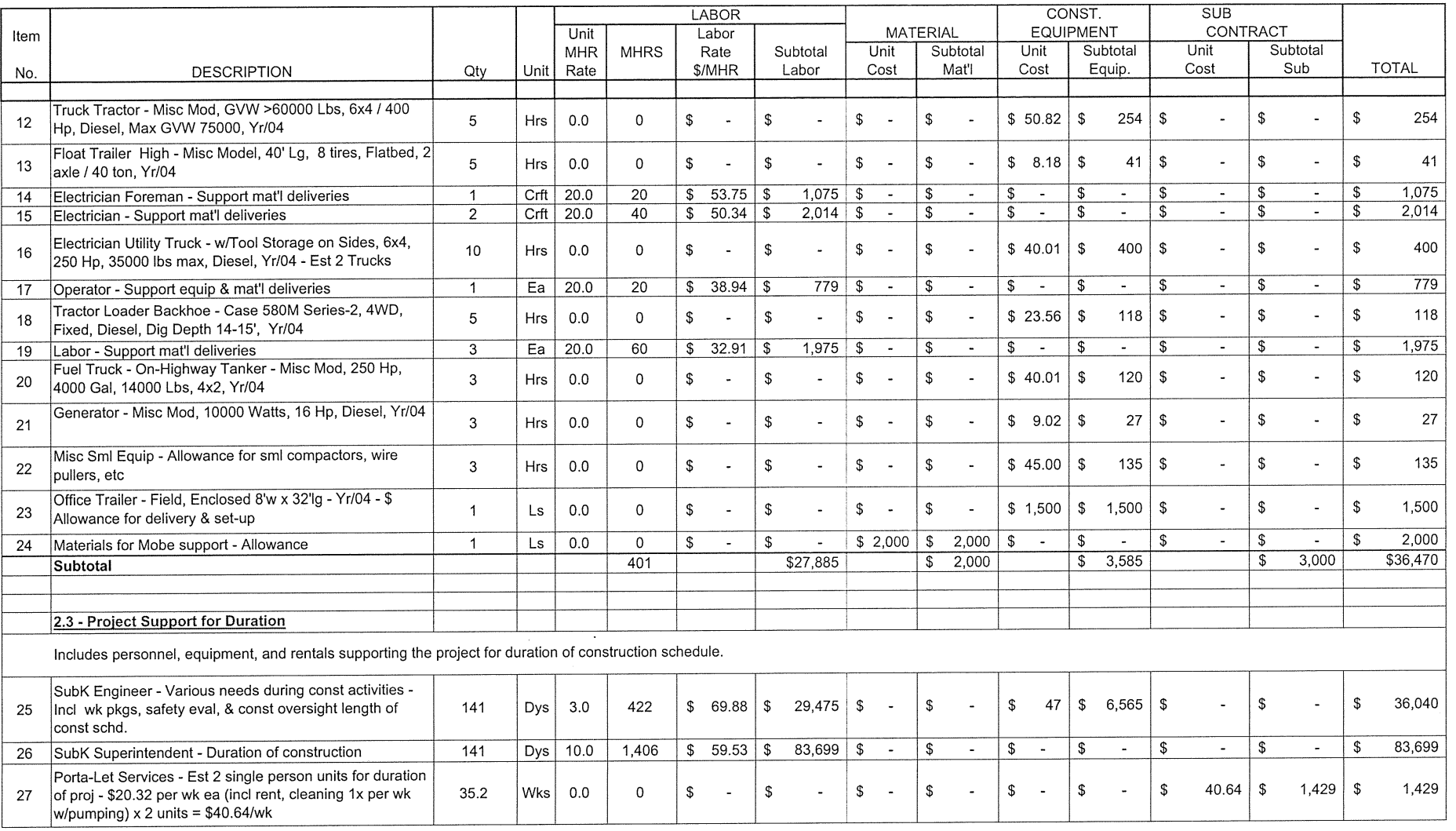


PROPRIETARY INFORMATION
Data furnished in connection with this proposal shall not be disclosed outside WCH approval, and shall not be duplicated, used, or discussed for any purpose other than to evaluate the proposal.

WASHINGTON CLOSURE HANFORD, INC. ESTIMATE PRICING SHEET RIVER CORRIDOR CLEAN UP PROJECT RICHLAND, WASHINGTON
TITLE: 300 Area Utility Repacement Project - Electrical - Option \#3 SUBJECT: 2.0 Feed Fron Richland \& 400 Area

* Rework Power Feeds At 5 Loc. Inside 300 Area

* Route Power From SHC SubSt. To 300 Area South

* Route Power From 400 Area To 300 Area North End
Estimate No: 1004-Elect-Opt\#3

Date: $04 / 24 / 07$

By: Dan Jakubek

Rev No: 0

Date: $05 / 16107$

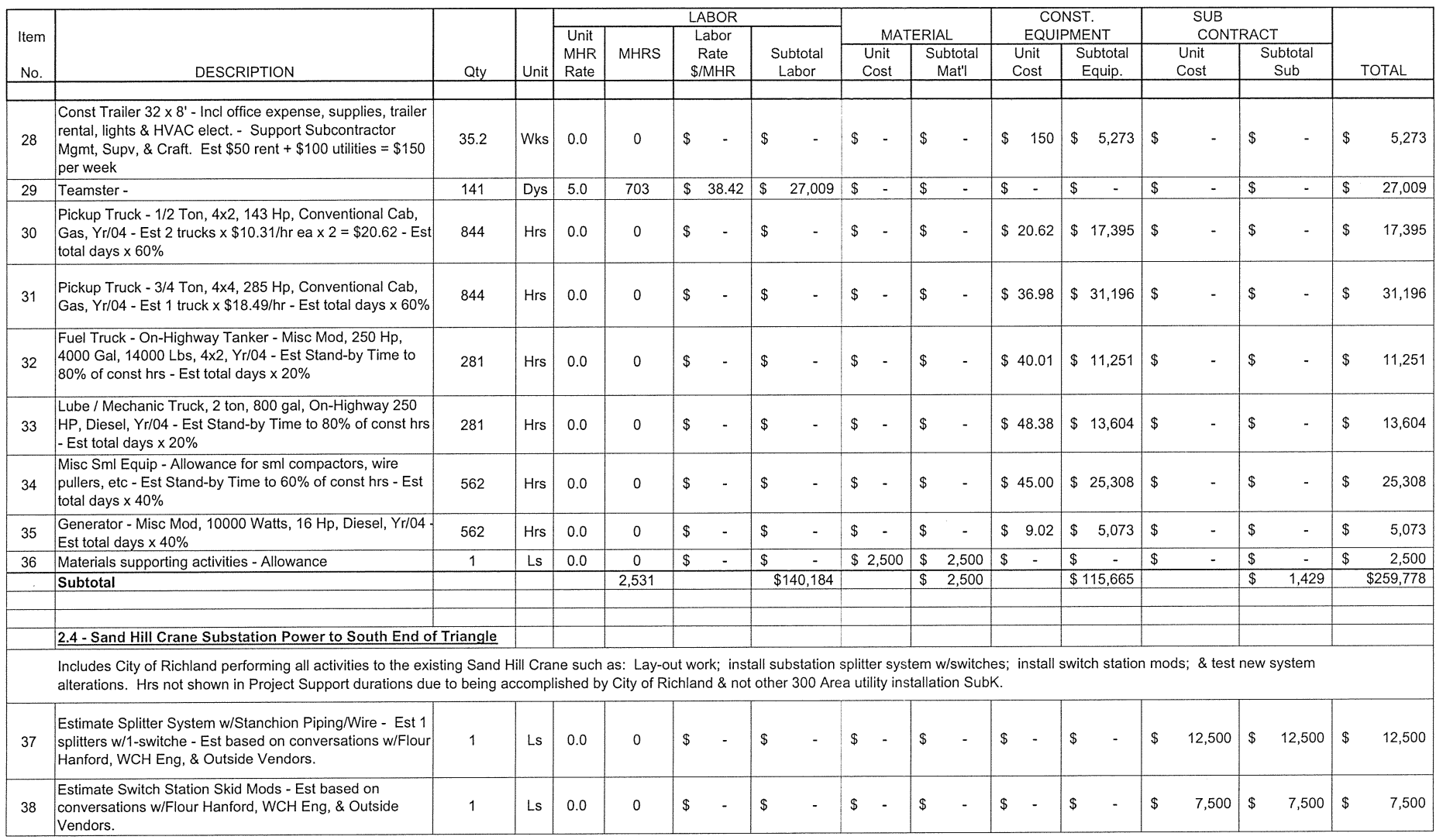


PROPRIETARY INFORMATION
Data funished in connection with this proposal shall not be disclosed outside WCH approval, and shall not be duplicated, used, or discussed for any purpose other than to evaluate the proposal.

WASHINGTON CLOSURE HANFORD, INC. ESTMATE PRICING SHEET RIVER CORRIDOR CLEAN UP PROJECT RICHLAND, WASHINGTON
TITLE: 300 Area Utility Repacement Project - Electrical - Option \#3 SUBJECT: 2.0 Feed Fron Richland \& 400 Area

$*$ Rework Power Feeds At 5 Loc. Inside 300 Area

* Route Power From SHC SubSt. To 300 Area South * Route Power From 400 Area To 300 Area North End
Estimate No: 1004-Elect-Opt\#3

Date: $04 / 24 / 07$

By: Dan Jakubek

RevNo: 0

Date: $05 / 16 / 07$

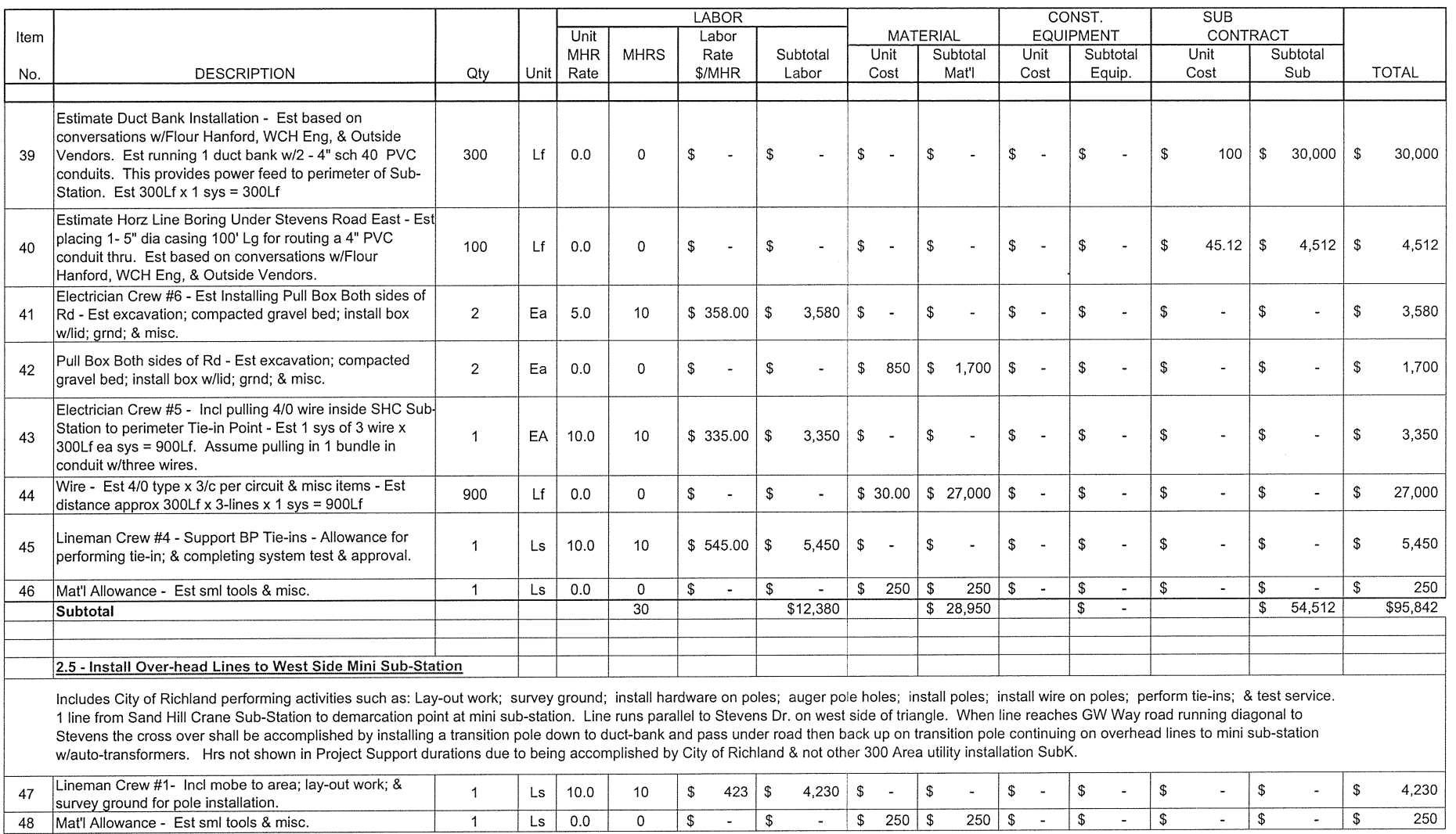


PROPRIETARY INFORMATION
Data fumished in connection with this proposal shall not be disclosed outside WCH approval, and shall not be duplicated, used, or ciscussed for any purpose other than to evaluate the proposal.

WASHINGTON CLOSURE HANFORD, INC. ESTIMATE PRICING SHEET RIVER CORRIDOR CLEAN UP PROJECT RICHLAND, WASHINGTON
TITLE: 300 Area Utility Repacement Project - Electrical - Option \#3 SUBJECT: 2.0 Feed Fron Richland \& 400 Area

$\star$ Rework Power Feeds At 5 Loc. Inside 300 Area

Rework Power Feeds At 5 Loc. Inside 300 Area

* Route Power From 400 Area To 300 Area North End
Estimate No: $1004-$ Elect-Opt\#3

Date : $04 / 24 / 07$

By: Dan Jakube

te : $05 / 16 / 07$

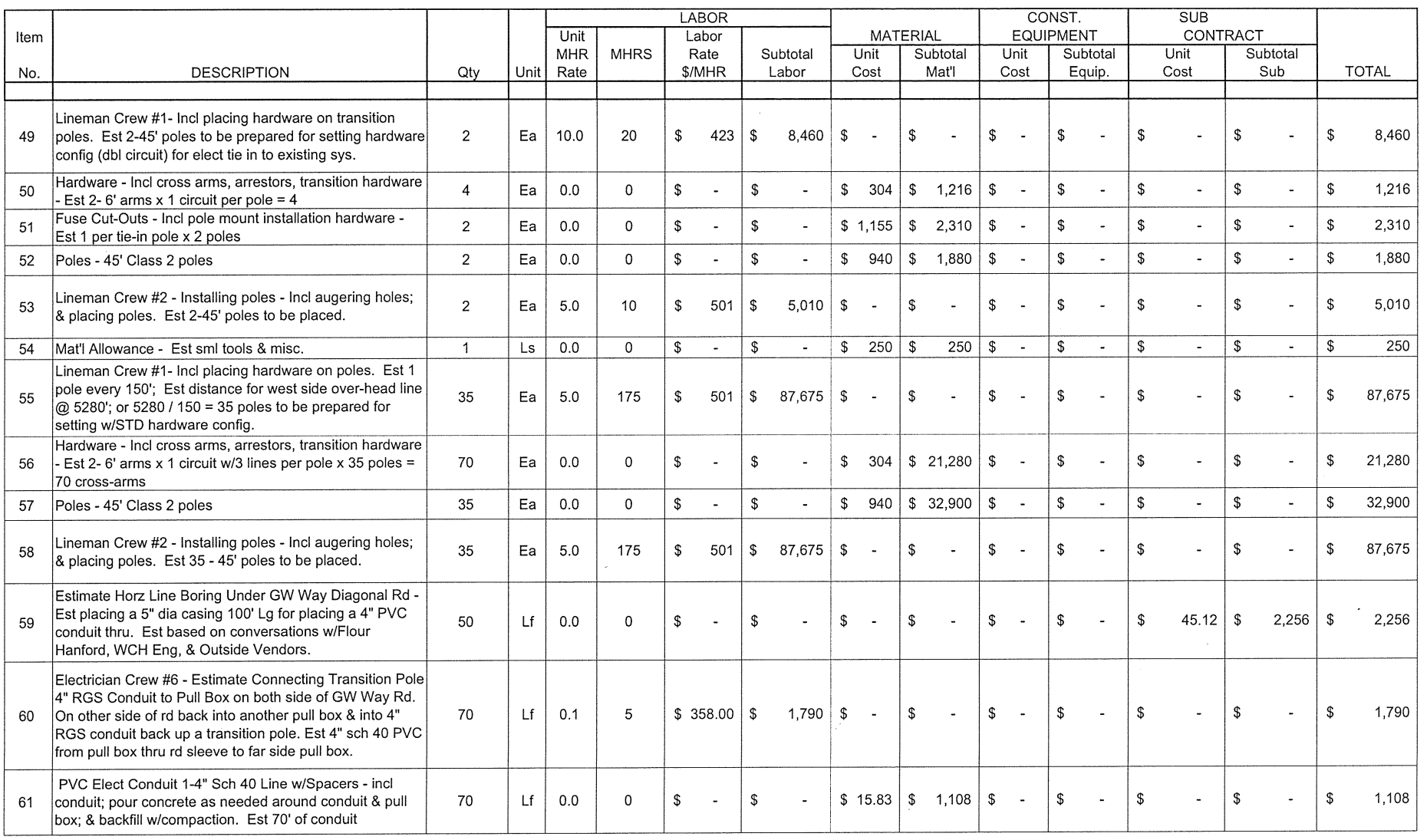


PROPRIETARY INFORMATION
Data funished in connection with this proposal shall not be disclosed outside WCH approval, and shall not be duplicated, used, or discussed for any purpose other than to evaluate the proposal.

WASHINGTON CLOSURE HANFORD, INC ESTIMATE PRICING SHEET RIVER CORRIDOR CLEAN UP PROJECT RICHLAND, WASHINGTON
TITLE: 300 Area Utility Repacement Project - Electrical - Option \#3 SUBJECT: 2.0 Feed Fron Richland \& 400 Area

* Rework Power Feeds At 5 Loc. Inside 300 Area

Rework Power Feeds At 5 Loc. Inside 300 Area

* Route Power From 400 Area To 300 Area North End
Estimate No: $1004-$ Elect-Opt\#3

Date : $04 / 24 / 07$

By: Dan Jakubek

Date: $05 / 16107$

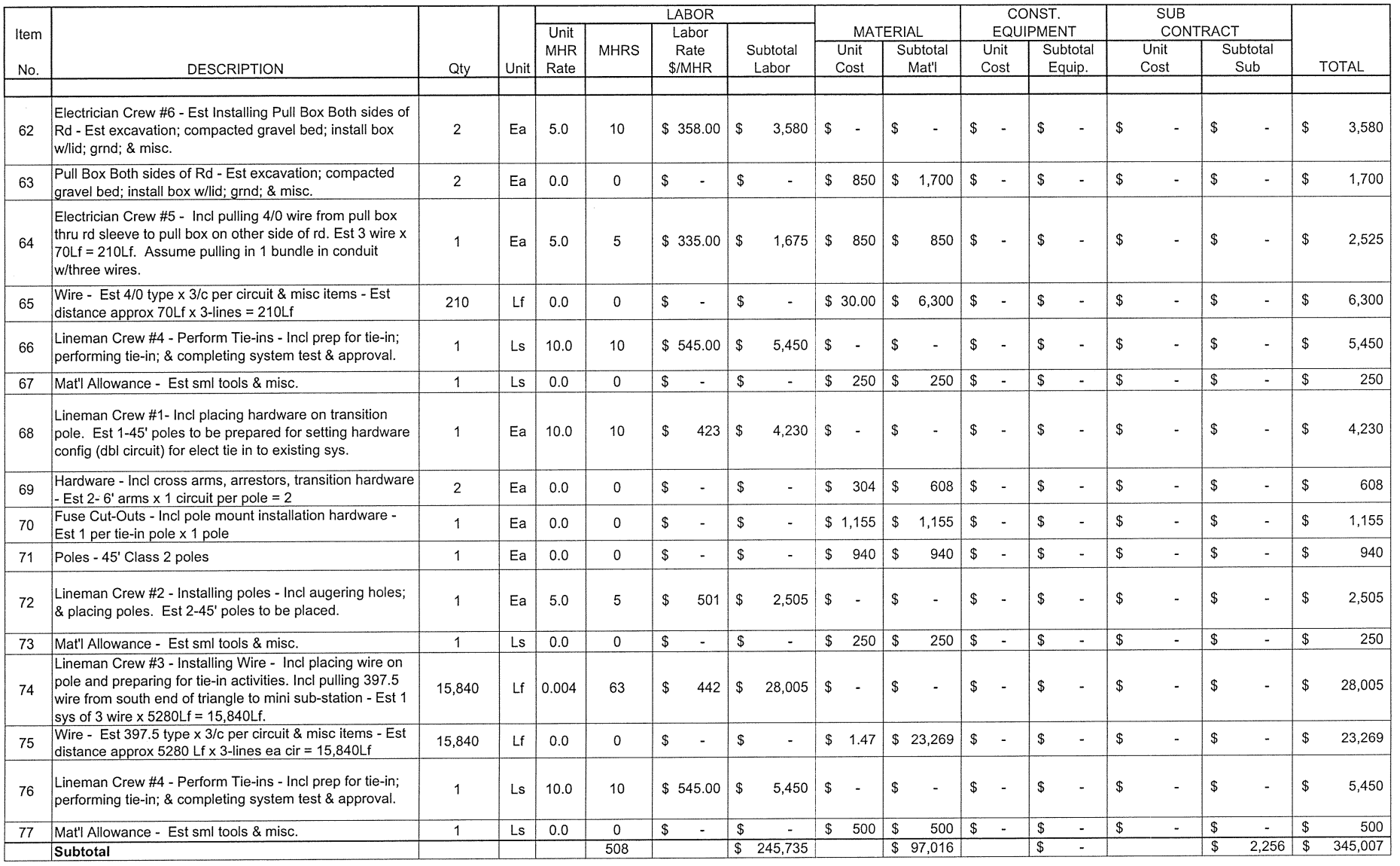


PROPRIETARY INFORMATION
Data furished in connection with this proposal shall not be disclosed outside WCH approval, and shall not be duplicated, used, or discussed for any purpose other than to evaluate the proposal.

WASHINGTON CLOSURE HANFORD, INC ESTIMATE PRICING SHEET UP PROJECT RICHLAND, WASHINGTON
TITLE: 300 Area Utility Repacement Project - Electrical - Option \#3 SUBJECT: 2.0 Feed Fron Richland \& 400 Area

$*$ Rework Power Feeds At 5 Loc. Inside 300 Area

* Route Power From SHC SubSt. To 300 Area South

* Route Power From 400 Area To 300 Area North End
Estimate No: 1004-Elect-Opt\#3

Date: $04 / 24 / 07$

By: Dan Jakubek

: $05 / 16107$

\begin{tabular}{|c|c|c|c|c|c|c|c|c|c|c|c|c|c|c|c|c|}
\hline \multirow[b]{2}{*}{ Item } & \multirow[b]{2}{*}{ DESCRIPTION } & \multirow[b]{2}{*}{ Qty } & \multirow[b]{2}{*}{ Unit } & \multicolumn{4}{|c|}{$\angle A B O R$} & \multicolumn{2}{|c|}{ MATERIAL } & \multicolumn{2}{|c|}{$\begin{array}{c}\text { CONST. } \\
\text { EQUIPMENT } \\
\end{array}$} & \multicolumn{3}{|c|}{$\begin{array}{l}\text { SUB } \\
\text { CONTRACT }\end{array}$} & \multirow{2}{*}{\multicolumn{2}{|c|}{ TOTAL }} \\
\hline & & & & $\begin{array}{l}\text { Unit } \\
\text { MHR } \\
\text { Rate }\end{array}$ & MHRS & $\begin{array}{l}\text { Labor } \\
\text { Rate } \\
\text { \$MHR }\end{array}$ & $\begin{array}{l}\text { Subtotal } \\
\text { Labor }\end{array}$ & $\begin{array}{l}\text { MAT } \\
\text { Unit } \\
\text { cost }\end{array}$ & \begin{tabular}{|c|} 
Subtotal \\
Mat'l
\end{tabular} & $\begin{array}{l}\text { Unit } \\
\text { Cost }\end{array}$ & $\begin{array}{l}\text { Subtotal } \\
\text { Equip. }\end{array}$ & \multicolumn{2}{|r|}{$\begin{array}{l}\text { Unit } \\
\text { Cost }\end{array}$} & $\begin{array}{c}\text { Subtotal } \\
\text { Sub }\end{array}$ & & \\
\hline & & & & & & & & & & & & & & & & \\
\hline & & & & & & & & & & & & & & & & \\
\hline & 2.6 - Install West Side Sub-Station & & & & & & & & & & & & & & & \\
\hline & $\begin{array}{l}\text { Includes - Meet w/Richland City Engineers for construc } \\
\text { install substation grounding system; install gravel \& co } \\
\text { system w/switches; install switch station; \& safety/sec }\end{array}$ & & & & 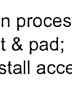 & $\begin{array}{l}\text { y-out wor } \\
\text { all } 1 \text { - auto } \\
\text { ad w/50' }\end{array}$ & $\begin{array}{l}\text { rk; survey are } \\
\text { o-transformers } \\
\text { ' } \times 24 \text { ' wide w/ }\end{array}$ & $\begin{array}{l}\text { clec } \\
\text { regul } \\
\text { oomp }\end{array}$ & $\begin{array}{l}\text { \&rub areas; } \\
\text { or to step up } \\
\text { ted gravel \& }\end{array}$ & $\begin{array}{l}\text { remo } \\
\text { voltage }\end{array}$ & $\begin{array}{l}\text { \& spreac } \\
\text { Richland } \\
\text { er } 300 \mathrm{Ar}\end{array}$ & & $\begin{array}{l}\text { of per } \\
\text { ed; ins } \\
\text { oads. }\end{array}$ & $\begin{array}{l}\text { neter areas; } \\
\text { el 1-leg spliter }\end{array}$ & & \\
\hline 78 & $\begin{array}{l}\text { Lineman Crew \#1 - Performing Other Activities - Incl } \\
\text { mobe to area; lay-out work; \& survey area for pole } \\
\text { installation. }\end{array}$ & 1 & Ls & 10.0 & 10 & $\$ 423.00$ & $\$ \quad 4,230$ & $\$-$ & $\$$ & $\$-$ & $\$$ & $\$$ & & $\$$ & $\$$ & 4,230 \\
\hline 79 & Mat' Allowance - Est sml tools \& misc. & 1 & Ls & 0.0 & 0 & $\$$ & $\$$ & $\$ 250$ & 250 & $\$-$ & $\$$ & $\$$ & & $\$$ & $\$$ & 250 \\
\hline 80 & $\begin{array}{l}\text { Estimate Yard Portion - Est yard based on conversations } \\
\text { w/Flour Hanford, WCH Est, \& Outside Vendors. }\end{array}$ & 1 & Ls & 0.0 & 0 & $\$$ & $\$$ & $\$$ & $\$$ & $\$-$ & $\$$ & $\$$ & 42,500 & $\$ 42,500$ & $\$$ & 42,500 \\
\hline 81 & $\begin{array}{l}\text { Estimate Elect Richland City Tie-in w/Wire \& Tubing to } \\
\text { Transformer - Est based on conversations w/Flour } \\
\text { Hanford, WCH Eng, \& Outside Vendors. }\end{array}$ & 1 & Ls & 0.0 & 0 & $\$$ & $\$$ & $\$-$ & $\$$ & $\$-$ & $\$$ & $\$$ & 37,500 & $\$ \quad 37,500$ & $\$$ & 37,500 \\
\hline 82 & $\begin{array}{l}\text { Estimate Installation of Auto-Transformer - Est based on } \\
\text { conversations w/Flour Hanford, WCH Eng, \& Outside } \\
\text { Vendors. }\end{array}$ & 1 & Ls & 0.0 & 0 & $\$$ & $\$$ & $\$$ & $\$$ & $\$$ & $\$$ & $\$$ & 630,000 & $\$ 630,000$ & $\$$ & 630,000 \\
\hline 83 & $\begin{array}{l}\text { Estimate Splitter System w/Stanchion Piping/Wire - Est } 3 \\
\text { splitters w/switches - Est based on conversations w/Flour } \\
\text { Hanford, WCH Eng, \& Outside Vendors. }\end{array}$ & 1 & Ls & 0.0 & 0 & $\$$ & $\$$ & $\$$ & $\$$ & $\$$ & $\$$ & $\$$ & 50,000 & $\$ 50,000$ & $\$$ & 50,000 \\
\hline 84 & $\begin{array}{l}\text { Estimate Switch Station Skid w/Out-Door Rated Equip - } \\
\text { Est based on conversations w/Flour Hanford, WCH Eng, } \\
\text { \& Outside Vendors. }\end{array}$ & 1 & Ls & 0.0 & 0 & $\$$ & $\$$ & $\$$ & $\$$ & $\$-$ & $\$$ & $\$$ & 81,000 & $\$ \quad 81,000$ & $\$$ & 81,000 \\
\hline 85 & $\begin{array}{l}\text { Estimate Road Extension \& Turn-in - Est based on } \\
\text { conversations w/Flour Hanford, WCH Eng, \& Outside } \\
\text { Vendors. }\end{array}$ & 1 & Ls & 0.0 & 0 & $\$$ & $\$$ & $\$$ & $\$$ & $\$$ & $\$$ & $\$$ & 12,500 & $\$ \quad 12,500$ & $\$$ & 12,500 \\
\hline 86 & $\begin{array}{l}\text { Electrician Crew \#6 - Install new duct bank from Sub- } \\
\text { station to Stevens Drive Connection point. Incl } \\
\text { excavating; placing 2-4" PVC elect conduit lines \& } \\
\text { spacers; pour concrete around conduit; \& backfill } \\
\text { w/compaction. Est 50' of new duct bank }\end{array}$ & 50 & Lf & 0.17 & 8 & $\$ 358.00$ & 2,983 & \$ - & $\$$ & $\$-$ & $\$$ & $\$$ & - & $\$$ & $\$$ & 2,983 \\
\hline 87 & $\begin{array}{l}\text { PVC Elect Conduit } 2-4 " \text { Sch } 40 \text { Lines w/Spacers - incl } \\
\text { conduit; pour concrete around conduit; } \& \text { backfill } \\
\text { w/compaction. Est } 50^{\prime} \text { of new duct bank }\end{array}$ & 50 & Lf & 0.0 & 0 & $\$$ & $\$$ & $\$ 22.62$ & $\$ \quad 1,131$ & $\$$ & $\$$ & $\$$ & - & $\$$ & $\$$ & 1,131 \\
\hline
\end{tabular}


PROPRIETARY INFORMATION
Data funished in connection with this proposal shall not be disclosed outside WCH approval, and shall not be duplicated, used, or discussed for any purpose other than to evaluate the proposal.

WASHINGTON CLOSURE HANFORD, INC. ESTIMATE PRICING SHEET

RVERCORRDOR SHEAN UP PROJECT

RICHLAND, WASHINGTON
TITLE: 300 Area Utility Repacement Project - Electrical - Option \#3 SUBJECT: 2.0 Feed Fron Richland \& 400 Area

* Rework Power Feeds At 5 Loc. Inside 300 Area

* Rework Power Feeds At 5 Loc. Inside 300 Area

* Route Power From SHC SubSt. To 300 Area South
Estimate No: $1004-$ Elect-Optt3

Date: $04 / 24 / 07$

By: Dan Jakubek

: 0511007

\begin{tabular}{|c|c|c|c|c|c|c|c|c|c|c|c|c|c|c|c|c|c|c|c|c|c|}
\hline \multirow[b]{2}{*}{$\begin{array}{l}\text { Item } \\
\text { No. }\end{array}$} & \multirow[b]{2}{*}{ ESCRI } & \multirow[b]{2}{*}{ Qty } & \multirow[b]{2}{*}{ Unit } & \multirow[b]{2}{*}{$\begin{array}{l}\text { Unit } \\
\text { MHR } \\
\text { Rate } \\
\end{array}$} & \multirow[b]{2}{*}{ MHRS } & \multicolumn{3}{|l|}{ LABOR } & \multicolumn{3}{|c|}{ MATERIAL } & \multicolumn{4}{|c|}{$\begin{array}{l}\text { CONST. } \\
\text { EQUIPMENT }\end{array}$} & \multicolumn{4}{|c|}{$\begin{array}{l}\text { SUB } \\
\text { CONTRACT }\end{array}$} & \multirow{2}{*}{\multicolumn{2}{|c|}{ TOTAL }} \\
\hline & & & & & & $\begin{array}{c}\text { Labor } \\
\text { Rate } \\
\text { S/MHR }\end{array}$ & \multicolumn{2}{|c|}{$\begin{array}{c}\text { Subtotal } \\
\text { Labor }\end{array}$} & $\begin{array}{l}M \\
\text { Unit } \\
\text { Cost }\end{array}$ & \multicolumn{2}{|c|}{$\begin{array}{c}\text { Subtotal } \\
\text { Mat'l }\end{array}$} & \multicolumn{2}{|c|}{$\begin{array}{l}\text { Unit } \\
\text { Unit } \\
\text { Cost }\end{array}$} & \multicolumn{2}{|c|}{$\begin{array}{c}\text { Subtotal } \\
\text { Equip. }\end{array}$} & \multicolumn{2}{|c|}{$\begin{array}{l}\text { Unit } \\
\text { Cost } \\
\end{array}$} & \multicolumn{2}{|c|}{$\begin{array}{c}\text { Subtotal } \\
\text { Sub }\end{array}$} & & \\
\hline 88 & $\begin{array}{l}\text { Electrician Crew \#5- Est pulling new wire into new duct } \\
\text { bank - Est } 50^{\prime} \text { of wire } \times 3 \times 1 \text { sys }=150 \text { Lf. Assume } \\
\text { pulling in bundles of three wires. }\end{array}$ & 50 & Lf & 0.07 & 3.5 & $\$ 335.00$ & $\$$ & 1,173 & $\$$ & $\$$ & $\$$ & $\$$ & & $\$$ & - & $\$$ & - & $\$$ & - & $\$$ & 1,173 \\
\hline 89 & $\begin{array}{l}\text { Wire - Est } 4 / 0 \text { type } \times 3 / c \text { per circuit \& misc items }- \text { Est } \\
\text { distance approx } 50 \text { Lf }-50 \times 3 \text {-lines ea cir } \times 1 \text { sys }=150 \text { Lf }\end{array}$ & 150 & Lf & 0.0 & 0 & $\$$ & $\$$ & - & $\$ 30.0$ & $0 \$$ & $\$ 4,50$ & $\$$ & & $\$$ & - & $\$$ & - & $\$$ & - & $\$$ & 4,500 \\
\hline 99 & $\begin{array}{l}\text { Mat'l Allowance - Est sml tools \& misc. } \\
\text { Subtotal }\end{array}$ & 1 & Ls & 0.0 & $\frac{0}{22}$ & $\$$ & $\$$ & 8,386 & $\$ 50$ & $\begin{array}{l}0 \$ \$ \\
\$\end{array}$ & 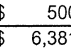 & $\$$ & - & \begin{tabular}{|l|}
$\$$ \\
$\$$
\end{tabular} & - & $\$$ & - & $\frac{\$}{\$}$ & $\frac{-}{853,500}$ & $\frac{\$}{\$}$ & $\begin{array}{r}500 \\
868,267\end{array}$ \\
\hline & & & & & & & & & & & & & & & & & & & & & \\
\hline & 2.7 - Install West Side Arial Lines to Existing 300 Area S & & & & & & & & & & & & & & & & & & & & \\
\hline & Includes - Lay-out work; s & bles: & & les; in & wire & $s ;$ & & -ins; \& & t serv & & & & & & & & & & & & \\
\hline 100 & $\begin{array}{l}\text { Lineman Crew \#1- Incl placing hardware on transition pole } \\
\text { on west side sub-st to existing west side } 300 \text { Ara power } \\
\text { lines. Est 2-45' poles to be prepared for setting hardware } \\
\text { config (dbl circuit) for elect tie in to existing sys. }\end{array}$ & 2 & Ea & 10.0 & 20 & $\$ 423.00$ & $\$$ & 8,460 & $\$$ & $\$$ & - & $\$$ & - & $\$$ & - & $\$$ & - & $\$$ & - & $\$$ & 8,460 \\
\hline 101 & $\begin{array}{l}\text { Hardware }- \text { Incl cross arms, arrestors, transition hardware } \\
- \text { Est dbl } 6 \text { ' arms } \times 1 \text { circuit }=2 \text { arms per pole } \times 2 \text { poles }= \\
4\end{array}$ & 4 & Ea & 0.0 & 0 & $\$$ & $\$$ & - & $\$ 30$ & $4 \$$ & \$ 1,216 & $\$$ & & $\$$ & - & $\$$ & - & $\$$ & - & $\$$ & 1,216 \\
\hline 102 & $\begin{array}{l}\text { Fuse Cut-Outs - Incl pole mount pull-dwn swt, \& mounting } \\
\text { items - Est } 1 \text { per sys }\end{array}$ & 2 & Ea & 0.0 & 0 & $\$$ & $\$$ & - & $\$ 1,15$ & $5 \$$ & $\$ 2,31 \mathrm{C}$ & $\$$ & - & $\$$ & - & $\$$ & - & $\$$ & - & $\$$ & 2,310 \\
\hline 103 & Poles - 45' Class \#2 pole & 2 & Ea & 0.0 & 0 & $\$$ & $\$$ & - & $\$ 94$ & $0 \$$ & \$ 1,88 & $\$$ & - & $\$$ & - & $\$$ & - & $\$$ & - & $\$$ & 1,880 \\
\hline 104 & $\begin{array}{l}\text { Lineman Crew \#2 - Installing poles - Incl augering holes; } \\
\text { \& placing poles. Est 2-45' poles to be placed. }\end{array}$ & 2.0 & Hrs & 5.0 & 10 & $\$ 501.00$ & $\$$ & 5,010 & $\$$ & $\$$ & - & $\$$ & - & $\$$ & - & $\$$ & - & $\$$ & - & $\$$ & 5,010 \\
\hline 105 & Mat'l Allowance - Est sml tools \& misc. & 1 & Ls & 0.0 & 0 & - & $\$$ & - & $\$ 25$ & 09 & 25 & $\$$ & - & $\$$ & - & $\$$ & - & $\$$ & - & $\$$ & 250 \\
\hline 106 & $\begin{array}{l}\text { Lineman Crew \#1- Incl placing hardware on poles. Est } 10 \\
45^{\prime} \text { poles to be prepared for setting w/STD hardware } \\
\text { config. }\end{array}$ & 10 & Ea & 5.0 & 50 & $\$ 423.00$ & $\$$ & 21,150 & $\$$. & $\$$ & - & $\$$ & - & $\$$ & - & $\$$ & - & $\$$ & - & $\$$ & 21,150 \\
\hline 107 & $\begin{array}{l}\text { Hardware - Incl cross arms, arrestors, etc }- \text { Est dbl } 6^{\prime} \\
\text { arms } \times 1 \text { circuit per pole }=2 \text { per pole } \times 10 \text { poles }=20\end{array}$ & 20 & Ea & 0.0 & 0 & $\$$ & $\$$ & - & $\$ 19$ & $8 \$$ & 3,95 & $\$$ & - & $\$$ & - & $\$$ & - & $\$$ & - & $\$$ & 3,952 \\
\hline 108 & Poles - $45^{\prime}$ Class 2 poles & 10 & Ea & 0.0 & 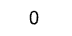 & $\$$ & $n^{2}$ & - & $\$ 94$ & $0 \$$ & 9,40 & $\left.\right|^{*}$ & 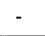 & $\$$ & - & $\$$ & +5 & $\$$ & & $\$$ & 9,401 \\
\hline
\end{tabular}


PROPRIETARY INFFRMATION
Data furnished in connection with this proposal shall not be disclosed outside WCH approval, and shall not be duplicated, used, or ciscussed tor any purpose other than to evaluate the proposal.

WASHINGTON CLOSURE HANFORD, INC ESTIMATE PRICING SHEET

RIVER CORRIDOR GIEAN UP PROJECT RICHLAND, WASHINGTON
TITLE: 300 Area Utility Repacement Project - Electrical - Option \#3 SUBJECT: 2.0 Feed Fron Richland \& 400 Area

* Rework Power Feeds At 5 Loc. Inside 300 Area

Rework Power Feeds At 5 Loc. Inside 300 Area

* Route Power From 400 Area To 300 Area North End
Estimate No: $1004-$ Elect-Opt\#3

Date : $04 / 24 / 07$

By: Dan Jakubek

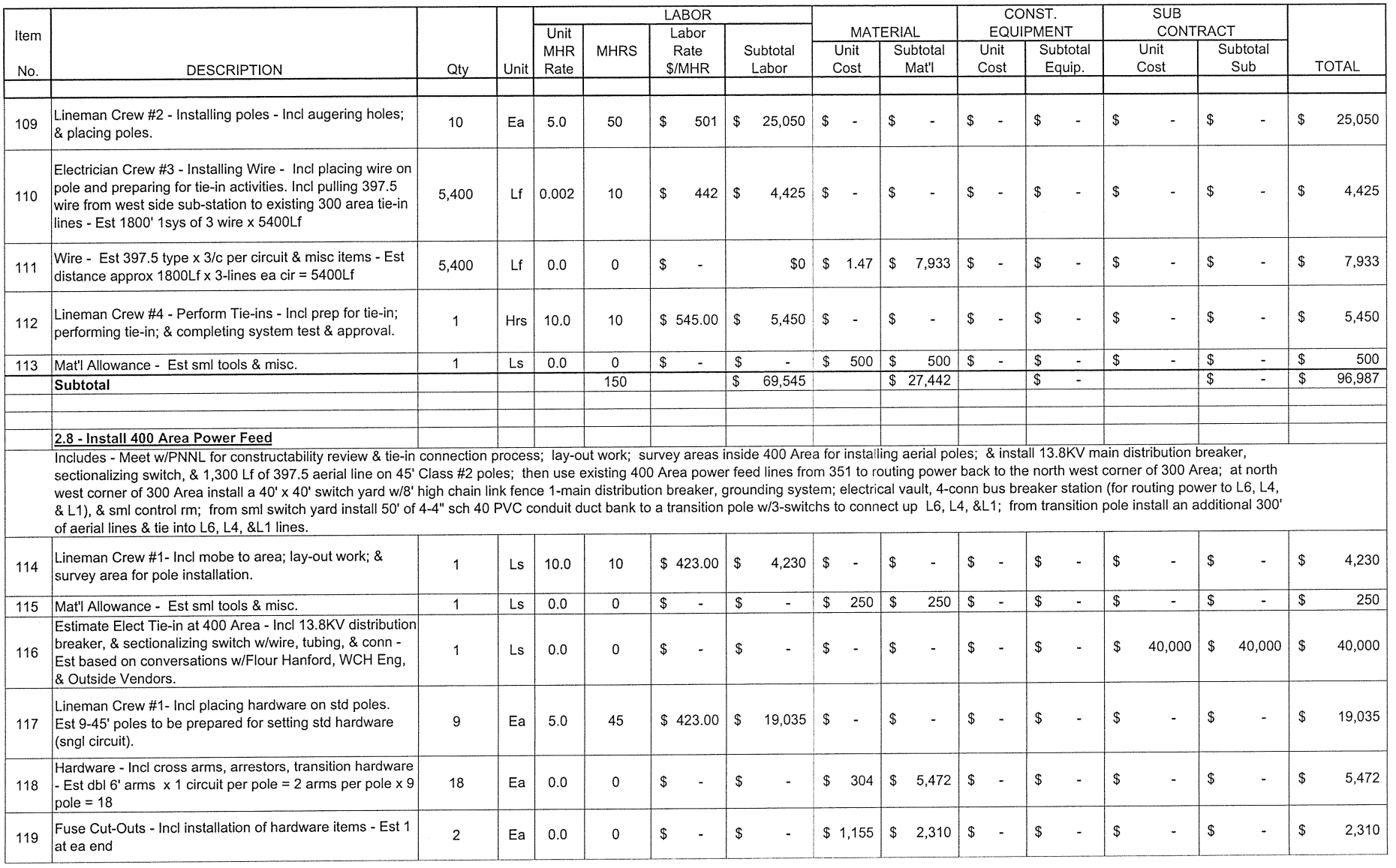


PROPRIETARY INFORMATION
Data furished in connection with this proposal shall not be disclosed outside WCH approval, and shall not be duplicated, used, or ciiscussed for any purpose other than to evaluate the proposal.

WASHINGTON CLOSURE HANFORD, INC. ESTIMATE PRICING SHEET RIVER CORRIDOR CLEAN UP PROJECT RICHLAND, WASHINGTON
TITLE: 300 Area Utility Repacement Project - Electrical - Option \#3 SUBJECT: 2.0 Feed Fron Richland \& 400 Area

* Rework Power Feeds At 5 Loc. Inside 300 Area

Rework Power Feeds At 5 Loc. Inside 300 Area

* Route Power From 400 Area To 300 Area North End
Estimate No : 1004-Elect-Optt3

Date : $04 / 24 / 07$

By: Dan Jakubek

: $05 / 16 / 07$

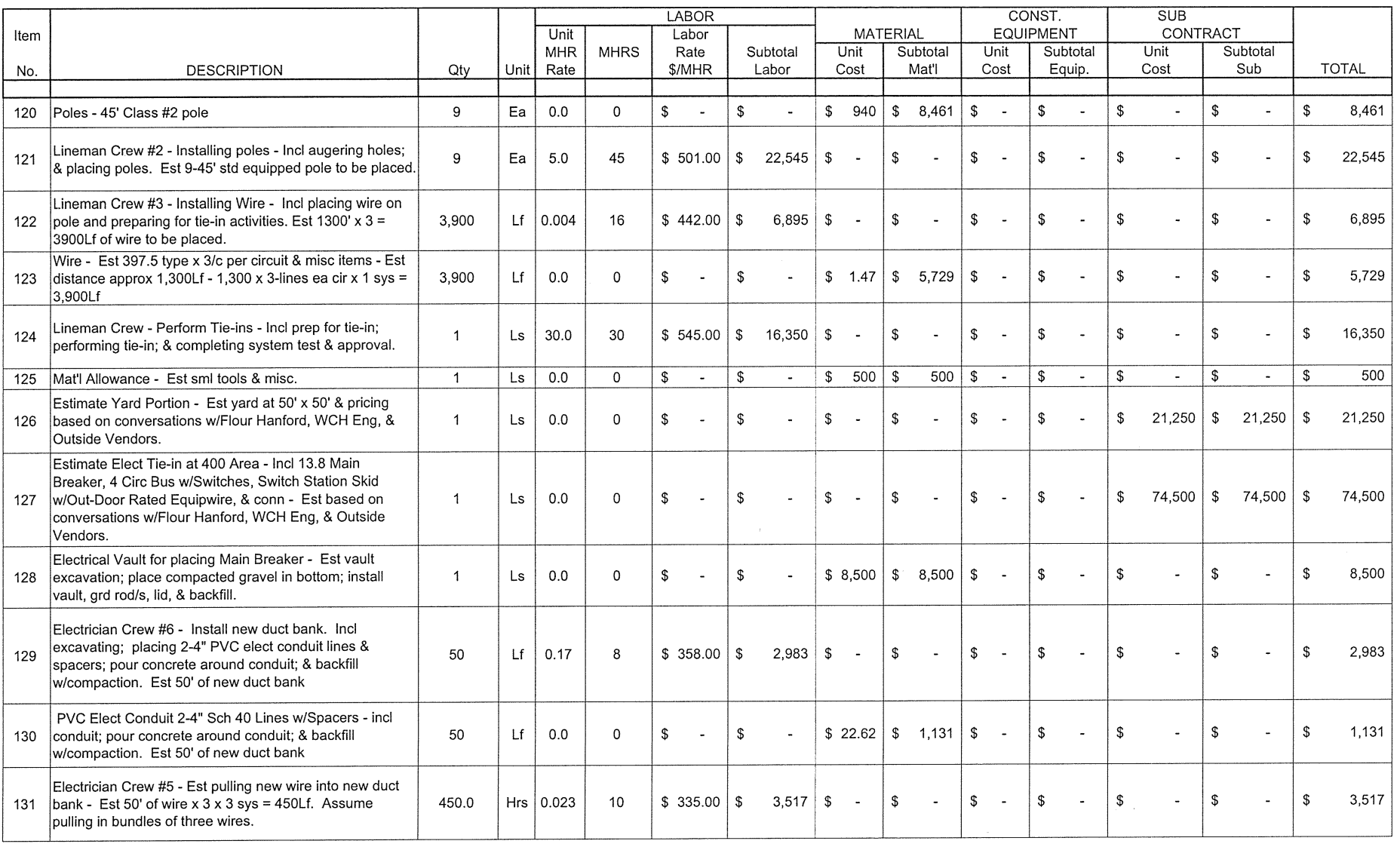


PROPRIETARY INFORMATION
Data funished in connection with this proposal shall not be disclosed outside WCH approval, and shall not be duplicated, used, or discussed for any purpose other than to evaluate the proposal.

WASHINGTON CLOSURE HANFORD, INC. ESTIMATE PRICING SHEET RIVER CORRIDOR CLEAN UP PROJECT RICHLAND, WASHINGTON
TITLE: 300 Area Utility Repacement Project - Electrical - Option \#3 SUBJECT: 20 Feed Fron Richland \& 400 Area

* Rework Power Feeds At 5 Loc. Inside 300 Area
Estimate No: 1004-Elect-Opt\#3

Date: $04 / 24 / 07$

By: Dan Jakubek

Date: $05 / 16 / 07$

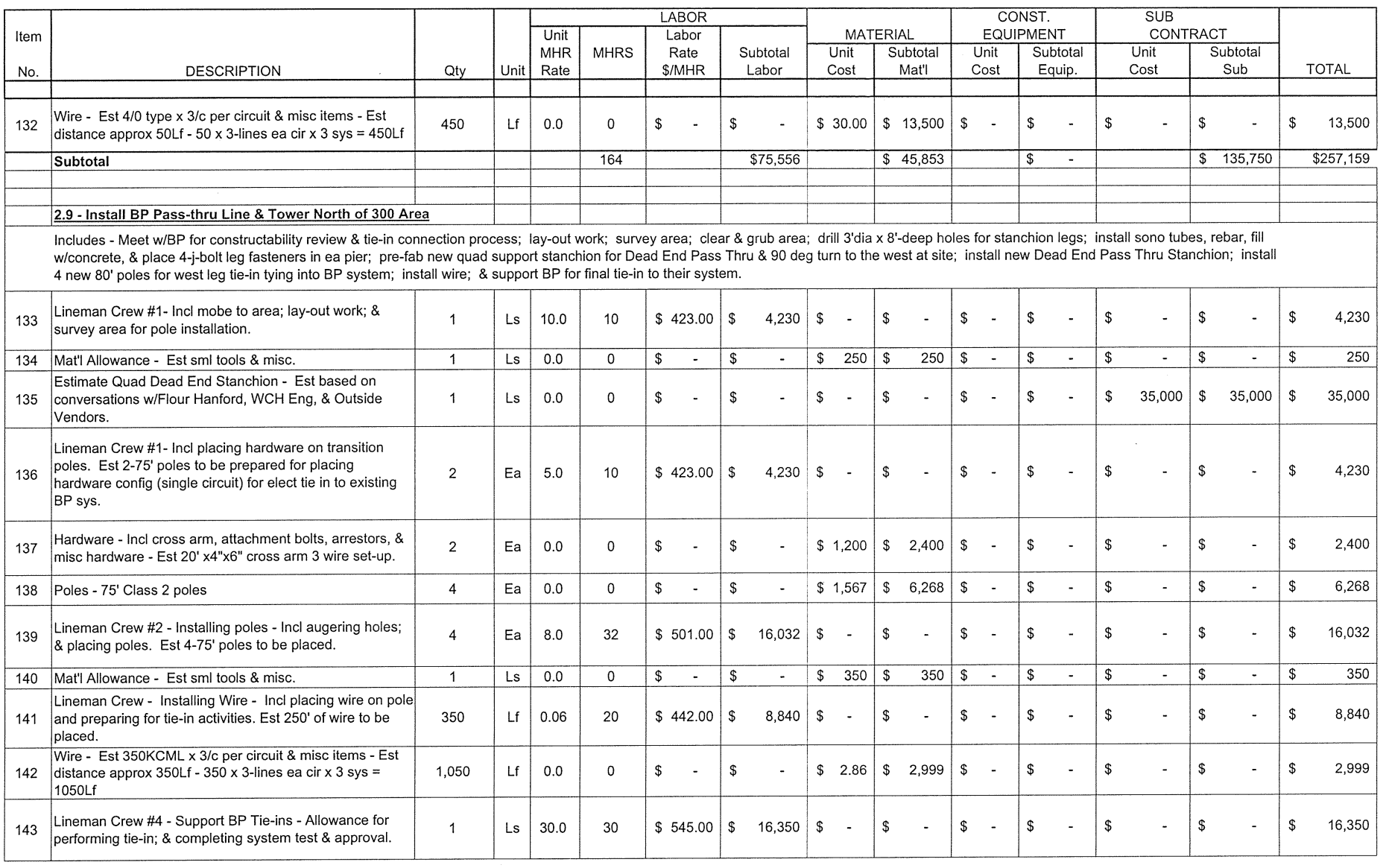

Page 12 of 21

$5 / 16 / 2007$ 
PROPRIETARY INFORMATION
Data fumished in connection with this proposal shall not be disclosed outside WCH approval, and shal not be duplicated, used, or discussed for any purpose other than to evaluate the proposal.

WASHINGTON CLOSURE HANFORD, INC ESTIMATE PRICING SHEET

UP PROJECT RICHLAND, WASHINGTON
TITLE: 300 Area Utility Repacement Project - Electrical - Option \#3 SUBJECT: 2.0 Feed Fron Richland \& 400 Area

* Rework Power Feeds At 5 Loc. Inside 300 Area

* Route Power From SHC SubSt. To 300 Area South

* Route Power From 400 Area To 300 Area North End
Estimate No: 1004-Elect-Opt\#3

Date: $04 / 24 / 07$

By: Dan Jakubek

: 0511007

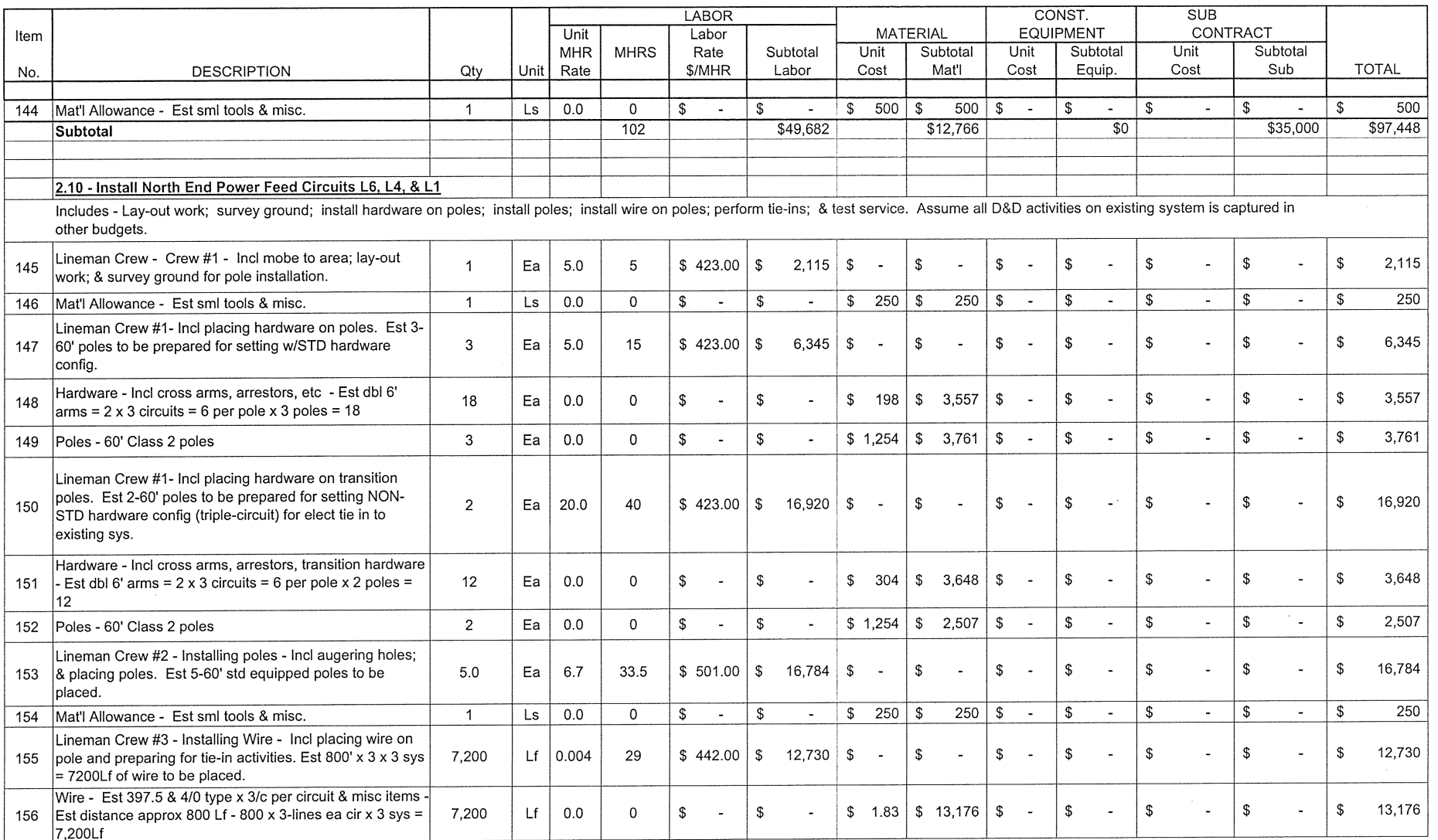


PROPRIETARY INFORMATION
Data funished in connection with this proposal shall not be disclosed outside WCH approval, and shall not be duplicated, used, or discussed for any purpose other than to evaluate the proposal.

WASHINGTON CLOSURE HANFORD, INC. ESTIMATE PRICING SHEET OR CLEAN UP PROJECT RICHLAND, WASHINGTON

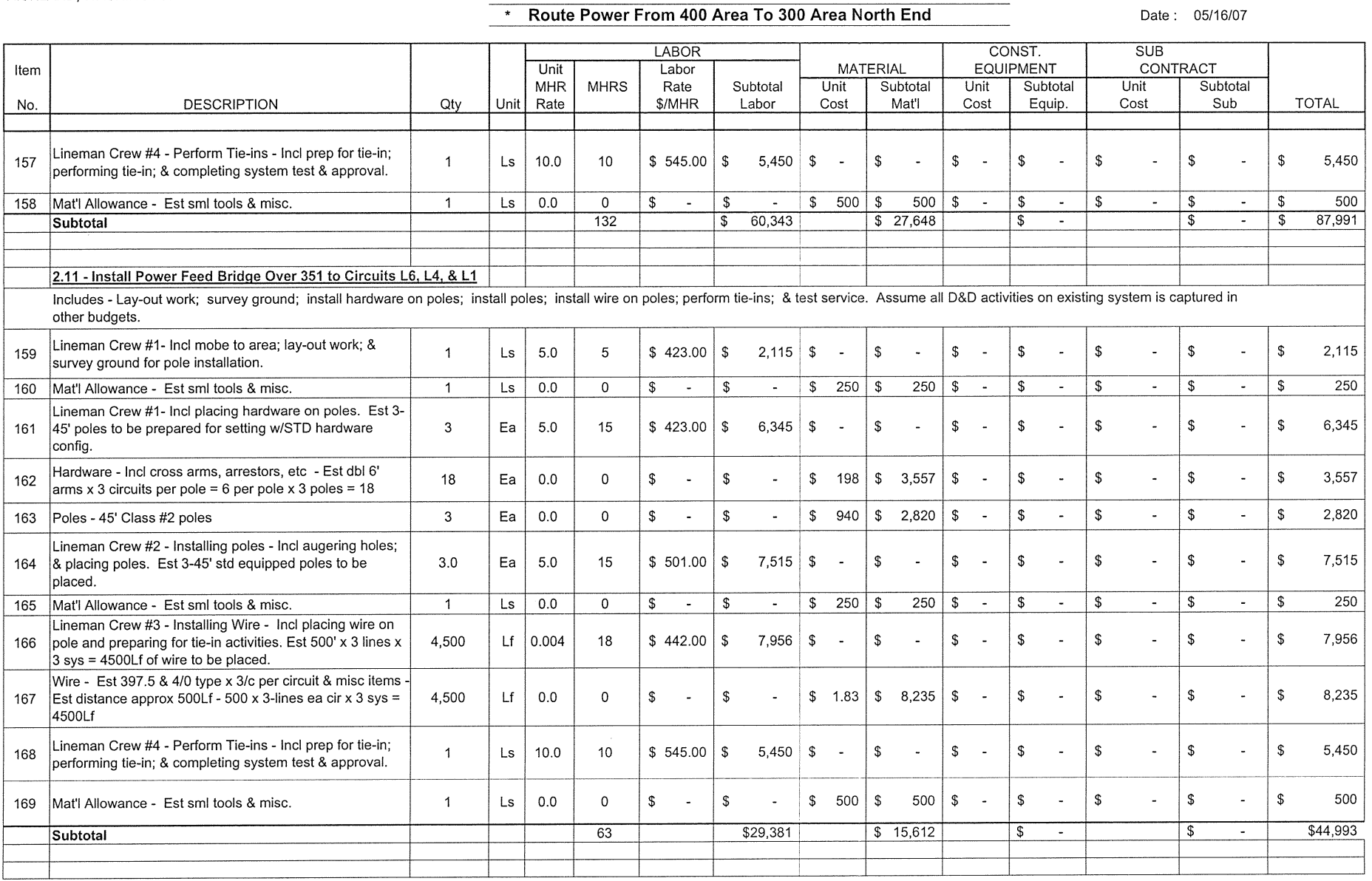

Estimate No: 1004-Elect-Opt\#3

Date: $04 / 24 / 07$

By : Dan Jakubek SUBJECT: $\frac{300 \text { Area Utility Repacement Project }}{2.0 \text { Feed Fron Richland } \& 400 \text { Area }}$

* Rework Power Feeds At 5 Loc. Inside 300 Area

Route Power From 400 Area To 300 Area North En 
PROPRIETARY INFORMATION
Data furished in connection with this proposal shall not be disclosed outside WCH approval, and shall not be dupicated, used, or discussed for any purpose other than to evaluate the proposal.

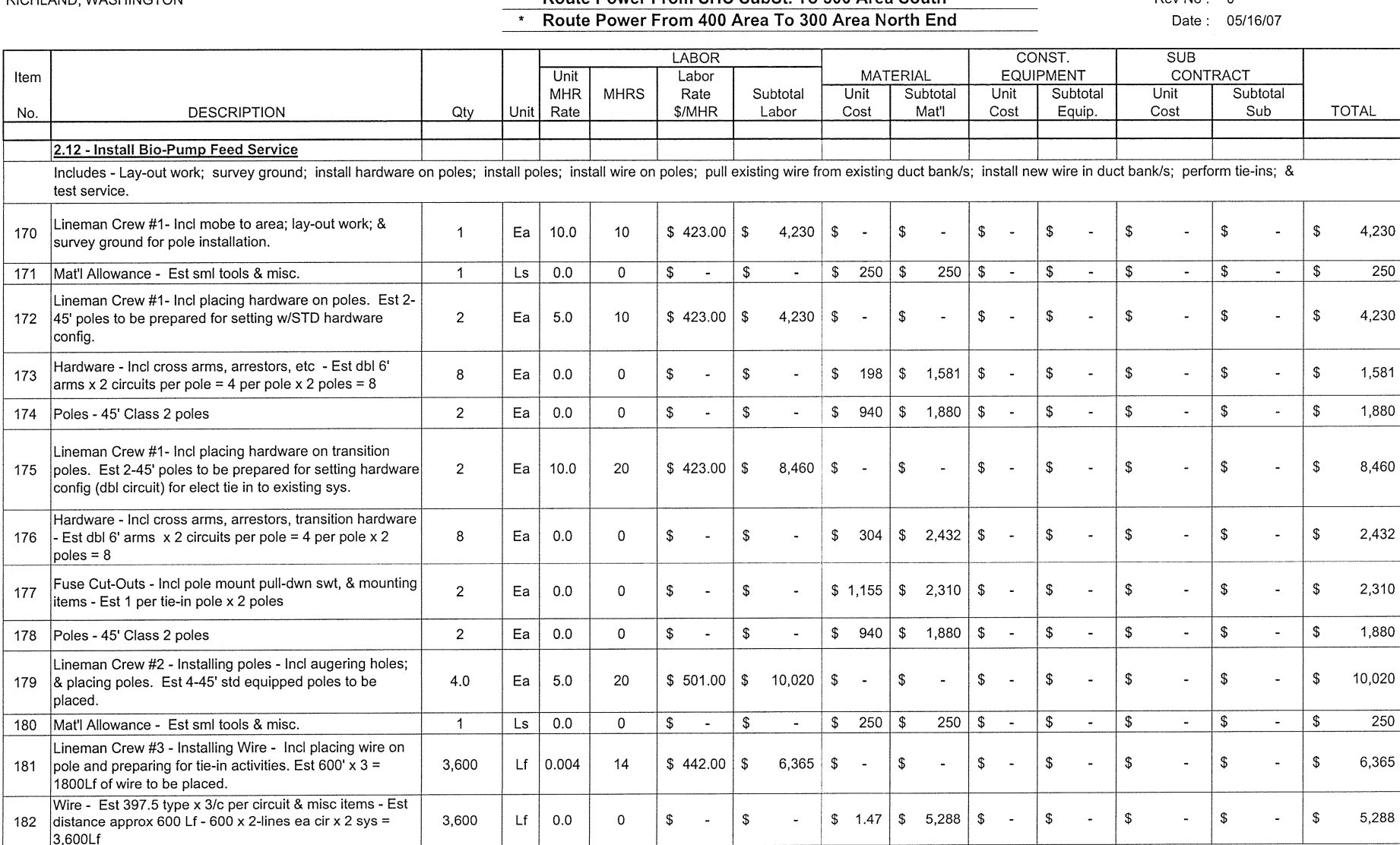

WASHINGTON CLOSURE HANFORD, INC. ESTIMATE PRICING SHEET RIVER CORRIDOR CLEAN UP PROJECT RICHLAND, WASHINGTON

TITLE: 300 Area Utility Repacement Project - Electrical - Option \#3 2.0Feed Fron Rich

in Area

Estimate No: 1004-Elect-Opt\#3

Date: $04 / 24 / 07$

$\begin{array}{ll}\text { Date : } & 4 / 24 / 07 \\ \text { By: Dan Jakubek } & 0\end{array}$

Rev No: 0

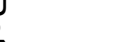


PROPRIETARY INFORMATION
Data furished in connection with this proposal shall not be disclosed outside WCH approval, and shall not be duplicated, used, or discussed for any purpose other than to evaluate the proposal.

WASHINGTON CLOSURE HANFORD, INC WTIMATE PRICING SHEET SLEAN UP PROJECT RICHLAND, WASHINGTON

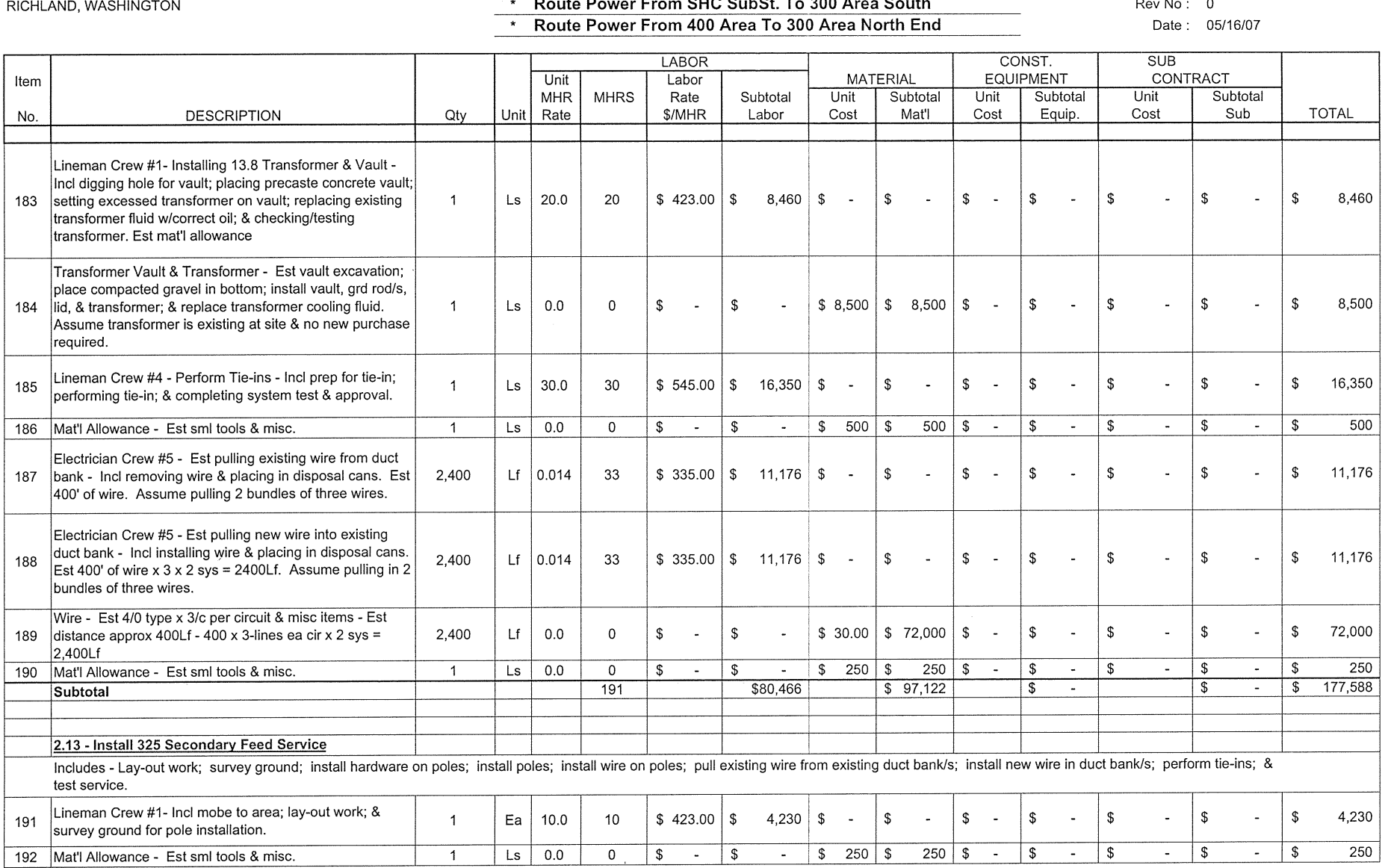

TITLE: 300 Area Utility Repacement Project - Electrical - Option t3 20 Feed Fron Richland 8400 Area

00 Area

Estimate No: 1004-Elect-Optt3

Date: $04 / 24 / 07$

$\begin{array}{cl}\text { Date: } & 4 / 24 / 07 \\ \text { By : Dan Jakube } & \end{array}$

Rev No: 0



192 Mat' Allowance - Est sml tools \& misc. 
PROPRIETARY INFORMATION
Data funished in connection with this proposal shall not be disclosed outside WCH approval, and shall not be duplicated, used, or discussed for any purpose other than to evaluate the proposal.

WASHINGTON CLOSURE HANFORD, INC ESTIMATE PRICING SHEET N UP PROJECT RICHLAND, WASHINGTON
TITLE: 300 Area Utility Repacement Project - Electrical - Option \#3 SUBJECT: 2.0 Feed Fron Richland \& 400 Area

* Rework Power Feeds At 5 Loc. Inside 300 Area

* Route Power From SHC SubSt. To 300 Area South

* Route Power From 400 Area To 300 Area North End
Estimate No: 1004-Elect-Opt\#3

Date: $04 / 24 / 07$

By: Dan Jak

Date: $05 / 16107$

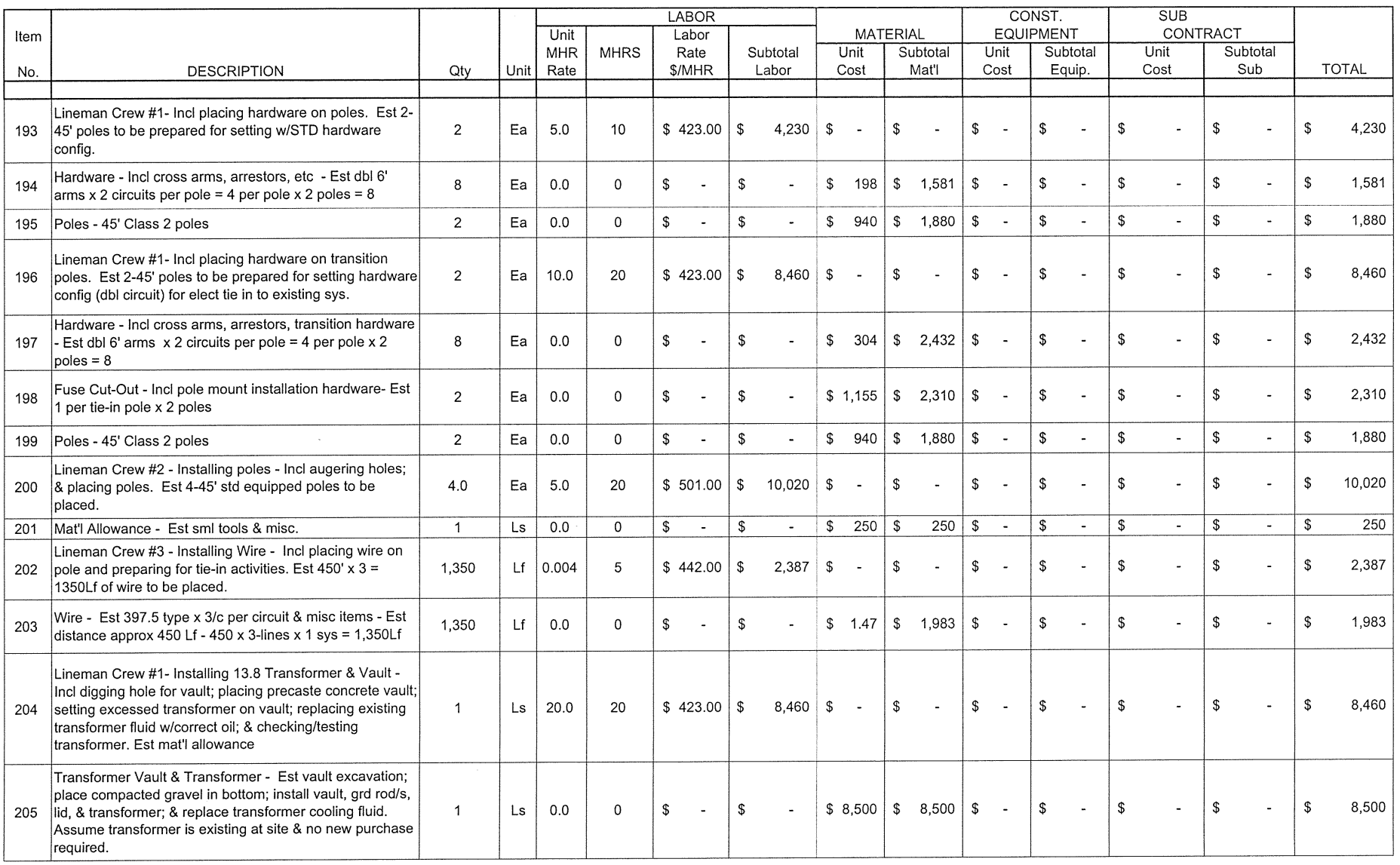

Page 17 of 21

$5 / 16 / 2007$ 
PROPRETARY INFORMATION
Data funished in connection with this proposal shall not be disclosed outside WCH approval, and shall not be duplicated, used, or ciscussed for any purpose other than to evaluate the proposal.

WASHINGTON CLOSURE HANFORD, INC ESTIMATE PRICING SHEET RIVER CORRIDOR CLEAN UP PROJECT RICHLAND, WASHINGTON
TITLE: 300 Area Utility Repacement Project - Electrical - Option \#3 SUBJECT: 2.0 Feed Fron Richland \& 400 Area

* Rework Power Feeds At 5 Loc. Inside 300 Area

* Route Power From SHC SubSt. To 300 Area South

* Route Power From 400 Area To 300 Area North End
Estimate No: 1004-Elect-Optts

Date : 04/24/07

By: Dan Jakubek

Dev : 0

Date: $05 / 16 / 07$

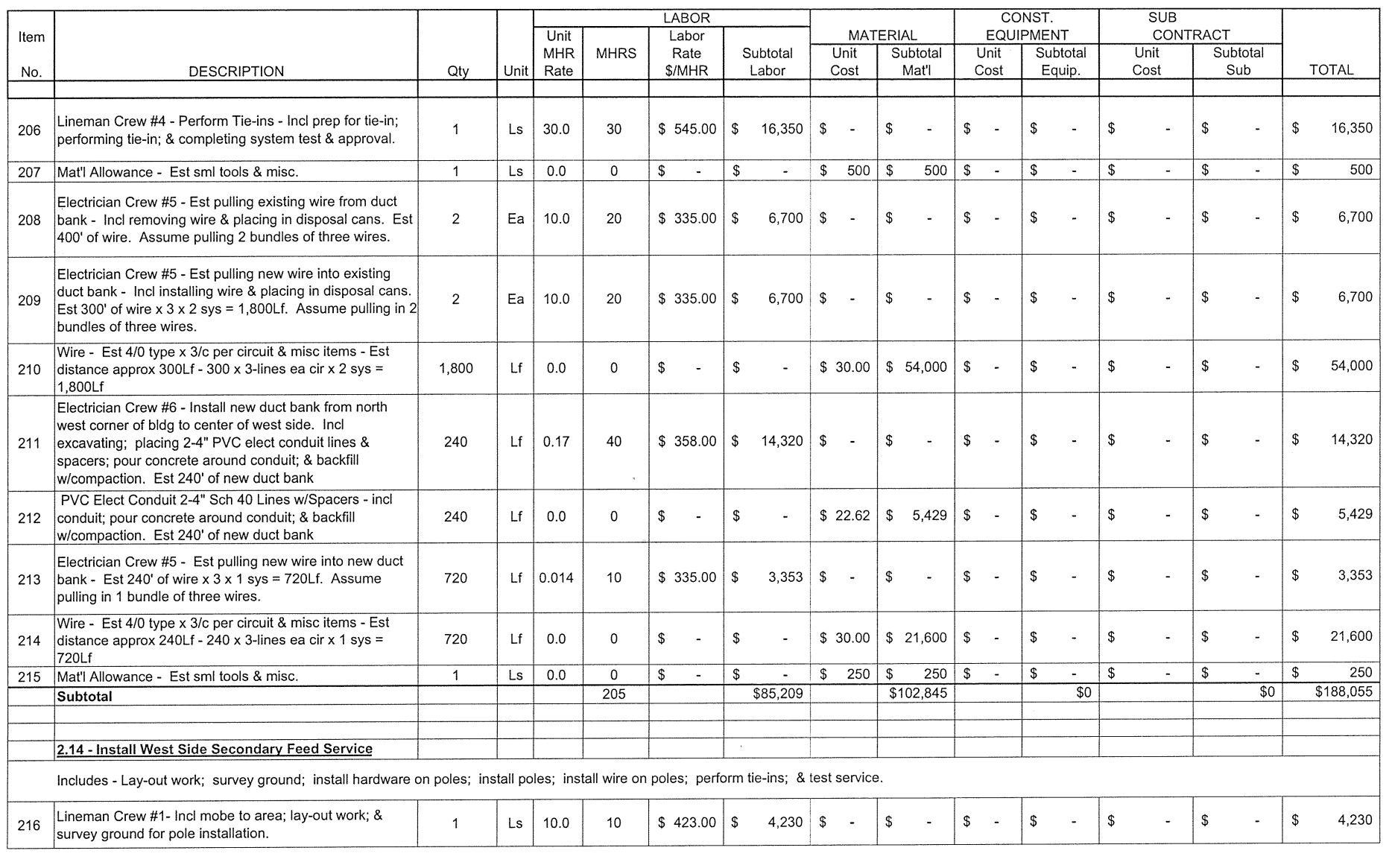

Page 18 of 21

$5 / 16 / 2007$ 
PROPRIETARY INFORMATION
Data furished in connection with this proposal shall not be disclosed outside WCH approval, and shall not be duplicated, used, or ciscussed for any purpose other than to evaluate the proposal.

WASHINGTON CLOSURE HANFORD, INC. ESTIMATE PRICING SHEET RIVER CORRIDOR CLEAN UP PROJECT RICHLAND, WASHINGTON
TITLE: 300 Area Utility Repacement Project - Electrical - Option \#3 SUBJECT: 2.0 Feed Fron Richland \& 400 Area

* Rework Power Feeds At 5 Loc. Inside 300 Area

* Rework Power Feeds At 5 Loc. Inside 300 Area

* Route Power From 400 Area To 300 Area North End
Estimate No: $1004-$ Elect-Opt\#3

Date : $04 / 24 / 07$

By: Dan Jakubek

0511007

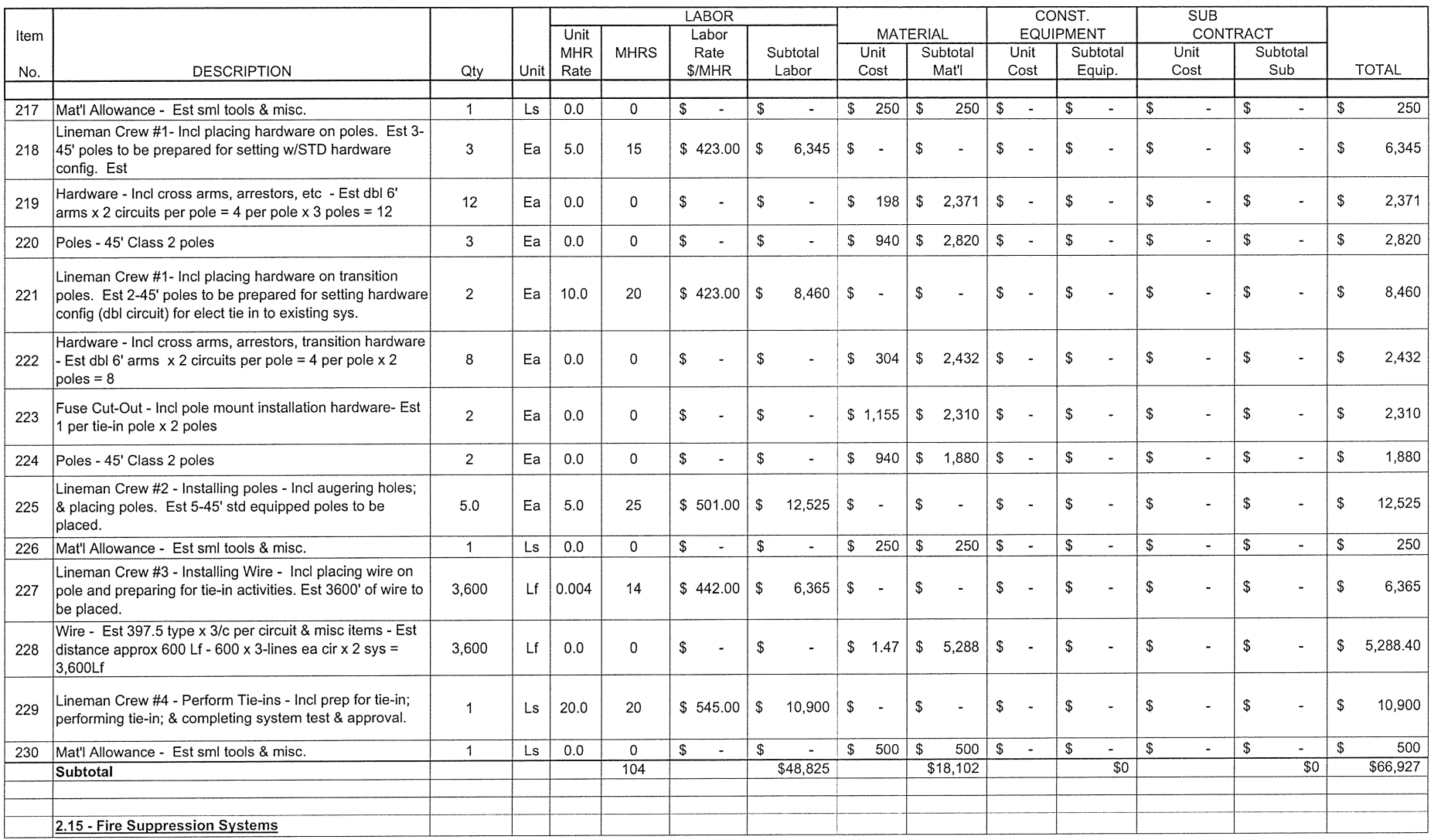


PROPRIETARY INFORMATION
Data furished in connection with this proposal shall not be disclosed outside WCH approval, and shall not be duplicated, used, or discussed for any purpose other than to evaluate the proposal.

WASHINGTON CLOSURE HANFORD, INC ESTIMATE PRICING SHEET UP PROJECT RICHLAND, WASHINGTON
TITLE: 300 Area Utility Repacement Project - Electrical - Option \#3 SUBJECT: 2.0 Feed Fron Richland \& 400 Area

* Rework Power Feeds At 5 Loc. Inside 300 Area

* Route Power From SHC SubSt. To 300 Area South

* Route Power From 400 Area To 300 Area North End
Estimate No: 1004-Elect-Opt\#3

Date : $04 / 24 / 07$

By: Dan Jakubek

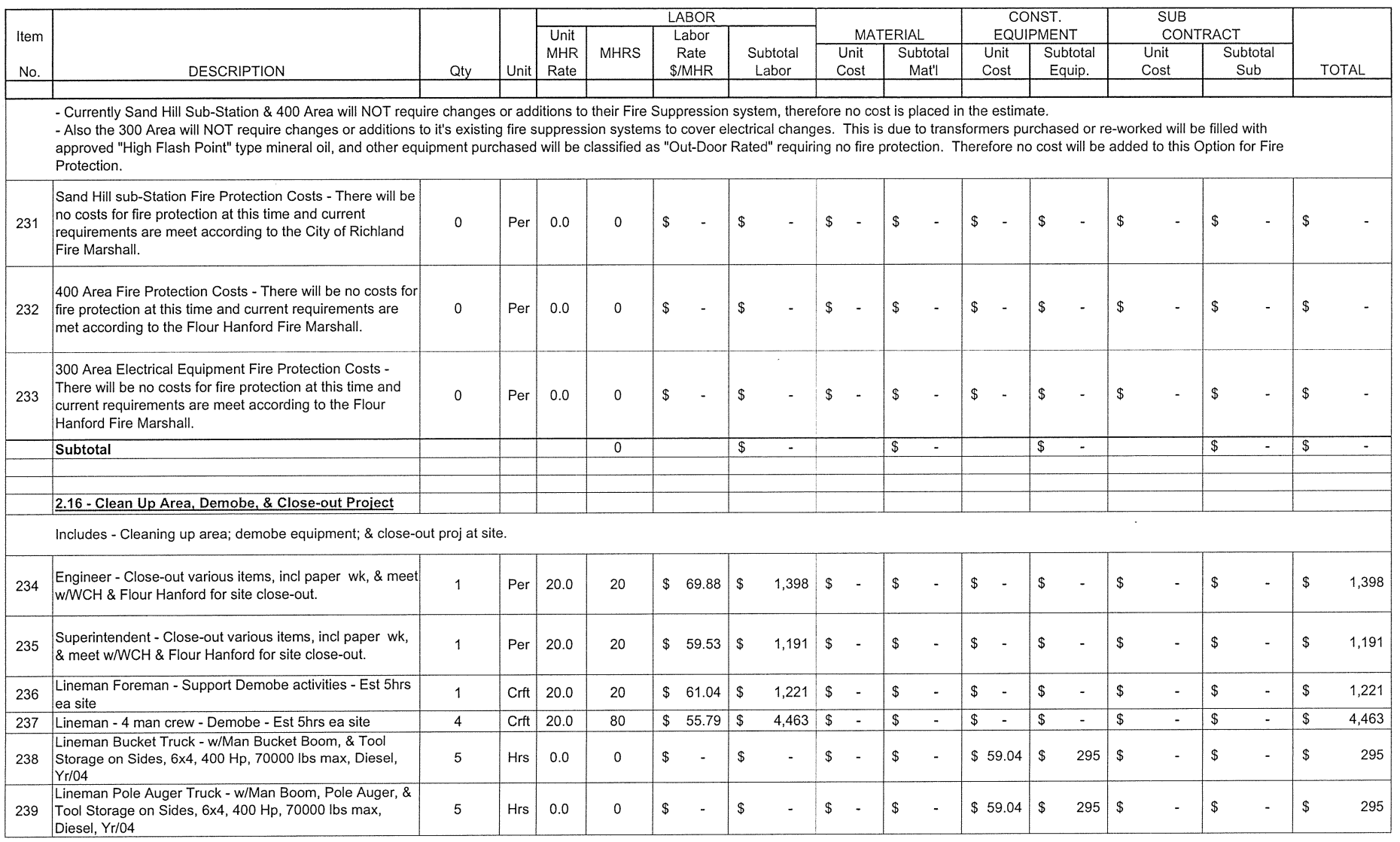


PROPRIETARY INFORMATION
Data funnished in connection with this proposal shall not be disclosed outside WCH approval, and shall hot be dup

Data fumished in connection with his proposal shall not be disclosed outside WCH approval, and shall not be duplicated, used, or ciscussed for any purpose other than to evaluate the proposal

WASHINGTON CLOSURE HANFORD, INC ESTIMATE PRICING SHEET RIVER CORRIDOR CLEAN UP PROJECT RICHLAND, WASHINGTON
TITLE: 300 Area Utility Repacement Project - Electrical - Option \#3 SUBJECT: 2.0 Feed Fron Richland \& 400 Area

$*$ Rework Power Feeds At 5 Loc. Inside 300 Area

* Route Power From SHC SubSt. To 300 Area South

* Route Power From 400 Area To 300 Area North End
Estimate No: 1004-Elect-Opttus

Date : $04 / 24 / 07$

By : Dan Jakubek

Nov: 0

Note : $05 / 16 / 07$

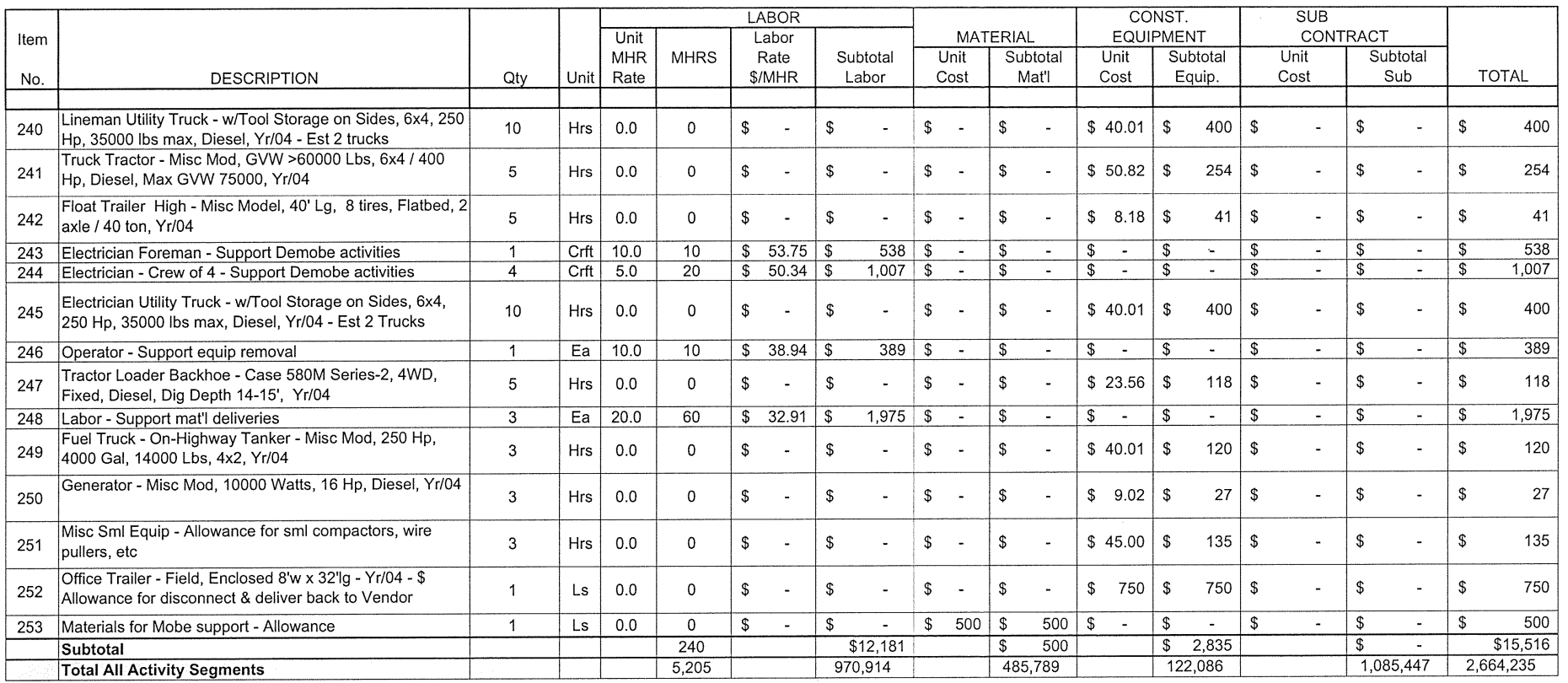


Dataf funished in connection with this proposal shall not be disclosed outside WCH appriETARYl, and shall not be duplicated, used, or discussed for any purpose other than to evaluate the proposal.

WASHINGTON CLOSURE HANFORD, INC. ESTIMATE PRICING SHEET

RIVER CORRIDOR CLEAN UP PROJECT RICHLAND, WASHINGTON
TITLE: 300 Area Utility Repacement Project - Electrical - Option \#4 SUBJECT: 2.0 Two Lines From Richland / Auto Transformers $*$ Rework Power Feeds At 5 Loc. Inside 300 Area $*$ Route Power From SHC Subst.
Estimate No: $1004-$ Elect-Optt4

Date: $04 / 18 / 07$

By: Dan Jakubek

$05 / 16107$

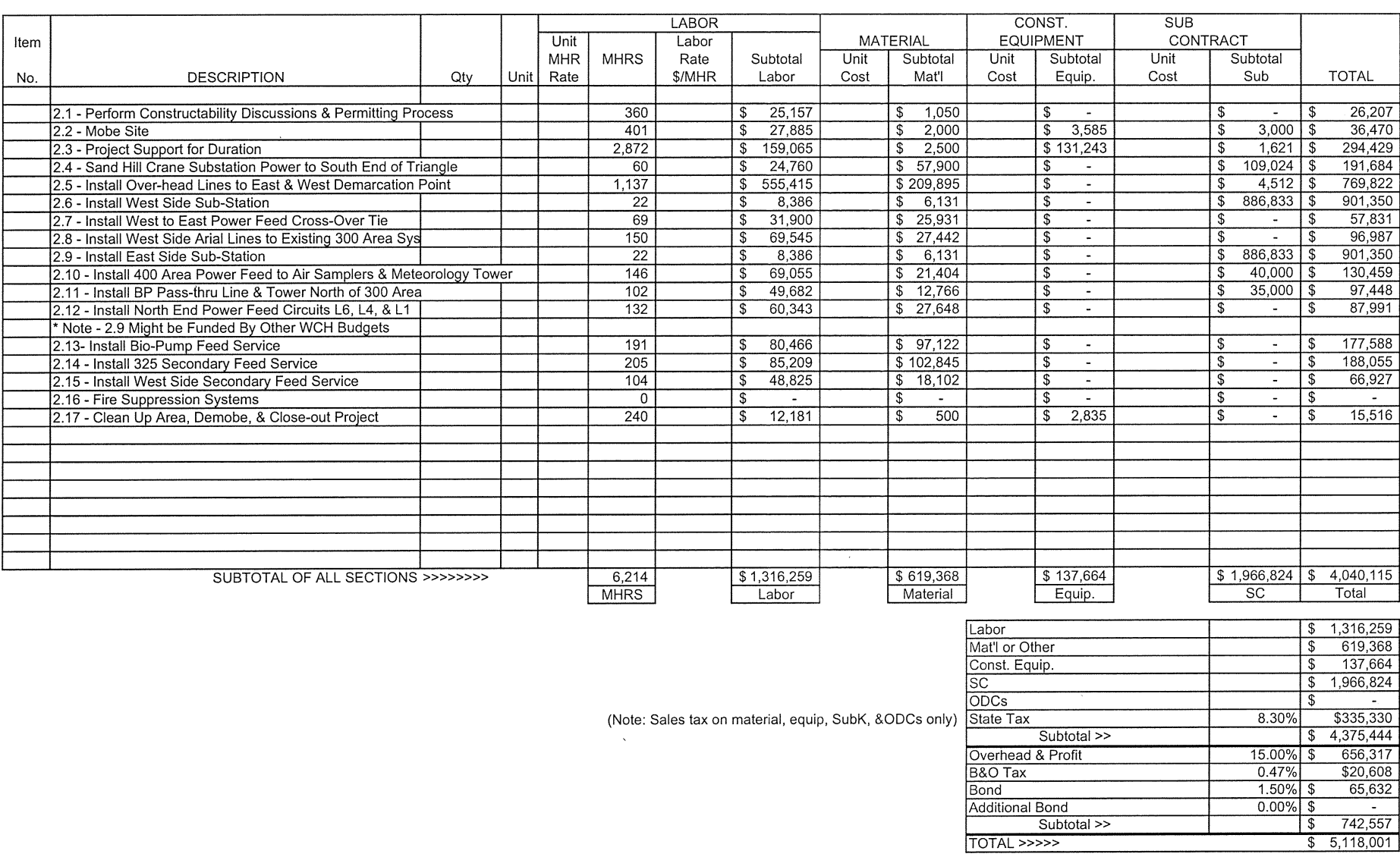


PROPRIETARY INFORMATION

TITLE: 300 Area Utility Repacement Project - Electrical - Option \#4 SUBJECT: 2.0 Two Lines From Richland / Auto Transformers

* Rework Power Feeds At 5 Loc. Inside 300 Area

* Route Power From SHC SubSt. To 300 Area South
Estimate No: 1004-Elect-Optth

Date : $04 / 18 / 07$

By : Dan Jakubek

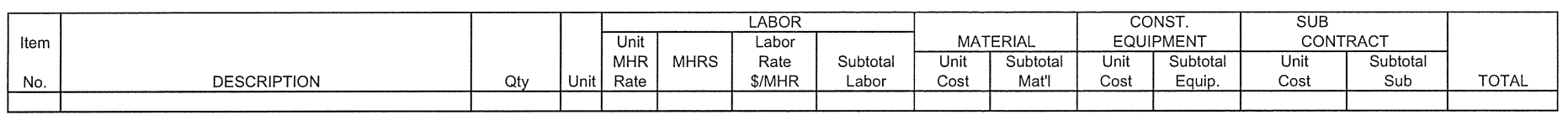

\begin{tabular}{|l|l|l|l|l|l|l|l|l|l|l|l|}
\hline 2.1. Perform Constructability Discussions \& Permitting Process & & & & & & & & &
\end{tabular} Includes activities such as: SubK perform constructability reviews for each system segment with approval organizations (Flour Hanford, PNNL, \& DOE, ; SubK perform construction start-up approval documentation \& work packages; \& develop procurement contracts.

SubK Meetings w/WCH, Flour Hanford, Others \& Discuss

develop schedule, procurements, etc: meet wWWCH \&

FH for discussing scope; prepare/review construction permitting docs. - Est 3 Design/Mgr personnel $\times 3$ wks \& mat'l allowance. Subtotal

2.2-Mobe Site

Includes personnel training, set up equipment, layout and survey area, \& prepare for construction activities. Est majority of equipment owned by SubK w/other pcs available in surrounding area with in 100 miles.

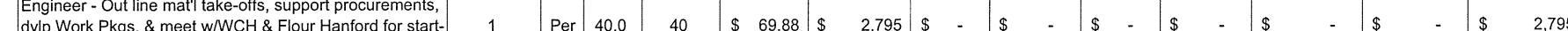
dvlp Work Pkgs, \& meet w/WCH \& Flour Hanford for startSuperintendent - Support mat'l take-offs, procurements, Surveyors - Used Fld Support Eng rate - 2 man crew 4 40hrs

Training Budget - Estimated amount for Subcontractor

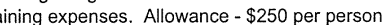

Training Labor - Estimated 8hrs per person to go thru sit training. See Training wk shts for Labor costs.

Lineman - 4 man crew - Mobe

Lineman Bucket Truck - w/Man Bucket Boom, \& Tool Storage on Sides, $6 \times 4,400 \mathrm{Hp}, 70000$ lbs max, Diese Yr/04

Yrou

Tool Storage on Sides, $6 \times 4,400 \mathrm{Hp}, 70000$ lbs max,

Lineman Utility Truck - w/Tool Storage on Sides, 6x4, 250

\begin{tabular}{|l|l|l|l|l|lll|ll|ll|ll|ll|lll|lllll}
1 & $\operatorname{Per}$ & 40.0 & 40 & $\$$ & 69.88 & $\$$ & 2,795 & $\$$ & - & $\$$ & - & $\$$ & - & $\$$ & - & $\$$ & - & $\$$ & - & $\$$ & 2,795 \\
\hline
\end{tabular}

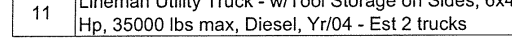

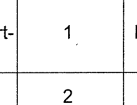

\begin{tabular}{llllllllllllll|lllllllllll} 
& 40.0 & 40 & $\$$ & 59.53 & $\$$ & 2,381 & $\$$ & - & $\$$ & - & $\$$ & - & $\$$ & - & $\$$ & - & $\$$ & - & $\$$ & 2,381
\end{tabular} \begin{tabular}{|c|c|c|c|cc|cccc|cc|cc|cc|cc|cc|cc}
\hline 12 & Ea & 0.0 & 0 & $\$$ & - & $\$$ & - & $\$$ & - & $\$$ & - & $\$$ & - & $\$$ & - & $\$$ & 250.00 & $\$$ & 3,000 & $\$$ & 3,000
\end{tabular}

\begin{tabular}{|l|l|l|l|llllll|ll|ll|ll|lll|ll|ll}
1 & Ls & 0.0 & 1 & $\$$ & 6,451 & $\$$ & 6,451 & $\$$ & - & $\$$ & - & $\$$ & - & $\$$ & - & $\$$ & - & $\$$ & - & $\$$ & 6,451 \\
\hline
\end{tabular}

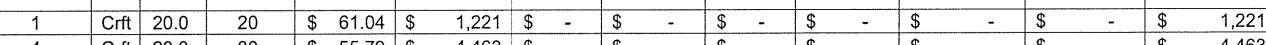

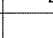

\begin{tabular}{l|l|l|l|ll|lllll|ll|l|ll|lll|ll|lr}
5 & Hrs & 0.0 & 0 & $\$$ & - & $\$$ & - & $\$$ & - & $\$$ & - & $\$ 59.04$ & $\$$ & 295 & $\$$ & - & $\$$ & - & $\$$ & 295 \\
\hline 5 & Hrs & 0.0 & 0 & $\$$ & - & $\$$ & - & $\$$ & - & $\$$ & - & $\$ 59.04$ & $\$$ & 295 & $\$$ & - & $\$$ & - & $\$$ & 295 \\
\hline
\end{tabular}

\begin{tabular}{|l|l|l|l|}
\hline 10 & Hrs & 0.0 \\
\hline
\end{tabular}

$$
\text { Page } 2 \text { of } 23
$$


PROPRIETARY INFORMATION
Data furished in connection with this proposal shall not be disclosed outside WCH approval, and shall not be duplicated, used, or ciscussed for any purpose other than to evaluate the proposal.

WASHINGTON CLOSURE HANFORD, INC. ESTIMATE PRICING SHEET RIVER CORRIDOR CLEAN UP PROJECT RICHLAND, WASHINGTON
TITLE: 300 Area Utility Repacement Project - Electrical - Option \#4 SUBJECT: 2.0 Two Lines From Richland / Auto Transformers

* Rework Power Feeds At 5 Loc. Inside 300 Area

* Route Power From SHC SubSt. To 300 Area South
Estimate No : 1004-Elect-Opt\#4

Date : $04 / 18 / 07$

By: Dan Jakubek

$05 / 16107$

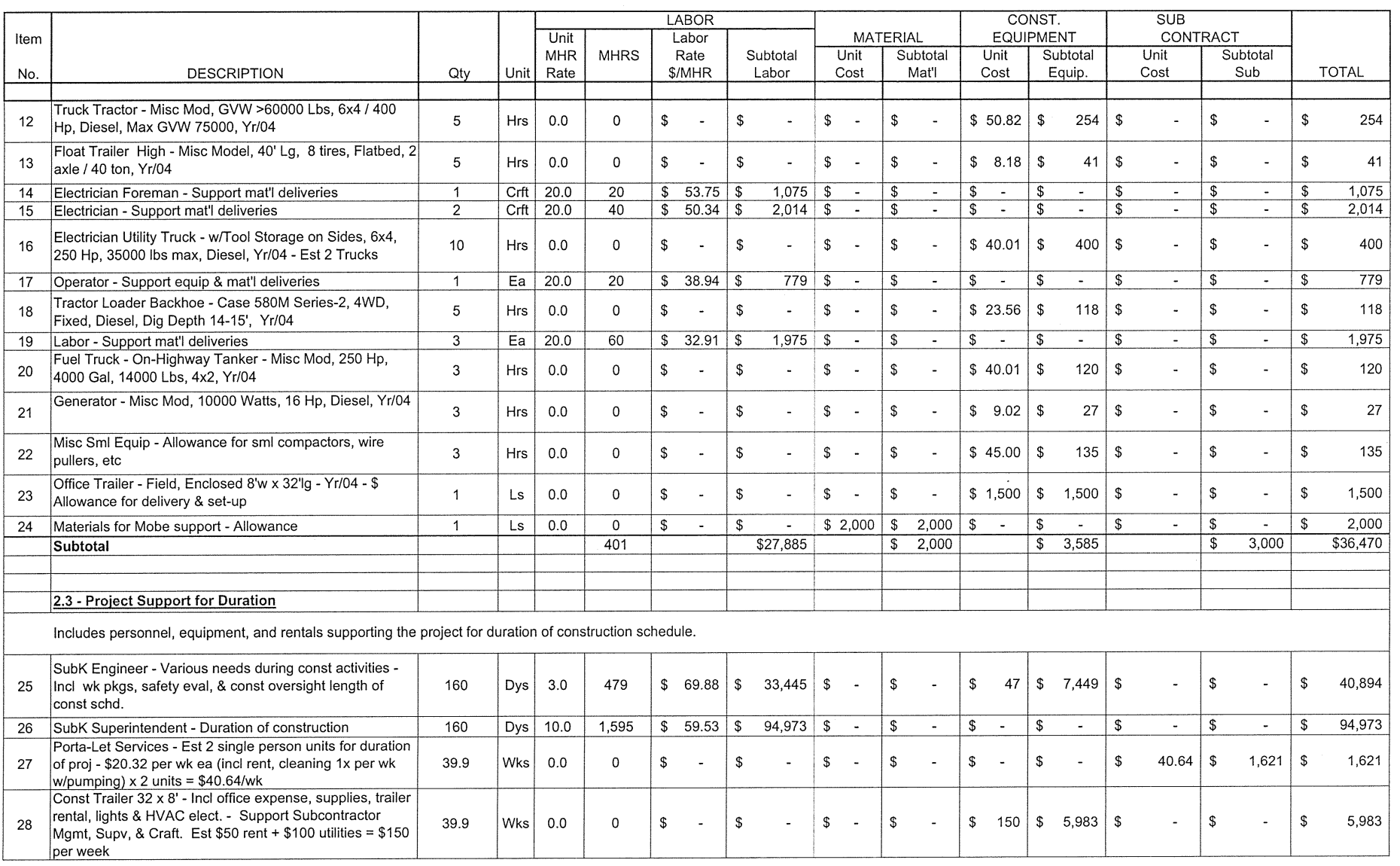


PROPRIETARY INFORMATION
Data furished in connection with this proposal shall not be disclosed outside WCH approval, and shall not be dupicated, used, or discussed for any purpose other than to evaluate the proposal.

WASHINGTON CLOSURE HANFORD, INC. ESTIMATE PRICING SHEET RIVER CORRIDOR CLEAN UP PROJECT RICHLAND, WASHINGTON
TITLE: 300 Area Utility Repacement Project - Electrical - Option \#4 SUBJECT: 2.0 Two Lines From Richland / Auto Transformers

* Rework Power Feeds At 5 Loc. Inside 300 Area

* Route Power From SHC SubSt. To 300 Area South
Estimate No: 1004-Elect-Opt\#4

Date: $04 / 18 / 07$

By: Dan Jakubek

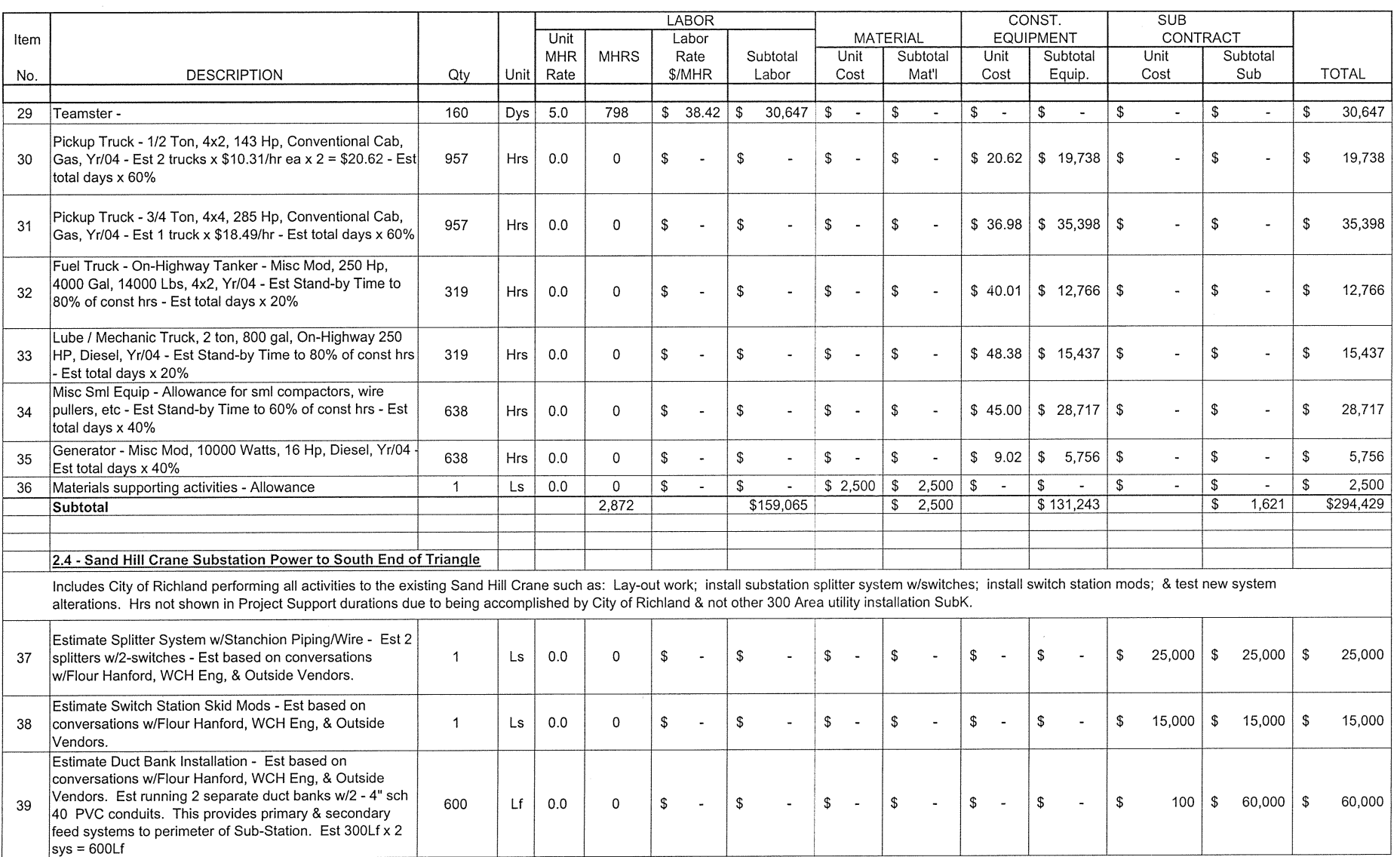


PROPRIETARY INFORMATION
Data funnished in connection with this proposal shall not be disclosed outside WCH approval, and shall not be duplicated, used, or discussed for any purpose other than to evaluate the proposal.

WASHINGTON CLOSURE HANFORD, INC ESTIMATE PRICING SHEET

RIVER CORRIDOR CLEAN UP PROJECT RICHLAND, WASHINGTON
TITLE: 300 Area Utility Repacement Project - Electrical - Option \#4 SUBJECT: 2.0 Two Lines From Richland / Auto Transformers

* Rework Power Feeds At 5 Loc Inside 300 Area

* Route Power From SHC SubSt. To 300 Area South
Estimate No: $1004-$ Elect-Opt\#4

Date: $04 / 18 / 07$

By: Dan Jakubek

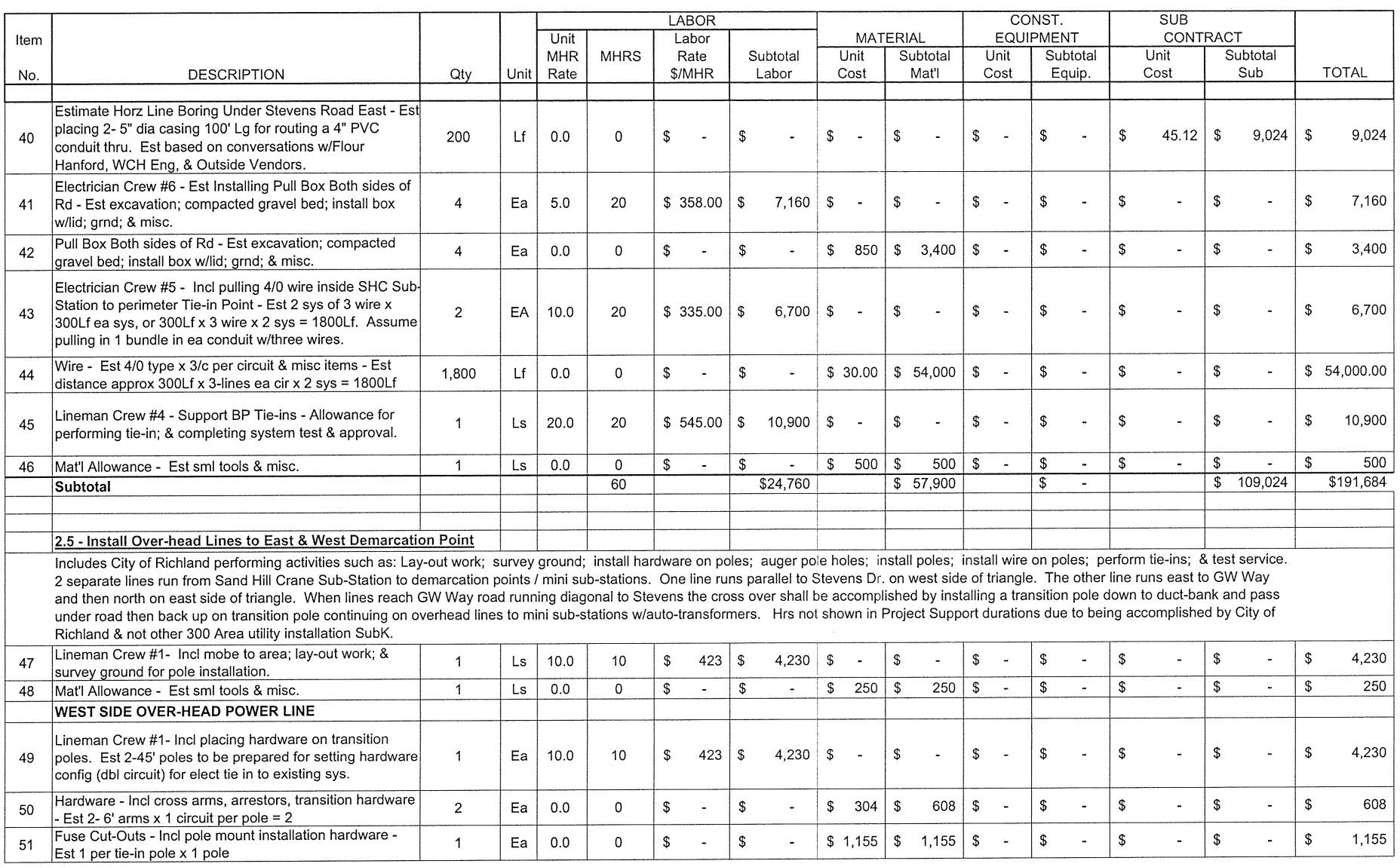


PROPRIETARY INFORMATION
Data funnished in connection with this proposal shall not be disclosed outside WCH approval, and shall not be duplicated, used, or discussed for any purpose other than to evaluate the proposal.

WASHINGTON CLOSURE HANFORD, INC. ESTIMATE PRICING SHEET RIVER CORRIDOR CLEAN UP PROJECT RICHLAND, WASHINGTON
TITLE: 300 Area Utility Repacement Project - Electrical - Option \#4 SUBJECT: 2.0 Two Lines From Richland / Auto Transformers * Rework Power Feeds At 5 Loc. Inside 300 Area * Route Power From SHC SubSt. To 300 Area South
Estimate No: 1004-Elect-Opt\#4

Date: $04 / 18 / 07$

By: Dan Jakubek

Rev No: 0

051107

\begin{tabular}{|c|c|c|c|c|c|c|c|c|c|c|c|c|c|c|c|c|c|c|c|}
\hline \multirow[b]{2}{*}{$\begin{array}{l}\text { Item } \\
\text { No. }\end{array}$} & \multirow[b]{2}{*}{ DESCRIPTION } & \multirow[b]{2}{*}{ Qty } & \multirow[b]{2}{*}{ Unit } & \multicolumn{5}{|c|}{$\angle A B O R$} & \multicolumn{2}{|c|}{ MATERIAL } & \multicolumn{3}{|c|}{$\begin{array}{c}\text { CONST. } \\
\text { EQUIPMENT }\end{array}$} & \multicolumn{4}{|c|}{$\begin{array}{l}\text { SUB } \\
\text { CONTRACT }\end{array}$} & & \multirow[b]{2}{*}{ TOTAL } \\
\hline & & & & $\begin{array}{l}\text { Unit } \\
\text { MHR } \\
\text { Rate }\end{array}$ & MHRS & $\begin{array}{c}\text { Labor } \\
\text { Rate } \\
\text { \$/MHR }\end{array}$ & & $\begin{array}{l}\text { ubtotal } \\
\text {-abor }\end{array}$ & $\begin{array}{l}\text { Unit } \\
\text { Cost }\end{array}$ & $\begin{array}{l}\text { Subtotal } \\
\text { Mat"l }\end{array}$ & $\begin{array}{l}\text { Un } \\
\text { Un } \\
\cos \end{array}$ & & $\begin{array}{l}\text { Subtotal } \\
\text { Equip. }\end{array}$ & & $\begin{array}{l}\text { Unit } \\
\text { Cost }\end{array}$ & & $\begin{array}{l}\text { Tubtotal } \\
\text { Sub }\end{array}$ & & \\
\hline 52 & Poles $45^{\prime} \mathrm{Cosc} 2$ oles & & $E_{0}$ & م0 & 0 & 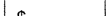 & $s$ & & 8090 & 940 & 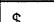 & & $\sigma_{0}$ & 5 & $x^{2}$ & 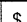 & & $\$$ & 940 \\
\hline 53 & $\begin{array}{l}\text { Lineman Crew \#2 - Installing poles - Incl augering holes; } \\
\text { \& placing poles. Est 1-45' poles to be placed. }\end{array}$ & 1 & Ea & 5.0 & 5 & $\$ \quad 501$ & $\$$ & 2,505 & $\$$. & $\$$ & $\$$ & & - & $\$$ & - & $\$$ & - & $\$$ & 2,505 \\
\hline 54 & Mat'l Allowance - Est sml tools \& misc. & 1 & Ls & 0.0 & 0 & $\$$ & $\$$ & - & $\$ 250$ & 250 & $\$$ & & - & $\$$ & - & $\$$ & - & $\$$ & 250 \\
\hline 55 & $\begin{array}{l}\text { Lineman Crew \#1- Incl placing hardware on poles. Est } 1 \\
\text { pole every } 150^{\prime \prime} \text {. Est distance for west side over-head line } \\
@ 5280^{\prime} \text {; or } 5280 / 150=35 \text { poles to be prepared for } \\
\text { setting w/STD hardware config. }\end{array}$ & 35 & Ea & 5.0 & 175 & $\$ 501$ & $\$$ & 87,675 & $\$$ & $\$$ & $\$$ & & - & $\$$ & - & $\$$ & - & $\$$ & 87,675 \\
\hline 56 & $\begin{array}{l}\text { Hardware - Incl cross arms, arrestors, transition hardware } \\
\text { - Est 2- } 6^{\prime} \text { arms } \times 1 \text { circuit } w / 3 \text { lines per pole } \times 35 \text { poles }= \\
70 \text { cross-arms }\end{array}$ & 70 & Ea & 0.0 & 0 & $\$$ & $\$$ & - & $\$ 304$ & $\$ 21,280$ & $\$$ & & - & $\$$ & - & $\$$ & - & $\$$ & 21,280 \\
\hline 57 & Poles - $45^{\prime}$ Class 2 poles & 35 & Ea & 0.0 & 0 & $\$$ & $\$$ & - & $\$ 940$ & $\$ 32,900$ & $\$$ & & - & $\$$ & - & $\$$ & - & $\$$ & 32,900 \\
\hline 58 & $\begin{array}{l}\text { Lineman Crew \#2 - Installing poles - Incl augering holes; } \\
\text { \& placing poles. Est } 35 \text { - } 45^{\prime} \text { poles to be placed. }\end{array}$ & 35 & Ea & 5.0 & 175 & $\$ 501$ & $\$$ & 87,675 & $\$-$ & $\$$ & $\$$ & & - & $\$$ & - & $\$$ & - & $\$$ & 87,675 \\
\hline 59 & $\begin{array}{l}\text { Estimate Horz Line Boring Under GW Way Diagonal Rd - } \\
\text { Est placing a 5" dia casing } 100^{\prime} \text { Lg for placing a 4" PVC } \\
\text { conduit thru. Est based on conversations w/Flour } \\
\text { Hanford, WCH Eng, \& Outside Vendors. }\end{array}$ & 50 & Lf & 0.0 & 0 & $\$$ & $\$$ & - & $\$$ & $\$$ & $\$$ & & - & $\$$ & 45.12 & $\$$ & 2,256 & $\$$ & 2,256 \\
\hline 60 & $\begin{array}{l}\text { Electrician Crew \#6 - Estimate Connecting Transition Pole } \\
\text { 4 RGS Conduit to Pull Boo on both side of GW Way Rd. } \\
\text { On other side of rd back into another pull box \& into 4" } \\
\text { RGS conduit back up a transition pole. Est } 4 \text { " sch } 40 \text { PVC } \\
\text { from pull box thru rd sleeve to far side pull box. }\end{array}$ & 70 & Lf & 0.1 & 5 & $\$ 358.00$ & $\$$ & 1,790 & $\$-$ & $\$$ & $\$$ & & - & $\$$ & - & $\$$ & - & $\$$ & 1,790 \\
\hline 61 & $\begin{array}{l}\text { PVC Elect Conduit 1-4" Sch } 40 \text { Line w/Spacers - incl } \\
\text { conduit; pour concrete as needed around conduit \& pull } \\
\text { box; \& backfill w/compaction. Est } 70^{\prime} \text { of conduit }\end{array}$ & 70 & Lf & 0.0 & 0 & $\$$ & $\$$ & - & $\$ 15.83$ & $\$ \quad 1,108$ & $\$$ & & - & $\$$ & - & $\$$ & - & $\$$ & 1,108 \\
\hline 62 & $\begin{array}{l}\text { Electrician Crew \#6 - Est Installing Pull Box Both sides of } \\
\text { Rd - Est excavation; compacted gravel bed; install box } \\
\text { w/lid; grnd; \& misc. }\end{array}$ & 2 & Ea & 5.0 & 10 & $\$ 358.00$ & $\$$ & 3,580 & $\$$ & $\$$ & $\$$ & & - & $\$$ & - & $\$$ & - & $\$$ & 3,580 \\
\hline 63 & $\begin{array}{l}\text { Pull Box Both sides of Rd - Est excavation; compacted } \\
\text { gravel bed; install box w/lid; grnd; \& misc. }\end{array}$ & 2 & Ea & 0.0 & 0 & $\$$ & $\$$ & - & $\$ 850$ & $\$ \quad 1,700$ & $\$$ & & - & $\$$ & - & $\$$ & - & $\$$ & 1,700 \\
\hline 64 & 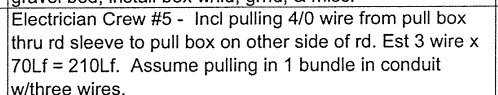 & 1 & Ea & 5.0 & 5 & $\$ 335.00$ & $\$$ & 1,675 & $\$ 850$ & 850 & $\$$ & & - & $\$$ & - & $\$$ & - & $\$$ & 2,525 \\
\hline 65 & $\begin{array}{l}\text { Wire - Est } 4 / 0 \text { type } \times 3 / \mathrm{c} \text { per circuit \& misc items - Est } \\
\text { distance aporo } 70 \mathrm{Lf} \times 3 \text {-lines }=210 \mathrm{Lf}\end{array}$ & 210 & Lf & 0.0 & 0 & $\$$ & $\$$ & $\begin{array}{lll}- & - \\
\end{array}$ & $\$ 30.00$ & $\$ \quad 6,300$ & $\$$ & & - & $\$$ & - & $\$$ & - & $\$$ & 6,300 \\
\hline
\end{tabular}


PROPRIETARY INFORMATION
Data funished in connection with this proposal shall not be disclosed outside WCH approval, and shall not be duplicated, used, or discussed for any purpose other than to evaluate the proposal.

WASHINGTON CLOSURE HANFORD, INC ESTIMATE PRICING SHEET N UP PROJECT RICHLAND, WASHINGTON
TITLE: 300 Area Utility Repacement Project - Electrical - Option \#4 SUBJECT: 2.0 Two Lines From Richland / Auto Transformers

* Rework Power Feeds At 5 Loc. Inside 300 Area

* Route Power From SHC SubSt. To 300 Area South
Estimate No: 1004-Elect-Opt\#4

Date: $04 / 18 / 07$

By : Dan Jakubek

\begin{tabular}{|c|c|c|c|c|c|c|c|c|c|c|c|c|c|c|c|c|c|c|c|}
\hline \multirow[b]{2}{*}{ Item } & \multirow[b]{2}{*}{ DESCRIPTION } & \multirow[b]{2}{*}{ Qty } & \multirow[b]{2}{*}{ Unit } & \multirow[b]{2}{*}{\begin{tabular}{|c|} 
Unit \\
MHR \\
Rate \\
\end{tabular}} & \multirow[b]{2}{*}{ MHRS } & $\frac{\text { LABOR }}{\text { Labor }}$ & & & \multicolumn{2}{|c|}{ MATERII } & \multicolumn{3}{|c|}{$\begin{array}{l}\text { CONST. } \\
\text { EQUIPMENT }\end{array}$} & \multicolumn{4}{|c|}{$\begin{array}{l}\text { SUB } \\
\text { CONTRACT }\end{array}$} & & \multirow[b]{2}{*}{ TOTAL } \\
\hline & & & & & & $\begin{array}{l}\text { Labor } \\
\text { Rate } \\
\text { \$/MHR } \\
\end{array}$ & & $\begin{array}{l}\text { ubtotal } \\
\text { abor }\end{array}$ & $\begin{array}{l}\text { MAI } \\
\text { Unit } \\
\text { Cost } \\
\end{array}$ & \begin{tabular}{|c|} 
Sula \\
Subtotal \\
Mat'I
\end{tabular} & $\begin{array}{l}\frac{\mathrm{EC}}{\mathrm{U}} \\
\text { Unit } \\
\text { Cos }\end{array}$ & & $\begin{array}{l}\text { Sult } \\
\text { Subtotal } \\
\text { Equip. }\end{array}$ & & $\begin{array}{l}\text { con } \\
\text { Unit } \\
\text { ost }\end{array}$ & & & & \\
\hline 66 & $\begin{array}{l}\text { Lineman Crew \#4 - Perform Tie-ins - Incl prep for tie-in; } \\
\text { performing tie-in; \& completing system test \& approval. }\end{array}$ & 1 & Ls & 10.0 & 10 & $\$ 545.00$ & $\$$ & 5,450 & $\$-$ & $\$$ & $\$$ & $\$$ & - & 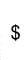 & - & $\$$ & - & $\$$ & 5,450 \\
\hline 67 & Mat' Allowance - Est sml tools \& misc. & 1 & Ls & 0.0 & 0 & - & $\$$ & - & $\$ \quad 250$ & 250 & $\$$ & $\$$ & - & & - & $\$$ & - & & \\
\hline 68 & $\begin{array}{l}\text { Lineman Crew \#1- Incl placing hardware on transition } \\
\text { pole. Est } 1-45^{\prime} \text { poles to be prepared for setting hardware } \\
\text { config (dbl circuit) for elect tie in to existing sys. }\end{array}$ & 1 & Ea & 10.0 & 10 & $\$ 423$ & $\$$ & 4,230 & $\$-$ & $\$$ & $\$$ & $\$$ & & $\$$ & - & $\$$ & - & $\$$ & 4,230 \\
\hline 69 & $\begin{array}{l}\text { Hardware }- \text { Incl cross arms, arrestors, transition hardware } \\
- \text { Est } 2-6^{\prime} \text { arms } \times 1 \text { circuit per pole }=2\end{array}$ & 2 & $\mathrm{Ea}$ & 0.0 & 0 & $\$$ & $\$$ & - & $\$ 304$ & 608 & $\$-$ & $\$$ & - & $\$$ & - & $\$$ & - & $\$$ & 608 \\
\hline 70 & $\begin{array}{l}\text { Fuse Cut-Outs - Incl pole mount installation hardware - } \\
\text { Est } 1 \text { per tie-in pole x } 1 \text { pole }\end{array}$ & 1 & $\mathrm{Ea}$ & 0.0 & 0 & $\$$ & $\$$ & - & $\$ 1,155$ & $\$ \quad 1,155$ & $\$$ & $\$$ & - & $\$$ & - & $\$$ & - & $\$$ & 1,155 \\
\hline 71 & Poles - $45^{\prime}$ Class 2 poles & 1 & $\mathrm{Ea}$ & 0.0 & 0 & $\$$ & $\$$ & - & $\$ 940$ & 940 & $\$$ & $\$$ & b & $\$$ & - & $\$$ & $\cdot$ & $\$$ & \\
\hline 72 & $\begin{array}{l}\text { Lineman Crew \#2 - Installing poles - Incl } \\
\& \text { placing poles. Est 1-45' pole to be pla }\end{array}$ & 1 & $\mathrm{Ea}$ & 5.0 & 5 & $\$ 501$ & $\$$ & 2,505 & $\$$ & $\$$ & $\$$. & $\$$ & - & $\$$ & - & $\$$ & - & $\$$ & 2,505 \\
\hline 73 & Mat'l Allowance - Est sml tools \& misc. & 1 & Ls & 0.0 & 0 & $\$$ & $\$$ & - & $\$ \quad 250$ & 250 & $\$-$ & $\$$ & - & $\$$ & - & $\$$ & - & $\$$ & 250 \\
\hline 74 & $\begin{array}{l}\text { Lineman Crew \#3 - Installing Wire - Incl placing wire on } \\
\text { pole and preparing for tie-in activities. Incl pulling } 397.5 \\
\text { wire from south end of triangle to mini sub-station - Est } 1 \\
\text { sys of } 3 \text { wire } \times 5280 \mathrm{Lf}(1 \text { mile })=15,840 \mathrm{Lf} \text {. }\end{array}$ & 15,840 & Lf & 0.004 & 63 & $\$ 442$ & $\$$ & 28,005 & $\$-$ & $\$$ & $\$-$ & $\$$ & - & $\$$ & - & $\$$ & - & $\$$ & 28,005 \\
\hline 75 & $\begin{array}{l}\text { Wire - Est } 397.5 \text { type } \times 3 / \mathrm{c} \text { per circuit \& misc items }- \text { Est } \\
\text { distance approx } 5280 \mathrm{Lf}(1 \mathrm{mile}) \times 3 \text {-lines ea cir }=15,840 \mathrm{Lf}\end{array}$ & 15,840 & Lf & 0.0 & 0 & $\$$ & & $\$ 0$ & $\$ 1.47$ & $\$ 5,288$ & $\$$ & $\$$ & & \$ & - & $\$$ & - & 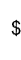 & 5,288 \\
\hline 76 & $\begin{array}{l}\text { Lineman Crew \#4 - Perform Tie-ins - Incl prep for tie-in; } \\
\text { performing tie-in; \& completing system test \& approval. }\end{array}$ & 1 & Ls & 10.0 & 10 & $\$ 545.00$ & $\$$ & 5,450 & $\$-$ & $\$$ & $\$-$ & $\$$ & & $\$$ & - & $\$$ & - & $\$$ & 5,450 \\
\hline 77 & $\mathrm{Ma}$ & 1 & Ls & 0.0 & 0 & $\$$ & $\$$ & - & $\$ 500$ & $\$ \quad 500$ & $\$$ & $\$$ & 5 & $\$$ & - & $\$$ & - & $\$$ & 500 \\
\hline & EAST SIDE OVER-HEAD P & & & & & & & & & & & & & & & & & & \\
\hline 78 & $\begin{array}{l}\text { Lineman Crew \#1- Incl placing hardware on transition } \\
\text { poles. Est 2-45' poles to be prepared for setting hardware } \\
\text { config (dbl circuit) for elect tie in to existing sys. }\end{array}$ & 1 & $\mathrm{Ea}$ & 10.0 & 10 & $\$ 423$ & $\$$ & 4,230 & $\$-$ & $\$$ & $\$-$ & $\$$ & - & $\$$ & - & $\$$ & - & $\$$ & 4,230 \\
\hline 79 & $\begin{array}{l}\text { Hardware - Incl cross arms, arrestors, transition hardware } \\
\text { - Est } 2-6^{\prime} \text { arms } \times 1 \text { circuit per pole }=2\end{array}$ & 2 & $\mathrm{Ea}$ & 0.0 & 0 & $\$$ & $\$$ & - & $\$ 304$ & 608 & $\$$ & $\$$ & & $\$$ & - & $\$$ & - & $\$$ & 608 \\
\hline 80 & $\begin{array}{l}\text { Fuse Cut-Outs - Incl pole mount installation hardware - } \\
\text { Est } 1 \text { per tie-in pole } \times 1 \text { pole }\end{array}$ & 1 & $\mathrm{Ea}$ & 0.0 & 0 & $\$$ & $\$$ & - & $\$ 1,155$ & $\$ \quad 1,155$ & $\$-$ & $\$$ & - & $\$$ & - & $\$$ & - & $\$$ & 1,155 \\
\hline 81 & Poles - $45^{\prime}$ Class 2 poles & 1 & $\mathrm{Ea}$ & 0.0 & 0 & $\$$ & $\$$ & - & $\$ 940$ & 940 & $\$-$ & $\$$ & s & $\$$ & - & $\$$ & - & $\$$ & 940 \\
\hline
\end{tabular}


PROPRIETARY INFORMATION
Data funished in connection with this proposal shall not be disclosed outside WCH approval, and shall not be duplicated, used, or discussed for any purpose other than to evaluate the proposal.

WASHINGTON CLOSURE HANFORD, INC. ESTIMATE PRICING SHEET

RIVER CORRIDOR CLEAN UP PROJECT RICHLAND, WASHINGTON
TITLE: 300 Area Utility Repacement Project - Electrical - Option \#4 SUBJECT: 2.0 Two Lines From Richland / Auto Transformers

* Rework Power Feeds At 5 Loc. Inside 300 Area

* Route Power From SHC SubSt. To 300 Area South
Estimate No: $1004-$ Elect-Opt\#4

Date : $04 / 18 / 07$

By: Dan Jakubek

\begin{tabular}{|c|c|c|c|c|c|c|c|c|c|c|c|c|c|c|c|c|c|c|}
\hline \multirow[b]{2}{*}{$\begin{array}{l}\text { Item } \\
\text { No. }\end{array}$} & \multirow[b]{2}{*}{ DESCRIPTION } & \multirow[b]{2}{*}{ Qty } & \multirow[b]{2}{*}{ Unit } & \multirow[b]{2}{*}{\begin{tabular}{|l|} 
Unit \\
MHR \\
Rate \\
\end{tabular}} & \multirow[b]{2}{*}{ MHRS } & \multicolumn{2}{|l|}{ LABOR } & & \multicolumn{3}{|c|}{$\begin{array}{l}\text { CONST. } \\
\text { EQUIPMENT }\end{array}$} & \multicolumn{4}{|c|}{$\begin{array}{l}\text { SUB } \\
\text { CONTRACT }\end{array}$} & \multirow{2}{*}{\multicolumn{2}{|c|}{ TOTAL }} \\
\hline & & & & & & $\begin{array}{c}\text { Labor } \\
\text { Rate } \\
\$ / M H R \\
\end{array}$ & $\begin{array}{c}\text { Subtotal } \\
\text { Labor }\end{array}$ & $\begin{array}{l}\text { MAT } \\
\text { Unit } \\
\text { Cost }\end{array}$ & \begin{tabular}{|l|l|} 
TERIAL \\
Subtotal \\
Mat'l
\end{tabular} & $\begin{array}{l}\text { EQ } \\
\text { Unit } \\
\text { Cost }\end{array}$ & & quip. & & $\begin{array}{l}\text { Coni } \\
\text { Unit } \\
\text { Cost }\end{array}$ & & $\begin{array}{l}\text { ubtotal } \\
\text { Sub }\end{array}$ & & \\
\hline 82 & $\begin{array}{l}\text { Lineman Crew \#2 - Installing poles - Incl augering holes; } \\
\text { \& placing poles. Est 1-45' poles to be placed. }\end{array}$ & 1 & Ea & 5.0 & 5 & $\$ 501$ & $\$ \quad 2,505$ & $\$-$ & $\$$ & $\$-$ & $\$$ & - & $\$$ & - & $\$$ & - & $\$$ & 2,505 \\
\hline 83 & Mat' Allowance - Est sml tools \& misc. & 1 & Ls & 0.0 & 0 & $\$$ & $\$$ & $\$ 250$ & 250 & $\$$ & $\$$ & - & $\$$ & - & $\$$ & - & $\$$ & 250 \\
\hline 84 & \begin{tabular}{|l|} 
Lineman Crew $\# 1$ - Incl placing hardware on poles. Est 1 \\
pole every $150^{\prime} ;$ Est distance for east side over-head line \\
@ 7920'; or $7920 / 150=53$ poles to be prepared for \\
setting w/STD hardware config.
\end{tabular} & 53 & Ea & 5.0 & 265 & $\$ 501$ & $\$ 132,765$ & $\$$ & $\$$ & & $\$$ & - & $\$$ & - & $\$$ & - & $\$$ & 132,765 \\
\hline 85 & $\begin{array}{l}\text { Hardware - Incl cross arms, arrestors, transition hardware } \\
- \text { Est } 2-6 \text { arms } \times 1 \text { circuit w/3 lines per pole } \times 53 \text { poles }= \\
106 \text { cross-arms }\end{array}$ & 106 & Ea & 0.0 & 0 & $\$$ & $\$$ & $\$ 304$ & $\$ 32,224$ & $\$$ & $\$$ & - & $\$$ & - & $\$$ & - & $\$$ & 32,224 \\
\hline 86 & Poles - $45^{\prime}$ Class 2 poles & 53 & Ea & 0.0 & 0 & - & $\$$ & $\$ 940$ & $\$ 49,820$ & $\$$ & $\$$ & - & $\$$ & - & $\$$ & - & $\$$ & 49,820 \\
\hline 87 & $\begin{array}{l}\text { Lineman Crew \#2 - Installing poles - Incl augering holes; } \\
\text { \& placing poles. Est } 53 \text { - } 45 \text { ' poles to be placed. }\end{array}$ & 53 & Ea & 5.0 & 265 & $\$ 501$ & $\$ 132,765$ & $\$-$ & $\$$ & & $\$$ & - & $\$$ & - & $\$$ & - & & 132,765 \\
\hline 88 & $\begin{array}{l}\text { Estimate Horz Line Boring Under GW Way Diagonal Rd - } \\
\text { Est placing a 5" dia casing } 100^{\prime} \mathrm{Lg} \text { for placing a 4" PVC } \\
\text { conduit thru. Est based on conversations w/Flour } \\
\text { Hanford, WCH Eng, \& Outside Vendors. }\end{array}$ & 50 & Lf & 0.0 & 0 & $\$$ & $\$$ & $\$$ & $\$$ & $\$$ & $\$$ & - & $\$$ & 45.12 & $\$$ & 2,256 & $\$$ & 2,256 \\
\hline 89 & $\begin{array}{l}\text { Electrician Crew \#6 - Estimate Connecting Transition Pole } \\
\text { 4" RGS Conduit to Pull Box on both side of GW Way Rd. } \\
\text { On other side of rd back into another pull box \& into 4" } 4 \text {. } \\
\text { RGS conduit back up a transition pole. Est 4" sch } 40 \text { PVC } \\
\text { from pull box thru rd sleeve to far side pull box. }\end{array}$ & 70 & Lf & 0.1 & 5 & $\$ 358.00$ & 1,790 & $\$$ & $\$$ & $\$$ & $\$$ & - & $\$$ & - & $\$$ & - & $\$$ & 1,790 \\
\hline 90 & $\begin{array}{l}\text { PVC Elect Conduit 1-4" Sch } 40 \text { Line w/Spacers - incl } \\
\text { conduit; pour concrete as needed around conduit \& pull } \\
\text { box; \& backfill w/compaction. Est } 70^{\prime} \text { of conduit }\end{array}$ & 70 & Lf & 0.0 & 0 & $\$$ & $\$$ & $\$ 15.83$ & $\$ \quad 1,108$ & $\$$ & $\$$ & - & $\$$ & - & $\$$ & - & $\$$ & 1,108 \\
\hline 91 & $\begin{array}{l}\text { Electrician Crew \#6 - Est Installing Pull Box Both sides of } \\
\text { Rd - Est excavation; compacted gravel bed; install box } \\
\text { wlid; grnd; \& misc. }\end{array}$ & 2 & Ea & 5.0 & 10 & $\$ 358.00$ & 3,580 & $\$$ & $\$$ & $\$$ & $\$$ & - & $\$$ & - & $\$$ & - & $\$$ & 3,580 \\
\hline 92 & $\begin{array}{l}\text { Pull Box Both sides of Rd - Est excavation; compacted } \\
\text { gravel bed; install box w/lid; grnd; \& misc. }\end{array}$ & 2 & Ea & 0.0 & 0 & $\$$ & $\$$ & $\$ 850$ & $\$ \quad 1,700$ & $\$$ & $\$$ & - & $\$$ & - & $\$$ & - & $\$$ & 1,700 \\
\hline 93 & $\begin{array}{l}\text { Electrician Crew } \# 5 \text { - Incl pulling } 4 / 0 \text { wire from pull box } \\
\text { thru rd sleeve to pull box on other side of rd. Est } 3 \text { wire } x \\
70 \text { Lf }=210 \text { Lf. Assume pulling in } 1 \text { bundle in conduit } \\
\text { w/three wires. }\end{array}$ & 1 & Ea & 5.0 & 5 & $\$ 335.00$ & 1,675 & $\$ 850$ & $\begin{array}{|ll|}\$ & 850\end{array}$ & $\$-$ & $\$$ & - & $\$$ & - & $\$$ & - & $\$$ & 2,525 \\
\hline 94 & $\begin{array}{l}\text { Wire - Est } 4 / 0 \text { type } \times 3 / \mathrm{c} \text { per circuit \& misc items - Est } \\
\text { distance approx } 70 \mathrm{Lf} \times 3 \text {-lines }=210 \mathrm{Lf}\end{array}$ & 210 & Lf & 0.0 & 0 & $\$$ & $\$$ & $\$ 30.00$ & $\$ \quad 6,300$ & $\$-$ & $\$$ & - & $\$$ & - & $\$$ & - & $\$$ & 6,300 \\
\hline
\end{tabular}


PROPRIETARY INFORMATION
Data funished in connection with this proposal shall not be disclosed outside WCH approval, and shall not be duplicated, used, or discussed for any purpose other than to evaluate the proposal.

WASHINGTON CLOSURE HANFORD, INC. ESTIMATE PRICING SHEET RIVER CORRIDOR CLEAN UP PROJECT RICHLAND, WASHINGTON
TITLE: 300 Area Utility Repacement Project - Electrical - Option \#4 SUBJECT: 2.0 Two Lines From Richland / Auto Transformers

* Rework Power Feeds At 5 Loc Inside 300 Area

* Route Power From SHC SubSt. To 300 Area South
Estimate No : 1004-Elect-Opt\#4 Date : 04/18/07

Rev No: 0

Date: 05110107

\begin{tabular}{|c|c|c|c|c|c|c|c|c|c|c|c|c|c|c|}
\hline \multirow[b]{2}{*}{$\begin{array}{l}\text { Item } \\
\text { No. }\end{array}$} & \multirow[b]{2}{*}{ DESCRIPTION } & \multirow[b]{2}{*}{ Qty } & \multirow[b]{2}{*}{ Unit } & \multicolumn{4}{|c|}{$\angle A B O R$} & & \multicolumn{2}{|c|}{$\begin{array}{c}\text { CONST. } \\
\text { EQUIPMENT }\end{array}$} & \multicolumn{2}{|c|}{$\begin{array}{l}\text { SUB } \\
\text { CONTRACT }\end{array}$} & \multirow[b]{2}{*}{ TOTAL } \\
\hline & & & & \begin{tabular}{|c|} 
Unit \\
MHR \\
Rate \\
\end{tabular} & MHRS & $\begin{array}{l}\text { Labor } \\
\text { Rate } \\
\text { \$/MHR }\end{array}$ & $\begin{array}{c}\text { Subtotal } \\
\text { Labor }\end{array}$ & $\begin{array}{l}\text { MAT } \\
\text { Unit } \\
\text { cost } \\
\end{array}$ & \begin{tabular}{|c|} 
ERIAL \\
Subtotal \\
Mat'l
\end{tabular} & $\begin{array}{l}\text { EQQ } \\
\text { Unit } \\
\text { Cost }\end{array}$ & $\begin{array}{l}\text { PMENT } \\
\text { Subtotal } \\
\text { Equip. }\end{array}$ & $\begin{array}{l}\text { CON } \\
\text { Unit } \\
\text { Cost } \\
\end{array}$ & $\begin{array}{c}\text { Subtotal } \\
\text { Sub }\end{array}$ & \\
\hline 95 & $\begin{array}{l}\text { Lineman Crew \#4 - Perform Tie-ins - Incl prep for tie-in; } \\
\text { performing tie-in; \& completing system test \& approval. }\end{array}$ & 1 & Ls & 10.0 & 10 & $\$ 545.00$ & 5,450 & $\$-$ & $\$$ & $\$-$ & $\$$ & $\$$ & $\$$ & 5,450 \\
\hline 96 & Mat' Allowance - Est sml tools \& misc. & 1 & Ls & 0.0 & 0 & $\$$ & $\$$ & $\$ 250$ & 250 & $\$$ & $\$$ & $\$$ & $\$$ & 250 \\
\hline 97 & $\begin{array}{l}\text { Lineman Crew \#1- Incl placing hardware on transition } \\
\text { poles. Est 1-455 poles to be prepared for setting hardware } \\
\text { config (dbl circuit) for elect tie in to existing sys. }\end{array}$ & 1 & Ea & 10.0 & 10 & $\$ 423$ & $\$ \quad 4,230$ & $\$-$ & $\$$ & $\$$ - & $\$$ & $\$$ & $\$$ & 4,230 \\
\hline 98 & $\begin{array}{l}\text { Hardware - Incl cross arms, arrestors, transition hardware } \\
- \text { Est } 2-6^{\prime} \text { arms } \times 1 \text { circuit per pole }=2\end{array}$ & 2 & Ea & 0.0 & 0 & $\$$ & $\$$ & $\$ 304$ & $\$ \quad 608$ & $\$$ & $\$$ & $\$$ & $\$$ & 608 \\
\hline 99 & $\begin{array}{l}\text { Fuse Cut-Outs - Incl pole mount installation hardware - } \\
\text { Est } 1 \text { per tie-in pole x } 1 \text { pole }\end{array}$ & 1 & $\mathrm{Ea}$ & 0.0 & 0 & $\$$ & $\$$ & $\$ 1,155$ & $\$ 1,155$ & $\$-$ & $\$$ & $\$$ & $\$$ & 1,155 \\
\hline 100 & Poles - $45^{\prime}$ Class 2 poles & 1 & Ea & 0.0 & 0 & $\$$ & $\$$ & $\$ 940$ & 940 & $\$-$ & $\$$ & $\$$ & $\$$ & 940 \\
\hline 101 & $\begin{array}{l}\text { Lineman Crew \#2 - Installing poles - Incl augering holes; } \\
\& \text { placing poles. Est 1-45' pole to be placed. }\end{array}$ & 1 & Ea & 5.0 & 5 & $\$ 501$ & 2,505 & $\$$ & $\$$ & $\$$ & $\$$ & $\$$ & $\$$ & 2,505 \\
\hline 102 & Mat'l Allowance - Est sml tools \& misc. & 1 & Ls & 0.0 & 0 & $\$$ & $\$$ & $\$ 250$ & 250 & $\$-$ & $\$$ & $\$$ & $\$$ & 250 \\
\hline 103 & $\begin{array}{l}\text { Electrician Crew } \# 3 \text { - Installing Wire - Incl placing wire on } \\
\text { pole and preparing for tie-in activities. Incl pulling } 397.5 \\
\text { wire from south end of triangle to mini sub-station - Est } 1 \\
\text { sys of } 3 \text { wire } x 7920 \mathrm{ff}(1.5 \text { miles })=23,760 \text { Lf. }\end{array}$ & 23,760 & Lf & 0.002 & 44 & $\$ 442$ & $\$ 19,470$ & $\$-$ & $\$$ & $\$-$ & $\$$ & $\$$ & $\$$ & 19,470 \\
\hline 104 & $\begin{array}{l}\text { Wire - Est } 397.5 \text { type } \times 3 / \mathrm{c} \text { per circuit } \& \text { misc items - Est } \\
\text { distance approx } 7920 \mathrm{Lf}(1.5 \text { miles }) \times 3 \text {-lines ea cir }= \\
23,760 \mathrm{Lf}\end{array}$ & 23,760 & Lf & 0.0 & 0 & $\$$ & $\$ 0$ & $\$ 1.47$ & $\$ 34,903$ & $\$-$ & $\$$ & $\$$ & $\$$ & 34,903 \\
\hline 105 & $\begin{array}{l}\text { Lineman Crew \#4 - Perform Tie-ins - Incl prep for tie-in; } \\
\text { performing tie-in; \& completing system test \& approval. }\end{array}$ & 1 & Ls & 10.0 & 10 & $\$ 545.00$ & $\$ \quad 5,450$ & $\$$ & $\$$ & $\$$ & $\$$ & $\$$ & $\$$ & 5,450 \\
\hline 106 & Mat'l Allowance - Est sml tools \& misc. & 1 & Ls & 0.0 & 0 & $\$$ & $\$$ & $\$ 500$ & & $\$$ & $\$$ & $\$$ & $\$$ & $\$$ \\
\hline & Subtotal & & & & 1,137 & & $\$ 555,415$ & & $\$ 209,895$ & & $\$$ & & 4,512 & $\$ 769,822$ \\
\hline & & & & & & & & & & & & & & \\
\hline & 2.6 - Install West Side Sub-Station & & & & & & & & & & & & & \\
\hline
\end{tabular}


PROPRIETARY INFORMATION
Data funished in connection with this proposal shall not be disclosed outside WCH approval, and shall not be duplicated, used, or discussed for any purpose other than to evaluate the proposal.

WASHINGTON CLOSURE HANFORD, INC ESTIMATE PRICING SHEET DOR CLEAN UP PROJECT RICHLAND, WASHINGTON
TITLE: 300 Area Utility Repacement Project - Electrical - Option \#4 SUBJECT: 2.0 Two Lines From Richland / Auto Transformers

* Rework Power Feeds At 5 Loc. Inside 300 Area

* Route Power From SHC SubSt. To 300 Area South
Estimate No: 1004-Elect-Opt\#4

Date: $04 / 18 / 07$

By: Dan Jakubek

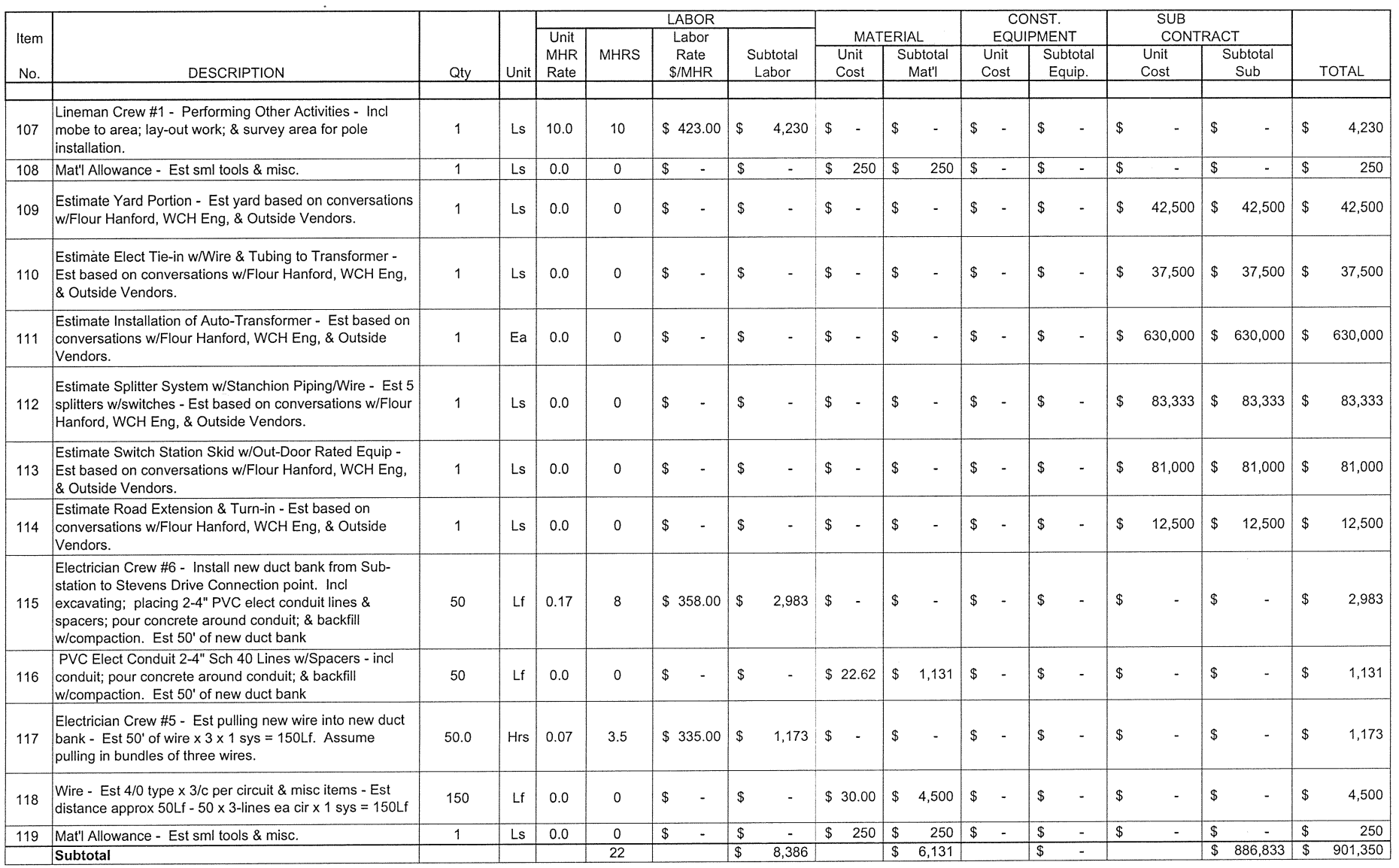

Page 10 of 23

$5 / 16 / 2007$ 
PROPRIETARY INFORMATION
Data funished in connection with this proposal shall not be disclosed outside WCH approval, and shall not be duplicated, used, or ciscussed for any purpose other than to evaluate the proposal.

WASHINGTON CLOSURE HANFORD, INC. ESTIMATE PRICING SHEET RIVER CORRIDOR CLEAN UP PROJECT RICHLAND, WASHINGTON
TITLE: 300 Area Utility Repacement Project - Electrical - Option \#4 SUBJECT: 2.0 Two Lines From Richland / Auto Transformers * Rework Power Feeds At 5 Loc. Inside 300 Area * Route Power From SHC SubSt. To 300 Area South
Estimate No: 1004-Elect-Optt4

Date : $04 / 18 / 07$

By: Dan Jakubek

Rev No: 0

Date: 05116107

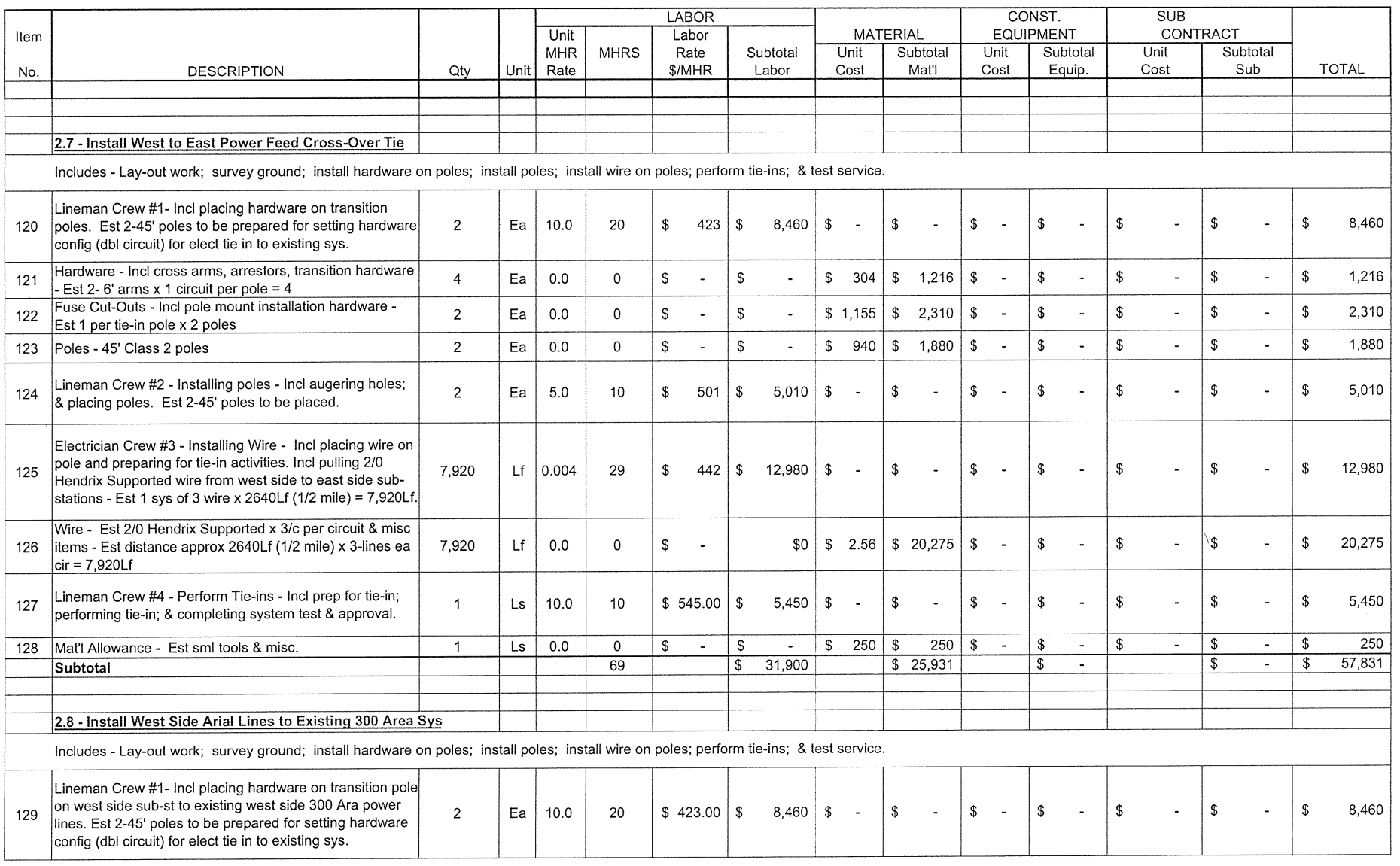


PROPRIETARY INFORMATION

TITLE: 300 Area Utility Repacement Project - Electrical - Option \#4

UP PROJECT

SUBJECT: 2.0 Two Lines From Richland / Auto Transformers

Pow

RICHLAND, WASHINGTON

Route Power From SHC SubSt. To 300 Area South

Date : $04 / 18 / 07$

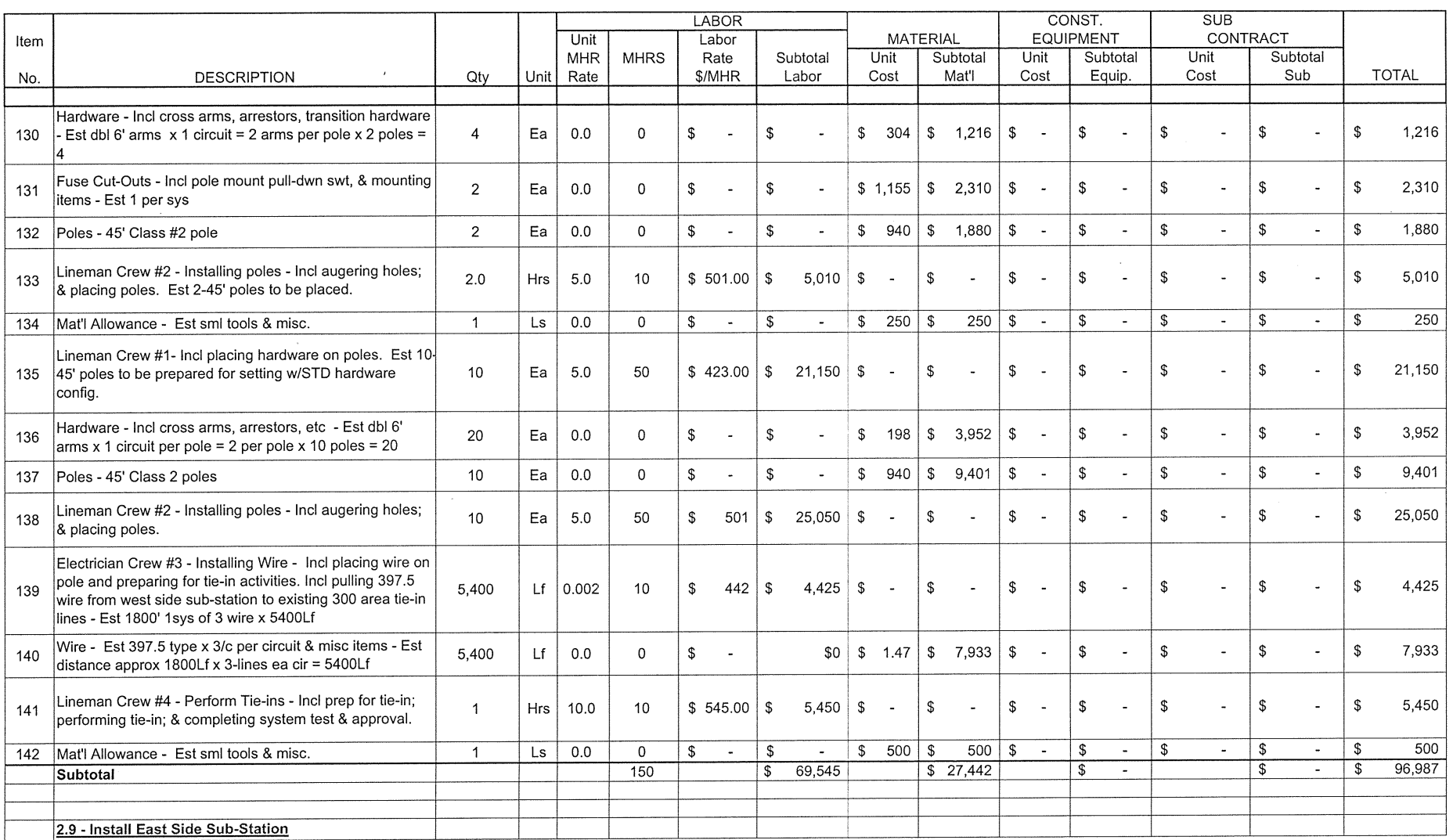


PROPRIETARY INFORMATION
Data funished in connection with this proposal shall not be disclosed outside WCH approval, and shall not be duplicated, used, or discussed for any purpose other than to evaluate the proposal.

WASHINGTON CLOSURE HANFORD, INC ESTIMATE PRICING SHEET N UP PROJECT RICHLAND, WASHINGTON
TITLE: 300 Area Utility Repacement Project - Electrical - Option \#4 SUBJECT: 2.0 Two Lines From Richland / Auto Transformers

* Rework Power Feeds At 5 Loc. Inside 300 Area

* Route Power From SHC SubSt. To 300 Area South
Estimate No: 1004-Elect-Opt\#4

Date : $04 / 18107$

By: Dan Jakubek

$05 / 16107$

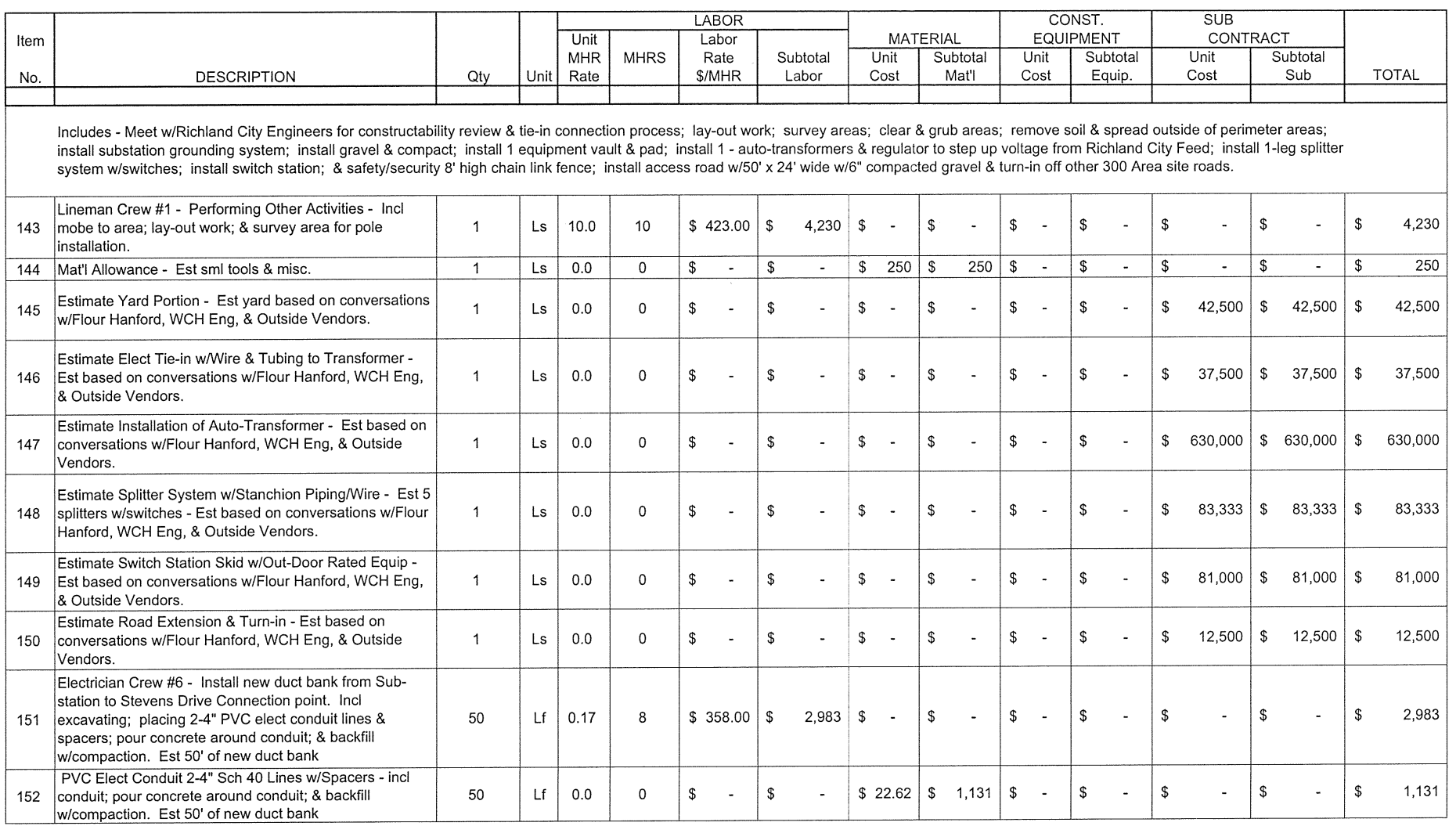


PROPRIETARY INFORMATION
Data fumished in connection with this proposal shall not be disclosed outside WCH approval, and shall not be duplicated, used, or discussed for any purpose other than to evaluate the proposal.

WASHINGTON CLOSURE HANFORD, INC STIMATE PRICING SHEET RIVER CORRIDOR CLEAN UP PROJECT RICHLAND, WASHINGTO
TITLE: 300 Area Utility Repacement Project - Electrical - Option \#4 SUBJECT: 2.0 Two Lines From Richland / Auto Transformers

Wo 5 Loc Inside 300 Area

* Route Power From SHC SubSt. To 300 Area South
Estimate No: 1004-Elect-Opt\#4

Date: $04 / 18 / 07$

By: Dan Jakubek

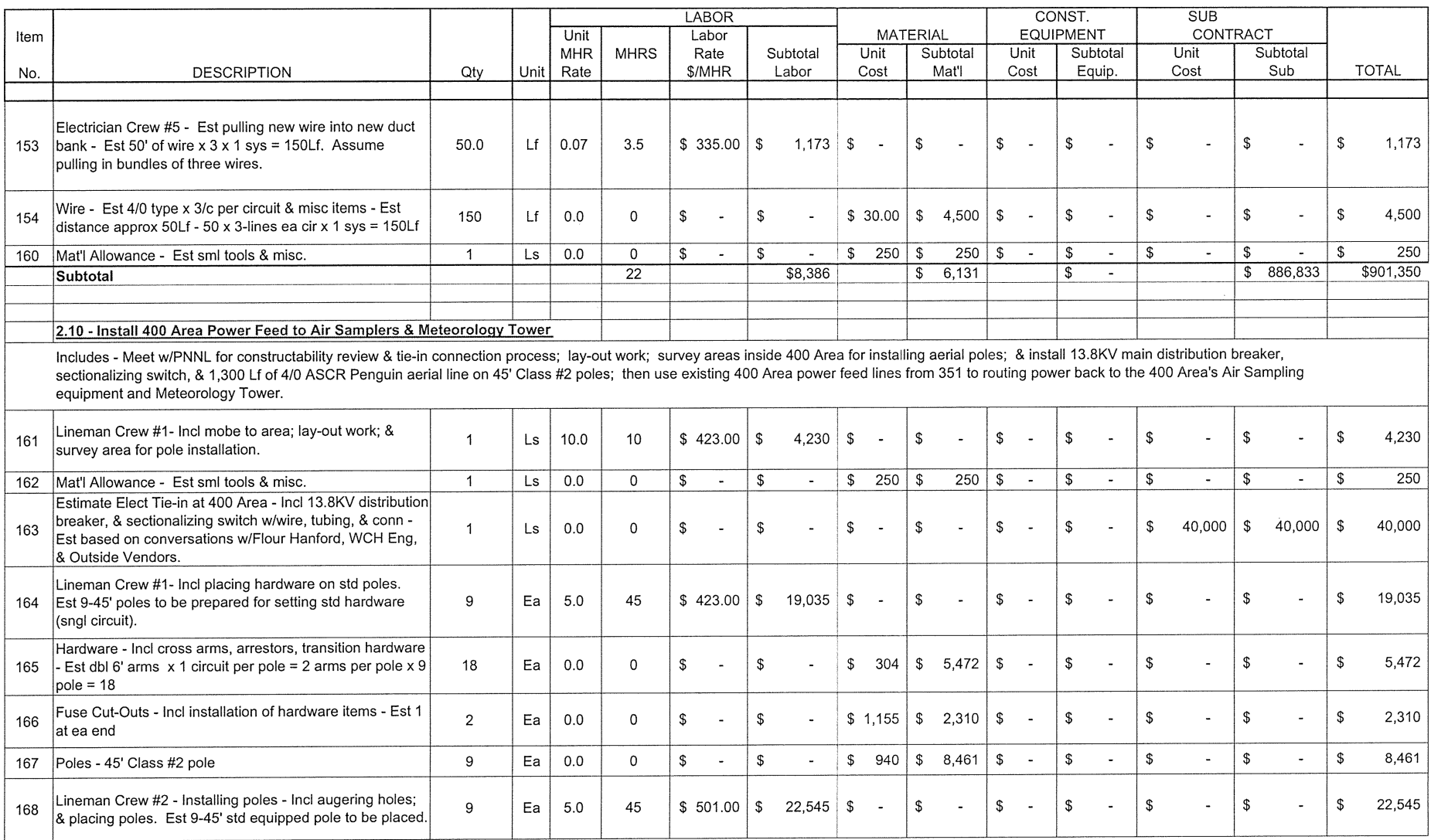


PROPRIETARY INFORMATION
Data funished in connection with this proposal shall not be disclosed outside WCH approval, and shall not be duplicated, used, or ciscussed for any purpose other than to evaluate the proposal.

WASHINGTON CLOSURE HANFORD, INC. ESTIMATE PRICING SHEET N UP PROJECT RICHLAND, WASHINGTON
TITLE: 300 Area Utility Repacement Project - Electrical - Option \#4 SUBJECT: 2.0 Two Lines From Richland / Auto Transformers

* Rework Power Feeds At 5 Loc. Inside 300 Area

* Route Power From SHC SubSt. To 300 Area South
Estimate No: 1004-Elect-Opt\#4

Date: $04 / 18 / 07$

By: Dan Jakubek

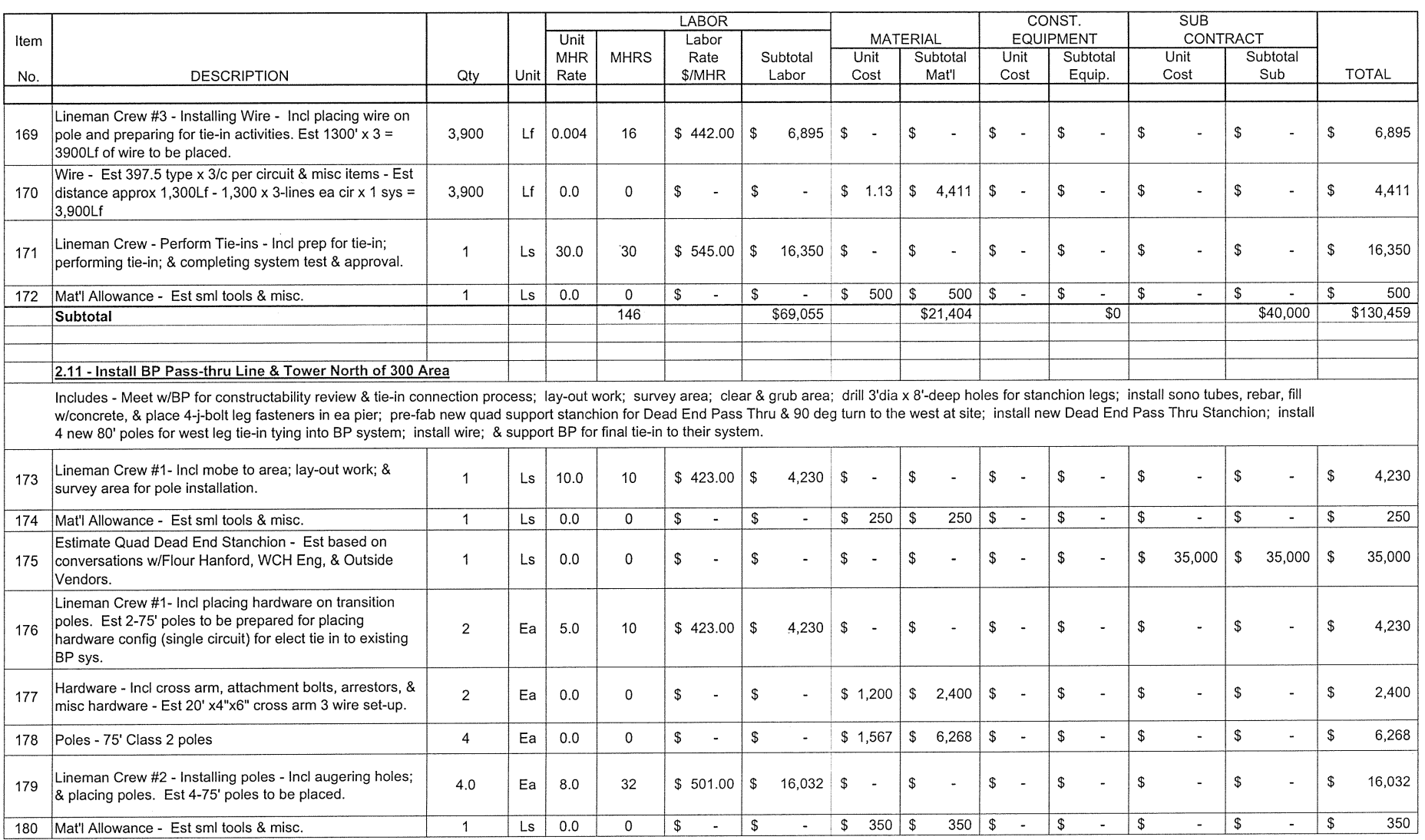


PROPRIETARY INFORMATION
Data funished in connection with this proposal shall not be disclosed outside WCH approval, and shall not be duplicated, used, or ciscussed for any purpose other than to evaluate the proposal.

WASHINGTON CLOSURE HANFORD, INC. ESTIMATE PRICING SHEET RIVER CORRIDOR CLEAN UP PROJECT RICHLAND, WASHINGTON
TITLE: 300 Area Utility Repacement Project - Electrical - Option \#4 SUBJECT: 2.0 Two Lines From Richland / Auto Transformers $\star$ Rework Power Feeds At 5 Loc. Inside 300 Area * Route Power From SHC SubSt. To 300 Area South
Estimate No: $1004-$ Elect-Opt\#4

Date : $04 / 18 / 07$

By: Dan Jakubek

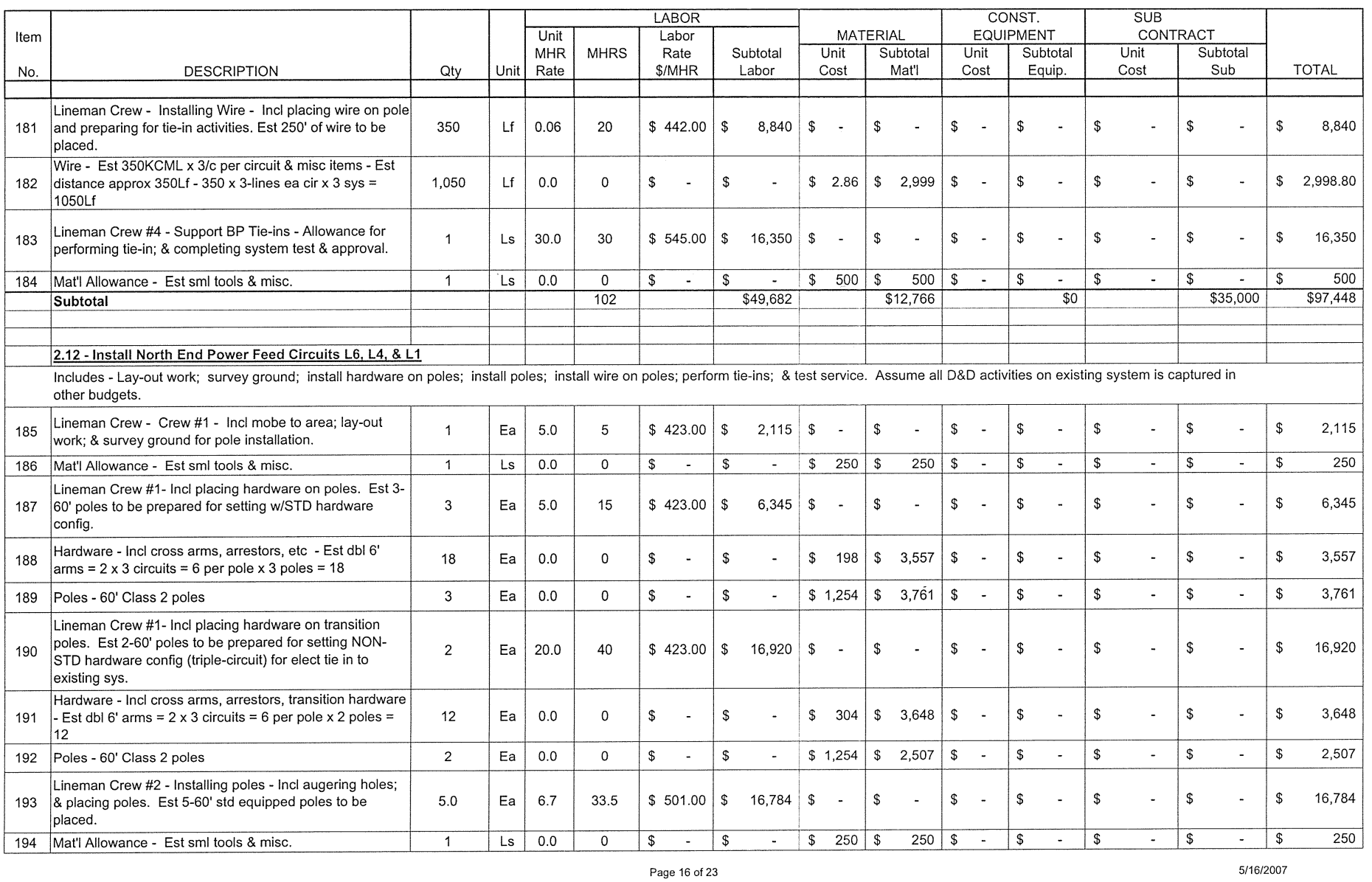


PROPRIETARY INFORMATION
Data furished in connection with this proposal shall not be disclosed outside WCH approval, and shall not be duplicated, used, or ciscussed for any purpose other than to evaluate the proposal.

WASHINGTON CLOSURE HANFORD, INC ESTIMATE PRICING SHEET

A

RICHLAND, WASHINGTON
TITLE: 300 Area Utility Repacement Project - Electrical - Option \#4 SUBJECT: 2.0 Two Lines From Richland / Auto Transformers

* Rework Power Feeds At 5 Loc. Inside 300 Area

* Route Power From SHC SubSt. To 300 Area South
Estimate No: $1004-E l e c t-O p t \# 4$

Date: $04 / 18 / 07$

By: Dan Jakube

Date: $05 / 16107$

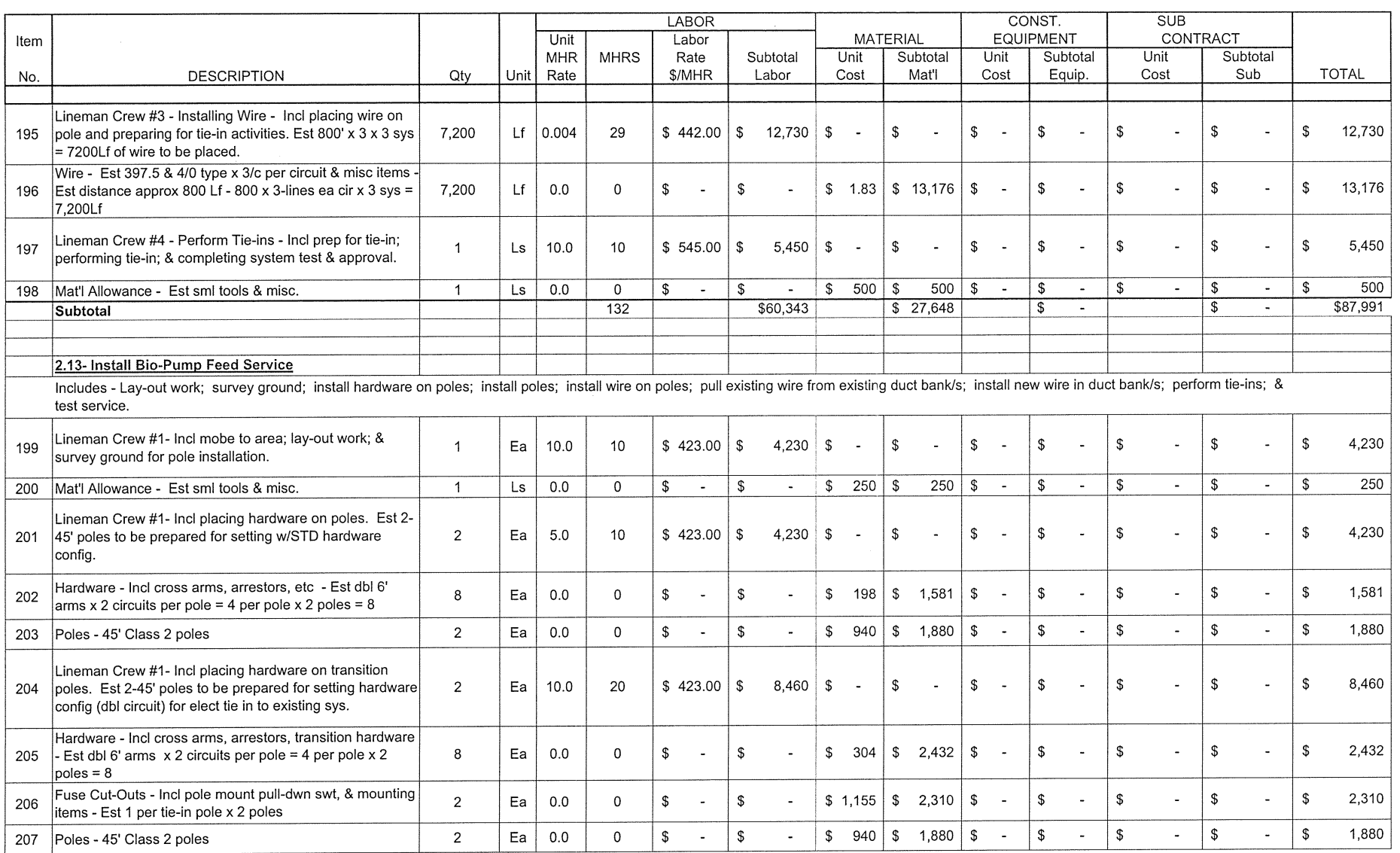


PROPRIETARY INFORMATION
Data fumished in connection with this proposal shall not be disclosed outside WCH approval, and shall not be duplicated, used, or ciscussed for any purpose other than to evaluate the proposal.

WASHINGTON CLOSURE HANFORD, INC. ESTIMATE PRICING SHEET RIVER CORRIDOR CLEAN UP PROJECT RICHLAND, WASHINGTON
TITLE: 300 Area Utility Repacement Project - Electrical - Option \#4 SUBJECT: 2.0 Two Lines From Richland / Auto Transformers

* Rework Power Feeds At 5 Loc. Inside 300 Area

* Route Power From SHC SubSt. To 300 Area South
Estimate No: $1004-$ Elect-Opt\#4

Date : $04 / 18 / 07$

By: Dan Jakubek

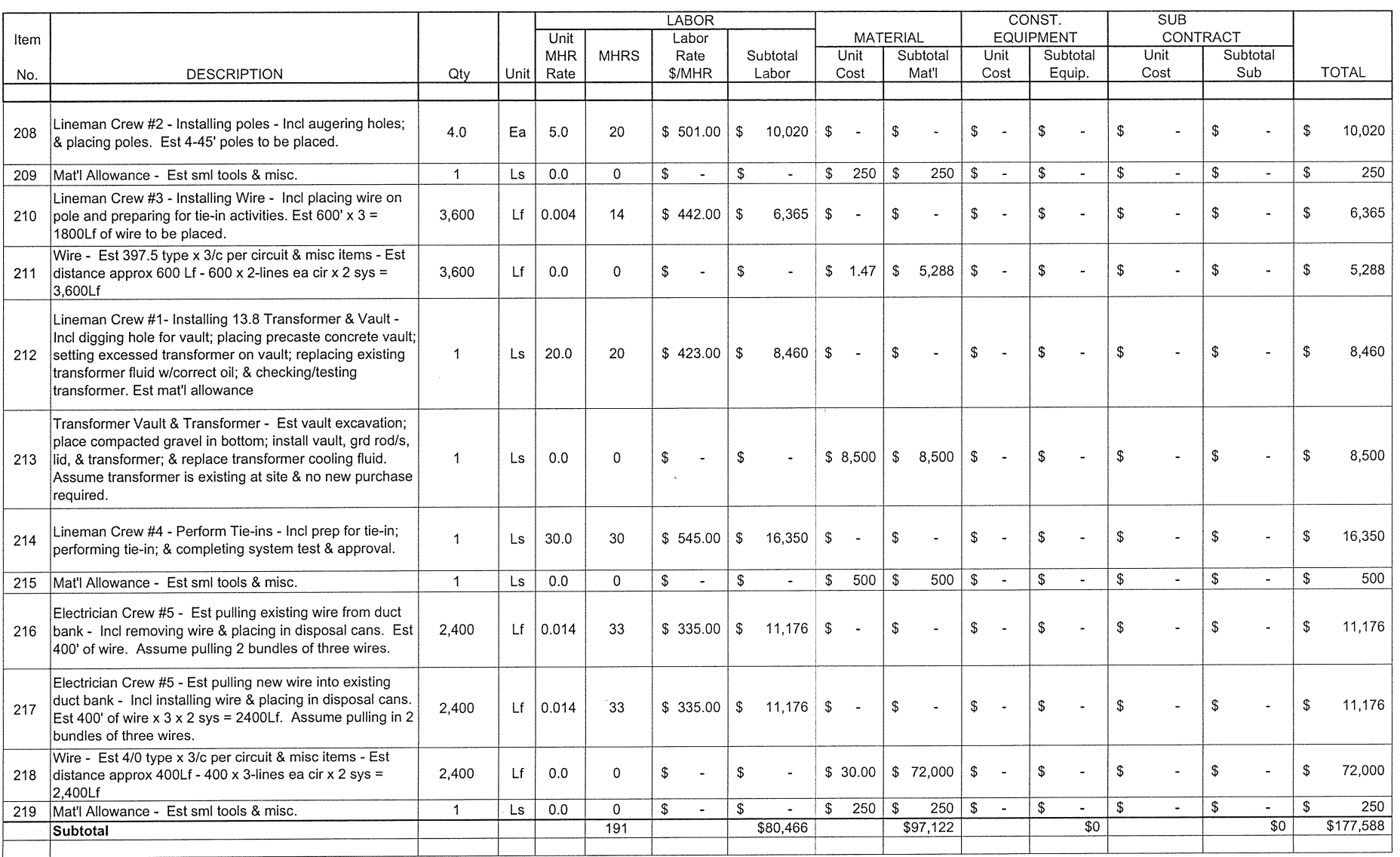


PROPRIETARY INFORMATION
Data funished in connection with this proposal shall not be disclosed outside WCH approval, and shall not be duplicated, used, or ciscussed for any purpose other than to evaluate the proposal.

WASHINGTON CLOSURE HANFORD, INC. ESTIMATE PRICING SHEET RIVER CORRIDOR CLEAN UP PROJECT RICHLAND, WASHINGTON
TITLE: 300 Area Utility Repacement Project - Electrical - Option \#4 SUBJECT: 2.0 Two Lines From Richland / Auto Transformers

* Rework Power Feeds At 5 Loc. Inside 300 Area

* Route Power From SHC SubSt. To 300 Area South
Estimate No: 1004-Elect-Opt\#4

Date : $04 / 18107$

By: Dan Jakubek

RevNo: 0

\begin{tabular}{|c|c|c|c|c|c|c|c|c|c|c|c|c|c|c|c|c|c|c|}
\hline \multirow{3}{*}{$\begin{array}{l}\text { Item } \\
\text { No. }\end{array}$} & \multirow[b]{3}{*}{ DESCRIPTION } & \multirow[b]{3}{*}{ Qty } & \multirow[b]{3}{*}{ Unit } & \multicolumn{5}{|c|}{$\angle A B O R$} & \multirow{2}{*}{\multicolumn{2}{|c|}{ MATERIAL }} & \multirow{2}{*}{\multicolumn{2}{|c|}{$\begin{array}{c}\text { CONST. } \\
\text { EQUIPMENT }\end{array}$}} & \multirow{2}{*}{\multicolumn{4}{|c|}{$\begin{array}{l}\text { SUB } \\
\text { CONTRACT }\end{array}$}} & & \\
\hline & & & & \multirow{2}{*}{\begin{tabular}{|l|} 
Unit \\
MHR \\
Rate \\
\end{tabular}} & \multirow[b]{2}{*}{ MHRS } & \multirow{2}{*}{$\begin{array}{l}\text { Labor } \\
\text { Rate } \\
\text { S/MHR } \\
\end{array}$} & \multirow{2}{*}{\multicolumn{2}{|c|}{$\begin{array}{c}\text { Subtotal } \\
\text { Labor }\end{array}$}} & & & & & & & & & \multirow[b]{2}{*}{ TOTAL } & \\
\hline & & & & & & & & & $\begin{array}{l}\text { Mnit } \\
\text { Unit } \\
\text { Cost }\end{array}$ & $\begin{array}{c}\text { Subtotal } \\
\text { Mat'l }\end{array}$ & $\begin{array}{l}\text { Unit } \\
\text { Cost }\end{array}$ & $\begin{array}{c}\text { Subtotal } \\
\text { Equip. }\end{array}$ & \multicolumn{2}{|c|}{$\begin{array}{l}\text { Unit } \\
\text { Cost } \\
\end{array}$} & \multicolumn{2}{|c|}{$\begin{array}{c}\text { Subtotal } \\
\text { Sub }\end{array}$} & & \\
\hline & & & & & & & & & & & & & & & & & & \\
\hline & 2.14 - Install 325 Secondary Feed Service & & & & & & & & & & & & & & & & & \\
\hline & $\begin{array}{l}\text { Includes - Lay-out work; survey ground; install hardware } \\
\text { test service. }\end{array}$ & oles; i & & & & les; $p$ & & $g$ wir & existil & uct bank & ; install $\mathrm{r}$ & $N$ wire in & 200 & & & & & \\
\hline 220 & $\begin{array}{l}\text { Lineman Crew \#1- Incl mobe to area; lay-out work; \& } \\
\text { survey ground for pole installation. }\end{array}$ & 1 & Ea & 10.0 & 10 & $\$ 423.00$ & $\$$ & 4,230 & $\$$ & $\$$ & $\$$ - & $\$$ & $\$$ & - & $\$$ & - & $\$$ & 4,230 \\
\hline 221 & Mat'l Allowance - Est sml tools \& misc. & 1 & Ls & 0.0 & 0 & $\$$ & $\$$ & - & $\$ 250$ & 250 & $\$-$ & $\$$ & $\$$ & - & $\$$ & - & $\$$ & 250 \\
\hline 222 & $\begin{array}{l}\text { Lineman Crew \#1- Incl placing hardware on poles. Est 2- } \\
45 \text { ' poles to be prepared for setting w/STD hardware } \\
\text { config. }\end{array}$ & 2 & Ea & 5.0 & 10 & $\$ 423.00$ & $\$$ & 4,230 & $\$-$ & $\$$ & $\$$ & $\$$ & $\$$ & - & $\$$ & - & $\$$ & 4,230 \\
\hline 223 & $\begin{array}{l}\text { Hardware }- \text { Incl cross arms, arrestors, etc }- \text { Est db } 6^{\prime} \\
\text { arms } \times 2 \text { circuits per pole }=4 \text { per pole } \times 2 \text { poles }=8\end{array}$ & 8 & Ea & 0.0 & 0 & $\$$ & $\$$ & - & $\$ \quad 198$ & $\$ \quad 1,581$ & $\$$ & $\$$ & $\$$ & - & $\$$ & - & $\$$ & 1,581 \\
\hline 224 & Poles - $45^{\prime}$ Class 2 poles & 2 & Ea & 0.0 & 0 & $\$$ & $\$$ & - & $\$ 940$ & $\$ 1,880$ & $\$-$ & $\$$ & $\$$ & - & $\$$ & - & $\$$ & 1,880 \\
\hline 225 & $\begin{array}{l}\text { Lineman Crew \#1- Incl placing hardware on transition } \\
\text { poles. Est 2-45' poles to be prepared for setting hardware } \\
\text { config (dbl circuit) for elect tie in to existing sys. }\end{array}$ & 2 & $\mathrm{Ea}$ & 10.0 & 20 & $\$ 423.00$ & $\$$ & 8,460 & $\$$. & $\$$ & $\$-$ & - & $\$$ & - & $\$$ & - & $\$$ & 8,460 \\
\hline 226 & $\begin{array}{l}\text { Hardware - Incl cross arms, arrestors, transition hardware } \\
- \text { Est db } 6^{\prime} \text { arms } \times 2 \text { circuits per pole }=4 \text { per pole } \times 2 \\
\text { poles }=8\end{array}$ & 8 & Ea & 0.0 & 0 & $\$$ & $\$$ & - & $\$ 304$ & $\$ 2,432$ & $\$-$ & $\$$ & $\$$ & - & $\$$ & - & $\$$ & 2,432 \\
\hline 227 & $\begin{array}{l}\text { Fuse Cut-Out - Incl pole mount installation hardware- Est } \\
1 \text { per tie-in pole } \times 2 \text { poles }\end{array}$ & 2 & Ea & 0.0 & 0 & $\$$ & $\$$ & - & $\$ 1,155$ & $\$ 2,310$ & $\$-$ & $\$$ & $\$$ & - & $\$$ & - & $\$$ & 2,310 \\
\hline 228 & Poles $-45^{\prime}$ Class 2 poles & 2 & $\mathrm{Ea}$ & 0.0 & 0 & $\$$ & $\$$ & - & $\$ 940$ & $\$ 1,880$ & $\$-$ & $\$$ & $\$$ & - & $\$$ & - & $\$$ & 1,880 \\
\hline 229 & $\begin{array}{l}\text { Lineman Crew \#2 - Installing poles - Incl augering holes; } \\
\& \text { placing poles. Est } 4-45^{\prime} \text { std equipped poles to be } \\
\text { placed. }\end{array}$ & 4.0 & Ea & 5.0 & 20 & $\$ 501.00$ & $\$$ & 10,020 & $\$-$ & $\$$ & $\$-$ & $\$$ & $\$$ & - & $\$$ & - & $\$$ & 10,020 \\
\hline 230 & Mat' Allowance - Est sml tools \& misc. & 1 & Ls & 0.0 & 0 & $\$$ & $\$$ & - & $\$ \quad 250$ & 250 & $\$$. & $\$$ & $\$$ & - & $\$$ & - & $\$$ & 250 \\
\hline 231 & $\begin{array}{l}\text { Lineman Crew \#3 - Installing Wire - Incl placing wire on } \\
\text { pole and preparing for tie-in activities. Est } 450^{\prime} \times 3= \\
1350 \text { L f of wire to be placed. }\end{array}$ & 1,350 & Lf & 0.004 & 5 & $\$ 442.00$ & $\$$ & 2,387 & $\$$ & $\$$ & $\$$ & - & $\$$ & - & $\$$ & - & $\$$ & 2,387 \\
\hline 232 & $\begin{array}{l}\text { Wire - Est } 397.5 \text { type } \times 3 / c \text { per circuit \& misc items - Est } \\
\text { distance approx } 450 \text { Lf }-450 \times 3 \text {-lines } \times 1 \text { sys }=1,350 \mathrm{Lf}\end{array}$ & 1,350 & Lf & 0.0 & 0 & $\$$ & $\$$ & & $\$ 1.47$ & $\$ \quad 1,983$ & $\$$ & $\$$ & $\$$ & - & $\$$ & - & $\$$ & 1,983 \\
\hline
\end{tabular}


PROPRIETARY INFORMATION
Data funished in connection with this proposal shall not be disclosed outside WCH approval, and shall not be duplicated, used, or ciscussed for any purpose other than to evaluate the proposal.

WASHINGTON CLOSURE HANFORD, INC. ESTIMATE PRICING SHEET AN UP PROJECT RICHLAND, WASHINGTON
TITLE: 300 Area Utility Repacement Project - Electrical - Option \#4 SUBJECT: 2.0 Two Lines From Richland / Auto Transformers

* Rework Power Feeds At 5 Loc Inside 300 Area

* Route Power From SHC SubSt. To 300 Area South
Estimate No: 1004-Elect-Opt\#4

Date : $04 / 18 / 07$

By: Dan Jakube

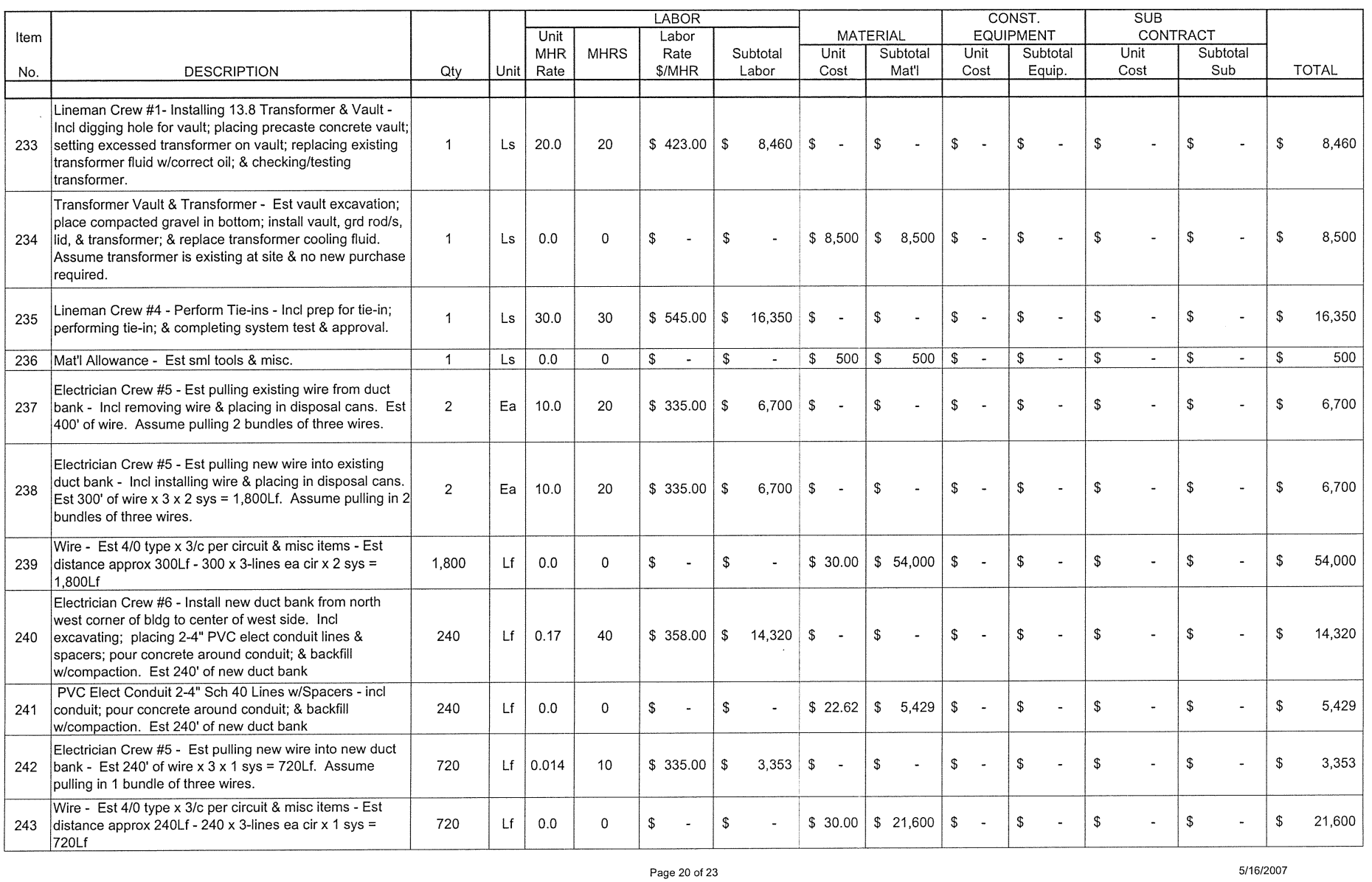


PROPRIETARY INFORMATION
Data funished in connection with this proposal shall not be disclosed outside WCH approval, and shall not be duplicated, used, or discussed for any purpose other than to evaluate the proposal.

WASHINGTON CLOSURE HANFORD, INC. ESTIMATE PRICING SHEET RIVER CORRIDOR CLEAN UP PROJECT RICHLAND, WASHINGTON

\begin{tabular}{|c|c|c|c|c|c|c|c|c|c|c|c|c|c|c|c|c|c|c|}
\hline \multirow{4}{*}{$\begin{array}{l}\text { Item } \\
\text { No. }\end{array}$} & \multirow{4}{*}{ DESCRIPTION } & & & & & & & & & & & & \multicolumn{4}{|r|}{07} & & \\
\hline & & \multirow{4}{*}{ Qty } & \multirow{3}{*}{ Unit } & \multicolumn{4}{|c|}{ LABOR } & \multirow{2}{*}{\multicolumn{2}{|c|}{ MATERIAL }} & \multirow{2}{*}{\multicolumn{4}{|c|}{$\begin{array}{l}\text { CONST. } \\
\text { EQUIPMENT }\end{array}$}} & \multirow{2}{*}{\multicolumn{3}{|c|}{$\begin{array}{l}\text { SUB } \\
\text { CONTRACT }\end{array}$}} & & \\
\hline & & & & \multirow{2}{*}{\begin{tabular}{|c|} 
Unit \\
MHR \\
Rate \\
\end{tabular}} & \multirow[b]{2}{*}{ MHRS } & \multirow{2}{*}{$\begin{array}{l}\text { Labor } \\
\text { Rate } \\
\$ \text { MHR } \\
\end{array}$} & \multirow[b]{2}{*}{$\begin{array}{c}\text { Subtotal } \\
\text { Labor }\end{array}$} & & & & & & & & & & & \\
\hline & & & & & & & & $\begin{array}{l}\text { Unit } \\
\text { Unit } \\
\text { Cost }\end{array}$ & $\begin{array}{l}\text { Subtotal } \\
\text { Mat"l }\end{array}$ & $\begin{array}{l}\text { Ev } \\
\text { Unit } \\
\text { Cost }\end{array}$ & \multicolumn{2}{|c|}{\begin{tabular}{|l} 
Subtotal \\
Equip.
\end{tabular}} & \multicolumn{2}{|r|}{$\begin{array}{l}\text { Unit } \\
\text { Cost }\end{array}$} & \multicolumn{2}{|c|}{$\begin{array}{c}\text { Subtotal } \\
\text { Sub }\end{array}$} & TOTAL & \\
\hline & & & & & & & & & & & & & & & & & & \\
\hline 244 & Mat' Allowance - Est sml tools \& misc. & 1 & Ls & 0.0 & 0 & $\$$ & $\$$ & $\$ 250$ & $\$ \quad 250$ & 4 & & $\$$ & 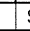 & $\$$ & $\$$ & & $\$$ & 250 \\
\hline & Subtotal & & & & 205 & & $\$ 85,209$ & & $\$ 102,845$ & & & $\$$ & & & & $\$ 0$ & & $\$ 188,055$ \\
\hline & & & & & & & & & & & & & & & & & & \\
\hline & 2.15 - Install West Side Secondary Feed Service & & & & & & & & & & & & & & & & & \\
\hline & Includes - Lay-out work; survey ground; install hardwar & oles; & po & bes & wir & s; & ie-ins; & serv & & & & & & & & & & \\
\hline 245 & $\begin{array}{l}\text { Lineman Crew \#1- Incl mobe to area; lay-out work; \& } \\
\text { survey ground for pole installation. }\end{array}$ & 1 & Ls & 10.0 & 10 & $\$ 423.00$ & $\$ \quad 4,230$ & $\$$ & $\$$ & $\$$ & & $\$$ & & $\$$ & $\$$ & & $\$$ & 4,230 \\
\hline 246 & Mat' Allowance - Est sml tools \& misc. & 1 & Ls & 0.0 & 0 & - & $\$$ & $\$ \quad 250$ & 250 & $\$$ & & $\$$ & & $\$$ & $\$$ & - & s & \\
\hline 247 & $\begin{array}{l}\text { Lineman Crew \#1- Incl placing hardware on poles. Est 3- } \\
45^{\prime} \text { poles to be prepared for setting w/STD hardware } \\
\text { config. }\end{array}$ & 3 & $\mathrm{Ea}$ & 5.0 & 15 & $\$ 423.00$ & $\$ \quad 6,345$ & $\$-$ & $\$$ & $\$$ & & $\$$ & & $\$$ & $\$$ & & $\$$ & 6,345 \\
\hline 248 & $\begin{array}{l}\text { Hardware - Incl cross arms, arrestors, etc }- \text { Est db } 6^{\prime} \\
\text { arms } \times 2 \text { circuits per pole }=4 \text { per pole } \times 3 \text { poles }=12\end{array}$ & 12 & $\mathrm{Ea}$ & 0.0 & 0 & $\$$ & $\$$ & \$ 198 & $\$ 2,371$ & $\$$ & & $\$$ & & $\$$ & $\$$ & - & $\$$ & 2,371 \\
\hline 249 & Poles - $45^{\prime}$ Class 2 poles & 3 & $\mathrm{Ea}$ & 0.0 & 0 & - & $\$$ & $\$ 940$ & $\$ \quad 2,820$ & $\$$ & & $\$$ & & - & $\$$ & - & $\$$ & 2,820 \\
\hline 250 & $\begin{array}{l}\text { Lineman Crew \#1- Incl placing hardware on transition } \\
\text { poles. Est 2-451 poles to be prepared for setting hardware } \\
\text { config (dbl circuit) for elect tie in to existing sys. }\end{array}$ & 2 & $\mathrm{Ea}$ & 10.0 & 20 & $\$ 423.00$ & $\$ \quad 8,460$ & $\$$ & $\$$ & $\$$ & & $\$$ & & $\$$ & $\$$ & - & $\$$ & 8,460 \\
\hline 251 & $\begin{array}{l}\text { Hardware }- \text { Incl cross arms, arrestors, transition hardware } \\
- \text {-Est dbb } 6^{\prime} \text { arms } \times 2 \text { circuits per pole }=4 \text { per pole } \times 2 \\
\text { poles }=8\end{array}$ & 8 & $\mathrm{Ea}$ & 0.0 & 0 & $\$$ & $\$$ & $\$ 304$ & $\$ 2,432$ & $\$$ & & $\$$ & & $\$$ & $\$$ & & $\$$ & 2,432 \\
\hline 252 & $\begin{array}{l}\text { Fuse Cut-Out - Incl pole mount installation hardware- Est } \\
1 \text { per tie-in pole } \times 2 \text { poles }\end{array}$ & 2 & $\mathrm{Ea}$ & 0.0 & 0 & $\$$ & $\$$ & $\$ 1,155$ & $\$ 2,310$ & $\$$ & & $\$$ & & $\$$ & $\$$ & & $\$$ & 2,310 \\
\hline 253 & Poles - $45^{\prime}$ Class 2 poles & 2 & $\mathrm{Ea}$ & 0.0 & 0 & - & $\$$ & $\$ 940$ & $\$ \quad 1,880$ & $\$$ & & $\$$ & & - & $\$$ & - & $\$$ & 1,880 \\
\hline 254 & $\begin{array}{l}\text { Lineman Crew \#2 - Installing poles - Incl augering holes; } \\
\text { \& placing poles. Est 5-45' std equipped poles to be } \\
\text { placed. }\end{array}$ & 5.0 & $\mathrm{Ea}$ & 5.0 & 25 & $\$ 501.00$ & $\$ 12,525$ & $\$$ & $\$$ & $\$$ & & $\$$ & & $\$$ & $\$$ & & $\$$ & 12,525 \\
\hline 255 & Mat' Allowance - Est sml tools \& misc. & 1 & Ls & 0.0 & 0 & $\$-$ & $\$$ & $\$ 250$ & 250 & $\$$ & & $\$$ & & - & $\$$ & - & $\$$ & 250 \\
\hline 256 & $\begin{array}{l}\text { Lineman Crew \#3 - Installing Wire - Incl placing wire on } \\
\text { pole and preparing for tie-in activities. Est } 3600^{\prime} \text { of wire to } \\
\text { be placed. }\end{array}$ & 3,600 & $\mathrm{Lf}$ & 0.004 & 14 & $\$ 442.00$ & $\$ \quad 6,365$ & $\$$ & $\$$ & $\$$ & & $\$$ & & $\$$ & $\$$ & & $\$$ & 6,365 \\
\hline
\end{tabular}

TITLE: 300 Area Utility Repacement Project - Electrical - Option \#4 SUBJECT: 2.0 Two Lines From

Estimate No: 1004-Elect-Opt\#4 oc. Inside 300 Area

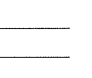

$-$
te No: 1004 -Elect-opt
Date : $04 / 18 / 07$
$\begin{aligned} \text { By: } & \text { Dan Jakubek } \\ \text { Rev No: } 0 & \end{aligned}$

事

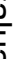


PROPRIETARY INFORMATION
Datat furmished in connection with this proposal shall not be disclosed outside WCH approval, and shall not be duplicated, used, or discussed for any purpose other than to evaluate the proposal.

WASHINGTON CLOSURE HANFORD, INC ESTIMATE PRICING SHEET

RIVER CORRIDOR CLEAN UP PROJECT RICHLAND, WASHINGTON
TITLE: 300 Area Utility Repacement Project - Electrical - Option \#4 SUBJECT: 2.0 Two Lines From Richland / Auto Transformers

* Rework Power Feeds At 5 Loc. Inside 300 Area

* Route Power From SHC SubSt. To 300 Area South
Estimate No: 1004-Elect-Optt4

Date: $04 / 18 / 07$

By: Dan Jakubek

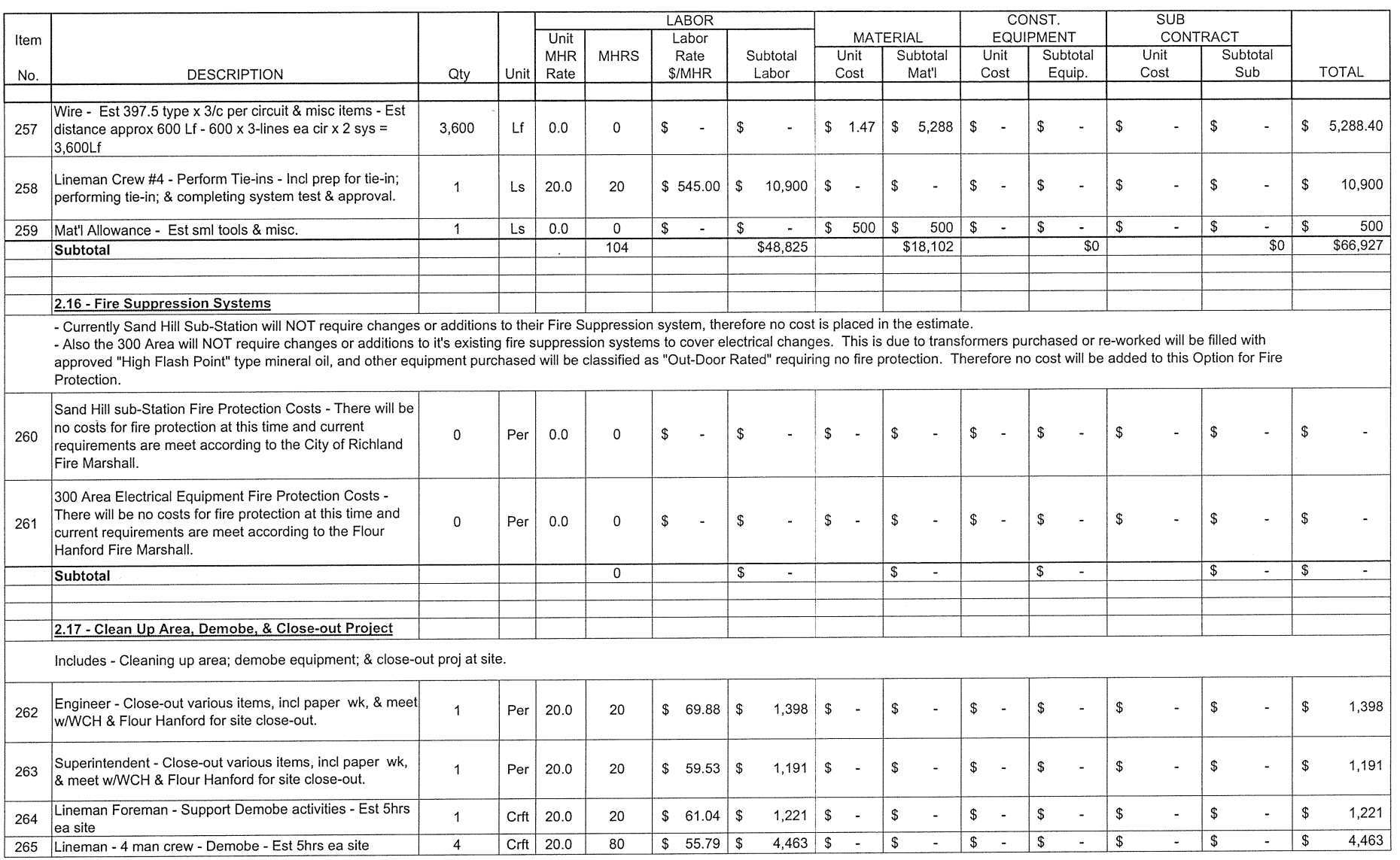

265 Lineman - 4 man crew - Demobe - Est 5hrs ea site 
PROPRIETARY INFORMATION
Data furished in connection with this proposal shall not be disclosed outside WCH approval, and shal not be duplicated, used, or discussed for any purpose other than to evaluate the proposal.

WASHINGTON CLOSURE HANFORD, INC. ESTIMATE PRICING SHEET RIVER CORRIDOR CLEAN UP PROJECT RICHLAND, WASHINGTON
TITLE: 300 Area Utility Repacement Project - Electrical - Option \#4 SUBJECT: 2.0 Two Lines From Richland / Auto Transformers

* Rework Power Feeds At 5 Loc. Inside 300 Area

* Route Power From SHC SubSt. To 300 Area South
Estimate No: $1004-$ Elect-Opt\#4

Date : $04 / 18 / 07$

By : Dan Jakubek

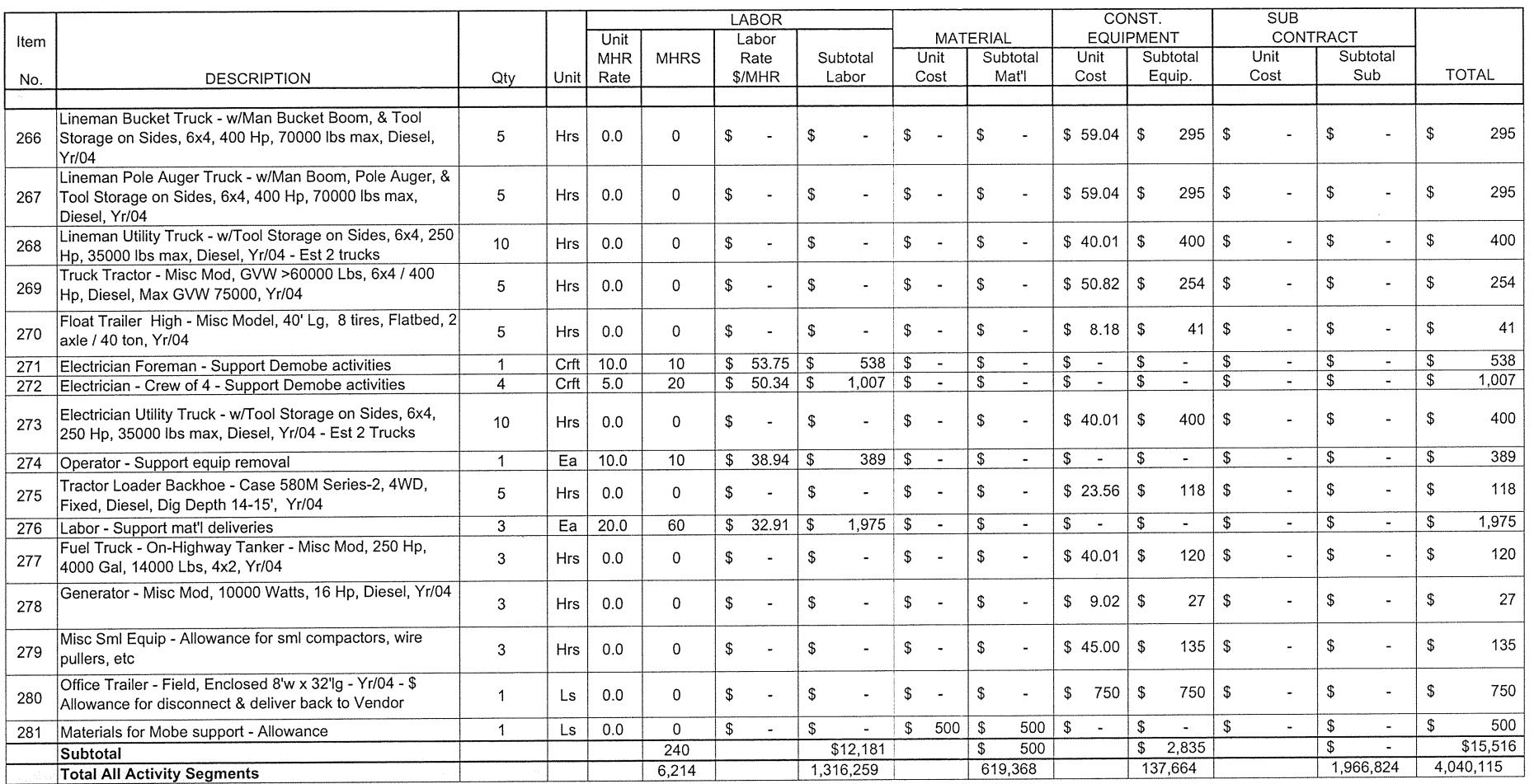


PROPRIETARY INFORMATION
PNOA

WASHINGTON CLOSURE HANFORD, INC. ESTIMATE PRICING SHEET

TVR CORRIDOR CLEAN UP PROJECT RICHLAND, WASHINGTON

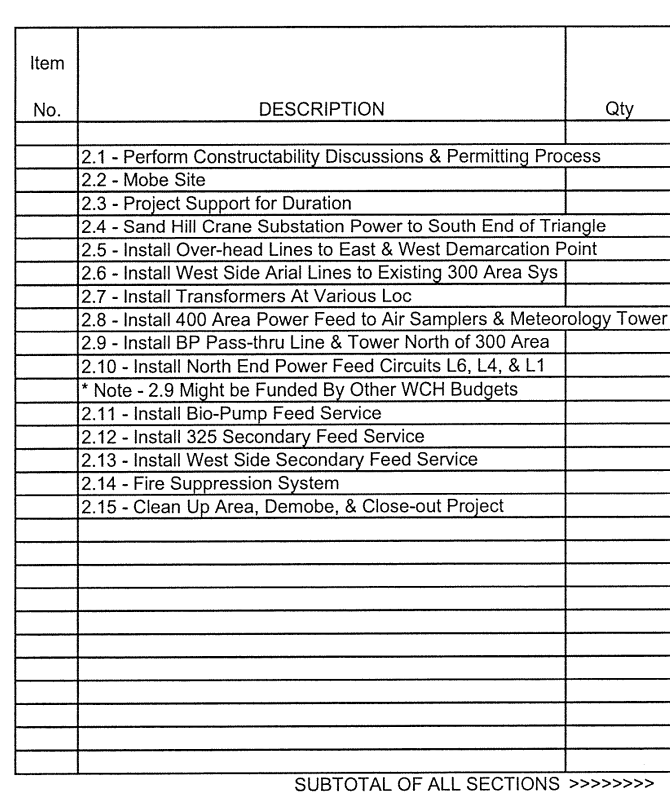

TITLE: 300 Area Utility Repacement Project - Electrical - Option \#5 SUBJECT: 2.0 Two Lines From Richland / Buildings Transformers * Rework Power Feeds At 5 Loc. Inside 300 Area

Pow From SHC SubSt. To 300 Area South

* Install Transformers in 300 Area From 12.74 to 13.8KVA
Estimate No: $1004-E l e c t-O p t \# 5$

$\begin{aligned} \text { Date: } & 05 / 01 / 07 \\ \text { By: } & \text { Dan Jakube }\end{aligned}$

Date: $05 / 16 / 07$

\section{\begin{tabular}{|c|c|c|c|}
\hline LABOR & & CONST.
\end{tabular}}

SUB

\begin{tabular}{|c|c|c|c|c|c|c|c|c|c|c|}
\hline \multirow{2}{*}{$\begin{array}{l}\text { Unit } \\
\text { MHR } \\
\text { Rate } \\
\end{array}$} & \multirow[b]{2}{*}{ MHRS } & \multirow{2}{*}{$\begin{array}{c}\text { Labor } \\
\text { Rate } \\
\text { S/MHR } \\
\end{array}$} & \multirow[b]{2}{*}{$\begin{array}{c}\text { Subtotal } \\
\text { Labor }\end{array}$} & \multicolumn{2}{|c|}{ MATERIAL } & \multicolumn{2}{|c|}{ EQUIPMENT } & \multicolumn{2}{|c|}{ CONTRACT } & \multirow[b]{2}{*}{ TOTAL } \\
\hline & & & & $\begin{array}{l}\text { Unit } \\
\text { Cost }\end{array}$ & $\begin{array}{c}\begin{array}{c}\text { Subtotal } \\
\text { Mat'l }\end{array} \\
\text { (a) }\end{array}$ & $\begin{array}{l}\text { Unit } \\
\text { Cost }\end{array}$ & $\begin{array}{l}\text { Subtotal } \\
\text { Equip. }\end{array}$ & $\begin{array}{l}\text { Unit } \\
\text { Cost }\end{array}$ & $\begin{array}{c}\text { Subtotal } \\
\text { Sub }\end{array}$ & \\
\hline & & & & & & & & & & \\
\hline & $\frac{360}{401}$ & & $\begin{array}{ll}\$ & 25,157 \\
\$ & 27,885\end{array}$ & & $\begin{array}{|ll|}\$ & 1,050 \\
\$ & 2,000 \\
\end{array}$ & & 3,585 & & \begin{tabular}{|l}
$\$ \$$ \\
$\$ \$$
\end{tabular} & $\begin{array}{l}26,207 \\
36,470\end{array}$ \\
\hline & 3,442 & & $\$ 190,668$ & & 2,500 & & $\$ 157,319$ & & 1,943 & 352,429 \\
\hline & 60 & & $\begin{array}{l}\$ 24,760 \\
\end{array}$ & & 57,900 & & & & $\begin{array}{ll}\$ & 109,024\end{array}$ & 191,684 \\
\hline & 1,137 & & 555,415 & & \begin{tabular}{|l|}
$\$ 209,895$ \\
\end{tabular} & & - & & 4,512 & 769,822 \\
\hline & 150 & & 69,545 & & \begin{tabular}{|lr}
$\$$ & 27,442 \\
\end{tabular} & & $\$$ & & $\$$ & 96,987 \\
\hline & 830 & & 351,090 & & $\$ 1,130,730$ & & s & & $\$$ & $1,481,820$ \\
\hline & 146 & & 69,055 & & $\begin{array}{|ll|}\$ & 21,404 \\
\end{array}$ & & $\$$ & & $\$ \quad 40,000$ & 130,459 \\
\hline & 102 & & 49,682 & & 12,766 & & $\$$ & & $\$ 35,000$ & 97,448 \\
\hline & 132 & & \begin{tabular}{l|l}
$\$$ & 60,343 \\
\end{tabular} & & \begin{tabular}{|l|}
$\$ 27,648$ \\
\end{tabular} & & - & & 8 & 87,991 \\
\hline & (1) & & & & 10 & & - & & - & $177>$ \\
\hline & 205 & & & & \begin{tabular}{|lr} 
& $91,12<2$ \\
& 102,845 \\
\end{tabular} & & 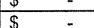 & & $+\frac{p}{4}$ & $\frac{177,588}{188,055}$ \\
\hline & 104 & & $\begin{array}{ll}\$ & 48,825 \\
\end{array}$ & & \begin{tabular}{|ll}
$\$$ & 18,102 \\
\end{tabular} & & $\$$ & & $\$$ & 66,927 \\
\hline & & & & & - & & - & & - & - \\
\hline & 240 & & $\begin{array}{l}\$ 12,181 \\
\end{array}$ & & 500 & & 2,835 & & $\$$ & 15,516 \\
\hline & & & & & & & & & & \\
\hline & & & & & & & & & & \\
\hline & & & & & & & & & & \\
\hline & & & & & & & & & & \\
\hline & & & & & & & & & & \\
\hline & & & & & & & & & & \\
\hline & & & & & & & & & & \\
\hline & $\begin{array}{r}7,501 \\
M H R S\end{array}$ & & $\$ 1,650,280$ & & $\$ 1,711,905$ & & \begin{tabular}{|l|l|l|l}
$\$ 163,740$ \\
Fowin
\end{tabular} & & \begin{tabular}{|l|l|}
$\$$ & 193,479 \\
& $S$ \\
\end{tabular} & $\$ 3,719,403$ \\
\hline & MHRS & & & & Material & & & & & \\
\hline
\end{tabular}

(Note: Sales tax on material, equip, SubK, \&ODCs only)

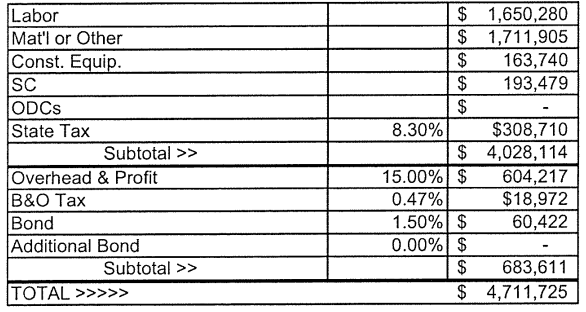


PROPRIETARY INFORMATION
Data funished in connection with this proposal shall not be disclosed outside WCH approval, and shall not be duplicated, used, or discussed for any purpose other than to evaluate the proposal.

WASHINGTON CLOSURE HANFORD, INC. ESTIMATE PRICING SHEET CLEAN UP PROJECT RICHLAND, WASHINGTON

\begin{tabular}{|c|c|c|c|c|c|c|c|c|c|c|c|c|c|c|}
\hline & & & & Instal & Iranst & mers in & 0 Area F & n 12.7 & 0 o & & & & 07 & \\
\hline
\end{tabular}

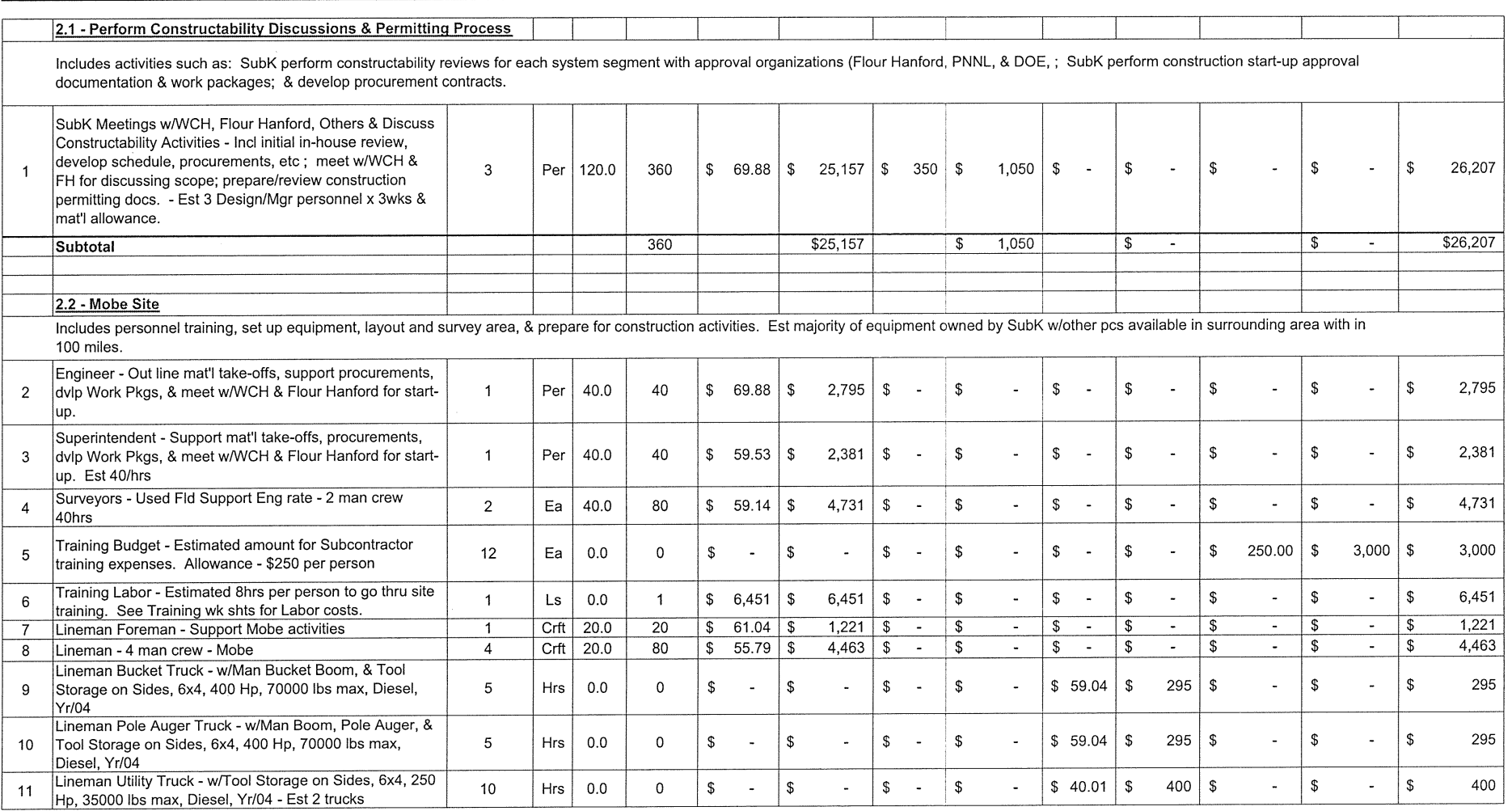


PROPRIETARY INFORMATION
Data furnished in connection with this proposal shall not be disclosed outside WCH approval, and shall not be duplicated, used, or discussed for any purpose other than to evaluate the proposal.

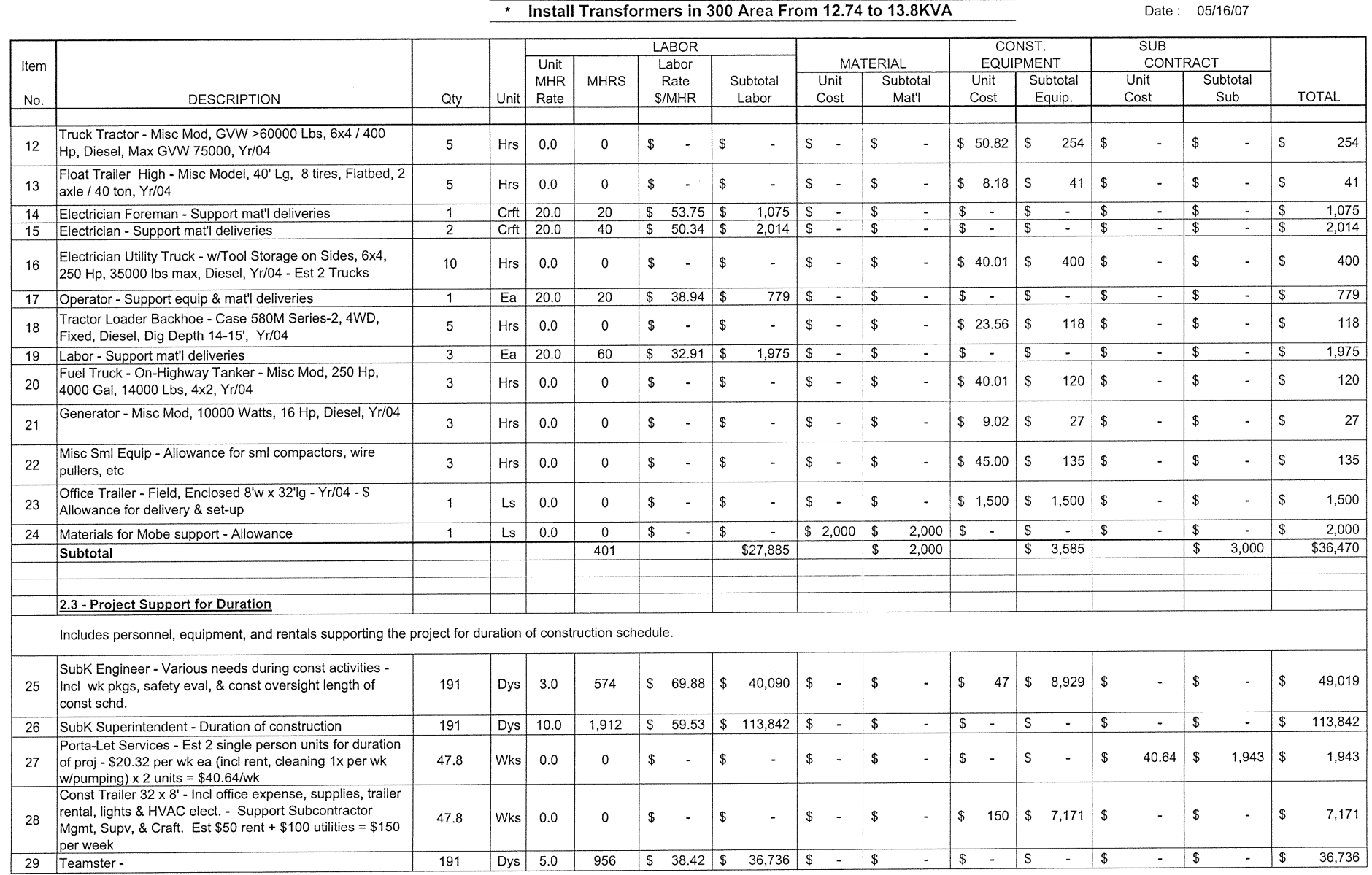

WASHINGTON CLOSURE HANFORD, INC. ESTIMATE PRICING SHEET 作 RICHLAND, WASHINGTON

TITLE: 300 Area Utility Repacement Project - Electrical - Option \#5 SUBJECT: 2.0 Two Lines From Richland/Buildings Transformers * Rework Power Feeds At 5 Loc. Inside 300 Area * Route Power From SHC SubSt. To 300 Area South Estimate No: $1004-$ Elect-Opt\#5 Date: $05 / 01 / 07$ By: Dan Jakubek Rev No: 0 
PROPRIETARY INFORMATION
Data furnished in connection with this proposal shall not be disclosed outside WCH approval, and shall not be duplicated, used, or discussed for any purpose other than to evaluate the proposal.

WASHINGTON CLOSURE HANFORD, INC. ESTIMATEPRINING SHEET

PROJECT RICHLAND, WASHINGTON
TITLE: 300 Area Utility Repacement Project - Electrical - Option \#5 SUBJECT: 2.0 Two Lines From Richland / Buildings Transformers * Rework Power Feeds At 5 Loc. Inside 300 Area

* Route Power From SHC SubSt. To 300 Area South

* Install Transformers in 300 Area From 12.74 to 13.8KVA
Estimate No : 1004 -Elect-Opt\#5

Date : $05 / 01 / 07$

By: Dan Jakube

Date: 051

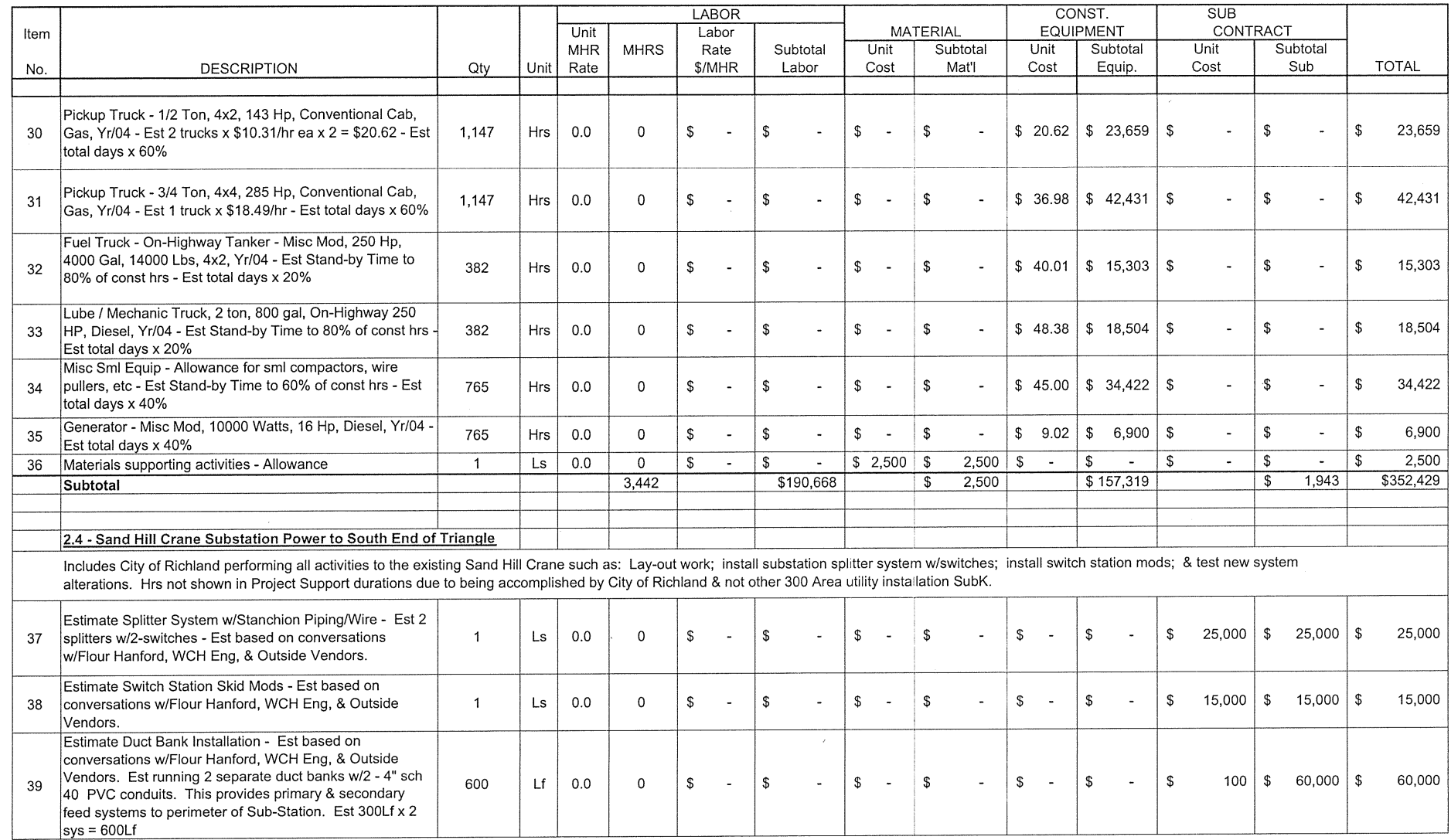


PROPRIETARY INFORMATION
Data furnished in connection with this proposal shall not be disclosed outside WCH approval, and shall not be dupicated, used, or discussed for any purpose other than to evaluate the proposal.

WASHINGTON CLOSURE HANFORD, INC. ESTIMATE PRICING SHEET RIVER CORRIDOR CLEAN UP PROJECT RICHLAND, WASHINGTON
TITLE: 300 Area Utility Repacement Project - Electrical - Option \#5 SUBJECT: 2.0 Two Lines From Richland / Buildings Transformers * Rework Power Feeds At 5 Loc. Inside 300 Area * Rework Power Feeds At 5 Loc. Inside 300 Area * Install Transformers in 300 Area From 12.74 to $13.8 \mathrm{KVA}$
Estimate No: $1004-E l e c t-O p t \# 5$

Date: $05 / 01 / 07$

By: Dan Jakubek

Rev No: 0

Date : $05 / 16 / 07$

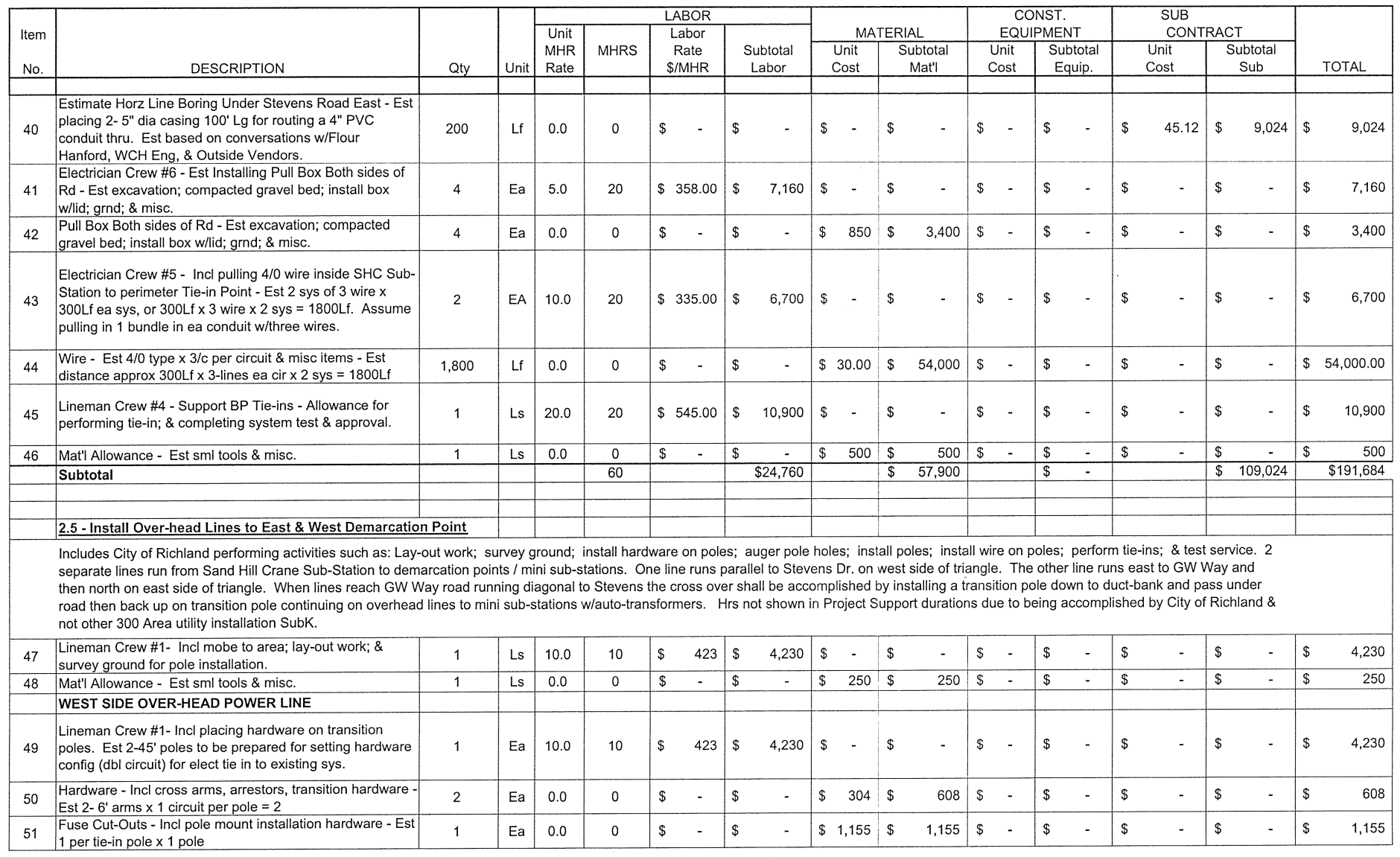

Page 5 of 21

$5 / 16 / 2007$ 
PROPRIETARY INFORMATION

WASHINGTON CLOSURE HANFORD, INC. ESTIMATE PRICING SHEET RIVER CORRIDOR CLEAN UP PROJECT RICHLAND, WASHINGTON
TITLE: 300 Area Utility Repacement Project - Electrical - Option \#5 SUBJECT: 2.0 Two Lines From Richland/ Buildings Transformers * Rework Power Feeds At 5 Loc. Inside 300 Area * Rework Power Feeds At 5 Loc. Inside 300 Area * Install Transformers in 300 Area From 12.74 to $13.8 \mathrm{KVA}$
Estimate No: $1004-$ Elect-Opt\#5

Date : $05 / 01 / 07$

By: Dan Jakubek

Date : $05 / 16 / 07$

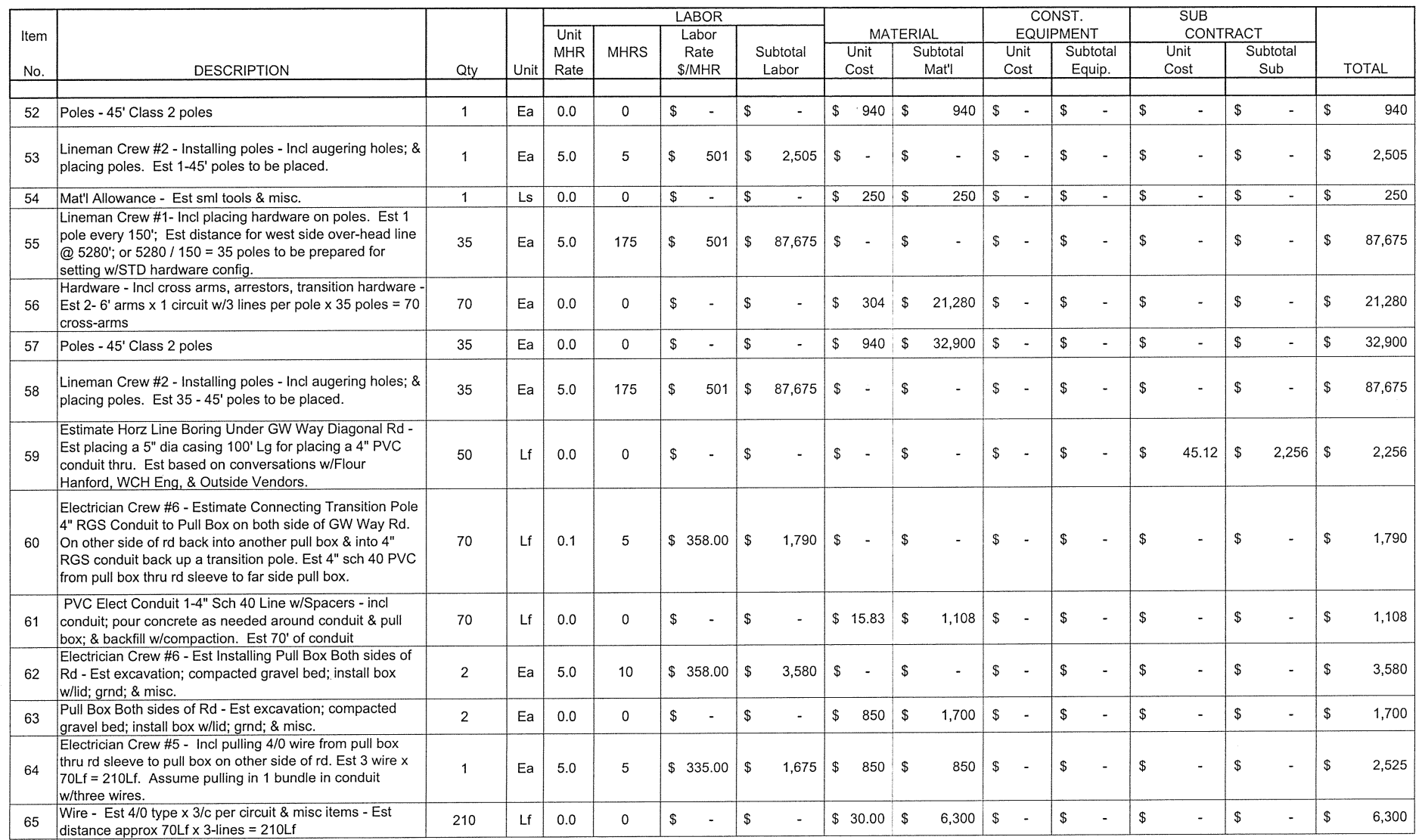


PROPRIETARY INFORMATION
Data furnished in connection with this proposal shall not be disclosed outside WCH approval, and shall not be duplicated, used, or discussed for any purpose other than to evaluate the proposal.

WASHINGTON CLOSURE HANFORD, INC. ESTIMATE PRICING SHEET RIVER CORRIDOR CLEAN UP PROJECT RICHLAND, WASHINGTON

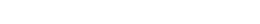

TITLE: 300 Area Utility Repacement Project - Electrical - Option \#5 SUBJECT: 2.0 Two Lines From Richland / Buildings Transformers * Rework Power Feeds At 5 Loc. Inside 300 Area * Route Power From SHC SubSt. To 300 Area South
Estimate No: $1004-E l e c t-O p t \# 5$ Date: $05 / 01 / 07$ By: Dan Jakubek Rev No: 0

Date : $05 / 16 / 07$

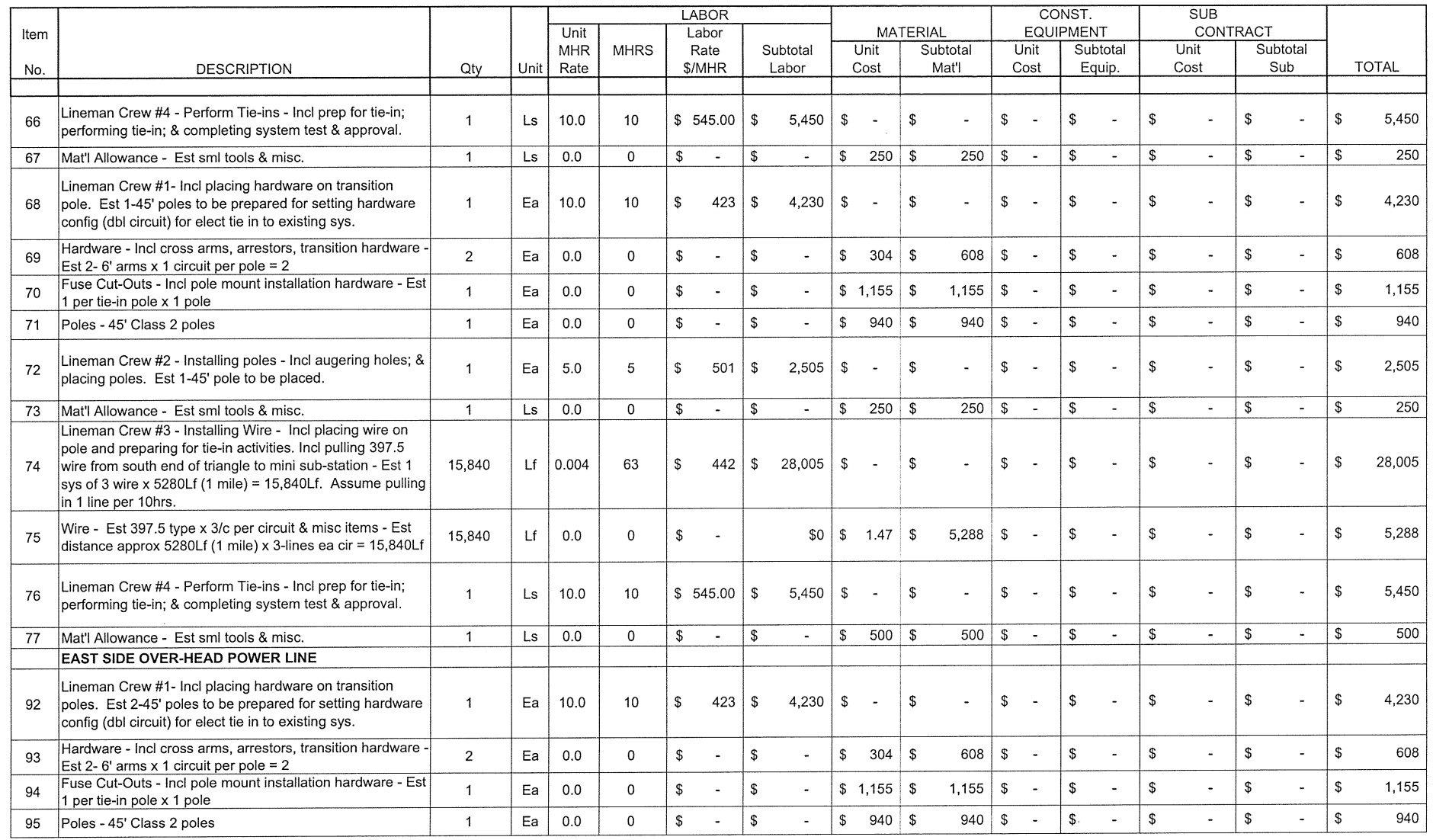


PROPRIETARY INFORMATION
Data furnished in connection with this proposal shall not be disclosed outside WCH approval, and shall not be dupli

WASHINGTON CLOSURE HANFORD, INC. ESTIMATE PRICING SHEET RIVER CORRIDOR CLEAN UP PROJECT RICHLAND, WASHINGTON

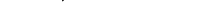

TITLE: 300 Area Utility Repacement Project - Electrical - Option \#5 SUBJECT: 2.0 Two Lines From Richland / Buildings Transformers * Rework Power Feeds At 5 Loc. Inside 300 Area * Rework Power Feeds At 5 Loc. Inside 300 Area * Install Transformers in 300 Area From 12.74 to $13.8 \mathrm{KVA}$
Estimate No: 1004-Elect-Opt\#5

Date: $05 / 01 / 07$

By: Dan Jakubek

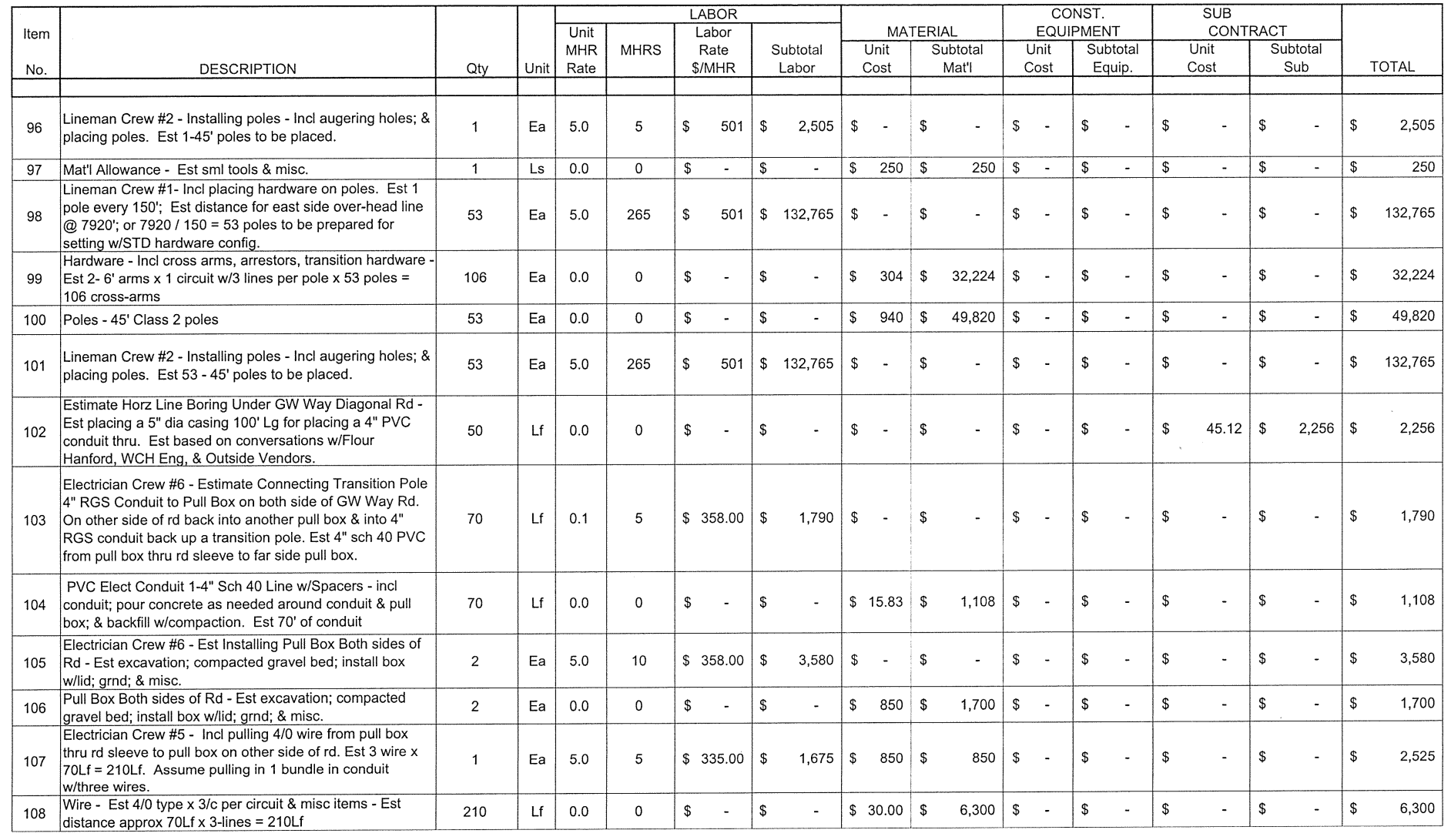


PROPRIETARY INFORMATION
Data funished in connection with this proposal shall not be disclosed outside WCH apporoval, and shall not be du

\begin{tabular}{|c|c|c|c|c|c|c|c|c|c|c|c|c|c|c|c|c|c|c|}
\hline \multirow{3}{*}{$\begin{array}{l}\text { Item } \\
\text { No. }\end{array}$} & \multirow[b]{3}{*}{ DESCRIPTION } & \multirow[b]{3}{*}{ Qty } & \multirow[b]{3}{*}{ Unit } & \multicolumn{4}{|c|}{$\angle A B O R$} & \multirow{2}{*}{\multicolumn{2}{|c|}{ MATERIAL }} & \multirow{2}{*}{\multicolumn{3}{|c|}{$\begin{array}{c}\text { CONST. } \\
\text { EQUIPMENT }\end{array}$}} & \multirow{2}{*}{\multicolumn{4}{|c|}{$\begin{array}{l}\text { SUB } \\
\text { CONTRACT }\end{array}$}} & & \multirow[b]{3}{*}{ TOTAL } \\
\hline & & & & \multirow{2}{*}{\begin{tabular}{|c|} 
Unit \\
MHR \\
Rate \\
\end{tabular}} & \multirow[b]{2}{*}{ MHRS } & \multirow{2}{*}{$\begin{array}{l}\text { Labor } \\
\text { Rate } \\
\text { SIMHR }\end{array}$} & \multirow[b]{2}{*}{$\begin{array}{c}\text { Subtotal } \\
\text { Labor }\end{array}$} & & & & & & & & & & & \\
\hline & & & & & & & & $\begin{array}{l}\text { Unit } \\
\text { Cost } \\
\end{array}$ & $\begin{array}{c}\text { Subtotal } \\
\text { Mat"' }\end{array}$ & $\begin{array}{l}\text { Unit } \\
\text { Cost } \\
\end{array}$ & \multicolumn{2}{|c|}{\begin{tabular}{|l} 
Subtotal \\
Equip.
\end{tabular}} & \multicolumn{2}{|c|}{$\begin{array}{l}\text { Unit } \\
\text { Cost } \\
\end{array}$} & \multicolumn{2}{|c|}{$\begin{array}{c}\text { Subtotal } \\
\text { Sub }\end{array}$} & & \\
\hline 109 & $\begin{array}{l}\text { Lineman Crew \#4 - Perform Tie-ins - Incl prep for tie-in; } \\
\text { performing tie-in; \& completing system test \& approval. }\end{array}$ & 1 & Ls & 10.0 & 10 & $\$ 545.00$ & 5,450 & $\$-$ & $\$$ & $\$$ & $\$$ & - & $\$$ & - & $\$$ & - & $\$$ & 5,450 \\
\hline 110 & Mat'l Allowance - Est sml tools \& misc. & 1 & Ls & 0.0 & 0 & $\$$ & $\$$ & $\$ \quad 250$ & 250 & $\$$ & $\$$ & - & $\$$ & - & $\$$ & - & $\$$ & 250 \\
\hline 111 & $\begin{array}{l}\text { Lineman Crew \#1- Incl placing hardware on transition } \\
\text { poles. Est } 1 \text {-45' poles to be prepared for setting hardware } \\
\text { config (dbl circuit) for elect tie in to existing sys. }\end{array}$ & 1 & Ea & 10.0 & 10 & $\$ 423$ & $\$ \quad 4,230$ & $\$$ & $\$$ & $\$$ & $\$$ & - & $\$$ & - & $\$$ & - & $\$$ & 4,230 \\
\hline 113 & $\begin{array}{l}\text { Fuse Cut-Outs - Incl pole mount installation hardware - Est } \\
1 \text { per tie-in pole } x 1 \text { pole }\end{array}$ & 1 & Ea & 0.0 & 0 & $\$$ & $\$$ & $\$ 1,155$ & 1,155 & $\$-$ & $\$$ & - & $\$$ & - & $\$$ & - & $\$$ & 1,155 \\
\hline 114 & Poles - $45^{\prime}$ Class 2 poles & 1 & Ea & 0.0 & 0 & $\$$ & $\$$ & $\$ \quad 940$ & 940 & $\$$ & $\$$ & - & $\$$ & - & $\$$ & - & $\$$ & 940 \\
\hline 115 & $\begin{array}{l}\text { Lineman Crew \#2 - Installing poles - Incl augering holes; \& } \\
\text { placing poles. Est } 1-45^{\prime} \text { pole to be placed. }\end{array}$ & 1 & Ea & 5.0 & 5 & $\$ 501$ & 2,505 & $\$$ & $\$$ & $\$$ & $\$$ & - & $\$$ & - & $\$$ & - & $\$$ & 2,505 \\
\hline 116 & Mat' Allowance - Est sml tools \& misc. & 1 & Ls & 0.0 & 0 & $\$$ & $\$$ & $\$ \quad 250$ & 250 & $\$-$ & $\$$ & - & $\$$ & - & $\$$ & - & $\$$ & 250 \\
\hline 117 & $\begin{array}{l}\text { Electrician Crew \#3 - Installing Wire - Incl placing wire on } \\
\text { pole and preparing for tie-in activities. Incl pulling } 397.5 \\
\text { wire from south end of triangle to mini sub-station - Est } 1 \\
\text { sys of } 3 \text { wire } x 7920 \mathrm{Lf}(1.5 \text { miles })=23,760 \text { Lf. }\end{array}$ & 23,760 & Lf & 0.002 & 44 & $\$ 442$ & $\$ \quad 19,470$ & $\$-$ & $\$$ & $\$$ & $\$$ & - & $\$$ & - & $\$$ & - & \$ & 19,470 \\
\hline 119 & $\begin{array}{l}\text { Lineman Crew \#4 - Perform Tie-ins - Incl prep for tie-in; } \\
\text { performing tie-in; \& completing system test \& approval. }\end{array}$ & 1 & Ls & 10.0 & 10 & $\$ 545.00$ & 5,450 & $\$$ & $\$$ & $\$$ & $\$$ & - & $\$$ & - & $\$$ & - & 1 & 5,450 \\
\hline 120 & $\begin{array}{l}\text { Mat' Allowance - Est smi tools \& misc. } \\
\text { Subtotal }\end{array}$ & 1 & Ls & 0.0 & $\begin{array}{c}0 \\
1,137\end{array}$ & $\$-$ & \begin{tabular}{|lc}
$\$$ & - \\
$\$$ & 555,415
\end{tabular} & $\$ 500$ & $\begin{array}{|lr|} & 500 \\
\$ & 209,895 \\
\end{array}$ & $\$$ - & $\frac{\$}{\$}$ & - & $\$$ & - & $\frac{\$}{\$}$ & $\frac{-}{4,512}$ & $\frac{\$}{\$}$ & $\begin{array}{r}500 \\
769,822 \\
\end{array}$ \\
\hline & & & & & & & & & & & & & & & & & & \\
\hline & 2.6 - Install West Side Arial Lines to Existing 300 Area S & & & & & & & & & & & & & & & & & \\
\hline & Includes - Lay-out work; survey ground; install hardware on & poles; in: & tall pol & es; inst & II wire on & ooles; perforn & m tie-ins; \& te & st service. & & & & & & & & & & \\
\hline 121 & $\begin{array}{l}\text { Lineman Crew \#1- Incl placing hardware on transition pole } \\
\text { on west side sub-st to existing west side } 300 \text { Ara power } \\
\text { lines. Est } 2-45 \text { ' poles to be prepared for setting hardware } \\
\text { config (dbl circuit) for elect tie in to existing sys. }\end{array}$ & 2 & Ea & 10.0 & 20 & $\$ 423.00$ & 8,460 & $\$$ & $\$$ & $\$$ & $\$$ & - & $\$$ & - & $\$$ & - & $\$$ & 8,460 \\
\hline
\end{tabular}

WASHINGTON CLOSURE HANFORD, INC. ESTIMATE PRICING SHEET PROJECT

TITLE: 300 Area Utility Repacement Project - Electrical - Option \#5 2.0 Two Lines From Richland / Buildings Transformers * Rework Power Feeds At 5 Loc. Inside 300 Area

- Reurk Power Feeds At 5 Loc. Inside 300 Area

Date: $05 / 01 / 07$

By: Dan Jakubek

Berv: : 0

$\prod_{\infty}^{-10}$ 
Data furnished in connection with this proposal shall not be disclosed outside WROPRIETARY INFORMATION

WASHINGTON CLOSURE HANFORD, INC. ESTIMATE PRICING SHEET RIVER CORRIDOR CLEAN UP PROJECT RICHLAND, WASHINGTON

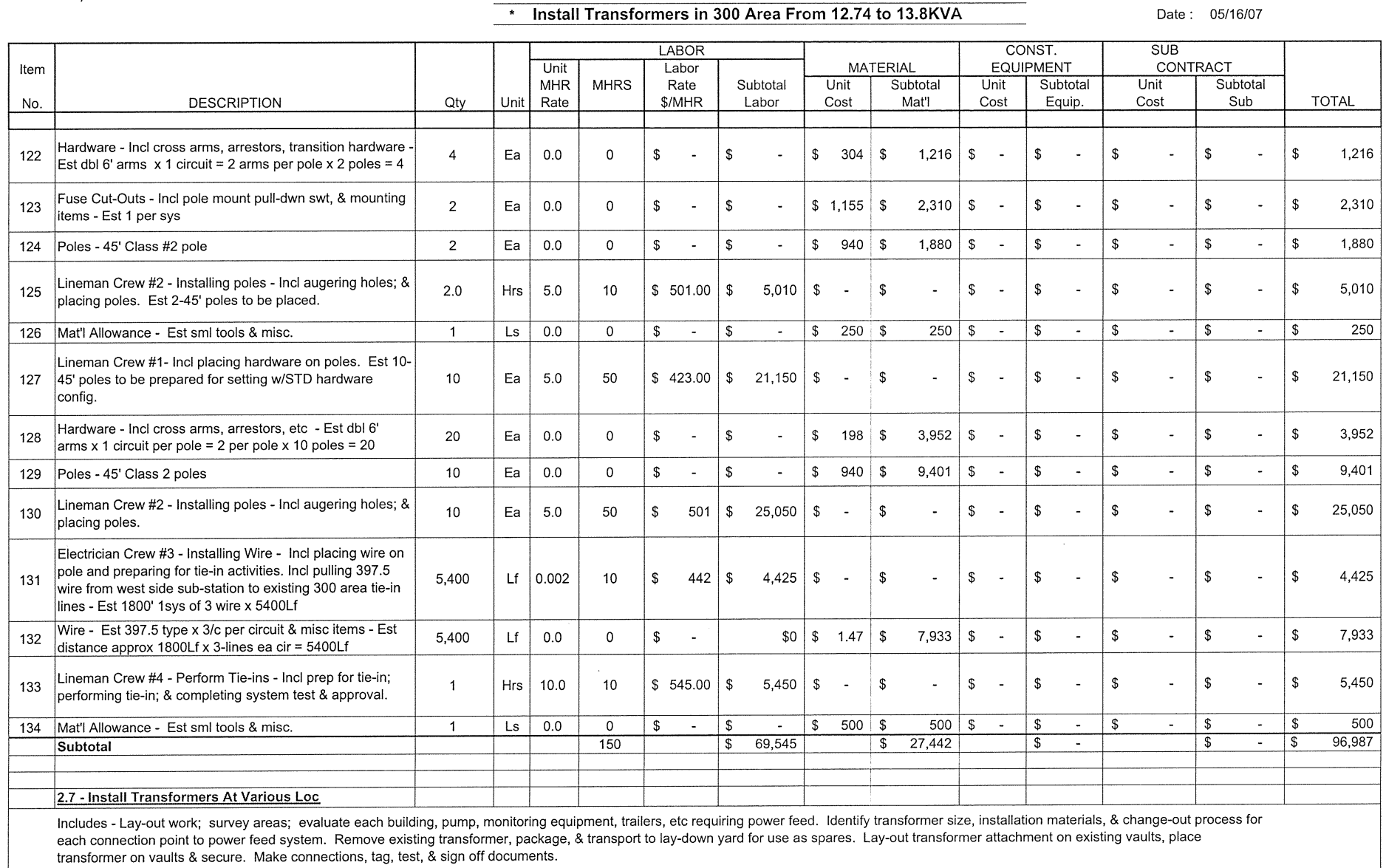

TITLE: 300 Area Utility Repacement Project - Electrical - Option \#5 SUBJECT: 20 Two Lines From Richland/ Buildings Transformers $*$ Rework Power Feeds At 5 Loc. Inside 300 Area * Route Power From SHC SubSt. To 300 Area South 10

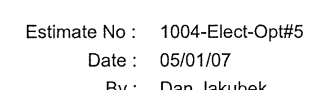


PROPRIETARY INFORMATION

WASHINGTON CLOSURE HANFORD, INC. ESTIMATE PRICING SHEET 促 RICHLAND, WASHINGTON
TITLE: 300 Area Utility Repacement Project - Electrical - Option \#5 SUBJECT: 2.0 Two Lines From Richland / Buildings Transformers * Rework Power Feeds At 5 Loc. Inside 300 Area * Rework Power Feeds At 5 Loc. Inside 300 Area * Install Transformers in 300 Area From 12.74 to $13.8 \mathrm{KVA}$
Estimate No: $1004-$ Elect-Opt\#5

Date: $05 / 01 / 07$

By: Dan Jakubek

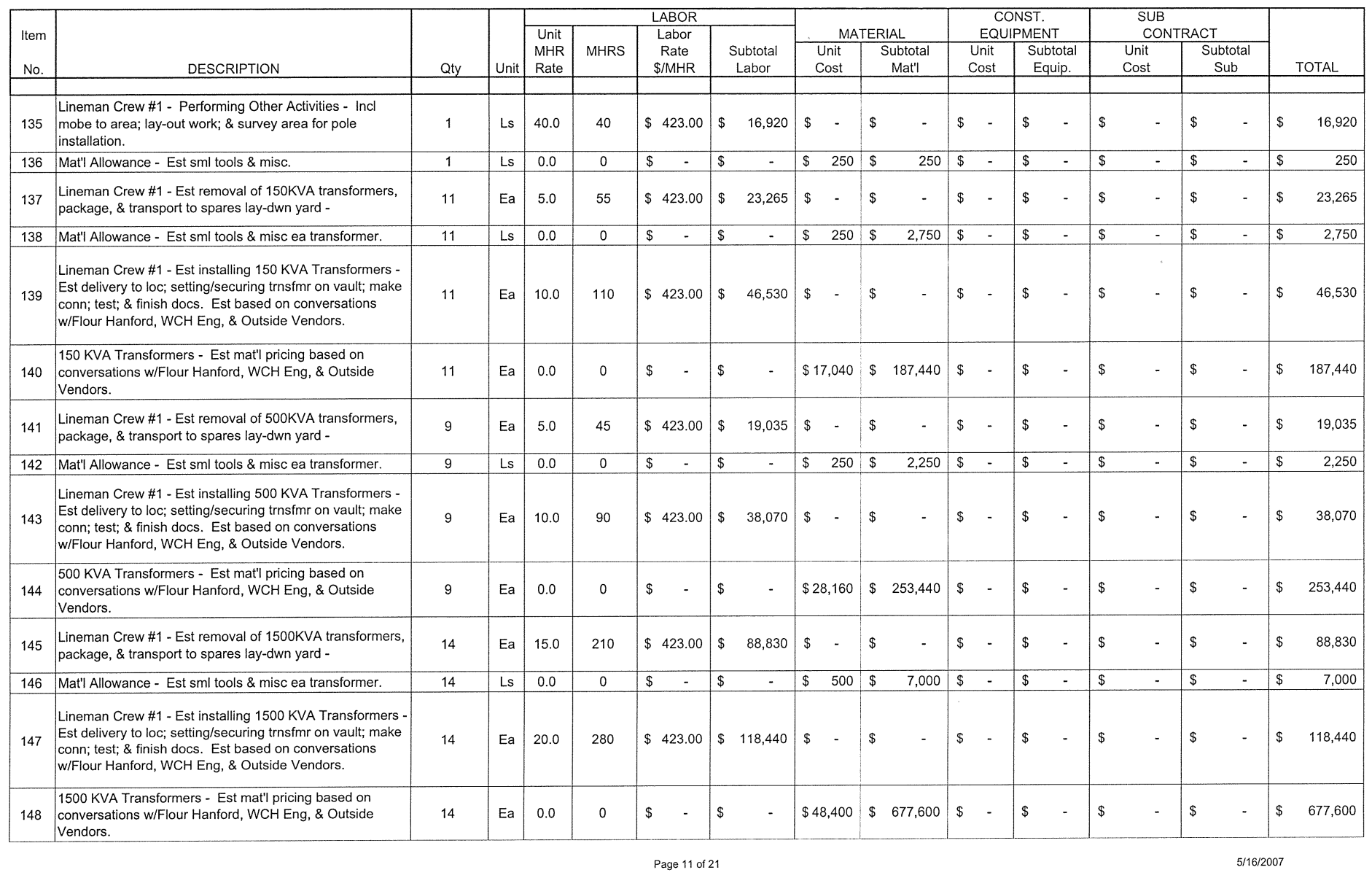


PROPRIETARY INFORMATION
Data furnished in connection with this proposal shall not be disclosed outside WCH approval, and shall not be duplicated, used, or discussed for any purpose other than to evaluate the proposal.

WASHINGTON CLOSURE HANFORD, INC. ESTIMATE PRICING SHEET RIVER CORRIDOR CLEAN UP PROJECT RICHLAND, WASHINGTON

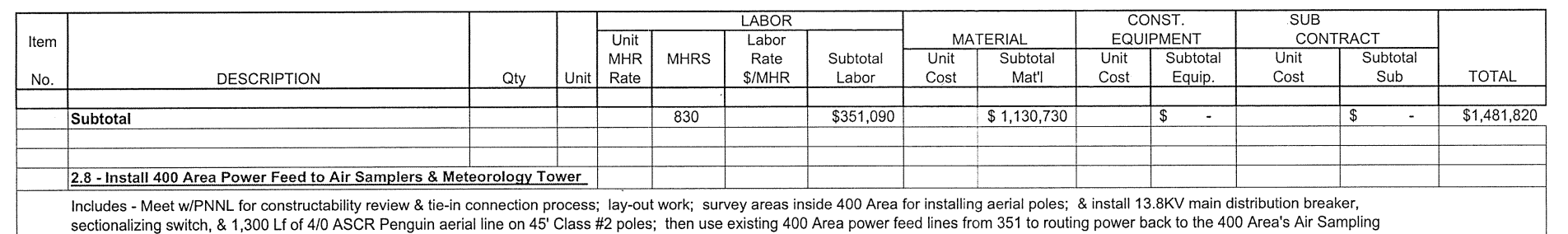
equipment and Meteorology Tower.

149 Lineman Crew \#1- Incl mobe to area; lay-out work; \&

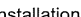

Mat'l Allowance - Est sml tools \& misc. Estimate Elect Tie-in at 400 Area - Incl 13.8KV distribution

151 Est based on conversations w/Flour Hanford, WCH Eng, \&

TITLE: 300 Area Utility Repacement Project - Electrical - Option \#5 SUBJECT: 2.0 Two Lines From Richland / Buildings Transformers $*$ Rework Power Feeds At 5 Loc. Inside 300 Area

Estimate No: $\quad$ 1004-Elect-Opt\#5 Date: $05 / 01 / 07$ * Route Power From SHC SubSt. To 300 Area South * Install Transformers in 300 Area From 12.74 to $13.8 \mathrm{KVA}$

Lineman Crew \#1- Incl placing hardware on std poles. Es circuit). (1)

Hardware - Incl cross arms, arrestors, transition hardware Eot dol $6^{\prime}$ arms $\times 1$ circuit per pole $=2$ arms per pole $\times 9$

Fuse Cut-Outs - Incl installation of hardware items - Est 1
at ea end

55 Poles - 45' Cass 42 pole

56 Lineman Crew \#2 Installing poles - Incl augering holes: \& Linemanan Crew $\# 2$ - Installing poles - Incl augering holes; \&

Lineman Crew \#3 - Installing Wire - Incl placing wire on pole and preparing for tie-in activities. Est $1300^{\prime} \times 3=$ 3900Lf of wire to be placed.

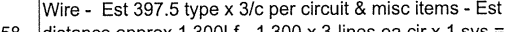
3.9000 f Lineman Crew - Perform Tie-ins - Incl prep for tie-in; 160 Matl' Allowance - Est sml tools \& misc. Subtotal

\begin{tabular}{|c|c|c|c|c|c|c|c|c|c|c|c|c|c|c|c|c|c|c|}
\hline 1 & Ls & 10.0 & 10 & $\$ 423.00$ & $\$$ & 4,230 & $\$$ & & $\$$ & $\$$ & $\$$ & - & $\$$ & - & $\$$ & - & $\$$ & 4,230 \\
\hline 1 & Ls & 0.0 & 0 & $\$$ & $\$$ & - & $\$$ & 250 & 250 & $\$-$ & $\$$ & - & $\$$ & - & $\$$ & - & $\$$ & 250 \\
\hline 1 & Ls & 0.0 & 0 & $\$$ & $\$$ & - & $\$$ & - & $\$$ & $\$-$ & $\$$ & - & $\$$ & 40,000 & $\$$ & 40,000 & $\$$ & 40,000 \\
\hline 9 & Ea & 5.0 & 45 & $\$ 423.00$ & $\$$ & 19,035 & $\$$ & - & $\$$ & $\$-$ & $\$$ & - & $\$$ & - & $\$$ & - & $\$$ & 19,035 \\
\hline 18 & Ea & 0.0 & 0 & $\$$ & $\$$ & - & $\$$ & 304 & 5,472 & $\$-$ & $\$$ & - & $\$$ & - & $\$$ & - & $\$$ & 5,472 \\
\hline 2 & $\mathrm{Ea}$ & 0.0 & 0 & $\$$ & $\$$ & - & $\$ 1$. & 155 & 2,310 & $\$-$ & $\$$ & . & $\$$ & - & $\$$ & - & $\$$ & 2,310 \\
\hline 9 & $\mathrm{Ea}$ & 0.0 & 0 & $\$$ & $\$$ & - & $\$$ & 940 & 8,461 & $\$$ & $\$$ & - & $\$$ & - & $\$$ & - & $\$$ & 8,461 \\
\hline 9 & $\mathrm{Ea}$ & 5.0 & 45 & $\$ 501.00$ & $\$$ & 22,545 & $\$$ & - & $\$$ & $\$$ & $\$$ & - & $\$$ & - & $\$$ & - & $\$$ & 22,545 \\
\hline 3,900 & Lf & 0.004 & 16 & $\$ 442.00$ & $\$$ & 6,895 & $\$$ & - & $\$$ & $\$$ & $\$$ & - & $\$$ & - & $\$$ & - & $\$$ & 6,895 \\
\hline 3,900 & $L f$ & 0.0 & 0 & - & $\$$ & - & $\$$ & 1.13 & 4,411 & $\$$ & $\$$ & - & $\$$ & - & $\$$ & - & $\$$ & 4,411 \\
\hline 1 & Ls & 30.0 & 30 & $\$ 545.00$ & $\$$ & 16,350 & $\$$ & - & $\$$ & $\$$ & $\$$ & - & $\$$ & - & $\$$ & - & $\$$ & 16,350 \\
\hline 1 & Ls & 0.0 & $\begin{array}{c}0 \\
146\end{array}$ & $\$ \quad-$ & $\$$ & \begin{tabular}{r|}
- \\
699055
\end{tabular} & $\$$ & 500 & $\begin{array}{|lr|}\$ \quad 500 \\
\$ 21404\end{array}$ & $\$-$ & $\$$ & - & $\$$ & - & $\$$ & - & $\$$ & $\begin{array}{r}500 \\
130459\end{array}$ \\
\hline
\end{tabular}


Data funished in connection with this proposal shall not be disclosed outside WCH HapriEval, and shall not be duplicated, used, or discussed for any purpose other than to evaluate the proposal

WASHINGTON CLOSURE HANFORD, INC. ESTIMATE PRICING SHEET RIVER CORRIDOR CLEAN UP PROJECT RICHLAND, WASHINGTON

TITLE: 300 Area Utility Repacement Project - Electrical - Option \#5 SUBJECT: 2.0 Two Lines From Richland / Buildings Transformers * Rework Power Feeds At 5 Loc. Inside 300 Area * Route Power From SHC SubSt. To 300 Area South * Install Transformers in 300 Area From 12.74 to 13.8KV
Estimate No: $1004-$ Elect-Opt\#5 Date: $05 / 01 / 07$ By: Dan Jakubek Rev No: 0

Date : $05 / 16 / 07$

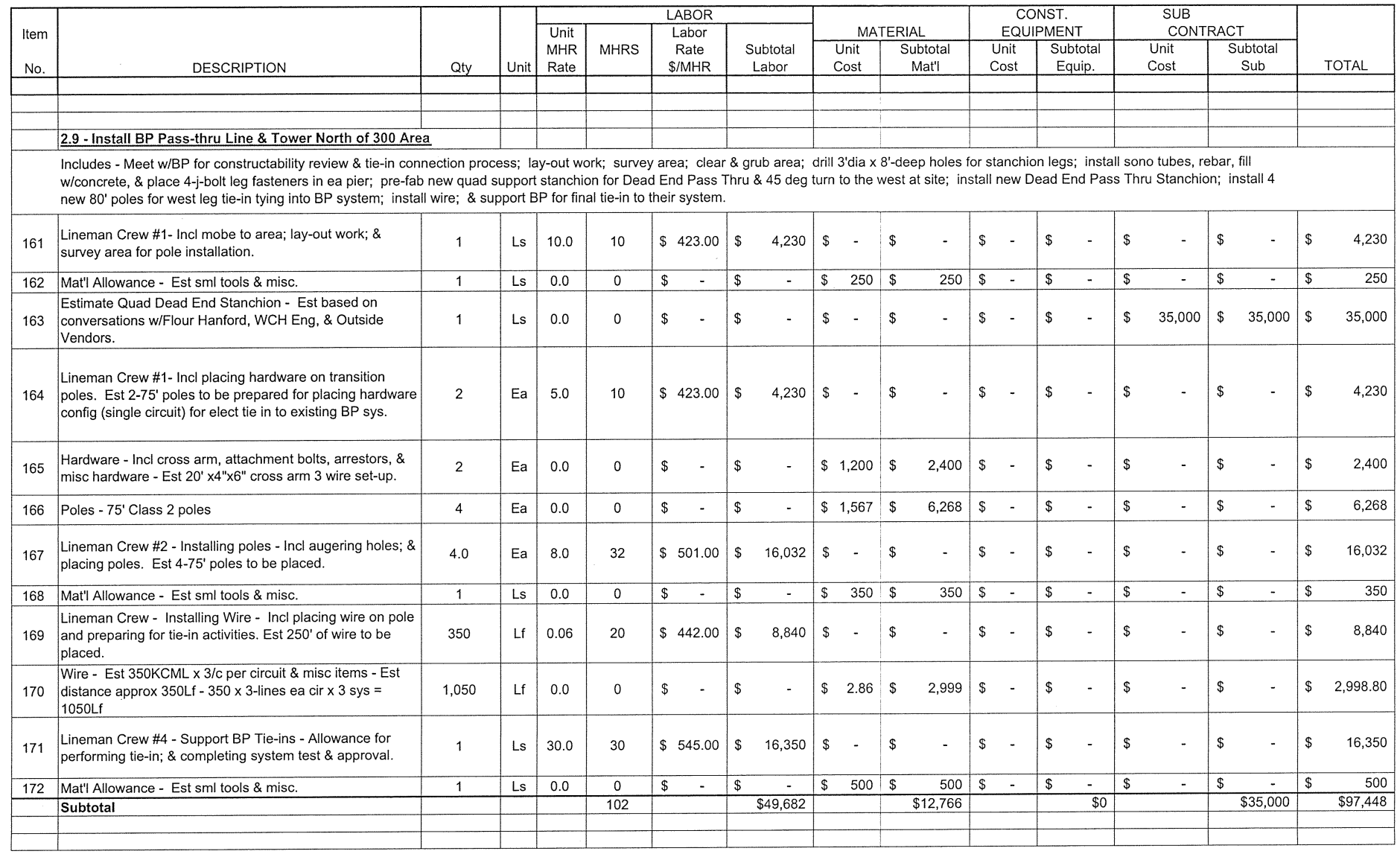


PROPRIETARY INFORMATION RICHLAND, WASHINGTON

TITLE: 300 Area Utility Repacement Project - Electrical - Option \#5 SUBJECT: 2.0 Two Lines From Richland / Buildings Transformers * Rework Power Feeds At 5 Loc. Inside 300 Area * Route Power From SHC SubSt. To 300 Area South * Install Transformers in 300 Area From 12.74 to 13.8KVA
Estimate No: 1004-Elect-Opt\#5

Date : $05 / 01 / 07$

By: Dan Jakubek

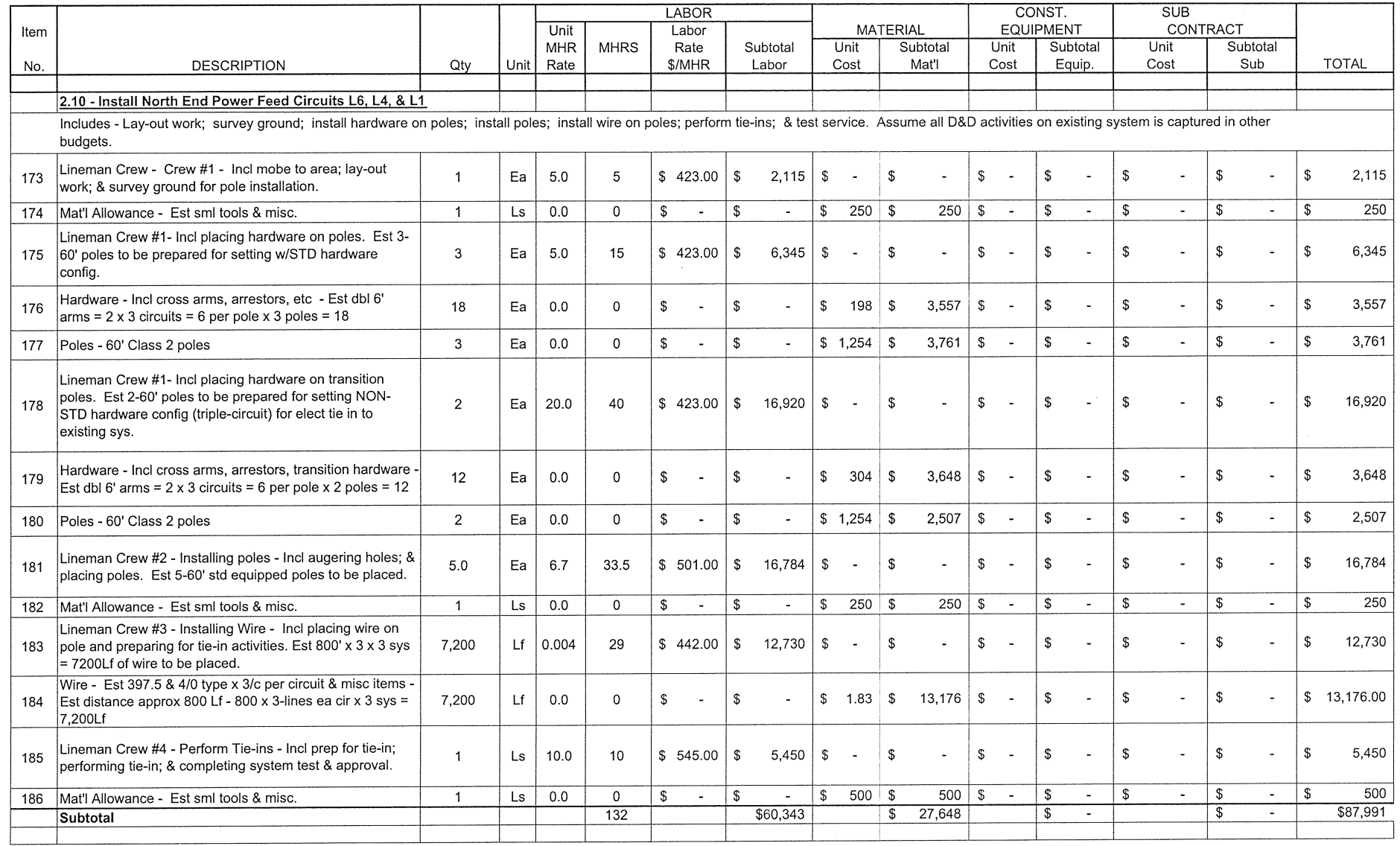




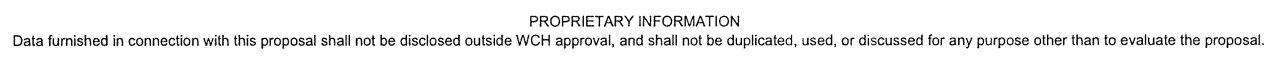

WASHINGTON CLOSURE HANFORD, INC. ESTIMATE PRICING SHEET RIVER CORRIDOR CLEAN UP PROJECT RICHLAND, WASHINGTON

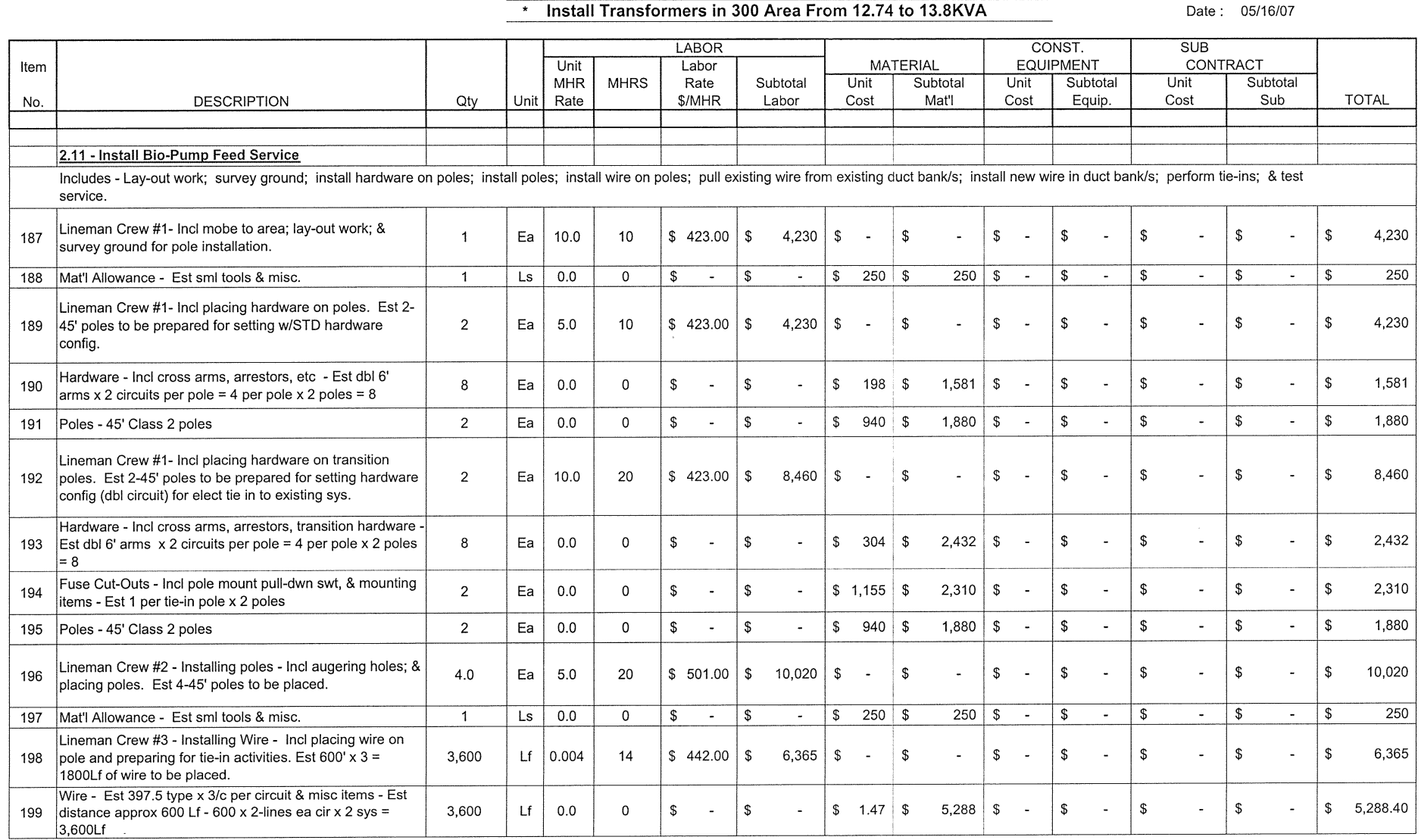

TITLE: 300 Area Utility Repacement Project - Electrical - Option \#5 SUBJECT: 20 Two Lines From Richland/Buildings Transformers * Rework Power Feeds At 5 Loc. Inside 300 Area * Route Power From SHC SubSt. To 300 Area South

Estimate No: 1004-Elect-Opt\#5 Date: $05 / 01 / 07$ 
PROPRIETARY INFORMATION
Data furnished in connection with this proposal shall not be disclosed outside WCH approval, and shall not be duplicated, used, or discussed for any purpose other than to evaluate the proposal.

WASHINGTON CLOSURE HANFORD, INC. ESTIMATE PRICING SHEET PROJEC NCRLAND, WASHINGTON
TITLE: 300 Area Utility Repacement Project - Electrical - Option \#5 SUBJECT: 2.0 Two Lines From Richland / Buildings Transformers * Rework Power Feeds At 5 Loc. Inside 300 Area * Install Transformers in 300 Area From 12.74 to $13.8 \mathrm{KVA}$
Estimate No: 1004-Elect-Opt\#5 Date: $05 / 01 / 07$ Rev No: 0

Date: $05 / 16 / 07$

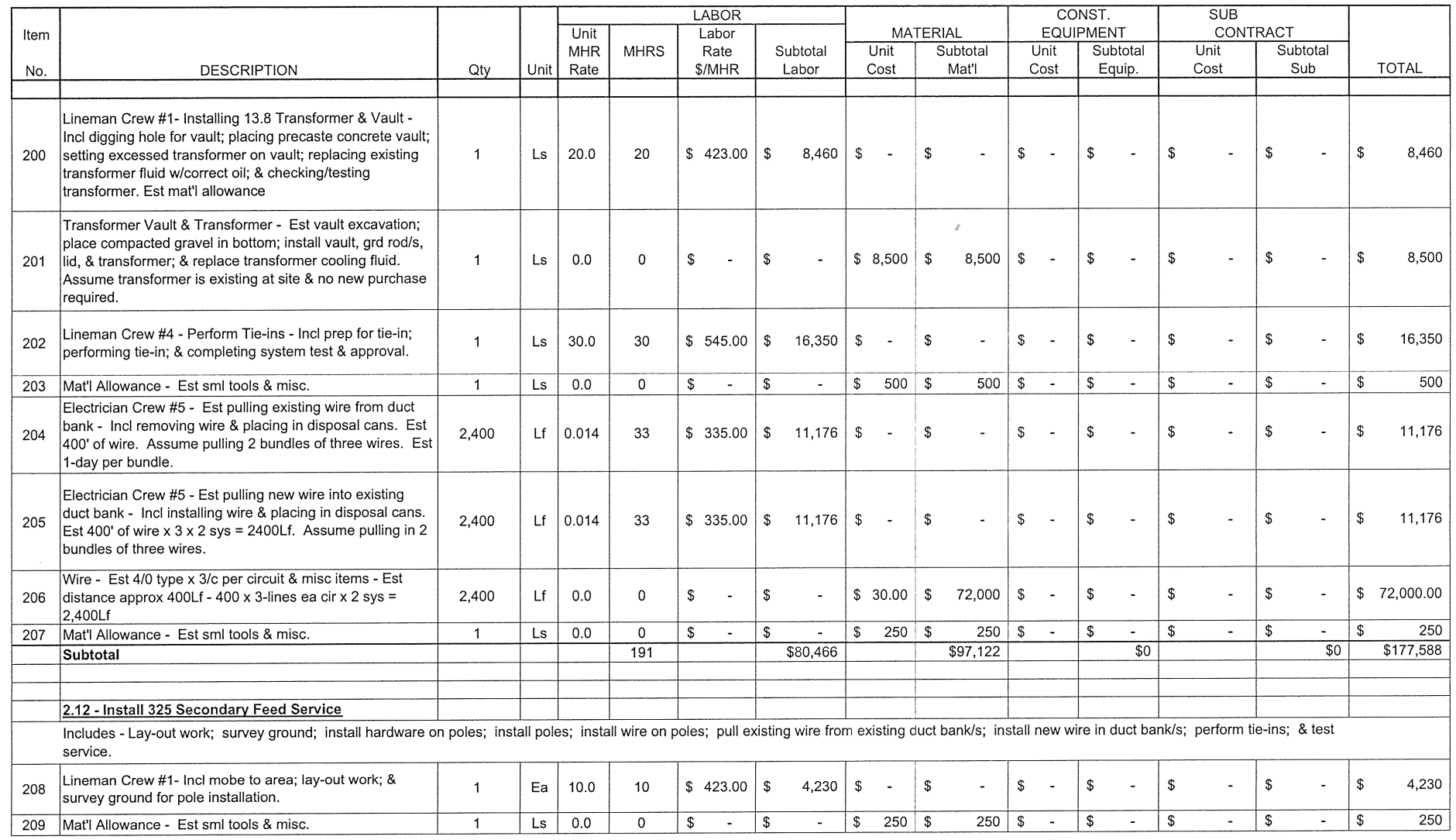


PROPRIETARY INFORMATION
Data furnished in connection with this proposal shall not be disclosed outside WCH apporval, and shall not be duf

WASHINGTON CLOSURE HANFORD, INC. ESTIMATE PRICING SHEET

TVE CORRIDOR CLEAN UP PROJECT RICHLAND, WASHINGTON
TITLE: 300 Area Utility Repacement Project - Electrical - Option \#5 SUBJECT: 20 Two Lines From Richland/Buildings Transformers * Rework Power Feeds At 5 Loc. Inside 300 Area

* Rework Power Feeds At 5 Loc. Inside 300 Area

* Install Transformers in 300 Area From 12.74 to 13.8KVA
Estimate No: $1004-$ Elect-OpttH5

Date: $05 / 01 / 07$

an Jakubek

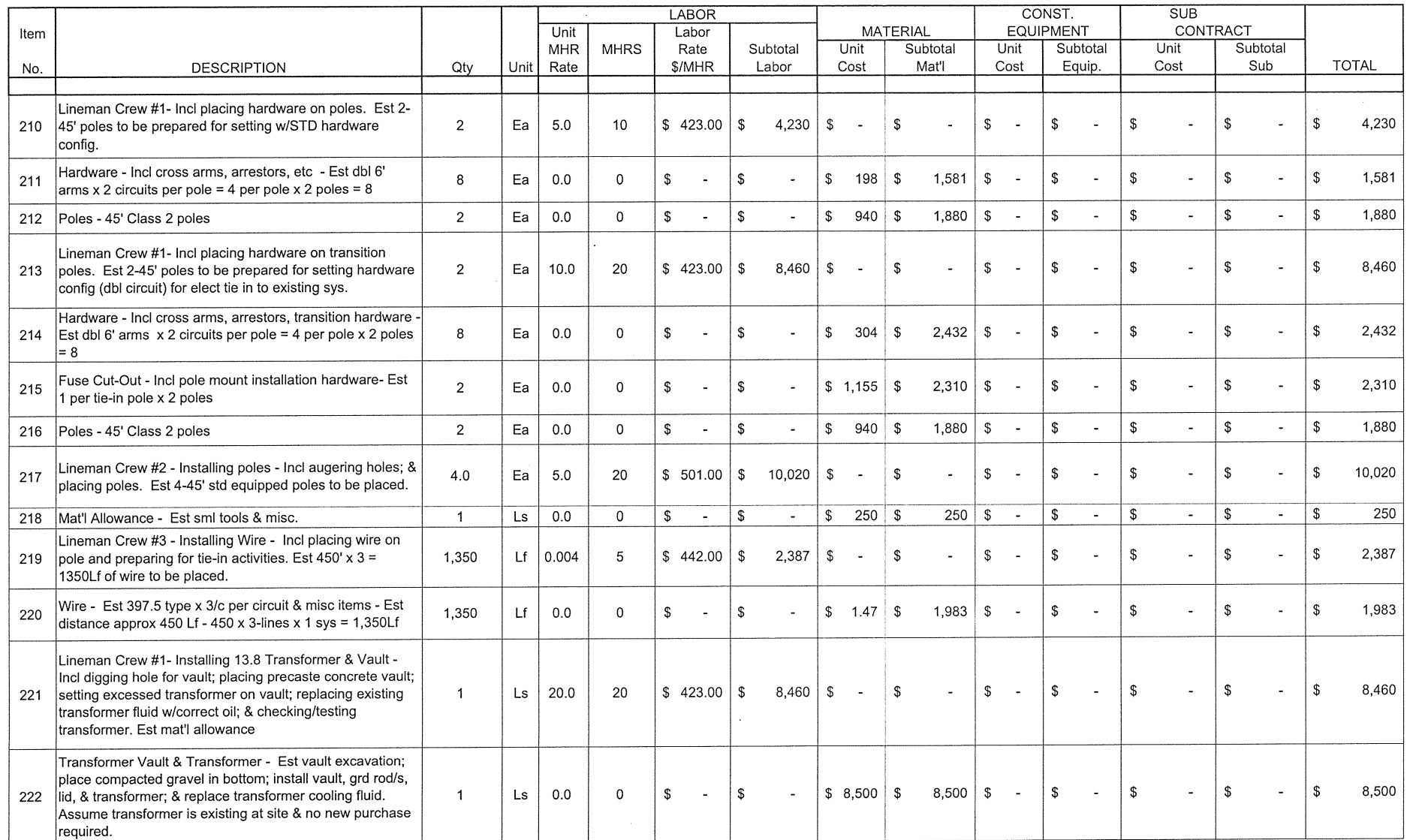


PROPRIETARY INFORMATION
Data furnished in connection with this proposal shall not be disclosed outside WCH approval, and shall not be duplicated, used, or discussed for any purpose other than to evaluate the proposal.

WASHINGTON CLOSURE HANFORD, INC. ESTIMATE PRICING SHEET RTERCORRDOR GIEAN UP PROJECT WASHINGTON

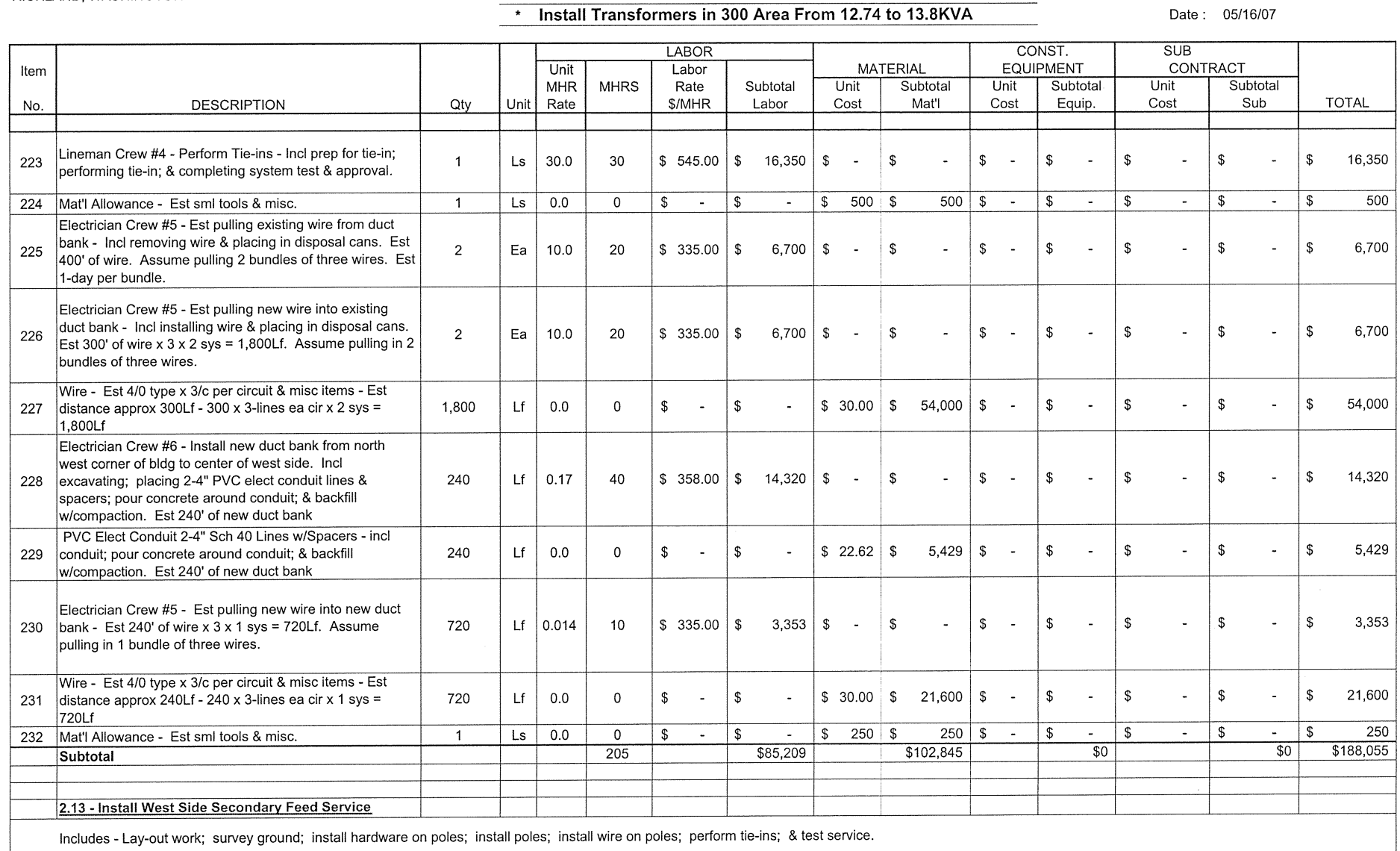

TITLE: 300 Area Utility Repacement Project - Electrical - Option \#5 SUBJECT: $\frac{\text { 2.0 Two Lines From Richland / Buildings Transformers }}{2}$ * Rework Power Feeds At 5 Loc. Inside 300 Area

Estimate No: $1004-$ Elect-Opt\#5 Date: $05 / 01 / 07$ RevNo: 0

Oun work, survey ground, install hardware on poles, install poles, install wire on poles; perform tie-ins; \& test senve. 
PROPRIETARY INFORMATION

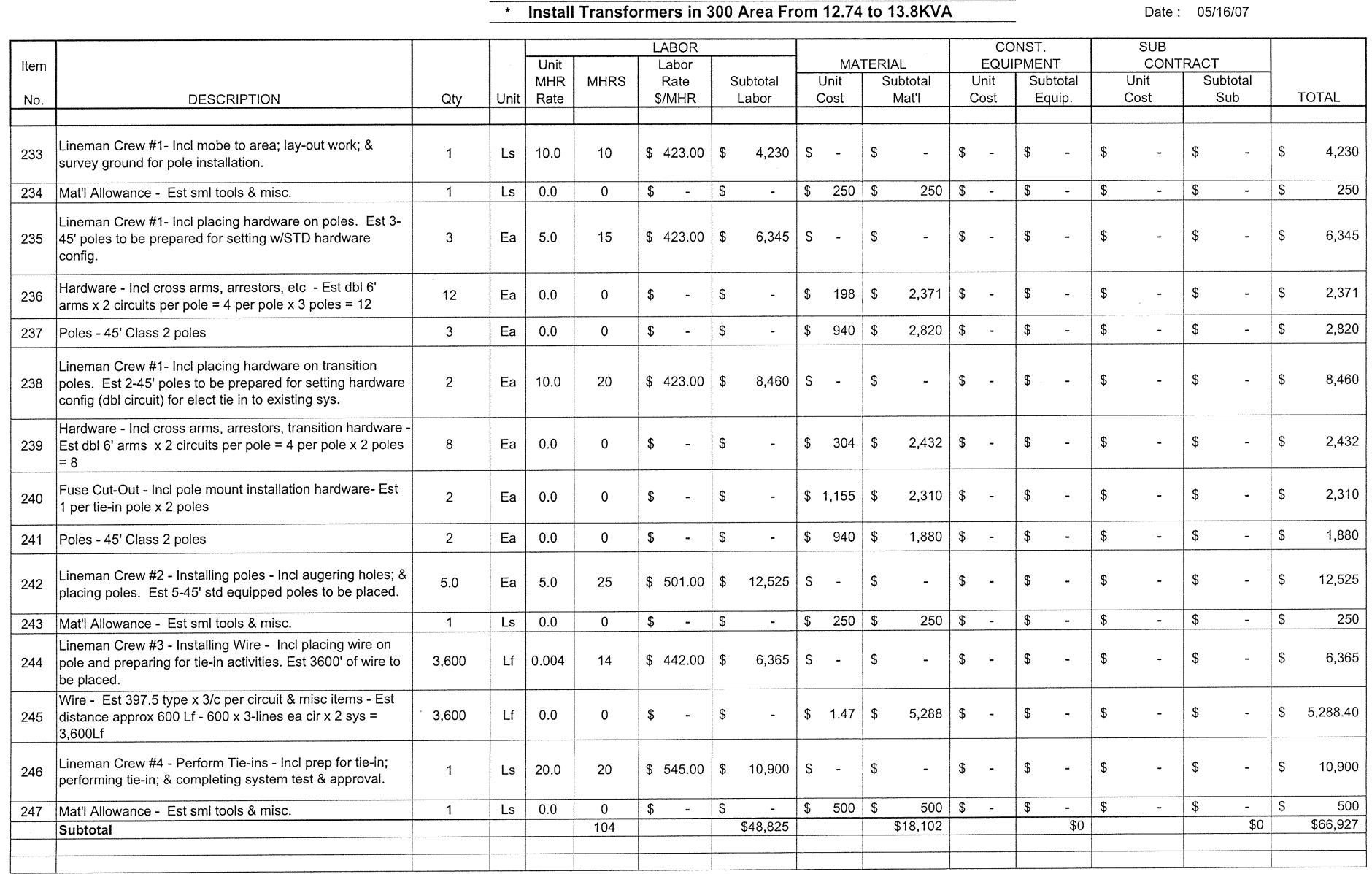

Estimate No: $1004-$ Elect-Opt\#5 Date: $05 / 01 / 07$
WASHINGTON CLOSURE HANFORD, INC. ESTIMATE PRICING SHEET PROJEC

TITLE: 300 Area Utility Repacement Project - Electrical - Option \#5 SUBJECT: 20 Two Lines From Richland/Buildings Transformers 2.0 Two Lines From Richland/Buildings Transformer * Route Power From SHC SubSt. To 300 Area South ד 


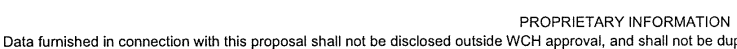

PROPRIETARY INFORMATION
WCH approval, and shall not be duplicated, used, or discussed for any purpose other than to evaluate the propos

WASHINGTON CLOSURE HANFORD, INC. ESTIMATE PRICING SHEET RIER CORRIDOR CLEAN UP PROJECT RICHLAND, WASHINGTON
TITLE: 300 Area Utility Repacement Project - Electrical - Option \#5 SUBJECT: 2.0 Two Lines From Richland / Buildings Transformers * Rework Power Feeds At 5 Loc. Inside 300 Area * Route Power From SHC SubSt. To 300 Area South

Date: $05 / 01 / 07$

By: Dan Jakubek

Rev No: 0

Date : $05 / 16 / 07$

\begin{tabular}{|c|c|c|c|c|c|c|c|c|c|c|c|c|c|c|}
\hline \multirow[b]{2}{*}{$\begin{array}{l}\text { Item } \\
\text { No. }\end{array}$} & \multirow[b]{2}{*}{ DESCRIPTION } & \multirow[b]{2}{*}{ Qty } & \multirow[b]{2}{*}{ Unit } & \multicolumn{4}{|c|}{$\angle A B O R$} & \multicolumn{2}{|c|}{ MATERIAL } & \multicolumn{2}{|c|}{$\begin{array}{c}\text { CONST. } \\
\text { EQUIPMENT }\end{array}$} & \multicolumn{2}{|c|}{$\begin{array}{l}\text { SUB } \\
\text { CONTRACT }\end{array}$} & \multirow[b]{2}{*}{ TOTAL } \\
\hline & & & & $\begin{array}{c}\text { Unit } \\
\text { MHR } \\
\text { Rate } \\
\end{array}$ & MHRS & $\begin{array}{c}\text { Labor } \\
\text { Rate } \\
\$ / M H R \\
\end{array}$ & $\begin{array}{c}\text { Subtotal } \\
\text { Labor }\end{array}$ & $\begin{array}{l}\text { M } \\
\text { Unit } \\
\text { Cost } \\
\end{array}$ & $\begin{array}{l}\text { RIAL } \\
\text { Subtotal } \\
\text { Mat"l }\end{array}$ & $\begin{array}{l}\text { EQL } \\
\text { Unit } \\
\text { Cost }\end{array}$ & $\begin{array}{l}\text { MENI } \\
\text { Subtotal } \\
\text { Equip. }\end{array}$ & $\begin{array}{l}\text { Co } \\
\text { Unit } \\
\text { Cost }\end{array}$ & $\begin{array}{c}\text { Subtotol } \\
\text { Sub }\end{array}$ & \\
\hline & 2.14 - Fire Suppression System & & & & & & & & & & & & & \\
\hline
\end{tabular}

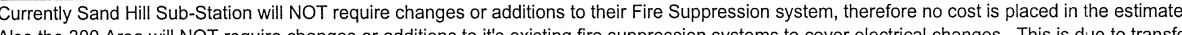

作 Protection.

Sand Hill sub-Station Fire Protection Costs - There will be

requirements Fire Marshall.

300 Area Electrical Equipment Fire Protection Costs -

249 current requirements are meet according to the Flour Hanford Fire Marshall.

\subsection{5-Clean Up Area, Demobe, \& Close-out Project}

Includes - Cleaning up area; demobe equipment; \& close-out proj at site.

250 \begin{tabular}{l}
$\begin{array}{l}\text { Engineer - Close-out various items, incl paper wk, \& meet } \\
\text { W/WCH \& Flour Hanford for site close-out. }\end{array}$ \\
\hline
\end{tabular}

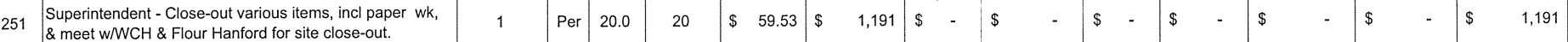

\& meet W/WCH \& Flour Hanford for sile close-out.

Lineman

Lineman - 4 man crew - Demobe - Est 5hrs ea site

34 Lineman Bucket Truck - W/Man Bucket Boom, \& Tool Yr/04 on Sides, 6x4, $400 \mathrm{Hp}, 7000 \mathrm{lbs}$ max, Dlesel, Lineman Pole Auger Truck - w/Man Boom, Pole Auger, \& s. 6x4, $400 \mathrm{Hp}, 70000 \mathrm{lbs}$ max

256 Lineman Utility Truck - $w /$ Tool Storage on Sides, $6 \times 4,250$ Hp, 35000 lbs max, Diesel, Yr/04 - Est 2 trucks
Truck Tractor - Misc Mod, GVW 600000 Lbs, $6 \times 4 / 400$

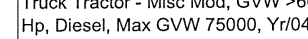

\begin{tabular}{l|l|l|}
\hline 1 & $c+4$ \\
\hline & 0 & 0 \\
\hline
\end{tabular}

\begin{tabular}{l|l|l|ll|lllll|ll|ll|ll|lll|ll|ll|}
$\mathrm{Crft}$ & 20.0 & 20 & $\$$ & 61.04 & $\$$ & 1,221 & $\$$ & - & $\$$ & - & $\$$ & - & $\$$ & - & $\$$ & - & $\$$ & - & $\$$ & 1,221 \\
\hline
\end{tabular}

5

20.0 | 180

\begin{tabular}{lll|ll|ll|ll|llll|llllllll} 
& 20.0 & 80 & $\$$ & 55.79 & $\$$ & 4,463 & $\$$ & - & $\$$ & - & $\$$ & - & $\$$ & - & $\$$ & - & $\$$ & - & $\$$ & 4,463 \\
\hline
\end{tabular}

\begin{tabular}{l|l}
\hline & 5
\end{tabular}

\begin{tabular}{l|l|l|l|l|l|l}
5 & Hrs & 0.0 & \\
\end{tabular}

\begin{tabular}{|c|c|c|c|c|c|c|c|c|c|}
\hline 5 & Hrs & 0.0 & 0 & $\$$ & - & $\$$ & $\$$ & & $\$ 59.04$ \\
\hline & Hrs & 0.0 & 0 & & & & $\$$ & & \\
\hline
\end{tabular}

\begin{tabular}{l|l|l|l|l}
5 & Hrs & 0.0
\end{tabular}

\begin{tabular}{|l|l|l|l}
\hline 0 & $\$$
\end{tabular}


PROPRIETARY INFORMATION

WASHINGTON CLOSURE HANFORD, INC. ESTIMATE PRICING SHEET

UP PROJECT RICHLAND, WASHINGTON
TITLE: 300 Area Utility Repacement Project - Electrical - Option \#5 SUBJECT: 2.0 Two Lines From Richland/Buildings Transformers * Rework Power Feeds At 5 Loc. Inside 300 Area

* Rework Power Feeds At 5 Loc. Inside 300 Area

* Install Transformers in 300 Area From 12.74 to 13.8KVA
Estimate No : 1004-Elect-Opt\#5

Date: $05 / 01 / 07$

By: Dan Jakube

Date: $05 / 16 / 07$

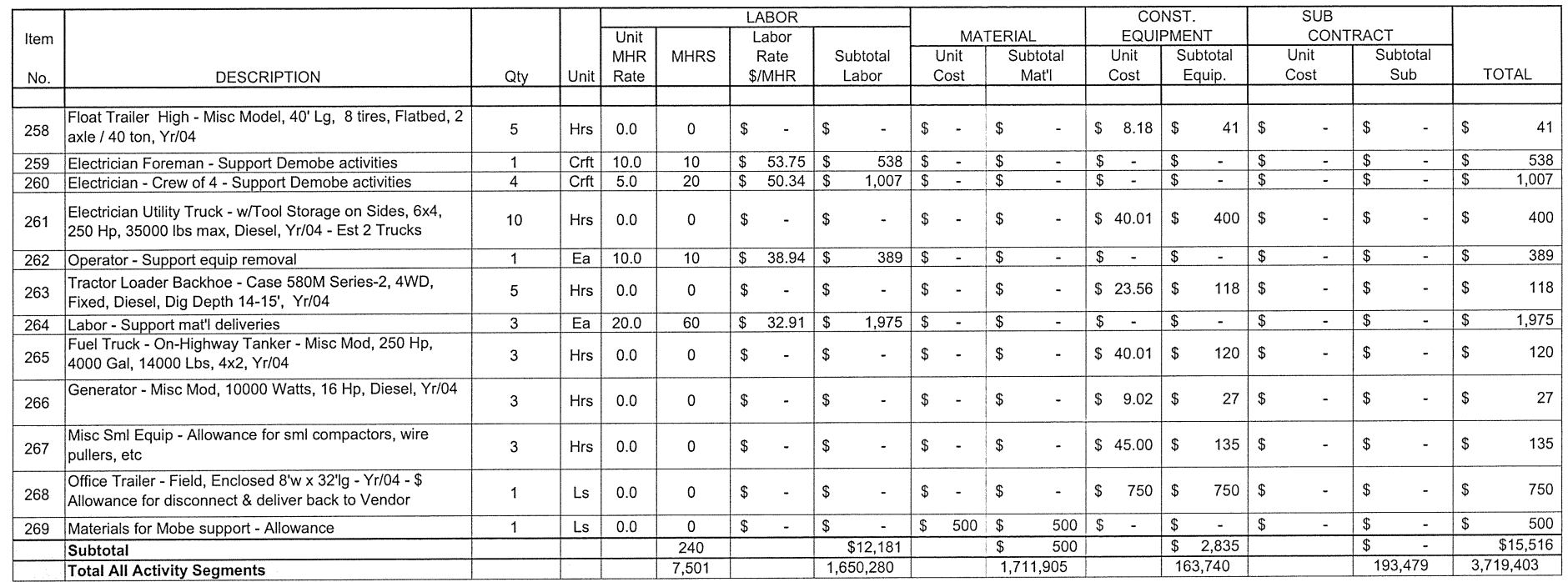




\section{APPENDIX C}

300 AREA ELECTRICAL UTILITY DECISION MEETING 
WCH-181

Rev. 0 
To:

COPIES:
DATE: $\quad$ May 22, 2007

FROM:

subject: SUMMARY OF DECISION MEETINGS FOR ELECTRICAL OPTIONS 300 AREA UTILITY RELOCATION PROJECT

Decision meetings were held on May 16 and May 17, 2007 to review and rank electrical service options as part of the 300 Area Utility Relocation Project. At the May 16 meeting, the Electrical Discipline Team and the Utility Relocation Project Core Team reviewed the pros and cons of the five options for providing reliable electrical service to the retained facilities in the 300 Area. An interoffice memorandum prepared by Arnold Gutmanis provided a description and cost estimate for each option. The IOM and its option maps were used as a basis of discussion of the options. A listing of the selection criteria was also distributed at the meeting.

A second meeting was called for the morning of May 17 to continue the decision process. A key decision by the team early in the May 17 meeting was elimination of Options 4 and 5 from further consideration. Options 4 and 5 both have an estimated capital cost of more than $\$ 5 \mathrm{M}$ exceeding the threshold that would cause the project to require line item funding. This cost level and its associated lengthy and uncertain funding process caused the team to assign a grade of "No-Go" to Options 4 and 5 for the schedule criteria. Due to this grade, those options were dropped from further consideration.

Continuing their grading process, the attendees discussed the assignment of a grade of high, medium or low $(\mathrm{H}, \mathrm{M}$ or $\mathrm{L})$ to indicate how well each of the three remaining options met each selection criterion. A spreadsheet (see attached two pages) was used to document the grade assignments. The attendees also identified a weighting factor for each criterion. Using the weighting factors assigned and a score associated with each grade (see lower left corner of ranking spreadsheet for weighting factor and grade scores), a weighted score was calculated for each option. After the initial grading effort and addition discussion, the grading for Option 2 was increased to $\mathrm{M}+$ for three criteria where the team felt that the grade was above an $\mathrm{M}$ but below $\mathrm{H}$.

The resulting weighted scores for each of the three options were compared against the total possible points. Option 1 was ranked highest ( $75 \%$ of possible points) followed by Options 2 and 3 with $71 \%$ and $41 \%$ of the possible points. The recommended option, Option 1, involves reuse of the existing 351 Substation. The estimated cost for Option 1 is approximately $\$ 1.3 \mathrm{M}$ less expensive than the next closest option.

JNW:ldh

Attachment: 300 Area Utility Relocation -- Electrical Options Worksheet 
WCH-181

Rev. 0

Meeting Attendees

S. I Bennion H7-21, w/a

D. E. Dieterle L1-04, w/a

G. A. Edwards E6-27, w/a

R. G. Egge X5-50, w/a

R. Gerk J2-18, w/a

R. F. Guercia A3-04, w/a

A. V. Gutmanis L1-01, w/a

D. J. Jakubek H4-15, w/a

R. N. Krekel A3-04, w/a

D. A. Larson J2-09, w/a

C. MacDonald J2-45, w/a

G. M. MacFarlan L6-06, w/a

D. J. McBride H4-15, w/a

A. G. Minister J2-38, w/a

M. E. Olson J2-09, w/a

J. Turner K9-42, w/a

\section{Copies}

S. Baker S4-12, w/a

C. E. Carlson S4-12, w/a

T. H. Leone L1-04, w/a

D. J. Tollefson E6-29, w/a

Document Control H4-11, w/a 


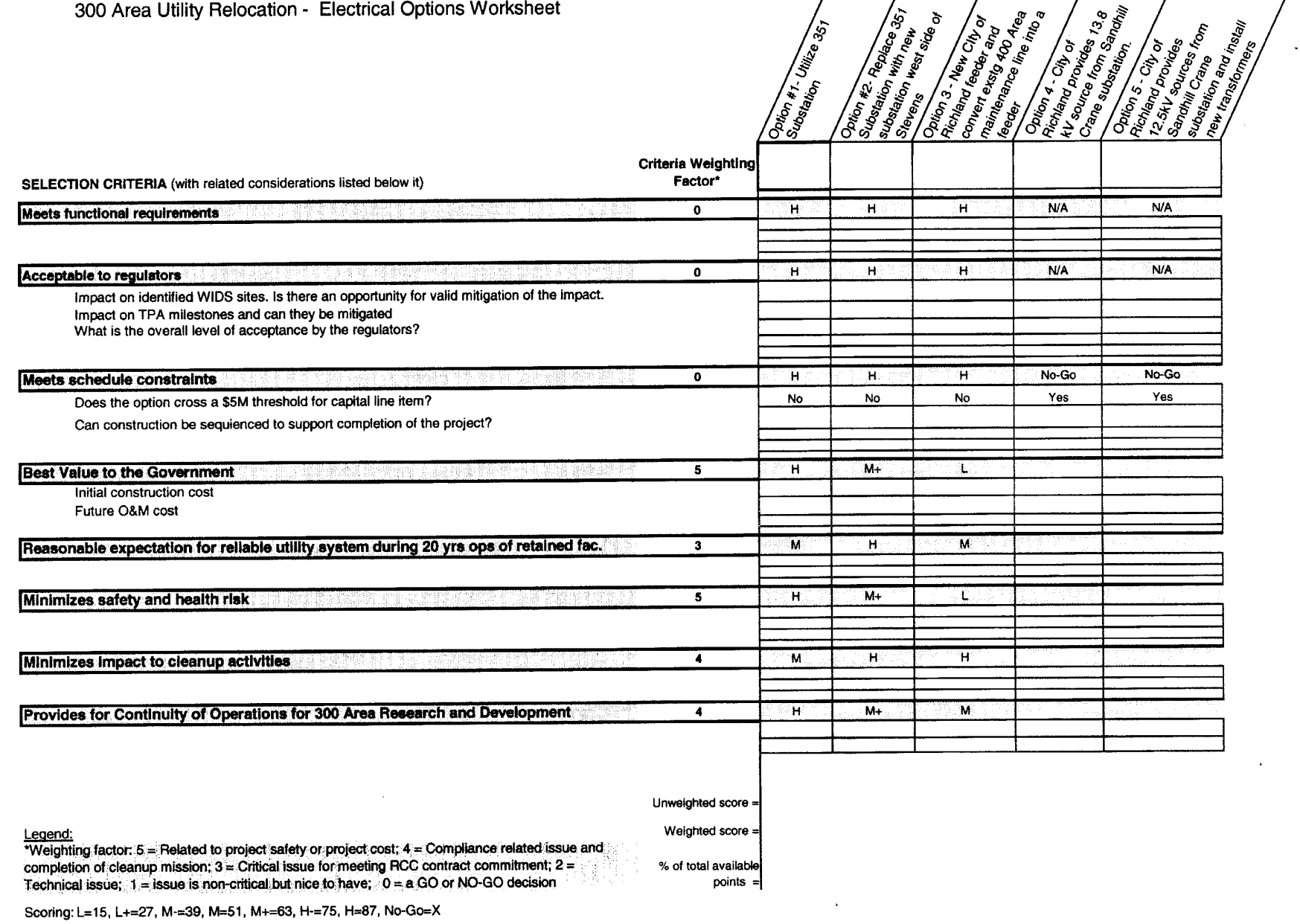




\begin{tabular}{|c|c|c|c|c|c|c|}
\hline SELECTION CRTTERIA (with related considerations listed below it) & $\begin{array}{l}\text { Criteria Welghtling } \\
\text { Factor" }\end{array}$ & & & & & \\
\hline Meots functional roquirementis & 0 & 87 & 87 & 87 & NA & NAA \\
\hline Acceptable to regulators & 0 & 8 & 87 & 87 & NA & N/A \\
\hline 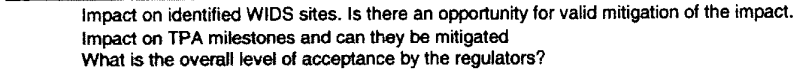 & & & & & & \\
\hline Can construction be sequienced to support completion of the project? & & & & & & \\
\hline 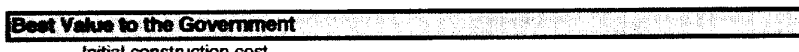 & 5 & 87 & 63 & 15 & NA & NA \\
\hline $\begin{array}{l}\text { hinitial construction cost } \\
\text { Future o\&M cost }\end{array}$ & & & & & & \\
\hline Heasonable expectation for relliable utillity system during 20 yrs ops of retalined fac.. & 3 & 51 & 87 & 51 & NA & NA \\
\hline Minimizes safiety and health risk & 5 & 87 & 63 & 15 & N/A & N/A \\
\hline Minimizes impact to cleanup activities. & 4 & 51 & 87 & 87 & NA & NA \\
\hline Provides for Continulity of Operatlons for 300 Area Research and Developmemt & 4 & 87 & 63 & 51 & NA & N/A \\
\hline Legend & $\begin{array}{r}\text { Unweighted score }= \\
\text { Weighted score }=\end{array}$ & $\begin{array}{r}624 \\
1575 \\
\end{array}$ & $\begin{array}{r}624 \\
1491 \\
\end{array}$ & $\begin{array}{l}480 \\
855 \\
\end{array}$ & $\begin{array}{l}\text { \#VALLEI } \\
\text { \#VALUEI }\end{array}$ & $\begin{array}{l}\text { \#VALUE } \\
\text { \#VALUEI }\end{array}$ \\
\hline 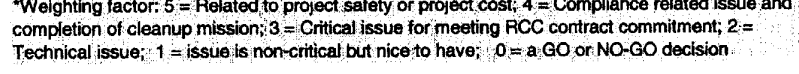 & $\begin{array}{c}\% \text { of total availabied } \\
\text { points }=\end{array}$ & $75 \%$ & $71 \%$ & $41 \%$ & \#VALUEI & \#VALUEI \\
\hline
\end{tabular}

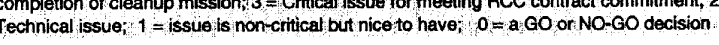

Scoring:L=15, L+=27, M=39, M=51, M+=63, H=75, H=87, No-Go=X 


\section{APPENDIX D}

300 AREA SANITARY AND FIRE PROTECTION WATER DECISION MEETING 
WCH-181

Rev. 0 


\section{WCH Wasturanon Closure Hanford Meeting Minutes}

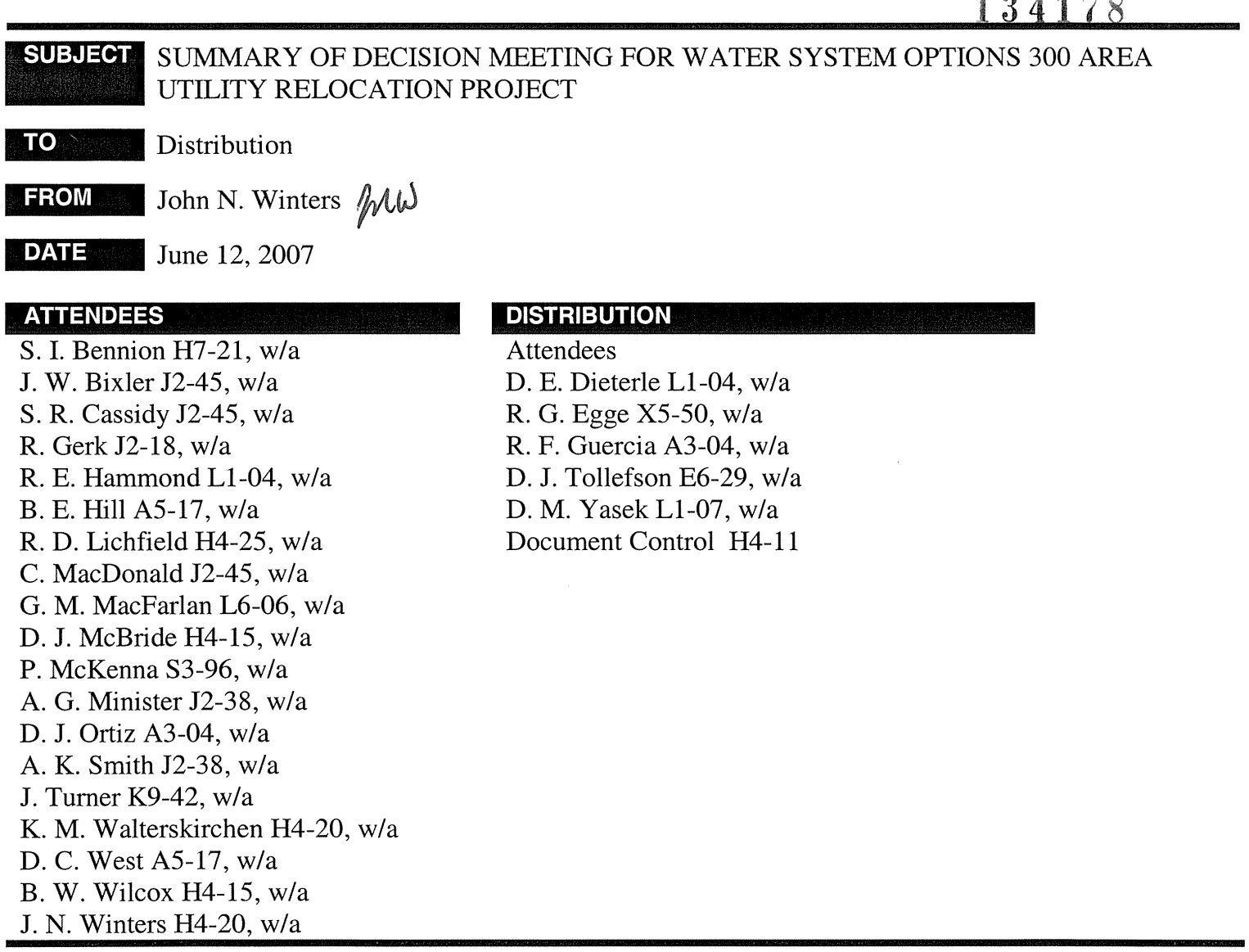

A decision meeting was held on May 23, 2007 to review and rank water system modification options as part of the 300 Area Utility Relocation Project. The Water Discipline Team and the Utility Relocation Project Core Team discussed the pros and cons of the four options for providing reliable water service to the retained facilities in the 300 Area. A summary scope description of the major components for each option was presented in the conceptual level cost estimate prepared by Bruce Wilcox. Copies of the cost estimate were distributed at the meeting. Color-coded maps showing the location of facilities associated with each option were also distributed.

Following the overview presentation, the meeting attendees discussed the selection criteria and weighting factors. They decided that selection criteria and weighting factors as used during the electrical utilities decision meeting should also be used for ranking the water system options.

From their discussion of each option, the attendees arrived at a consensus of a grade between high and low (available grades included $\mathrm{H}, \mathrm{H}-, \mathrm{M}+, \mathrm{M}, \mathrm{M}-, \mathrm{L}+$ or $\mathrm{L}$ ). The letter grade indicated how well each option 
Distribution

Page 2

met the selection criterion. A spreadsheet (Attachment 1) was used to document the grade assignments. Using the weighting factors assigned and a score associated with each grade (see lower left corner of ranking spreadsheet for weighting factor and grade scores), a weighted score was calculated for each option.

The resulting weighted scores for each of the water source options were compared against the total possible points. Option 1 was ranked highest ( $81 \%$ of possible points) followed by Options 4,3 and 2 with $65 \%$, $58 \%$ and $55 \%$ of the possible points. The recommended option, Option 1, involves installation of a new booster pump station and a new water supply main. These new facilities will replace the 382 Complex. The estimated construction cost for Option 1 is approximately $\$ 0.5 \mathrm{M}$ higher than the lowest construction cost option (Option 2). However, it is estimated that Option 1 will have significantly lower annual operation and maintenance $(\mathrm{O} \& \mathrm{M})$ costs. When construction and $\mathrm{O} \& \mathrm{M}$ are considered together, Option 1 is lowest cost option.

For reference, a detailed description and analysis of the four waste system options is included with this IOM as Attachment 2. This analysis was prepared by Don McBride/Polestar. Also included are Attachments 3 and 4 which are cost estimate information and water system option schematics. This information was used by the water discipline team during the evaluation of the options. The cost estimates were prepared by Bruce Wilcox/WCH. The schematic development was lead by Karl Walterskirchen/White Shield Inc.

Attachments: 1. 300 Area Utility Relocation - Water Options Worksheet (2 pages)

2. 300 Area Water System Options Analysis (9 pages)

3. Cost Estimate Summary ( 2 pages) and Cost Estimate for Option 1 ( 2 pages)

4. Water System Alternatives - Schematics (4 pages) 


\section{ATTACHMENT 1}

300 AREA UTILITY RELOCATION - WATER OPTIONS WORKSHEET

(consisting of 2 pages) 


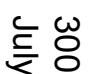

号

흐.

D

$\stackrel{\vec{D}}{\overrightarrow{0}}$

윽.

m

$\stackrel{\varliminf}{\equiv}$

$\stackrel{\frac{0}{0}}{\frac{0}{2}}$

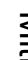

言:

SELECTION CRITERIA (with related considerations listed below it) Meets functional requirements

300 Area Utility Relocation - Water Options Worksheet

Meets functional requirements 0

\section{Acceptable to regulators}

Impact on identified WIDS sites. Is there an opportunity for valid mitigation of the impact.

Impact on TPA milestones and can they be mitigated

What is the overall level of acceptance by the regulators?

\section{Meets schedule constraints}

Does the option cross a $\$ 5 \mathrm{M}$ threshold for capital line item?

Can construction be sequienced to support completion of the project?

\section{Best Value to the Government} Initial construction cos

Future O\&M cost

Reasonable Expectation for reliable utility system during expected 20 yrs ops of retained

\section{Minimizes safety and health risk}

\section{Minimizes impact to cleanup activities}

\section{Provides for Continuity of Operations for 300 Area Research and Developmen}

\section{Unweighted score}

$\frac{\text { LEGEND: }}{* \text { Weighting }}$

- $5=$ Related to project safety or project cost; $4=$ Compliance related issue and

Weighted score =

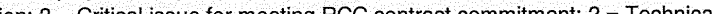
issue; $1=$ issue is non-critical but nice to have; $0=\mathrm{a} \mathrm{GO}$ or NO-GO decision

Scoring: $L=15, L+=27, M-=39, M=51, M+=63, H-=75, H=87$, No-Go=X

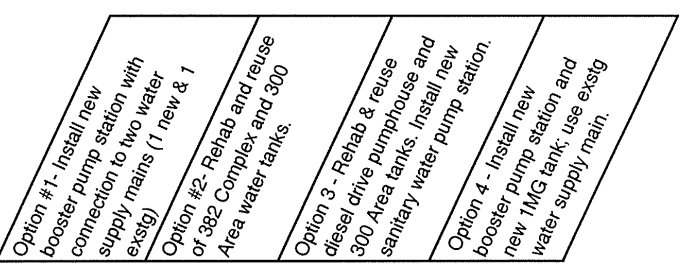

eria Weighting

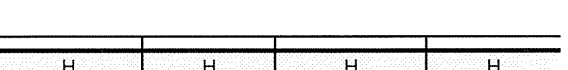


300 Area Utility Relocation - Water Options Worksheet

SELECTION CRITERIA (with related considerations listed below it)

Criteria Weighting
Factor"

\begin{tabular}{|c|c|c|c|c|c|}
\hline Meets functional requirements & 0 & 87 & 87 & 87 & 87 \\
\hline Acceptable to regulators & 0 & 87 & 87 & 87 & 87 \\
\hline $\begin{array}{l}\text { Impact on identified WIDS sites. Is there an opportunity for valid mitigation of the impact. } \\
\text { Impact on TPA milestones and can they be mitigated } \\
\text { What is the overall level of acceptance by the regulators? }\end{array}$ & & & & & \\
\hline Meets schedule constraints & 0 & 87 & 87 & 87 & 87 \\
\hline $\begin{array}{l}\text { Does the option cross a } \$ 5 \mathrm{M} \text { threshold for capital line item? } \\
\text { Can construction be sequienced to support completion of the project? }\end{array}$ & & & & & \\
\hline Best Value to the Government & 5 & 63 & 51 & 51 & 27 \\
\hline $\begin{array}{l}\text { Initial construction cost } \\
\text { Future } O \& M \text { cost }\end{array}$ & & & & & \\
\hline Reasonable Expectation for reliable utility system during expected 20 yrs ops of retained & 3 & 87 & 15 & 51 & 75 \\
\hline Minimizes safety and health risk & 5 & 87 & 51 & 51 & 63 \\
\hline Minimizes impact to cleanup activities & 4 & 87 & 75 & 75 & 87 \\
\hline Provides for Continuity of Operations for 300 Area Research and Development & 4 & 87 & 75 & 63 & 87 \\
\hline & $\begin{array}{r}\text { Unweighted score }= \\
\text { Weighted score }=\end{array}$ & $\begin{array}{l}672 \\
1707\end{array}$ & $\begin{array}{r}528 \\
1155\end{array}$ & $\begin{array}{c}552 \\
1215\end{array}$ & $\begin{array}{r}600 \\
1371\end{array}$ \\
\hline 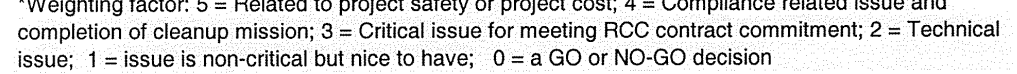 & $\begin{array}{l}\% \text { of total available } \\
\text { points }=\end{array}$ & $81 \%$ & $55 \%$ & $58 \%$ & $65 \%$ \\
\hline
\end{tabular}


ATTACHMENT 2

\section{AREA WATER SYSTEM OPTIONS ANALYSIS}

(consisting of 9 pages) 


\section{Area Water System Modifications Options Analysis Prepared by D. J. McBride/Polestar \\ May 2007}

\subsection{Background}

The existing water supply to the 300 Area consists of a 16" main from the City of Richland that supplies water to 382-C \& 382-D tank at about 50-60 psi. The 382-D tank has 6" and 12" level control valves to maintain level. The 382-C tank can be filled manually. The 382-C and 382-D tanks supply about 20 psi positive suction head to the pumps in 382 . The pumps in 382 then boost the pressure to about $120 \mathrm{psi}$, and distribute the water via looped underground piping systems throughout the 300 Area for potable (domestic) requirements as well as fire protection and process water uses. Modifications to the 300 Area water system are needed to accommodate the demolition of old 300 Area buildings and remediation of waste sites and to assure a reasonable expectation of service life to the facilities planned for extended operation ( $>20$ years).

Because of the fire protection role of the water supply system, the 300 Area water system needs to have built in redundancy so that a single failure of the water supply, pumps, or mains will not prevent water from being supplied to the system for fire suppression. A looped fire protection water distribution system is required by DOE Orders wherever practicable.

The Water Sub-team (Team) proposed four options to keep the 300 Area water system operational for an additional 20 years. The options are as follows:

Option 1: Install a new pumping station with two water supply mains from the City of Richland (one new and one existing) along with system modifications per the functional design criteria defined in 0300X-DC-G0001. Unused water mains will be isolated from the system when the facilities they serve are razed.

Option 2: Keep the existing 300 Area water tanks and pumping station (382 Complex) along with the existing water system mains to serve the facilities that will remain in the 300 Area. Repair/rehabilitate components to meet a reasonable expectation of service life. Unused water mains will be isolated from the system when the facilities they serve are razed.

Option 3: Keep the existing 300 Area water tanks and diesel fire pumping station along with the existing water system mains to serve the facilities that will remain in the 300 Area. Install a new sanitary water pumping facility to replace the existing 382 Building. Repair/rehabilitate components to meet a reasonable expectation of service life. Unused water mains will be isolated from the system when the facilities they serve are razed.

Option 4: Install a new pumping station with a new ground storage tank (using the existing 16" water main from the City of Richland) along with system modifications per the functional design criteria defined in $0300 \mathrm{X}-\mathrm{DC}-\mathrm{G} 0001$. Unused water mains will be isolated from the system when the facilities they serve are razed.

The Team evaluated each of these options and included the results below. Preconceptual designs and cost estimates have been prepared for each option. 


\subsection{Option 1. New Pump Station and Water Main}

In Option 1, a new pump station will be built south of Cypress Street in a location that would be outside of the WCH remediation areas. Building a new pump station would allow the old pumps and tanks in the 382 Complex to be removed and the waste site below it to be remediated, as well as the 382-BA boiler annex. The existing 16" City of Richland water main will be rerouted to directly feed the new pump station and a new 16" City of Richland water main will be installed along Stevens Drive to the new pump station. New water mains will be installed on Cypress Street and to supply the 3709-A \& 3220 Buildings. Existing 8 " water mains in the area of the 325 Building are over 50 years old and will be cleaned and lined. Approximately, 4700 feet of existing 8 " water main will have to be retained to supply water to the retained facilities. Approximately 3500 feet of the pipe is assumed to require cleaning and mortar-lining and an additional $\sim 1240$ feet is assumed to be cleaned by "pigging" only. New sectional valves will be installed as needed.

The new pumphouse would consist of a skid-mounted pumping station with three electric and one diesel pump. Two electric booster pumps would be configured for domestic water flow rates and one would be sized for fire flows. The diesel pump would be sized for fire flows and would be separated from the electric pumps by a fire-rated wall to ensure redundant fire water supply. A test drain would be installed from the pump station to the stormwater swale on Cypress Street. A more detailed description of the design criteria for the pumphouse is provided in Appendix A.

If the 351-B electrical substation is to be retained as part of the electrical distribution options, the water supply mains to and fire hydrants at the substation may have to be retained also.

Approximately 2000 feet of existing 8 " water main may have to be retained to provide water to the substation for fire fighting and would be cleaned by pigging as part of the electrical option (not included in this water estimate). This portion of the distribution system would be the same for all four water options.

\subsection{Option 2. Retain 382 Complex}

Under this option, the 382 complex of buildings, tanks and piping would remain and would be used to supply water to the 300 Area distribution piping. The condition of the 382 complex equipment is mixed with some equipment in good condition and some in poor condition.

The 382 Fire Water Complex consists of the following components:

382 Pumphouse Building: a "T" shaped concrete block building, approximately 51 feet by 40.75 with a 5.5" thick flat concrete roof covered with tar and gravel. Building area is 1451 square feet. The building contains the following electrical driven pumps:

1. 480 volts, VFD. 2050 GPM - out of service/broken shaft

2. 480 volts, constant, $1050 \mathrm{GPM}$ - in service/running

3. 2400 volts, constant, 3,000 GPM - operable/available

4. 2400 volts, constant, 1,600 GPM - operable/available

5. 480 volts, VFD. 2050 GPM - out of service/failed circuit board 
Total system water flow

300A Water meter data.

\begin{tabular}{ccc}
\multicolumn{2}{c}{ Annual gallons } & Monthly average gallons \\
2002 & $83.7 \mathrm{M}$ & $7.0 \mathrm{M}$ \\
2003 & $97.8 \mathrm{M}$ & $8.0 \mathrm{M}$ \\
2004 & $92.8 \mathrm{M}$ & $7.7 \mathrm{M}$ \\
2005 & $67.0 \mathrm{M}$ & $5.5 \mathrm{M}$ \\
2006 & $82.0 \mathrm{M}$ & $6.8 \mathrm{M}$
\end{tabular}

The 382 Pumphouse building includes a suction header drawing from C\&D tanks. The suction header lies in a trench in the floor of the 382 Building and each of the five electric pumps draws from the header. Condition of the suction header is suspect due to likely corrosion in the wet trench location.

The pumps feed into a discharge header running to 3 main loop header locations. The north and west loops each have pressure control valves that allow header pressure to be regulated when the system is running on constant flow pumps (the control valves are fully opened when running the Variable Frequency Drive pumps). The south loop has a manual control valve.

The 382 Building was built in the early 1950's and is currently in fair to poor condition. The building has cracks in the walls, but appears to be structurally sound. The roofing system is very degraded with several visible leaks and was categorized in 2003 as past due for evaluation but safe.

The pumps in the building are in fair condition; the suction/discharge piping is in poor condition and should be replaced. The pumps are oversized for the current 300 Area water demand and operation of the pumps in low flow situations (weekends) has led to degradation and premature pump failure of the variable speed pumps. Two of the pumps are powered with $2400 \mathrm{VAC}$ motors and associated switchgear. Spare or replacement parts are not available for the high voltage equipment and the 300 Area $2400 \mathrm{VAC}$ system is planned for demolition. The 382 Building also contains a chemical treatment room where liquid sodium hypochlorite is injected as needed into the tank water recirculation system to maintain free chlorine residual between 0.5 and $1.5 \mathrm{mg} / \mathrm{L}$ in the 382-C and D tanks.

382-B Diesel Pumphouse: The 382-B building is a 1709 square foot concrete building containing two 3,000 GPM, diesel driven fire pumps and the tank water heating and recirculation systems. The building and pumps were installed in 1993. Run time is a little over 200 hours on each engine, good overall condition. Suction header for the fire pumps comes from the bottom of the 382-C\&D tanks and therefore can access the full capacity of both 382-C and 382-D tanks below the level of the standpipe (1.7 MGal total, 1.4MGal able to be reserved for fire protection if crosstie is closed). The heating and recirculation systems are in good condition, but need some repair.

382-BA Boiler Annex - Heat for the 382 Complex buildings, pits and water heating systems is provided by the $382-\mathrm{BA}$ boiler annex building. The annex is a standard Johnson Controls, Inc. boiler annex, 599 square feet, containing a 200hp, 15 psi steam boiler. The boilers and annex, which were constructed in the late 1990s, are in good condition.

382-C Tank. - The tank, which was built in 1979 , is circular steel with a capacity of 900,000 gallons. The tank measures $60 \mathrm{ft}$. in diameter by $45 \mathrm{ft}$ high. It is normally cross connected to 
$382 \mathrm{D}$ to maintain water level. Condition is fair with some corrosion above the waterline and is due for some cleaning and minor repairs.

382-D Tank - The tank, which was built in 1993, is circular steel with a capacity of 800,000 gallons. The tank measures $56.5 \mathrm{ft}$. in diameter by $45 \mathrm{ft}$ high. City of Richland water supply is normally lined up to this tank via 6" and 12" automatic level control valves. The tank contains an internal $36 \mathrm{ft}$ standpipe to supply the domestic water pump suction header in the 382 Building (which is currently cross-tied to the $382-\mathrm{B}$ fire pump suction header). Condition is good and was recently refurbished with coatings.

Water distribution piping - potable and fire protection water is distributed throughout the 300 area via looped piping systems, primarily 8 " with several larger and smaller legs.

The existing water distribution piping that would remain to feed the remaining 300 Area buildings would include about 7,000 feet of 1950's era 8" pipe of which approximately 5800 feet would be scraped and mortar-lined and approximately 1240 feet would be cleaned by pigging. Sectional valves would be replaced as needed.

In this alternative, selected pumps and components in the 382 Complex would be replaced or repaired to establish a condition with a reasonable expectation of service life in support of a 20year operating mission. The following activities would be performed:

382 Building:

Pumps/Piping:

Repair/Replace/Resize electric pumps/motors as appropriate to match anticipated flow requirements

Assess/Replace if necessary suction header

Assess/Replace if necessary discharge lines from pumps to header

Assess/Replace if necessary discharge header

Repair West loop header pressure control valve controller (Routine maintenance, planned by WCH)

Repair North loop header pressure control valve controller (Routine maintenance, planned by WCH)

Replace leaking valve on Pump \#1 (Routine maintenance, planned by WCH)

Reroute sampler recirculation from hypochlorinator room back to tank 382C

Integrate controls for remote monitoring and operation of the water system (includes

replacement of incompatible sensors and controllers)

Building Structure:

Install new roof membrane or pitched roof (verify condition of roof structure)

Repair siding/facing

Paint external and internal surfaces (including walls and piping)

382-B Building

Repair leaking recirculation pump (routine maintenance, planned by $\mathrm{WCH}$ )

\section{$\underline{382-\mathrm{C} \text { Tank }}$}

Clean and inspect tank and apply coating if necessary

Reroute tank discharge drain to stormwater discharge system 
382-D Tank

Reroute tank discharge drain to stormwater discharge system

382-BA Building

None

Outside 382 Complex

Reroute 382 Complex process sewer manhole to sanitary sewer (part of wastewater team activities if 382 Complex is retained).

Water distribution piping

Clean/reline water distribution mains as described above

\subsection{Option 3. Retain Portions of 382 Complex With New Electric Pumphouse}

This option is the same as Option 2 except a new sanitary water pumping station would be built to replace the existing 382 pump house and pumps. New electric sanitary water pumps sized to supply the domestic water system demand for the remaining facilities and a new electric fire pump would be installed in the new pump house. The water distribution piping associated with the retained facilities would be used with some modifications and repairs.

In this option, selected pumps and components in the 382 Complex would be replaced or repaired to establish a condition with a reasonable expectation of service life in support of a 20 -year operating mission. The following activities would be performed to establish this improved operating condition:

\section{Building:}

Replace entire structure and pumps with a skid-mounted enclosed electric pump system consisting of three electric pumps with integrated control systems. The pump skid would include two variable-speed electric domestic booster pumps and a constant speed electric fire pump, with the enclosure installed near the existing 382 building. A new suction header would be routed from the 382-C and 382-D tanks parallel to the existing header, allowing startup and testing of the new pump skid prior to termination of the 382 Building. Discharge headers from the pump skid would be tied into the existing north, west and south water distribution loops.

\section{2-B Building}

Repair leaking recirculation pump (routine maintenance, planned by WCH)

\section{$\underline{382-\mathrm{C} \text { Tank }}$}

Clean and inspect tank and apply coating if necessary

Reroute tank discharge drain to stormwater discharge system

382-D Tank

Reroute tank discharge drain to stormwater discharge system

\section{2-BA Building}

None

Outside 382 Complex 
Reroute 382 Complex process sewer manhole to sanitary sewer (part of wastewater team activities if 382 Complex is retained).

Water distribution piping

The existing water distribution piping that would remain to feed the remaining 300 Area buildings would include about 7,000 feet of 1950's era 8" pipe of which approximately 5800 feet would be scraped and mortar-lined and approximately 1240 feet would be cleaned by pigging. Sectional valves would be replaced as needed.

\subsection{Option 4. Install New Pumphouse With New Storage Tank}

This option is similar to Option 1 except a new $1 \mathrm{M}$ gallon water storage tank would be used in place of installing a second water main from the City of Richland. All other aspects would be the same as Option 1.

\subsection{Advantages and Disadvantages of Options}

Option 1: Advantages:

- New pumping equipment sized to the demands of the reduced 300 Area.

- Lowest annual and life cycle cost for operations.

- Eliminates requirement to continue operations of the 382-BA boiler annex.

- Avoids the need to route sanitary sewer and storm sewer lines from 382 Complex.

- Retains the least amount of old 8" pipe and valves that may need to be replaced.

- No discharges to the process sewer during pump operations/testing.

- No water storage tanks or chemical treatment system to operate or maintain.

- Allows remediation of the small waste site (300-11) located under the 382 Complex.

- Reduce risk of water main failures that could spread contamination from existing underground waste sites to clean areas or the Columbia River.

- The new facility will have a simpler system design with fewer valves and equipment to maintain.

- The new pumping system can be automated easily for remote monitoring and operation.

Option 1: Disadvantages:

- Higher initial cost for installation than Option 2.

- Requires substantial startup and operations testing.

Option 2: Advantages:

- Least initial cost option.

- Requires least startup and operations testing

- Some portions of work can be integrated with routine operations and maintenance of utility systems in the 300 area (part of routine scope).

Option 2: Disadvantages:

- Highest annual and life cycle cost for operations.

- Retains the largest amount of old 8" pipe and valves that may need to be replaced.

- Stormwater and sanitary wastewater system modifications are required to handle tank overflows and routine boiler blowdown effluents.

- Water storage tanks and chemical treatment system to operate or maintain. 
- The small waste site (300-11) located under the 382 Complex cannot be remediated.

- Old equipment, valves and piping that would require routine maintenance or replacement.

- The existing pumping equipment is not connected for remote monitoring or operation.

- Requires continued operation of the 382-BA boiler annex.

- Electrical system upgrades needed to replace the 2400 VAC system.

Option 3: Advantages:

- New pumping equipment sized to the demands of the reduced 300 Area.

- Reduced operating cost (higher than Option 1; lower than Option 2)

- Improved system reliability.

- No discharges to the process sewer during pump operations/testing.

- The new facility will have a simpler system design with fewer valves and equipment to maintain.

- The new pumping system can be automated easily for remote monitoring and operation.

Option 3: Disadvantages:

- Higher cost than Option 2.

- No convenient location to install a new building to house the pumps while the current system is in operation.

- Retains approximately the same quantity of the old 8" pipe and valves as Option 2 that may need to be replaced.

- The small waste site (300-11) located under the 382 Complex cannot be remediated.

- Requires stormwater and sanitary wastewater system modifications to accommodate tank overflows and routine steam boiler blowdowns.

- Water storage tanks and chemical treatment system to operate or maintain.

Option 4: Advantages:

- New pumping equipment sized to the demands of the reduced 300 Area.

- Low annual and life cycle cost for operations.

- Eliminates requirement to continue operations of the 382-BA boiler annex.

- Avoids the need to route sanitary sewer and storm sewer lines from 382 Complex.

- Retains the least amount of old 8" pipe and valves that may need to be replaced.

- No discharges to the process sewer during pump operations/testing.

- Allows remediation of the small waste site (300-11) located under the 382 Complex.

- Reduce risk of water main failures that could spread contamination from existing underground waste sites to clean areas or the Columbia River.

- The new facility will have a simpler system design with fewer valves and equipment to maintain.

- The new pumping system can be automated easily for remote monitoring and operation.

- Eliminates need to construct new City of Richland water main

Option 4: Disadvantages:

- Highest initial cost for installation.

- Requires substantial startup and operations testing.

- Water storage tanks and chemical treatment system to operate or maintain. 


\subsection{Water Distribution System Discussion}

The tuberculation in the old 8" water mains has reduced the inside diameter by about 2 inches based on photos taken at several different locations. This has effectively reduced the flow capacity of the 8 " mains to less than a 6 " main. A new 8" water main will deliver 2.1 times more water than a new 6" main. The flow capability of suspect mains based on limited flow testing is significantly impaired and the project assumes substantial cleaning. For most domestic applications, pipe cleaning is typically followed by mortar lining to improve water quality and reduce opportunities for future tuberculation. The majority of the iron 8" pipes are planned for cleaning and mortarlining with limited portions planned for cleaning by pigging, without mortar lining. It may be necessary to periodically clean the un-lined portions and the pig launching and retrieval stations will be left in place to facilitate future cleaning. 


\section{APPENDIX A. PUMPHOUSE DESIGN CRITERIA FOR OPTIONS 1 AND 4}

The water subteam prepared design information relevant to the requirements for a pressure boosting station that would be constructed for Options \#1 or 4.

The new booster pumping station for options 1 or 4 would have the following features and capabilities:

1. Located west of the 318 Building and south of Cypress Street.

2. Heated, ventilated and insulated modular or pre-engineered building.

3. Designed and installed in accordance with NFPA 20 and 24 including seismic design features.

4. Redundant electric domestic water supply pumps each capable of supplying the maximum daily water supply requirements. Capacity shall not be less than 500 GPM at a delivery pressure of 120 psi. Motors for pumps shall be variable speed with variable speed controllers.

5. UL list/FM Approved redundant fire pumps capable of delivering the required water system demand including fire flow for a period of not less then 4 hours. One pump shall be powered by an electric motor and one pump shall be powered by a diesel engine. The pumps shall be separated by a minimum 2-hour fire rated wall if in the same building or located within 50 feet of each other.

6. Fire pump controllers shall be UL listed/FM approved for the equipment being controlled. The controllers shall have normally open contacts for remote monitoring of the alarms as required by NFPA 20.

7. Fire pump test header with FM approved flow test meter. The test header piping shall be installed and valved to allow each fire pump to be tested independently without shutting down the water supply from the other pumps to the 300 Area water system. The discharge piping of the test header shall be routed to the Cypress Street parking lot storm drainage swale located NW of the pumping station.

8. Pressure gages on the suction and discharge sides of each fire pump.

9. Isolation gate valves on the suction and discharge sides of each pump. Fire pump supply and discharge valves shall be provided with valve position supervisory switches. Pump test discharge valves shall be supervised in the closed position.

10. Check valves on the discharge side of each pump.

11. Diesel fuel tank shall be a double wall UL listed tank.

12. Fire sprinkler protection for the pump building(s).

13. A Notifier NFS2-640 fire alarm control panel (FACP) to monitor the fire sprinkler system, manual fire alarm pull boxes, valve supervisory switches, building temperature supervisory switches, and fire pump supervisory functions. The FACP shall transmit alarm messages to the Hanford Fire Department or the PNNL Operations Center via Notifier NFN gateway.

14. Pumping station status and alarm capabilities should be provided to a continuously staffed location.

15. Bypass piping and valves shall be provided to allow City of Richland water to feed directly into the 300 Area water system without going through the pumps. Bypass line shall be not less than 12 -inch in diameter.

16. Underground valves supplying water to the pump building shall be post indicator type valves with valve position supervisory switches that are monitored by the FACP. 


\section{ATTACHMENT 3}

\section{COST ESTIMATE SUMMARY AND COST ESTIMATE FOR OPTION 1}

(consisting of 4 pages) 


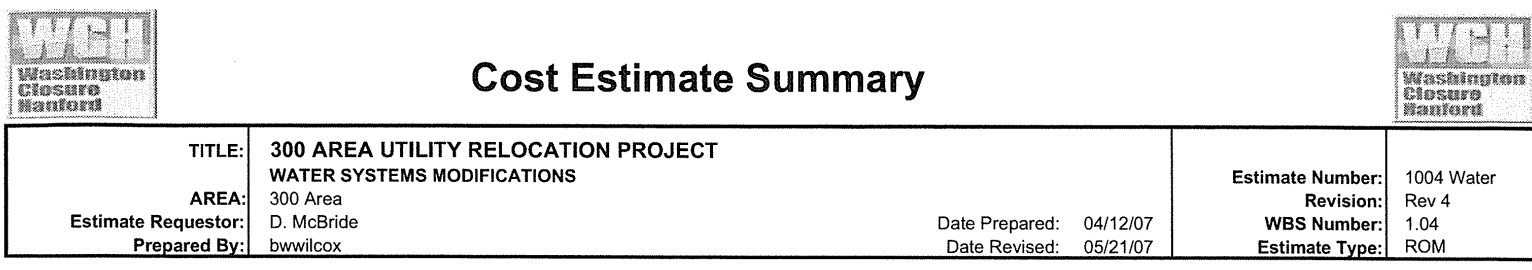

\begin{tabular}{|l|}
\hline 1.0 Purpose / Scope Description: \\
\hline Provide estimates for 4 options to modify the 300 Area water systems. \\
\hline 2.0 Scope of Estimate \\
\hline
\end{tabular}

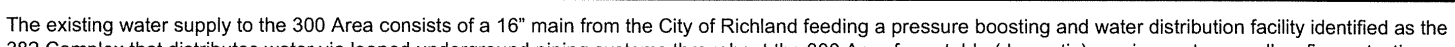
382 Complex that distributes water via looped underground piping systems throughout the 300 Area for potable (domestic) requirements as well as fire protection and process water uses. Modifications to the 300 Area water system are needed to accommodate the demolition of old 300 Area buildings, remediation of waste sites and to assure a reasonable expectation of service life to facilities that are planned for extended operation ( $>20$ years).

Because of the fire protection role, the system is required by DOE orders to have built in redundancy so that a single failure of the water supply, pumps, or mains will not prevent water from being supplied to the system for fire suppression. A looped system is required wherever practicable.

This estimate examines 4 options to modify or upgrade the 300 Area water system.

OPTION 1: Install a new pumping station on Cypress St. near Bldg 318 and abandon the 382 Complex of pump houses and storage tanks including:

* Abandon 382 complex including tanks \& fire pumping station (382-B) and replace with new skid mounted pumping facility.

* Install new skid mounted pumping station consisting of 4 new pumps including one diesel firewater pump. Equipment will be provided and installed by Original Equipment Manufacturer (OEM).

* Tie new skid into existing 16 " water line from the City of Richland.

* Install a new second 16 " water line from the city and tie into the new pump station providing redundancy.

* Install two new 12" water lines at Cypress St and from Wisconsin Ave to the existing Fire Station.

* Install new 12" test drain line along Cypress St to grassy swale.

* Clean \& re-line $\sim 3,500$ LF of existing 8 " underground water lines. Install new valves as required.

* Pig clean only $\sim 1,240$ LF of existing 8" underground water lines from Wisconsin at Hemlock to 6 "line near Fire Hydrant 80 . Requires installation of launch and retrieval spools in existing lines.

OPTION 2: Keep existing 382 water tanks, BIdg 382 pump station and existing water system mains. Upgrade components to meet 20 year service life including:

* Repair Bldg 382, repair/replace 382 service pumps, service piping \& valves and controls systems as required. Keep existing diesel fire pumping station (382-B).

* Repair Bldg 382-B recirculation pumps.

* Drain \& refurbish Tank 382-C

* Re-route 382 process sewer manhole to grassy swale at Wisconsin St. and Cypress St.

* Install new 12 " water line from Wisconsin Ave to the existing Fire Station.

* Clean \& re-line $\sim 5,800$ LF of existing 8 " underground water lines. Install new valves as required.

* Pig clean only 1,240 LF of existing 8" underground water lines from Wisconsin at Hemlock to 6" line near Fire Hydrant 80 . Requires installation of launch and retrieval spools in existing lines.

OPTION 3: Keep the existing 382 water tanks and diesel fire pumping station. Install a new sanitary water pumping facility to replace the existing 382 Building including:

* Abandon Bldg 382 and replace with new skid mounted pumping facility. Keep existing diesel fire pumping station (382-B).

* Repair Bldg 382-B recirculation pumps.

* Drain \& refurbish Tank 382-C

* Re-route 382 process sewer manhole to grassy swale at Wisconsin St. and Cypress St.

* Install new 12" water line from Wisconsin Ave to the existing Fire Station.

* Clean \& re-line $~ 5,800 \mathrm{LF}$ of existing 8 " underground water lines. Install new valves as required.

* Pig clean only $\sim 1,240$ LF of existing 8" underground water lines from Wisconsin at Hemlock to 6 " line near Fire Hydrant 80 . Requires installation of launch and retrieval spools in existing lines.

OPTION 4: Install a new pumping station on Cypress St., abandon the 382 Complex and construct new water storage tank including:

* Abandon 382 complex including tanks \& fire pumping station (382-C) and replace with new skid mounted pumping facility.

* Install new skid mounted pumping station consisting of 4 new pumps including one diesel firewater pump. Equipment will be provided and installed by Original Equipment Manufacturer (OEM).

* Tie new skid into existing 16 " water line from the City of Richland

* Construct new 1,000,000 gallon field erected tank adjacent to new pump station for firewater redundancy. Cone headed tank is insulated and includes dry well heating for freeze protection.

* Install two new 12" water lines at Cypress St and from Wisconsin Ave to the existing Fire Station.

* Install new 4" test drain line along Cypress St to grassy swale.

* Clean \& re-line $\sim 3,500$ LF of existing 8 " underground water lines. Install new valves as required.

* Pig clean only $\sim 1,240$ LF of existing 8" underground water lines from Wisconsin at Hemlock to 6 " line near Fire Hydrant 80 . Requires installation of launch and retrieval spools in existing lines.

3.0 Basis and Assumptions:

1. Options are estimated to be performed by a Subcontractor. Costs for SubK OH\&P are included in the estimate.

2. Scope does not include work with radioactive or hazardous materials. Assume Personal Protection Equipment (PPE) beyond hard hat, steel toes \& protective eye wear will not be required by OEM or Subcontractor personnel.

3. Engineering and design basis is conceptual.

4. Labor pricing based on FY07 Hanford Site Stabilization Agreement (HSSA) rates.

5. Equipment priced using $80 \%$ of current Blue Book rates.

6. Bulk material pricing and labor unit rates from RS Means Estimating Guide are used where applicable. Local and national vendor pricing is used for major equipment and sub-tier Subcontractors work, 


\begin{tabular}{|c|c|c|c|c|c|c|}
\hline \multicolumn{6}{|l|}{ 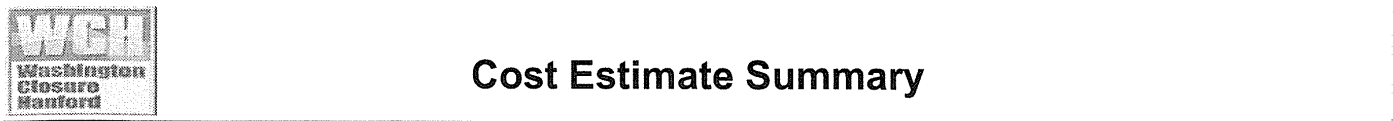 } & 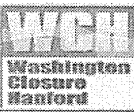 \\
\hline $\begin{array}{r}\text { TITLE: } \\
\text { AREA: } \\
\text { Estimate Requestor: } \\
\text { Prepared By: }\end{array}$ & $\begin{array}{l}300 \text { AREA UTILITY RELOCATION PROJECT } \\
\text { WATER SYSTEMS MODIFICATIONS } \\
300 \text { Area } \\
\text { D. McBride } \\
\text { bwwilcox } \\
\end{array}$ & $\begin{array}{l}\text { Date Prepared: } \\
\text { Date Revised: }\end{array}$ & $\begin{array}{l}04 / 12 / 07 \\
05 / 21 / 07 \\
\end{array}$ & \multicolumn{2}{|c|}{$\begin{array}{r}\text { Estimate Number: } \\
\text { Revision: } \\
\text { WBS Number: } \\
\text { Estimate Type: }\end{array}$} & $\begin{array}{l}1004 \text { Water } \\
\text { Rev } 4 \\
1.04 \\
\text { ROM }\end{array}$ \\
\hline \multicolumn{7}{|c|}{$\begin{array}{l}\text { 7. Pricing for Option } 4 \text { new tank is based on actual costs for } 600 \mathrm{~K} \text { gallon tank erected by vendor at the Hanford Waste Treatment Plant (WTP) project FY05 scaled to } \\
1 \mathrm{M} \text { gallons. Material pricing (steel) has been escalated to reflect current market conditions. } \\
\text { 8. See individual estimate sheets for additional scope and assumptions. }\end{array}$} \\
\hline \multicolumn{7}{|l|}{ 4.0 Exclusions: } \\
\hline \multicolumn{7}{|c|}{$\begin{array}{l}\text { 1. Costs for Contractor overhead, fee, contingency or risk ARE NOT included for this initial analysis. Costs for WCH or other Hanford Contractors for design, support } \\
\text { or oversight ARE NOT included in this estimate. Contingency percentages shown below are for construction General Subcontractor only and are based on the } \\
\text { conceptual nature of the design. } \\
\text { 2. Long term operating (lifecycle) costs ARE NOT included in the estimates. } \\
\text { 3. Costs are in current dollars. Costs for escalation (other than steel tank materials) ARE NOT included in the estimates. }\end{array}$} \\
\hline \multicolumn{7}{|l|}{ 5.0 Estimated Cost } \\
\hline \multicolumn{2}{|c|}{ Total estimated cost $(\$ 1,000 \mathrm{~s})$} & $\begin{array}{c}\text { Estimated } \\
\text { cost }\end{array}$ & $\begin{array}{c}\text { Contingency } \\
\%\end{array}$ & $\begin{array}{c}\text { Contingency } \\
\$ \$ \$ \$\end{array}$ & TEC & \\
\hline \multicolumn{2}{|c|}{ Option 1: New Pump Station - New 16" Water Line } & $\$ 2,921$ & $30 \%$ & $\$ 876$ & $\$ 3,797$ & \\
\hline \multicolumn{2}{|c|}{ Option 2: Keep 382 Complex - Upgrade All Major Components } & $\$ 2,324$ & $40 \%$ & $\$ 930$ & $\$ 3,254$ & \\
\hline \multicolumn{2}{|c|}{ Option 3: Keep 382 Complex - Replace 382 Pump Facility } & $\$ 2,536$ & $30 \%$ & $\$ 761$ & $\$ 3,297$ & \\
\hline \multicolumn{2}{|c|}{ Option 4: New Pump Station - New 1M Gal Water Tank } & $\$ 3,087$ & $30 \%$ & $\$ 926$ & $\$ 4,013$ & \\
\hline \multicolumn{7}{|l|}{ 6.0 Estimate Review } \\
\hline \multicolumn{2}{|r|}{ Name (print) } & \multicolumn{2}{|c|}{ Signature } & \multicolumn{3}{|c|}{ Date } \\
\hline Estimator & \multicolumn{3}{|l|}{ Bruce Wilcox } & & & \\
\hline Estimating Manager & \multicolumn{3}{|l|}{ Doug Ahmer } & & & \\
\hline Task Manager & \multicolumn{3}{|l|}{ Don McBride } & & & \\
\hline Project Controls Lead & & & & & & \\
\hline
\end{tabular}


Washington Group International, Inc.

300 AREA WATER 4 - Est 1004 - 300 Area Utility Relocation Project

02 - WATER

\begin{tabular}{|c|c|c|c|c|c|c|c|c|c|c|c|}
\hline Code & Description & Quantity & & Manhours & Labor Pe & Materials & Equipment & Supplies & Subcontracts & Other & Total \\
\hline \multicolumn{12}{|c|}{ 1.0-UTILITY OPTIONS: WI - WATER - OPT 1} \\
\hline & WW1MOB01 - * SubK Work Planning \& Preparation & 160.000 & $\mathrm{HR}$ & 960 & 59,443 & & & & & 10,285 & 69,727 \\
\hline & WW1MOB02 - * On-Site Requried Training \& Badging & 0.500 & LS & 186 & 9,460 & & & & 4,942 & 2,492 & 16,894 \\
\hline & WW1MOB03 - * Baseline Physical For Hanford Workers & 1.000 & LS & 40 & 1,828 & & & & & 316 & 2,144 \\
\hline & WW1MOB04 - * SubK Mob Equip, Tools, Materials & 1.000 & LS & 100 & 3,651 & & 1,290 & 1,618 & & 1,135 & 7,693 \\
\hline & WWIMOB05 - * Portable Toilets & 12.000 & мо & & & & & & 5,256 & 909 & 6,165 \\
\hline & WWIMOB06 - * Two Way Radios & 12.000 & $\mathrm{EA}$ & & & & & 5,415 & & 937 & 6,352 \\
\hline & WW1MOB07 - * SubK Field Office Facilitics Setup & 1.000 & LS & 120 & 5,232 & & & 11,754 & 9,150 & 4,522 & 30,659 \\
\hline & WWIMOPS1 - * Monthly Operations \& Overhead & 12.000 & MO & 8,964 & 540,355 & & & 650 & 17,038 & 96,554 & 654,597 \\
\hline & WWINEW01 - * New 16 " Main - Asphalt Cutting \& Removal & 266.000 & SY & 20 & 726 & & 410 & 496 & 720 & 407 & 2,759 \\
\hline & WWINEW02 - * New 16 " Main - Excavation \& Sand Bedding. & $6,700.000$ & $\mathrm{BCY}$ & 258 & 9,273 & 13,538 & 6,403 & 5,797 & 10,000 & 7,788 & 52,798 \\
\hline & WWINEW03 - * New 16 " Main - Pipe \& Valve Installation & $6,700.000$ & LF & 2,785 & 114,694 & 271,145 & 10,559 & 21,238 & & 72,260 & 489,897 \\
\hline & WWINEW04 - * New 16" Main - Backfill \& Compaction & $7,370.000$ & LCY & 524 & 18,627 & 16,307 & 7,491 & 6,981 & & 8,548 & 57,954 \\
\hline & WWINEW05 - * New 16" Main - Pipeline Bridge at Heavy H & 1.000 & $\mathrm{EA}$ & 200 & 7,203 & 3,812 & 85 & 589 & & 2,022 & 13,712 \\
\hline & WWINEW06 - * New 16" Main - Road Repair & 108.000 & SY & & & & & & 1,809 & 313 & 2,122 \\
\hline & WWINEW07 - * New 16" Main - Flush \& Test New Line & 1.000 & LS & 160 & 7,234 & & 136 & 223 & & 1,314 & 8,907 \\
\hline & WWINEW11 - * 12" Cypress Main - Asphalt Cutting \& Remo & 1.000 & LS & 20 & 726 & & 410 & 496 & 600 & 386 & 2,618 \\
\hline & WWINEWI2 - * $12 "$ Cypress Main - Excavation \& Sand Bed & 650.000 & $\mathrm{BCY}$ & 125 & 4,473 & 1,354 & 3,278 & 2,937 & 10,000 & 3,814 & 25,855 \\
\hline & WWINEW13 - * 12" Cypress Main - Pipe \& Valve Installation & 650.000 & $\mathrm{LF}$ & 388 & 15,887 & 24,229 & 3,837 & 4,722 & & 8,422 & 57,097 \\
\hline & WWINEW14 - * 12" Cypress Main - Backfill \& Compaction & 715.000 & LCY & 113 & 3,978 & 1,745 & 717 & 672 & & 1,231 & 8,344 \\
\hline & WW1NEW16 - * 12" Cypress Main - Road Repair & 108.000 & SY & & & & & & 838 & 145 & 982 \\
\hline & WWINEW17 - * 12" Cypress Main - Flush \& Test New Line & 1.000 & LS & 80 & 3,617 & & 68 & 112 & & 657 & 4,453 \\
\hline & WW1NEW21 - * 12" Fire Station Main - Asphalt Cutting \& R & 1.000 & LS & 20 & 726 & & 410 & 496 & 600 & 386 & 2,618 \\
\hline & WW1NEW22 - * 12 " Fire Station Main - Excavation \& Sand B & 650.000 & $\mathrm{BCY}$ & 125 & 4,473 & 1,354 & 3,278 & 2,937 & 10,000 & 3,814 & 25,855 \\
\hline & WW1NEW23 - * 12" Fire Station Main - Pipe \& Valve Inst & 650.000 & LF & 388 & 15,887 & 21,793 & 3,837 & 4,722 & & 8,000 & 54,239 \\
\hline & WWINEW24 - * 12" Fire Station Main - Backfill \& Compac & 715.000 & LCY & 113 & 3,978 & 1,745 & 717 & 672 & & 1,231 & 8,344 \\
\hline & WWINEW26 - * 12" Fire Station Main - Road Repair & 0.010 & LS & & & & & & 838 & 145 & 982 \\
\hline & WWINEW27 - * 12" Fire Station Main - Flush \& Test New L & 1.000 & LS & 80 & 3,617 & & 68 & 112 & & 657 & 4,453 \\
\hline & WW1NEW31 - * 12" Test Drain - Asphalt Cutting \& Removal & 1.000 & LS & 10 & 363 & & 80 & 129 & 600 & 203 & 1,374 \\
\hline & WWINEW32 - * 12" Test Drain - Excavation \& Backfill. & 650.000 & $\mathrm{BCY}$ & 30 & 1,028 & & 165 & 182 & & 238 & 1,613 \\
\hline & WWINEW33 - * 12" Test Drain - Pipe \& Valve Installation & 390.000 & $\mathrm{LF}$ & 218 & 9,194 & 8,769 & 197 & 839 & & 3,287 & 22,286 \\
\hline & WWINEW36 - * 12" Test Drain - Road Repair & 0.010 & LS & & & & & 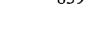 & 168 & 29 & 196 \\
\hline & WWIPIG01 - * Install Pig Launcher & 1.000 & EA & 60 & 3,030 & 3,791 & 395 & 413 & 2,120 & 1,687 & 11,435 \\
\hline & WWIPIG02 - * Construct End of Line Pig Retrieval & 1.000 & EA & 48 & 2,591 & 1,083 & 190 & 165 & 2,000 & 1,043 & 7,071 \\
\hline & WWIPIG03 - * Clean (Pig Only) 8" Water LIne & $1,240.000$ & $\mathrm{LF}$ & 30 & 1,233 & 1,083 & & 67 & & 412 & 2,795 \\
\hline & WWIPIG04 - * Backfill, Compaction \& Road Repair & 1.000 & LS & 30 & 1,047 & & 707 & 632 & 838 & 558 & 3,781 \\
\hline & WWIPMP01 - * Now Pump Station - Excavation \& Backfill & 100.000 & BCY & 10 & 366 & & 212 & 199 & 2,000 & 481 & 3,258 \\
\hline & WWIPMP02 - * New Pump Station - Modular Bldg Foundation & 30.000 & CY & 200 & 7,310 & 3,899 & 714 & 1,208 & 2,000 & 2,272 & 15,403 \\
\hline & WWIPMPO - * New Pump Station - Pump Station Installation & 1.000 & LS & 240 & 9,740 & 434,283 & 1,779 & 2,057 & 10,000 & 79,220 & 537,077 \\
\hline & WW1PMP04 - * New Pump Station - New Electrical Service & 1.000 & LS & 220 & 9,528 & 30,866 & 320 & 834 & & 7,189 & 48,737 \\
\hline & WWIPMP05 - * New Pump Station - Chlorination System & 1.000 & LS & 120 & 6,291 & 6,498 & & 341 & & 2,272 & 15,401 \\
\hline & WW1PMP06 - * New Pump Station - Main LIne Connections & 1.000 & LS & 240 & 11,149 & 20,880 & 639 & 1,241 & & 5,867 & 39,777 \\
\hline & WW1PMP07 - * New Pump Station - Test Opcrating Systems & 1.0001 & LS & 480 & 24,075 & & & 1,304 & & 4,391 & 29,770 \\
\hline & WW1WLN01 - * Water Main Clean \& Line - Excavation Scan & 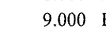 & EA & & & & & & 18,000 & 3,114 & 21,114 \\
\hline & WW1 WLN02 - * Water Main Clean \& Line - Asphalt Cutting \& & 9.000 & $\mathrm{EA}$ & 180 & 6,531 & & 3,691 & 4,466 & 5,400 & 3,476 & 23,563 \\
\hline & WW1WLN03 - * Water Main Clean \& Line - Site Excavation & $9.000 \mathrm{r}$ & $\mathrm{EA}$ & 1,584 & 57,652 & 2,112 & 22,366 & 21,862 & & 17,993 & 121,985 \\
\hline
\end{tabular}




\begin{tabular}{|c|c|c|c|c|c|c|c|c|c|}
\hline Code & Description & Quantity & Manhours & Labor Perm Materials & Equipment & Supplies & Subcontracts & Other & Total \\
\hline \multicolumn{10}{|c|}{ 1.0-UTILITY OPTIONS: WI - WATER - OPT 1} \\
\hline & WW1WLN04 - * Water Main Clean \& Line - Pipe Cleaning & $.3,480.000 \mathrm{LF}$ & 259 & 9,024 & 2,060 & 2,880 & 95,489 & 18,938 & 128,391 \\
\hline & WW1WLN05 - * Water Main Clean \& Line - Spool \& Valve R & $9.000 \mathrm{EA}$ & 1,080 & 47,119 & 1,817 & 5,705 & & 17,268 & 117,069 \\
\hline & WW1WLN06 - * Water Main Clean \& Line - Backfill \& Com & $9.000 \mathrm{EA}$ & 810 & 28,460 & 9,812 & 8,995 & & 8,880 & 60,203 \\
\hline & WW1WLN07 - * Water Main Clean \& Line - Road Repair & $9.000 \mathrm{EA}$ & & & & & 7,538 & 1,304 & 8,842 \\
\hline & WWIWND01 - * Flush \& Test Entire System & $1.000 \mathrm{LS}$ & 640 & 28,934 & 273 & 446 & & 5,131 & 34,784 \\
\hline & WWIWND02 - * Site Cleanup & $60.000 \mathrm{HF}$ & 360 & 12,529 & 1,172 & 2,278 & & 2,765 & 18,743 \\
\hline & WW1WND03 - * SubK DeMob Equip, Tools, Materials & $20.000 \mathrm{HF}$ & 100 & 3,651 & 1,290 & 1,618 & & 1,135 & 7,693 \\
\hline & WW1WND04 - * Close Out & $1.000 \mathrm{LS}$ & 270 & 17,017 & & & & 2,944 & 19,961 \\
\hline Subtc & W1 - WATER & & 22,985 & 919,502 & 90,873 & 130,495 & 215,942 & 430,784 & $2,920,544$ \\
\hline
\end{tabular}


ATTACHMENT 4

WATER SYSTEM ALTERNATIVE - SCHEMATICS

(consisting of 4 pages) 
WCH-181

Rev. 0

300 Area Building Retention Evaluation Mitigation Plan 


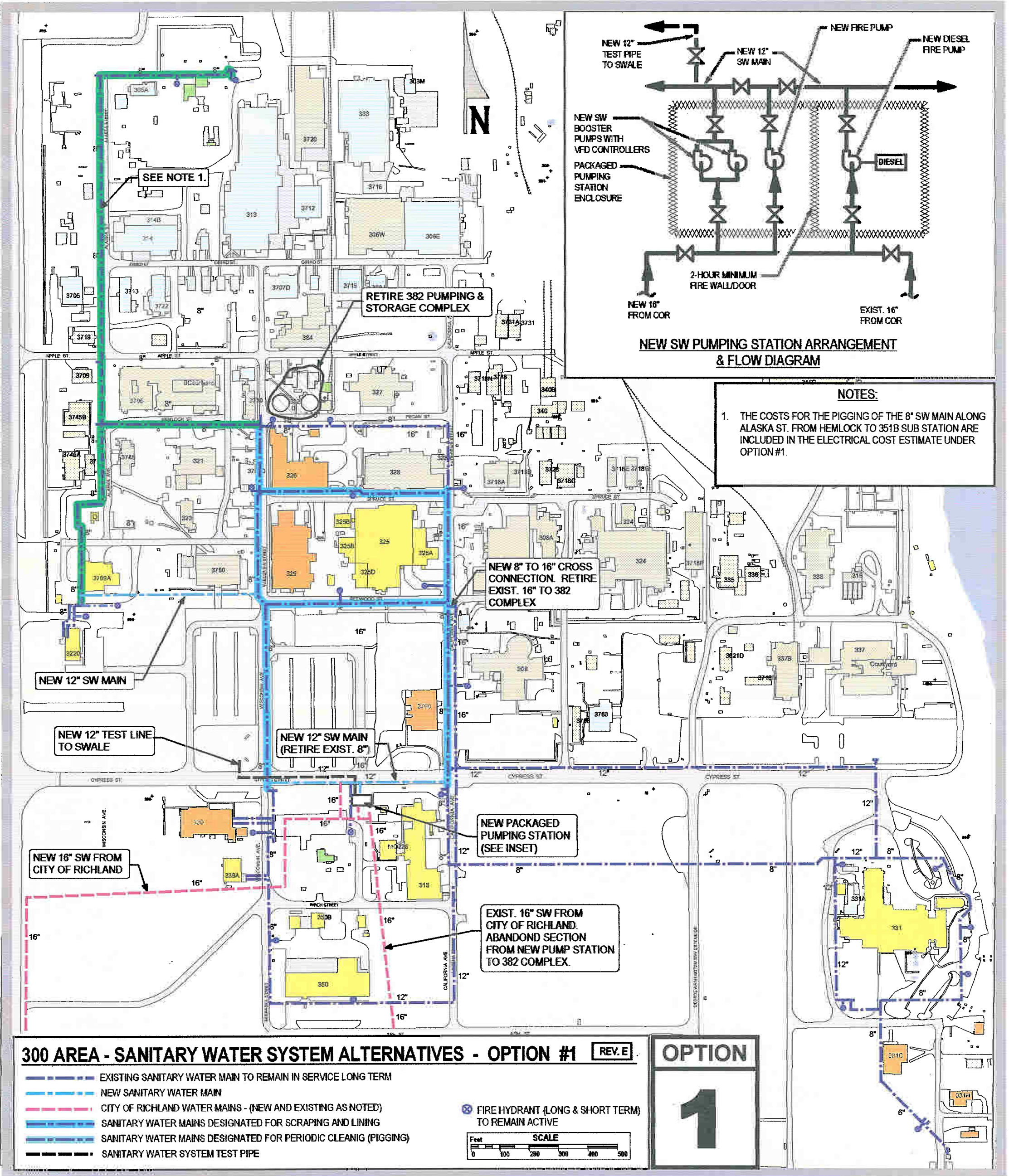




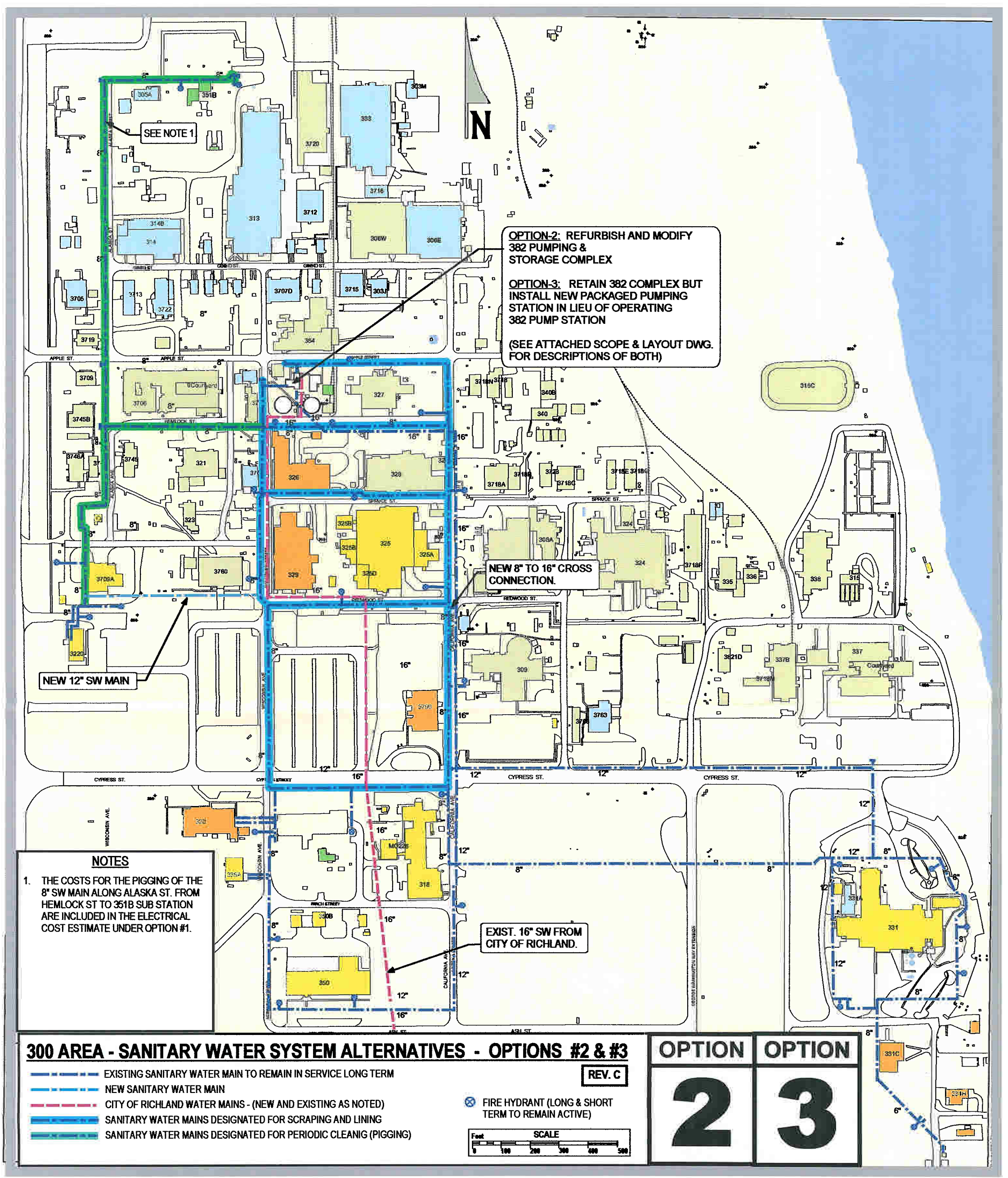



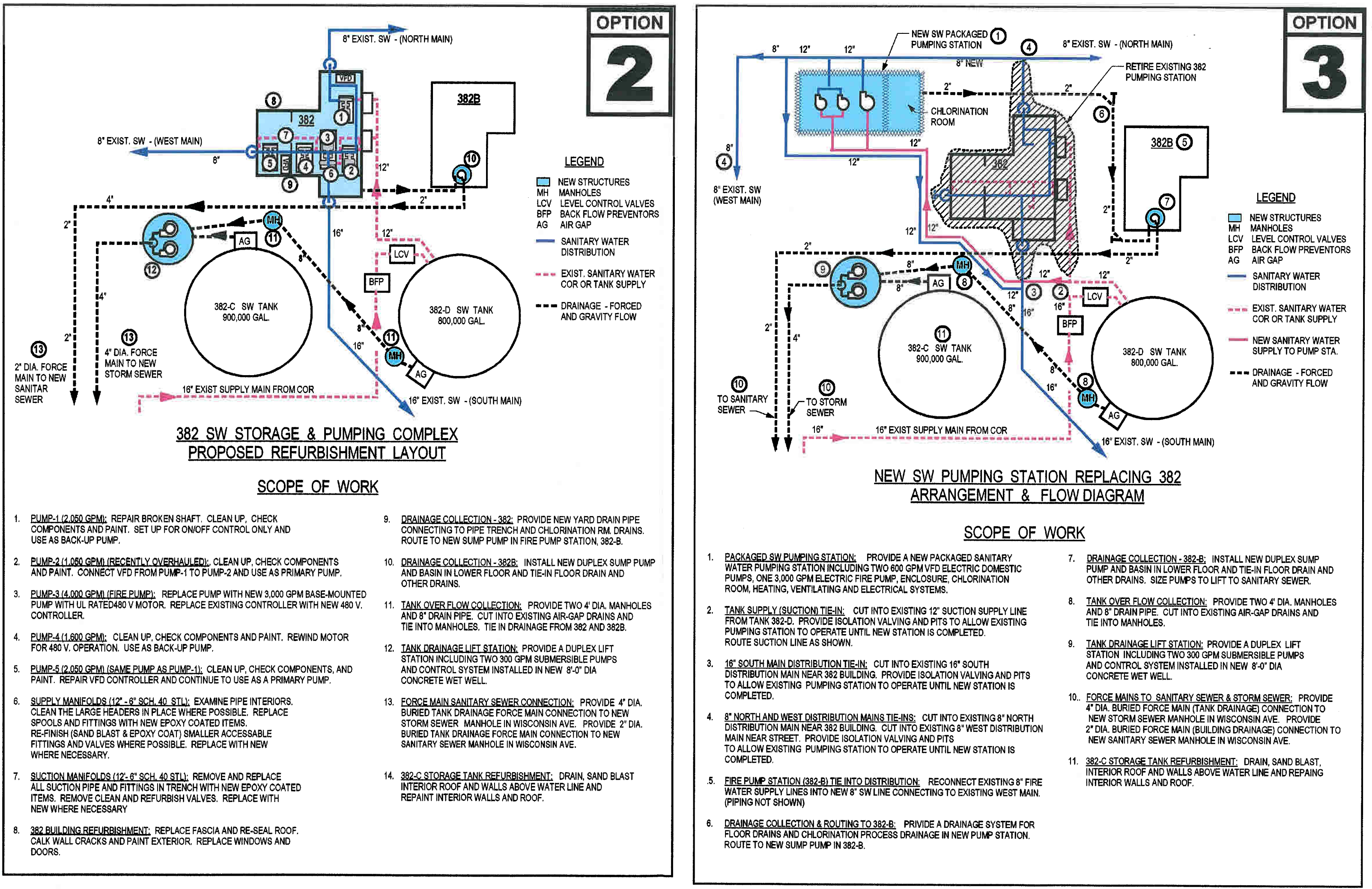


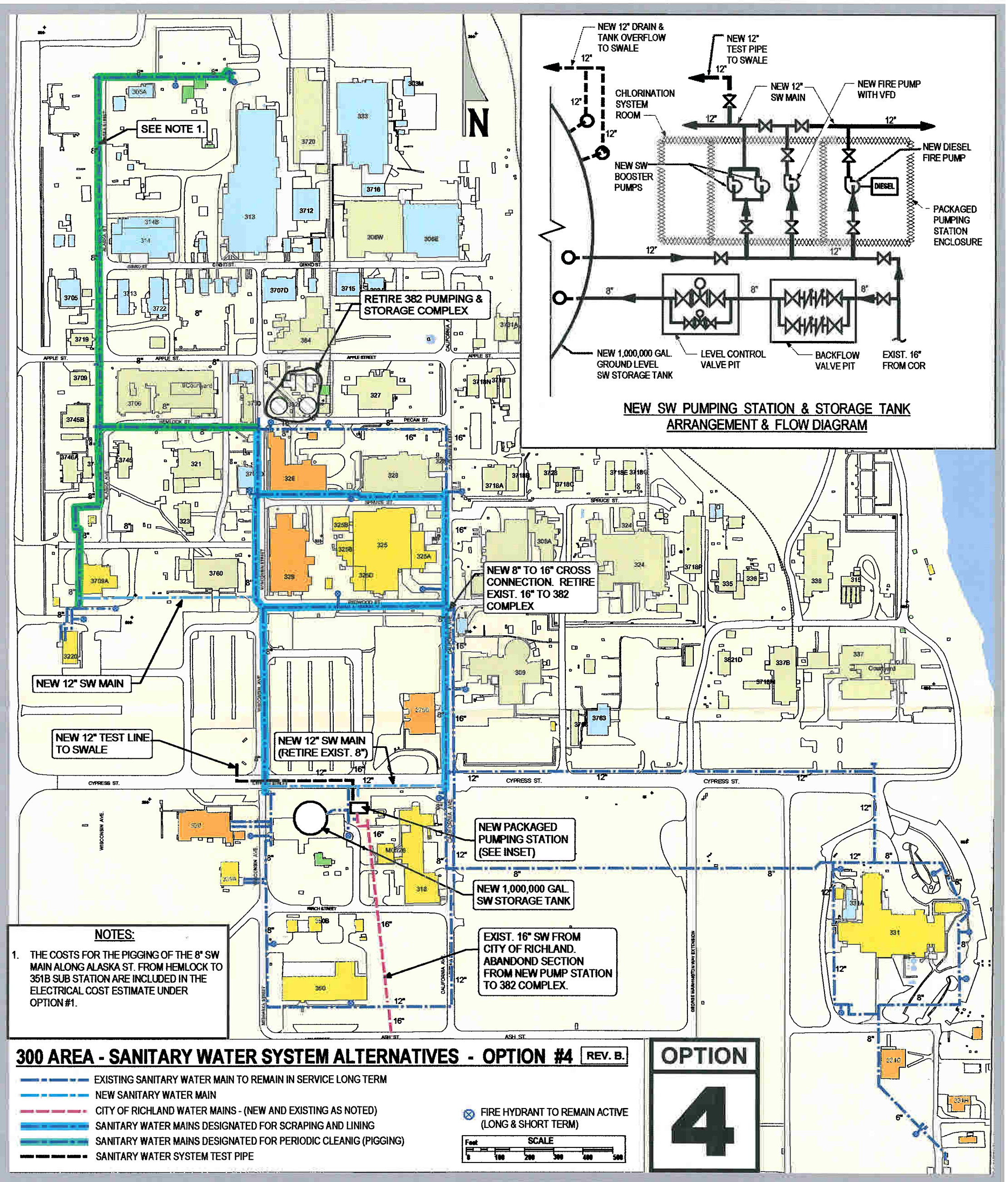




\section{APPENDIX E}

300 AREA SANITARY AND FIRE PROTECTION WATER CONCEPTUAL DESIGN 
WCH-181

Rev. 0 


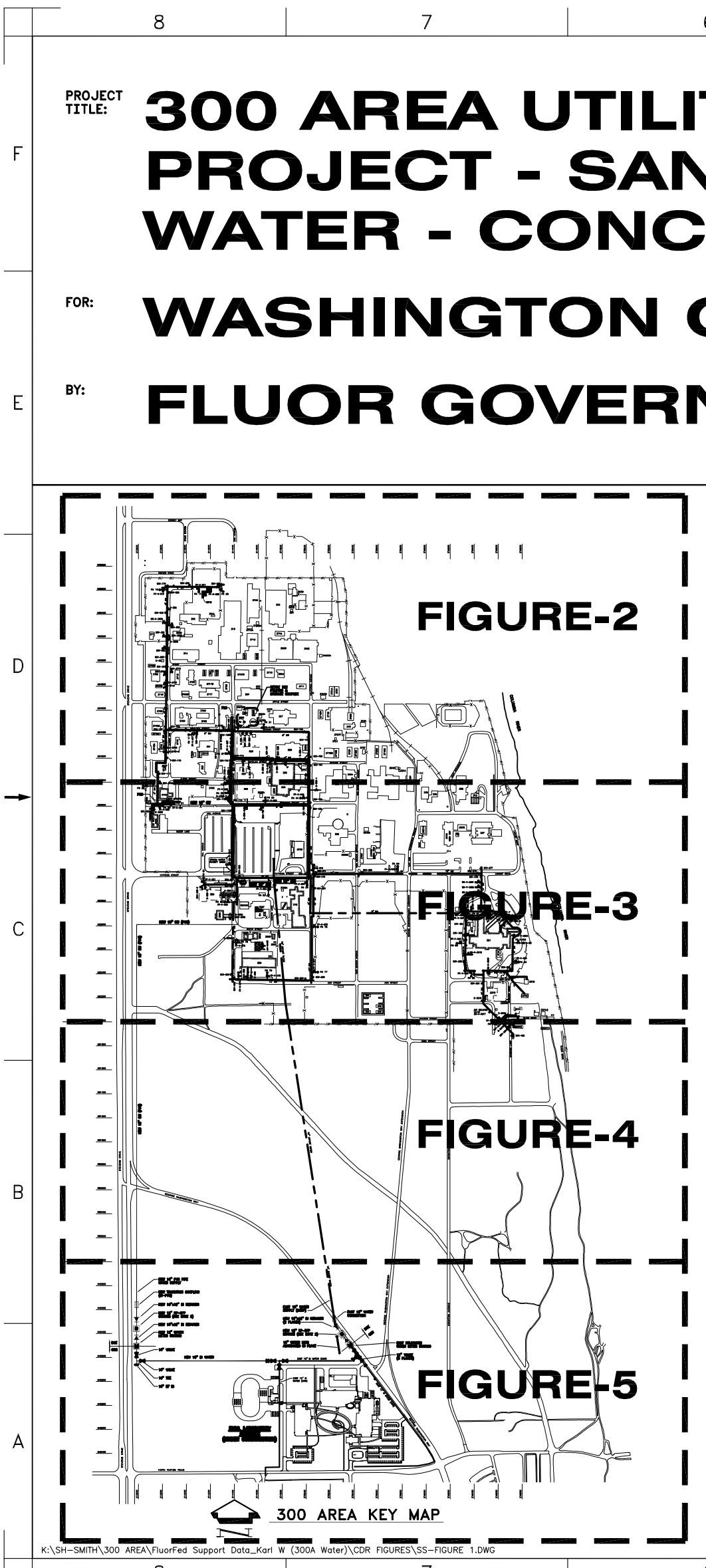

ITY RELOCATION

PROJECT - SANITARY \& FIRE PROTECTION WATER - CONCEPTUAL DESIGN

WASHINGTON CLOSURE HANFORD

FLUOR GOVERNMENT GROUP

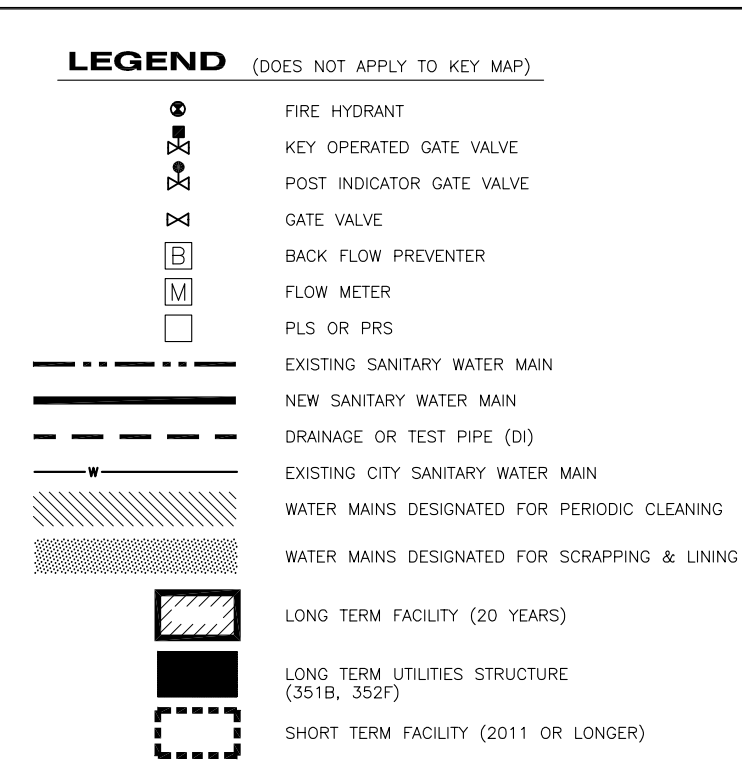

ABBREVIATIONS (DOES NOT APPLY TO KEY MAP)

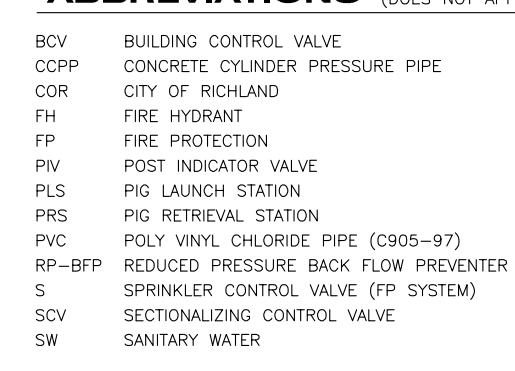

DRAWING LIST

GENERAL NOTES:

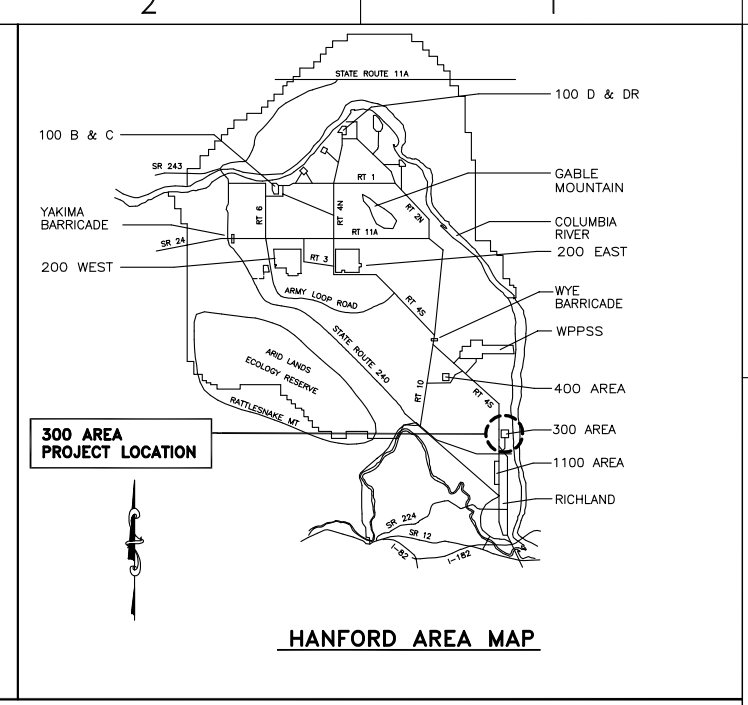

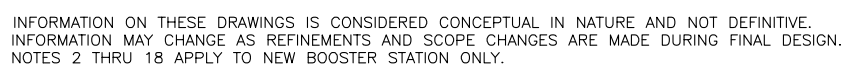

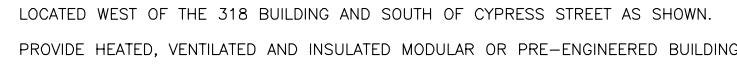

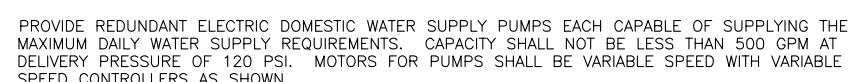

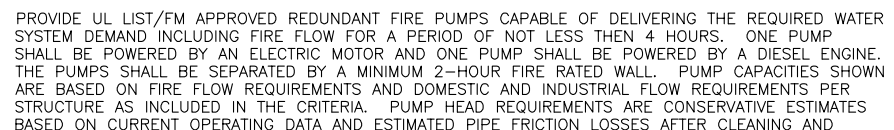

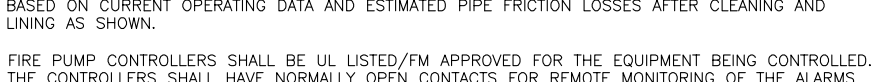

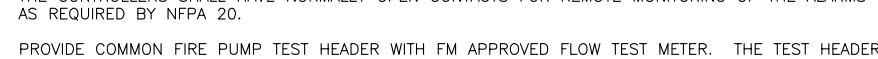

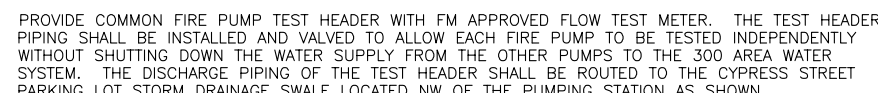

PPROUDE PRESSURE GAGES ON THE SUCTION AND DISCHAREE SIDES OF EACH FRE PUMP.

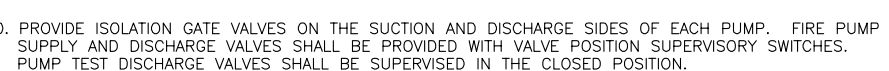

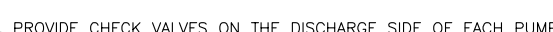

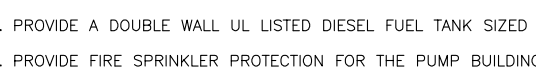

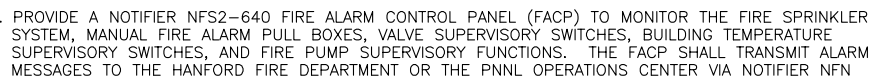

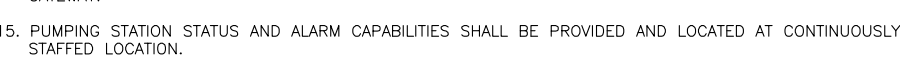

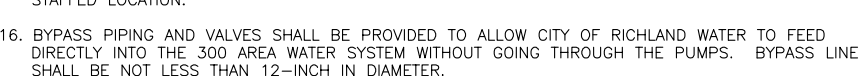

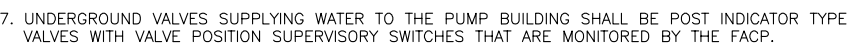

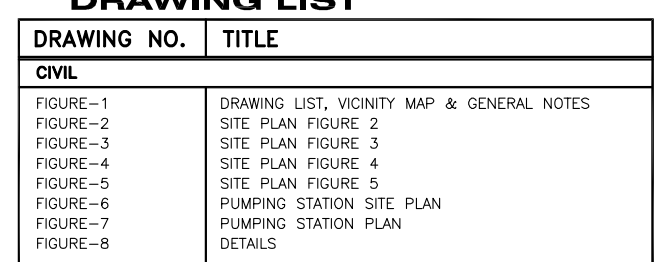




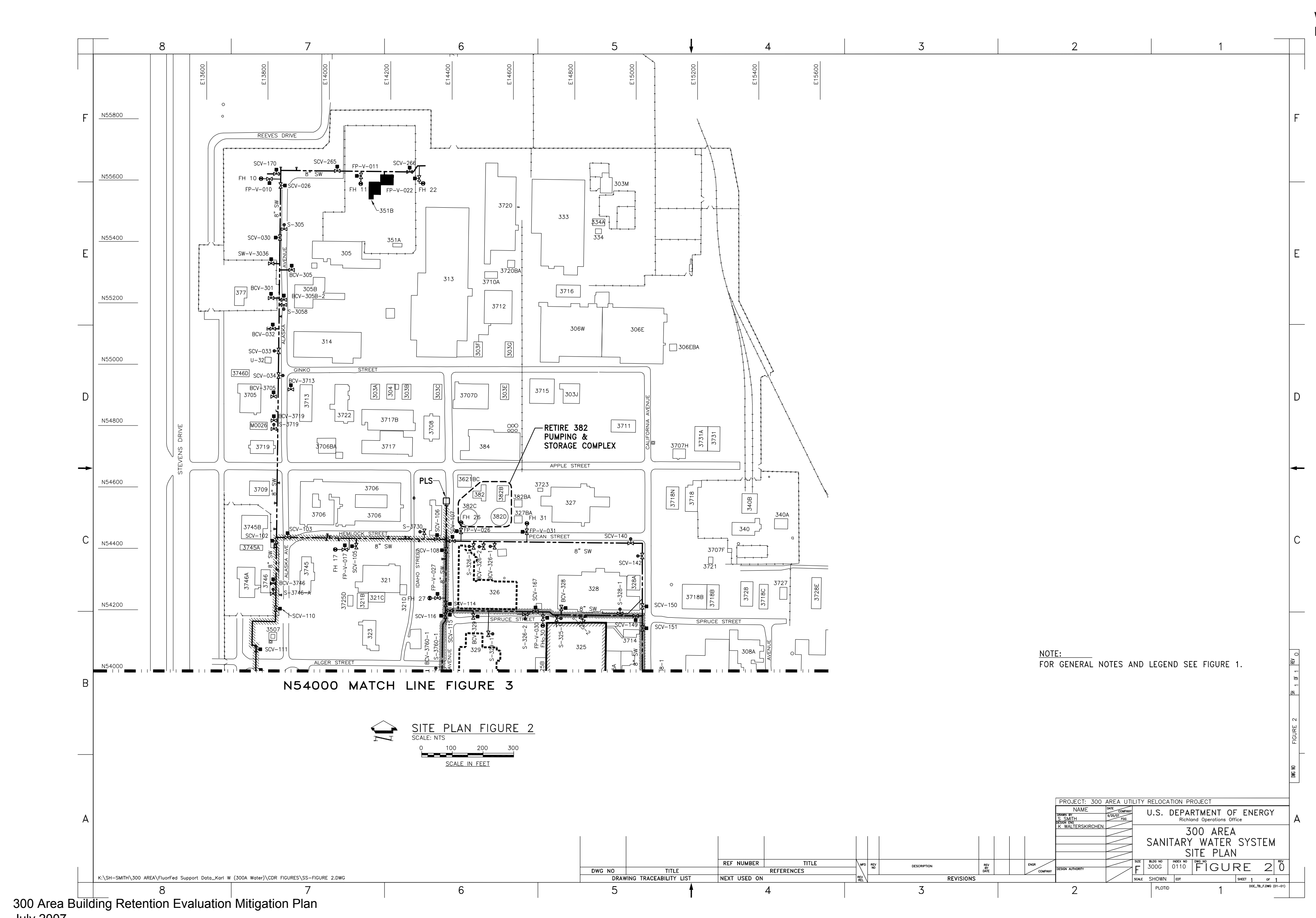




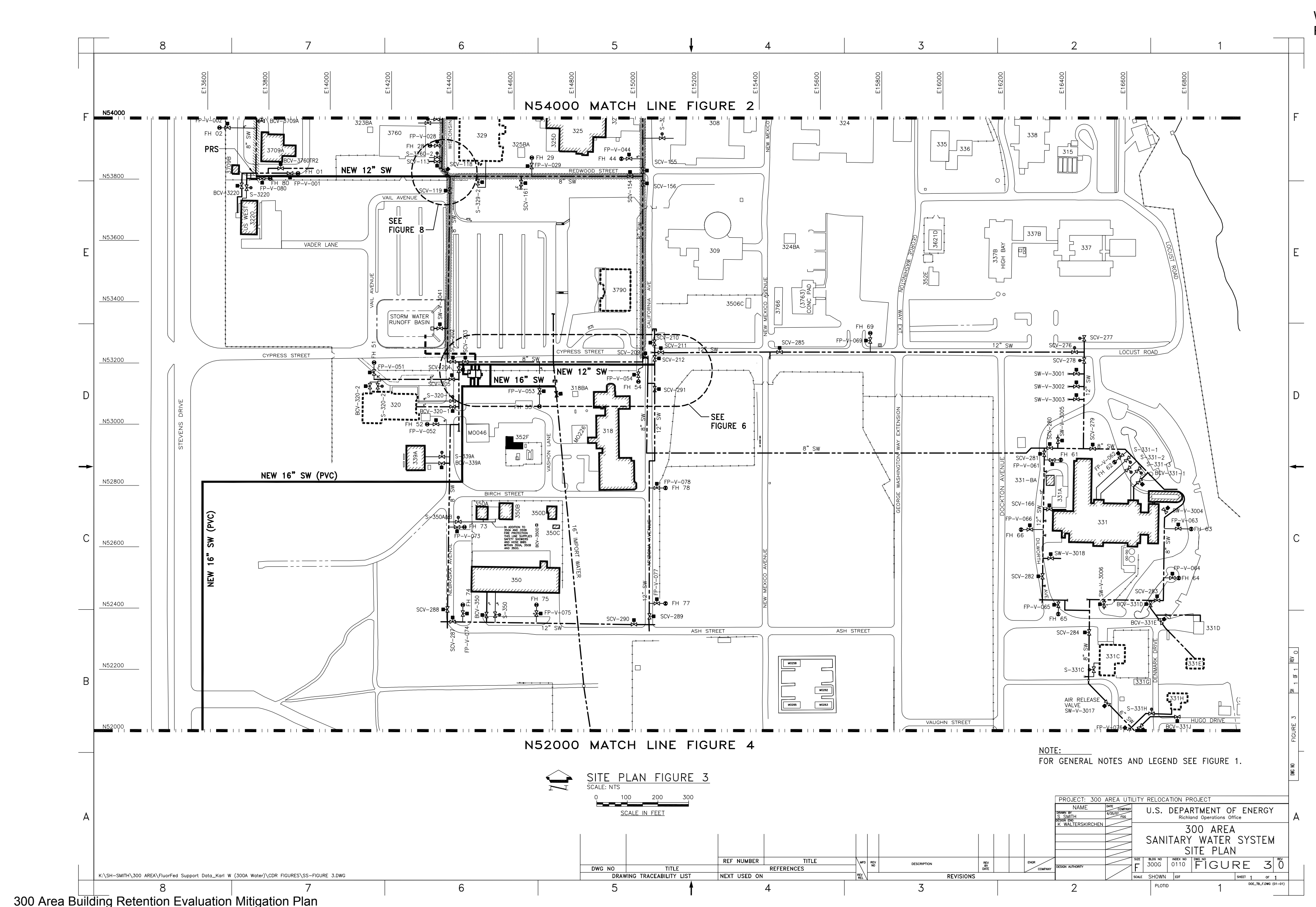




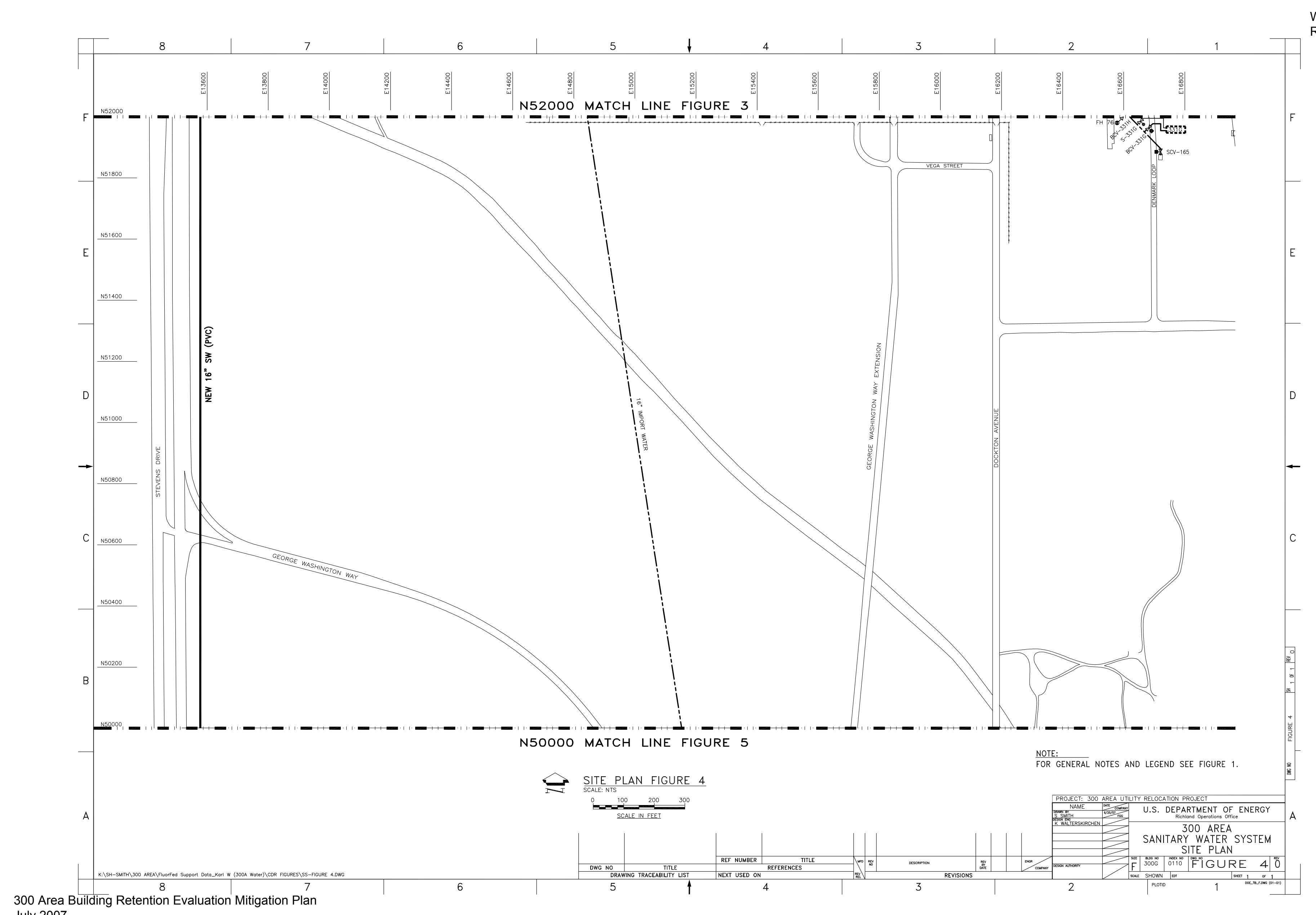




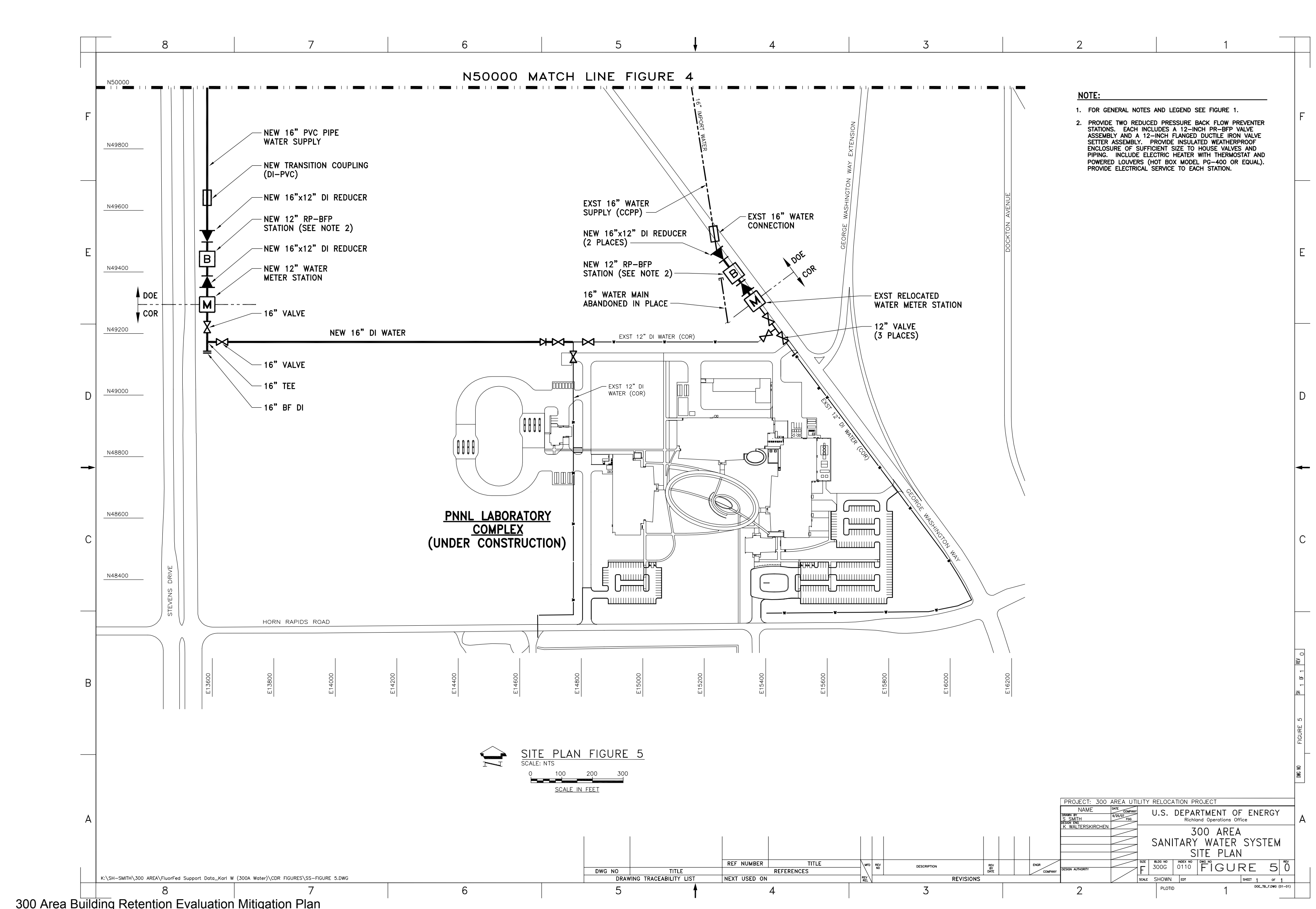




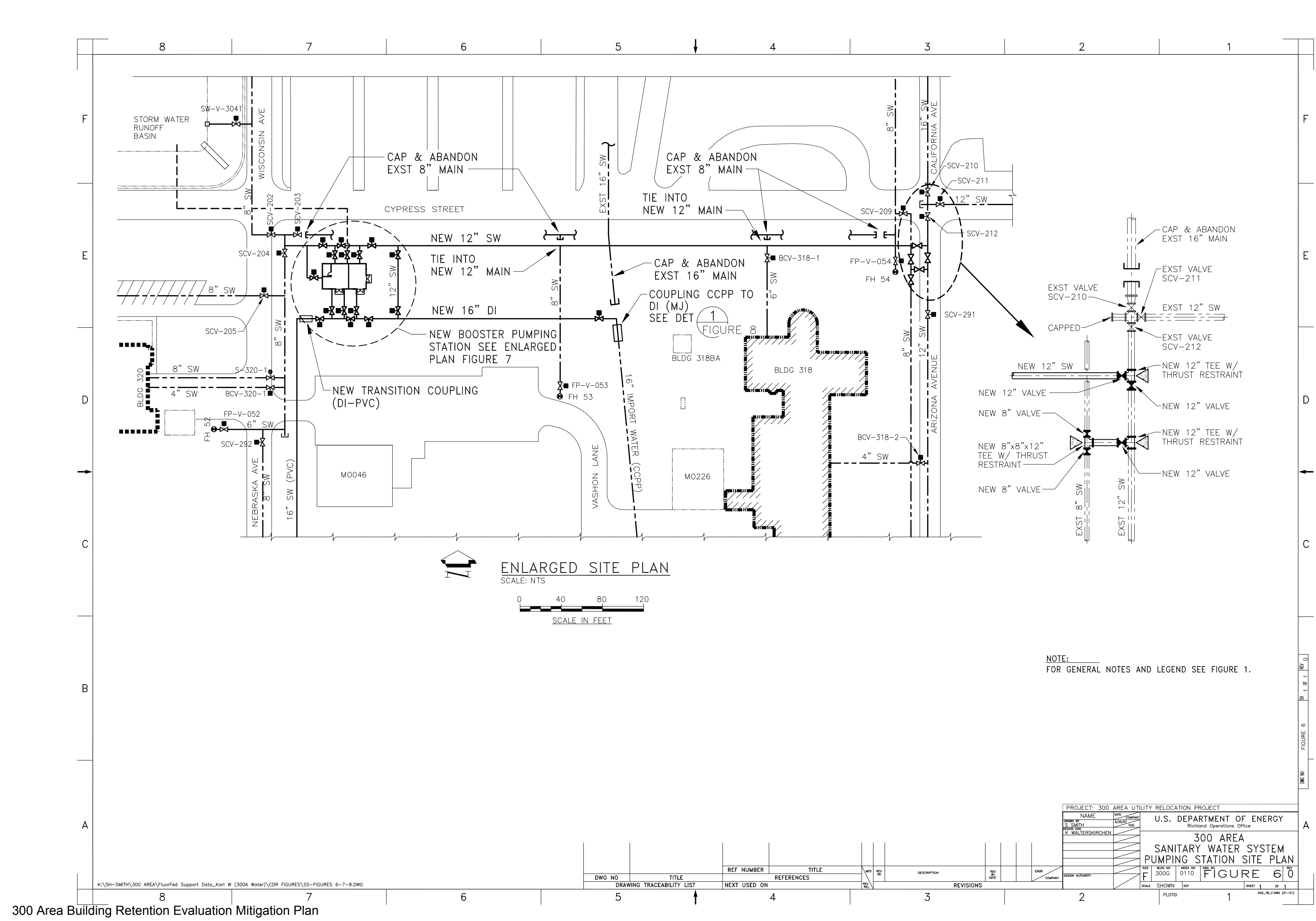




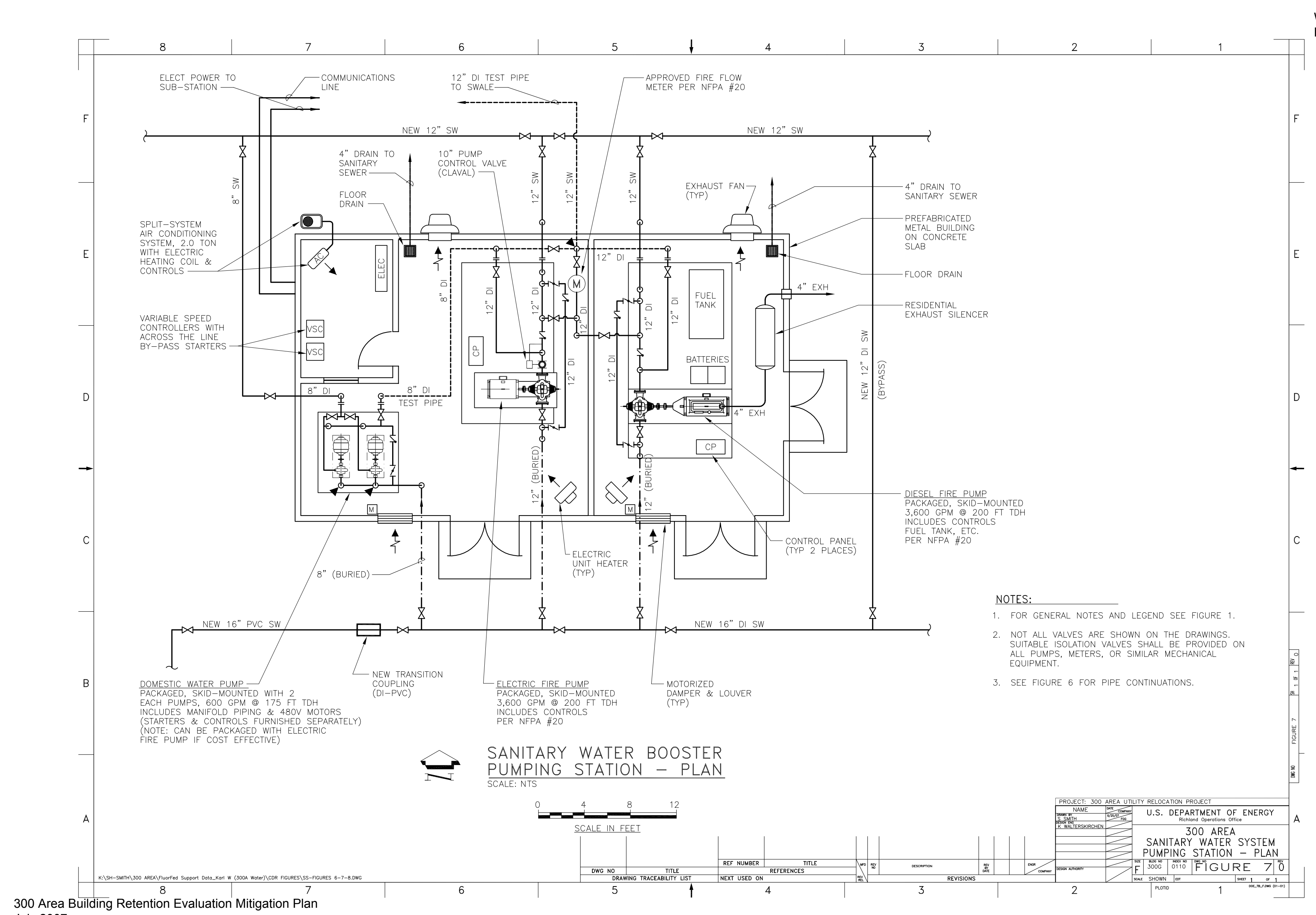




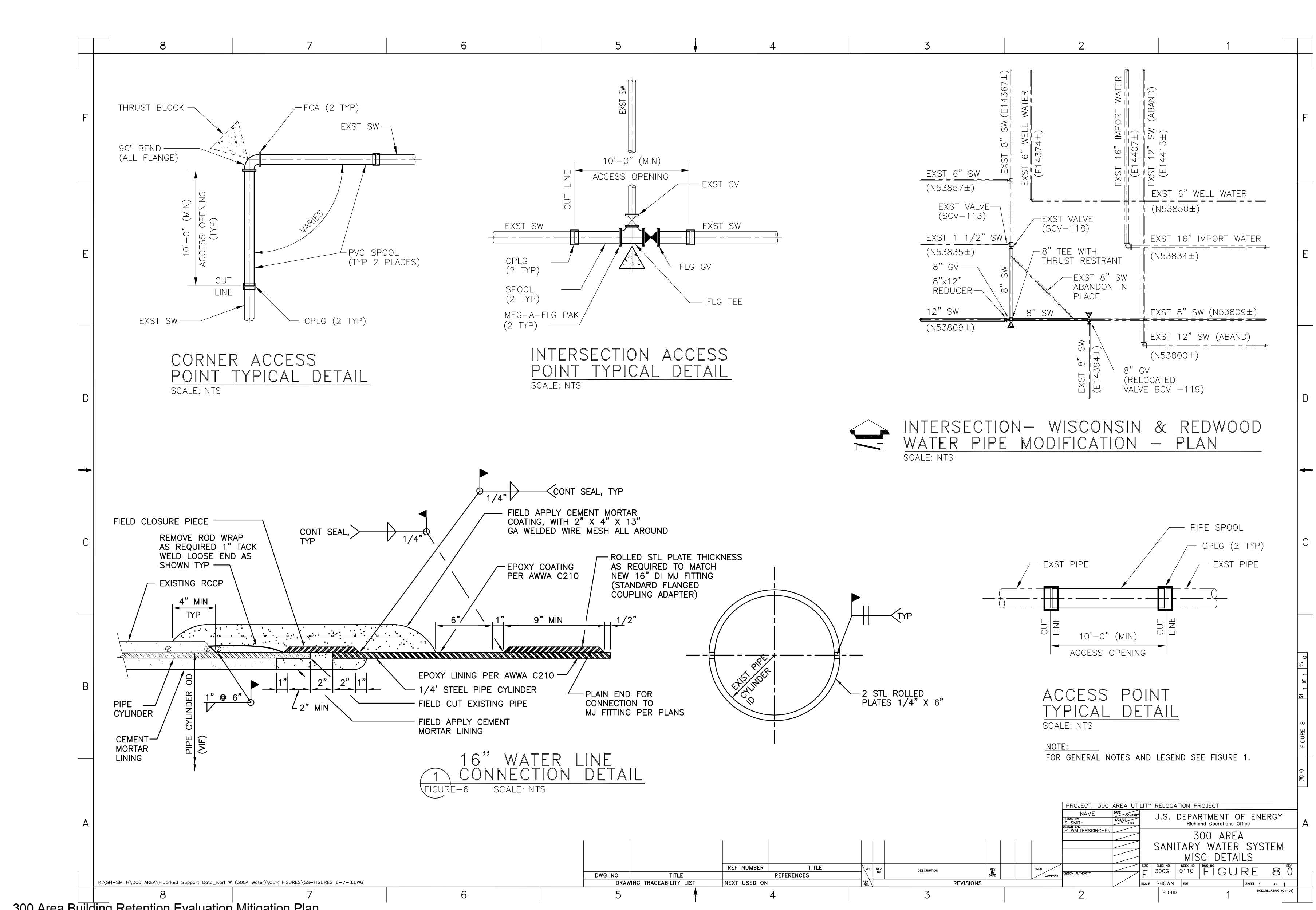




\section{APPENDIX F}

300 AREA WASTEWATER SUMMARY 
WCH-181

Rev. 0 


\section{OPTIONS FOR THE DISPOSITION OF WASTEWATER FOR 300A RETAINED FACILITIES}

\subsection{Introduction}

The Washington Closure Hanford (WCH) River Corridor Closure (RCC) scope includes the deactivation, decommissioning, decontamination and demolition (D4) of 210 buildings located in the Hanford 300 Area, followed by field remediation of waste sites in the affected areas. Thirteen facility complexes in this area are currently occupied by the Pacific Northwest National Laboratory (PNNL) and have a delayed release to WCH.

The RCC contract specifies a release date of October 1, 2009 for turnover of these facilities. However, the Department of Energy, Richland Operations Office (RL) has informed WCH that the replacement laboratory facilities that will be used to relocate PNNL's activities will not be ready for occupancy by the 2009 release date and changes to the WCH contract will be necessary. Several of the facilities will be retained by PNNL long-term (assumed $>20$ years) and several support facilities will be retained by other Hanford contractors such as the Project Hanford Management Contractor (PHMC) or Johnson Controls, Inc. (JCI).

The purpose of this document is to outline the options for disposition of wastewater utilities required to serve delayed release and retained 300A facilities occupied by PNNL, PHMC and JCI. There are four active wastewater disposal systems in the 300A which are required to support continued operations beyond 2009:

1. Sanitary sewage is currently routed to the Richland Publicly Owned Treatment Works (POTW) and discharged to the Columbia River following treatment. Note: No change is proposed to the final disposal method for existing sanitary sewage. Reroutes of the sewer and lift stations are necessary due to waste site remediation activities that will impact the existing active sewer mains.

2. Wastewater from the Process Sewer (PS) is routed to the 300A Treated Effluent Disposal Facility (TEDF) and discharged to the Columbia River following treatment. Note: TEDF is currently anticipated to be terminated at the end of FY 2009 and turned over to WCH.

3. The Retention Process Sewer (RPS) collects wastewater from buildings 324, 325, 326, 327 and 329. RPS wastewater has the potential to contain radioactive materials in an upset condition; however it is normally expected to be free of radioactive contamination. Wastewater from the RPS is collected at the 307 basins and screened for the presence of radioactive materials. Under normal operations the RPS wastewater is discharged to the 300A TEDF.

4. Storm water collection and disposal in the 300A is achieved via a variety of methods including: disposal to engineered storm water system such as grassy swales or injection wells; and cross connections to the PS and possibly the SNS. 


\subsection{Disposition of Wastewater from the Sanitary Sewer (SS)}

There is not an identified alternative to the final disposition pathway for the sanitary sewer system. The current tie-in to the City of Richland main near George Washington Way and Horn Rapids Road is assumed to be retained via an existing trunk sewer running along George Washington Way starting near Cypress Street and using the sample station near the 300 area perimeter, 3906C.

Reroutes of the sanitary sewer mains will be required using lift stations and force mains to provide a pathway avoiding field remediation planned excavations that will impact the existing active sewer mains. A summary of the disposition pathways is provided below. For each pathway there are minor design options that the final design will incorporate, these options were evaluated by the 300 Area Utility Relocation Project core team.

Facilities located East of George Washington Way (Buildings 331, 331-C, -D, -G, -H and -BA) will require no modification and will continue to flow through existing Lift Station \#2 (LS \#2, also identified as 3906B) located near the NE corner of Building 337, except the process sewer and sanitary sewer will be interconnected in the parking lot outside Building 331. All retained facilities south of Cypress Street (Buildings 318, 320, 350, 339-A, Mobile Office trailers) will continue to flow through the existing gravity sewer system and upon collection will be pumped through a new lift station LS \#11, located at the intersection of Cypress and Vail Avenue (NW corner of Building 320), through a new pressure (force main) pipe system to discharge into the interceptor at George Washington Way. Flows from Buildings 3709A and 3220 will be collected in a new lift station LS \#10 through existing and new gravity sewer laterals and pumped through a force main sleeved through the unused portion of the sanitary sewer system in Vail Avenue to LS \#11. In addition, two lift stations LS\#13 and LS\#14 will be built in Spruce Street to collect wastewater from Buildings 325, 326, 329 and 3790. LS\#13 will be located in the SW corner of \#326 to collect and pump wastewater from \#326 and \#329 and discharge into LS\#14 located at NW corner of \#325. LS\#14 will also collect the waste water from \#325, \#3790, a portion of \#326 and RPS tank pad and pumps to LS\#11. LS \#11 pumps all of the sanitary waste water from the retained buildings north and south of the Cypress street and West of George Washington Way to the interceptor where the discharges are commingled with flows from the LS \#2, and delivered into the city sewer system.

\subsection{Disposition of Wastewater from the Retention Process Sewer (RPS)}

\subsection{INTRODUCTION}

The 300 Area retention process sewer (RPS) stream for buildings 325, 326, and 329 currently flows to the 307 basins and then to TEDF. Since TEDF is scheduled for deactivation before the RPS system is deactivated, an alternate means of managing the RPS effluents from the 325, 326, and 329 buildings is required. In addition, it was proposed that the Process Sewer streams be tied into the RPS stream for the 326 and 329 
buildings. This was based on an assumption that the PS stream from 326 and 329 could not be introduced into the sanitary sewer (SS) system.

\subsection{SCOPE}

\subsubsection{RPS Disposition}

The conceptual design provides layouts, general arrangements, and calculations to support the rerouting of the current RPS stream to a holding tank system. The holding tank system has provision for sampling of the RPS fluids prior to routing to the sanitary sewer (SS-83). A load-out station is also provided to manage alternate disposal of contaminated fluids. A similar holding tank system is located at the Environmental Molecular Sciences Laboratory (EMSL). This system was directly used to model the 300 area holding tank system.

\subsubsection{Process Sewer Tie-In}

The conceptual design also includes the necessary modifications to tie the PS streams into the RPS streams within the 326 and 329 buildings.

\subsubsection{Stormwater Isolation}

There is currently, one storm catch basin located on the east side of the 329 building that is tied into the RPS system. The RPS holding tanks will not be large enough to manage stormwater as well as RPS streams. In addition, the City of Richland has stipulated that it is not acceptable to route stormwater into the SS system. The tie-in must therefore be isolated.

\subsection{SIGNIFICANT DESIGN CRITERIA}

\subsubsection{Criteria}

Criteria for the RPS system reroute and PS tie-ins have been established and are as follows.

- $\quad$ The RPS collection system shall have the capability to transfer wastewater to a tanker truck for wastewater which does not comply with the treatment facility's acceptance criteria.

- $\quad$ The RPS collection system provide sufficient ( 1 week per tank) storage capacity to allow operation in the following mode:

o One active tank / basin filling

o One full tank / basin awaiting sampling and analysis

o One additional tank / basin to hold off spec wastewaters requiring load-out by tanker truck. 
o One standby tank / basin

- $\quad$ Non-radiological facility wastewater discharges such as boiler blow down or roof / parking lot runoff should be segregated from the RPS collection system.

\subsubsection{Codes and Standards}

- Uniform Plumbing Code

- City of Richland Standard Specification Section 7

- NFPA 70 - National Electrical Code

- NFPA 820 - Standard for Fire Protection in Wastewater Treatment and Collection Facilities

- City of Richland Municipal Code, Richland Pretreatment Act - Chapter 17.30

\subsection{FUNCTIONAL OBJECTIVES}

\subsubsection{Effluent Flows}

Effluent flow rates from the buildings are listed below. While there are efforts underway to reduce flows, these efforts are not yet complete. It is therefore necessary at this stage of the design to account for the known flows as listed.

- $325 \mathrm{RPS}-4 \mathrm{gal} / \mathrm{min}$

- 326/329 RPS - 5 gal/day

- 326 PS - 100 gal/day

- 329 PS - 44 gal/day

\subsubsection{Tank Load-Out Facility}

The tank load out facility must accommodate a tanker sized vehicle. During load-out activities, the vehicle must be located on a concrete pad that provides spill containment and routing to a sump that pumps spillage back to one of the holding tanks. The tanks are to be located on a pad that provides spill containment for a minimum of $10 \%$ of the total tank volume, or the volume of the largest tank, whichever is larger.

\subsection{CONCEPTUAL LAYOUTS AND GENERAL ARRANGEMENTS}

The overall concept of the 300 Area Retention Process Sewer system reroute consists of 3 primary activities.

\section{Lift Station}

All retention process sewer lines between the 325,326 , and 329 buildings currently flow to the existing RPS-3 manhole, and then through an existing 8" clay pipe to the existing 
307 basins. The 8 " line is to be capped off, and a new lift station is to be installed in the RPS-3 manhole. A new 1" PVC discharge line is to be installed in the RPS-3 manhole from the new dual sump pumps to feed the RPS Load-Out Station. A new valve box is installed over the discharge line to provide access to check valves and isolation valves in the new discharge line.

\section{RPS Load-Out Station}

The RPS Load-Out Station will consist of four, 4300 gallon tanks situated on a 30' x 30' pad with appropriate spill containment. Tank EFT-1 will be the active tank, continually receiving effluent from RPS-3. When EFT-1 is full, it is emptied to EFT-2 to await sampling and analysis. Should the analysis show that the contents of EFT-2 require load out, it will be transferred to EFT-3. Otherwise, tank EFT-2 is gravity drained through a 2” PVC line to the sanitary sewer at the SS-83 manhole. The control system will time the drain to SS-83 during a time of low SS flow, such as 0100 hours. Tank EFT-4 will be a stand-by tank.

A new asphalt drive and concrete pad with spill containment are also provided for loadout activities. The truck will receive the EFT-3 contents while parked on the concrete pad. Both pads will be covered to prevent stormwater from accumulating in the sump. All spillage from at the truck pad or tank pad will be routed to the central sump and returned to tank EFT-1.

Adequate valving and piping will be provided such that any tank can serve any of the functions described.

\section{Process Sewer to RPS Tie-ins}

The process sewer (PS) streams at the 326 and 329 buildings will be tied into the RPS stream prior to exiting the buildings.

\section{a. 329 PS Tie-in}

The 329 tie-in is to be located on the north wall of the service tunnel and is described in Figure 5. The 3-inch carbon steel PS lines will be cut, capped, and converted to PVC lines as they tie-in to the 4-inch stainless steel RPS line.

b. 326 PS Tie-in

The PS stream will be collected in a new sump, located in room 21-A, in the basement. The existing 8” PS line exiting the building in that room will be capped. The sump will collect the discharge from the 8" line and several additional existing lines in located in the room. A new sump pump will send the contents of the 50 gallon sump through a 1 " PVC line to room 24-A1, where the RPS stream is collected and routed to the existing RPS-2 manhole just outside the building. The new 1" PVC line ties into an existing 2" carbon steel line in room 24-A1, just above the ceiling tiles. 
Secondarily, there is one stormwater catch basin currently tied into the RPS stream at the South East corner of the 329 building. This 4-inch PVC line is to be cut and capped as shown in Figure 1 to isolate stormwater flow to the RPS Load-Out Tanks.

\subsection{FLOW DIAGRAMS}

Process and Instrumentation Diagrams (P\&IDs) were available from the EMSL design.

\subsection{SIZING AND PROCESS CALCULATIONS}

Calculation document 0300X-CA-M0001 was developed for the RPS reroute and contains all pertinent conceptual level calculations.

\subsection{PRELIMINARY DESIGN PARAMETERS}

The following parameters will need to be addressed at preliminary design.

\subsubsection{Effluent Flow Rates}

As previously mentioned, a PNNL effort is underway to reduce flows from the 325, 326, and 329 buildings. Flow criteria will need to be finalized based on those efforts.

\subsubsection{Tanker Truck Configuration}

The conceptual design does not account for any specific requirements that the tanker truck may have for load out. A specific truck will need to be identified from which the load out facility design can be finalized.

\subsubsection{Site Characterization}

Building 328 currently exists at the proposed site for the tank load out facility. If building 328 has been remediated prior to preliminary design, then the site will need to be characterized for the spill containment pad, load-out pad, and road design.

\subsubsection{Component Sizing}

Components were sized and selected as follows.

\section{Tank Drain to SS-83:}

The drain line from the tanks to the SS-83 manhole is to be a 2-inch schedule 40 PVC pipe. PVC pipe was selected for all piping in the RPS reroute, since some of the existing RPS lines have already been converted to PVC. 
$\underline{\text { RPS-3 Lift Station: }}$

The RPS-3 Lift station discharge line is to be a 1-inch schedule 40 PVC pipe. The pump for the lift station is to be an Aquatic ECO-Systems Inc., Model SP750 (or equivalent) high-head submersible pump, operating at 20gpm and $30 \mathrm{ft}$ head.

\section{Process Sewer Sump Dimensions:}

The new sump for the 326 process sewer is to be 2 foot square, by 3 foot deep. The width dimension is restricted; however the remaining dimensions can be increased as needed. The volume of the sump is sized to handle 50 gallons of the $100 \mathrm{gal} /$ day PS flow.

326 Process Sewer Sump Pump and discharge line:

This sump pump is sized to provide $18 \mathrm{gpm}$ at 36 feet head through a 1-inch schedule 40 PVC pipe.

\section{Tank Pad Spill Containment Curb:}

The spill containment curb surrounding the retention tank pad is required to be 3" high, to contain $10 \%$ of the total volume of the 4 tanks as required per WCH-56.

\section{Load-Out Tanks:}

The load out tanks were sized to 4300 gallons based on known flows to TEDF from the 300 Area RPS system. It so happens that the tanks used at the EMSL design were the exact size required based on the known flows. As a result, the complete EMSL design was adapted to the 300 Area RPS Load Out system. The material of the tanks was selected to be FRP due to the universal compatibility with potential constituents within the RPS stream.

\subsection{MATERIAL SELECTION, PROCUREMENTS SPECFICIATIONS}

Procurements specifications will need to be written for the following components.

1. Tanks. The four tanks have been conceptualized as 4300 gallon tanks fabricated from fiberglass reinforced plastic (FRP). The tanks are free standing and elevated to allow full drainage from a bottom center fitting. 
2. Pumps. Three sump pumps are needed; two for the RPS-3 lift station and one for the new 326 building PS sump. The pumps selected in the analysis are the Aquatic Eco-Systems, Inc, High Head submersible pump, model SP750, but any submersible pump providing equivalent flow and head characteristics is acceptable. The load out pumps were not sized or selected since the characteristics of the receiver truck were not known. The pumps shown were simply copied from the EMSL design, which featured tanks that were located in a below-grade vault. It is quite possible that the final design of the load out facility could eliminate the need for the pumps entirely.

3. "Rain Hat." It is suggested that the carport-like structure over the tank load out facility be specified and procured from a vendor specializing in such structures.

\subsection{ENVIRONMENTAL IMPACT}

There is no expected environmental impact. The RPS and PS effluents from buildings 325, 326, and 329 are contained in their entirety and sampled prior to release or load-out. All new installations of piping and facilities are being located at pre-existing facility or road locations. No significant radiological or chemical hazards are foreseen for construction or isolation activities.

\subsection{LONG LEAD PROCUREMENT ITEMS}

The FRP tanks are expected to be long lead items requiring approximately 3 weeks for vendor drawings and 16 weeks to fabricate.

\subsection{IDENTIFICATION OF POTENTIAL SAFETY HAZARDS AND PROVISIONS FOR HAZARD CONTROLS}

No safety hazards other than occupational during construction are foreseen.

\subsection{ESTIMATED PROCUREMENT/CONSTRUCTION SCHEDULE.}

While the tanks are long-lead items, they are not required at the start of construction. Delivery of the tanks should coincide with construction completion of the pad on which they are installed. Procurement/construction duration is estimated to 6 months. This does not include final design, which precedes the construction start date, but could end during the first phases of construction.

\subsection{Disposition of Stormwater}




\subsection{INTRODUCTION}

The 300 area storm water system consists of roof drains, downspouts to ground, injection wells, catch basins, and a grassy swale. In some cases, storm water is interconnected with Retention Process Sewer (RPS), or Process Sewer (PS). City of Richland Pretreatment Ordinance prohibits storm water from being discharged to the City of Richland sanitary sewer, which is the ultimate destination of RPS or PS streams*. While all buildings have storm water run-off engineered or otherwise, only a few result in potential discharge to non-permitted destinations.

*City of Richland Pretreatment Ordinance, Exhibit A to Title 17.30, Part 2, "General Requirements”, section 2.1, "Prohibited Discharge Standards", (12), "Stormwater, surface water, ground water, artesian well water, roof runoff, subsurface drainage, swimming pool drainage, condensate, deionized water, non-contact cooling water and unpolluted wastewater, unless specifically authorized by Public Works Director.”

\subsection{SCOPE}

The conceptual design is limited to the buildings at which there are cross connects with the storm water streams. Table 1 provides a list of the buildings within scope and the nature of their cross connects.

\begin{tabular}{|c|c|c|}
\hline Building & Nature of Cross-Connect & Proposed Resolution \\
\hline 3709A & $\begin{array}{l}\text { Roof drain goes to the sanitary } \\
\text { sewer }\end{array}$ & Reroute drains to the building exterior. \\
\hline 3790 & $\begin{array}{l}4 \text { catch basins to the NE are } \\
\text { connected to the PS (H-3-304714 } \\
\text { SH. 3) }\end{array}$ & $\begin{array}{l}\text { The } 4 \text { basins are in series. Isolate the } \\
\text { most downstream basin by partially } \\
\text { filling with concrete. Resulting surface } \\
\text { flow gravity flows toward the } \\
\text { stormwater swale at Cypress Street as } \\
\text { is currently occurring due to sediment } \\
\text { blocking the catch basins. }\end{array}$ \\
\hline 329 & $\begin{array}{l}\text { Catch Basins at SE corner connect } \\
\text { to RPS. }\end{array}$ & $\begin{array}{l}\text { Cut and cap cross connection, then } \\
\text { install a lift station and route about } 120 \\
\text { feet of 2" line to the catch basins } \\
\text { located on the SW corner of the } \\
\text { building (H-3-300799). These CB's } \\
\text { are connected to the swale. }\end{array}$ \\
\hline 318 & $\begin{array}{l}\text { A drain located in a below grade } \\
\text { load-out area may be connected to } \\
\text { the sanitary sewer within the } \\
\text { building. }\end{array}$ & $\begin{array}{l}\text { Reroute the drain to a new lift station to } \\
\text { be installed in the load-out area. Route } \\
\text { the discharge to grade. }\end{array}$ \\
\hline 331 & $\begin{array}{l}\text { A line on the north side of the } \\
\text { building is fed by storm water and } \\
\text { condensate from within the } \\
\text { mechanical rooms } 100 \text { and } 118 . \\
\text { There are two additional storm }\end{array}$ & $\begin{array}{l}\text { Plug all interconnecting floor drains } \\
\text { and route all lines flowing to the floor } \\
\text { drains in rooms } 100 \text { and } 118 \text { to a new } \\
\text { sump and lift station. Discharge the lift } \\
\text { station to a new header on the north }\end{array}$ \\
\hline
\end{tabular}




\begin{tabular}{|l|l|l|}
\hline Building & $\begin{array}{l}\text { Nature of Cross-Connect } \\
\text { water lines that feed into the fish } \\
\text { tank drains on the south side of the } \\
\text { building. }\end{array}$ & $\begin{array}{l}\text { Proposed Resolution } \\
\text { side of the building and route it to } \\
\text { sanitary sewer. Storm drains on the } \\
\text { south side of the building } \\
\text { interconnected with the fish tank drain } \\
\text { is not considered to be in scope. }\end{array}$ \\
\hline 326 & $\begin{array}{l}\text { There is a known cross connect at } \\
\text { the east storm drain with the SS; } \\
\text { however it has been plugged. }\end{array}$ & $\begin{array}{l}\text { Install a new lift station to convey } \\
\text { storm water to the new lift station being } \\
\text { installed at the south east corner of the } \\
\text { 329 building. }\end{array}$ \\
\hline
\end{tabular}

\subsection{SIGNIFICANT DESIGN CRITERIA}

\subsubsection{Criteria}

Existing storm water connections to the sanitary sewer and process sewer need to be rerouted to existing or new storm water structures.

Criteria for storm water discharge are found in State Waste Discharge Permit Number ST 4511, issued February 16, 2005. Storm water regulated under the permit is defined per section S.1.A.3 as:

“....industrial stormwater that discharges to ground and is collected in an engineered structure and is subsequently discharged to an engineered disposal structure."

The three underlined terms are defined within the permit language as follows.

Industrial Stormwater. Stormwater discharge with the potential to come in contact with an industrial activity or that is collected within an area of industrial activity.

Collected in an Engineering Structure. Stormwater must be collected in a structure such as a lined trench, basin, retention structure, secondary containment, tank, sump, roof, and other impervious surfaces directly associated with industrial activities.

Discharged to an Engineered Structure. The industrial stormwater must be discharged to an engineered disposal structure such as an injection well, dry well, catch basin, infiltration basin, infiltration trench, or retention basin.

\subsubsection{Codes and Standards}

- Uniform Plumbing Code

- City of Richland Standard Specification Section 7 
- $\quad$ NFPA 70 - National Electrical Code

- NFPA 820 - Standard for Fire Protection in Wastewater Treatment and Collection Facilities

- City of Richland Municipal Code, Richland Pretreatment Act - Chapter 17.30

\subsection{FUNCTIONAL OBJECTIVES}

Cross connections of the storm water streams with process or sanitary sewer streams must be eliminated prior to tie-in of remaining process sewer contributors to the sanitary sewer.

\subsection{CONCEPTUAL LAYOUTS AND GENERAL ARRANGEMENTS}

The following describes the conceptual design for the reroutes of storm water at each applicable facility.

Building 3790

To the north east of building 3790, there are four catch basins. The catch basins are installed in series. Drawings indicate the catch basins are tied into the process sewer system. Field observations during rain fall indicate that the basins may be clogged or plugged. However, the design delineates the necessary activities to ensure the basins are plugged and do not connect with the process sewer. Field observations also indicate that plugging the basins will not affect appropriate storm water drainage of the area.

Building 3709A Fire Station

The fire station has four roof drains that are interconnected with the sanitary sewer system. The design conceptualizes routing each roof drain to the exterior of the building and subsequently allowing the stormwater to flow to ground.

\section{Building 326}

There is a catch basin at the bottom of the loading doc on the east side of the building. This catch basin is currently plugged; however a long term solution is required to manage stormwater collection in that area. A lift station is conceptualized to receive the stormwater from the loading doc and discharge it towards building 329, to a new lift station that is being installed at the south east corner of the building.

Building 329 
Two catch basins on the south east corner of the building collect stormwater and route it to the RPS system. The concept is to cap the RPS connection and reroute the catch basin discharge to a new lift station at the south east corner of the building. The lift station discharges stormwater to one of two existing catch basins on the south west corner of the building. These catch basins feed to the grassy swale. As stated previously, the new lift station also receives stormwater from the south east loading dock at building 326.

\section{Building 318}

There is a loading dock on the North West corner of the building that is about 14 feet below grade. Steps lead down to the floor of the loading dock. There is a floor drain at the bottom of the loading dock that reportedly is cross connected with the sanitary sewer. While this connection could not be verified, the design conceptualizes a lift station installed in the floor of the loading dock that receives re-routed stormwater from the drain and discharges it to ground at grade level.

\section{Building 331}

The primary roof drains are routed through the building and pick up process streams from various floor drains. This is shown diagrammatically in H-3-57950. According to the building engineers, all other process flows are routed to the mechanical rooms (rooms 100 and 118) where they are collected in floor drains, which are again tied into the roof drain piping and routed to a header below grade on the north side of the building. The header is routed through a number of catch basins and then to a manhole that sends the process/stormwater to a process sewer main. The concept is to plug all of the floor drains that connect to roof drain piping, and re-route process lines to a sump in each of the mechanical rooms. The sumps discharge process streams to a new header to be installed on the north side of the building and routed to sanitary sewer. This leaves only storm water flowing into the existing header on the north side of the building. The connection downstream of the manhole is then capped and the stormwater is then routed to an injection well 300 feet from the building to be in compliance with permit 4511 to maintain a 300 foot boundary with WIDS sites that happen to exist in the area.

\subsection{FLOW DIAGRAMS}

No flow diagrams were prepared as a part of the conceptual design.

\subsection{SIZING AND PROCESS CALCULATIONS}

No calculations were necessary or prepared as a part of the conceptual design. 


\subsection{ENVIRONMENTAL IMPACT}

There is no expected environmental impact.

\subsection{LONG LEAD PROCUREMENT ITEMS}

No long lead procurement items are anticipated.

\subsection{IDENTIFICATION OF POTENTIAL SAFETY HAZARDS AND PROVISIONS FOR HAZARD CONTROLS}

No safety hazards other than occupational during construction are foreseen.

\subsection{ESTIMATED PORCUREMENT/CONSTRUCTION SCHEDULE.}

Procurement of items is estimated to require 1 month and construction to require 3 months to modify all facilities in scope.

\subsection{Disposition of Process Sewer}

Current contributors to the process sewer will be split into three disposition pathways and discharges to the 310 TEDF will be discontinued. Stormwater contributors will be addressed as described in section 4.0. Process sewer discharges from Buildings 326 and 329 will be combined with the Retention Process Sewer stream as described in Section 3.0. Remaining process contributors in the 318, 320, and 331 buildings will be permitted using the City of Richland Municipal Pretreatment Permit process and tied into the sanitary sewer system. 
WCH-181

Rev. 0

300 Area Building Retention Evaluation Mitigation Plan 


\section{APPENDIX G}

300 AREA SANITARY SEWER DECISION MEETING 
WCH-181

Rev. 0 


\section{WCH Masintaten Hanford Meeting Minutes}

134186

\section{SUBJECT

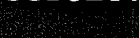

TO

FROM

\section{SUMMARY OF DECISION MEETING FOR SANITARY SEWER SYSTEM OPTIONS 300 AREA UTILITY RELOCATION PROJECT}

Distribution

John N. Winters $\Re W$

DATE

June 12, 2007

\section{ATTENDEES}

T. Ambalam E6-46, w/a

S. I. Bennion H7-21, w/a

S. R. Cassidy J2-45, w/a

E. G. Damberg J2-25, w/a

R. Gerk J2-18, w/a

C. MacDonald J2-45, w/a

G. M. MacFarlan L6-06, w/a

D. J. McBride H4-15, w/a

D. J. Ortiz A3-04, w/a

B. W. Wilcox H4-15, w/a

J. N. Winters H4-20, w/a

\section{DISTRIBUTION}

Attendees

D. E. Dieterle L1-04, w/a

R. G. Egge X5-50, w/a

R. F. Guercia A3-04, w/a

D. J. Tollefson E6-29, w/a

J. Turner K9-42, w/a

D. M. Yasek L1-07, w/a

Document Control H4-11

On May 30, 2007, a decision meeting was held to review and rank the two options for sanitary sewer system modification as part of the 300 Area Utility Relocation Project. The Wastewater Discipline Team discussed the pros and cons of the baseline and alternative options. Each option can provide sanitary sewer service to the retained facilities in the 300 Area. In Attachment 1, Tom Ambalam/Fluor Federal Services summarizes the key differences in the options. This information was distributed and reviewed at the beginning of the decision meeting. During the meeting, the conceptual cost estimates for the Baseline and Alternate options were given by Bruce Wilcox/WCH as $\$ 620,000$ and $\$ 867,000$, respectively. These cost estimates include a $30 \%$ contingency amount.

A ranking process used in the electrical and water utility options decision meetings was used at the May 30 meeting to rank the sanitary sewer options. The same selection criteria and weighting factors were also used.

As with previous decision meetings, the attendees discussed how each option could satisfy each selection criterion and then arrived at a consensus of a grade between high and low (available grades included $\mathrm{H}, \mathrm{H}-$, $\mathrm{M}+, \mathrm{M}, \mathrm{M}-, \mathrm{L}+$ or L). A spreadsheet (Attachment 2) was used to document the grade assignments. Using the weighting factors assigned and a score associated with each grade (see lower left corner of ranking spreadsheet for weighting factor and grade scores), a weighted score was calculated for each option.

The resulting weighted scores for the sanitary sewer system options were compared against the total possible points. Using the ranking spreadsheet (Attachment 2), the Baseline and Alternate options scored 70 and $71 \%$, respectively. Based on the fact that the baseline option maintains the use of a sewer pipeline 
Distribution

Page 2

on Spruce Street adjacent to the 325 Facility (which was raised as an area of potential concern by regulators) while the alternate option eliminates the use of this sewer pipeline, it was the consensus of the decision meeting participants that the Alternative Option is the recommended option.

Following the ranking meeting, Mr. Wilcox updated the cost estimate for the alternate option to include additional scope that would have also applied equally to the baseline option. With that update, the estimated cost is $\$ 903,000$. That updated cost estimate summary is provided in Attachment 3 . The cost summary also includes a scope description of the major components for the Alternate Option.

Attachments: 1. Sanitary Sewer System Options - Baseline and Alternative Option Comparison (1 page)

2. Sanitary Sewer Options Worksheet (2 pages)

3. Cost Estimate Summary for Sanitary Sewer Alternate Option (1 page) 
WCH-181

Rev. 0

ATTACHMENT 1

\section{SANITARY SEWER SYSTEM OPTIONS - BASELINE AND ALTERNATIVE OPTION COMPARISON \\ (consisting of 1 page)}




\section{ATTACHMENT 1}

\section{SANITARY SEWER SYSTEM OPTIONS \\ By Tom Ambalam/Fluor Federal Services}

PROJECT: 300A - URP

The tabulation below compares the two options (Baseline and Alternate) for Sanitary Sewer System Modifications in the Project: 300 A - URP.

Baseline Option -Sewer system layout depends on the existing pipelines in Spruce Street, regardless of its condition or adjacent utilities, involves a lift station (LS-12) and avoids excavation in the congested utility corridor, except at the intersection of Spruce at California.

Alternate Option -Sewer system layout avoids the use of the sewer pipes within the Spruce Street by intercepting the flows upstream at Wisconsin Street and involves two pump stations (LS-13 by \#326 and LS-14 by \#325). Shallow excavation for RPS and laterals across and adjacent to the congested utility corridor of Spruce street will be required.

\section{Table: Comparison of Sewer System Options}

\begin{tabular}{|c|c|c|c|c|}
\hline No & $\begin{array}{c}\text { BASE LINE OPTION } \\
\text { SANITARY SEWER SYSTEM }\end{array}$ & & $\begin{array}{c}\text { ALTERNATE OPTION } \\
\text { SANITARY SEWER SYSTEM }\end{array}$ & \\
\hline 1 & Construction costs lower by $\$ 200 \mathrm{~K}$ & + & Construction costs higher & - \\
\hline 2 & $\begin{array}{l}\text { Operation and maintenance costs will } \\
\text { lower with one lift station though pipe } \\
\text { lengths are longer }\end{array}$ & 0 & $\begin{array}{l}\text { Operation and maintenance costs will } \\
\text { be higher with additional lift station for } \\
\text { short term and pipe liners are shorter }\end{array}$ & 0 \\
\hline 3 & $\begin{array}{l}\text { Requires less of operation and } \\
\text { maintenance of a lift station (LS-12) }\end{array}$ & + & $\begin{array}{l}\text { Requires additional lift station(LS-13), } \\
\text { though short term }\end{array}$ & - \\
\hline 4 & $\begin{array}{l}\text { Without the evaluation of sewer pipes } \\
\text { for condition, leaks or future } \\
\text { serviceability may be at risk. }\end{array}$ & - & $\begin{array}{l}\text { Regardless of condition of the sewers in } \\
\text { the Spruce street the system will } \\
\text { function during its service life- the risk } \\
\text { of contamination spread due to leaks or } \\
\text { excavation is minimized. }\end{array}$ & ++ \\
\hline 5 & $\begin{array}{l}\text { Excavation near contamination zone is } \\
\text { not a significant risk and potential for } \\
\text { cost escalation is minimized. }\end{array}$ & + & $\begin{array}{l}\text { Lift station \#14 is located near a UPR at } \\
\# 325 \text { and the proximity of UPR may } \\
\text { escalate cost of construction beyond } \\
\text { contingencies }\end{array}$ & - \\
\hline 6 & $\begin{array}{l}\text { Construction schedule for completion is } \\
\text { not dependent on site conditions } \\
\text { involving contamination }\end{array}$ & + & $\begin{array}{l}\text { Construction schedule may depend on } \\
\text { site conditions due to the proximity of } \\
\text { the UPR and the congested corridor }\end{array}$ & - \\
\hline 7 & $\begin{array}{l}\text { Regulator acceptance is a concern due } \\
\text { to potential for old vitrified clay pipe to } \\
\text { leak during service }\end{array}$ & - & $\begin{array}{l}\text { Regulator acceptance anticipated to be } \\
\text { high because of responsiveness to } \\
\text { concern for waste piping underlying } \\
\text { Spruce Street }\end{array}$ & ++ \\
\hline & & & & \\
\hline
\end{tabular}




\section{ATTACHMENT 2}

\section{SANITARY SEWER OPTIONS WORKSHEET}

(consisting of 2 pages) 


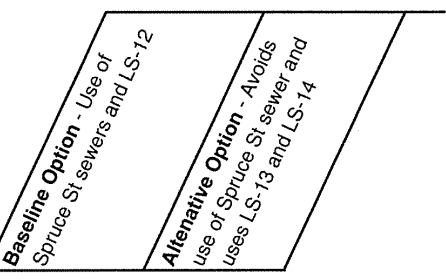

SELECTION CRITERIA (with related considerations listed below it)

Criteria Weighting

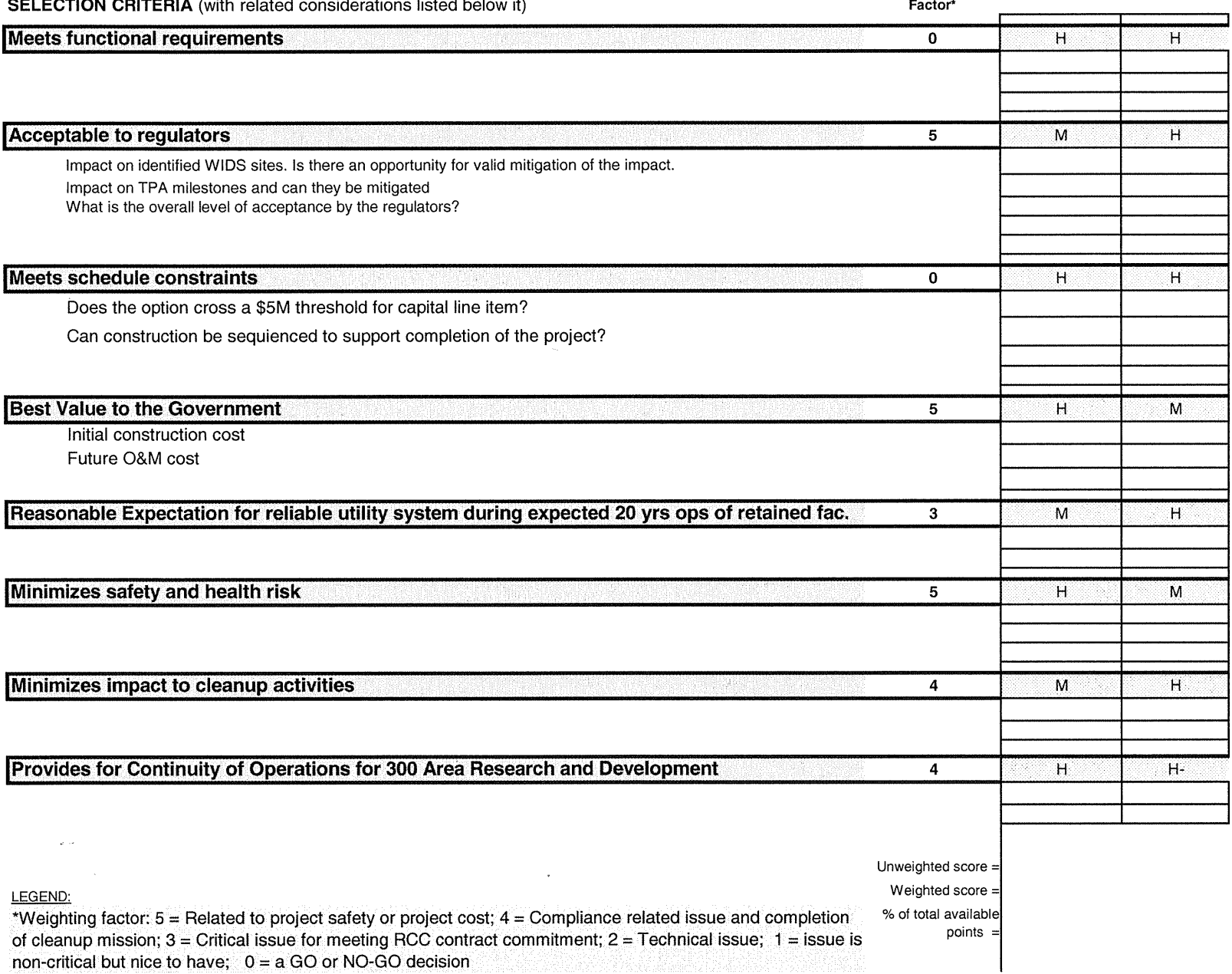

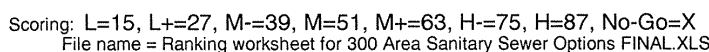


300 Area Utility Relocation - Sanitary Sewer Options Worksheet

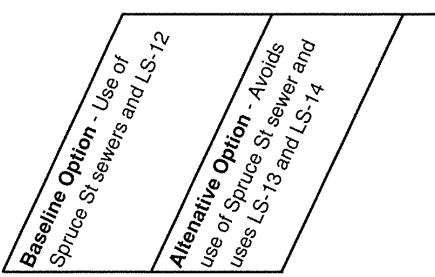

\begin{tabular}{|c|c|c|c|}
\hline SELECTION CRITERIA (with related considerations listed below it) & $\begin{array}{l}\text { Criteria Weighting } \\
\text { Factor" }\end{array}$ & & \\
\hline Meets functional requirements & 0 & 87 & 87 \\
\hline Acceptable to regulators & 5 & 51 & 87 \\
\hline $\begin{array}{l}\text { Impact on identified WIDS sites. Is there an opportunity for valid mitigation of the impact. } \\
\text { Impact on TPA milestones and can they be mitigated } \\
\text { What is the overall level of acceptance by the regulators? }\end{array}$ & & & \\
\hline Meets schedule constraints & 0 & 87 & 87 \\
\hline $\begin{array}{l}\text { Does the option cross a } \$ 5 \mathrm{M} \text { threshold for capital line item? } \\
\text { Can construction be sequienced to support completion of the project? }\end{array}$ & & & \\
\hline Best Value to the Government & 5 & 87 & 51 \\
\hline $\begin{array}{l}\text { Initial construction cost } \\
\text { Future O\&M cost }\end{array}$ & & & \\
\hline Reasonable Expectation for reliable utility system during expected 20 yrs ops of retained fac. & 3 & 51 & 87 \\
\hline Minimizes safety and health risk & 5 & 87 & 51 \\
\hline Minimizes impact to cleanup activities & 4 & 51 & 87 \\
\hline Provides for Continuity of Operations for 300 Area Research and Development & 4 & 87 & 75 \\
\hline & $\begin{array}{c}\text { Unweighted score }= \\
\text { Weighted score }=\end{array}$ & $\begin{array}{l}588 \\
1830\end{array}$ & $\begin{array}{l}612 \\
1854\end{array}$ \\
\hline $\begin{array}{l}\text { Weighting factor: } 5=\text { Related to project safety or project cost; } 4=\text { Compliance related issue and completion } \\
\text { of cleanup mission; } 3=\text { Critical issue for meeting RCC contract commitment; } 2=\text { Technical issue; } 1=\text { issue is } \\
\text { non-critical but nice to have; } 0=\text { aO or NO-GO decision }\end{array}$ & $\begin{array}{r}\% \text { of total available } \\
\text { points }\end{array}=$ & $70 \%$ & $71 \%$ \\
\hline
\end{tabular}

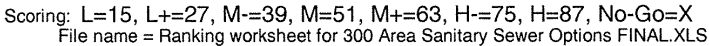


WCH-181

Rev. 0

ATTACHMENT 3

COST ESTIMATE SUMMARY FOR SANITARY SEWER ALTERNATE OPTION

(consisting of 1 page) 


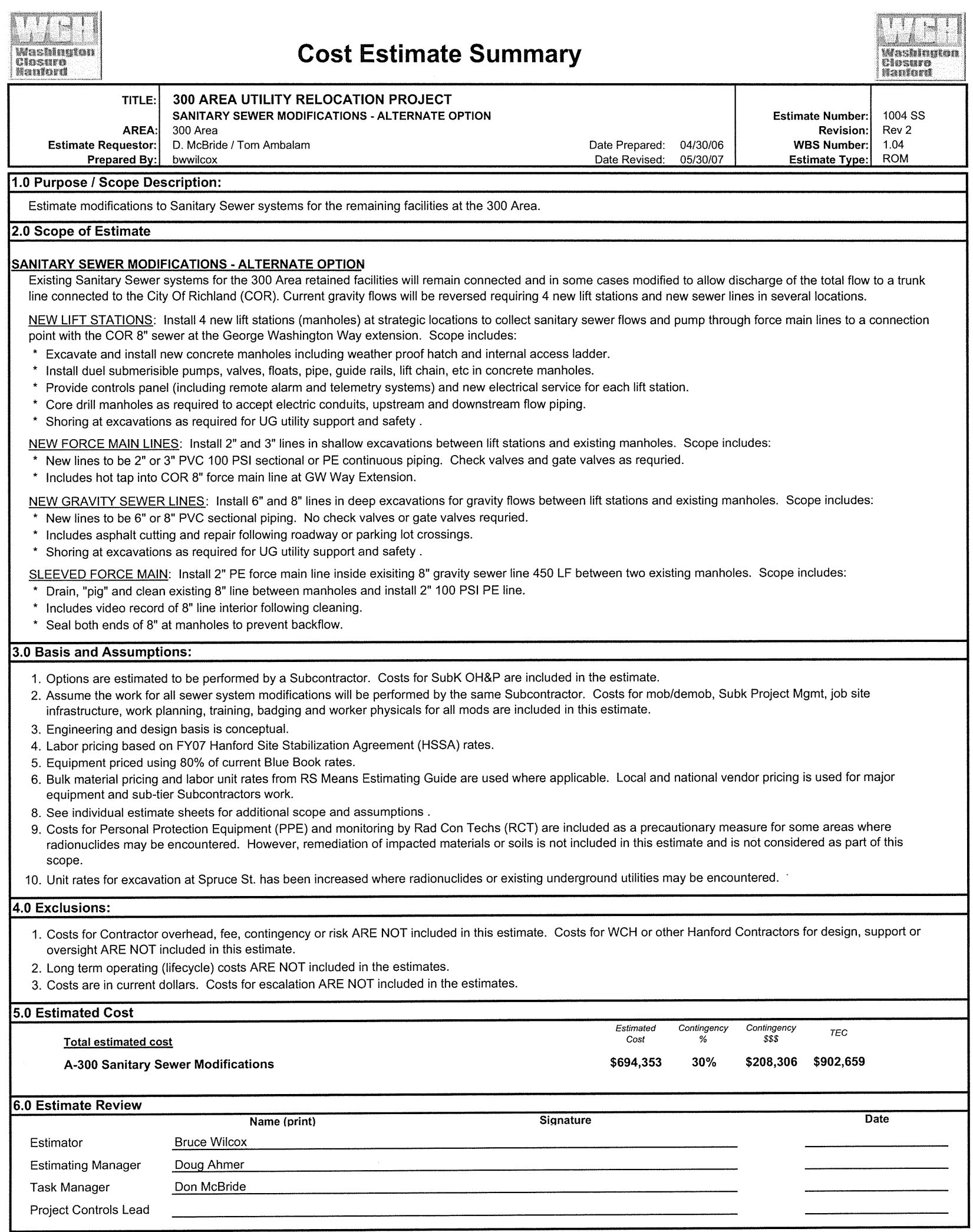


WCH-181

Rev. 0

300 Area Building Retention Evaluation Mitigation Plan 


\section{APPENDIX H}

300 AREA SANITARY SEWER CONCEPTUAL DESIGN 
WCH-181

Rev. 0 


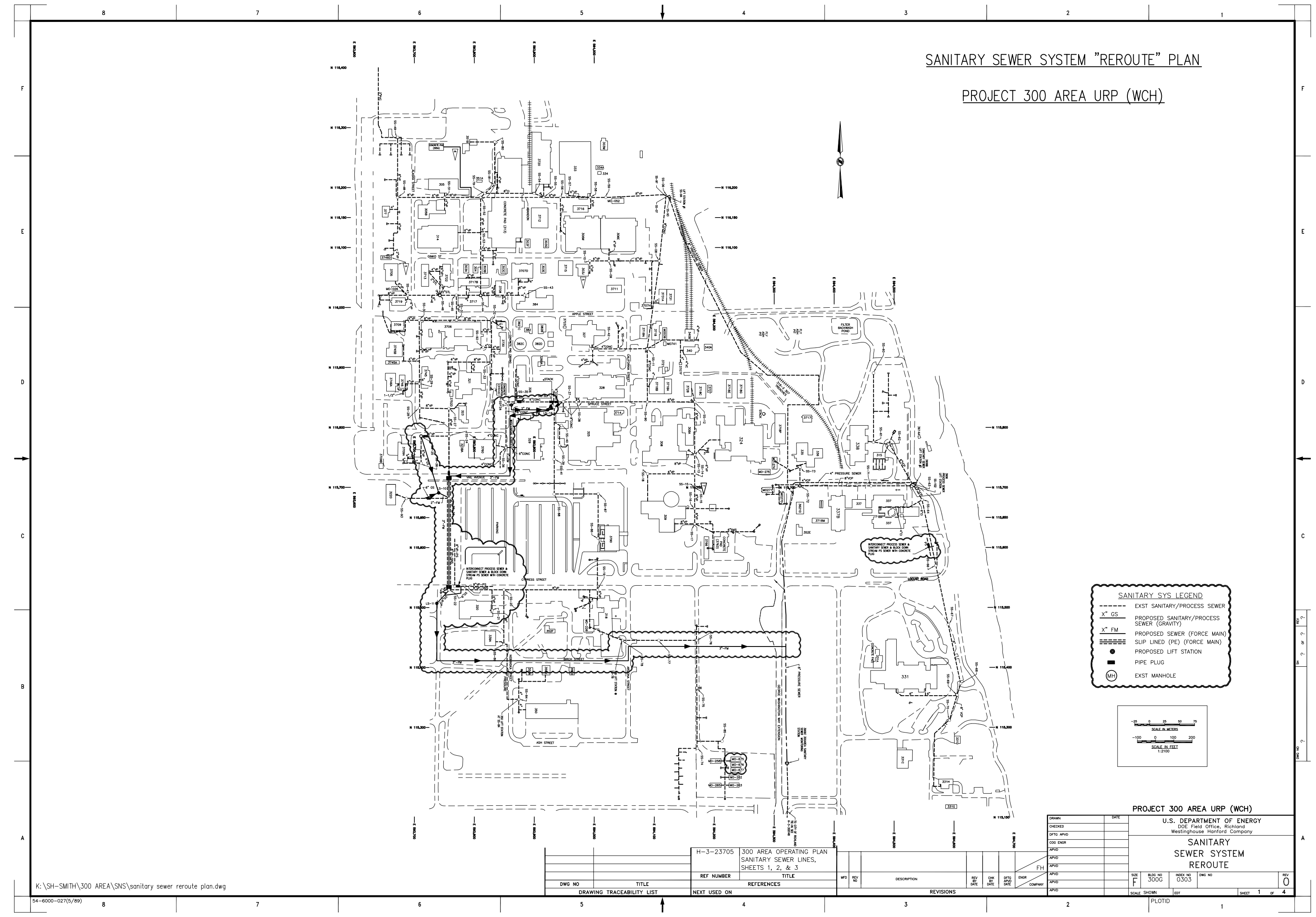




\section{APPENDIX I}

300 AREA RETENTION PROCESS SEWER CONCEPTUAL DESIGN 
WCH-181

Rev. 0 


\section{Conceptual Design Package For 300 Area Retention Process Sewer Reroute and Process Sewer Tie-ins}

Revision 1 


\section{Area Retention Process Sewer (RPS) Reroute}

\subsection{INTRODUCTION}

The 300 Area retention process sewer (RPS) stream for buildings 325, 326, and 329 currently flows to the 307 basins and then to TEDF. Since TEDF is scheduled for deactivation before the RPS system is deactivated, an alternate means of managing the RPS effluents from the 325, 326, and 329 buildings is required. In addition, it was proposed that the Process Sewer streams be tied into the RPS stream for the 326 and 329 buildings. This was based on an assumption that the PS stream could not be introduced into the sanitary sewer (SS) system.

\subsection{SCOPE}

\subsection{RPS Disposition}

This conceptual design provides, layouts, general arrangements, and calculations to support the rerouting of the current RPS stream to a holding tank system. The holding tank system has provision for sampling of the RPS fluids prior to routing to the sanitary sewer (SS-83). A load-out station is also provided to manage alternate disposal of contaminated fluids. A similar holding tank system is located at the Environmental Molecular Sciences Laboratory (EMSL). This system was directly used to model the 300 area holding tank system.

\subsection{Process Sewer Tie-In}

This conceptual design also includes the necessary modifications to tie the PS streams into the RPS streams within the 326 and 329 buildings.

\subsection{Stormwater Isolation}

There is currently, one catch basin located on the east side of the 329 building that is tied into the RPS system. The RPS holding tanks will not be large enough to manage stormwater as well as RPS streams. In addition, the City of Richland has stipulated that it is not acceptable to route stormwater into the SS system. The tie-in must therefore, be isolated.

\subsection{SIGNIFICANT DESIGN CRITERIA}

\subsection{Criteria}

Criteria for the RPS system reroute and PS tie-ins have been established and are as follows. 
- $\quad$ The RPS collection system shall have the capability to transfer wastewater to a tanker truck for wastewater which does not comply with the treatment facility's acceptance criteria.

- $\quad$ The RPS collection system provide sufficient ( 1 week per tank) storage capacity to allow operation in the following mode:

o One active tank / basin filling

o One full tank / basin awaiting sampling and analysis

o One additional tank / basin to hold off spec wastewaters requiring load-out by tanker truck.

o One standby tank / basin

- $\quad$ Non-radiological facility wastewater discharges such as boiler blow down or roof / parking lot runoff should be segregated from the RPS collection system.

\subsection{Codes and Standards}

- Uniform Plumbing Code

- $\quad$ City of Richland Standard Specification Section 7

- NFPA 70 - National Electrical Code

- NFPA 820 - Standard for Fire Protection in Wastewater Treatment and Collection Facilities

- City of Richland Municipal Code, Richland Pretreatment Act - Chapter 17.30

\subsection{FUNCTIONAL OBJECTIVES}

\subsection{Effluent Flows}

Effluent flow rates from the buildings are listed below. While there are efforts underway to reduce flows, these efforts are not yet complete. It is therefore necessary at this stage of the design to account for the known flows as listed.

- $325 \mathrm{RPS}-4 \mathrm{gal} / \mathrm{min}$

- 326/329 RPS - 5 gal/day

- 326 PS - 100 gal/day

- $329 \mathrm{PS}-44 \mathrm{gal} / \mathrm{day}$

\subsection{Tank Load-Out Facility}

The tank load out facility must accommodate a tanker sized vehicle. During load-out activities, the vehicle must be located on a concrete pad that provides spill containment and routing to a sump that pumps spillage back to one of the holding tanks. The tanks are to be located on a pad that provides spill containment for a minimum of $10 \%$ of the total tank volume, or the volume of the largest tank, whichever is larger. 


\subsection{CONCEPTUAL LAYOUTS AND GENERAL ARRANGEMENTS}

Figures, 1 through 7 describe the conceptual layouts and general arrangements.

The overall concept of the 300 Area Retention Process Sewer system reroute is shown in Figure 1 . The rerouted system configuration consists of 3 primary activities.

\section{Lift Station}

All retention process sewer lines between the 325, 326, and 329 buildings currently flow to the existing RPS-3 manhole, and then through an existing 8” clay pipe to the existing 307 basins. The 8" line is to be capped off, and a new lift station is to be installed in the RPS-3 manhole as shown in Figure 2. A new 1" PVC discharge line is to be installed in the RPS-3 manhole from the new dual sump pumps to feed the RPS Load-Out Station. A new valve box is installed over the discharge line to provide access to check valves and isolation valves in the new discharge line.

\section{RPS Load-Out Station}

The RPS Load-Out Station is described in Figures 3, 4, and 5. This new station will consist of four, 4300 gallon tanks situated on a 30' x 30' pad with appropriate spill containment. As required per section 1.3, each tank serves a specific purpose. Tank EFT-1 will be the active tank, continually receiving effluent from RPS-3. When EFT-1 is full, it is emptied to EFT-2 to await sampling and analysis. Should the analysis show that the contents of EFT-2 require load out, it will be transferred to EFT-3. Otherwise, tank EFT-2 is gravity drained through a 2" PVC line to the sanitary sewer at the SS-38 manhole. The control system will time the drain to SS-38 during a time of low SS flow, such as 0100 hours. Tank EFT-4 is will be a stand-by tank.

A new asphalt drive and concrete pad with spill containment are also provided for loadout activities. The truck will receive the EFT-3 contents while parked on the concrete pad. Both pads will be covered to prevent stormwater from accumulating in the sump. All spillage from at the truck pad or tank pad will be routed to the central sump and returned to tank EFT-1.

Adequate valving and piping will be provided such that any tank can serve any of the functions described.

\section{Process Sewer to RPS Tie-ins}

The process sewer (PS) streams at the 326 and 329 buildings will be tied into the RPS stream prior to exiting the buildings.

a. 329 PS Tie-in 
The 329 tie-in is to be located on the north wall of the service tunnel and is described in Figure 5. The 3-inch carbon steel PS lines will be cut, capped, and converted PVC lines as they tie-in to the 4-inch stainless steel RPS line.

\section{b. 326 PS Tie-in}

The PS stream will be collected in a new sump, located in room 21-A, in the basement. The configuration is shown in Figures 6 \& 7. The existing 8” PS line exiting the building in that room will be capped. The sump will collect the discharge from the 8 ” line and several additional existing lines in located in the room. A new sump pump will send the contents of the 50 gallon sump through a 1" PVC line to room 24-A1, where the RPS stream is collected and routed to the existing RPS-2 manhole just outside the building. The new 1" PVC line ties into an existing 2" carbon steel line in room 24-A1, just above the ceiling tiles.

Secondarily, there is one stormwater catch basin currently tied into the RPS stream at the South East corner of the 329 building. This 4-inch PVC line is to be cut and capped as shown in Figure 1 to isolate stormwater flow to the RPS Load-Out Tanks.

\subsection{FLOW DIAGRAMS}

Process and Instrumentation Diagrams (P\&IDs) were available from the EMSL design. Figures 4, and 5, were developed directly from those drawings.

\subsection{SIZING AND PROCESS CALCULATIONS}

Calculation document 0300X-CA-M0001 was developed for the RPS reroute and contains all pertinent conceptual level calculations.

\subsection{PRELIMINARY DESIGN PARAMETERS}

The following parameters will need to be addressed at preliminary design.

\subsection{Effluent Flow Rates}

As previously mentioned, a PNNL effort is underway to reduce flows from the 325, 326, and 329 buildings. Flow criteria will need to be finalized based on those efforts.

\subsection{Tanker Truck Configuration}

The conceptual design does not account for any specific requirements that the tanker truck may have for load out. A specific truck will need to be identified from which the load out facility design can be finalized. 


\subsection{Site Characterization}

Building 328 currently exists at the proposed site for the tank load out facility. If building 328 has been remediated prior to preliminary design, then the site will need to be characterized for the spill containment pad, load-out pad, and road design.

\subsection{Component Sizing}

Components were sized and selected as follows.

\section{Tank Drain to SS-38:}

The drain line from the tanks to the SS-38 manhole is to be a 2-inch schedule 40 PVC pipe. PVC pipe was selected for all piping in the RPS reroute, since some of the existing RPS lines have already been converted to PVC.

\section{RPS-3 Lift Station:}

The RPS-3 Lift station discharge line is to be a 1-inch schedule 40 PVC pipe. The pump for the lift station is to be an Aquatic ECO-Systems Inc., Model SP750 (or equivalent) high-head submersible pump, operating at $20 \mathrm{gpm}$ and $30 \mathrm{ft}$ head.

\section{Process Sewer Sump Dimensions:}

The new sump for the 326 process sewer is to be 2 foot square, by 3 foot deep. The width dimension is restricted; however the remaining dimensions can be increased as needed. The volume of the sump is sized to handle 50 gallons of the 100 gal/day PS flow.

326 Process Sewer Sump Pump and discharge line:

This sump pump is sized to provide $18 \mathrm{gpm}$ at 36 feet head through a 1-inch schedule 40 PVC pipe.

\section{$\underline{\text { Tank Pad Spill Containment Curb: }}$}

The spill containment curb surrounding the retention tank pad is required to be 3" high, to contain $10 \%$ of the total volume of the 4 tanks as required per WCH- 56 .

Load-Out Tanks: 
The load out tanks were sized to 4300 gallons based on known flows to TEDF from the 300 Area RPS system. It so happens that the tanks used at the EMSL design were the exact sized required based on the known flows. As a result, the complete EMSL design was adapted to the 300 Area RPS Load Out system. The material of the tanks was selected to be FRP due to the universal compatibility with potential constituents within the RPS stream.

\subsection{MATERIAL SELECTION, PROCUREMENTS SPECFICIATIONS}

Procurements specifications will need to be written for the following components.

1. Tanks. The four tanks have been conceptualized as 4300 gallon tanks fabricated from fiberglass reinforced plastic (FRP). The tanks are free standing and elevated to allow full drainage from a bottom center fitting.

2. Pumps. Three sump pumps are needed; two for the RPS-3 lift station and one for the new 326 building PS sump. The pumps selected in the analysis are the Aquatic Eco-Systems, Inc, High Head submersible pump, model SP750, but any submersible pump providing equivalent flow and head characteristics is acceptable. The load out pumps were not sized or selected since the characteristics of the receiver truck were not known. The pumps shown were simply copied from the EMSL design, which featured tanks that were located in a below-grade vault. It is quite possible that the final design of the load out facility could eliminate the need for the pumps entirely.

3. "Rain Hat." It is suggested that the carport-like structure over the tank load out facility be specified and procured from a vendor specializing in such structures.

\subsection{ENVIRONMENTAL IMPACT}

There is no expected environmental impact. The RPS and PS effluents from buildings 325,326 , and 329 are contained in their entirety and sampled prior to release or load-out. All new installations of piping and facilities are being located at pre-existing facility or road locations. No significant radiological or chemical hazards are foreseen for construction or isolation activities.

\subsection{BASELINE COST ESTIMATE}

The cost estimate is being performed by WCH personnel.

\subsection{LONG LEAD PROCUREMENT ITEMS}


The FRP tanks are expected to be long lead items requiring approximately 3 weeks for vendor drawings and 16 weeks to fabricate.

\subsection{IDENTIFICATION OF POTENTIAL SAFETY HAZARDS AND PROVISIONS FOR HAZARD CONTROLS}

No safety hazards other than occupational during construction are foreseen.

\subsection{ESTIMATED PORCUREMENT/CONSTRUCTION SCHEDULE.}

While the tanks are long-lead items, they are not required at the start of construction. Delivery of the tanks should coincide with construction completion of the pad on which they are installed. Procurement/construction duration is estimated to 6 months. This does not include final design, which precedes the construction start date, but could end during the first phases of construction. 

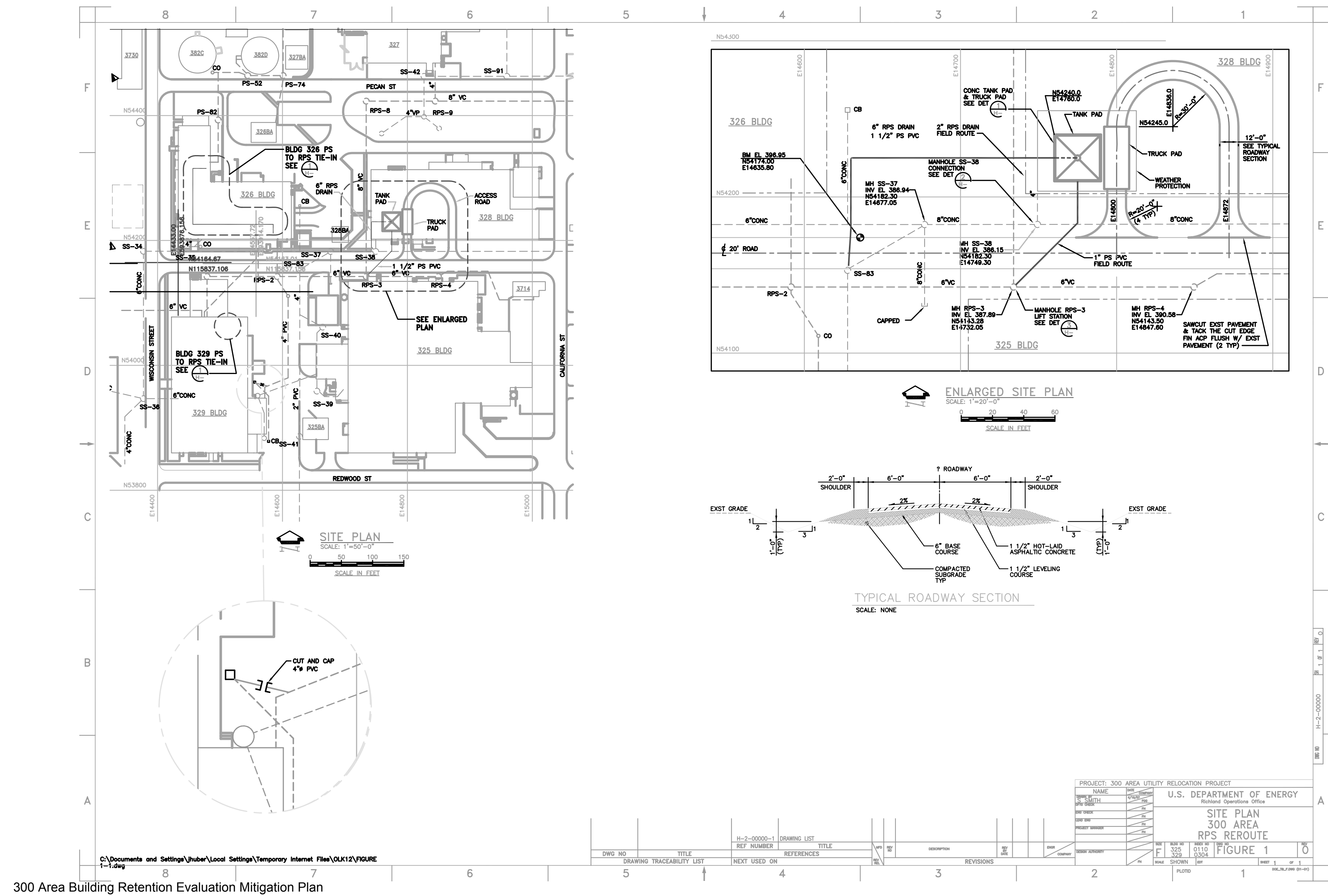


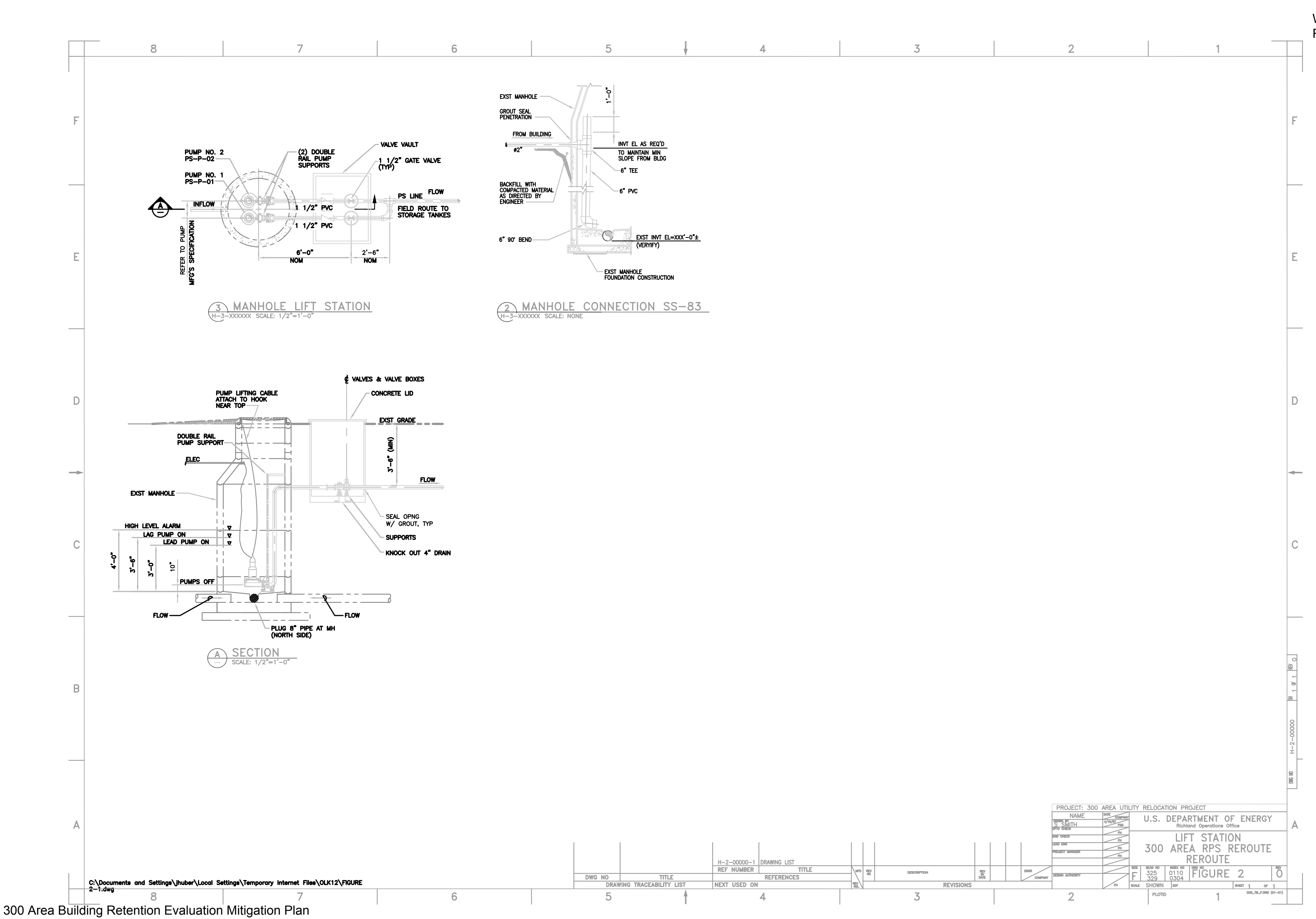




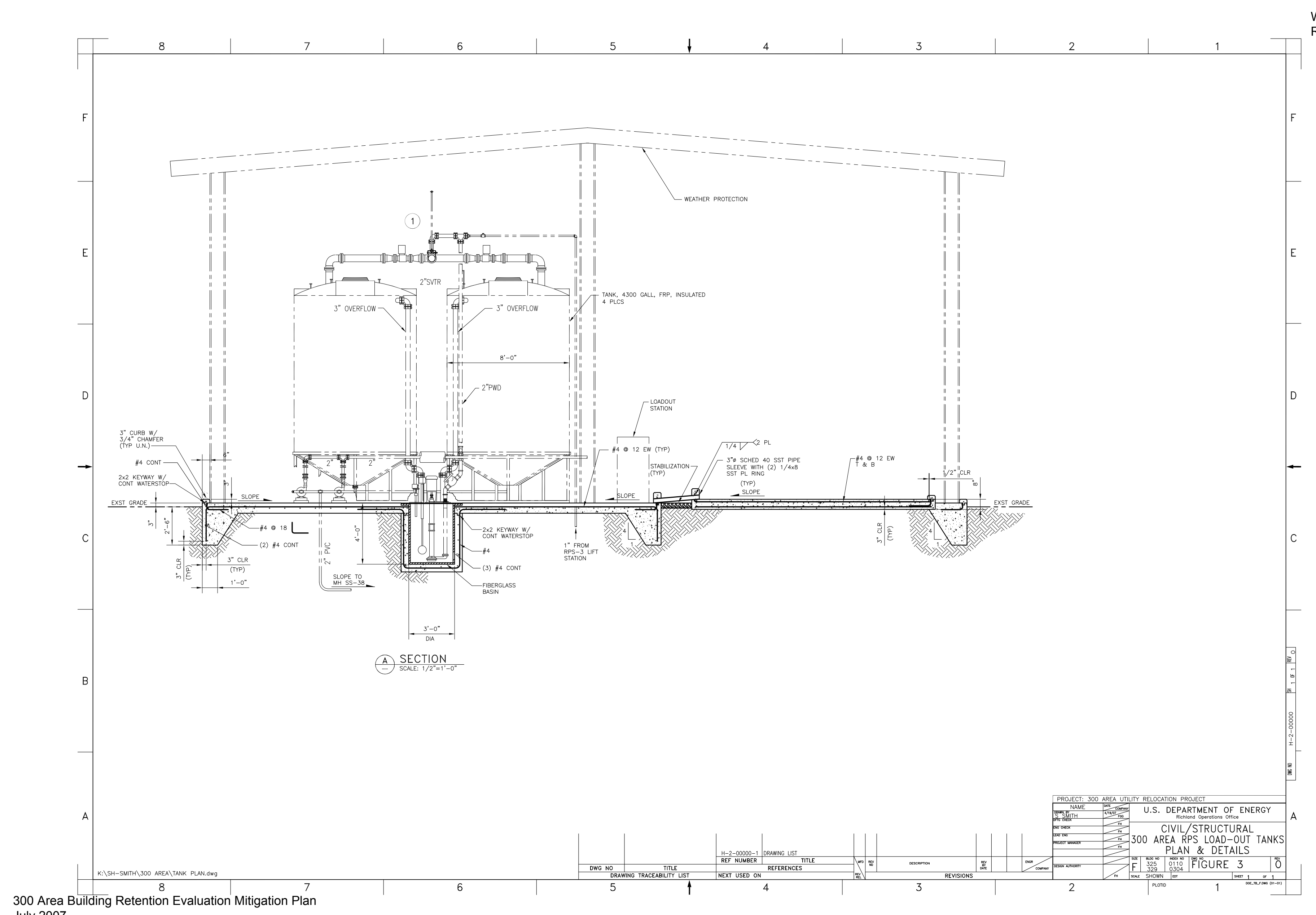




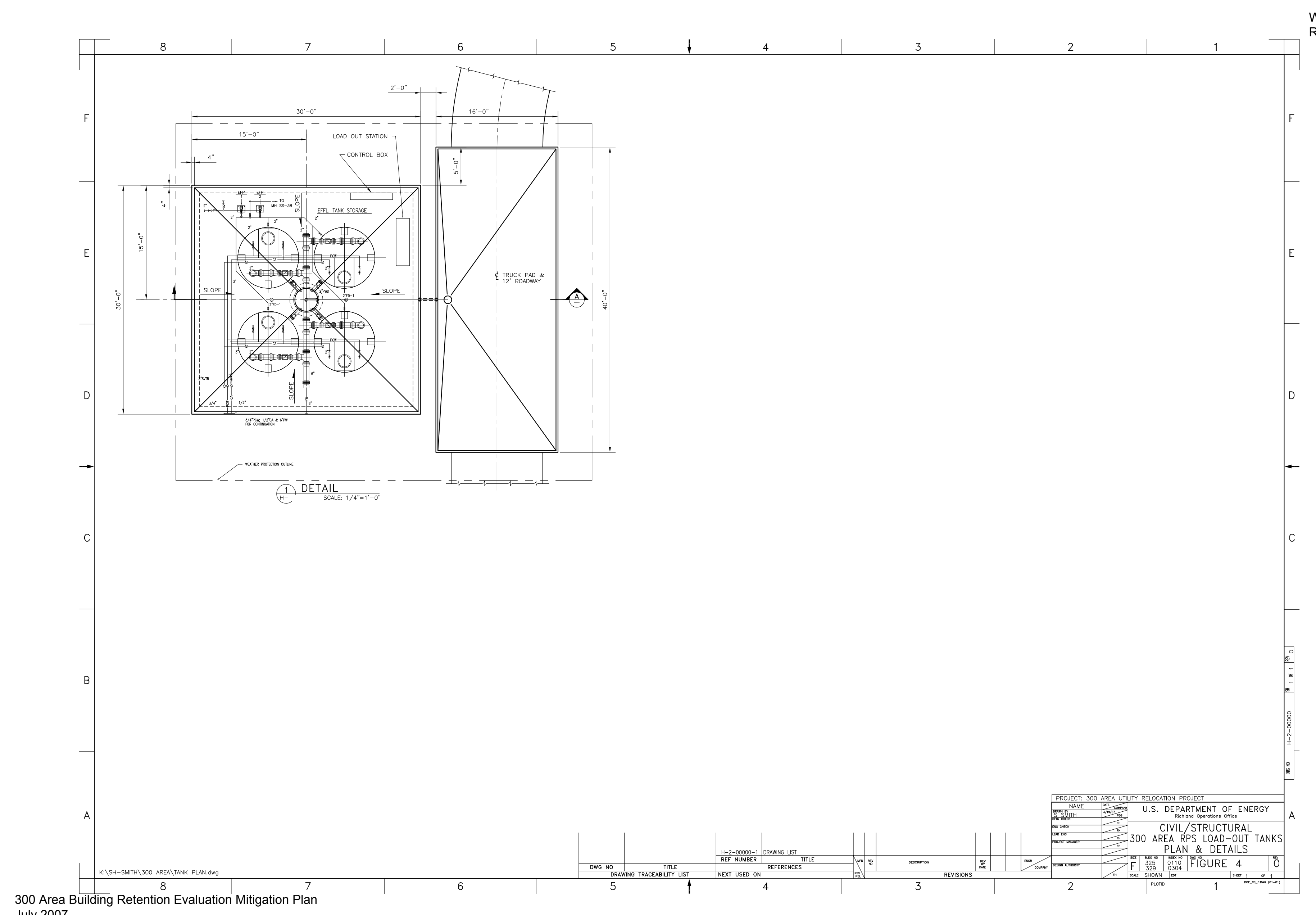




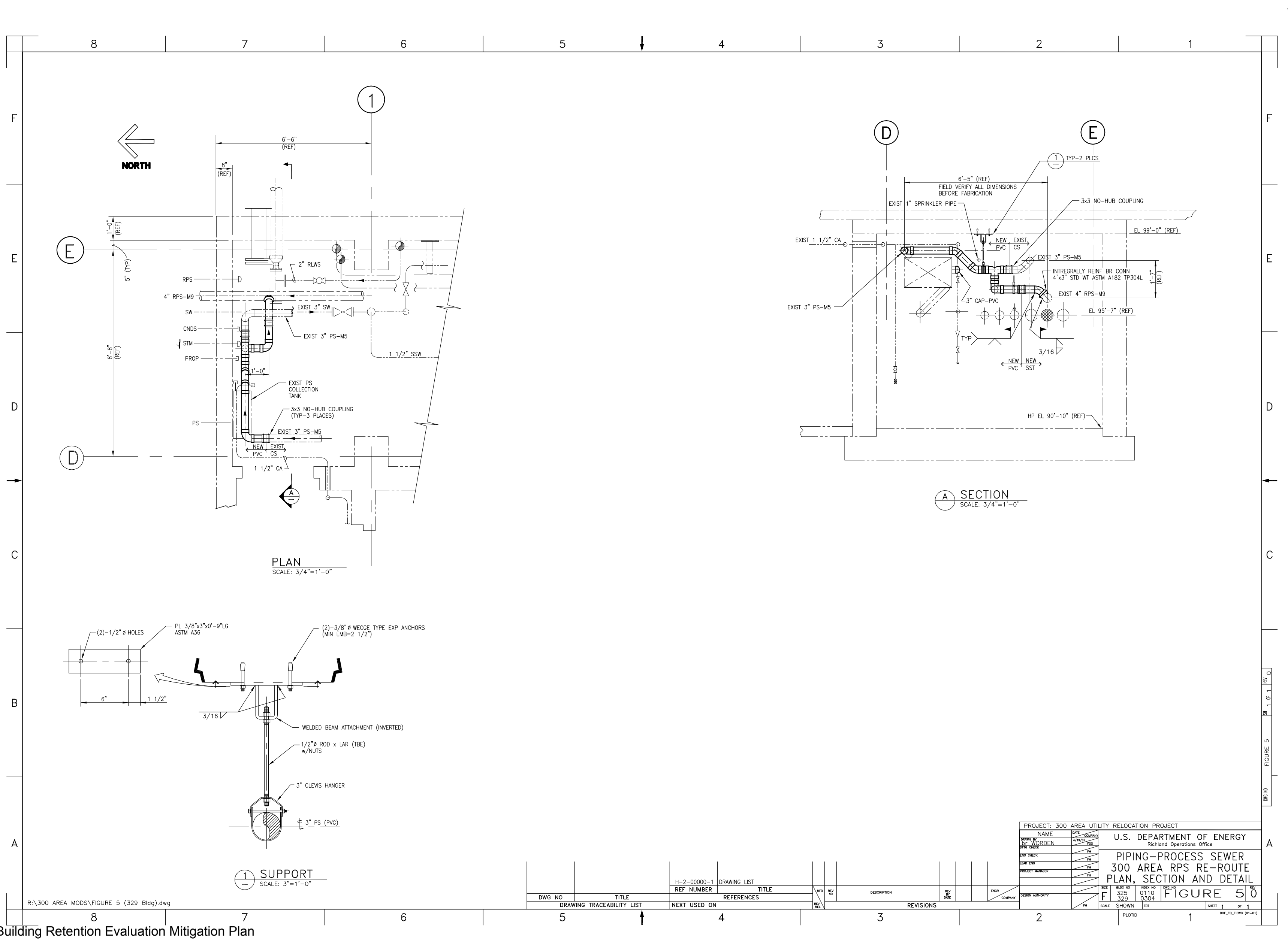




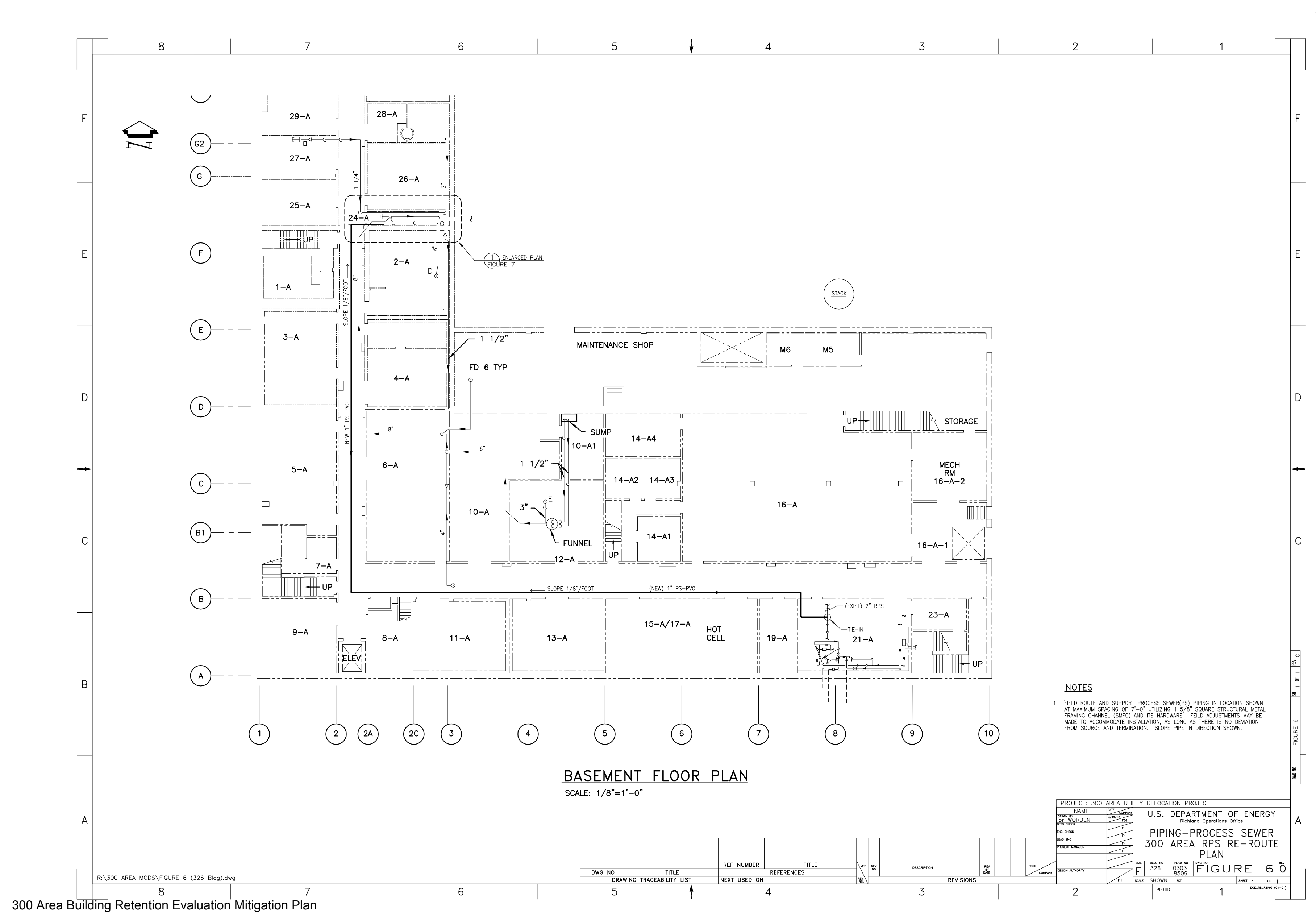




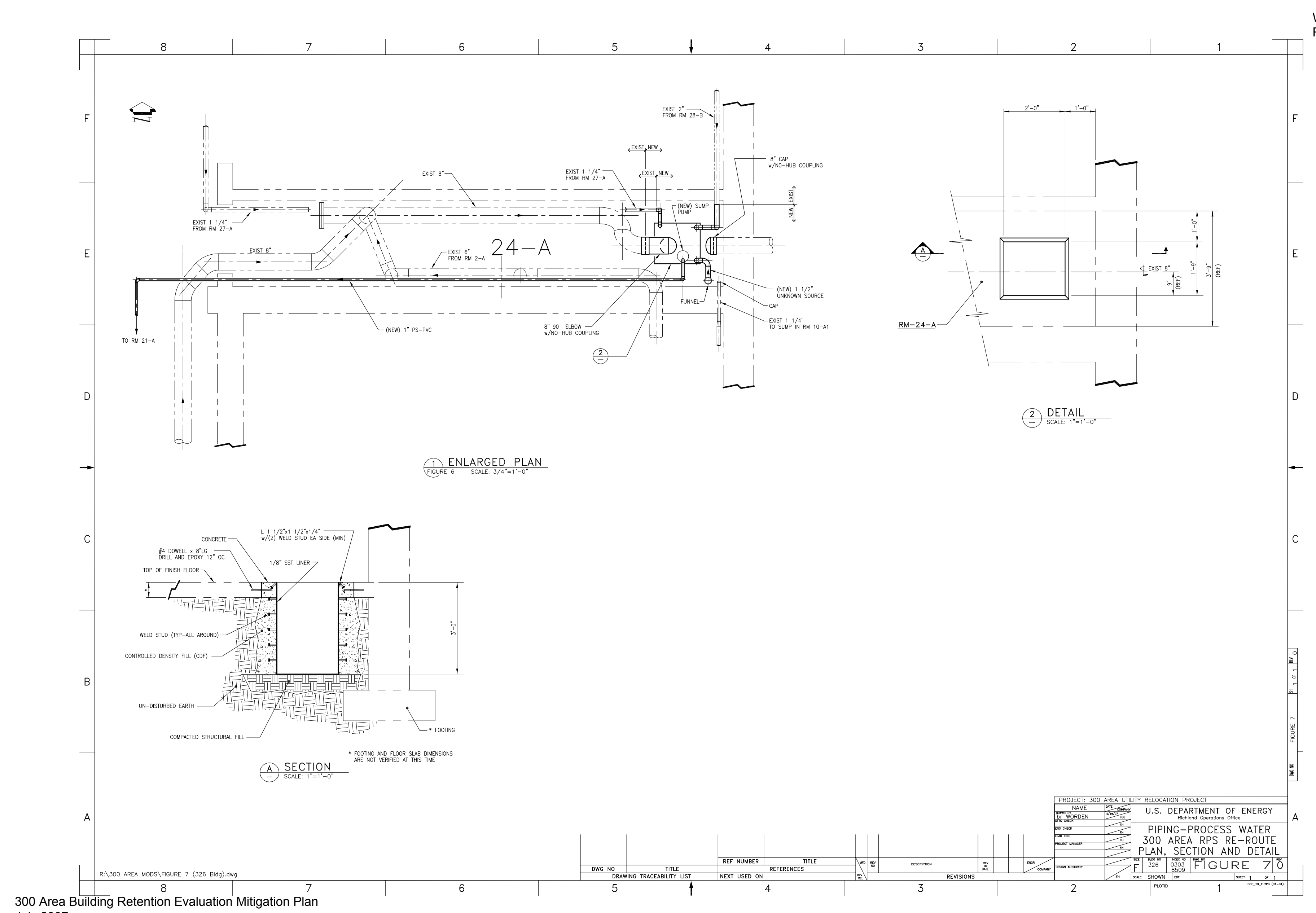




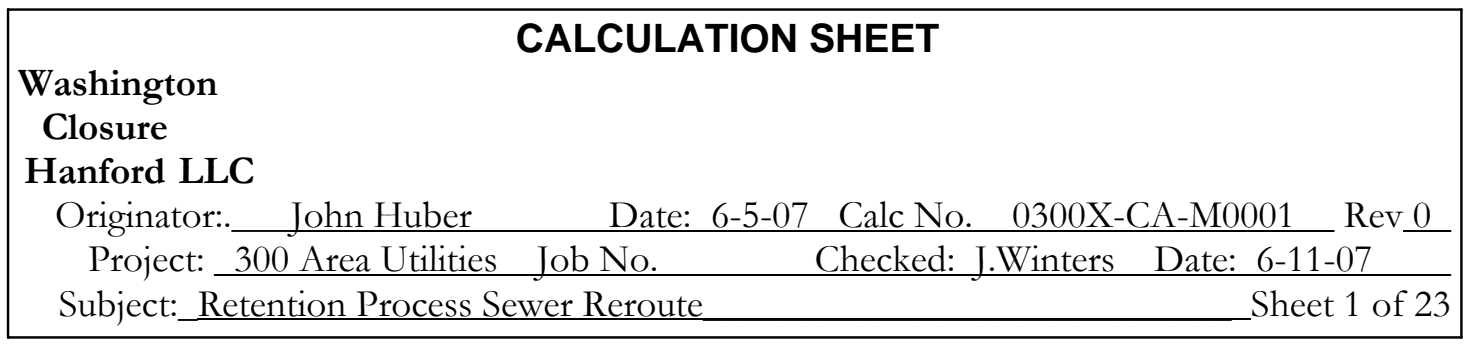

\section{Table of Contents}

Section

Page

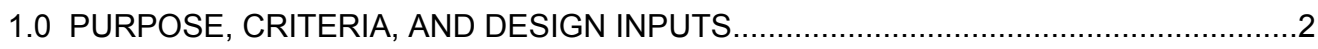

2.0 APPLICABLE CODES, STANDARDS, REGULATORY REQUIREMENTS ........................

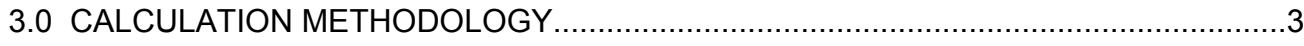

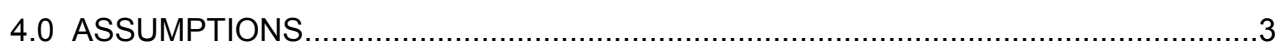

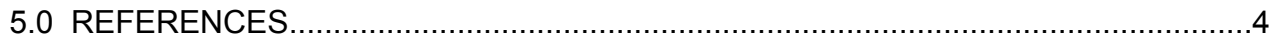

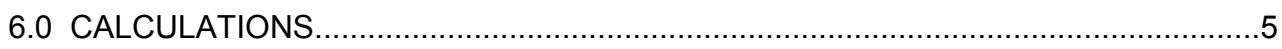

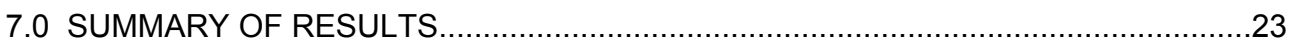

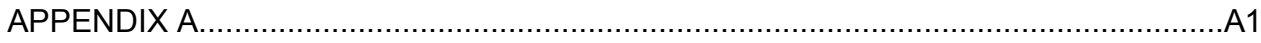

\section{Table of Figures}

$\begin{array}{lll}\text { Figure No. } & \text { Title } & \text { Page }\end{array}$

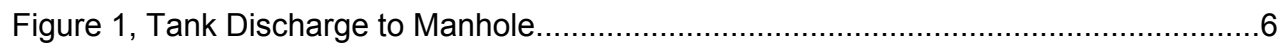

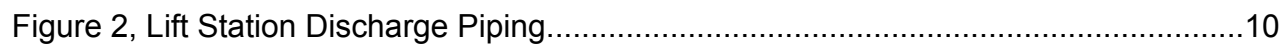

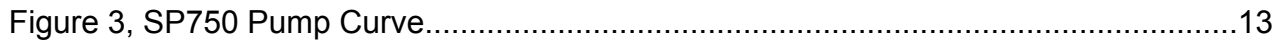

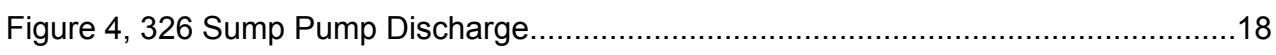




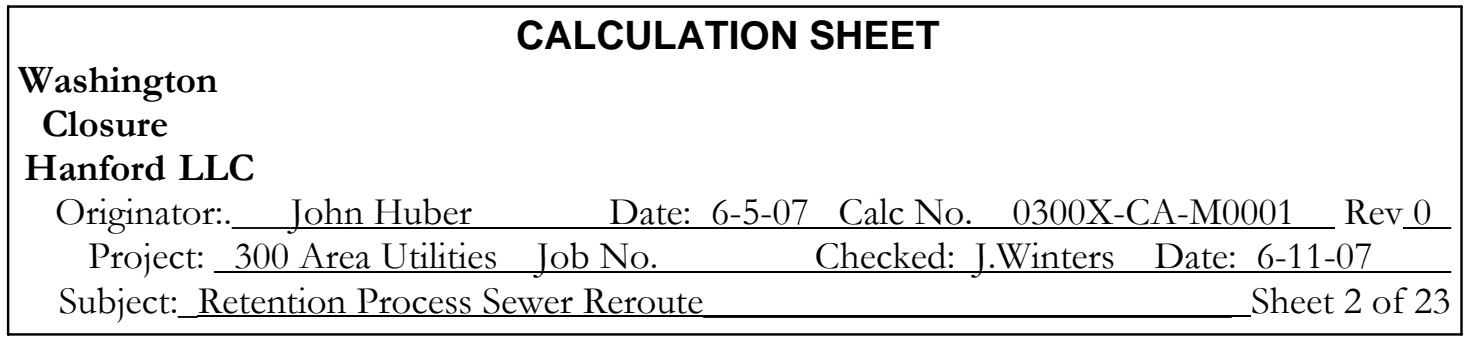

\subsection{PURPOSE, CRITERIA, AND DESIGN INPUTS}

\subsection{Purpose}

This calculation supports conceptual design related to reroute of the Retention Process Sewer system in the 300 area. It specifically addresses the sizing of the tank drain to sanitary sewer SS-38, as well as the lift station being proposed for installation into RPS-3 manhole. Also addressed is sump and sump pump sizing in the 326 building.

\subsection{Scope}

This calculation is performed in several parts. Part 1 determines the drain line size between the tanks and the SS-38 manhole. Part 2 determines pumping requirements for the RPS-3 lift station and discharge line sizing. Part 3 sizes the new sump proposed for the building 326 process sewer. Part 4 sizes the new sump pump to be installed in the new 326 sump. Part 5 sizes the load-out pumps.

\subsection{Design Criteria}

At this stage of the conceptual design, very little design criteria has been established. However, a draft criteria document has been developed and the applicable criteria are listed below.

1.3.1 The RPS collection system provide sufficient ( 1 week per tank) storage capacity. 1.3.2 The following flows must be managed by the system:

325 RPS:

$$
\mathrm{Q}_{325 \mathrm{rps}}:=4 \frac{\mathrm{gal}}{\mathrm{min}}
$$

326/329 RPS:

$$
\mathrm{Q}_{\text {329326RPS }}:=5 \frac{\text { gal }}{\text { day }}
$$

326 PS:

$$
\mathrm{Q}_{326 \mathrm{PS}}:=100 \frac{\mathrm{gal}}{\text { day }}
$$

329 PS:

$$
\mathrm{Q}_{329 \mathrm{PS}}:=44 \frac{\text { gal }}{\text { day }}
$$




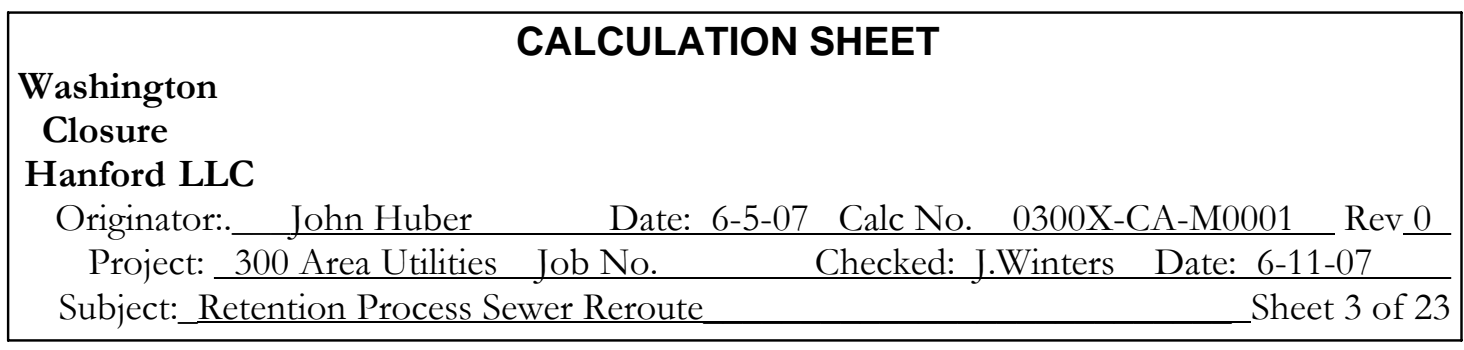

\subsection{Design Inputs}

See Section 1.3.

\subsection{APPLICABLE CODES, STANDARDS, REGULATORY REQUIREMENTS}

\subsection{Applicable Code}

2.1.1 Uniform Plumbing Code 2003 Edition

\subsection{CALCULATION METHODOLOGY}

The methodology used for this calculation is based on those presented in Crane Technical Paper 410 (Ref. 5.2). Mathcad 2001 Professional was used. Results were verified using standard hand calculations.

\subsection{ASSUMPTIONS}

\subsection{Assumptions With Technical Justification}

4.1.1 Roughness of PVC pipe is $.000005 \mathrm{ft}$ which is within the range listed in MERM (Ref. 5.5)

4.1.2 Add $10 \%$ to fitting and pipe friction loss for conservatism.

4.1.3 Pipelines will be sized for fluid velocities of 2-10 ft/sec which is industry standard.

4.1.4 Fluid properties are equivalent to water at STP.

\subsection{Unverified Assumptions}

The following assumptions are unverified due to the conceptual nature of the design.

4.2.1 Lengths of straight pipe and exact configuration of fittings is approximate to that accounted for in the figures and calculation.

4.2.2 Required tank capacity is $\mathbf{4 3 0 0}$ gallons based on recent flow readings. 


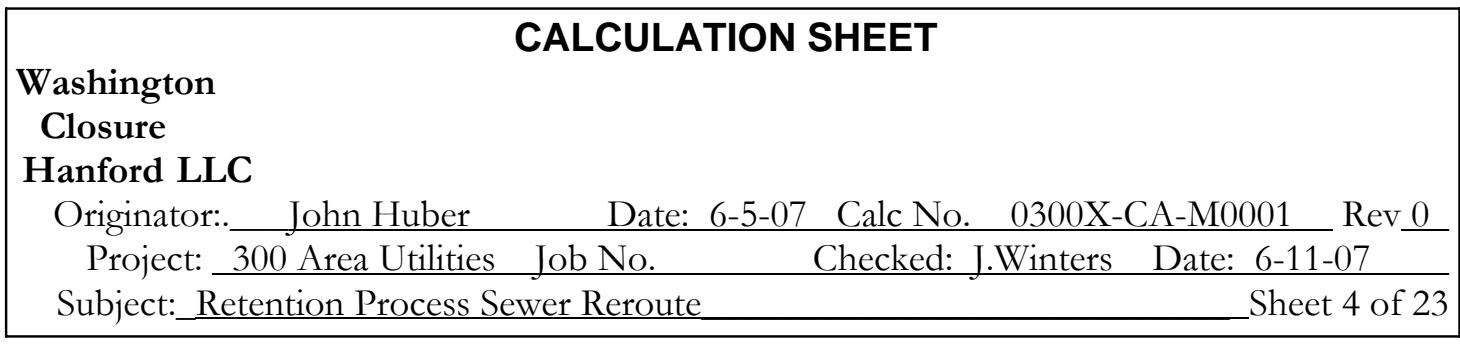

4.2.3 Grade level in the area of RPS-3 is 400 feet.

4.2.4 Estimated pump efficiency at max flow is $60 \%$.

4.2.5 Liquid is free of solids.

\subsection{REFERENCES}

5.1 "Functional Requirements and Design Criteria For 300 Area Utility Services," 0300X-DC-G0001, Rev 0, Washington Closure Hanford, April 2007.

5.2 Technical Paper No. 410, 1982, Flow of Fluids Through Valves, Fittings, and Pipe, Crane CO., New York, New York.

5.3 Swamee, P.K.; Jain, A.K. (1976). "Explicit equations for pipe-flow problems". Journal of the Hydraulics Division, ASCE 102 (5): 657-664. [Swamee \& Jain Equation]

5.4 ASME B31.3, 1999 Edition With 2000 Addenda, Process Piping, ASME Code for Pressure Piping, B31 An American National Standard, , American Society of Mechanical Engineers, New York, NY.

5.5 Mechanical Engineering Reference Manual, 8th Ed., 1990, Michael R. Lindeburg, P.E., Professional Publications, Belmont, California.

5.6 Harrington Industrial Plastics, 9th Edition, Chino, California

5.7 General Design Criterial for River Corridor Closure Contract, WCH-56 Rev. 0, Washington Closure Hanford, June 2006 


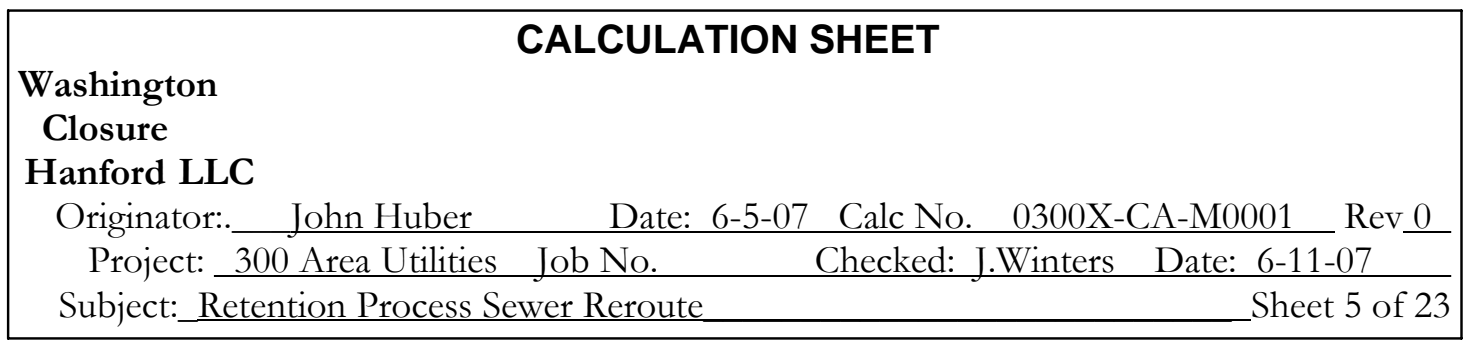

\subsection{CALCULATIONS}

\subsection{Input Data}

\subsubsection{Dimension Definitions and Unit Conversion}

$$
\begin{aligned}
& \mathrm{fpm}:=\frac{\mathrm{ft}}{\min } \quad \mathrm{gpm}:=\frac{\mathrm{gal}}{\mathrm{min}} \quad \mathrm{psig}:=\mathrm{psi} \quad \text { psia }:=\mathrm{psi} \quad \mathrm{psi}:=\frac{\mathrm{ft}}{2.31} \quad \mathrm{hp}:=\frac{\mathrm{lb} \cdot \mathrm{ft}}{550 \cdot \mathrm{sec}} \\
& \mathrm{SG}:=1 \quad \text { Specific gravity of water }
\end{aligned}
$$

\subsubsection{Physical Properties}

$$
\begin{array}{ll}
\rho:=62.371 \cdot \frac{\mathrm{lb}}{\mathrm{ft}^{3}} & \begin{array}{l}
\text { Density of water at } 60 \text { degrees F, Crane (Ref. 5.2), pg. } \\
\text { A-6. }
\end{array} \\
\varepsilon:=0.000005 \cdot \mathrm{ft} & \text { Relative roughness of clean PVC pipe } \\
& \text { Crane (Ref. 5.2), pg. A-23, conservative. } \\
\mathrm{P}_{\mathrm{atm}}:=14.7 \cdot \mathrm{psi} & \text { Atmospheric pressure at Hanford }
\end{array}
$$

\subsubsection{Design Flows}

There are no design flows other than those listed in Section 1.3, Criteria

\subsubsection{Pipe Data}
$\mathrm{D}_{10}:=1.049$ in
I.D. of 1-inch nominal Sched 40 PVC Pipe (Ref 5.6)
$\mathrm{D}_{125}:=1.38$ in
I.D. of 1.25-inch nominal Sched 40 PVC Pipe (Ref 5.6)
$\mathrm{D}_{150}:=1.61$ in
I.D. of 1.5-inch nominal Sched 40 PVC Pipe (Ref 5.6)
$\mathrm{D}_{20}:=2.067$ in
I.D. of 2-inch nominal Sched 40 PVC Pipe (Ref 5.6) 


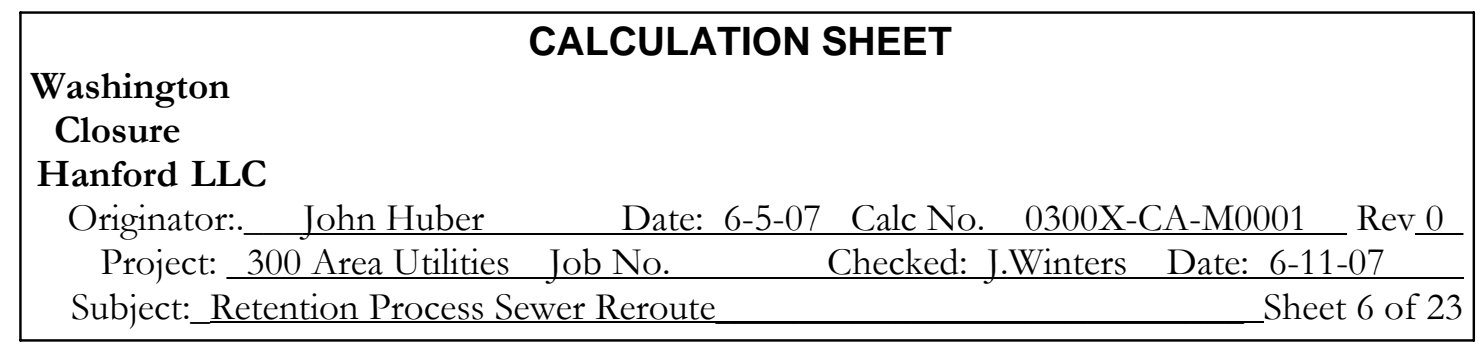

\subsubsection{Design Configuration}

Due to the conceptual status of the design, the configuration is as described in the figures included in this calculation.

\subsection{Calculation}

\subsubsection{Tank Drain Sizing}

Objective: Determine the discharge flow rate from draining one tank to the sanitary sewer system. The configuration is shown in Figure 1.

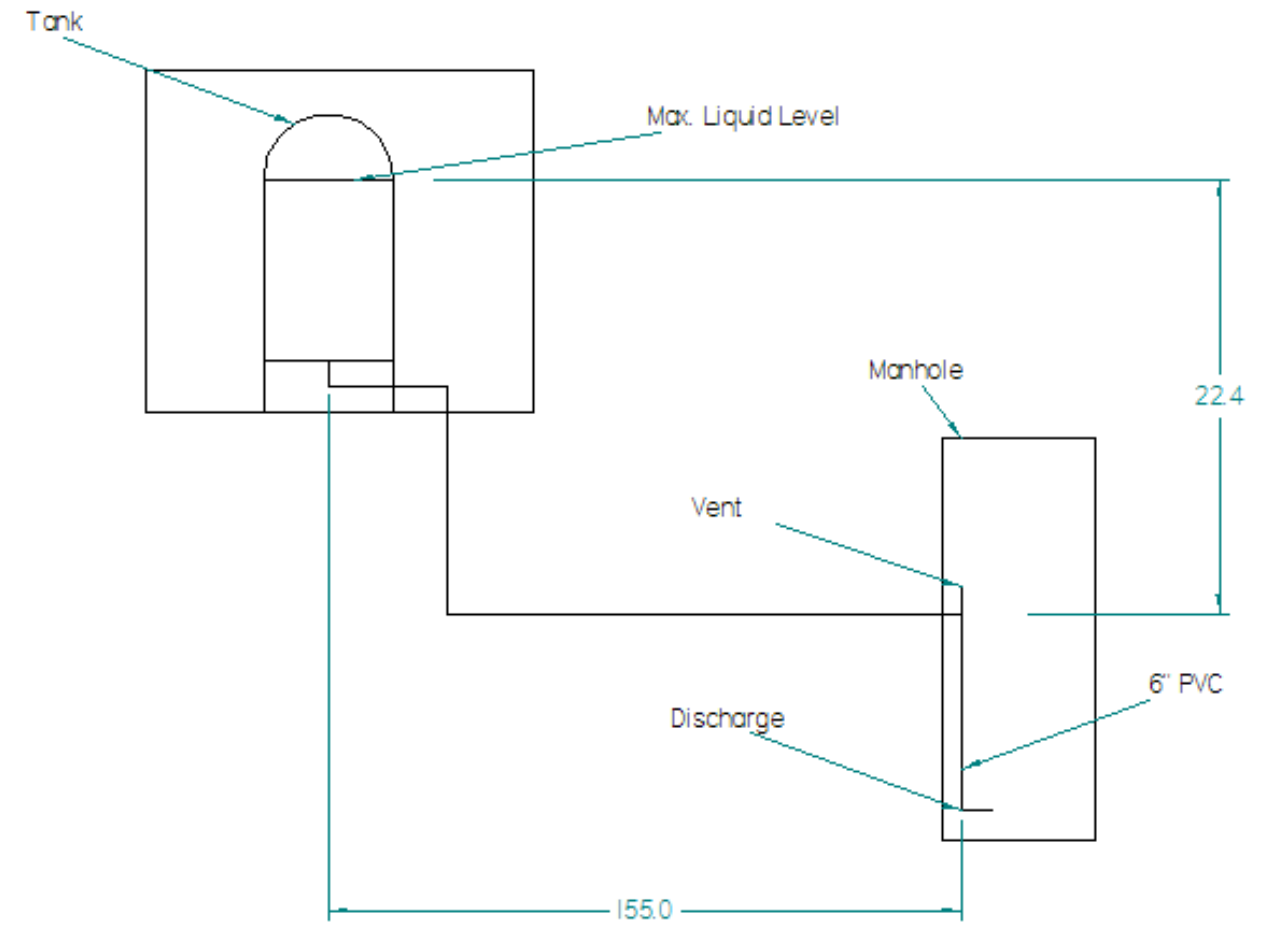

Figure 1, Tank Discharge to Manhole 


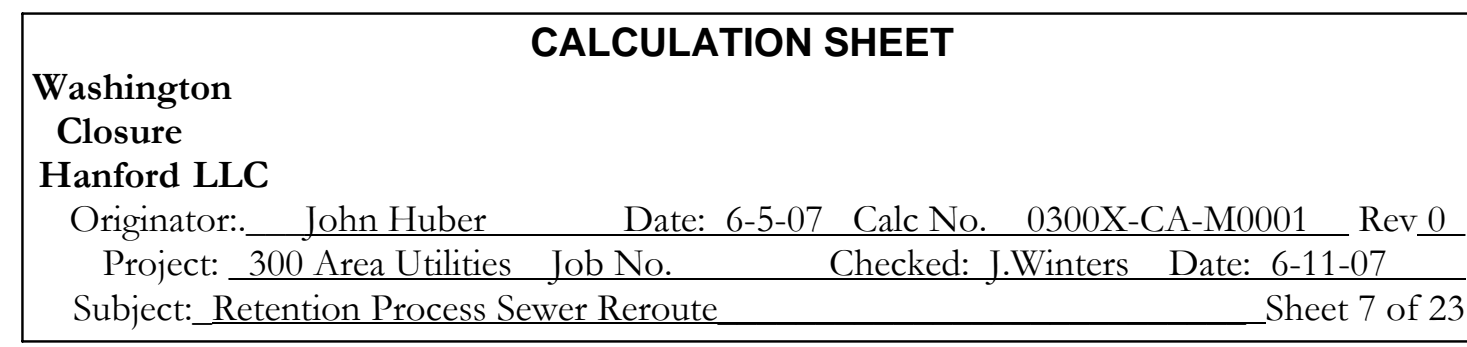

Specific Inputs:

$$
\begin{array}{ll}
\mathrm{g}_{\mathrm{C}}:=32.2 \frac{\mathrm{ft}}{\mathrm{sec}^{2}} & \\
\mathrm{D}_{20}:=2.067 \mathrm{in} & \\
\mathrm{H}_{\mathrm{S}}:=22.4 \mathrm{ft} & \text { Static head as shown in Figure } 1 \\
\mathrm{~L}_{\mathrm{Sp}}:=170 \mathrm{ft} & \text { Length of Straight Pipe, adding } 15 \text { feet to that } \\
\nu:=.00001059 \frac{\mathrm{ft}^{2}}{\mathrm{sec}} & \text { Numematic viscosity of water at } 70 \mathrm{~F} \\
\mathrm{~N}_{\mathrm{els}}:=7 & \text { for PVC pipe }
\end{array}
$$

Determine Fitting Losses

$$
\begin{array}{ll}
\mathrm{f}:=.015 & \text { Assumed friction factor - to be finalized later } \\
\mathrm{K}_{\mathrm{pipe}}:=\mathrm{f} \cdot \frac{\mathrm{L}_{\mathrm{sp}}}{\mathrm{D}_{20}} & \mathrm{~K}_{\text {pipe }}=14.804 \\
\mathrm{~K}_{\text {pipes }}:=\mathrm{K}_{\mathrm{pipe}} \cdot \mathrm{ft} & \\
\mathrm{K}_{\mathrm{els}}:=30 \cdot \mathrm{f} \cdot \mathrm{N}_{\mathrm{els}} & \mathrm{K}_{\mathrm{els}}=3.15 \\
\mathrm{~K}_{\text {elbows }}:=\mathrm{K}_{\mathrm{els}} \cdot \mathrm{ft} & \text { (Ref. 5.2 A-29) } \\
\mathrm{K}_{\text {entrance }}:=.5 \mathrm{ft} & \text { (Ref. 5.2 A-27, gate valve) } \\
\mathrm{K}_{\mathrm{v}}:=8 \mathrm{ft} &
\end{array}
$$




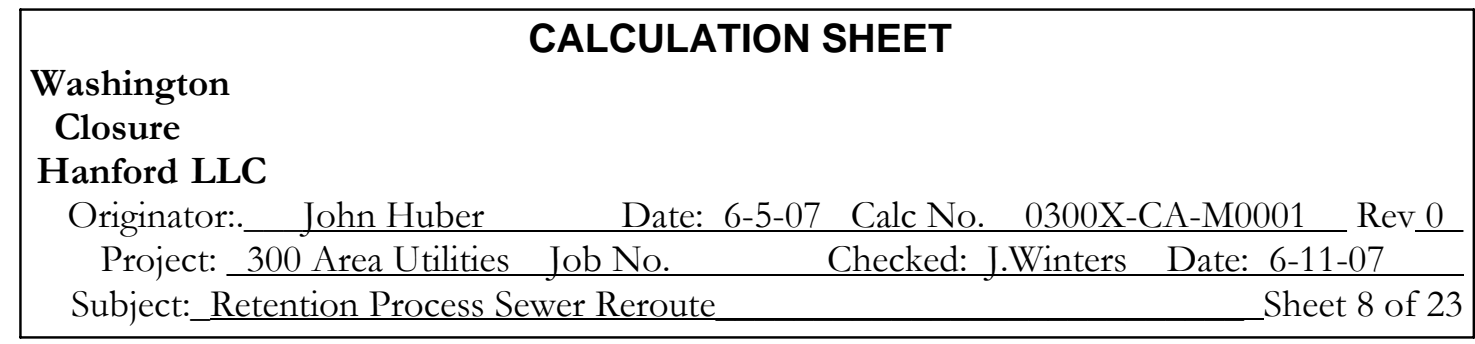

$$
\mathrm{K}_{\text {total }}:=\mathrm{K}_{\text {pipes }}+\mathrm{K}_{\text {elbows }}+\mathrm{K}_{\text {entrance }}+\mathrm{K}_{\mathrm{v}}
$$$$
\mathrm{K}_{\text {total }}=26.454 \mathrm{ft}
$$

\section{Calculate Flow Velocity}

Ref. 5.2 provides an equation for flow rate from a gravity discharge. The equation involves, as with many CFF equations, an undefined conversion factor. In order for MathCAD units to work out, a dummy dimension has been assigned to the conversion factor $\mathrm{C}$, numerically equivalent to 19.65 :

$$
\mathrm{C}:=19.65 \frac{\mathrm{gal}}{\mathrm{in}^{2} \cdot \min }
$$

From Ref 5.2:

$$
\mathrm{Q}:=\mathrm{C} \cdot\left(\mathrm{D}_{20}\right)^{2} \cdot \sqrt{\frac{\mathrm{H}_{\mathrm{S}}}{\mathrm{K}_{\text {total }}}} \quad \mathrm{Q}=77.254 \cdot \frac{\mathrm{gal}}{\mathrm{min}}
$$

The flow velocity for this pipe diameter is:

$$
\mathrm{V}:=\frac{\mathrm{Q}}{\frac{\pi}{4} \cdot \mathrm{D}_{20}^{2}} \quad \mathrm{~V}=7.386 \frac{\mathrm{ft}}{\mathrm{s}}
$$

The Reynold's number at this velocity:

$$
\mathrm{N}_{\mathrm{re}}:=\frac{\mathrm{D}_{20} \cdot \mathrm{V}}{\nu} \quad \mathrm{N}_{\mathrm{re}}=1.201 \times 10^{5}
$$




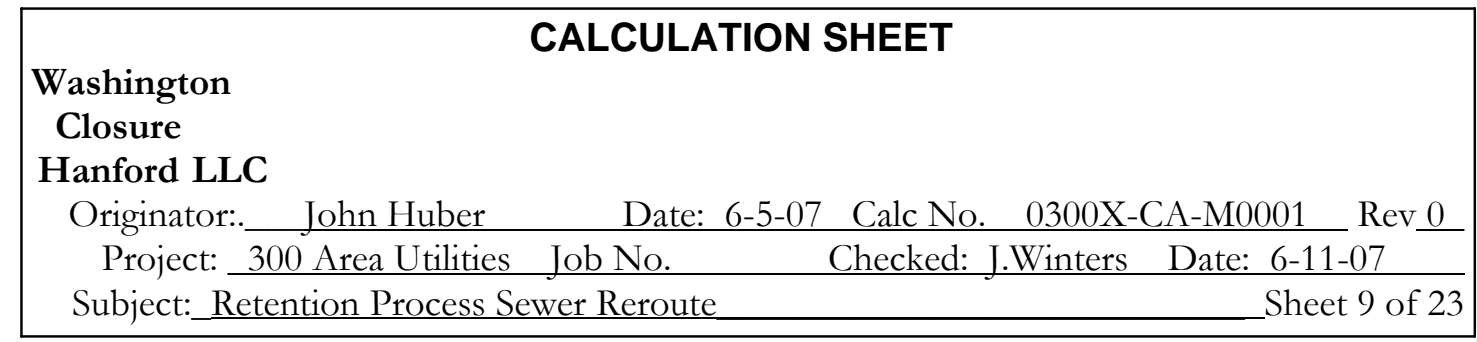

From the Swamee-Jain Equation, calculate a new friction factor:

$$
\mathrm{f}:=\frac{1.325}{\ln \left(\frac{\varepsilon}{3.7 \mathrm{D}_{20}}+\frac{5.74}{\mathrm{~N}_{\mathrm{re}} .9}\right)^{2}} \quad \mathrm{f}=0.017
$$

Use this new $f$ value to re-calculate losses

$$
\begin{gathered}
\mathrm{K}_{\text {pipe }}:=\mathrm{f} \cdot \frac{\mathrm{L}_{\mathrm{sp}}}{\mathrm{D}_{20}} \quad \mathrm{~K}_{\text {pipe }}=17.16 \quad \mathrm{~K}_{\text {pipes }}:=\mathrm{K}_{\text {pipe }} \cdot \mathrm{ft} \\
\mathrm{K}_{\text {els }}:=30 \cdot \mathrm{f} \cdot \mathrm{N}_{\text {els }} \quad \mathrm{K}_{\text {els }}=3.651 \quad \mathrm{~K}_{\text {elbows }}:=\mathrm{K}_{\text {els }} \cdot \mathrm{ft} \\
\mathrm{K}_{\text {total }}:=\mathrm{K}_{\text {pipes }}+\mathrm{K}_{\text {elbows }}+\mathrm{K}_{\text {entrance }}+\mathrm{K}_{\mathrm{v}} \quad \quad \mathrm{K}_{\text {total }}=29.311 \mathrm{ft} \\
\mathrm{Q}:=\mathrm{C} \cdot \mathrm{D}_{20}{ }^{2} \cdot \sqrt{\frac{\mathrm{H}_{\mathrm{S}}}{\mathrm{K}_{\text {total }}}} \quad \mathrm{Q}=73.392 \cdot \frac{\mathrm{gal}}{\mathrm{min}} \\
\mathrm{V}:=\frac{\mathrm{Q}}{\frac{\pi}{4} \cdot \mathrm{D}_{20}^{2}} \quad \mathrm{~V}=7.017 \frac{\mathrm{ft}}{\mathrm{s}}
\end{gathered}
$$

Since the new flow rate and velocity are not significantly different from the original calculated values, the original assumed friction factor was adequate.

Conclusion:

The selected line size is adequate. 


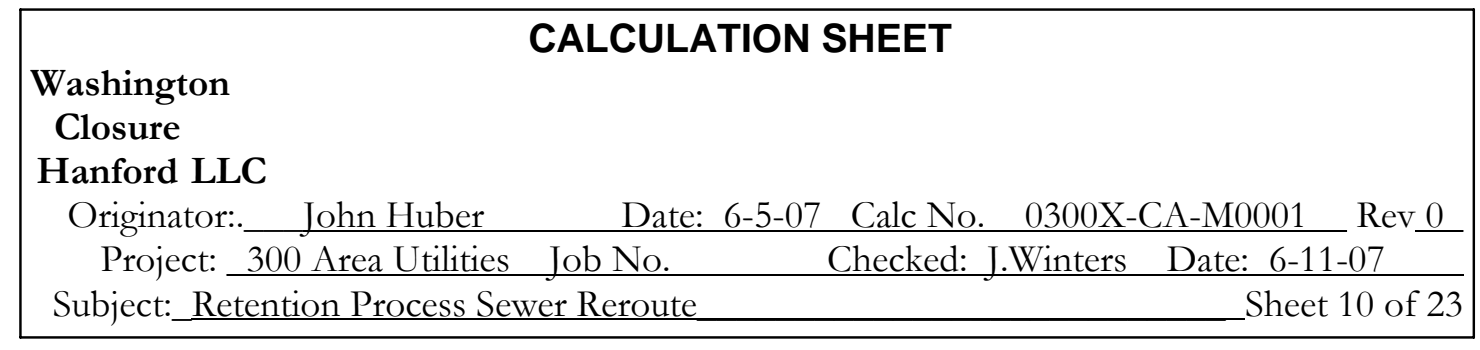

\subsubsection{RPS-3 Lift Station Discharge}

Determine discharge line size and pump requirments for the RPS-3 lift station. The configuration is shown in Figure 2.

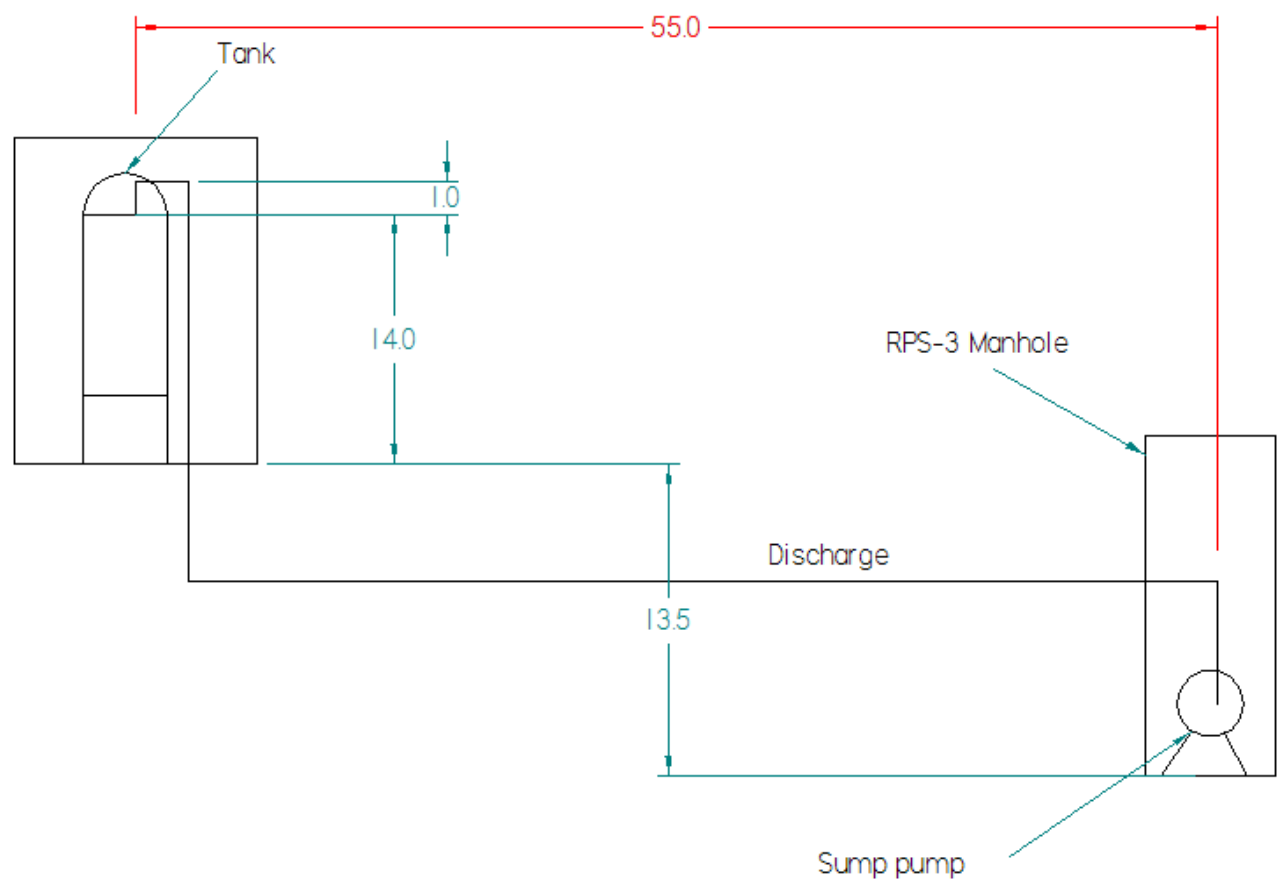

Figure 2, Lift Station Discharge Piping

Determine minimum flow required of the pump based on the maximum inflows to manhole RPS-3.

The total maximum inflow to the manhole is determined as follows:

Re-iterating flows from the criteria 1.3.

$\mathrm{Q}_{325 \mathrm{rps}}:=4 \frac{\mathrm{gal}}{\mathrm{min}}$ 


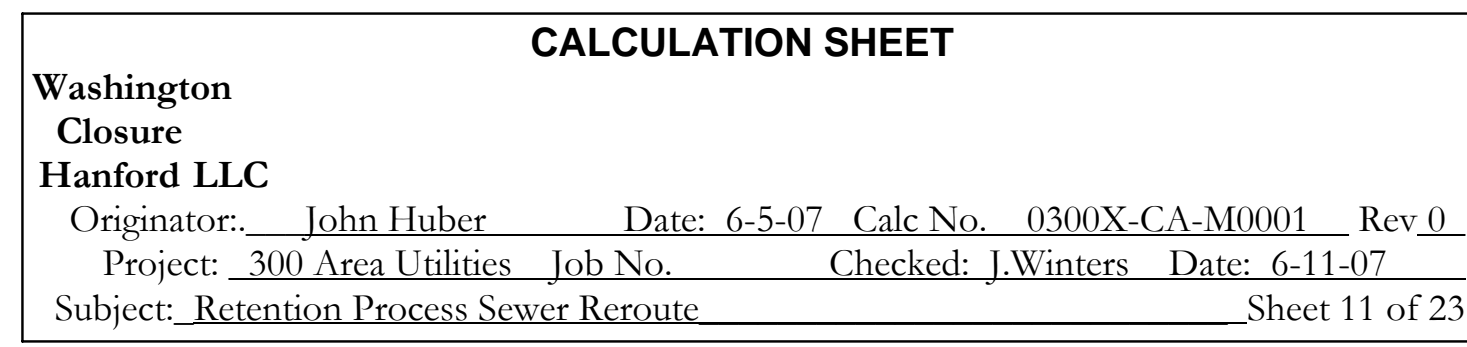

$$
\begin{aligned}
& Q_{329326 R P S}:=5 \frac{\text { gal }}{\text { day }} \\
& Q_{326 P S}:=100 \frac{\text { gal }}{\text { day }} \\
& Q_{329 P S}:=44 \frac{\text { gal }}{\text { day }} \\
& Q_{\text {totalrps } 3}:=Q_{325 \text { rps }}+Q_{329326 R P S}+Q_{326 P S}+Q_{329 P S} \\
& \quad Q_{\text {totalrps3 }}=4.103 \cdot \frac{\text { gal }}{\mathrm{min}}
\end{aligned}
$$

Rough dimensions of the manhole:

$$
\begin{aligned}
& \mathrm{D}_{\mathrm{mh}}:=4 \mathrm{ft} \\
& \mathrm{H}_{\mathrm{mh}}:=10 \mathrm{ft}
\end{aligned}
$$

Capacity of the manhole:

$$
\begin{aligned}
& \mathrm{V}_{\mathrm{mh}}:=\frac{\pi}{4} \mathrm{D}_{\mathrm{mh}}{ }^{2} \cdot \mathrm{H}_{\mathrm{mh}} \\
& \mathrm{V}_{\mathrm{mh}}=940.03 \cdot \mathrm{gal}
\end{aligned}
$$

Time to fill manhole:

$$
\mathrm{T}_{\mathrm{mh}}:=\frac{\mathrm{V}_{\mathrm{mh}}}{\mathrm{Q}_{\text {totalrps3 }}} \quad \mathrm{T}_{\mathrm{mh}}=3.818 \cdot \mathrm{hr}
$$

Assuming worst case conditions, where sump floats are inoperable and the manhole must be emptied faster than it is filled, select a pump with minimum flow rate as follows:

$$
\mathrm{Q}_{\text {sump }}:=5 \mathrm{gpm}
$$




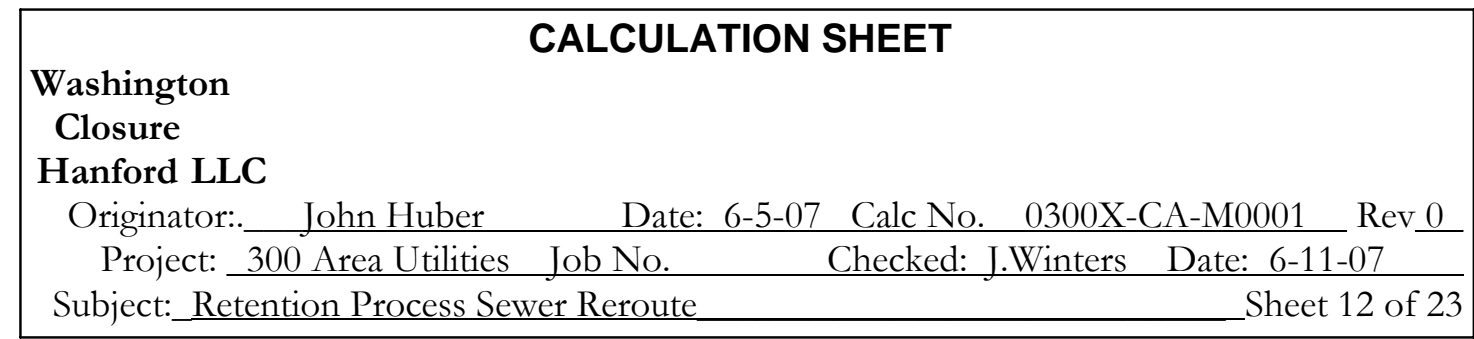

Sizing the discharge line:

Using the 2-10fps criteria, use Table B-14 from Ref 5.2 to select pipe size options. For a 1" line, the flow velocity ranges from 2-7 fps for 6-20 gpm. For $11 / 2$ inch line, 2-10 fps ranges from 15 to $60 \mathrm{gpm}$. A 1 inch nominal pipe will be selected.

Select a pump:

In order to select a pump, a first estimate of the total dynamic head is needed. This can be estimated by taking the static head and adding a conservative factor of $30 \%$ to account for line losses.

$$
\begin{array}{lll}
\mathrm{H}_{\mathrm{sh}}:=13.5 \mathrm{ft}+14 \mathrm{ft} & \mathrm{H}_{\mathrm{sh}}=27.5 \mathrm{ft} & \text { Static head from Figure } 2 \\
\mathrm{H}_{\mathrm{tdh}}:=\mathrm{H}_{\mathrm{Sh}}+\mathrm{H}_{\mathrm{sh}} \cdot 3 & \mathrm{H}_{\mathrm{tdh}}=35.75 \mathrm{ft} & \text { Total Dynamic Head estimated }
\end{array}
$$

The Aquatic Eco-Systems SP750 provides adquate discharge head requirements and is supplied with a 1" nominal threaded connection. The pump curve is shown in Figure 3. 


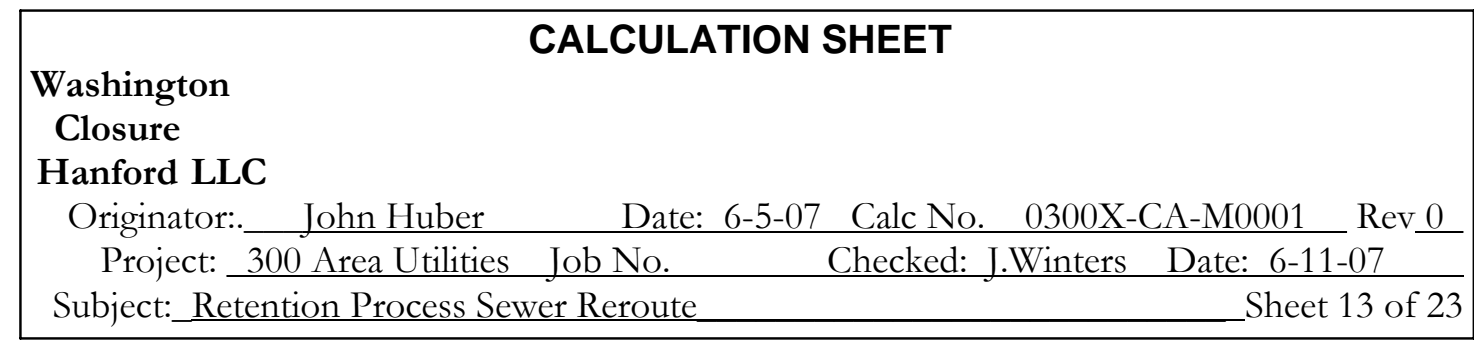

\section{Pump Curve}

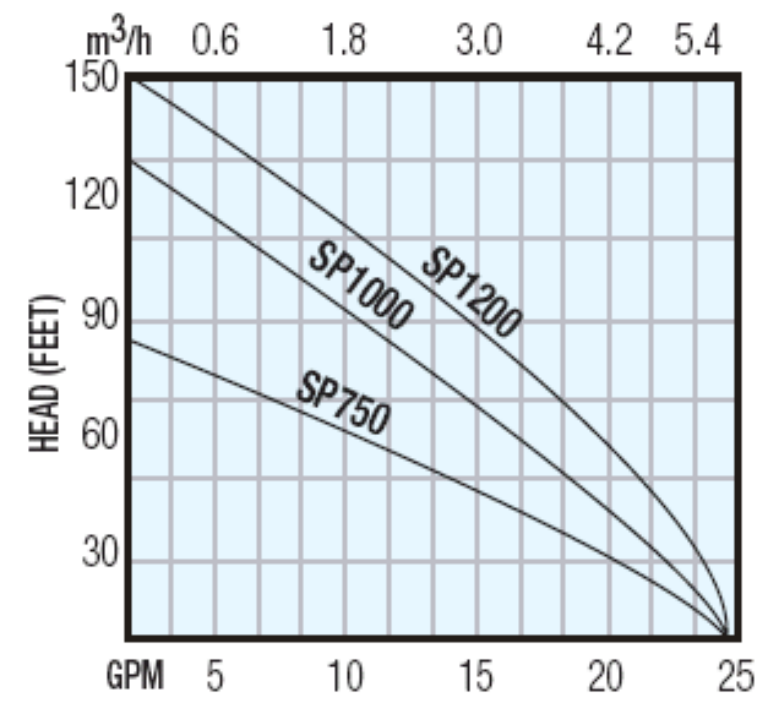

Figure 3, SP750 Pump Curve

From the Figure 3 pump curve for the SP750, the flow rate at the estimated TDH is:

$$
\mathrm{Q}_{\text {pump }}:=18 \mathrm{gpm}
$$

A more definitive system analysis can now be determined. From Ref 5.2, the pressure drop per 100 feet of 1 " line is:

$$
\text { DeltaP }_{100}:=1.07 \mathrm{psi} \quad \text { Ref. } 5.2 \text { Table B-14 by interpolation }
$$




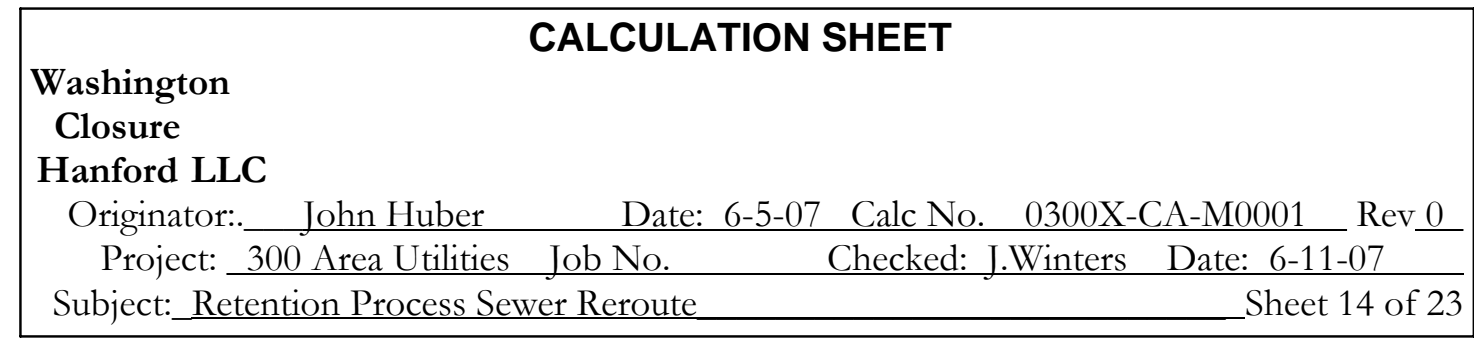

Numbers and equivalent length of fittings. Equivalent lengths are taken from Ref 5.5 Section 3 Appendix $\mathrm{J}$ for Screwed Steel pipe. This is expected to be conservative when applied to a PVC pipe system.

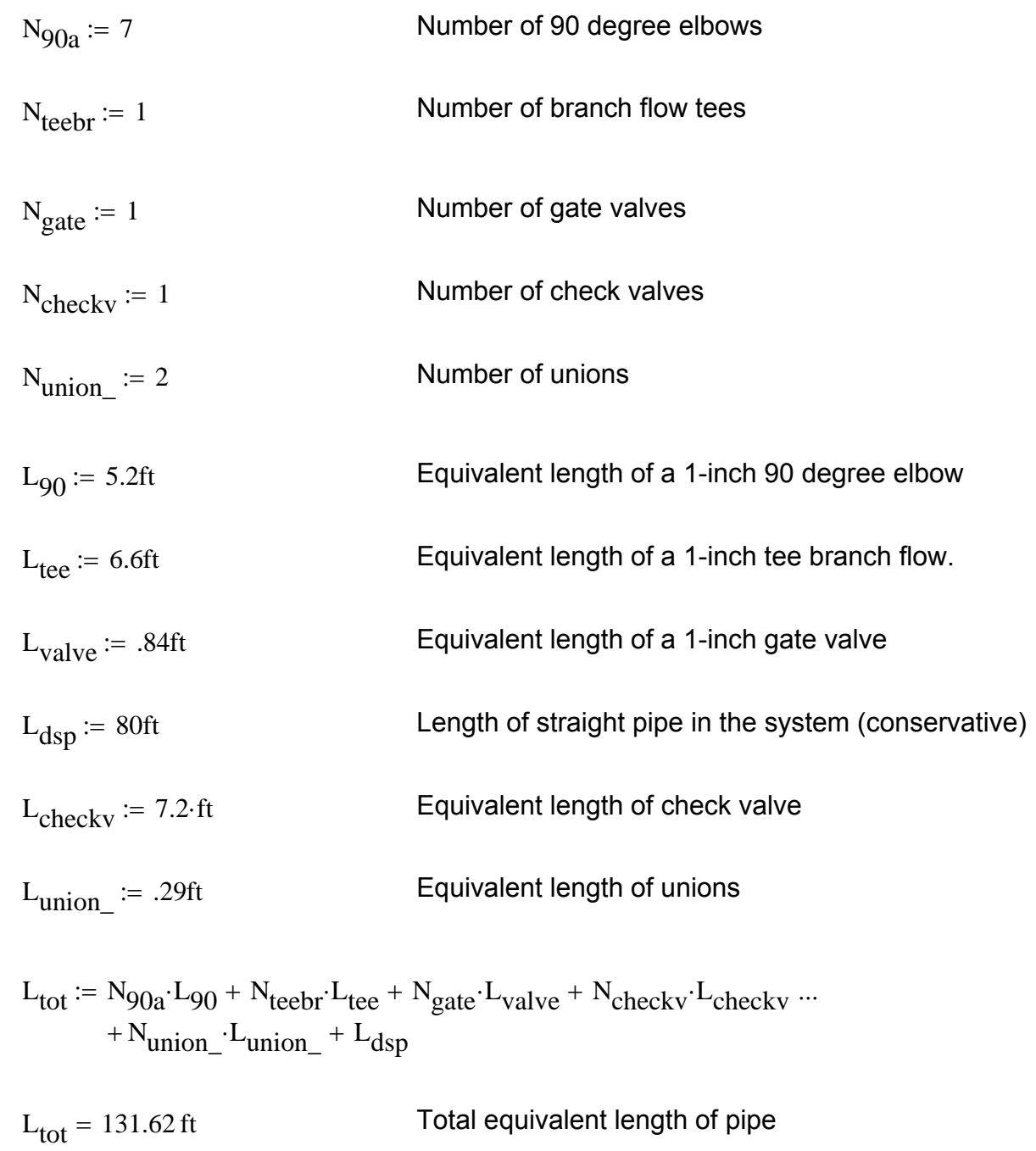




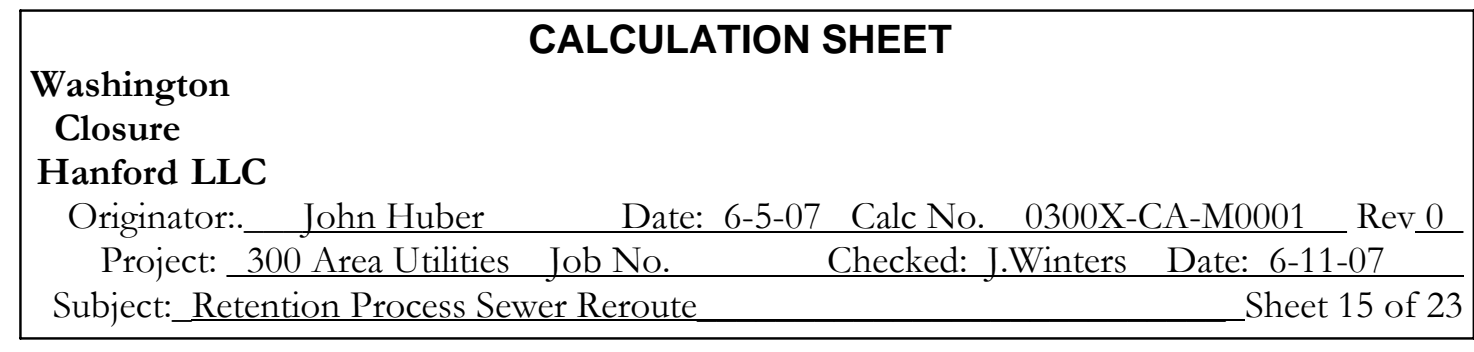

Pressure drop over the total equivalent pipe length

$$
\begin{array}{ll}
\mathrm{P}_{\text {drop }}:=\frac{\mathrm{L}_{\text {tot }}}{100 \mathrm{ft}} \cdot \text { DeltaP }_{100} & \mathrm{P}_{\mathrm{drop}}=1.408 \cdot \mathrm{psi} \\
\mathrm{H}_{\text {tdhrps } 3}:=\mathrm{H}_{\mathrm{sh}}+\mathrm{P}_{\mathrm{drop}} \cdot 2.31 \frac{\mathrm{ft}}{\mathrm{psi}} & \\
\mathrm{H}_{\text {tdhrps } 3}=30.753 \mathrm{ft} & \text { Total dynamic head }
\end{array}
$$

From Figure 3, at the calculated Total Dynamic Head, the pump will output:

$$
\mathrm{Q}_{\text {pumpRPSLift }}:=20 \mathrm{gpm}
$$

Horsepower required to pump:

The equation for horsepower is taken from Ref. 5.5, Table 4.3. The authors of the reference manual already worked out conversion factors for their equations. The equation is known to be accurate, but since MathCAD checks all units, a dummy conversion factor $\mathrm{C}_{1}$ was inserted following the 3956 value to make the units of the solution work out.

$\mathrm{C}_{1}:=\frac{\mathrm{gpm} \cdot \mathrm{ft}}{\mathrm{hp}}$

From assumption 4.2.4:

$$
\eta_{\mathrm{p}}:=0.60
$$

$$
\begin{aligned}
\text { bhp }_{\text {rps }}:=\frac{\mathrm{H}_{\text {tdhrps } 3} \cdot Q_{\text {pumpRPSLift }}}{3956 \cdot \mathrm{C}_{1} \cdot \eta_{\mathrm{p}}} \\
\text { bhp }_{\mathrm{rps}}=0.259 \cdot \mathrm{hp}
\end{aligned}
$$

If selecting a pump other than that used for this analysis, choose a $1 / 3 \mathrm{hp} \mathrm{pump}$ to account for electric motor inefficiency. 


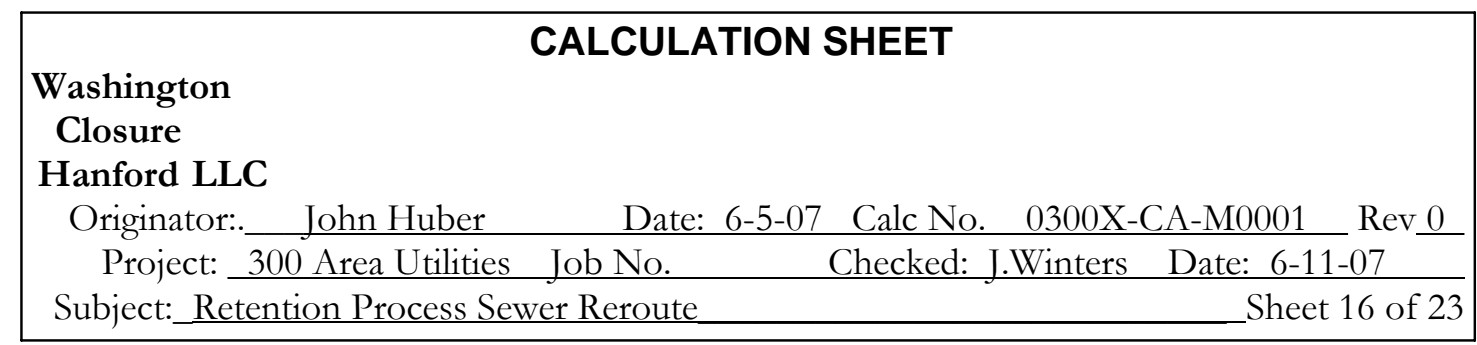

Lift Station Cycle Time:

\begin{tabular}{|c|c|c|}
\hline $\mathrm{D}_{\mathrm{mh}}=4 \mathrm{ft}$ & \multicolumn{2}{|c|}{ Manhole Diameter } \\
\hline $\mathrm{h}_{\mathrm{on}}:=3 \mathrm{ft}$ & \multicolumn{2}{|c|}{ Pump "ON" Level } \\
\hline $\mathrm{h}_{\mathrm{off}}:=10$ in & \multicolumn{2}{|c|}{ Pump "OFF" Level } \\
\hline $\mathrm{V}_{\mathrm{in}}:=\frac{\pi}{4} \cdot \mathrm{D}_{\mathrm{mh}}^{2}$ & \multicolumn{2}{|c|}{ Volume of liquid per inch } \\
\hline $\mathrm{V}_{\text {off_on }}:=\left(\mathrm{h}_{\mathrm{on}}-\mathrm{h}_{\mathrm{off}}\right) \cdot \mathrm{V}_{\text {in }}$ & \multicolumn{2}{|c|}{ Volume between "off" and "on" level } \\
\hline $\mathrm{T}_{\text {empty }}:=\frac{\mathrm{V}_{\text {off_on }}}{\mathrm{Q}_{\text {pumpRPSLift }}}$ & \multicolumn{2}{|l|}{$\begin{array}{l}\text { Time to empty } \\
\text { (Neglecting } \\
\text { incomming } \\
\text { flow) }\end{array}$} \\
\hline $\mathrm{T}_{\text {fill }}:=\frac{\mathrm{V}_{\text {off_on }}}{\mathrm{Q}_{\text {sump }}}$ & Time to fill & $\mathrm{T}_{\text {fill }}=40.735 \cdot \mathrm{min}$ \\
\hline
\end{tabular}




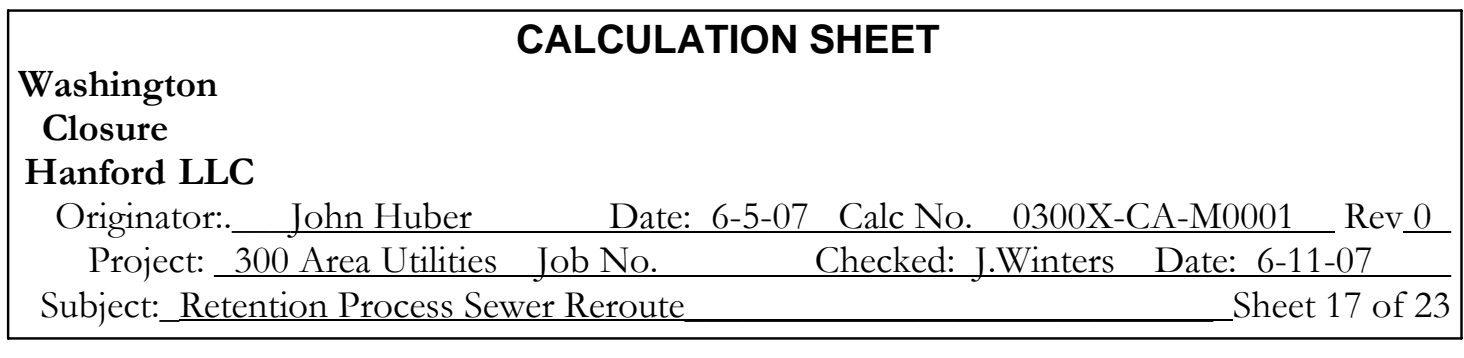

\subsubsection{Sizing of the new 326 PS Sump}

The sump needs to accomodate a certain amount of flow from the 326 building process sewer system. Since the sump pump will automatically activate and remove liquid, the sump does not need to hold a day's worth of accumulation. This calculation arbitrarily consideres the sump to accumulate $1 / 2$ day's effluents from 326 .

The 326 PS flow rate is (from Section 1.3 Criteria):

$$
\begin{aligned}
\mathrm{Q}_{326 \mathrm{PS}} & =100 \cdot \frac{\text { gal }}{\text { day }} \\
\mathrm{V}_{326 \text { Sump }}:=\mathrm{Q}_{326 \mathrm{PS}} \cdot \text {.5day } & \text { Volumetric capacity of the } 326 \text { Sump } \\
\mathrm{V}_{326 \text { Sump }} & =50 \cdot \text { gal }
\end{aligned}
$$

There are dimensional limits imposed upon the 326 sump due to the size of the room in which it is located. The sump is limited to 24 -inches wide. The length can be up to $3 \mathrm{feet}$, and the depth has no known limitation.

Try a 2-foot depth

$$
\begin{array}{ll}
\mathrm{L}_{\mathrm{W}}:=2 \mathrm{ft} & \text { Width of the sump } \\
\mathrm{L}_{\mathrm{d}}:=2 \mathrm{ft} & \text { Depth of the sump } \\
\mathrm{L}_{\mathrm{L}}:=\frac{\mathrm{V}_{326 S u m p}}{\mathrm{~L}_{\mathrm{W}} \cdot \mathrm{L}_{\mathrm{d}}} & \text { Resulting length of the sump }
\end{array}
$$

These reflect the minimum dimensions of the 326 sump. It can be deeper or longer, if desired, without requiring a revision to this calculation. 


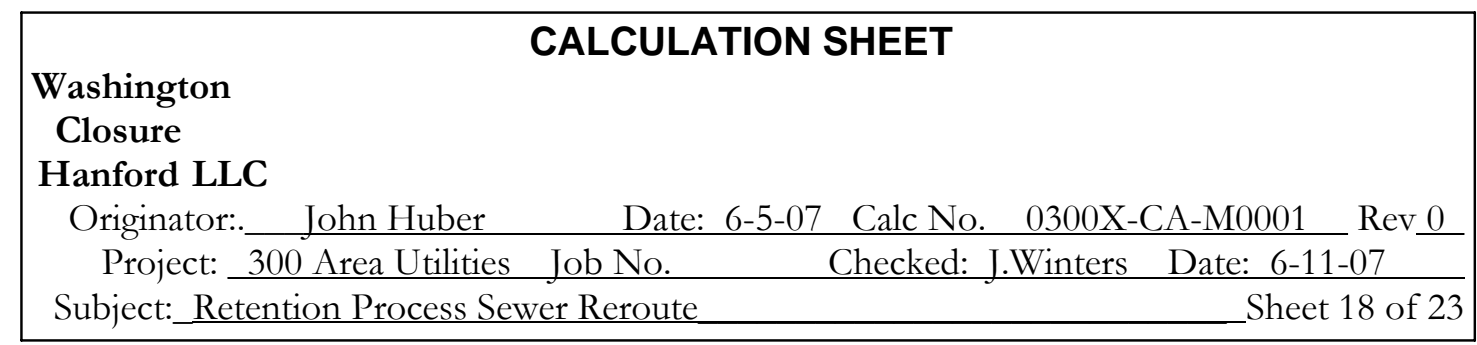

\subsubsection{Size the 326 Sump Pump}

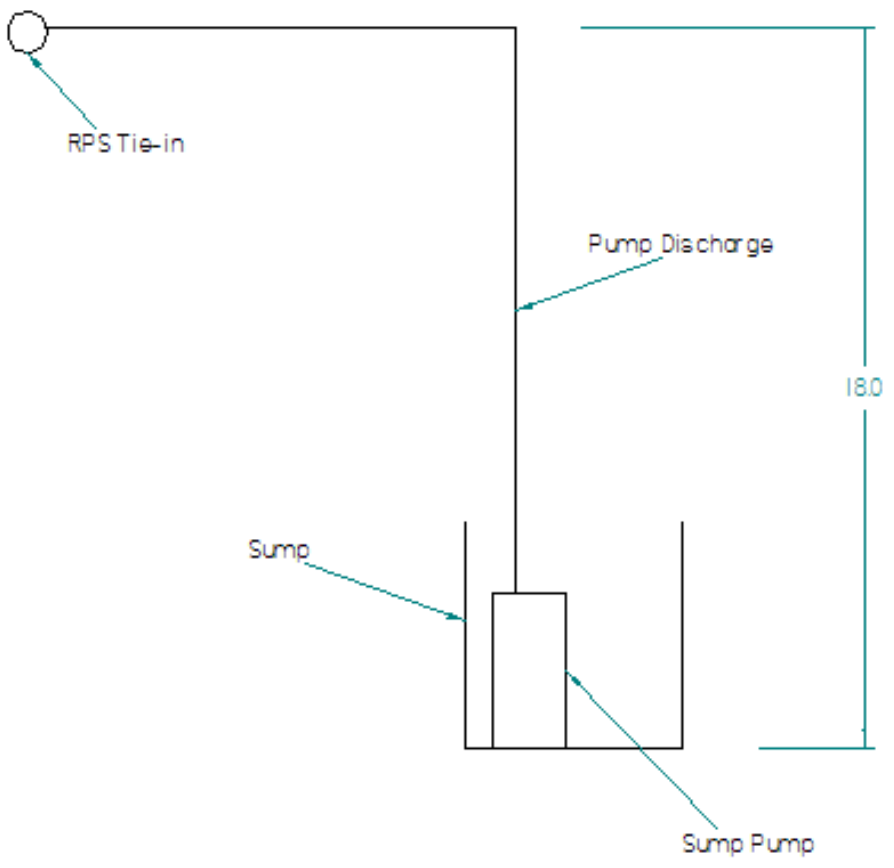

Figure 4, 326 Sump Pump Discharge

Estimate the TDH based on the static head requirment, and add 100\% to account for friction head losses.

$\mathrm{H}_{\text {stat }}:=18 \mathrm{ft}$

$\mathrm{H}_{\text {tdhest }}:=2 \cdot \mathrm{H}_{\text {stat }}$

$\mathrm{H}_{\text {tdhest }}=36 \mathrm{ft}$

Estimated TDH

The SP750 submersible pump, as shown in Figure 3, will provide about $18 \mathrm{gpm}$ at 36 feet of head. Select this pump and use it to size the discharge line. 


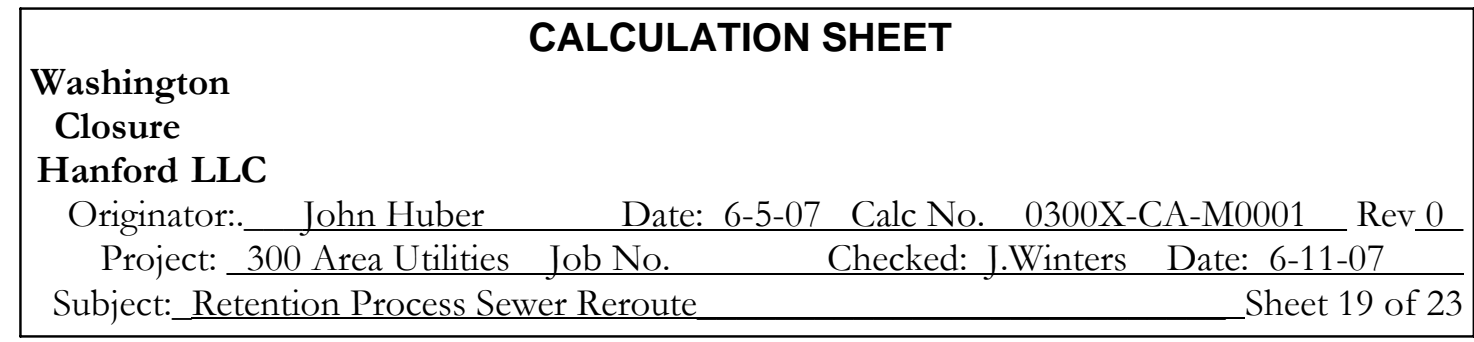

At $18 \mathrm{gpm}$, and using Table B-14 from Ref. 5.2, a 1 1/2 inch line provides flows and pressure drop as shown.

$\mathrm{Q}_{326 \mathrm{pump}}:=18 \mathrm{gpm}$

$\begin{array}{ll}\mathrm{V}_{\text {326pump }}:=2.84 \frac{\mathrm{ft}}{\mathrm{sec}} & \begin{array}{l}\text { Velocity per Ref. } 5.2, \text { Table B-14, for } 18 \\ \text { gpm interpolating }\end{array}\end{array}$

This velocity is borderline low. A 1-inch nominal line would be a better selection.

$\mathrm{V}_{\text {326pump }}:=6.68 \frac{\mathrm{ft}}{\mathrm{sec}} \quad$ Velocity per Ref 5.2, Table B-14, for 18 gpm and 1-inch pipe, interpolated

DeltaP1 $100:=9.08$ psi Pressure drop per 100 feet of pipe, Ref.

5.2, Table B-14, for $18 \mathrm{gpm}$ interpolating

Numbers and equivalent length of fittings. Equivalent lengths are taken from Ref 5.5 Section 3 Appendix $\mathrm{J}$ for Screwed Steel pipe. This is expected to be conservative when applied to a PVC pipe system.
$\mathrm{N}_{90 b}:=2$
Number of 90 degree elbows
$\mathrm{N}_{45}:=6$
Number of 45 degree elbows
$\mathrm{N}_{\text {teebr1 }}:=1$
Number of branch flow tees
$\mathrm{N}_{\text {gate1 }}:=1$
Number of gate valves
$\mathrm{N}_{\text {union }}:=3$
Number of unions
$\mathrm{N}_{\text {check }}:=1$
Number of check valves
$\mathrm{N}_{\text {lat }}:=1$
Number of laterals
$\mathrm{L}_{90 \mathrm{~b}}:=5.2 \mathrm{ft}$
Equivalent length 90 deg elbow 


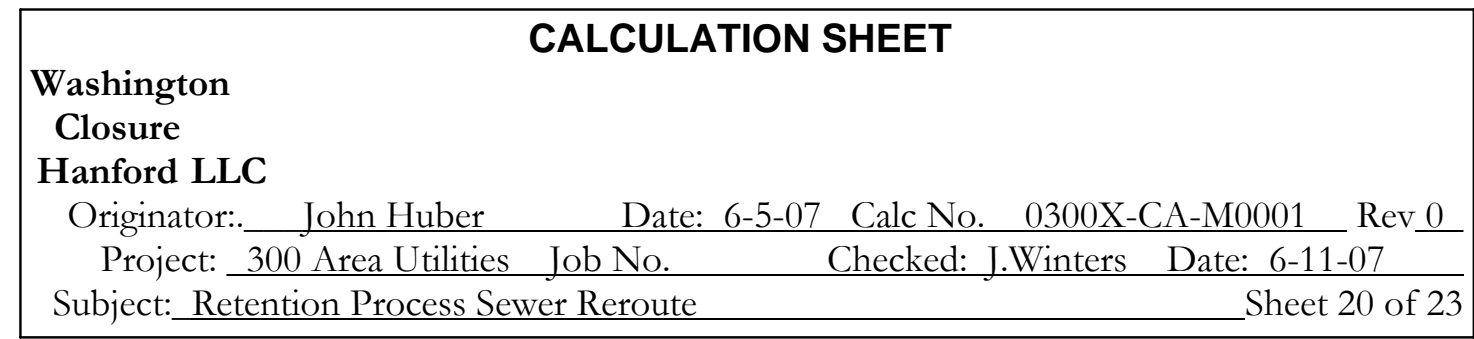

\begin{tabular}{|c|c|}
\hline $\mathrm{L}_{45}:=.81 \mathrm{ft}$ & Equivalent length 45 deg elbow \\
\hline $\mathrm{L}_{\text {teebr1 }}:=3.3 \mathrm{ft}$ & Equivalent length tee branch flow \\
\hline $\mathrm{L}_{\text {globe1 }}:=29 \mathrm{ft}$ & Equivalent length globe valve \\
\hline $\mathrm{L}_{\text {union }}:=.29 \mathrm{ft}$ & Equivalent length union \\
\hline $\mathrm{L}_{\text {check }}:=11 \mathrm{ft}$ & Equivalent length check valve \\
\hline $\mathrm{L}_{\text {lat }}:=3.3 \mathrm{ft}$ & $\begin{array}{l}\text { Equivalent length lateral - assume equivalent to a } \\
\text { branch flow tee. }\end{array}$ \\
\hline $\mathrm{L}_{\mathrm{sp} 1}:=230 \mathrm{ft}$ & Length of straight pipe in the system \\
\hline $\begin{aligned} \mathrm{L}_{\text {fitgs }}:= & \mathrm{N}_{90 \mathrm{~b}} \cdot \mathrm{L}_{90 \mathrm{~b}}+ \\
& +\mathrm{N}_{\text {check }} \cdot \mathrm{L}_{\mathrm{ch}}\end{aligned}$ & $\begin{array}{l}\mathrm{N}_{45} \cdot \mathrm{L}_{45}+\mathrm{N}_{\text {teebr1 }} \cdot \mathrm{L}_{\text {teebr1 }}+\mathrm{N}_{\text {gate } 1} \cdot \mathrm{L}_{\text {globe1 }}+\mathrm{N}_{\text {union }} \cdot \mathrm{L}_{\text {union }} \cdots \\
\text { eck } \\
+\mathrm{N}_{\text {lat }} \mathrm{L}_{\text {lat }}+\mathrm{L}_{\mathrm{sp} 1}\end{array}$ \\
\hline $\mathrm{L}_{\text {fitgs }}=292.73 \mathrm{ft}$ & Equivalent length of all pipe and fittings \\
\hline $\mathrm{P}_{\mathrm{drop} 1}:=\operatorname{DeltaP}_{100}$ & $\left(\frac{L_{\text {fitgs }}}{100 \mathrm{ft}}\right)$ \\
\hline $\mathrm{P}_{\mathrm{drop} 1}=26.58 \cdot \mathrm{psi}$ & Total system head loss, psi \\
\hline $\mathrm{P}_{\mathrm{drop} 1}=11.506 \mathrm{ft}$ & System head loss in feet \\
\hline \multicolumn{2}{|c|}{$\mathrm{TDH}_{326 \text { sump }}:=\mathrm{P}_{\mathrm{drop} 1}+\mathrm{H}_{\text {stat }}$} \\
\hline \multicolumn{2}{|l|}{$\mathrm{TDH}_{326 \mathrm{sump}}=29.506 \mathrm{ft}$} \\
\hline \multicolumn{2}{|c|}{ Reentering Figure 3 for the SP750 pump, the flow at $30 \mathrm{ft}$ head is $20 \mathrm{gpm}$} \\
\hline $\mathrm{Q}_{326 \mathrm{pump}}:=20 \mathrm{gpm}$ & \\
\hline
\end{tabular}




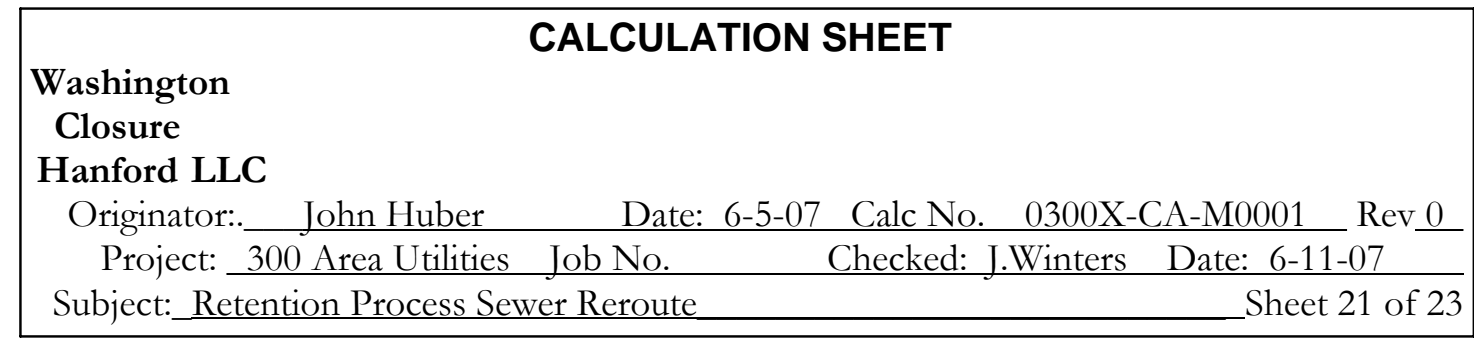

Horsepower required to pump:

The equation for horsepower is taken from Ref. 5.5, Table 4.3. The authors of the reference manual already worked out conversion factors for their equations. The equation is known to be accurate, but since MathCAD accounts for all units, a dummy conversion factor $\mathrm{C}_{1}$ (from the RPS pump calculation in Section 6.2.2) was inserted following the 3956 value to make the units of the solution work out.

$\operatorname{bhp}_{326}:=\frac{\mathrm{TDH}_{326 \text { sump }} \cdot \mathrm{Q}_{326 \mathrm{pump}}}{3956 \cdot \mathrm{C}_{1} \cdot \eta_{\mathrm{p}}}$

bhp $_{326}=0.249 \cdot \mathrm{hp}$

If selecting a pump other than that used for this analysis, choose a $1 / 3 \mathrm{hp}$ pump to account for electric motor inefficiency.

Sump pump cycle time:

Actual dimensions of the designed 326 sump are larger than the minimums calculated and will be redefined here.

$$
\begin{aligned}
& \mathrm{L}_{\text {width }}:=24 \text { in } \quad \text { Length of square sump side } \\
& \mathrm{L}_{\text {depth }}:=36 \text { in } \quad \text { Depth of sump } \\
& \mathrm{V}_{\text {in_sump }}:=\mathrm{L}_{\text {width }}{ }^{2} \quad \text { Volume of sump per inch } \\
& \mathrm{L}_{3260 n}:=326 \text { Sump Pump "ON" Level } \\
& \mathrm{L}_{326 \mathrm{off}}:=2 \text { in } \quad 326 \text { Sump Pump "OFF" level } \\
& \mathrm{V}_{3260 f f \_ \text {on }}:=\left(\mathrm{L}_{3260 n}-\mathrm{L}_{326 \mathrm{off}}\right) \cdot \mathrm{V}_{\text {in_sump }} \quad \text { Volume between "OFF" and "ON" } \\
& \mathrm{T}_{\text {326empty }}:=\frac{\mathrm{V}_{\text {326off_on }}}{\mathrm{Q}_{\text {326pump }}} \quad \begin{array}{l}
\text { Time to empty } \\
\text { (neglecting }
\end{array} \quad \mathrm{T}_{326 \mathrm{empty}}=3.491 \cdot \mathrm{min} \\
& \text { incomming } \\
& \text { flow) } \\
& \mathrm{T}_{\text {326fill }}:=\frac{\mathrm{V}_{\text {326off_on }}}{\mathrm{Q}_{\text {326PS }}} \quad \text { Time to fill } \quad \mathrm{T}_{326 \text { fill }}=16.756 \cdot \mathrm{hr}
\end{aligned}
$$




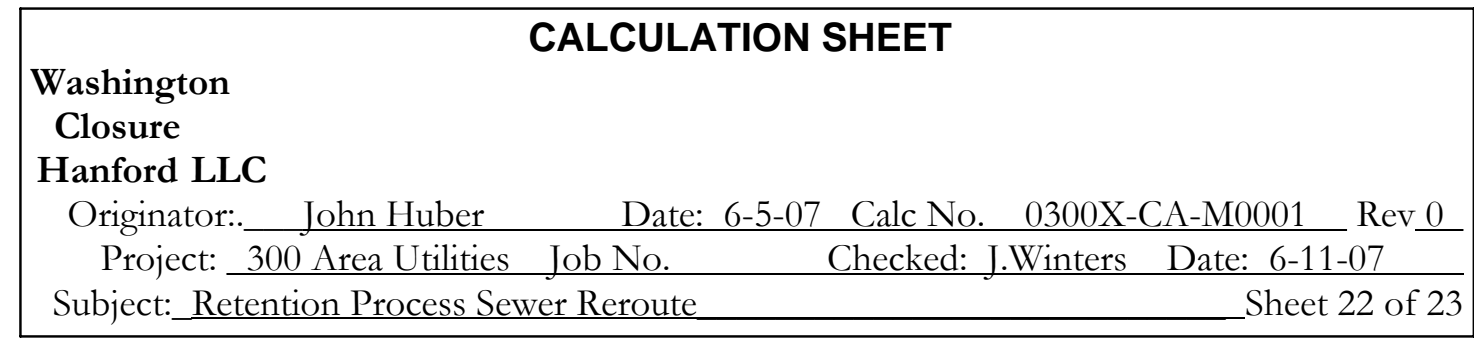

\subsubsection{Size the Spill Retention Curb for the Tank Pad}

Reference 5.7, Section 4.9.2 requires a spill containment system capable of holding spills and leaks equal to $10 \%$ of the total volume, or $10 \%$ of the largest container; whichever is greater.

$10 \%$ of the total volume, given 4 tanks at 4300 gal each:

$\operatorname{Tank}_{\text {voltotal }}:=4 \cdot 4300$ gal

Tank $_{\text {voltotal }}=1.72 \times 10^{4}$ gal Capacity of all 4 tanks

$\mathrm{Vol}_{\text {contmnt }}:=0.1 \cdot$ Tank $_{\text {voltotal }}$

$\mathrm{Vol}_{\text {contmnt }}=1.72 \times 10^{3} \cdot$ gal

Containment volume required based on total tank volume

$10 \%$ of the largest container's volume (all tanks are the same size):

Tank $_{\text {volone }}:=4300$ gal

$\mathrm{Vol}_{\text {contmnt2 }}:=0.1 \cdot$ Tank $_{\text {volone }}$

Vol $_{\text {contmnt2 }}=430 \cdot$ gal

Containment volume required based on 1 tank volume

The capacity of the containment will need to be based on total volume since that value is greater.

Determine the spill retention curb height based on a 30 foot square pad with a 4 foot square by 5 foot deep sump in the center.
$\mathrm{L}_{\text {pad }}:=30 \mathrm{ft}$
Length of one side of the pad
$\mathrm{L}_{\text {smp }}:=3 \mathrm{ft}$
Length of one side of the sump
$\mathrm{h}_{\mathrm{smp}}:=4 \mathrm{ft}$
Depth of the sump 


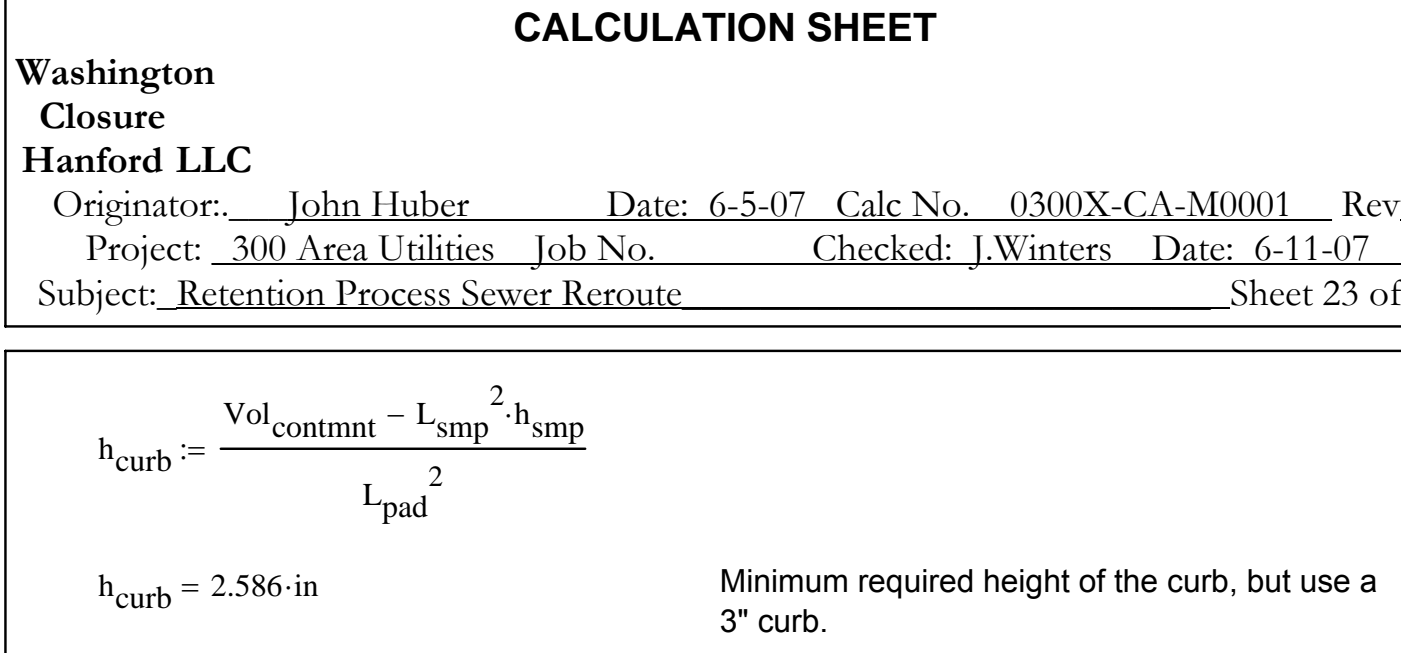

\subsection{SUMMARY OF RESULTS}

The following values summarize the results of this calculation.

\section{Tank Drain to SS-83:}

The drain line from the tanks to the SS-83 manhole is to be a 2-inch schedule 40 PVC pipe.

\section{RPS-3 Lift Station:}

The RPS-3 Lift station discharge line is to be a 1 -inch schedule 40 PVC pipe. The pump for the lift station is to be an Aquatic ECO-Systems Inc., Model SP750 high-head submersible pump, operating at $20 \mathrm{gpm}$ and $30 \mathrm{ft}$ head.

\section{Process Sewer Sump Dimensions:}

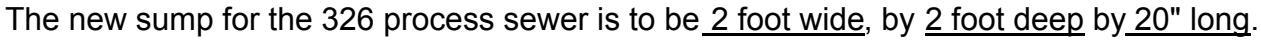
The width dimension is restricted, however the remaining dimensions can be increased as needed. The volume of the sump is sized to handle 50 galons of the 100 gal/day PS flow.

\section{Process Sewer Sump Pump and discharge line:}

This sump pump is sized to provide $\underline{20}$ gpm at 30 feet head through a 1 -inch schedule 40 PVC pipe.

\section{Tank Pad Spill Containment Curb:}

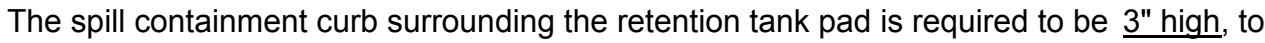
contain $10 \%$ of the total volume of the 4 tanks as required per $\mathrm{WCH}-56$. 


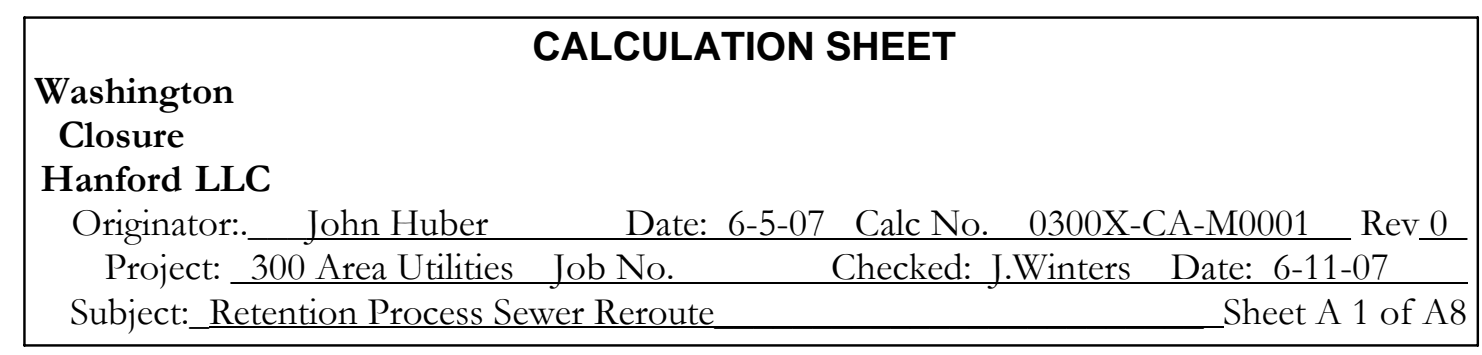

\section{Appendix A (Reference Data)}




\section{CALCULATION SHEET}

\section{Washington \\ Closure}

Hanford LLC

Originator:. John Huber Date: 6-5-07 Calc No. 0300X-CA-M0001 Rev 0 Project: 300 Area Utilities Job No. Checked: J.Winters Date: 6-11-07

Subject:_Retention Process Sewer Reroute_Sheet A 2 of A8

\begin{tabular}{lll} 
4-12 CHAPTER 4- DCumpres of ROW Prostems & CRANE \\
\hline & Discharge of Fluids from Piping Systems
\end{tabular}

Discharge of Fluids from Piping Systems

Example 4-19...Water

Given: Water at $60 \mathrm{~F}$ is flowing from a reservoit through the piping system below. The reservoir has

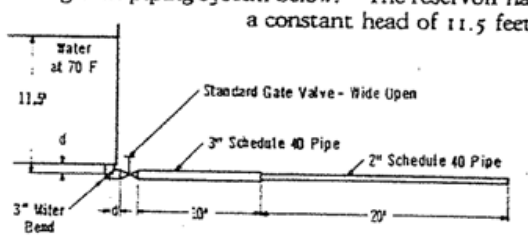

Find: The flow rate in gallons per minute.

Solution: 1. $Q=19.65 d^{2} \sqrt{\frac{h_{t}}{K}} \quad$..page 3-4

$R_{e}=\frac{50.6 Q_{\rho}}{d \mu} \quad \ldots \ldots \ldots \ldots \ldots \ldots$ page $3-2$

$\beta=d_{1} / d_{2} \quad \ldots \ldots \ldots \ldots \ldots \ldots \ldots$ page A.26

2. $K=0.5 \quad \ldots \ldots \ldots \ldots$ entrance; page A.29

$K=60 f_{T} \quad \ldots \ldots \ldots \ldots$ mitre bend; page A.29

$K_{1}=8 f_{T} \quad \ldots \ldots \ldots \ldots$ gate valve; page $A-27$

$K=f \frac{L}{D} \quad \ldots \ldots \ldots \ldots$ straight pipe; page $3-4$

$K_{2}=\frac{0.5\left(1-\beta^{2}\right) \sqrt{\sin \frac{\theta}{2}}}{\beta^{4}}$

.... sudden contraction; page A-26

$K=\frac{f L}{D \beta^{4}} \quad \ldots \ldots \ldots \ldots\left\{\begin{array}{l}\text { small pipe, in terms of } \\ \text { larger pipe; page } 2-5\end{array}\right.$

$K=\frac{1}{\beta^{4}} \quad \ldots \ldots \ldots \ldots \ldots\left\{\begin{array}{l}\text { exit from small pipe } \\ \text { in terms of larger pipe }\end{array}\right.$

3. $d=2.067 \quad \ldots \ldots \ldots 2^{*}$ Sched. 40 pipe; page B-16

$d=3.068 \quad \ldots \ldots .3^{*}$ Sched. 40 pipe; page B-16

$\mu=1, \mathrm{t} \quad \ldots \ldots \ldots \ldots \ldots \ldots \ldots \ldots$ page A-3

$\rho=62.371 \quad \ldots \ldots \ldots \ldots \ldots \ldots$ page A-6

$f_{T}=0.019 \quad \ldots \ldots \ldots \ldots \ldots 2^{\prime}$ pipe; page A-26

$f_{T}=0.018 \quad \ldots \ldots \ldots \ldots \ldots 3^{*}$ pipe; page $\mathrm{A}=26$

4. $\beta=2.067 \div 3.068=0.67$

$K=0.5 \quad \ldots \ldots \ldots \ldots \ldots \ldots \ldots \ldots 3^{*}$ entrance

$K=60 \times 0.018=1.08 \quad \ldots \ldots .3^{*}$ mitre bend

$K_{:}=8 \times \operatorname{cots}==14 \quad \ldots \ldots \ldots 3^{*}$, thate valve
$K=\frac{0.018 \times 10 \times 12}{3.068}=0.70 \quad \ldots 10$ feer, $3^{\circ}$ pipe

For 20 feet of 2 -inch pipe, in terms of 3 -inch pipe,

$K=\frac{0.019 \times 20 \times 12}{2.067 \times 0.67}-10.9$

For 2 -inch exit, in terms of 3 -inch pipe,

$K=\mathrm{t} \div 0.67^{4}=5.0$

For sudden contraction,

$K_{2}=\frac{0.5\left(1-0.67^{2}\right)(1)}{0.67^{4}}=1.37$

and, $K_{\text {TOTAL }}=0.5+1.0 \% \mp 0.14 \div 0.70+$

$$
10.9+5.0+1.37=19.7
$$

5. $Q=19.65 \times 3.068^{2} \sqrt{11.5 \div 19.7}=1.41$

(this solution assumes flow in fully turbulent zone)

6. Calculate Reynolds numbers and check friction factors for flow in straight pipe of the 2-inch size:

$R_{6}=\frac{50.6 \times 141 \times 62.371}{2.067 \times 1.1}=1.96 \times 10^{5}$

$f=0.021 \quad \ldots \ldots \ldots \ldots \ldots \ldots \ldots \ldots$ page A -25

and for flow in straight pipe of the 3 -inch size: $R_{c}=\frac{50.6 \times 141 \times 62.371}{3.068 \times 1.1}=1.32 \times 10^{5}$

$f=0.020 \quad \ldots \ldots \ldots \ldots \ldots \ldots \ldots$ page $\mathrm{A} .25$

7. Since assumed friction factors used for straight pipe in Step 4 are not in agreement with those based on the approximate flow rate, the $K$ factors for these items and the total system should be corrected accordingly.

$K=\frac{0.020 \times 10 \times 12}{3.068}=0.78 \quad \ldots 10$ feet, $3^{*}$ pipe

For 20 feet of 2 -inch pipe, in terms of 3 -inch pipe,

$$
\begin{aligned}
& K=\frac{0.021 \times 20 \times 12}{2.067 \times 0.67^{4}}=12.1 \\
& \text { and, } K_{\text {TOTAL }}=0.5+1.08+0.14+0.78+ \\
& 12 . t+5.0+1.37=21.0 \\
& ?-10.65 \times 3.203^{2}, \longdiv { 1 1 . 5 - 2 1 } = 1 3 7
\end{aligned}
$$




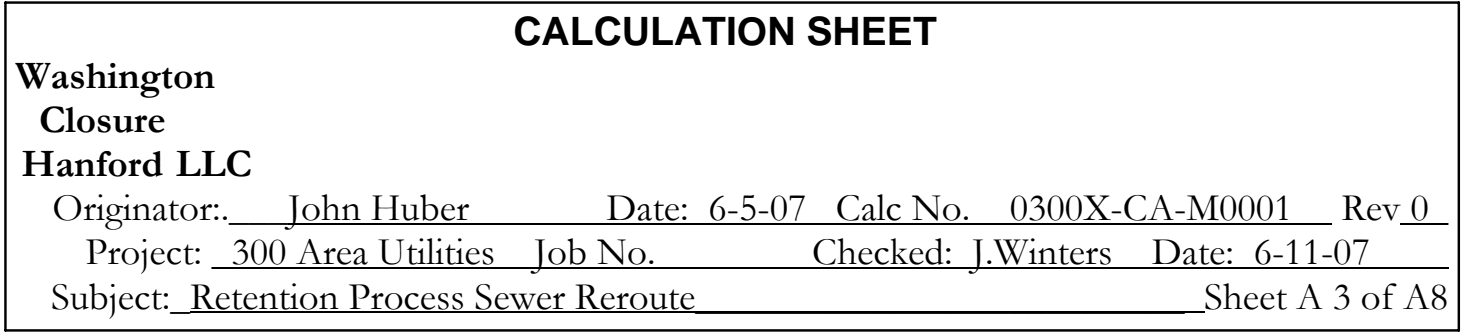

\begin{tabular}{|c|c|c|c|c|c|c|c|c|c|c|c|c|c|}
\hline \multirow[t]{5}{*}{ A -26} & \multicolumn{12}{|c|}{ 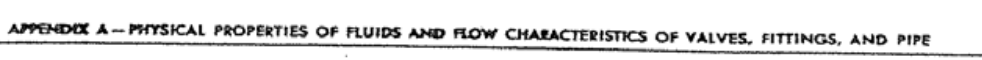 } & CRANE \\
\hline & \multirow{2}{*}{\multicolumn{12}{|c|}{$\begin{array}{l}\text { "K" FACTOR TABLE_SHETI } 1 \text { of } 4 \\
\text { Representative Resistance Coefficients }(K) \text { for Valves and Fittings }\end{array}$}} & \\
\hline & & & & & & & & & & & & & \\
\hline & \multicolumn{12}{|c|}{ 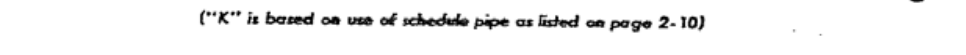 } & \\
\hline & \multicolumn{12}{|c|}{$\begin{array}{l}\text { PIPE FRICTION DATA FOR CLEAN COMMERCIAL STEEL PIPE } \\
\text { WITH FLOW IN ZONE OF COMPLETE TURBULENCE }\end{array}$} & $\because$ \\
\hline Norminal Size & $1 / 2^{-2}$ & $3 / 4^{*}$ & $I^{\prime \prime}$ & $11 / 4^{n}$ & $1 \frac{1}{2}$ & $2^{\prime \prime}$ & $2 \frac{1 / 2,3^{*}}{}$ & $4^{-}$ & $5^{*}$ & $\sigma^{\prime \prime}$ & $8-10^{\prime \prime}$ & $12-16^{\prime \prime}$ & 18-24 \\
\hline $\begin{array}{l}\text { Friction } \\
\text { Foctor }\left(f_{\mathrm{Y}}\right)\end{array}$ & .027 & .025 & .023 & .022 & .021 & .019 & .018 & .017 & .016 & .015 & .014 & .013 & .012 \\
\hline
\end{tabular}

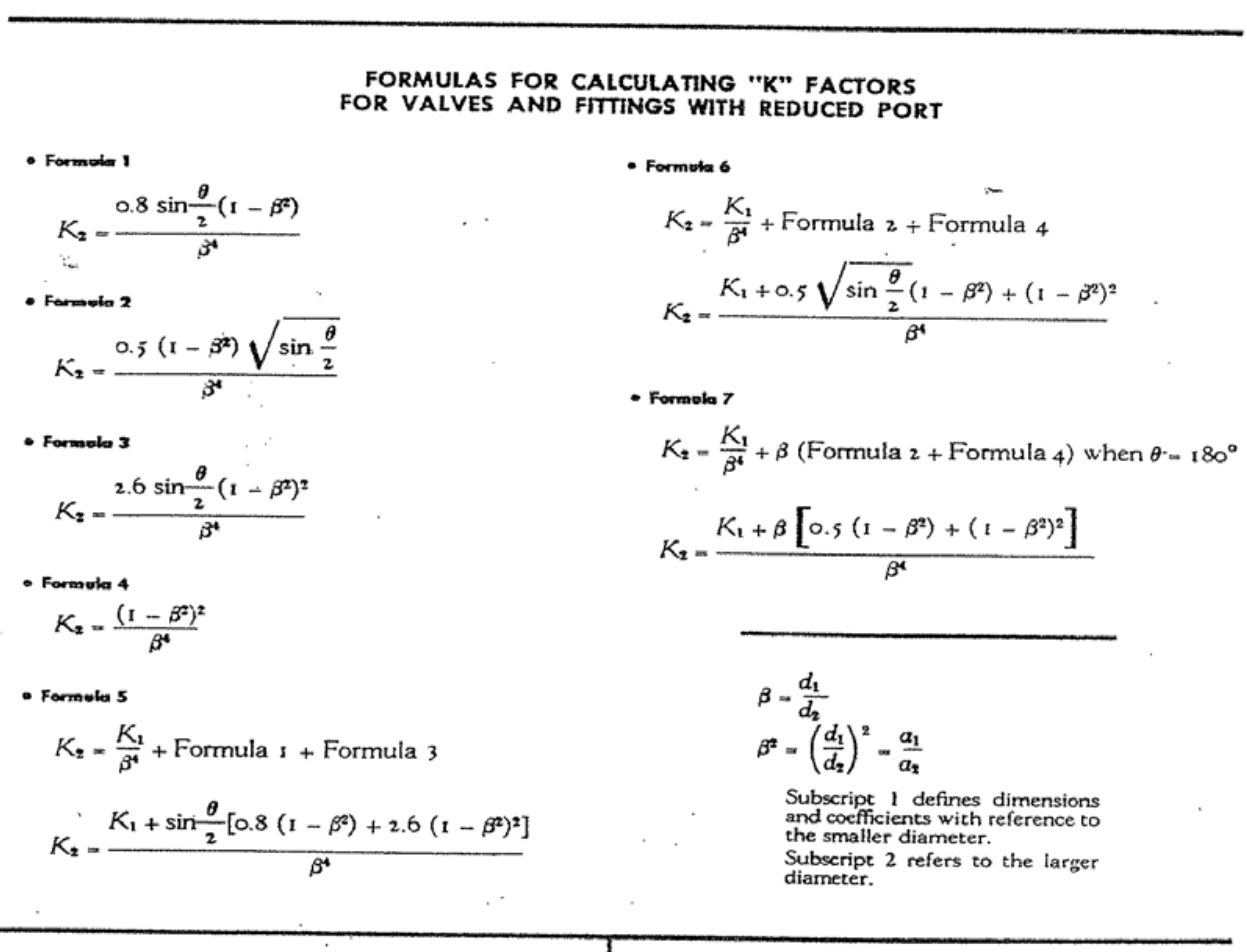

SUDDEN AND GRADUAL CONTRACTION

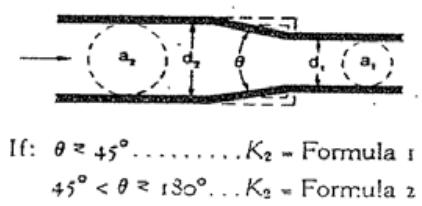

SUDDEN AND GRADUAL ENLARGEMENT

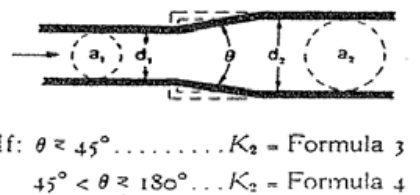




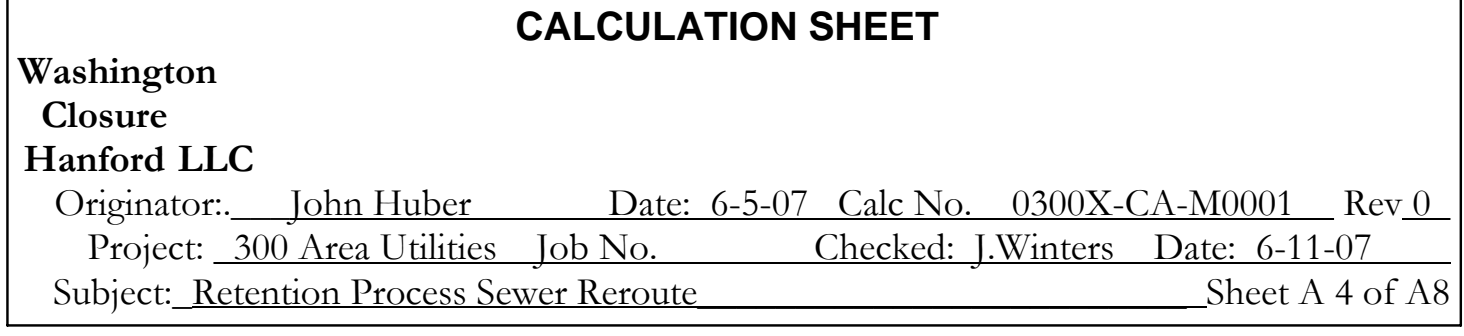

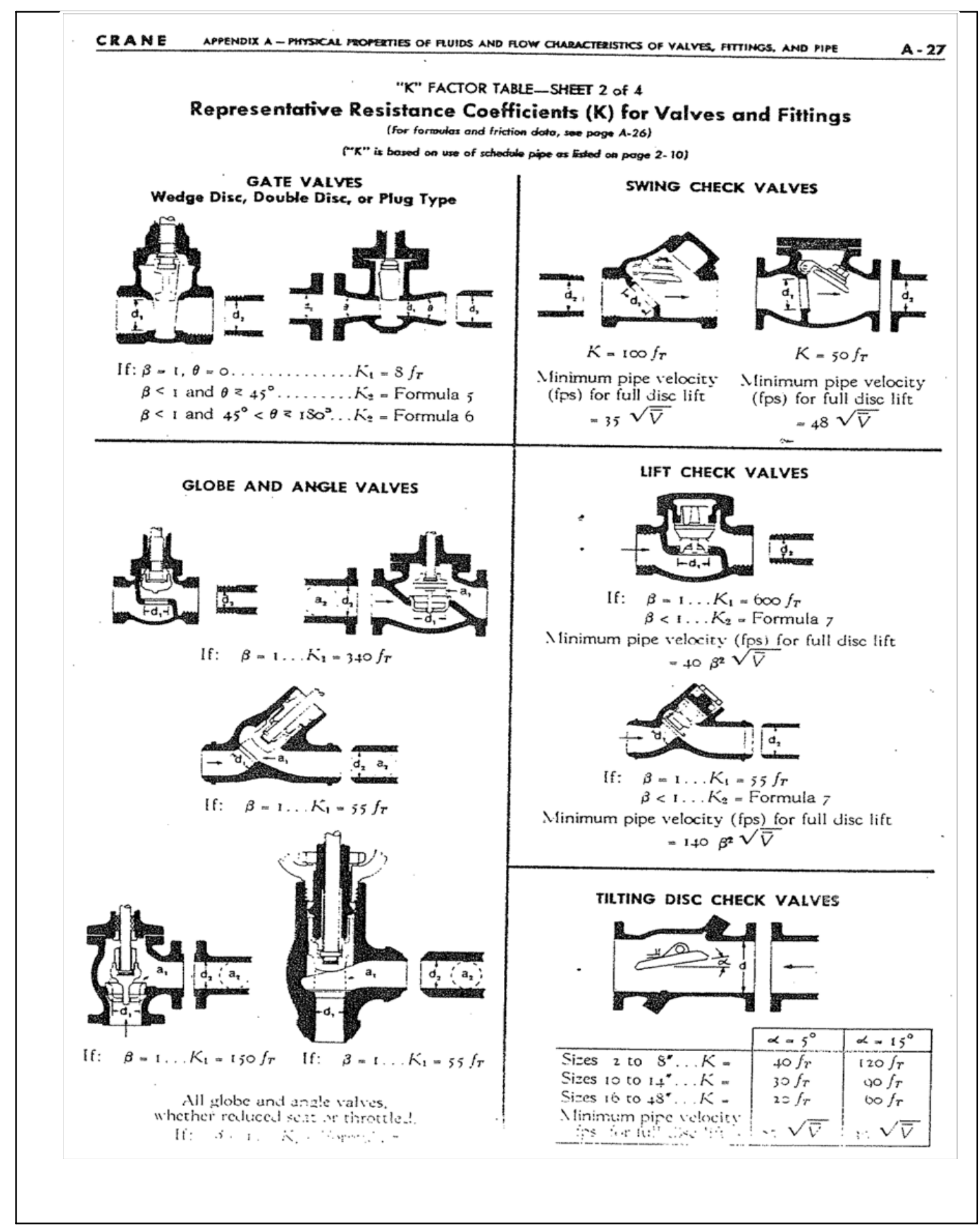

300 Area Building Retention Evaluation Mitigation Plan 


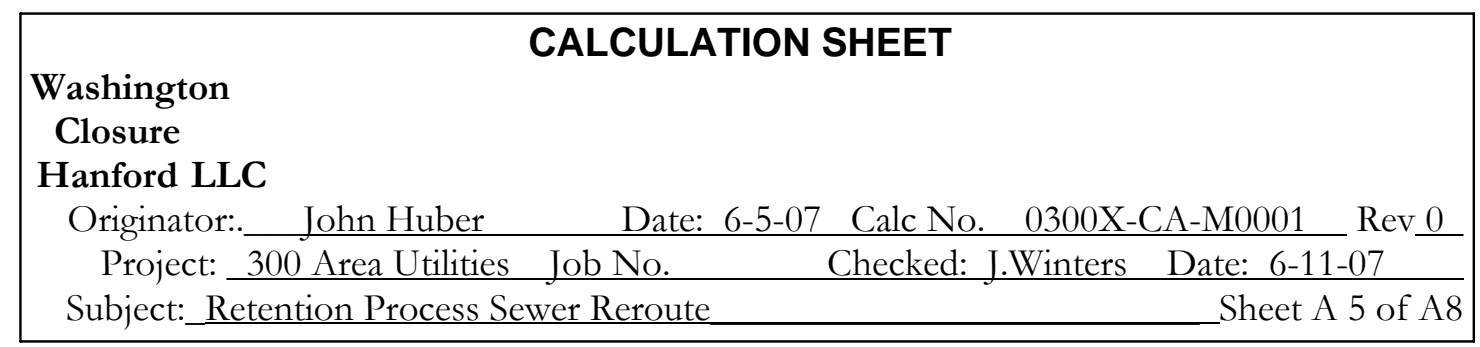

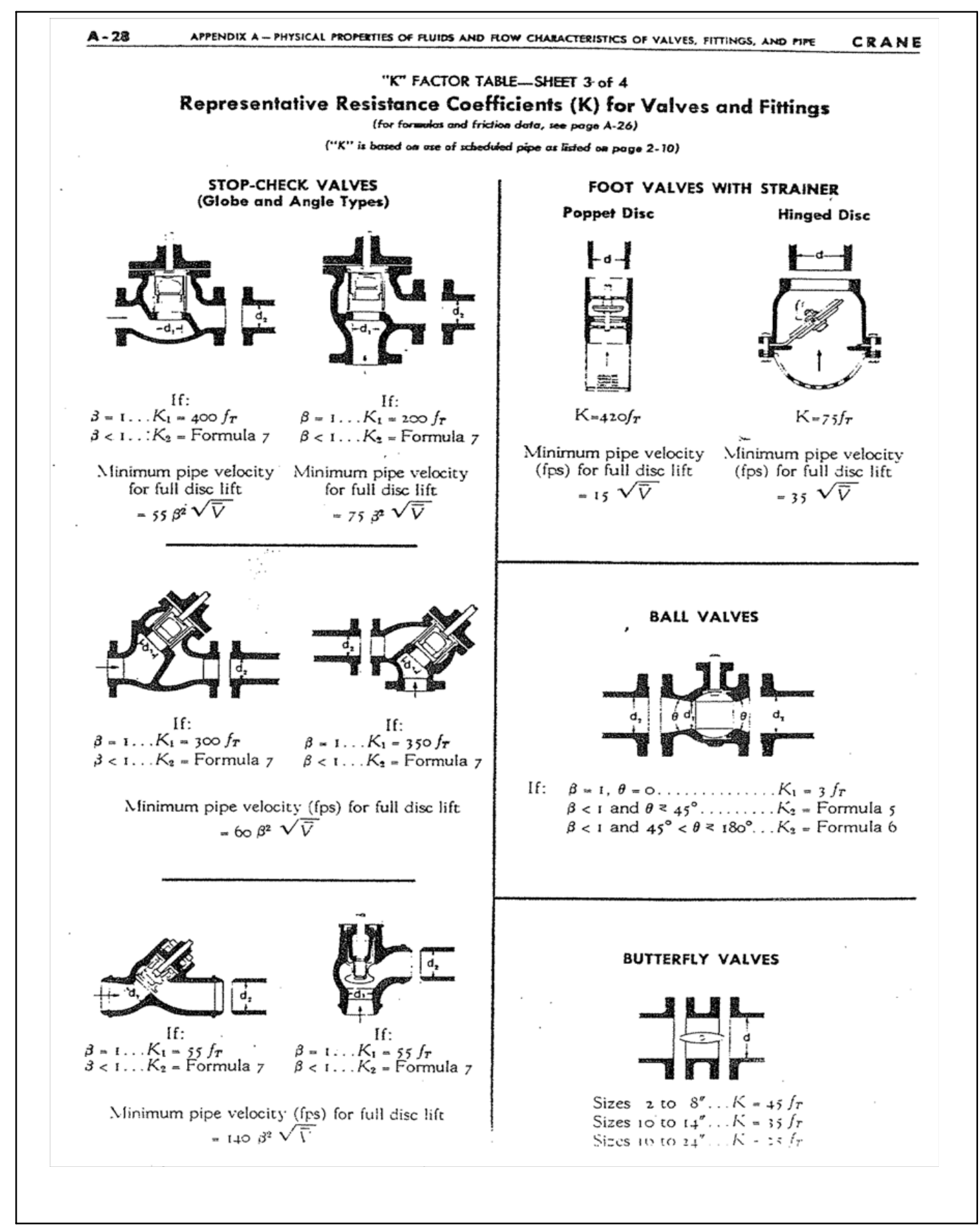




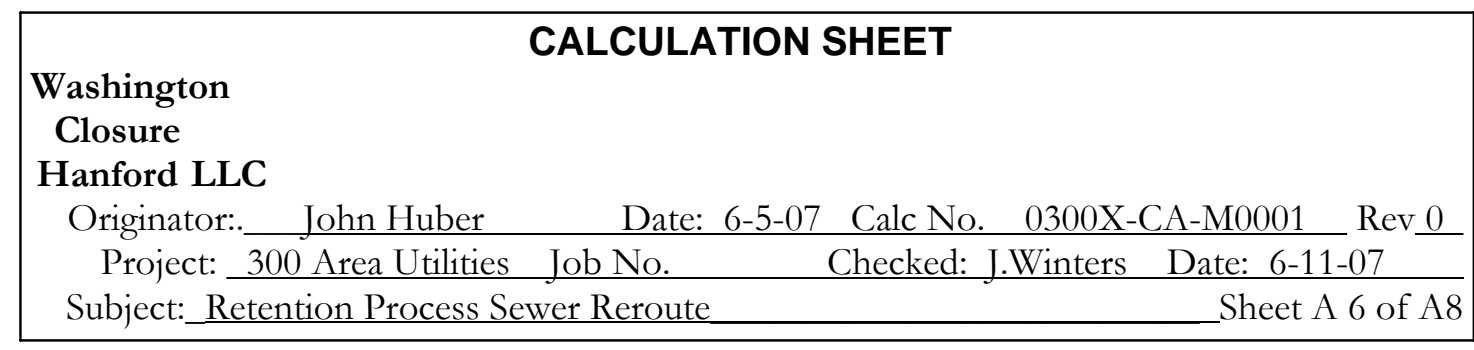

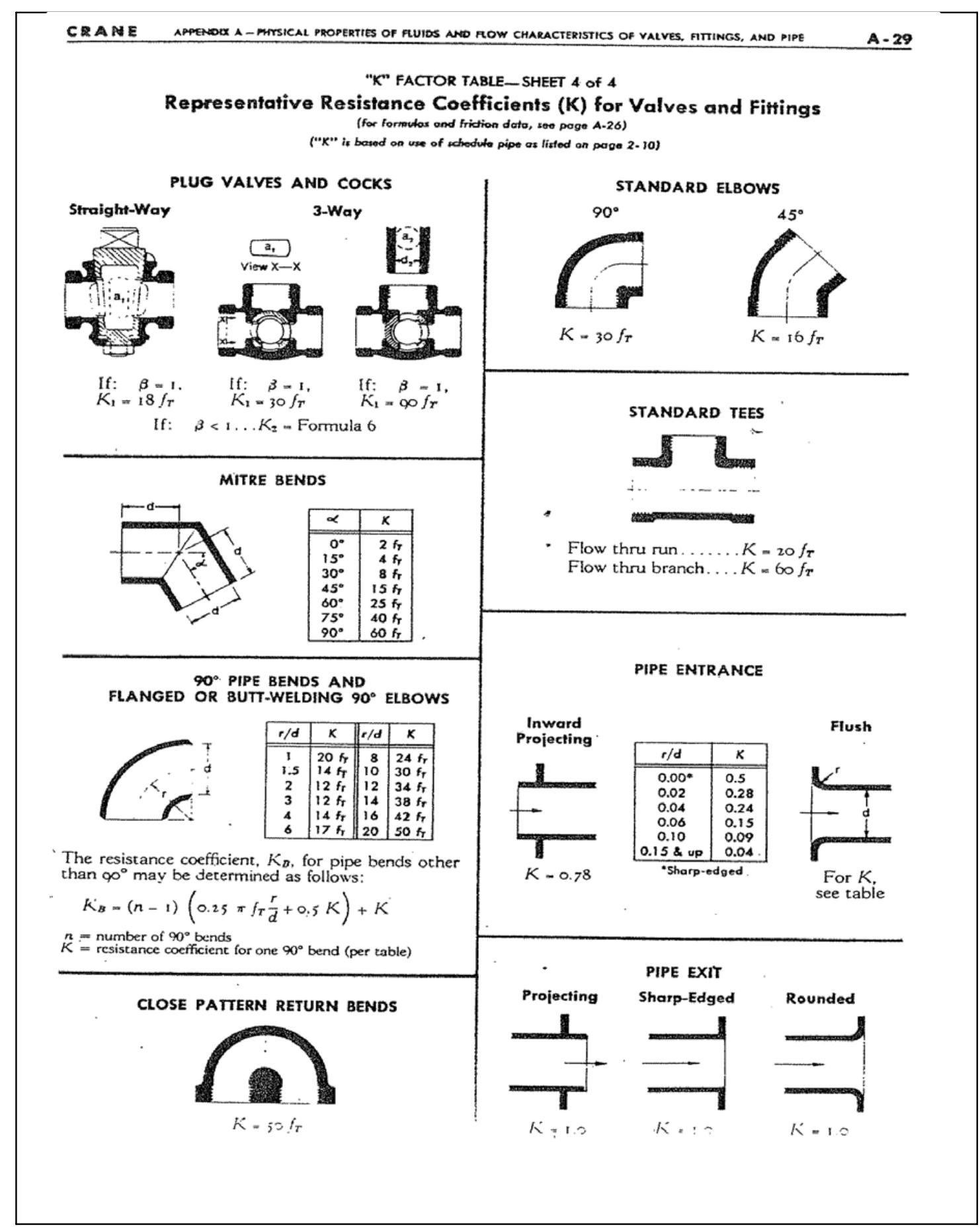




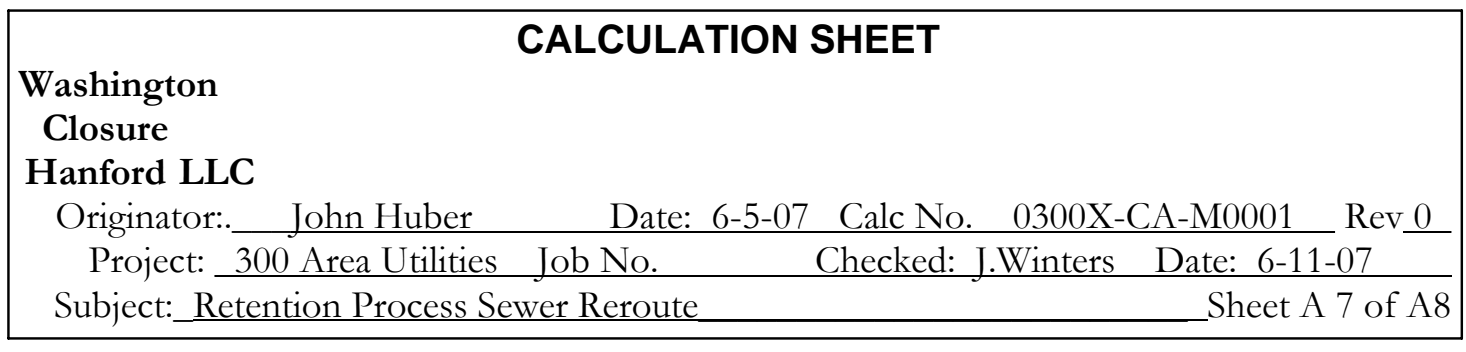

Power Required for Pumping

\begin{tabular}{|c|c|c|c|c|c|c|c|c|c|c|c|c|c|c|c|}
\hline \multirow[t]{2}{*}{$\begin{array}{c}\text { Gale. } \\
\text { per } \\
\text { Min. }\end{array}$} & \multicolumn{15}{|c|}{$\begin{array}{l}\text { Theoretical Horsepower Required to Raiee Water (at } 60 \text { F) } \\
\text { To Different Heights }\end{array}$} \\
\hline & $\begin{array}{c}5 \\
\text { feet }\end{array}$ & $\begin{array}{l}10 \\
\text { feet }\end{array}$ & $\begin{array}{l}15 \\
\text { feet }\end{array}$ & $\begin{array}{l}20 \\
\text { feet }\end{array}$ & $\begin{array}{l}25 \\
\text { foet }\end{array}$ & $\begin{array}{l}30 \\
\text { foet }\end{array}$ & $\begin{array}{l}35 \\
\text { feet }\end{array}$ & $\begin{array}{l}40 \\
\text { feet }\end{array}$ & $\begin{array}{l}45 \\
\text { feet }\end{array}$ & $\begin{array}{c}50 \\
\text { feet }\end{array}$ & $\begin{array}{l}60 \\
\text { feet }\end{array}$ & $\begin{array}{l}70 \\
\text { feet }\end{array}$ & $\begin{array}{l}80 \\
\text { feet }\end{array}$ & $\begin{array}{c}90 \\
\text { feet }\end{array}$ & $\begin{array}{l}100 \\
\text { foet }\end{array}$ \\
\hline $\begin{array}{c}5 \\
10 \\
15 \\
20\end{array}$ & $\begin{array}{l}0.006 \\
0.013 \\
0.019 \\
0.025\end{array}$ & \begin{tabular}{|l|}
0.013 \\
0.025 \\
0.038 \\
0.051
\end{tabular} & $\left|\begin{array}{l|}0.019 \\
0.038 \\
0.057 \\
0.076\end{array}\right|$ & $\left|\begin{array}{l}0.025 \\
0.051 \\
0.076 \\
0.101\end{array}\right|$ & $\left|\begin{array}{l}0.032 \\
0.063 \\
0.095 \\
0.126\end{array}\right|$ & $\left|\begin{array}{l}0.038 \\
0.076 \\
0.114 \\
0.152\end{array}\right|$ & \begin{tabular}{|l|}
0.044 \\
0.088 \\
0.133 \\
0.177
\end{tabular} & \begin{tabular}{|l|}
0.051 \\
0.101 \\
0.152 \\
0.202 \\
\end{tabular} & $\left|\begin{array}{l|}0.057 \\
0.114 \\
0.171 \\
0.227\end{array}\right|$ & \begin{tabular}{l|}
0.063 \\
0.126 \\
0.190 \\
0.253
\end{tabular} & \begin{tabular}{l|}
0.076 \\
0.152 \\
0.227 \\
0.303
\end{tabular} & \begin{tabular}{|l|}
0.088 \\
0.177 \\
0.265 \\
0.354
\end{tabular} & \begin{tabular}{|l|}
0.101 \\
0.202 \\
0.303 \\
0.404 \\
\end{tabular} & \begin{tabular}{|l|}
0.111 \\
0.227 \\
0.341 \\
0.455
\end{tabular} & $\begin{array}{l}0.126 \\
0.253 \\
0.379 \\
0.505\end{array}$ \\
\hline $\begin{array}{l}25 \\
30 \\
35 \\
40\end{array}$ & $\begin{array}{l}0.032 \\
0.038 \\
0.044 \\
0.051\end{array}$ & $\begin{array}{l}0.053 \\
0.076 \\
0.088 \\
0.101\end{array}$ & $\begin{array}{l}0.095 \\
0.114 \\
0.133 \\
0.152\end{array}$ & $\begin{array}{l}0.126 \\
0.152 \\
0.177 \\
0.202\end{array} \mid$ & $\begin{array}{l}0.158 \\
0.190 \\
0.221 \\
0.253\end{array}$ & $\left|\begin{array}{l|}0.190 \\
0.227 \\
0.265 \\
0.303\end{array}\right|$ & $\begin{array}{l}0.221 \\
0.265 \\
0.310 \\
0.354\end{array}$ & $\left|\begin{array}{l|}0.253 \\
0.303 \\
0.354 \\
0.404\end{array}\right|$ & $\mid$\begin{tabular}{l|}
0.284 \\
0.341 \\
0.398 \\
0.455
\end{tabular} & $\begin{array}{l}0.316 \\
0.379 \\
0.442 \\
0.505\end{array}$ & $\begin{array}{l}0.379 \\
0.455 \\
0.531 \\
0.606\end{array}$ & \begin{tabular}{l|}
0.442 \\
0.531 \\
0.619 \\
0.707
\end{tabular} & $\begin{array}{l}0.505 \\
0.606 \\
0.707 \\
0.808\end{array}$ & \begin{tabular}{l|}
0.568 \\
0.882 \\
0.796 \\
0.910
\end{tabular} & $\begin{array}{l}0.632 \\
0.758 \\
0.884 \\
1.011\end{array}$ \\
\hline $\begin{array}{l}45 \\
50 \\
60 \\
70\end{array}$ & $\begin{array}{l}0.057 \\
0.063 \\
0.076 \\
0.088\end{array}$ & $\mid \begin{array}{l}0.114 \\
0.126 \\
0.152 \\
0.177\end{array}$ & $\left|\begin{array}{l|}0.171 \\
0.190 \\
0.227 \\
0.265\end{array}\right|$ & \begin{tabular}{|l|}
0.227 \\
0.253 \\
0.303 \\
0.354
\end{tabular} & $\left|\begin{array}{l|}0.284 \\
0.316 \\
0.379 \\
0.442\end{array}\right|$ & \begin{tabular}{|l|}
0.341 \\
0.379 \\
0.455 \\
0.531 \\
\end{tabular} & \begin{tabular}{|l|}
0.398 \\
0.442 \\
0.531 \\
0.619 \\
\end{tabular} & $\begin{array}{l}0.455 \\
0.505 \\
0.606 \\
0.707\end{array}$ & \begin{tabular}{l|}
0.512 \\
0.568 \\
0.682 \\
0.796
\end{tabular} & $\begin{array}{l}0.568 \\
0.632 \\
0.758 \\
0.884\end{array}$ & $\begin{array}{l}0.682 \\
0.758 \\
0.910 \\
1.061\end{array}$ & $\begin{array}{l}0.796 \\
0.884 \\
1.061 \\
1.238\end{array}$ & $\begin{array}{l}0.910 \\
1.011 \\
1.213 \\
1.415\end{array}$ & $\begin{array}{l}1.023 \\
1.137 \\
1.364 \\
1.592\end{array}$ & $\begin{array}{l}1.137 \\
1.263 \\
1.516 \\
1.768\end{array}$ \\
\hline $\begin{array}{r}80 \\
90 \\
100 \\
125\end{array}$ & $\begin{array}{l}0.101 \\
0.114 \\
0.126 \\
0.158\end{array}$ & \begin{tabular}{|l|}
0.202 \\
0.227 \\
0.253 \\
0.316
\end{tabular} & \begin{tabular}{|l|}
0.303 \\
0.341 \\
0.379 \\
0.474 \\
\end{tabular} & \begin{tabular}{l|l|}
0.404 \\
0.455 \\
0.505 \\
0.632
\end{tabular} \mid & $\begin{array}{l}0.505 \\
0.568 \\
0.632 \\
0.790\end{array}$ & \begin{tabular}{|l|}
0.606 \\
0.682 \\
0.758 \\
0.947
\end{tabular} & \begin{tabular}{|l|}
0.707 \\
0.796 \\
0.884 \\
1.105
\end{tabular} & \begin{tabular}{|l|}
0.808 \\
0.910 \\
1.011 \\
1.263
\end{tabular} & $\begin{array}{l}0.910 \\
1.023 \\
1.137 \\
1.421\end{array}$ & $\begin{array}{l}1.011 \\
1.137 \\
1.263 \\
1.579\end{array}$ & $\begin{array}{l}1.213 \\
1.364 \\
1.516 \\
1.895\end{array}$ & $\begin{array}{l}1.415 \\
1.592 \\
1.768 \\
2.211\end{array}$ & $\begin{array}{l}1.617 \\
1.819 \\
2.021 \\
2.526\end{array}$ & \begin{tabular}{l|}
1.819 \\
2.206 \\
2.274 \\
2.842
\end{tabular} & $\begin{array}{l}2.021 \\
2.274 \\
2.526 \\
3.158\end{array}$ \\
\hline $\begin{array}{l}150 \\
175 \\
200 \\
250\end{array}$ & $\begin{array}{l}0.190 \\
0.221 \\
0.253 \\
0.316\end{array}$ & $\begin{array}{l}0.379 \\
0.442 \\
0.505 \\
0.632\end{array}$ & \begin{tabular}{|l|}
0.568 \\
0.663 \\
0.758 \\
0.947
\end{tabular} & \begin{tabular}{|l|}
0.758 \\
0.884 \\
1.011 \\
1.263 \\
\end{tabular} & $\begin{array}{l}0.947 \\
1.105 \\
1.263 \\
1.579\end{array}$ & \begin{tabular}{|l|}
1.137 \\
1.326 \\
1.516 \\
1.895 \\
\end{tabular} & \begin{tabular}{l|}
1.326 \\
1.547 \\
1.768 \\
2.211 \\
\end{tabular} & $\begin{array}{l}1.516 \\
1.768 \\
2.021 \\
2.526\end{array}$ & $\begin{array}{l}1.705 \\
1: 990 \\
2,274 \\
2: 842\end{array}$ & $\begin{array}{l}1.895 \\
2.211 \\
2.526 \\
3.158\end{array}$ & $\begin{array}{l}2.274 \\
2.653 \\
3.032 \\
3.790\end{array}$ & $\begin{array}{l}2.653 \\
3.095 \\
3.537 \\
4.421\end{array}$ & $\begin{array}{l}3.032 \\
3.537 \\
4.042 \\
5.053\end{array}$ & \begin{tabular}{|l|}
3.411 \\
3.979 \\
4.548 \\
5.684 \\
\end{tabular} & $\begin{array}{l}3.790 \\
4.421 \\
5.053 \\
6.316\end{array}$ \\
\hline $\begin{array}{l}300 \\
350 \\
400 \\
500 \\
\end{array}$ & $\left|\begin{array}{l}0.379 \\
0.442 \\
0.505 \\
0.632\end{array}\right|$ & $\mid \begin{array}{l}0.758 \\
0.884 \\
1.011 \\
1.263\end{array}$ & $\begin{array}{l}1.137 \\
1.326 \\
1.516 \\
1.895 \\
\end{array}$ & \begin{tabular}{|l|}
1.516 \\
1.768 \\
2.021 \\
2.526 \\
\end{tabular} & $\begin{array}{l}1.895 \\
2.211 \\
2.526 \\
3.158 \\
\end{array}$ & $\begin{array}{l}2.274 \\
2.653 \\
3.032 \\
3.790 \\
\end{array}$ & $\begin{array}{l}2.653 \\
3.095 \\
3.537 \\
4.421\end{array}$ & $\left|\begin{array}{l}3.032 \\
3.537 \\
4.042 \\
5.053\end{array}\right|$ & \begin{tabular}{|l|}
3.411 \\
3.979 \\
4.548 \\
5.684
\end{tabular} & $\begin{array}{l}3.790 \\
4.421 \\
5.053 \\
6.316\end{array}$ & $\begin{array}{l}4.548 \\
5.305 \\
6.063 \\
7.579\end{array}$ & $\begin{array}{l}5.305 \\
6.190 \\
7.074 \\
8.842\end{array}$ & $\mid$\begin{tabular}{c|}
6.063 \\
7.074 \\
8.084 \\
10.11
\end{tabular} & $\mid \begin{array}{c}6.821 \\
7.958 \\
9.095 \\
11.37\end{array}$ & \begin{tabular}{|l|}
7.579 \\
8.842 \\
10.11 \\
12.63 \\
\end{tabular} \\
\hline $\begin{array}{c}\text { Gals. } \\
\text { per. } \\
\text { Min. }\end{array}$ & $\begin{array}{l}125 \\
\text { feet }\end{array}$ & $\begin{array}{l}150 \\
\text { feet }\end{array}$ & $\begin{array}{l}175 \\
\text { feet }\end{array}$ & $\begin{array}{l}200 \\
\text { feet }\end{array}$ & $\begin{array}{l}250 \\
\text { feet }\end{array}$ & $\begin{array}{l}300 \\
\text { feet }\end{array}$ & $\begin{array}{l}350 \\
\text { feet }\end{array}$ & $\begin{array}{l}400 \\
\text { feet }\end{array}$ & \multicolumn{7}{|c|}{ HORSEPOWER $=33000 \ldots \mathrm{ft}-1 \mathrm{~b} / \mathrm{min}$} \\
\hline $\begin{array}{r}5 \\
10 \\
15 \\
20\end{array}$ & $\left|\begin{array}{l}0.158 \\
0.316 \\
0.474 \\
0.632\end{array}\right|$ & \begin{tabular}{|l|}
0.190 \\
0.379 \\
0.568 \\
0.758 \\
\end{tabular} & \begin{tabular}{|l|}
0.221 \\
0.442 \\
0.663 \\
0.884 \\
\end{tabular} & \begin{tabular}{|l|}
0.253 \\
0.505 \\
0.758 \\
1.011 \\
\end{tabular} & \begin{tabular}{|l|}
0.316 \\
0.632 \\
0.947 \\
1.263 \\
\end{tabular} & \begin{tabular}{|l|}
0.379 \\
0.758 \\
1.137 \\
1.516
\end{tabular} & \begin{tabular}{|l|}
0.442 \\
0.884 \\
1.326 \\
1.768
\end{tabular} & \begin{tabular}{|l|}
0.505 \\
1.011 \\
1.516 \\
2.021
\end{tabular} & \multirow{2}{*}{\multicolumn{7}{|c|}{$\begin{array}{l}(w h p)=Q H_{\rho} \div 247000=Q P \div 17.14 \\
(\text { bhp })=(w h p) \div e_{p}=Q H_{\rho} \div 247000 e_{p} \\
\left(e_{p}\right)=Q H_{\rho} \div 247000(\text { bhp })\end{array}$}} \\
\hline $\begin{array}{l}25 \\
30 \\
35\end{array}$ & $\begin{array}{l}0.790 \\
0.947 \\
1.105\end{array}$ & $\begin{array}{l}0.947 \\
1.137 \\
1.326\end{array}$ & $\begin{array}{l}1.105 \\
1.326 \\
1.547\end{array}$ & \begin{tabular}{|l|}
1.263 \\
1.516 \\
1.768
\end{tabular} & $\begin{array}{l}1.579 \\
1.895 \\
2.211\end{array}$ & $\mid \begin{array}{l}1.895 \\
2.274 \\
2.653\end{array}$ & $\begin{array}{l}2.211 \\
2.653 \\
3.095\end{array}$ & $\begin{array}{l}2.526 \\
3.032 \\
3.537\end{array}$ & & & & & & & \\
\hline 40 & 1.263 & 1.516 & $|1.768|$ & 2.021 & 2.526 & 3.032 & 3.537 & 4.042 & \multicolumn{7}{|c|}{$\begin{aligned} \text { where: }(w h p) & =\text { water horsepower } \\
H & =\text { purmp head in feet } \\
\text { (bhp) } & =\text { brake horsepower } \\
e_{\boldsymbol{y}} & =\text { pump efficiency }\end{aligned}$} \\
\hline $\begin{array}{l}45 \\
50 \\
60 \\
70\end{array}$ & $\mid \begin{array}{l}1.421 \\
1.579 \\
1.895 \\
2.211\end{array}$ & $\left|\begin{array}{l}1.705 \\
1.895 \\
2.274 \\
2.653\end{array}\right|$ & $\left|\begin{array}{l}1.990 \\
2.211 \\
2.653 \\
3.095\end{array}\right|$ & $\left|\begin{array}{l}2.274 \\
2.526 \\
3.032 \\
3.537\end{array}\right|$ & $\begin{array}{l}2.842 \\
3.158 \\
3.790 \\
4.421\end{array}$ & $\begin{array}{l}3.411 \\
3.790 \\
4.548 \\
5.305\end{array}$ & $\begin{array}{l}3.979 \\
4.421 \\
5.305 \\
6.190\end{array}$ & $\begin{array}{l}4.548 \\
5.053 \\
6.063 \\
7.074\end{array}$ & \multicolumn{7}{|c|}{$\begin{array}{l}\text { Overall efficiency }\left(e_{a}\right) \text { takes into account all } \\
\text { losses in the pump and driver. }\end{array}$} \\
\hline $\begin{array}{r}80 \\
90 \\
100 \\
125\end{array}$ & $\begin{array}{l}2.526 \\
2.842 \\
3.158 \\
3.948\end{array}$ & \begin{tabular}{|l|}
3.032 \\
3.411 \\
3.790 \\
4.737 \\
\end{tabular} & \begin{tabular}{l|}
3.537 \\
3.979 \\
4.421 \\
5.527
\end{tabular} & \begin{tabular}{|l|}
4.042 \\
4.548 \\
5.053 \\
6.316 \\
\end{tabular} & \begin{tabular}{|l|}
5.053 \\
5.684 \\
6.316 \\
7.895 \\
\end{tabular} & $\begin{array}{l}6.063 \\
6.821 \\
7.579 \\
9.474 \\
\end{array}$ & \begin{tabular}{|c|}
7.074 \\
7.958 \\
8.842 \\
11.05
\end{tabular} & $\begin{array}{l}8.084 \\
9.095 \\
10.11 \\
12.63\end{array}$ & \multicolumn{7}{|c|}{$\begin{aligned} e_{0} & =e_{,} e_{D} e_{T} \\
\text { where: } e_{D} & =\text { driver efficiency } \\
\epsilon_{T} & =\text { transmission efficiency } \\
e_{V} & =\text { volumetric efficiency }\end{aligned}$} \\
\hline $\begin{array}{l}150 \\
175 \\
200 \\
250\end{array}$ & $\begin{array}{l}4.737 \\
5.527 \\
6.316 \\
7.895\end{array}$ & $\begin{array}{l}5.684 \\
6.632 \\
7.579 \\
9.474\end{array}$ & $\mid$\begin{tabular}{c|}
6.632 \\
7.737 \\
8.842 \\
11.05
\end{tabular} & \begin{tabular}{c|}
7.579 \\
8.842 \\
10.11 \\
12.63
\end{tabular} & $\begin{array}{c}9.474 \\
11.05 \\
12.63 \\
15.79\end{array}$ & $\begin{array}{l}11.37 \\
13.26 \\
15.16 \\
18.95\end{array}$ & $\begin{array}{l}13.26 \\
15.47 \\
17.68 \\
22.11\end{array}$ & $\begin{array}{l}15.16 \\
17.68 \\
20.21 \\
25.26\end{array}$ & \multirow{3}{*}{\multicolumn{7}{|c|}{$\begin{array}{l}\text { Note: For fluids other than water, multiply } \\
\text { table values by specific gravity. In pumping } \\
\text { liquids with a viscosity considerably higher } \\
\text { than that of water, the pump capacity and } \\
\text { head are reduced. To calculate the horse- } \\
\text { power for such fuids, pipe friction head must } \\
\text { be added to the elevation head to obtain the } \\
\text { total head; this value is inserted in the first } \\
\text { horsepower equation given above. }\end{array}$}} \\
\hline $\begin{array}{l}300 \\
350 \\
400 \\
500\end{array}$ & $\mid \begin{array}{l}9.474 \\
11.05 \\
12.63 \\
15.79\end{array}$ & \begin{tabular}{|l|}
11.37 \\
13.26 \\
15.16 \\
18.95 \\
\end{tabular} & \begin{tabular}{|l|}
13.26 \\
15.47 \\
17.68 \\
22.11
\end{tabular} & \begin{tabular}{|l|l}
15.16 & 1 \\
17.68 & 2 \\
20.21 & 2 \\
25.26 & 3 \\
\end{tabular} & $\begin{array}{l}18.95 \\
22.11 \\
25.26 \\
31.58\end{array}$ & $\mid$\begin{tabular}{l|}
22.74 \\
26.53 \\
30.32 \\
37.90
\end{tabular} & $\begin{array}{l}26.53 \\
30.95 \\
35.37 \\
44.21\end{array}$ & $\begin{array}{l}30.32 \\
35.37 \\
40.42 \\
50.53\end{array}$ & & & & & & & \\
\hline & & & & the & then water. & $\ldots \ldots p$ & & & & & & & & & \\
\hline
\end{tabular}




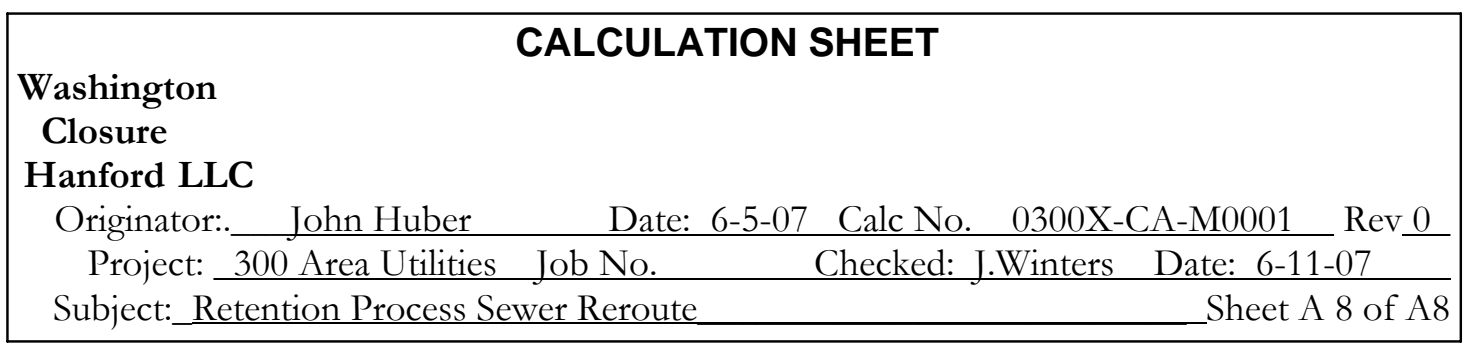

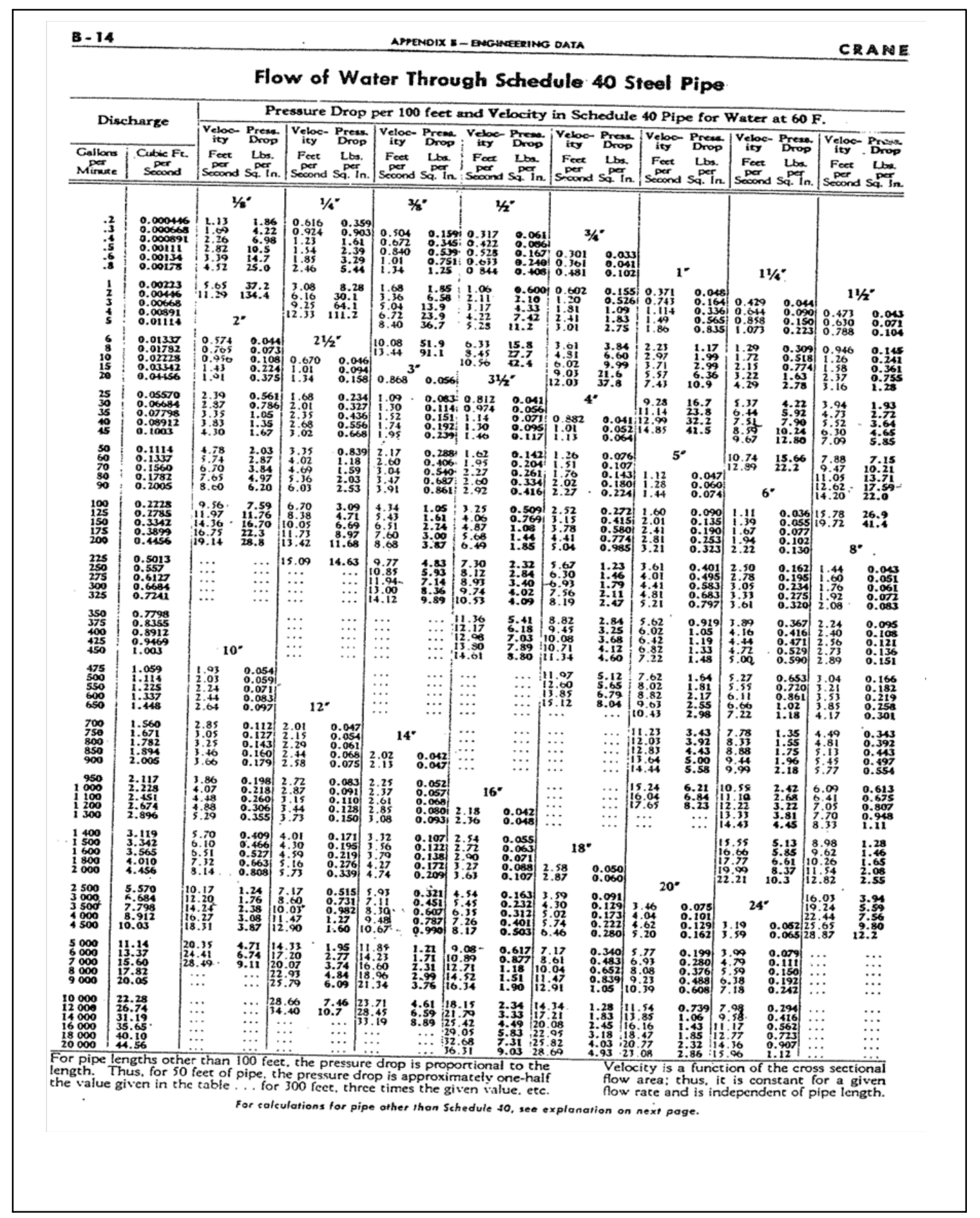





\section{APPENDIX J}

\section{AREA STORM WATER CONCEPTUAL DESIGN}


WCH-181

Rev. 0 


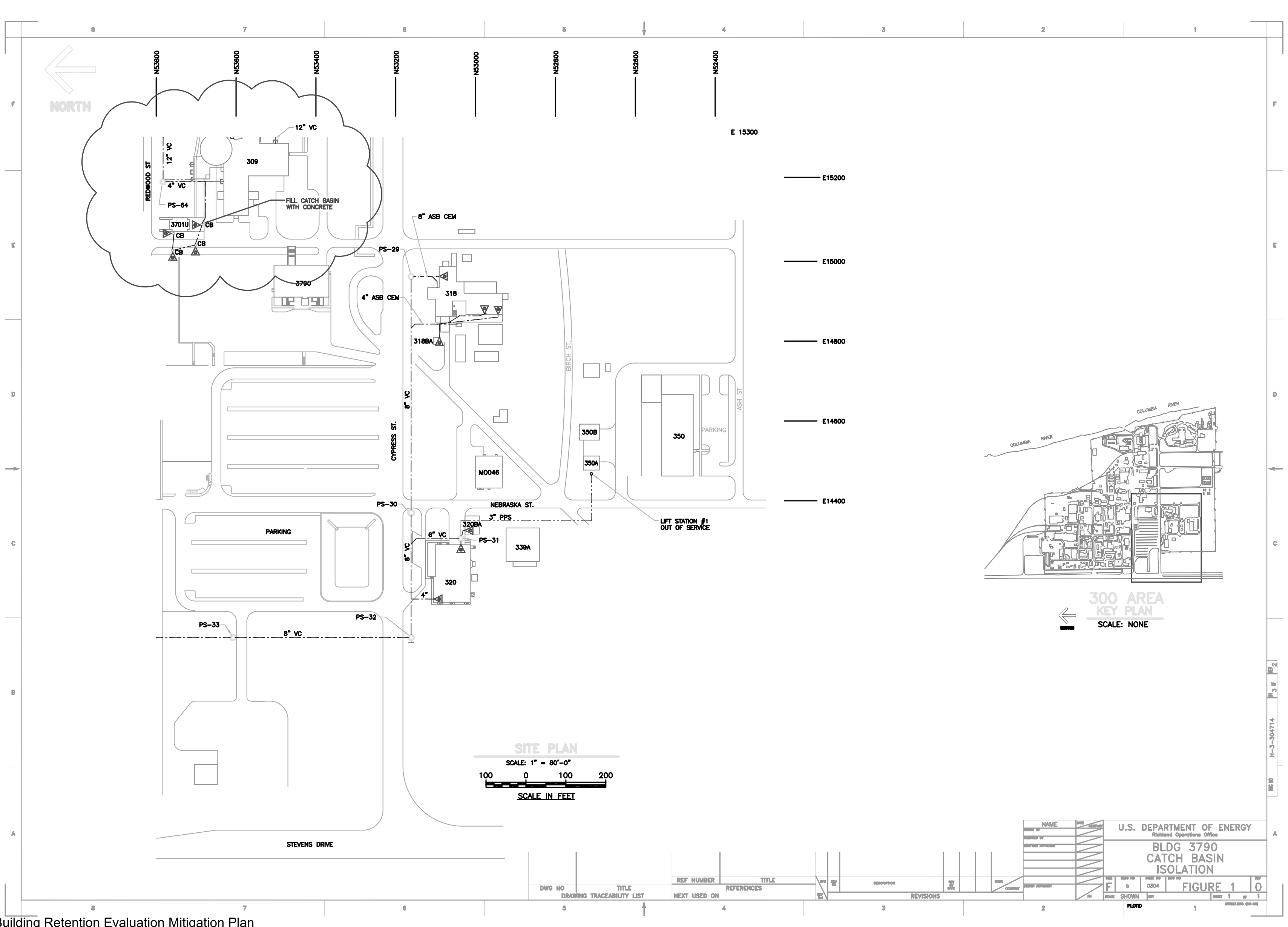




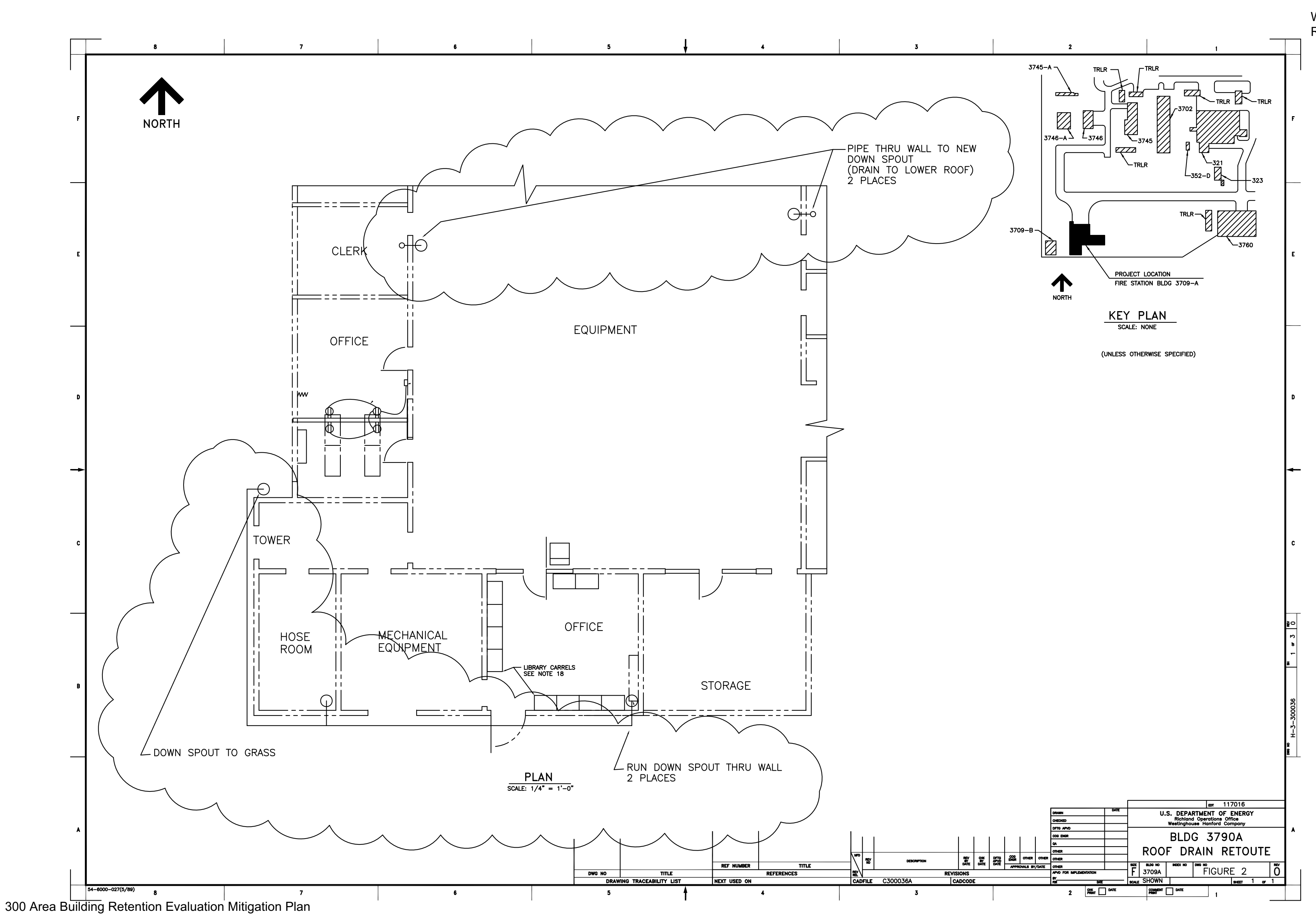




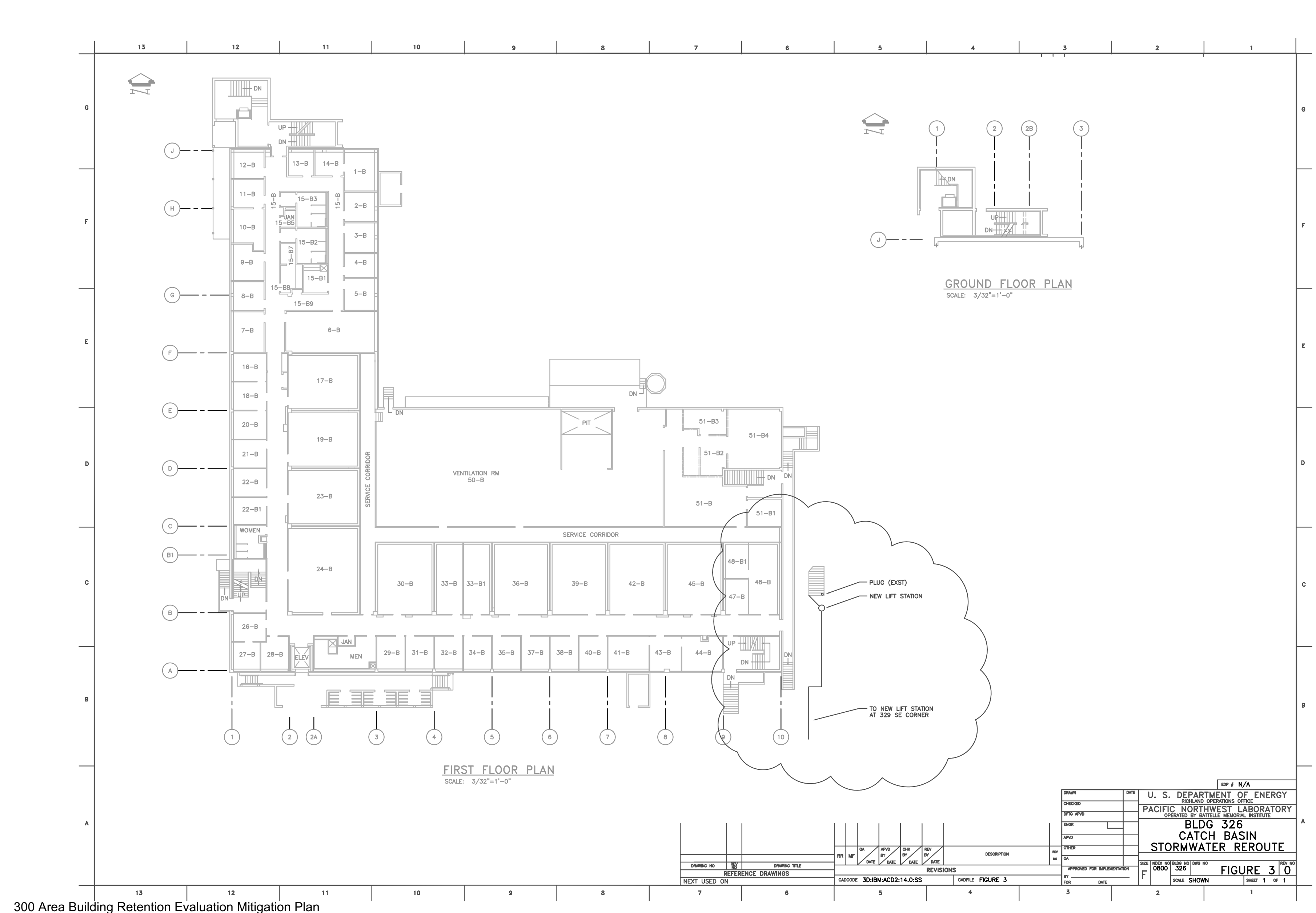




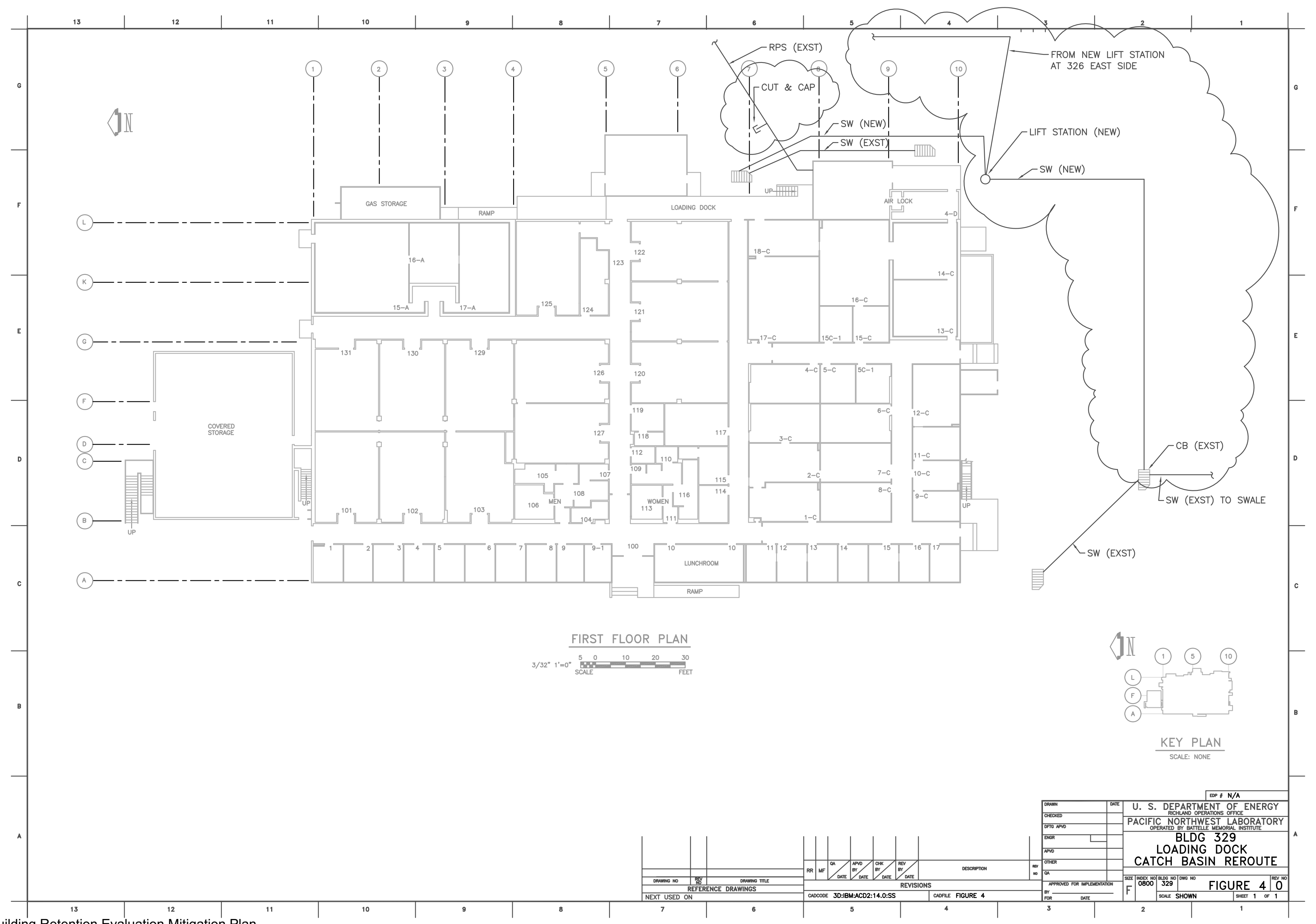




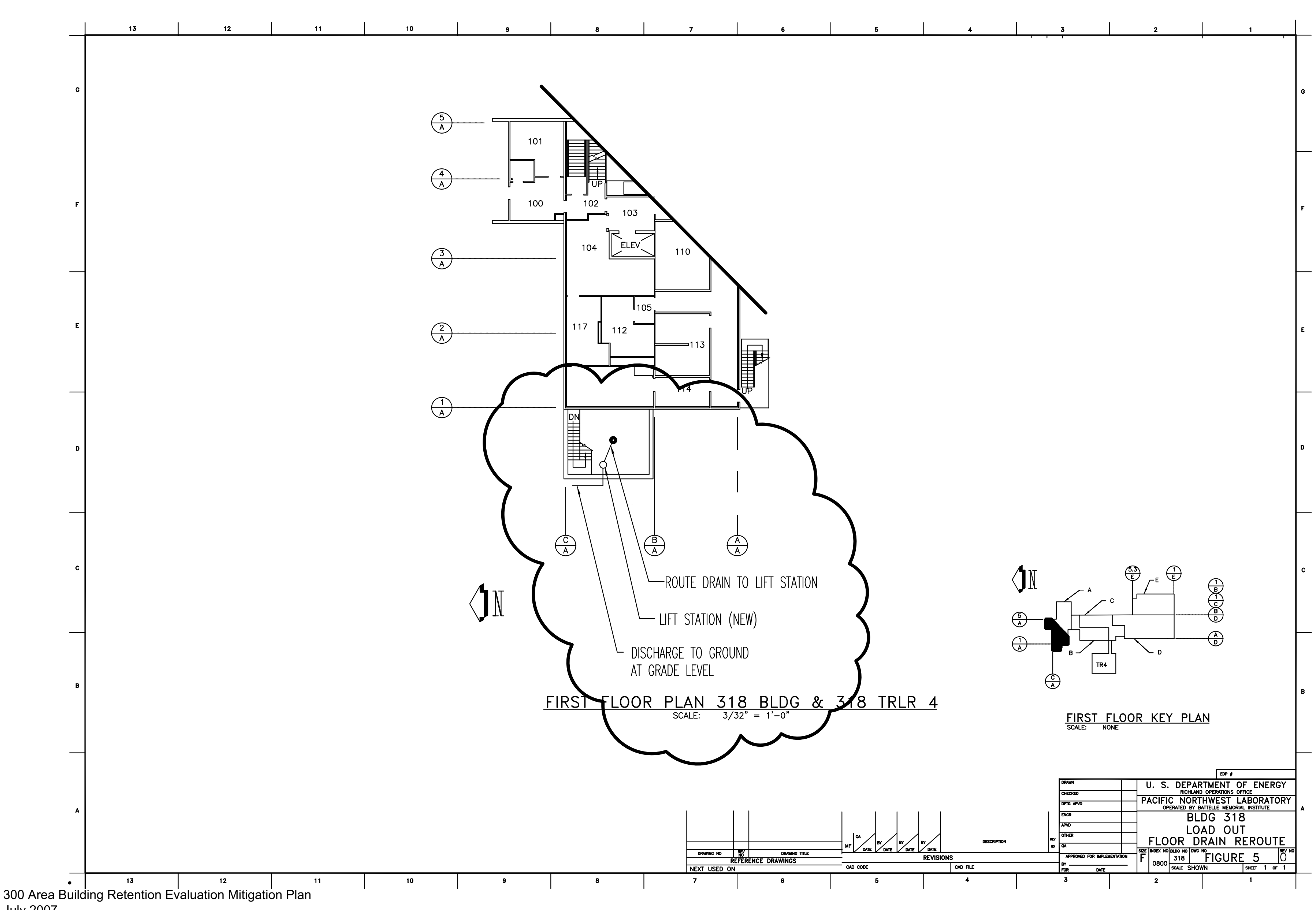




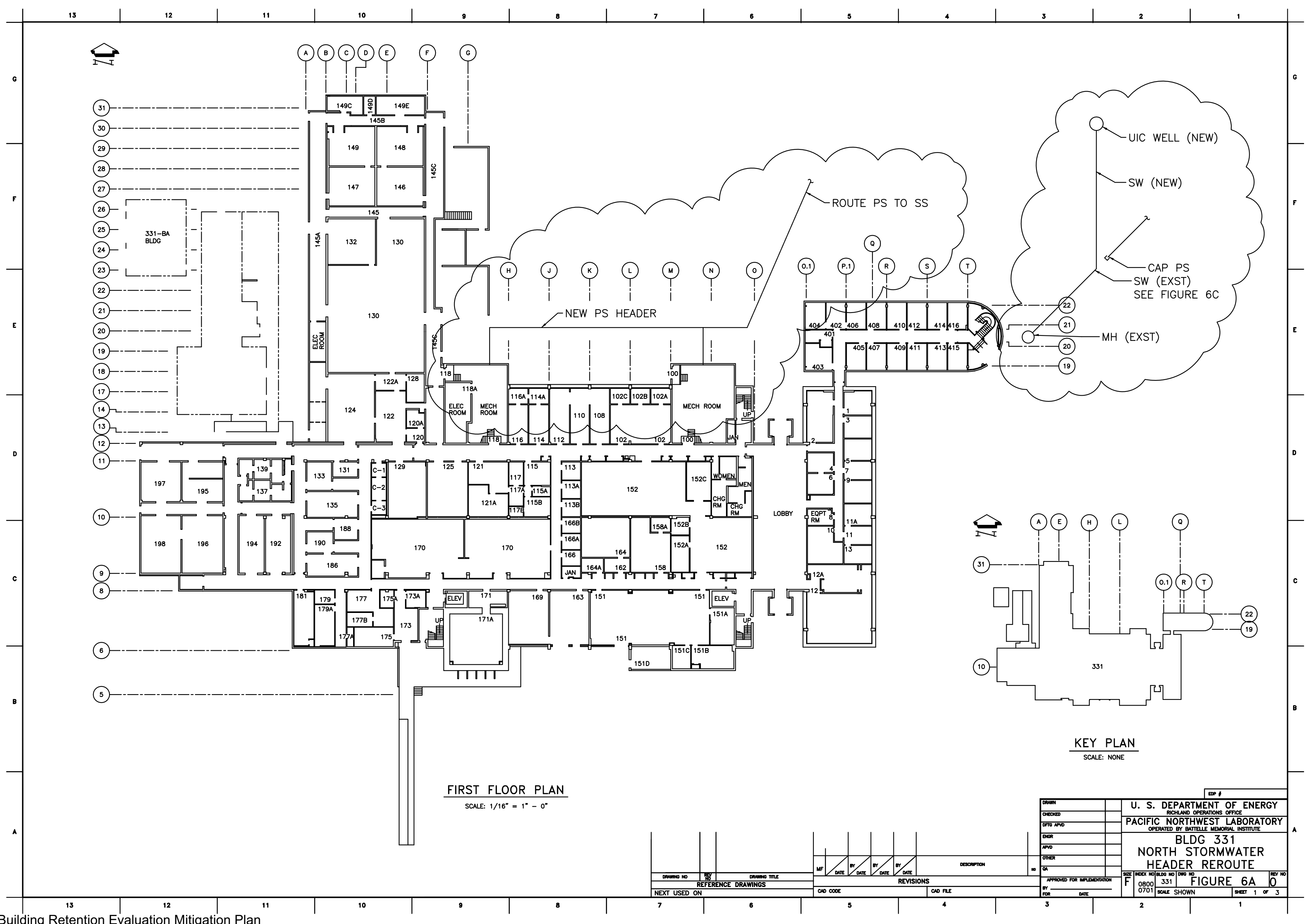




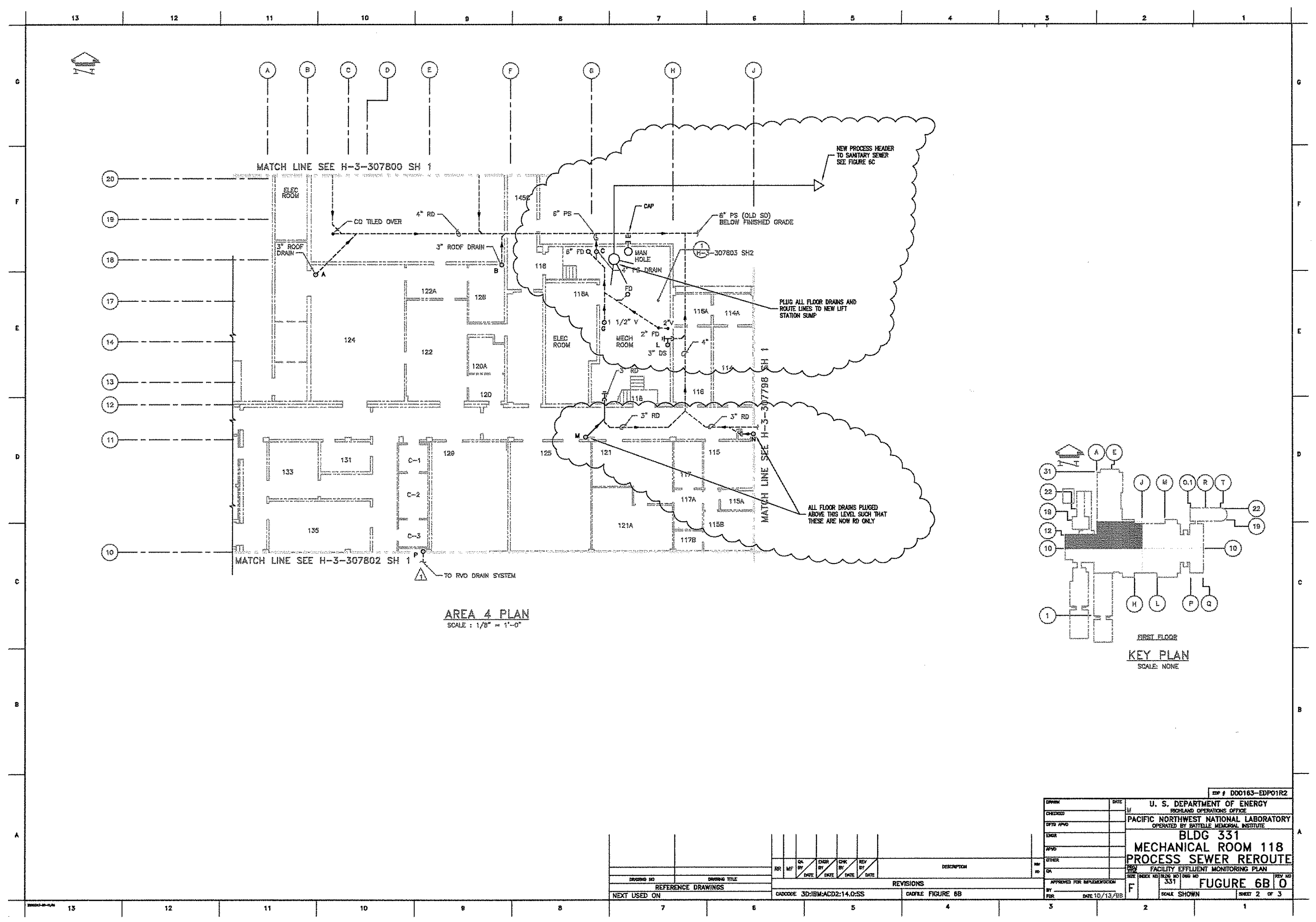




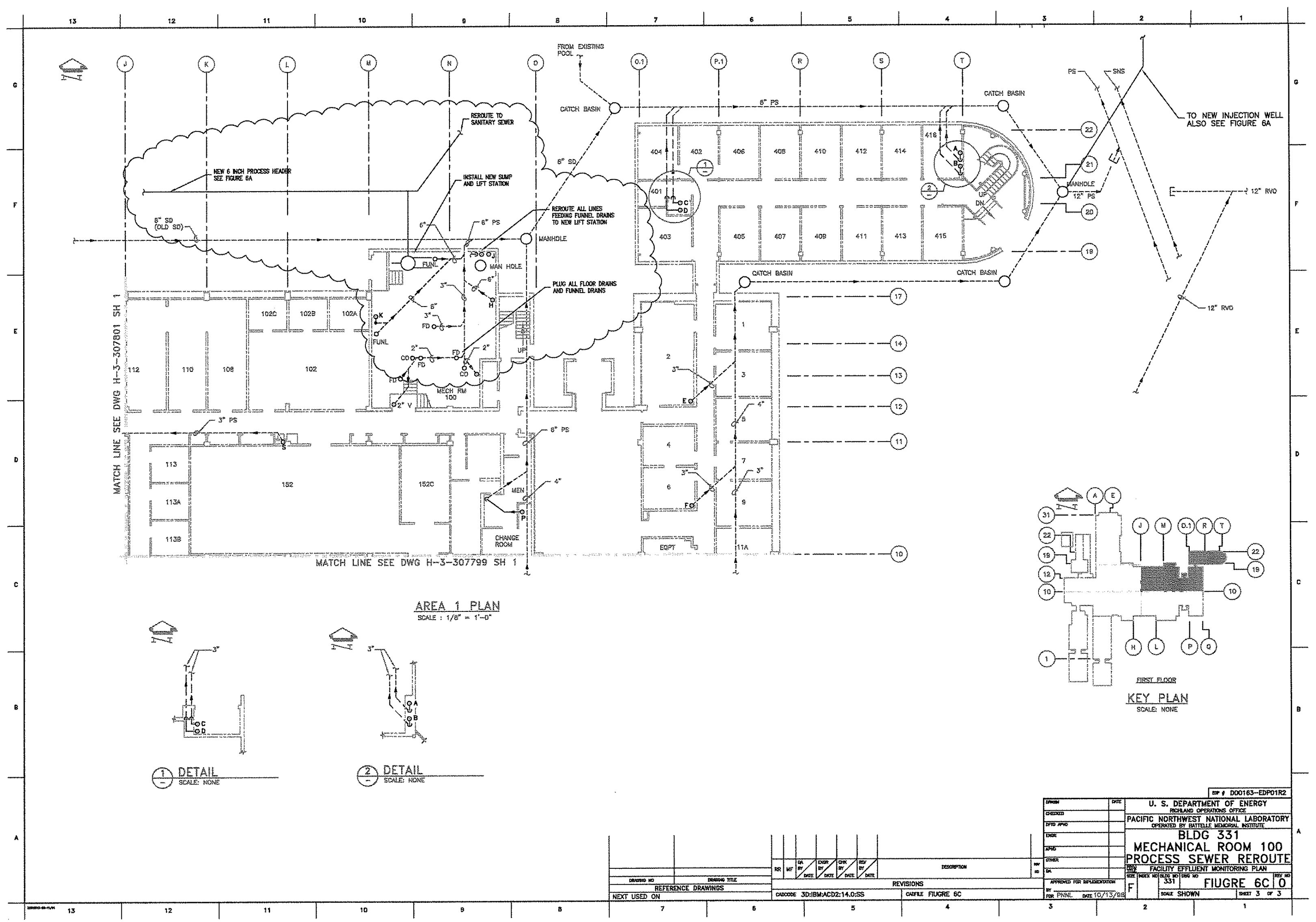




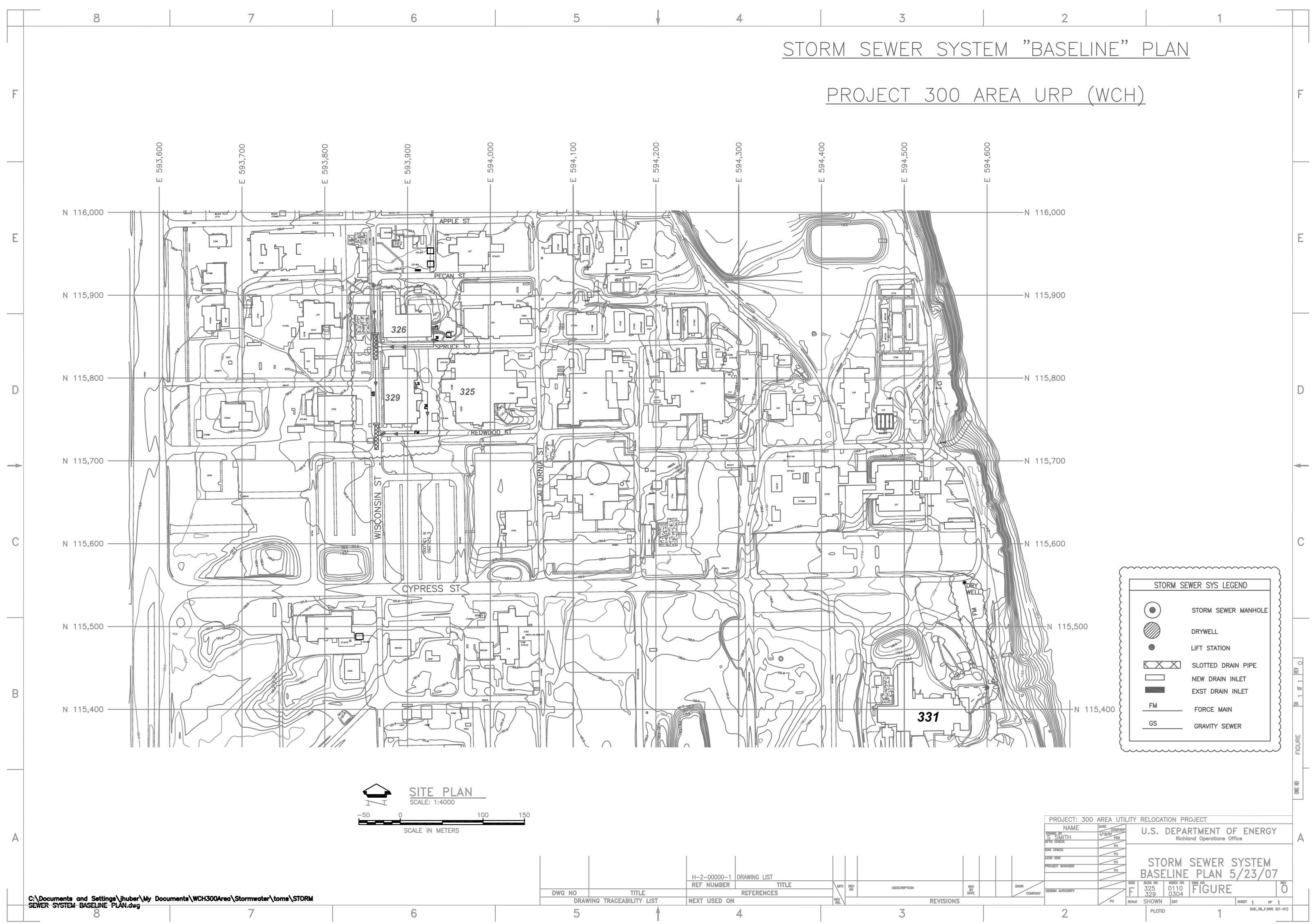




\section{APPENDIX K}

\section{AREA INFORMATION TECHNOLOGY DECISION MEETING}


WCH-181

Rev. 0 


\section{WCH Mastimanam \\ Whe cisisure \\ Meeting Minutes}

SUBUEGT SUMMARY OF DECISION MEETING FOR INFORMATION TECHNOLOGY OPTIONS
300 AREA UTILITY RELOCATION PROJECT

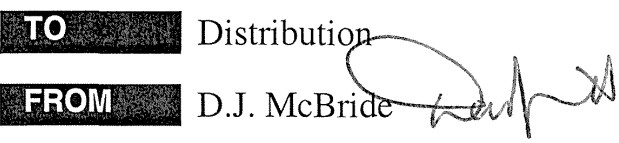

DATE June 25, 2007

\section{ATTENDEES}

J. W. Bixler J2-45, w/a

K. Butz H7-22, w/a

S. E. Dieterle L1-04, w/a

R. Gerk J2-18, w/a

P. A. George K7-53, w/a

G. M. MacFarlan L6-06, w/a

D. J. McBride H4-15, w/a

D.L. Plung H4-10, w/a

D. J. Ortiz A3-04, w/a

J. Turner K9-42, w/a

\section{DISTRIBUTION}

Attendees

S. I. Bennion H7-21, w/a

S. T. Burnum A3-04, w/a

S. R. Cassidy J2-45, w/a

R. G. Egge X5-50, w/a

G. A. Gosney H4-16, w/a

R. F. Guercia A3-04, w/a

C. MacDonald J2-45, w/a

D. J. Tollefson E6-29, w/a

D. M. Yasek L1-07, w/a

Document Control H4-11

On May 1, 2007, a decision meeting was held to review and rank the two options for the Information Technology (IT) system for facilities retained "long term" and the two options for interim facilities as part of the 300 Area Utility Relocation Project. The IT Sub Team led a discussion with the Project Core team on the pros and cons of each option. In Attachment 1, the options are summarized and key differences highlighted.

Due to the relative simplicity of the possible options, it was decided that the preferred options would be chosen through open discussion among the Project Core team with support from the IT Sub Team. Criteria discussed included, but were not limited to: 1) Does the option meet all the Functional Requirements, 2) Does the option present any outstanding issues with Regulatory Agencies, 3) Does the option meet scheduling deadlines, and 4) Does the option cost fall within reasonable and defendable limits.

The resulting decisions concerning the IT options were consistent with the recommendations made by the IT Sub Team, namely:

Based on the functional requirements and the information contained within this options document (Attachment 1), the IT Sub team recommended the following options be taken to address IT infrastructure rerouting requirements in the 300 Area as a result of D4 and field remediation activities associated with Buildings 309 and $3506 \mathrm{C}$ at an estimated cost of approximately $\$ 545 \mathrm{~K}$. Factoring in contingency, a 
Distribution

Page 2

high-end total cost estimate is $\$ 655 \mathrm{k}$.

$\checkmark$ Install new optical fiber cabling as the recommended long term option for the retained PNNL facilities $(318,325,331 \& 350)$ (note this includes $\$ 5 \mathrm{k}$ for $622 \mathrm{R}$ fiber reroute which may be covered by existing River Corridor Closure scope). Option L1

$\checkmark \quad$ Install new optical fiber cabling as the recommended option for the interim PNNL facilities (320, 326 and 329). Install new optical fiber cabling between Buildings 339A to 3790 for the retained PHMC facility. Option I1

$\checkmark$ Reuse existing optical fiber cabling from 350 to the trailers. Plus deploy wireless network to provide interconnections between the trailers. Option M2

Attachments:

1. 300 Area Utility Relocation Project - IT Options Study

2. Cost Estimate Summary IT Options 
Distribution

Page 3

\author{
Attachment 1 \\ 300 Area Utility Relocation Project \\ IT Options Study \\ Prepared by IT Sub Team \\ 05/08/2007
}

\title{
Executive Summary
}

Based on the functional requirements and the information contained within this options document, the IT Sub team recommends the following options be taken to address IT infrastructure rerouting requirements in the 300 Area as a result of D4 and field remediation activities associated with Buildings 309 and 3506C at an estimated cost of approximately $\$ 545 \mathrm{~K}$. Factoring in contingency, a high-end total cost estimate is $\$ 655 \mathrm{k}$.

$\checkmark \quad$ Install new optical fiber cabling as the recommended long term option for the retained PNNL facilities $(318,325,331$ \& 350) (note this includes $\$ 5 \mathrm{k}$ for $622 \mathrm{R}$ fiber reroute which may be covered by existing River Corridor Closure scope). Option L1

$\checkmark$ Install new optical fiber cabling as the recommended option for the interim PNNL facilities (320, 326 and 329). Install new optical fiber cabling between Buildings 339A to 3790 for the retained PHMC facility. Option I1

$\checkmark$ Reuse existing optical fiber cabling from 350 to the trailers. Plus deploy wireless network to provide interconnections between the trailers. Option M2

\subsection{Introduction}

The majority of the existing IT and telecommunications cabling that supports PNNL activities in the 300 Area is served out of Building 3506C (a.k.a. "Bundy Hut") and/or through the fiber optic and copper cables that are routed along New Mexico Avenue in the vicinity of Building 309. The associated infrastructure and cable routes are expected to be impacted by the D4 and Field Remediation activities in and around 309 and underlying waste sites and will require rerouting. The waste sites are scheduled for remediation starting in 2009.

Currently, optical fiber connectivity to the PNNL staff in the long term facilities, (318, 325,331 and 350) is provided through DOE owned, FH/LMSI managed infrastructure, centered in 3506C. This will be impacted by the D4 activities around 309, and alternative configurations need to be considered to meet the long-term needs of the facilities.

The $3760,323,3730,3718 \mathrm{P}, 336$ and 338 Buildings shall remain on existing optical fiber 
Distribution

Page 4

and voice services until the demolition of these buildings, as it is assumed that the services provided by or through $3506 \mathrm{C}$ and its corresponding cabling routes will outlast these facilities. If any acceleration of the planned D4 or remediation activities around 309 and 3506C were to occur this plan would be invalidated.

Rerouted fiber optic connections are needed to 320,326 and 329 as these are scheduled for occupancy beyond October 2009. It is proposed that telephone services in these buildings remain on the Hanford IVDTS service as the copper cabling feeding these buildings is not impacted by the remediation activities per FH/LMSI.

In addition there are several modular offices (trailers) housing Johnson Controls staff (MO262 and MO263) and PNNL BOA contractors (MO675, MO676 and MO677) which are impacted by $\mathrm{D} 4$ and remediation activities associated with 309 .

The continued use of 3790 to support PHMC activities will require a fiber optic cable reroute due to D4 and remediation activities associated with 309 .

The IT sub-team has broken the scope of work into three main categories:

- Long term PNNL/PHMC facilities

- Interim PNNL/PHMC facilities (scheduled for turnover by 2011)

- Modular offices (JCI and American Electric)

\subsection{Long Term PNNL/PHMC Facilities Options - Summary}

This section is concerned with providing long term optical fiber/copper connectivity to the following facilities:

$\checkmark$ PNNL Facilities 318, 325, 331, 350 and 622R buildings, plus their associated boiler annexes and outbuildings. (includes connections to ISB2 and Math Bldg)

$\checkmark$ PHMC Facilities - 339, 3220, 3507, and 3709 A\&B

PNNL's Information Technology (IT) requirement to support voice and data services to the $325,318,350$ and 331 Buildings is to do so on PNNL-owned structured cabling network and voice / data switches independent of the Hanford site utilities which will be accomplished as a result of the rerouting activity.

The existing optical fiber connection from $3506 \mathrm{C}$ to $622 \mathrm{R}$ needs to be rerouted to originate from ISB2 to remove any dependency on the 300 Area infrastructure. This will only involve splicing the existing cabling in the vicinity of ISB2 and is not anticipated to cost more than $\$ 5 \mathrm{k}$ (this activity may be funded within existing River Corridor Closure scope).

300 Area IT Options Study

4 of 12 
Distribution

Page 5

The copper cabling to the long term PNNL facilities will be unaffected, except for 331 . However, if 3506C remains in place up to September 2009, it will be possible to provide voice services over the newly provided optical fiber cabling identified in Option L1, assuming that it is installed and fully functional by March 2009. If 3506C or 309 is subject to D4 activities prior to September 2009, additional mitigations will need to be implemented in support of 331.

No additional work is anticipated to be required to maintain the long term connectivity for the remaining PHMC facilities - 339A, 3220, and 3709 A\&B. IT services to all PHMC long term facilities are expected to not be impacted by D4 and remediation activities assuming that current remediation processes and plans remain consistent. Hence, no cost estimate is identified in the options. There is also no additional infrastructure costs anticipated to consider 3790 a long term use structure other than for the fiber reroute included in the Interim Option I1 


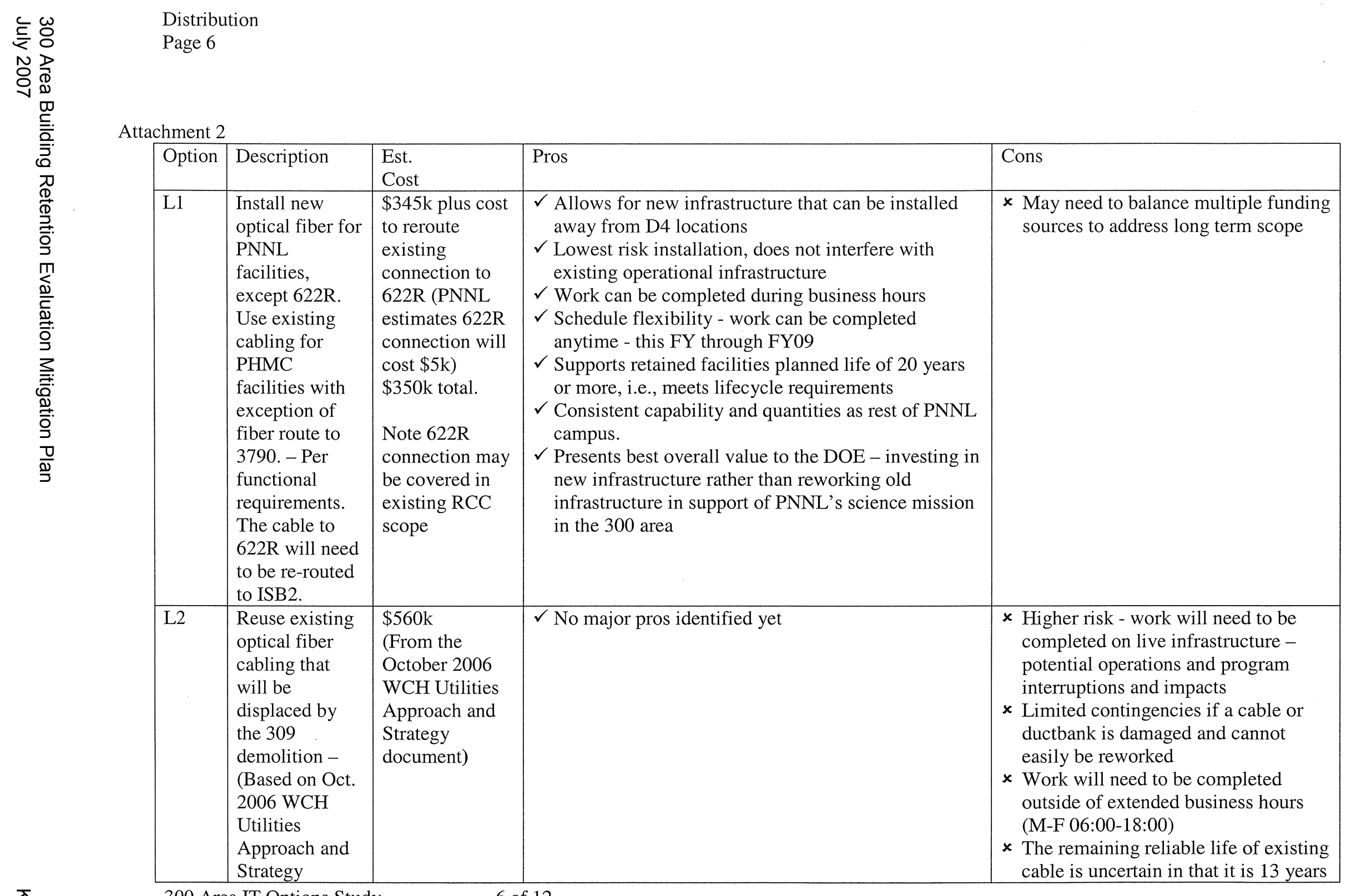


Page 7

document)

ld and industry standard lifecycle is $15-20$ years

The IT sub-team recommends Option L1 - Install new optical fiber as the long term option for the retained PNNL facilities. 
Distribution

Page 8

\section{Option L1 Cost Assumptions}

- Assumes that the existing cabling to PHMC facilities is undisturbed by the 309 D4 activities with exception of the fiber route to 3790 , this has been confirmed by FH/LMSI. The 3790 reroute is covered in option I1

- Assumes contractor competitive bid material and standard labor costs (non Davis Bacon)

- Does not include Project Management costs, it is assumed this will either by managed by WCH or PNNL staff and costs will be covered by those organizations

- Assumes that identified conduits are available and usable (though it should be noted that the schedule can be built to allow for minor conduit repairs as it is not operational infrastructure.) For the run along Stevens Drive, there are no costs included for conduit build out. If a new electrical ductbank is installed for power, it is recommended that additional communications conduits be added.

- The run from ISB2-318 along GW Way extension will utilize available conduit but could be aerial until Cypress Street where it will enter vaults if an unanticipated issue arises with the existing conduit, this has been verified by FH/LMSI

- This does not include any costs for the 331 outbuildings (C, D, G and H)

- Assume that the boiler annexes have copper communications cabling running to their host buildings (to support JCI requirements)

- Active (powered) networking and telecommunications equipment will be provided by PNNL. This is estimated to cost approximately $\$ 300 \mathrm{k}$.

\section{Option L2 Cost Assumptions}

Option 2 cost estimate of $\$ 560 \mathrm{k}$ was prepared as a part of the October $2006 \mathrm{WCH}$ Utilities Approach and Strategy document. (Total cost was $\$ 670 \mathrm{k}$, $\$ 560$ for Long Term and $\$ 110 \mathrm{k}$ for Interim, which includes $\$ 30 \mathrm{k}$ for 3790 that was not in the original scope)

\subsection{Interim/Short Term PNNL/PHMC Facilities Options - Summary}

This section is concerned with providing optical fiber/copper connectivity to the following interim facilities that are scheduled to outlive the infrastructure provided through or around Buildings 309 and 3506C (Bundy Hut):

$\checkmark$ PNNL Facilities 320,326 and 329

$\checkmark$ PHMC Facilities -3790
300 Area IT Options Study
8 of 12 


\begin{tabular}{|c|c|c|c|c|c|}
\hline 送 & $\begin{array}{l}\text { Distribu } \\
\text { Page } 9\end{array}$ & & & & \\
\hline & Option & Description & $\begin{array}{l}\text { Est. } \\
\text { Cost }\end{array}$ & Pros & Cons \\
\hline 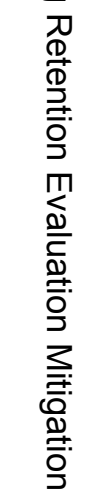 & I1 & $\begin{array}{l}\text { Install new optical } \\
\text { fiber for PNNL } \\
\text { facilities, as } \\
\text { follows: } \\
\text { - } 318 \text { to } 320 \\
\text { - } 325 \text { to } 326 \\
\text { - } 325 \text { to } 329 \\
\text { Install new optical } \\
\text { fiber cabling for } \\
\text { PHMC facility: } \\
\text { - } 339 \text { A-3790 }\end{array}$ & $\begin{array}{l}\$ 145 \mathrm{k} \text { ( } \$ 115 \mathrm{k} \text { for } \\
320,326 \text { and } 329 \\
\text { and } \$ 30 \mathrm{k} \text { for } 3790 \text { ) } \\
\text { (Note that there } \\
\text { would be no } \\
\text { incremental } \\
\text { mitigation cost if } \\
3790 \text { 's lifetime is } \\
\text { extended beyond } \\
2011 \text { ) }\end{array}$ & $\begin{array}{l}\checkmark \text { Allows for new infrastructure } \\
\text { that can be installed away } \\
\text { from D4 locations } \\
\checkmark \text { Lowest risk installation, does } \\
\text { not interfere with existing } \\
\text { operational infrastructure } \\
\checkmark \text { Work can be completed } \\
\text { during business hours } \\
\checkmark \text { Schedule flexibility - work } \\
\text { can be completed anytime - } \\
\text { this FY through FY09 }\end{array}$ & $x$ No major cons identified yet \\
\hline$\frac{\Phi}{5}$ & $\mathrm{I} 2$ & $\begin{array}{l}\text { Reuse existing } \\
\text { optical fiber cabling } \\
\text { that will be } \\
\text { displaced by the } \\
309 \text { demolition. } \\
\text { Requires new } \\
\text { cabling from } 318 \text { to } \\
320 / 350 \text { and } \\
\text { rework existing } \\
\text { cabling running n } \\
\text { north side of } 325 \\
\text { that serves } 326 \& \\
329 \text {. }\end{array}$ & $\begin{array}{l}\text { \$110k } \\
\text { (From the October } \\
2006 \text { WCH Utilities } \\
\text { Approach and } \\
\text { Strategy document } \\
\text { plus an incremental } \\
\$ 30 \mathrm{k} \text { for } 3790 \\
\text { mitigation that was } \\
\text { not in the original } \\
\text { scope) }\end{array}$ & $\checkmark$ No major Pros identified yet & $\begin{array}{l}\times \text { Higher risk - work will need to be } \\
\text { completed on live infrastructure- } \\
\text { potential operations and program } \\
\text { interruptions and impacts } \\
\times \text { Limited contingencies if a cable or } \\
\text { ductbank is damaged and cannot easily } \\
\text { be reworked } \\
\times \text { Work will need to be completed outside } \\
\text { of extended business hours (M-F 06:00- } \\
\text { 18:00) }\end{array}$ \\
\hline
\end{tabular}

The IT sub-team recommends Option I1. Option I2 cost estimate is less, however, schedule and scope/performance risks are much greater such that Option I1 recommended. 
Distribution

Page 10

\section{Option I1 Cost Assumptions}

- Assumes contractor competitive bid material and standard labor costs (non Davis Bacon)

- Does not include Project Management costs, it is assumed this will either by managed by WCH or PNNL staff and cost covered by those organizations

- Assumes that conduits are available and usable. (though it should be noted that the schedule can be built to allow for minor conduit repairs as it is not operational infrastructure

- Assume that the boiler annexes have copper communications cabling running to their host buildings (to support JCI requirements)

- Assumes L1 scope has been completed.

Option I2 Cost Assumptions

- LMSI ROM estimates provided for the new cable and rework scope.

- Reuse existing fiber scope is dependent on demolition efforts and is more complex

\subsection{Modular Offices (JCI and PNNL contractors) Options - Summary}

This section is concerned with providing optical fiber/copper connectivity to the following interim facilities that are scheduled to outlive 3506C (Bundy Hut):

$\checkmark$ MO262, MO263 (JCI)

$\checkmark$ MO675, MO676 and MO677 (American Electric / Thompson Mechanical). 


\begin{tabular}{|c|c|c|c|c|c|}
\hline \multirow{4}{*}{ 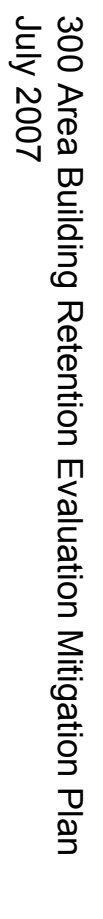 } & \multicolumn{5}{|c|}{$\begin{array}{l}\text { Distribution } \\
\text { Page } 11\end{array}$} \\
\hline & Option & Description & $\begin{array}{l}\text { Est. } \\
\text { Cost }\end{array}$ & Pros & Cons \\
\hline & M1 & $\begin{array}{l}\text { Maintain existing } \\
\text { telephone/data } \\
\text { services }\end{array}$ & $\begin{array}{l}\text { Not identified in } \\
\text { light of D4 } \\
\text { impacts. }\end{array}$ & $\checkmark$ No major pros identified yet & $\begin{array}{l}\times \text { The copper cabling supporting these } \\
\text { trailers will be impacted by the D4 } \\
\text { activities around 3506C. } \\
\times \text { Inconsistent with the support model for } \\
\text { PNNL contractors } \\
\times \text { Would require optical fiber cabling to } \\
\text { be installed in order for PNNL network } \\
\text { connectivity to be provided. }\end{array}$ \\
\hline & M2 & $\begin{array}{l}\text { Reuse existing } \\
\text { optical fiber cabling } \\
\text { that runs from } 350 \\
\text { to } 2 \text { of the trailers. } \\
\text { Wireless links for } \\
\text { the remaining } \\
\text { trailers that require } \\
\text { connectivity. }\end{array}$ & $\begin{array}{l}\$ 50 \mathrm{k} \\
\text { (PNNL rough } \\
\text { ROM estimate) }\end{array}$ & $\begin{array}{l}\checkmark \text { Lowest cost option } \\
\checkmark \text { Consistent with the Site services } \\
\text { architecture for PNNL to service } \\
\text { it's supporting organizations. }\end{array}$ & $\begin{array}{l}\text { Will depend on PNNL being able to } \\
\text { provide telephone service over optical } \\
\text { fiber cabling }\end{array}$ \\
\hline
\end{tabular}

The IT sub-team recommends Option M2 - Reuse existing optical fiber cabling from 350 to the trailers. Plus deploy wireless network to provide interconnections between the trailers. 
Distribution

Page 12

Option M1 Cost Assumptions

- Assumption of the copper cabling running to the modular offices was considered but dismissed in that it is impacted by D4 activities

Option M2 Cost Assumptions

- Assumes there is copper cabling interconnecting the trailers that will allow for telephone service to be provided

- PNNL rough ROM estimate 


\section{Customer To Complete:}

$\square$ This has action - Written response required: Yes

Actionee

Distribution Completed: Yes

$\square$ This closes CCN

$\square$ Please call me for pick up/hand delivery

$\square$ Please expedite - Please hand deliver to WCH Document Control, do not put in basket

Any Special Directions (i.e., added distribution, reproduction instructions, colored items, extra attachments, sensitive documents, etc.) Please include name and telephone number of the person to contact if WCH Document Control has questions.

Additional distribution (please include MSINs):

\begin{tabular}{|c|c|c|c|}
\hline Name: & MSIN: & NAME: & MSIN: \\
\hline & & & \\
\hline & & & \\
\hline & & RECEIVED & \\
\hline & & JUN 262007 & \\
\hline & & WCH= DOCUMENT & \\
\hline & & Gotingen & \\
\hline & & & \\
\hline & & & \\
\hline & & & \\
\hline
\end{tabular}

TO BE COMPLETED BY R\&DC:

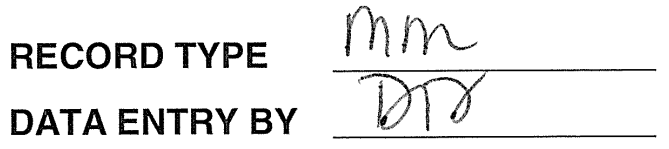

REPRO BY

SCANNED/\# PGS

DOCSOPEN \#

OUTGOING COVERSHEET 11/29/2005 (DOC \# 12336 ver. 4) 
WCH-181

Rev. 0

300 Area Building Retention Evaluation Mitigation Plan 


\section{APPENDIX L}

300 AREA INFORMATION TECHNOLOGY CONCEPTUAL DESIGN 
WCH-181

Rev. 0 


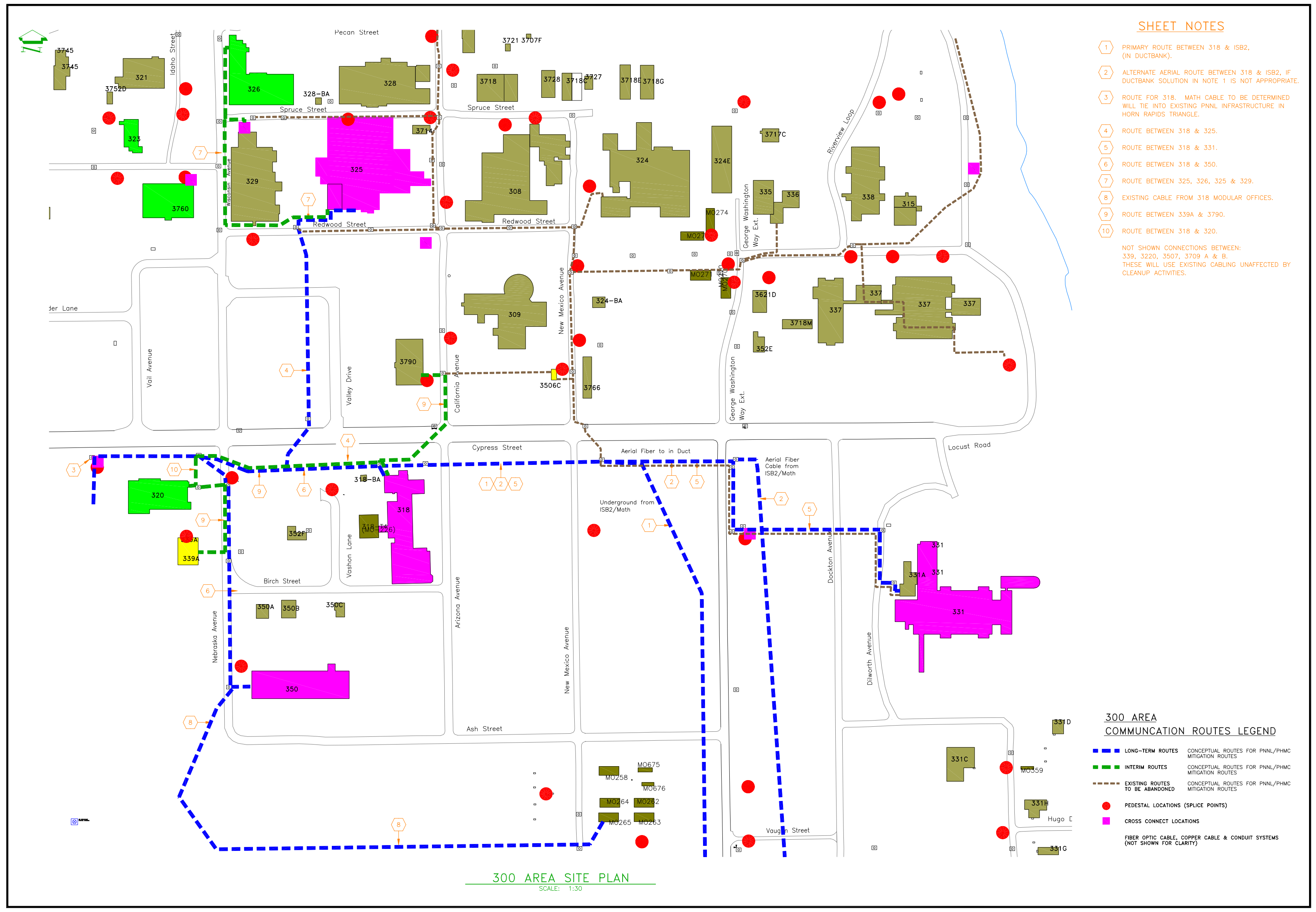




\section{APPENDIX M}

\section{FIELD REMEDIATION IMPACT FROM RETAINED FACILITIES}


WCH-181

Rev. 0 
WCH-181

Rev. 0

\section{McBride, Donald J}

From:

Sent:

To:

Subject:

Importance:

Attachments:
McBride, Donald J

Thursday, June 28, 2007 10:29 AM

Donahoe, Richard L; Carlson, Richard A; MacFarlan, Gary M; Fox, Michael B; Irwin, Gerald L; Dieterle, Steven E; Lee, Miu (Mel)

Potentially affected waste sites from long-term utilities

High

Affected Geographical Zones and Waste Sites.xls

Rick, Mike--

In response to our discussion, Gary MacFarlan and I reviewed 91 waste sites in the 300 Area to assess the potential for impacts on remediation activities. We reviewed the results with Rich Carlson who concurred with our conclusions.

For each site we considered the baseline (IPB) dates planned for excavation of the sites, as well as the IPB-planned status of surrounding utility systems and facilities. Our assumption was that sites that were baselined for remediation while nearby utilities would have still been active would already be assumed to require temporary rerouting of utilities to support the baseline activities. Sites that were baselined for remediation after nearby utilities would have been deactivated (in the baseline) were considered candidates for impact. We then assessed the potentially impacted sites against the new planned configuration and timeframes under the mitigation plan. Sixteen sites, of which five are pipeline sites, were identified as potentially impacted by the presence of retained utility systems and are highlighted in the attached spreadsheet. Examples of impacts were sites in the proximity of active water, sewer, or electric lines that would require extra care or controls to avoid safety or outage impacts. Pipeline sites were typically impacted by the need to start and stop excavations in multiple areas while performing isolations of portions of the pipelines that would be left in place.

For the sixteen impacted sites, we have requested Mel to input an increased cost and duration of $25 \%$ for the excavation phase of the remediation activity.

Thanks--

Don McBride

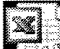

$$
\text { Affected }
$$

ographical Zones ar 
曼

승

Ш

음

D

胥

음

茂

ำ

3

음

300 Area Geographical Zones and Associated Waste Sites

\begin{tabular}{|c|c|c|c|c|c|}
\hline Geographical Zone & Site Number & Excavation Start Date & Loadout Completion Date & Confirmatory Sampling Date & Potential Impact \\
\hline & & (IPB) & $(\mathrm{IPB})$ & (IPB) & \\
\hline \multirow[t]{3}{*}{ A } & 331 LSLT1 & & & 30 May, 2006 & \\
\hline & 331 LSLT2 & & & 01 June, 2006 & \\
\hline & 331 LSLDF & & & 24 May, 2006 & \\
\hline & & & & & \\
\hline \multirow[t]{11}{*}{ B } & $300-32$ & & & 04 September, 2007 & \\
\hline & $618-1$ & 25 October, 2007 & 12 February, 2008 & & \\
\hline & $300-109$ & 21 January, 2008 & 26 February, 2008 & & \\
\hline & $300-110$ & 25 October, 2007 & 04 December, 2007 & & \\
\hline & $300-258$ & 25 January, 2007 & 06 March, 2007 & & \\
\hline & $300-259$ & 25 October, 2007 & 20 December, 2007 & & \\
\hline & 303-M SA & 21 January, 2008 & 27 February, 2008 & & \\
\hline & 303-M UOF & & & 15 May, 2006 & \\
\hline & 333 ESHWSA & 21 January, 2008 & 26 February, 2008 & & \\
\hline & UPR-300-17 & 21 January, 2008 & 04 March, 2008 & & \\
\hline & UPR-300-46 & 25 October, 2007 & 13 December, 2007 & & \\
\hline \multirow{19}{*}{ C } & 300-16(Partial) & 29 Octoher 2009 & 09 December 2009 & & \\
\hline & $300-28$ & $\frac{290 \text { ctober, } 2009}{17 \text { June, } 2009}$ & $\frac{09 \text { December, } 2009}{28 \text { July, } 2009}$ & & \\
\hline & $300-40$ & 08 October, 2007 & 08 November, 2007 & & \\
\hline & $300-43$ & 08 January, 2009 & 17 February, 2009 & & \\
\hline & $300-48$ & 07 January, 2009 & 12 February, 2009 & & \\
\hline & $300-219$ & 17 June, 2009 & 24 August, 2009 & & \\
\hline & $300-224$ & 17 June, 2009 & 24 August, 2009 & & \\
\hline & $300-249$ & Included with $304 \mathrm{Bldg}$ & & & \\
\hline & $300-251$ & 03 February, 2009 & 12 March, 2009 & & \\
\hline & $300-260$ & 03 February, 2009 & 16 March, 2009 & & \\
\hline & $300-270$ & 18 March, 2009 & 05 May, 2009 & & \\
\hline & 313 ESSP & 08 October, 2007 & 12 December, 2007 & & \\
\hline & 333 WSTF & 01 October, 2009 & 10 November, 2009 & & \\
\hline & 3712 USSA & 01 October, 2009 & 09 December, 2009 & & \\
\hline & UPR-300-38 & 08 October, 2007 & 29 January, 2008 & & \\
\hline & UPR-300-39 & 09 June, 2009 & 23 July, 2009 & & \\
\hline & UPR-300-40 & 17 June, 2009 & 05 August, 2009 & & \\
\hline & UPR-300-45 & 17 June, 2009 & 05 August, 2009 & & \\
\hline & & & & & \\
\hline D & $300-46$ & 01 October, 2008 & 03 December, 2008 & & \\
\hline \multirow[t]{5}{*}{$\bar{E}$} & 300-16(Partial) & 29 October, 2009 & 09 December, 2009 & & \\
\hline & $300-24$ & 01 October, 2007 & 14 November, 2007 & & \\
\hline & $300-80$ & 03 February, 2009 & 11 March, 2009 & & \\
\hline & $300-218$ & 04 October, 2010 & 03 January, 2011 & & \\
\hline & $305-\mathrm{BSF}$ & $12 \mathrm{March}, 2009$ & 06 October, 2009 & & \\
\hline
\end{tabular}


300 Area Geographical Zones and Associated Waste Sites

\begin{tabular}{|c|c|c|c|c|c|}
\hline Geographical Zone & Site Number & Excavation Start Date & Loadout Completion Date & Confirmatory Sampling Date & Potential Impact \\
\hline & & (IPB) & (IPB) & (IPB) & \\
\hline \multirow[t]{4}{*}{$\mathbf{F}$} & $300-25$ & 13 September, 2010 & 02 November, 2010 & & \\
\hline & $300-93$ & 23 September, 2010 & 20 January, 2011 & & \\
\hline & $300-94$ & 23 September, 2010 & 20 January, 2011 & & \\
\hline & $300-95$ & 23 September, 2010 & 20 January, 2011 & & $\begin{array}{l}\text { Located near active retained } \\
\text { sanitary sewer and electrical lines }\end{array}$ \\
\hline $\mathbf{G}$ & $300-269$ & 01 October, 2009 & 23 November, 2009 & & \\
\hline \multirow{11}{*}{$\mathrm{H}$} & & & & & \\
\hline & $\frac{300-22}{300-39}$ & $\frac{01 \text { October, } 2009}{29 \text { February, } 2012}$ & $\frac{05 \text { November, } 2009}{03 \text { April, } 2012}$ & & \\
\hline & $300-255$ & 04 October, 2010 & 09 November, 2010 & & $\begin{array}{l}\text { Potential for excavation footprint to } \\
\text { impact electrical duct bank north of } \\
309\end{array}$ \\
\hline & $300-257$ & 04 October, 2010 & 02 December, 2010 & & $\begin{array}{c}\text { Crosses active sanitary sewer from } \\
331 \text { Building and parallels active } \\
\text { sewer and electrical }\end{array}$ \\
\hline & 309-TW-1 & 04 October, 2010 & 29 November, 2010 & & $\begin{array}{l}\text { Potential for excavation footprint to } \\
\text { impact electrical duct bank north of } \\
309\end{array}$ \\
\hline & 309-TW-2 & 04 October, 2010 & 10 November, 2010 & & $\begin{array}{l}\text { Potential for excavation footprint to } \\
\text { impact electrical duct bank north of } \\
309\end{array}$ \\
\hline & 309-TW-3 & 04 October, 2010 & 10 November, 2010 & & $\begin{array}{l}\text { Potential for excavation footprint to } \\
\text { impact electrical duct bank north of } \\
309\end{array}$ \\
\hline & 309-WS-1 & 04 October, 2010 & 28 December, 2010 & & \\
\hline & $309-W S-2$ & 04 October, 2010 & 23 November, 2010 & & \\
\hline & 309-WS-3 & 04 October, 2010 & 15 November, 2010 & & \\
\hline & UPR-300-5 & 04 October, 2010 & 18 November, 2010 & & \\
\hline \multirow[t]{5}{*}{1} & $300-6$ & 04 October, 2010 & 01 November, 2010 & & \\
\hline & $300-123$ & 09 May, 2012 & 14 June, 2012 & & \\
\hline & $300-268$ & 17 October, 2011 & 17 November, 2011 & & \\
\hline & $300-273$ & 05 July, 2011 & 10 August, 2011 & & \\
\hline & UPR-300-42 & 05 July, 2011 & 17 August, 2011 & & \\
\hline \multirow{3}{*}{$\mathrm{J}$} & $300-11$ & 01 May, 2012 & 11 June, 2012 & & \\
\hline & $300-34$ & 01 December, 2010 & 10 January, 2011 & & \\
\hline & $300-264$ & 05 January, 2011 & $07 \mathrm{March}, 2011$ & & Proximity to active water mains \\
\hline
\end{tabular}


300 Area Geographical Zones and Associated Waste Sites

\begin{tabular}{|c|c|c|c|c|c|}
\hline Geographical Zone & Site Number & Excavation Start Date & Loadout Completion Date & Confirmatory Sampling Date & Potential Impact \\
\hline & & (IPB) & (IPB) & (IPB) & \\
\hline \multirow[t]{5}{*}{$\mathrm{K}$} & $307 \mathrm{RB}$ & 10 March, 2011 & 03 May, 2011 & & \\
\hline & 340 Complex & 10 March, 2011 & 12 May, 2011 & & \\
\hline & UPR-300-1 & 10 March, 2011 & 02 May, 2011 & & \\
\hline & UPR-300-2 & & & 10 March, 2011 & \\
\hline & UPR-300-11 & 10 March, 2011 & 27 April, 2011 & & \\
\hline \multirow[t]{2}{*}{ L } & $300-263$ & 24 May, 2011 & 14 July, 2011 & & \\
\hline & $316-3$ & 03 October, 2011 & 17 April, 2012 & & $\begin{array}{l}\text { Active overhead electrical crosses } \\
\text { waste site }\end{array}$ \\
\hline \multirow[t]{6}{*}{ M } & $300-5$ & 02 May, 2011 & 09 June, 2011 & & $\begin{array}{l}\text { Located in yard of active fire } \\
\text { station, proximity to sanitary sewer } \\
\text { and water main }\end{array}$ \\
\hline & 323 Tank 1 & 04 May, 2011 & 14 June, 2011 & & \\
\hline & 323 Tank 2 & 04 May, 2011 & 15 June, 2011 & & \\
\hline & 323 Tank 3 & 04 May, 2011 & 15 June, 2011 & & \\
\hline & 323 Tank 4 & 04 May, 2011 & 15 June, 2011 & & \\
\hline & UPR-300-4 & 10 July, 2012 & 16 August, 2012 & & $\begin{array}{l}\text { Potential to impact active water } \\
\text { main on Wisconsin Street }\end{array}$ \\
\hline \multirow[t]{3}{*}{$\mathbf{N}$} & $300-33$ & 27 March, 2012 & 19 June, 2012 & & \\
\hline & $300-41$ & 31 May, 2012 & 09 July, 2012 & & \\
\hline & $300-256$ & 21 February, 2012 & 30 May, 2012 & & \\
\hline \multirow[t]{5}{*}{0} & $300-175$ & 14 June, 2012 & 23 July, 2012 & & \\
\hline & 325 WTF & 15 May, 2012 & 26 June, 2012 & & \\
\hline & UPR-300-10 & 16 May, 2012 & 09 July, 2012 & & \\
\hline & UPR-300-12 & 14 June, 2012 & 02 August, 2012 & & \\
\hline & UPR-300-48 & 16 May, 2012 & 09 July, 2012 & & \\
\hline $\mathbf{P}$ & $300-4$ & 09 May, 2012 & 14 June, 2012 & & \\
\hline \multirow[t]{2}{*}{$Q$} & $300-2$ & & & 01 November, 2012 & \\
\hline & $300-121$ & 09 May, 2012 & 13 June, 2012 & & $\begin{array}{l}\text { Proximity to active electrical duct } \\
\text { and sanitary sewer }\end{array}$ \\
\hline Process Sewer & $300-15$ & 25-May-11 & 16Mav 2012 & & $\begin{array}{l}\text { Multiple isolation points and partial } \\
\text { excavations }\end{array}$ \\
\hline Retention Process Sewer & $300-214$ & 01 October, 2009 & 15 May, 2012 & & $\begin{array}{l}\text { Multiple isolation points and partial } \\
\text { excavations }\end{array}$ \\
\hline Transfer line 325 to 324 & $300-265$ & 23 September, 2010 & 11 November, 2010 & & $\begin{array}{l}\text { Multiple isolation points and partial } \\
\text { excavations }\end{array}$ \\
\hline 300 RLWS & 300-RLWS & 04 October, 2010 & 04 June, 2012 & & $\begin{array}{l}\text { Multiple isolation points and partial } \\
\text { excavations }\end{array}$ \\
\hline 300 RRLWS & 300-RRLWS & 04 October, 2010 & 03 May, 2012 & & $\begin{array}{c}\text { Multiple isolation points and partial } \\
\text { excavations }\end{array}$ \\
\hline
\end{tabular}




\section{APPENDIX N}

\section{SCENARIO 1 VARIANCE SCHEDULE}


WCH-181

Rev. 0 


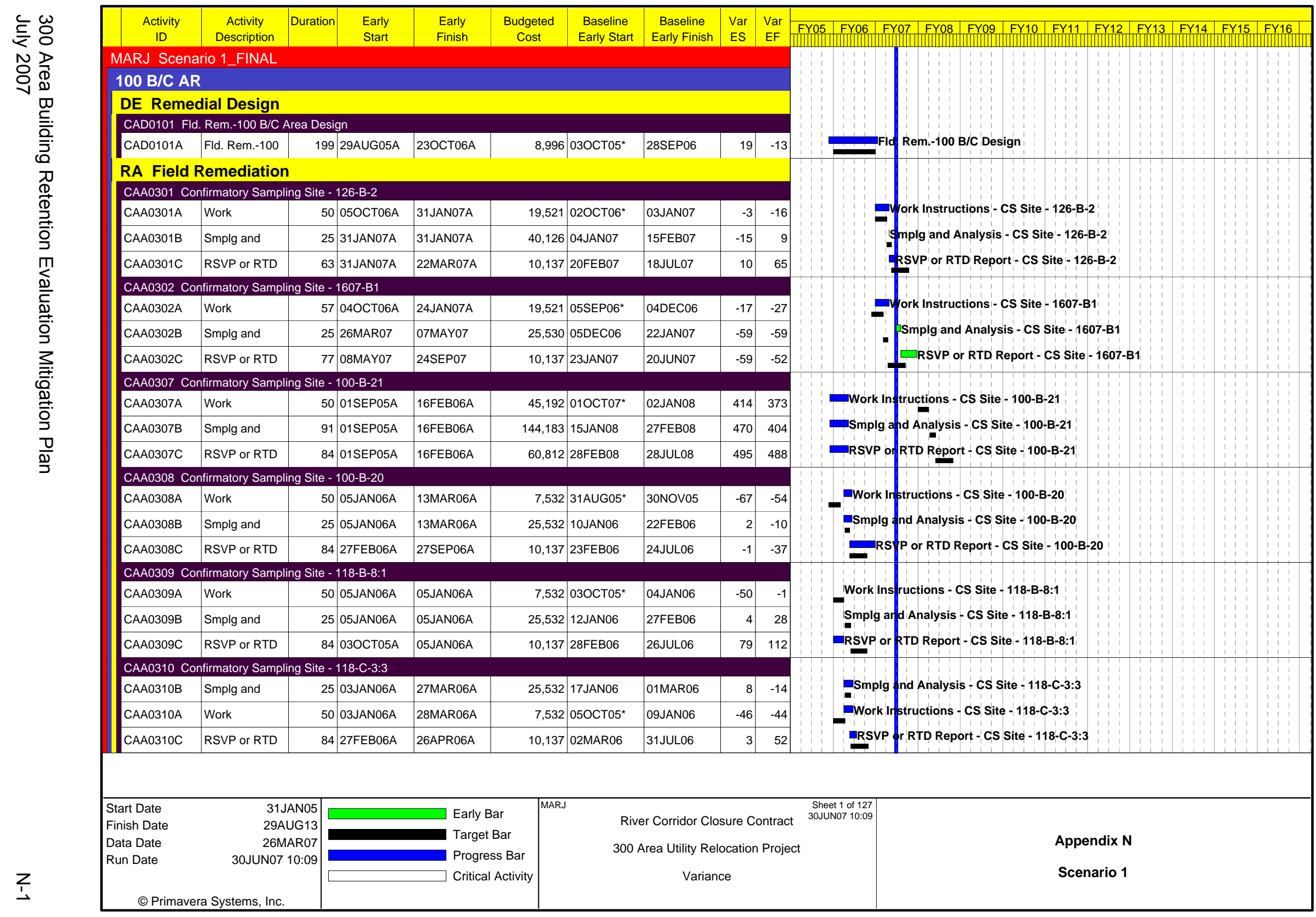




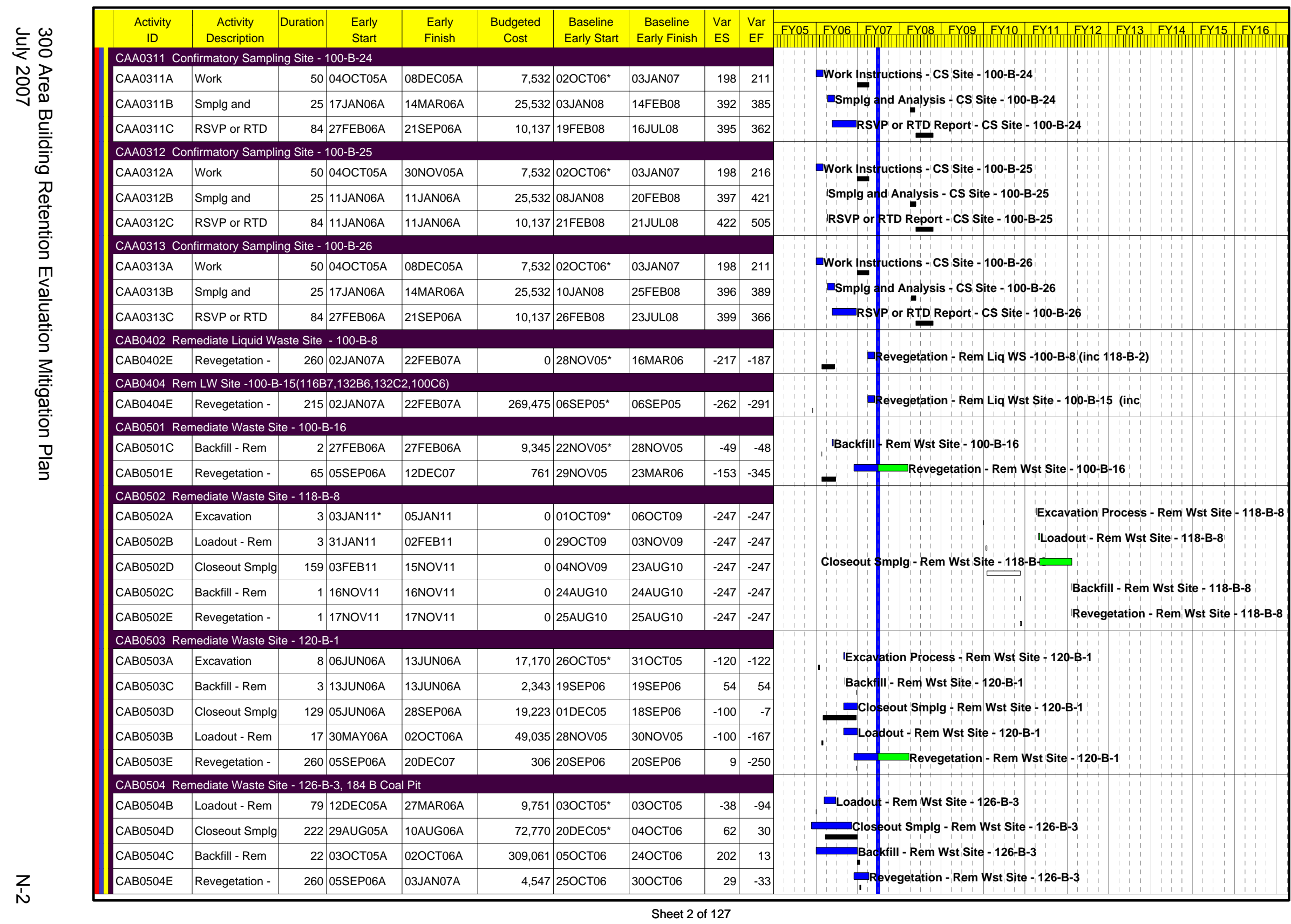




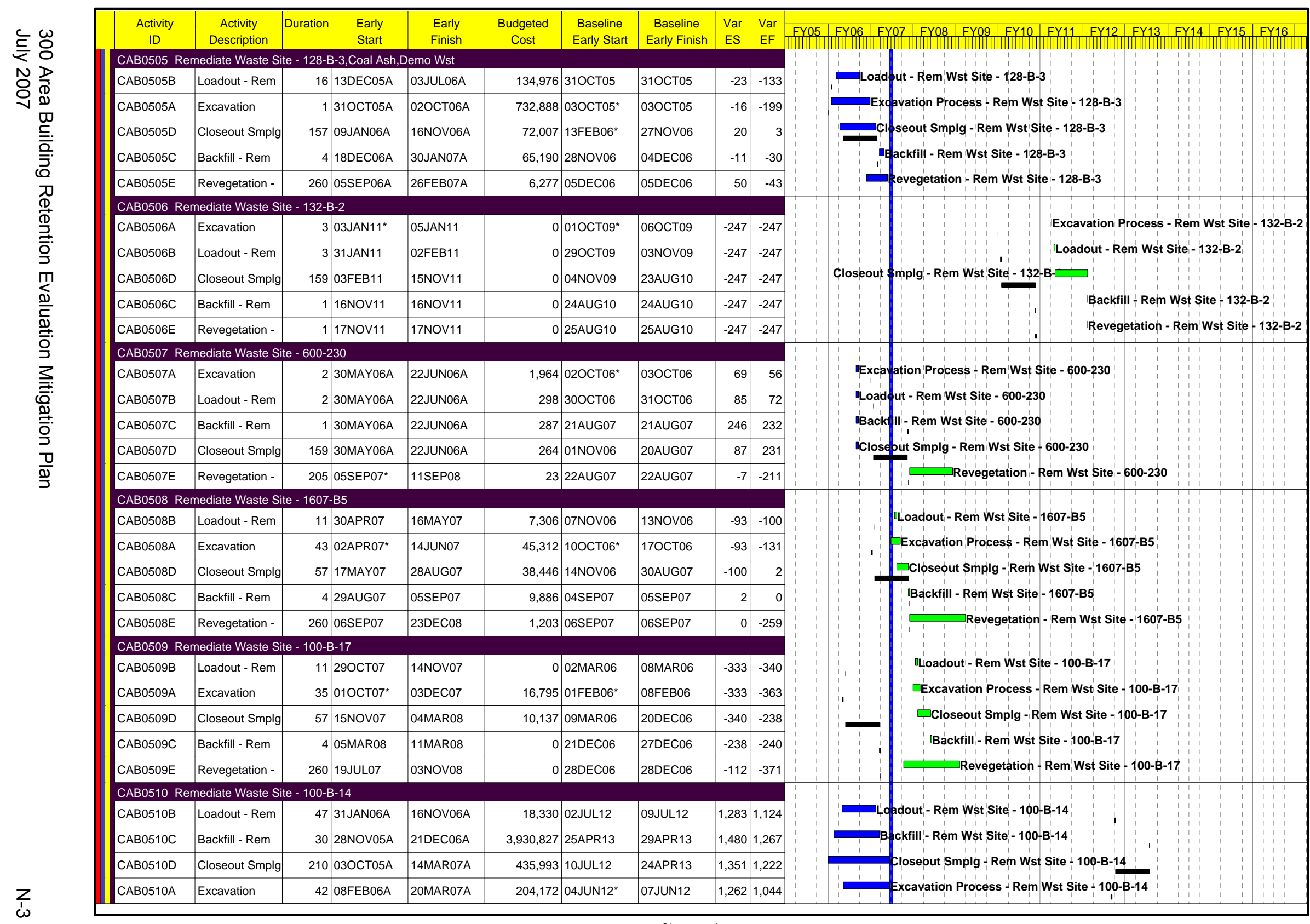




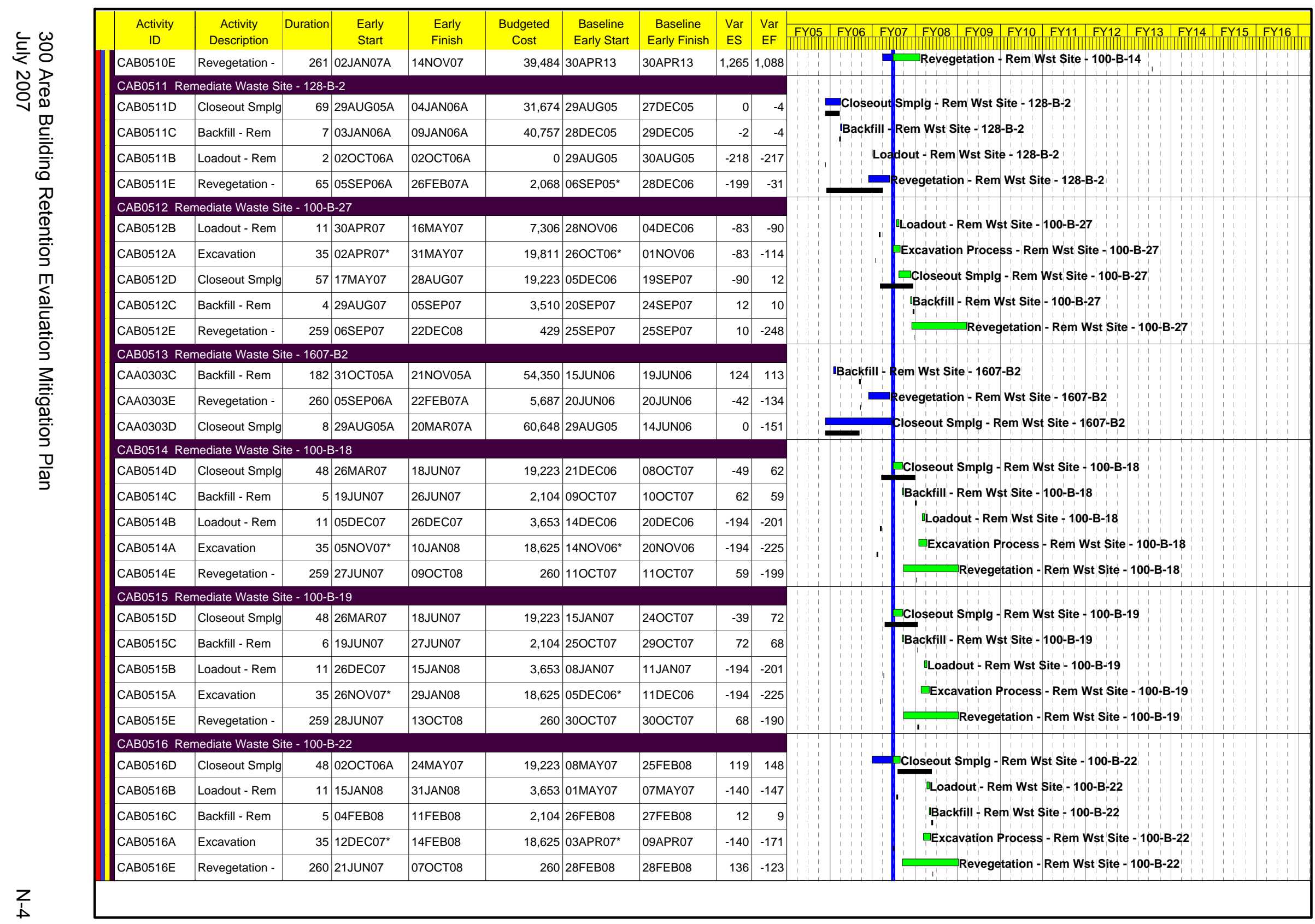




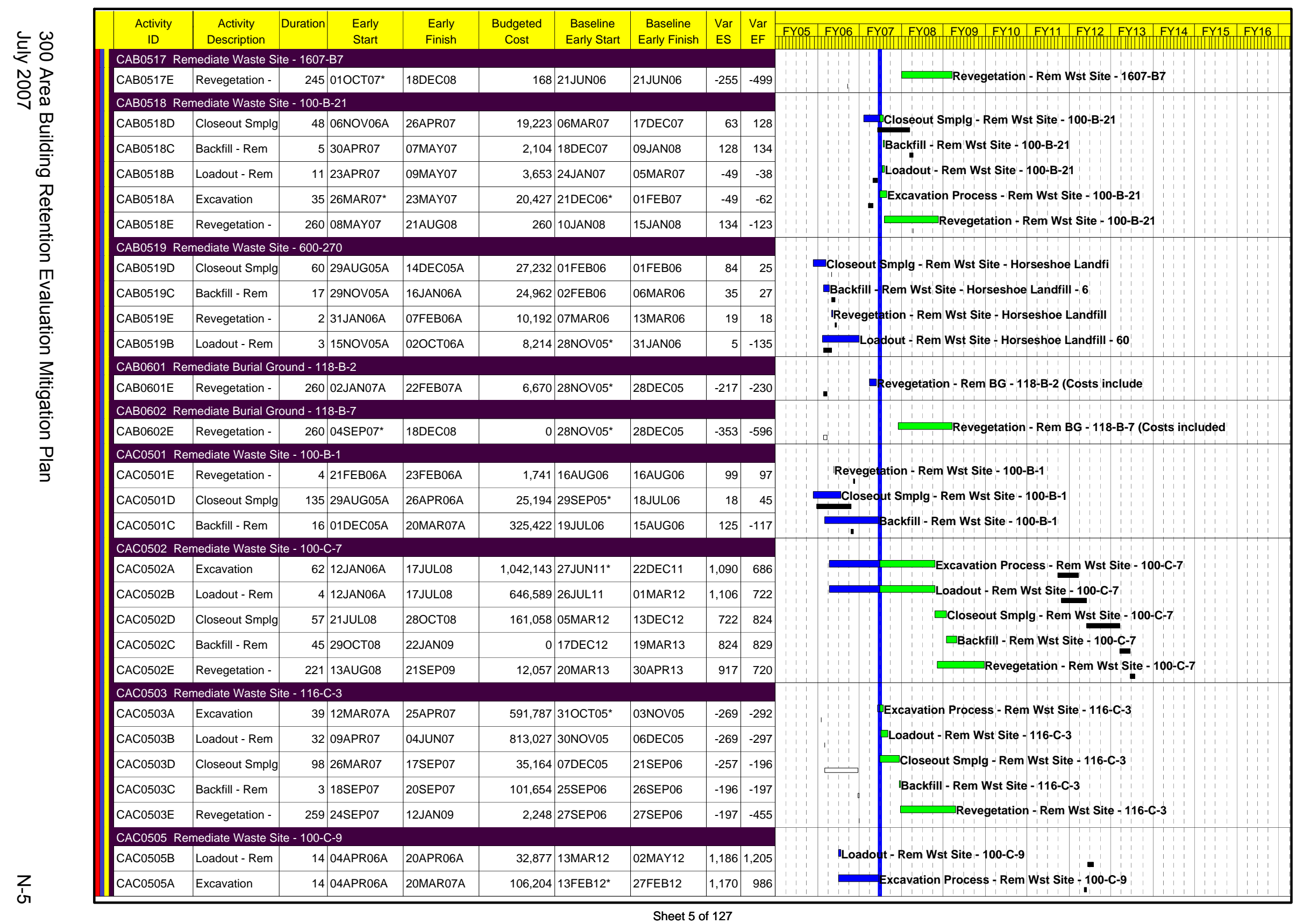




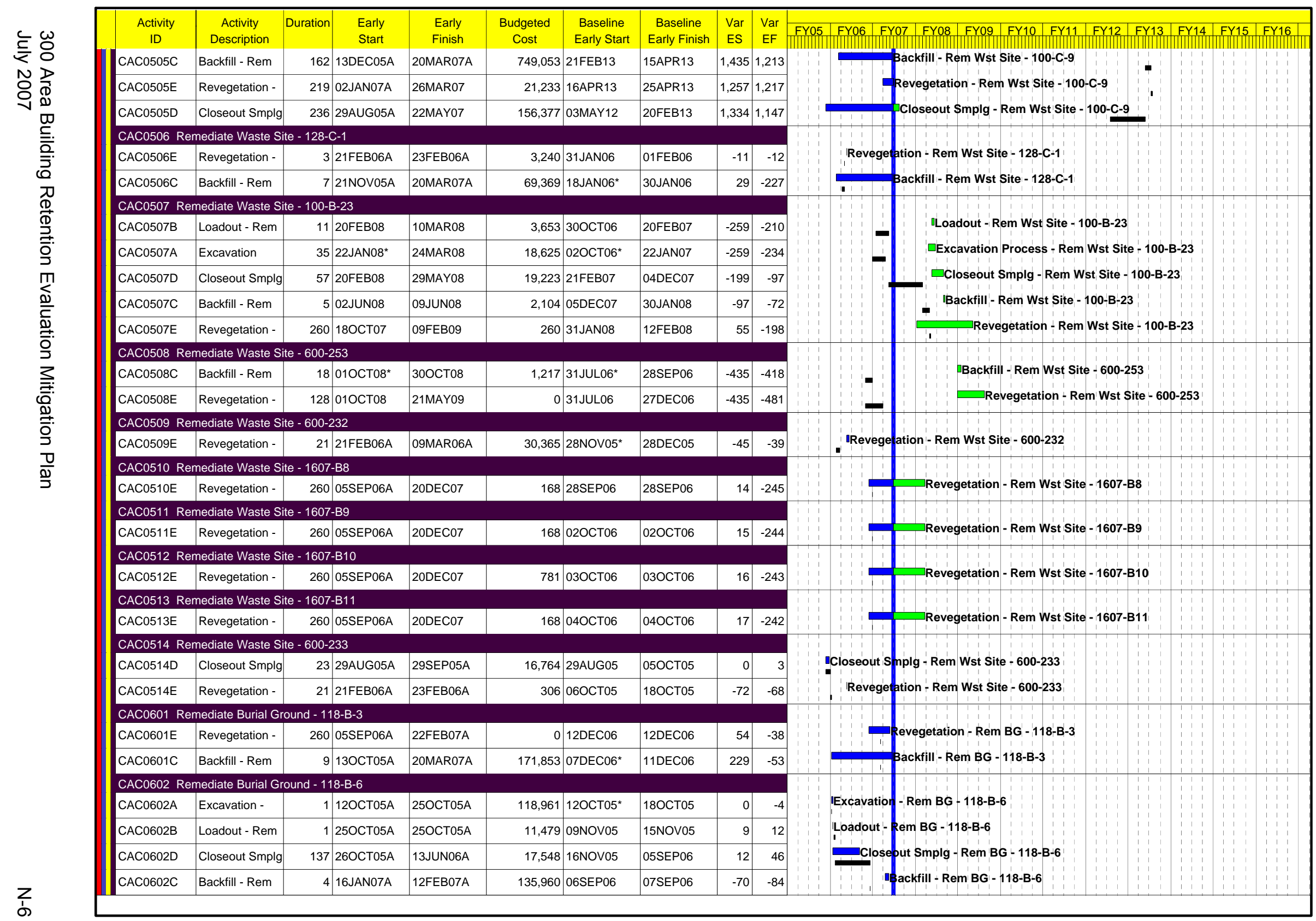




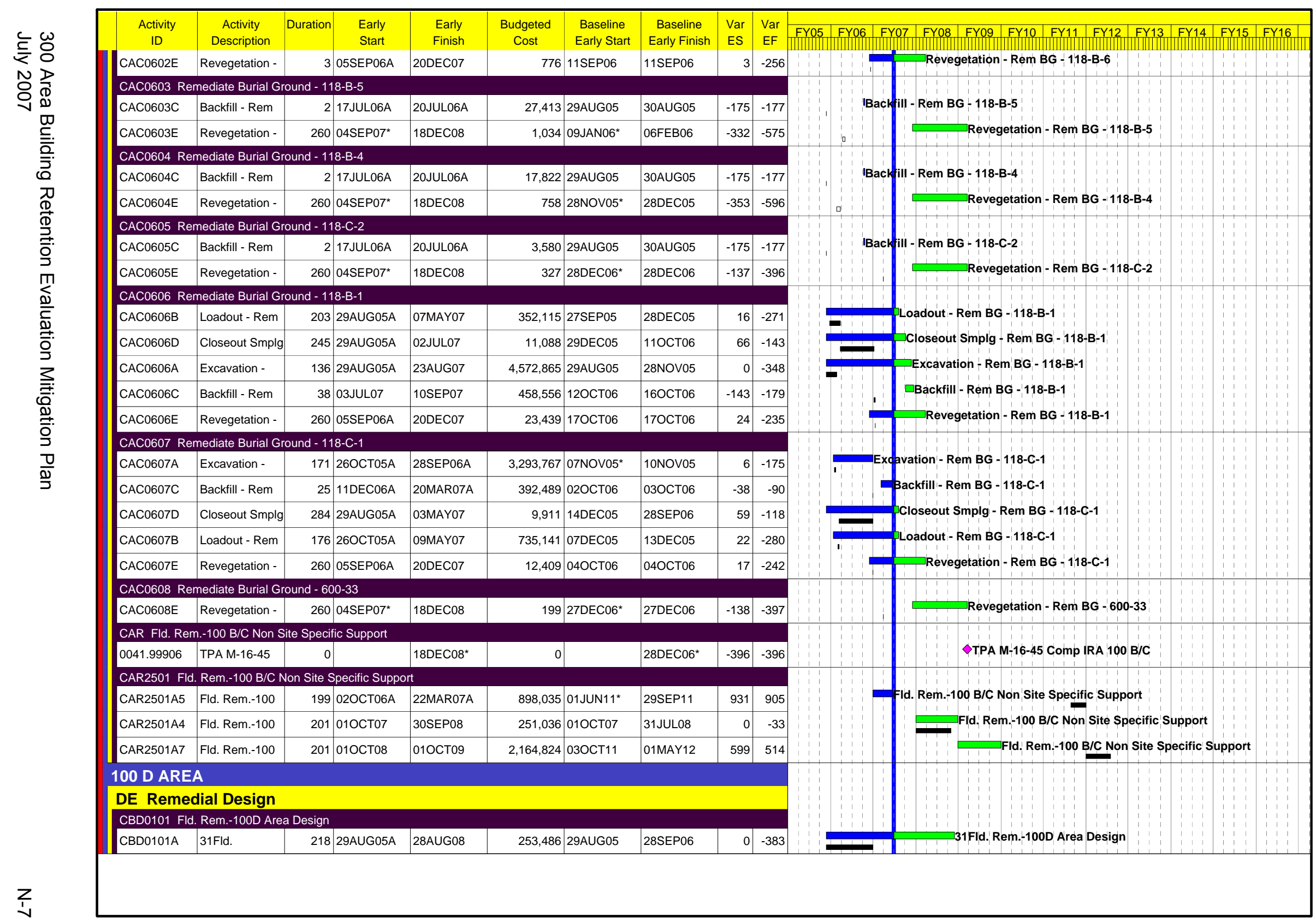




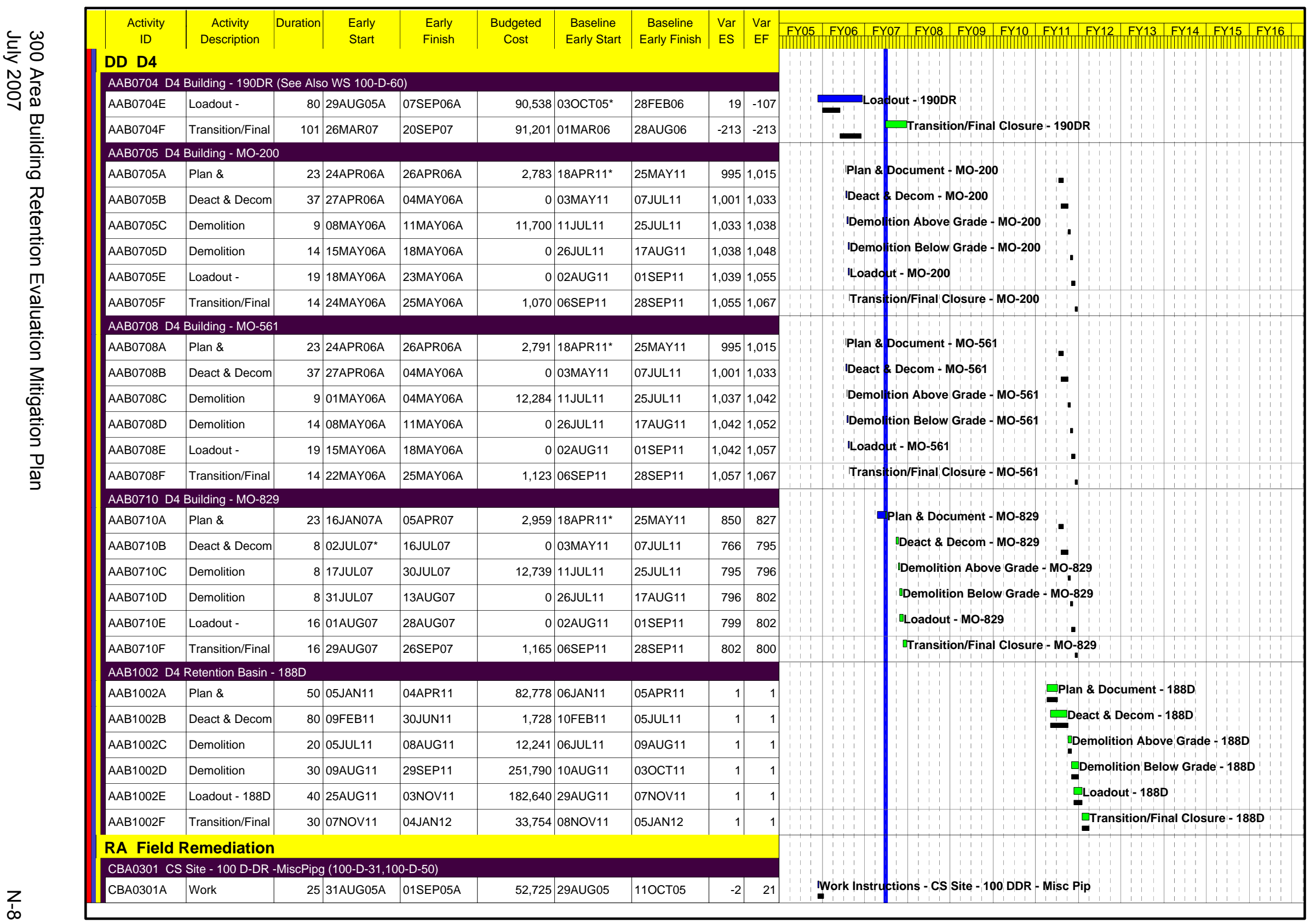




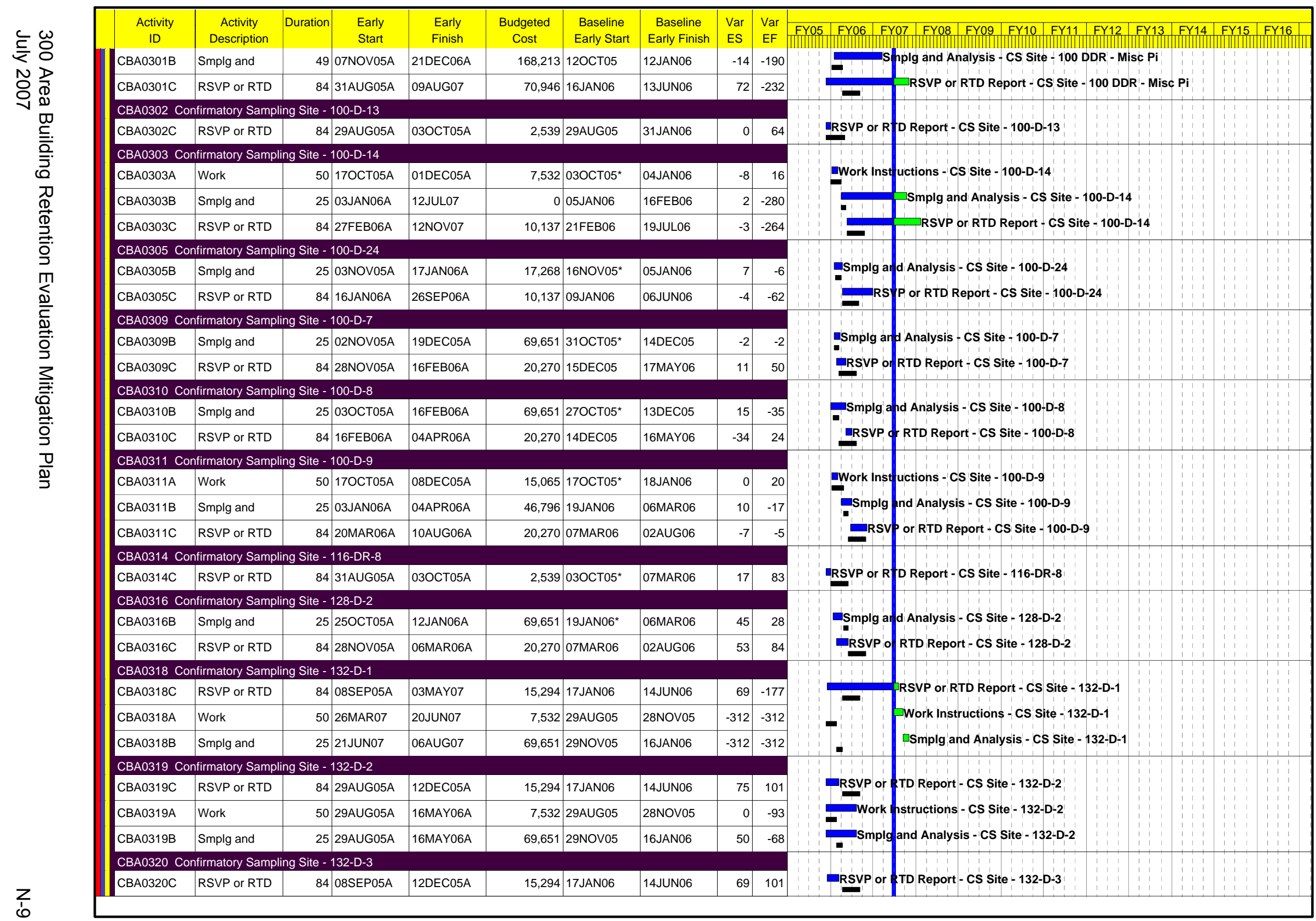

Sheet 9 of 127 


\begin{tabular}{|c|c|c|c|c|c|c|c|c|c|c|c|c|}
\hline \multirow{2}{*}{\multicolumn{2}{|c|}{ 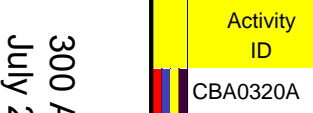 }} & $\begin{array}{l}\text { Activity } \\
\text { Description }\end{array}$ & $\begin{array}{l}\text { Early } \\
\text { Start }\end{array}$ & $\begin{array}{l}\text { Early } \\
\text { Finish }\end{array}$ & $\begin{array}{l}\text { Budgeted } \\
\text { Cost }\end{array}$ & $\begin{array}{l}\text { Baseline } \\
\text { Early Start }\end{array}$ & $\begin{array}{l}\text { Baseline } \\
\text { Early Finish }\end{array}$ & $\begin{array}{l}\text { Var } \\
\text { ES }\end{array}$ & $\begin{array}{l}\text { Var } \\
\mathrm{EF}\end{array}$ & \multirow{2}{*}{\multicolumn{3}{|c|}{ 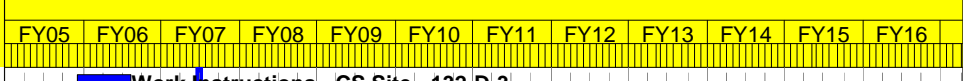 }} \\
\hline & & Work & 50 08SEP05A & 16MAY06A & 15,065 & 29AUG05 & $28 \mathrm{NOV} 05$ & -6 & -93 & \multirow{2}{*}{ - Work } & \multirow{2}{*}{$\begin{array}{l}\text { fstructions - CS Site - 132-D-3 } \\
\text { and Analysis - cS Site - 132-D-3 }\end{array}$} & \\
\hline & СВАОЗ20B & Smplg and & \begin{tabular}{l|l|}
25 & 08SEP05A
\end{tabular} & 16MAY06A & 46,796 & 29NOV05 & 16JAN06 & 44 & -68 & & & \\
\hline & \multicolumn{9}{|c|}{ CBA0321 Confirmatory Sampling Site - 132-DR-1 } & \multirow{2}{*}{ Work Instru } & \multirow{4}{*}{$\begin{array}{l}\text { ctions - CS Site - 132-DR-1 } \\
\text { Analysis - CS Site - 132-DR-1 } \\
\text { D Report - CS Site - 132-DR-1 }\end{array}$} & \\
\hline & СВА0321A & Work & 50 ОзОст05А & Озост05А & 15,065 & 29AUG05 & 28NOV05 & -19 & 30 & & & \\
\hline & СВА0321B & Smplg and & \begin{tabular}{l|l|}
25 & $030 С т 05 \mathrm{~A}$ \\
\end{tabular} & 0зост05А & 46,796 & 29NOV05 & 16JAN06 & 31 & 55 & & & \\
\hline & СBA0321C & RSVP or RTD & 84 ОзОсто5А & Озост05А & 20,270 & 17JAN06 & 14JUN06 & 56 & 139 & & & \\
\hline & \multicolumn{9}{|c|}{ CBA0322 Confirmatory Sampling Site - 1607-D1 } & \multirow{4}{*}{ Work Inst } & \multirow{4}{*}{$\begin{array}{l}\text { uctions - CS Site - 1607-D1 } \\
\text { Analysis - CS Site - 1607-D1 } \\
\text { or RTD Report - CS Site - 1607-D1 }\end{array}$} & \\
\hline & СВА0З22А & Work & 50 170Ст05A & O8DEC05A & 7,532 & 310сто5* & 01FEB06 & 8 & 28 & & & \\
\hline F & СВА0З22B & Smplg and & $\begin{array}{ll}25 & 29 D E C 05 A \\
\end{array}$ & 16FEB06A & 29,530 & O2FEB06 & 20MAR06 & 19 & 16 & & & \\
\hline 1 & СВА0322C & RSVP or RTD & \begin{tabular}{l|l}
84 & $21 \mathrm{FEB} 06 \mathrm{~A}$ \\
\end{tabular} & 13JUN06A & 20,270 & 21MAR06 & 16AUG06 & 16 & 36 & & & \\
\hline$=$ & \multicolumn{9}{|c|}{ CBA0323 Confirmatory Sampling Site - 1607-D4 } & \multirow{3}{*}{$\sigma^{R S V P}$ o } & \multirow{13}{*}{$\begin{array}{l}\text { RTD Report - CS Site - 1607-D4 } \\
\text { Analysis - CS Site - 1607-D5 } \\
\text { RTD Report - CS Site - 1607-D5 }\end{array}$} & \\
\hline t. & СВАОЗ2ЗС & RSVP or RTD & $\begin{array}{lll}84 & 29 A U G 05 A \\
\end{array}$ & 27FEB06A & 2,539 & 29AUG05 & 31JAN06 & 0 & 14 & & & \\
\hline 5 & CBA0324 C & onfirmatory Samp & ling Site - 1607-D5 & & & & & & & & & \\
\hline & СВАОЗ24В & Smplg and & 1 0зОсто5А & 29SEP05A & 29,530 & 29AUG05 & 29AUG05 & -19 & -18 & \multirow{2}{*}{ ISmplg and $A$} & & \\
\hline & СВАОЗ24С & RSVP or RTD & 84 12JAN06A & 30JANO6A & 20,270 & 29AUG05 & 31JAN06 & -73 & & & & \\
\hline & \multicolumn{9}{|c|}{ CBA0328 Confirmatory Sampling Site - 100-D-65 } & \multirow{8}{*}{$\begin{array}{c}\text { EWork Inst } \\
\text { SSmplg } \\
\text { IRSVP } \\
\text { ENork Inst } \\
\text { ISmplg } \\
\text { IRSVP }\end{array}$} & & \\
\hline & СВА0328A & Work & 50 ОзОст05А & O8DEC05A & 22,596 & Озосто5* & 04JANO6 & 0 & 12 & & & \\
\hline & СВА0З28B & Smplg and & 25 O4JANO6A & 29MAR06A & 80,594 & 05JAN06 & 16FEB06 & 1 & -22 & & & \\
\hline & СВА0328C & RSVP or RTD & 84 20MAR06A & 26APR06A & 30,406 & 21FEB06 & 19JUL06 & -15 & 46 & & & \\
\hline & \multicolumn{9}{|c|}{ CBA0329 Confirmatory Sampling Site - 100-D-66 } & & & \\
\hline & СВАОЗ29A & Work & 50 ОЗОСТ05А & 08DEC05A & 22,596 & 170ст05* & 18JAN06 & 8 & 20 & & & \\
\hline & СВА0329B & Smplg and & \begin{tabular}{l|l|}
25 & O5JANO6A \\
\end{tabular} & 29MAR06A & 80,594 & 19JAN06 & 06MAR06 & 8 & -14 & & & \\
\hline & СВА0329C & RSVP or RTD & 84 20MAR06A & 26APR06A & 30,406 & O7MAR06 & 02AUG06 & -7 & 54 & & & \\
\hline & CBA0330 C & onfirmatory Samp & ling Site - 100-D-67 & & & & & & & & & \\
\hline & СВАОЗЗОА & Work & 50 120ст05A & 27DEC05A & 15,065 & 310ст05* & 01FEB06 & 10 & 20 & Wo & fuctions - CS Site - 100-D-67 & \\
\hline & СВАОЗЗОВ & Smplg and & \begin{tabular}{l|l|}
25 & $09 F E B 06 A$ \\
\end{tabular} & O9FEB06A & 55,062 & 02FEB06 & 20MAR06 & -4 & 20 & & hd Analysis - CS Site - 100-D-67 & \\
\hline & СВАОЗ3ОС & RSVP or RTD & 84 O9FEB06A & 23FEB06A & 20,270 & 21MAR06 & 16AUG06 & 21 & 97 & IRSVP of & RTD Report - CS Site - 100-D-67 & \\
\hline & CBA0331 C & onfirmatory Samp & ling Site - 100-D-62 & & & & & & & & & \\
\hline & СВА0З31А & Work & 50 010ст07* & 02JAN08 & 15,065 & озосто5* & O4JAN06 & -398 & -398 & = & $\square$ Work Instructions - CS Site - 100-D-62 & \\
\hline & СВА0З31B & Smplg and & 25 O3JAN08 & 14FEB08 & 55,062 & 05JAN06 & 16FEB06 & -398 & -398 & & $\square$ ¿Smplg and Analysis - CS Site - 100-D-62 & \\
\hline & СВА0З31C & RSVP or RTD & \begin{tabular}{l|l|}
84 & $19 F E B 08$ \\
\end{tabular} & 16JUL08 & 20,270 & 21FEB06 & 19JUL06 & -398 & -398 & & $\square R S V P$ or RTD Report - CS Site - 100-D-62 & \\
\hline & CBA0332 C & onfirmatory Samp & ling Site - 100-D-63 & & & & & & & & & \\
\hline & СВА0З32A & Work & 50 010ст07* & 02JAN08 & 82,852 & озосто5* & 04JAN06 & -398 & -398 & $\mathbf{E}$ & $\square$ Work Instructions - CS Site - 100-D-63 & \\
\hline & СВАОЗЗ2В & Smplg and & 25 O3JAN08 & 14FEB08 & 269,834 & 05JAN06 & 16FEB06 & -398 & -398 & & $\square$ पSmplg and Analysis - CS Site - 100-D-63 & \\
\hline & СВА0З32С & RSVP or RTD & 84 19FEB08 & 16JUL08 & 111,488 & 21FEB06 & 19JUL06 & -398 & -398 & & $\square R S V P$ or RTD Report - CS Site - 100-D-63 & \\
\hline
\end{tabular}




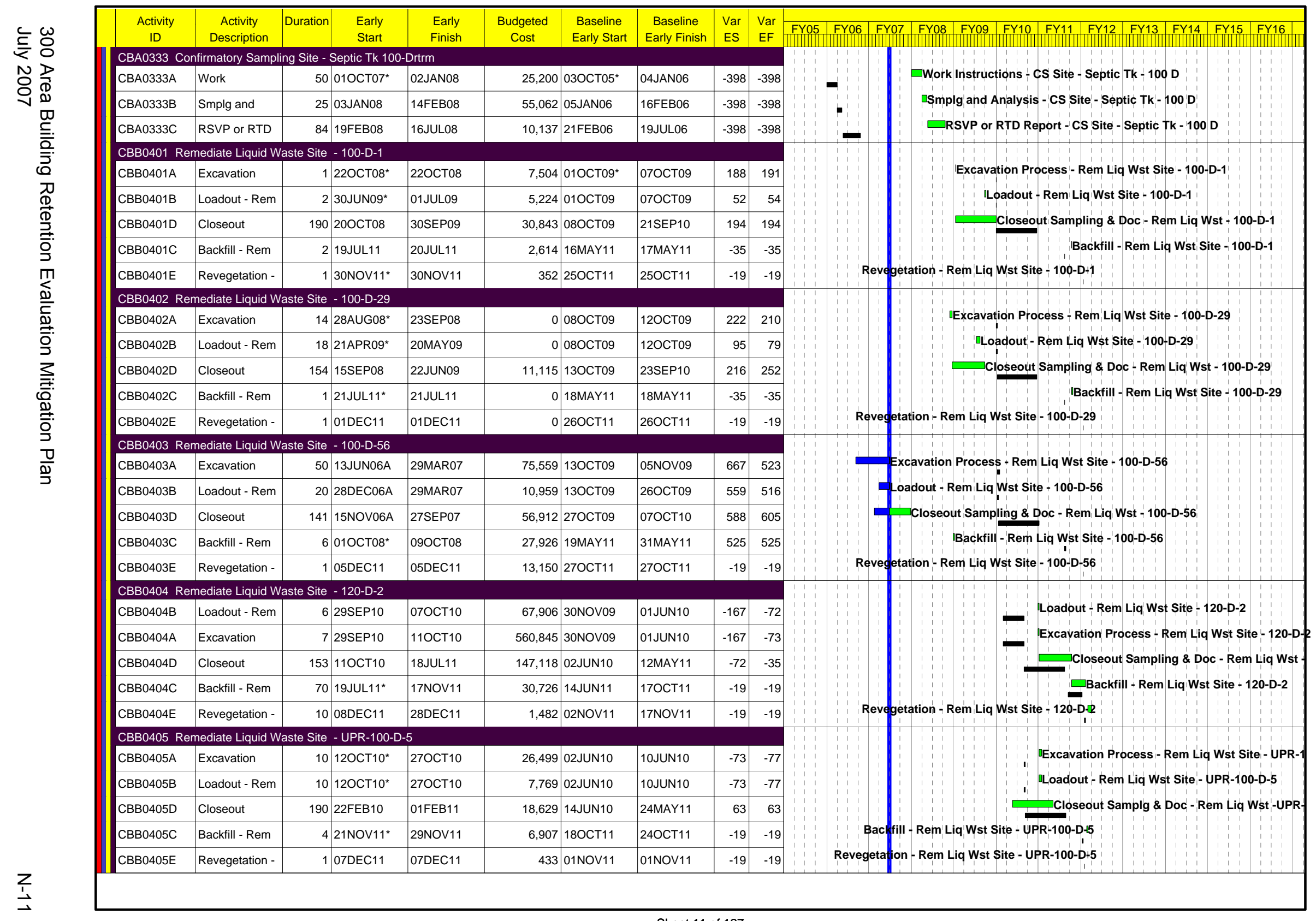




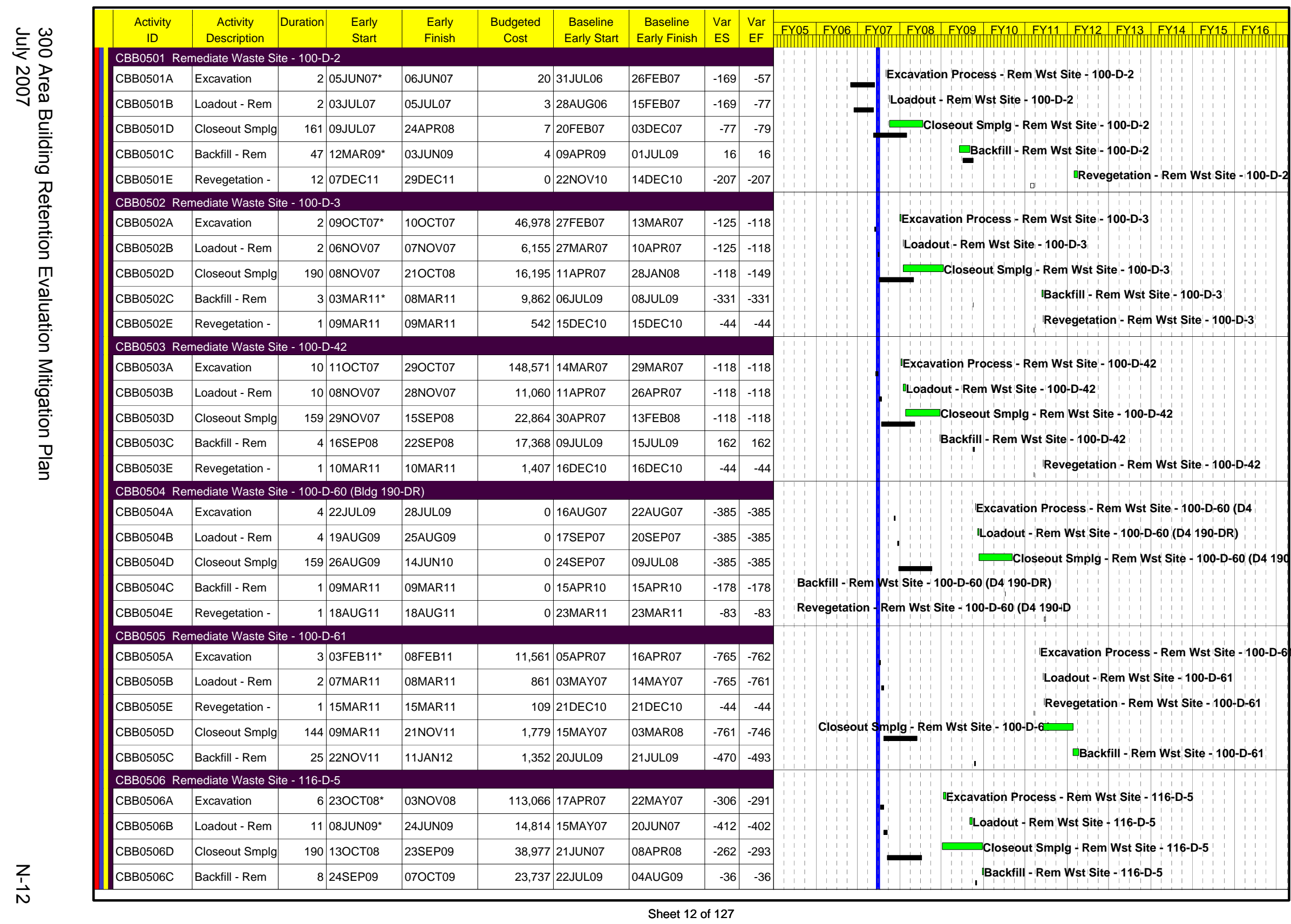




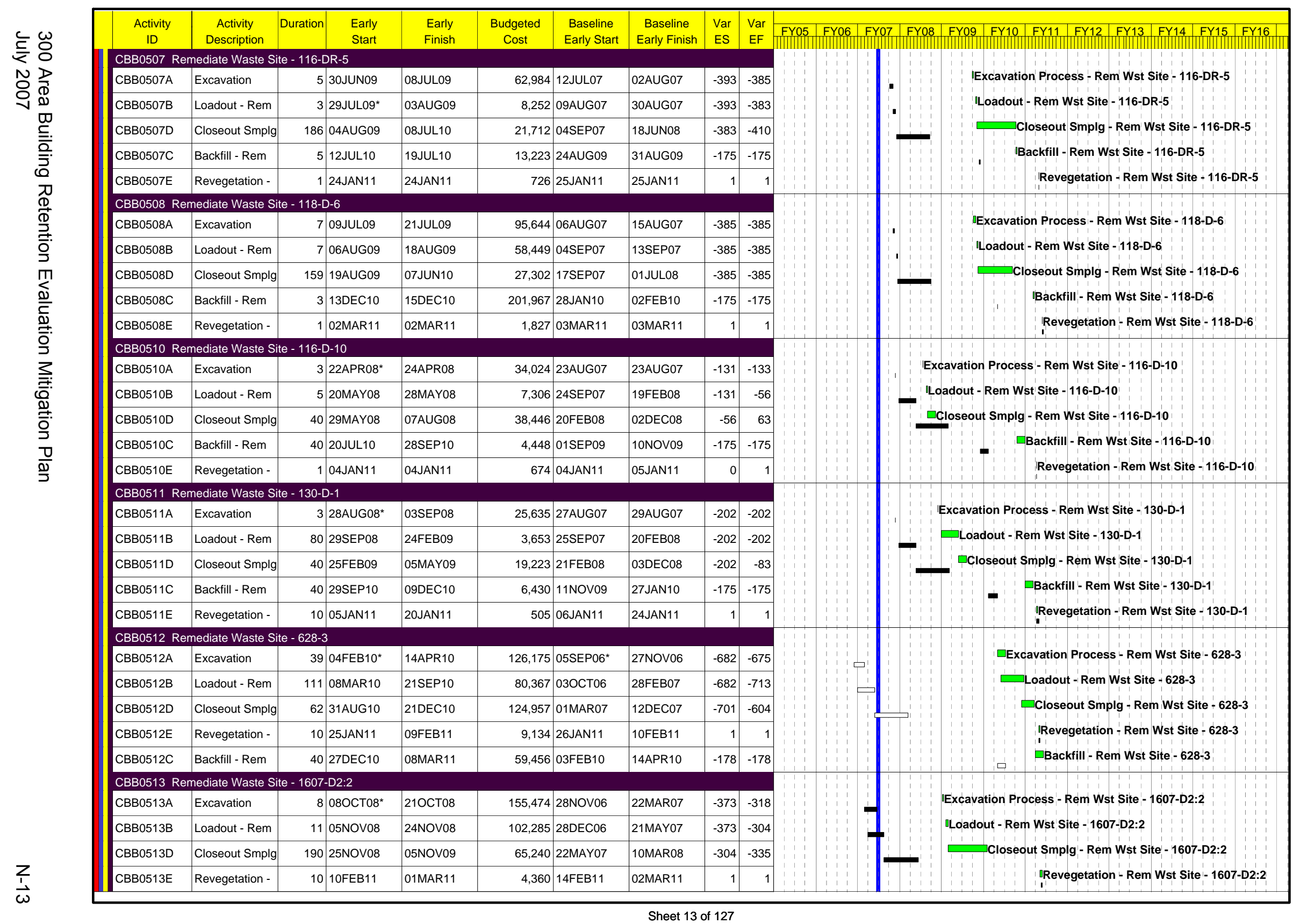




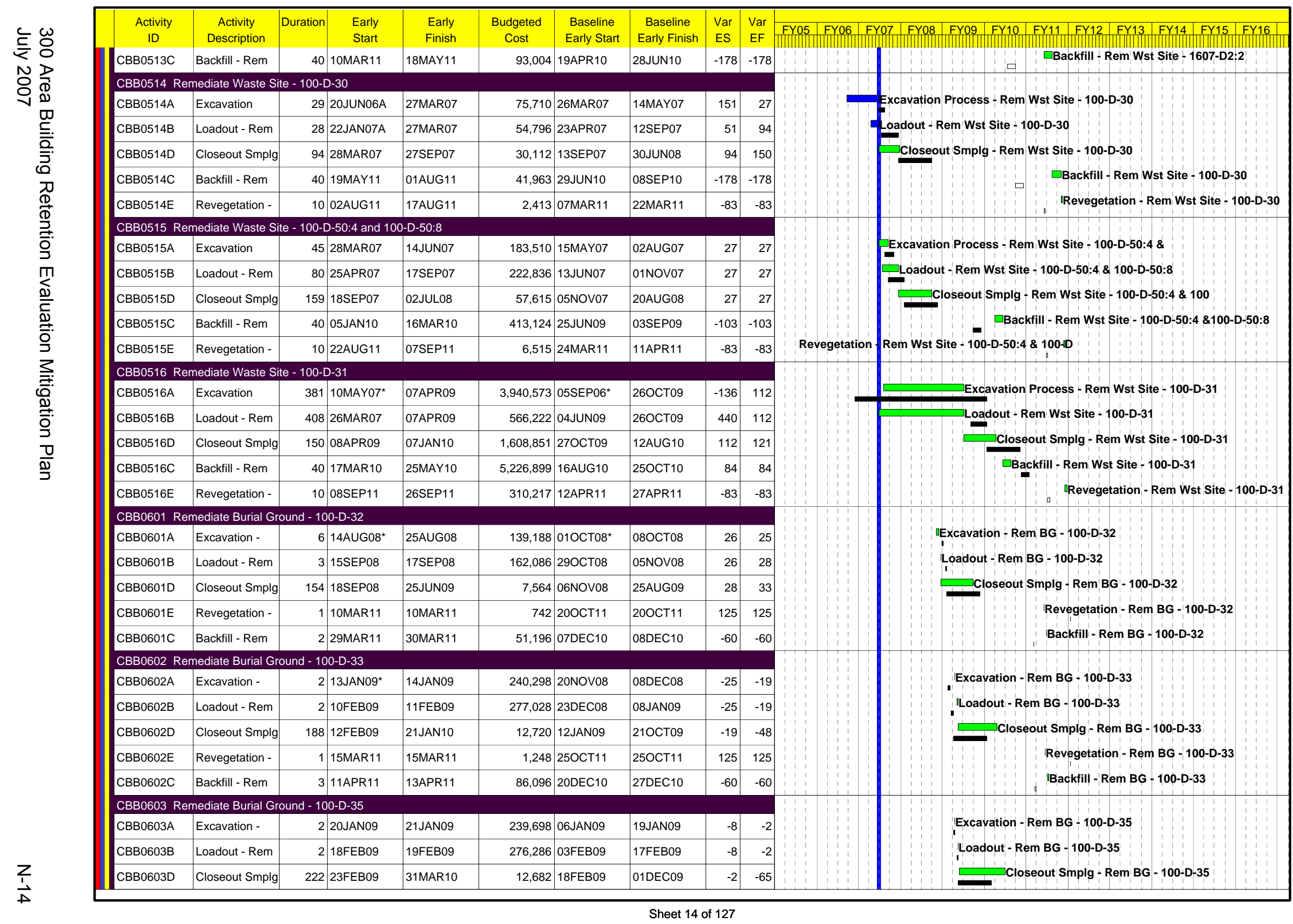




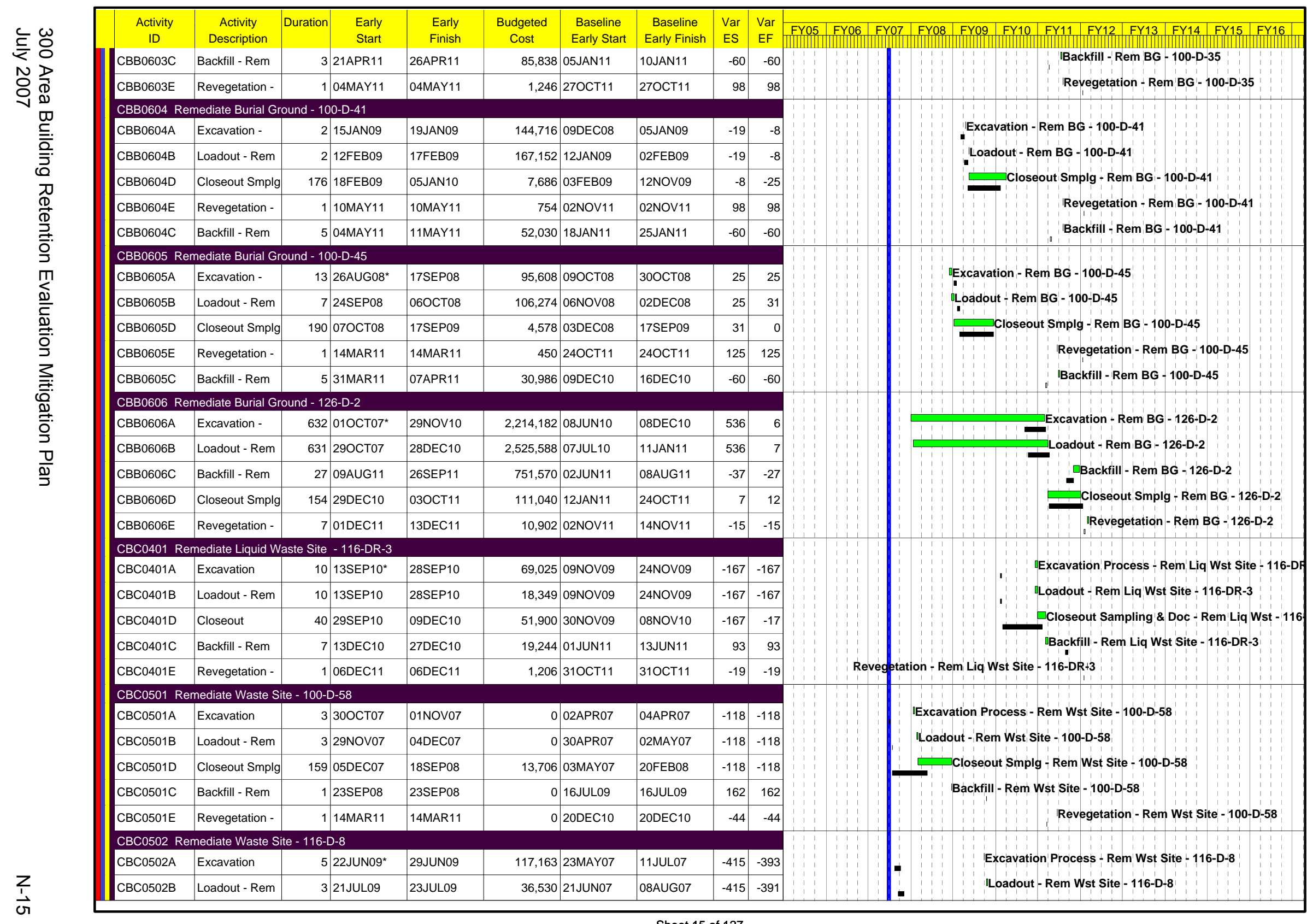




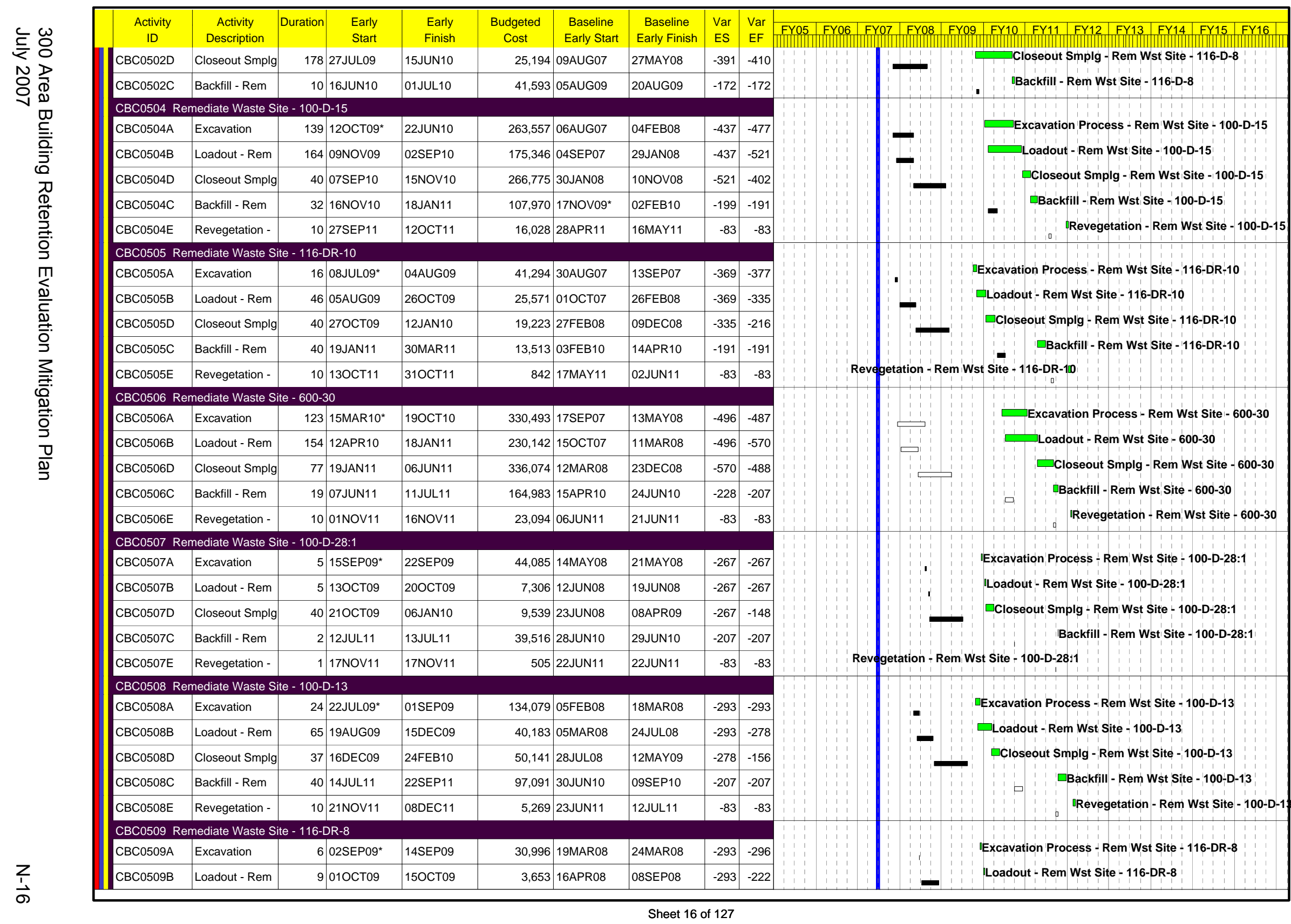




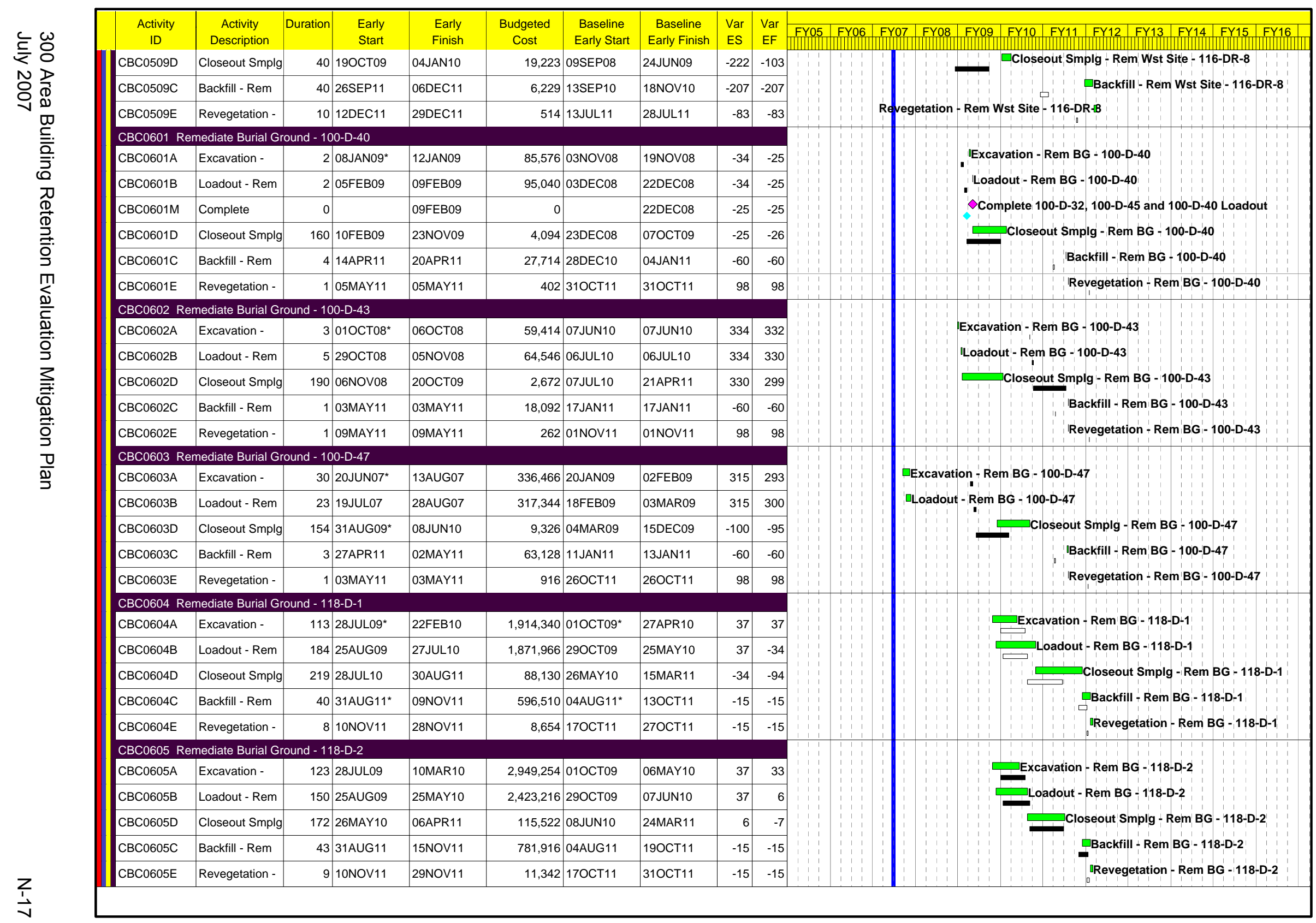




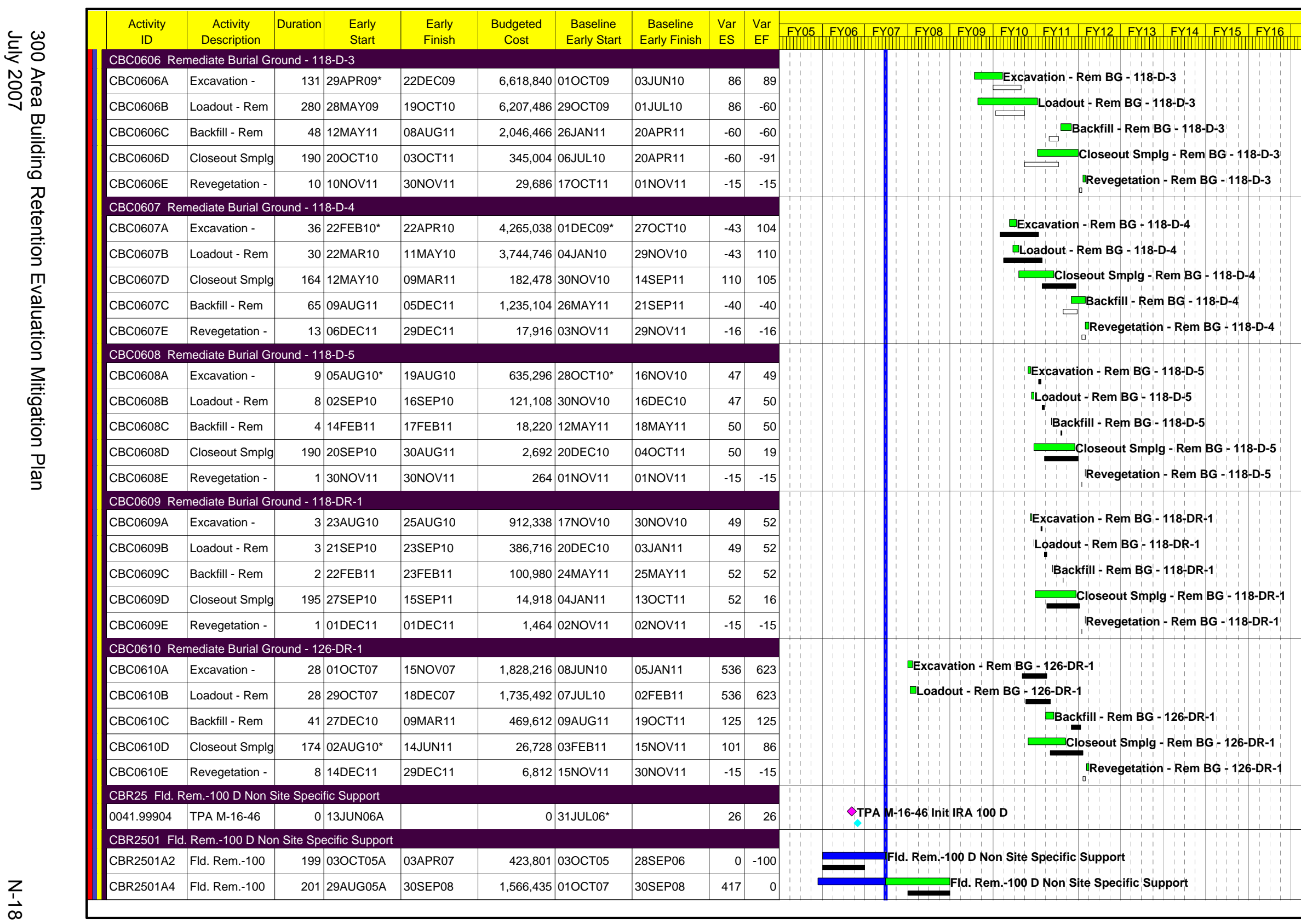




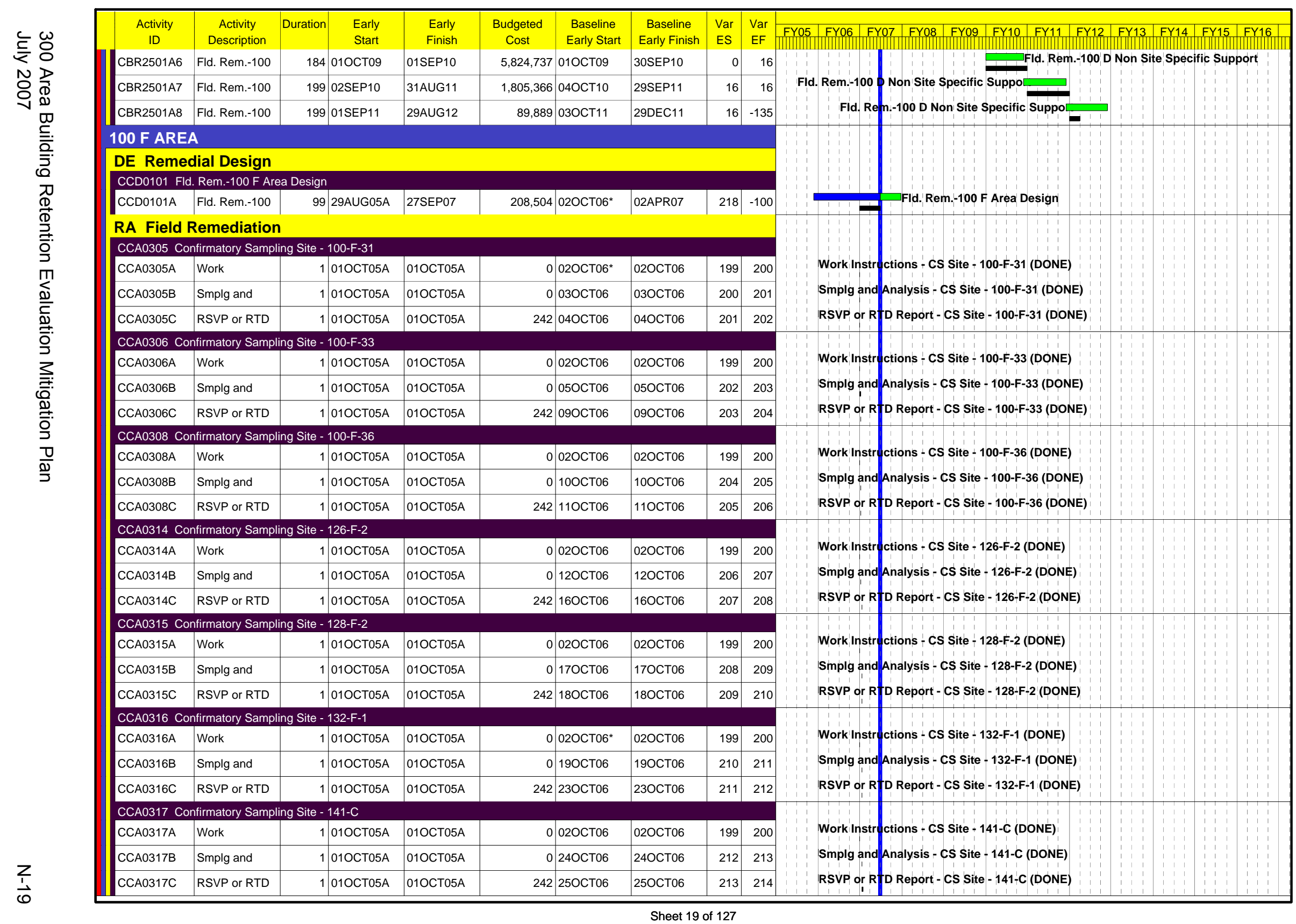




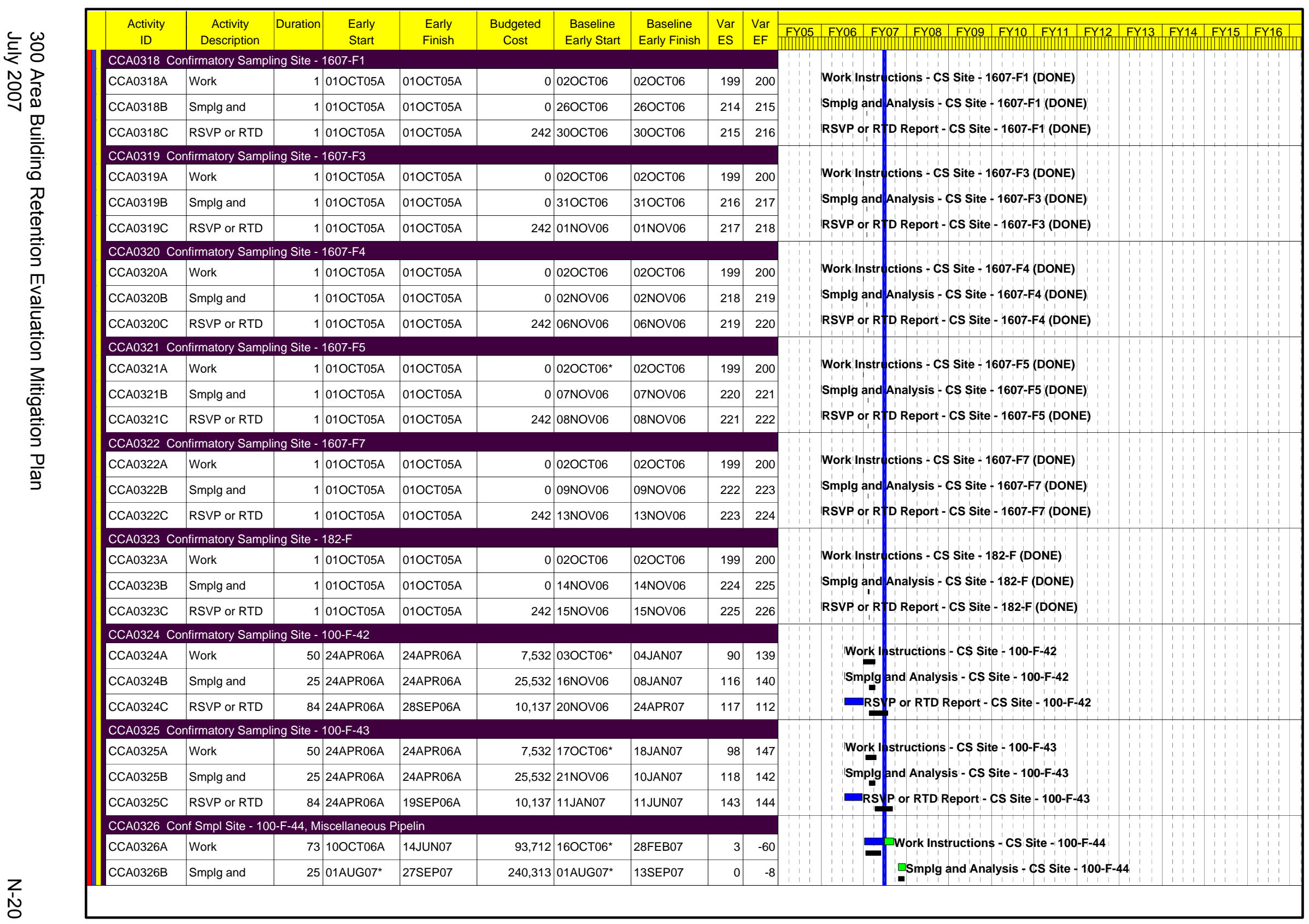




\begin{tabular}{|c|c|c|c|c|c|c|c|c|c|c|c|}
\hline$€ \omega$ & $\begin{array}{l}\text { Activity } \\
\text { ID }\end{array}$ & $\begin{array}{c}\text { Activity } \\
\text { Description }\end{array}$ & Duration & $\begin{array}{l}\text { Early } \\
\text { Start }\end{array}$ & $\begin{array}{l}\text { Early } \\
\text { Finish }\end{array}$ & $\begin{array}{l}\text { Budgeted } \\
\text { Cost }\end{array}$ & $\begin{array}{l}\text { Baseline } \\
\text { Early Start }\end{array}$ & $\begin{array}{l}\text { Baseline } \\
\text { Early Finish }\end{array}$ & $\begin{array}{ll}\text { Var } & \text { Var } \\
\text { ES } & E F\end{array}$ & 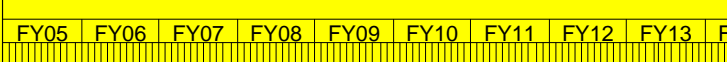 & $\begin{array}{l}\text { Y14 } \\
\text { YY15 }\end{array}$ \\
\hline & CCA0327 C & If Smpl Site - $1 \mathrm{c}$ & 0-F-41, Se & Service Water & Sipelin & & & & & & \\
\hline & ССА0327A & Work & & 307DEC06A & 15FEB07A & 13,977 & 160 сто6* & 28FEB07 & -29 & IInstructions - CS Site - 100-F-41 & \\
\hline & CCA0327B & Smplg and & 25 & 21FEB07A & 21FEB07A & 25,792 & $01 \mathrm{MAR} 07^{*}$ & 12APR07 & \begin{tabular}{c|c|cccc}
5 & 29 \\
\end{tabular} & mplg and Analysis - CS Site - 100-F-41 & \\
\hline & CСA0327C & RSVP or RTD & & 4 21FEB07A & 21FEB07A & 12,012 & 16APR07 & 12SEP07 & \begin{tabular}{l|l}
30 & 113 \\
\end{tabular} & SVP or RTD Report - CS Site - 100-F-41 & \\
\hline & CCA0328 C & nf Smpl Site - 1 & $0-F-45, \mathrm{Bu}$ & Buried River E & iluent & & & & & & \\
\hline & ССА0328A & Work & & 27DEC06A & 15MAY07 & 13,977 & 160 ст06* & 28FEB07 & 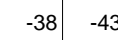 & Work Instructions - cS Site - 100-F-45 & \\
\hline & CСA0329 C & If Smpl Site - 1 & 0-F-46, 11 & 19-F Stack S & mplg BI & & & & & & \\
\hline & ССАОЗ29A & Work & & $3110 C T 06 \mathrm{~A}$ & 14DEC06A & 13,977 & 160 сто6* & 28FEB07 & 2 & Mprk Instructions - CS Site - 100-F-46 & \\
\hline & CCA0330 C & If Smpl Site - 1 & 0-F-55, 16 & 607-F Contan & inated $A$ & & & & & & \\
\hline & ССАОЗЗОВ & Sampg and & & 5 22FEB07A & 22FEB07A & 17,439 & 12MAR07* & 23APR07 & \begin{tabular}{c|cccrl}
9 & 33
\end{tabular} & ampg and Analysis - CS Site - 100-F-55 & \\
\hline & CCA0330A & Work & & 721DECO6A & 27FEB07A & 13,977 & O6NOV06* & 21MAR07 & -25 & k Instructions - cS Site - 100-F-55 & \\
\hline & ССАОЗЗОС & RSVP or RTD & & 4 22FEB07A & 07JUN07 & 12,012 & 24APR07 & 20SEP07 & 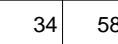 & RSVP or RTD Report - CS Site - 100-F-55 & \\
\hline & CCA0331 C & Inf Smpl Site - $1 \mathrm{c}$ & $0-F-47,15$ & 51-F Substati & & & & & & & \\
\hline & ССАОЗЗ1A & Work & 57 & 721DEC06A & 24MAY07 & 13,977 & 230сто6* & 07MAR07 & -33 & Work Instructions - CS Site - 100-F-47 & \\
\hline & CCA0331B & Sampg and & & 5 07APR08* & 19MAY08 & 40,443 & 06AUG07* & 18SEP07 & \begin{tabular}{|l|l|l|l|l|l|l}
-133 & -133 \\
\end{tabular} & ISampg and Analysis - CS Site - 100-F-47 & \\
\hline & ССАОЗЗ1С & RSVP or RTD & & 4 20MAY08 & 160сто8 & 12,012 & 010сто7* & 04MAR08 & \begin{tabular}{|l|l|l|l|l|l|l}
-127 & -127 \\
\end{tabular} & $\square$ RSVP or RTD Report - CS Site - 100-F-4 & \\
\hline & CCA0333 C & nf Smpl Site - 16 & $0-F-48,18$ & 84-F Coal Pit & Debris & & & & & & \\
\hline & ССАОЗЗЗА & Work & & $718 D E C 06 \mathrm{~A}$ & 16MAY07 & 13,977 & 23осто6* & 07MAR07 & -30 & Work Instructions - CS Site - 100-F-48 & \\
\hline & CСА0З3ЗB & Sampg and & & $529 A \cup G 07^{*}$ & 110ст07 & 40,443 & 15 AUG 07* & 27SEP07 & -8 & पSampg and Analysis - CS Site - 100-F-48 & \\
\hline & CCA0333C & RSVP or RTD & & 4 150ст07 & 18MAR08 & 12,012 & 010ст07 & 04MAR08 & -8 & RSVP or RTD Report - CS Site - 100-F-48 & \\
\hline & CCA0335 C & nf Smpl Site - & $0-F-49,17$ & 716-F Mainte & ance $\mathrm{Ga}$ & & & & & & \\
\hline & CСА0З35А & Work & & $728 \mathrm{NOV} 06 \mathrm{~A}$ & 23MAY07 & 13,977 & 230сто6* & O7MAR07 & 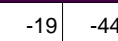 & Work Instructions - cs Site - 100-F-49 & \\
\hline & CCA0336 C & If Smpl Site - 1 (c & 0-F-50, 10 & .00-F Railroad & French & & & & & Work Instructions - cS Site - 100-F-50 & \\
\hline & ССАОЗЗ6А & Work & & $728 \mathrm{NOV} 06 \mathrm{~A}$ & 01MAY07 & 13,977 & $230 \mathrm{OT} 06^{*}$ & O7MAR07 & 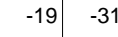 & Work Instructions - CS Site - 100-F-50 & \\
\hline & CCA0337 C & If Smpl Site - & 0-F-51, 14 & 46-F Fish Lat & oratory & & & & & & \\
\hline & ССАОЗ37А & Work & & 719DECO6A & 23MAY07 & 13,977 & 300сто6* & 14MAR07 & -27 & Work Instructions - cs Site - 100-F-51 & \\
\hline & CCA0338 C & nf Smpl Site - & $0-F-52,14$ & 46-FR Radioc & cology/A & & & & & & \\
\hline & ССАОЗЗВА & Work & & 719DECO6A & 23MAY07 & 13,977 & 30осто6* & 14MAR07 & -27 & Work Instructions - CS Site - 100-F-52 & \\
\hline & CCA0339 C & nf Smpl Site - 10 & 0-F-53, 10 & 08-F Septic S & stem & & & & & Instructions - CS Site - 100-F- 53 & \\
\hline & $\begin{array}{l}\text { ССАОЗ39A } \\
\text { CСАОЗ } 40 \text { C }\end{array}$ & Work & \begin{tabular}{|r|}
$0-57,19$ \\
$0-5$
\end{tabular} & $\begin{array}{l}714 \mathrm{DEC} 06 \mathrm{~A} \\
\text { 90-F Animal } \mathrm{F}\end{array}$ & 12FEB07A & 13,977 & 300 TTO6* $^{*}$ & 14MAR07 & & Drk IIstructions - CS Site - 100-F-53 & \\
\hline & CCA0340A & Work & & $706 \mathrm{DEC} 06 \mathrm{~A}$ & 04JUN07 & 13,977 & 300 TTO6* $^{*}$ & 14MAR07 & -20 & Work Instructions - cs Site - 100-F-54 & \\
\hline & 341 & nf Smpl Site & 56,10 & .00-F Surface & ebris/ & & & & & & \\
\hline & CCA0341A & Work & & 721DEC06A & 12JUN07 & 13,977 & o6NOV06* & 21MAR07 & 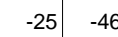 & Work Instructions - cs Site - 100-F-56 & \\
\hline & CCA0342 C 20 & S Site - & 57,19 & F Proc We & er Pump & & & & & & \\
\hline & ССАОЗ $42 \mathrm{~A}$ & Work & 57 & 7 O9JAN07A & 04JUN07 & 13,977 & O6NOV06* & 21MAR07 & 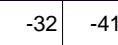 & Work Instructions - cs Site - 100-F-57 & \\
\hline$z$ & CСА0342B & Smplg and & & $505 J U N 08^{*}$ & 21JUL08 & 40,443 & $22 \mathrm{FEB} 07^{*}$ & 05APR07 & \begin{tabular}{|l|l|l|l|l|l|}
-258 & -258 \\
\end{tabular} & ESmplg and Analysis - CS Site - 100-F-57 & \\
\hline
\end{tabular}




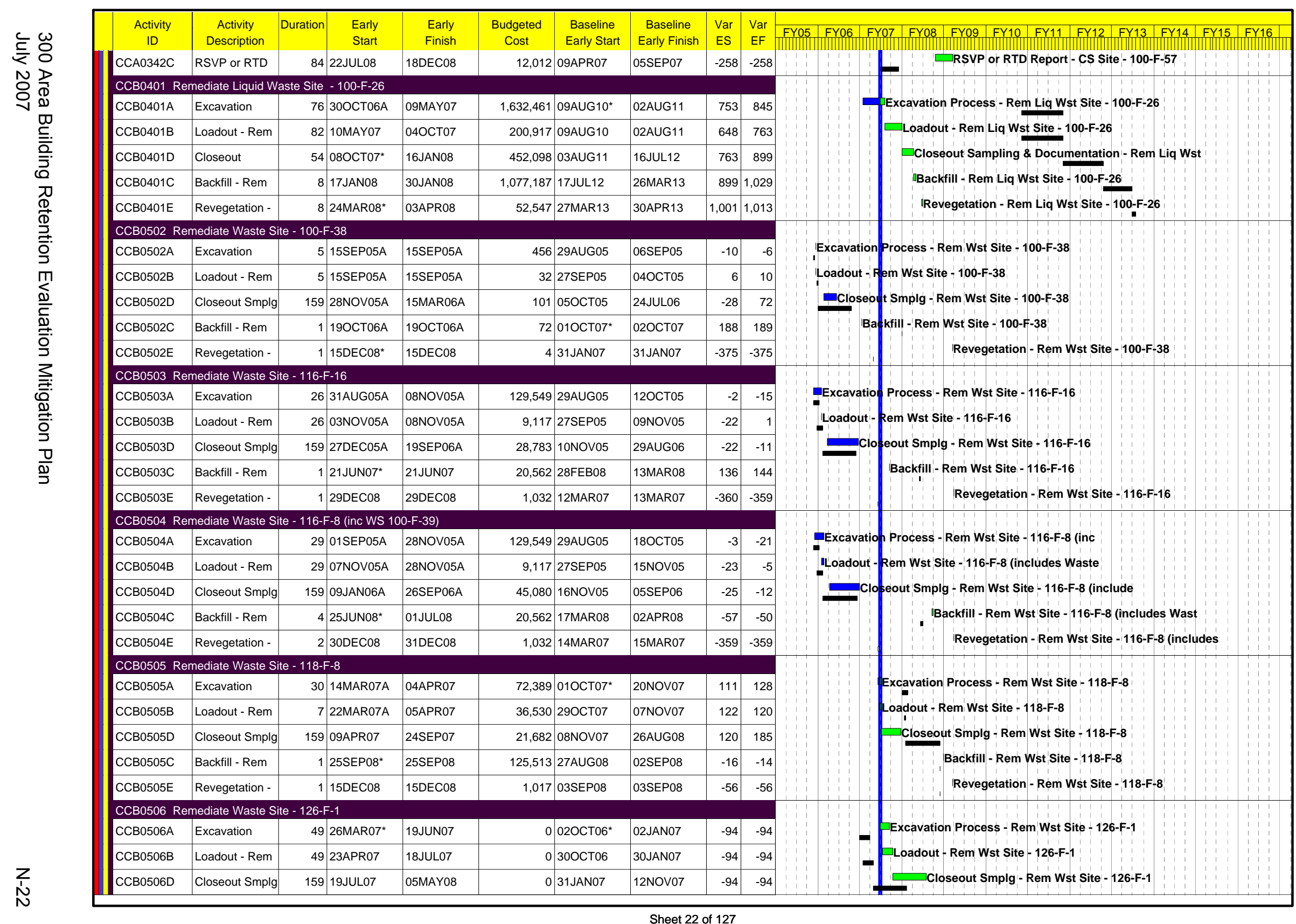




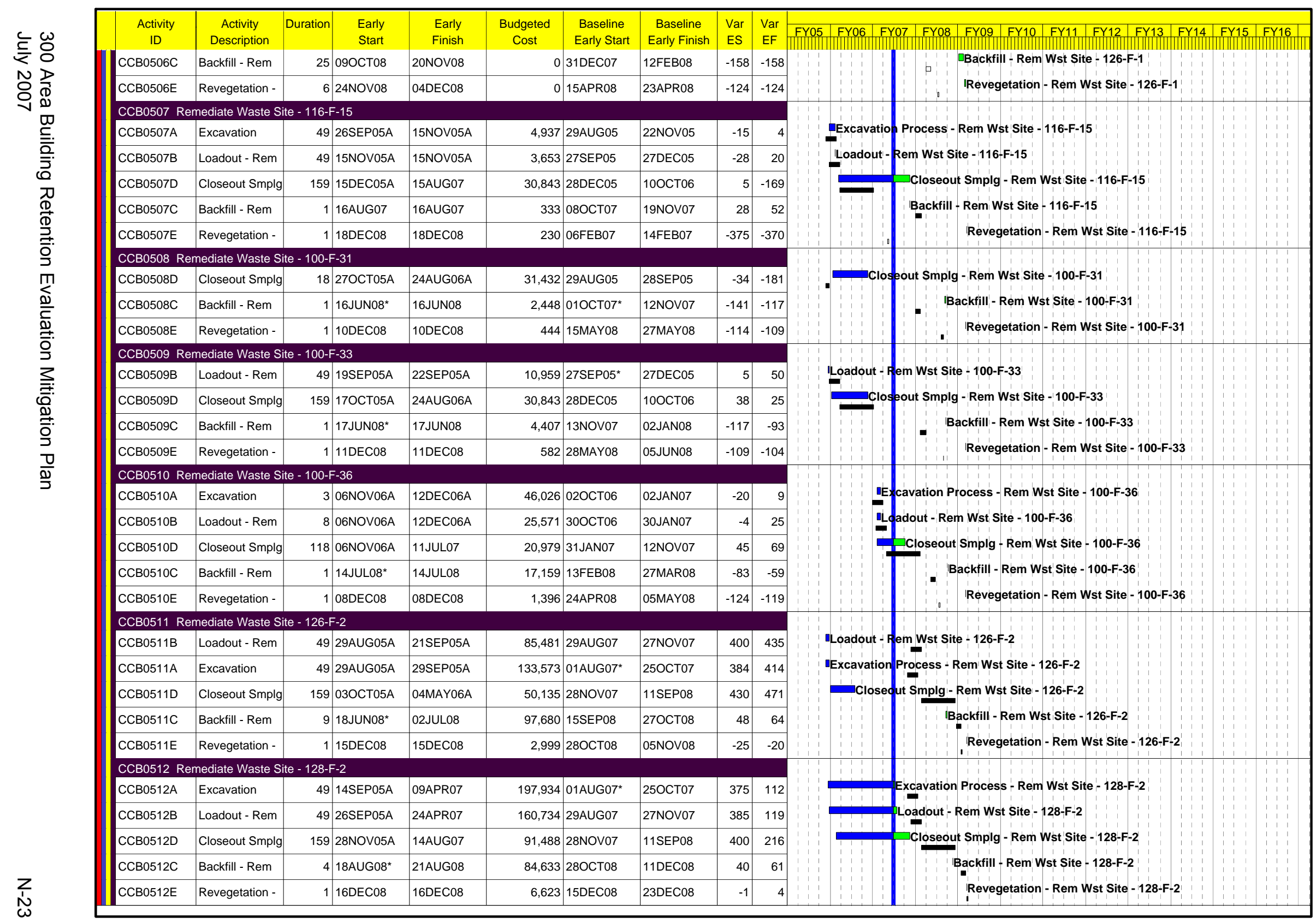

Sheet 23 of 127 


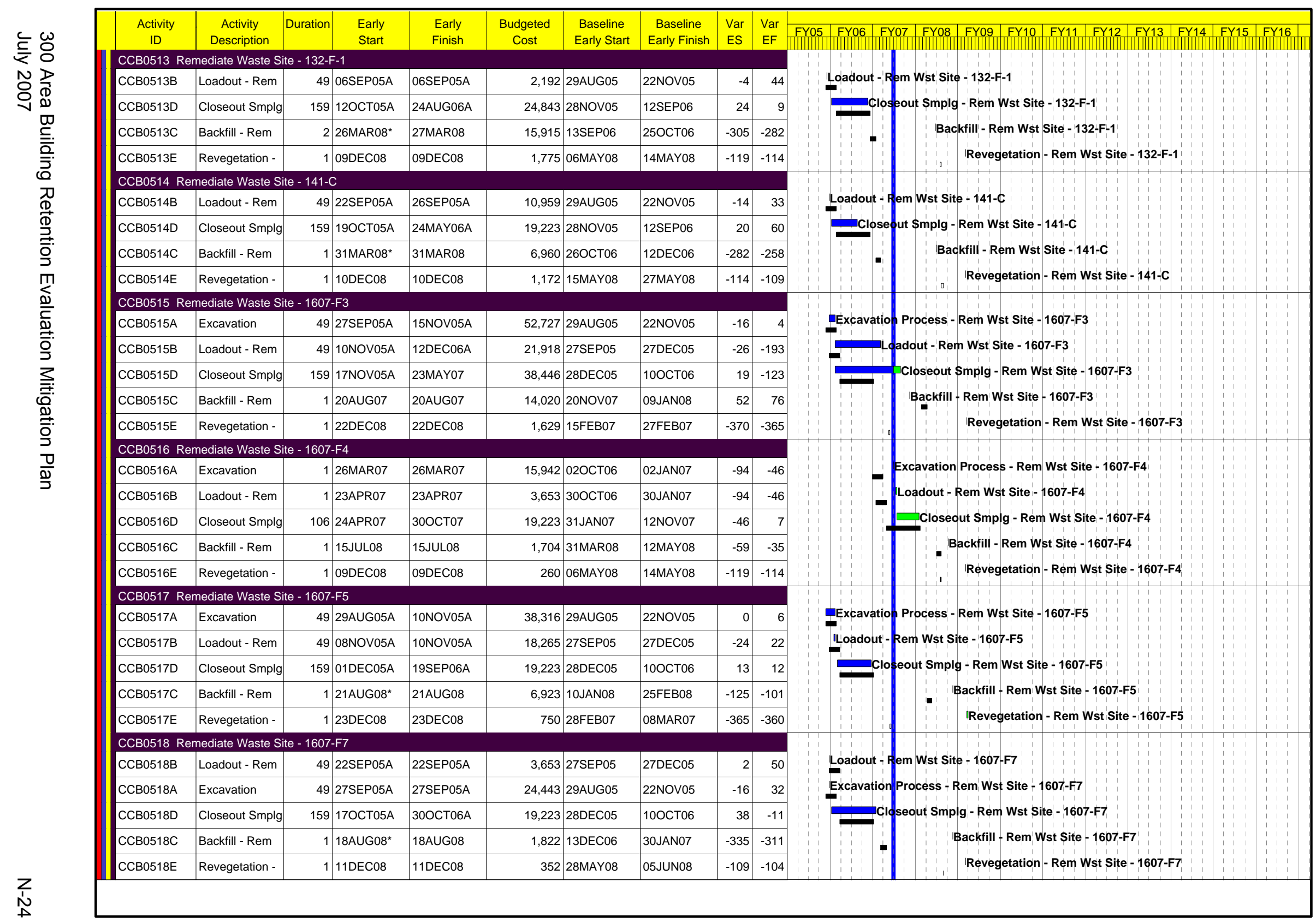




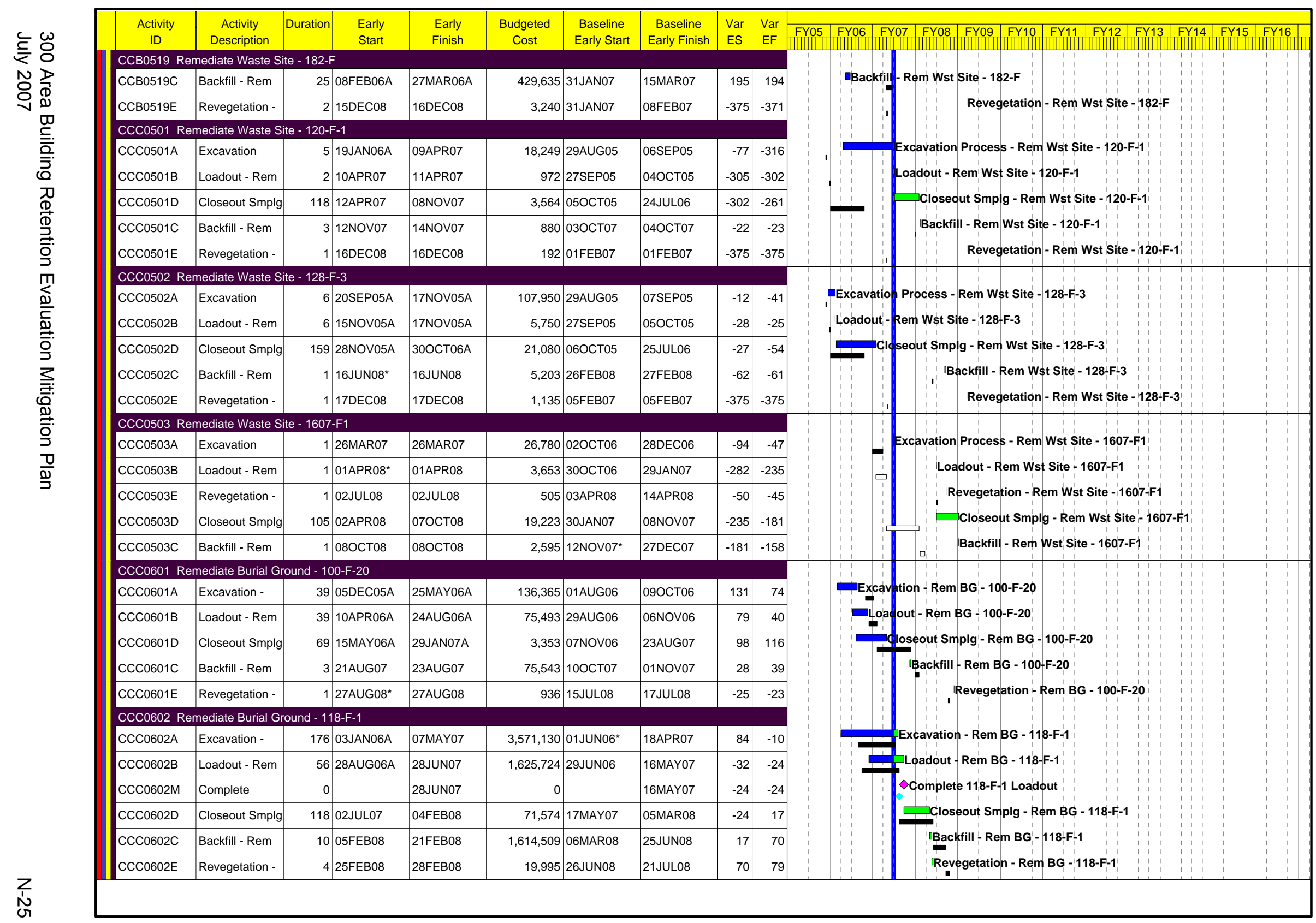




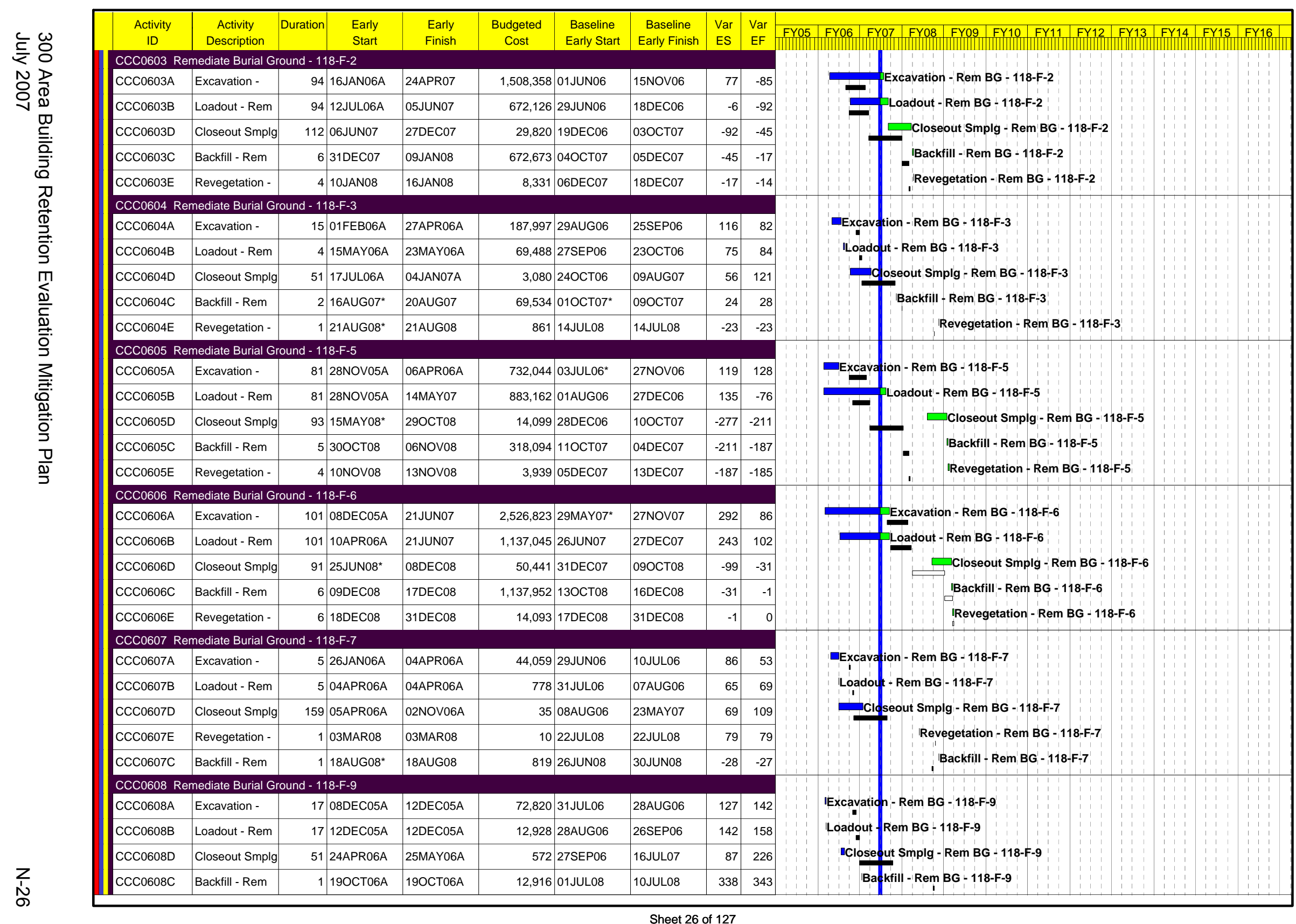




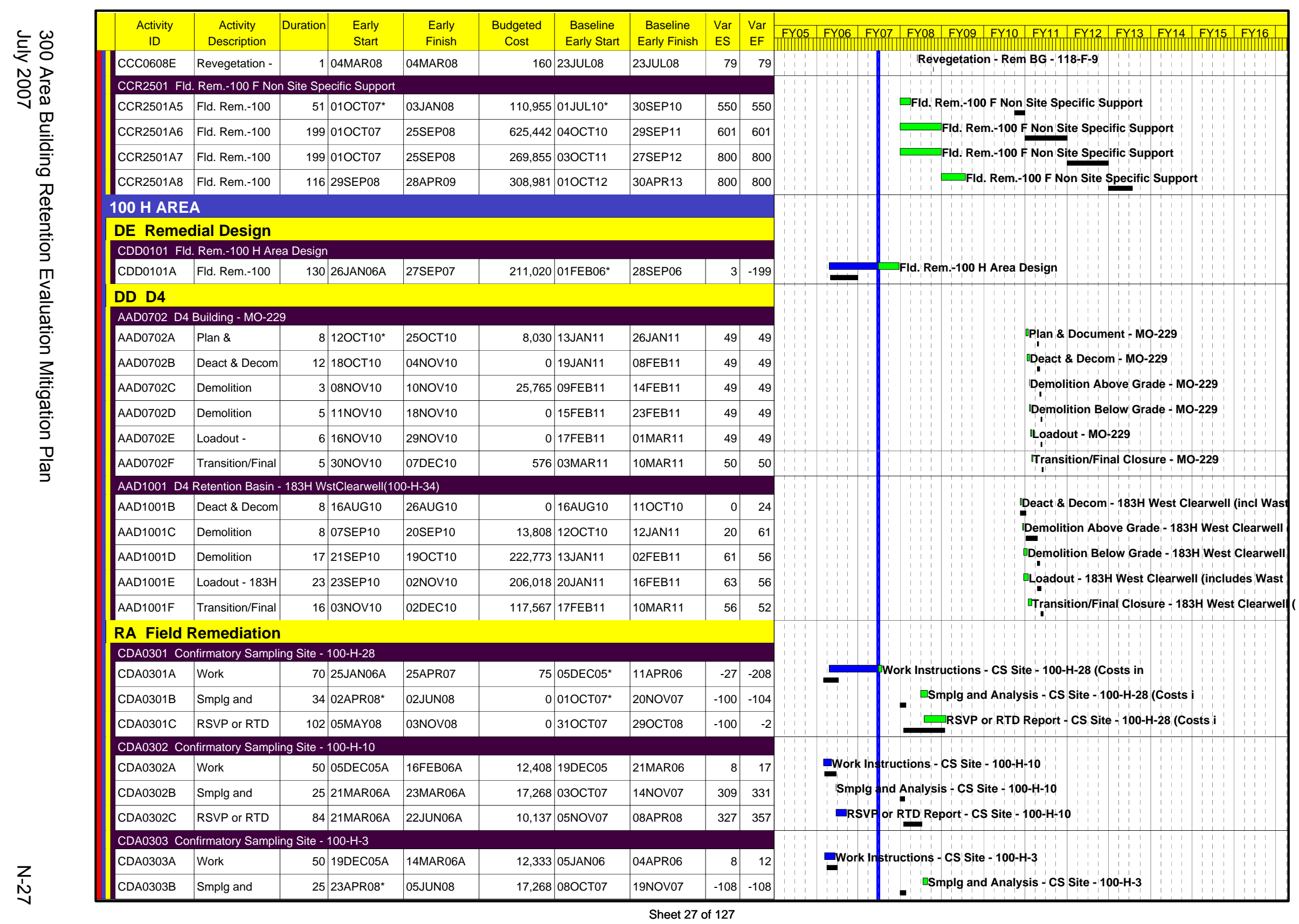




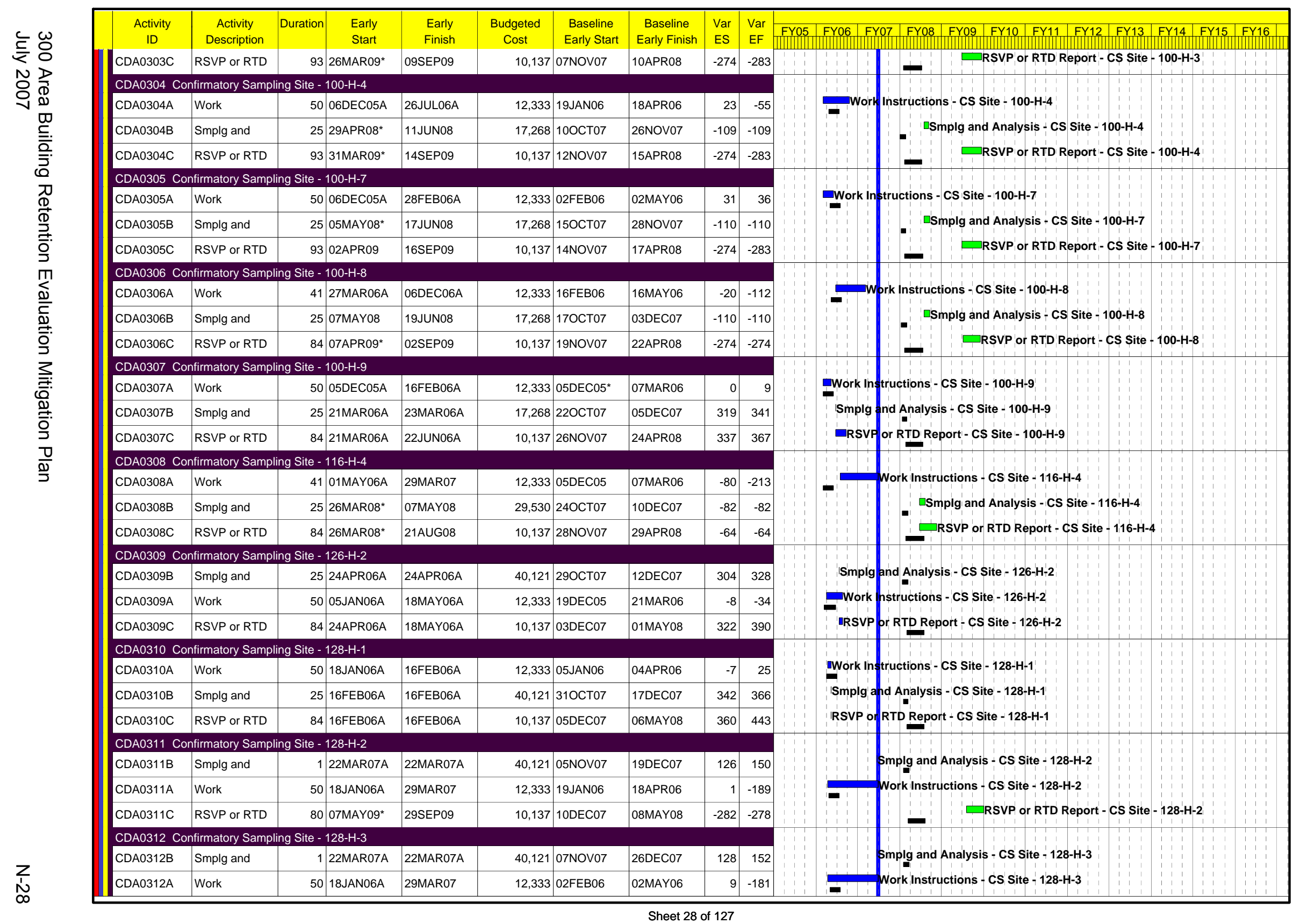




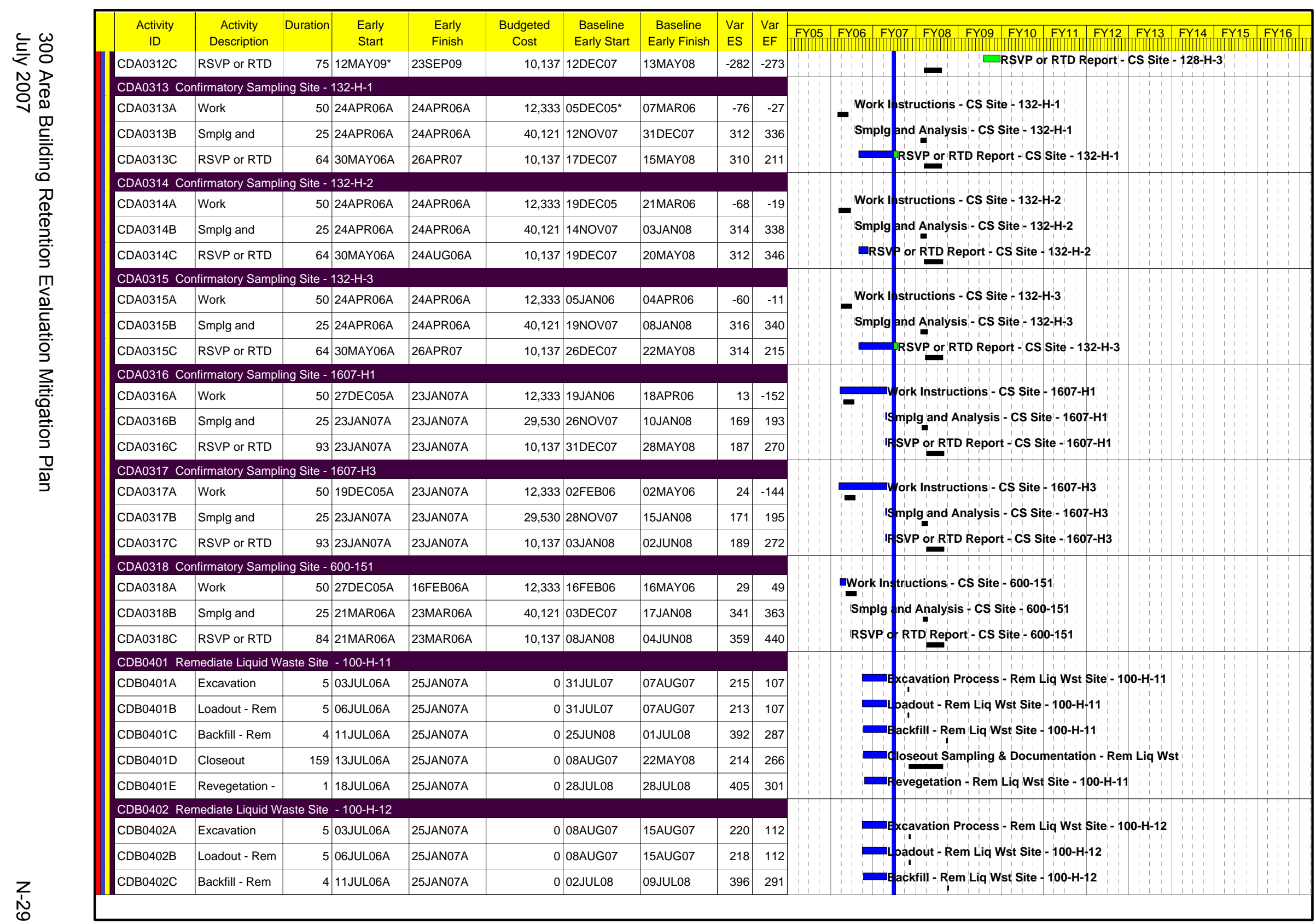




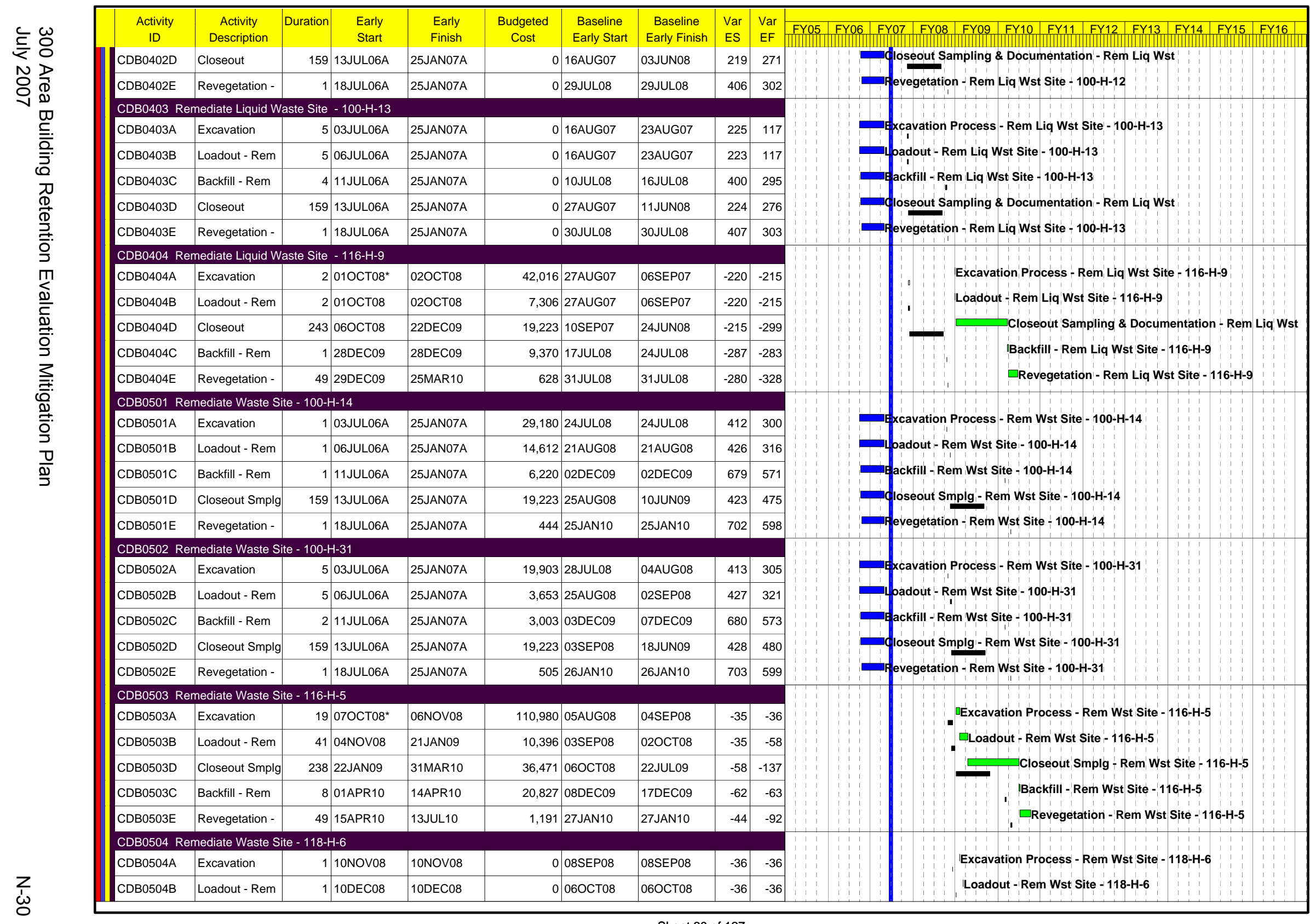




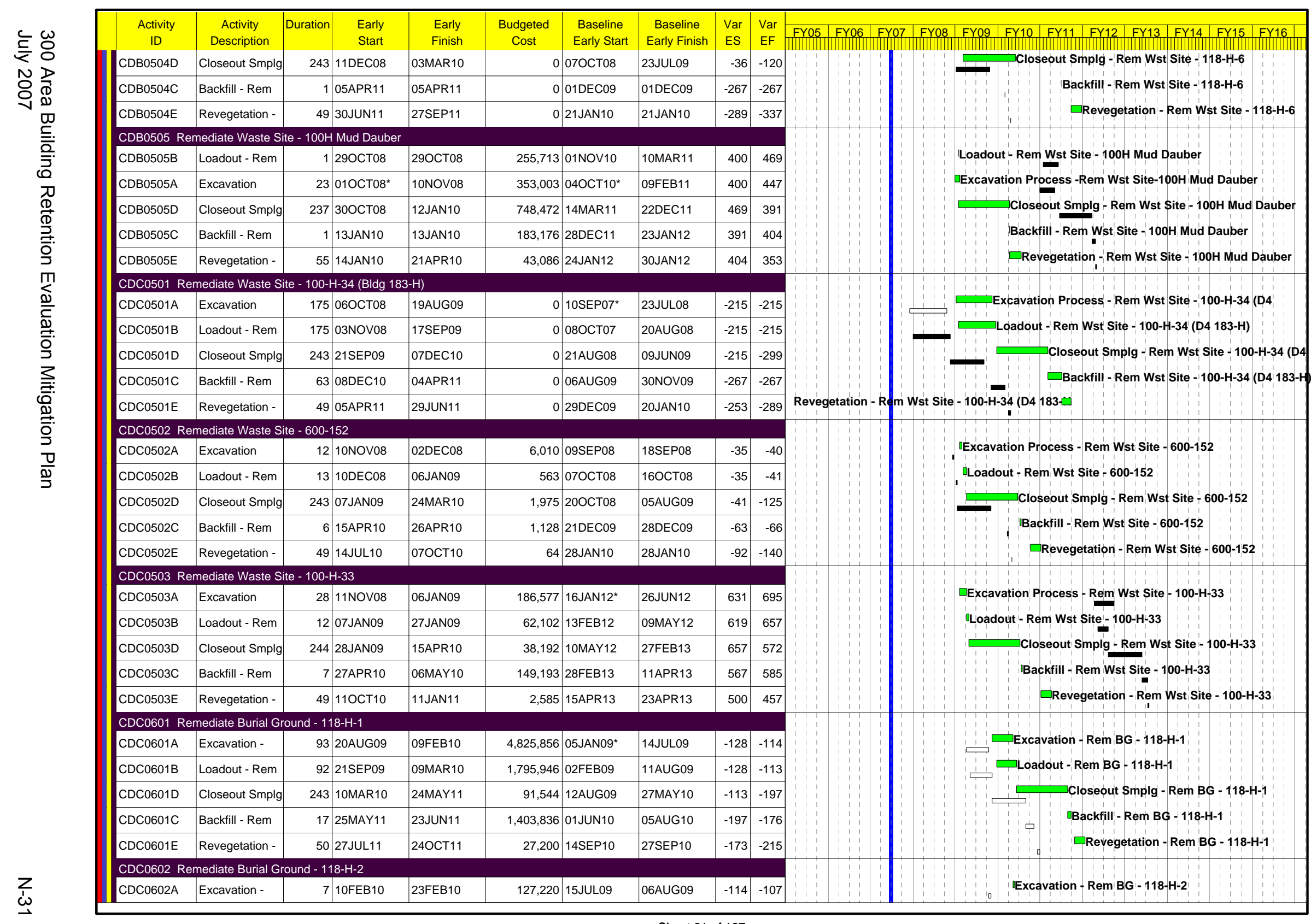




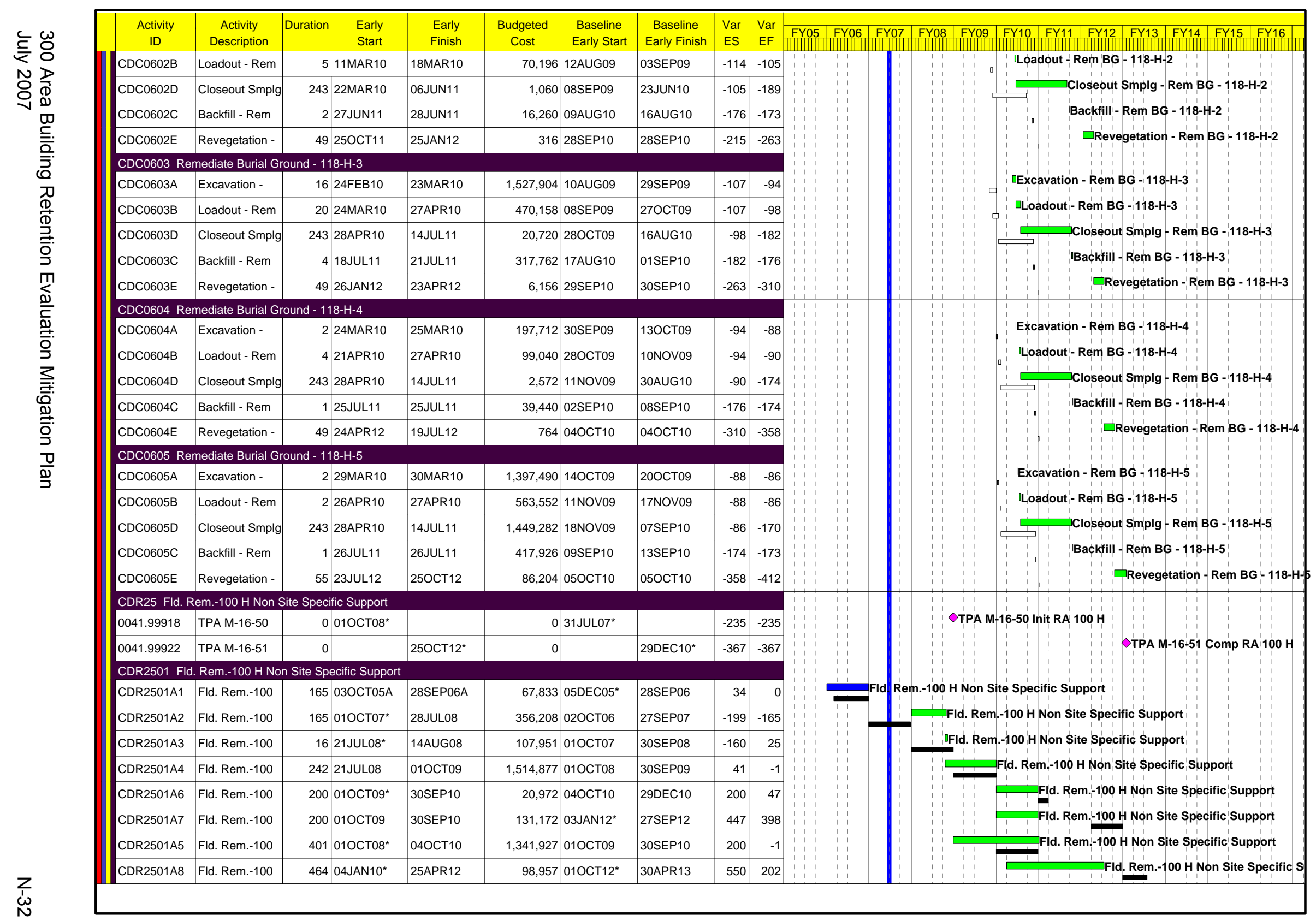




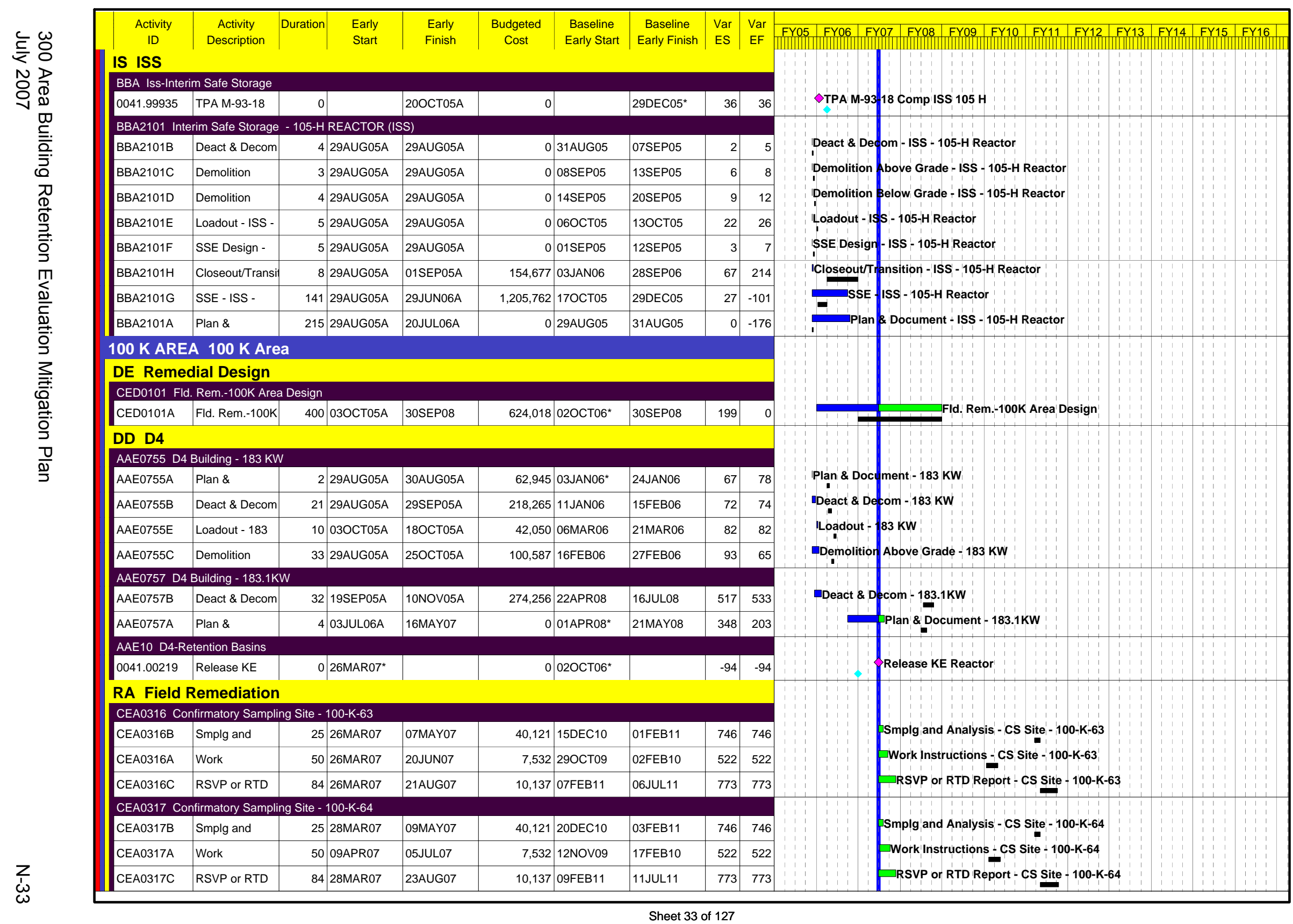




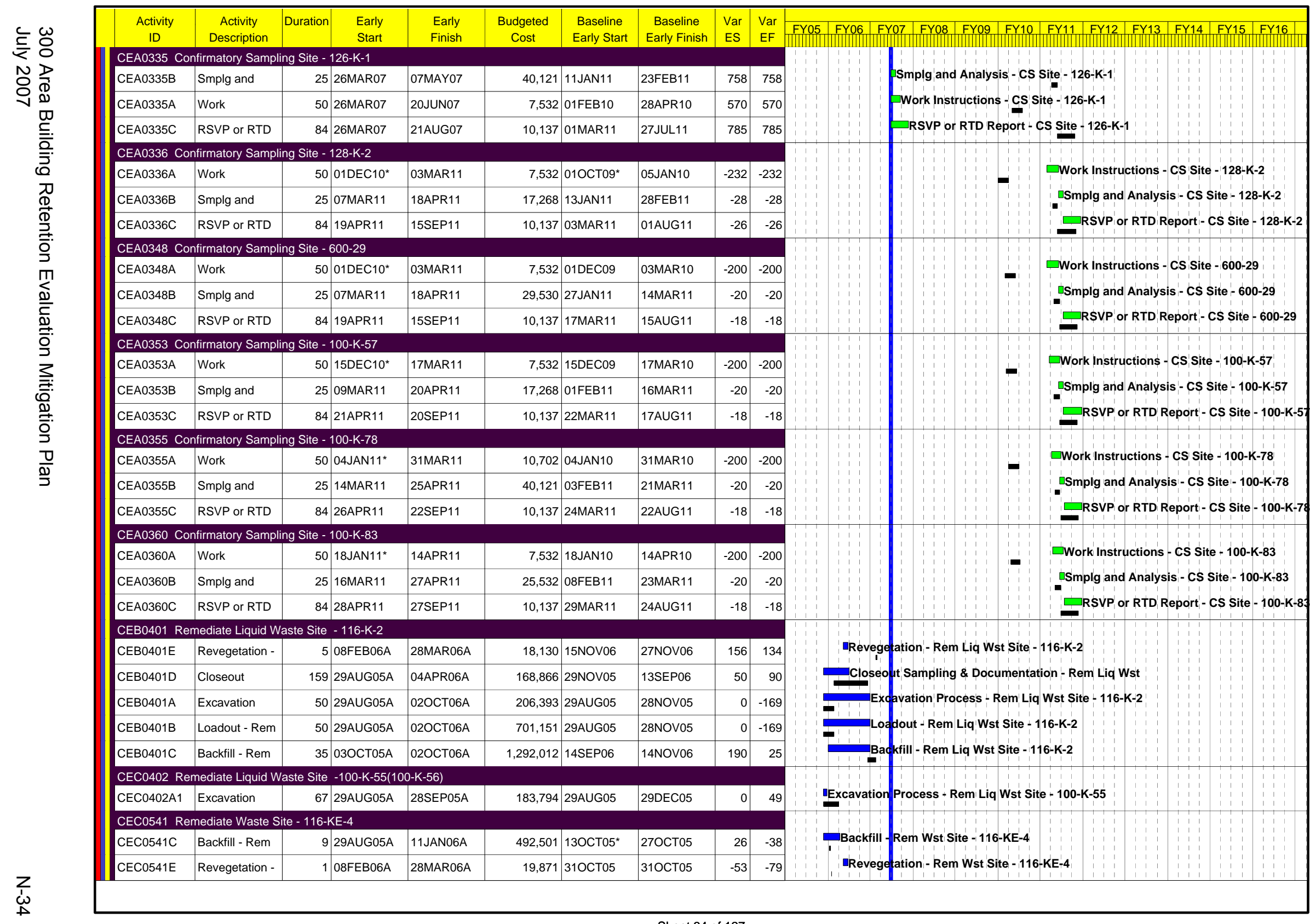




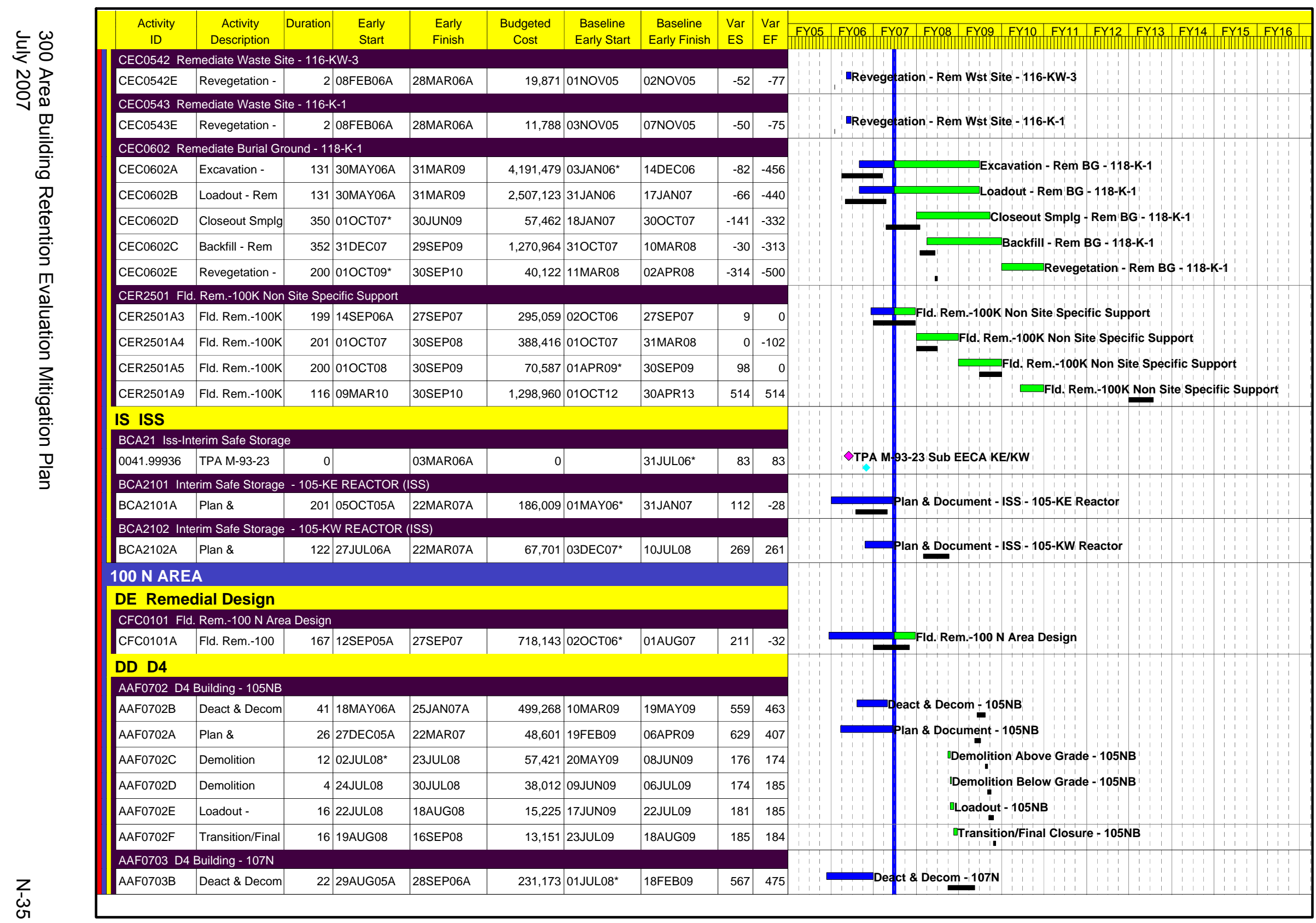




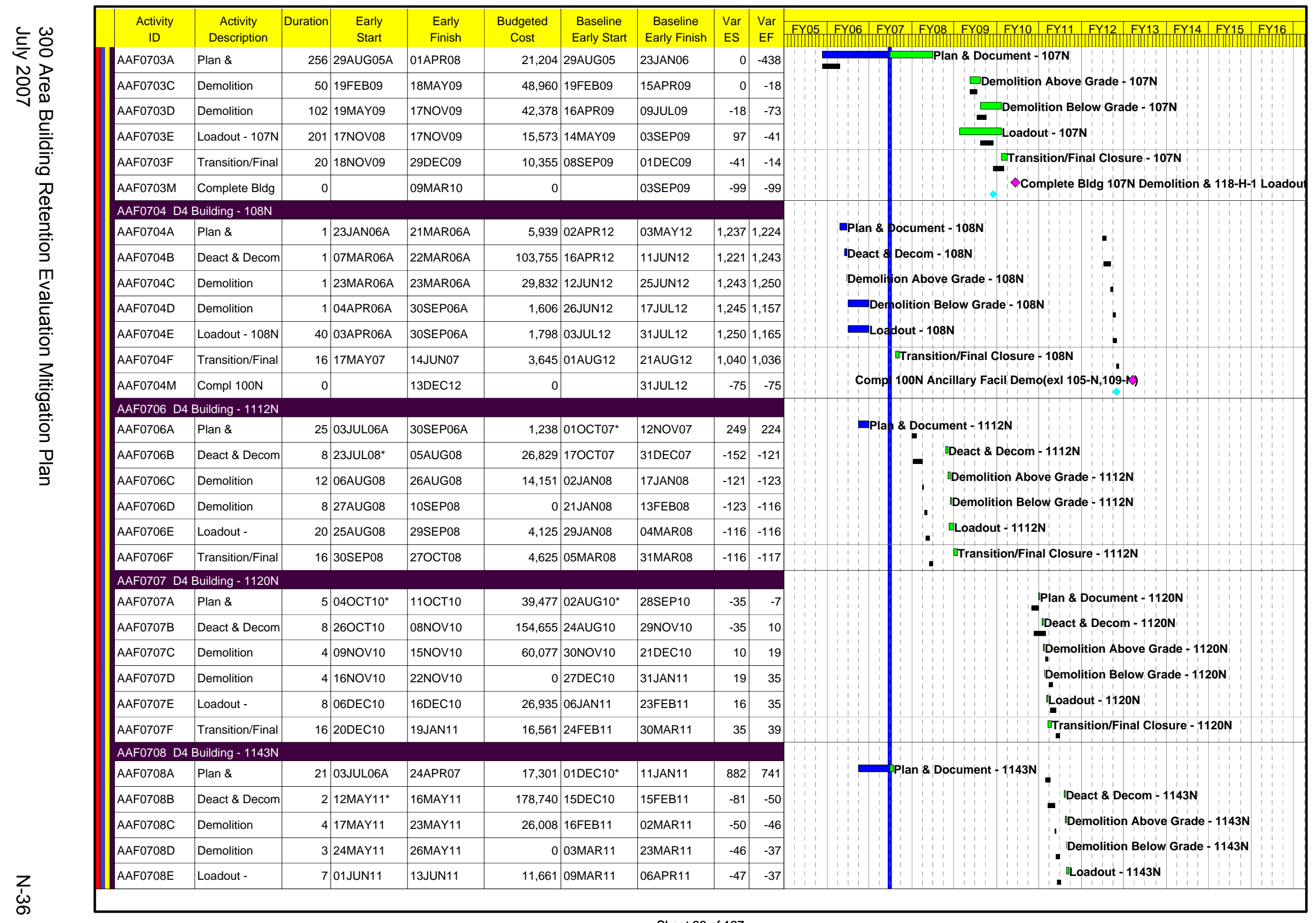




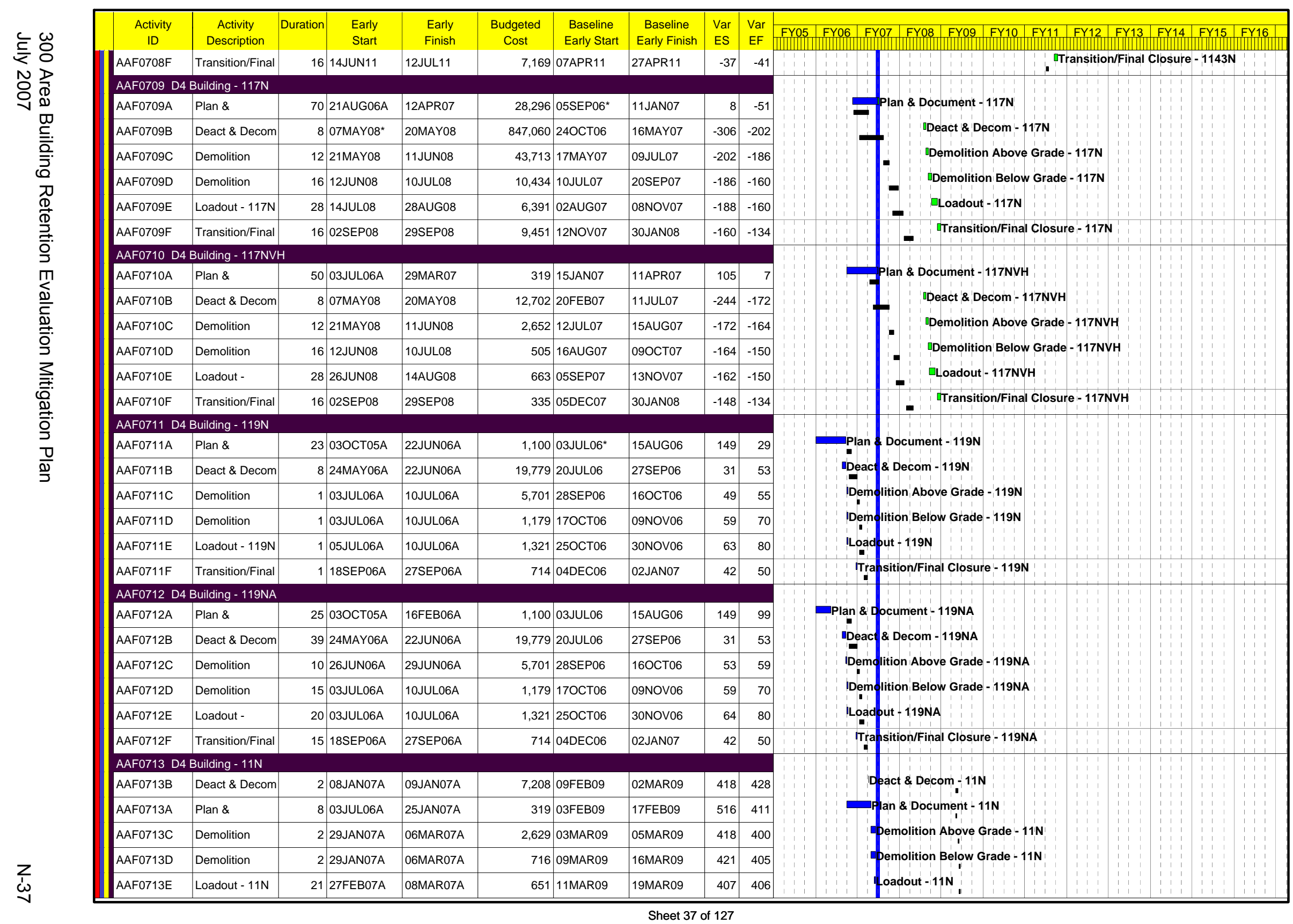




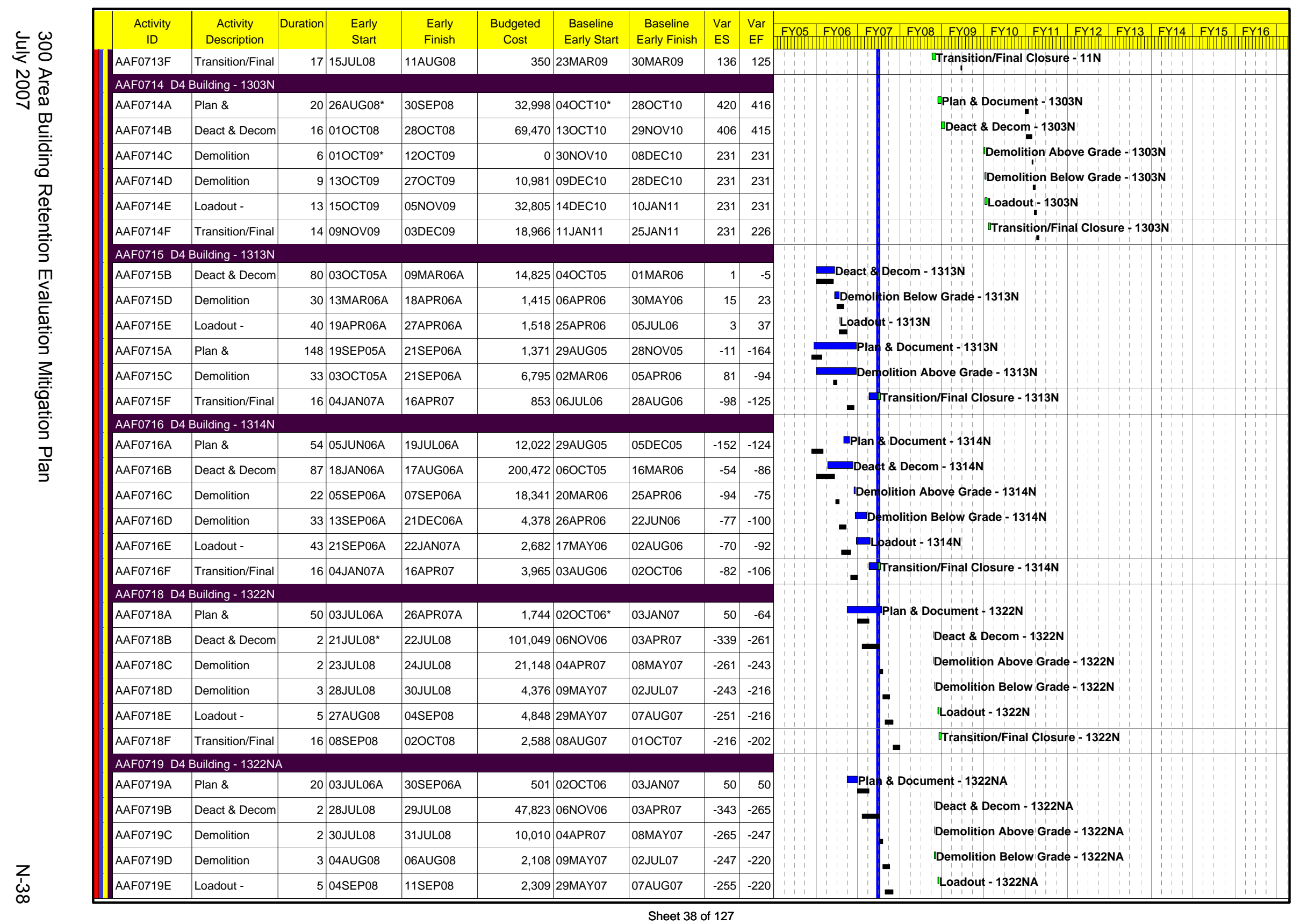




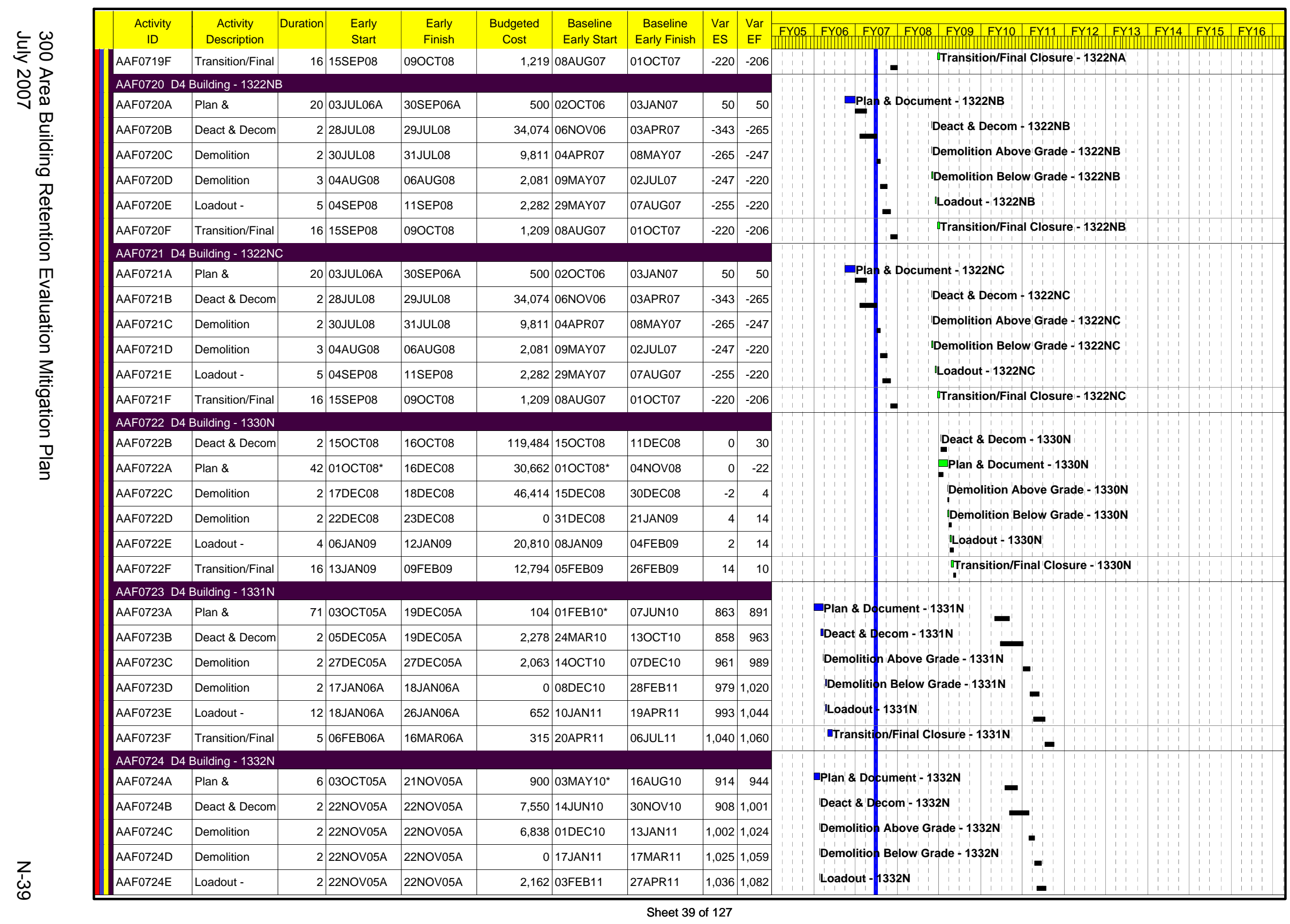




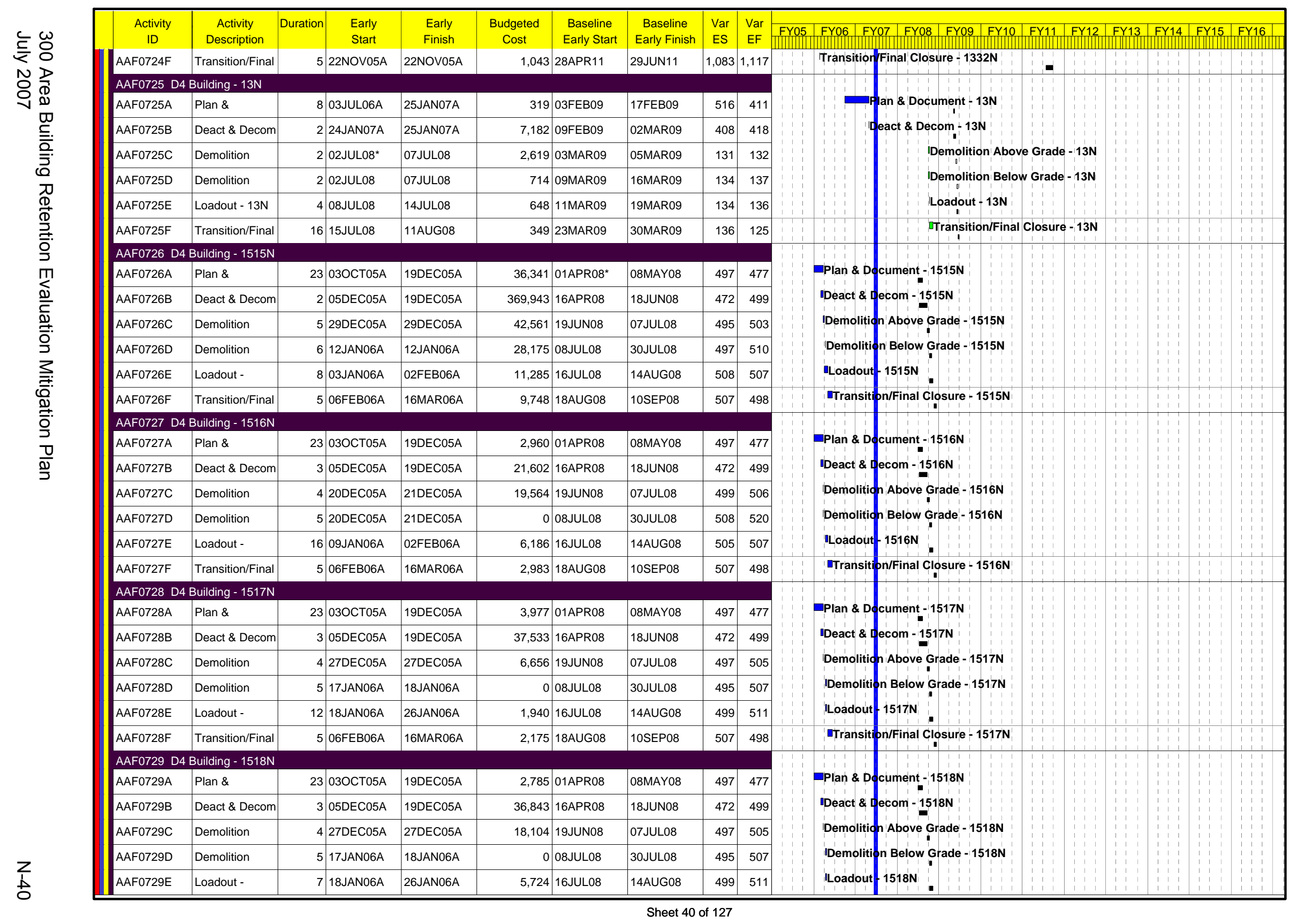




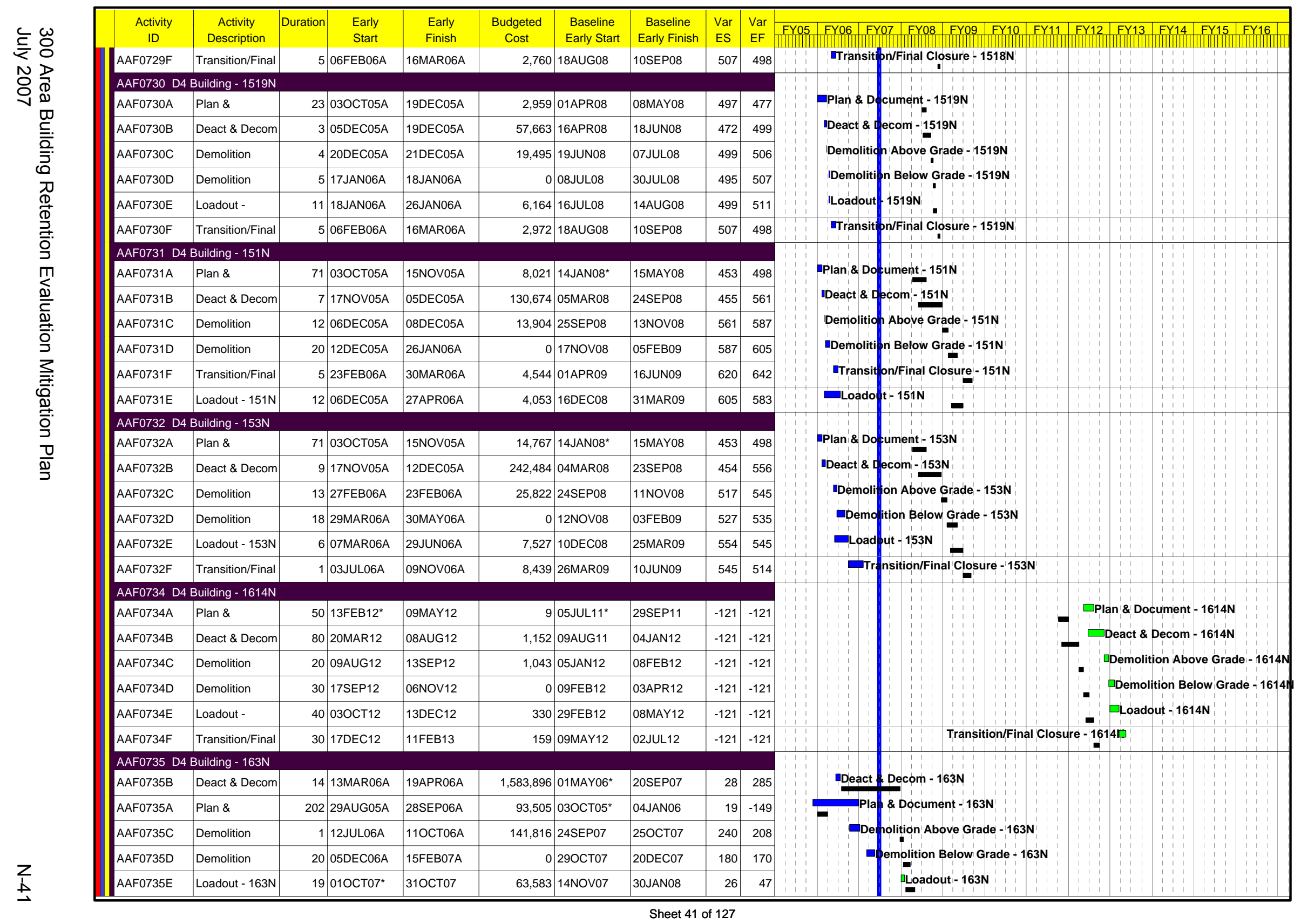




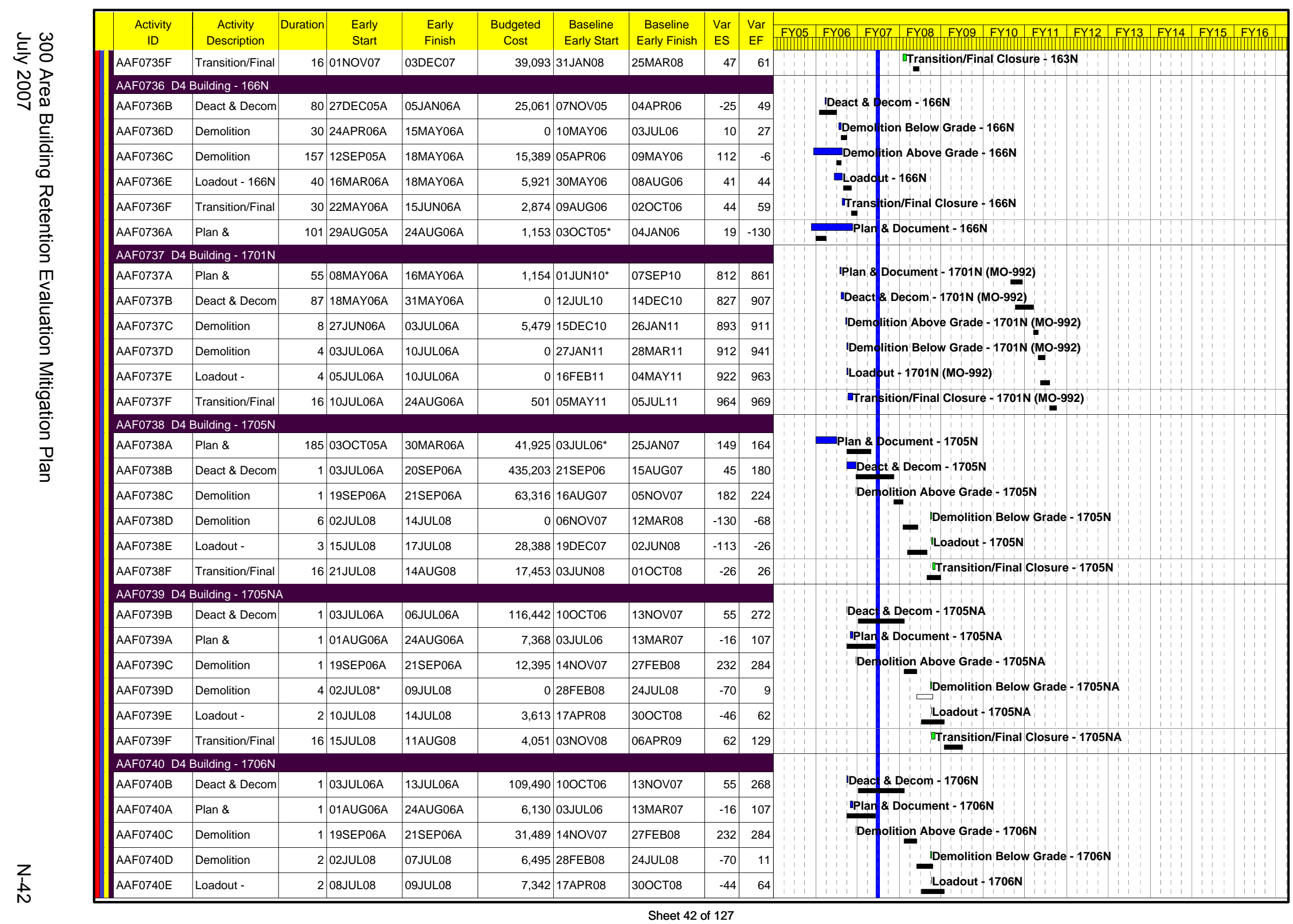




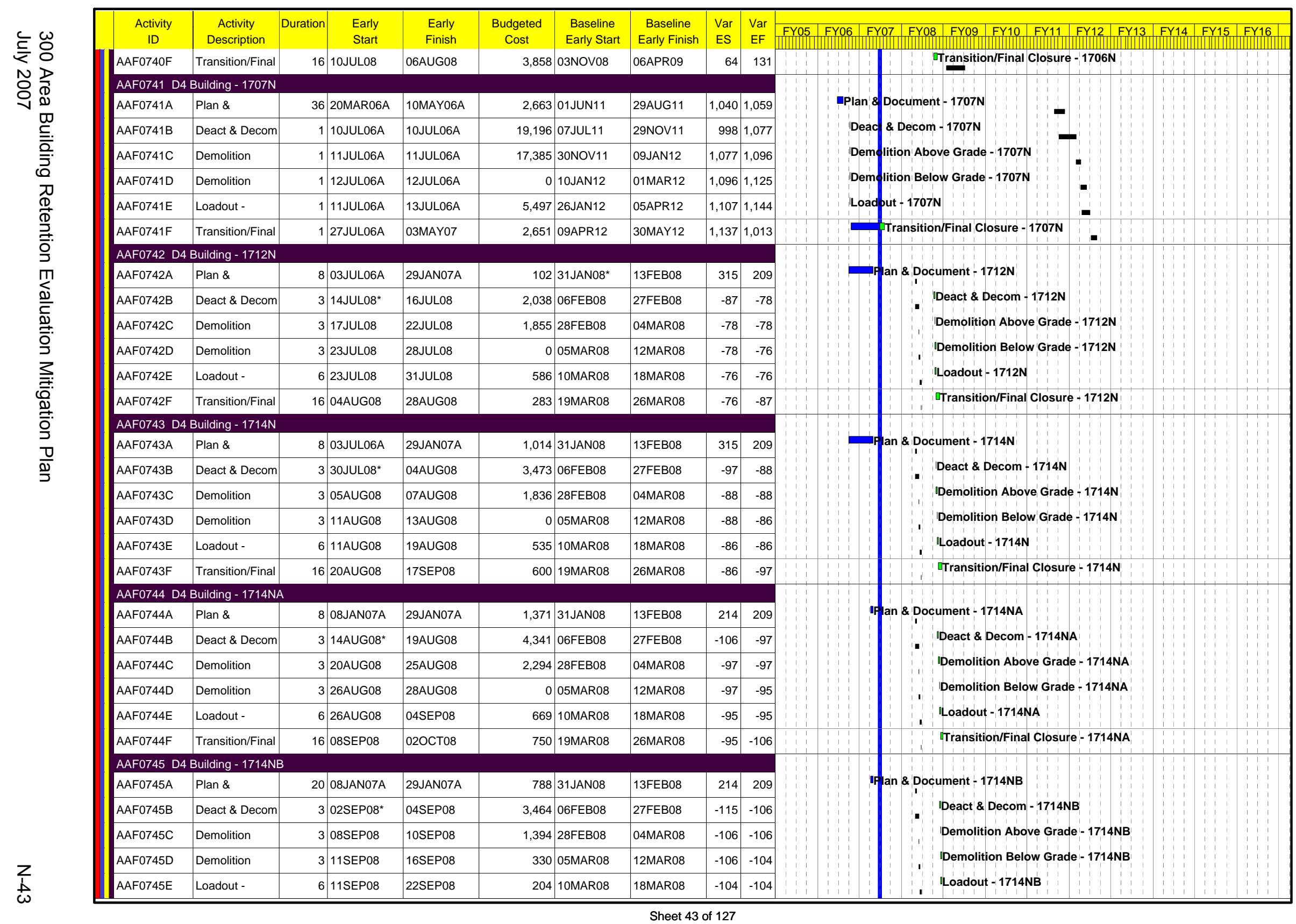




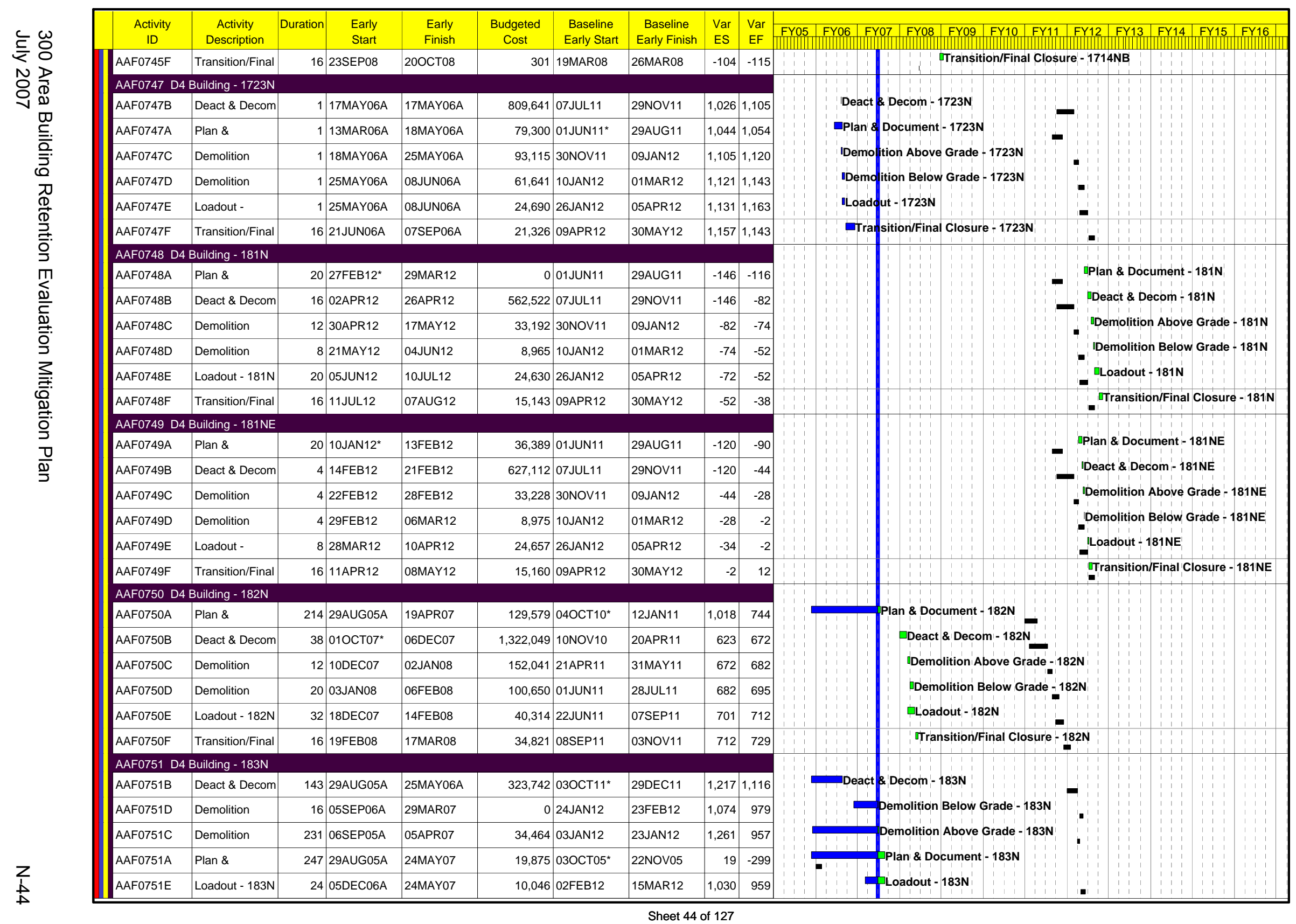




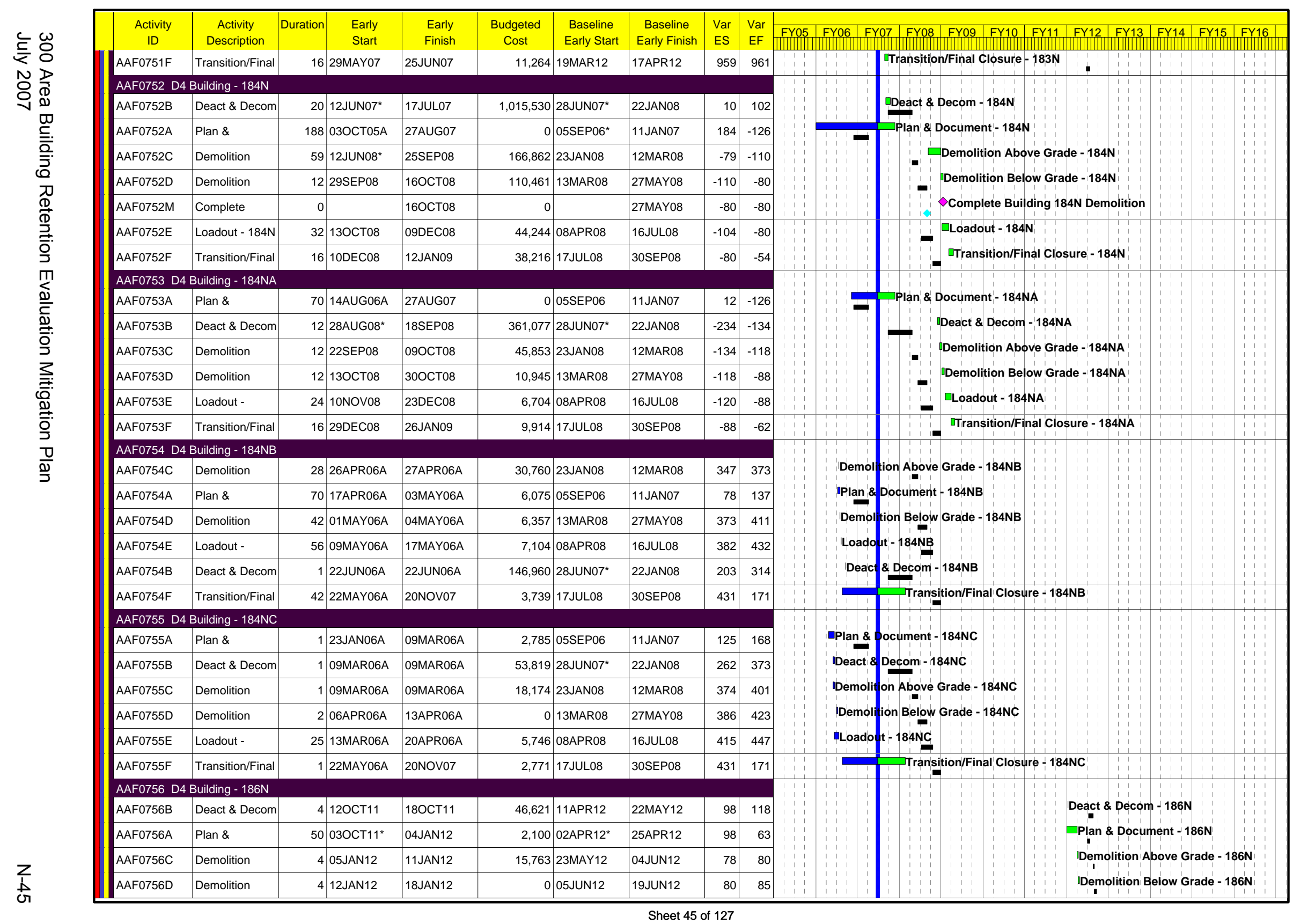




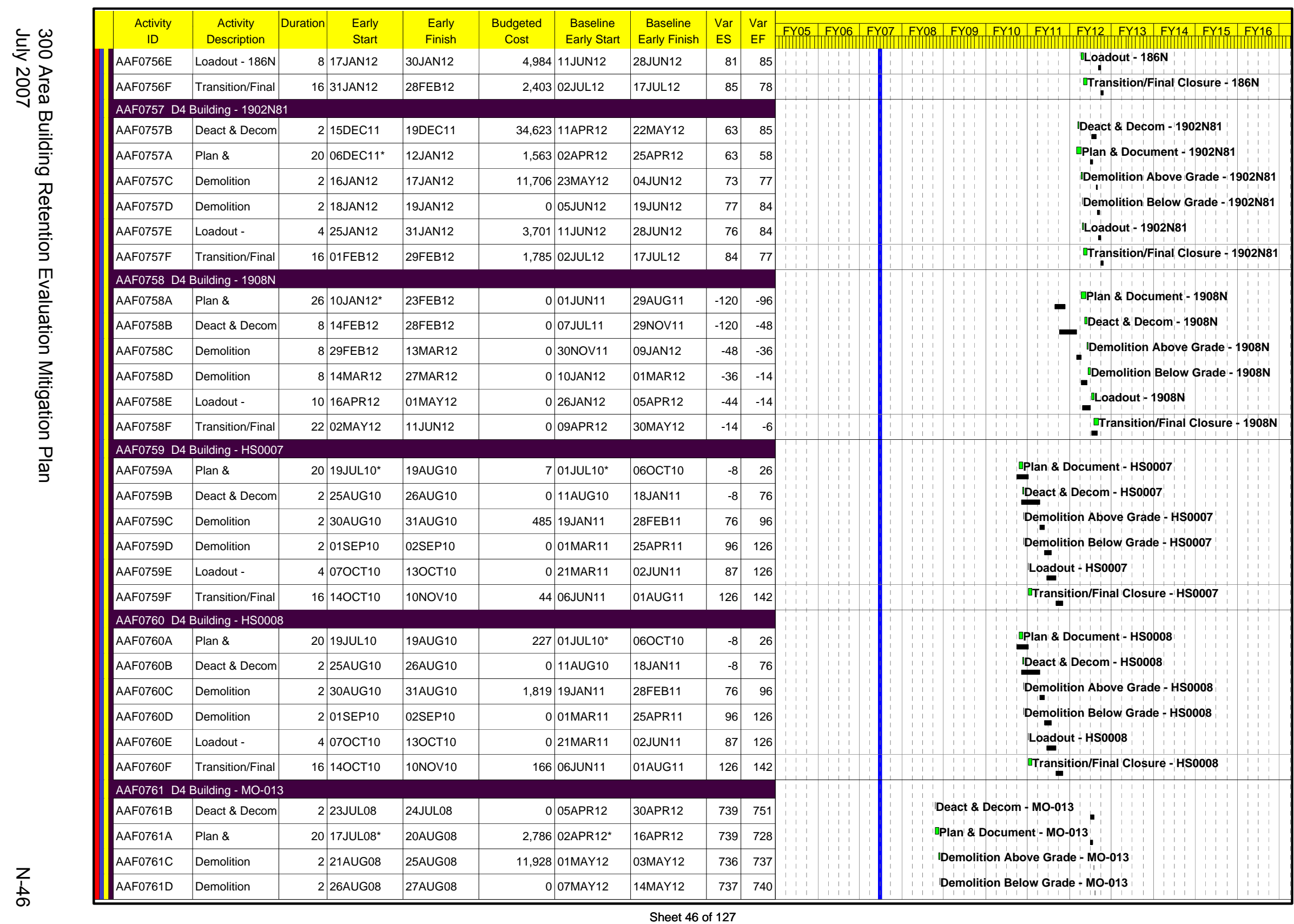




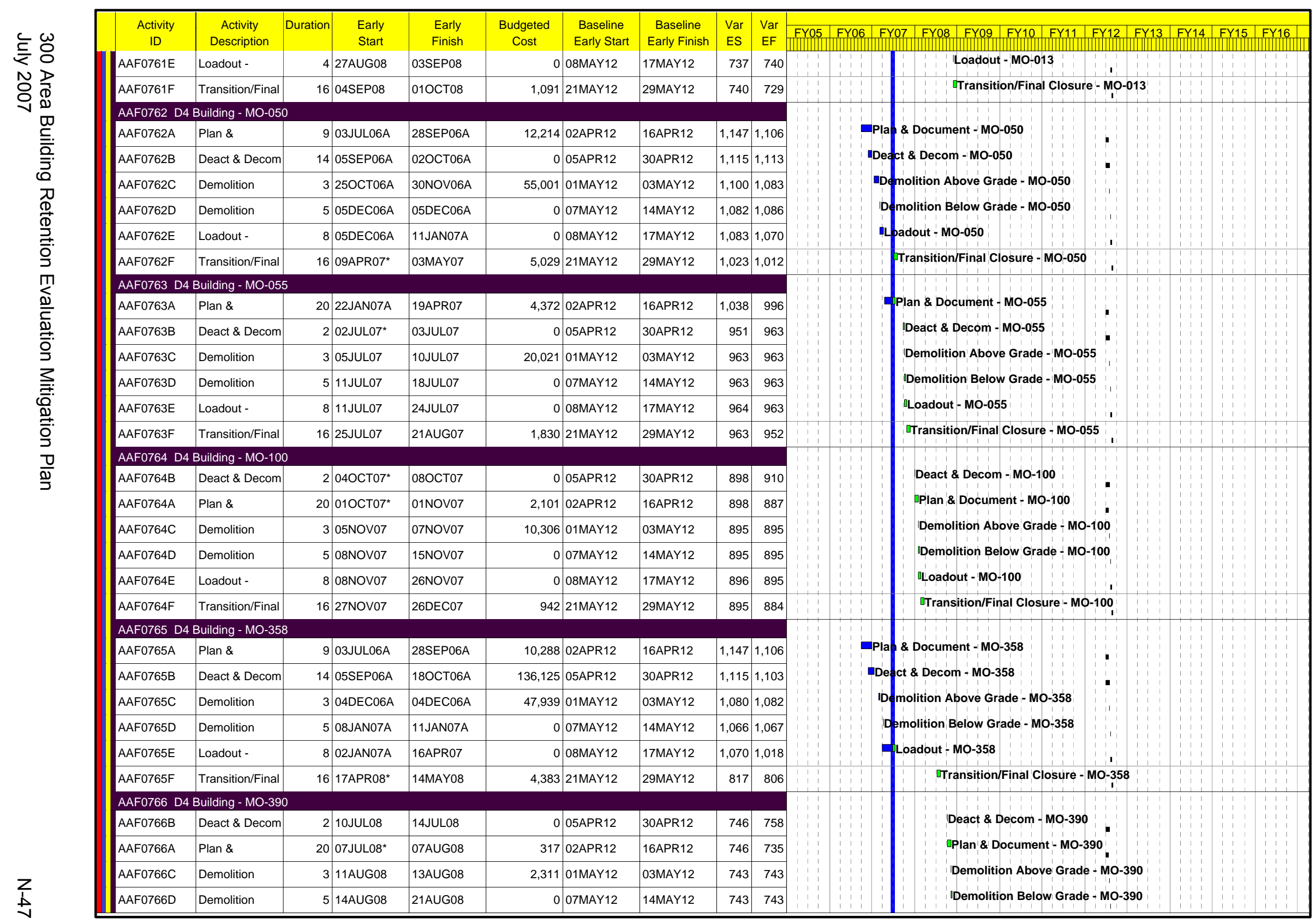




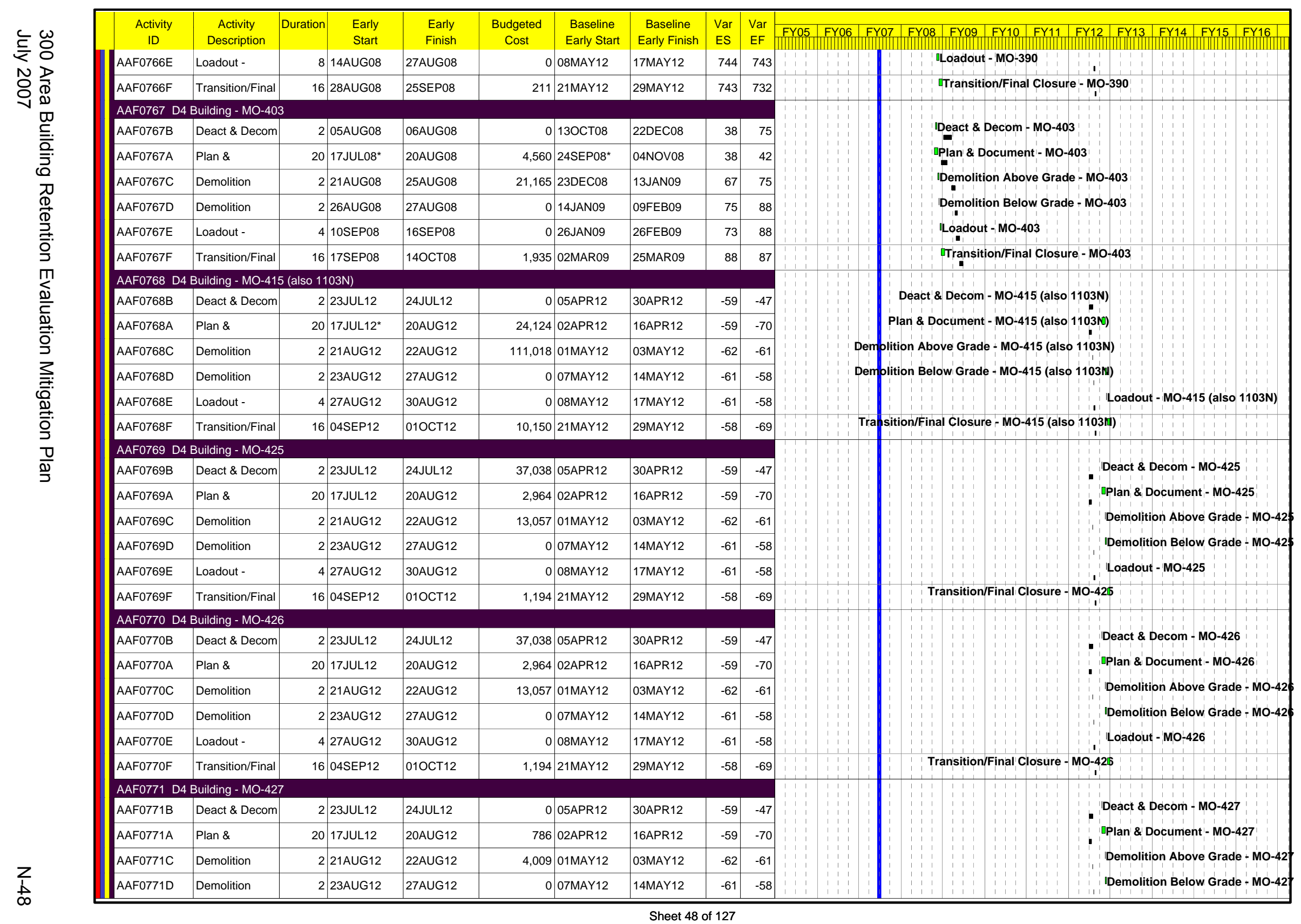




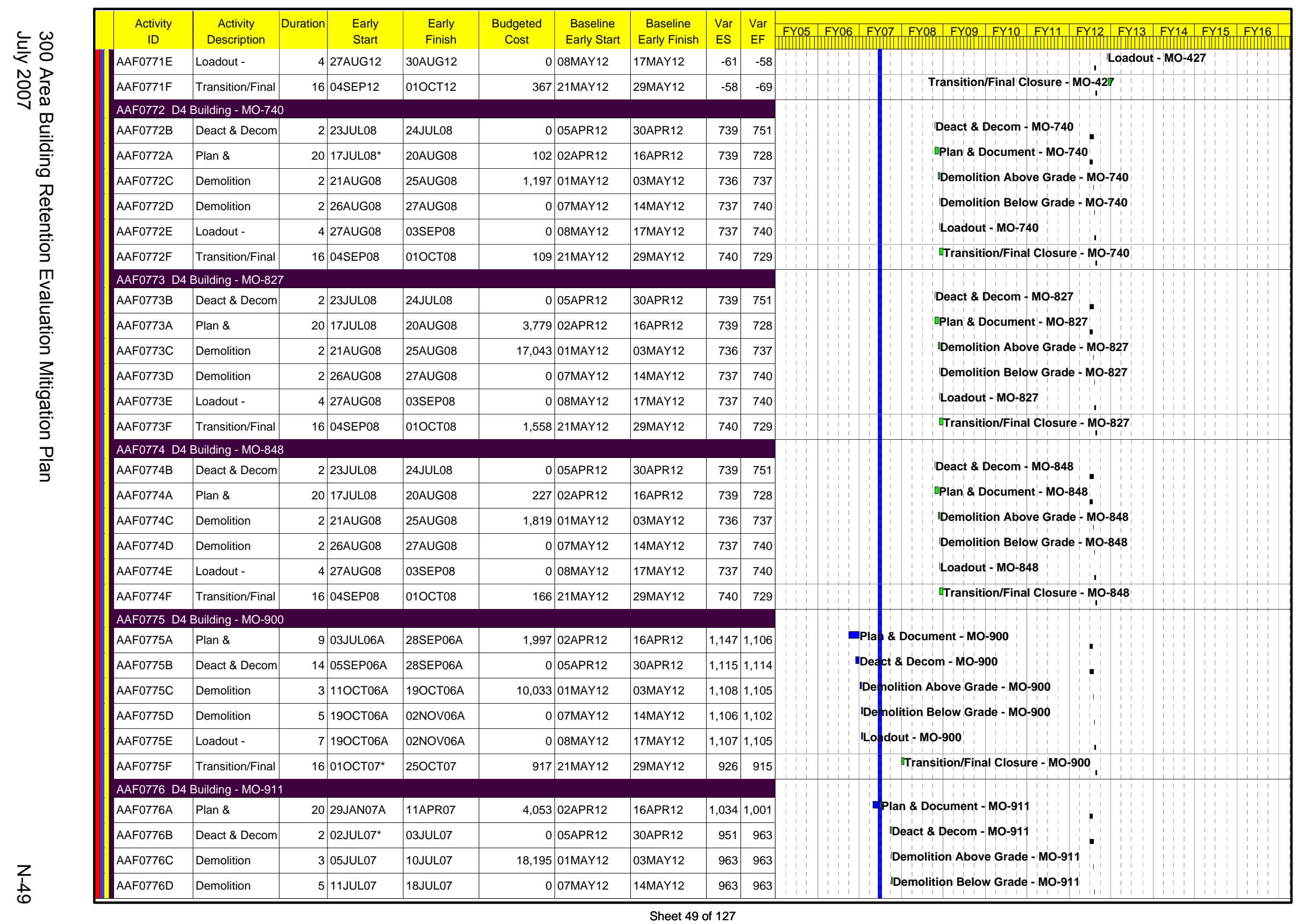




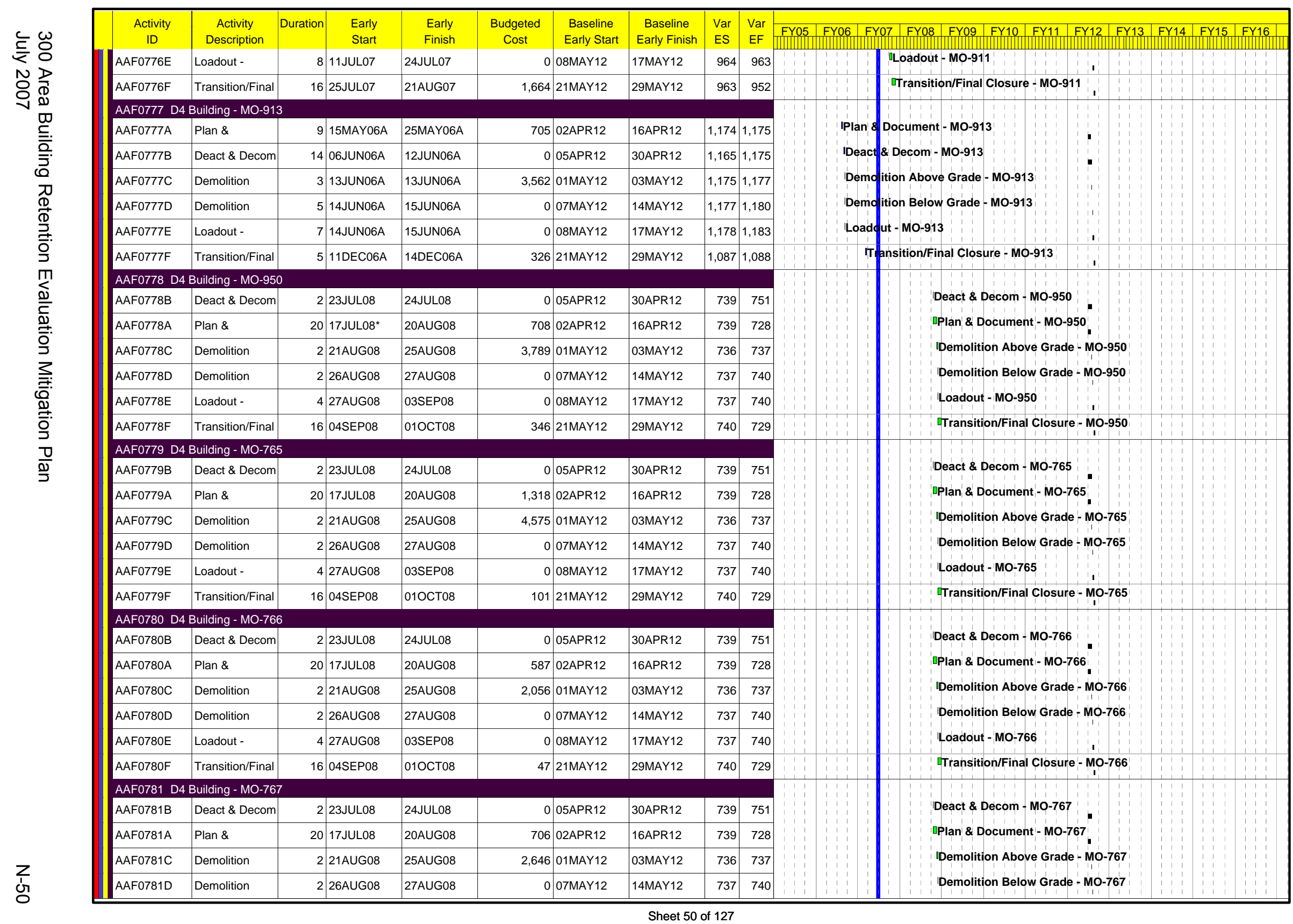




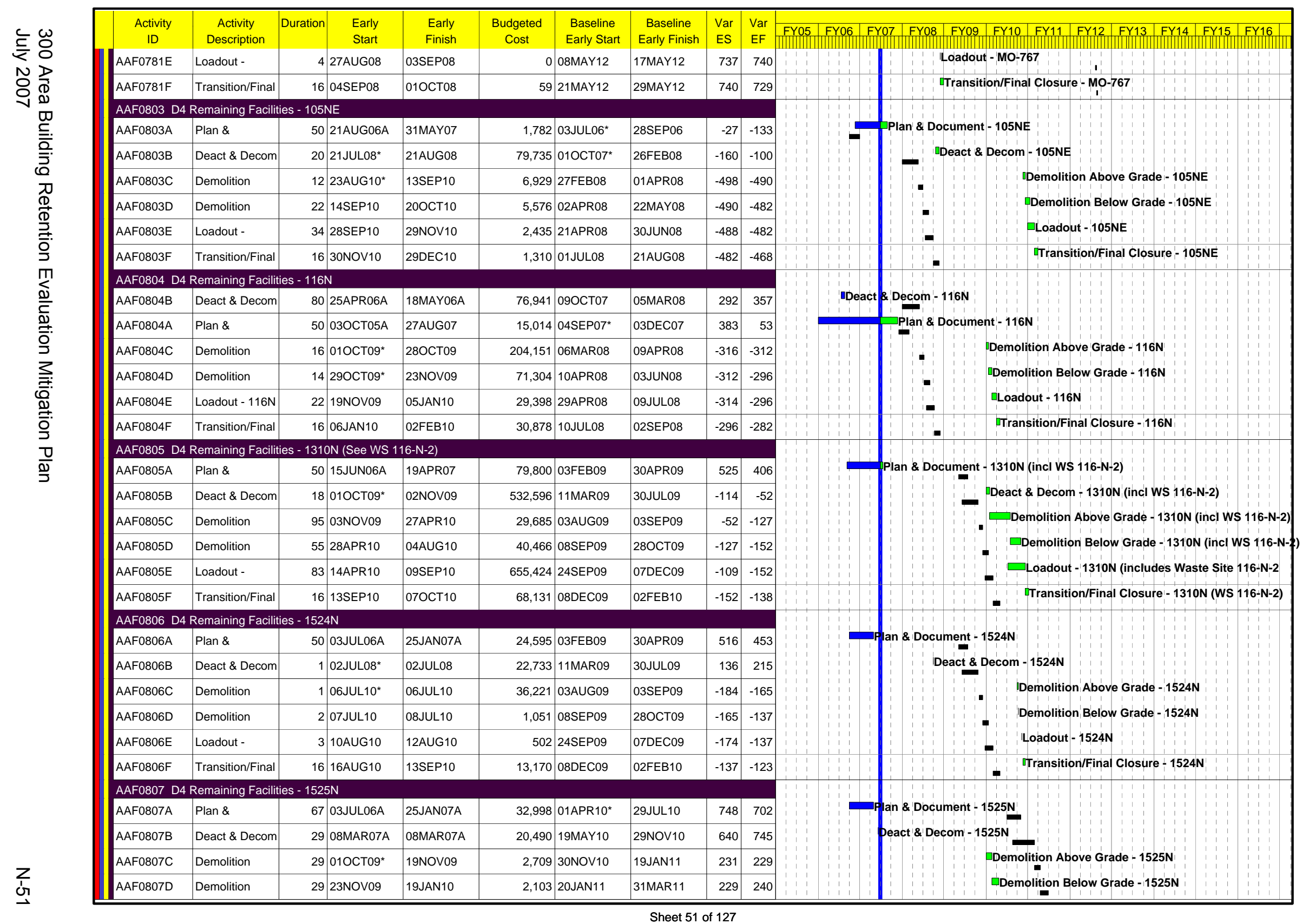




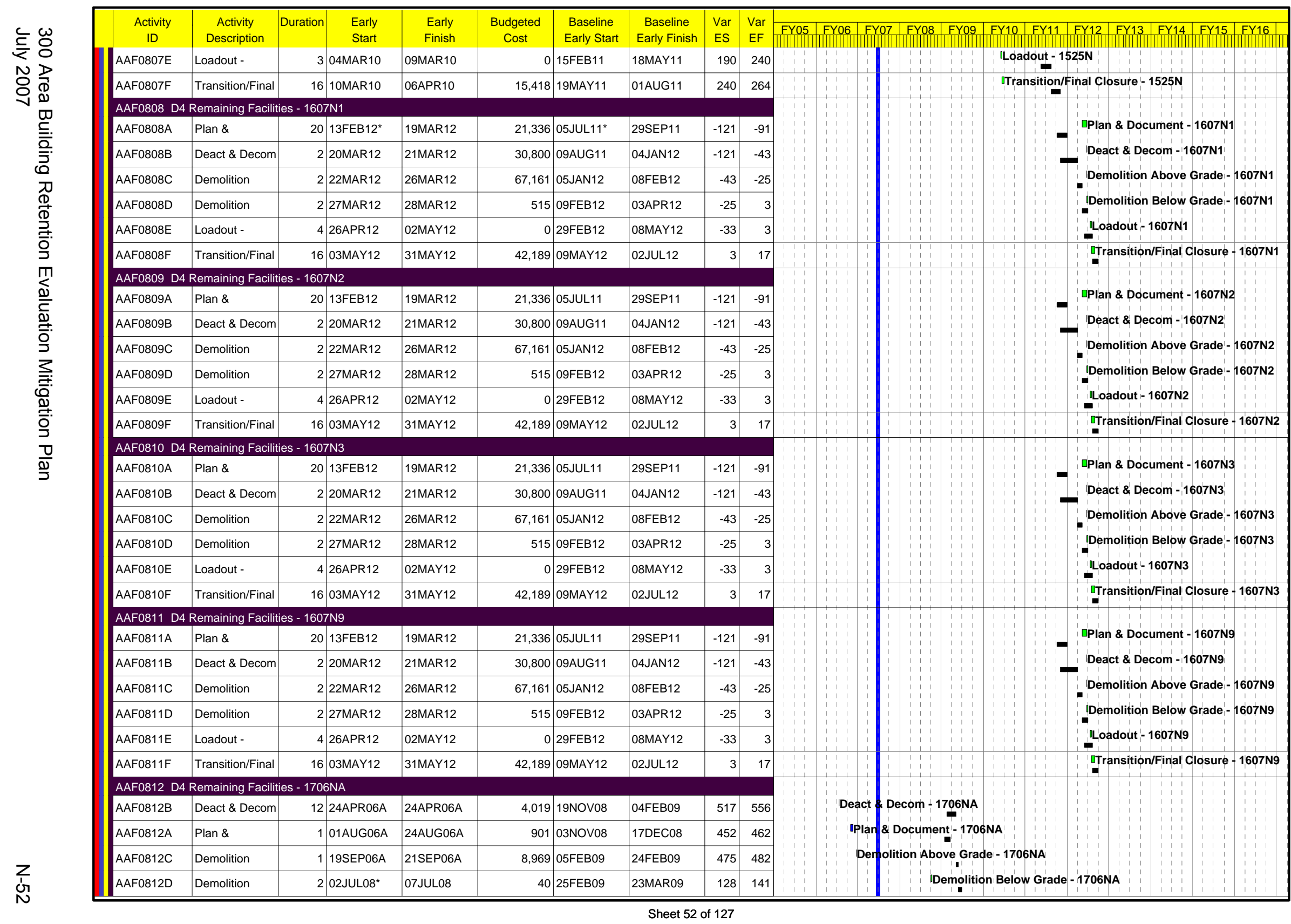




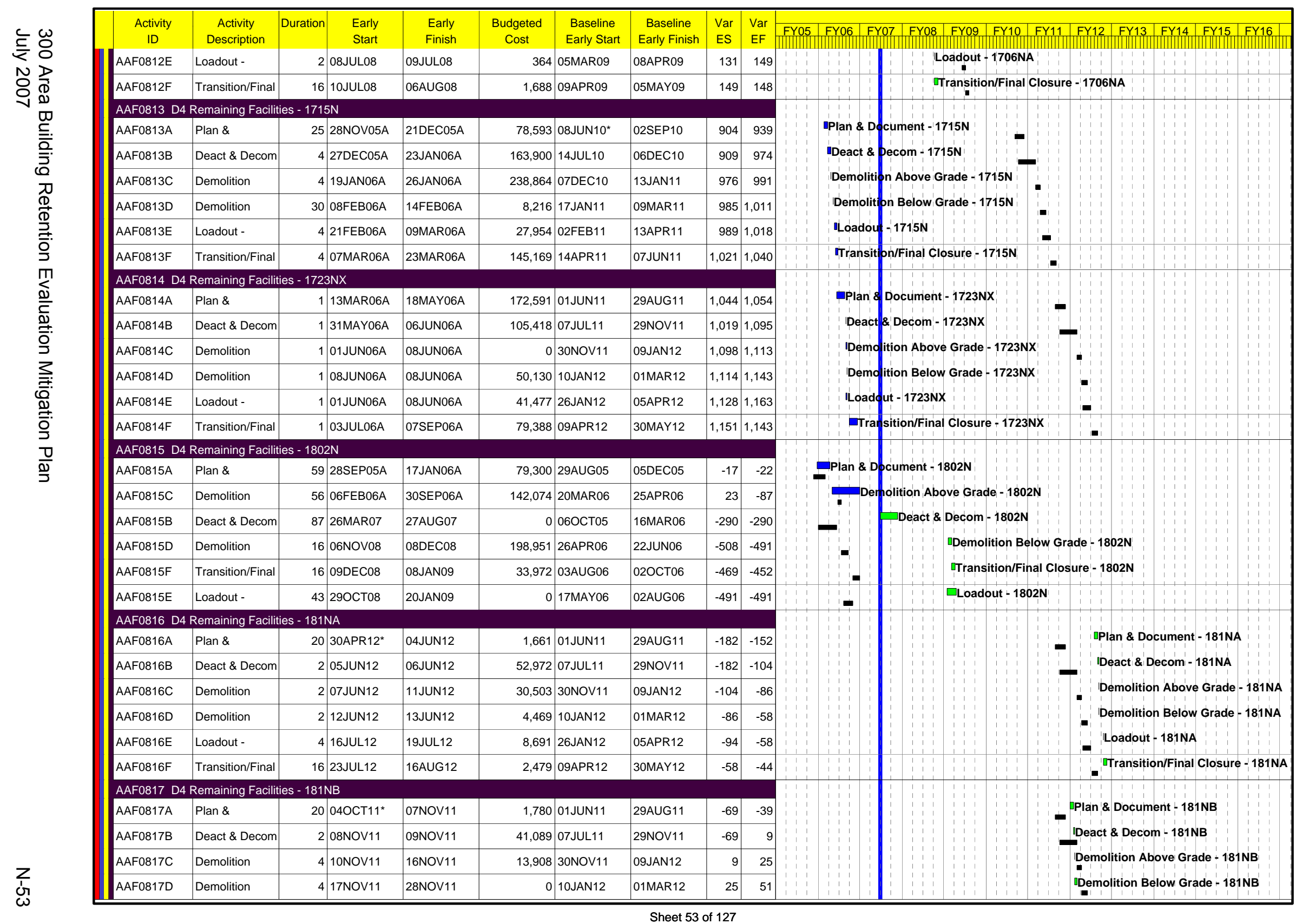




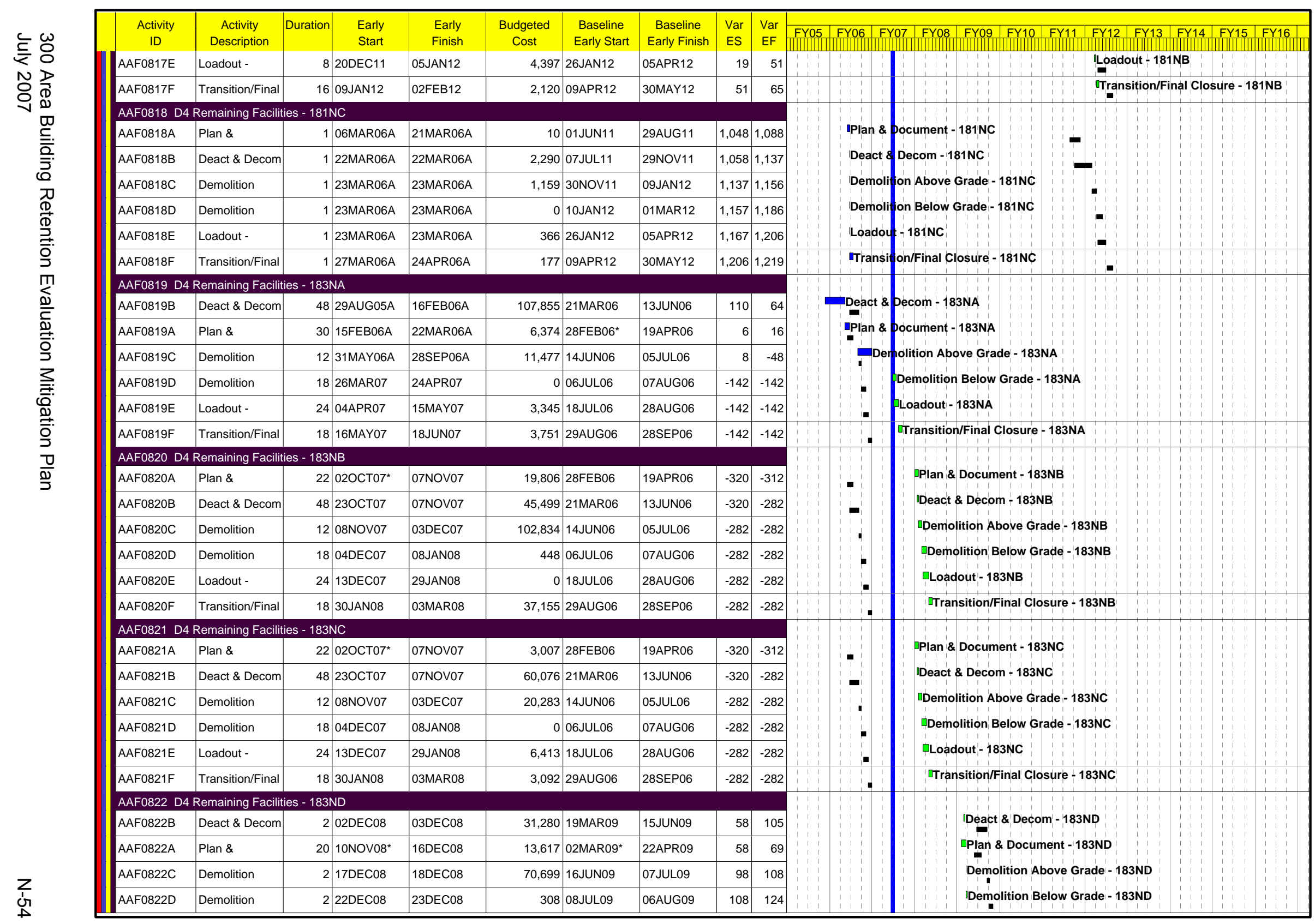




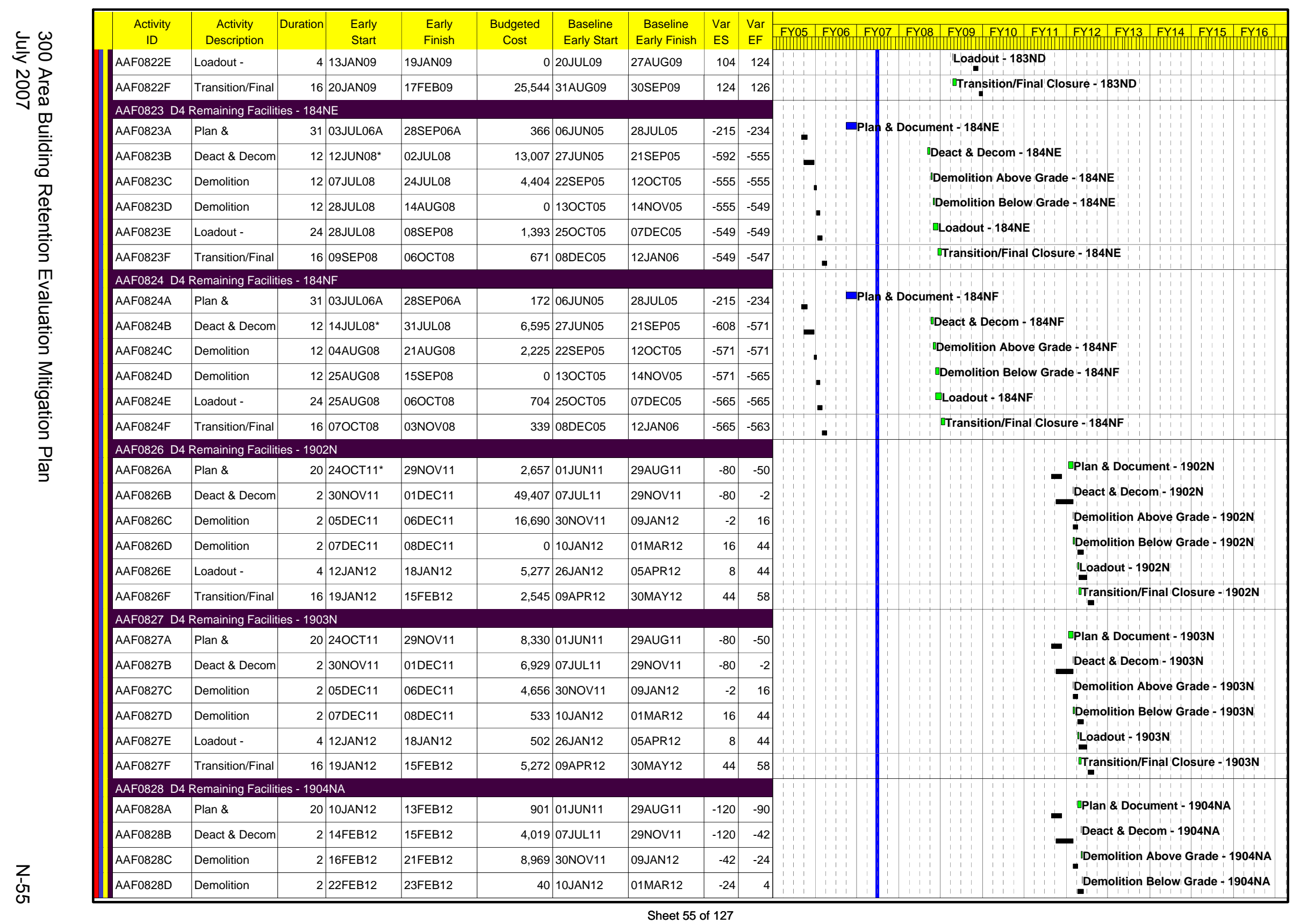




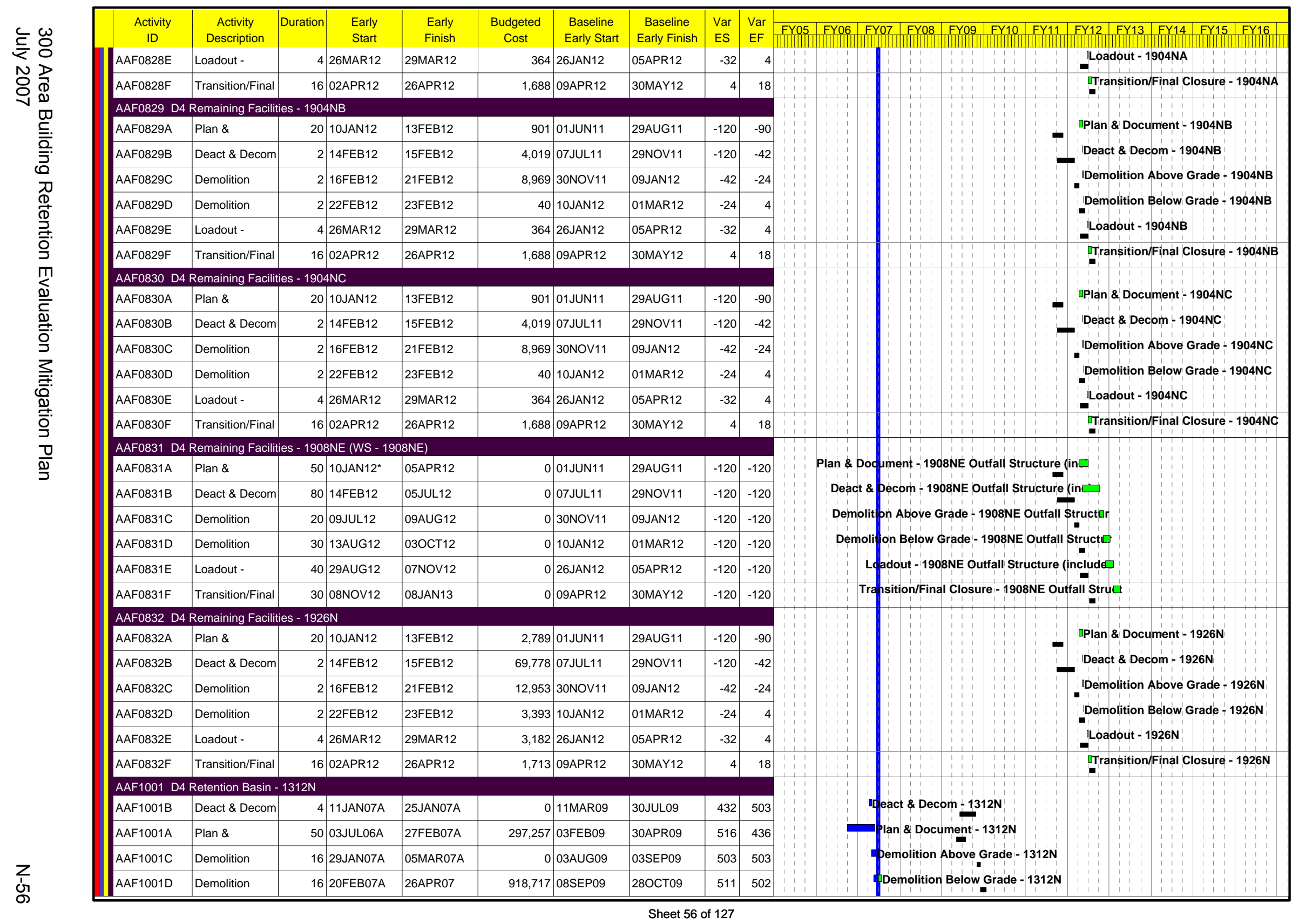




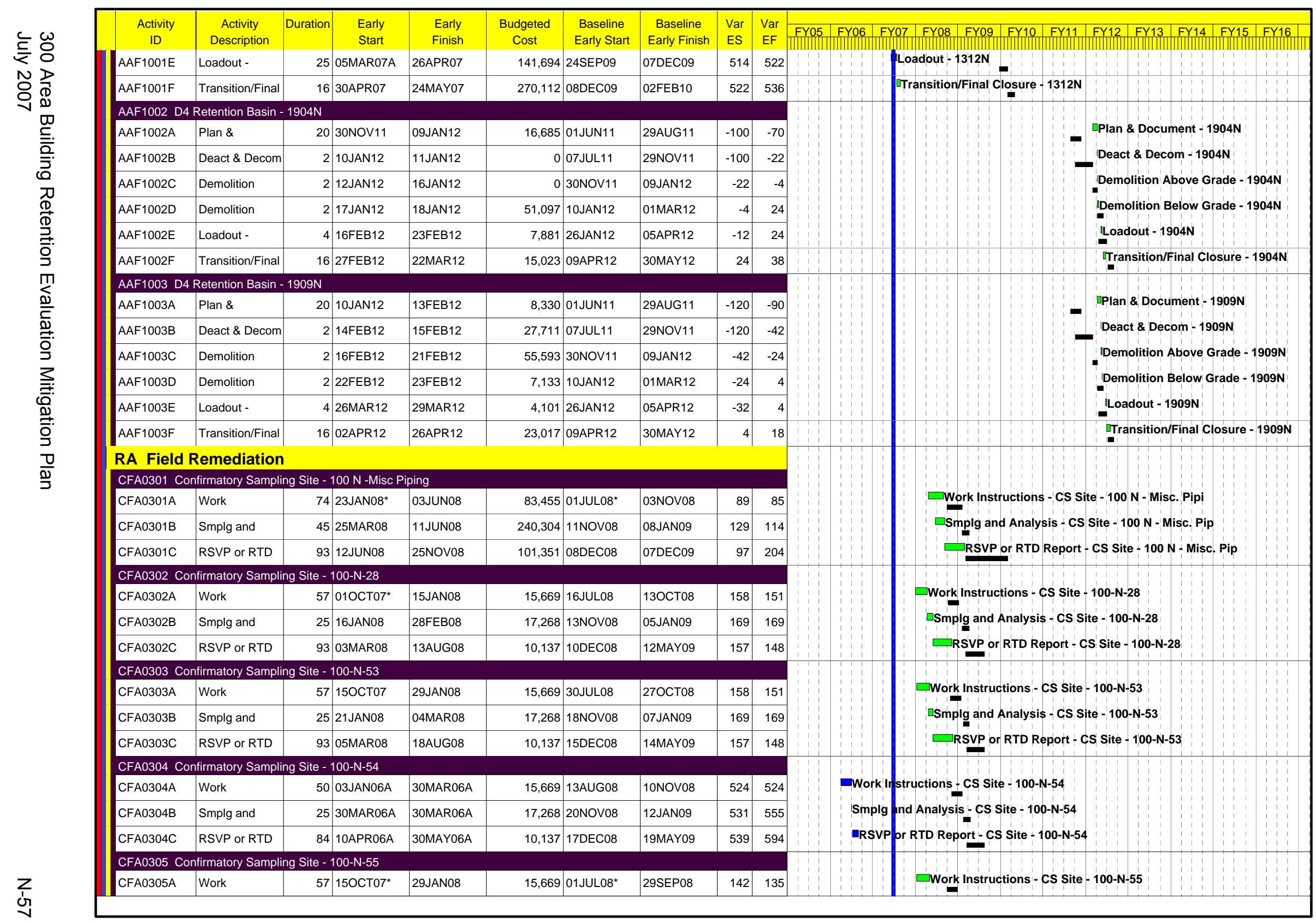




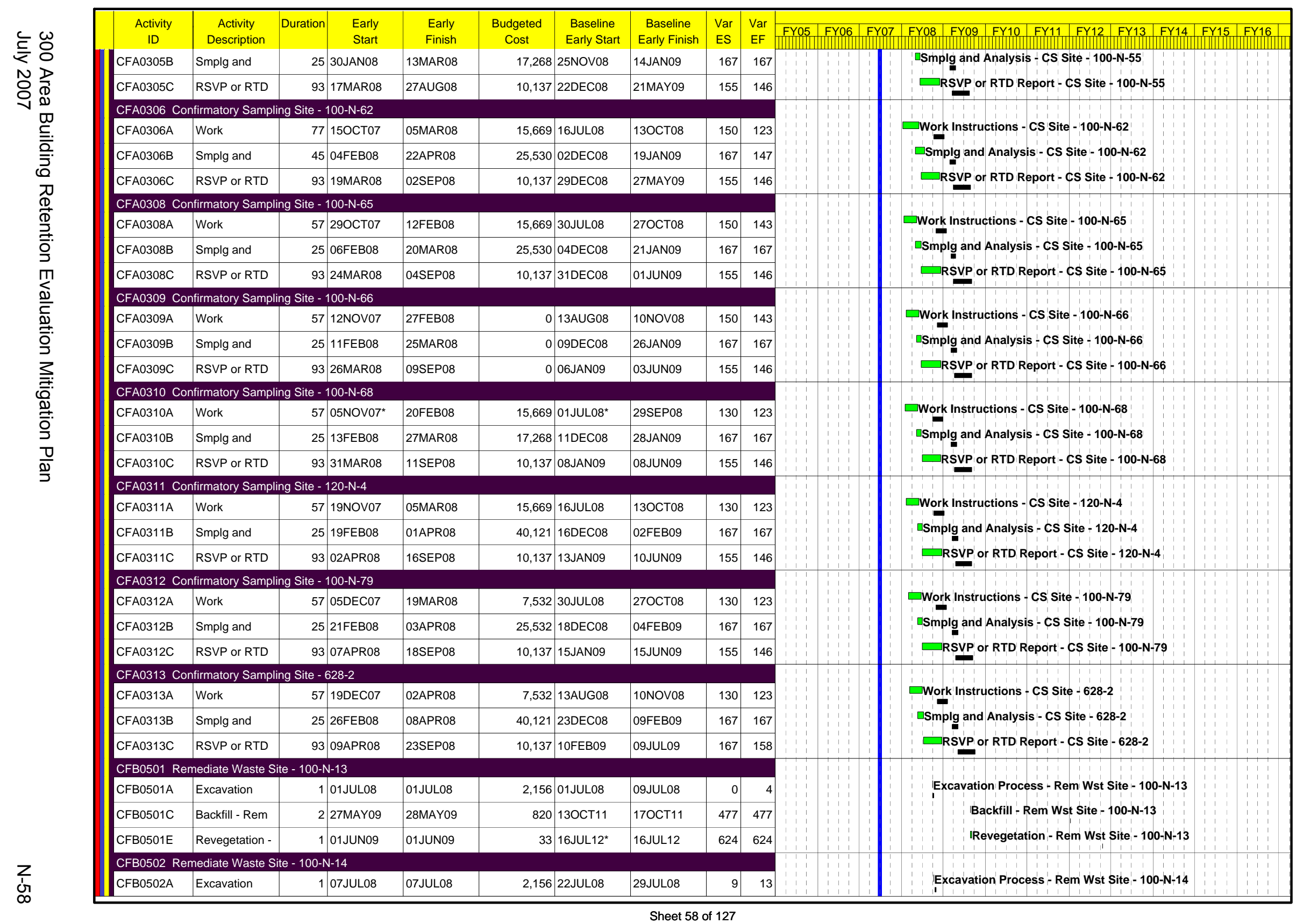




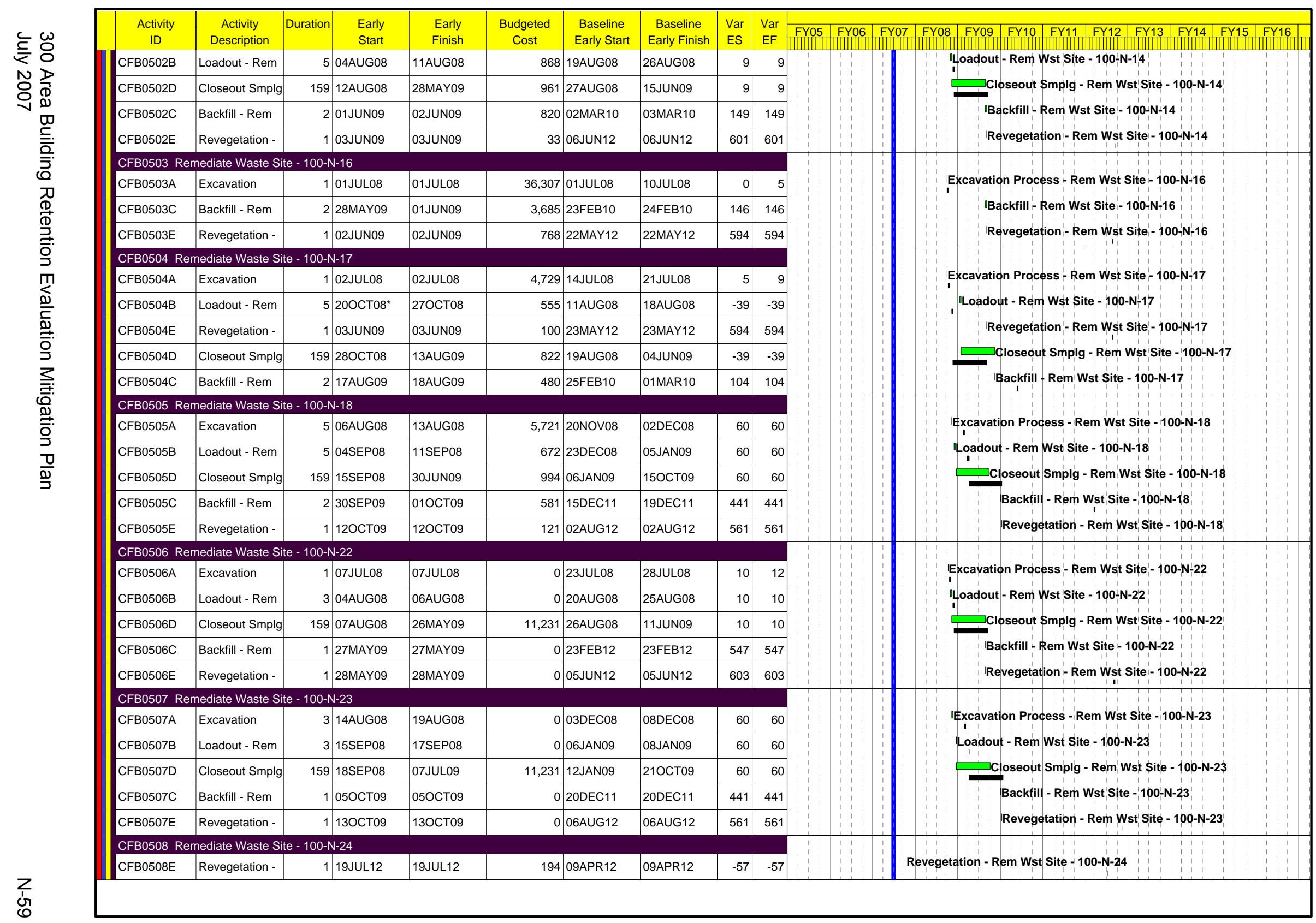




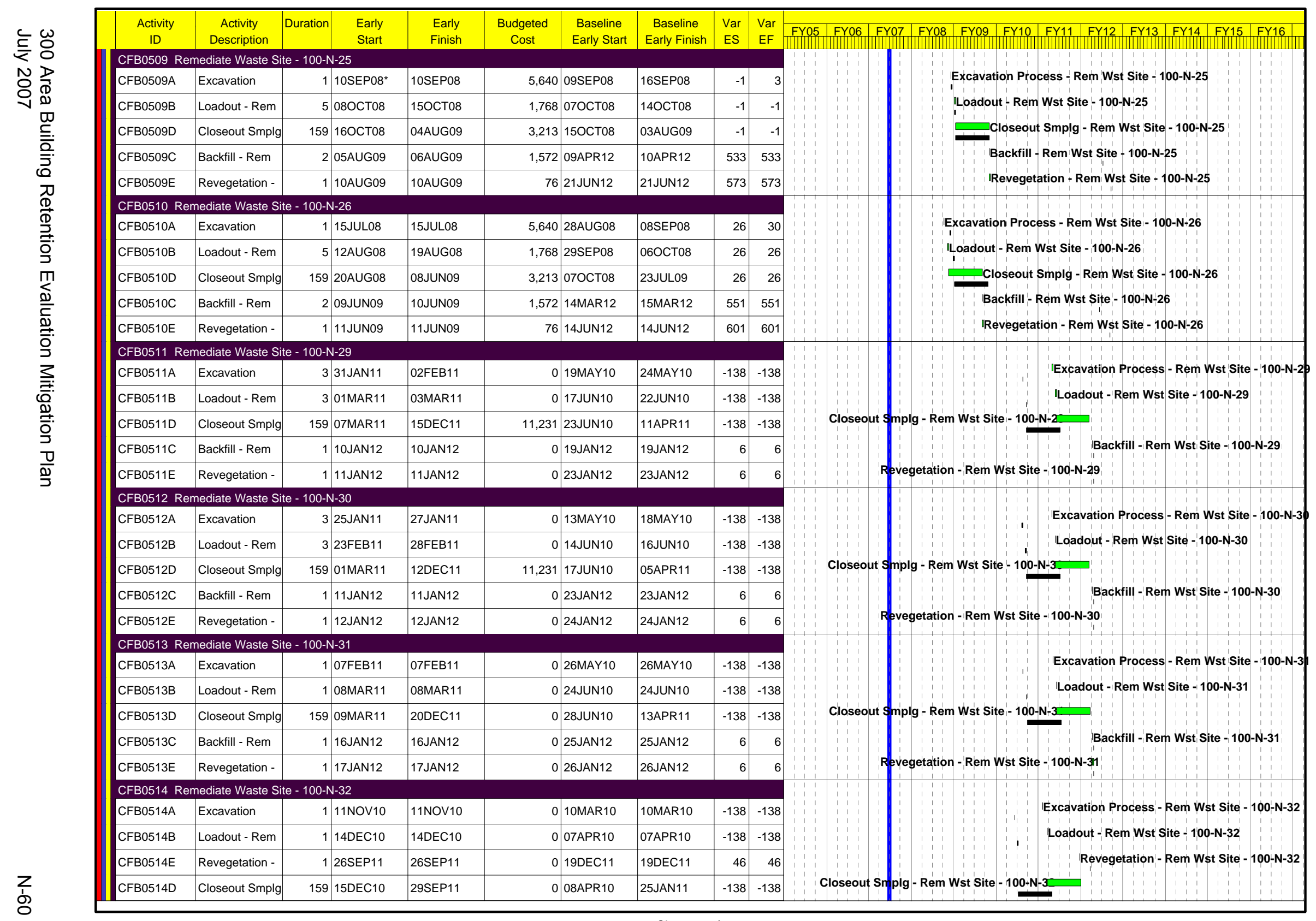




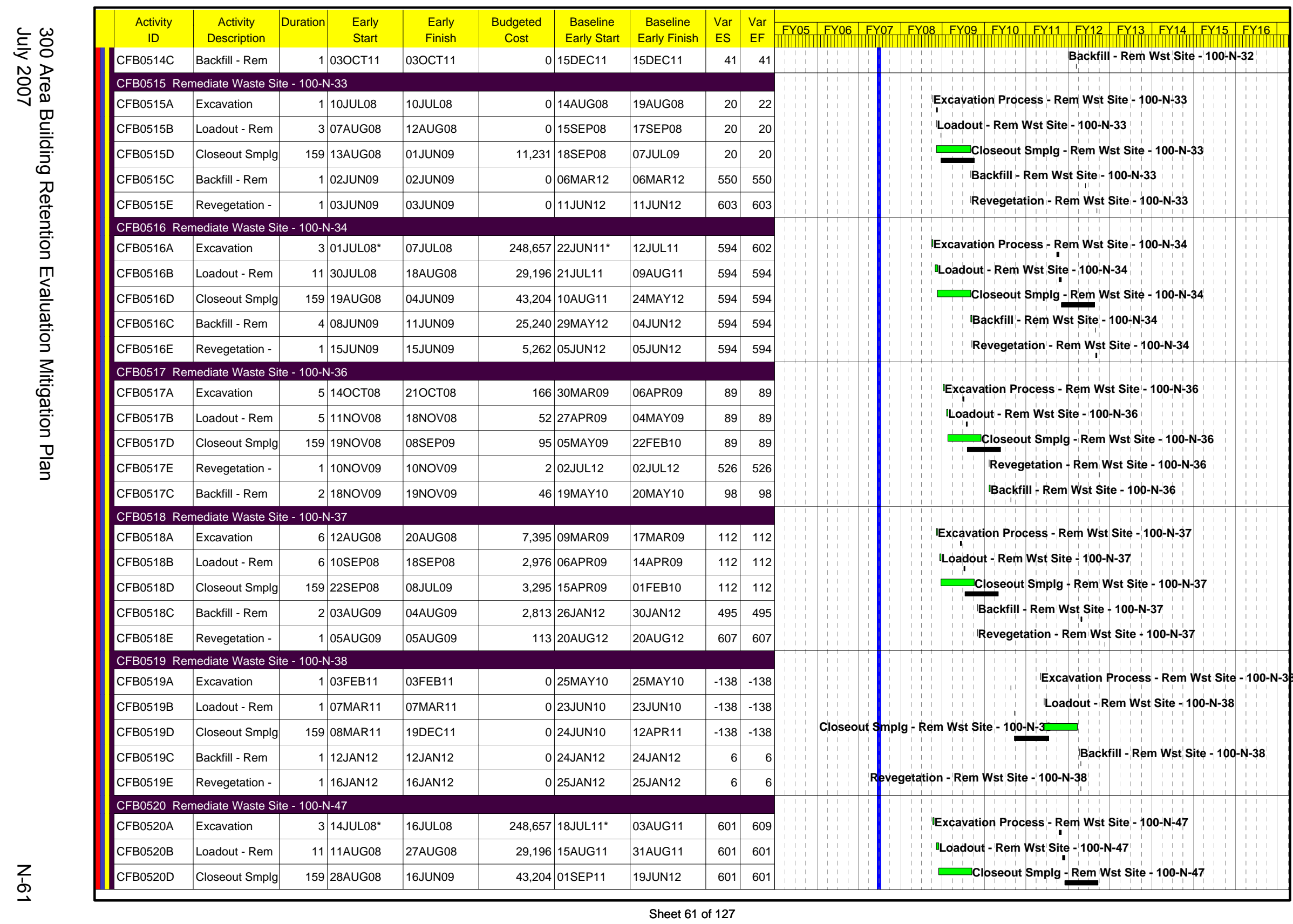




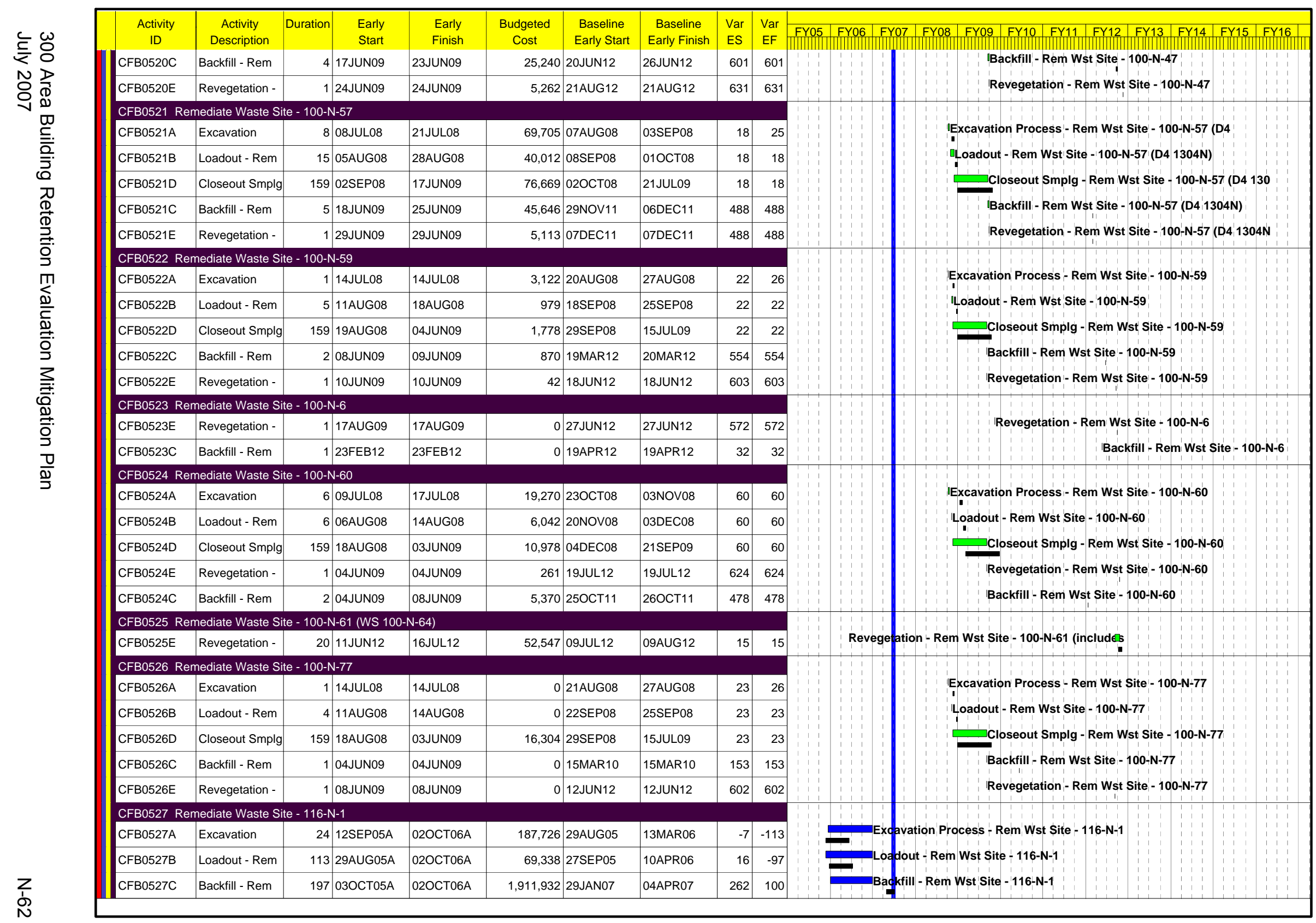




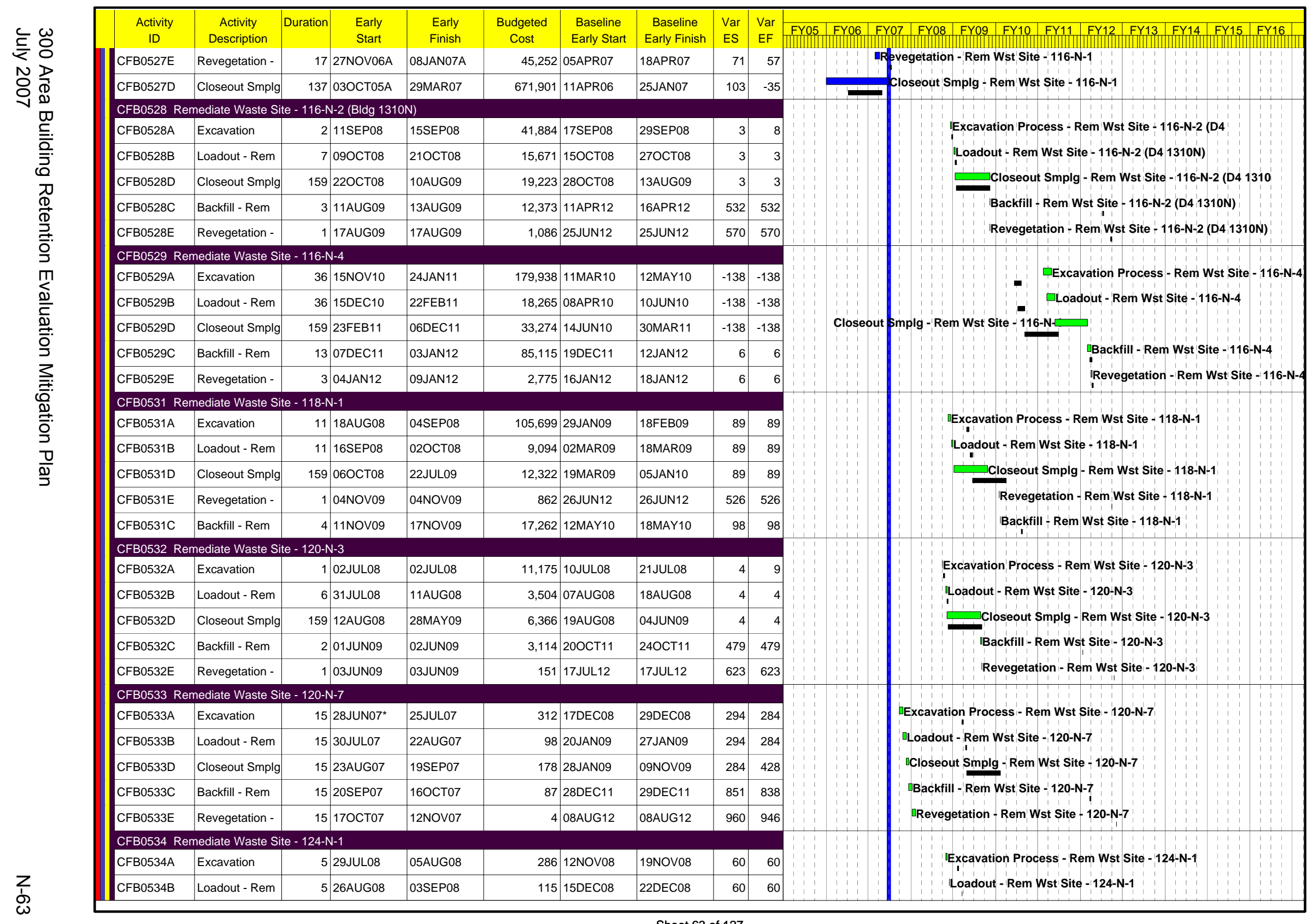




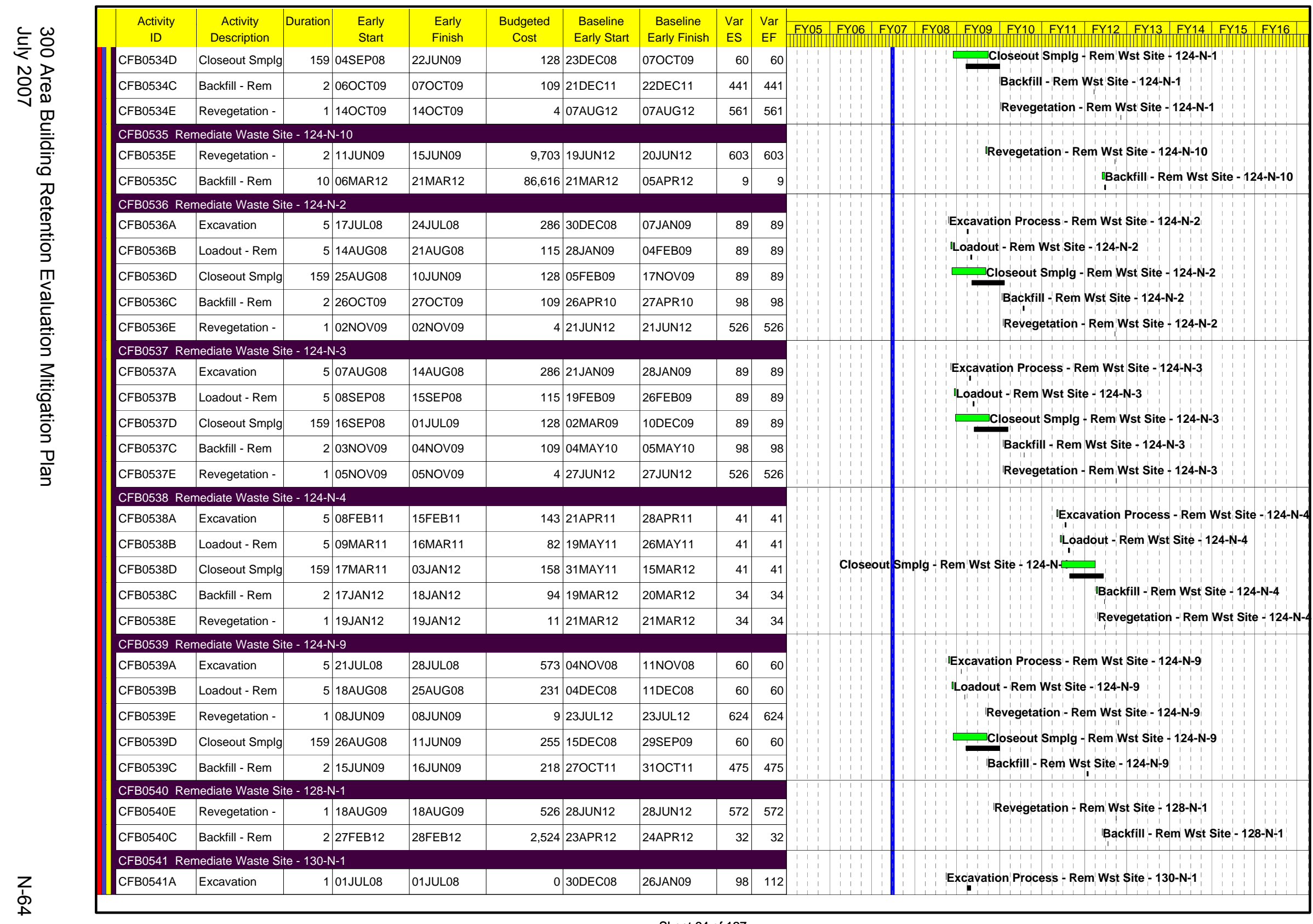




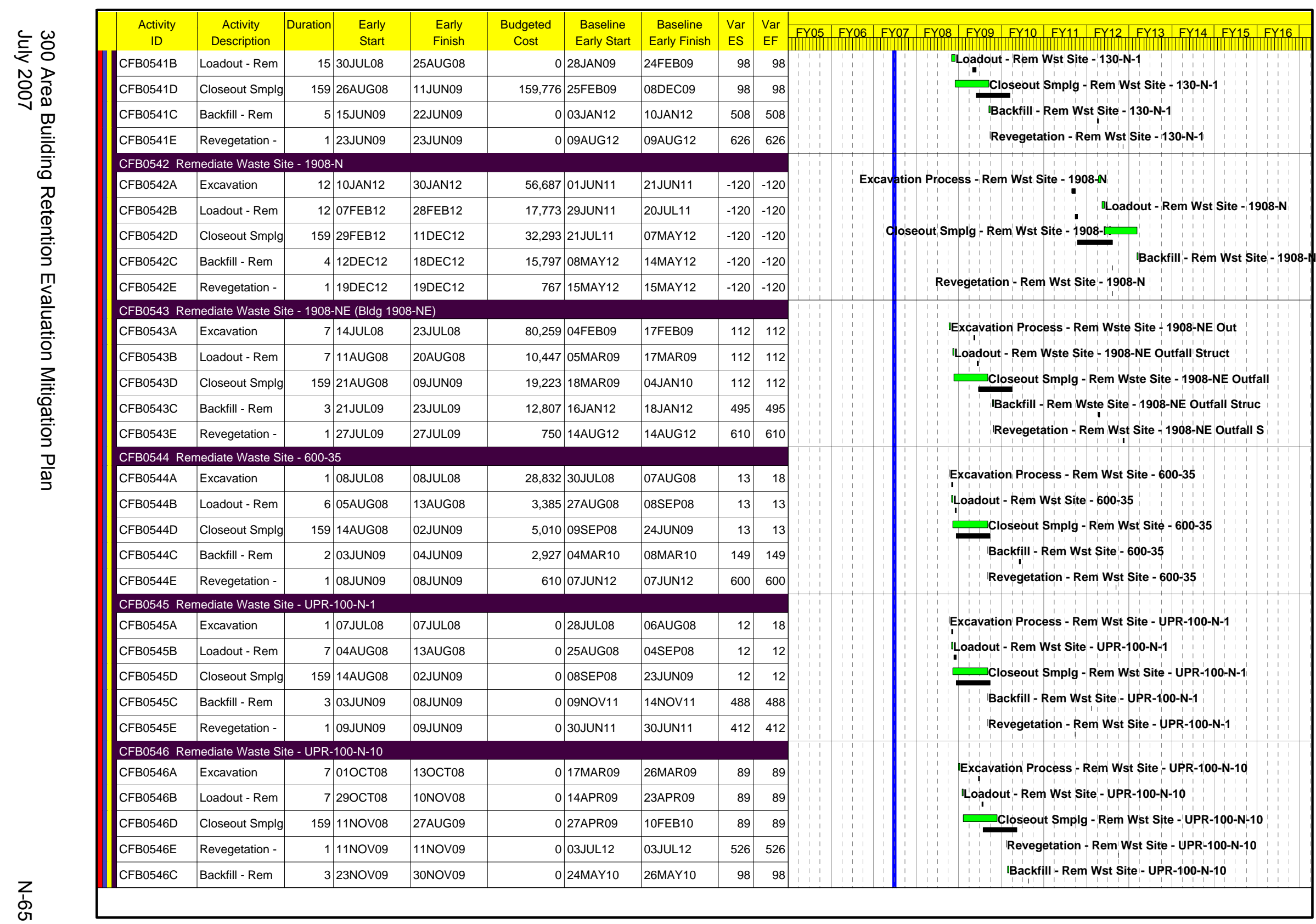




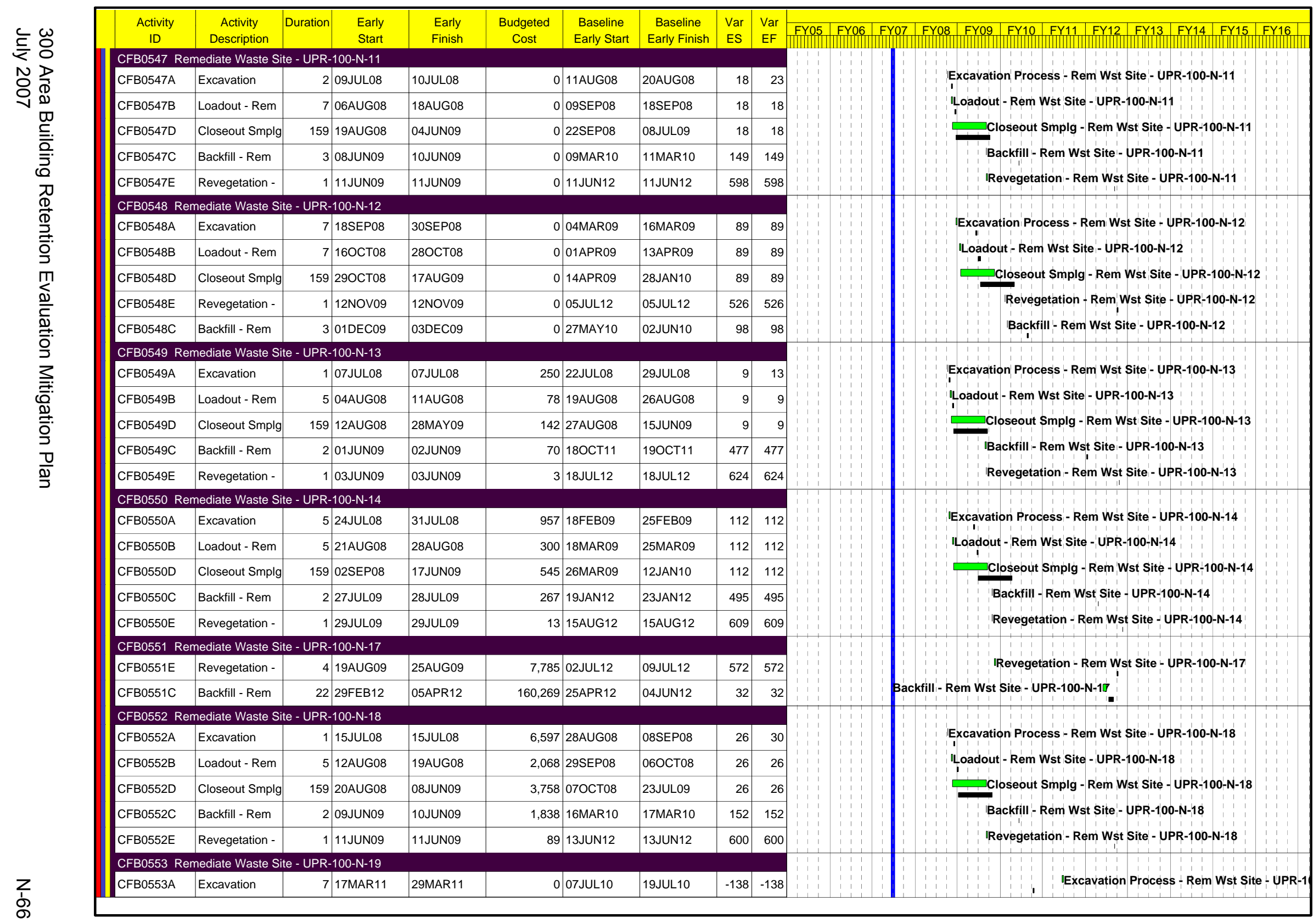




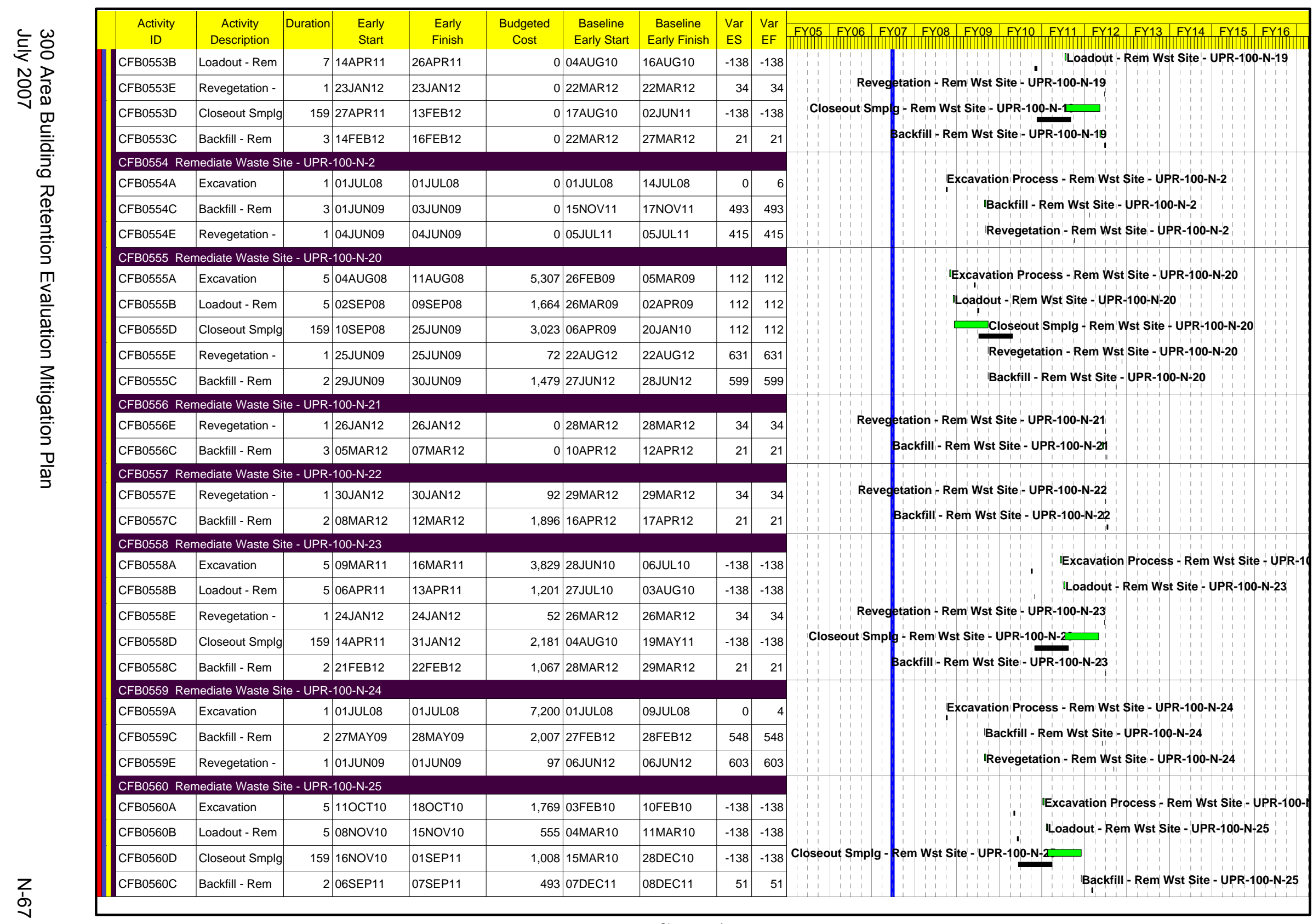




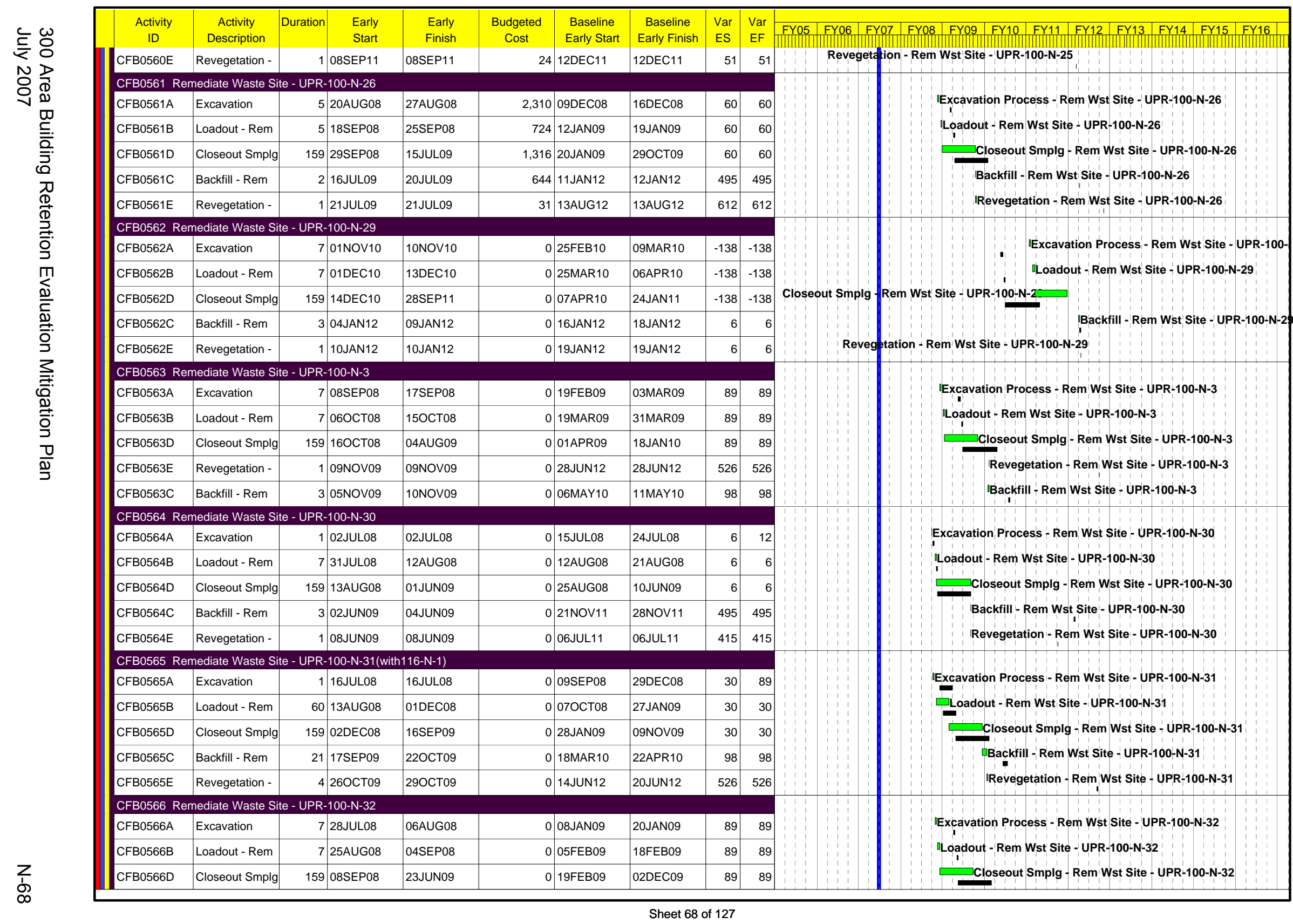




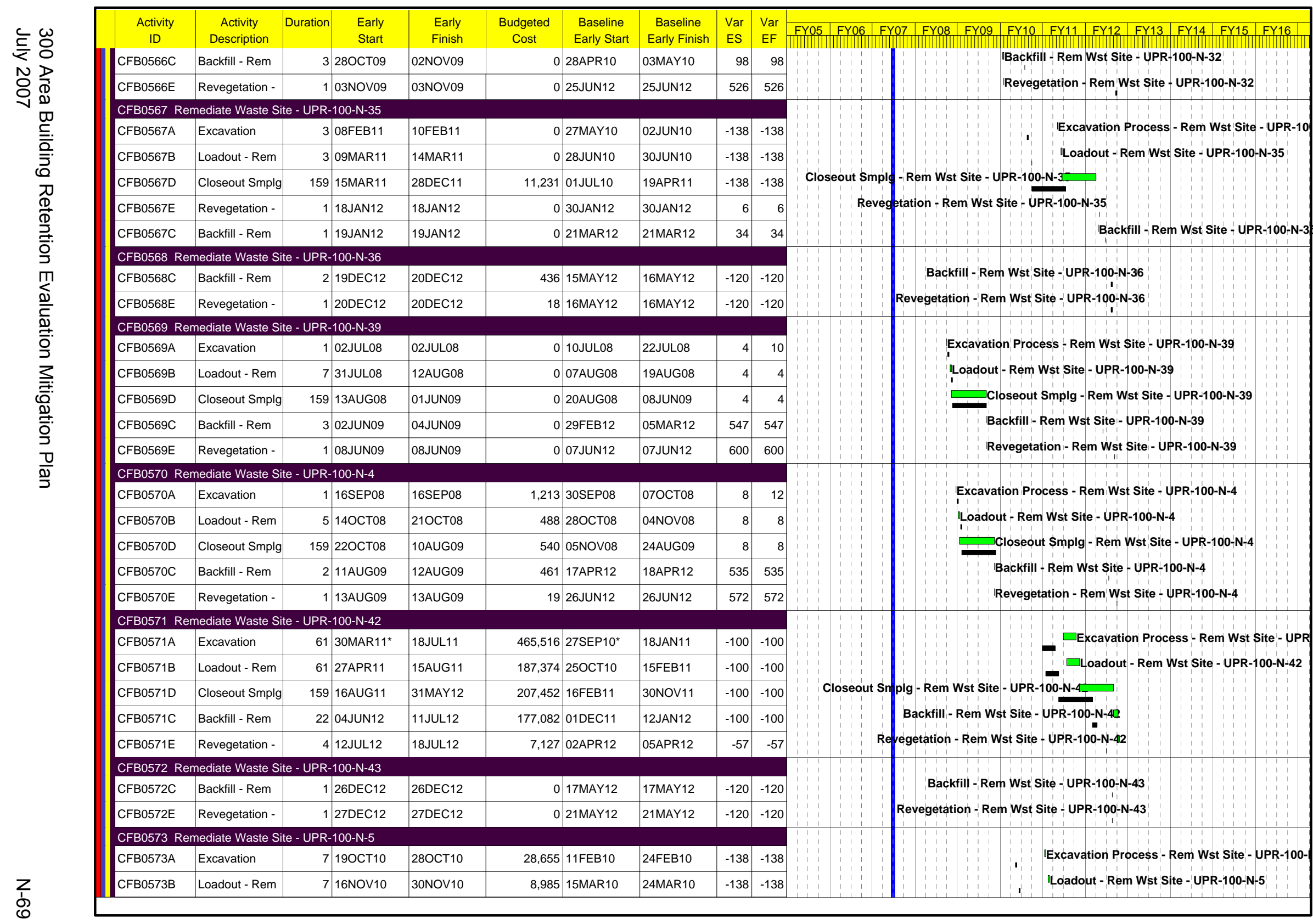




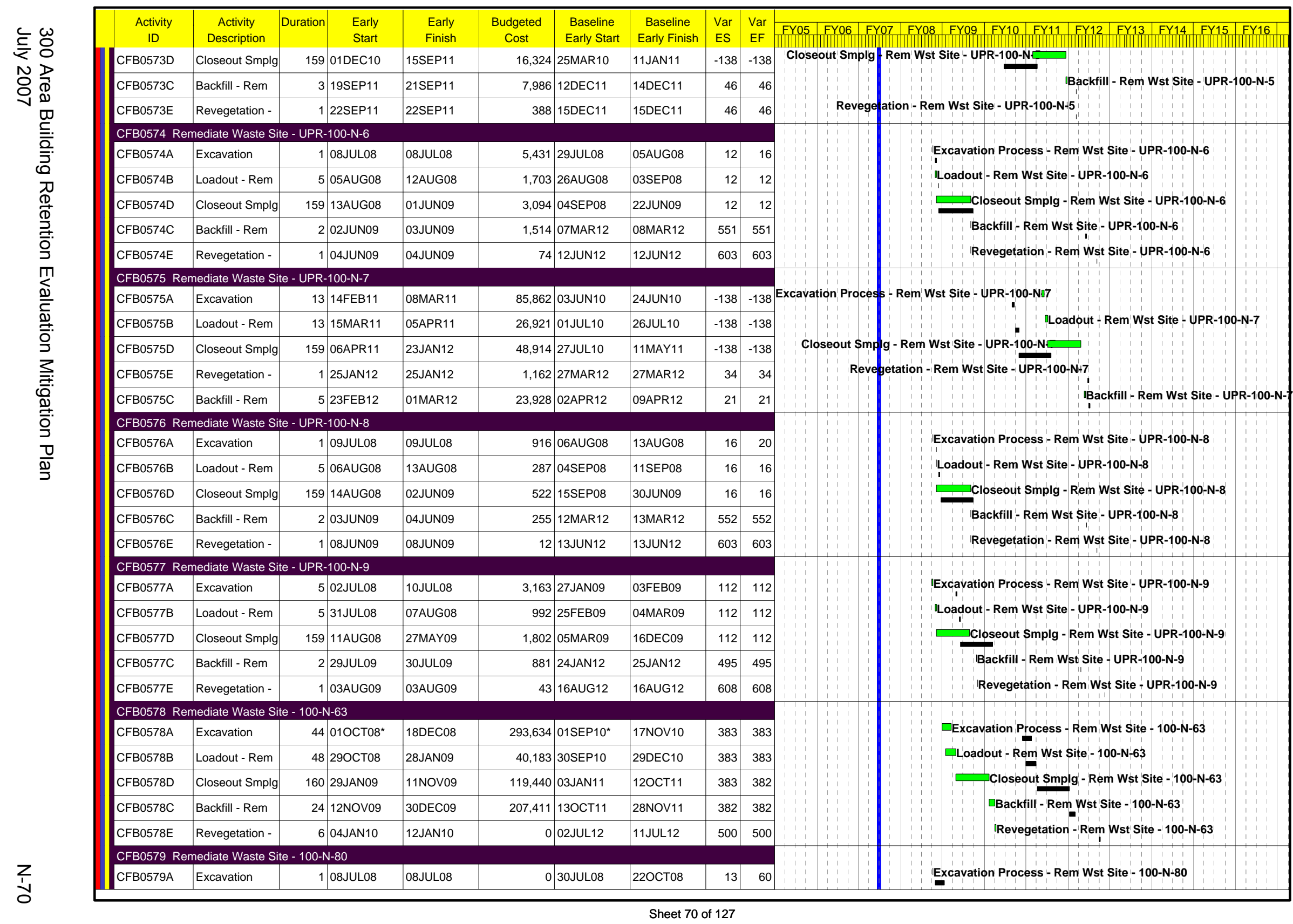




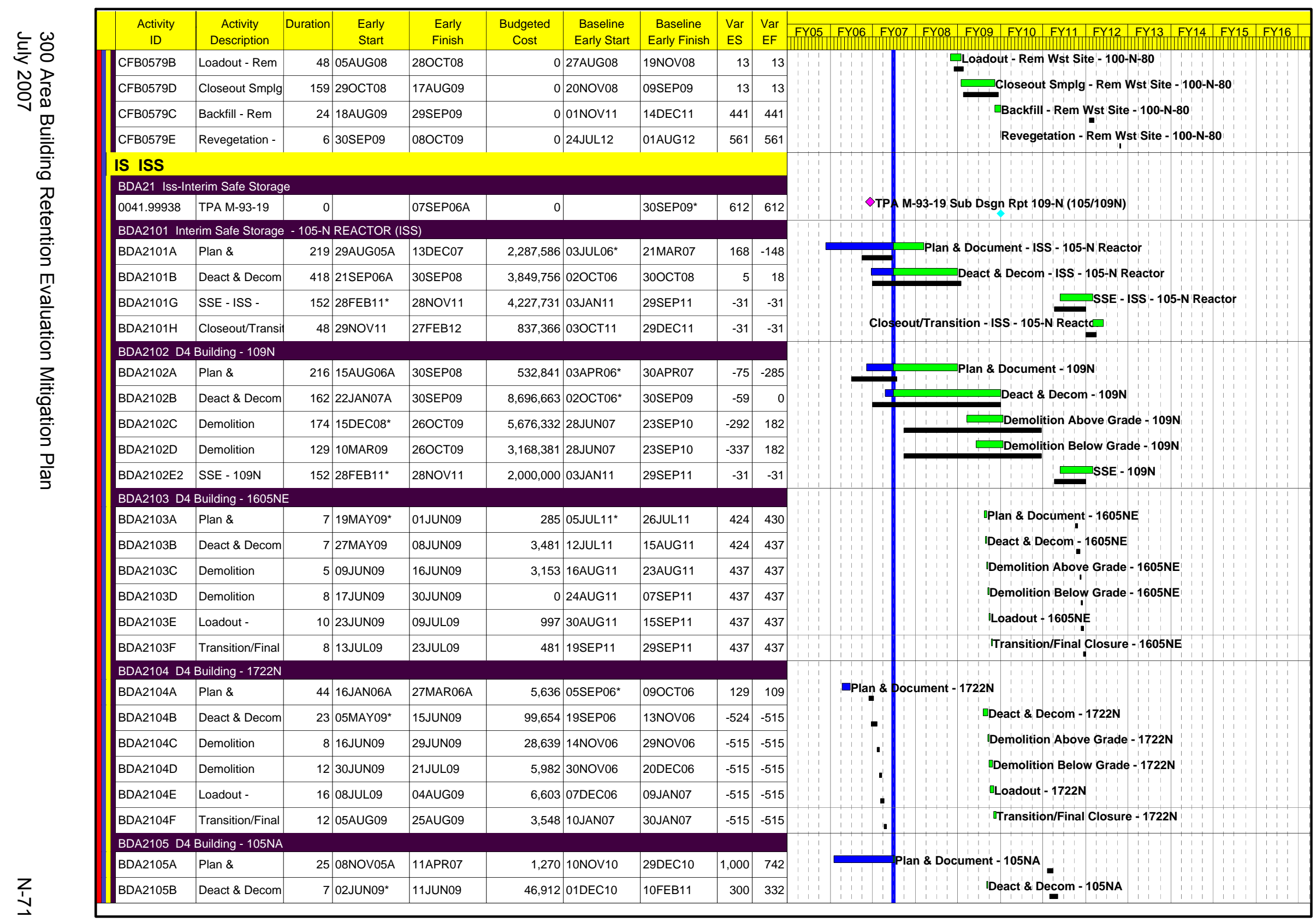




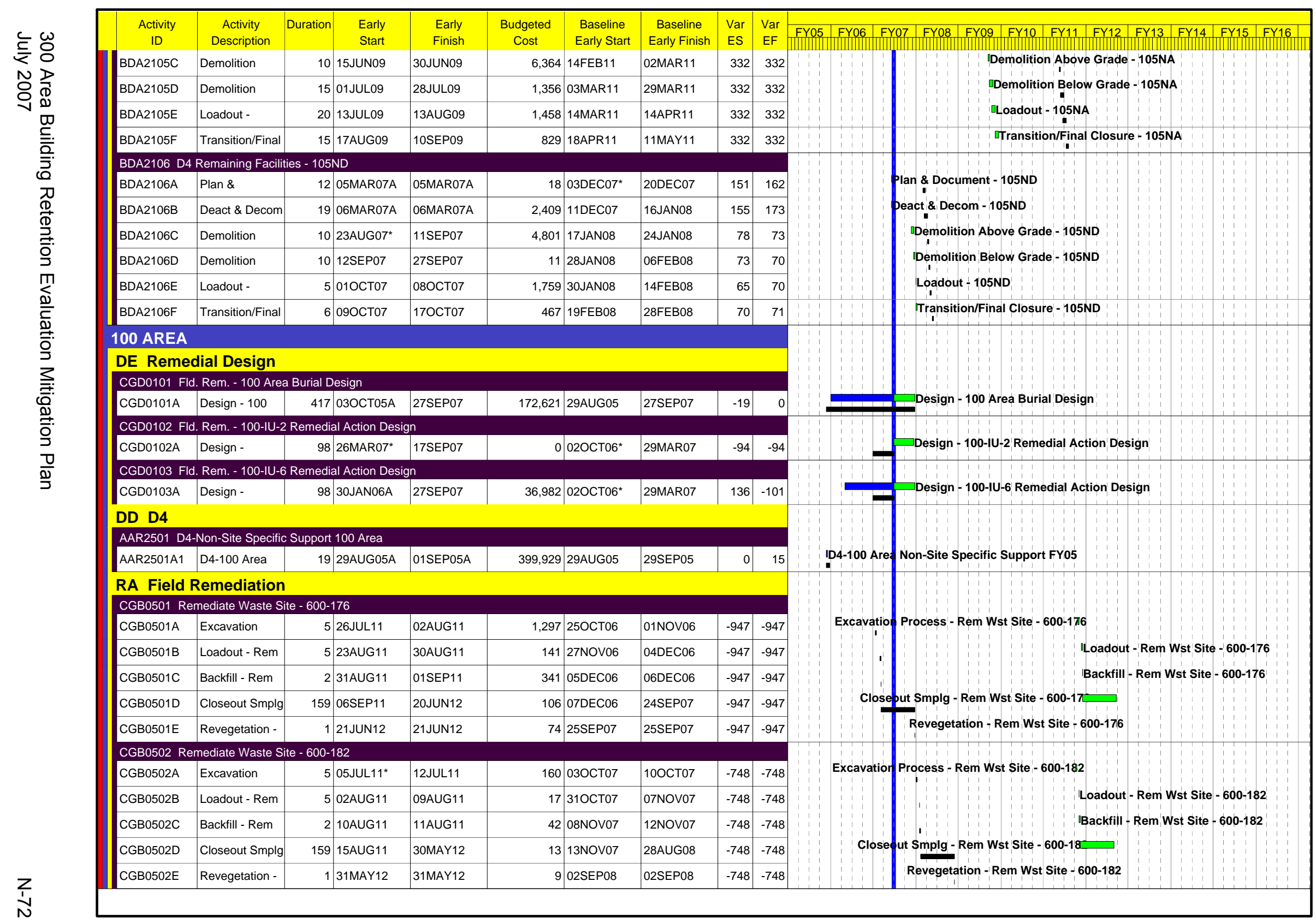




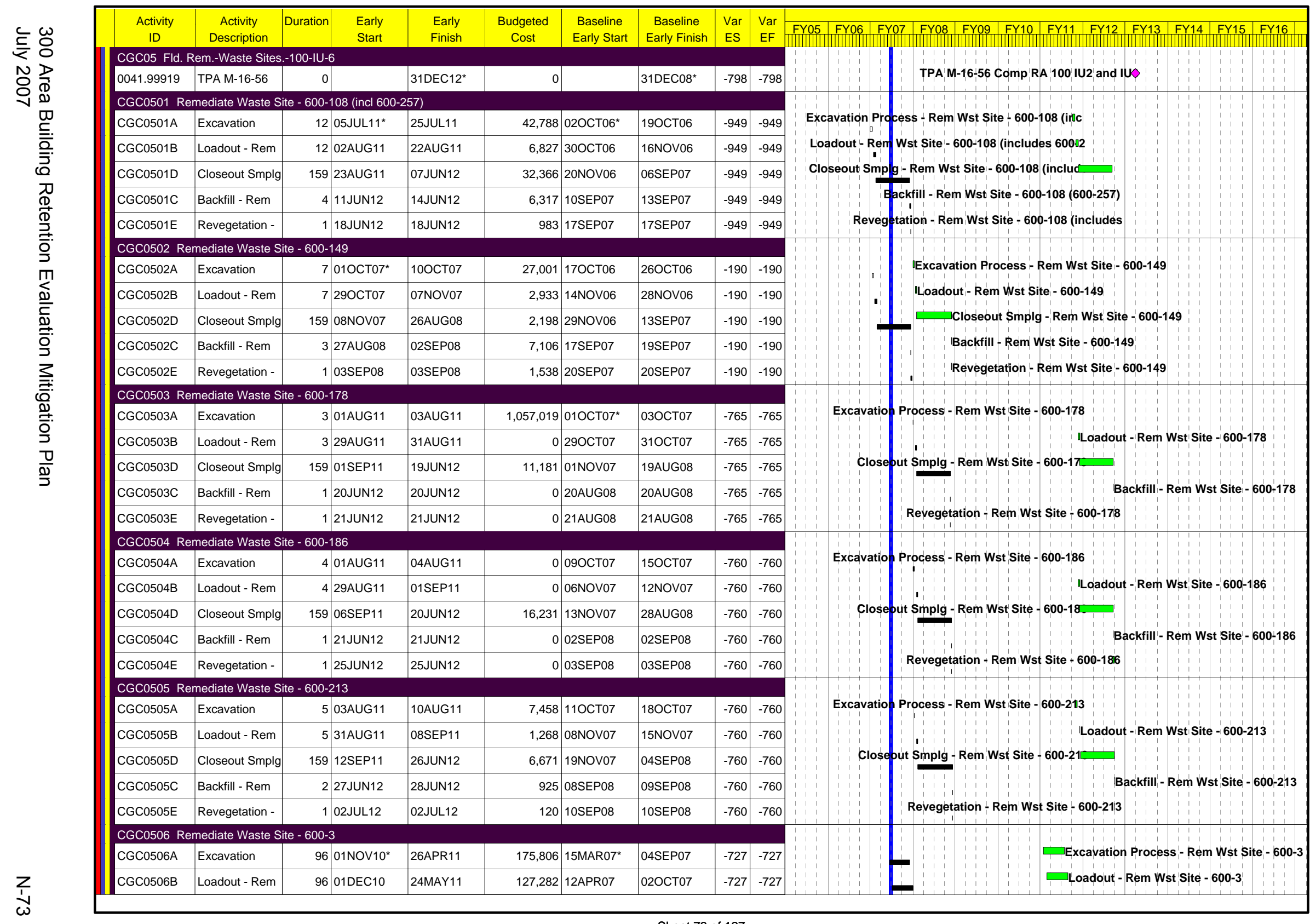




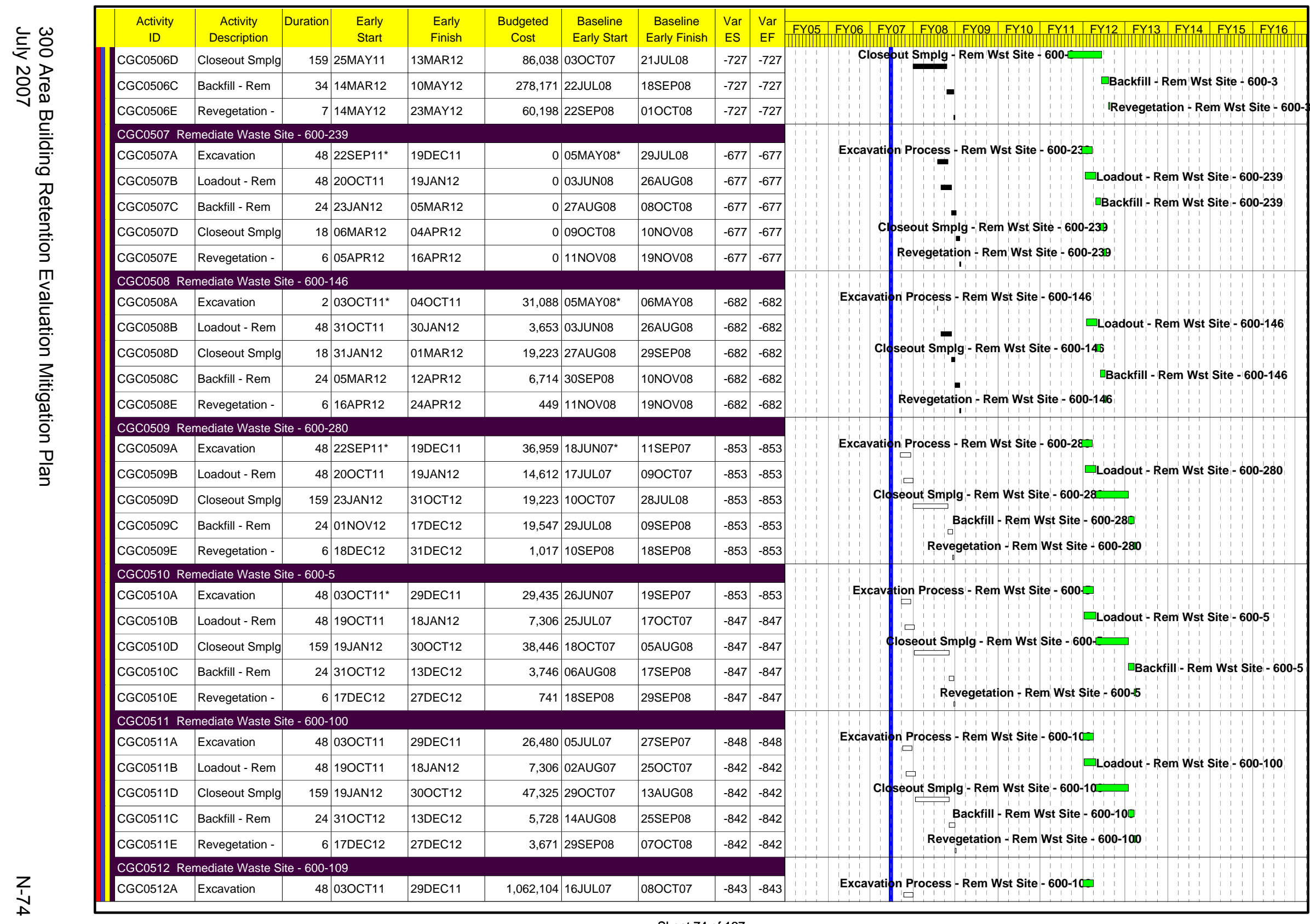




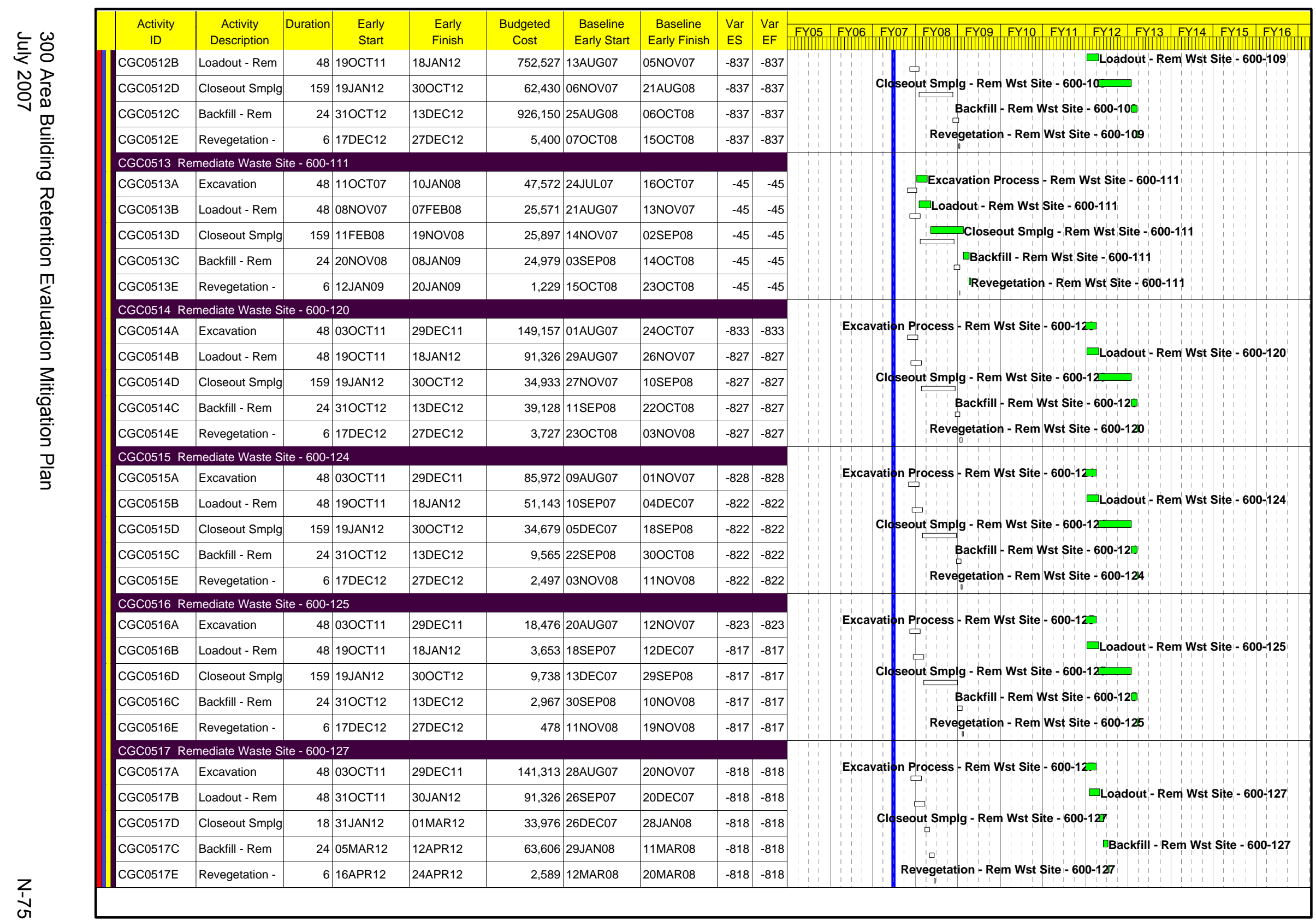




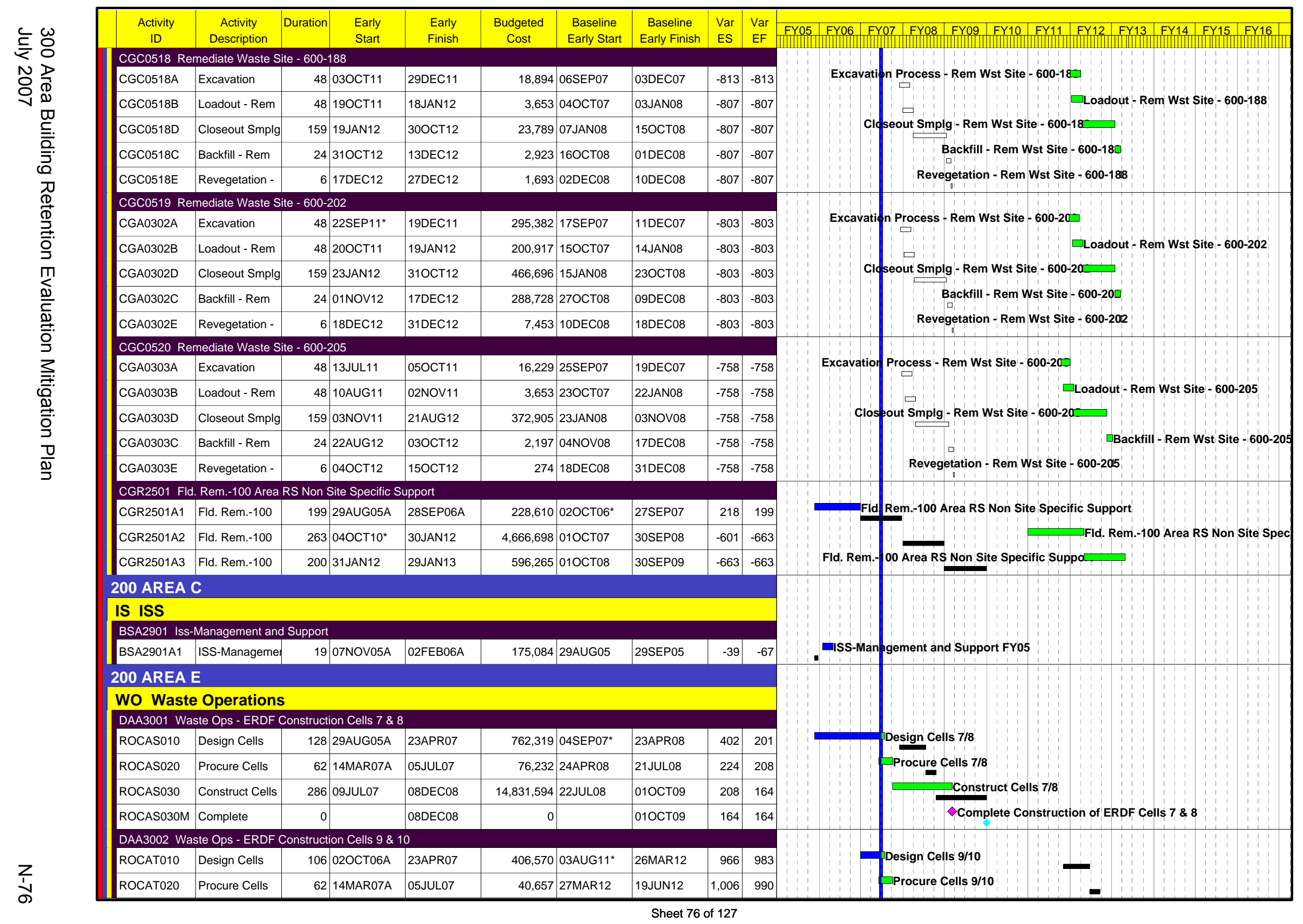




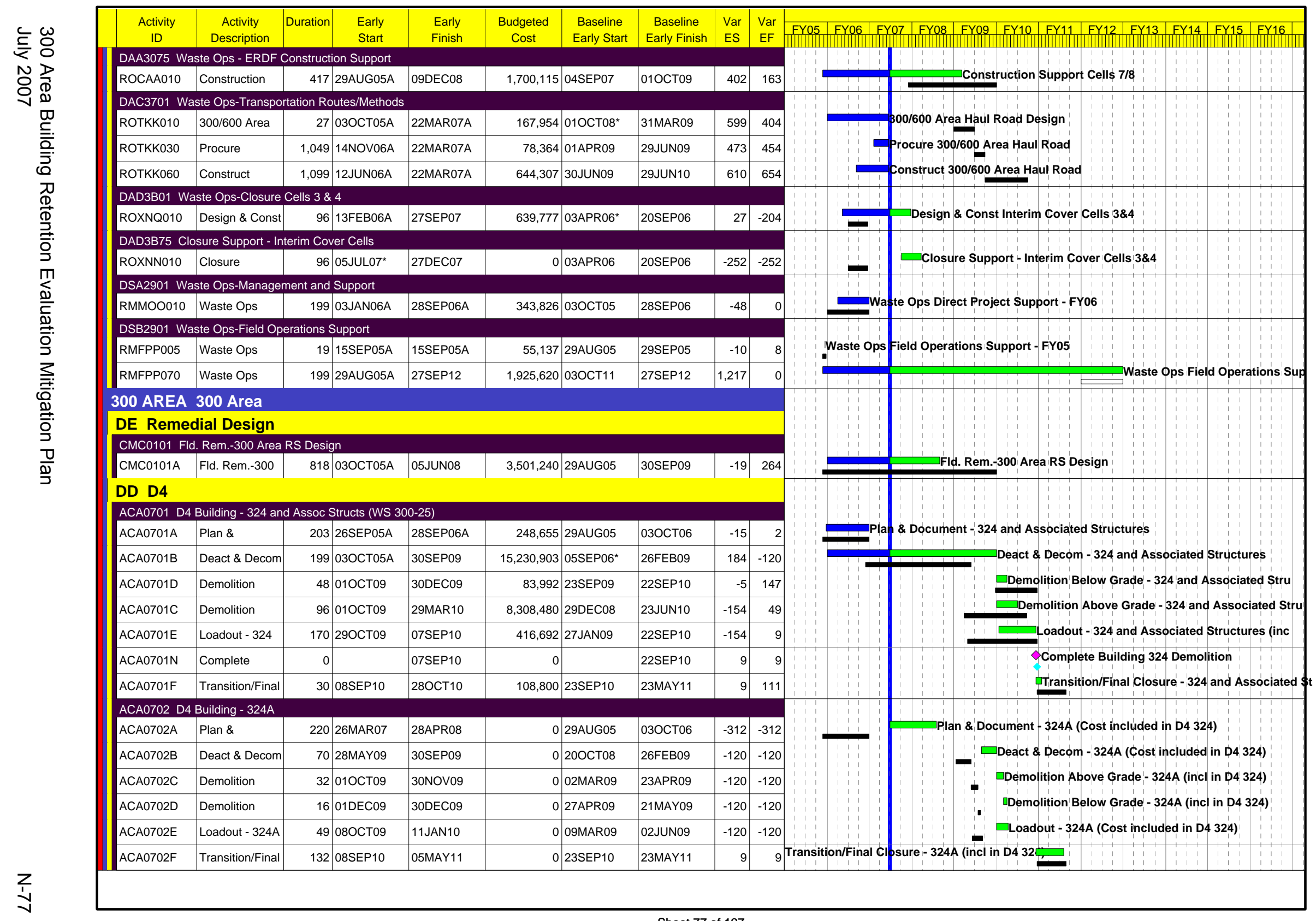




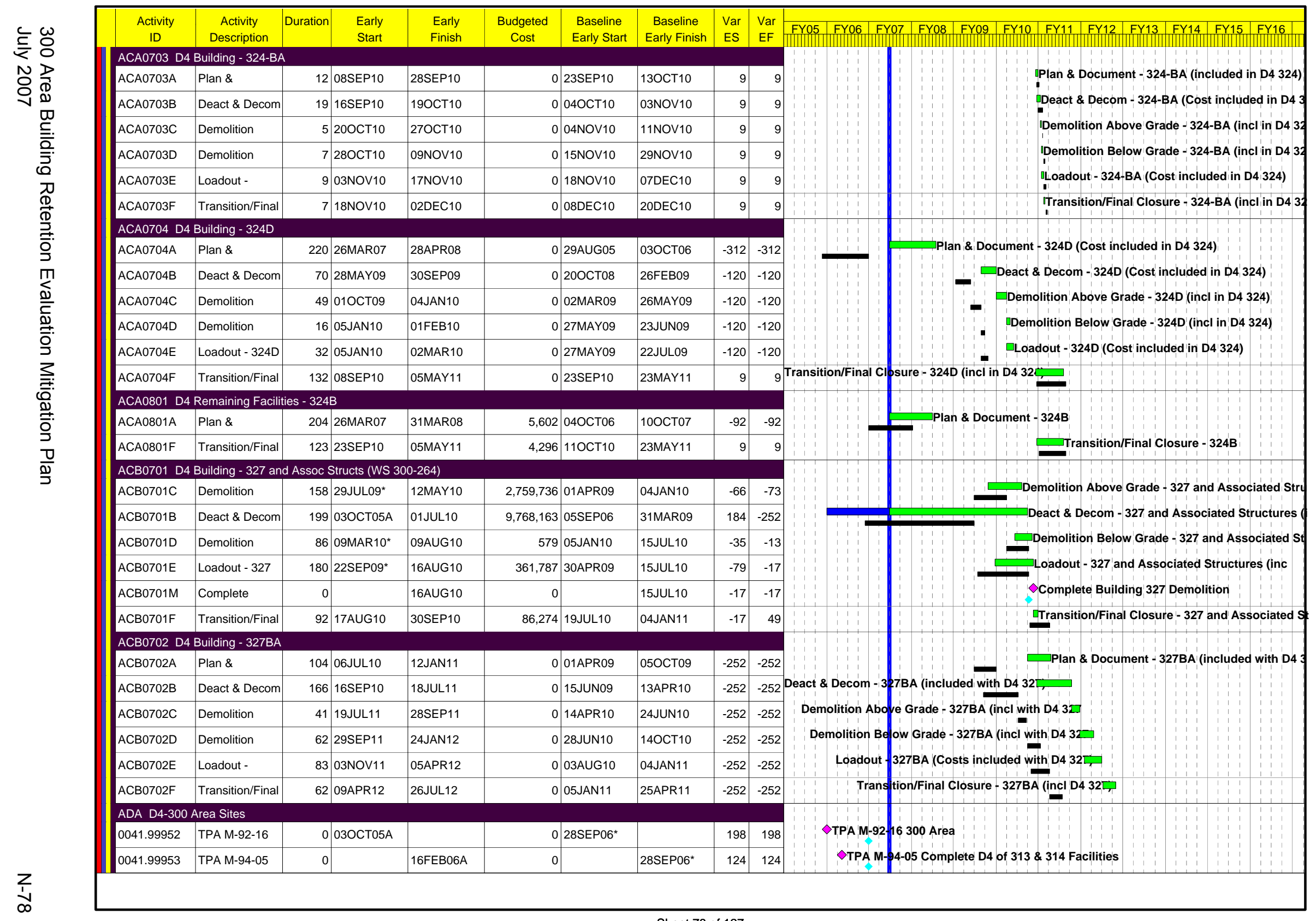




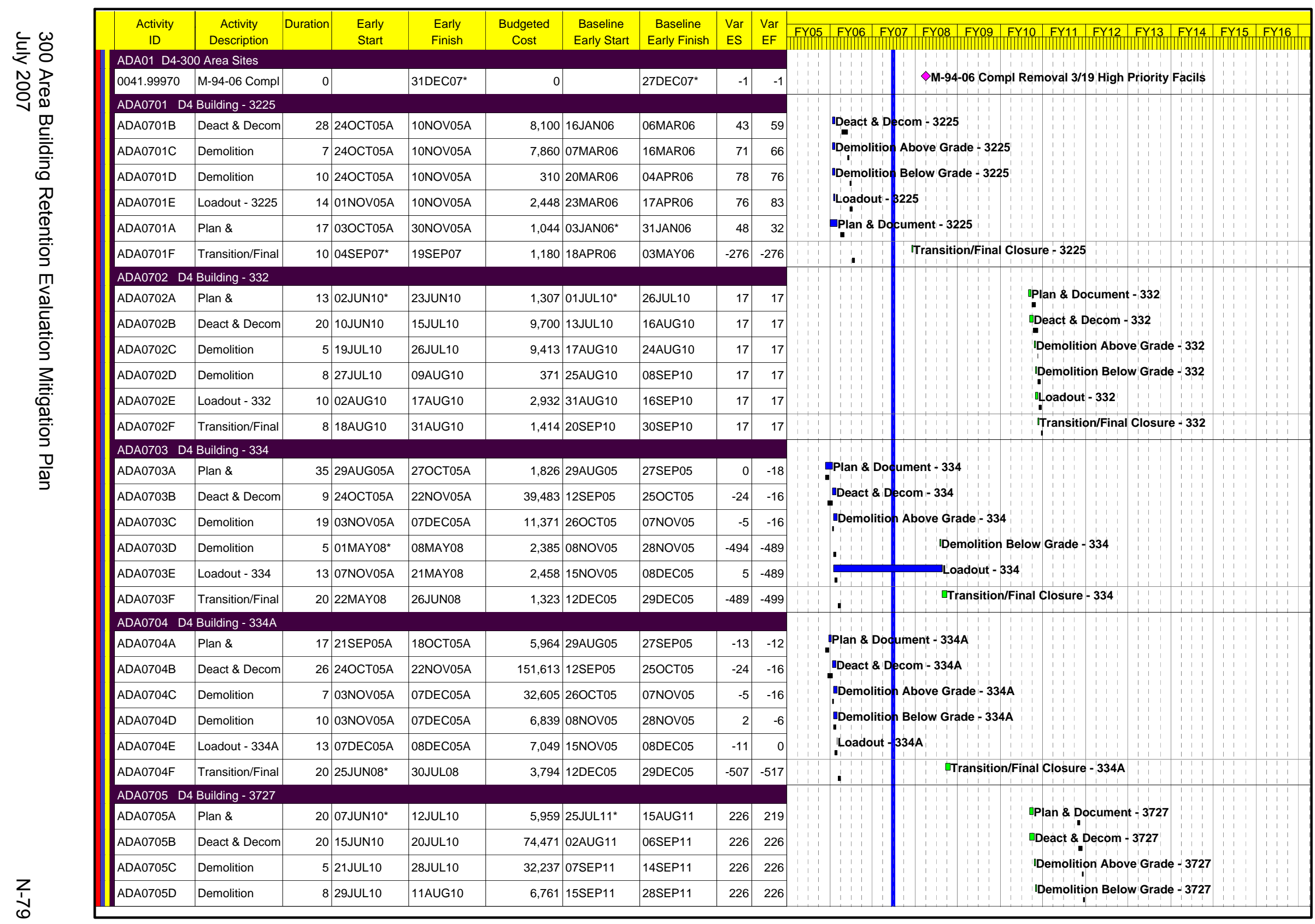




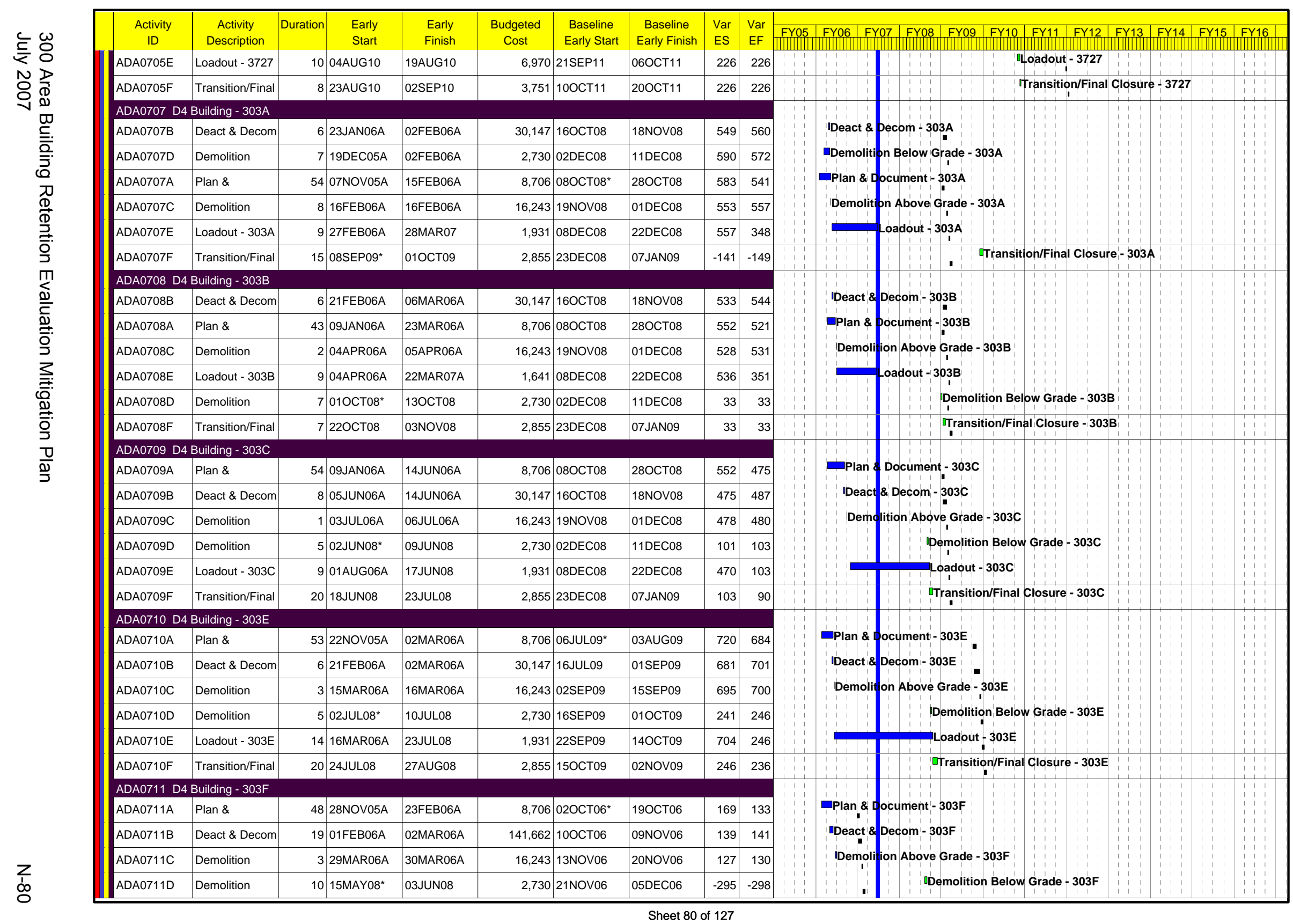




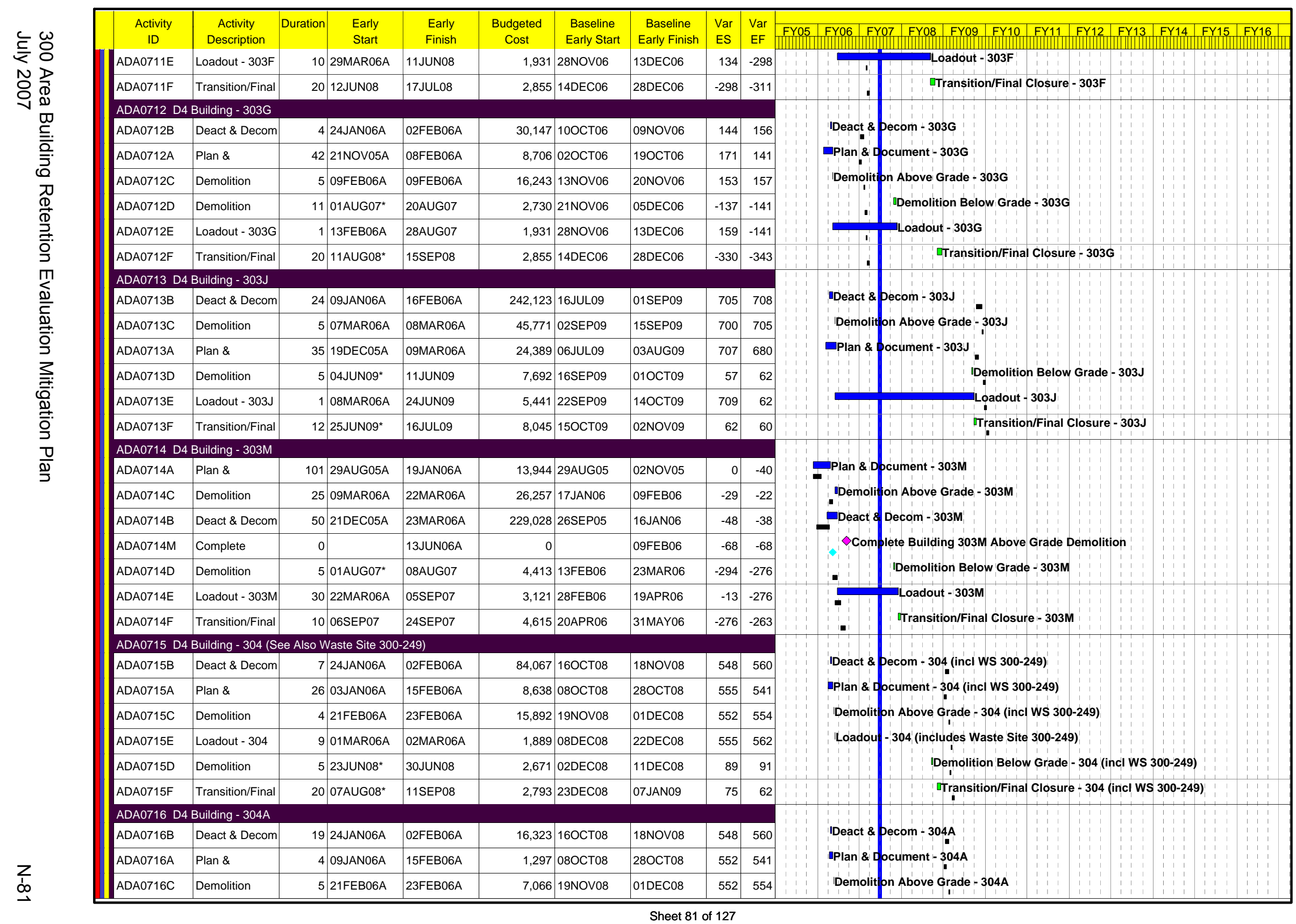




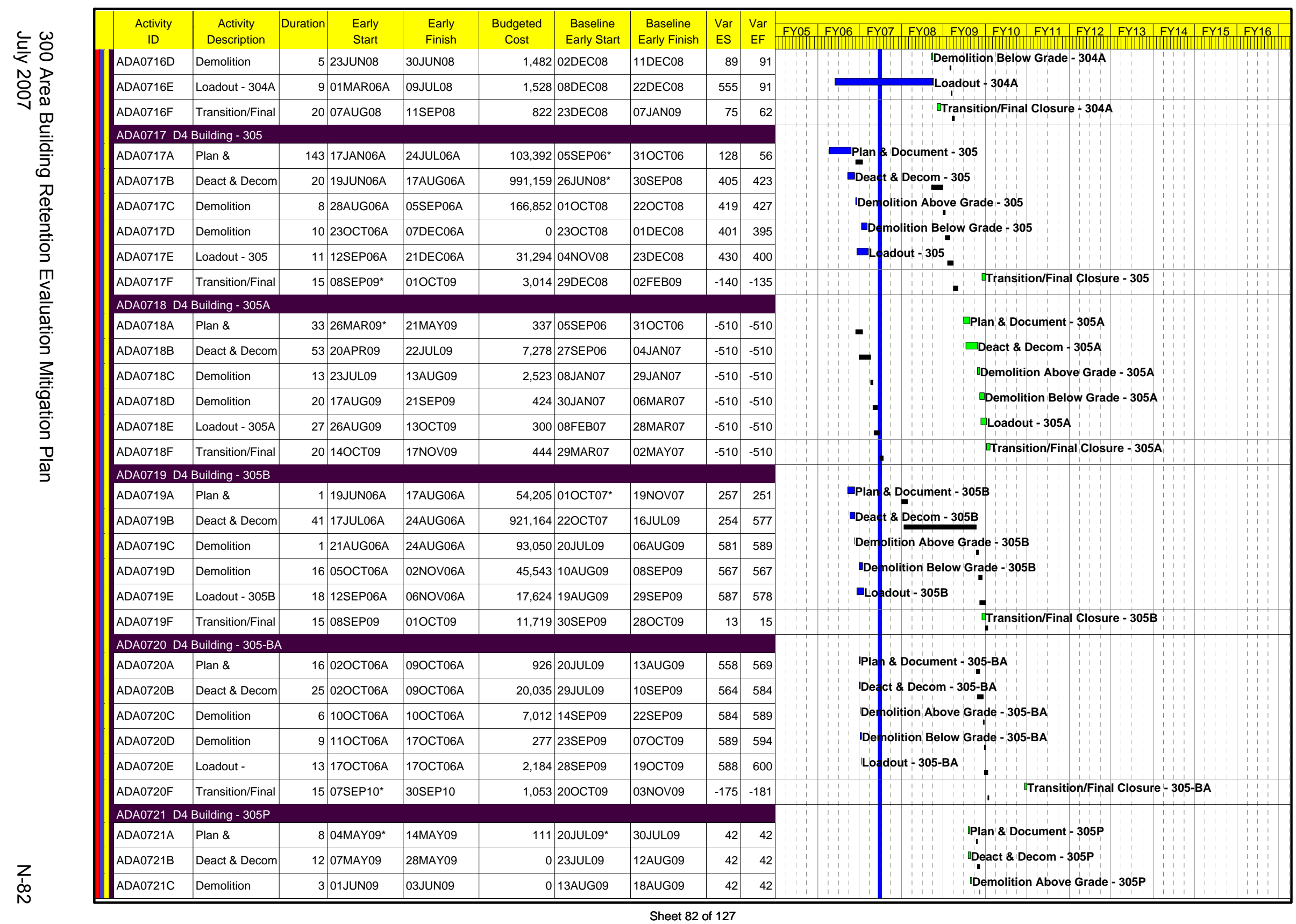




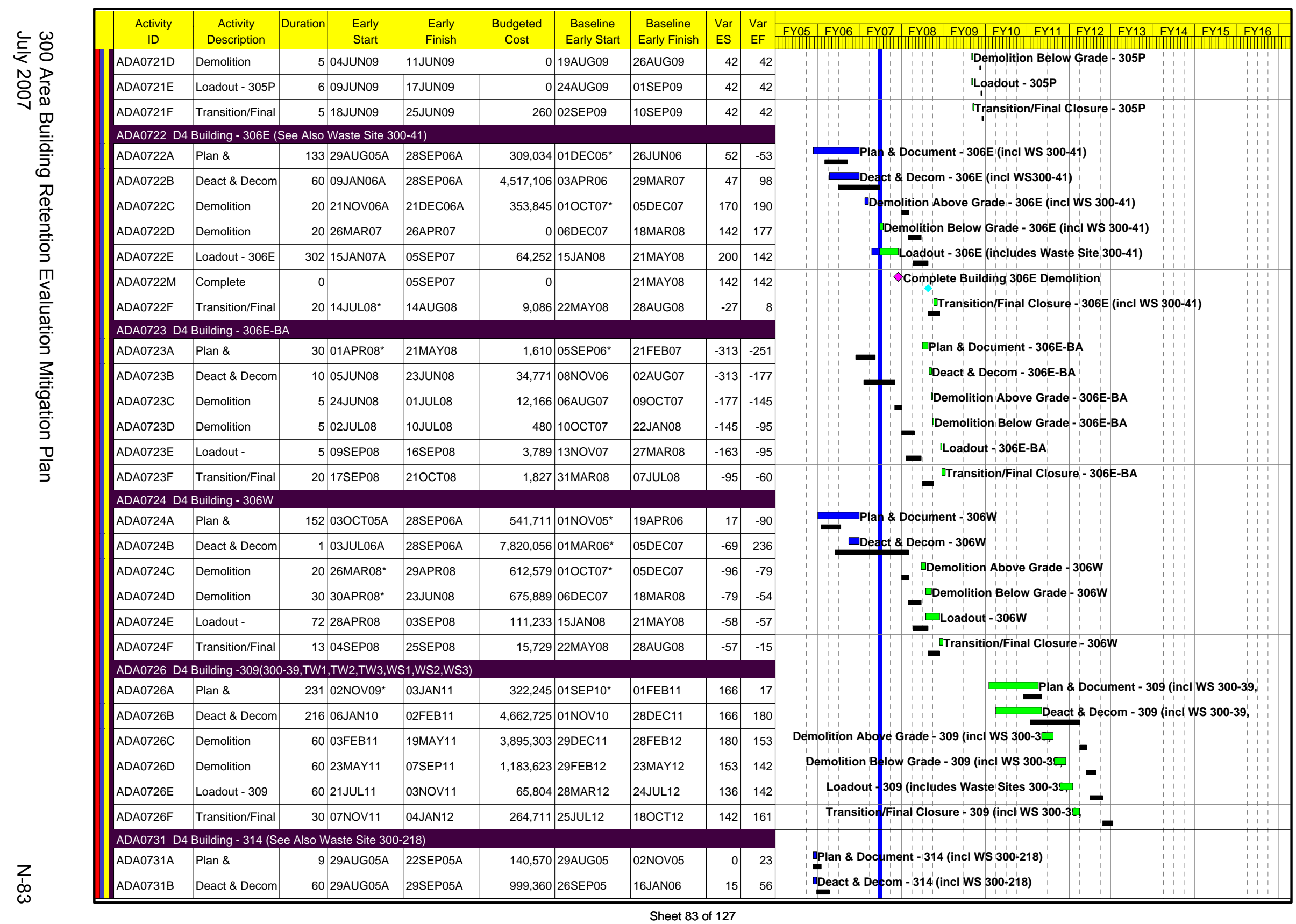




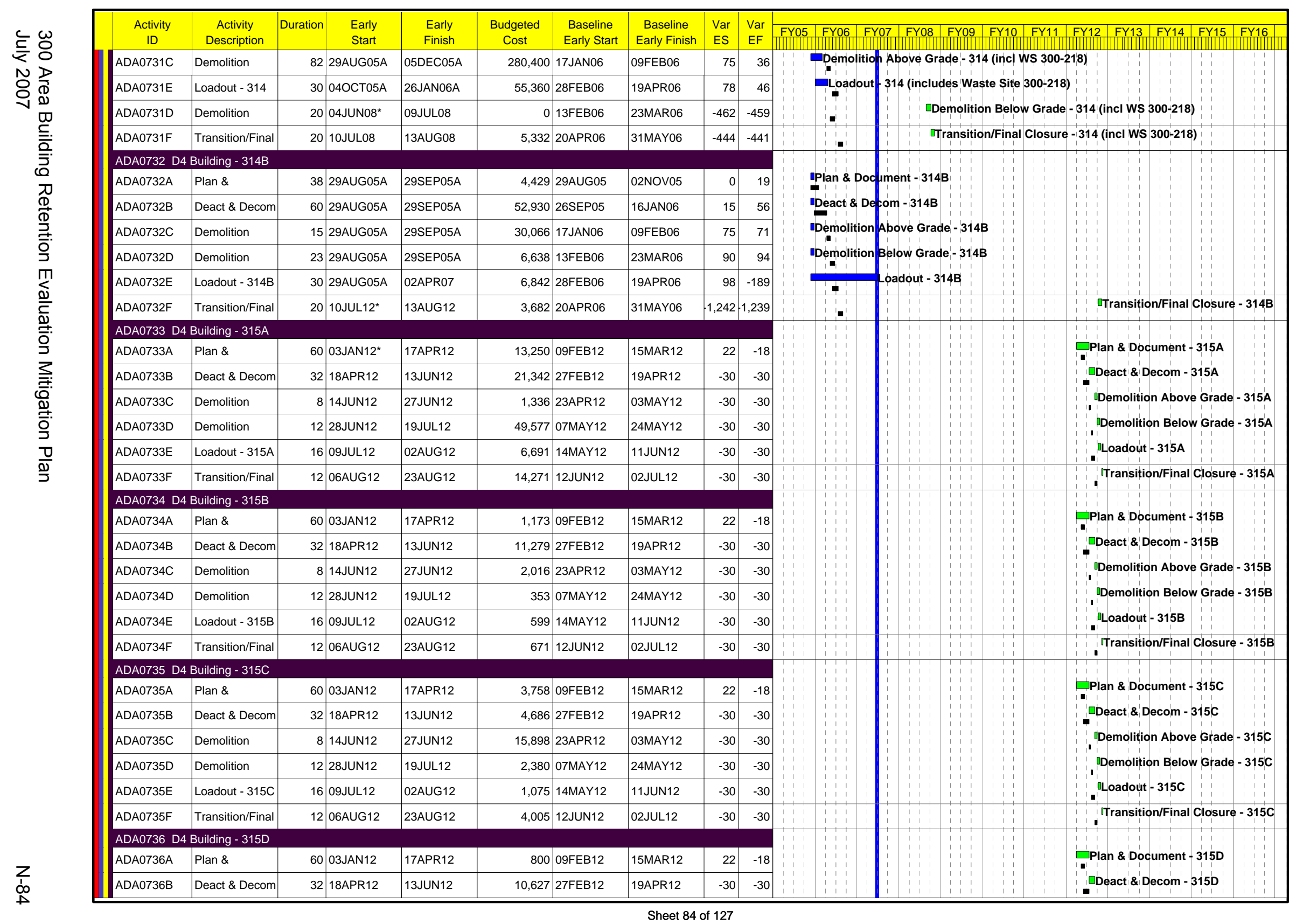




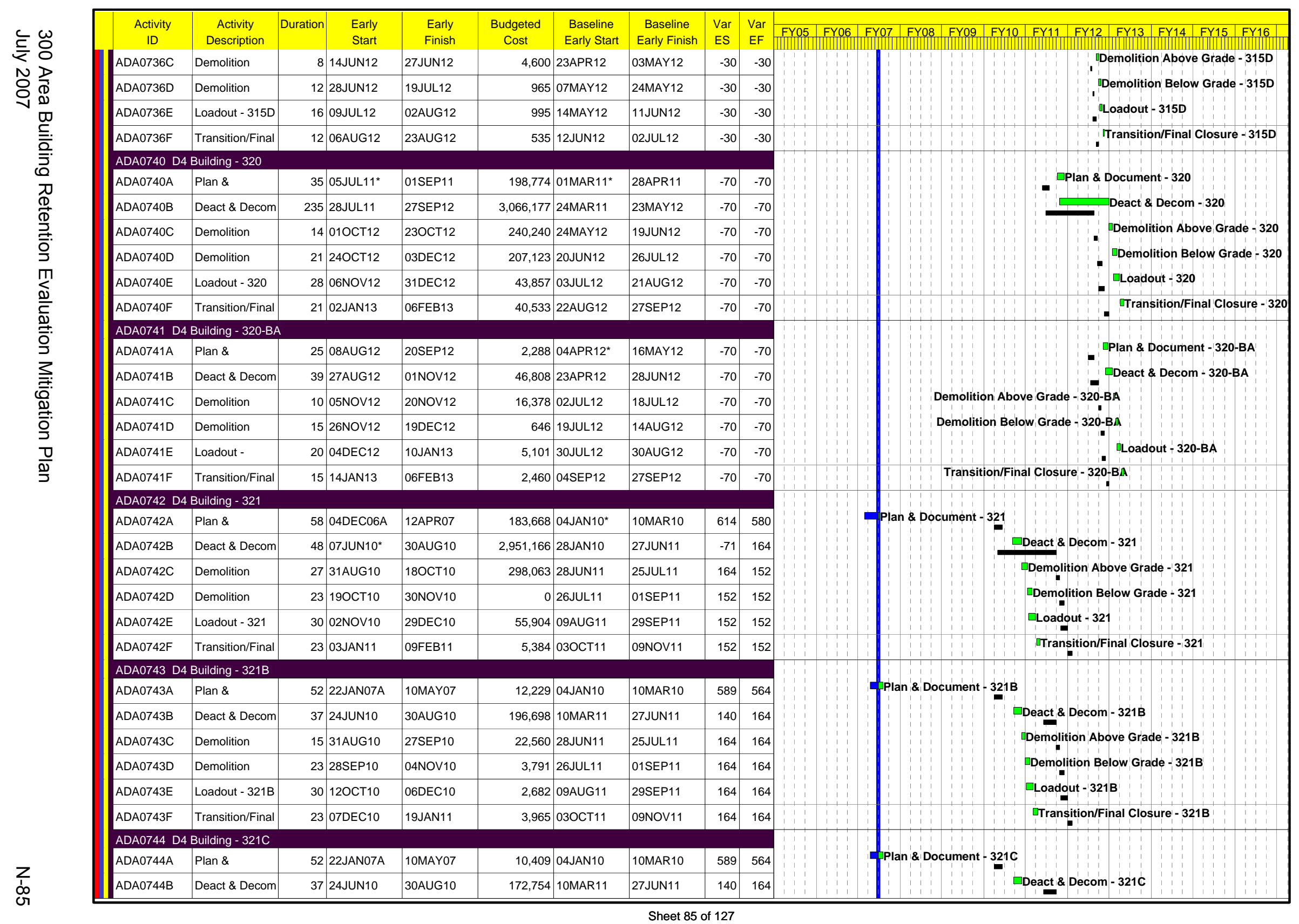




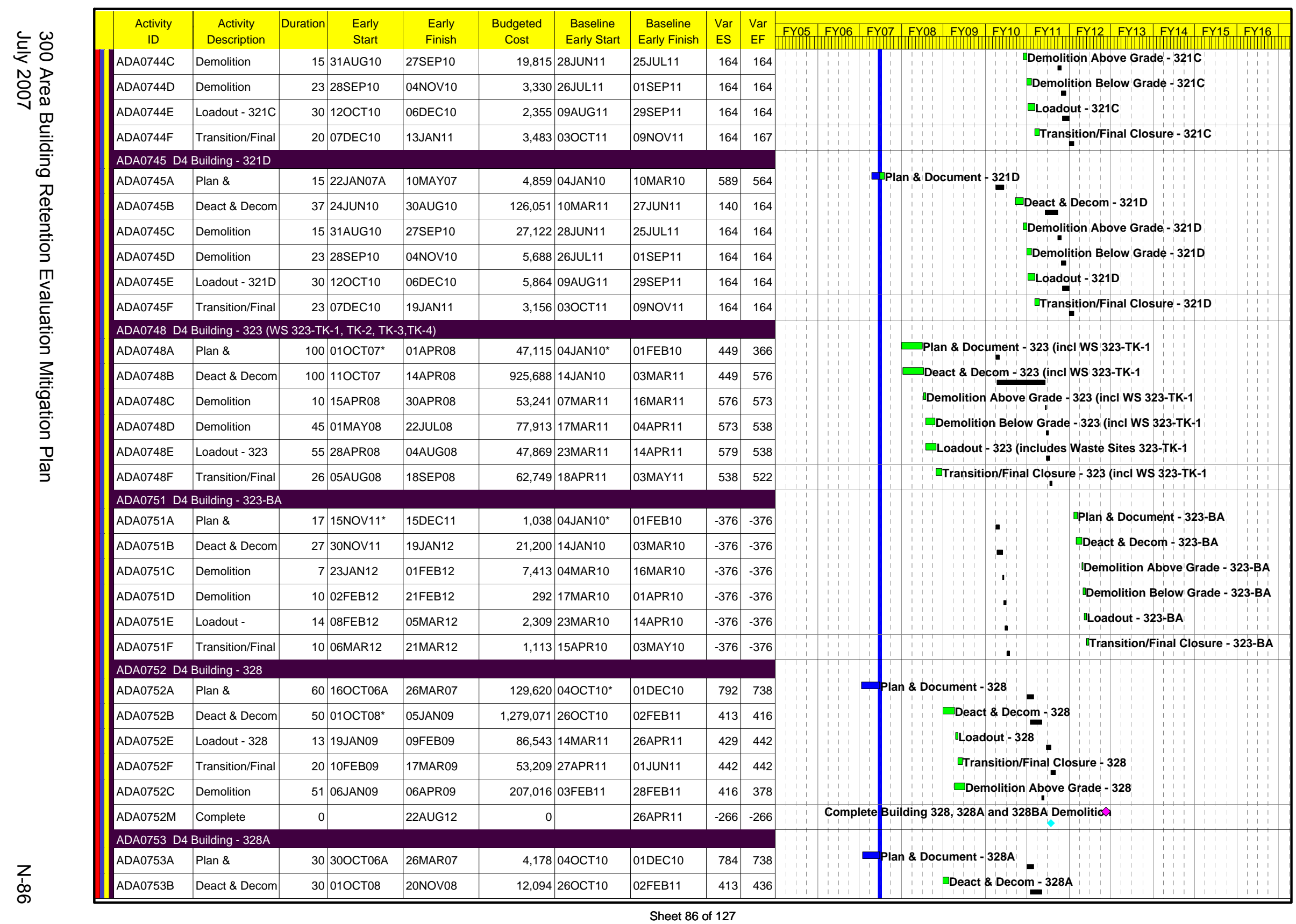




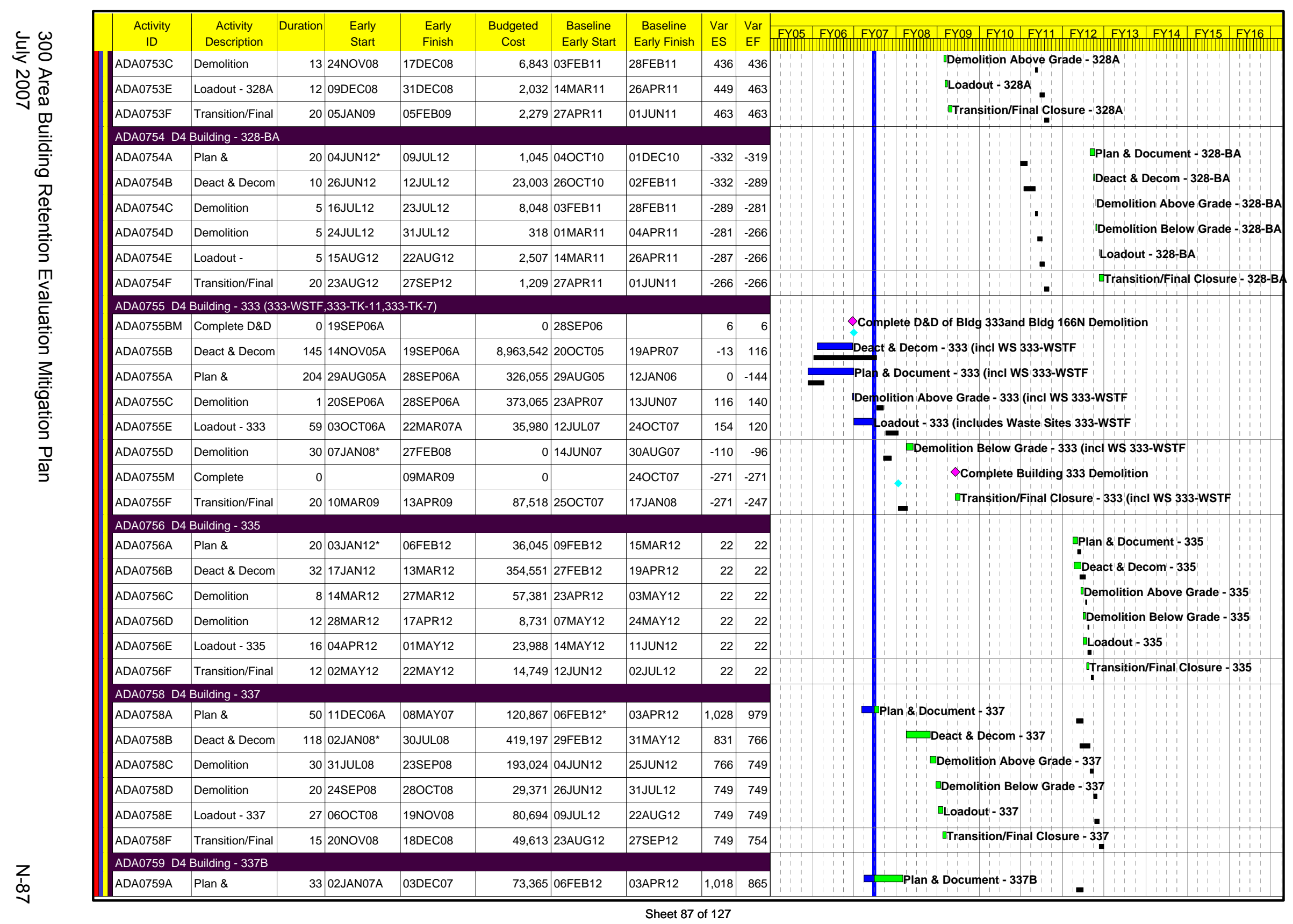




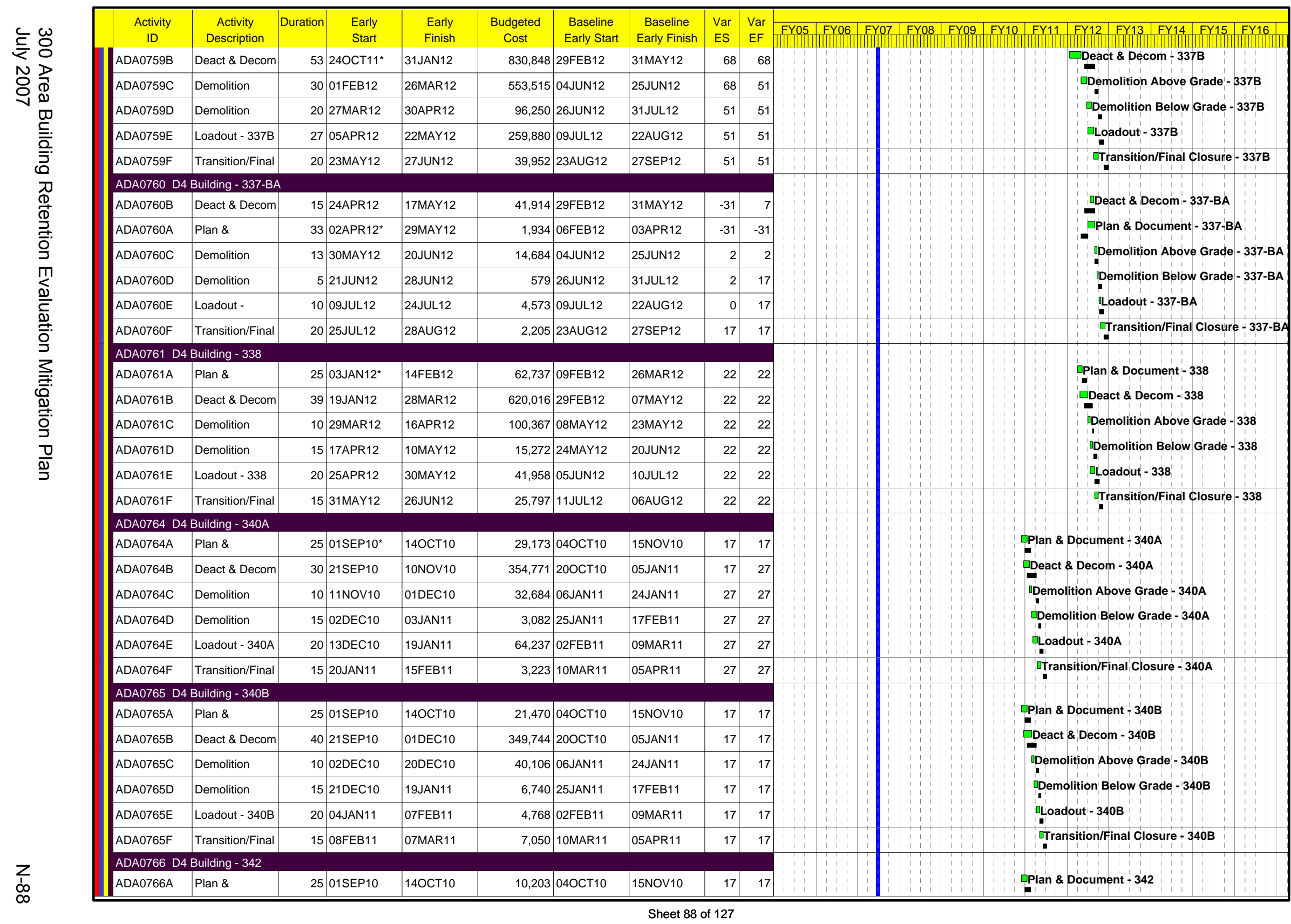




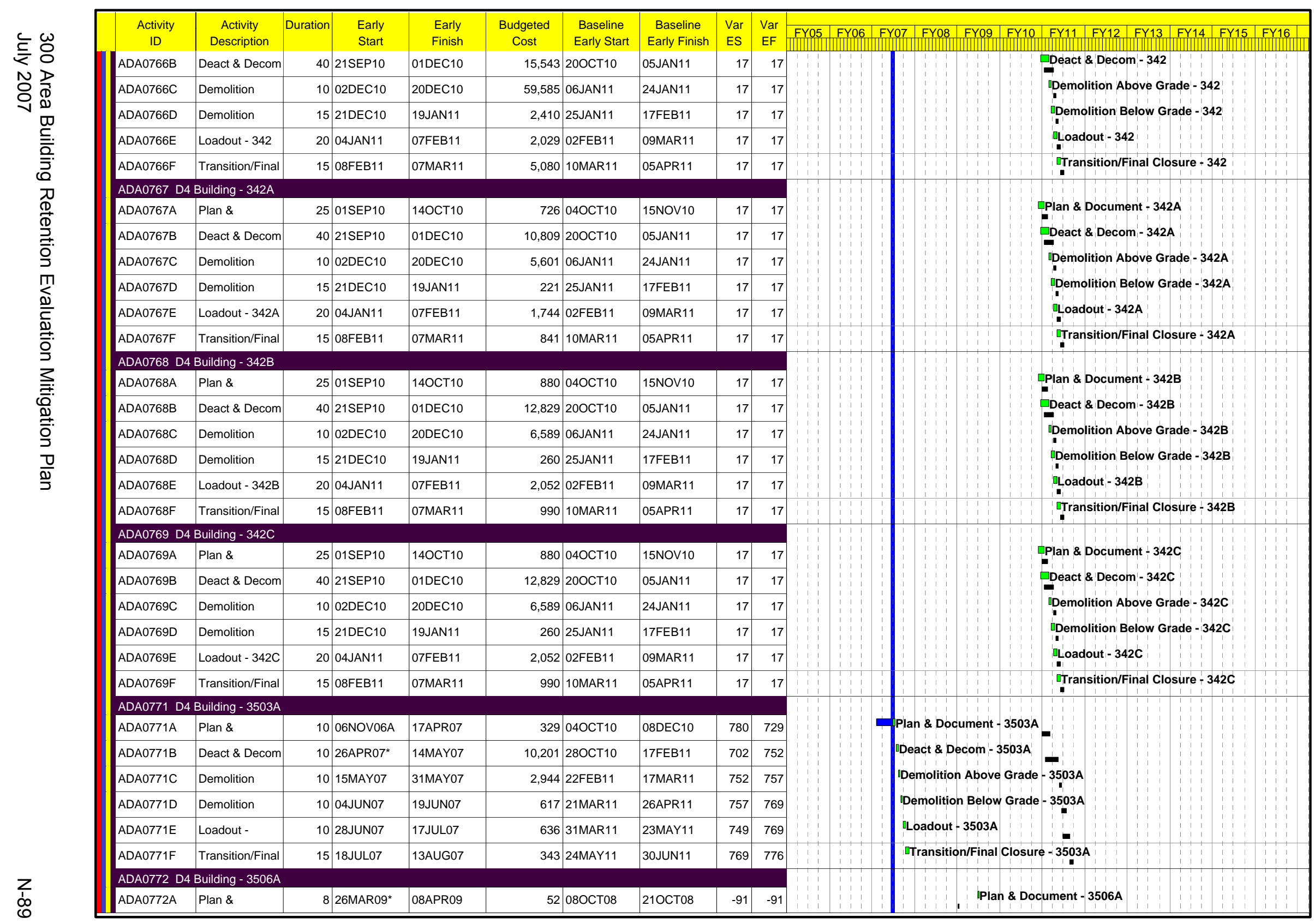




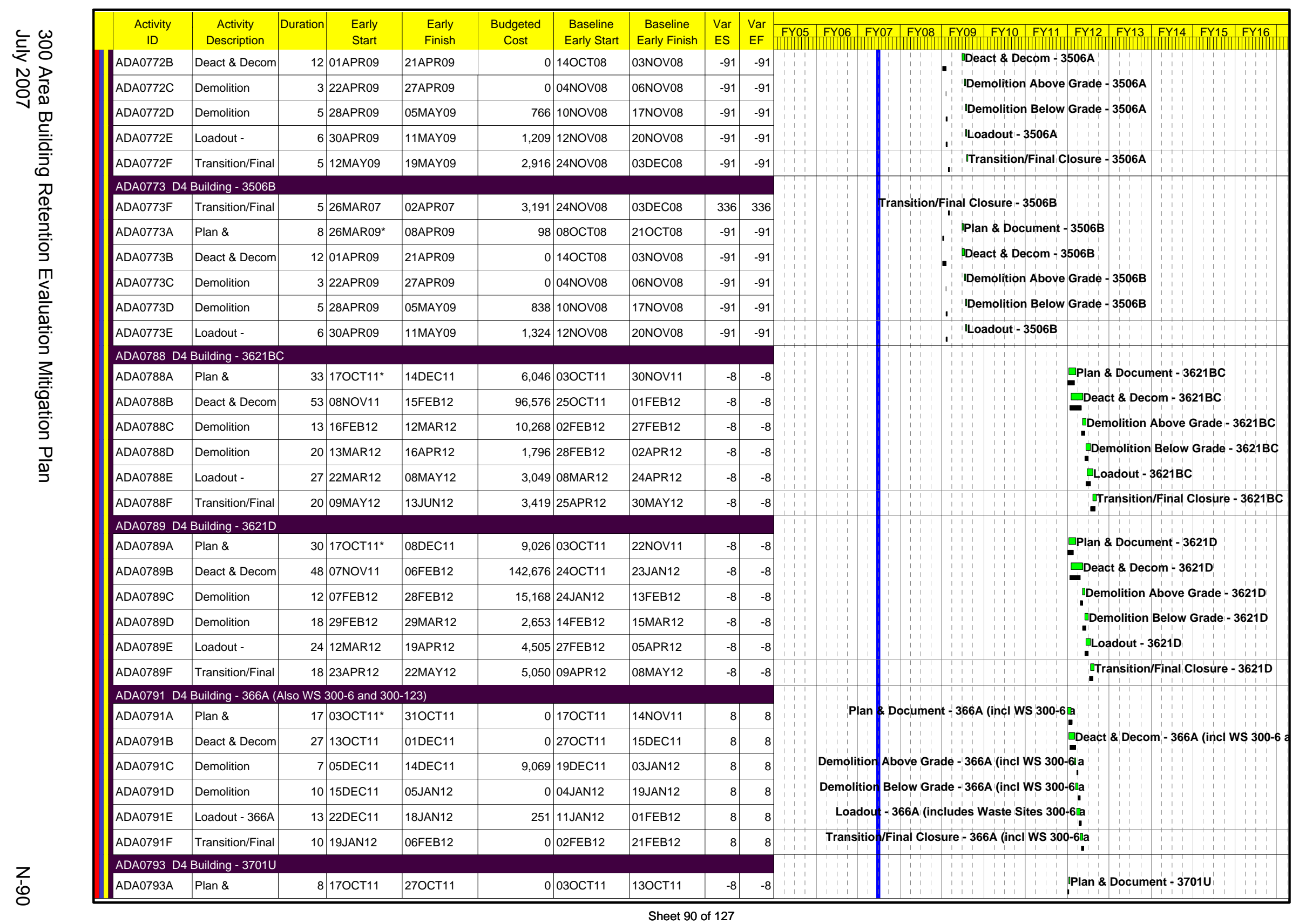




\begin{tabular}{|c|c|c|c|c|c|c|c|c|c|c|c|c|c|c|c|c|c|}
\hline \multirow{6}{*}{ 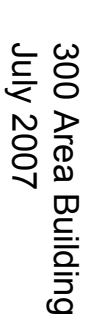 } & $\begin{array}{l}\text { Activity } \\
\text { ID }\end{array}$ & $\begin{array}{c}\text { Activity } \\
\text { Description }\end{array}$ & Duration & $\begin{array}{l}\text { Early } \\
\text { Start }\end{array}$ & $\begin{array}{l}\text { Early } \\
\text { Finish }\end{array}$ & $\begin{array}{l}\text { Budgeted } \\
\text { Cost }\end{array}$ & $\begin{array}{l}\text { Baseline } \\
\text { Early Start }\end{array}$ & $\begin{array}{l}\text { Baseline } \\
\text { Early Finish }\end{array}$ & $\begin{array}{l}\text { Var } \\
\text { ES }\end{array}$ & $\begin{array}{l}\text { Var } \\
\text { EF }\end{array}$ & 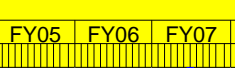 & \multirow{2}{*}{\multicolumn{2}{|c|}{ 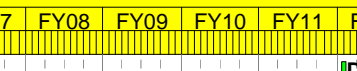 }} & FY12 & \multicolumn{2}{|r|}{\begin{tabular}{|l|l|}
\multicolumn{2}{|c|}{$\mid$} \\
FY14 & FY15 \\
\end{tabular}} & \begin{tabular}{|l|} 
FY16 \\
|||||||||| $\mid$
\end{tabular} \\
\hline & ADA0793B & Deact \& Decom & 12 & $200 C T 11$ & 09NOV11 & \multicolumn{2}{|c|}{0 060CT11 } & 260CT11 & -8 & -8 & & & & \multirow{3}{*}{\multicolumn{4}{|c|}{$\begin{array}{l}\text { UDeact \& Decom - 3701U } \\
\text { Demolition Above Grade - } 3701 \mathrm{U} \\
\text { DDemolition Below Grade - } 3701 \mathrm{U}\end{array}$}} \\
\hline & ADA0793C & Demolition & 3 & 10NOV11 & 15NOV11 & & $270 \mathrm{TT11}$ & 01NOV11 & -8 & -8 & & & & & & & \\
\hline & ADA0793D & Demolition & 5 & 16NOV11 & 28NOV11 & 1,883 & 02NOV11 & 09NOV11 & -8 & -8 & & & & & & & \\
\hline & ADA0793E & Loadout - & 6 & 21NOV11 & 01DEC11 & 639 & 07NOV11 & 15NOV11 & -8 & -8 & & & & ILoadout & t - $3701 \mathrm{c}$ & & \\
\hline & ADA0793F & Transition/Final & 5 & 05DEC11 & 12DEC11 & 3,584 & 16 NOV11 & 28NOV11 & -8 & -8 & & & & ITransiti & ion/Fina & Closure -370 & D1U \\
\hline$\pi$ & ADA0796 D & Building - 3705 & & & & & & & & & & & & & & & \\
\hline$\stackrel{\mathbb{D}}{\oplus}$ & ADA0796B & Deact \& Decom & 30 & 03MAY06A & 12JUN06A & 449,834 & 24MAY10 & 22JUL10 & 810 & 822 & Deact \& & Decom - 3705 & & & & & \\
\hline$\stackrel{2}{=}$ & ADA0796A & Plan \& & 21 & 17APR06A & 19JUN06A & 46,549 & 10MAY10 & 15JUN10 & 812 & 797 & DPlan \& D & Document - 3705 & & & & & \\
\hline 윽 & ADA0796C & Demolition & 7 & 19JUN06A & 22JUN06A & 75,724 & 26JUL10 & 05AUG10 & 819 & 823 & nqiti & ion Above Grade - 3705 & & & & & \\
\hline$\underset{s}{m}$ & ADA0796D & Demolition & 1 & 26JUN06A & 29JUN06A & & 09AUG10 & 30AUG10 & 823 & 832 & IDemqliti & tion Below Grade - 3705, & & & & & \\
\hline$\frac{\omega}{c}$ & ADA0796E & Loadout - 3705 & 1 & 26JUN06A & 29JUNO6A & 14,203 & 16AUG10 & 14SEP10 & 827 & 840 & ILoadput & t -3705 & & & & & \\
\hline$\stackrel{\oplus}{\overline{0}}$ & ADA0796F & Transition/Final & 13 & 07SEP10* & 28SEP10 & 1,368 & 15SEP10 & 060Ст10 & 5 & 5 & & & Transitic & ion/Final C & Closure & -3705 & \\
\hline-7 & ADA0797 D & Building - 3705-B & & & & & & & & & & & & & & & \\
\hline 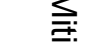 & ADA0797B & Deact \& Decom & 10 & 01DEC10 & 16DEC10 & 12,253 & 24MAY10 & 22JUL10 & -105 & -81 & & & uDeact & \& Decom & n - 3705- & & \\
\hline$\stackrel{0}{\mathscr{D}}$ & ADA0797A & Plan \& & 21 & 15NOV10* & 27DEC10 & 380 & 10MAY10 & 15JUN10 & -105 & -105 & & - & 口Plan \& & \& Docume & ent - 370 & 55-BA & \\
\hline о믐 & ADA0797C & Demolition & 8 & 28DEC10 & 11JAN11 & 4,283 & 26JUL10 & 05AUG10 & -84 & -84 & & . & IDemo & olition Abc & ove Gra & de - 3705-BA & \\
\hline$\underline{\underline{D}}$ & ADA0797D & Demolition & 4 & 12JAN11 & 18JAN11 & 169 & 09AUG10 & 30AUG10 & -84 & -75 & & I & IDemo & olition Bel & low Grac & de - 3705-BA & \\
\hline & ADA0797E & Loadout - & 4 & 26JAN11 & 01FEB11 & 1,334 & 16AUG10 & 14SEP10 & -88 & -75 & & . & lLoad & dout - 370 & 5-BA & & \\
\hline & ADA0797F & Transition/Final & 13 & 02FEB11 & 24FEB11 & 643 & 15SEP10 & 060Ст10 & -75 & -75 & & & Trans & nsition/Fin & aal Closu & ure - 3705-BA & \\
\hline & ADA0798 D & Building - 3706 & & & & & & & & & & & & & & & \\
\hline & ADA0798B & Deact \& Decom & 20 & 110СТ06А & 29MAR07 & $2,125,662$ & 01NOV06 & 16AUG07 & 12 & 78 & & eact \& Decom - 3706 & & & & & \\
\hline & ADA0798A & Plan \& & 193 & 03ОСТ05А & 10APR07 & 263,185 & 01AUG06* & 310ст06 & 165 & -86 & & Ian \& Document - 3706 & & & & & \\
\hline & ADA0798C & Demolition & 12 & 11APR07 & O1MAY07 & 297,883 & 20AUG07 & 13SEP07 & 72 & 75 & & emolition Above Grade - & 3706 & & & & \\
\hline & ADA0798M & Complete & 0 & & O1MAY07 & 0 & & 13SEP07 & 75 & 75 & & Complete Building 3706 & Above $\mathrm{G}$ & Grade Der & molition & & \\
\hline & ADA0798D & Demolition & 15 & 05MAY08* & 29MAY08 & 328,926 & 17SEP07 & 230ст07 & -126 & -119 & & aDemolition Below & Grade - & -3706 & & & \\
\hline & ADA0798E & Loadout - 3706 & 30 & 05MAY08 & 25JUN08 & 54,090 & 27SEP07 & 19NOV07 & -119 & -119 & & - $\quad$ Loadout - 3706 & & & & & \\
\hline & ADA0798F & Transition/Final & 15 & 26JUN08 & 23JUL08 & 7,649 & 20NOV07 & 03JAN08 & -119 & -112 & & sition/Final C & Closure & -3706 & & & \\
\hline & ADA07A1 D & Building - 3706A & & & & & & & & & & & & & & & \\
\hline & ADA07A1A & Plan \& & 30 & 02FEB06A & 15MAR07A & 10,906 & 01AUG06* & З10сто6 & 99 & -72 & la & an \& Document - 3706A & & & & & \\
\hline & ADA07A1B & Deact \& Decom & 18 & 05FEB07A & 29MAR07 & 165,222 & O3MAY07 & 16AUG07 & 50 & 78 & & eact \& Decom - 3706A & & & & & \\
\hline & ADA07A1C & Demolition & 8 & 18APR07 & 01MAY07 & 18,938 & 20AUG07 & 13SEP07 & 68 & 75 & & emolition Above Grade - & $6 \mathrm{~A}$ & & & & \\
\hline & ADA07A1D & Demolition & 22 & 05MAY08* & 11JUN08 & 3,183 & 17SEP07 & $230 \mathrm{OCT07}$ & -126 & -126 & & - $\quad$ aDer & Grade & $-3706 A$ & & & \\
\hline & ADA07A1E & Loadout - & 30 & 15MAY08 & 09JUL08 & 2,251 & 27SEP07 & 19NOV07 & -126 & -126 & & GLoadout - 3706A & & & & & \\
\hline$z$ & ADA07A1F & Transition/Final & 15 & 10JUL08 & 05AUG08 & 3,329 & 20NOV07 & 03JAN08 & -126 & -119 & & - $\quad$ Transition/Final C & Closure & $e-3706 A$ & & & \\
\hline
\end{tabular}




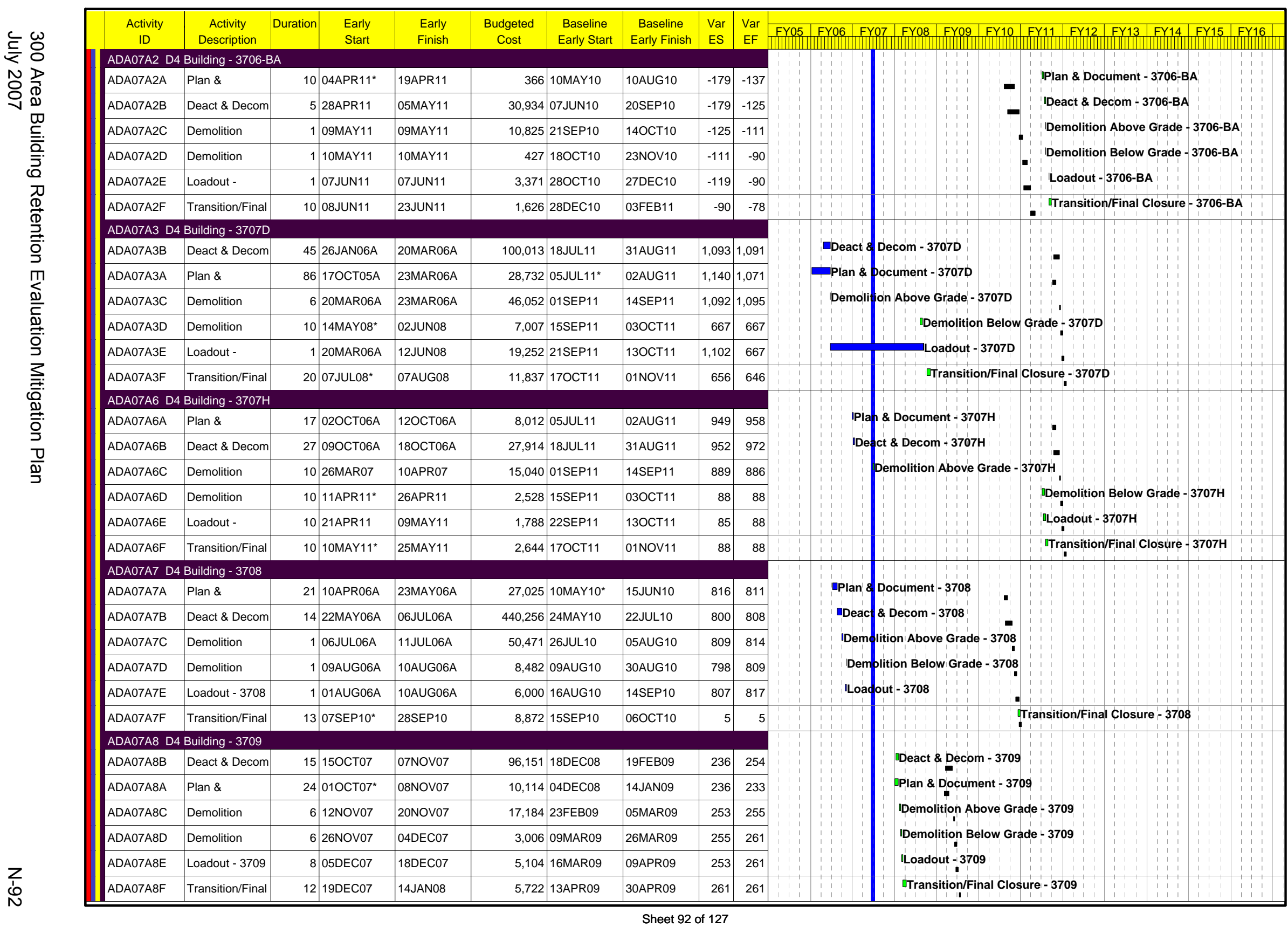




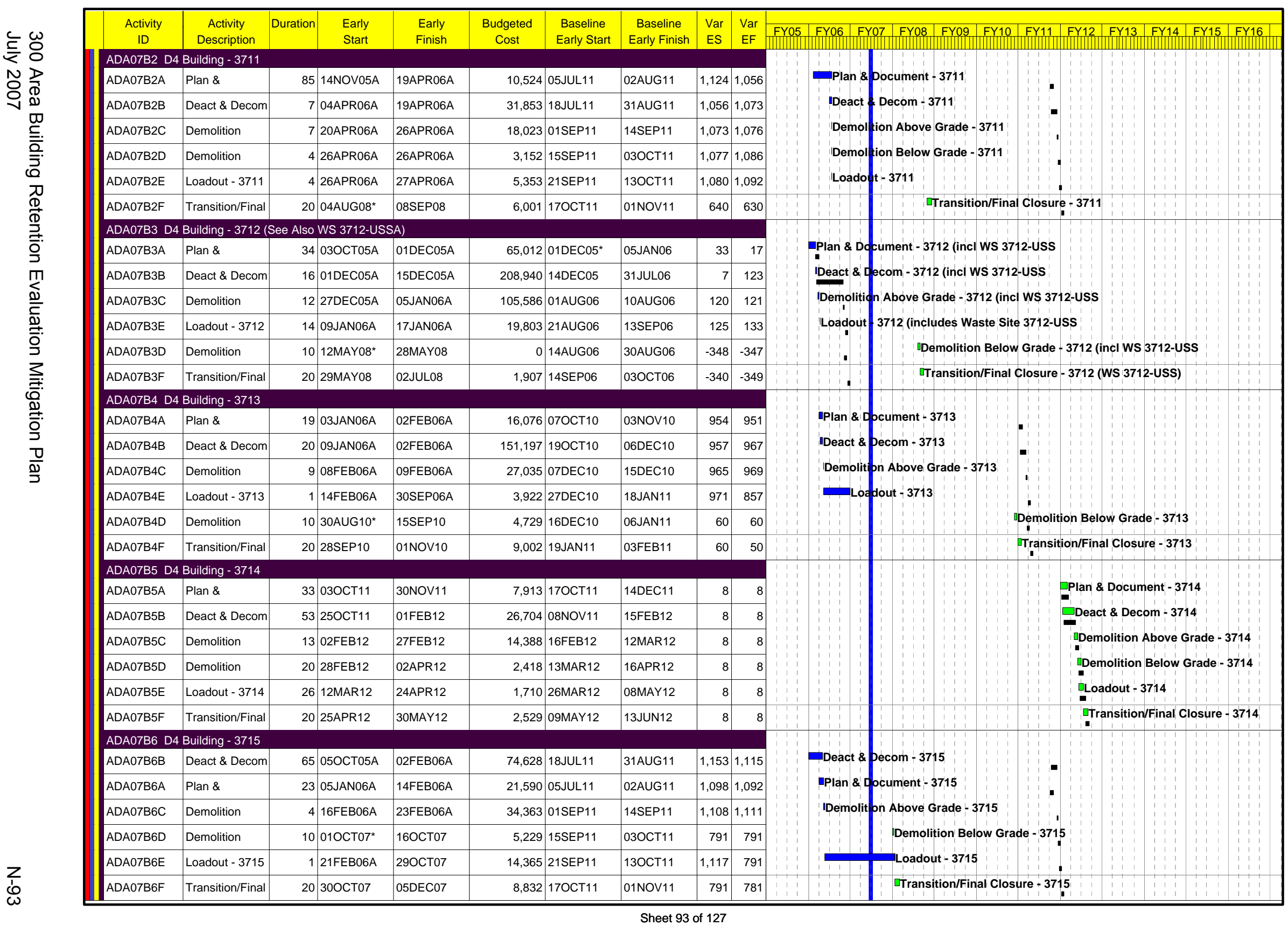




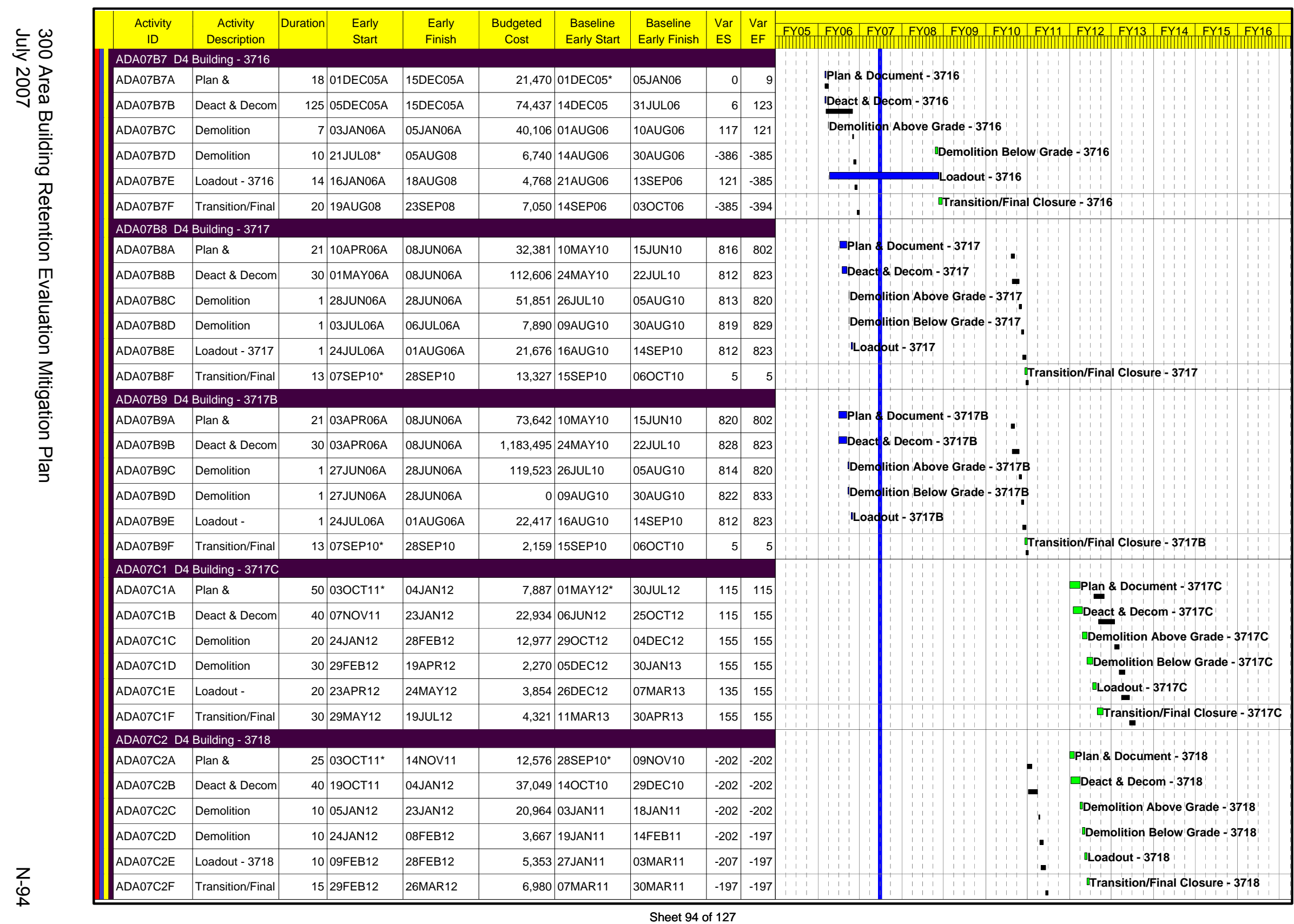




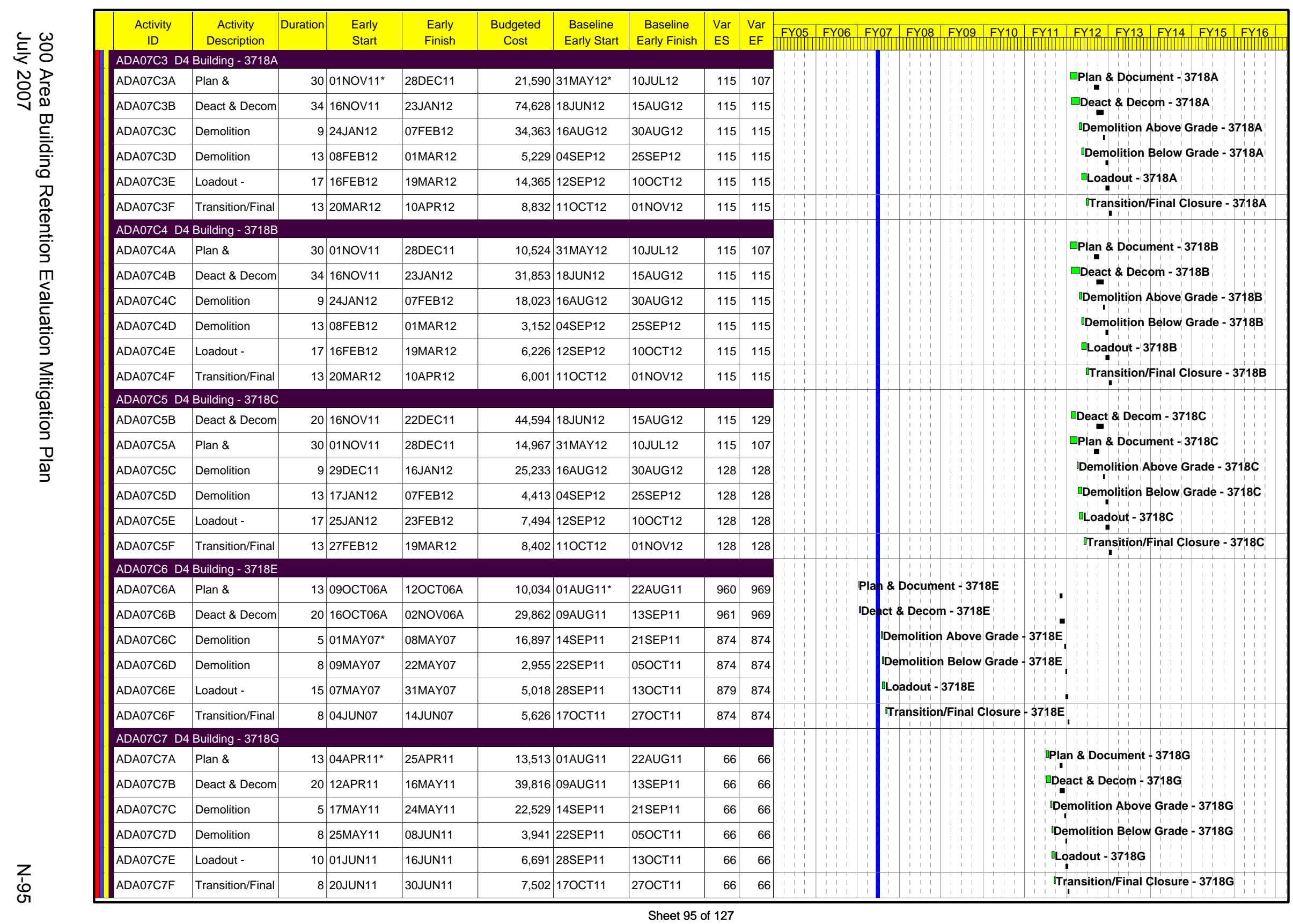




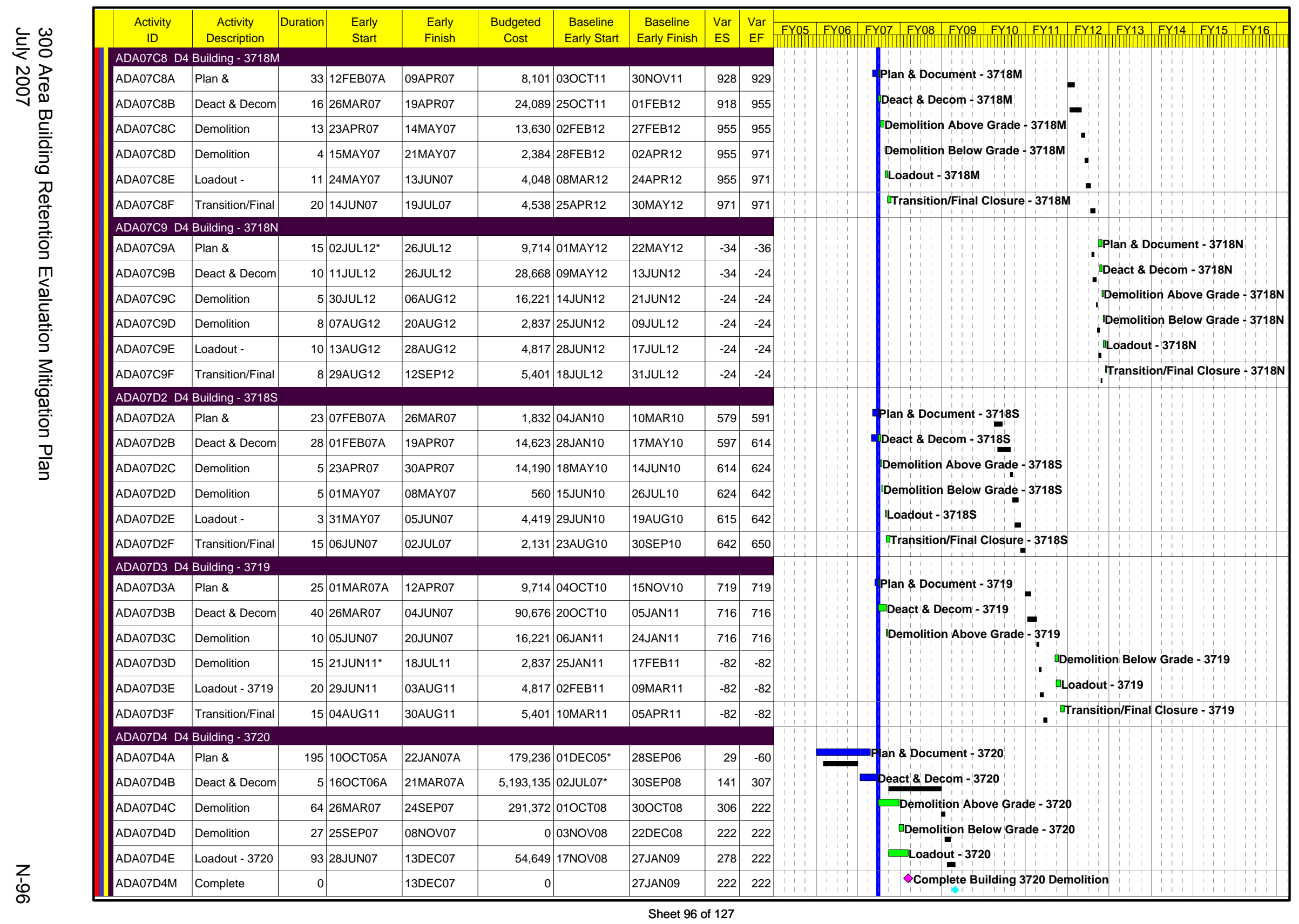




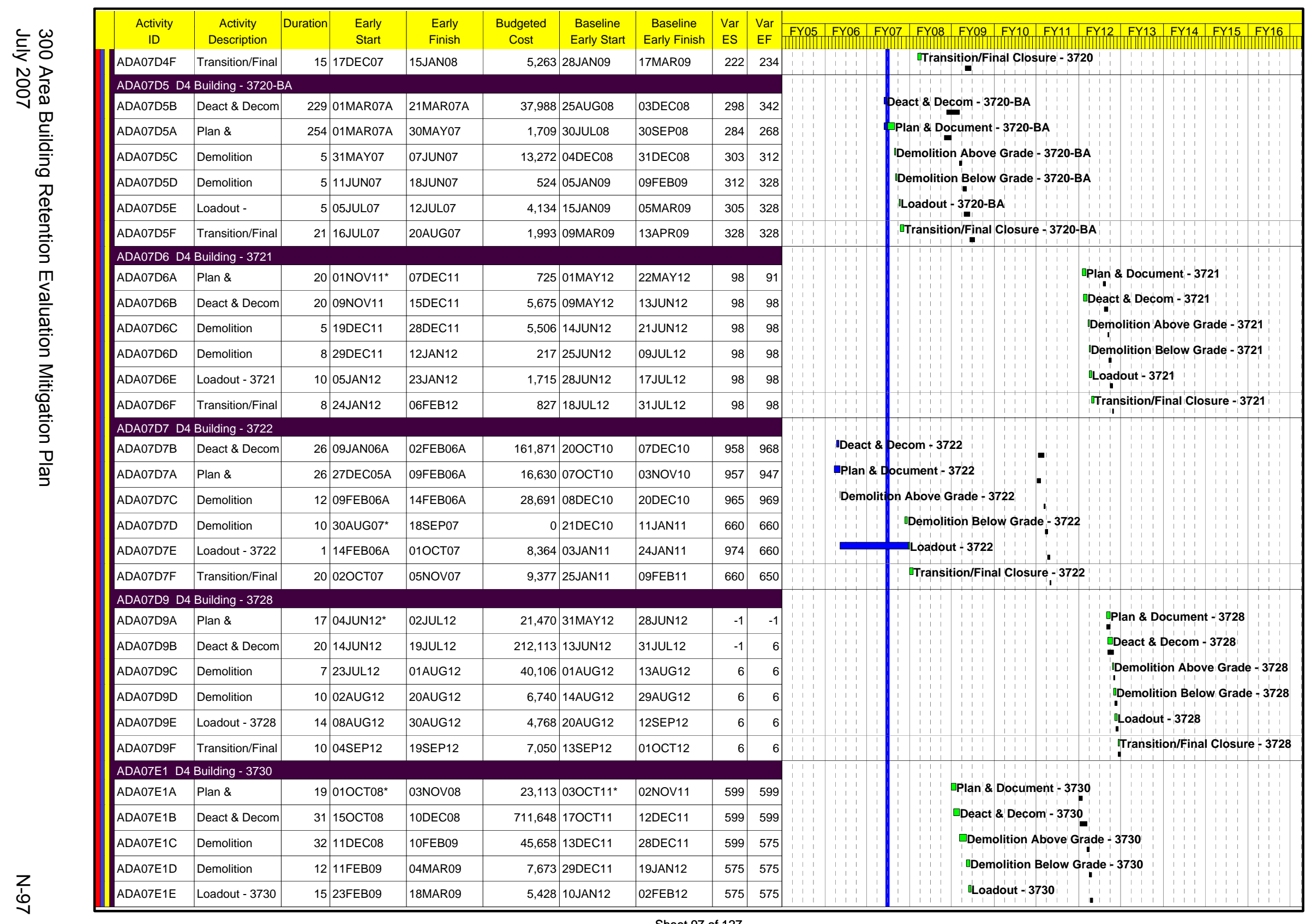




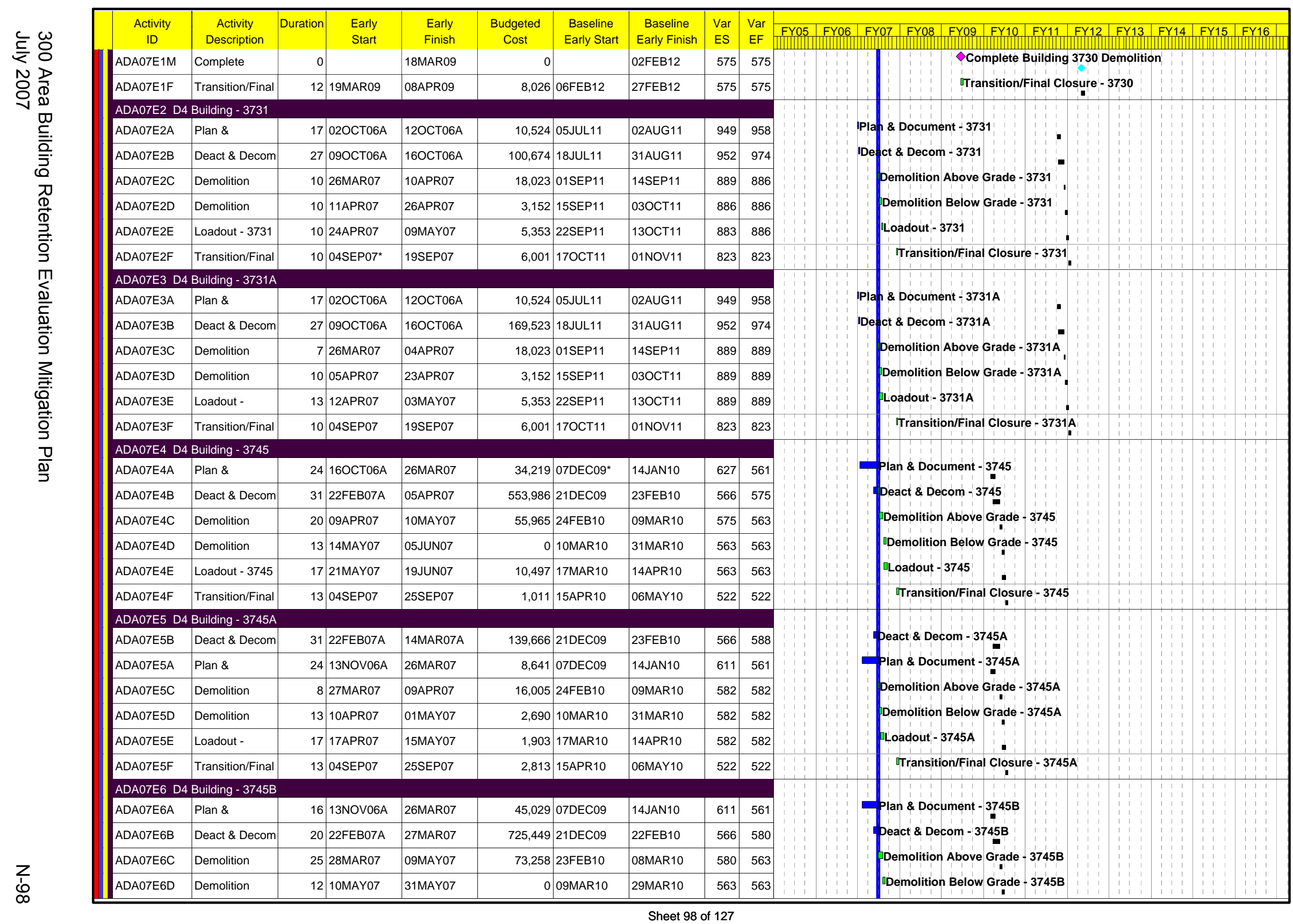




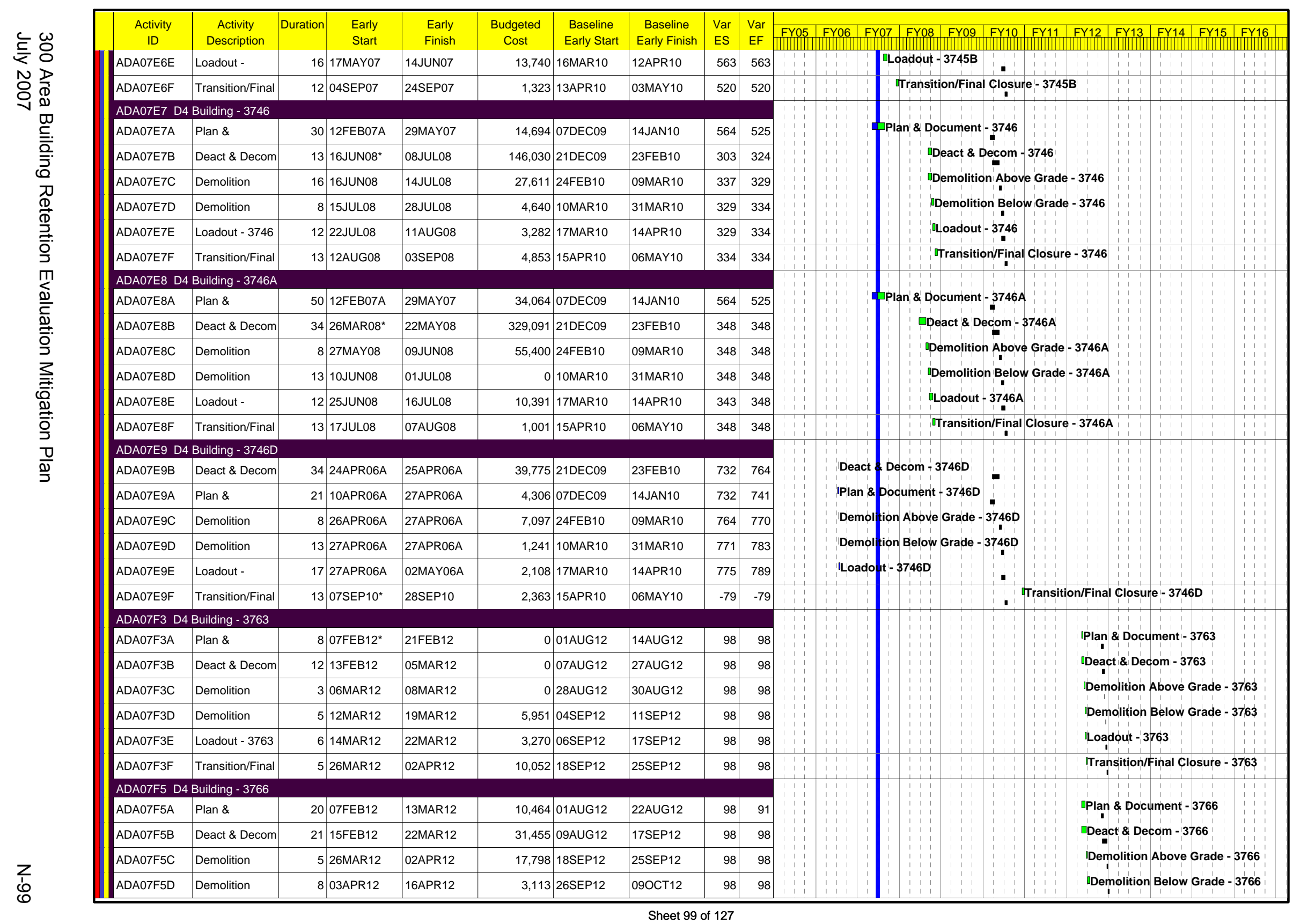




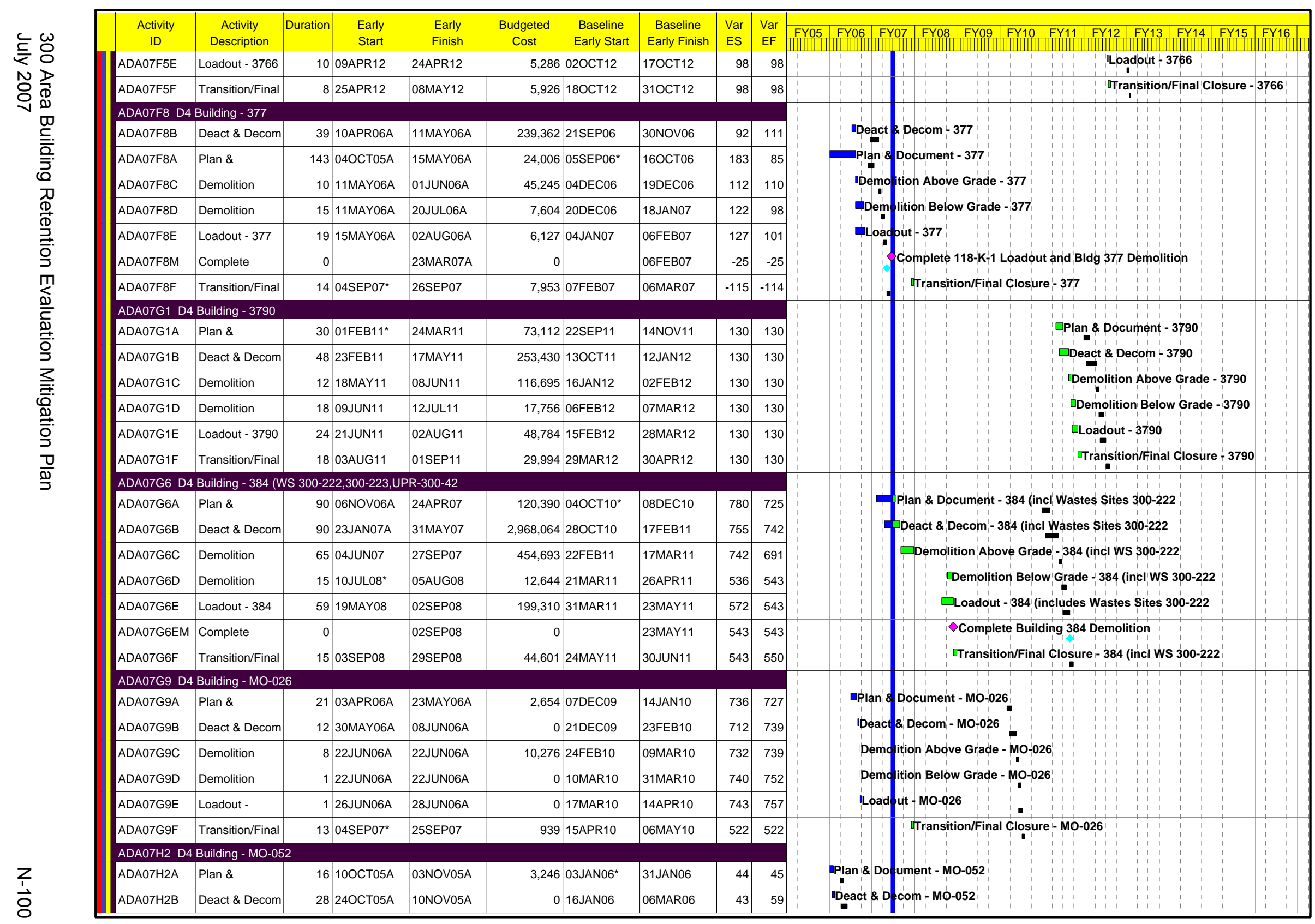




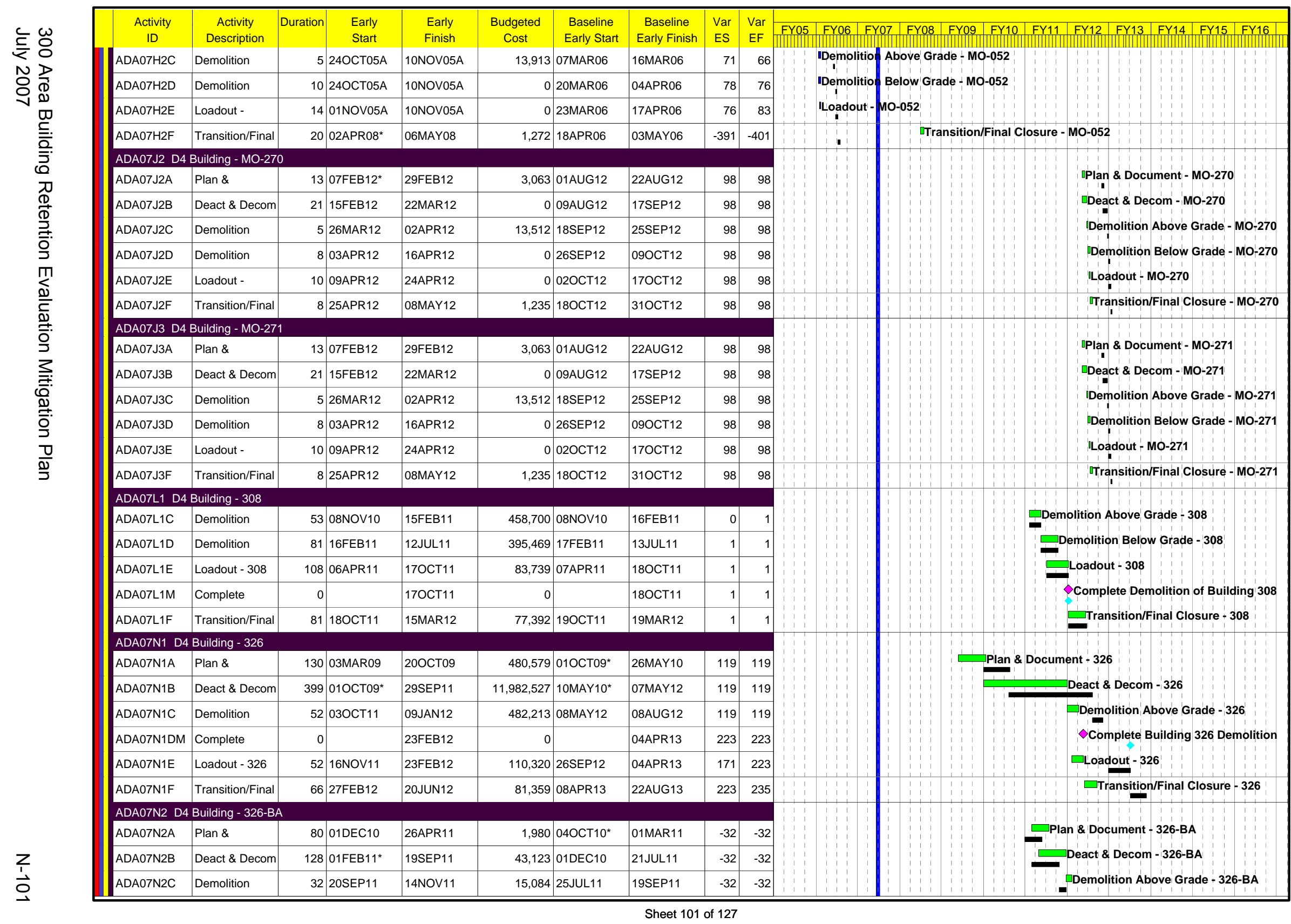




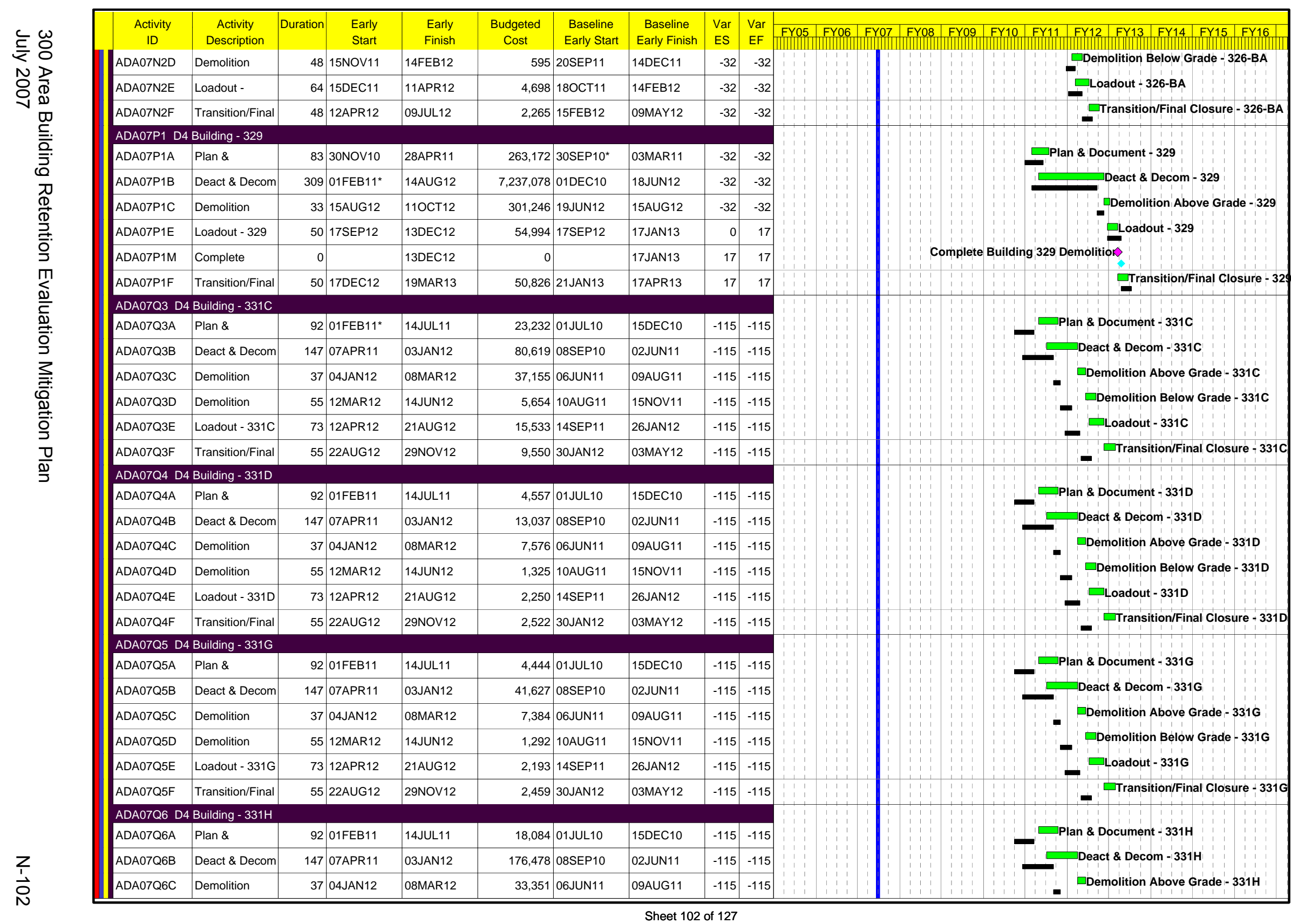




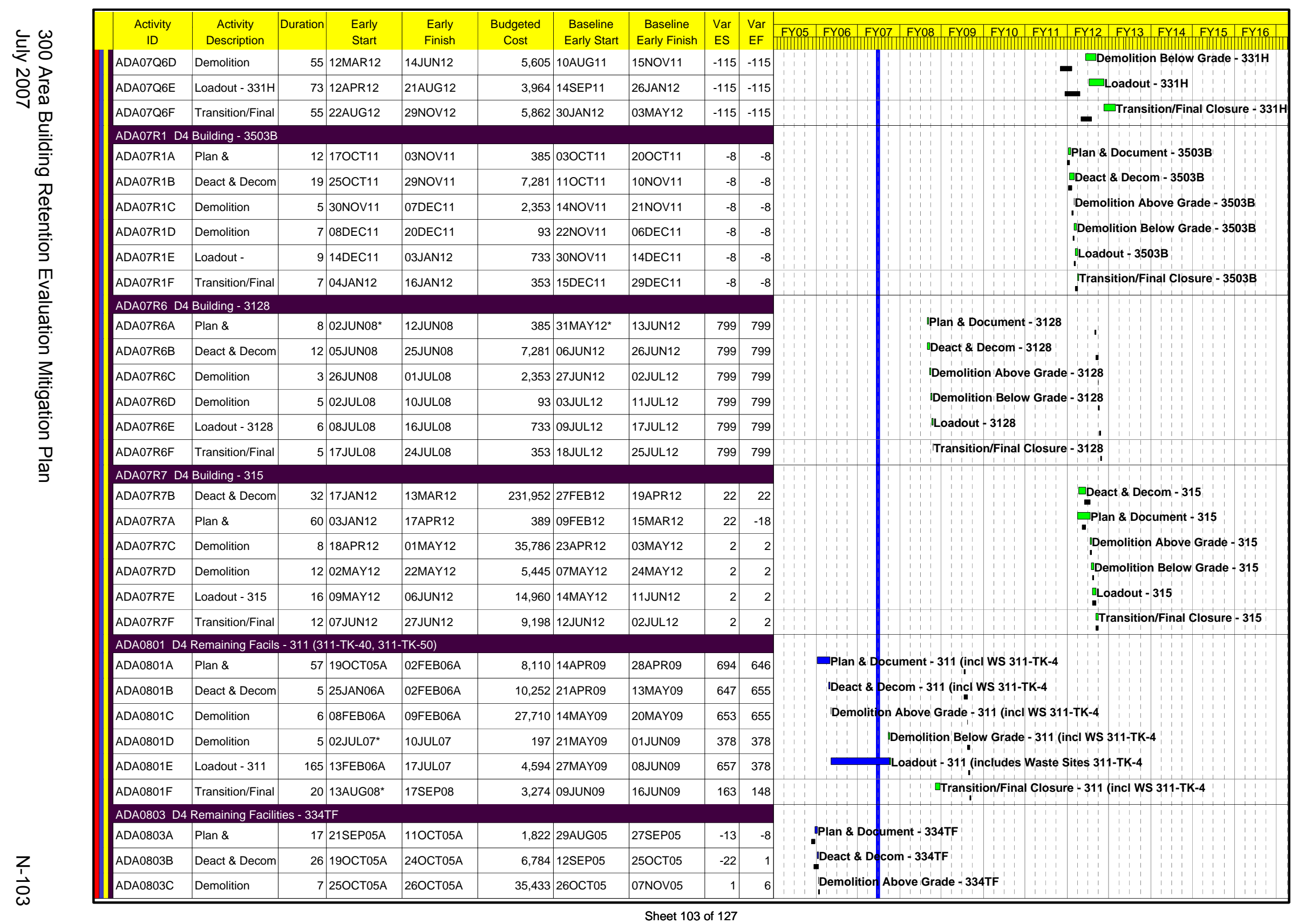




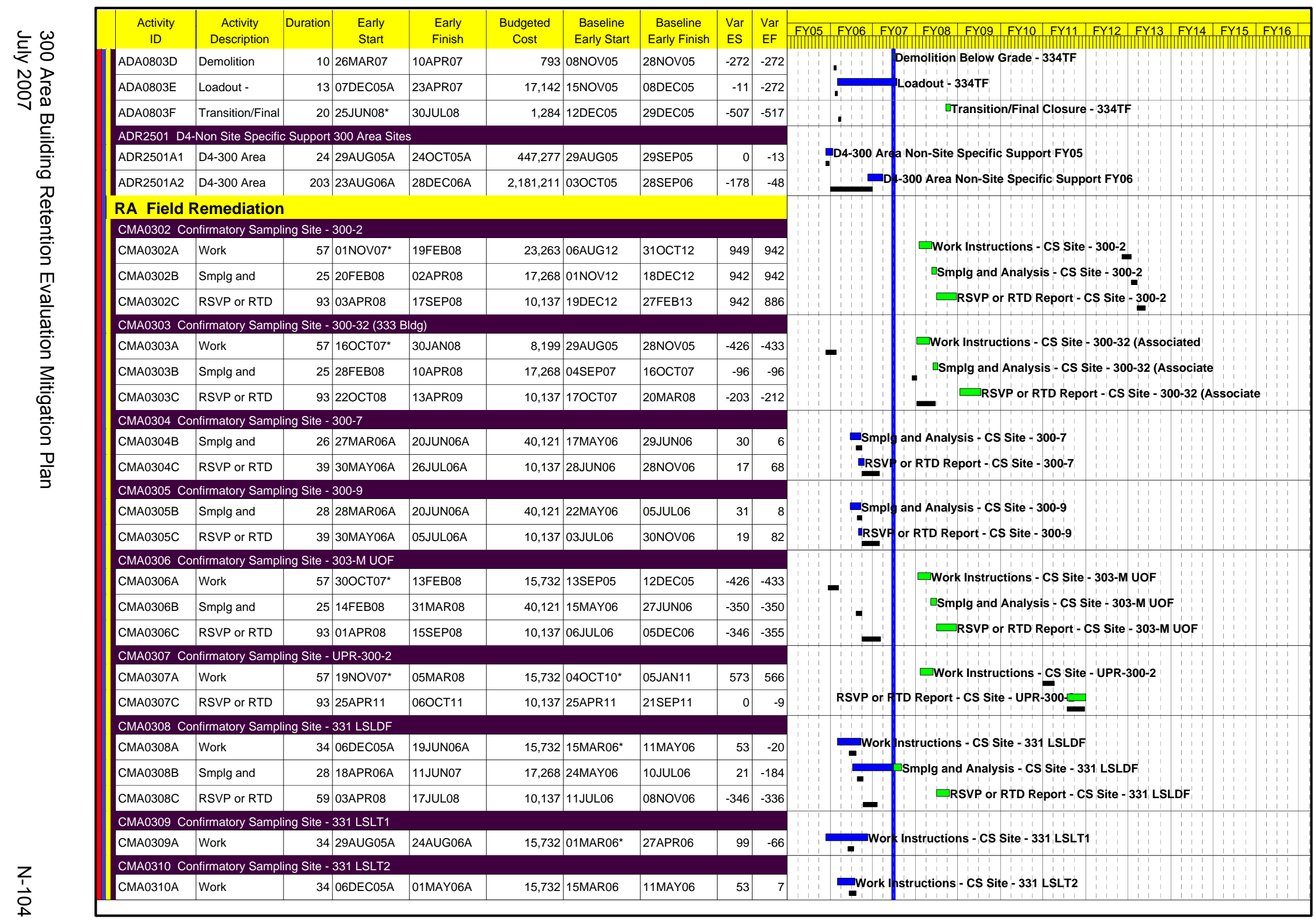




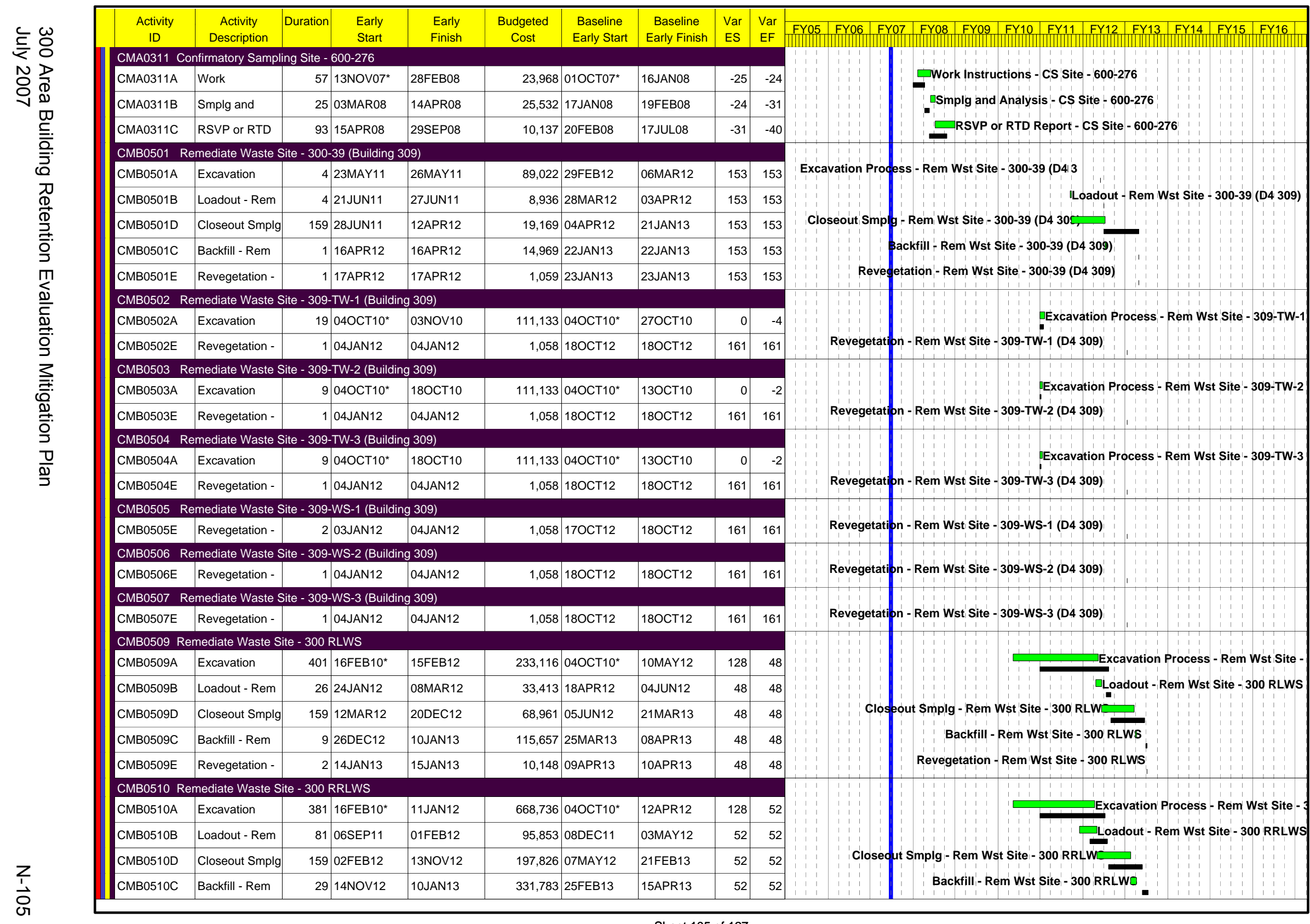




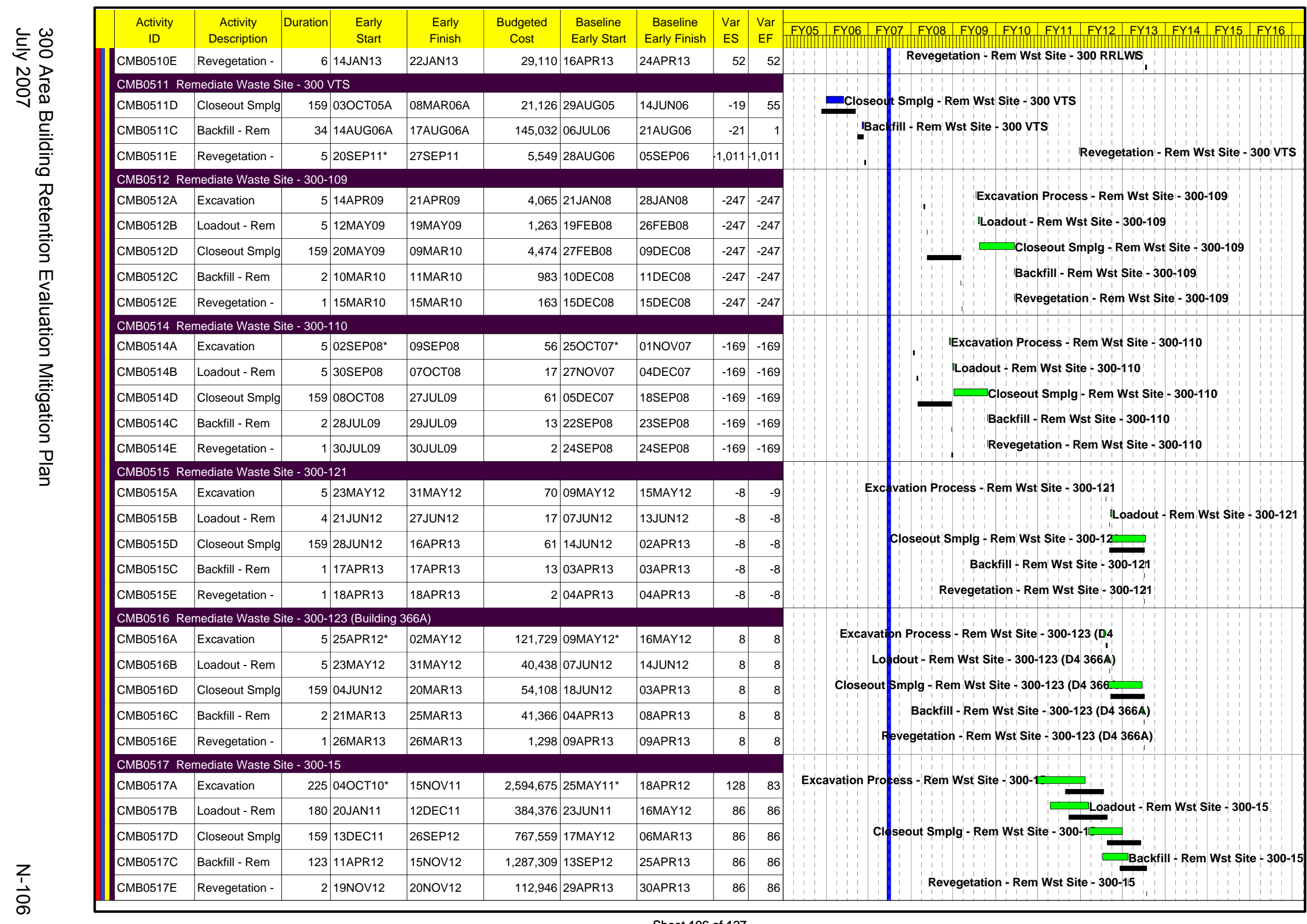




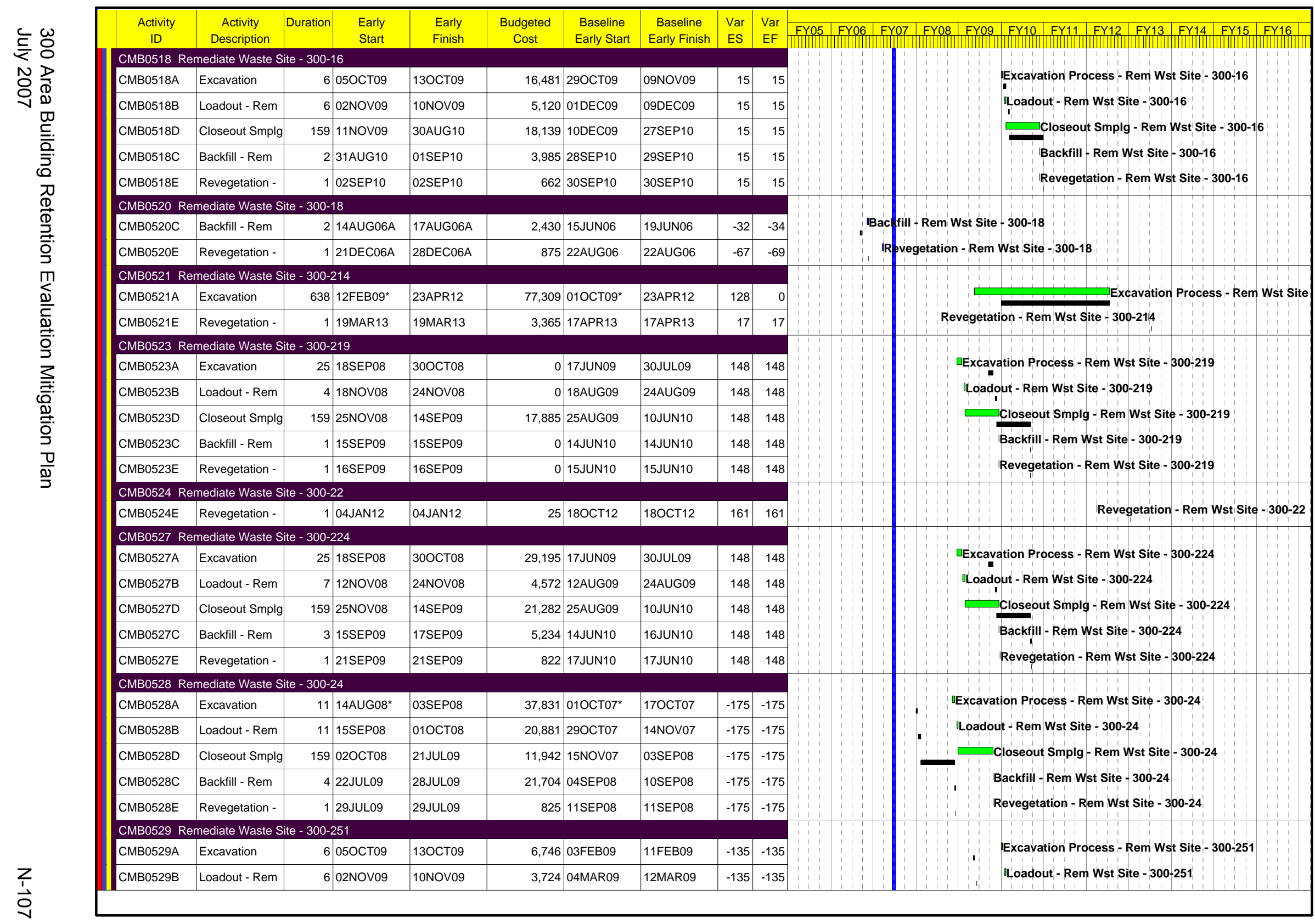




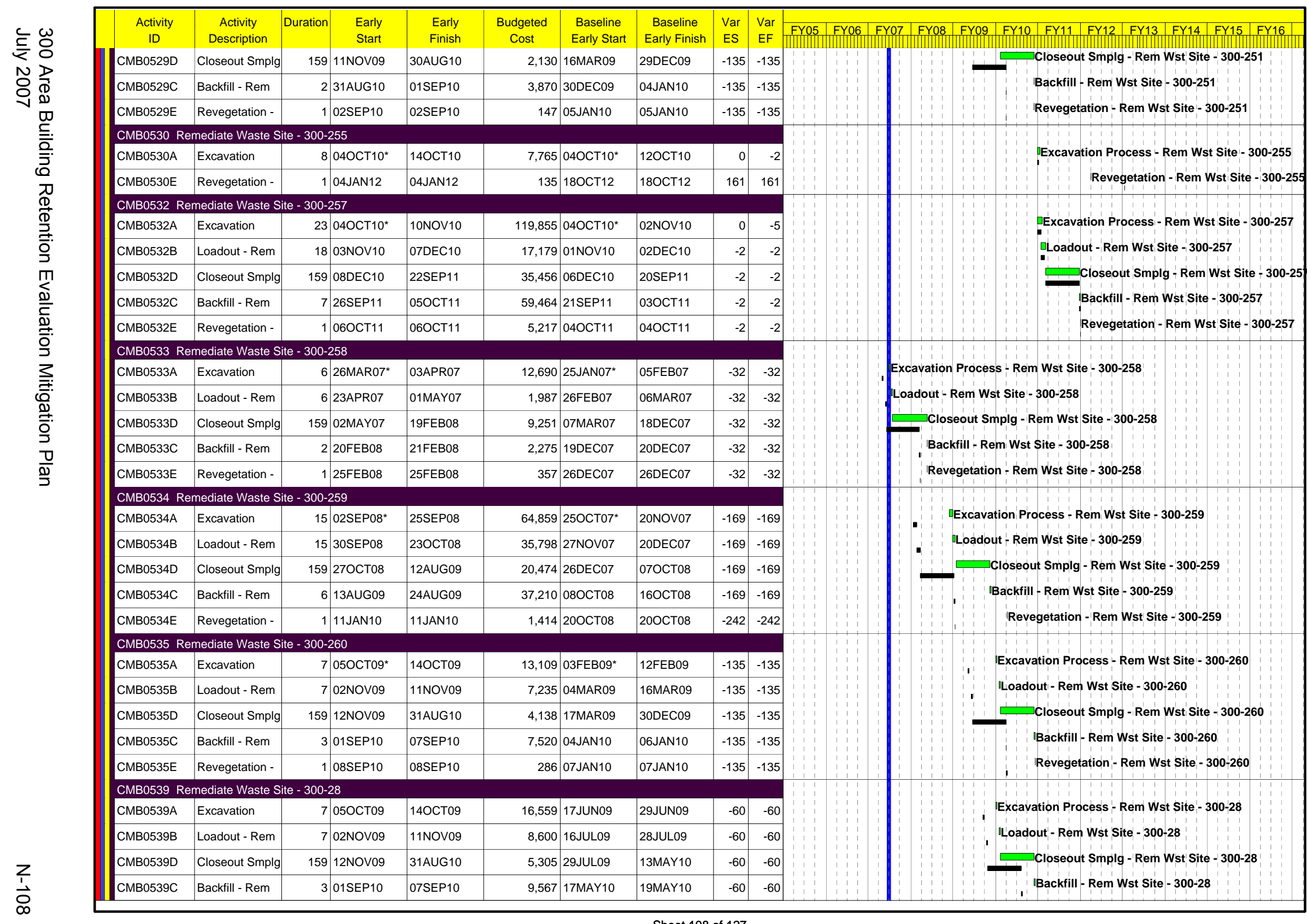




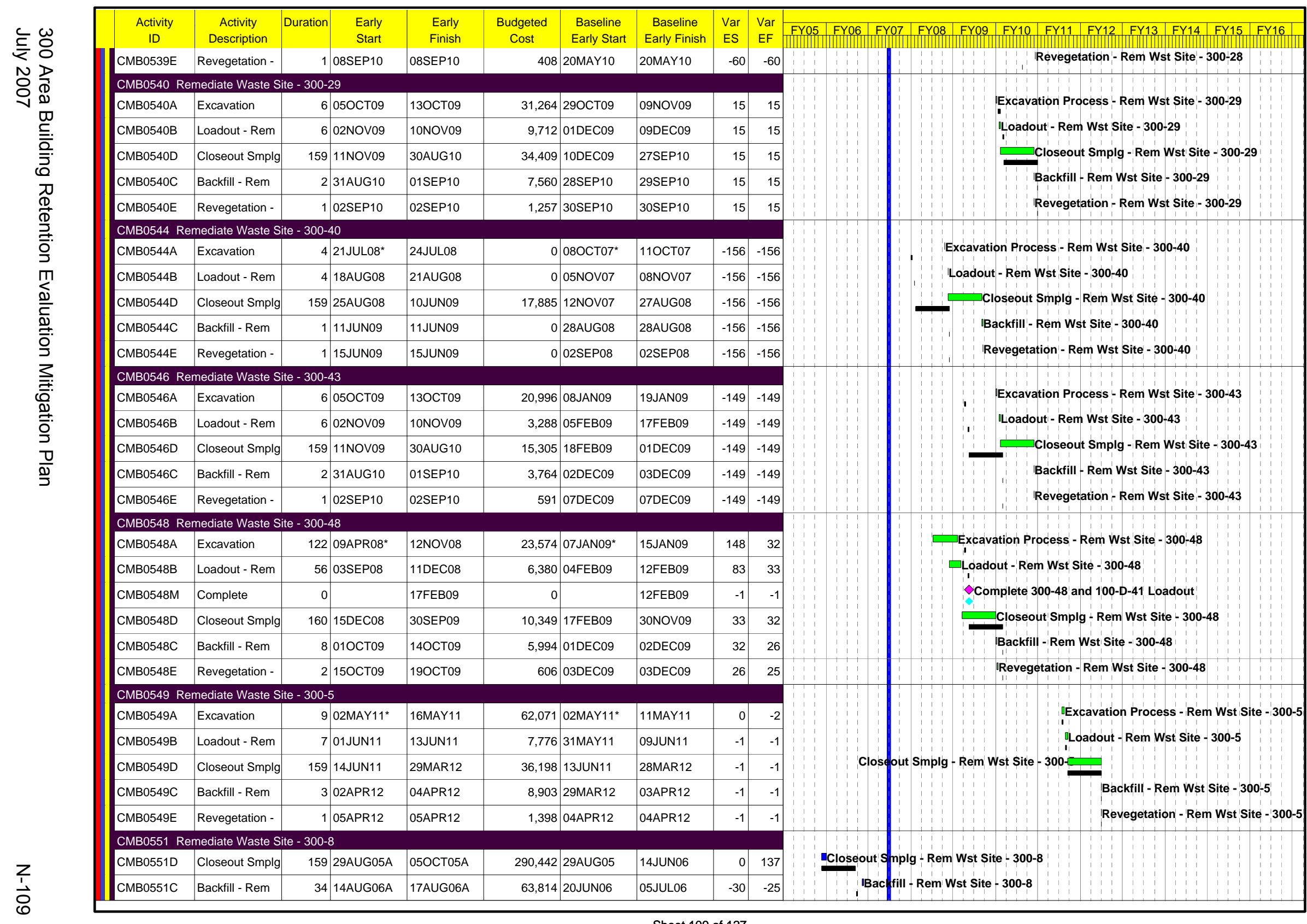




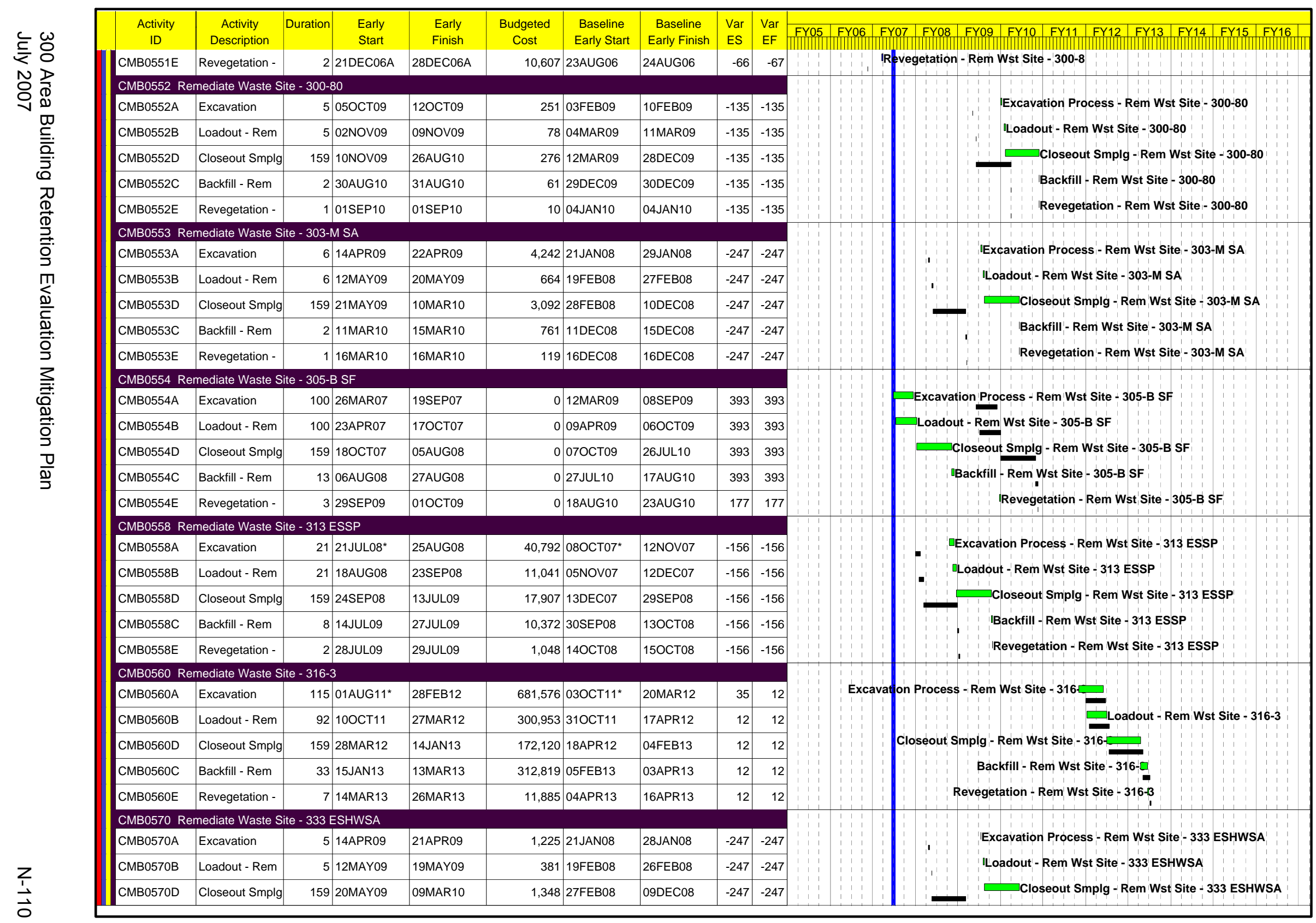




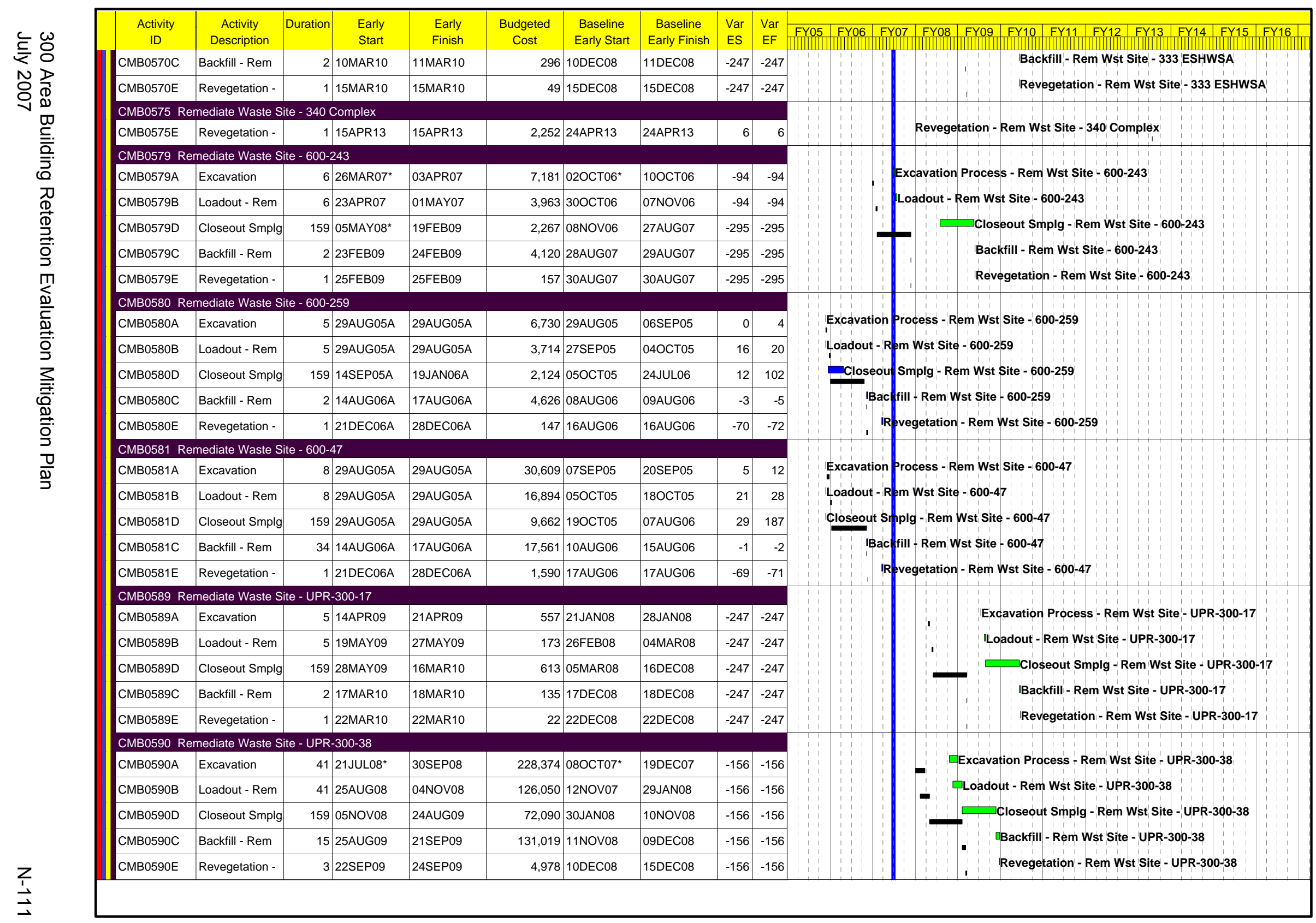




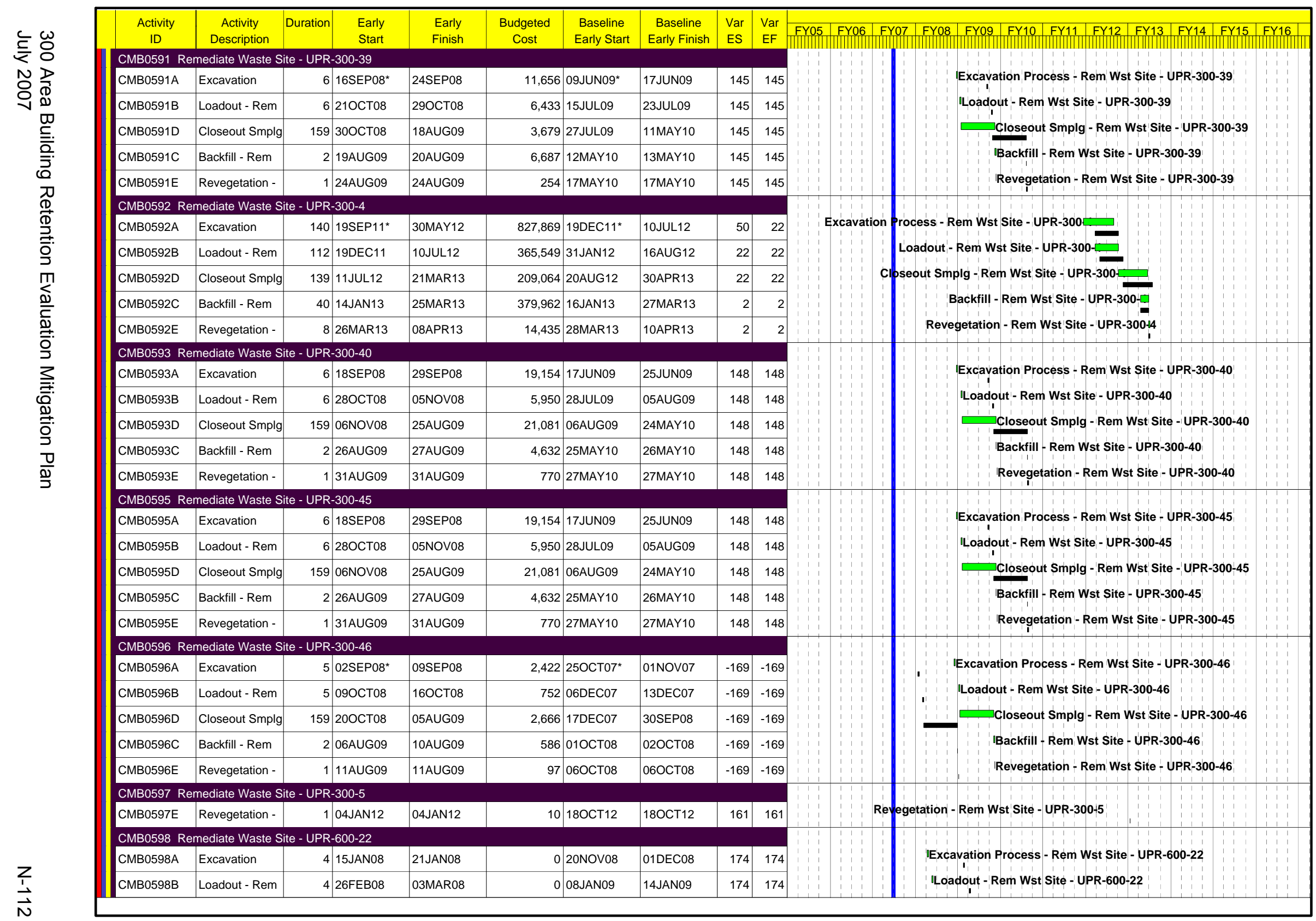




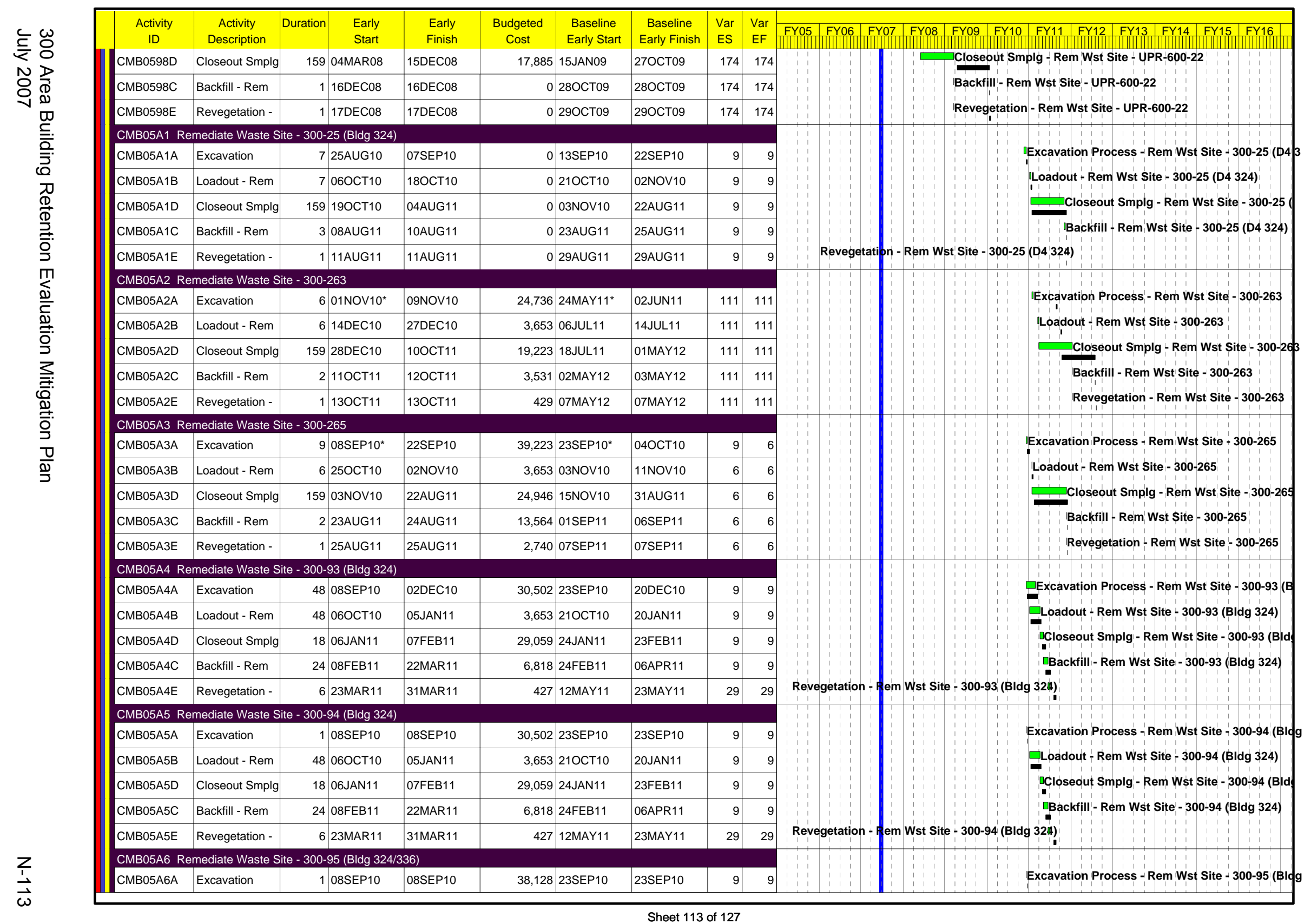




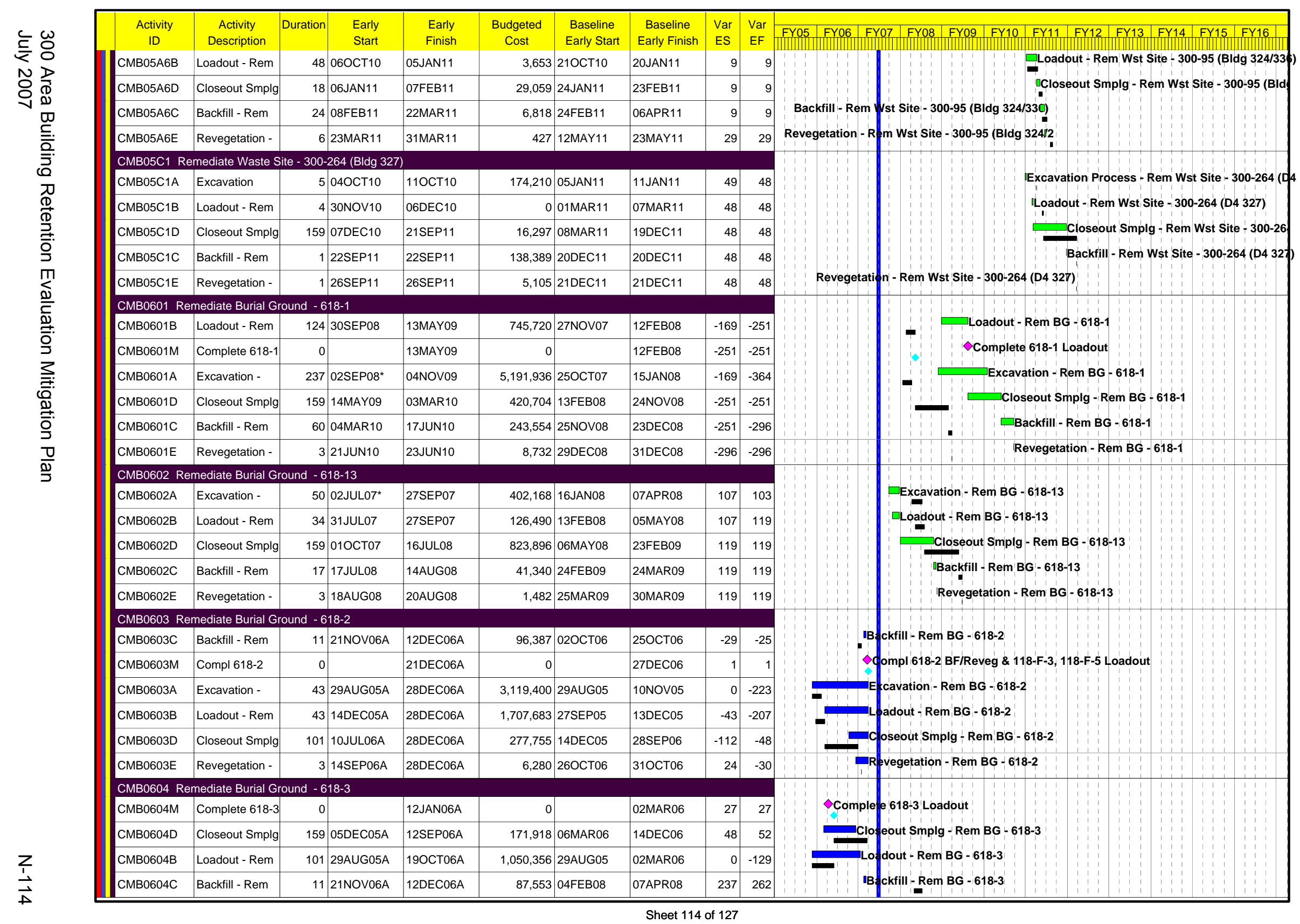




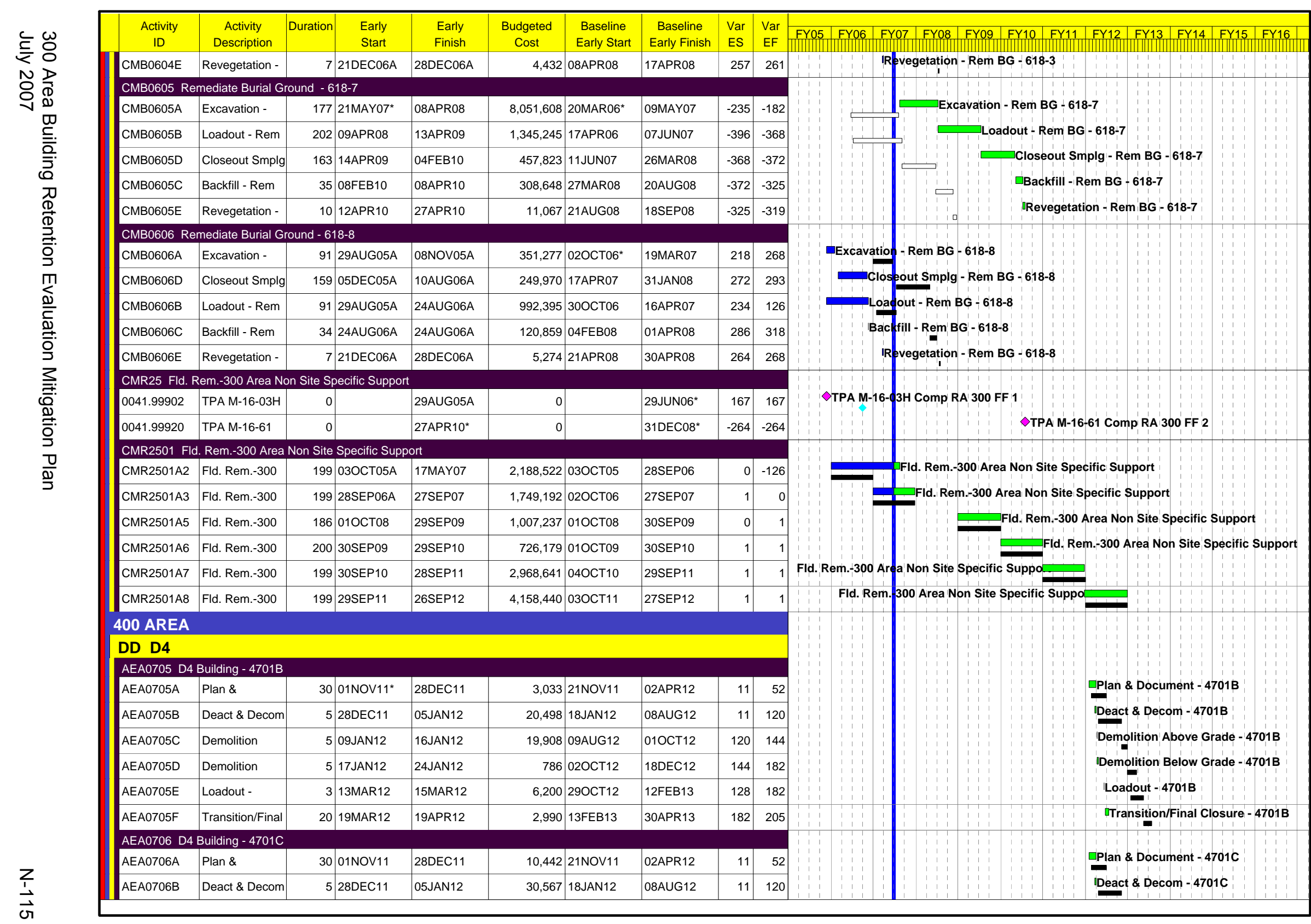




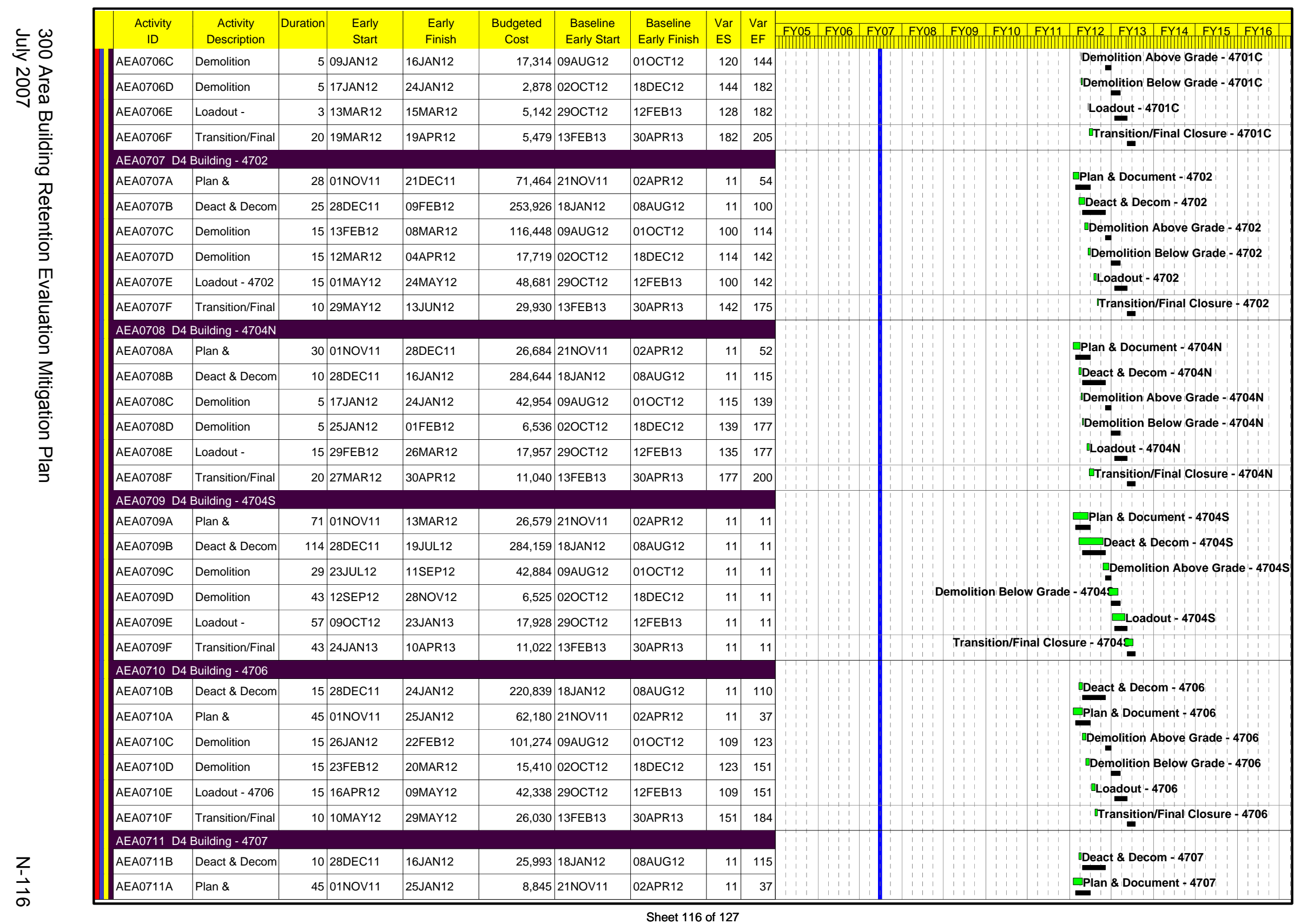




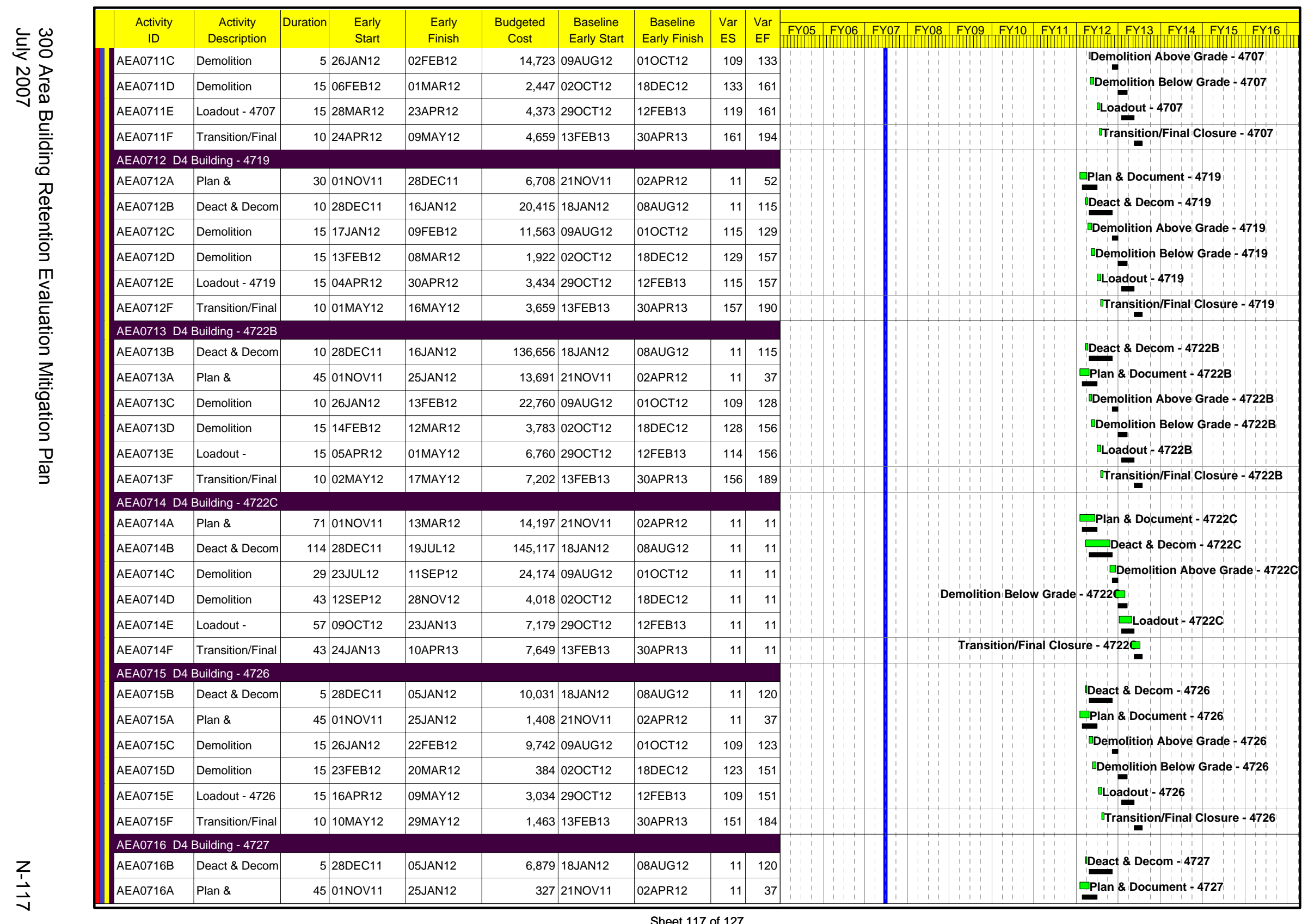




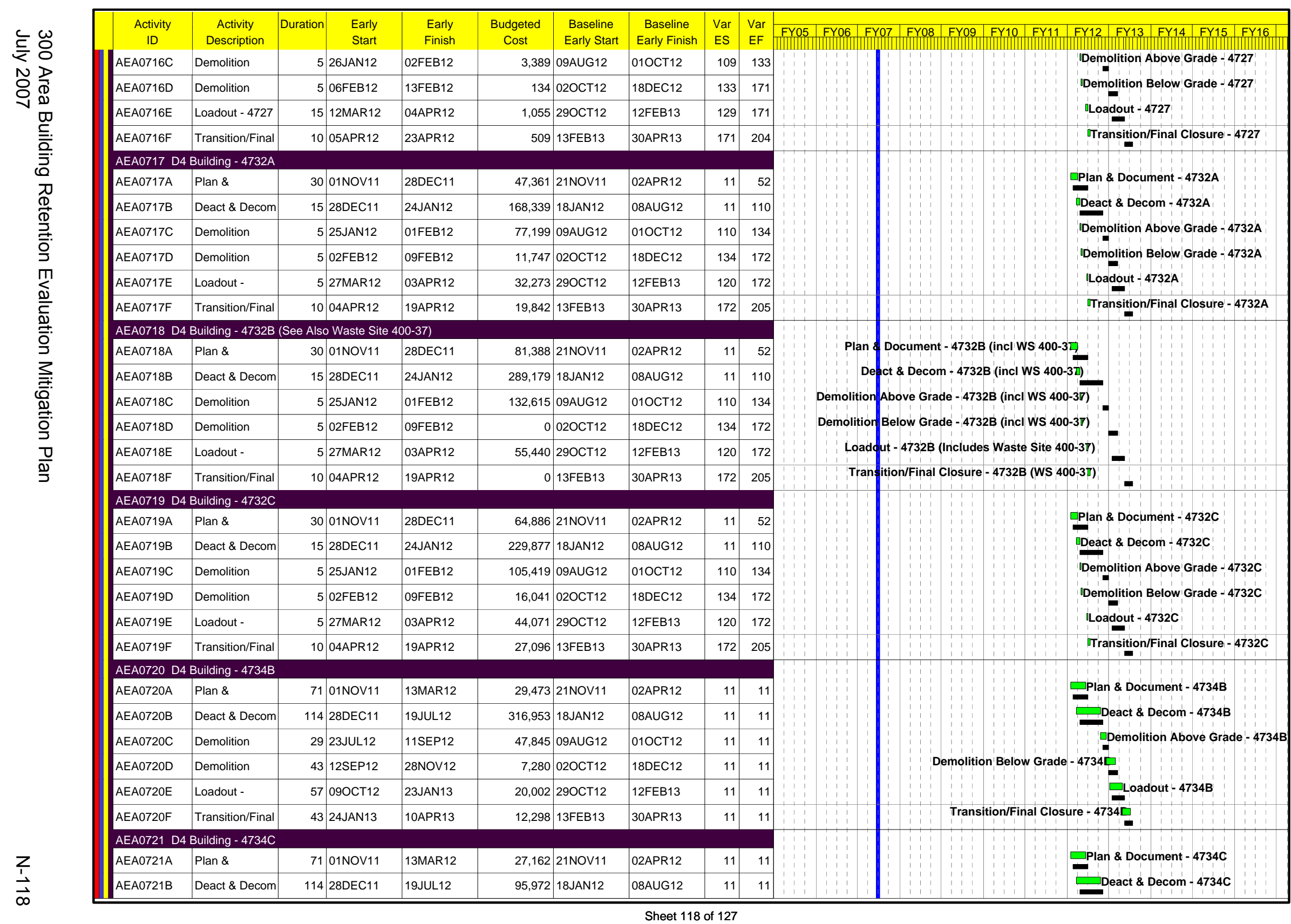




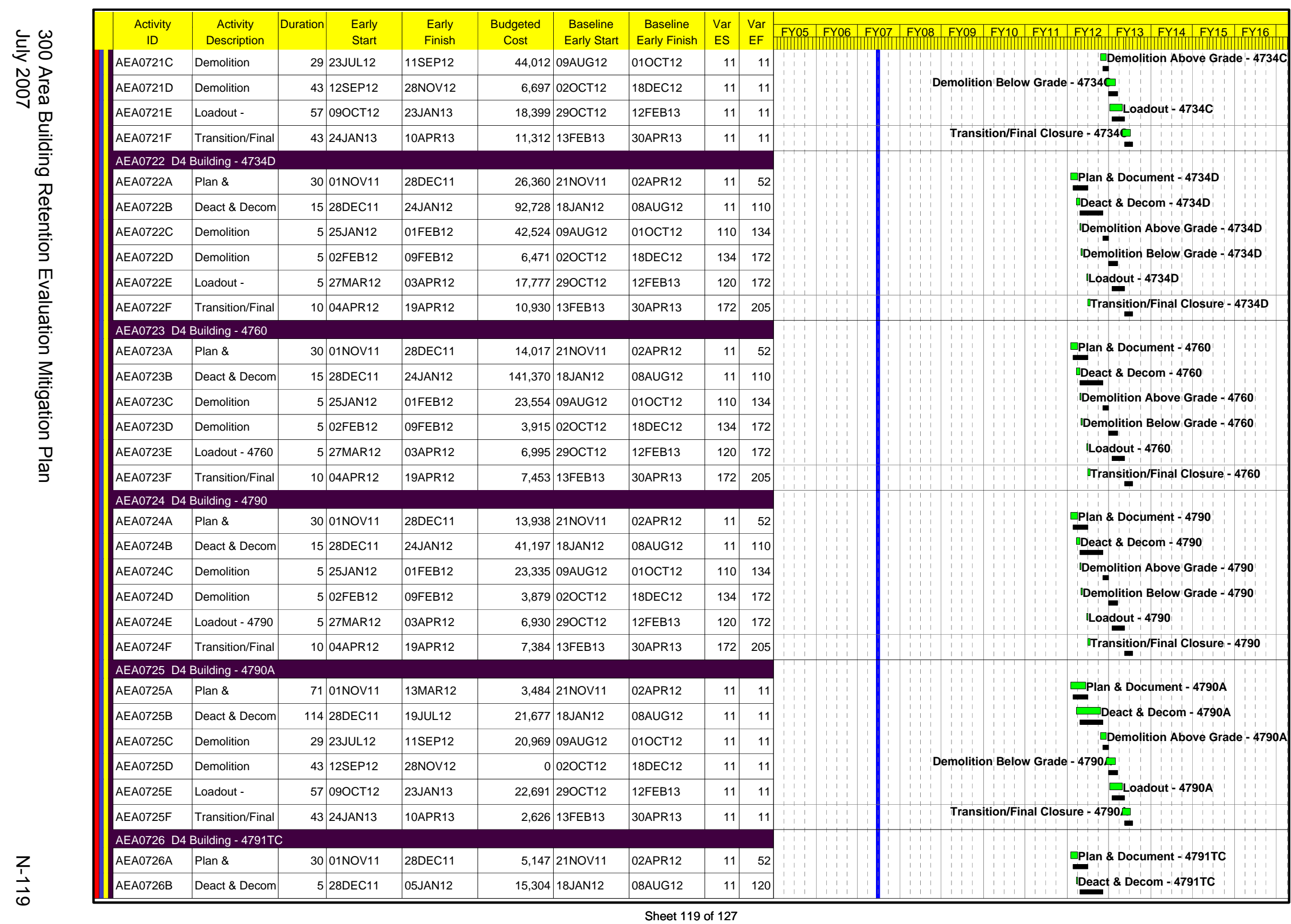




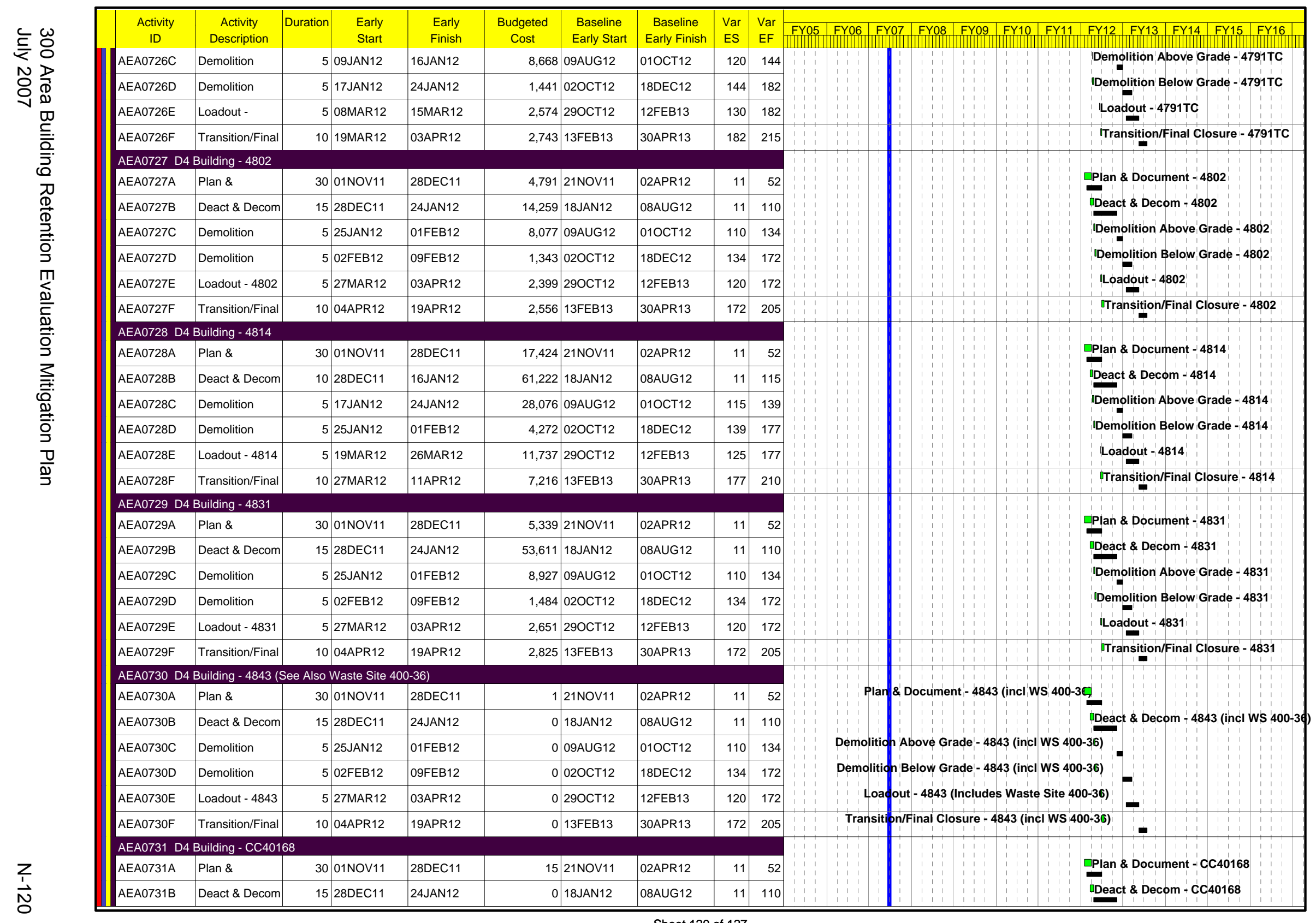




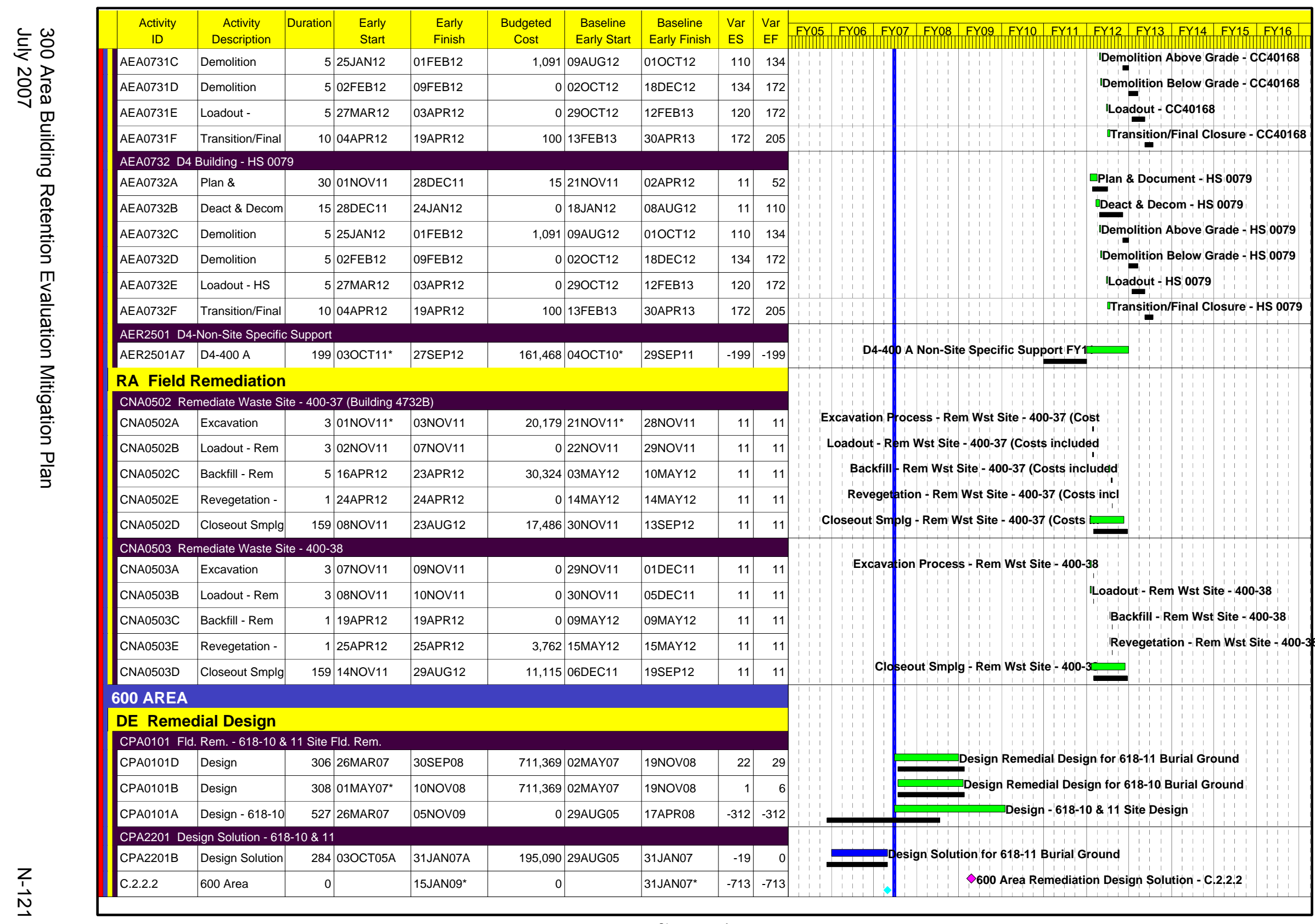




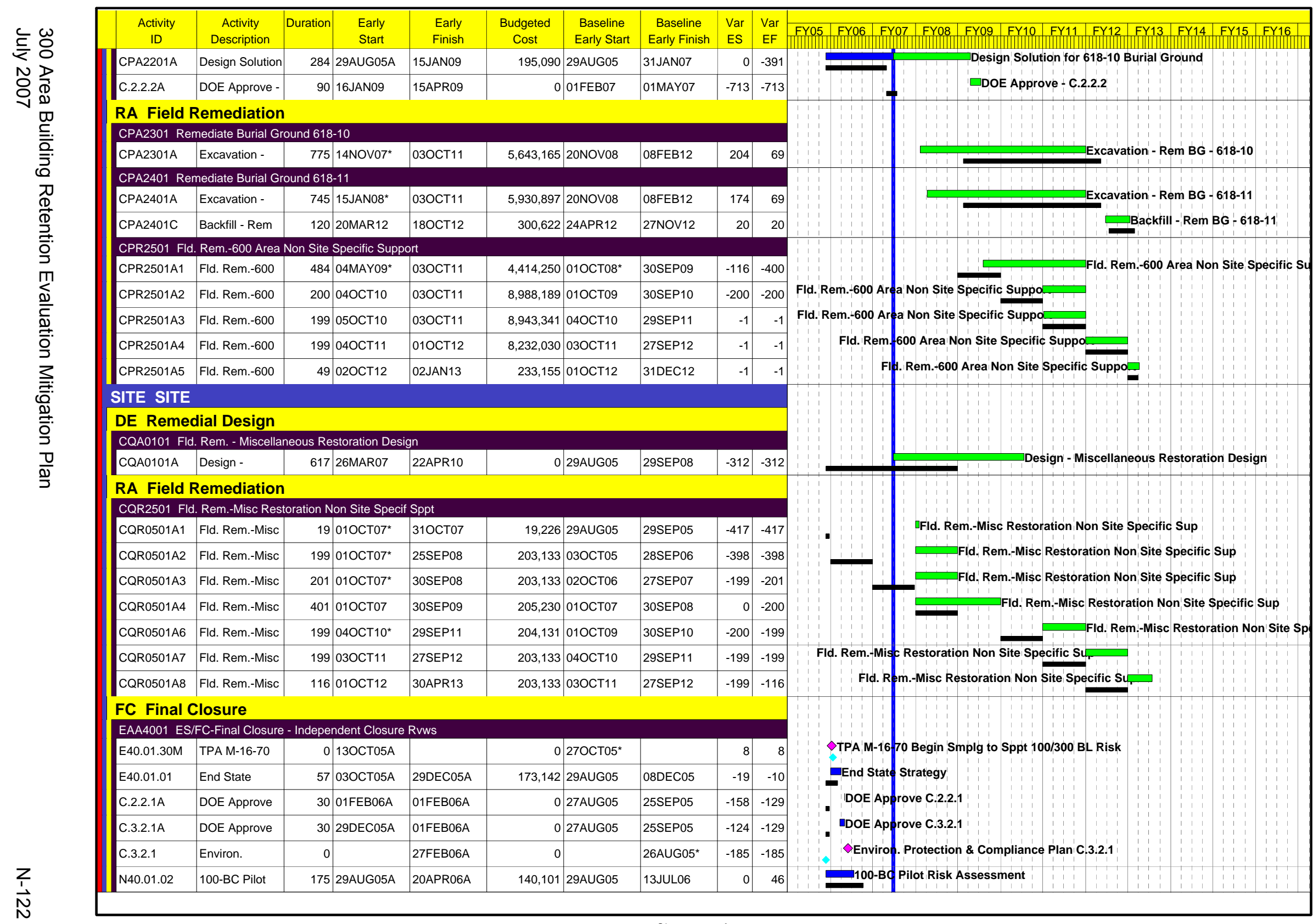




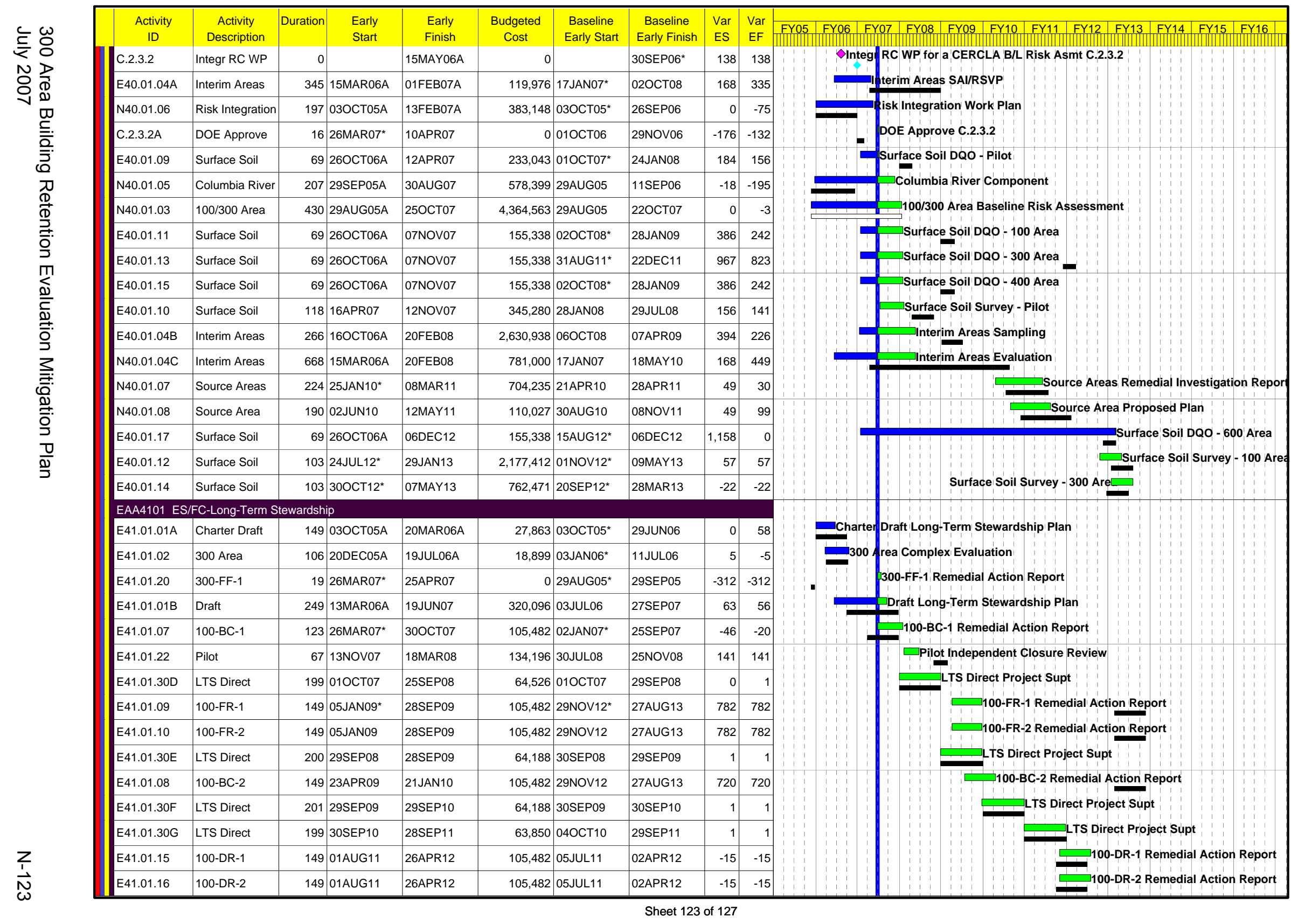




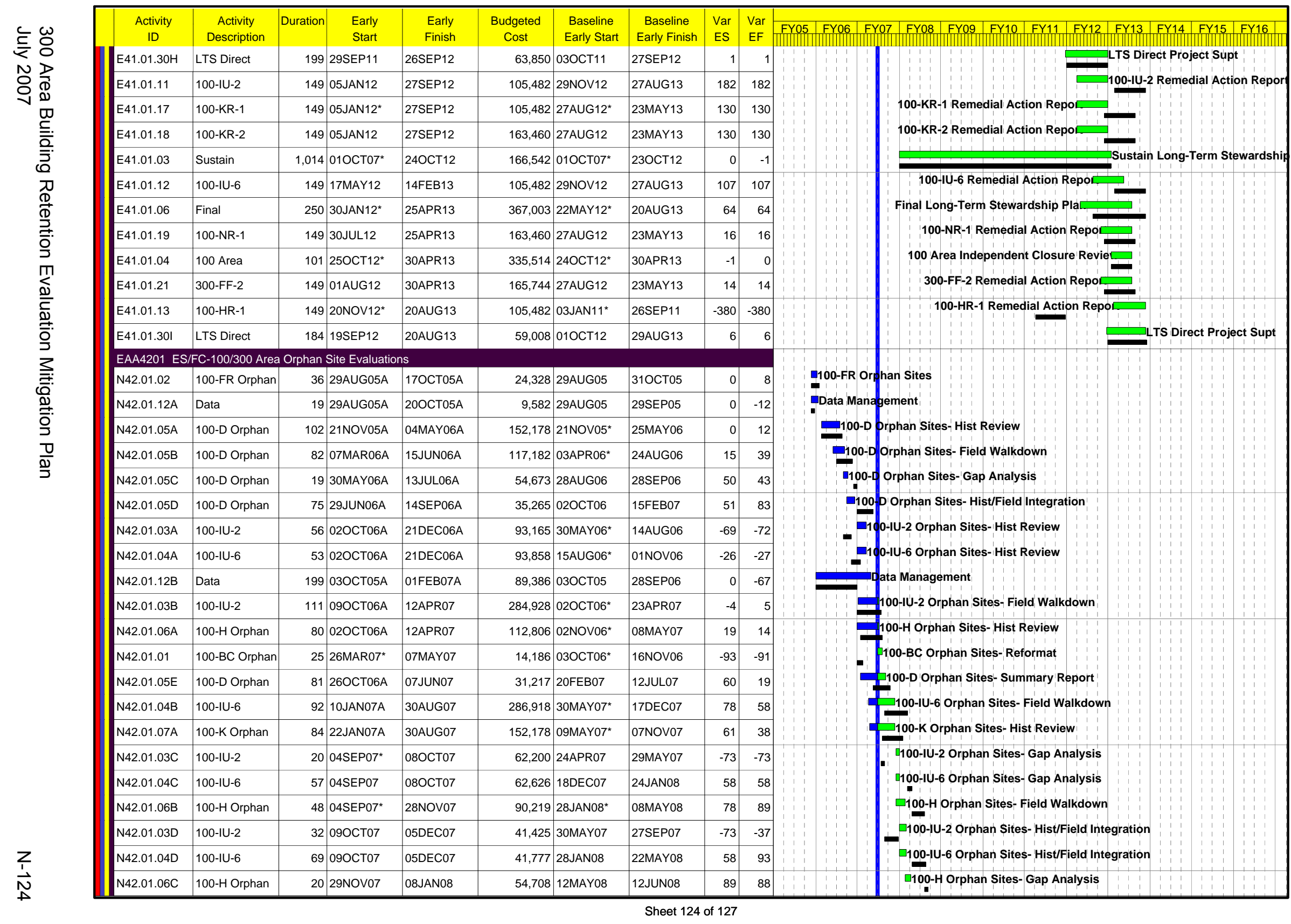




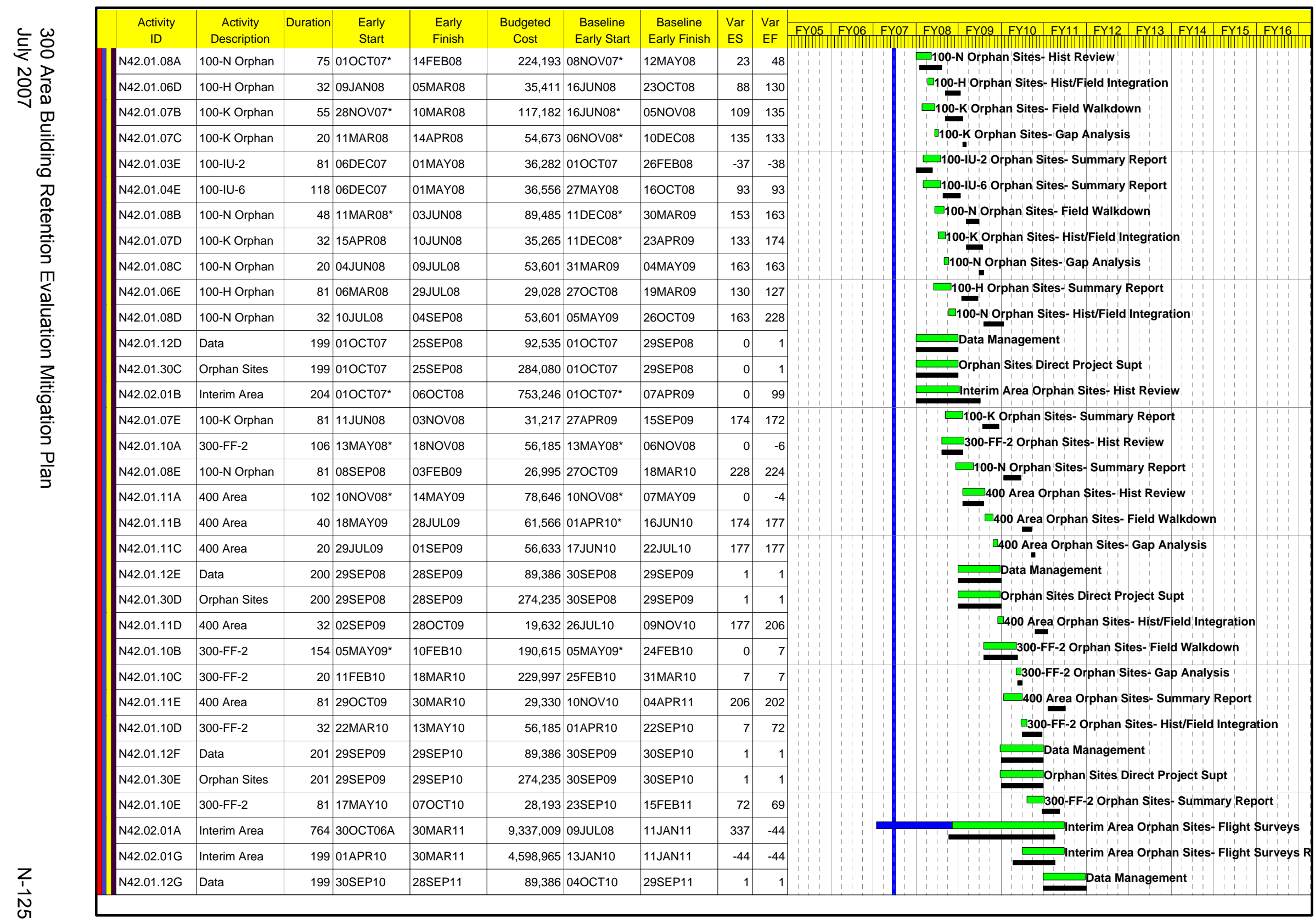




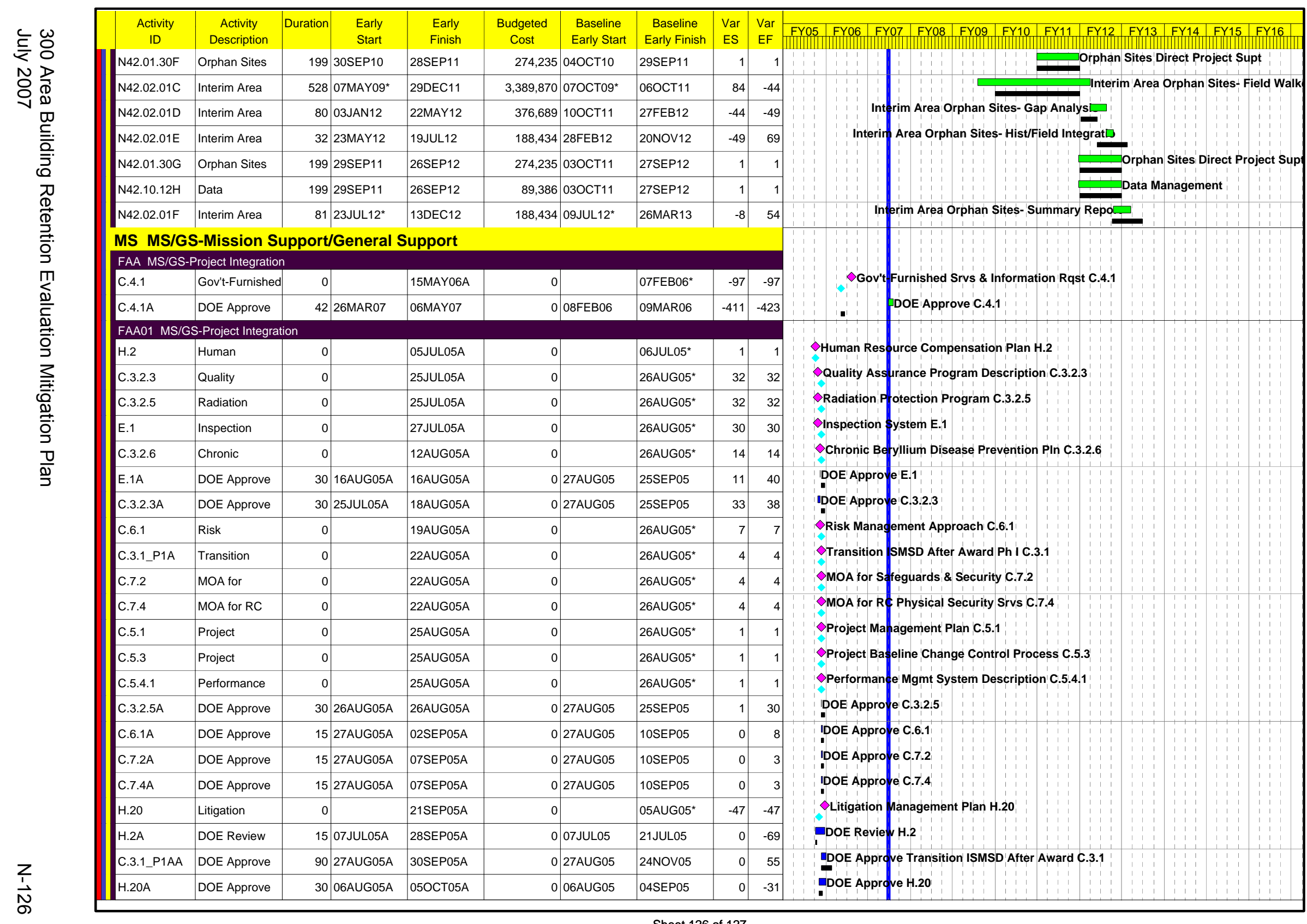




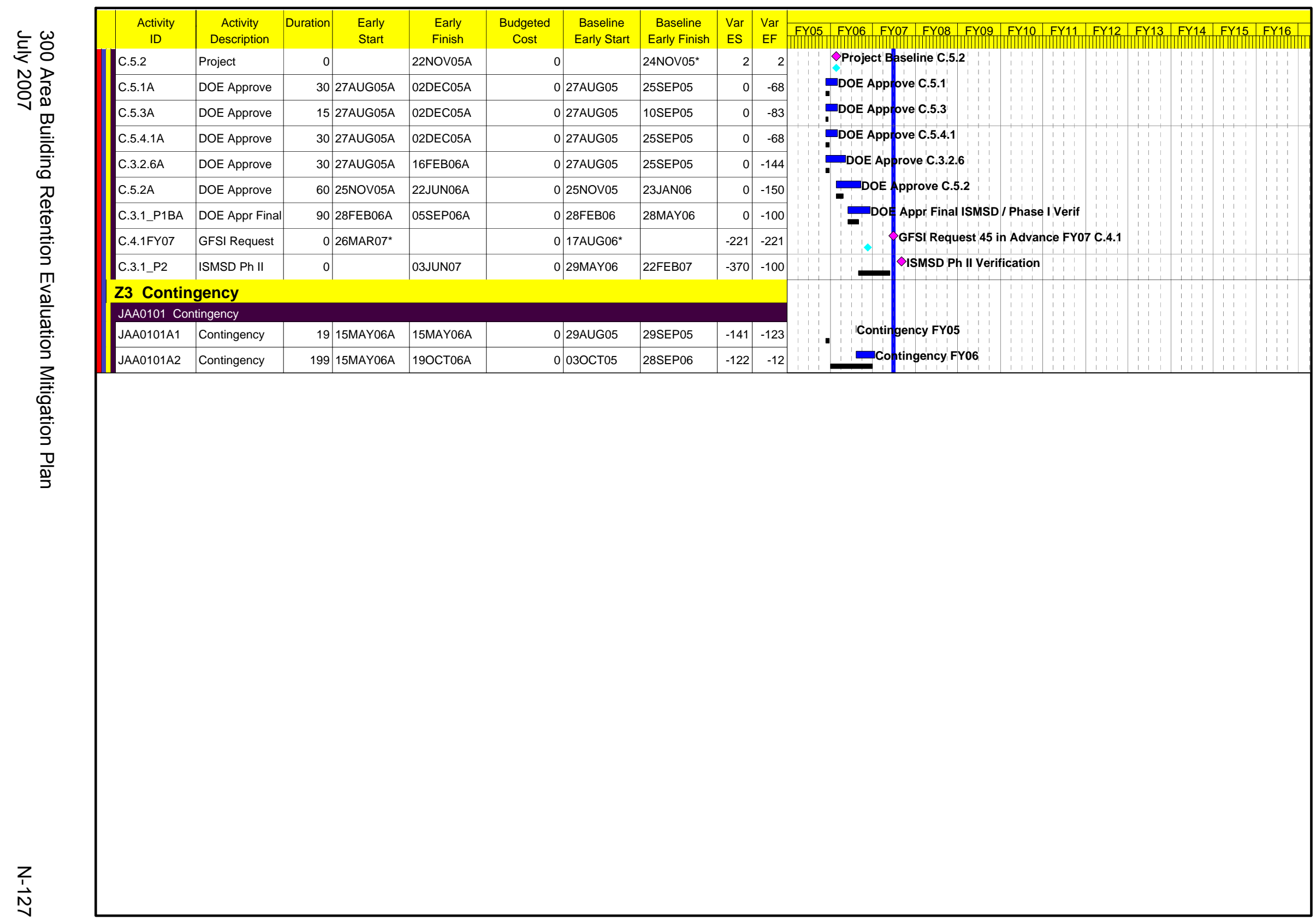


WCH-181

Rev. 0

300 Area Building Retention Evaluation Mitigation Plan 


\section{APPENDIX 0}

\section{SCENARIO 2 VARIANCE SCHEDULE}


WCH-181

Rev. 0 


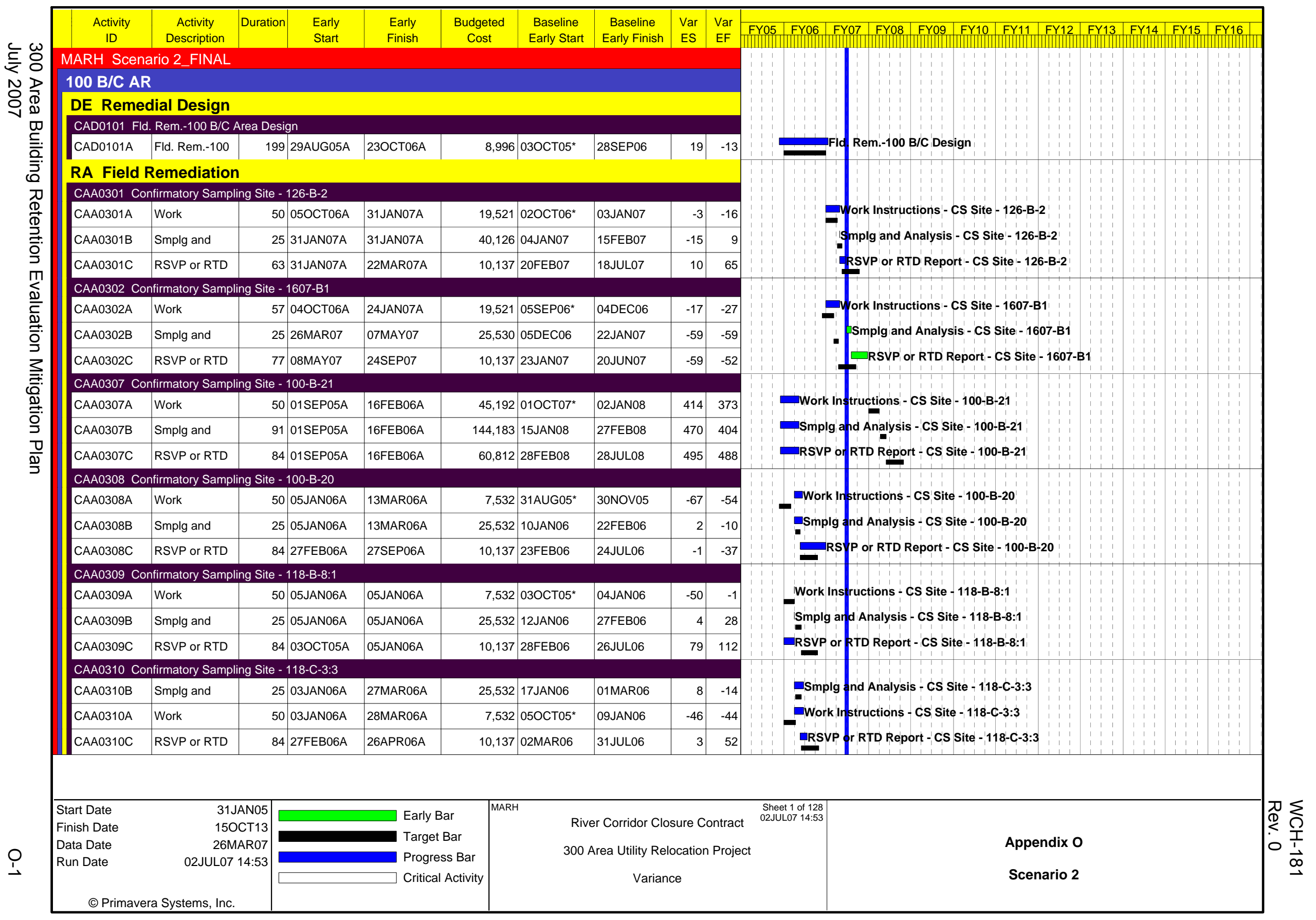




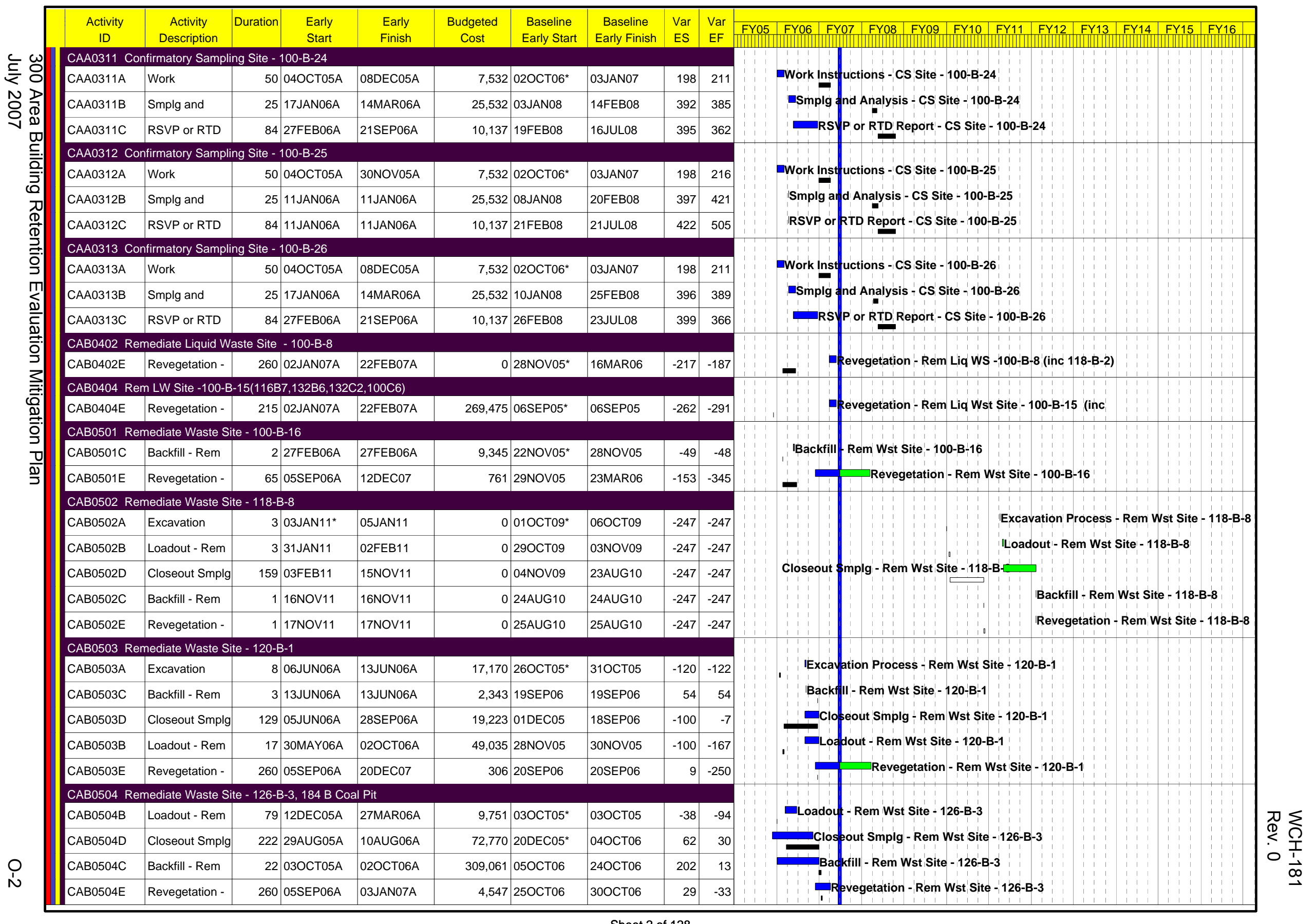

Sheet 2 of 128 


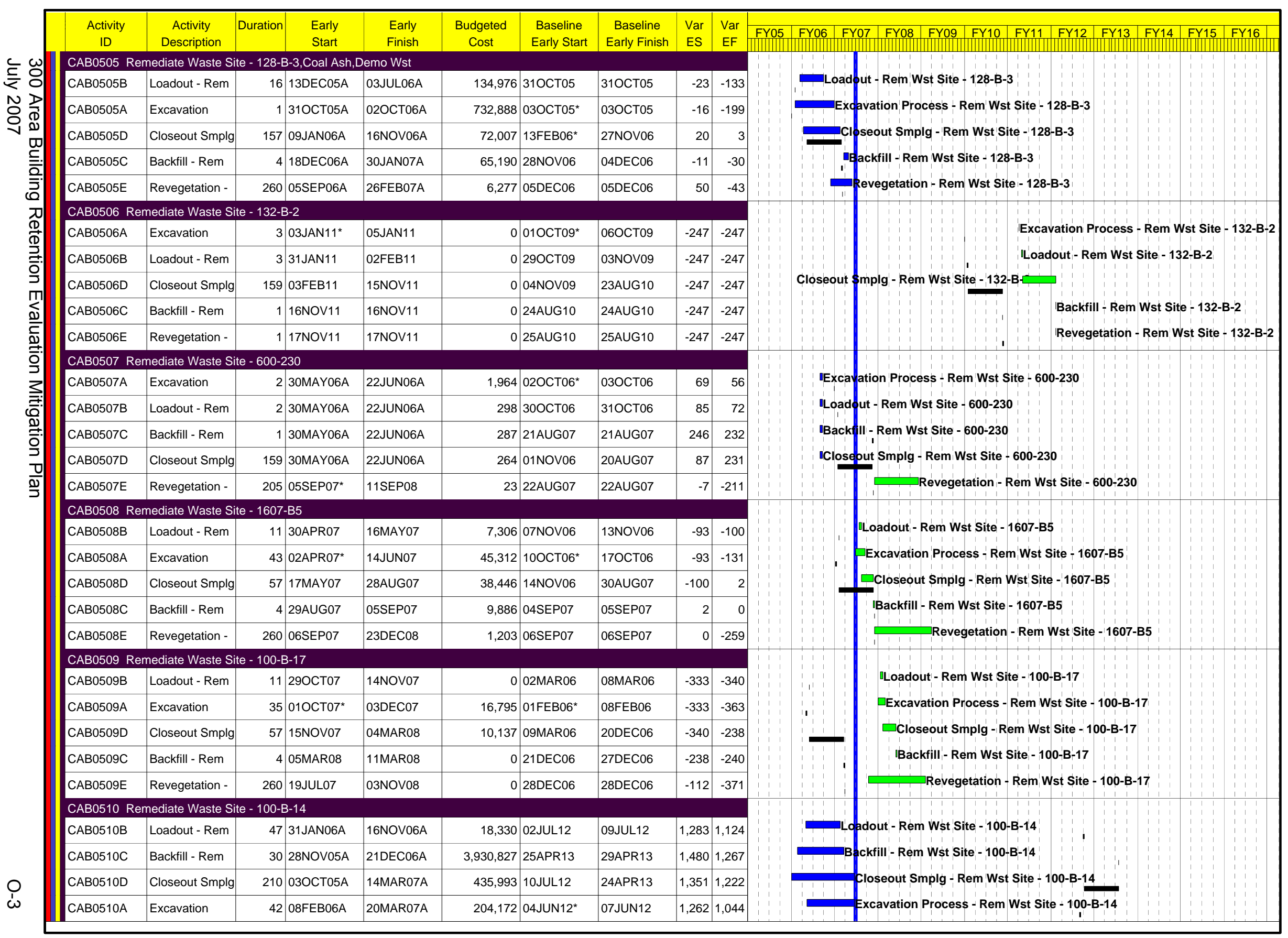




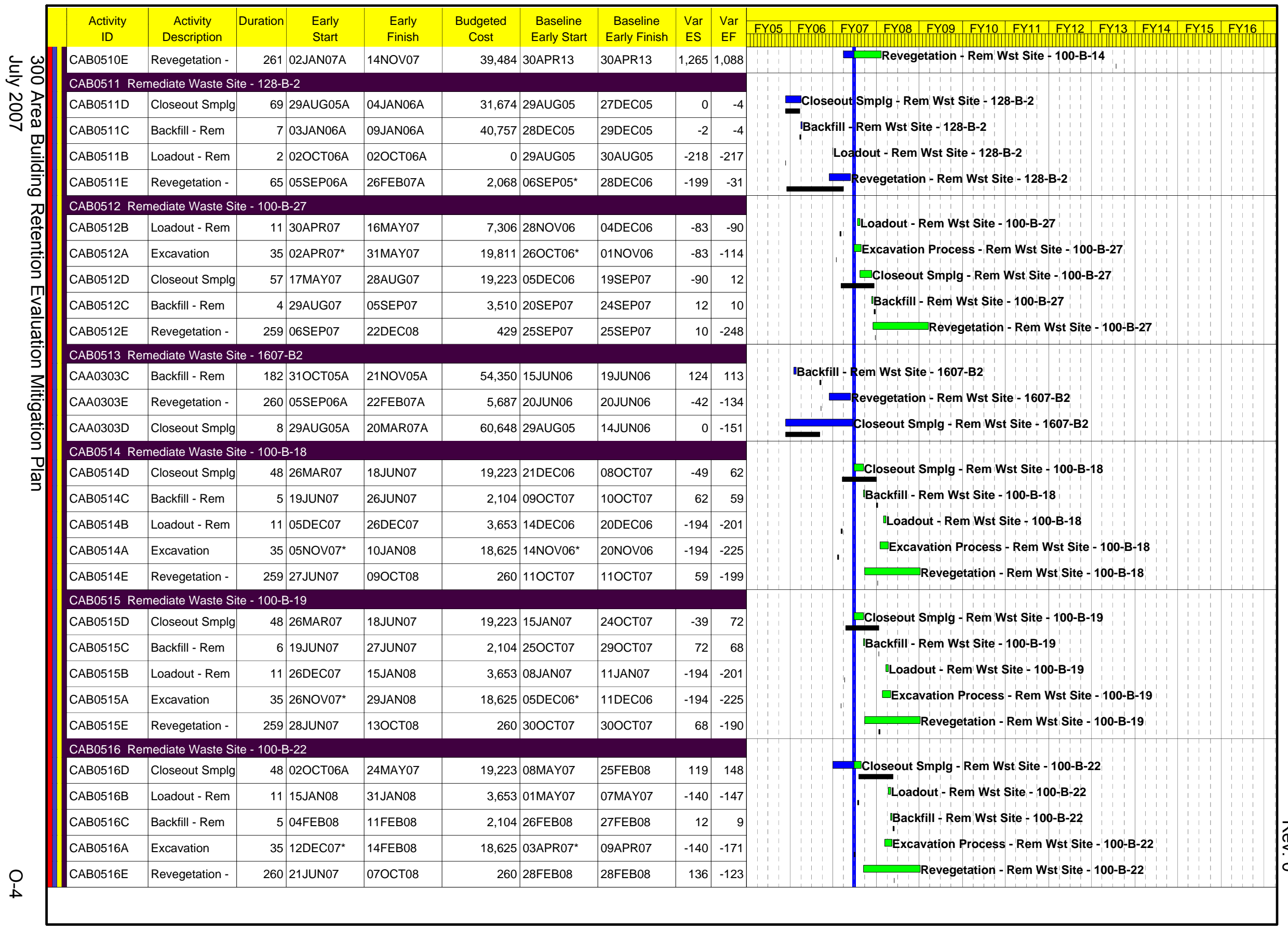




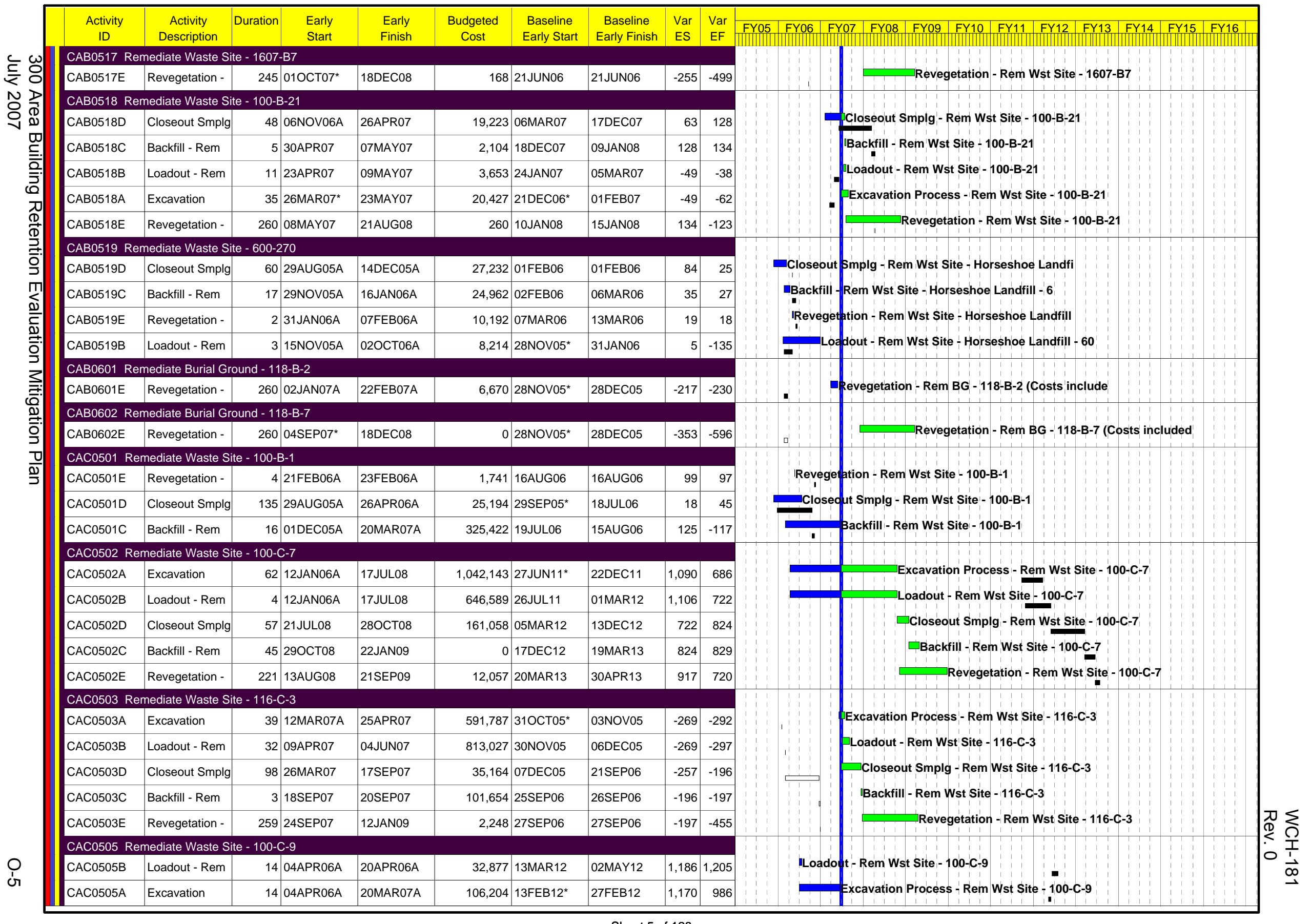

Sheet 5 of 128 


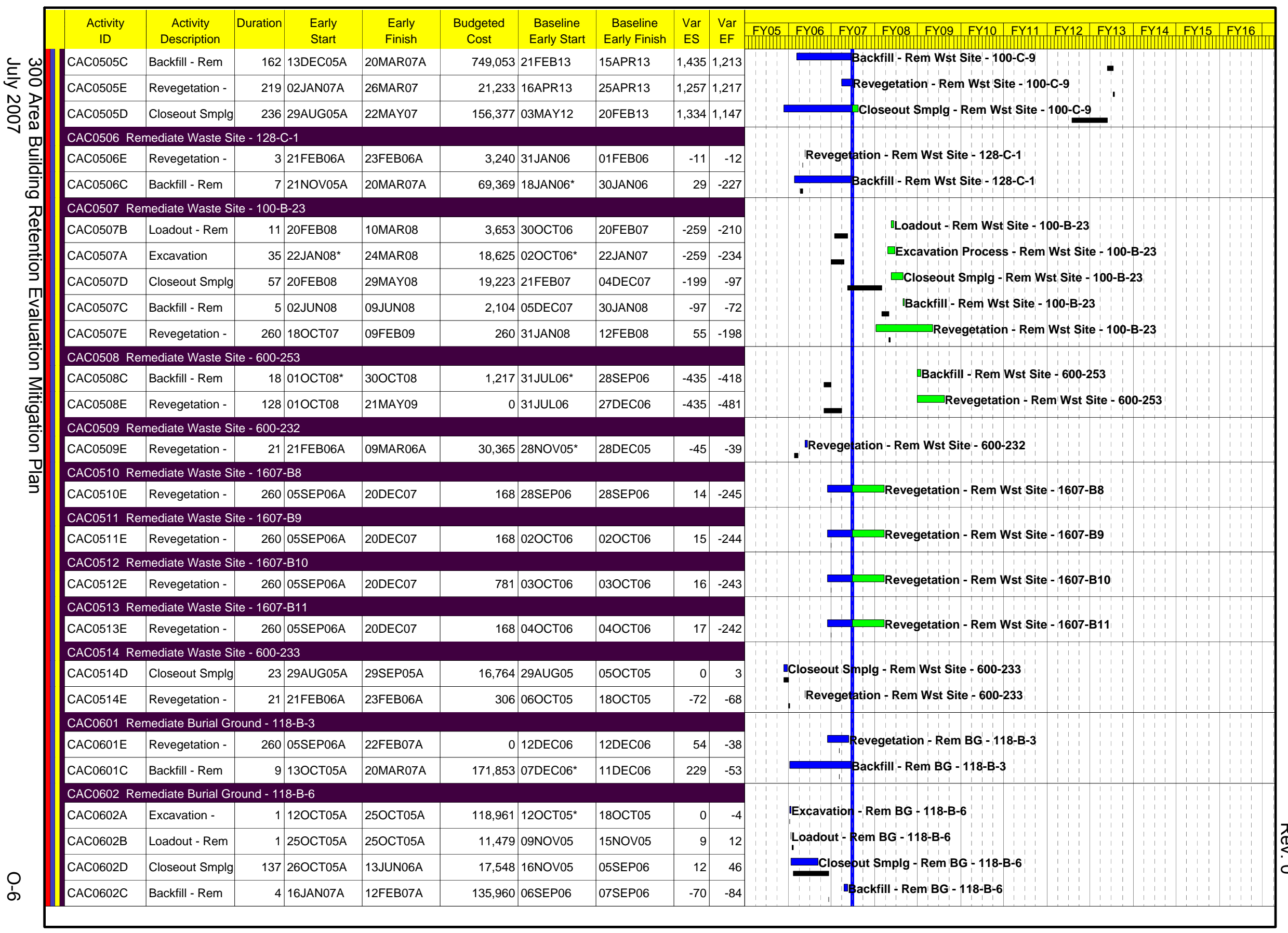




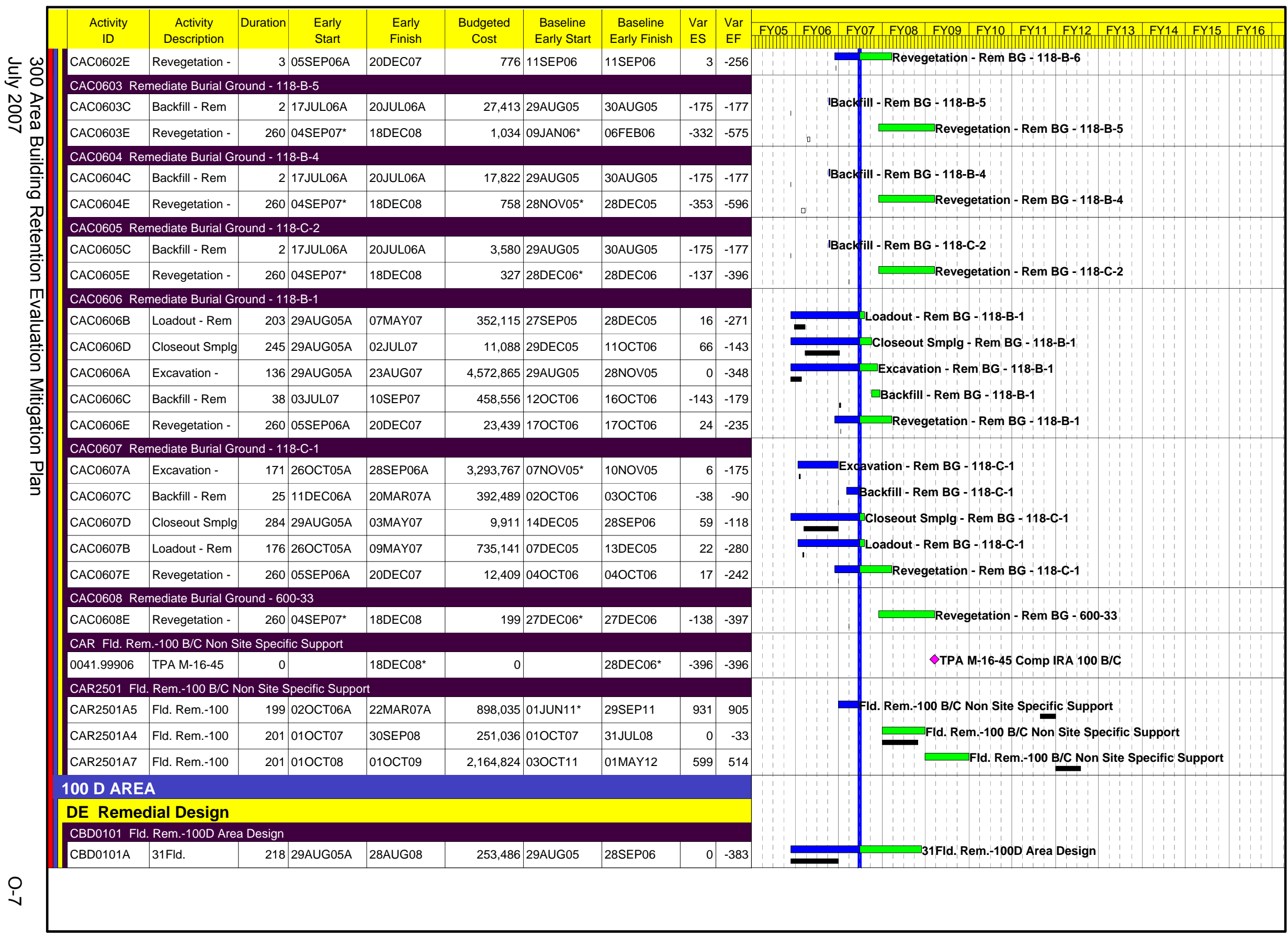




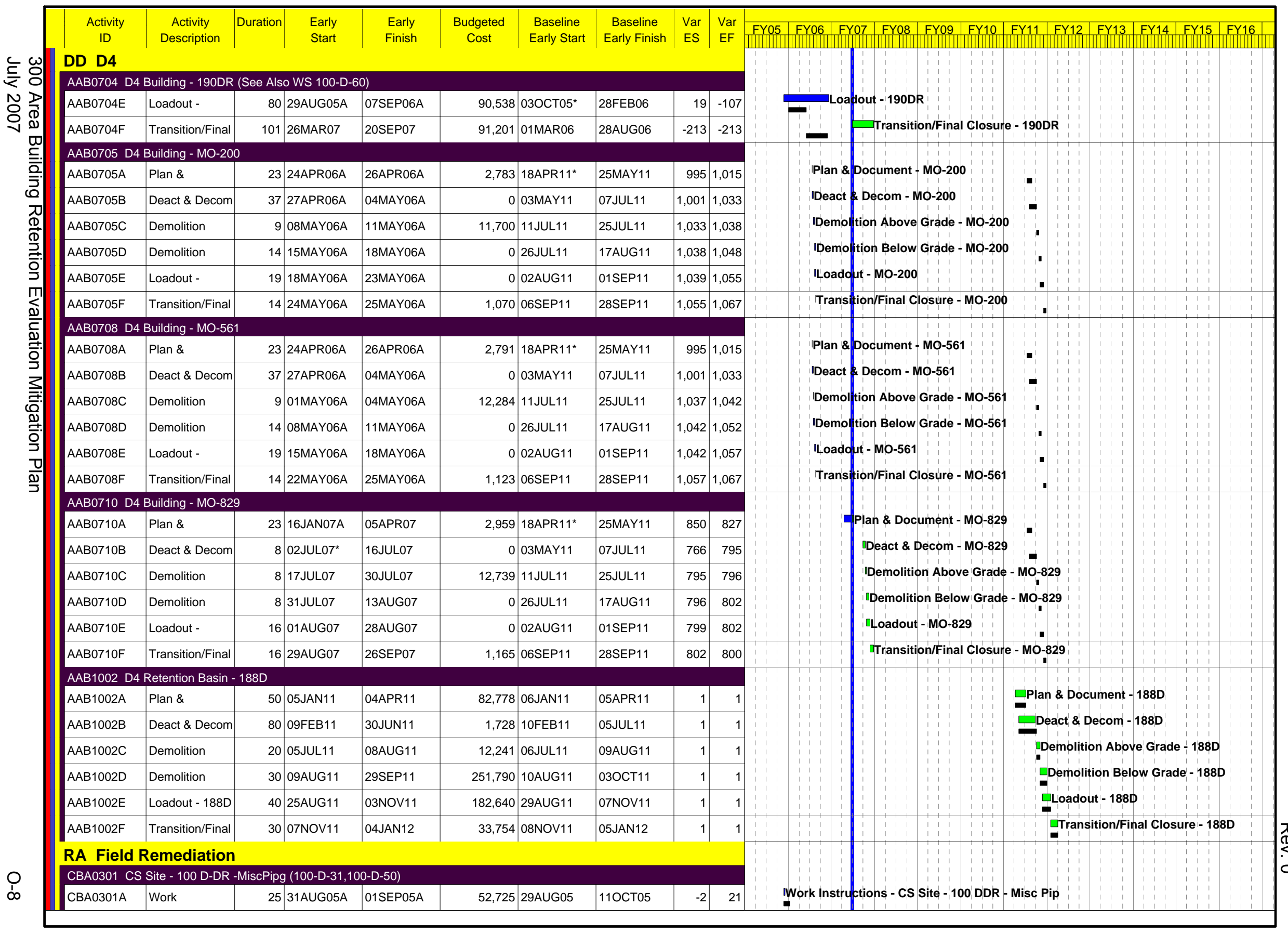




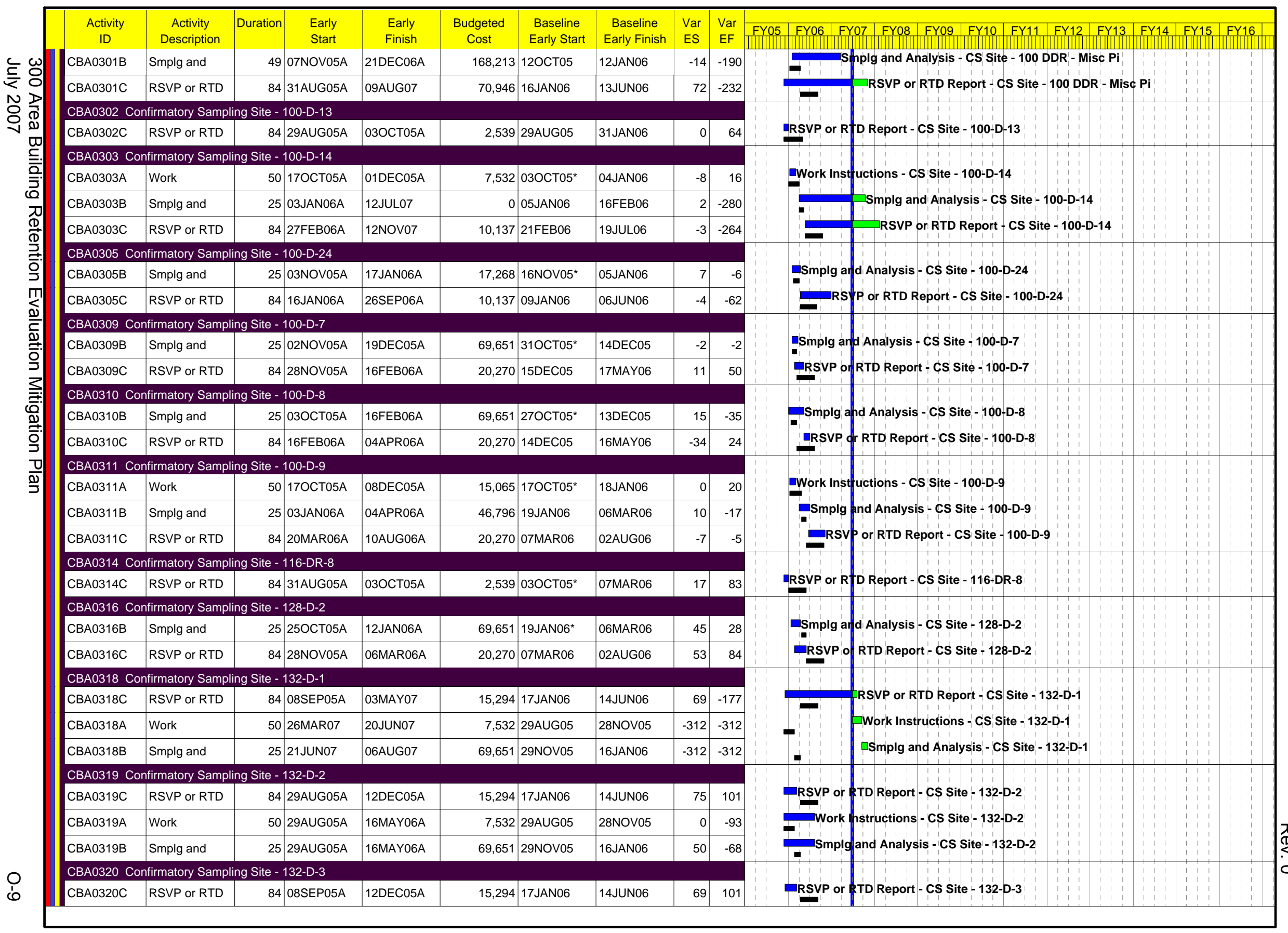




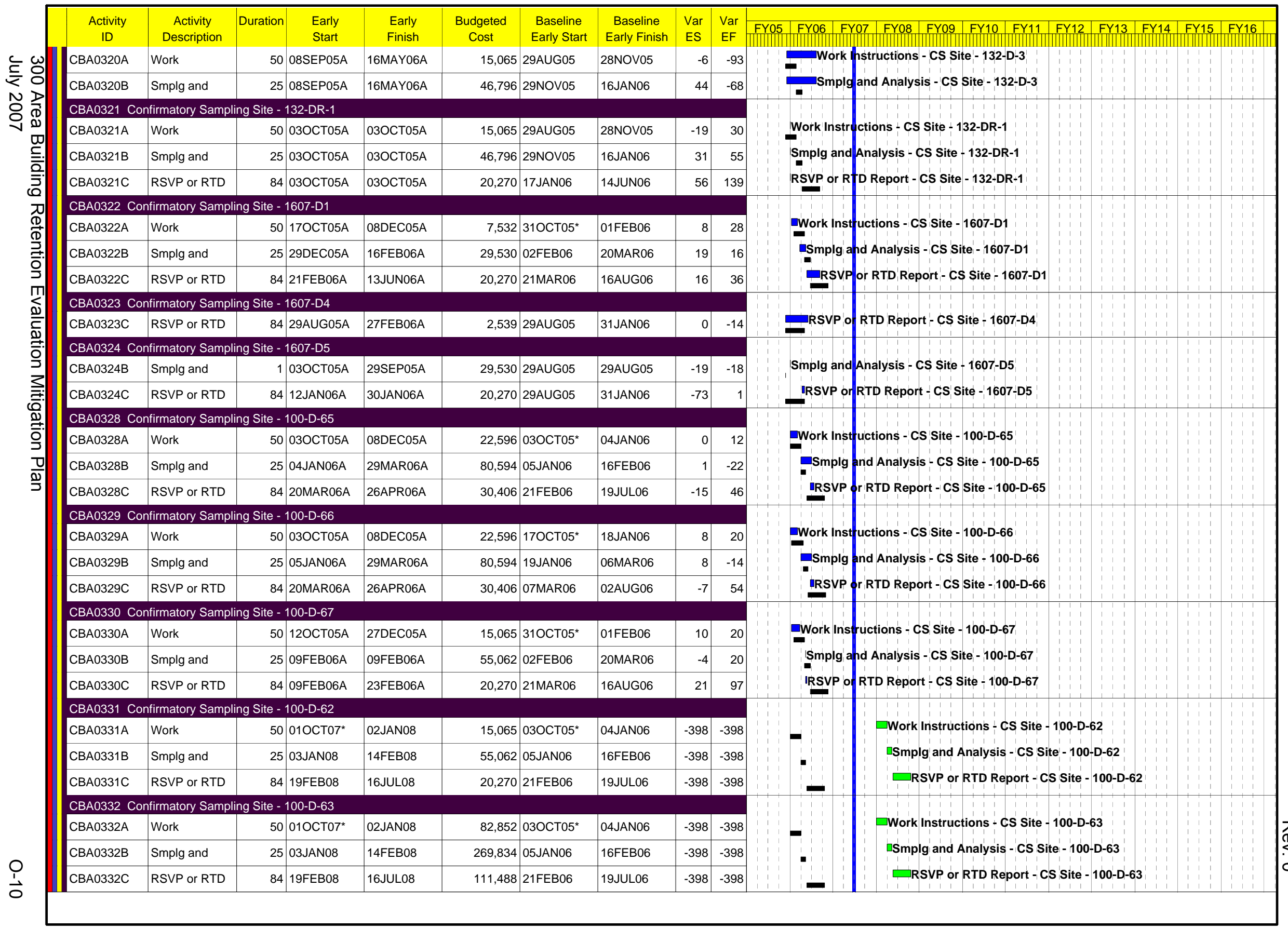




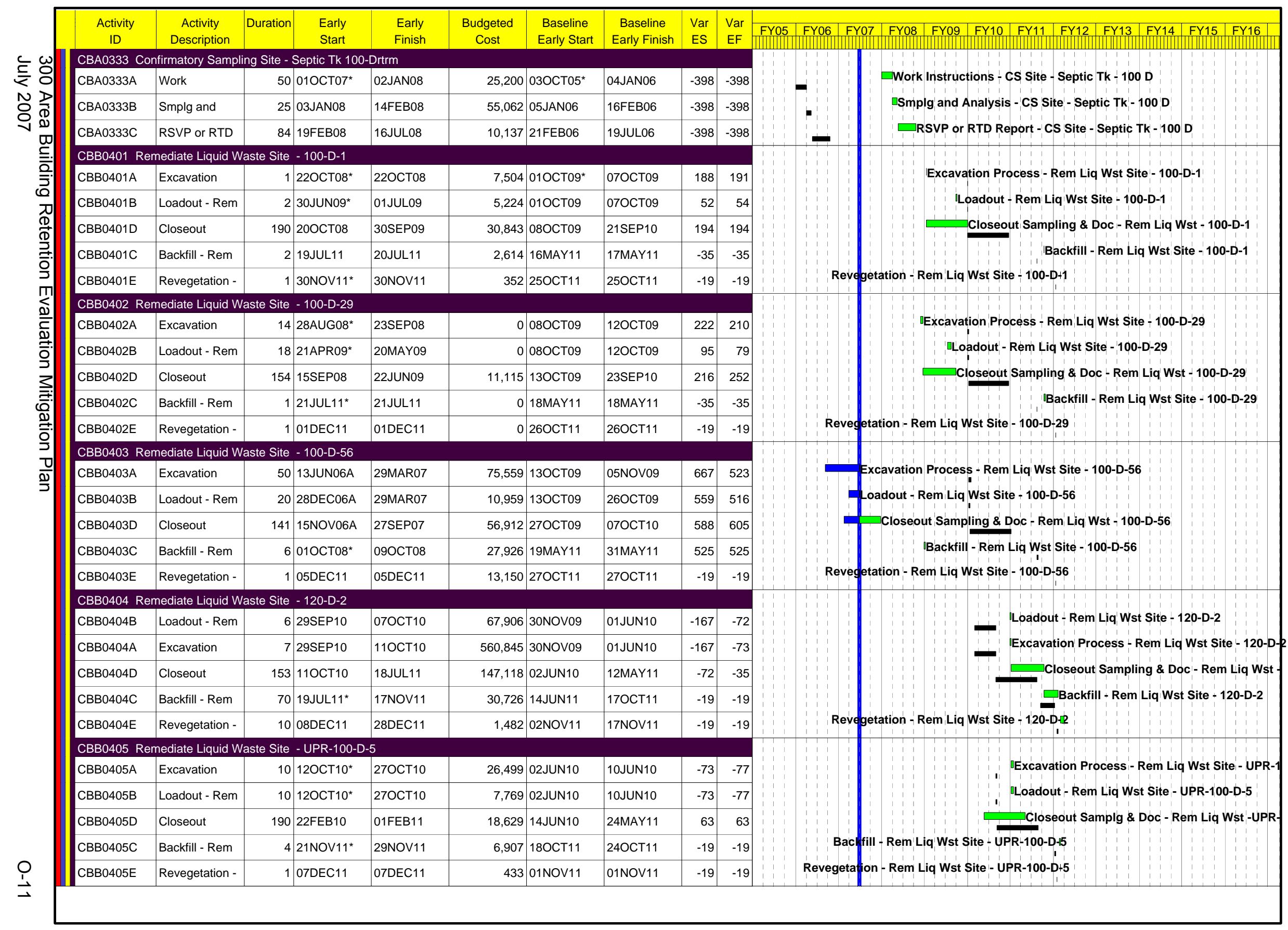




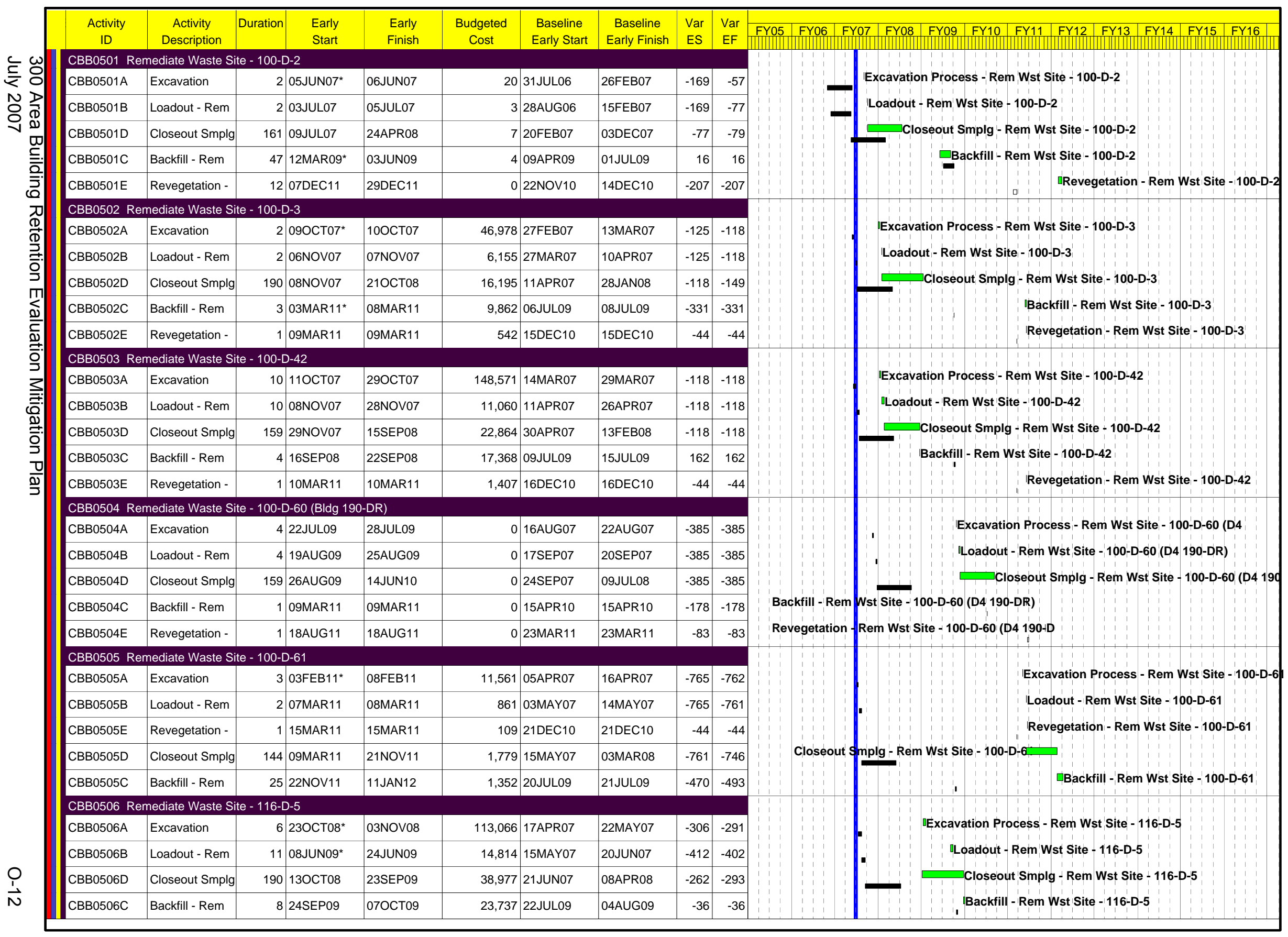




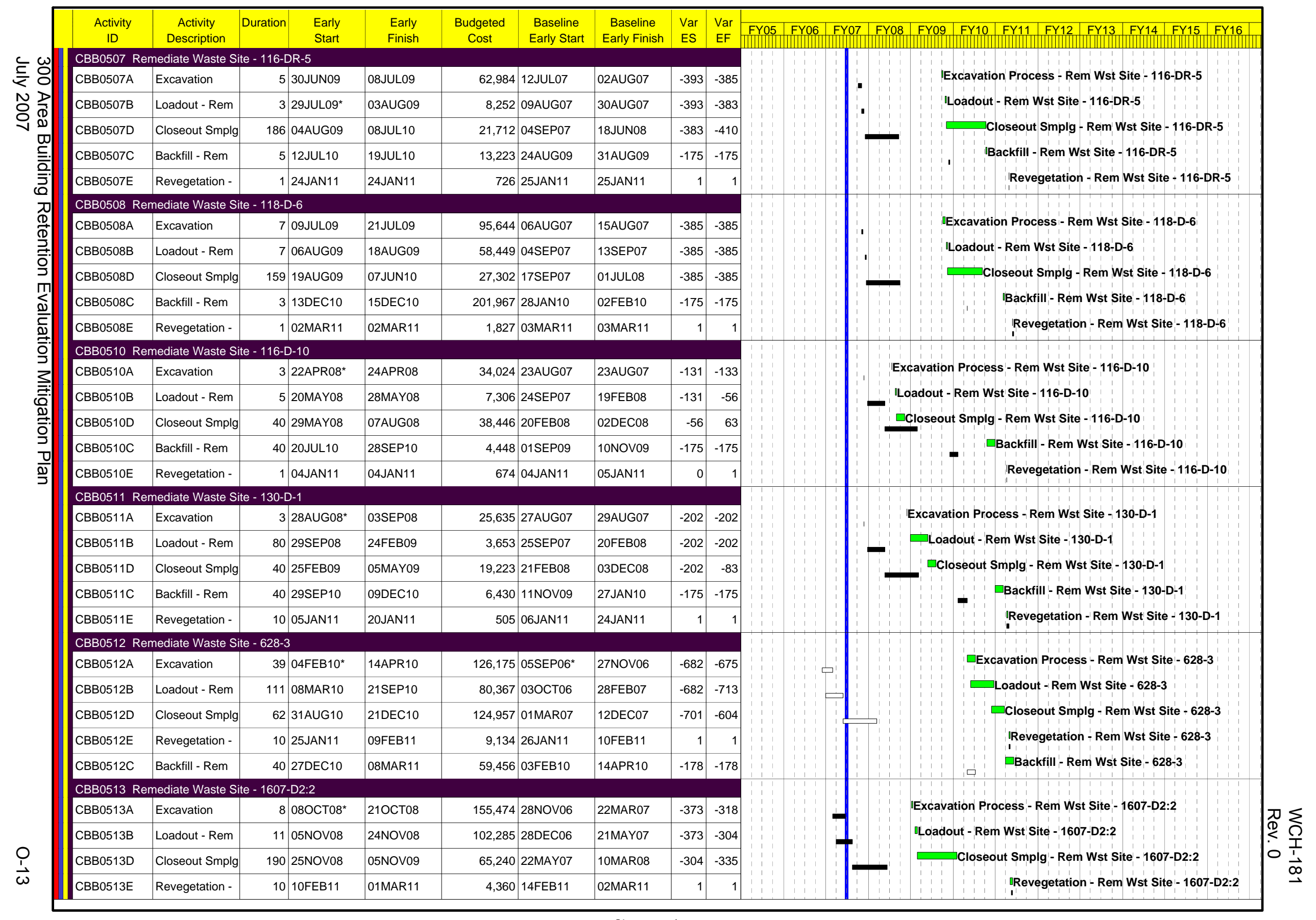




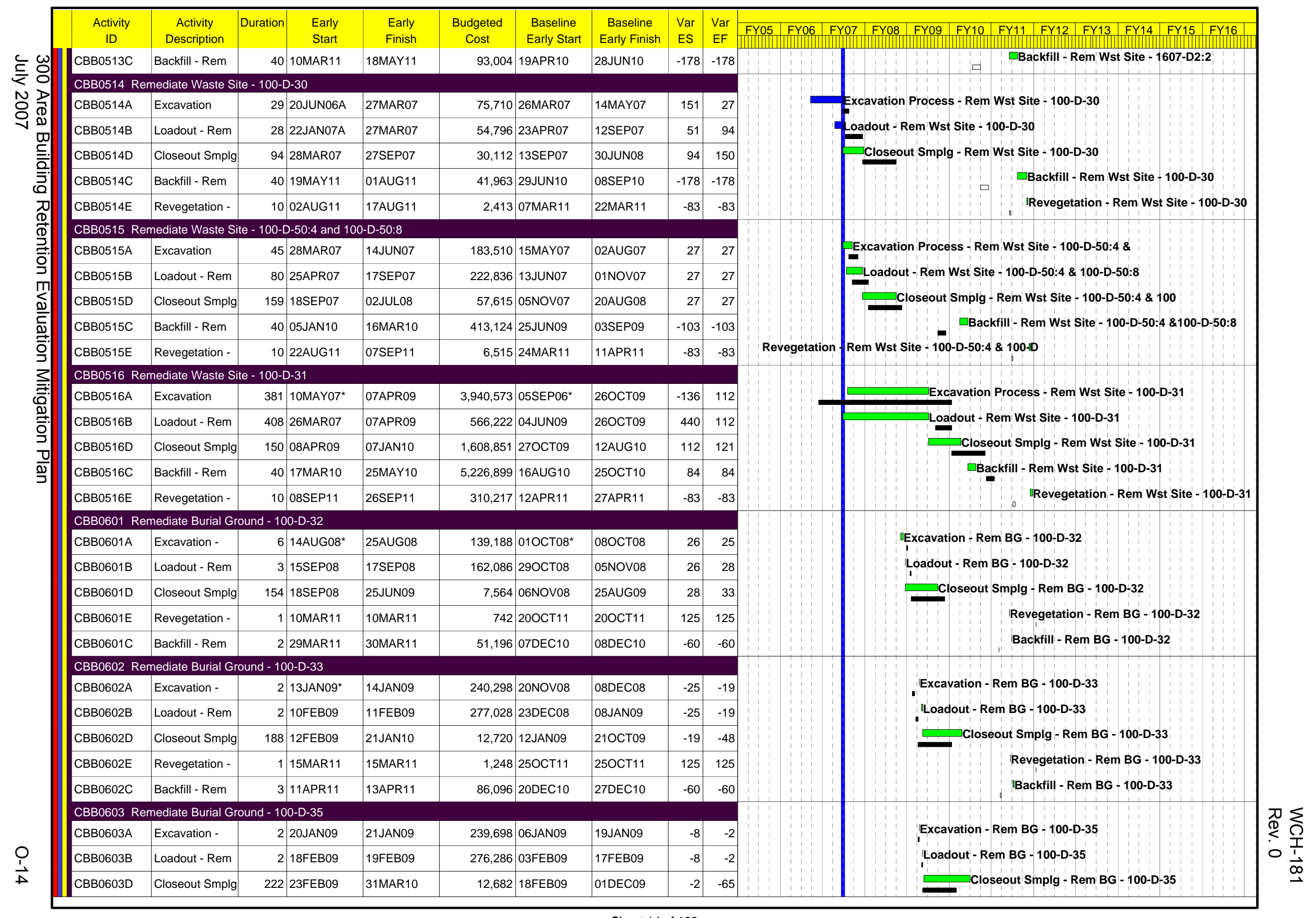




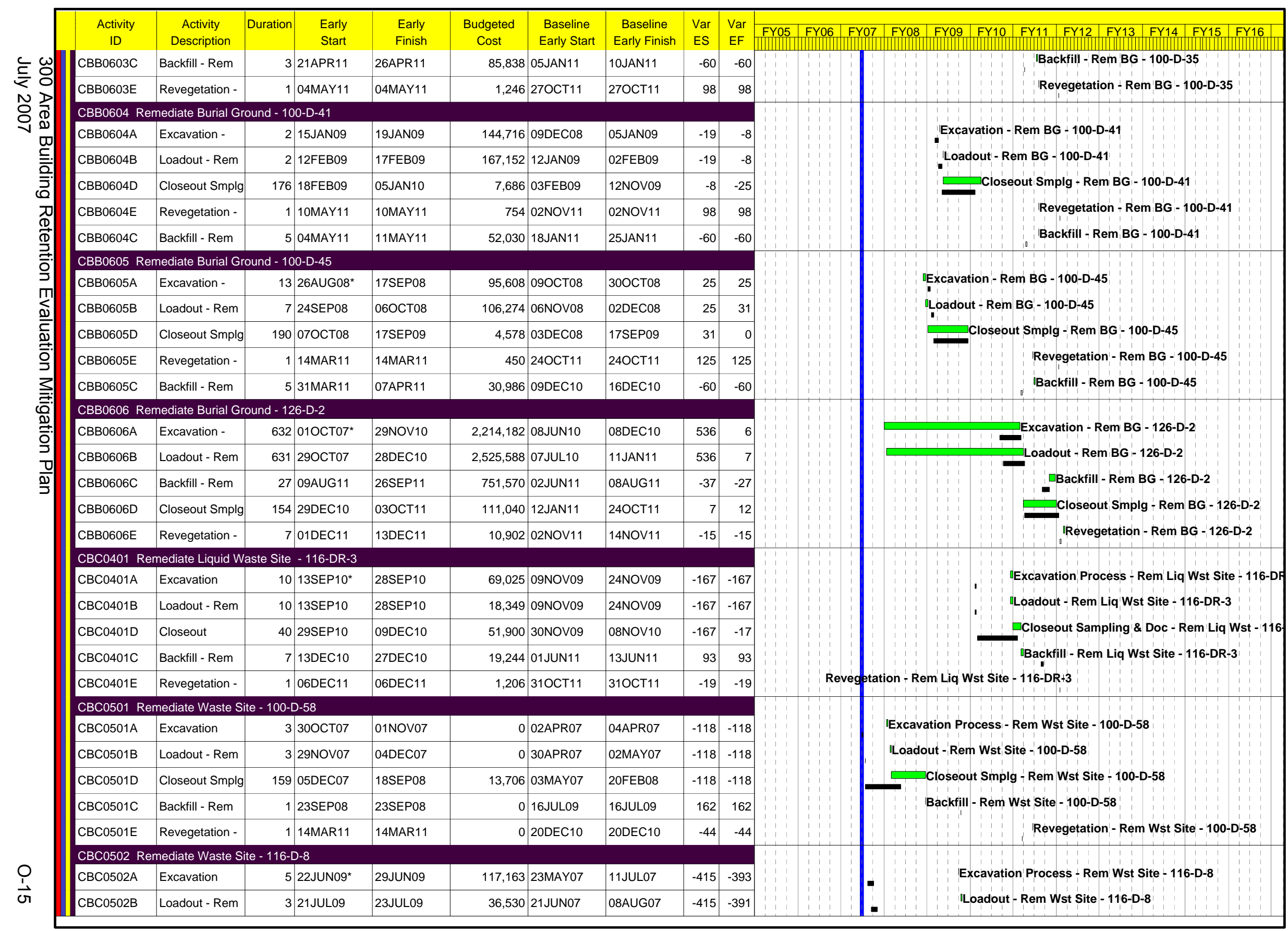




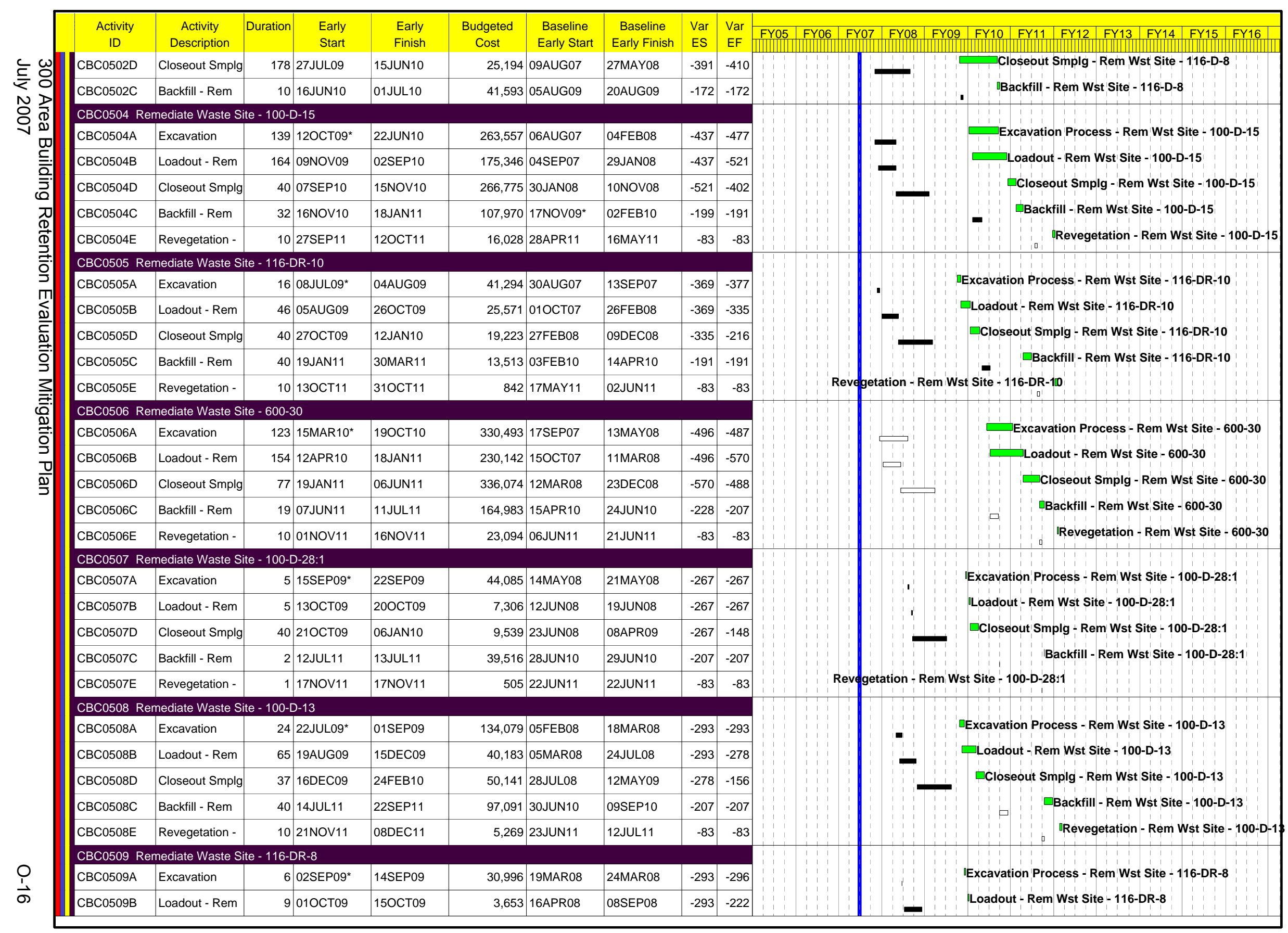




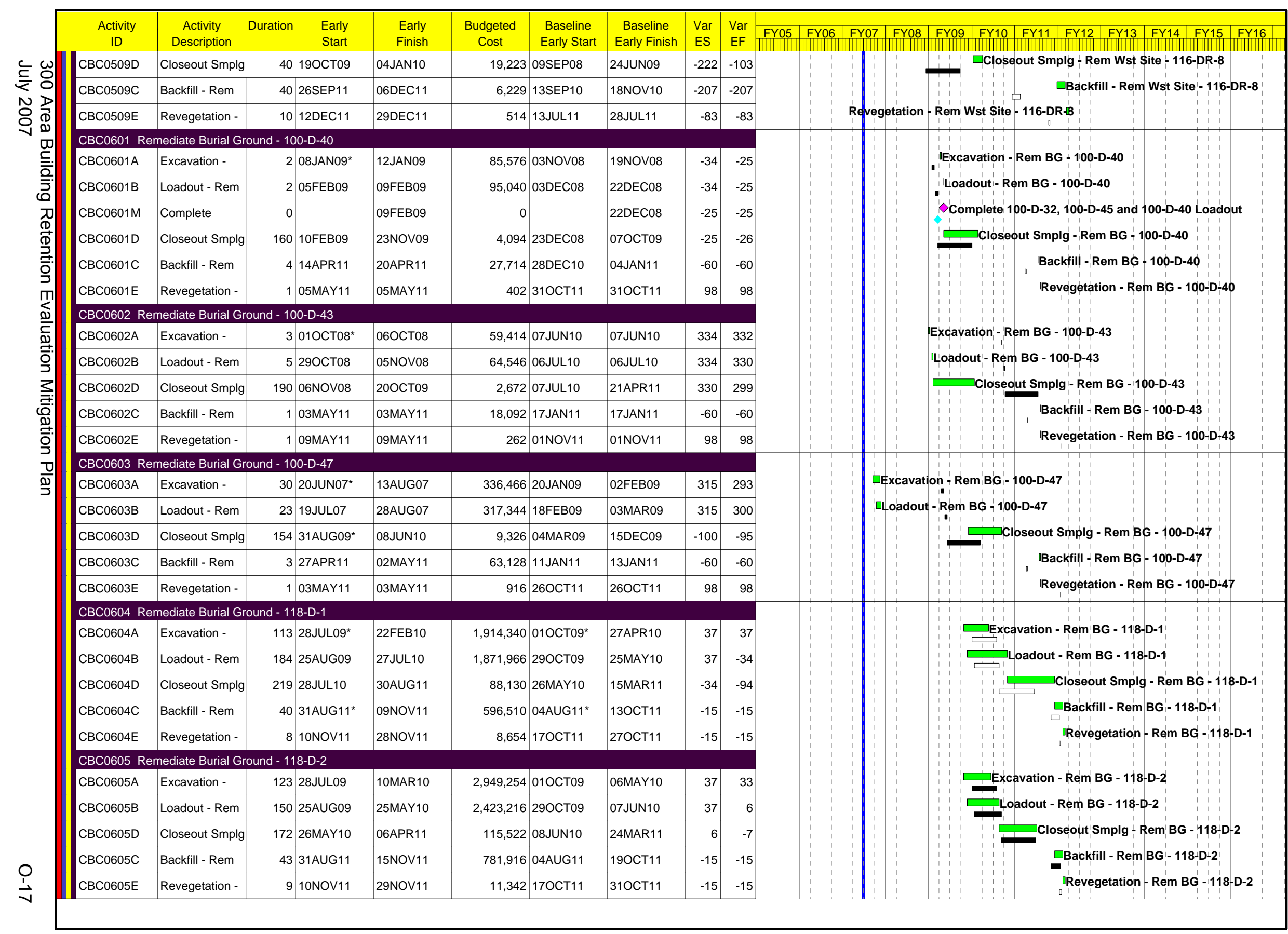




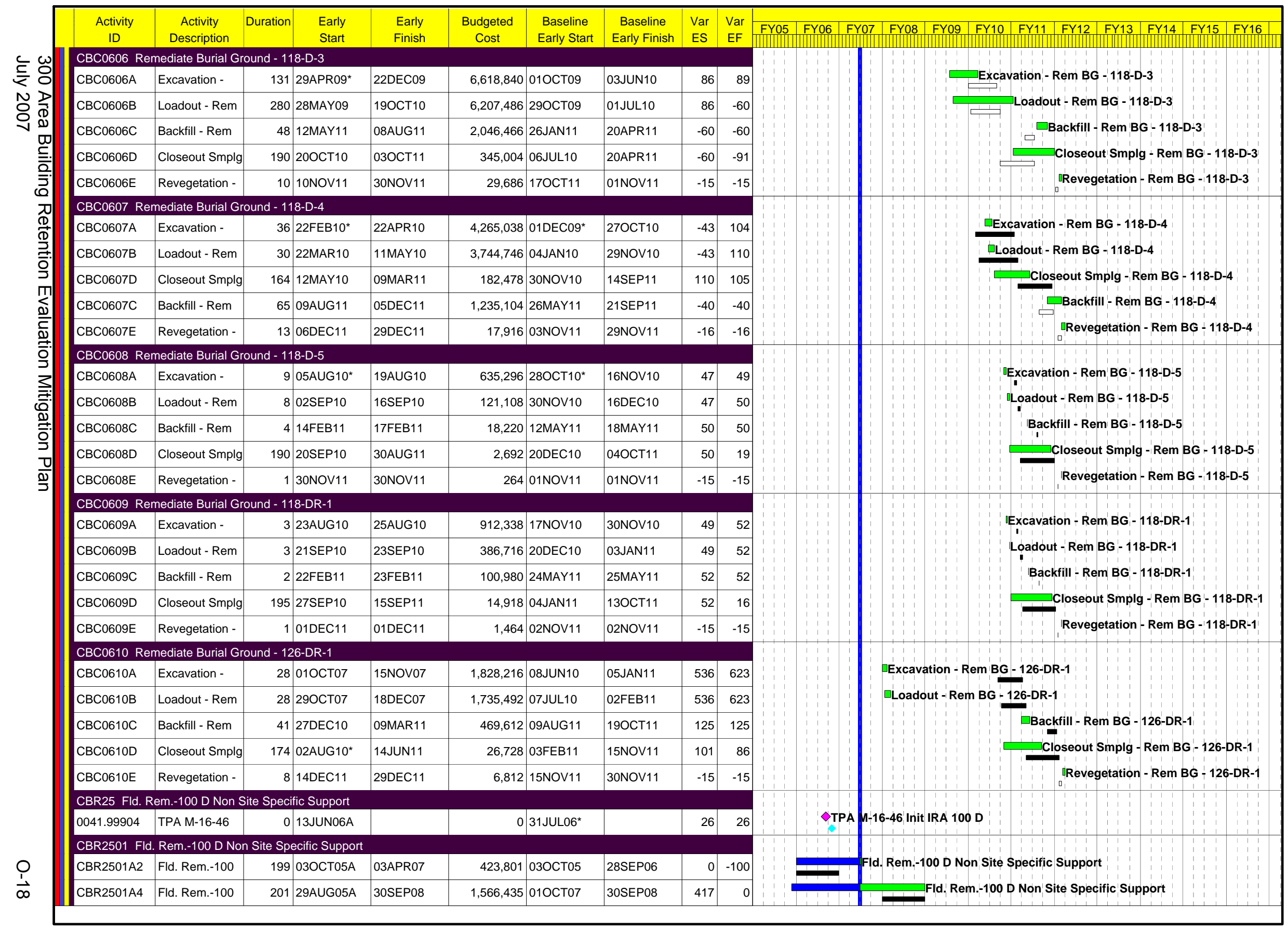




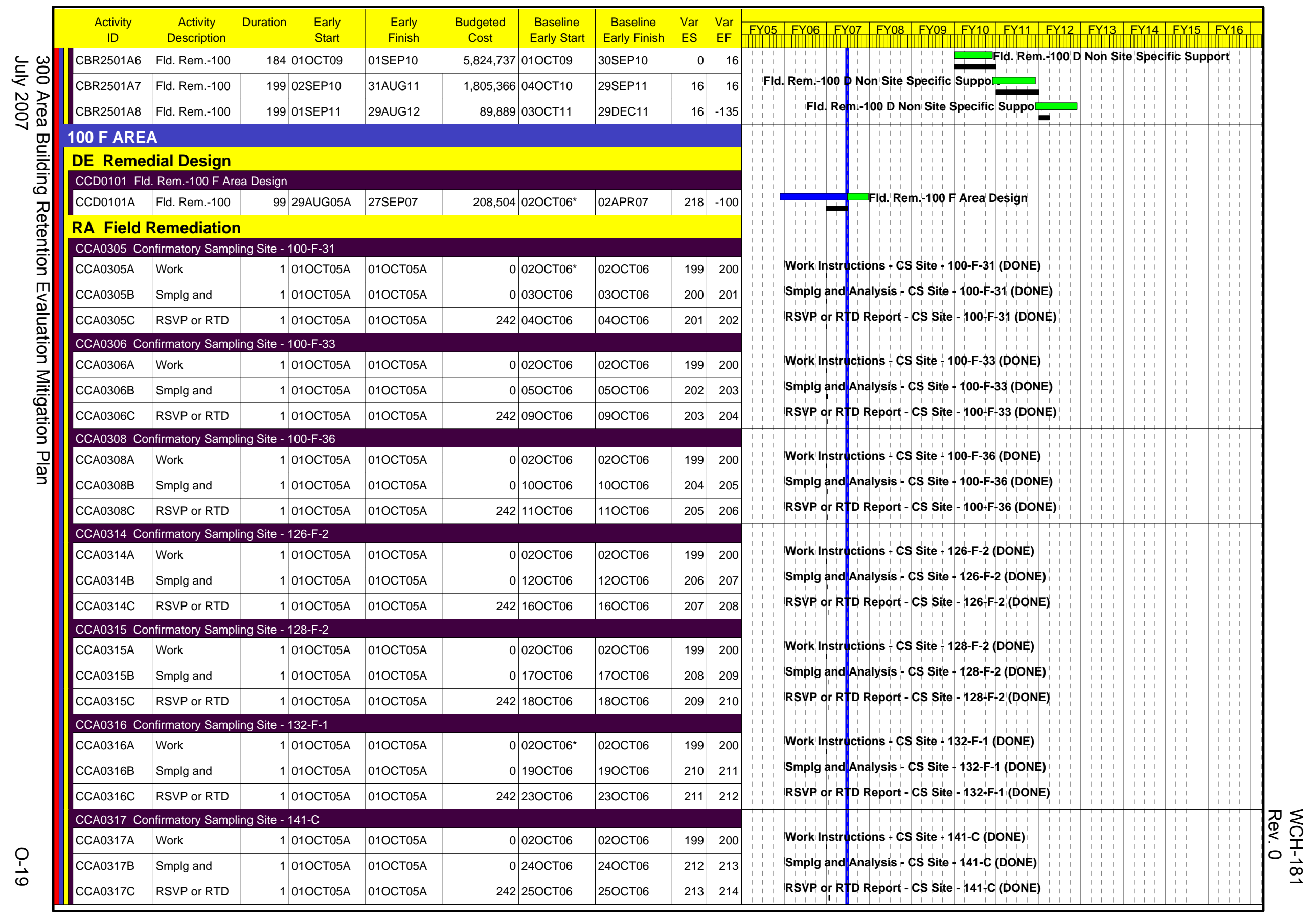

Sheet 19 of 128 


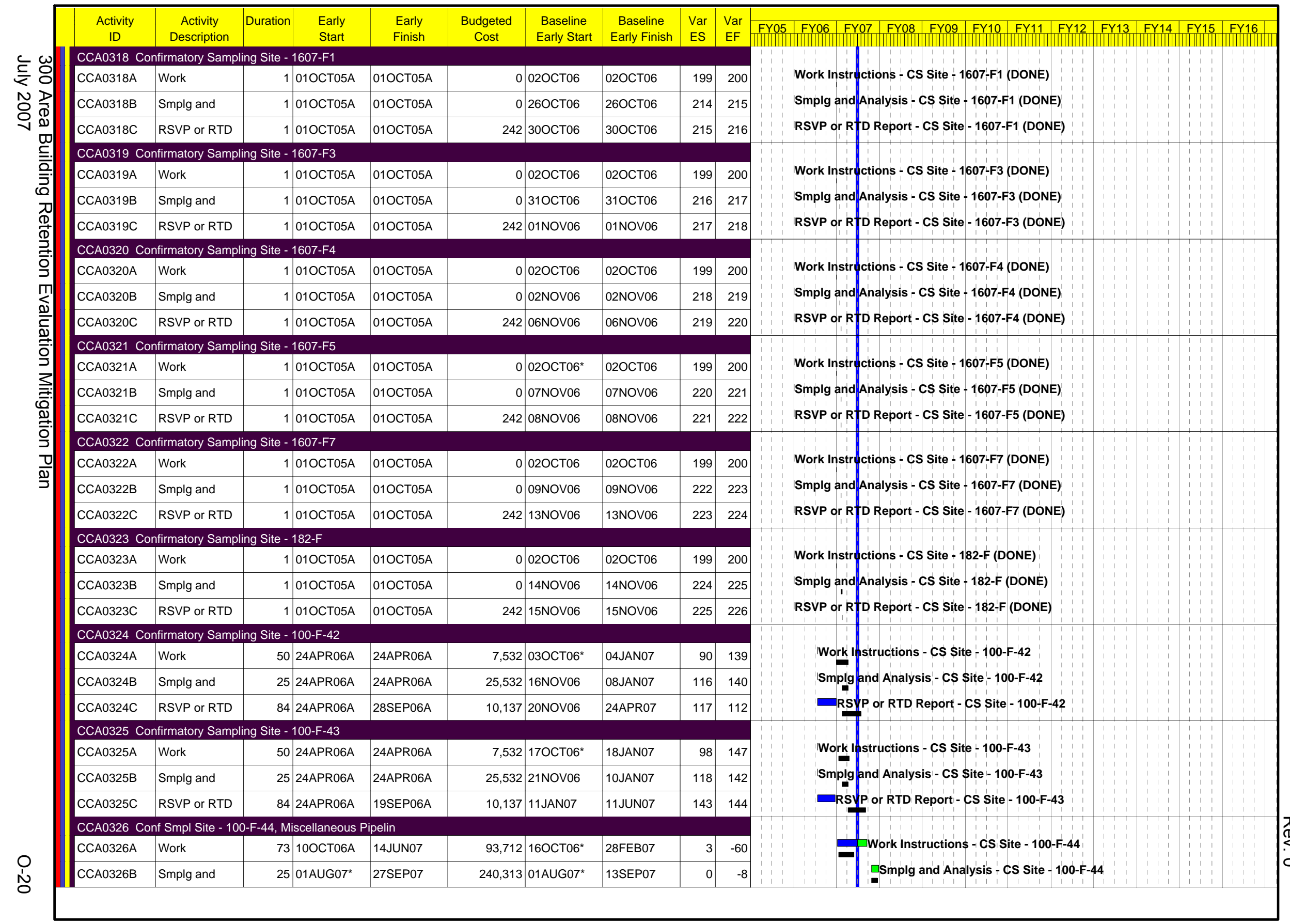




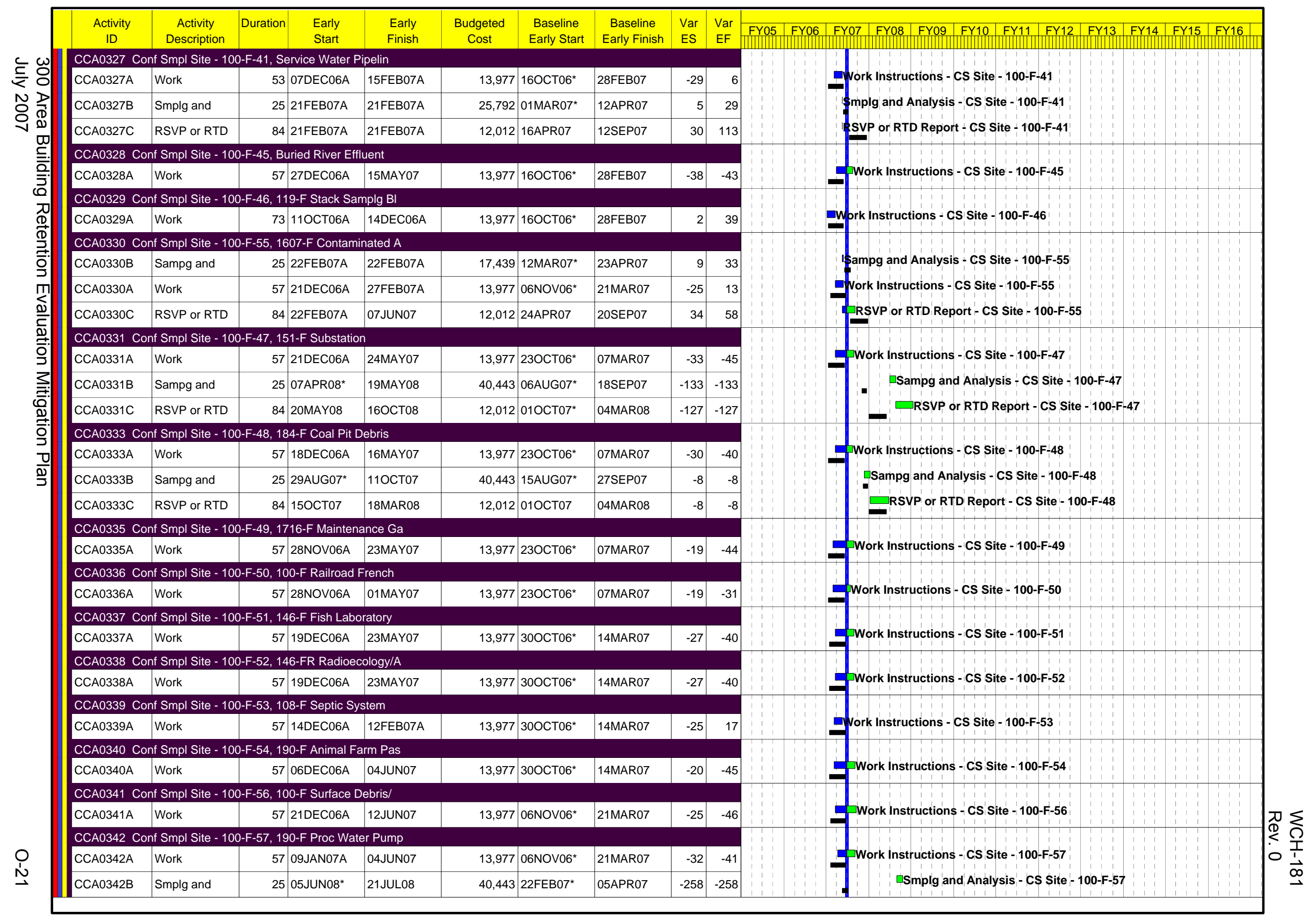




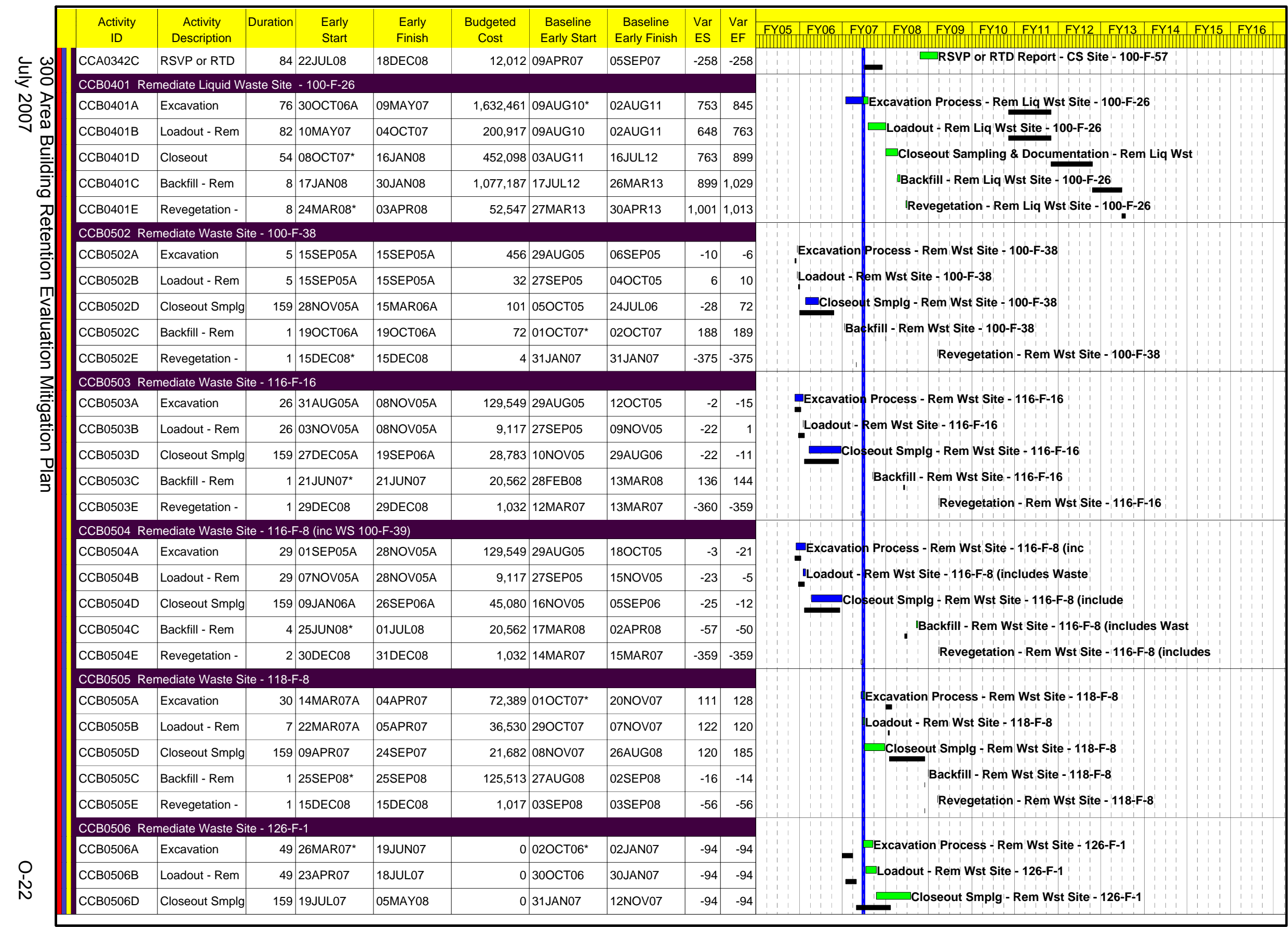




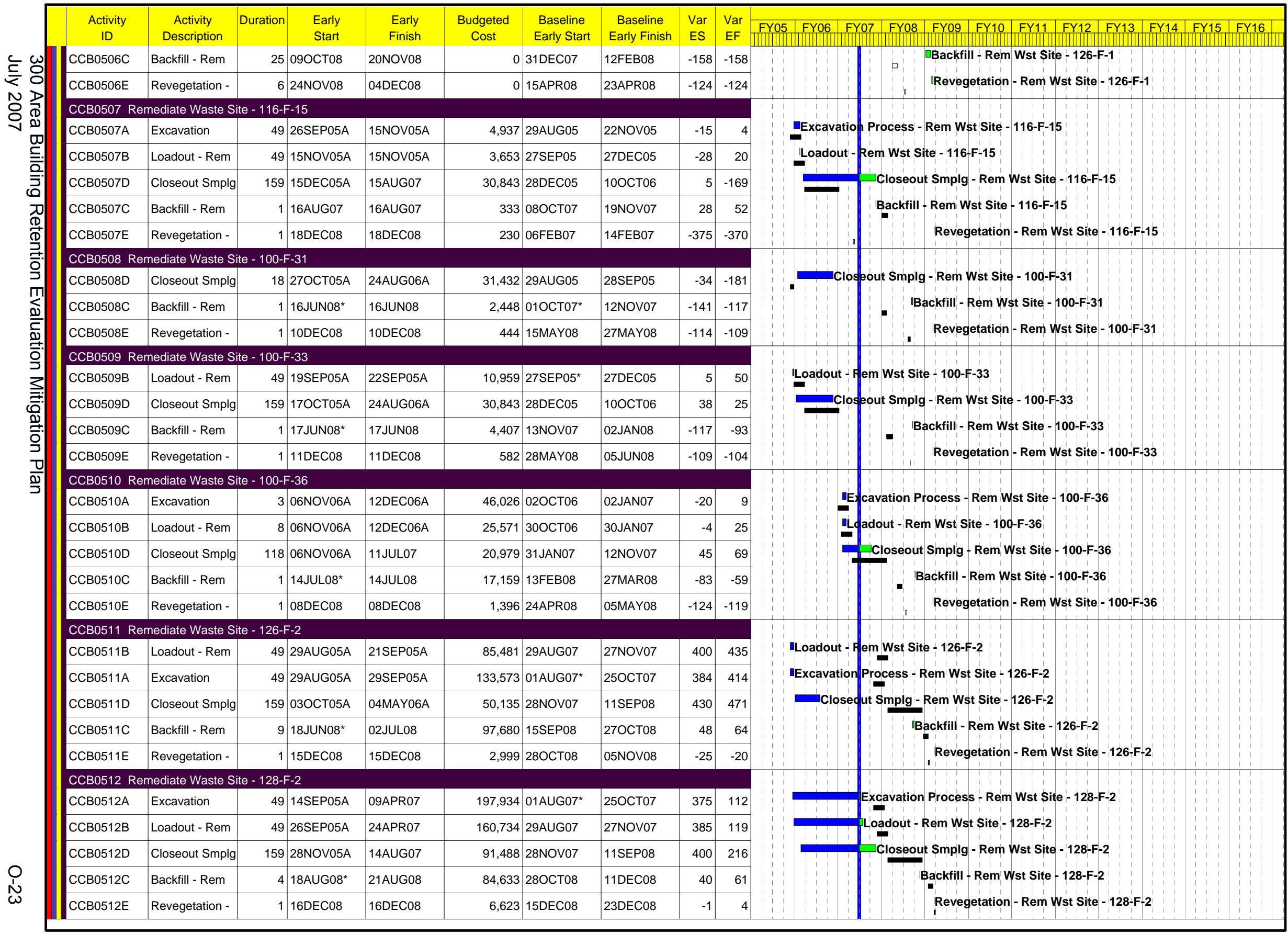




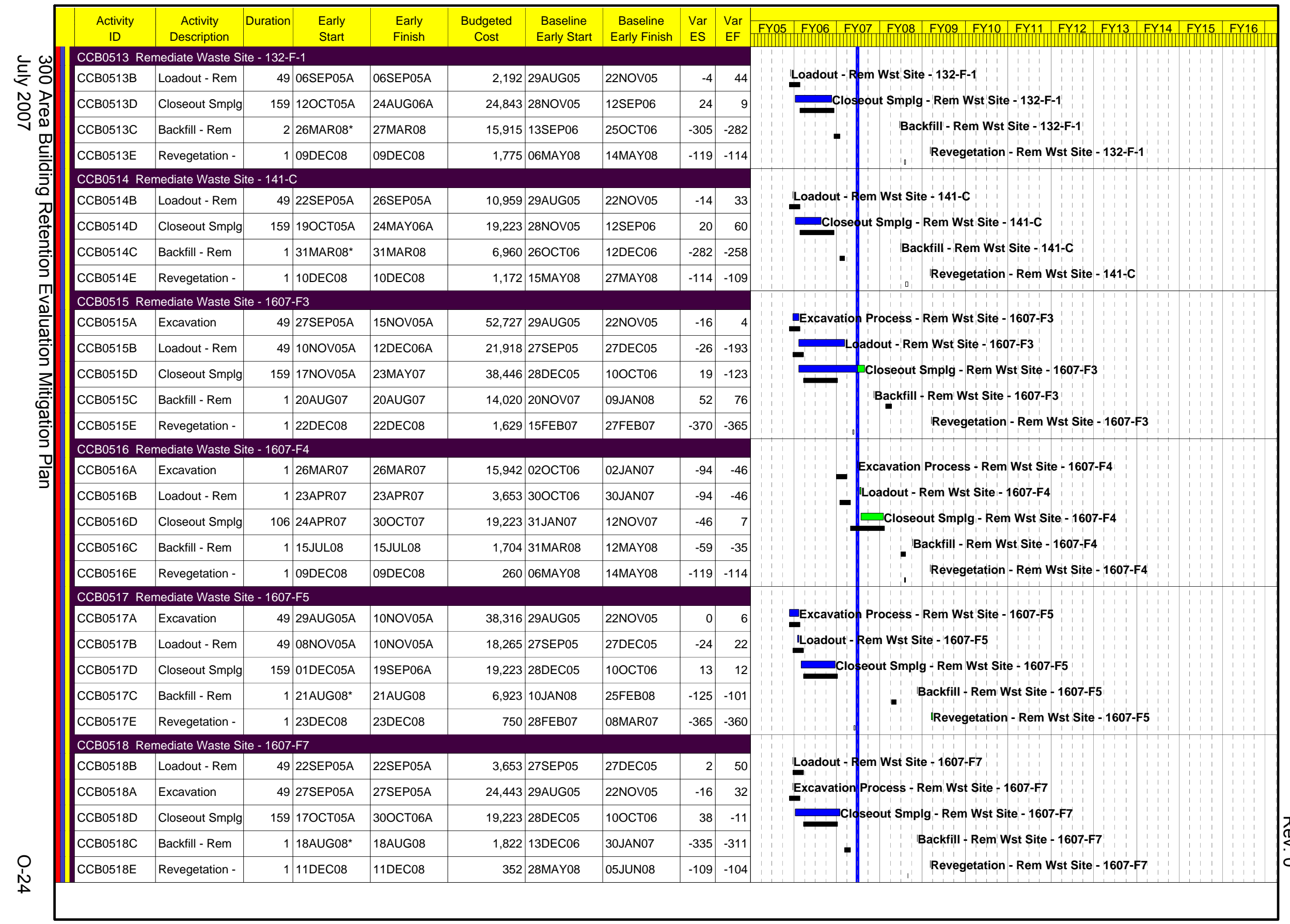




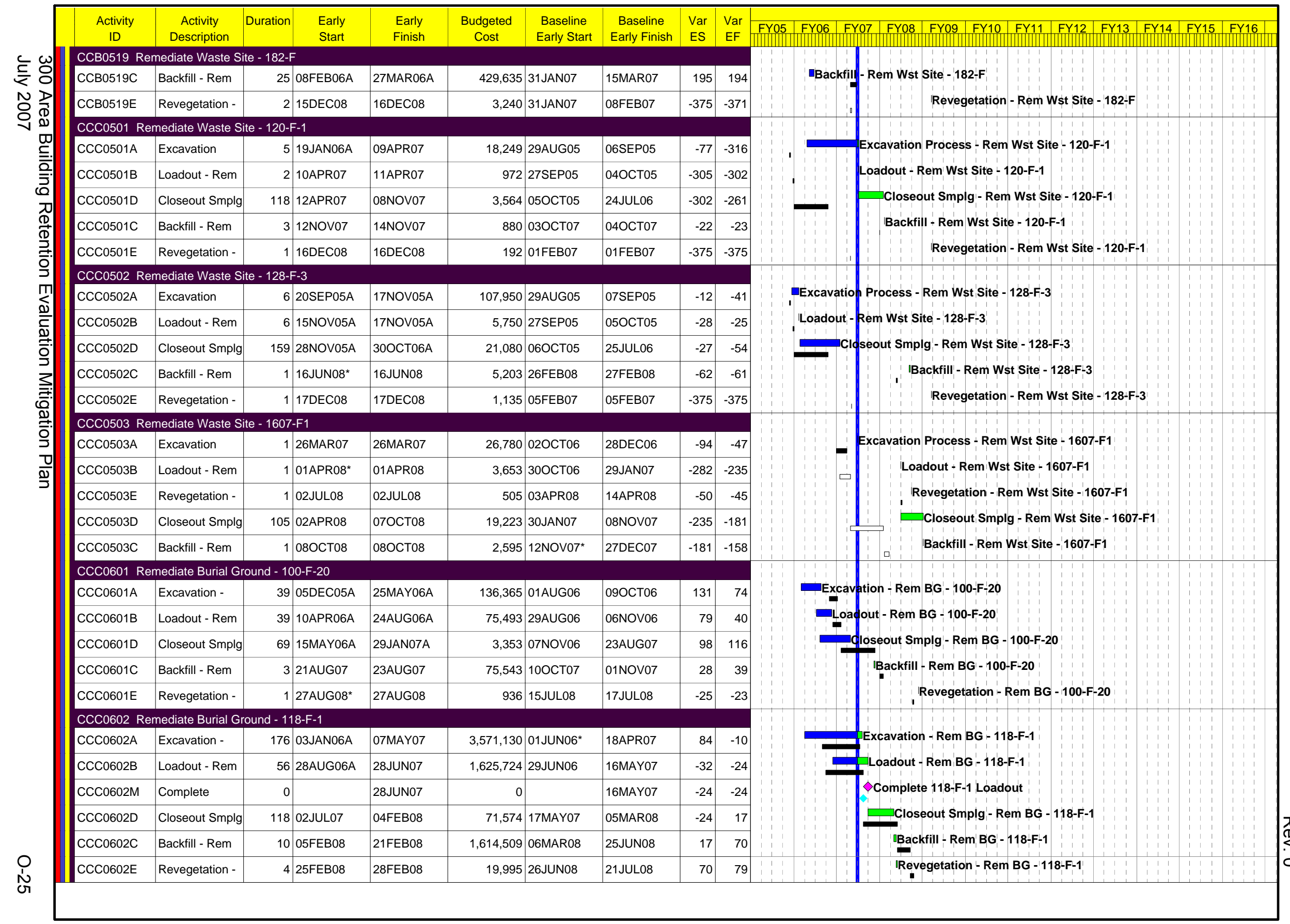




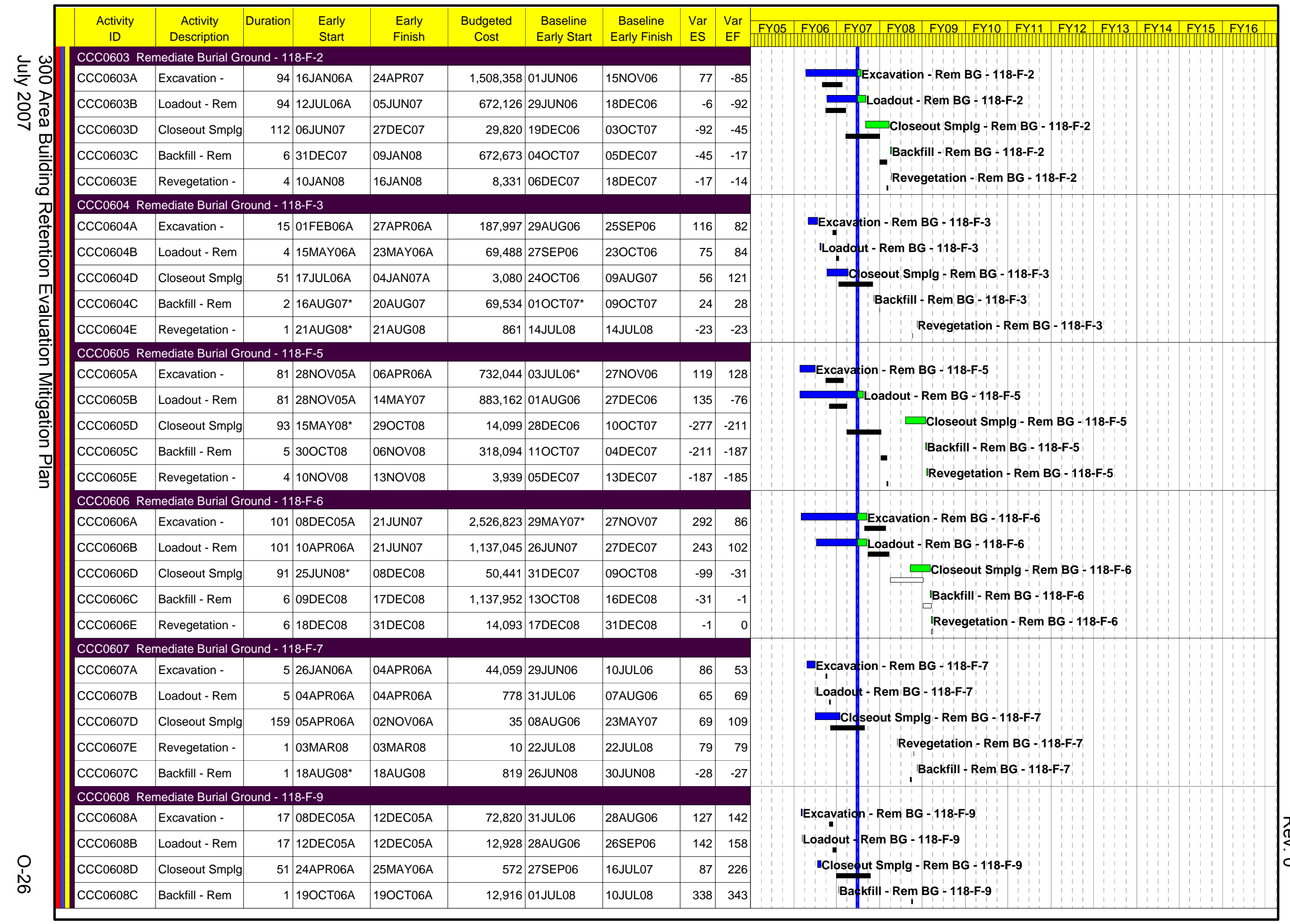




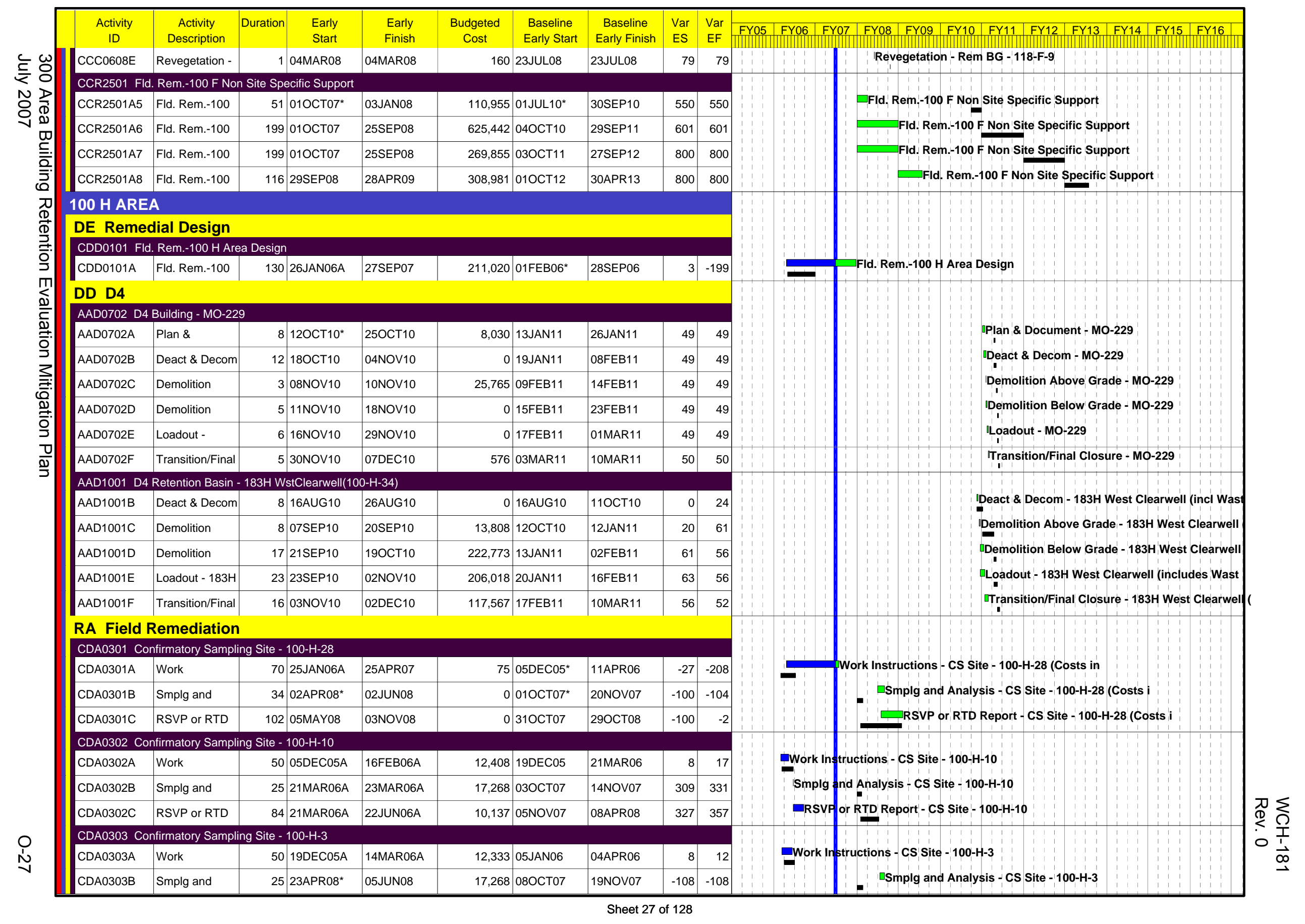




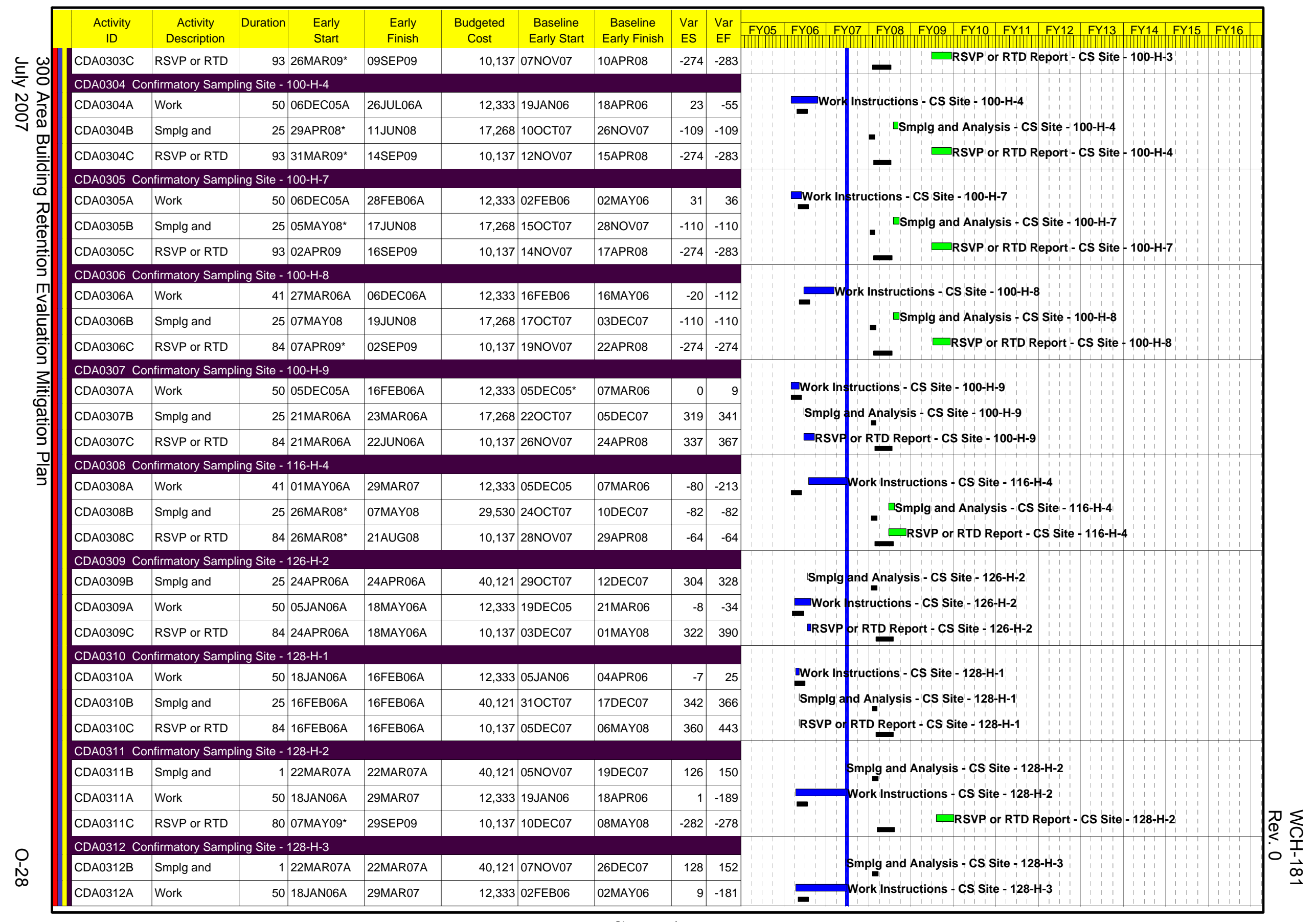

Sheet 28 of 128 


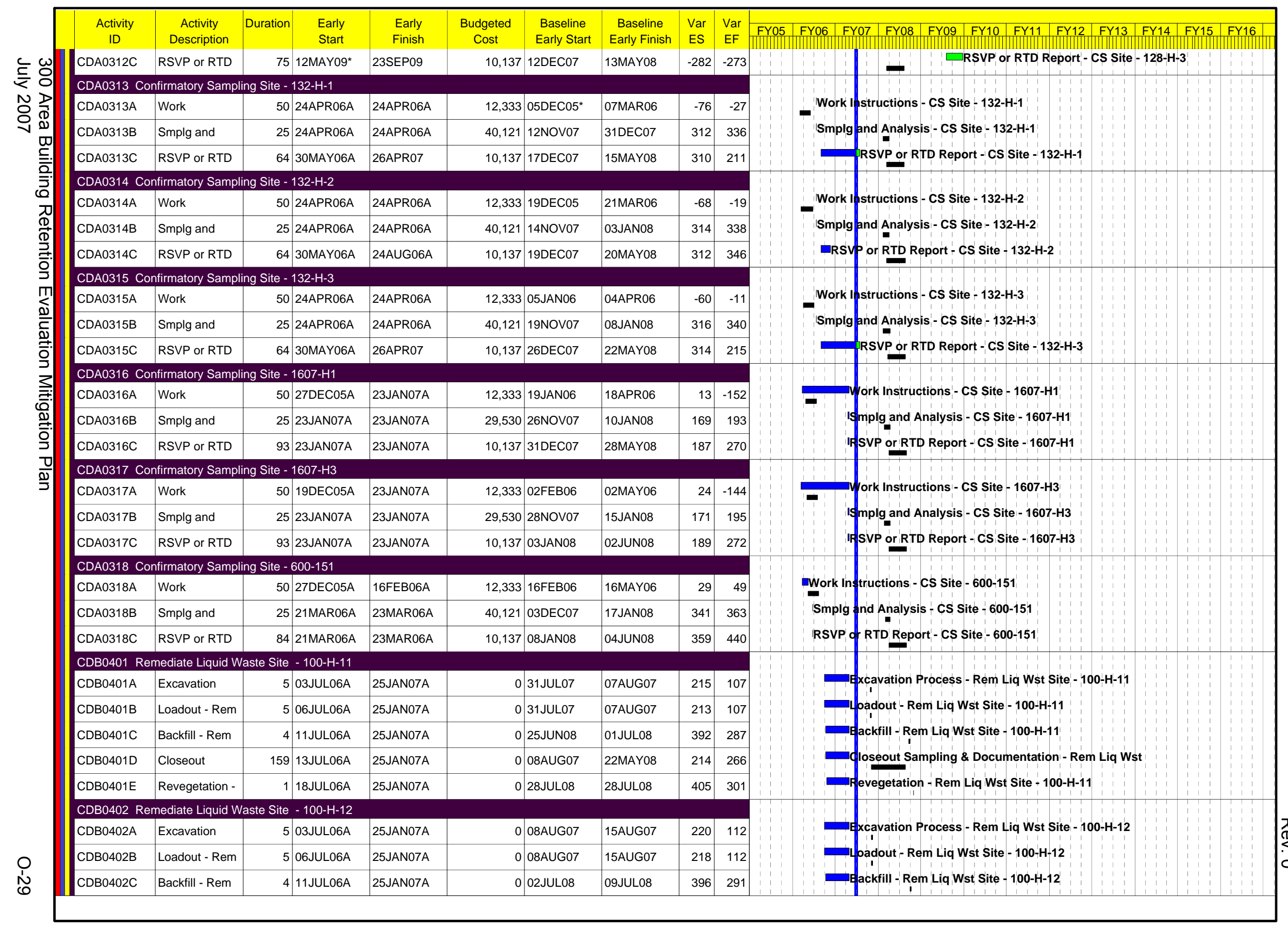




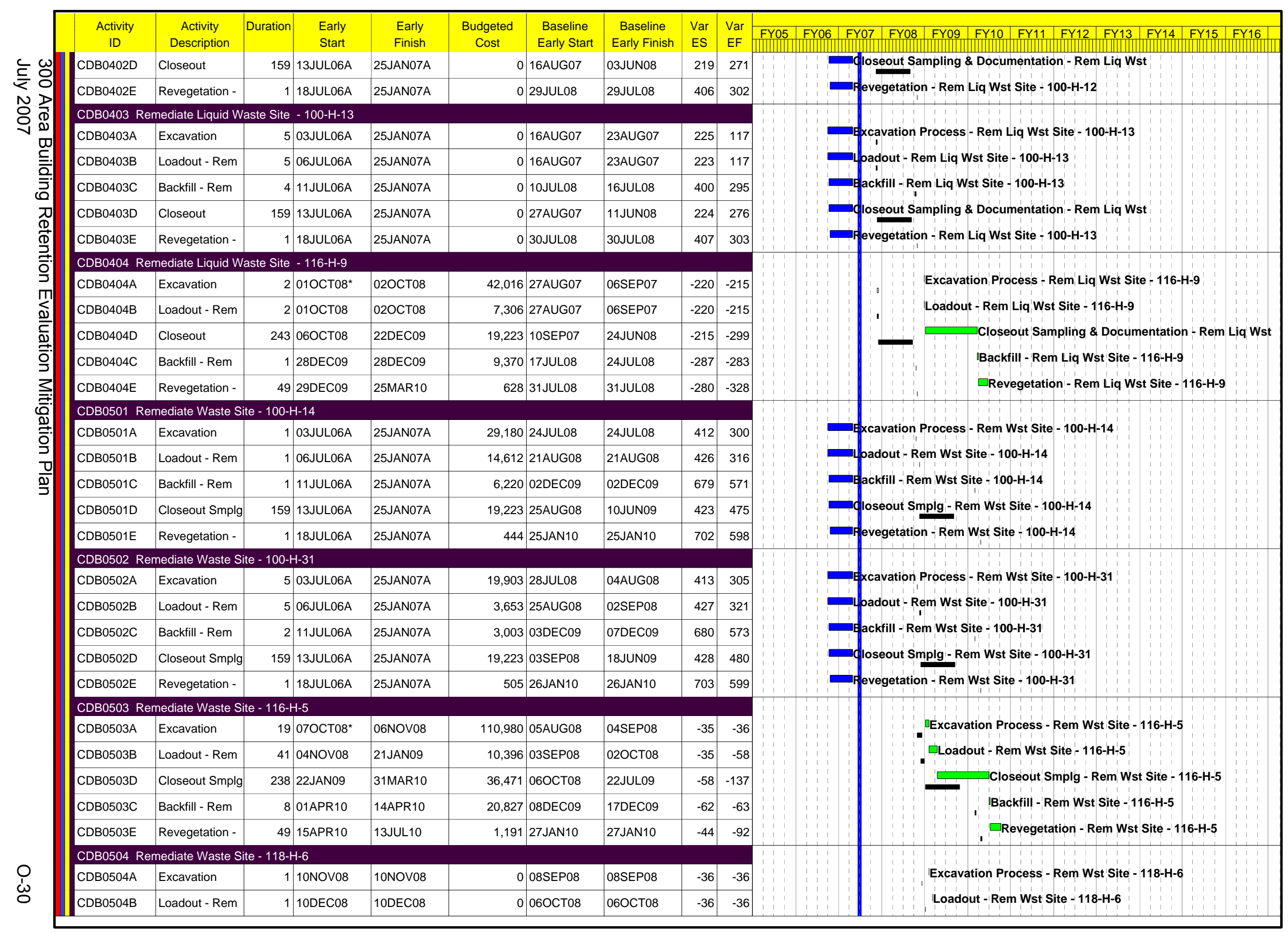




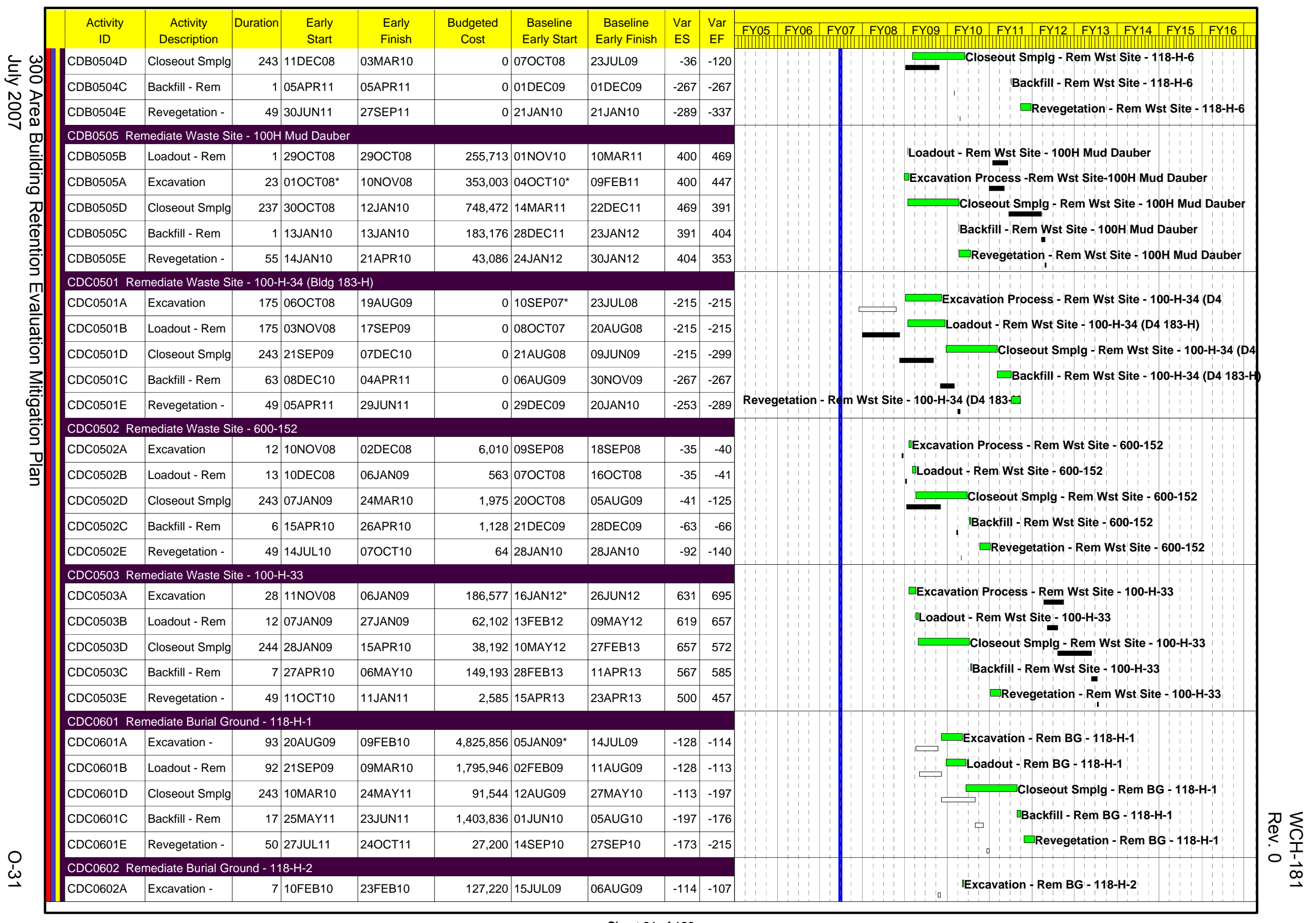




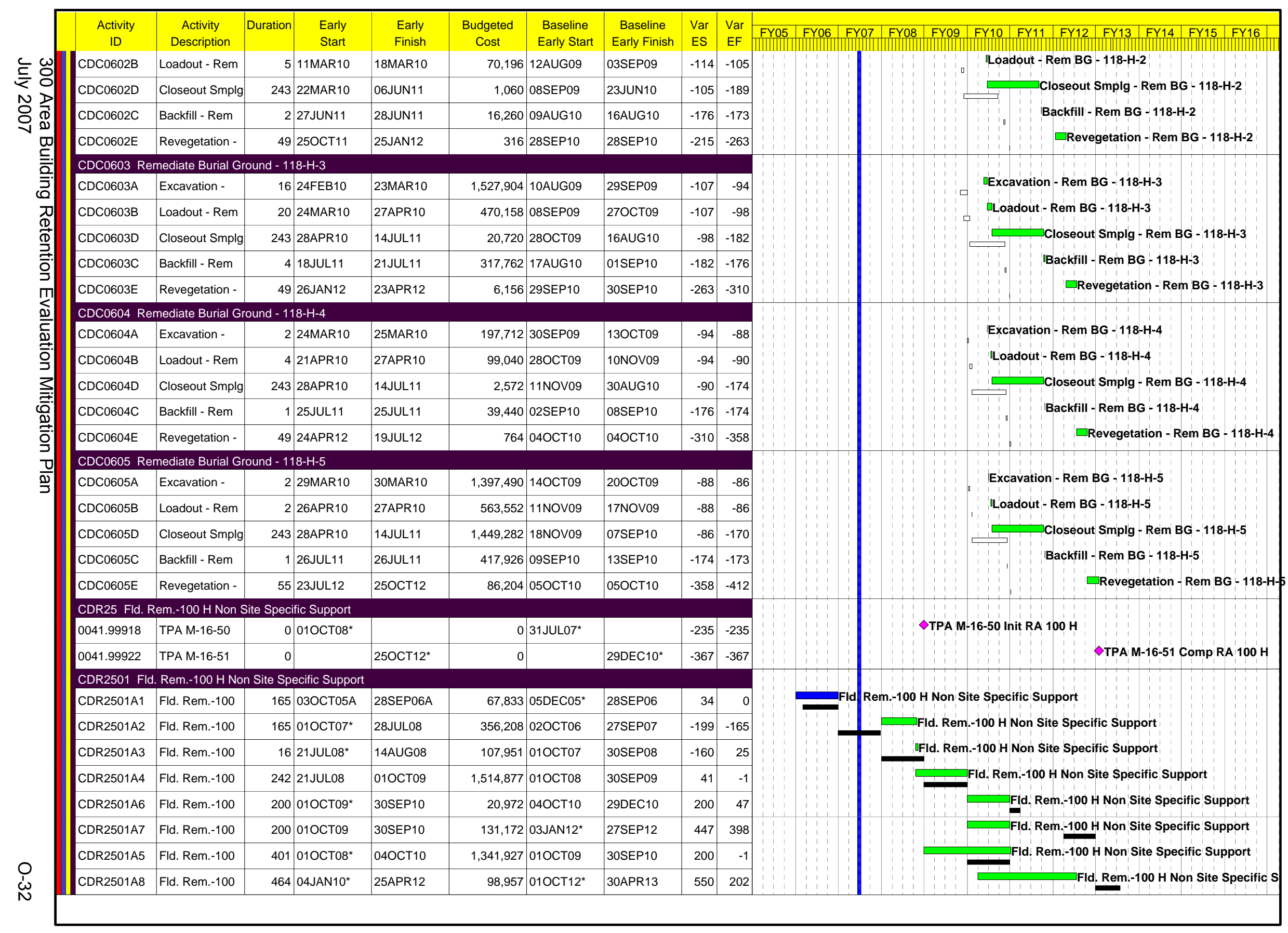




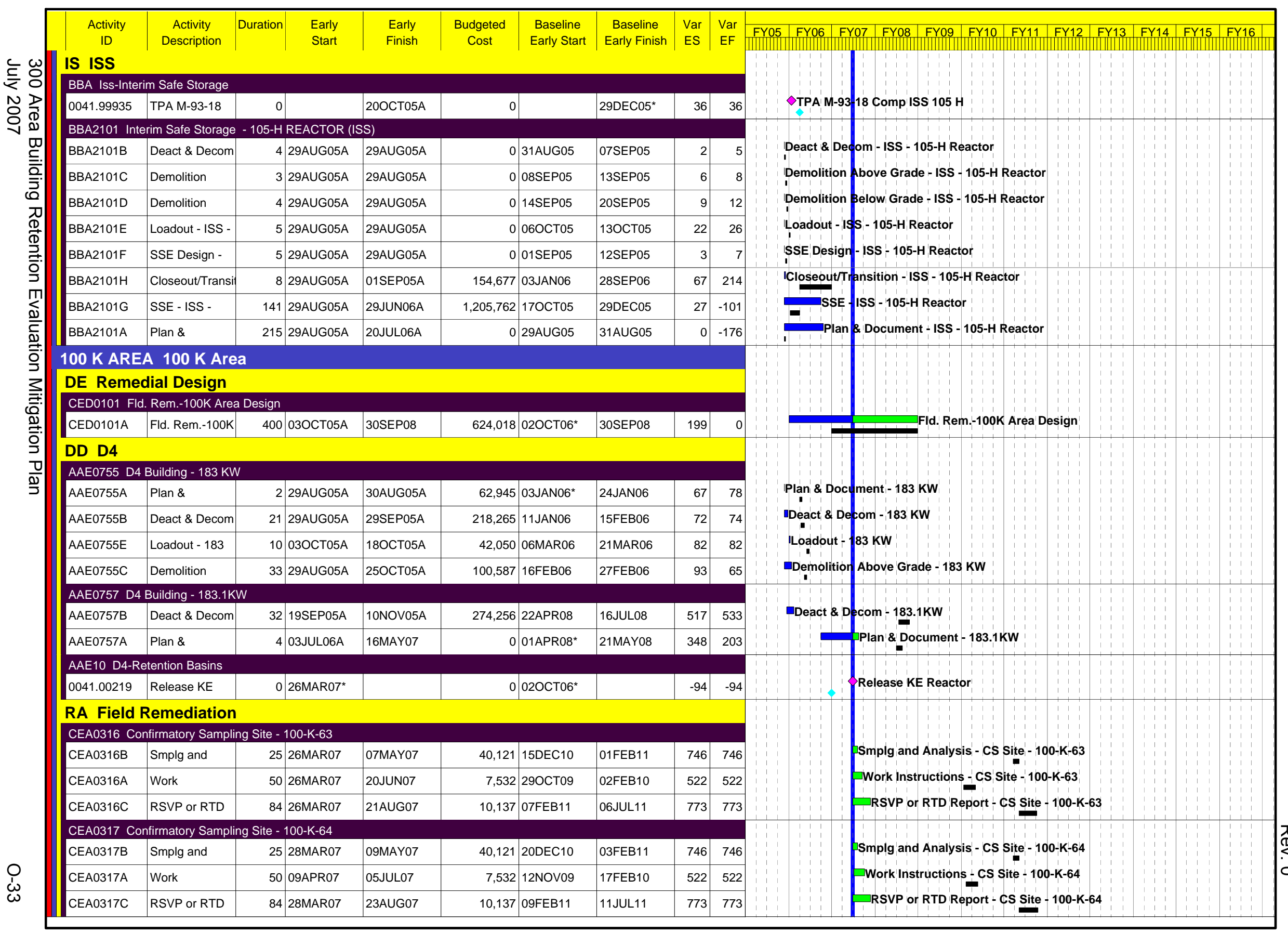




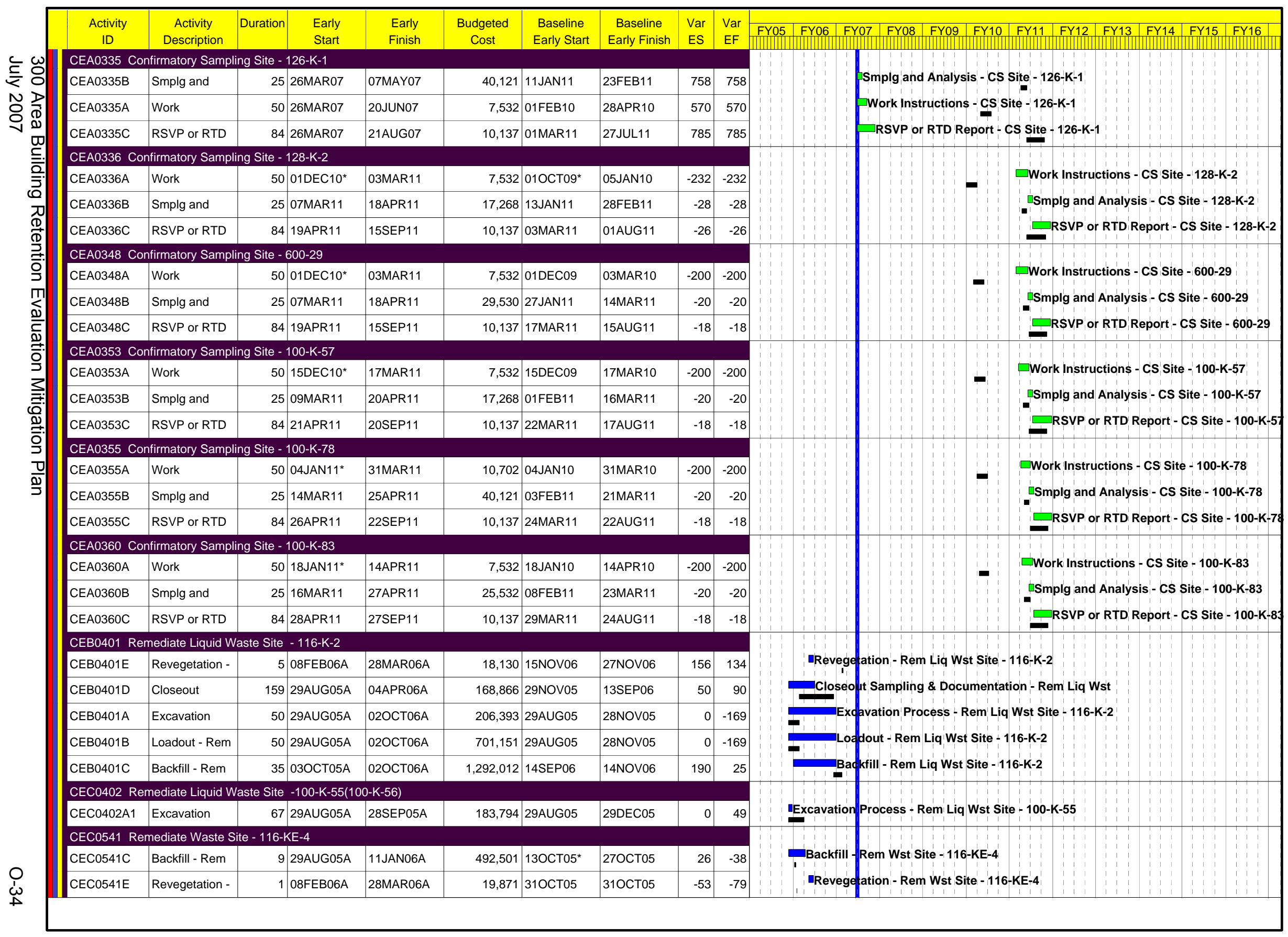




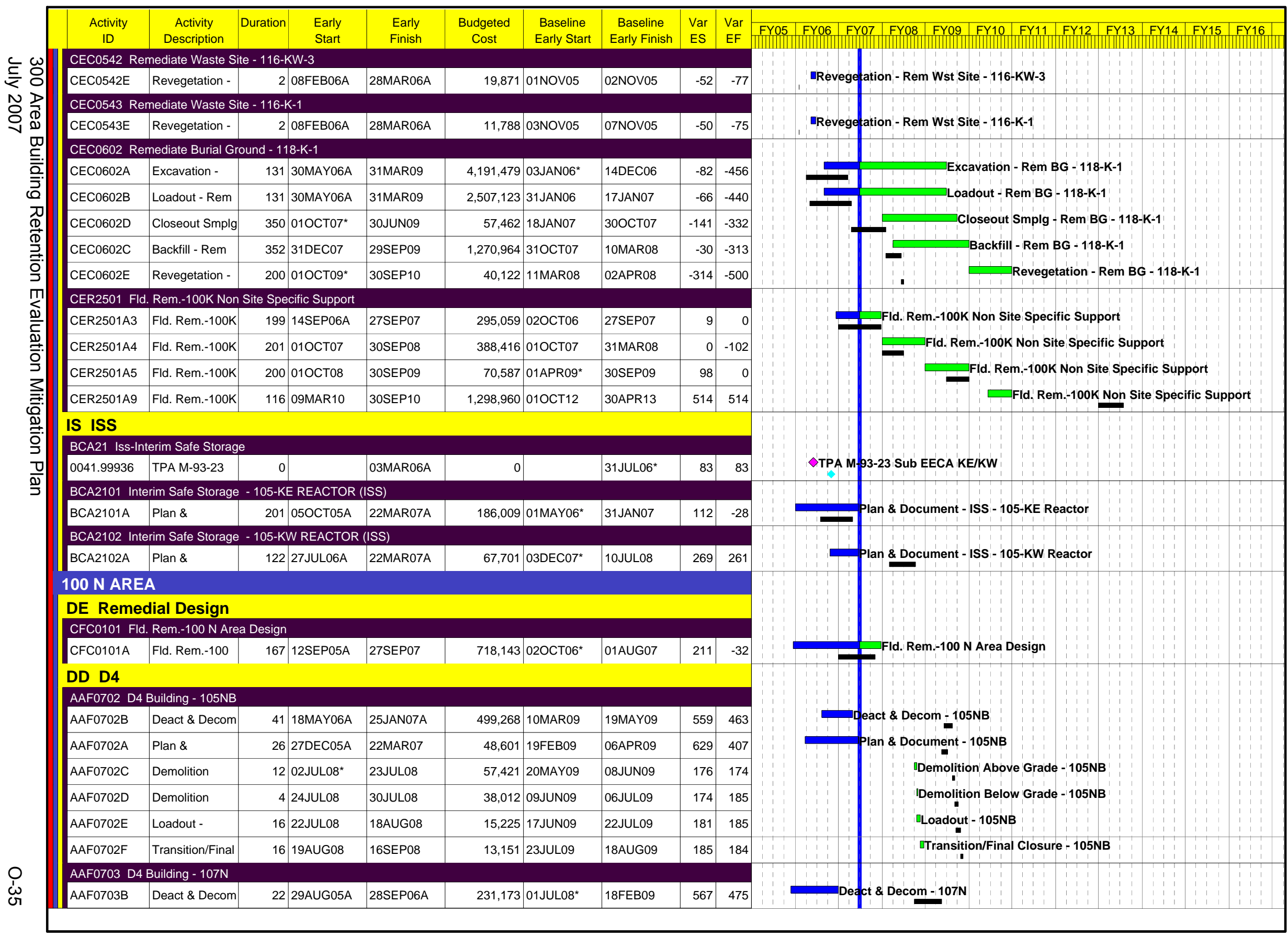




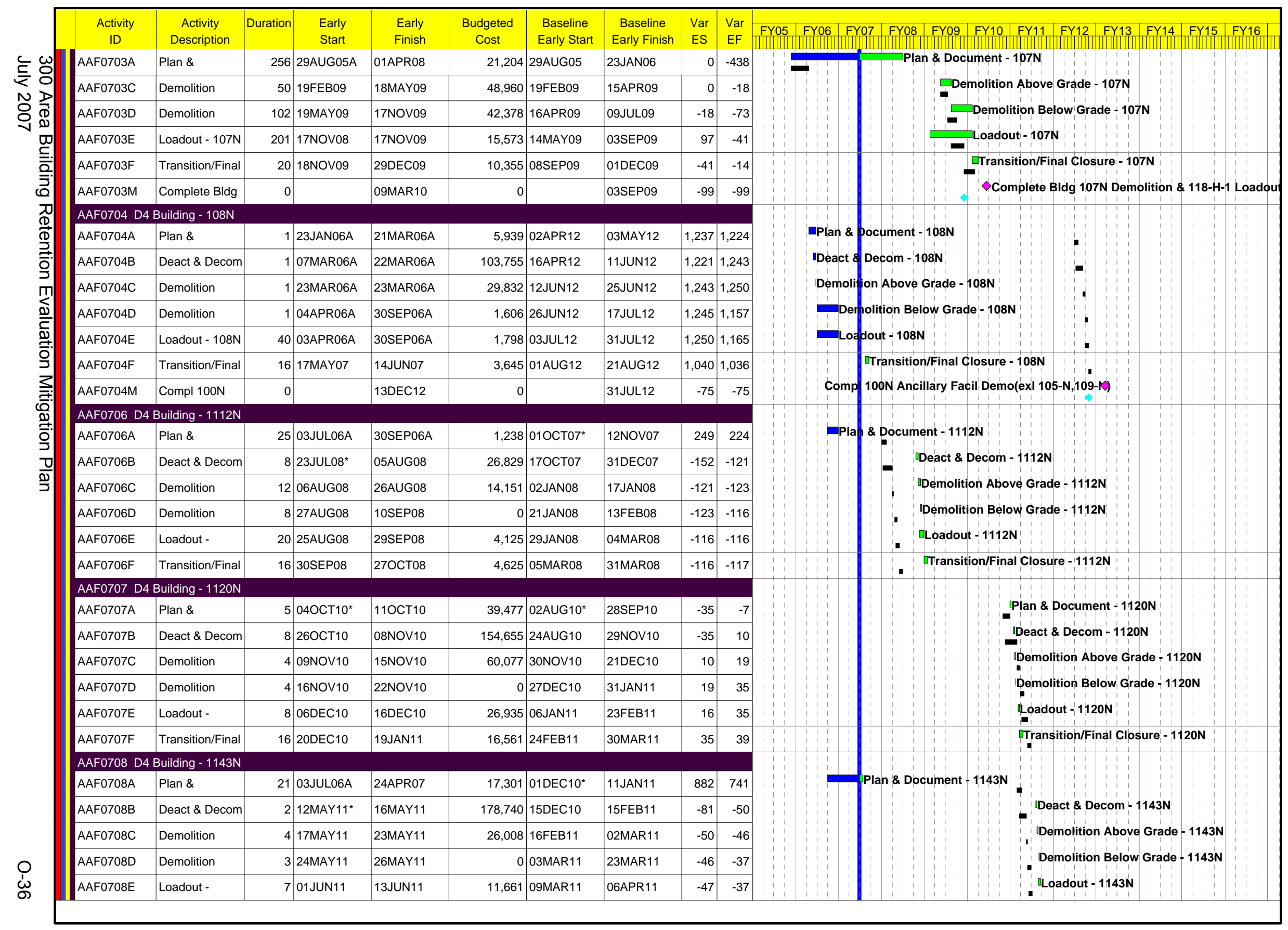




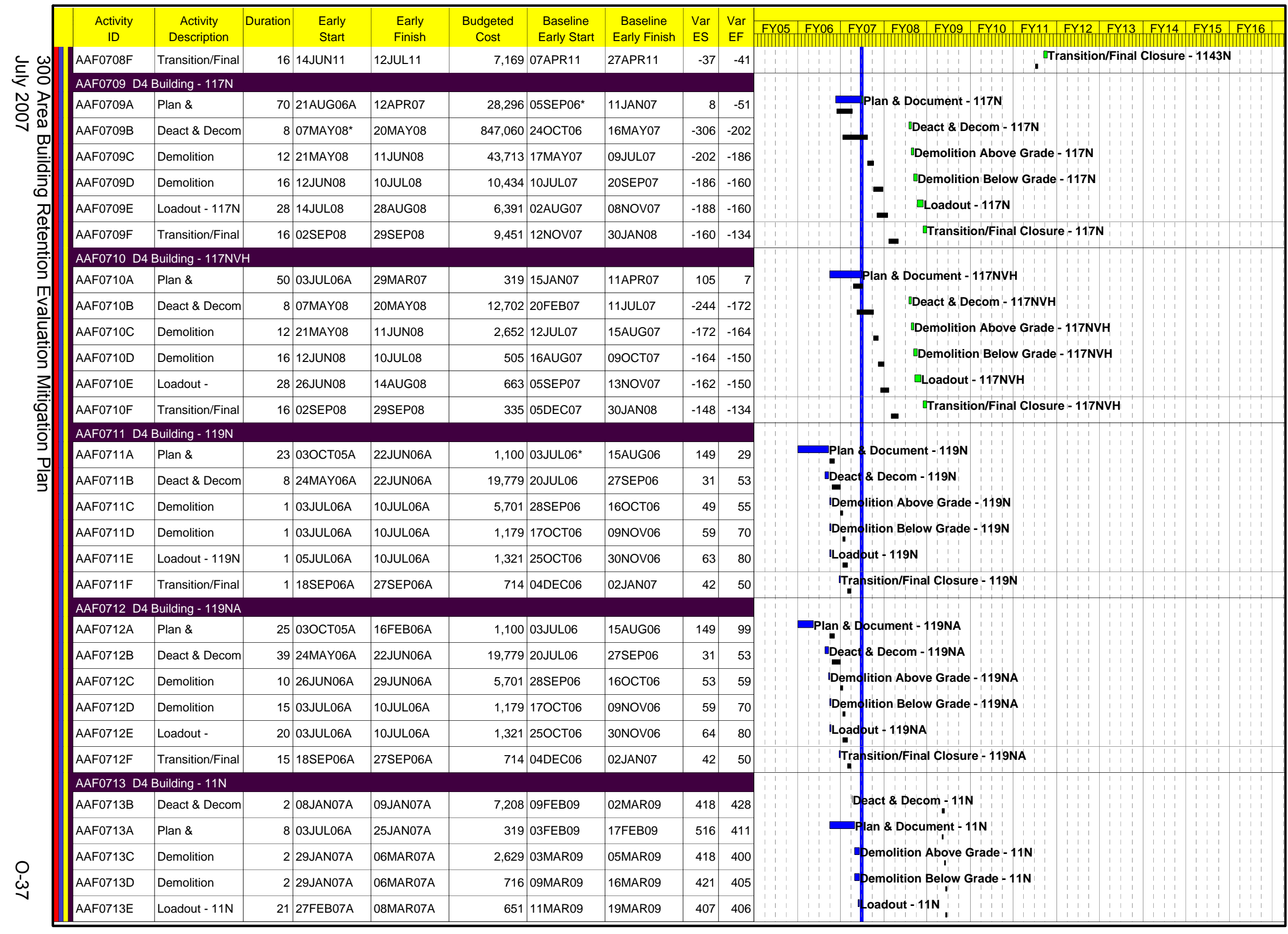




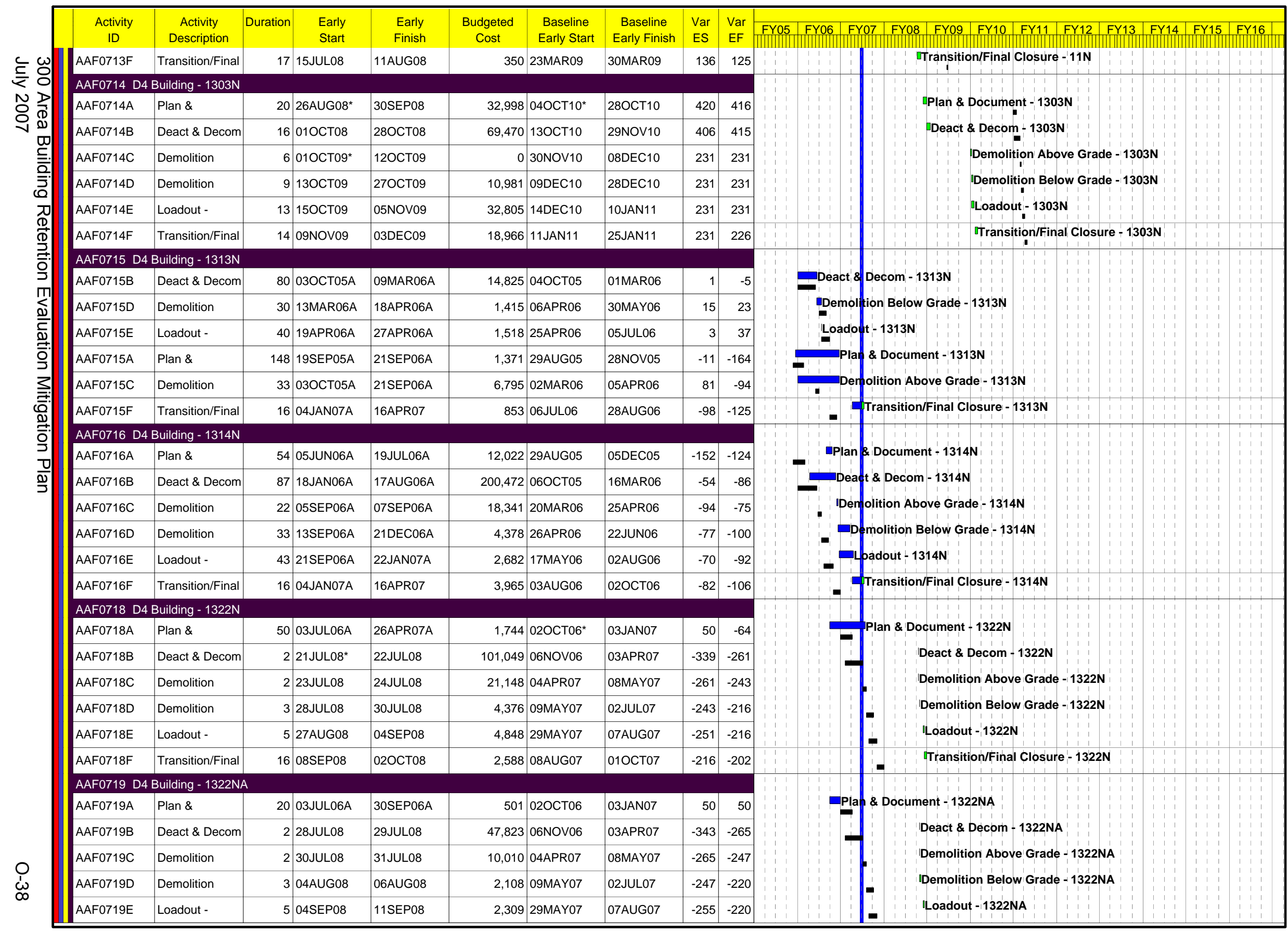




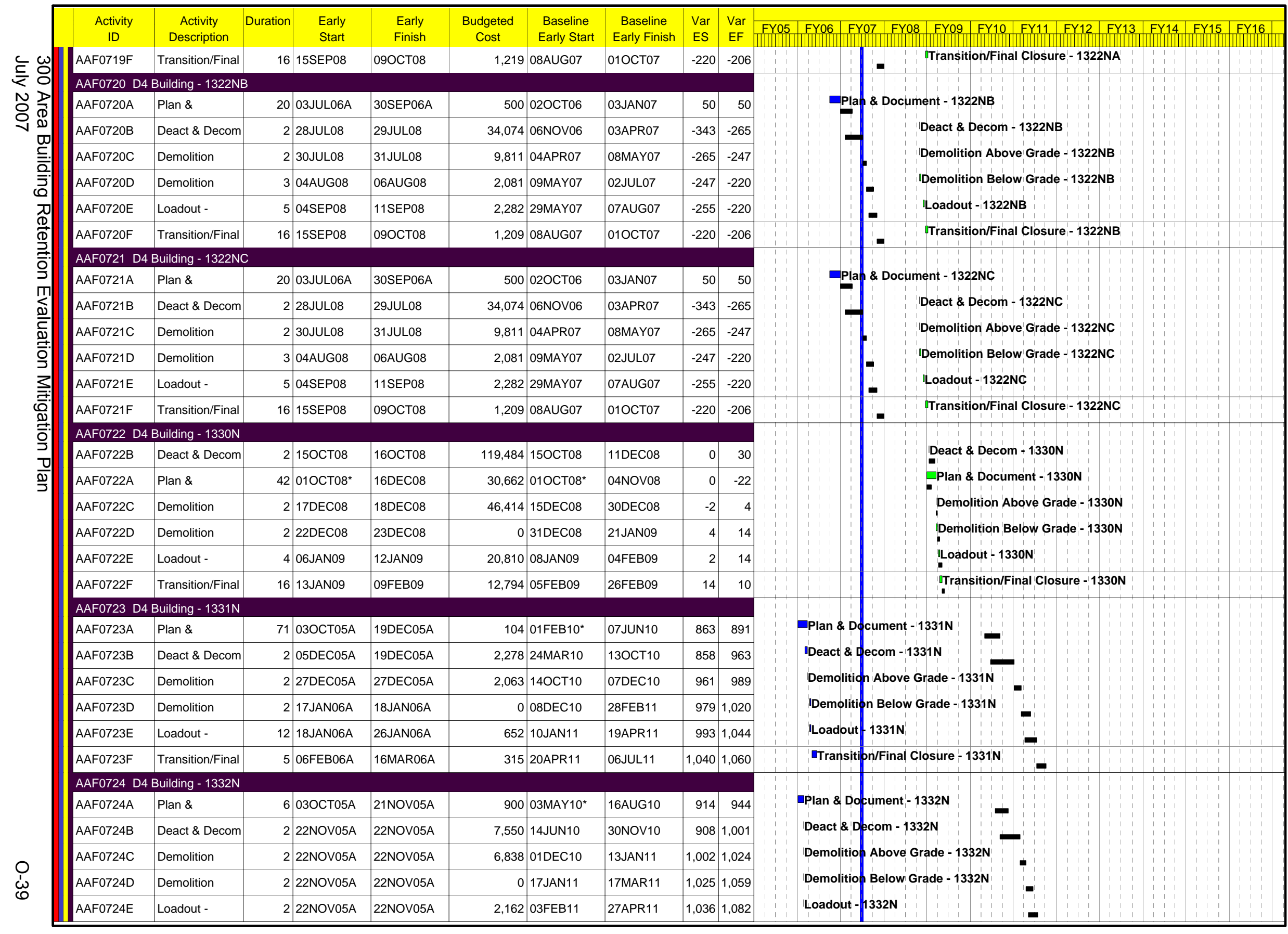




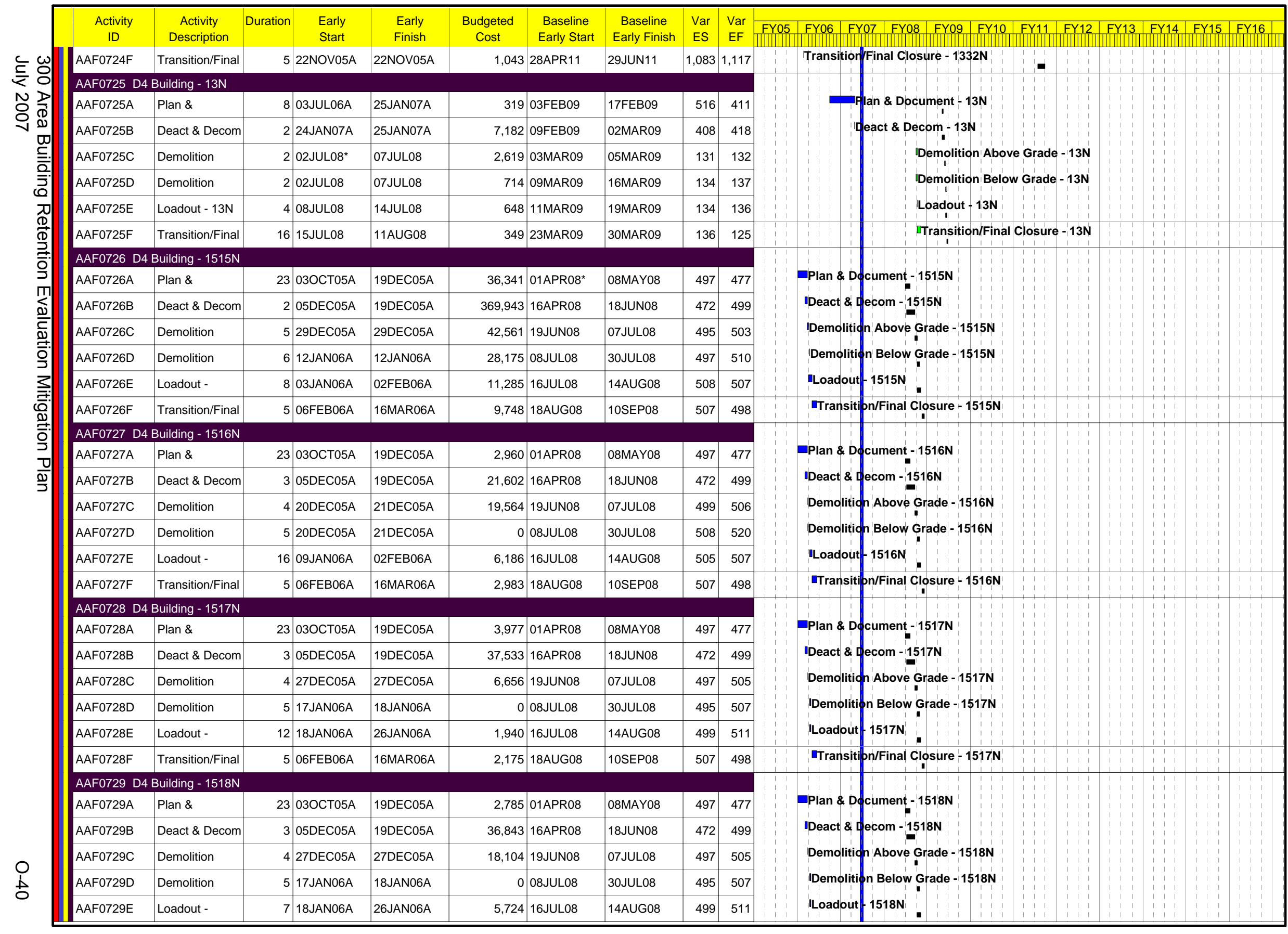




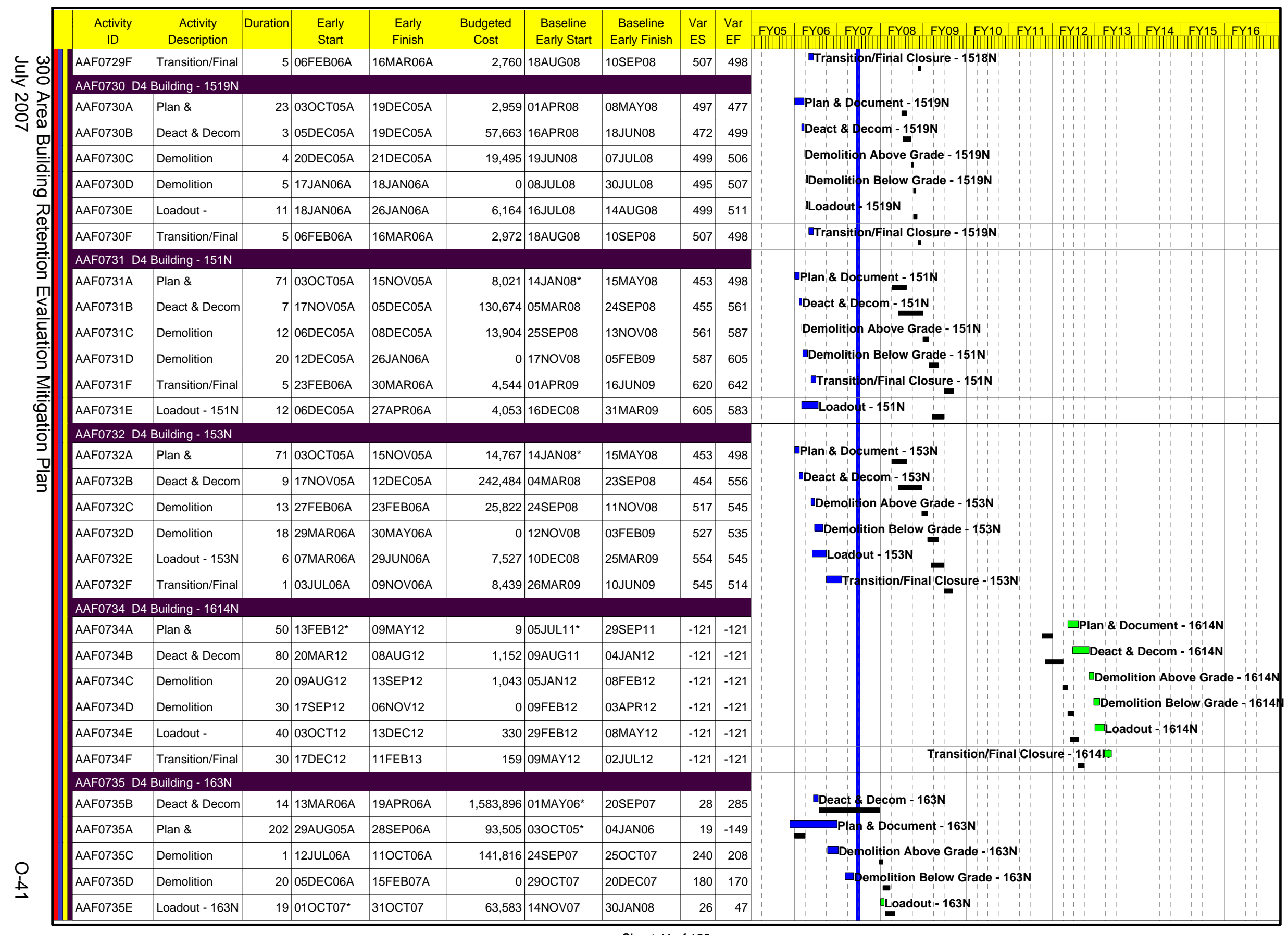




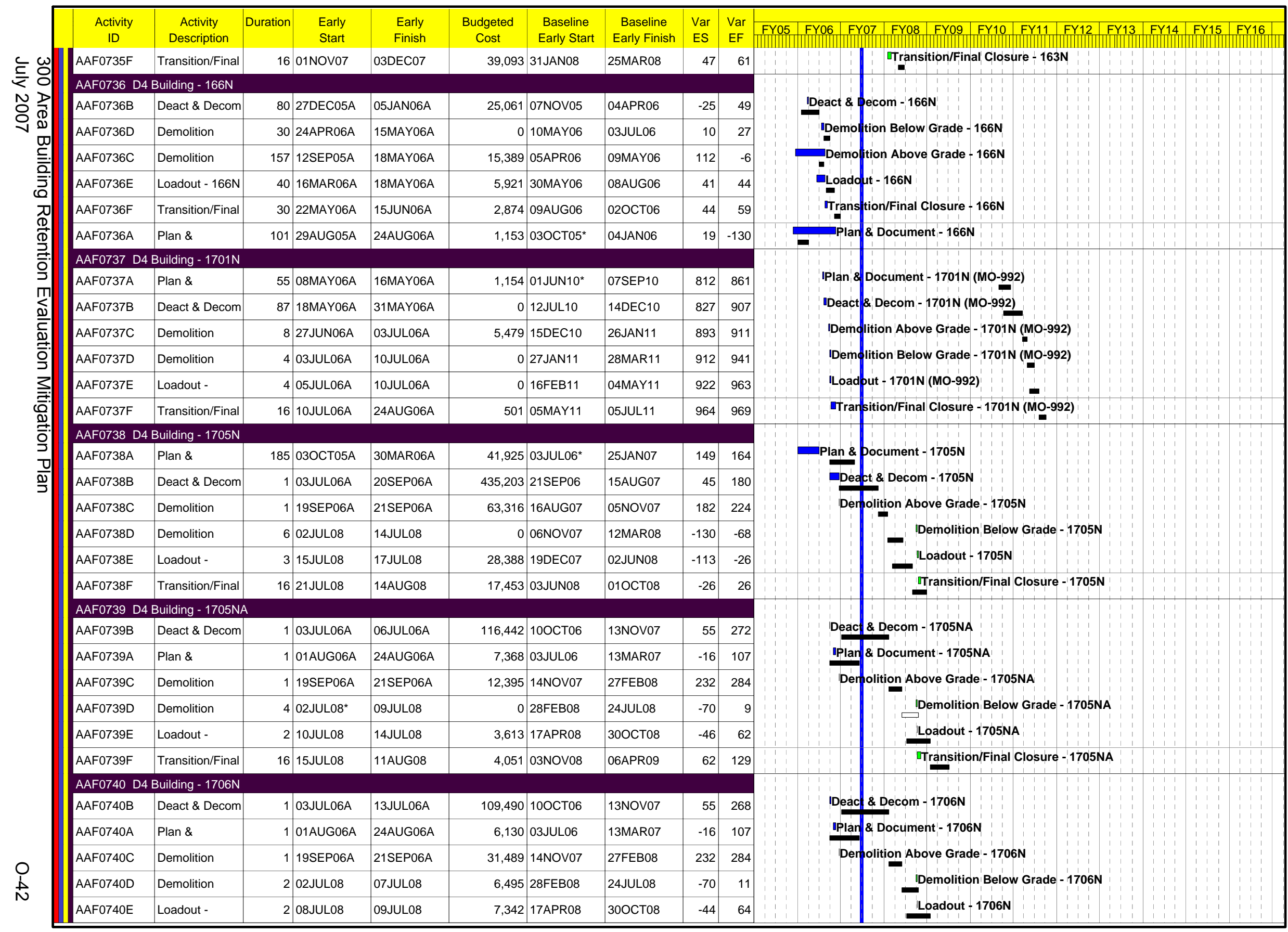




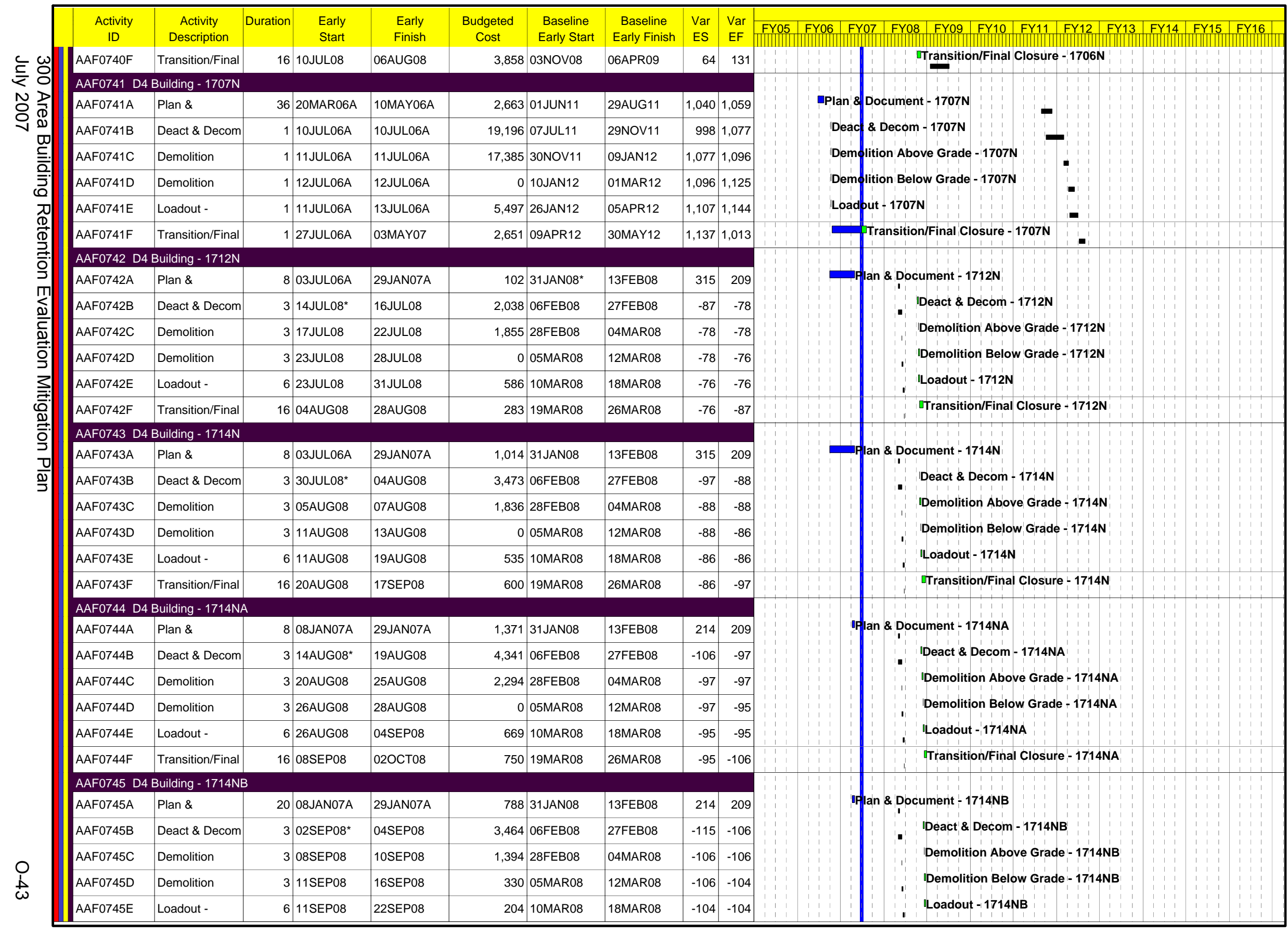




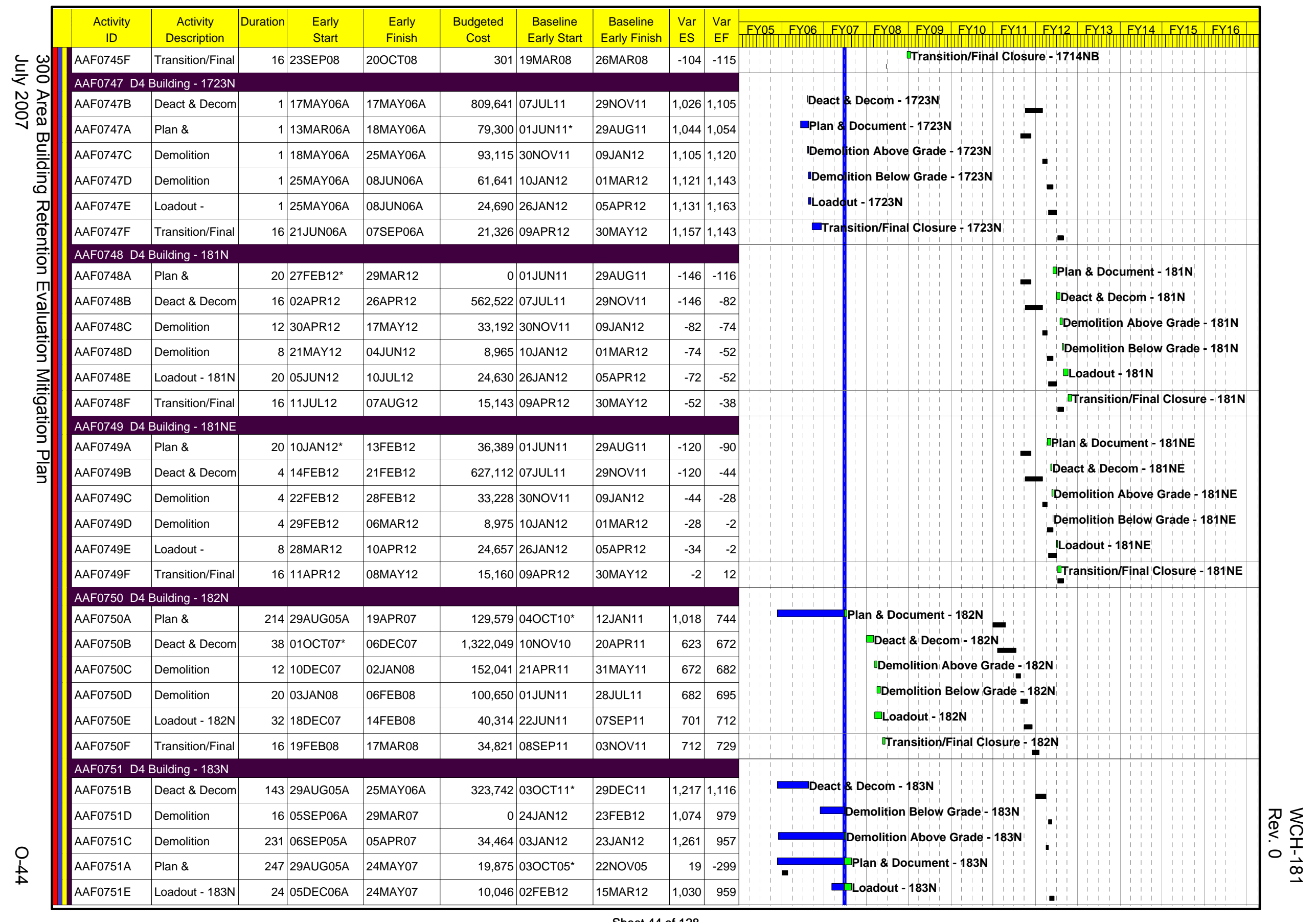

Sheet 44 of 128 


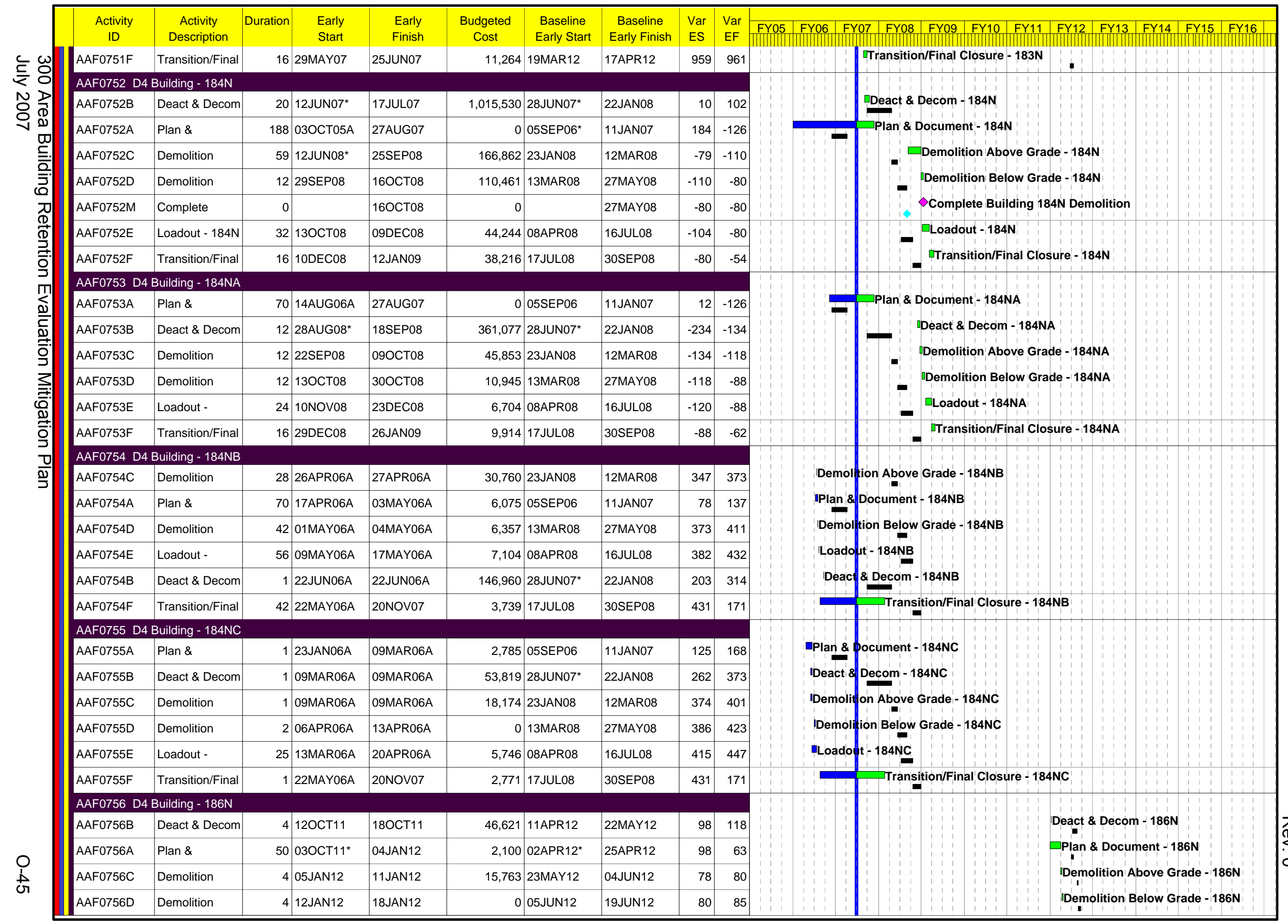




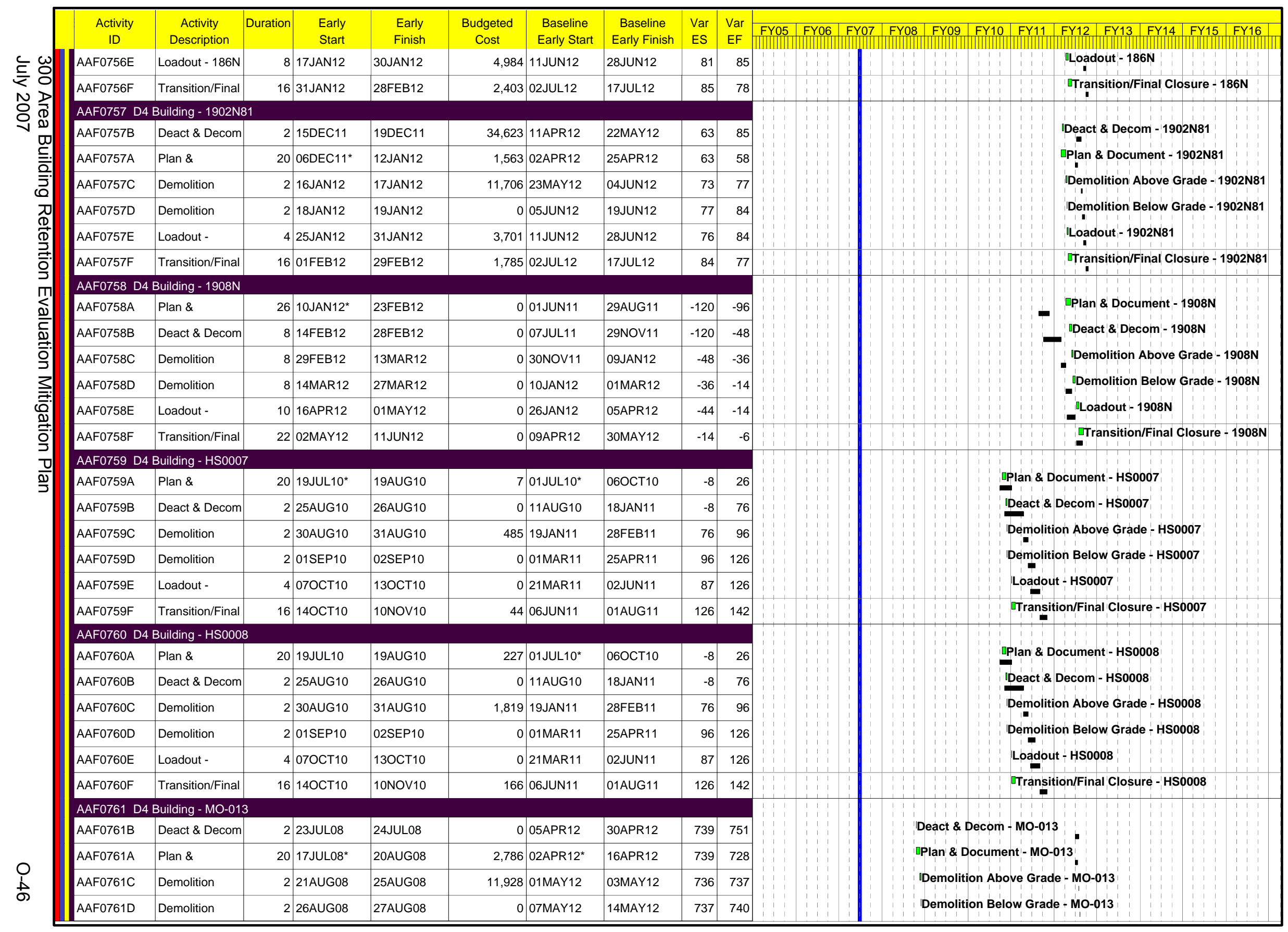




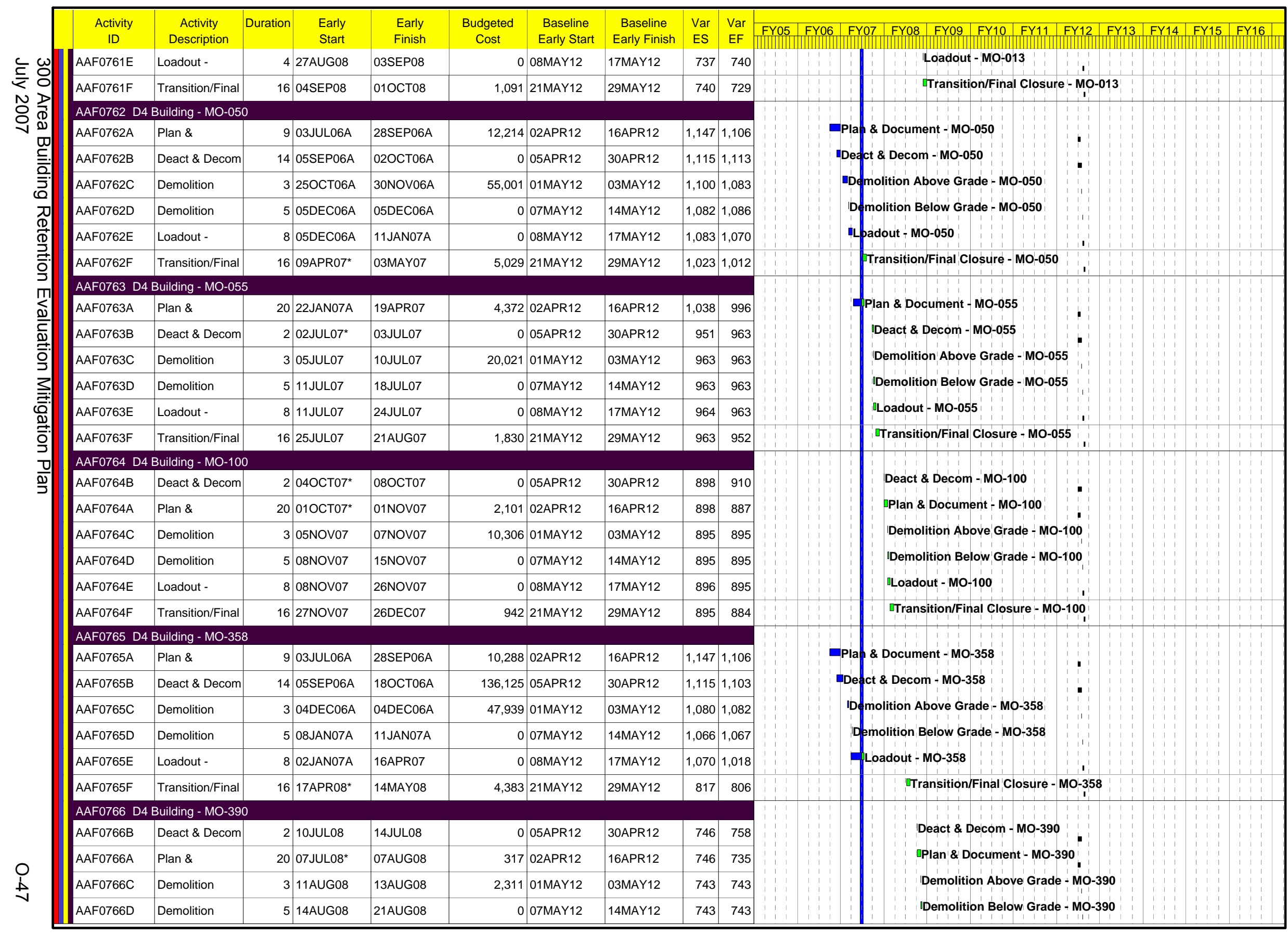




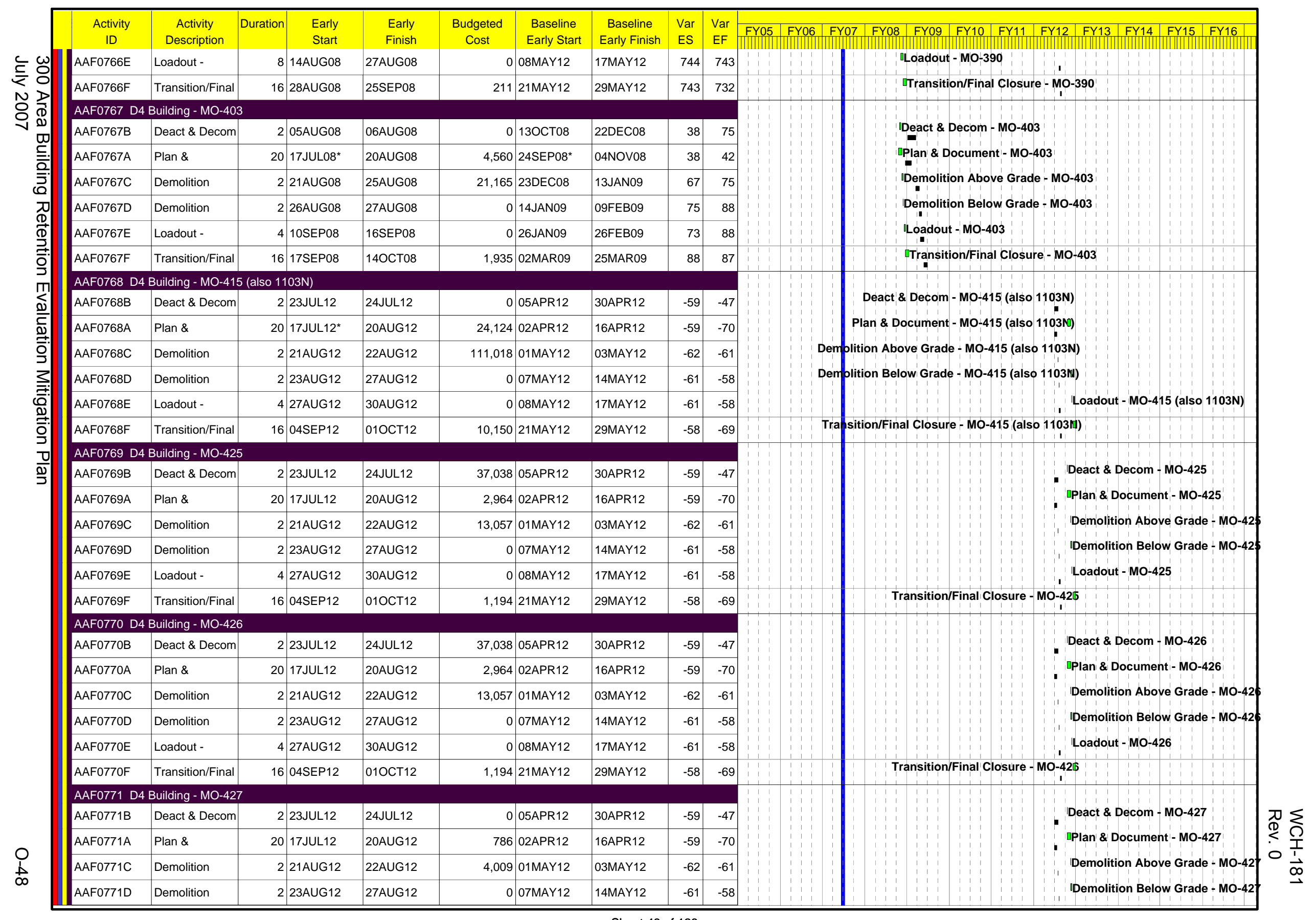

Sheet 48 of 128 


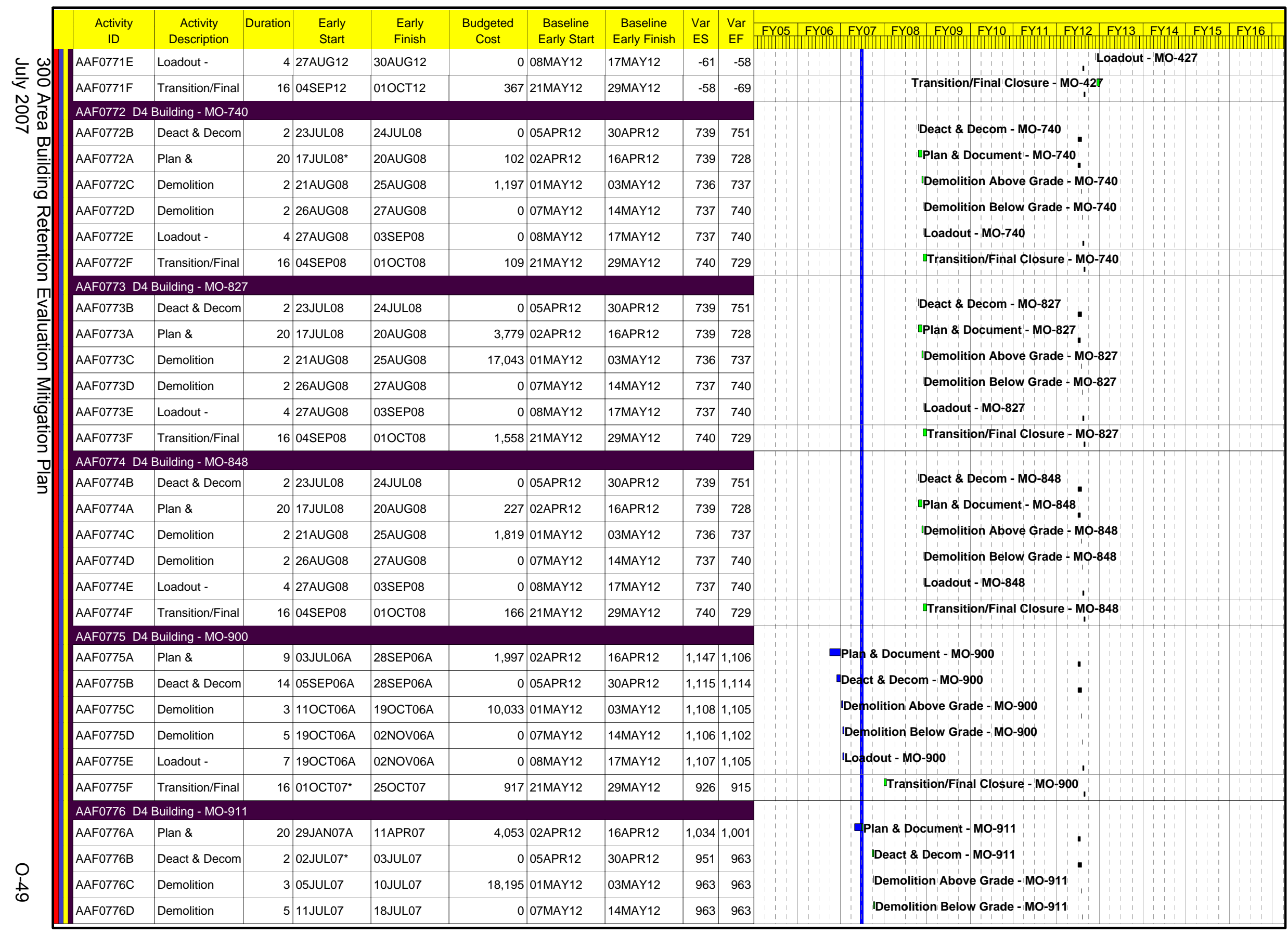




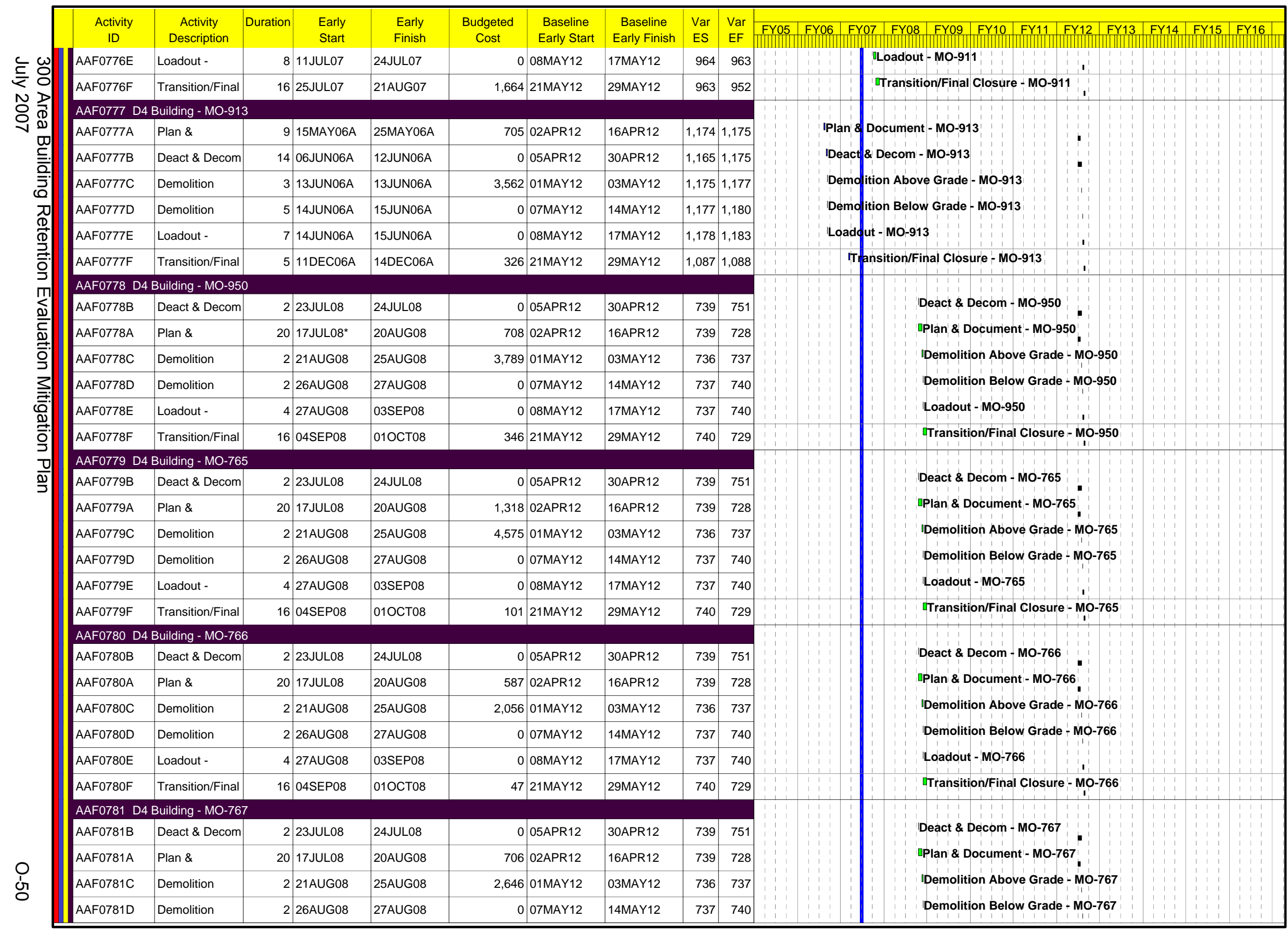




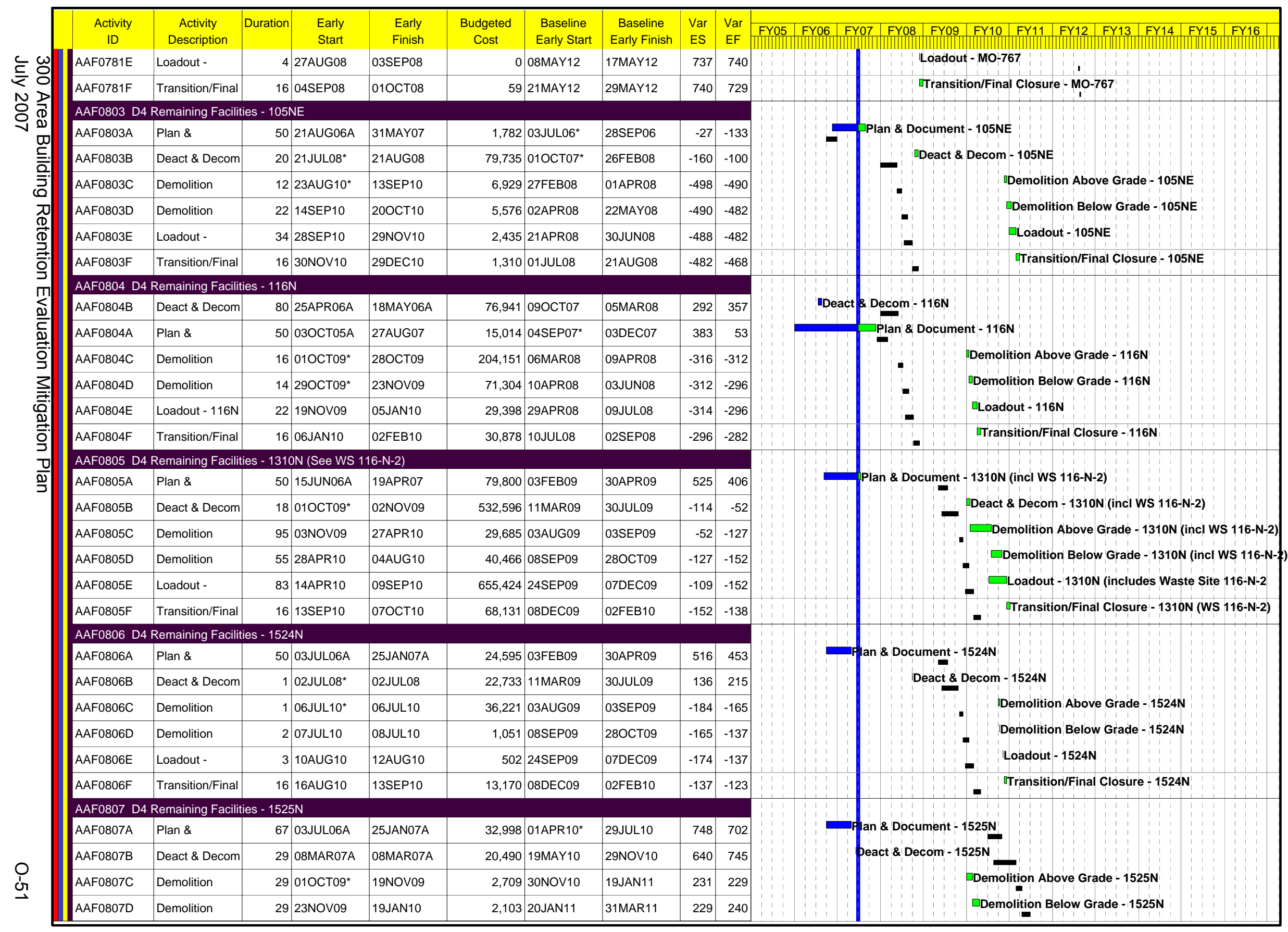




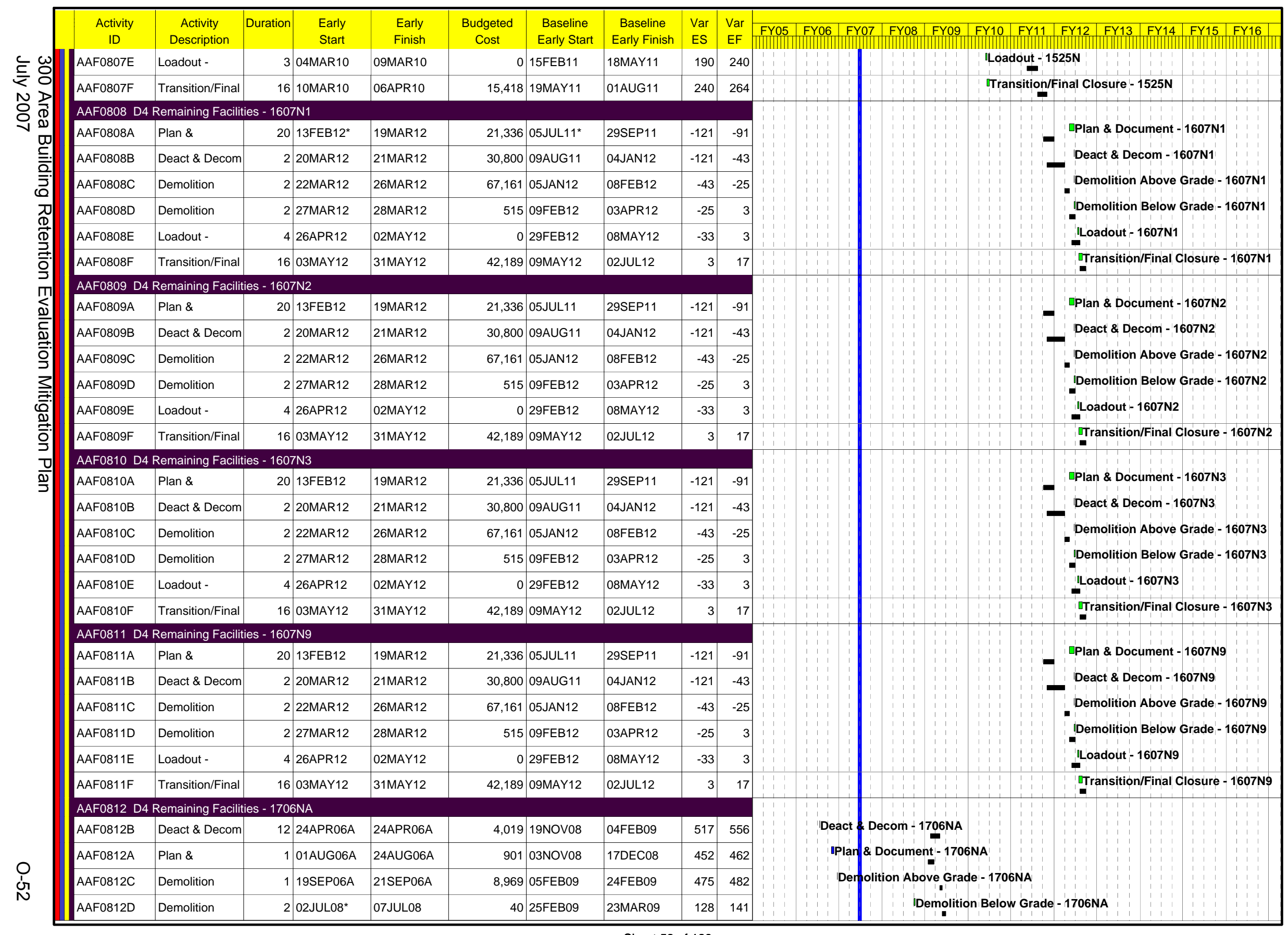




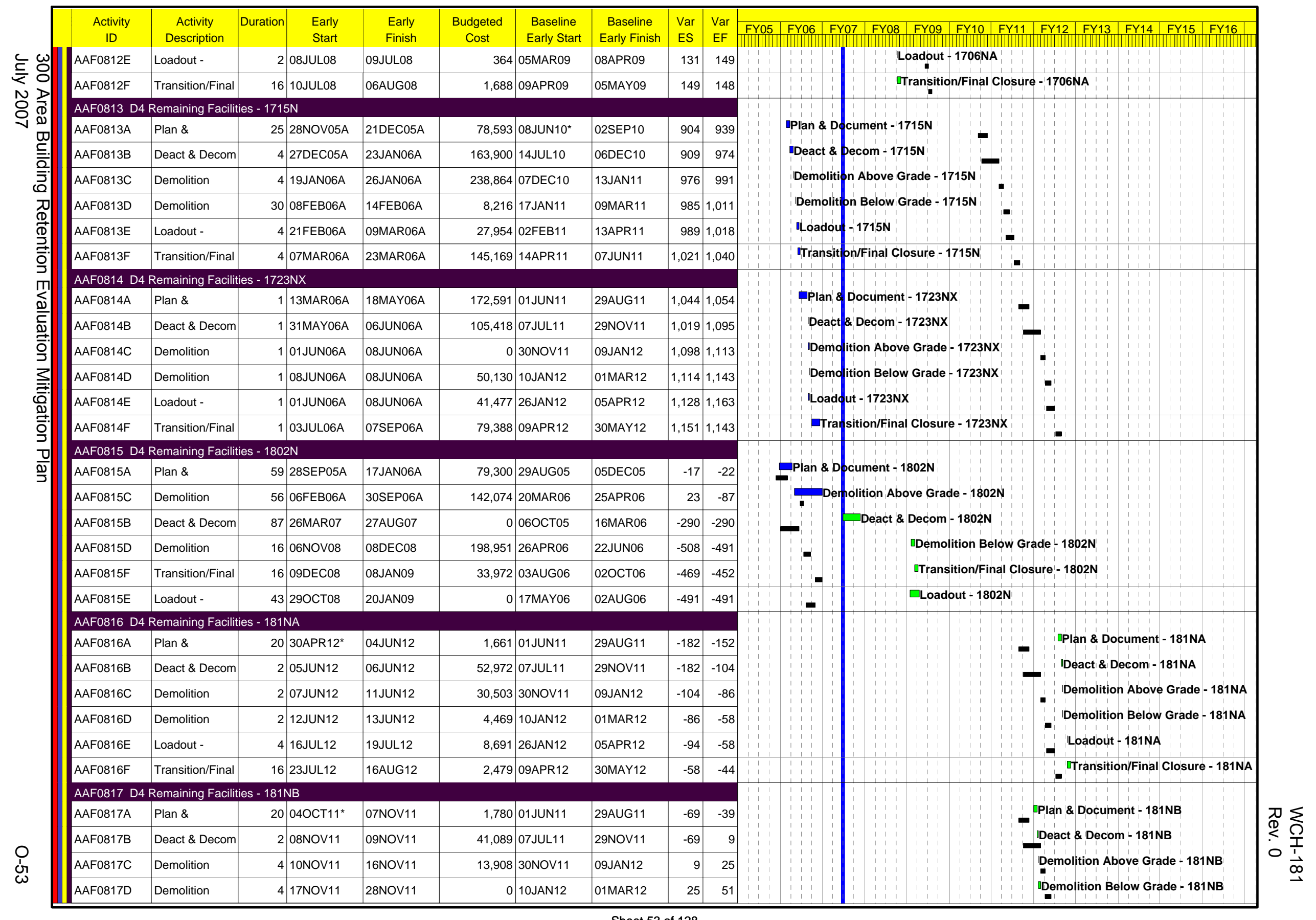




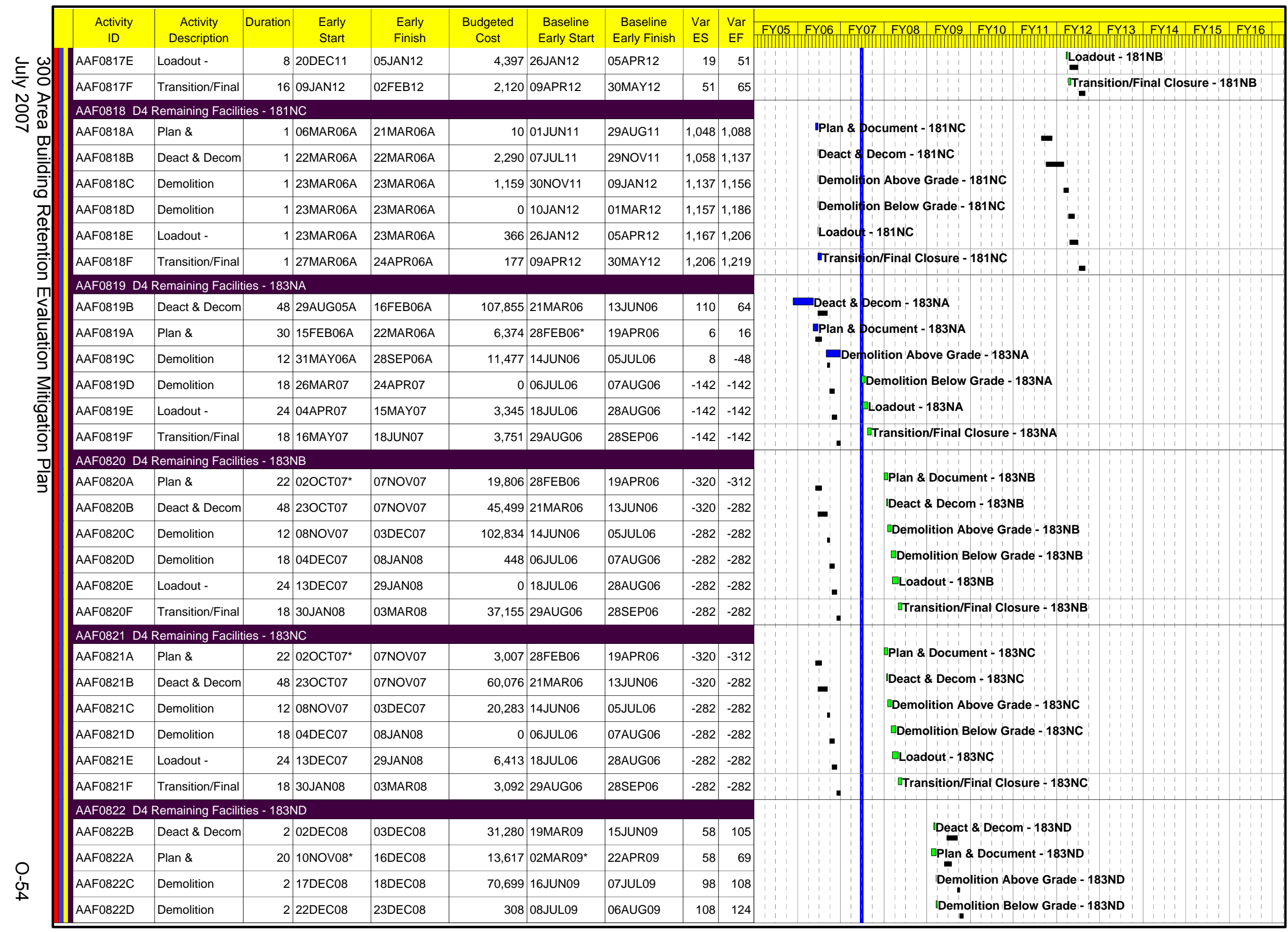




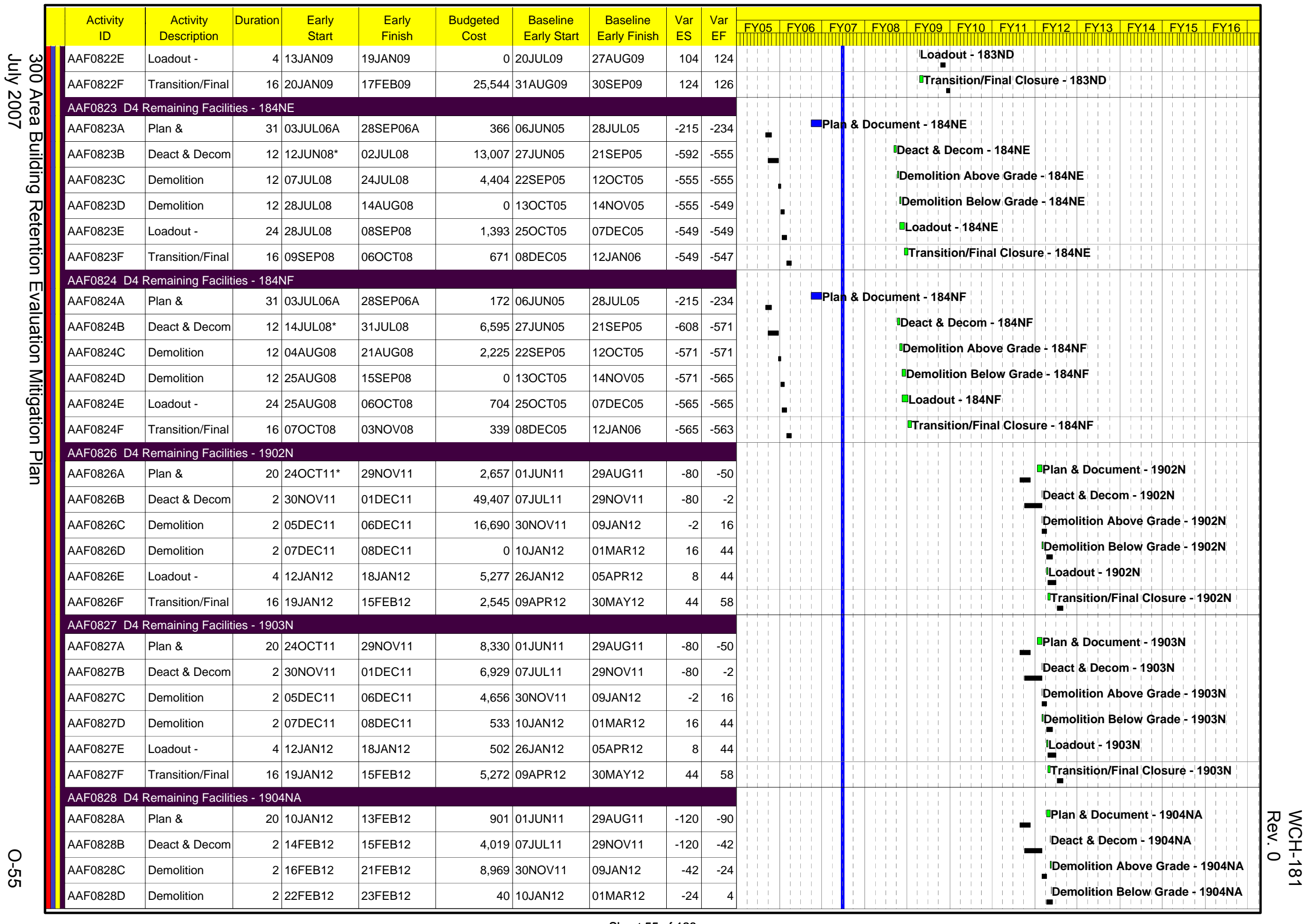




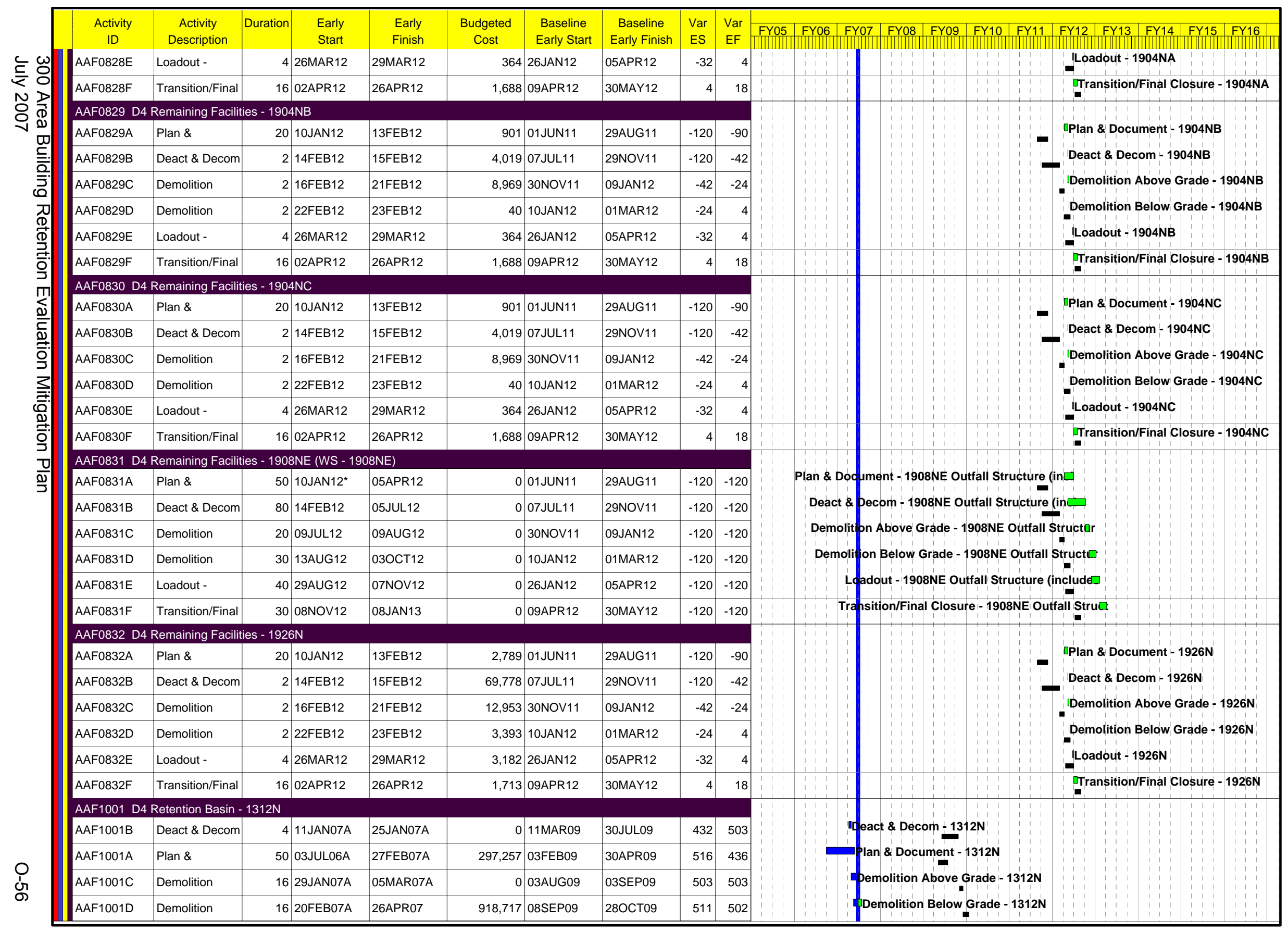




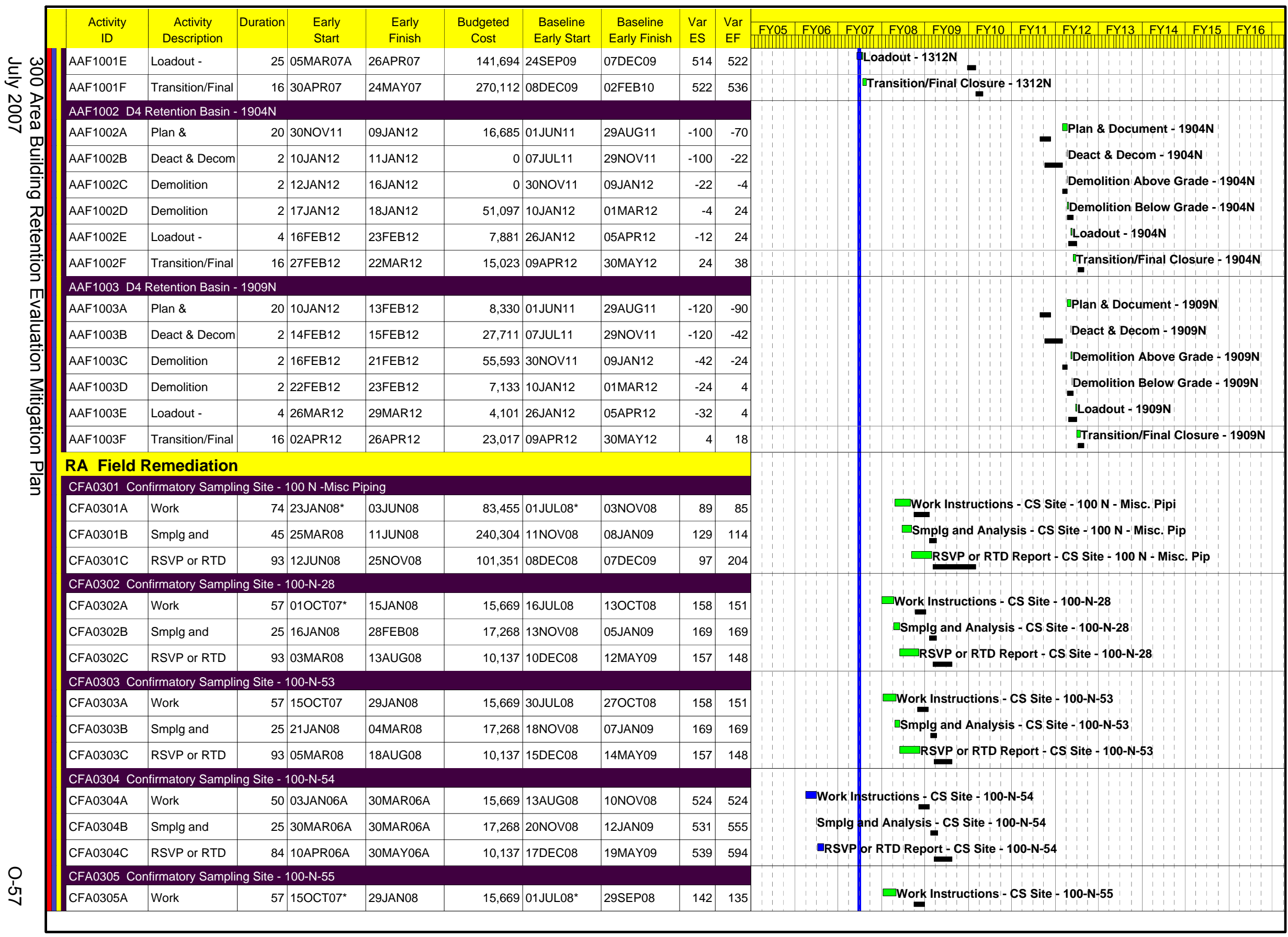




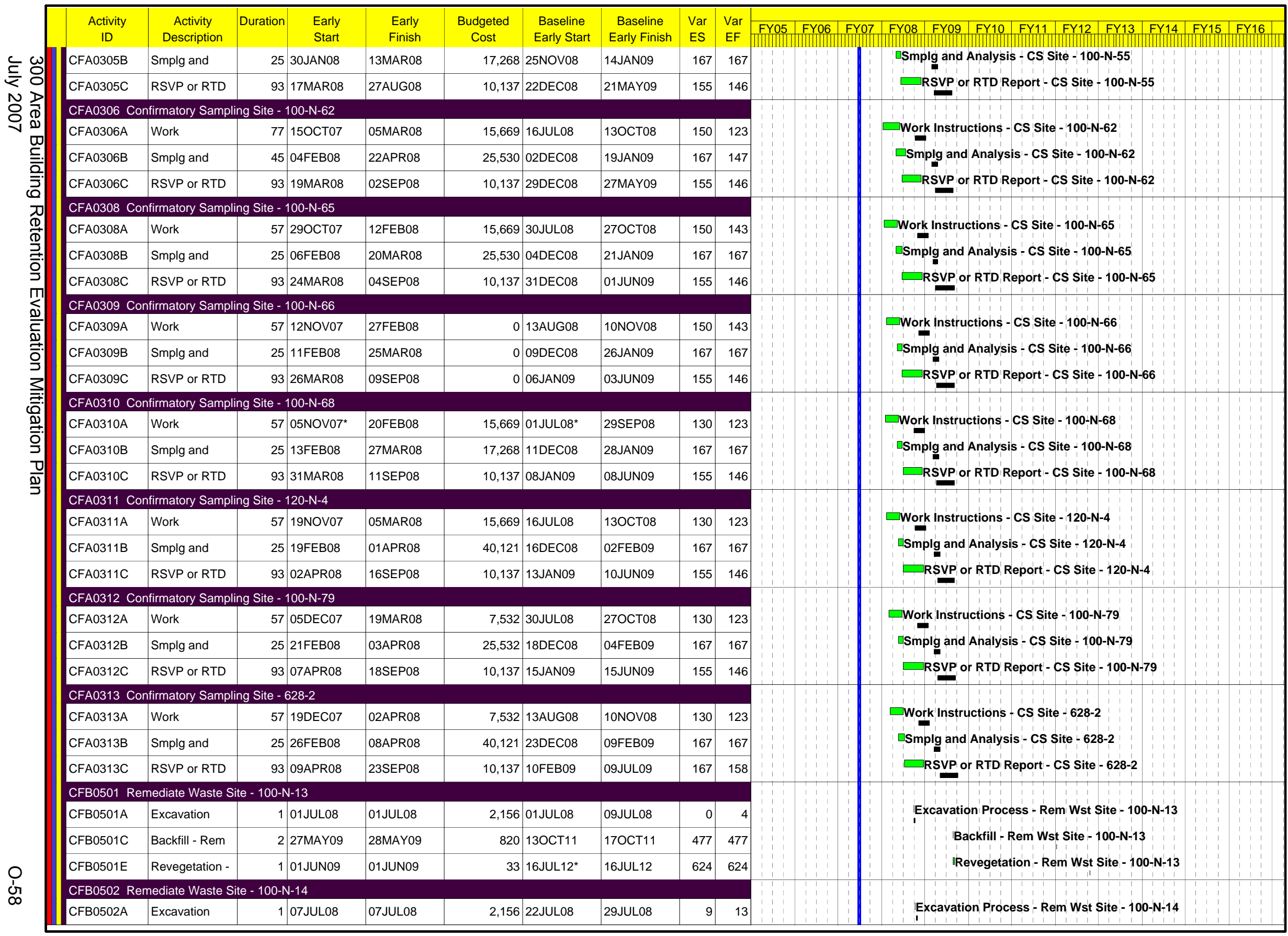




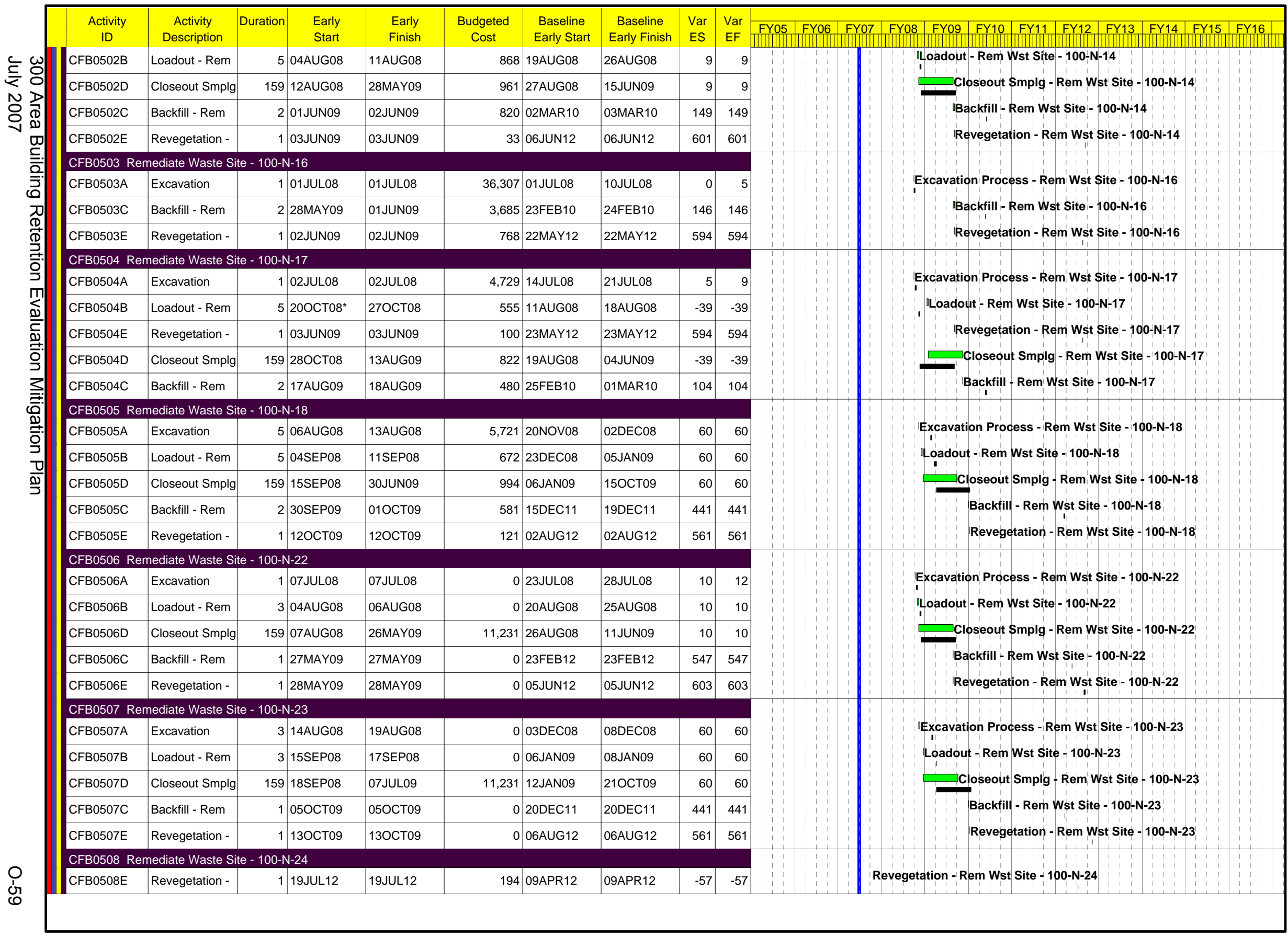




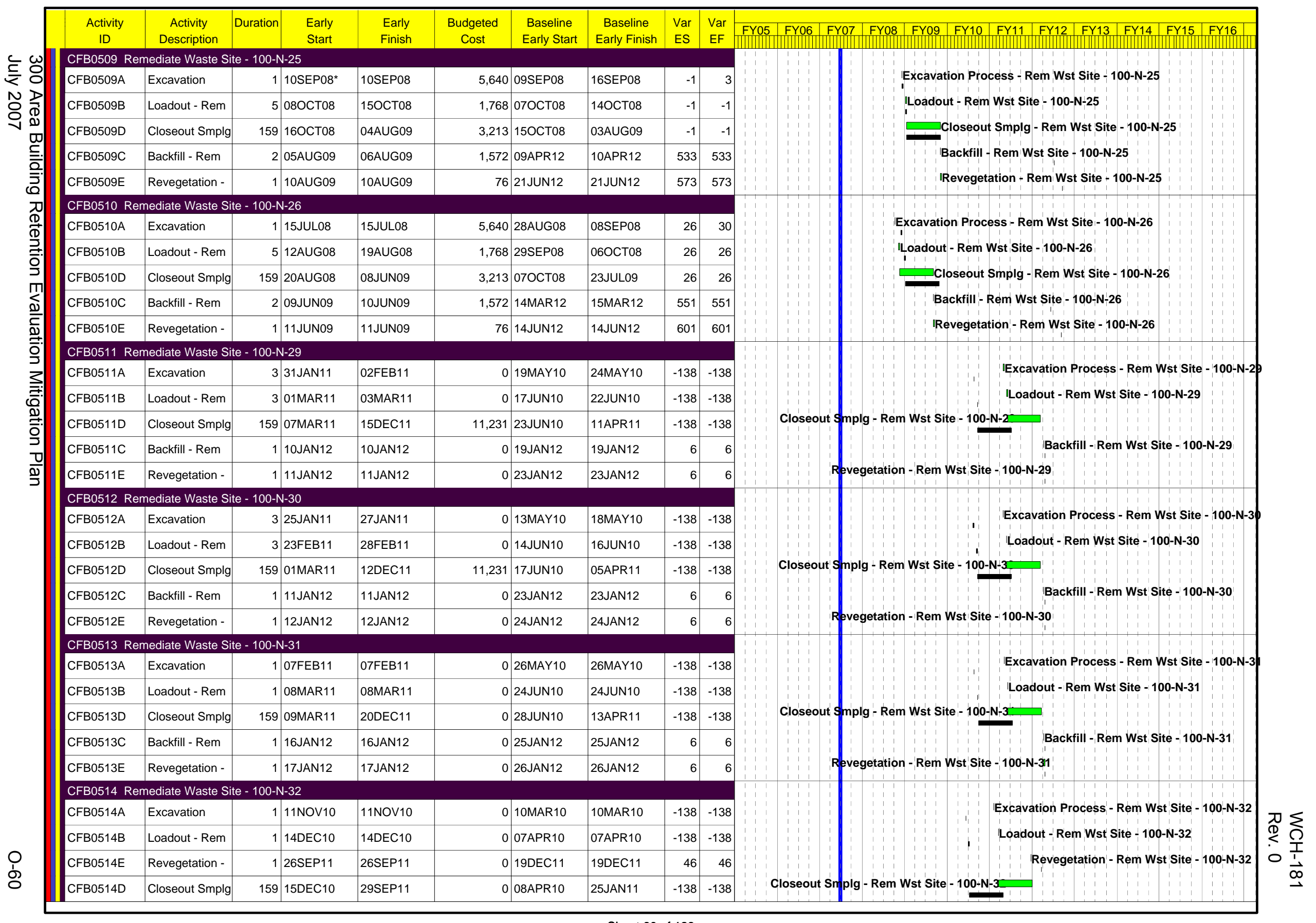




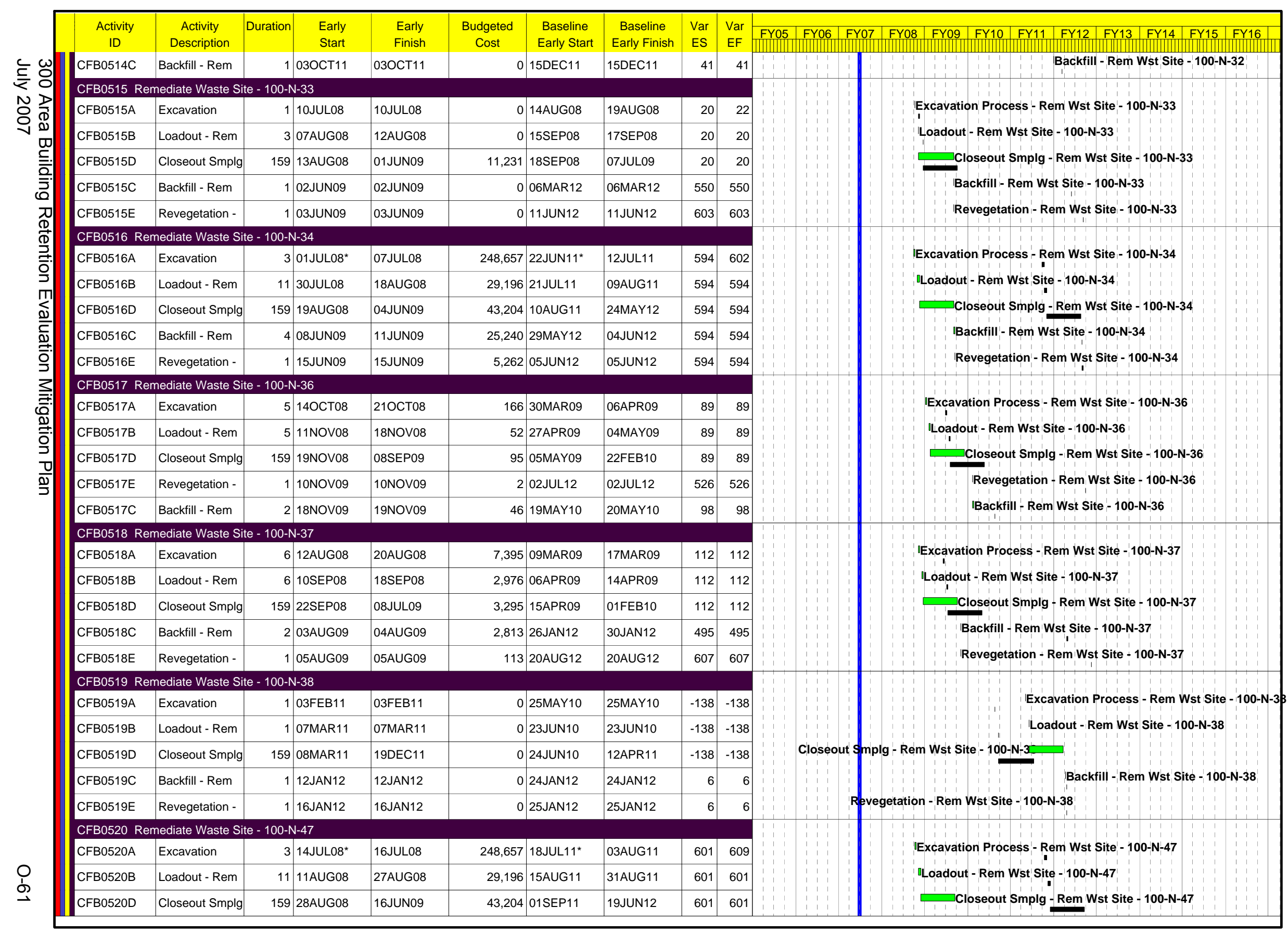




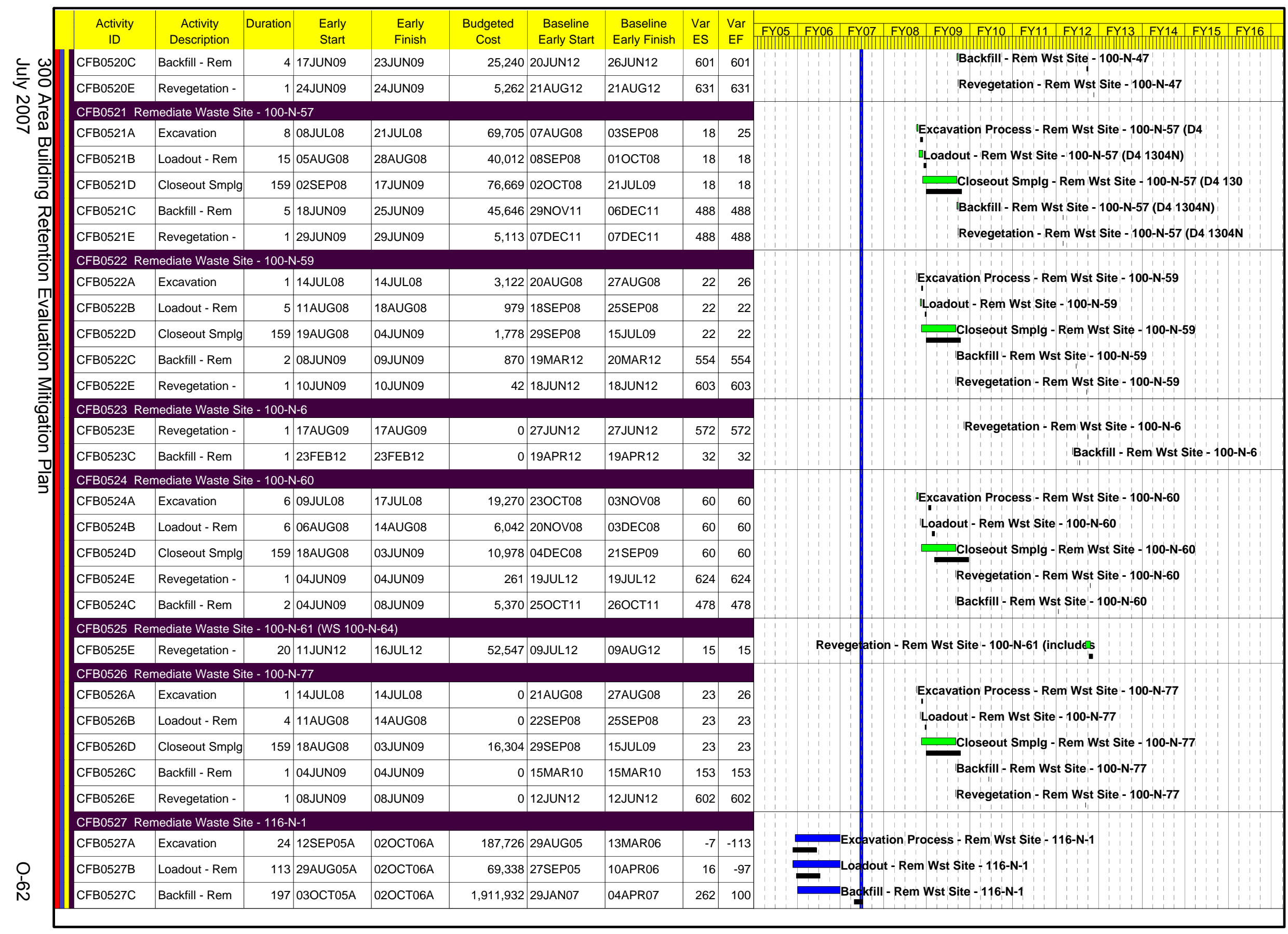




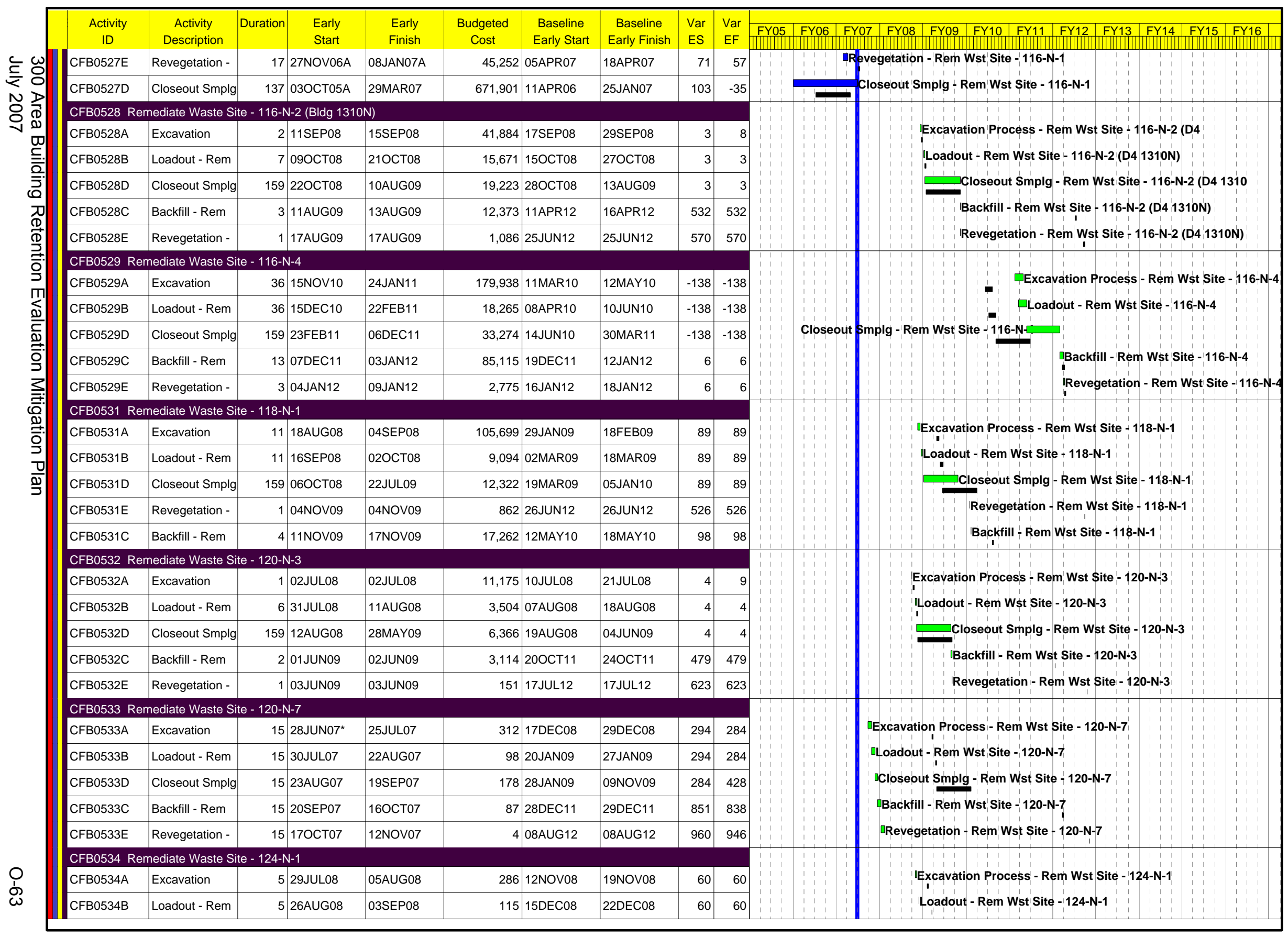




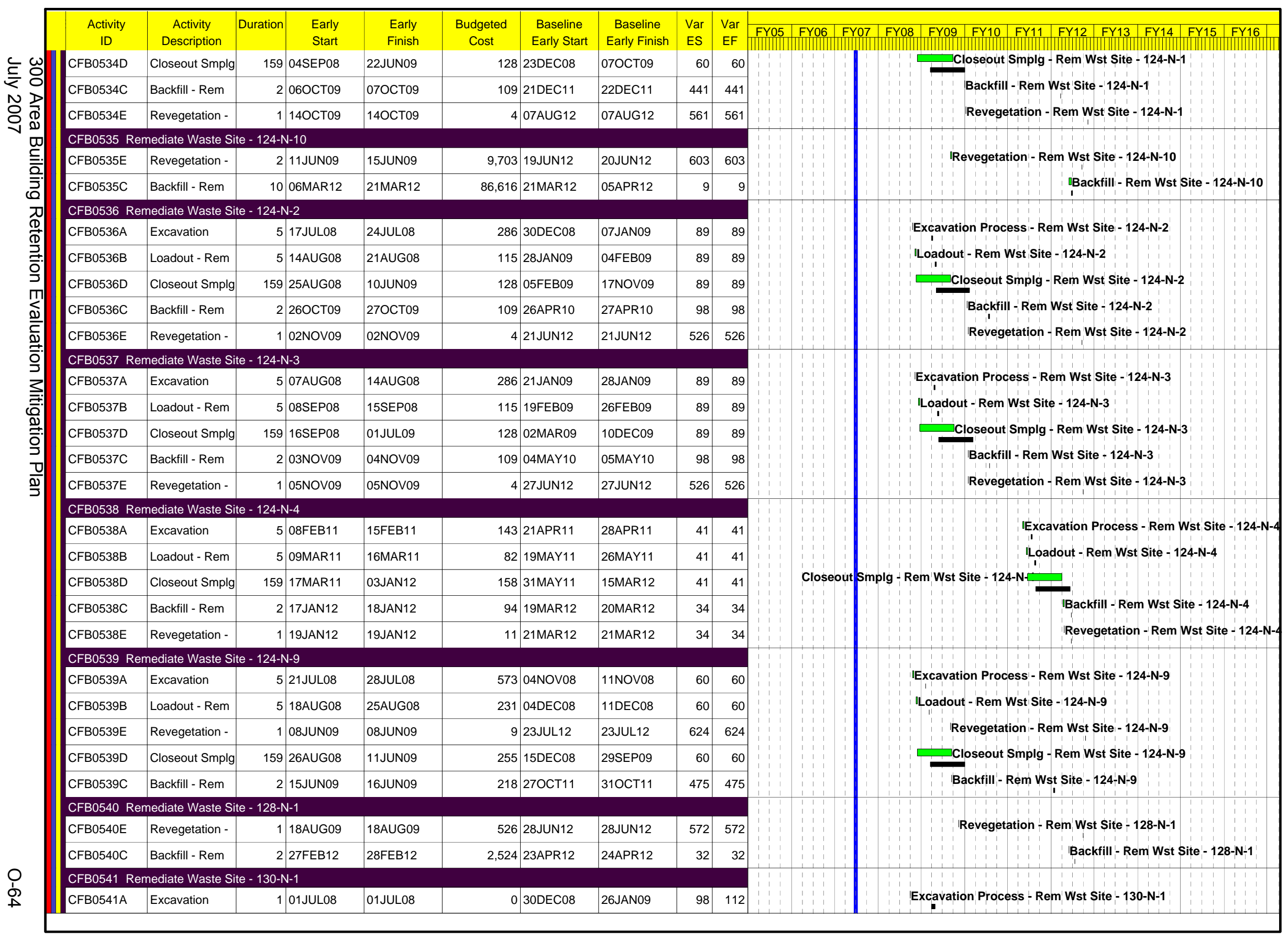




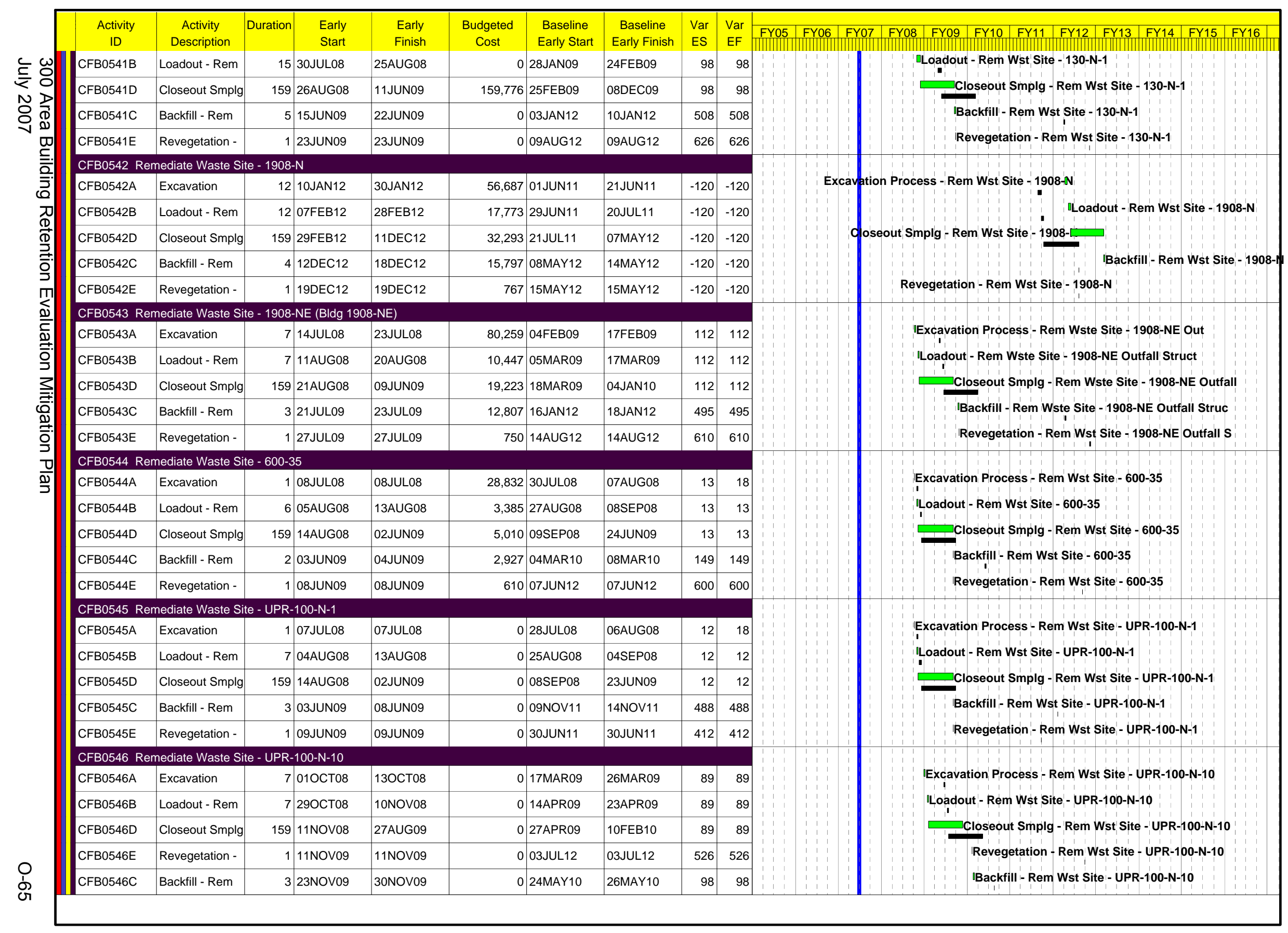




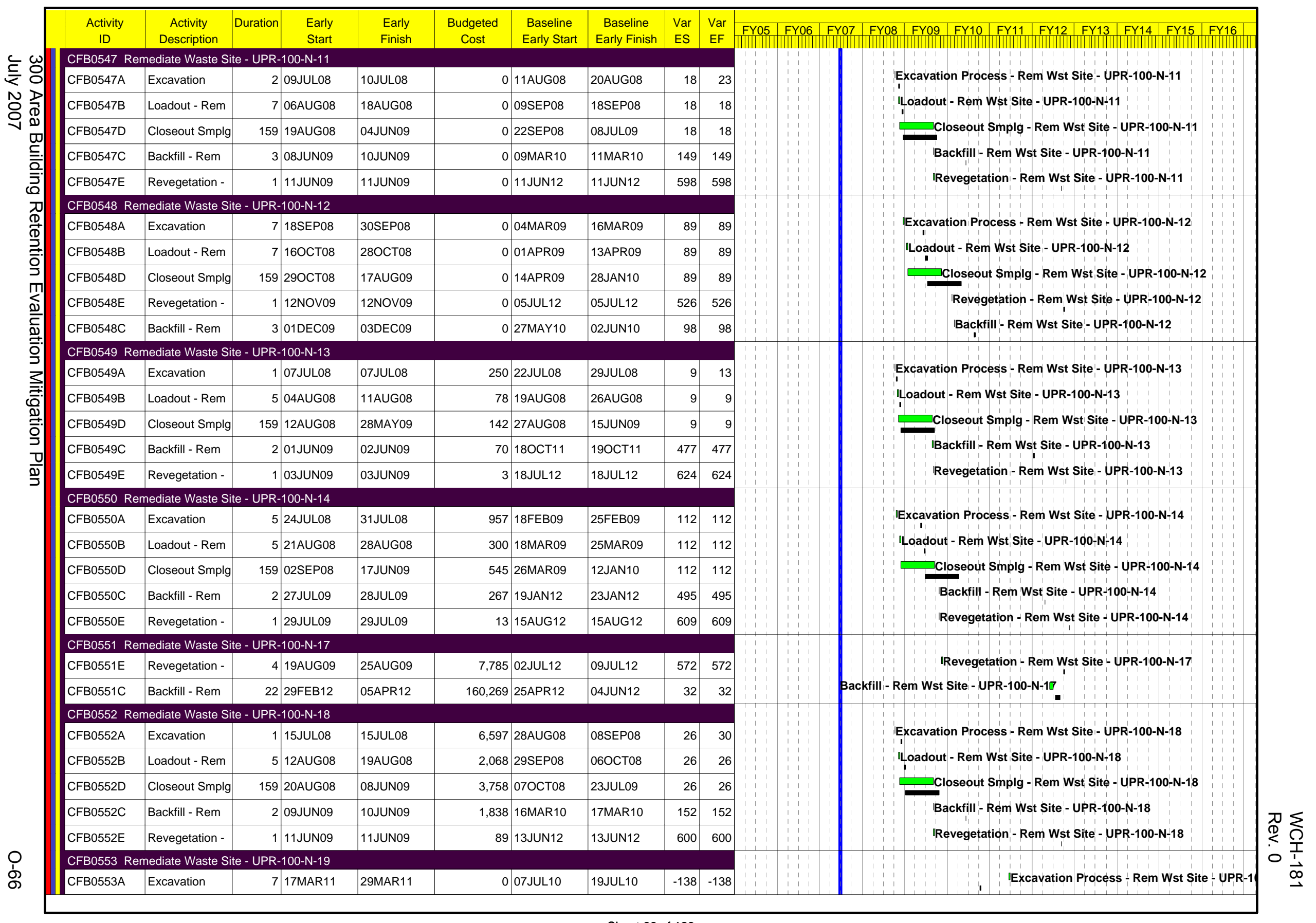




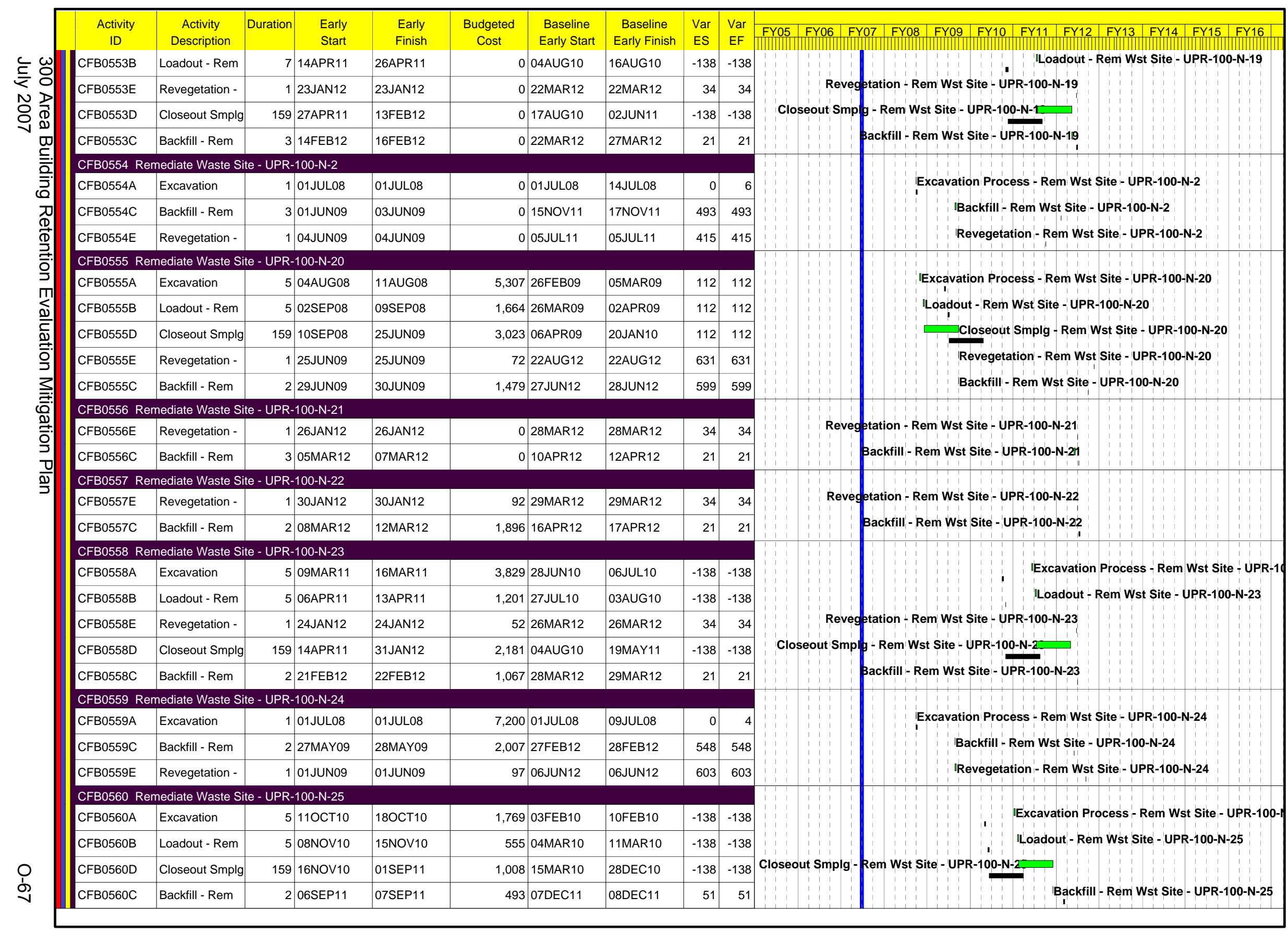




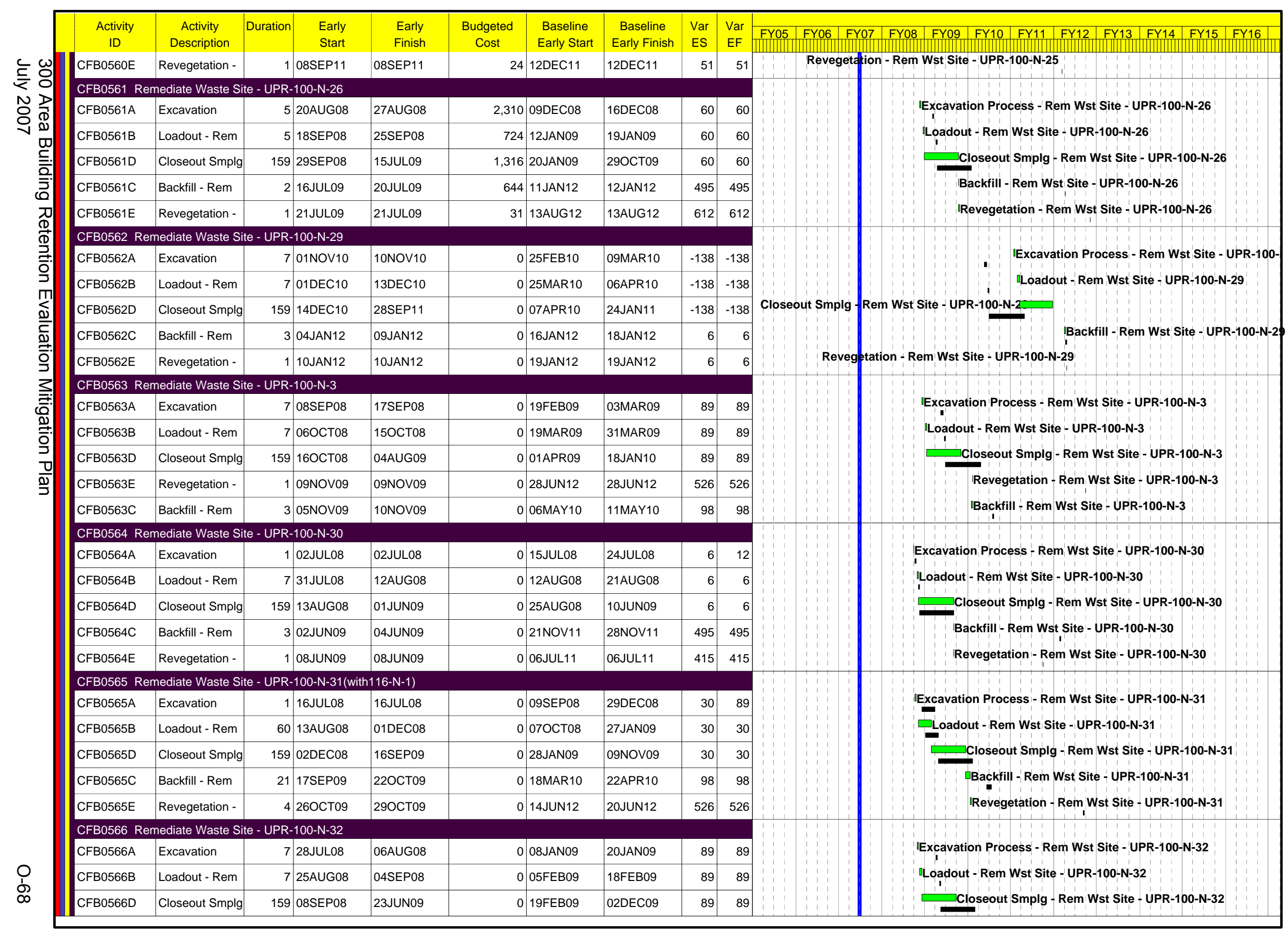




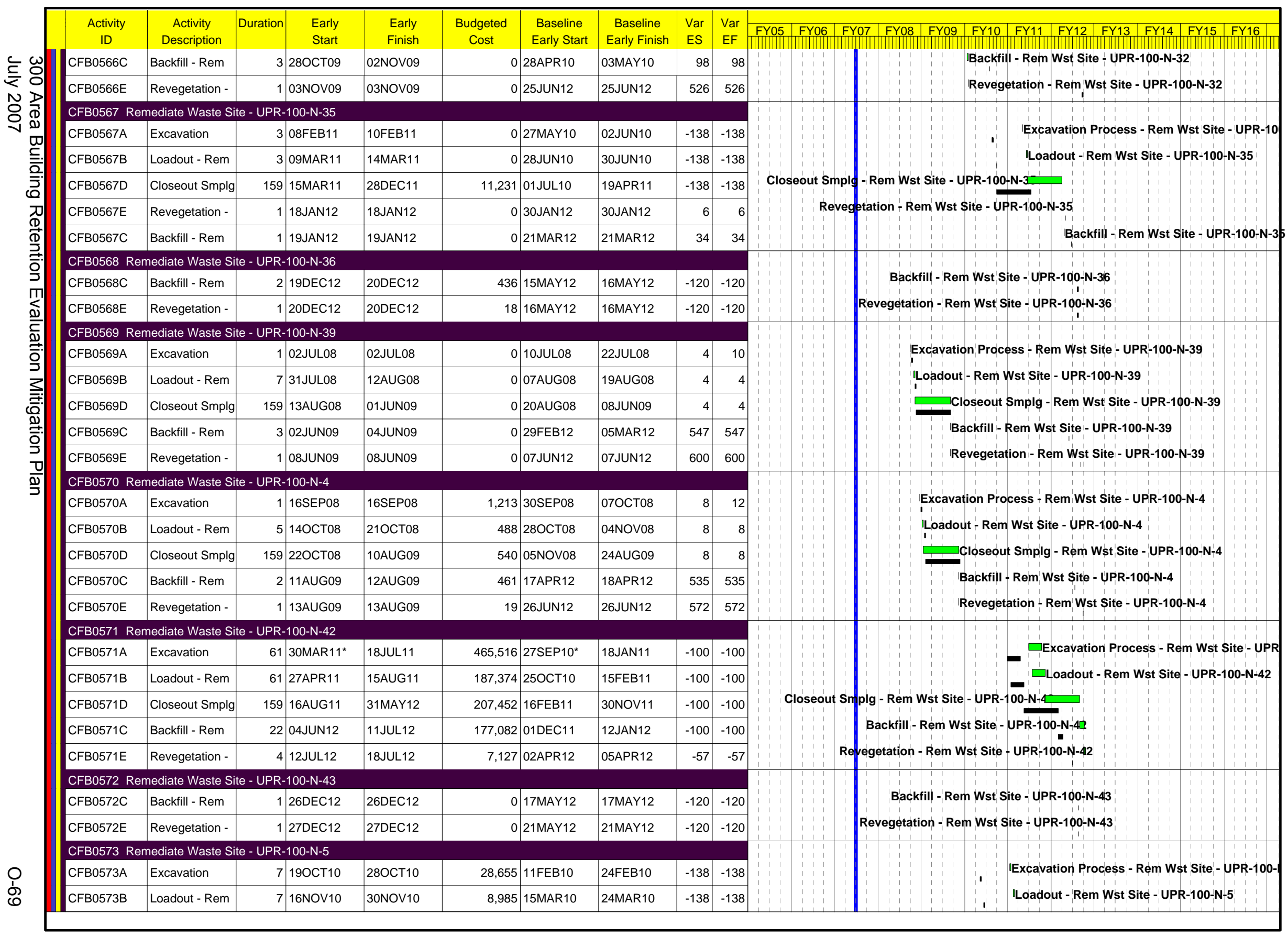




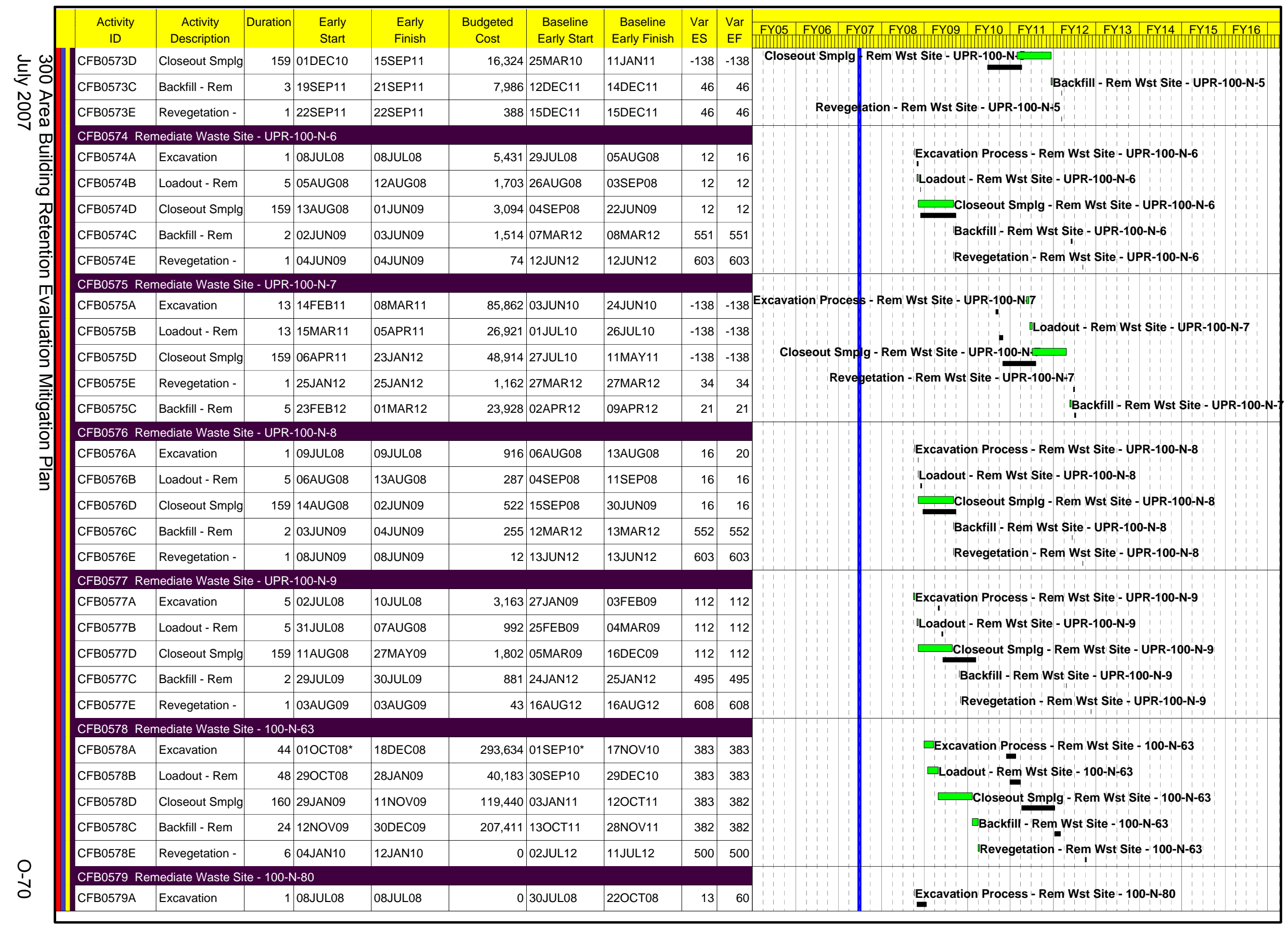




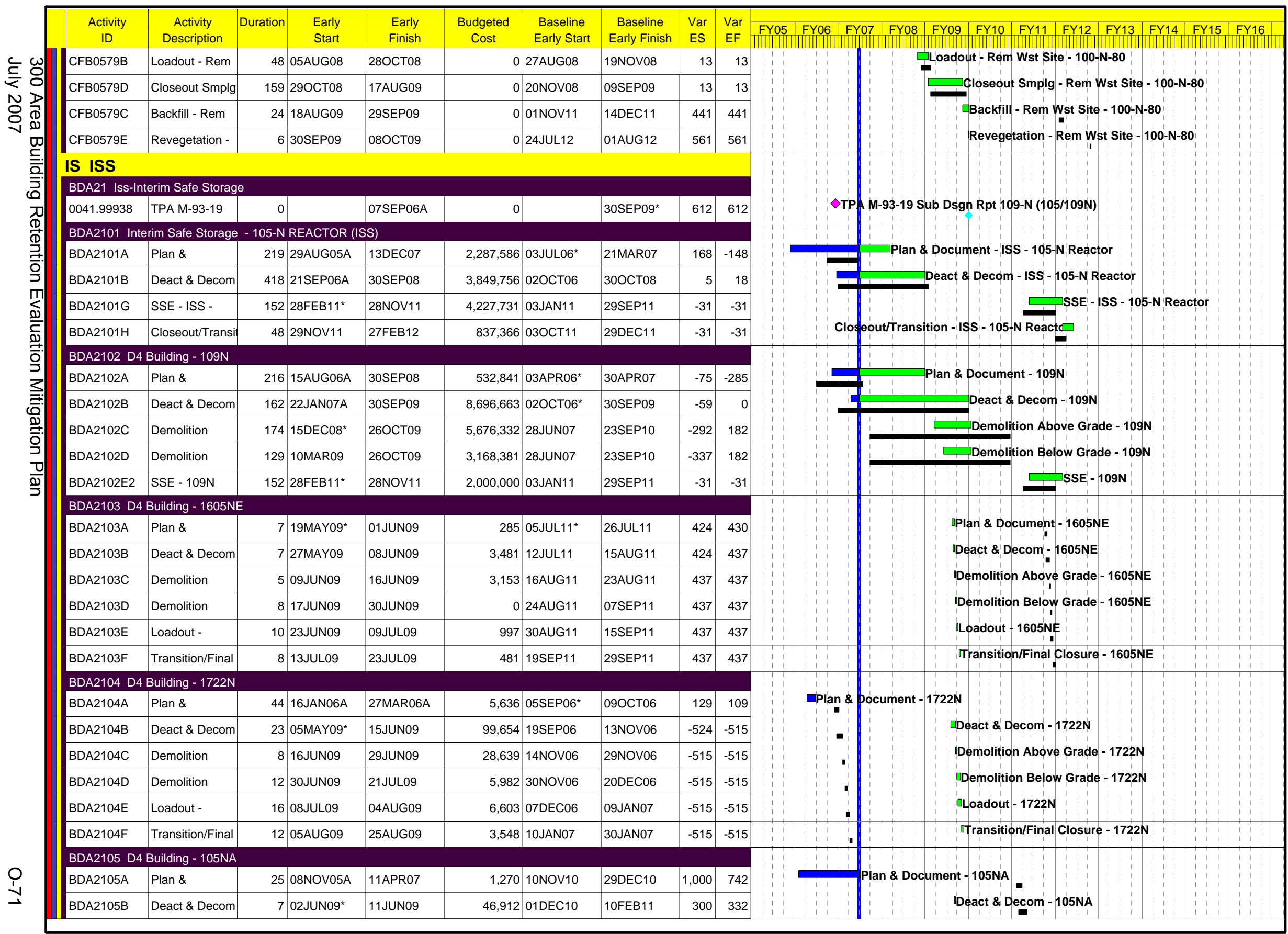




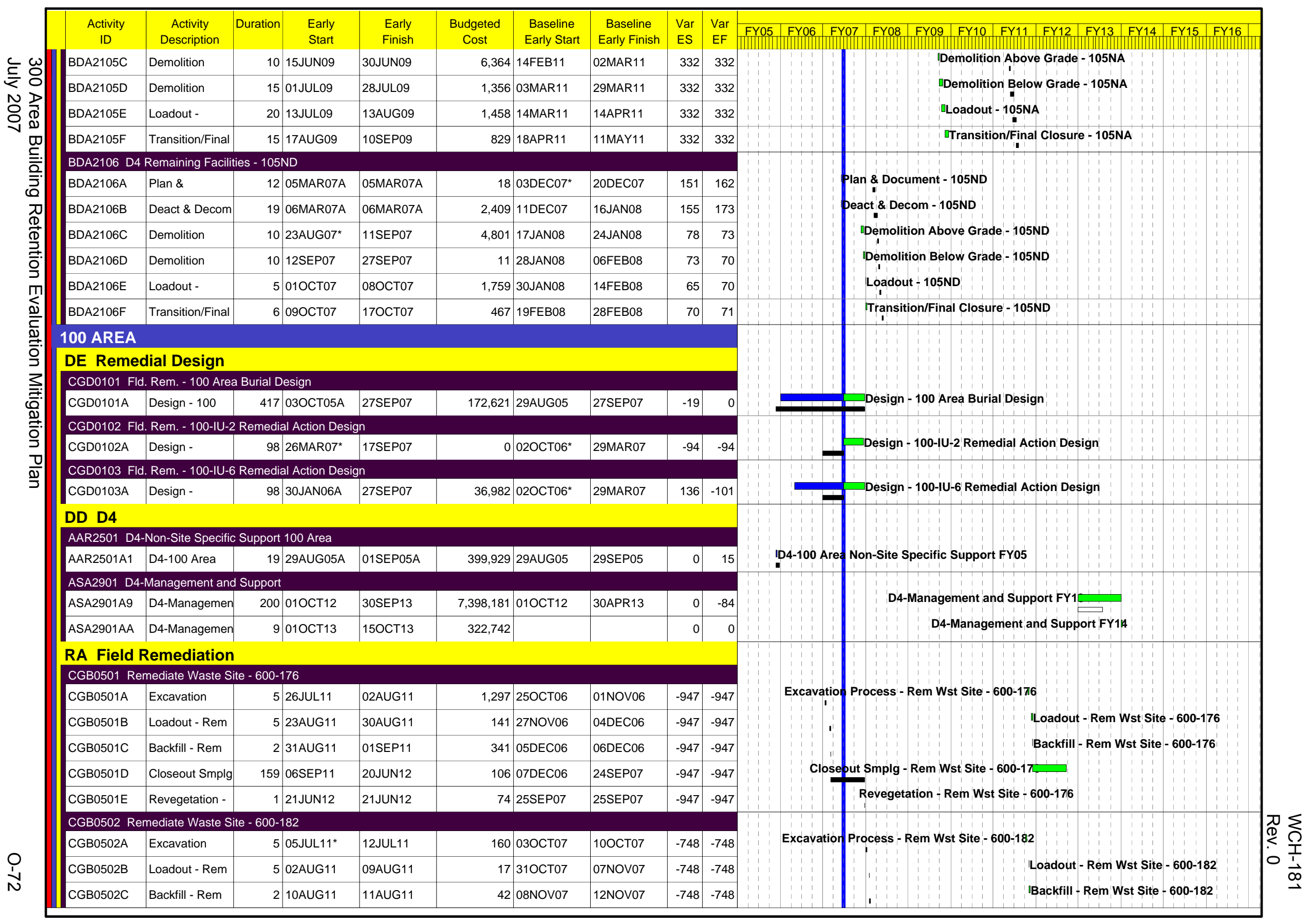




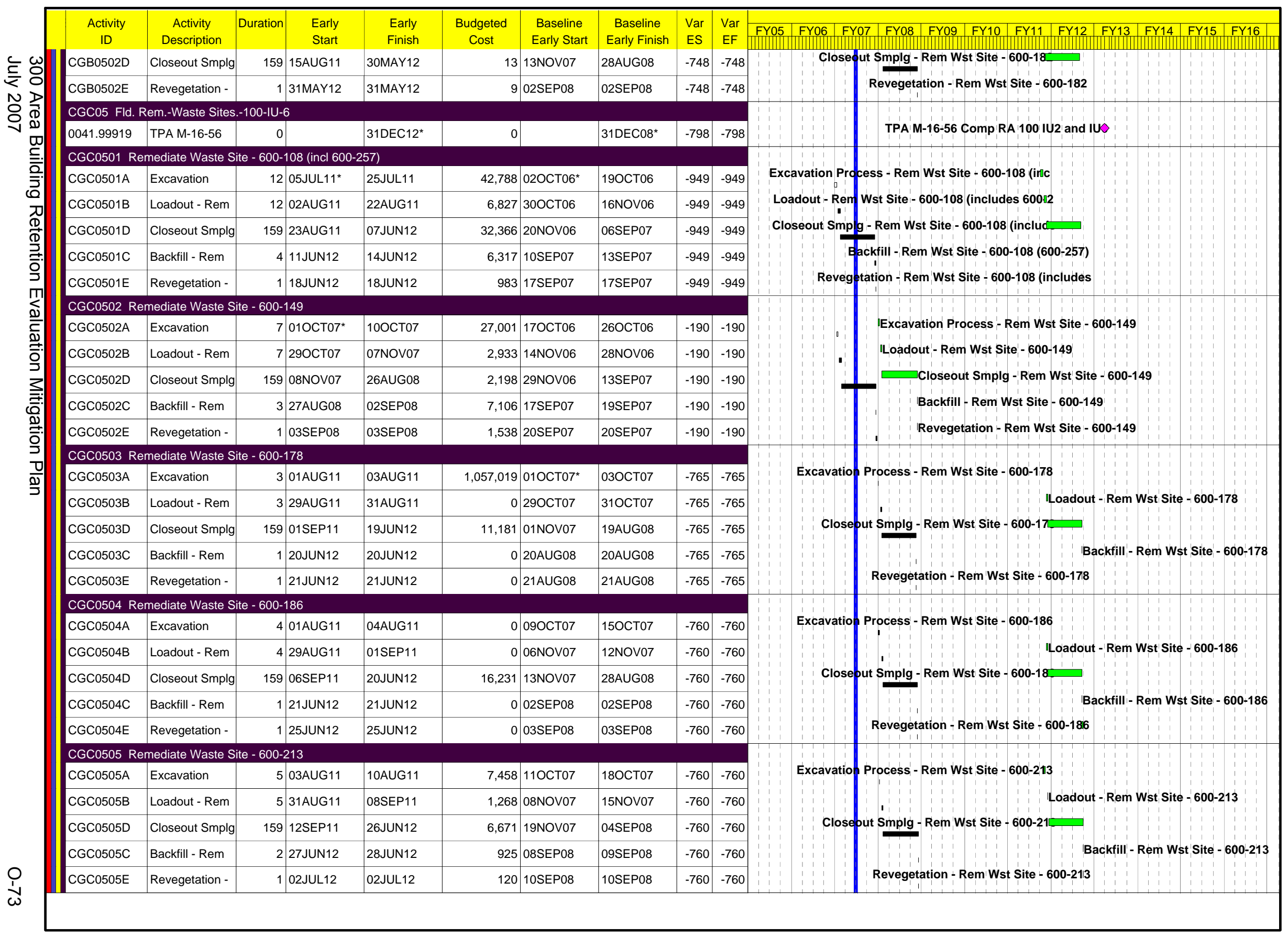




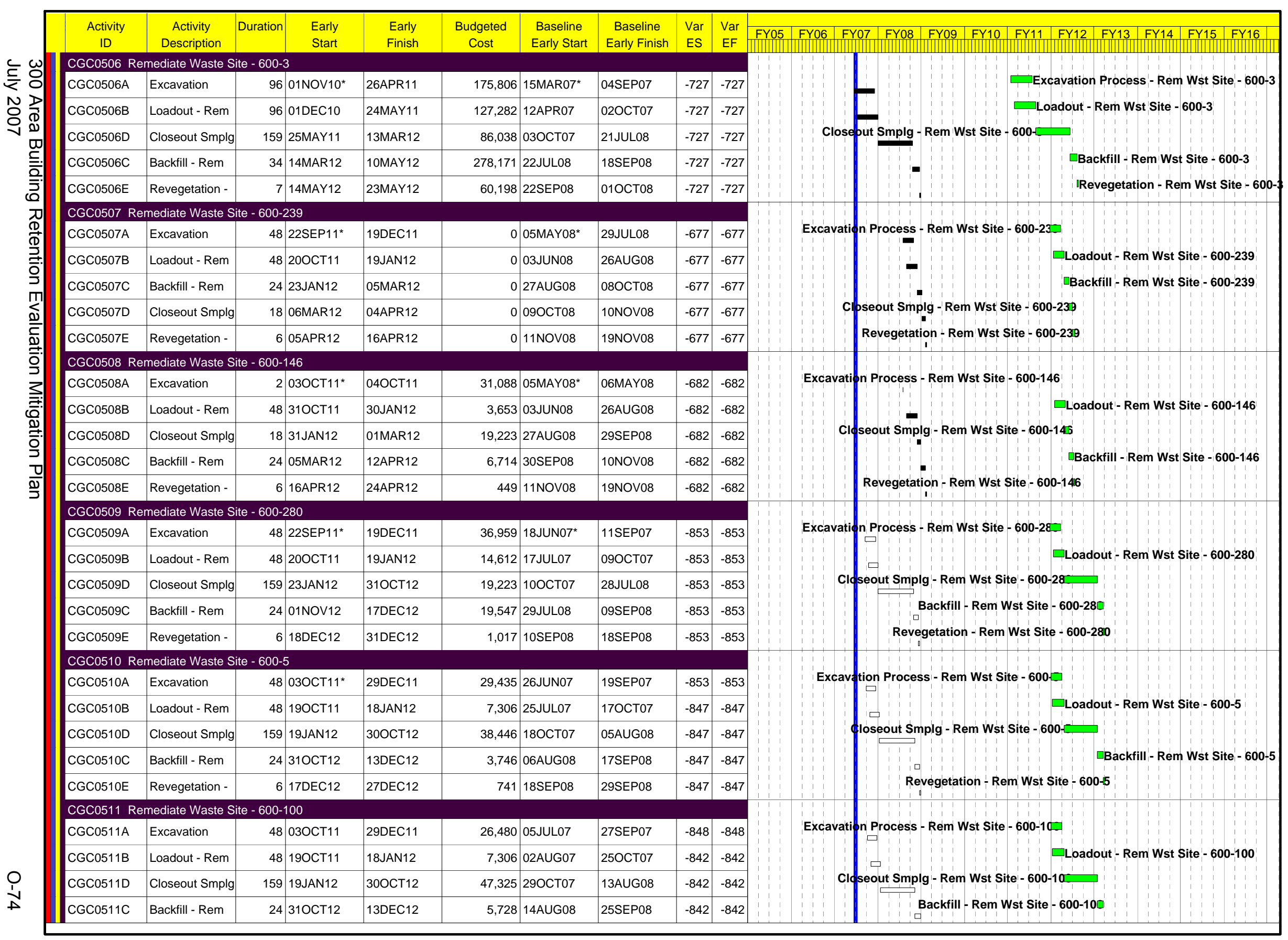




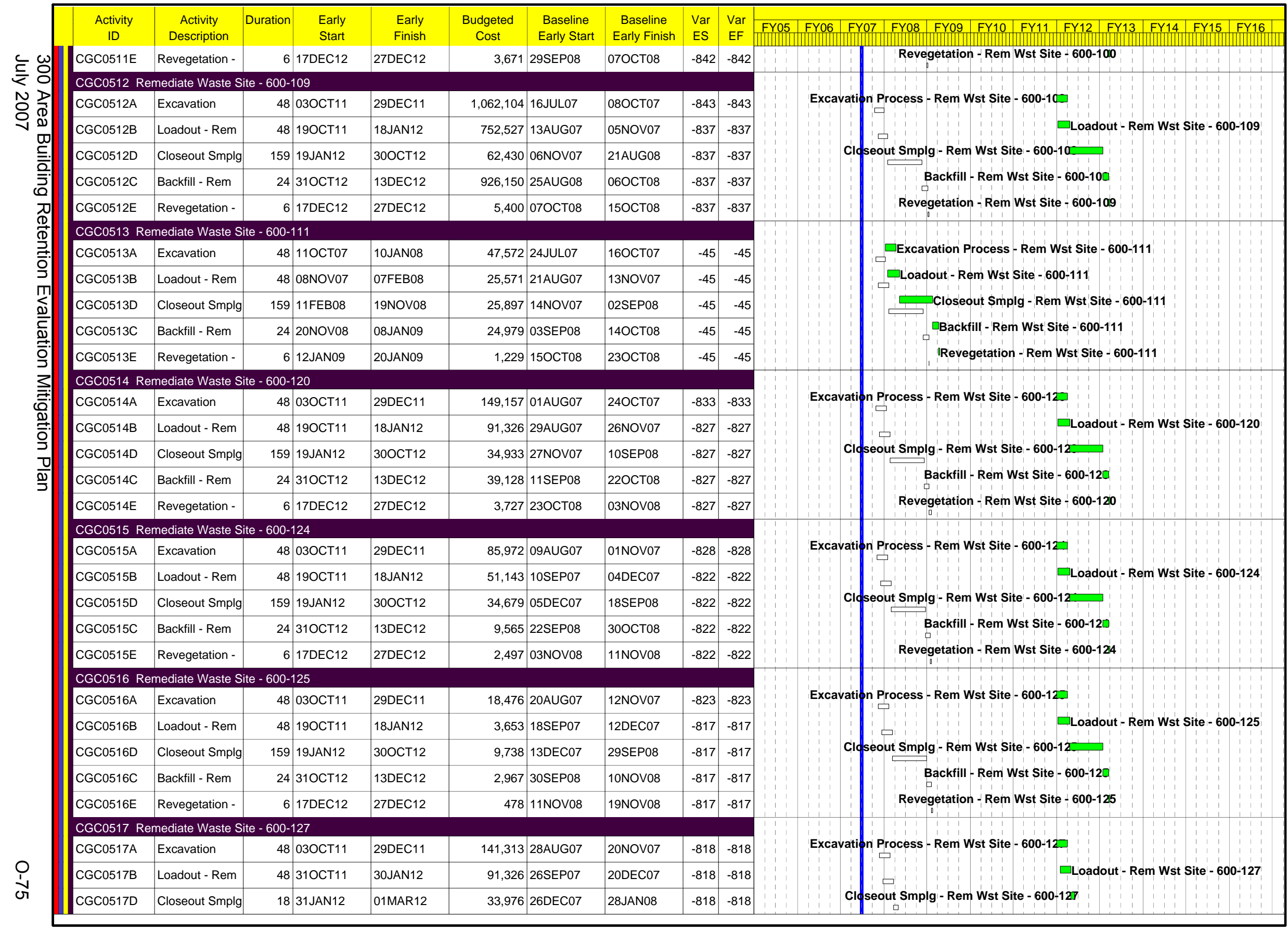




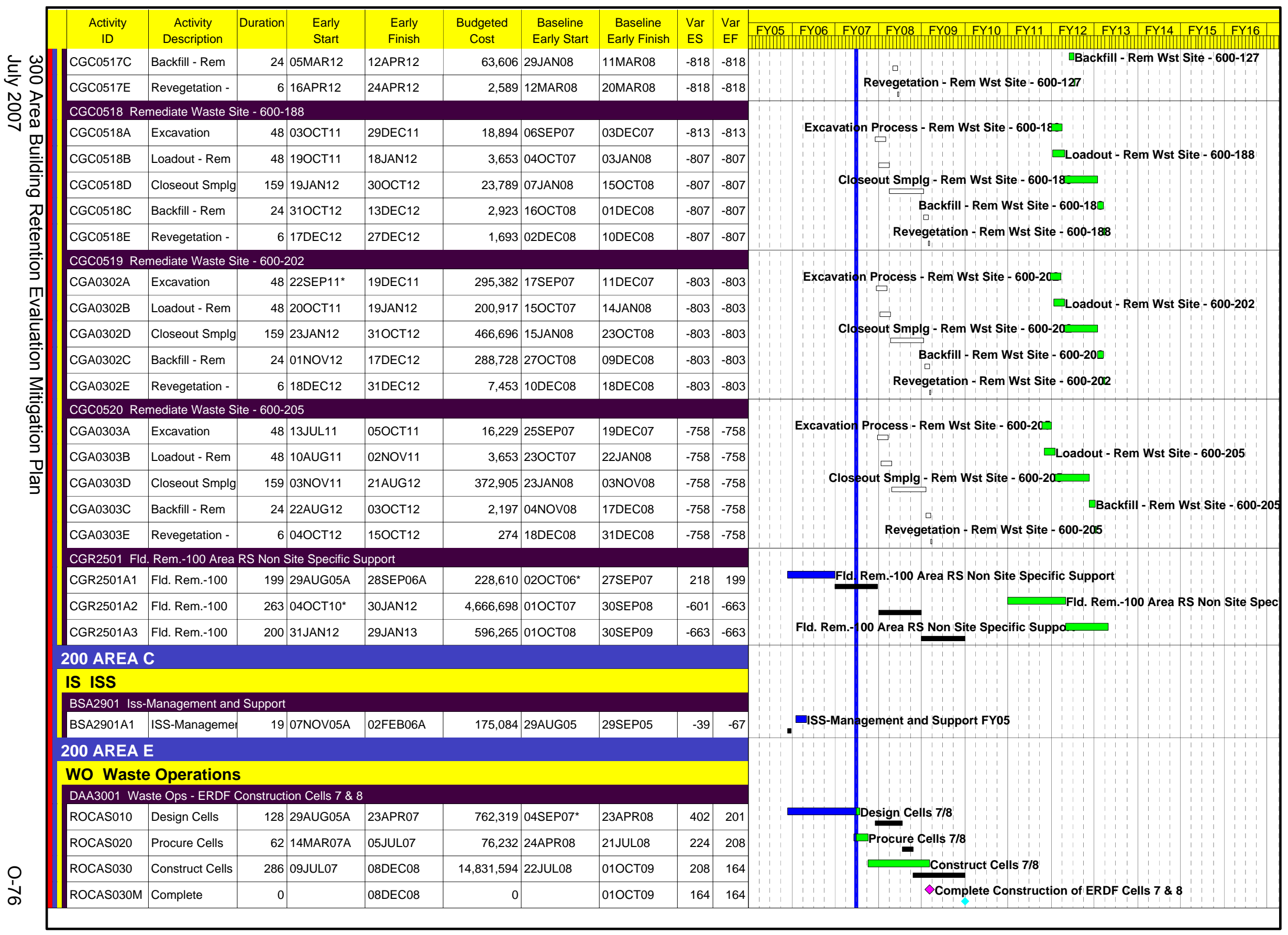




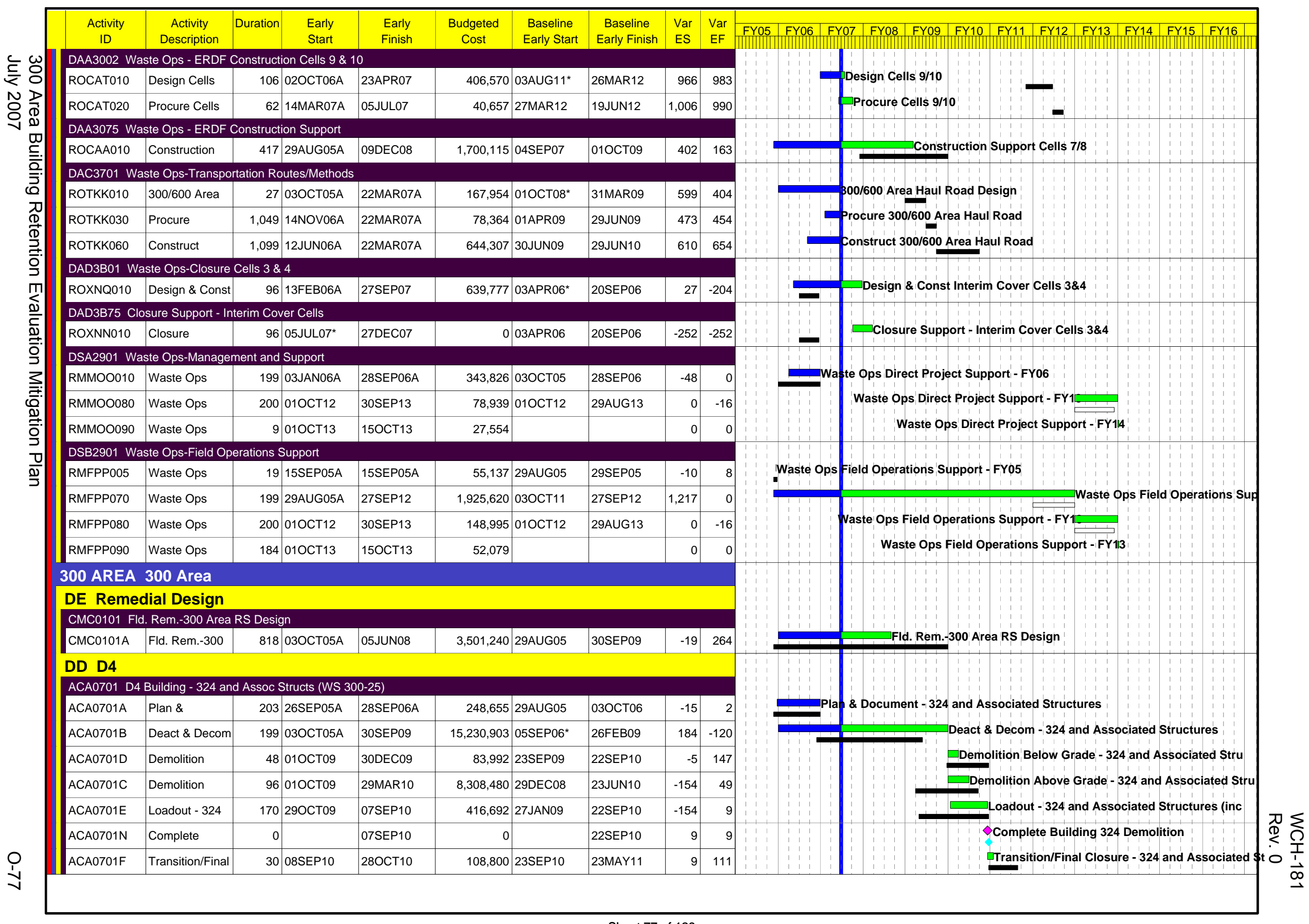




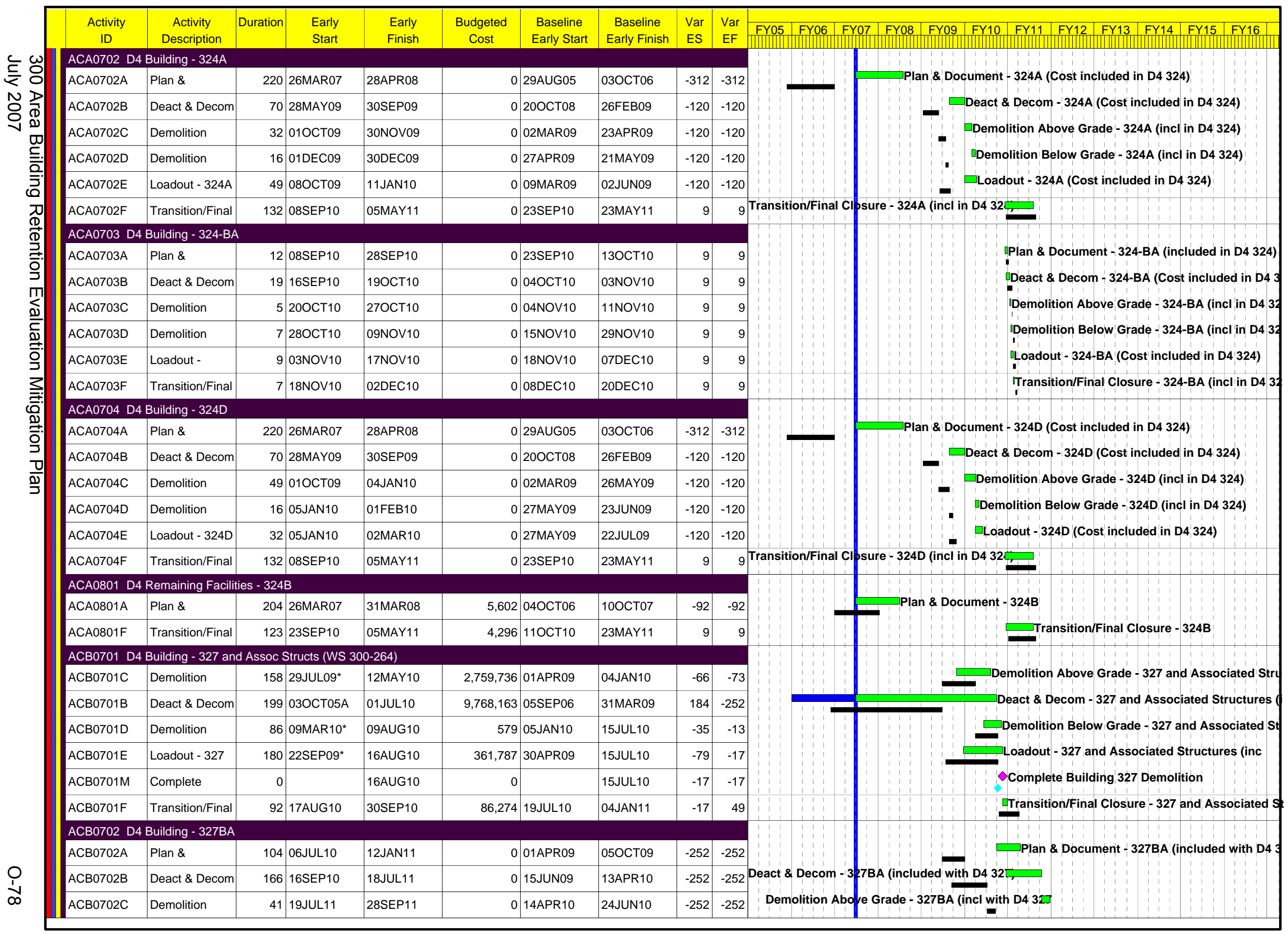




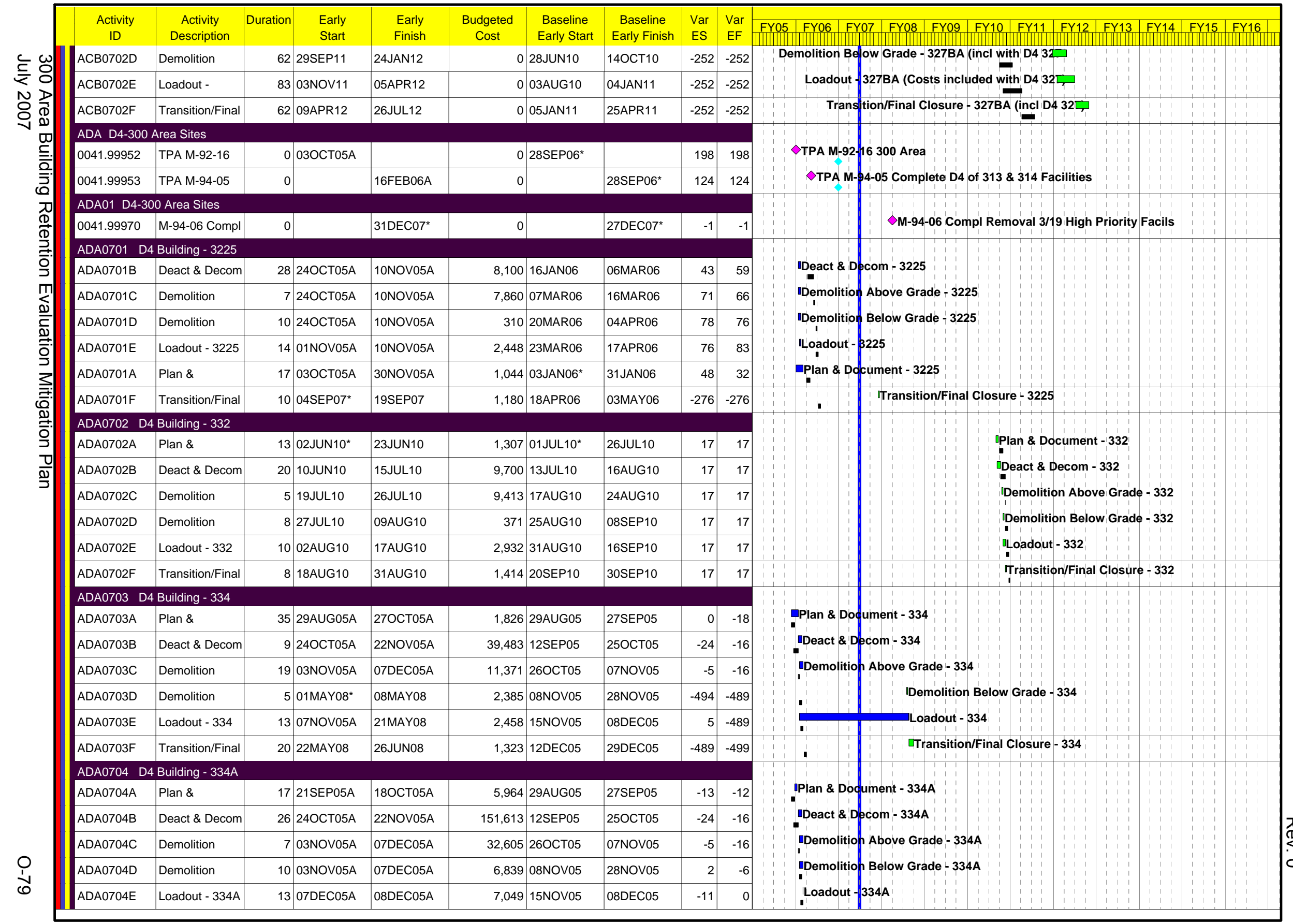




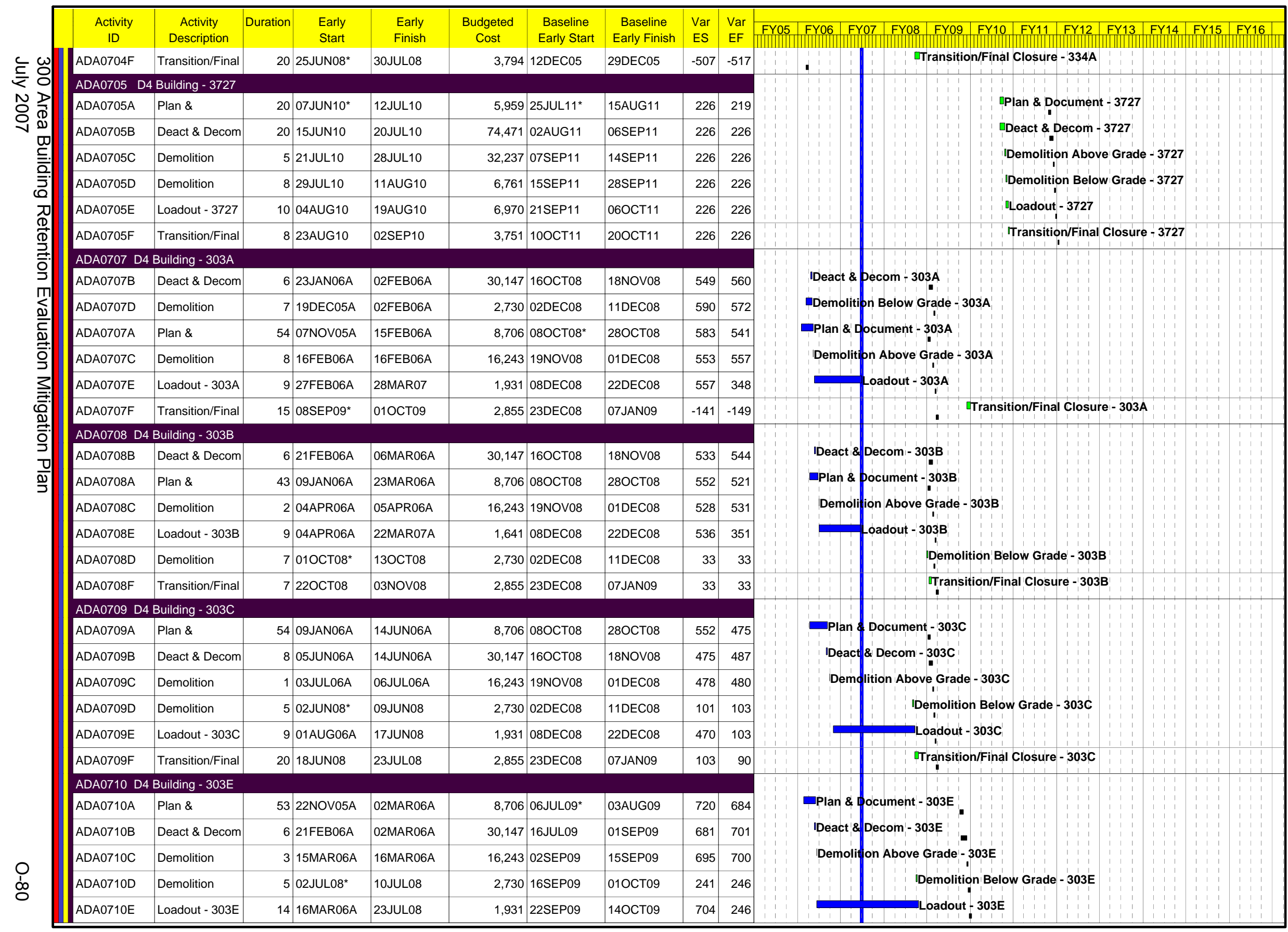




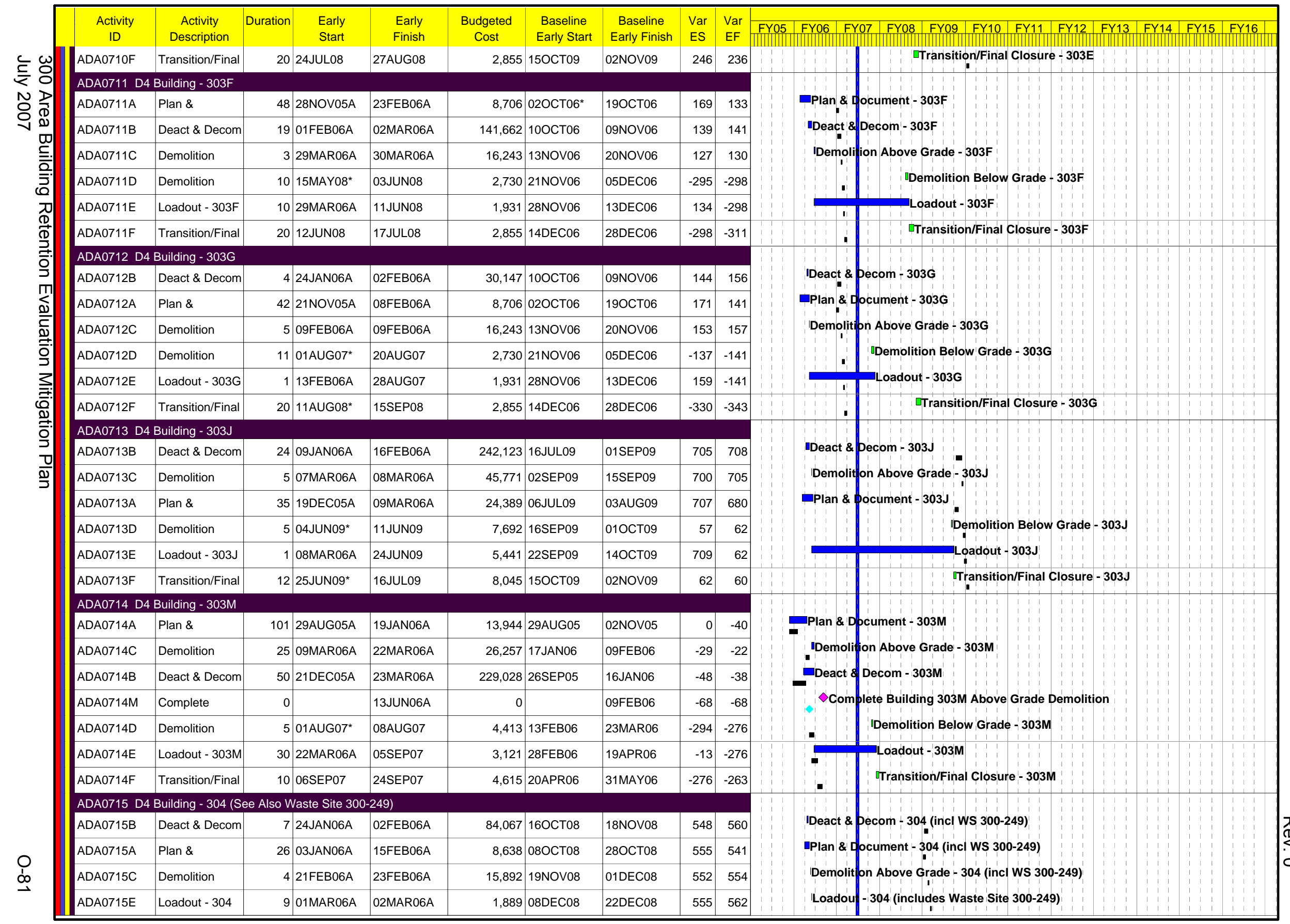




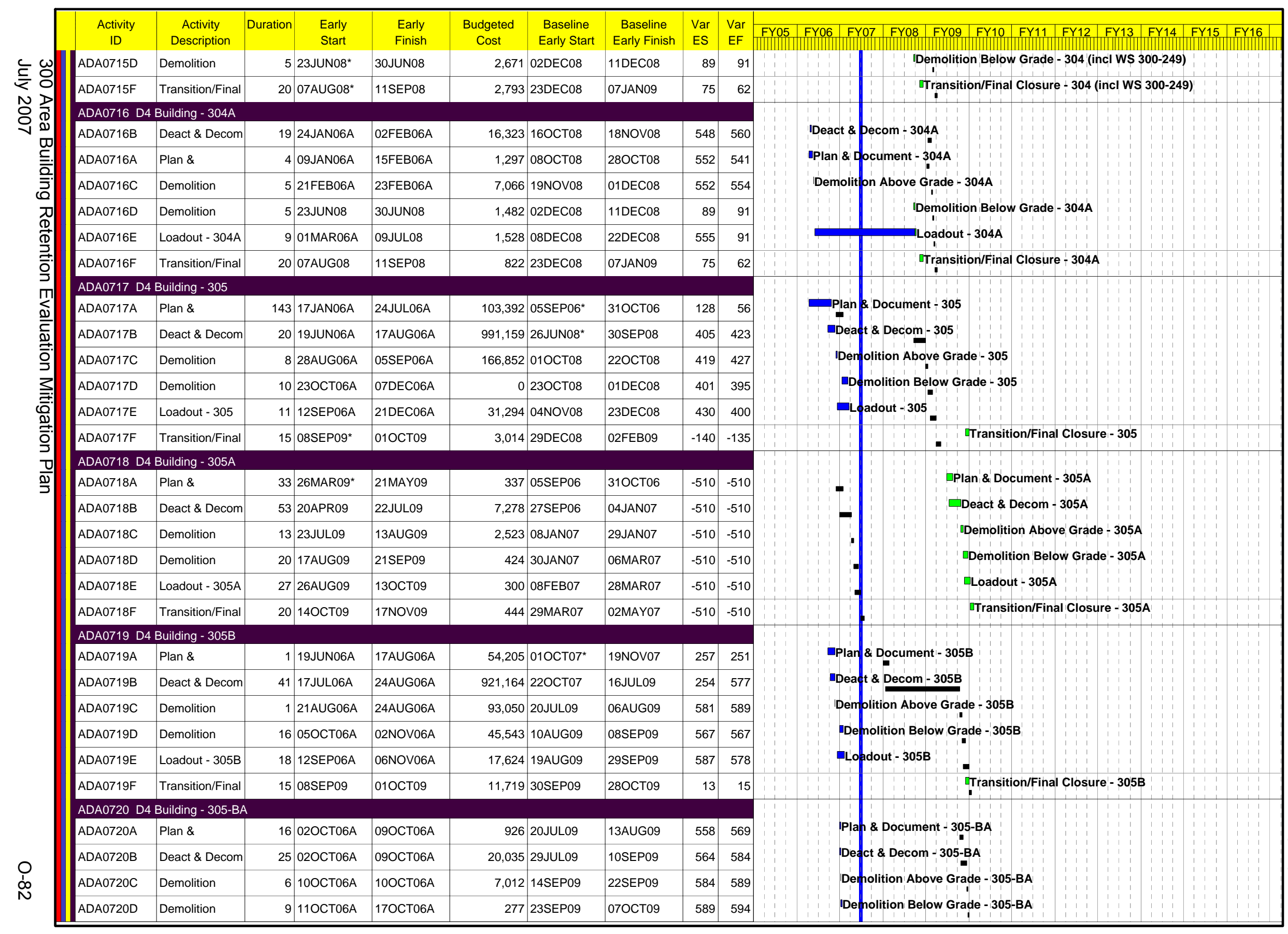




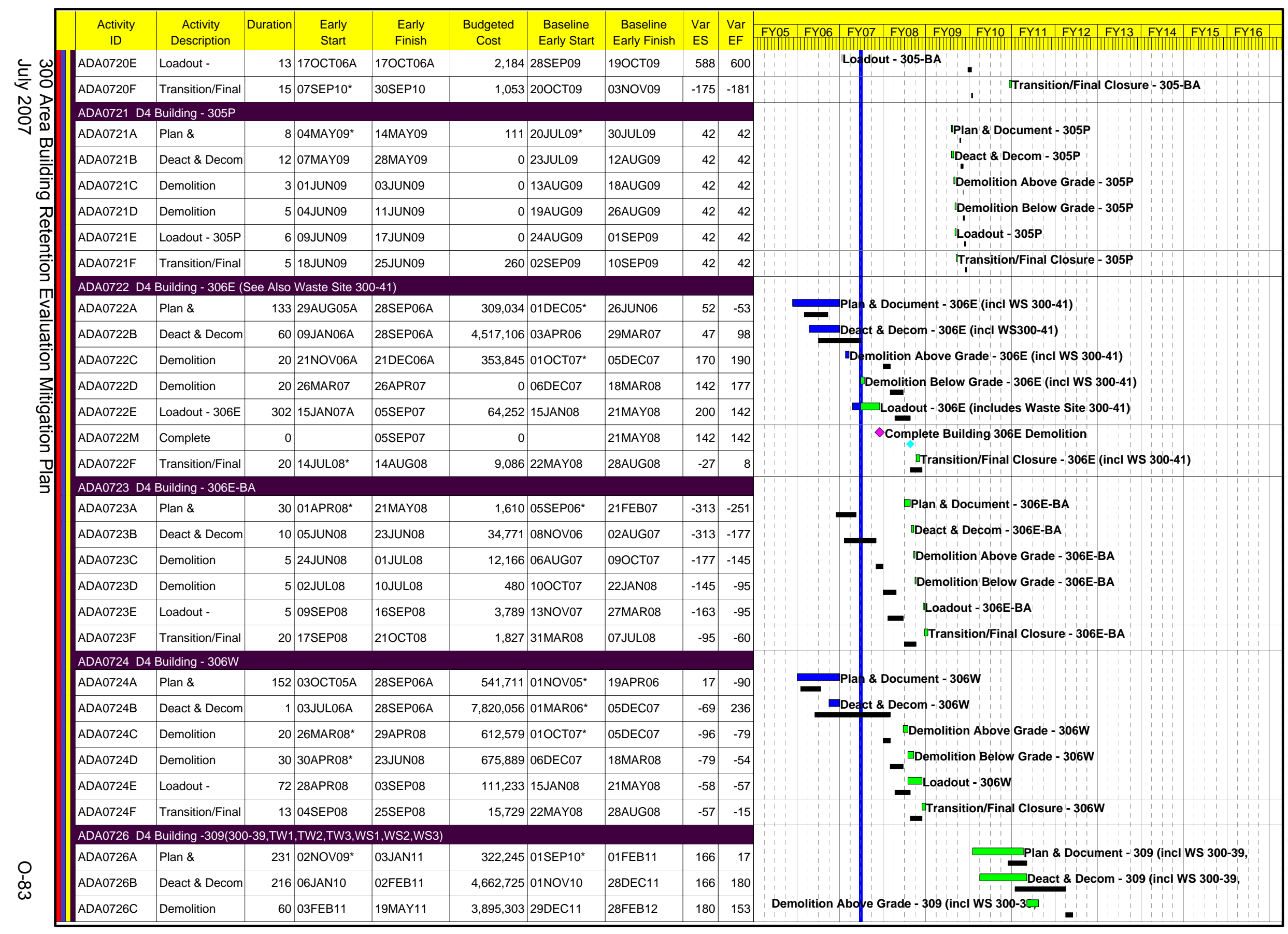




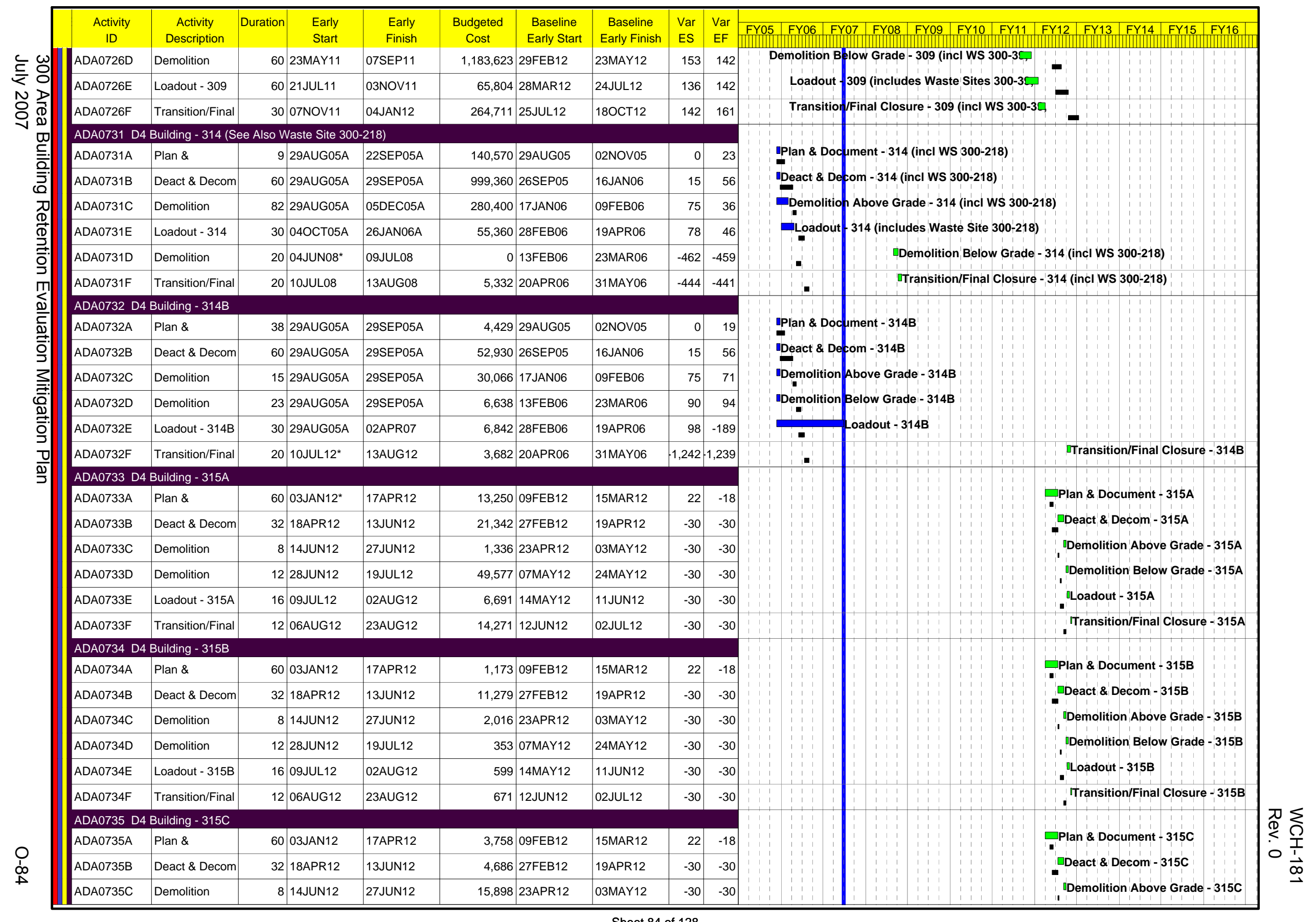




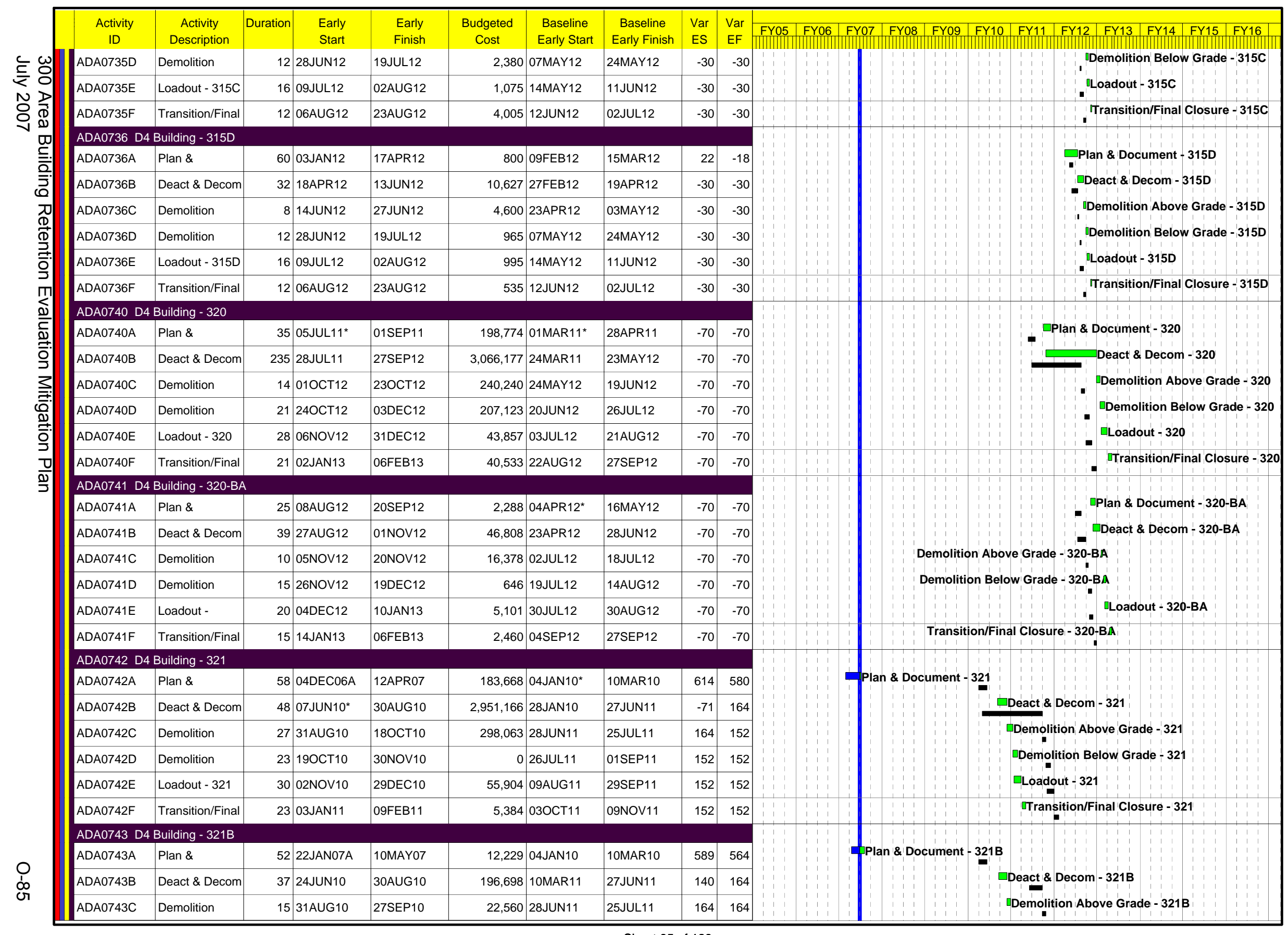




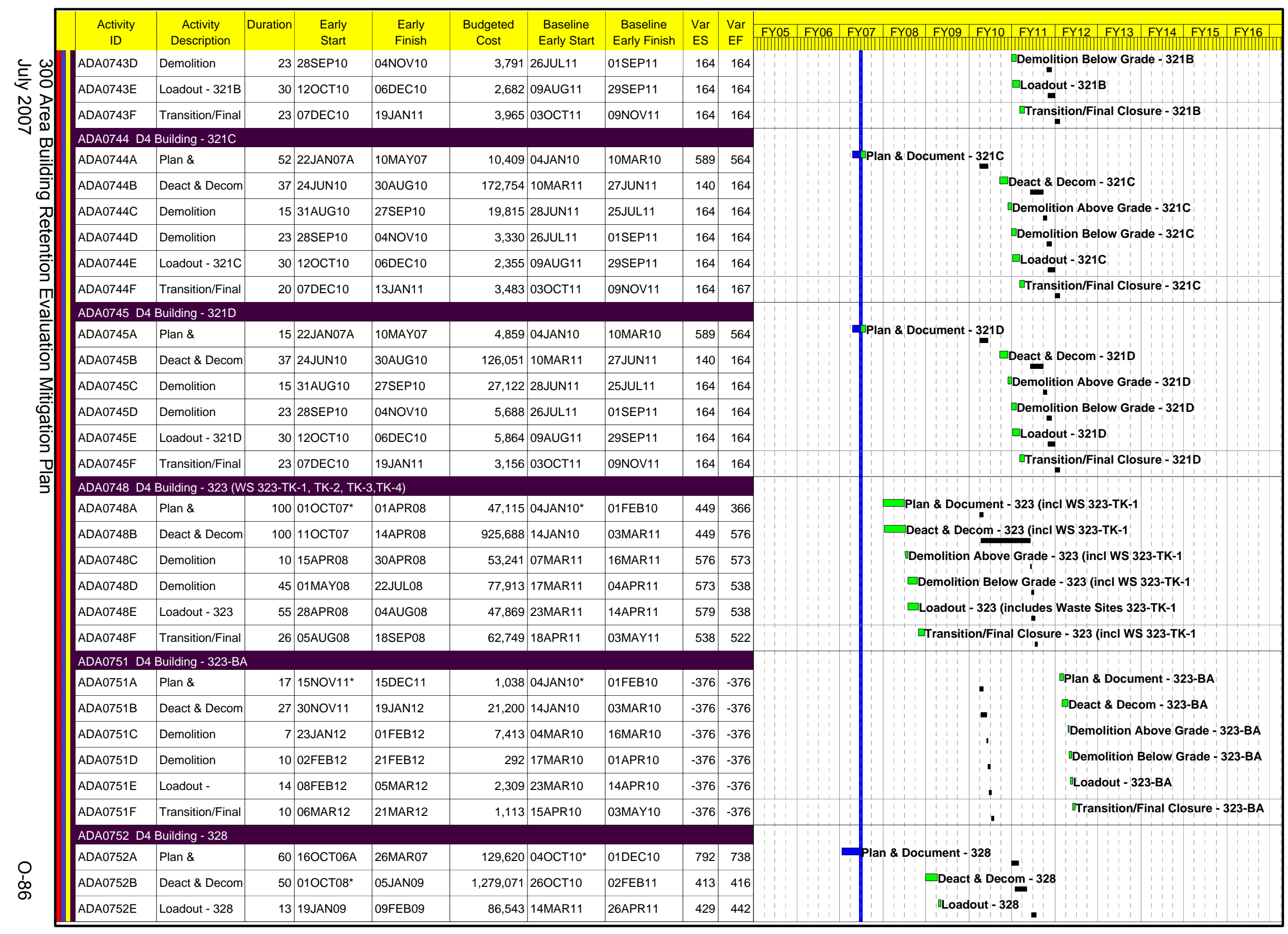




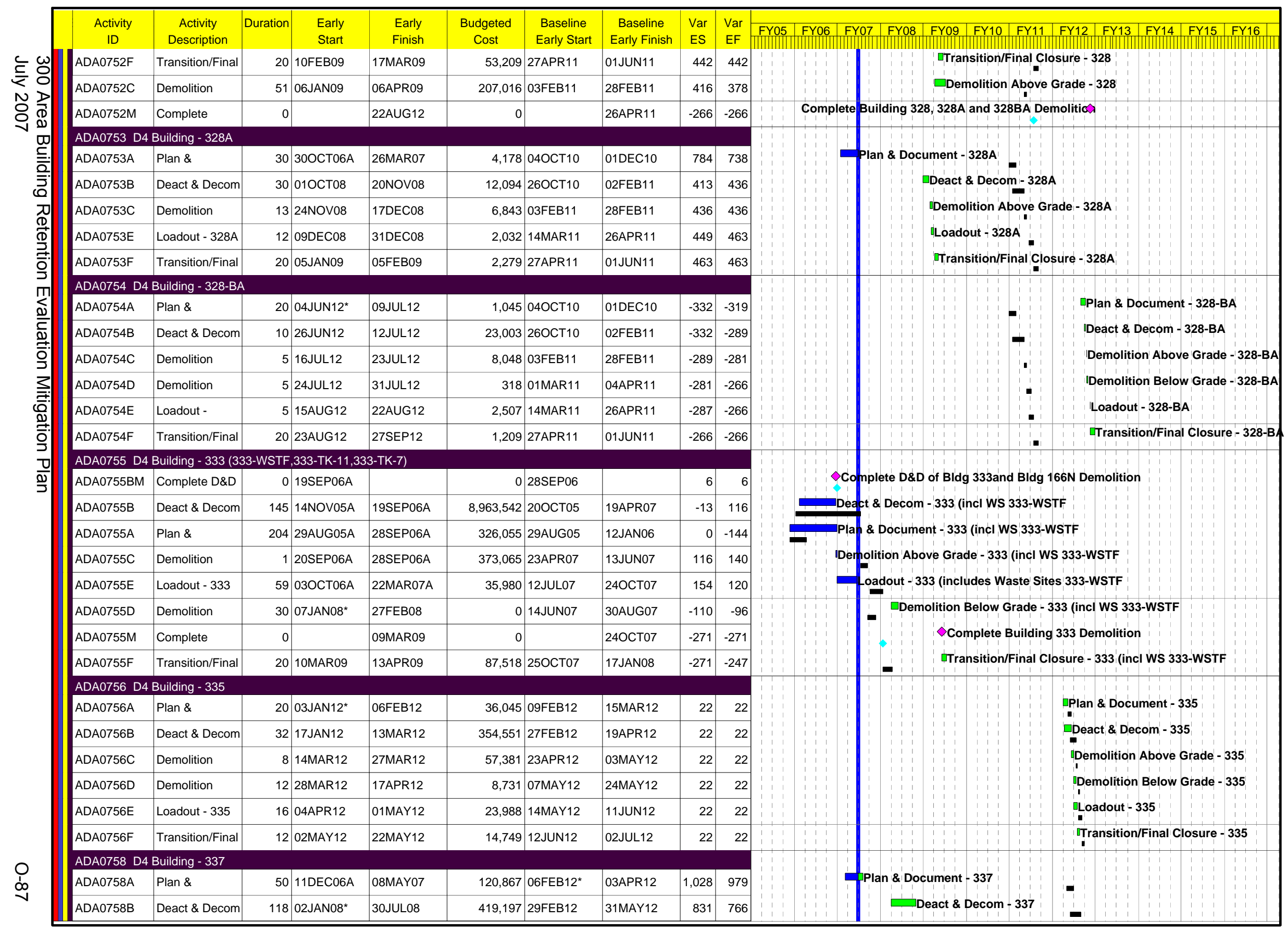




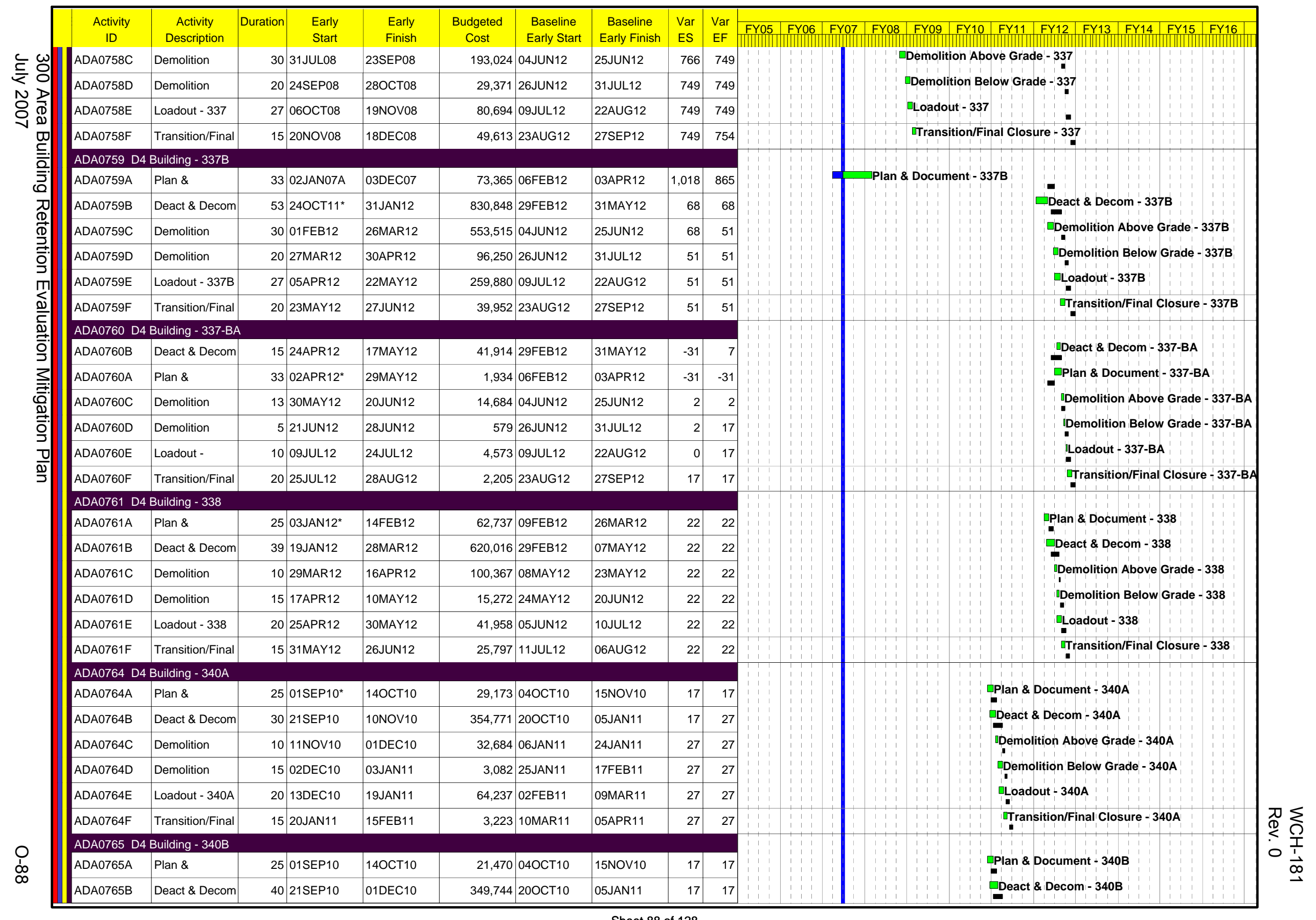

Sheet 88 of 128 


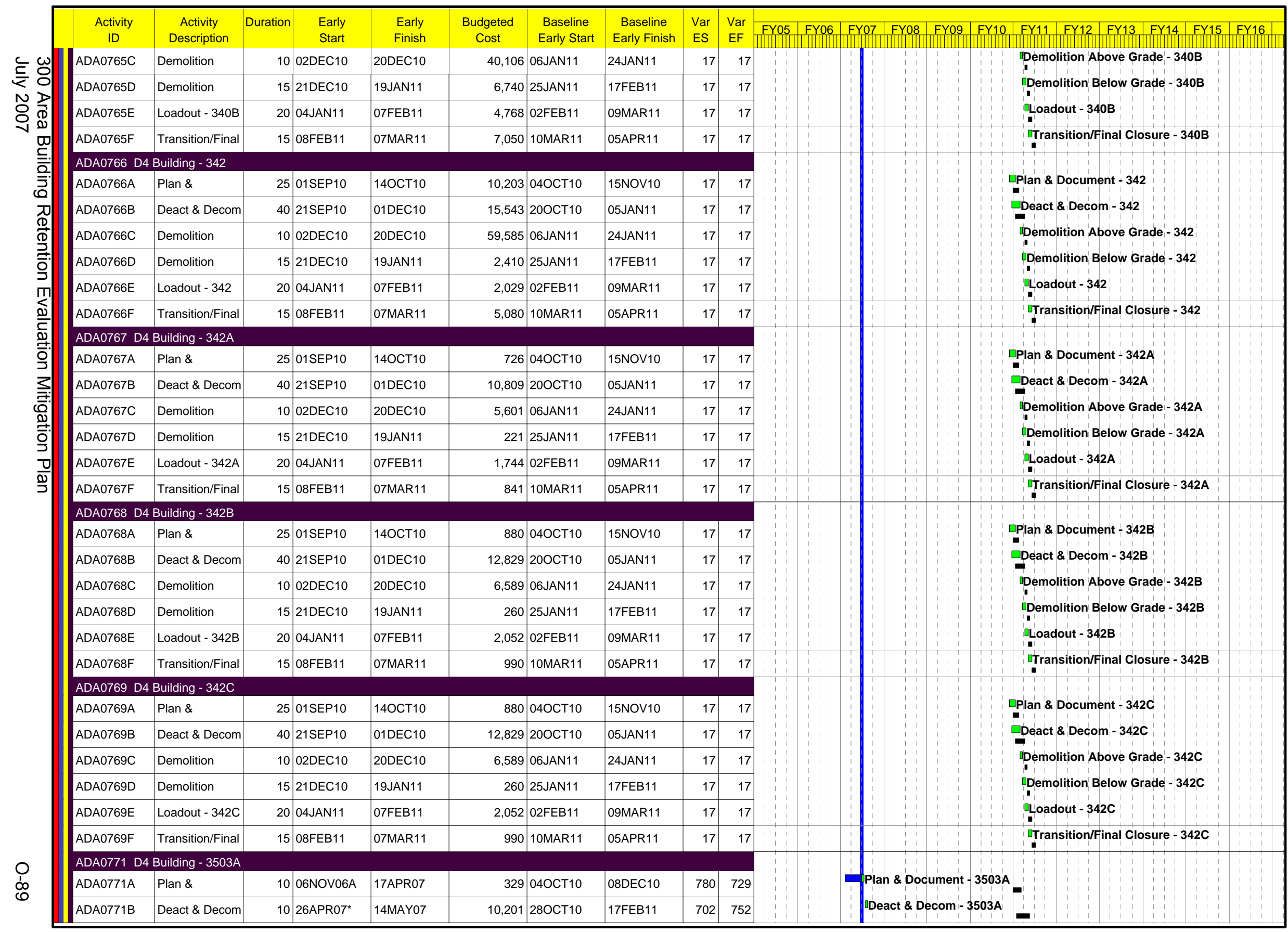




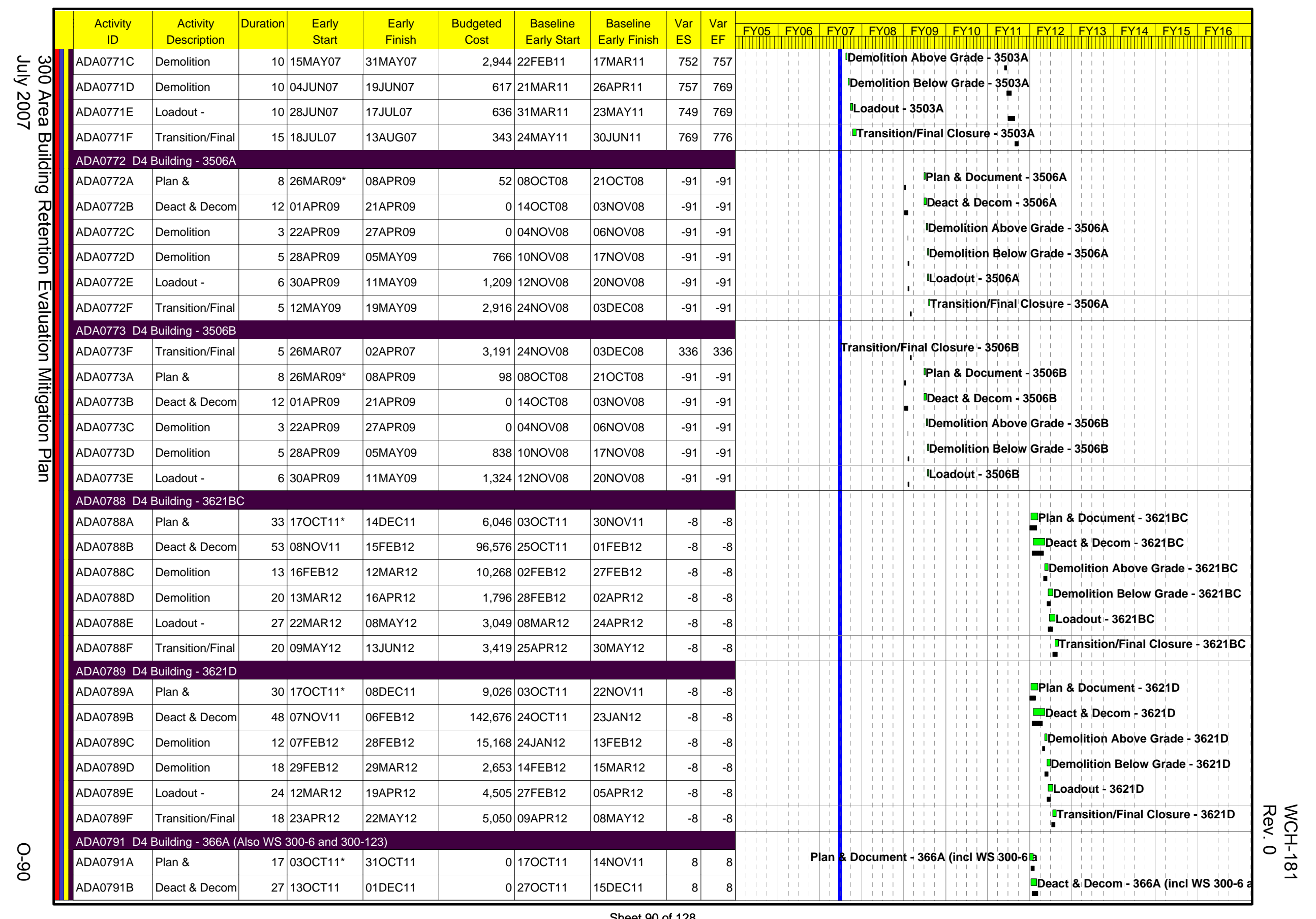




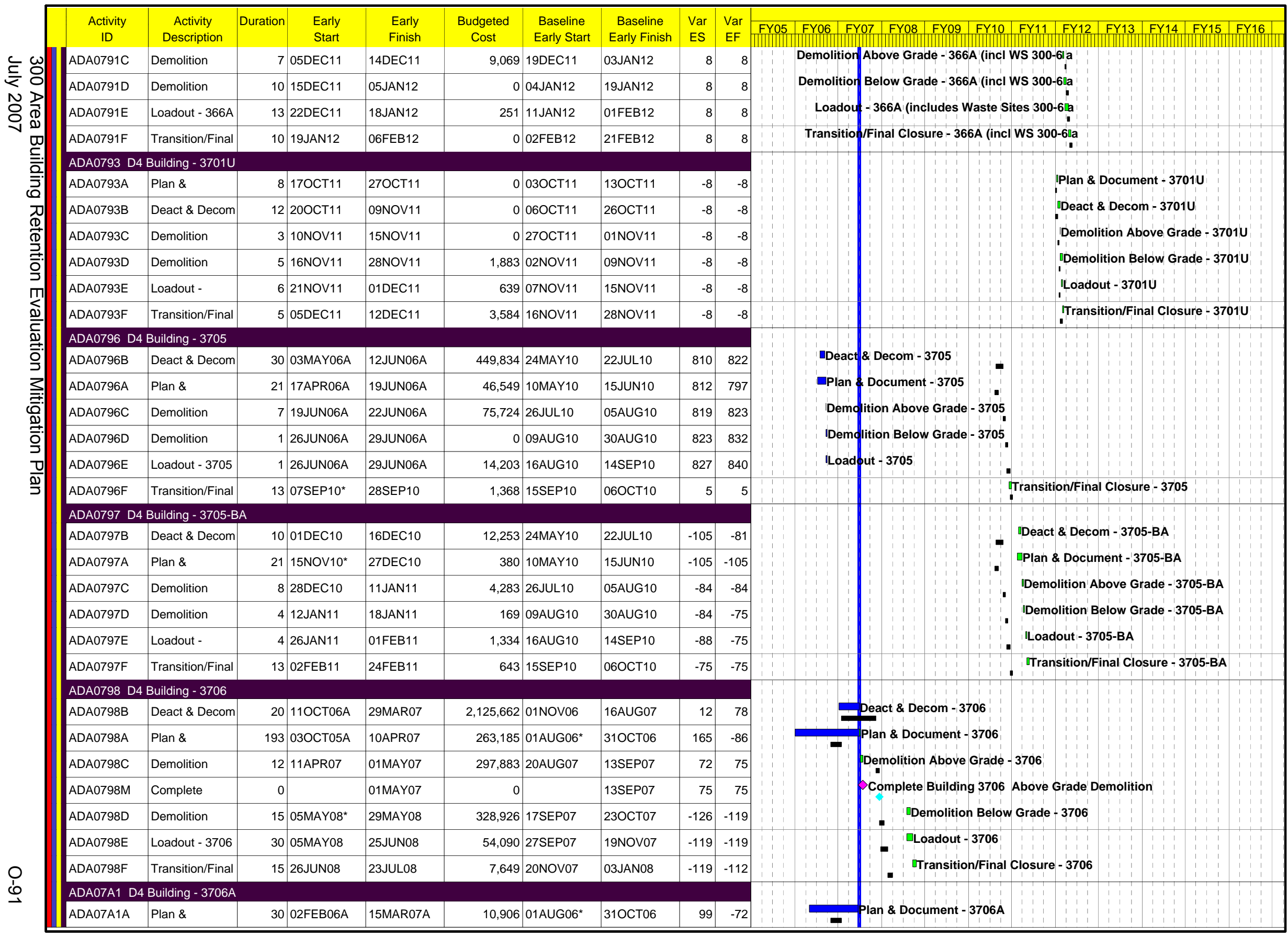




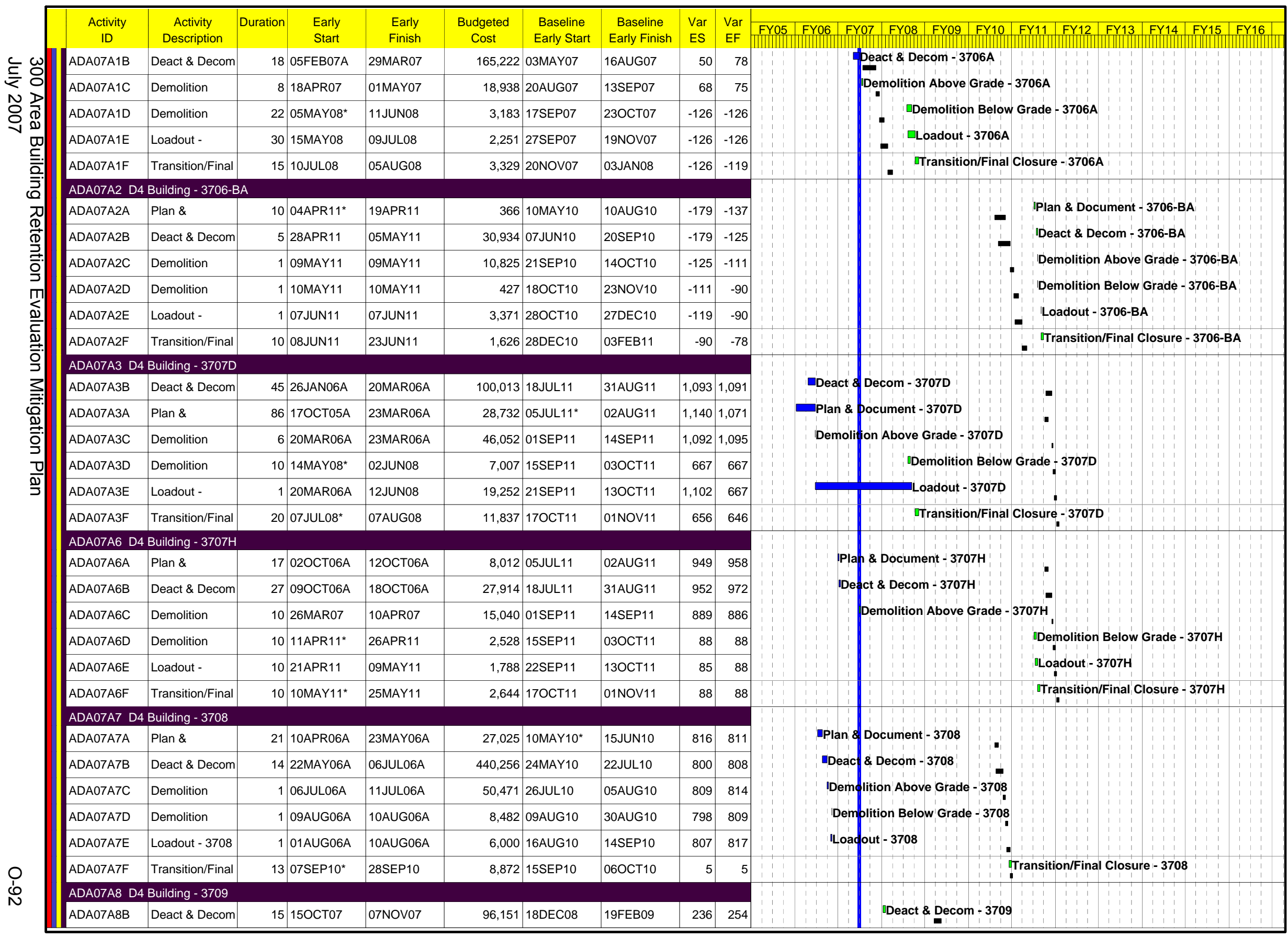




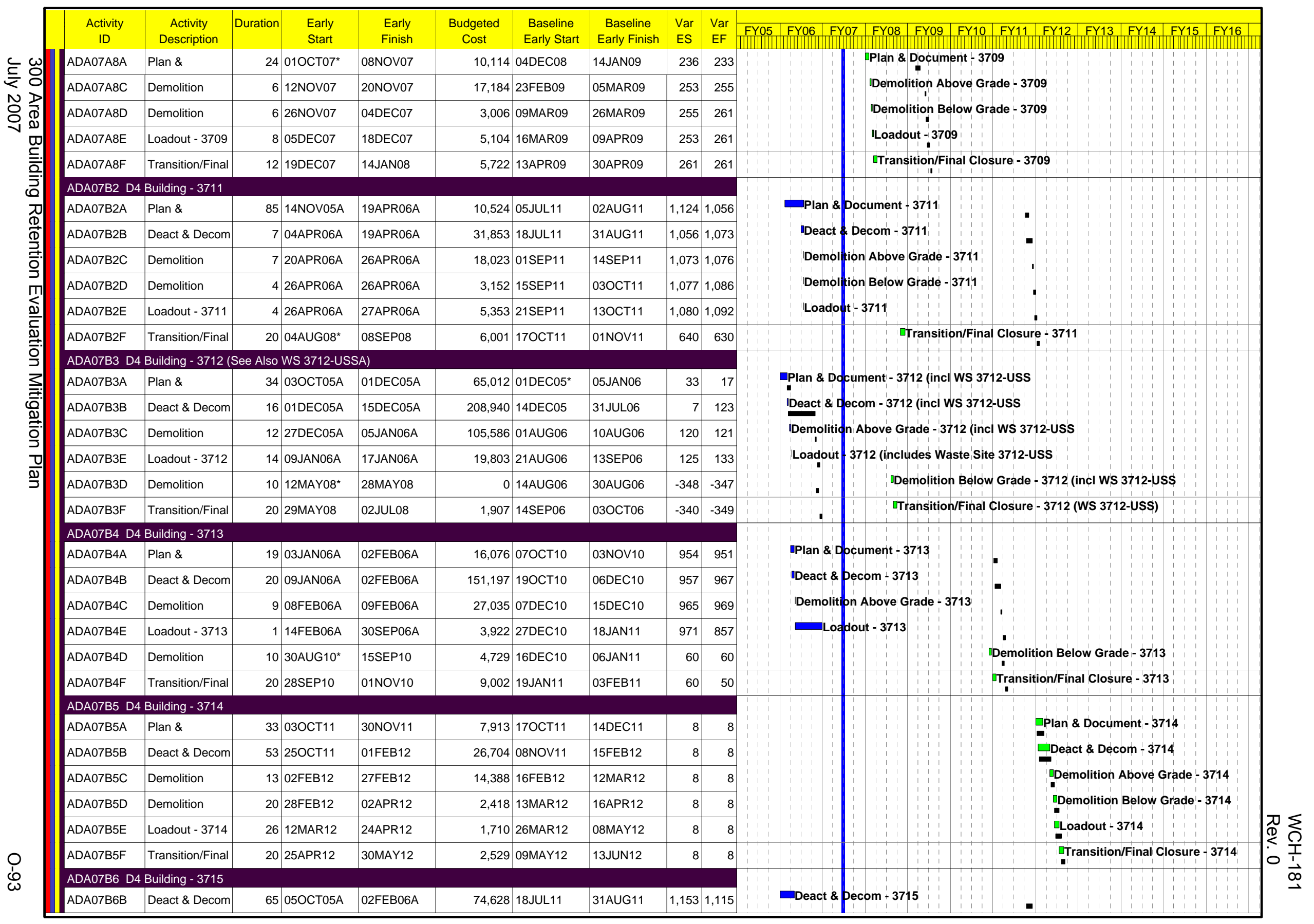

Sheet 93 of 128 


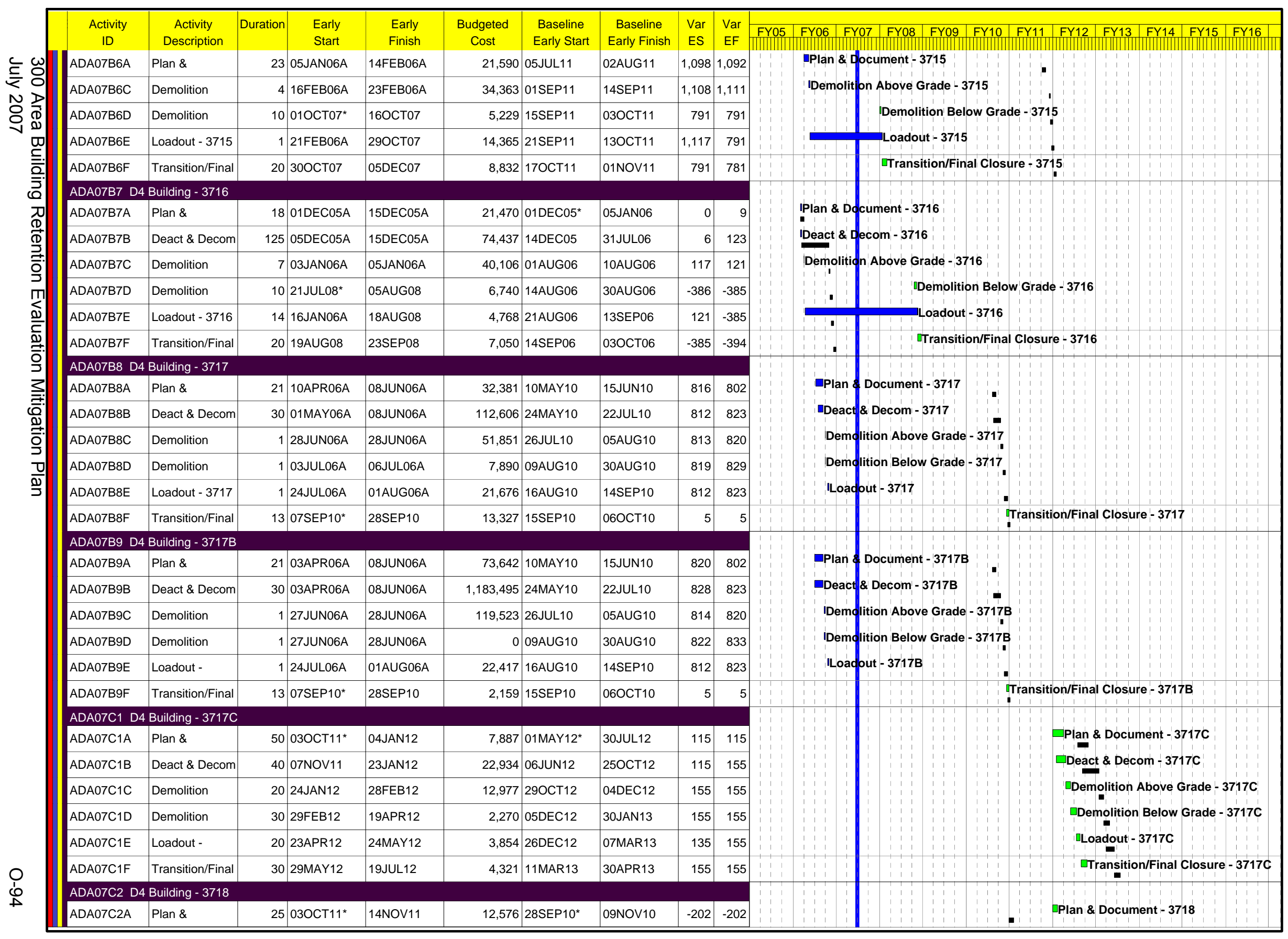




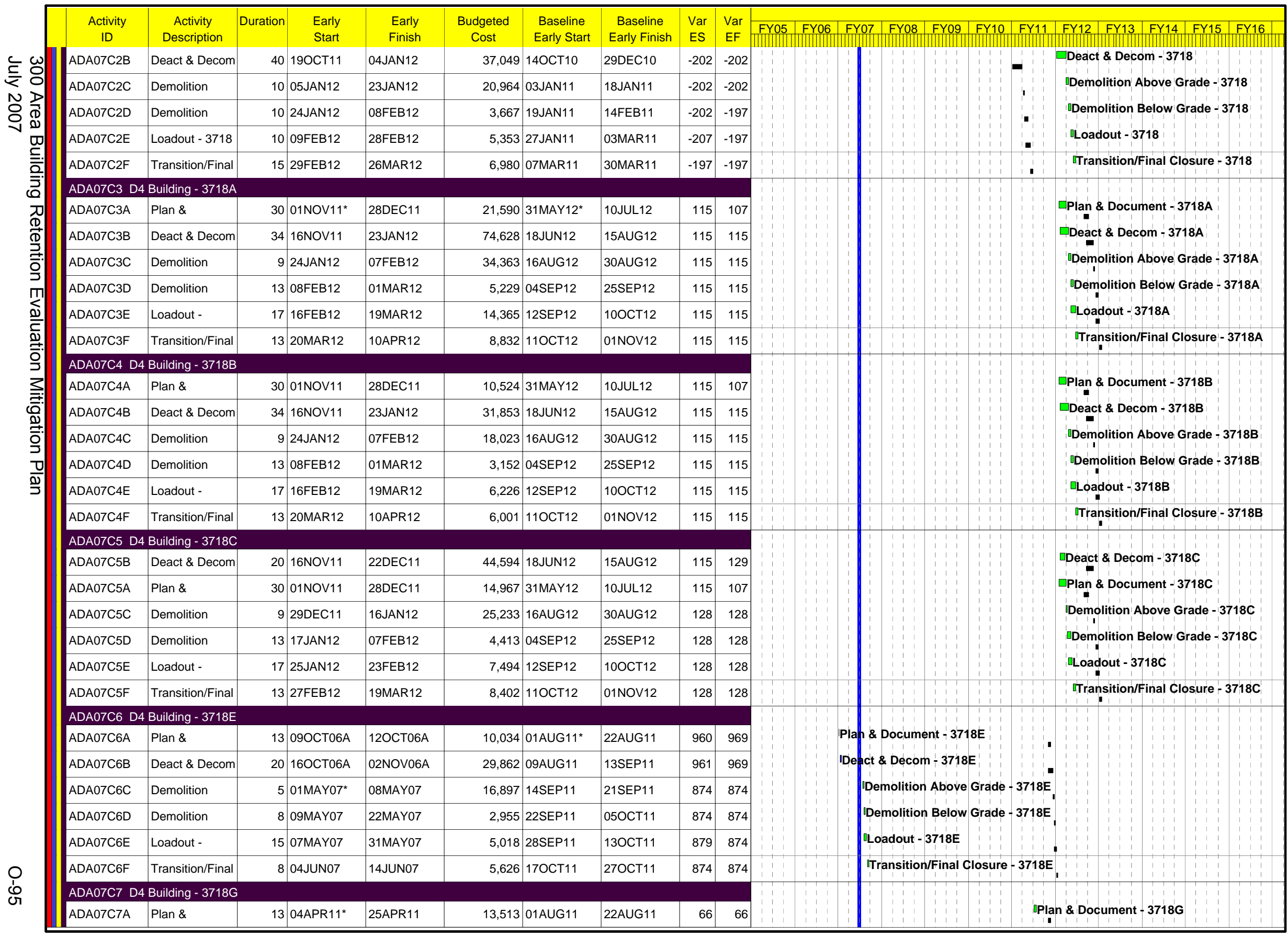




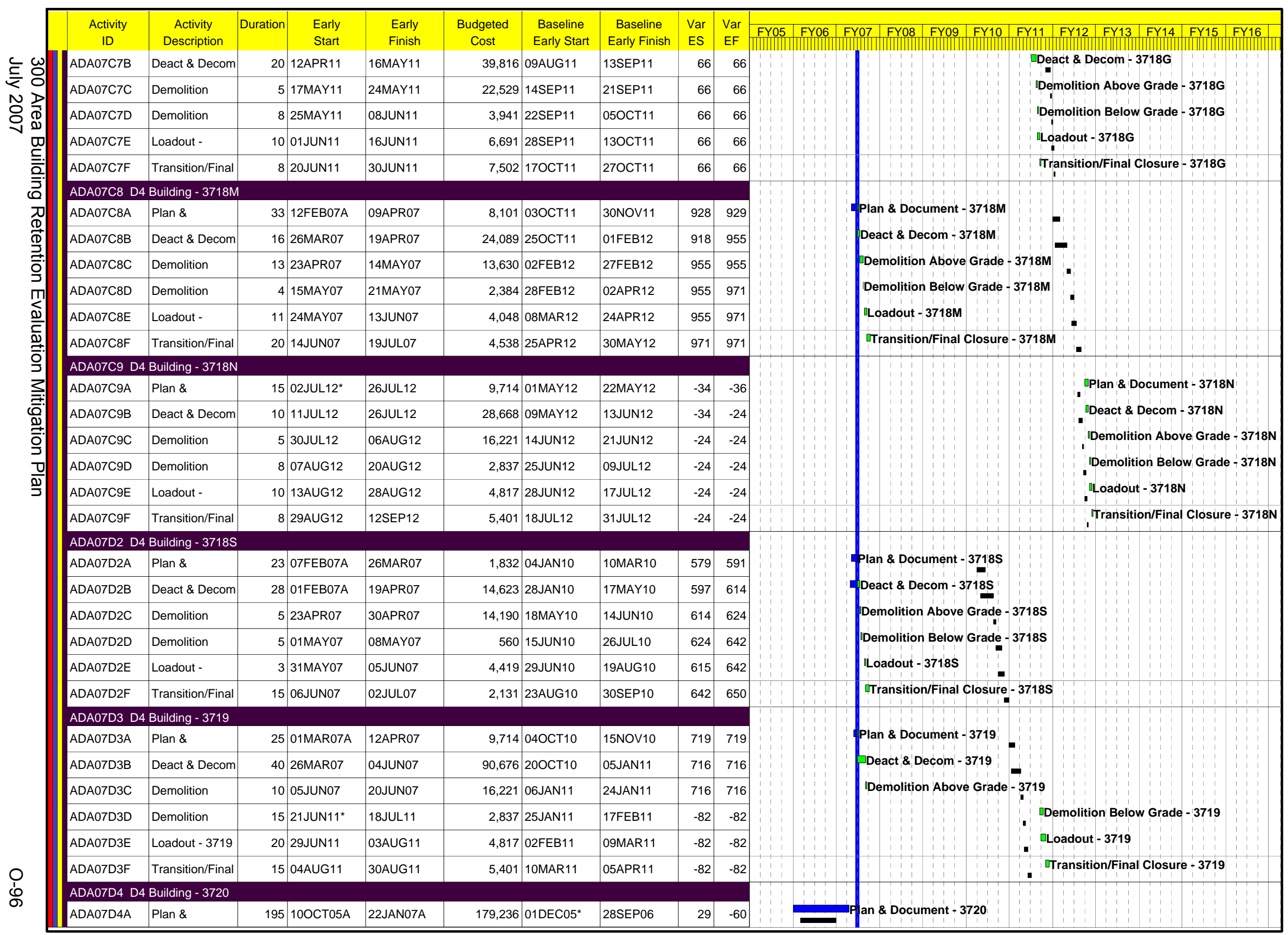




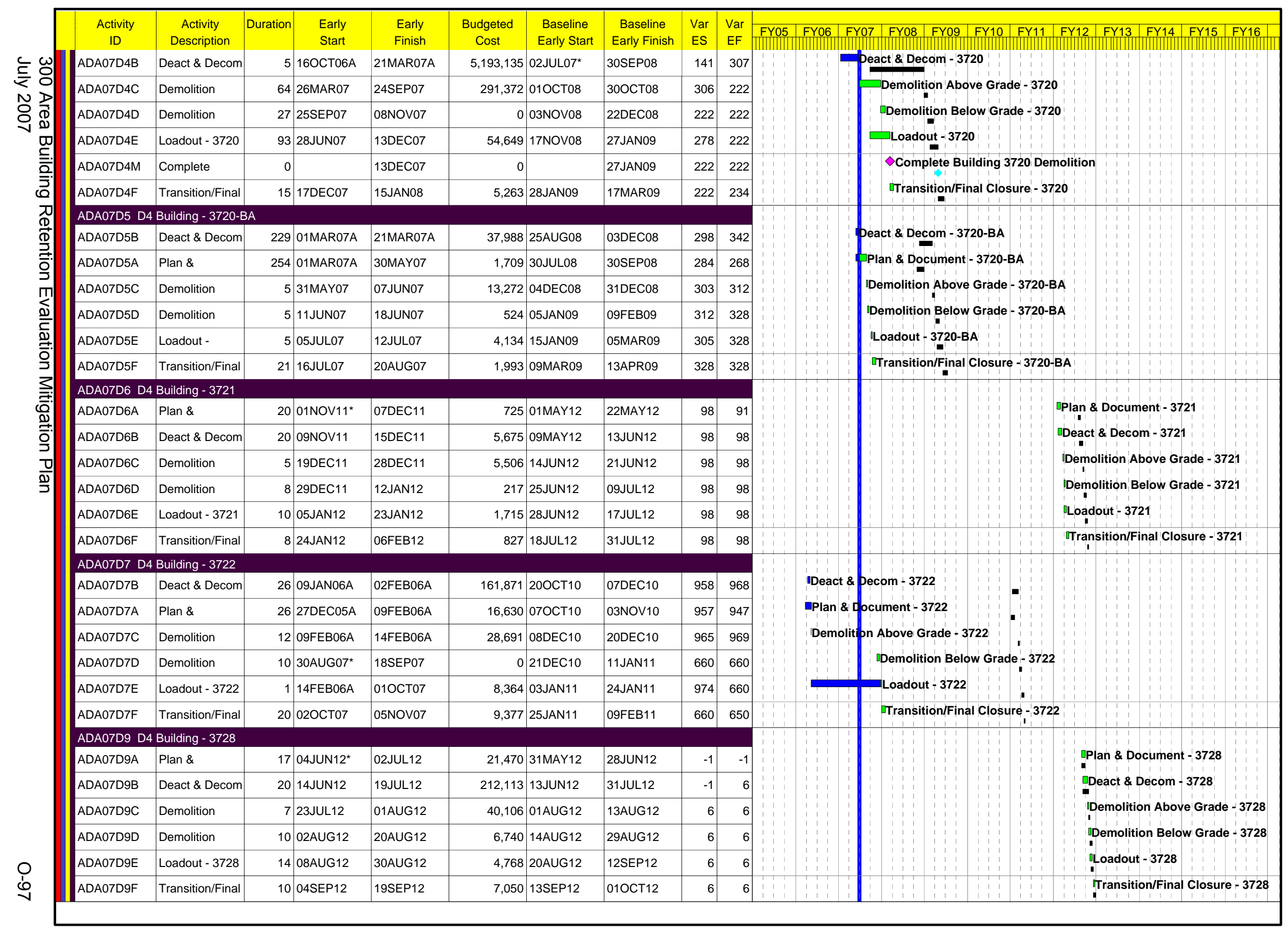




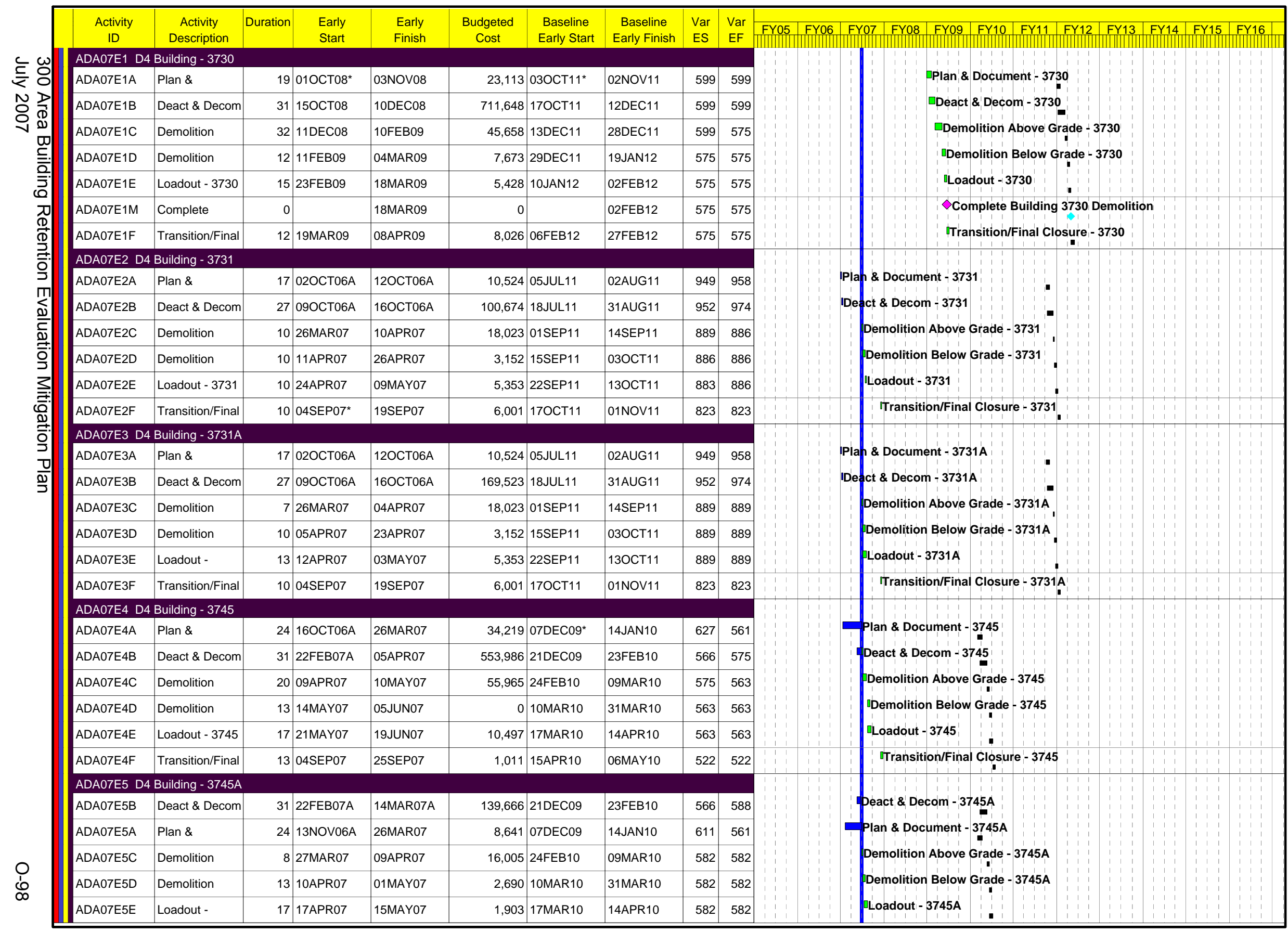




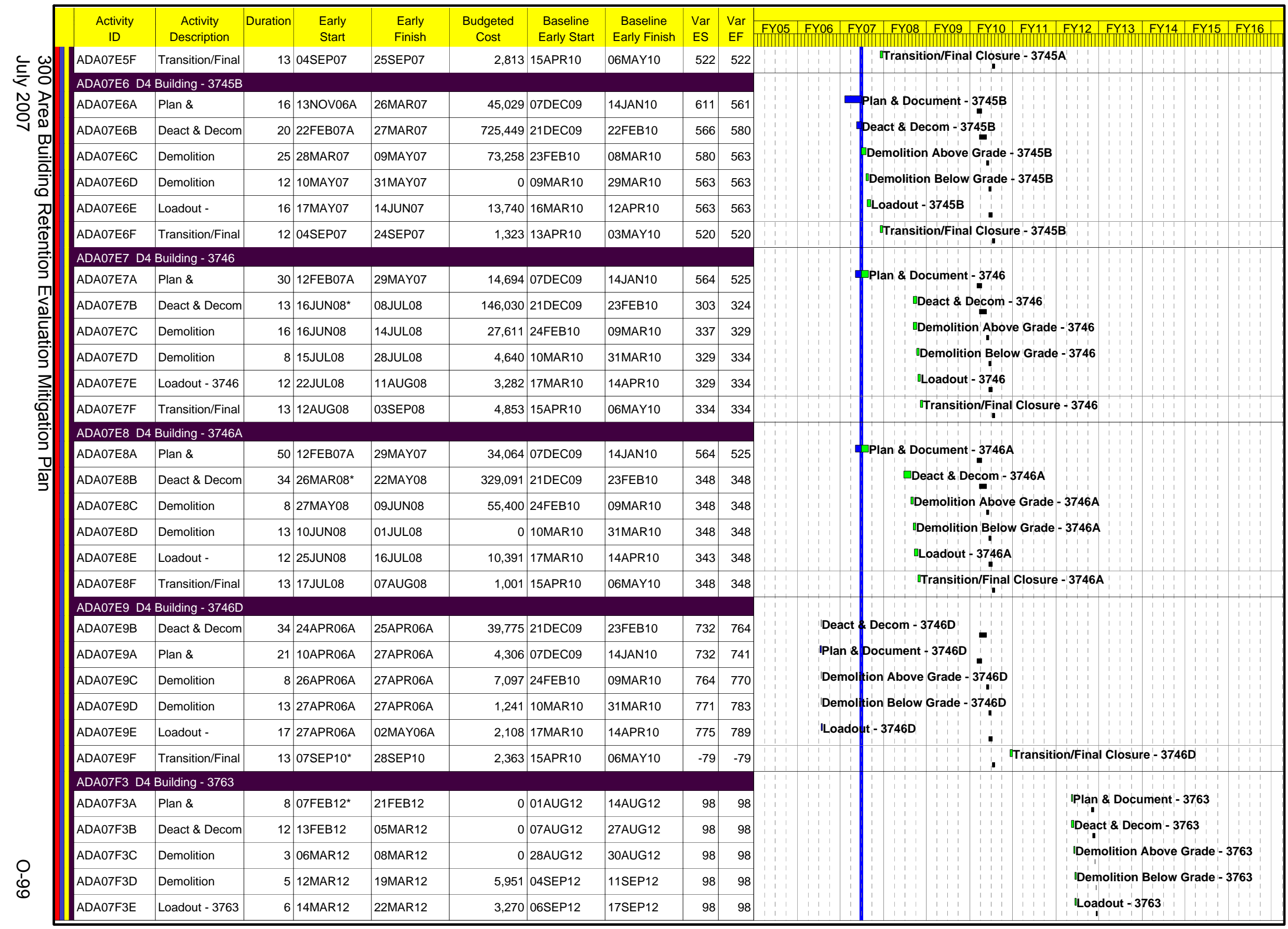




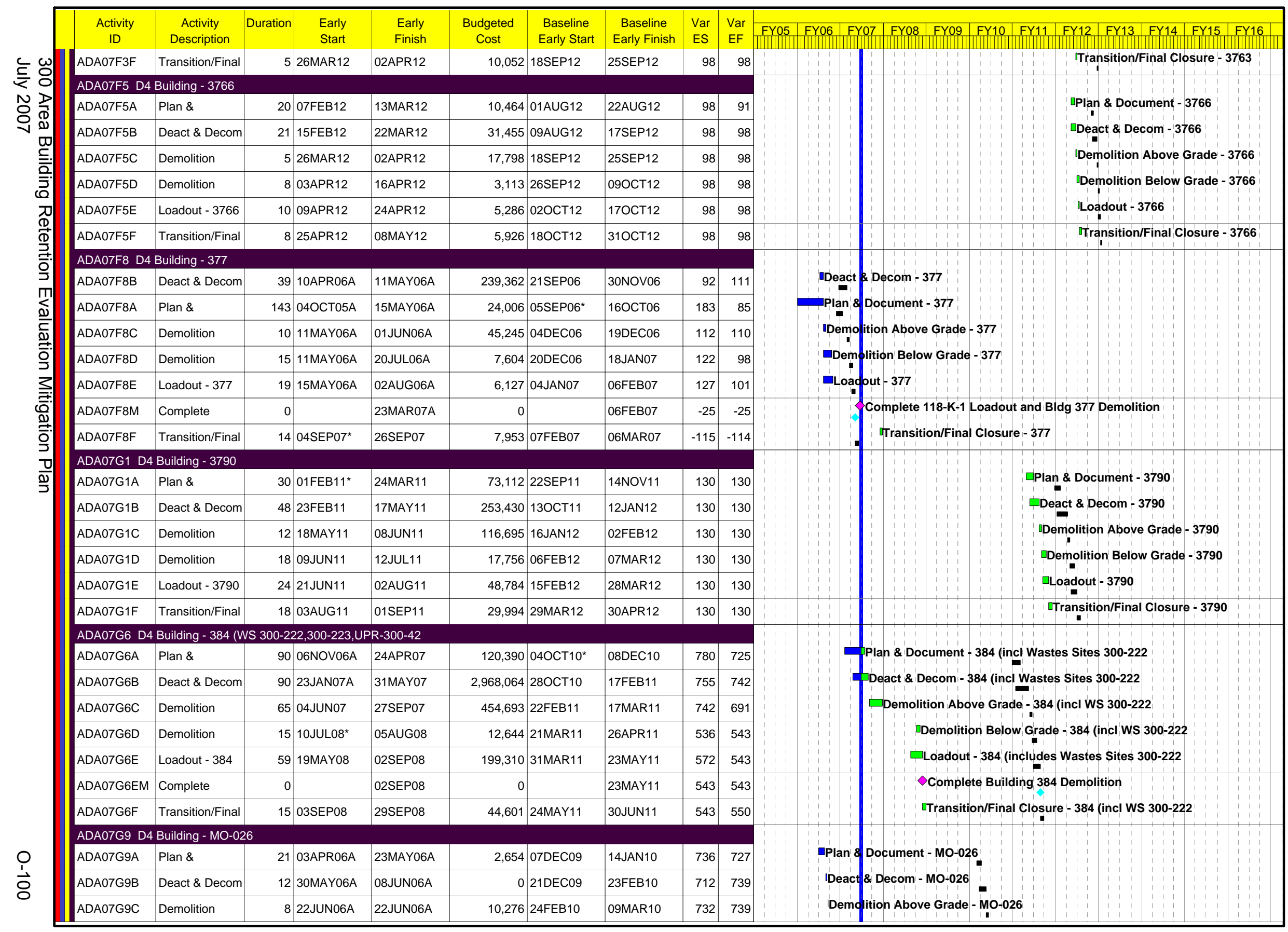




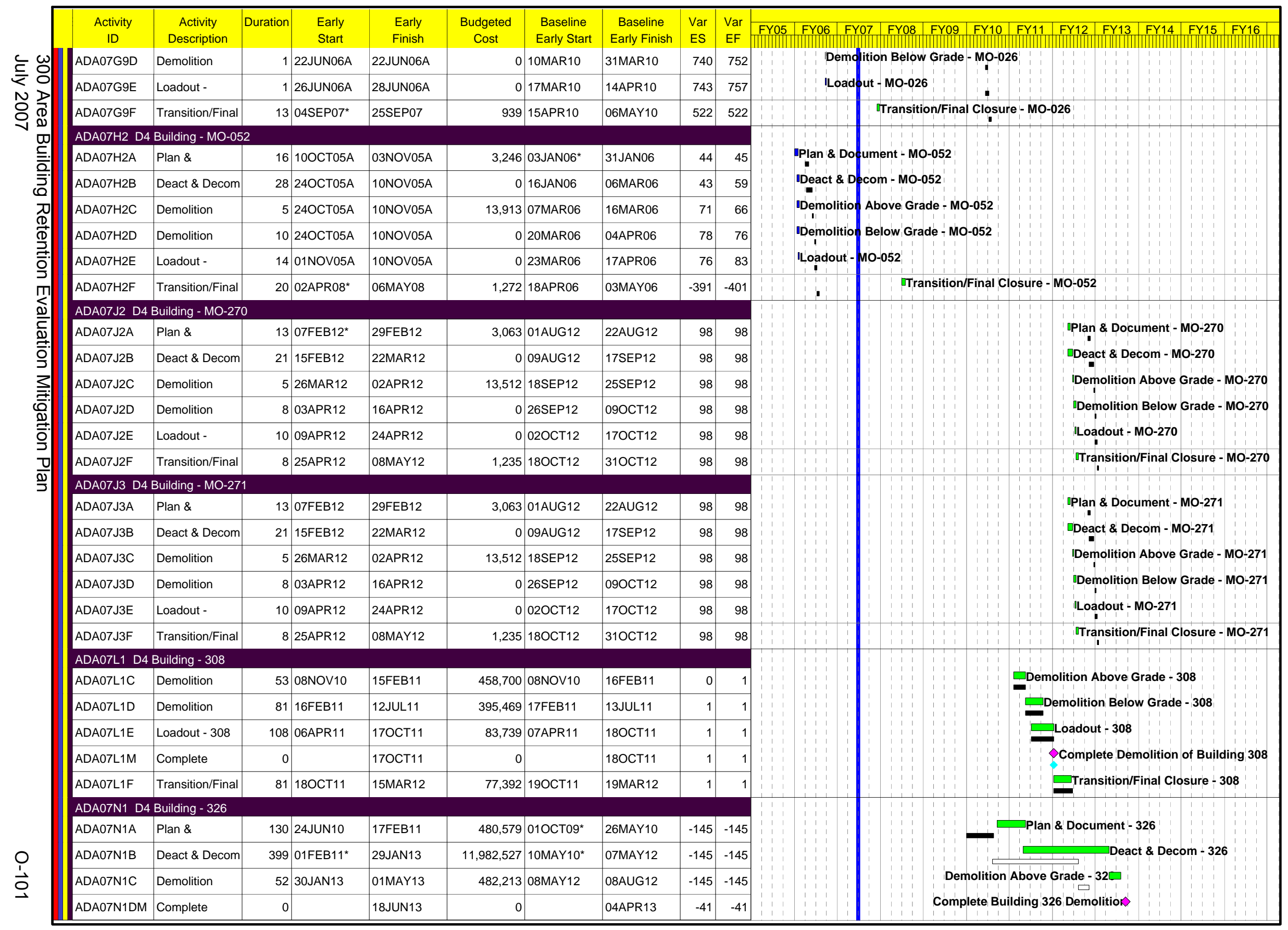




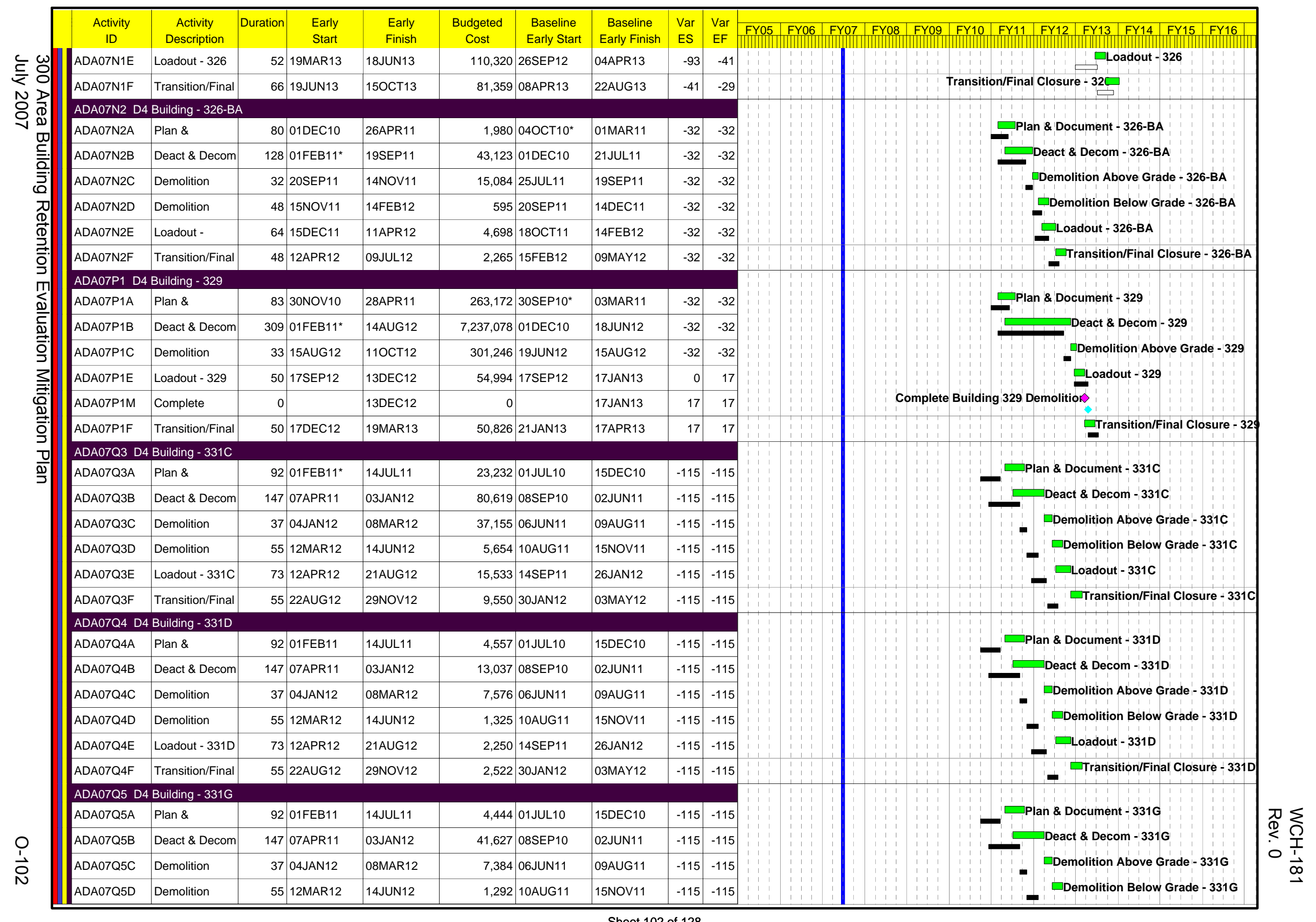




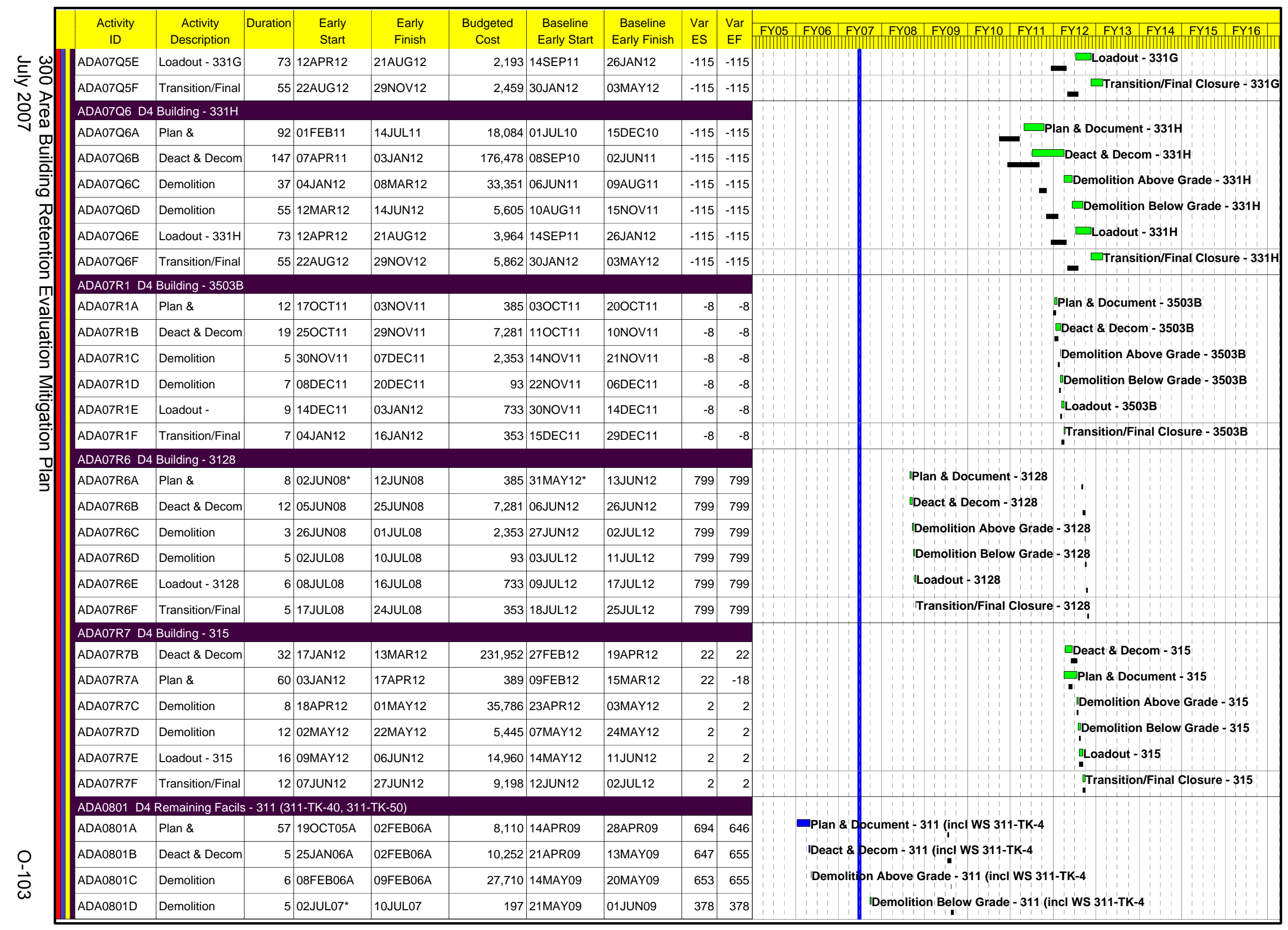




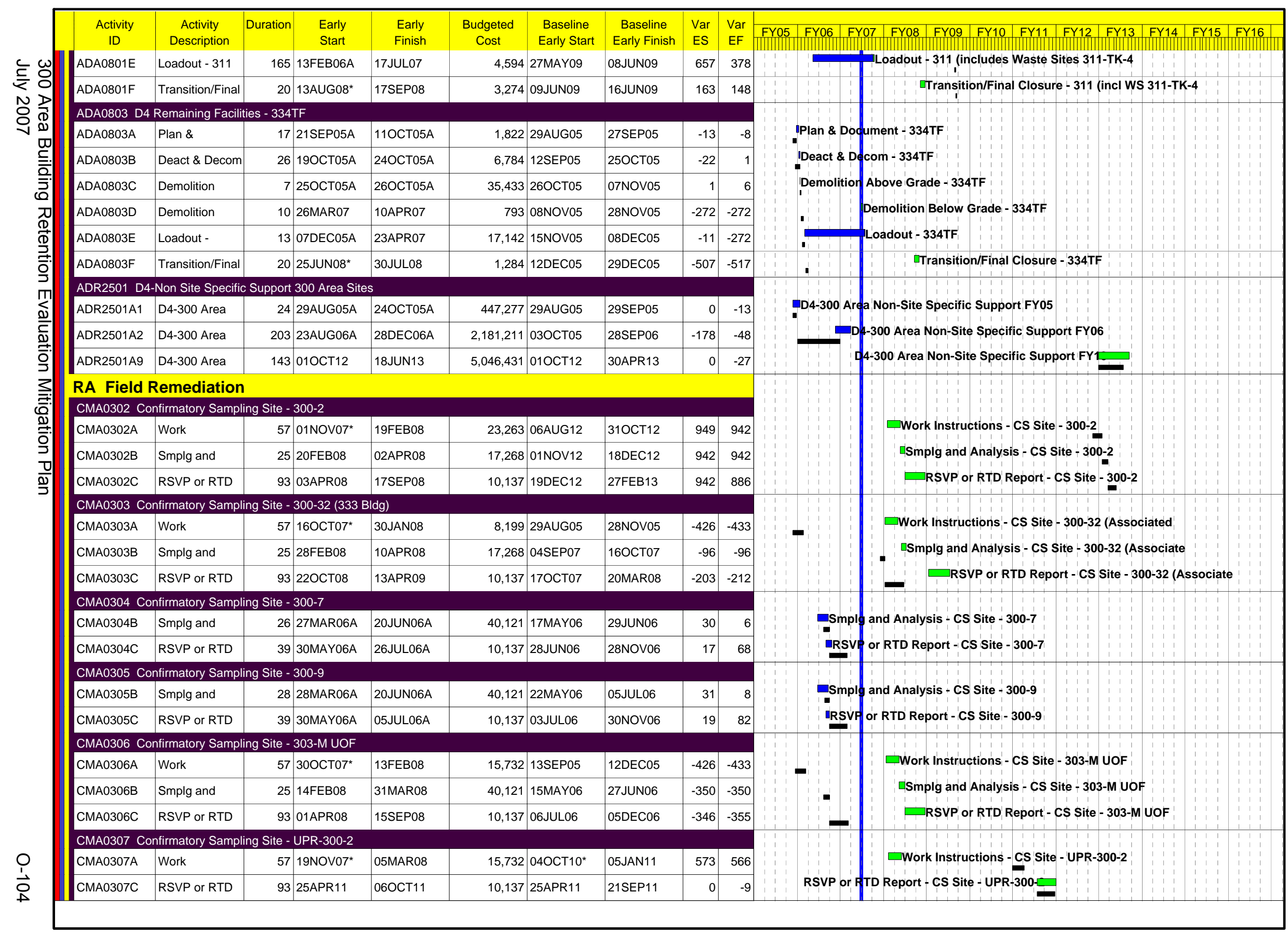




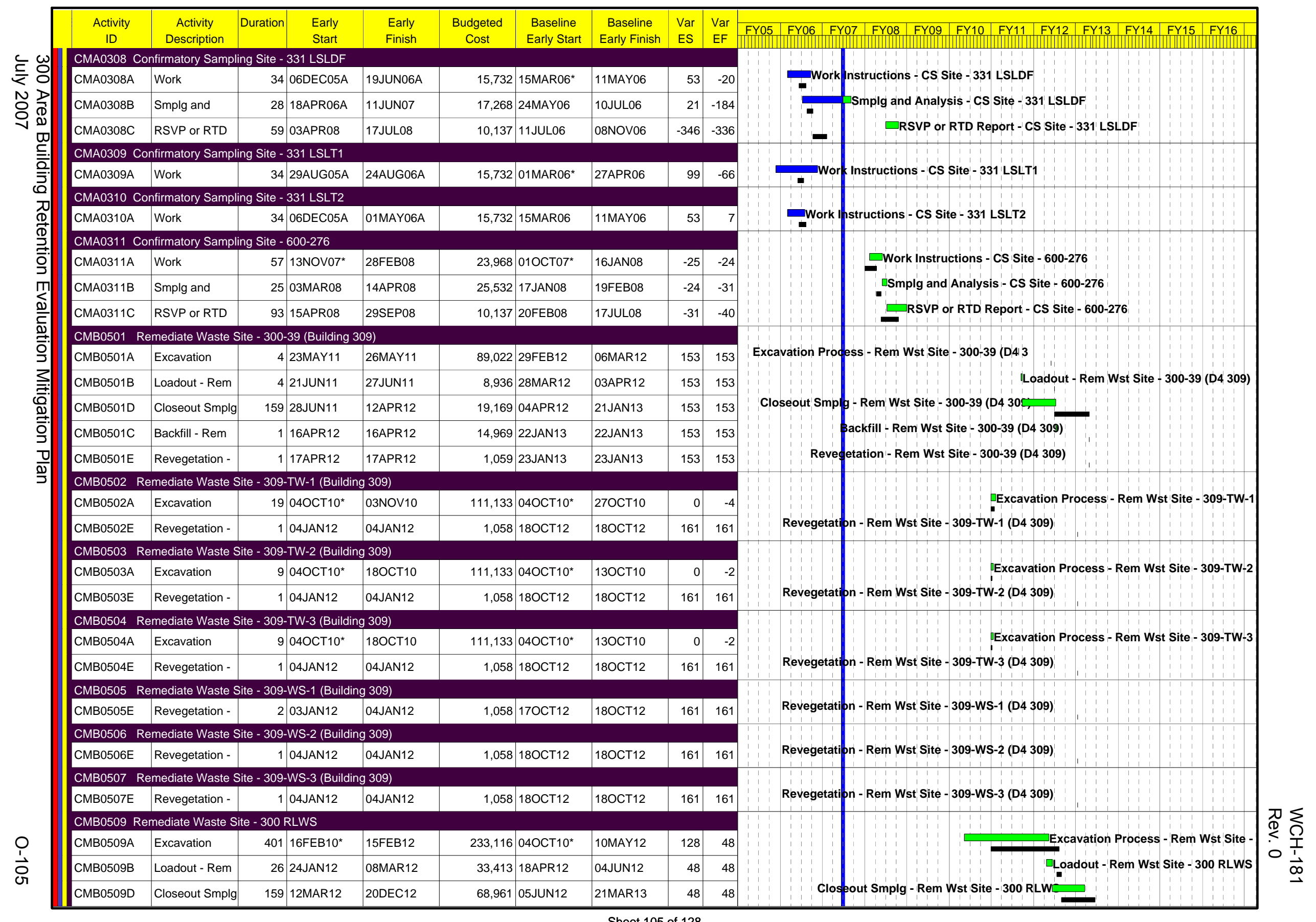




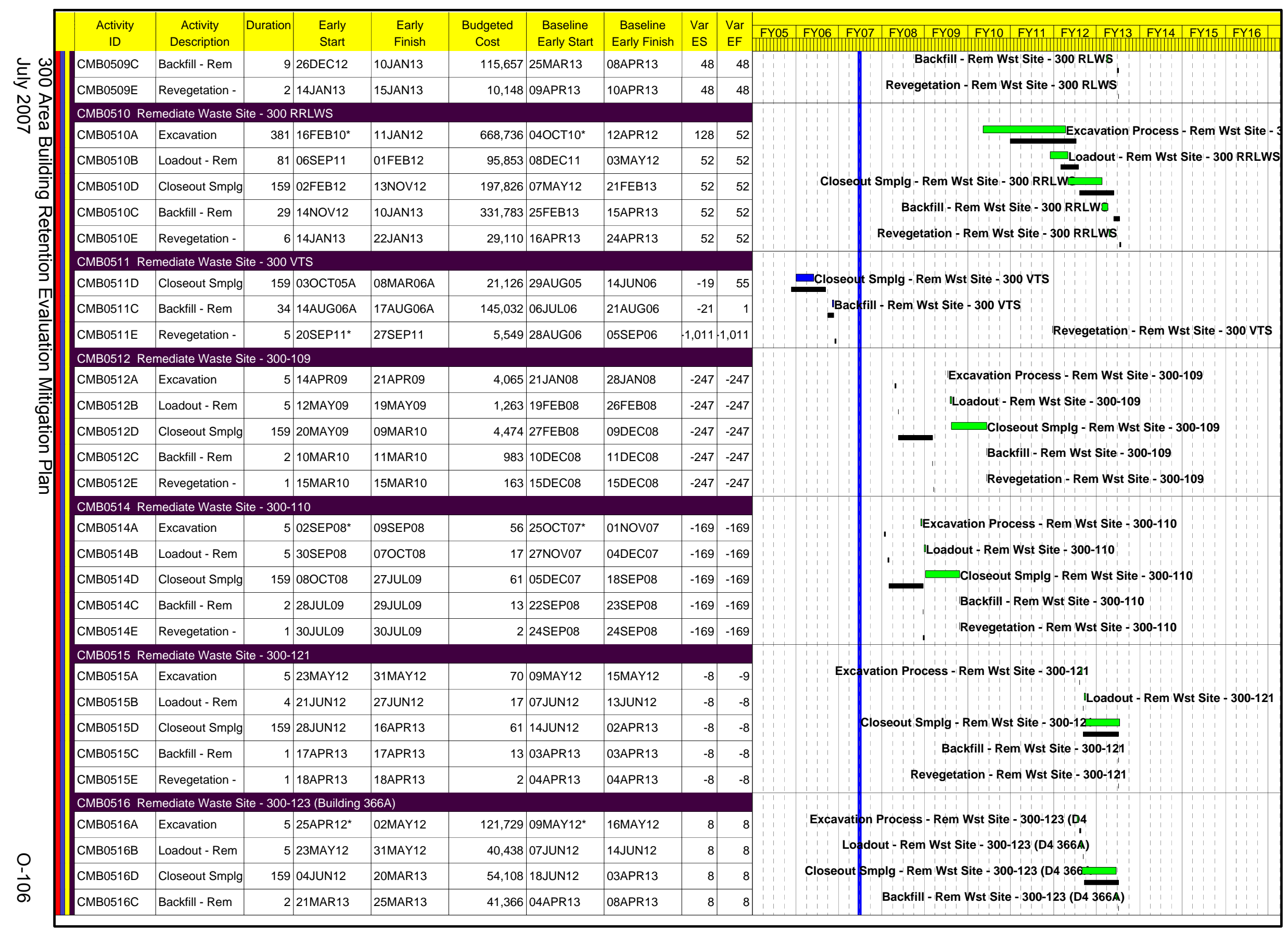




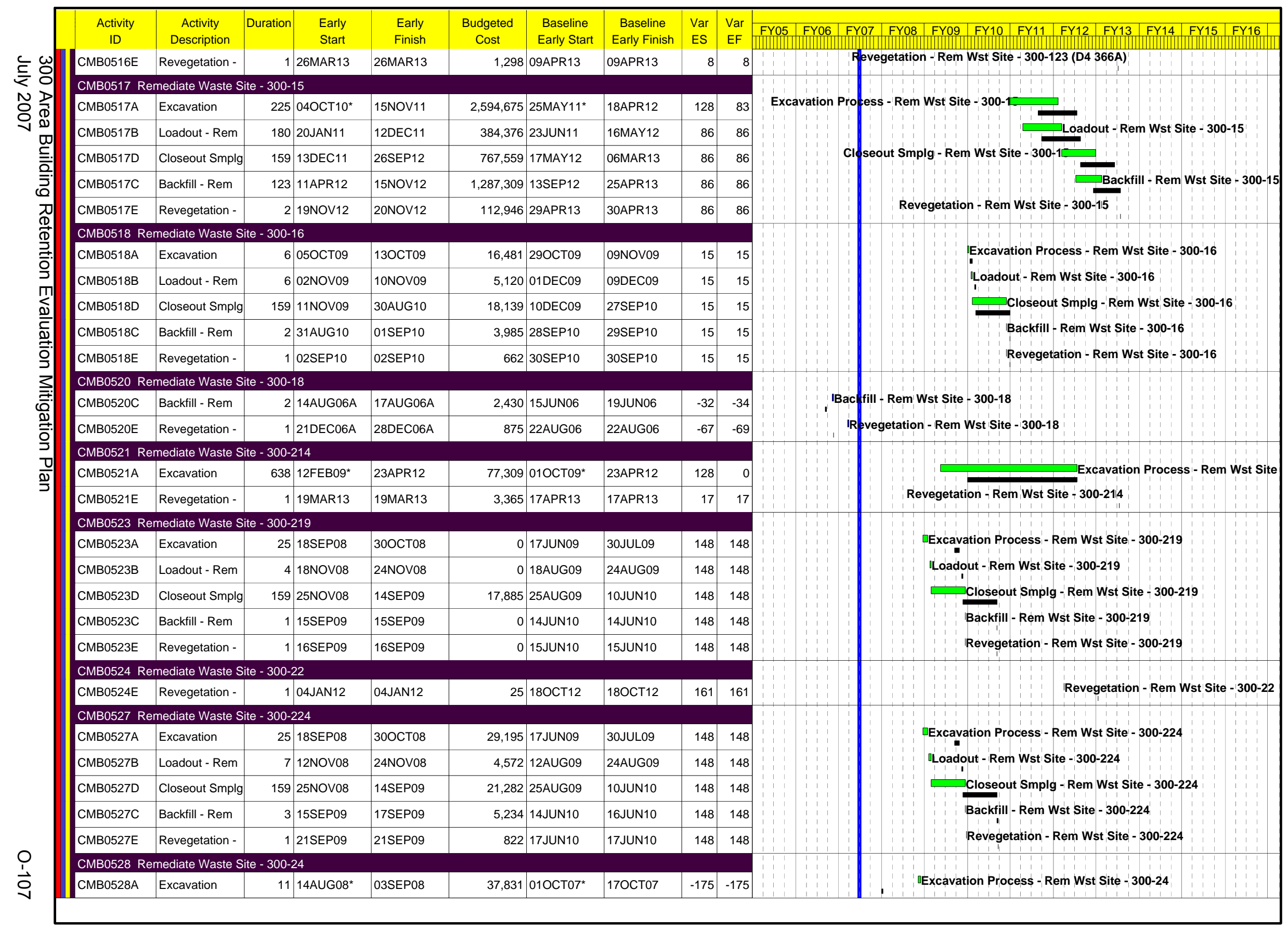




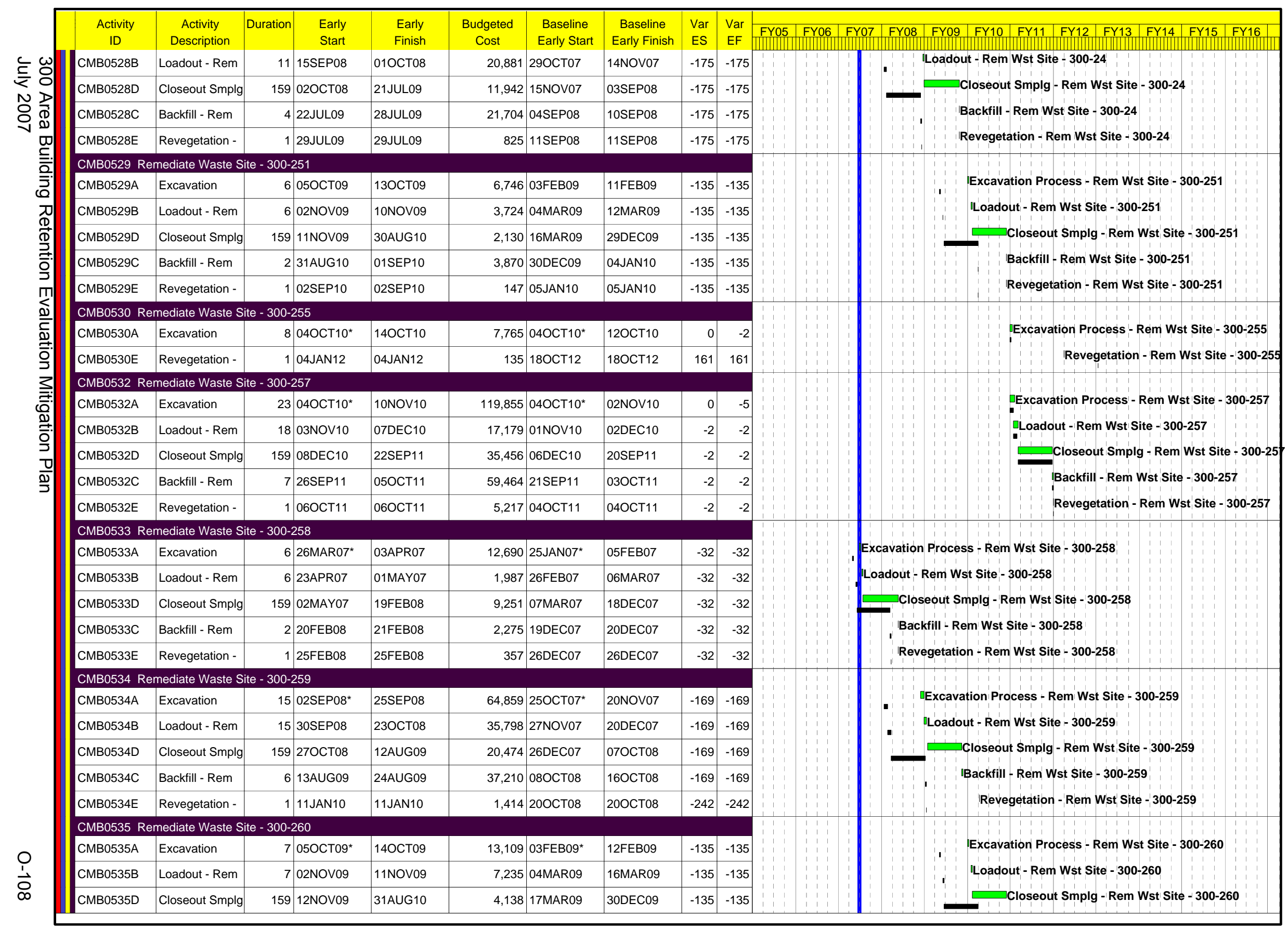




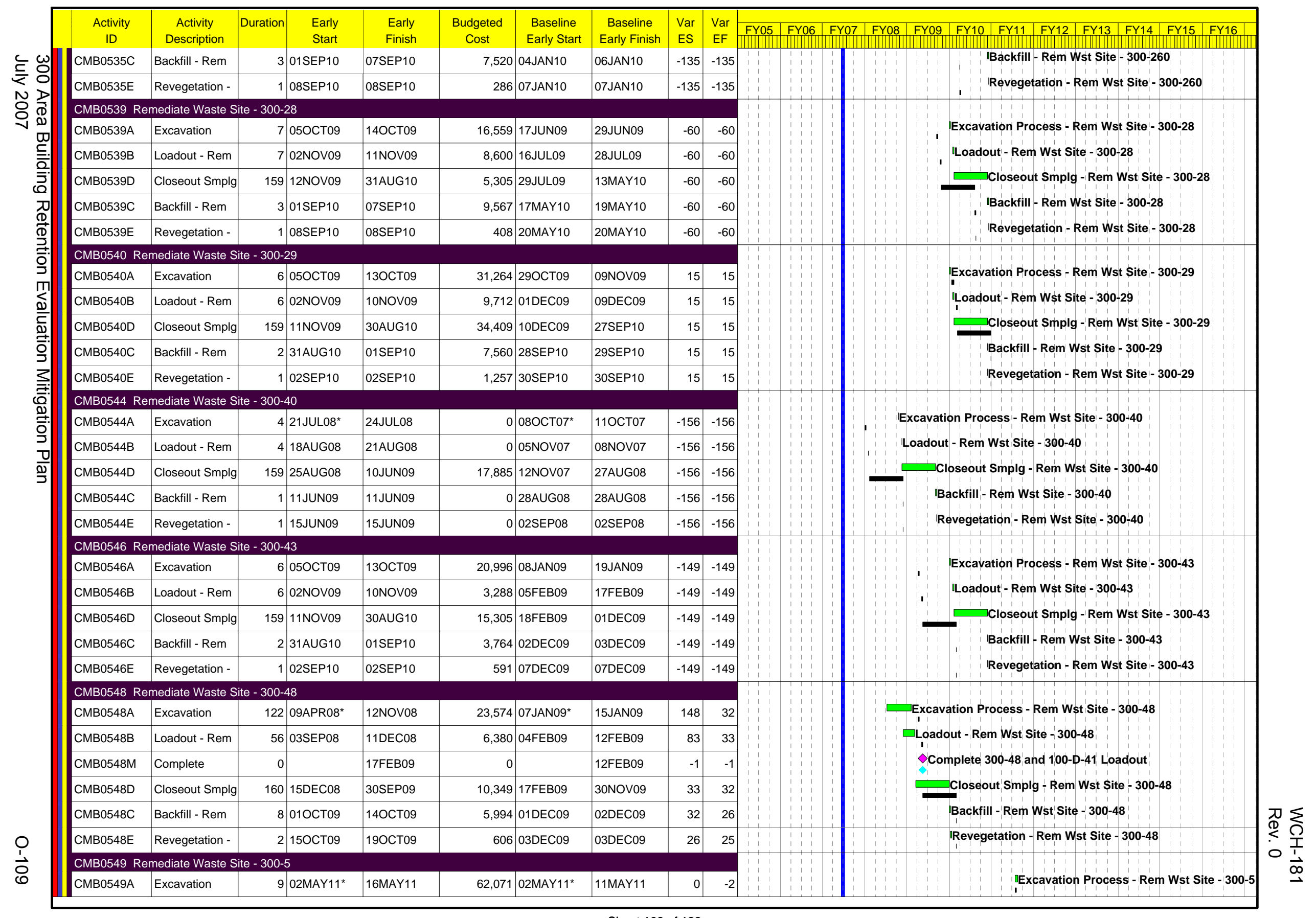




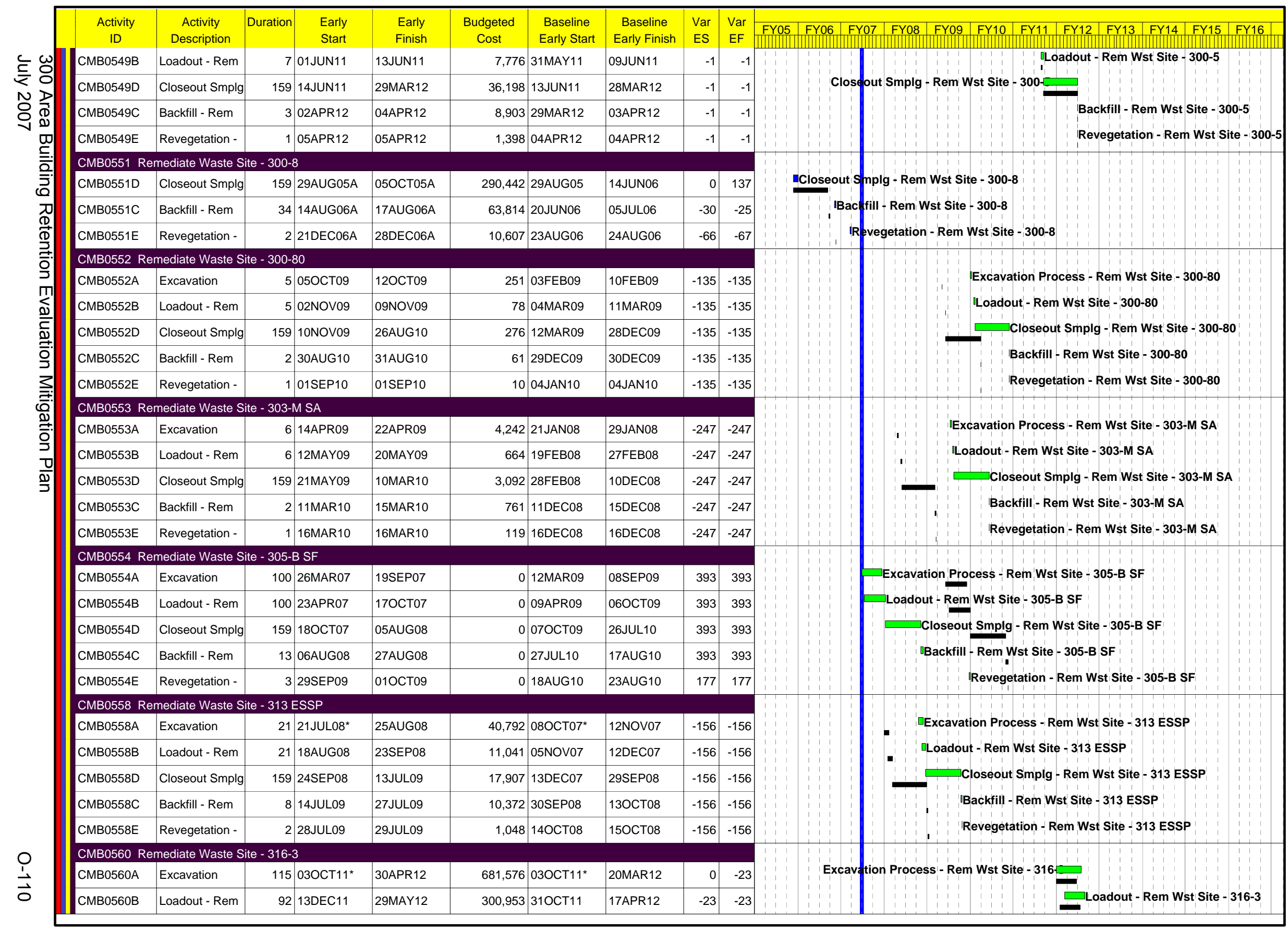




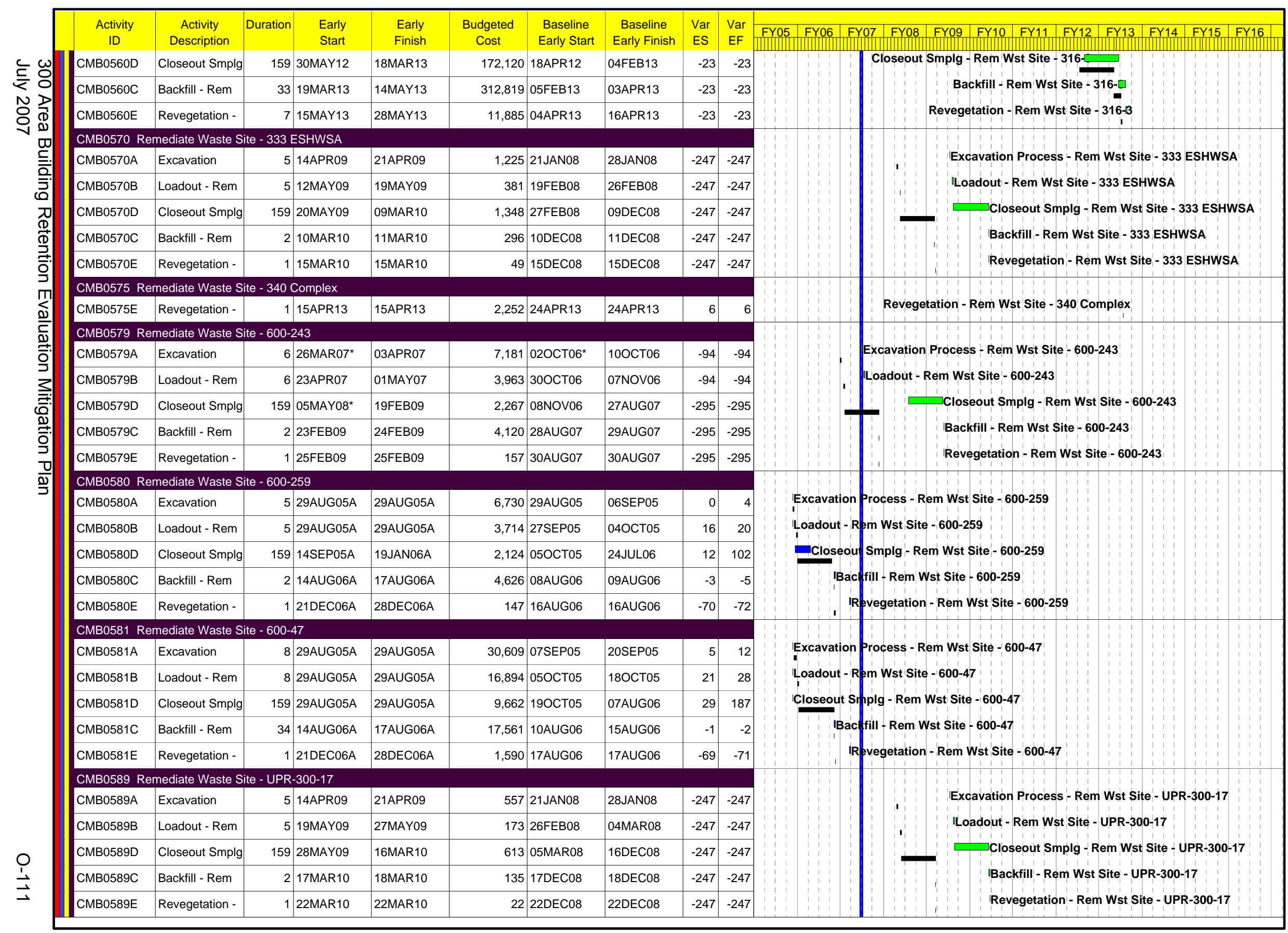




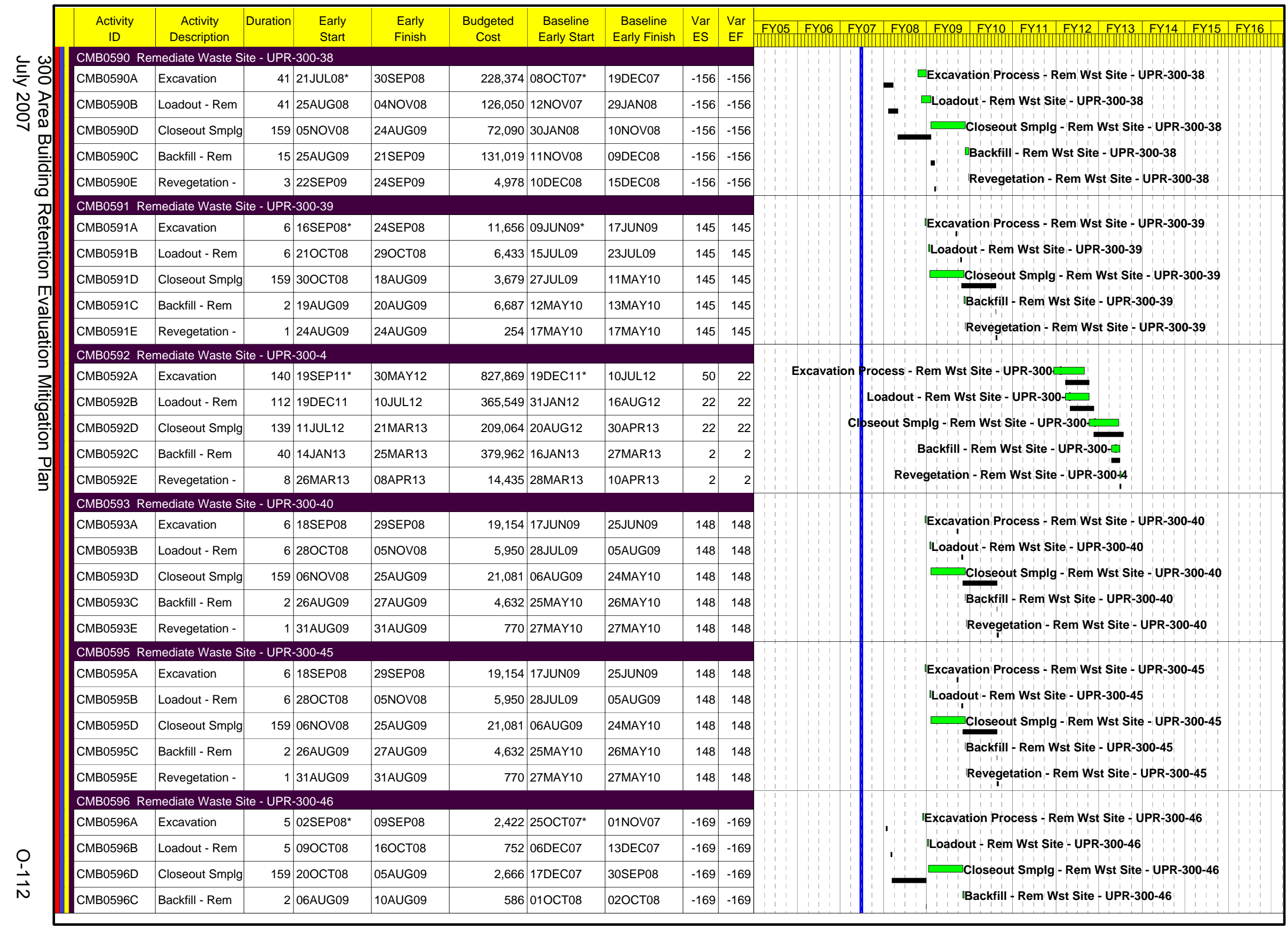




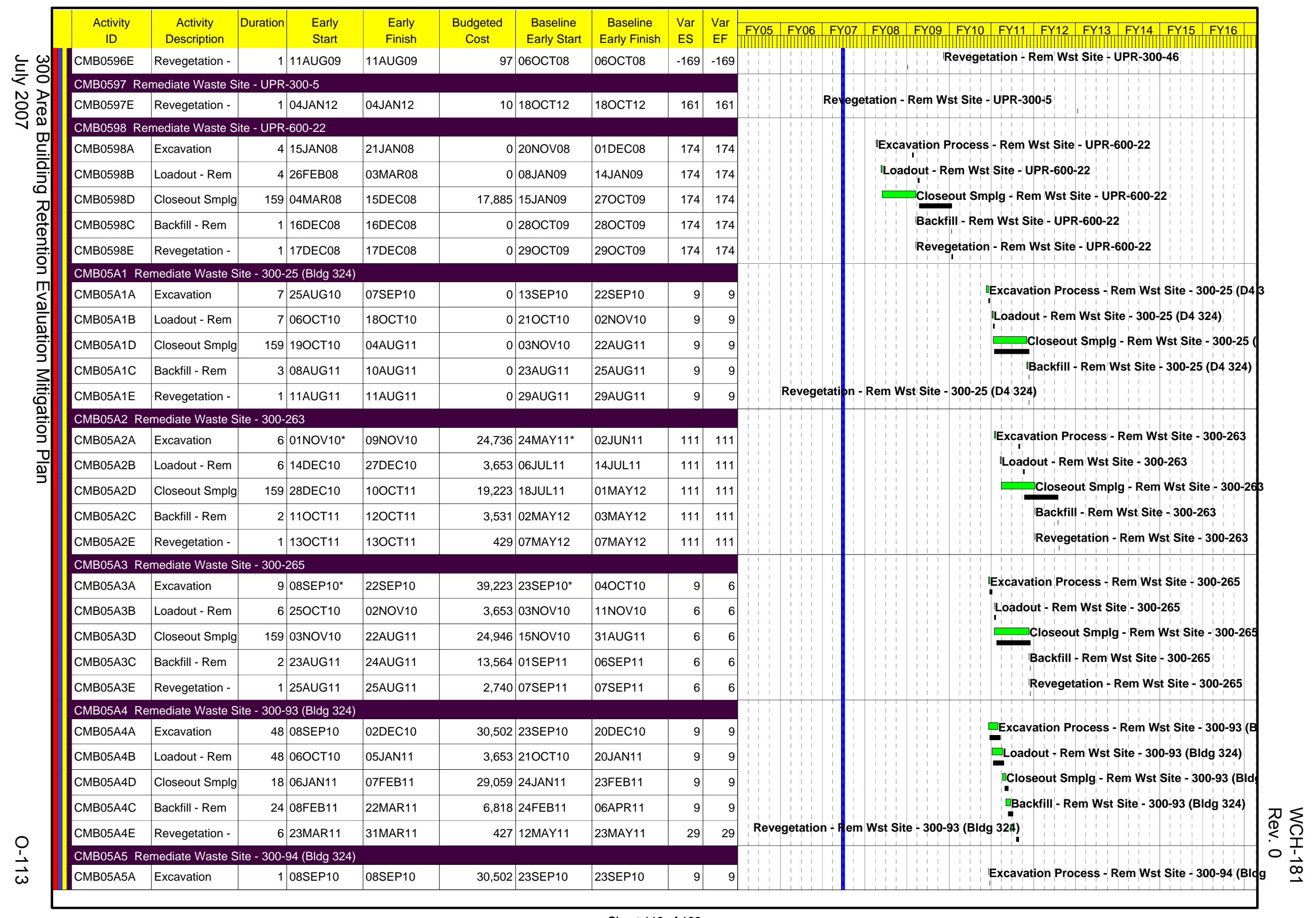




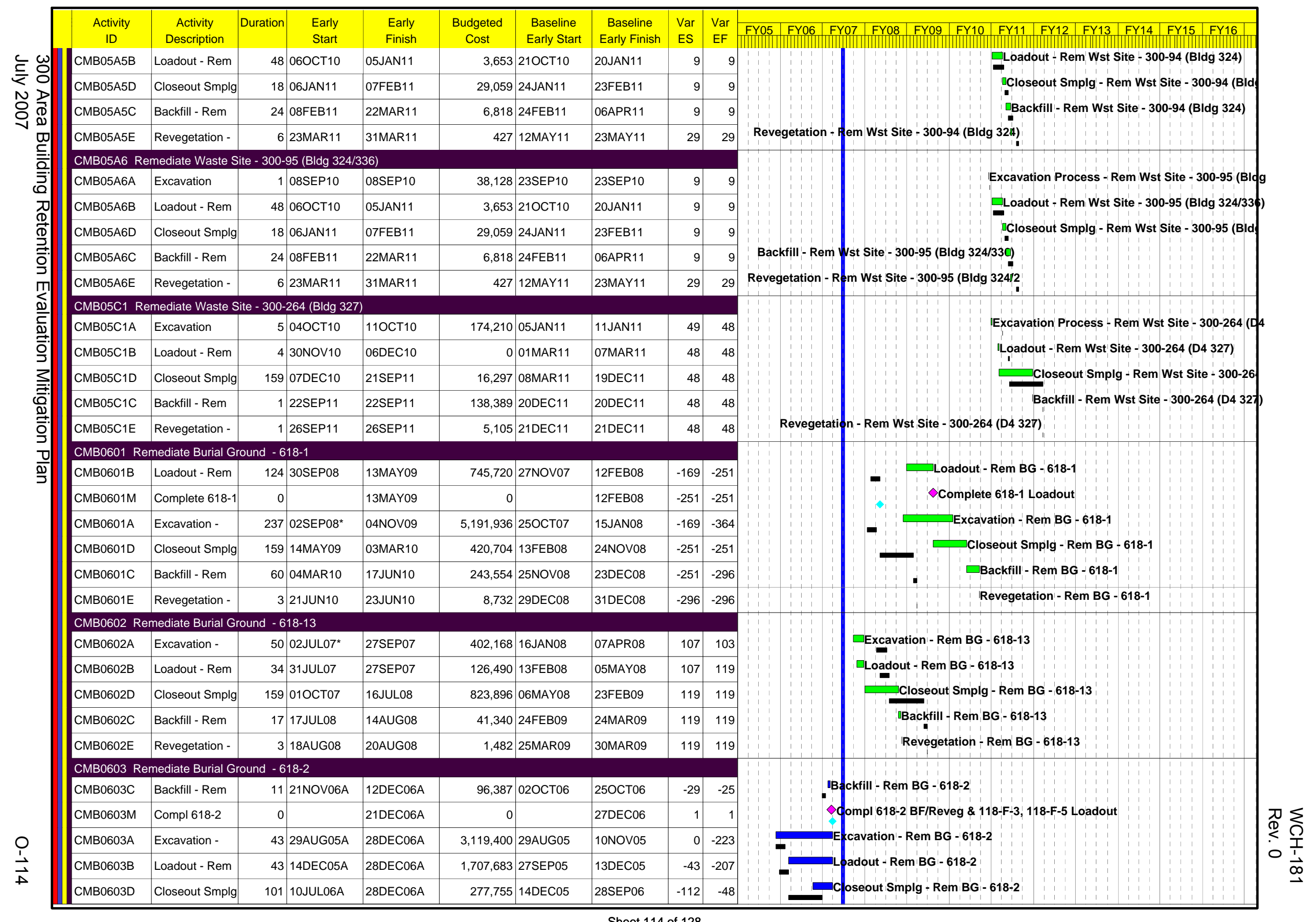

Sheet 114 of 128 


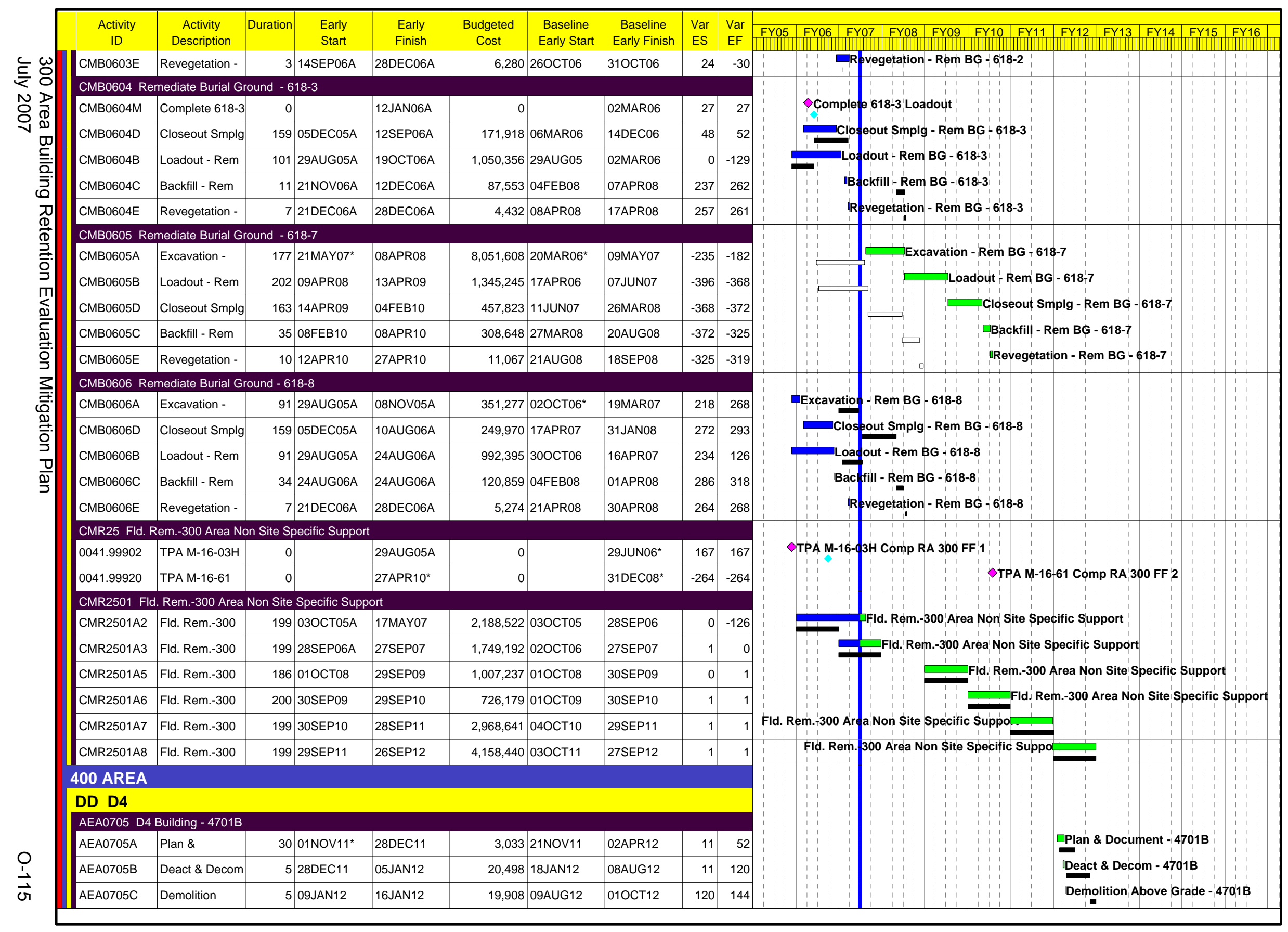




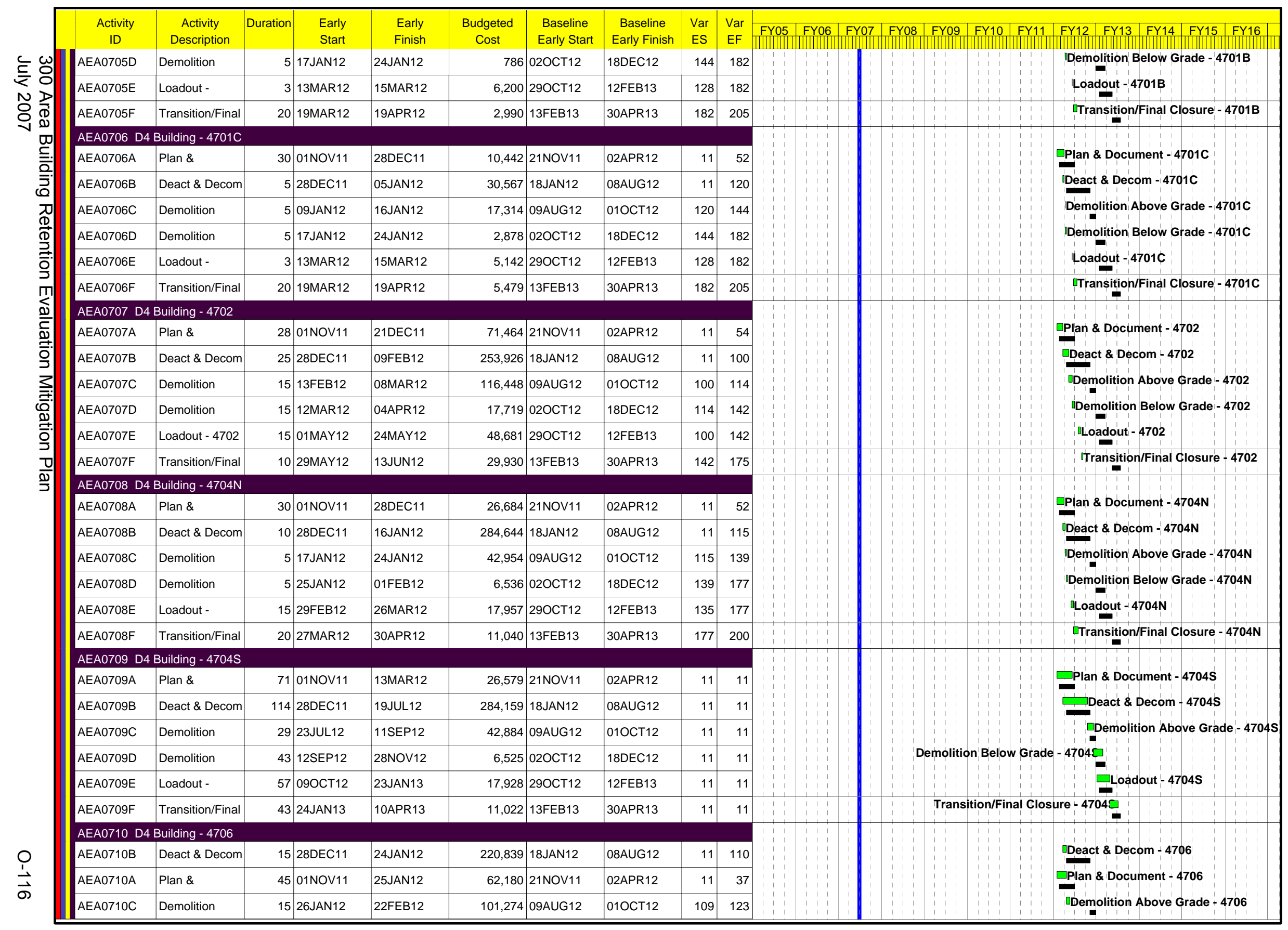




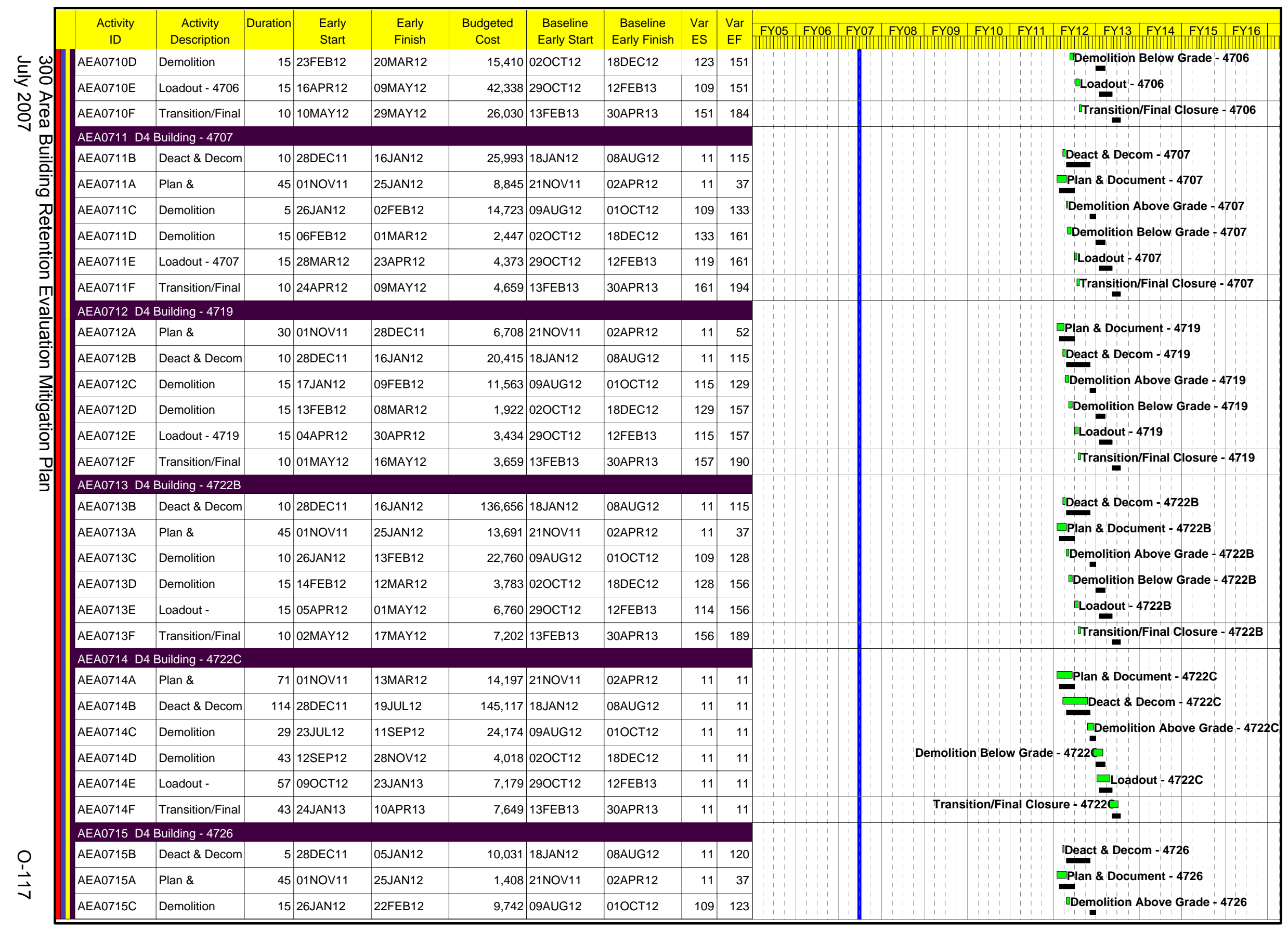




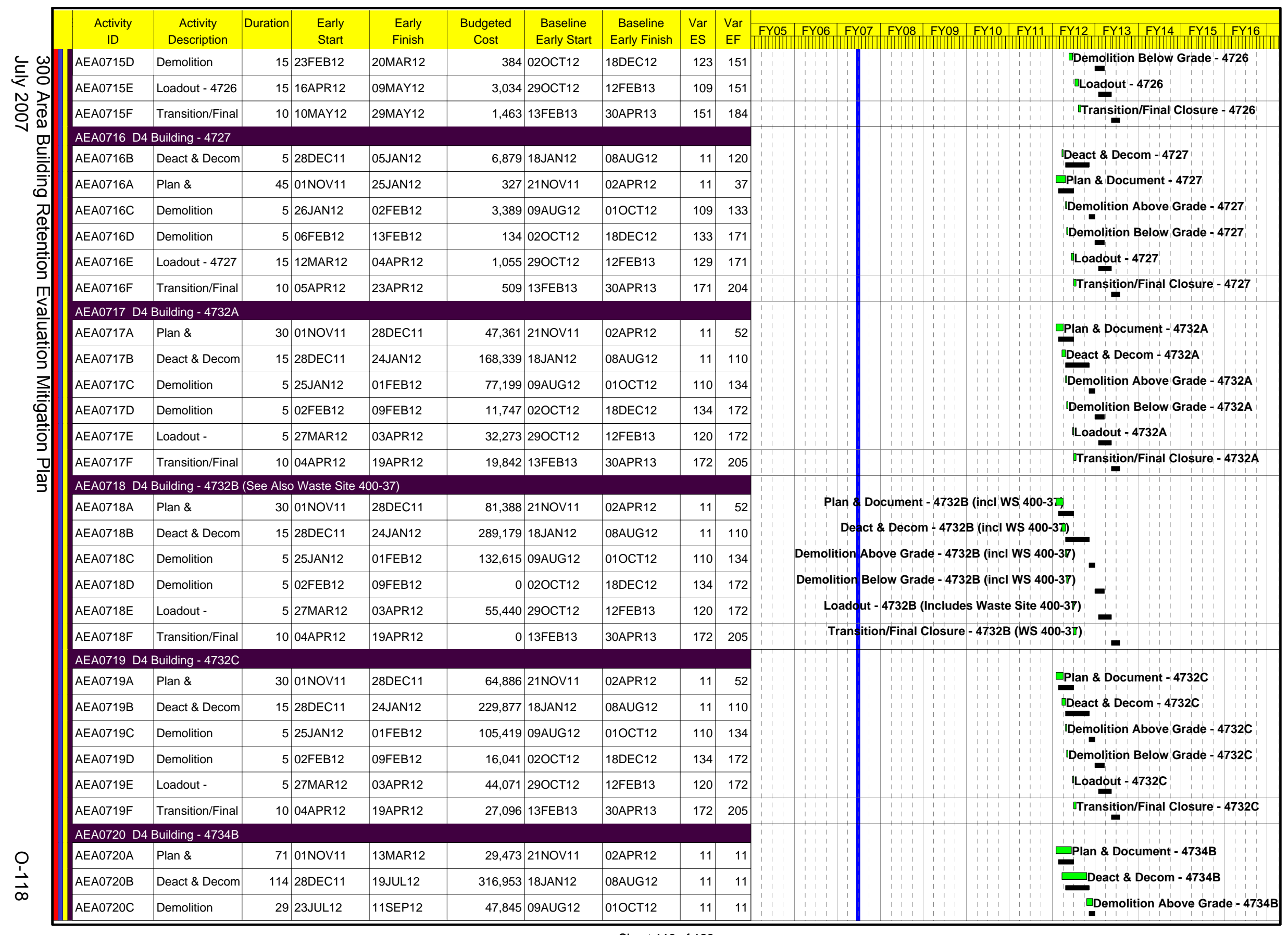




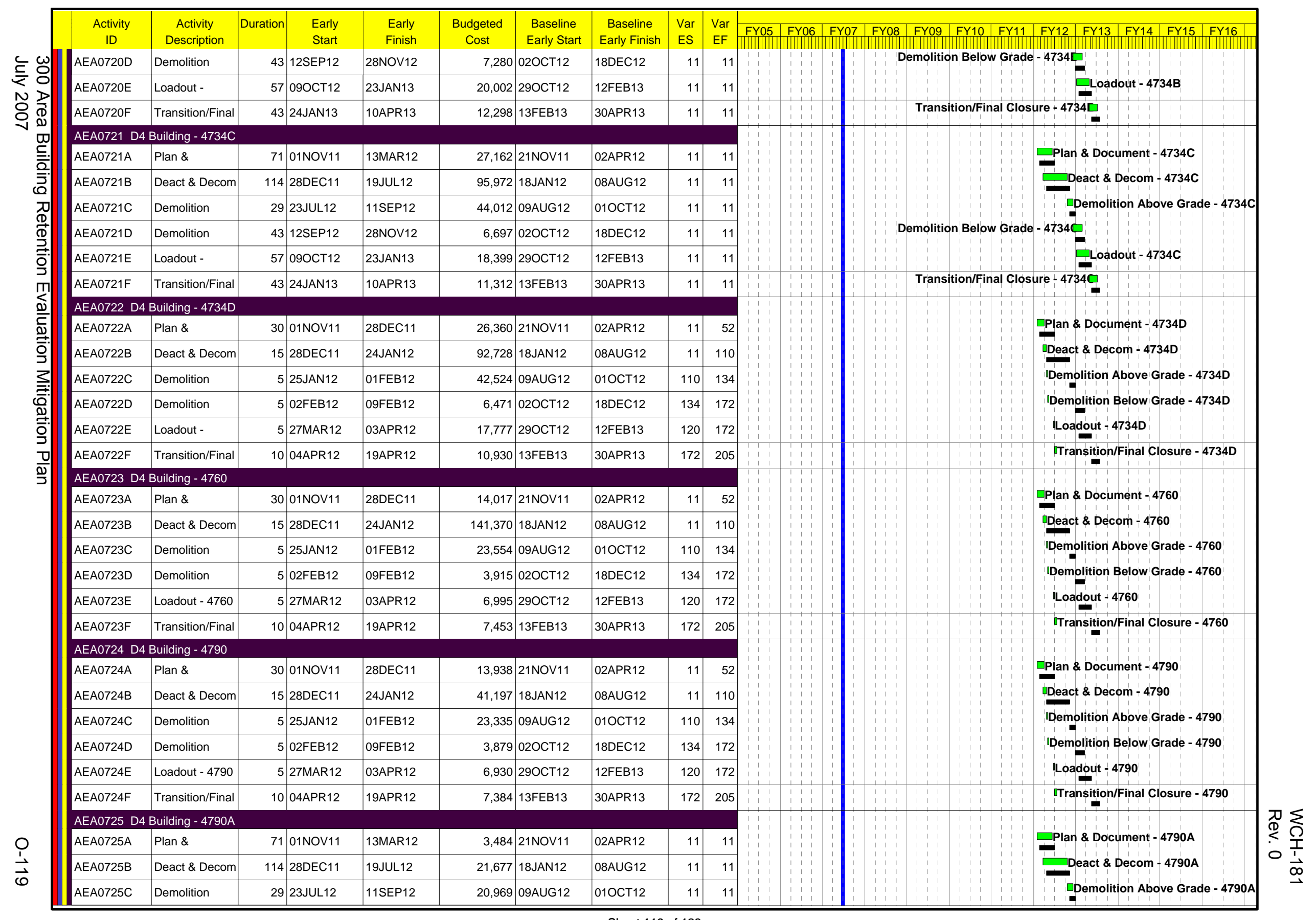




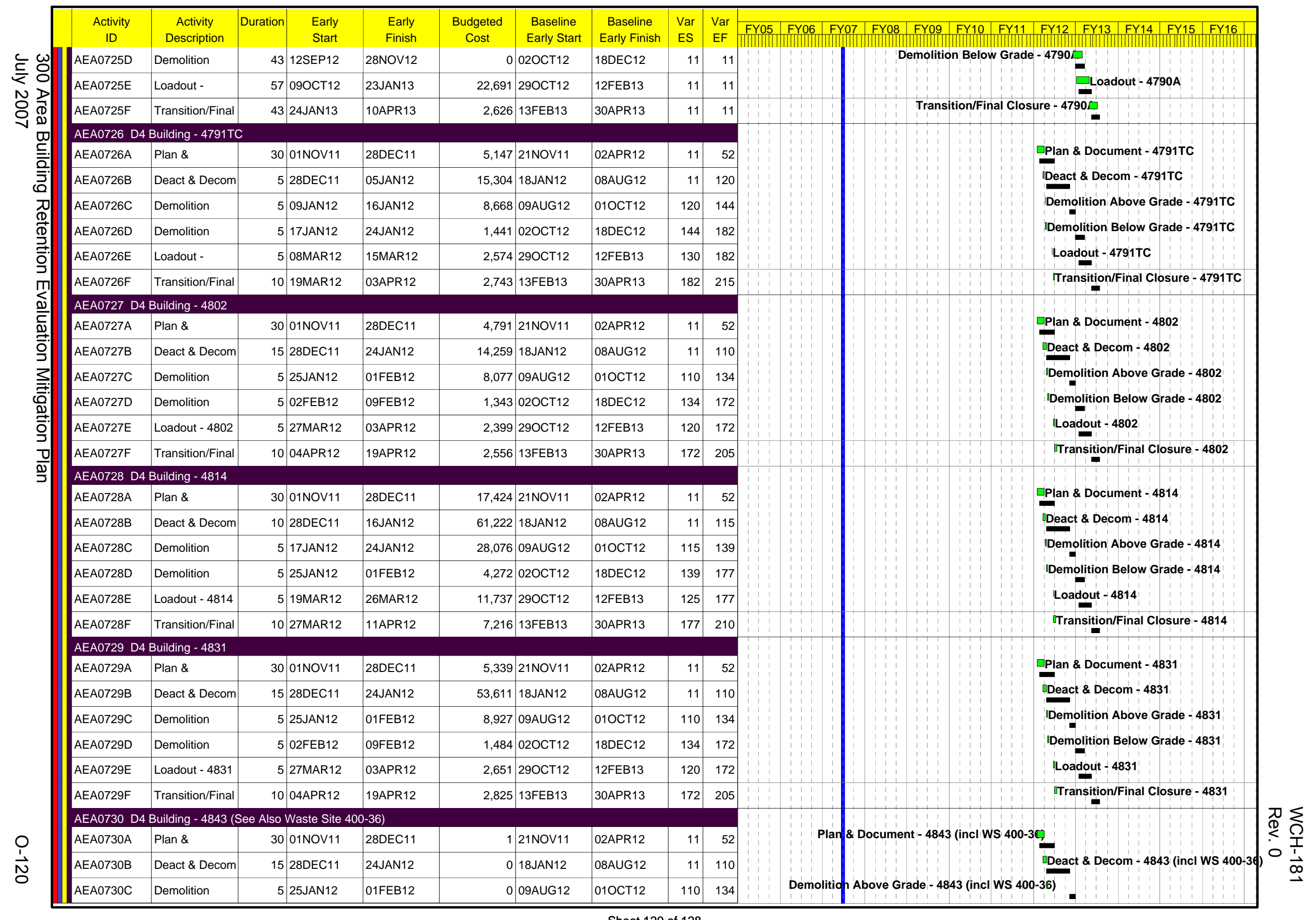

Sheet 120 of 128 


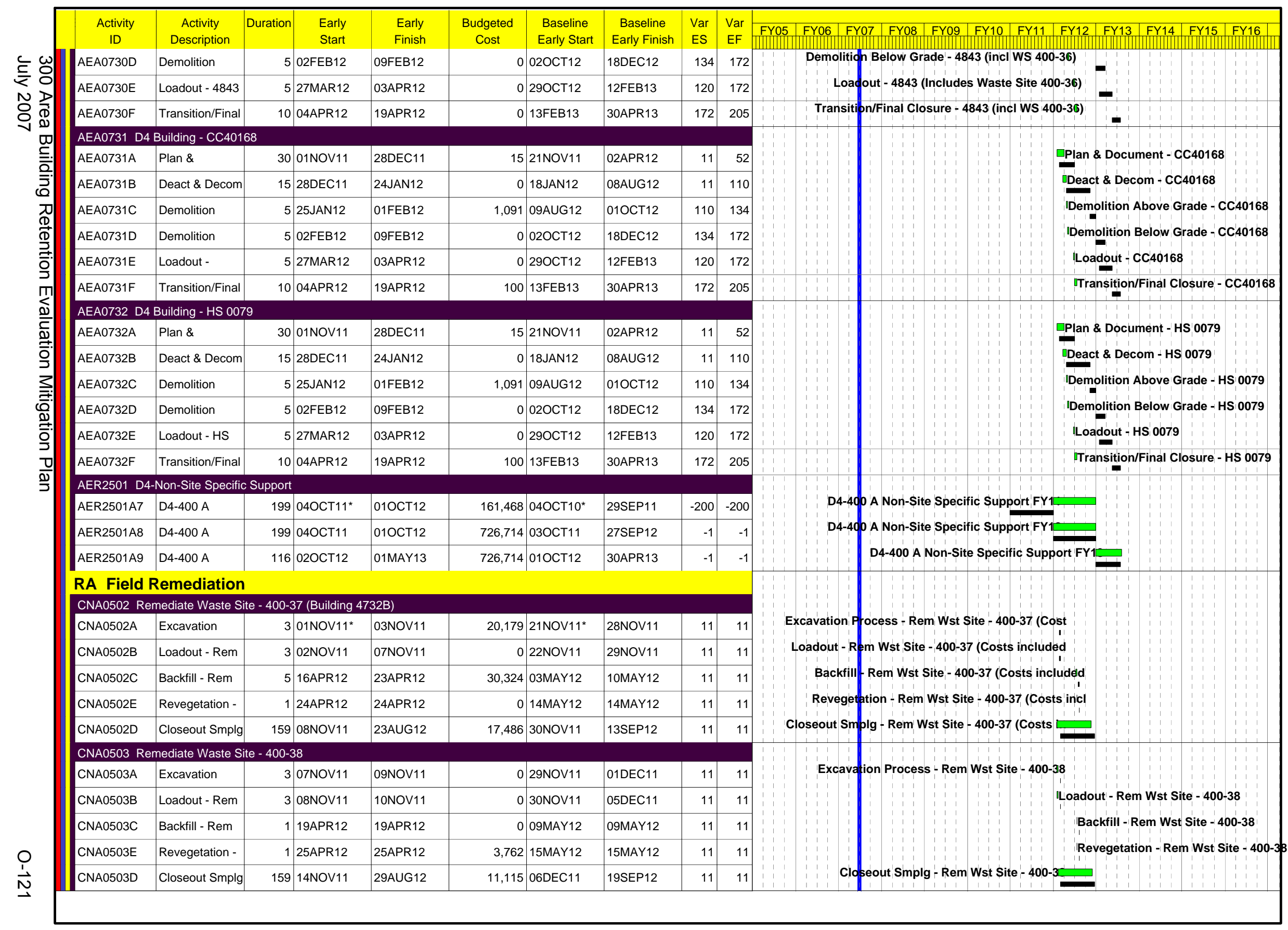




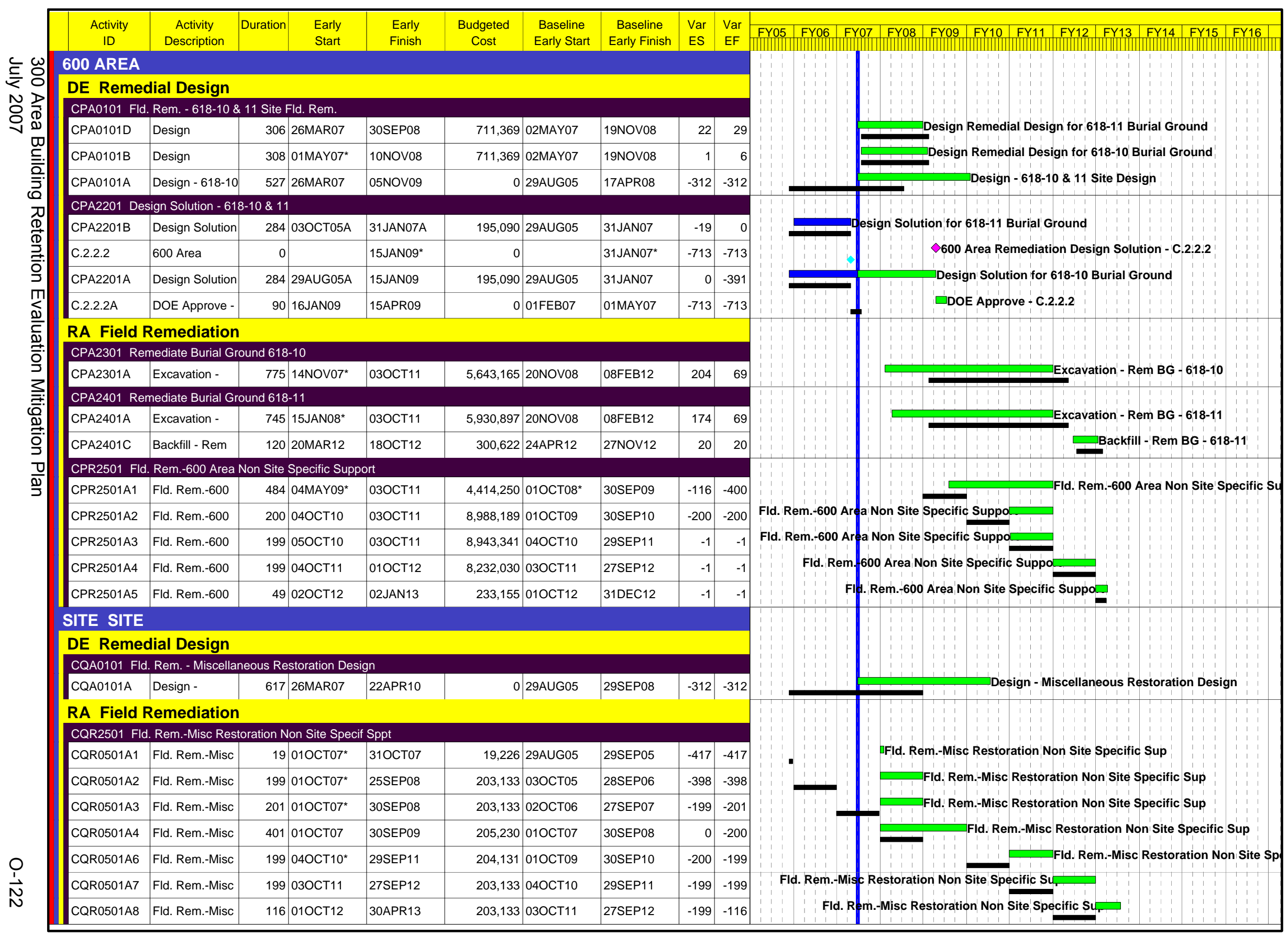




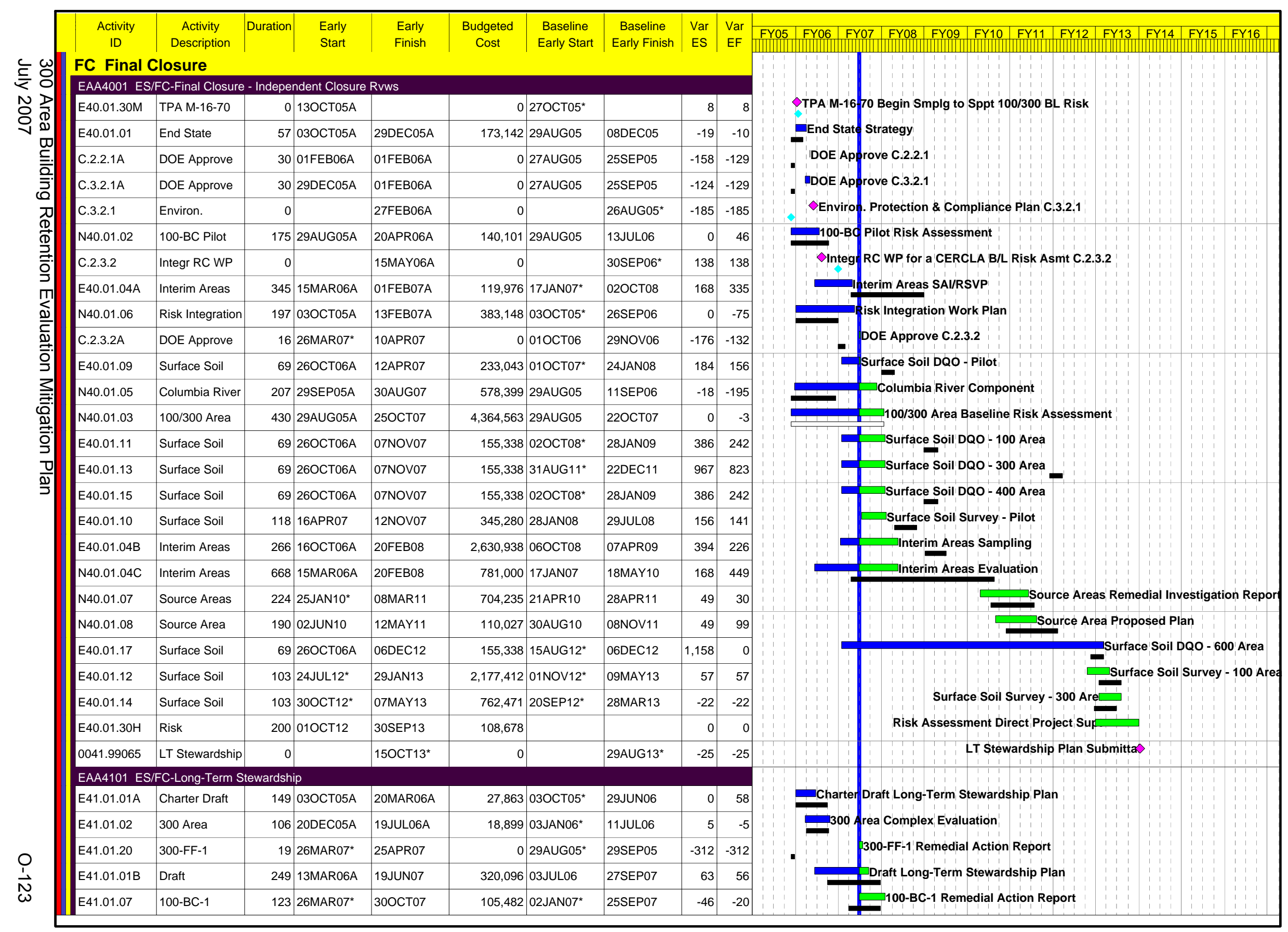




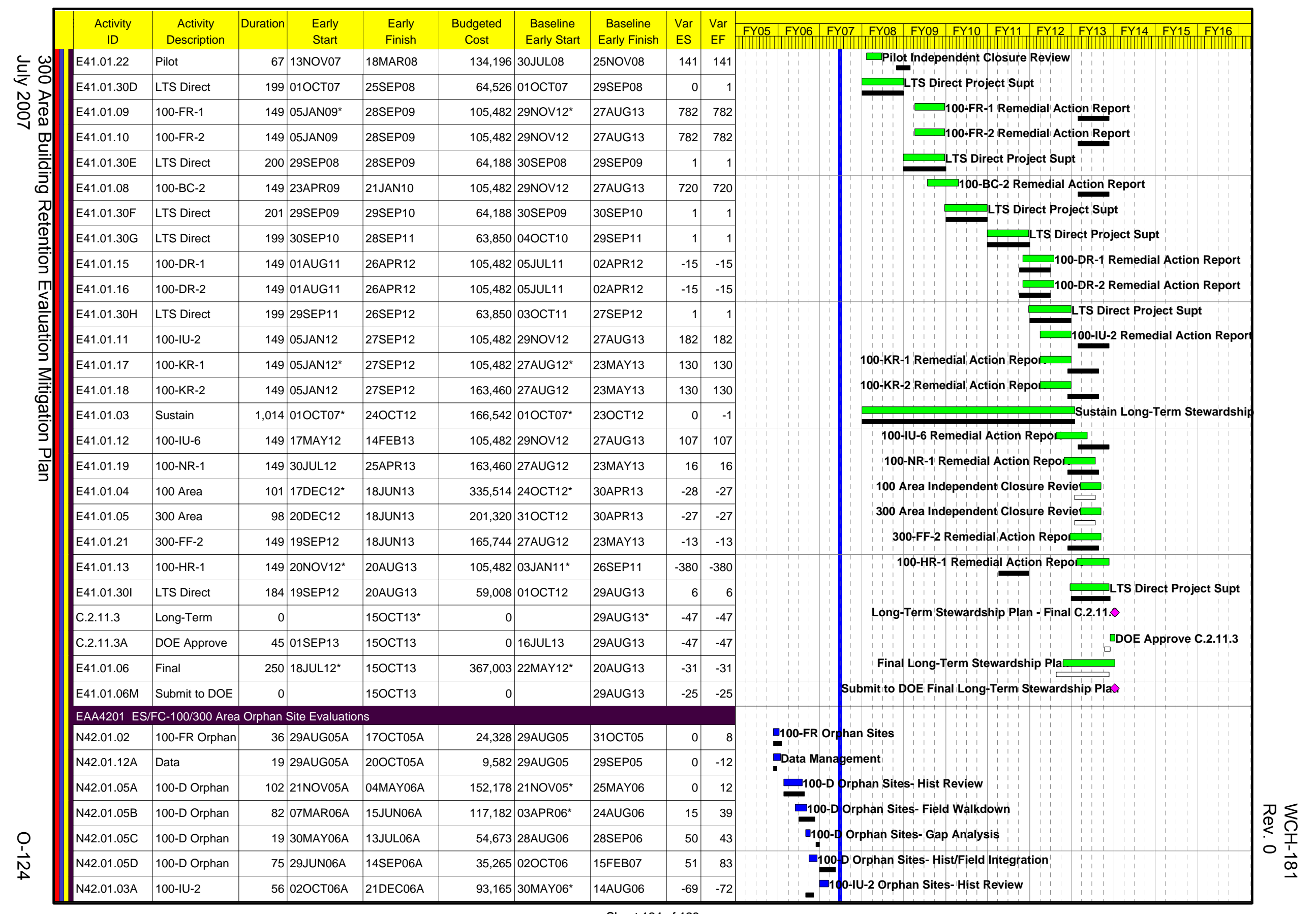




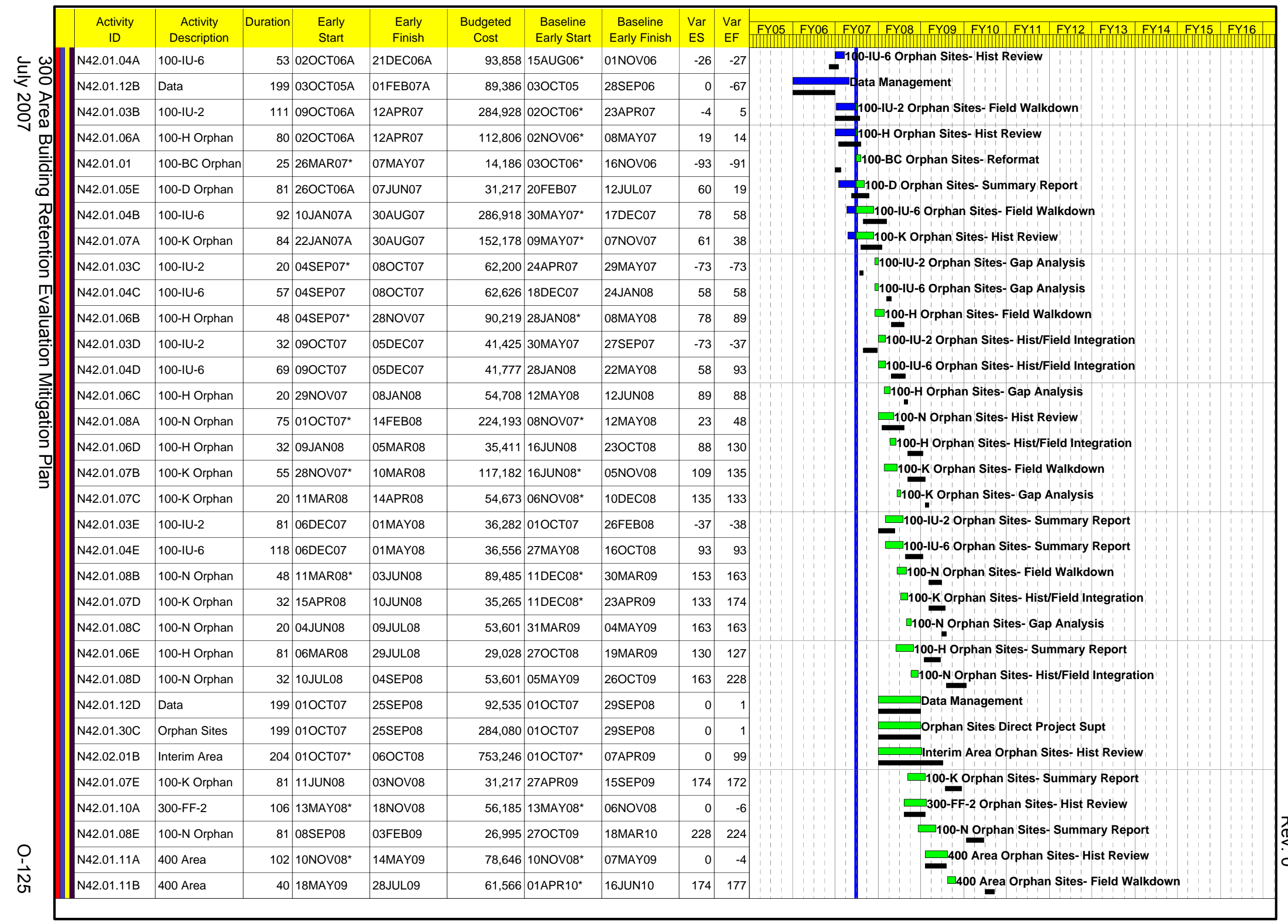




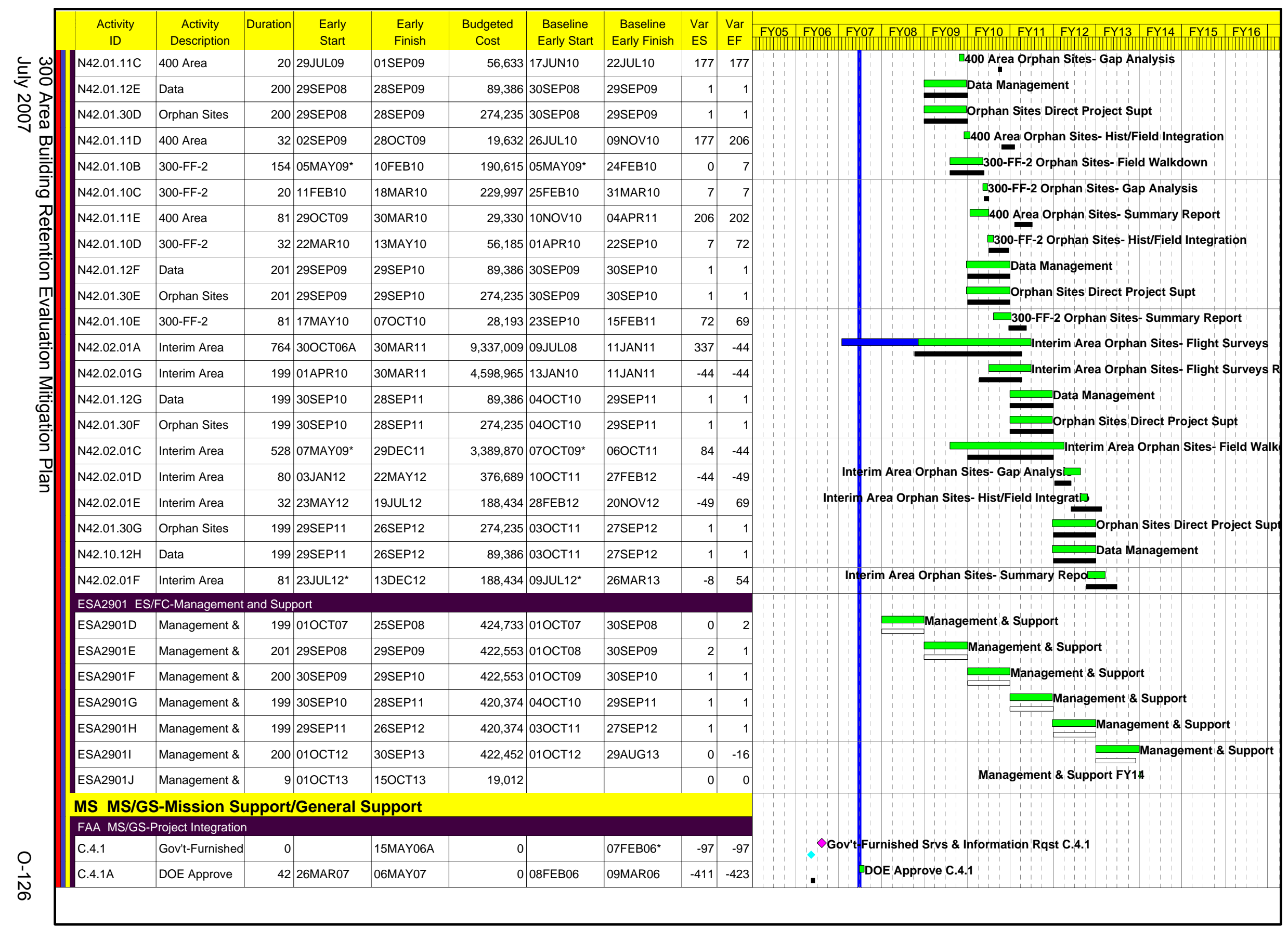




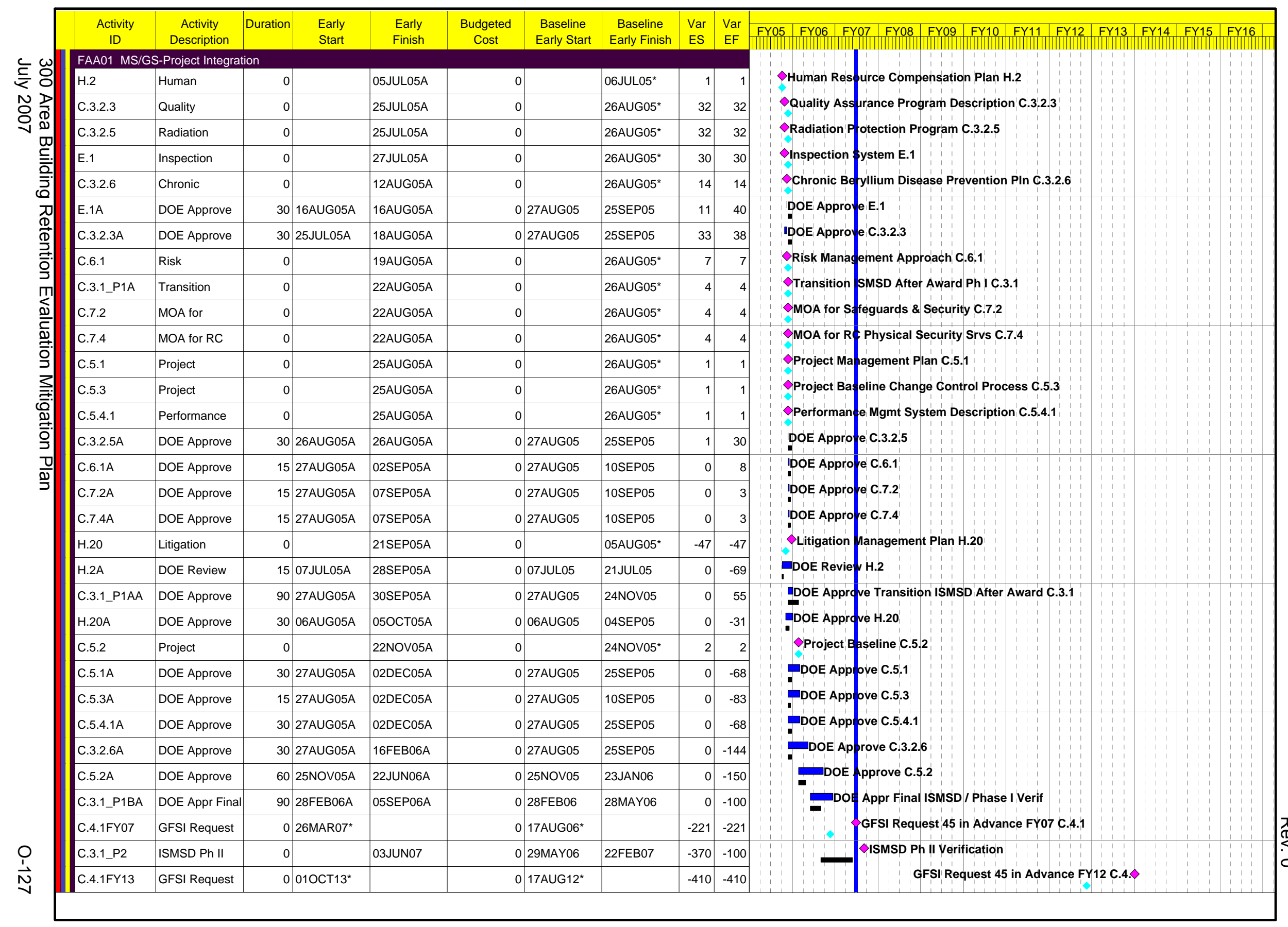




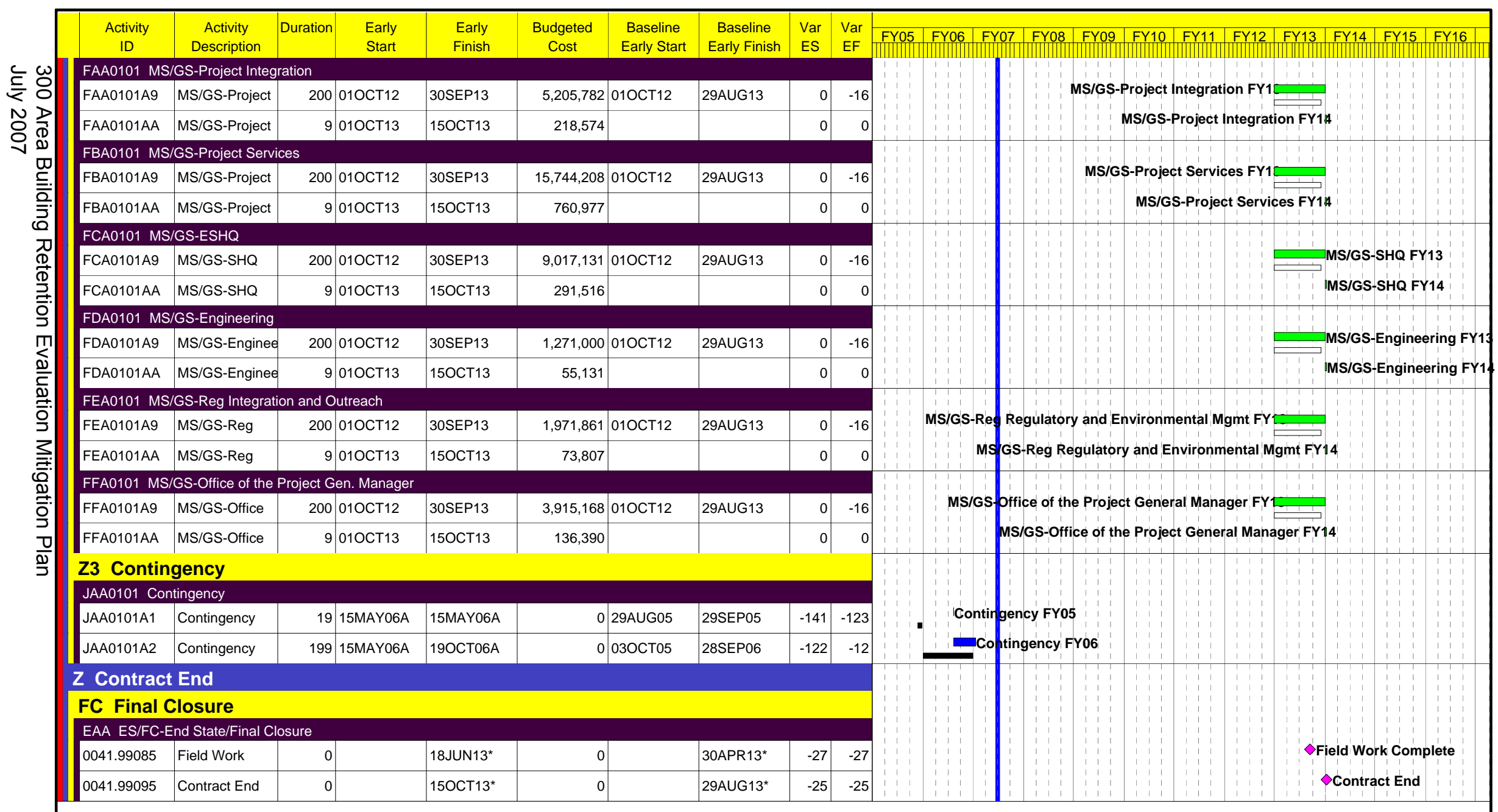

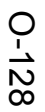




\section{APPENDIX P}

\section{SCENARIO 3 VARIANCE SCHEDULE}


WCH-181

Rev. 0 


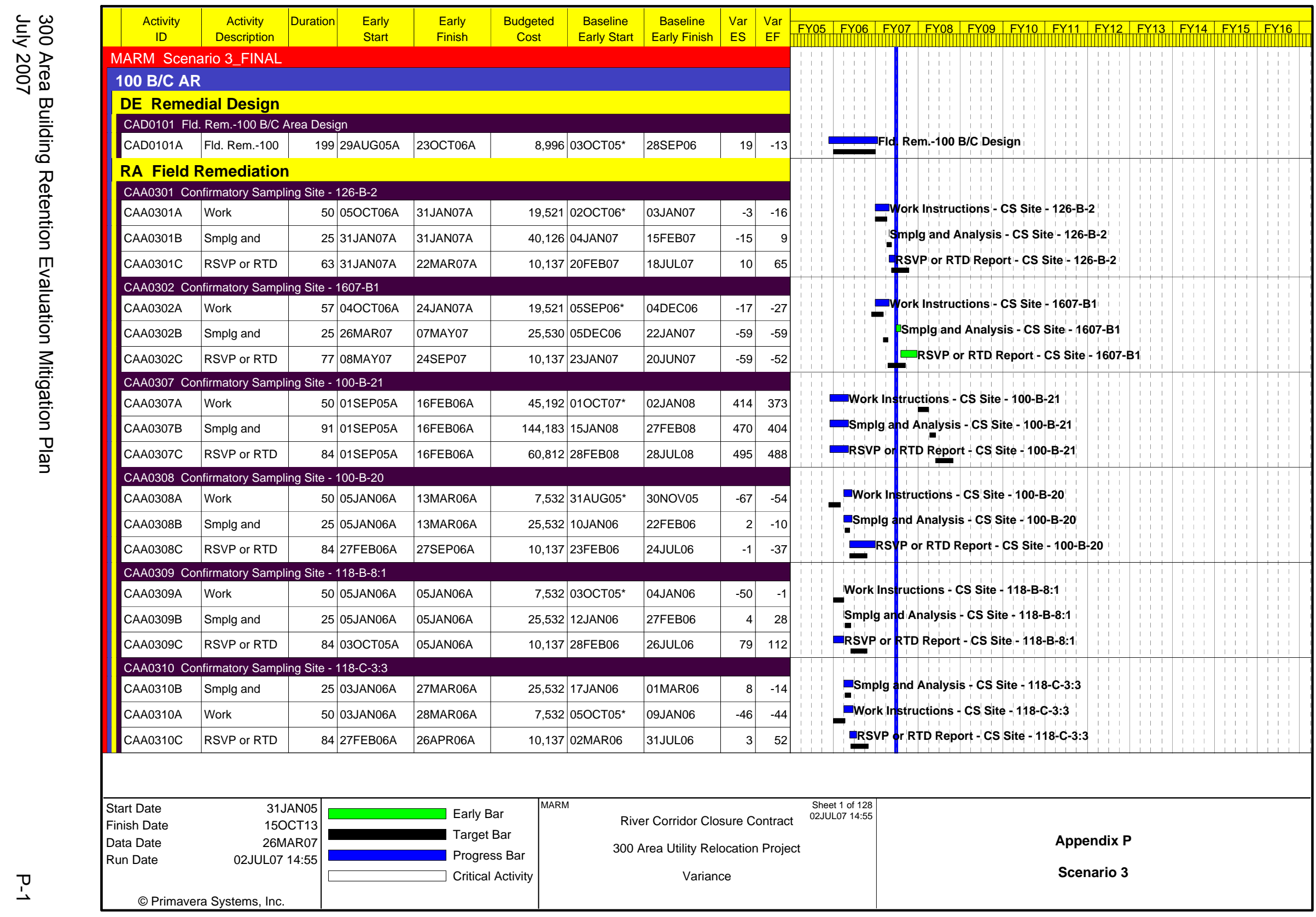




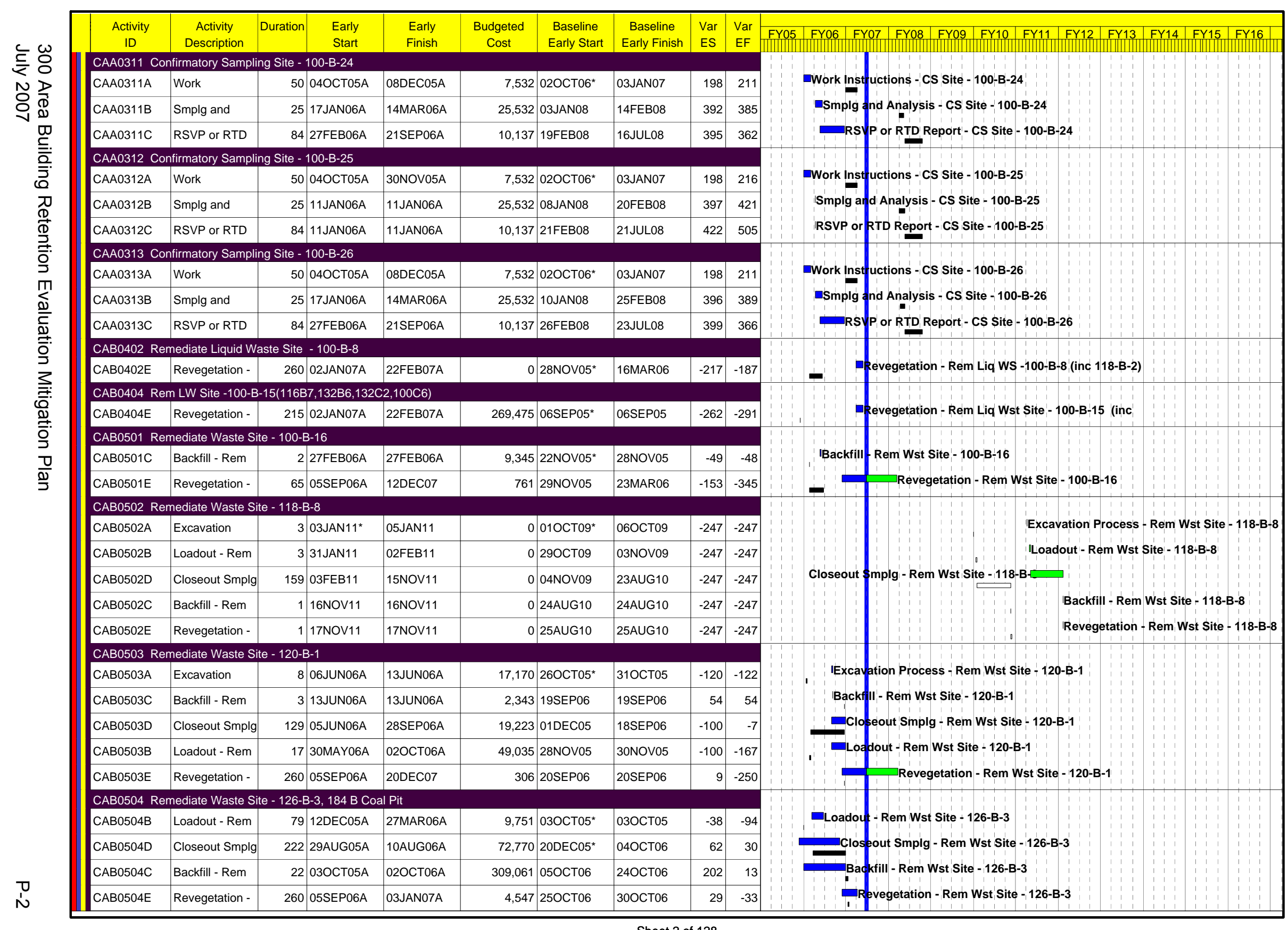




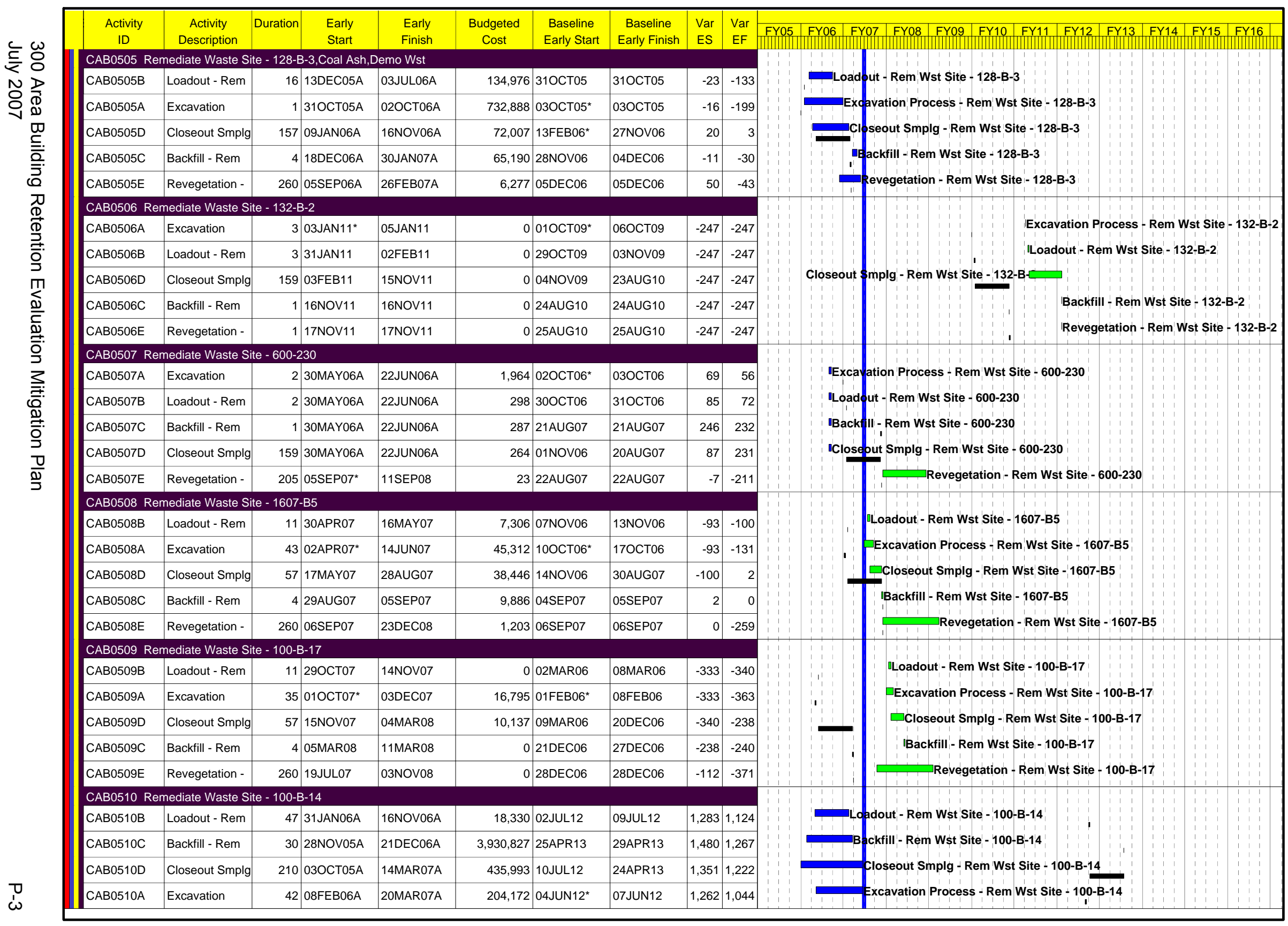




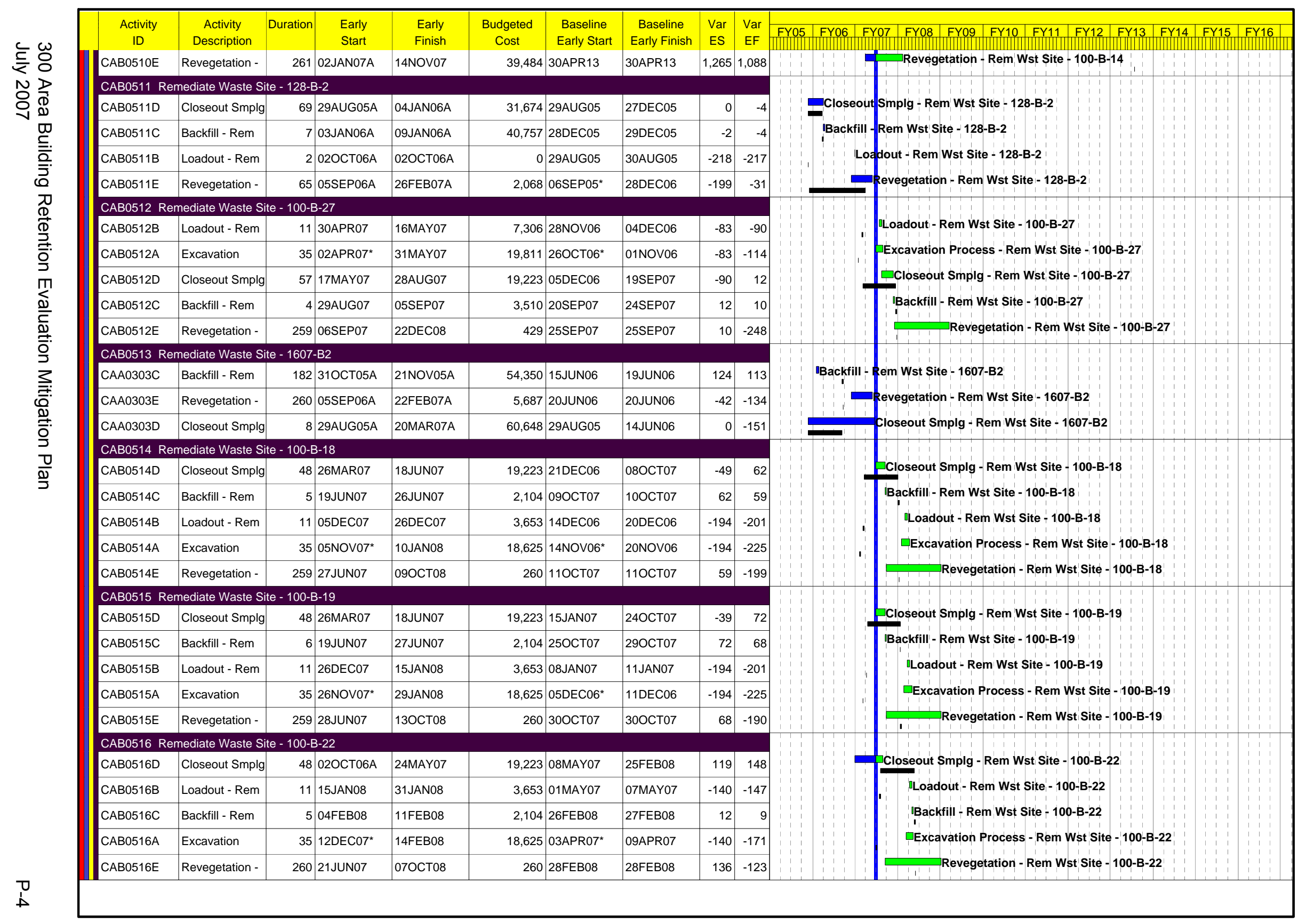




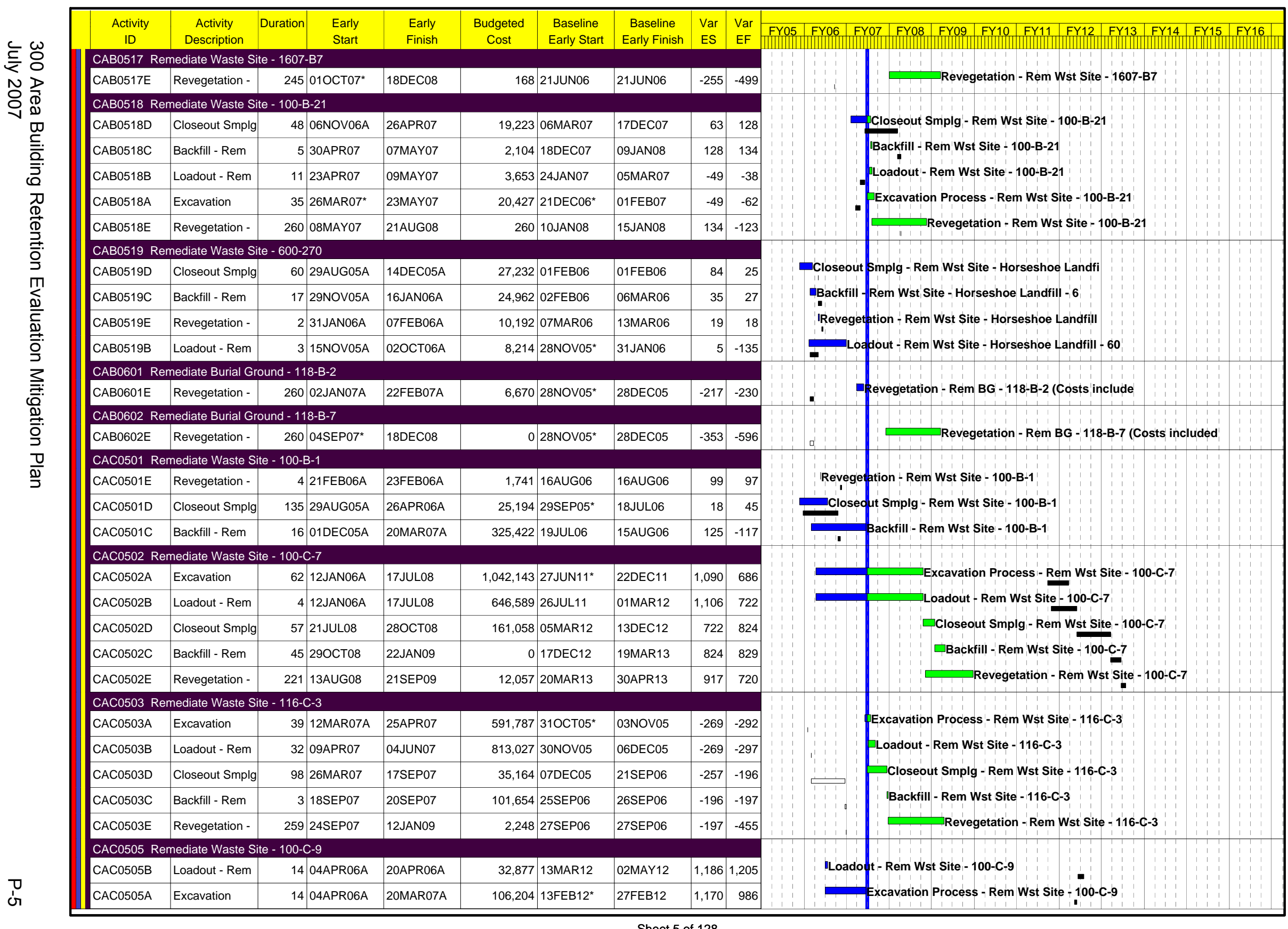




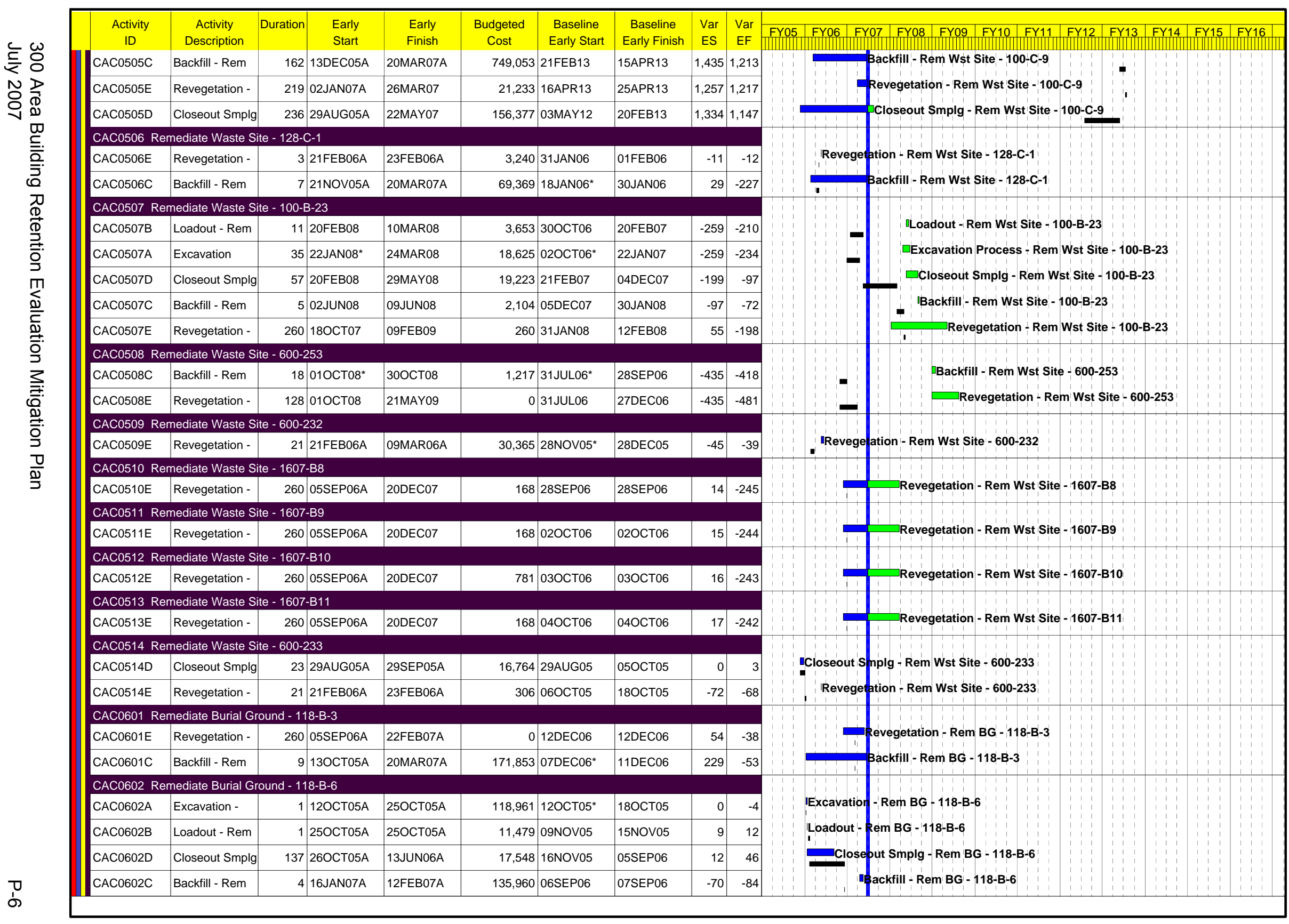




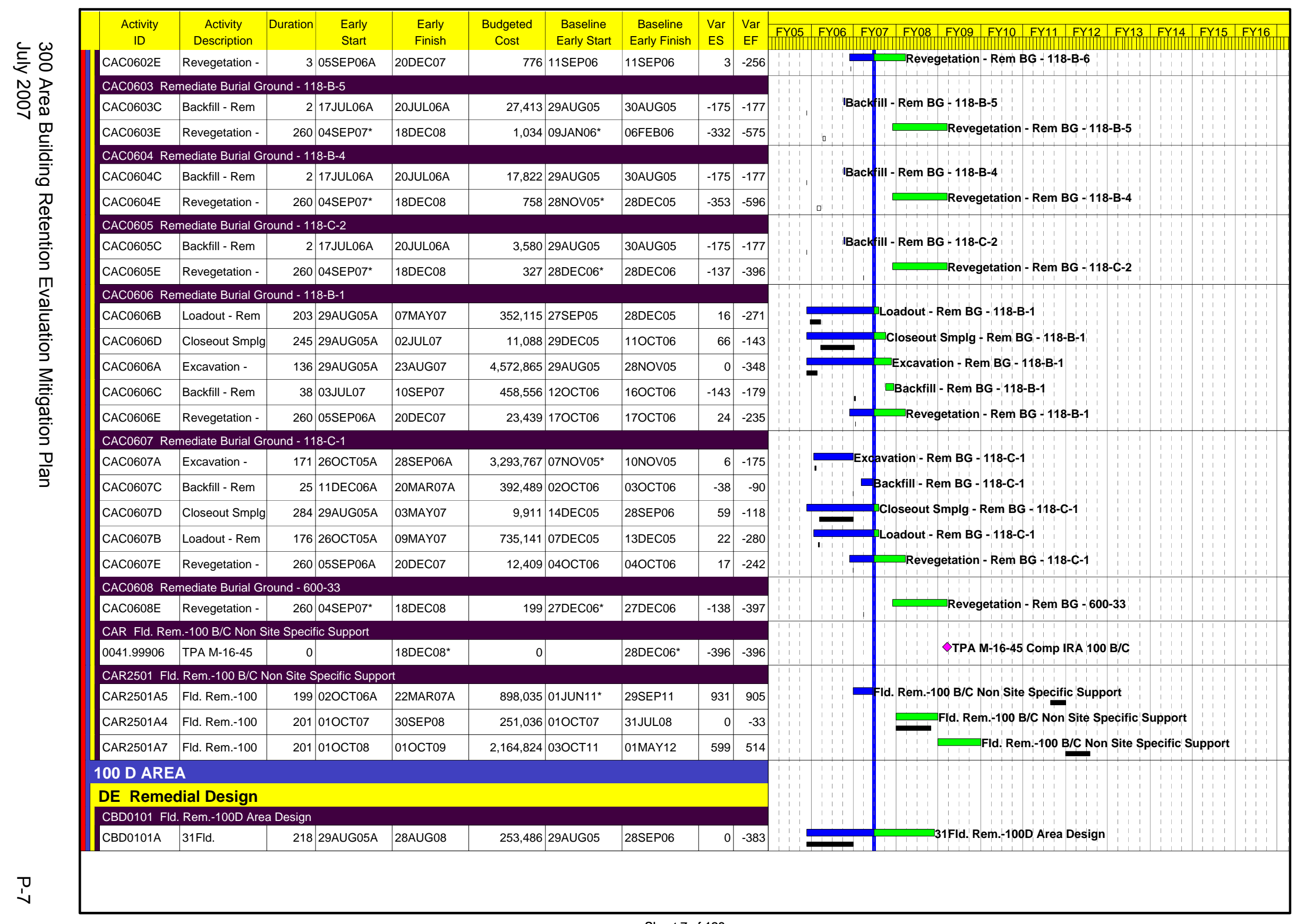




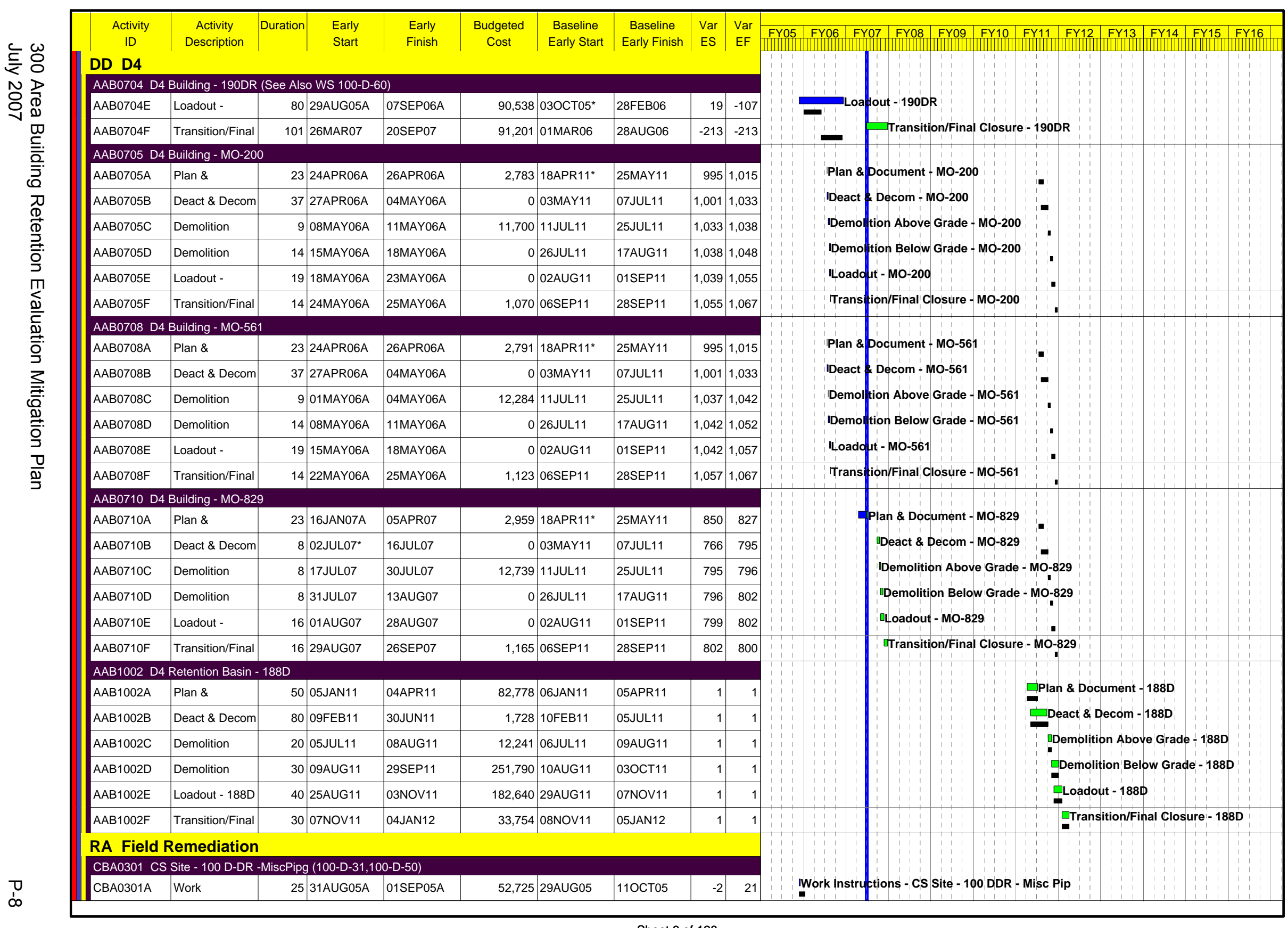




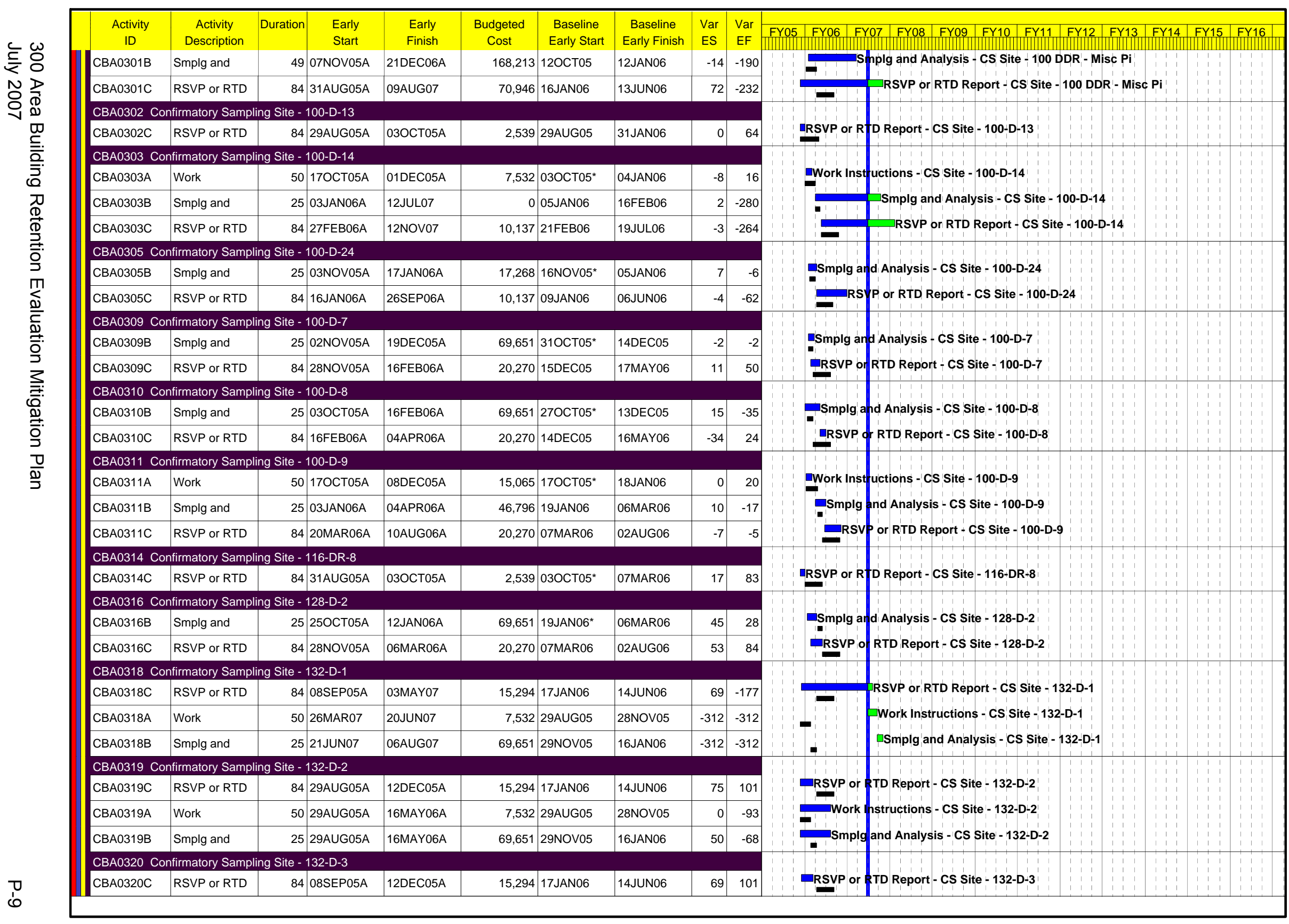




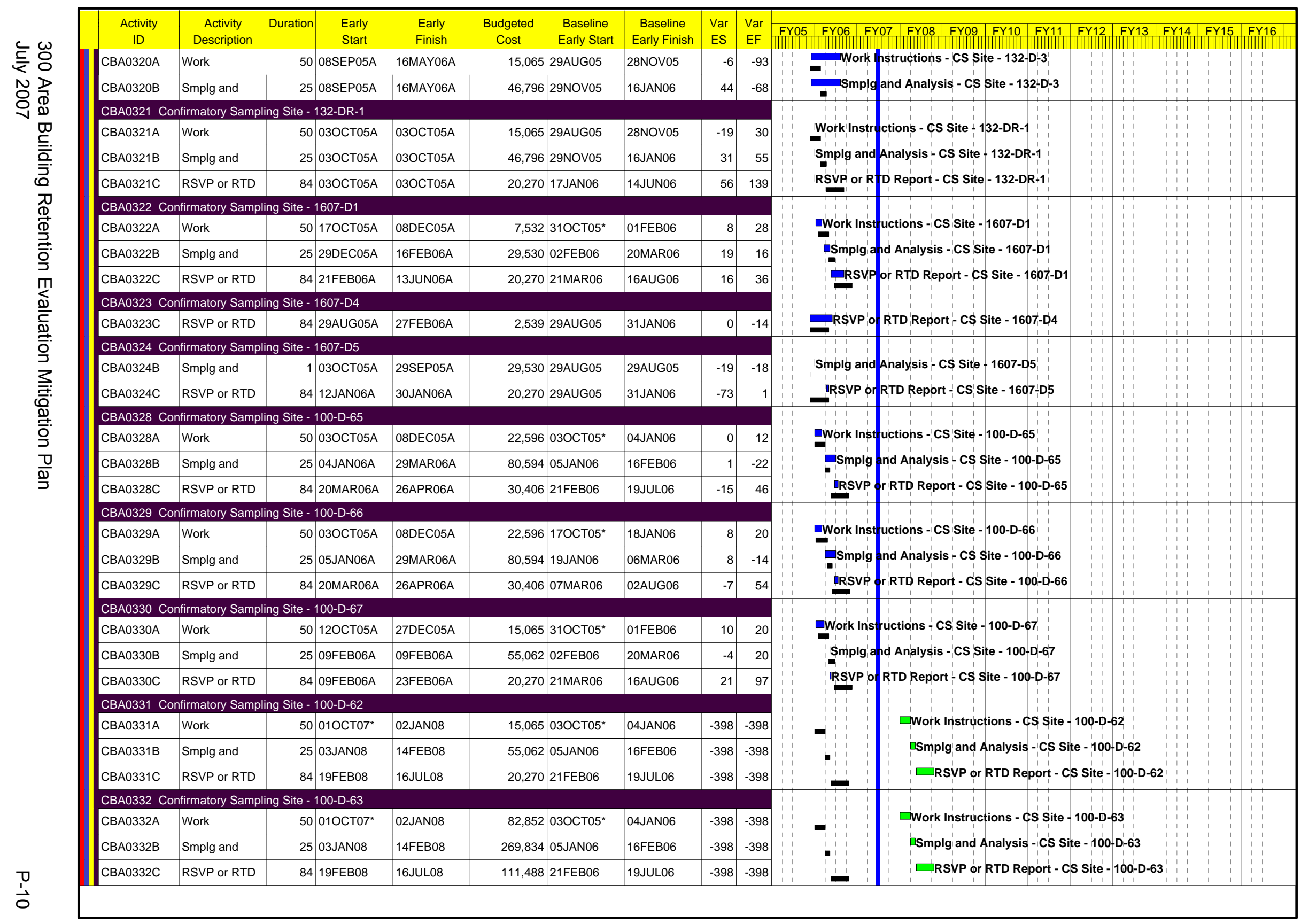




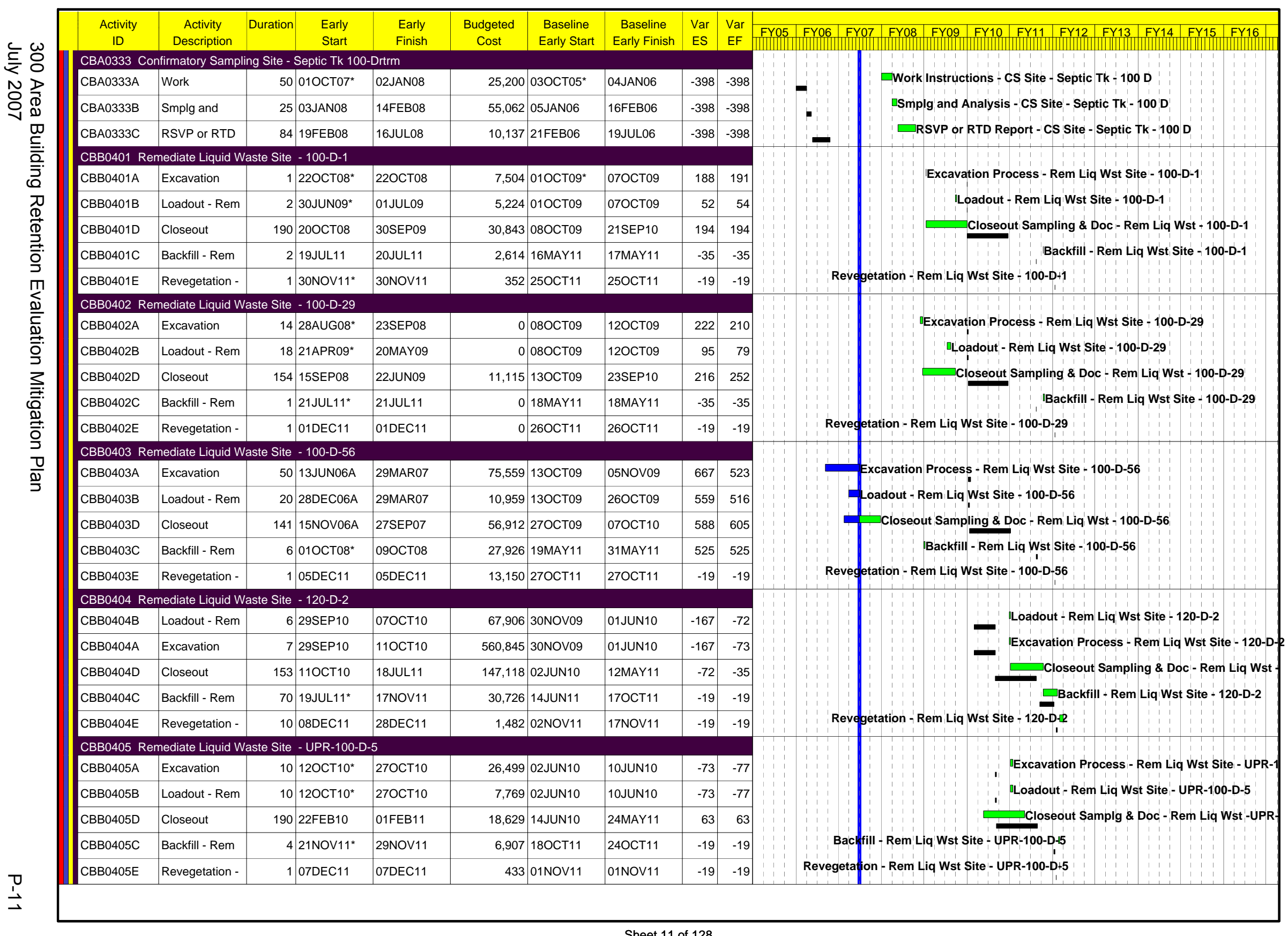




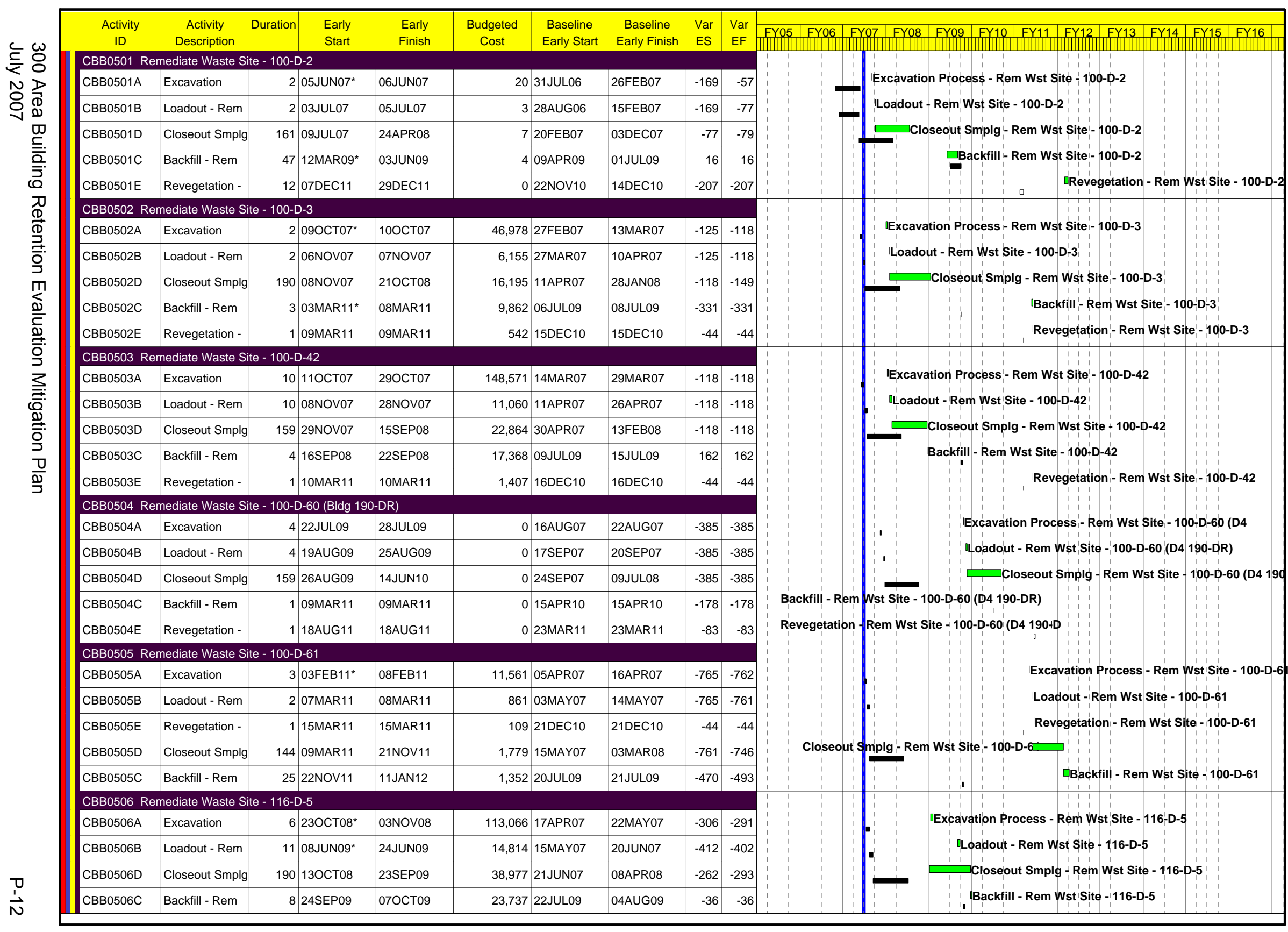




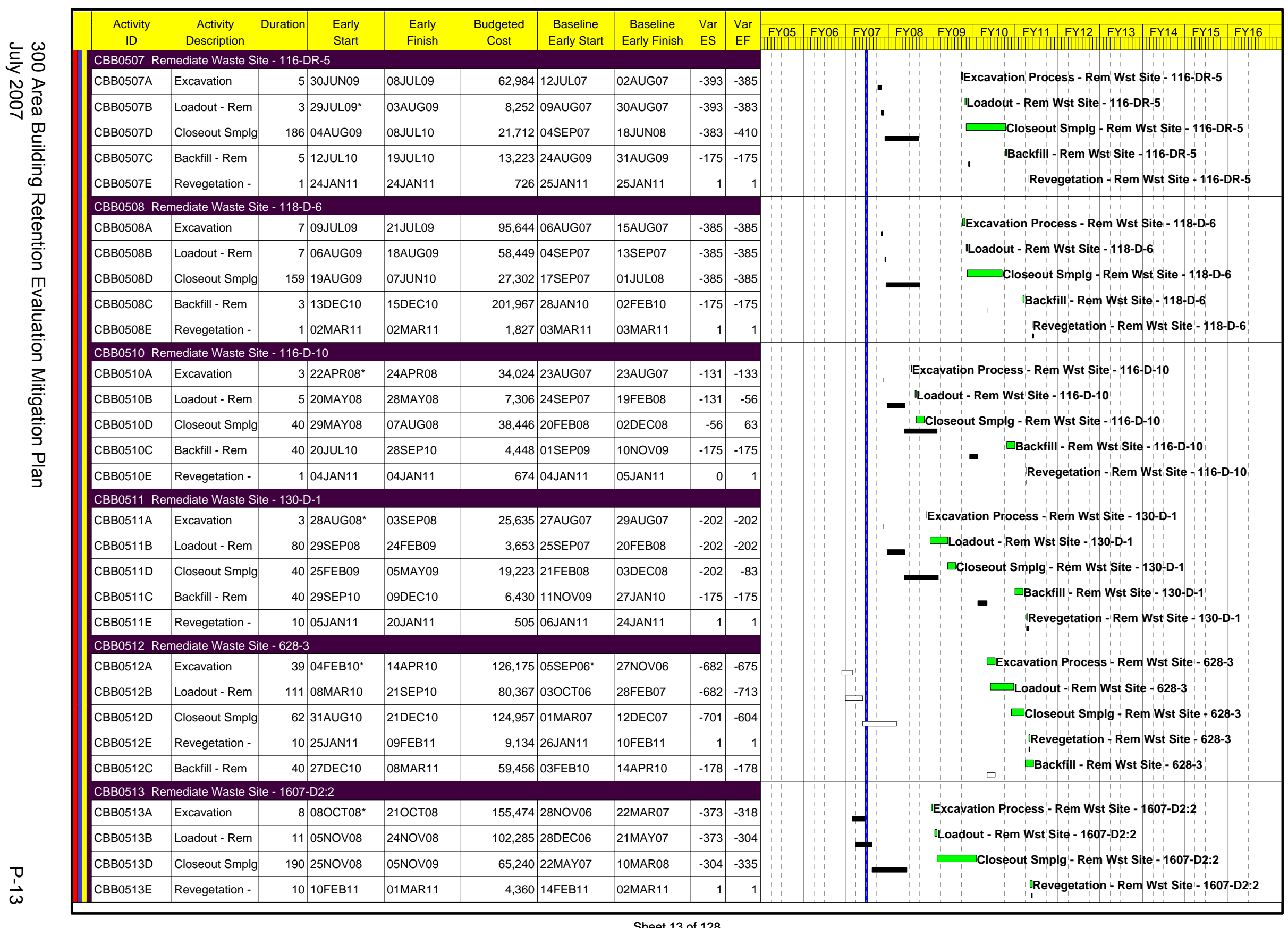




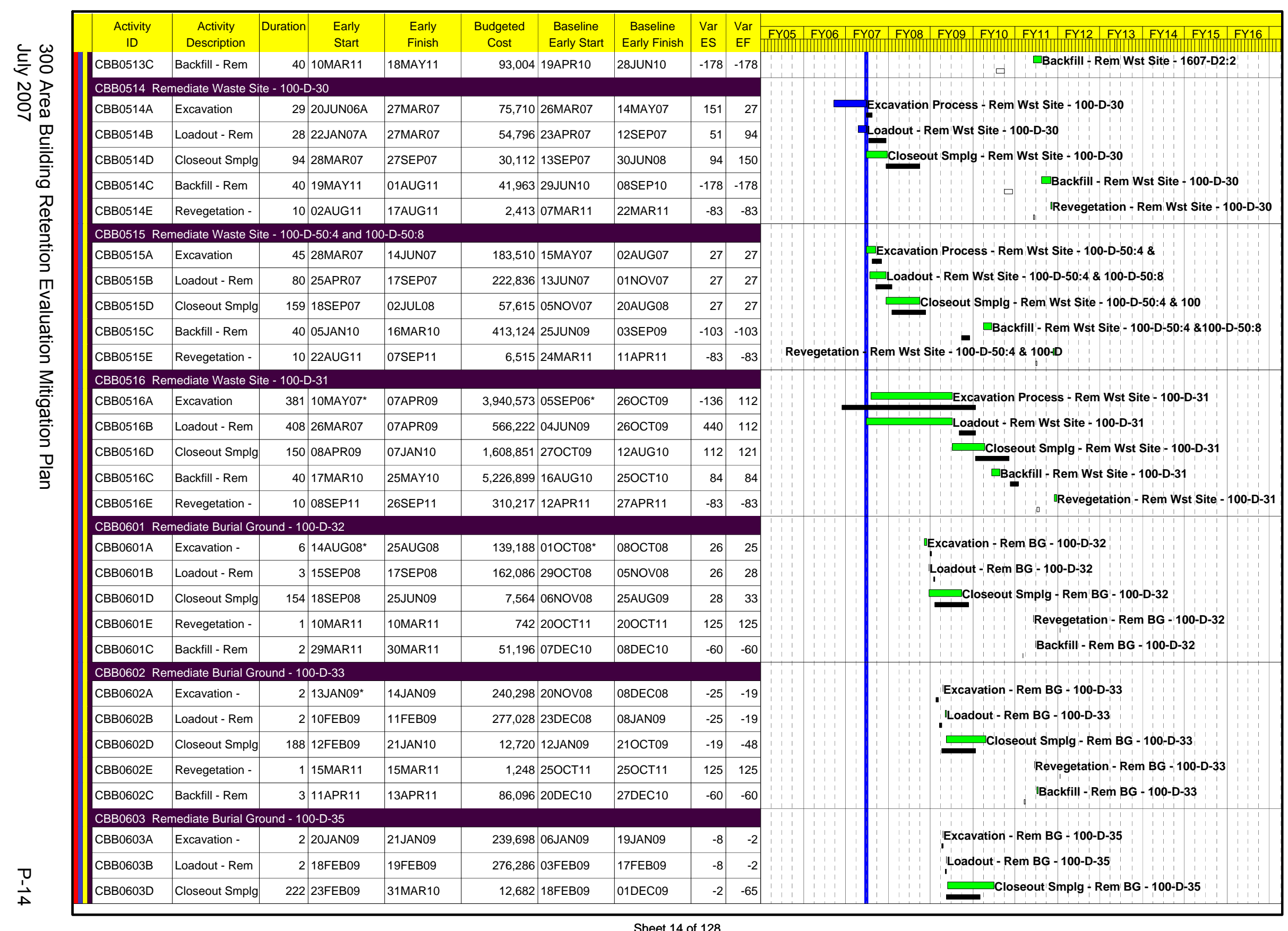




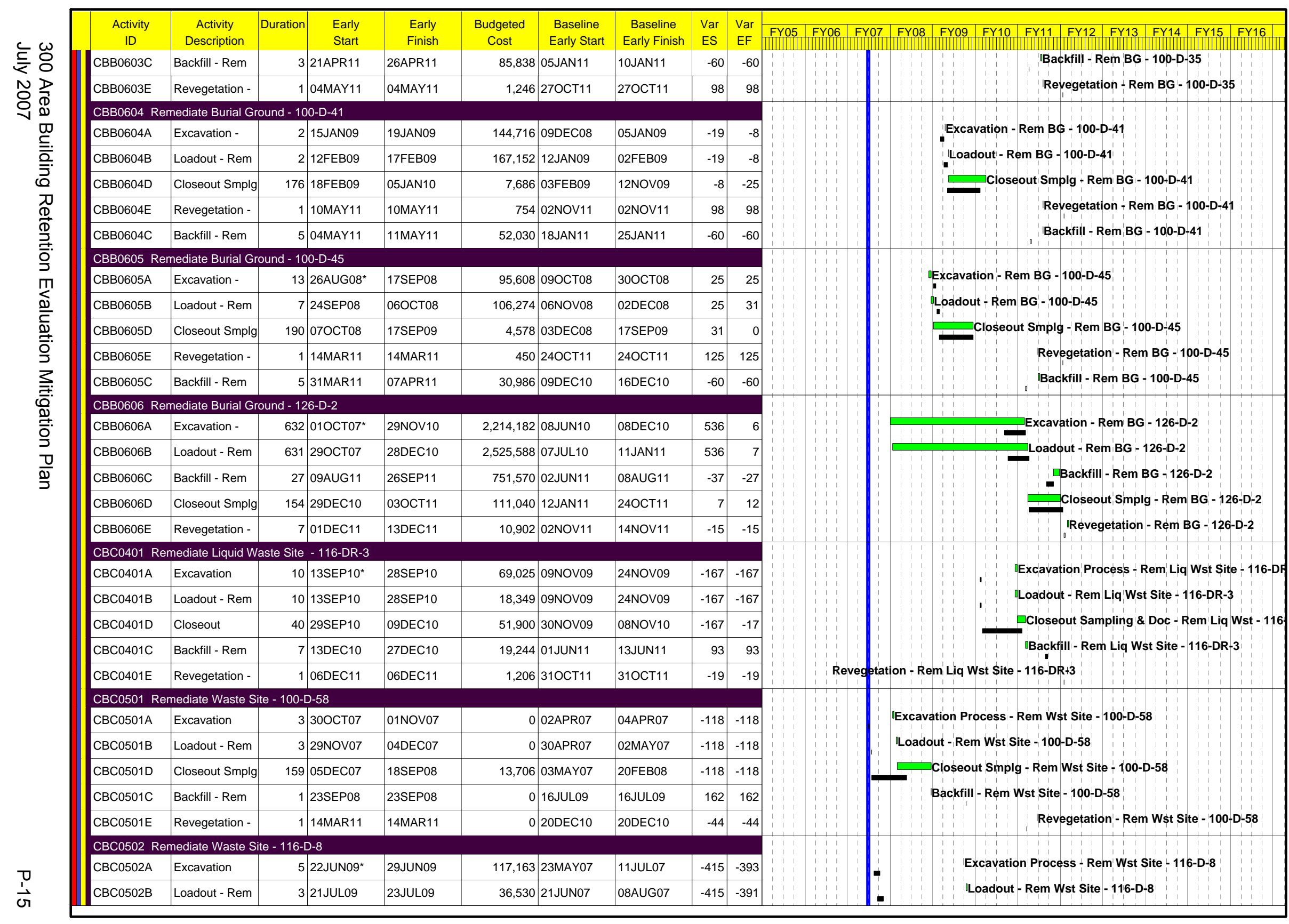




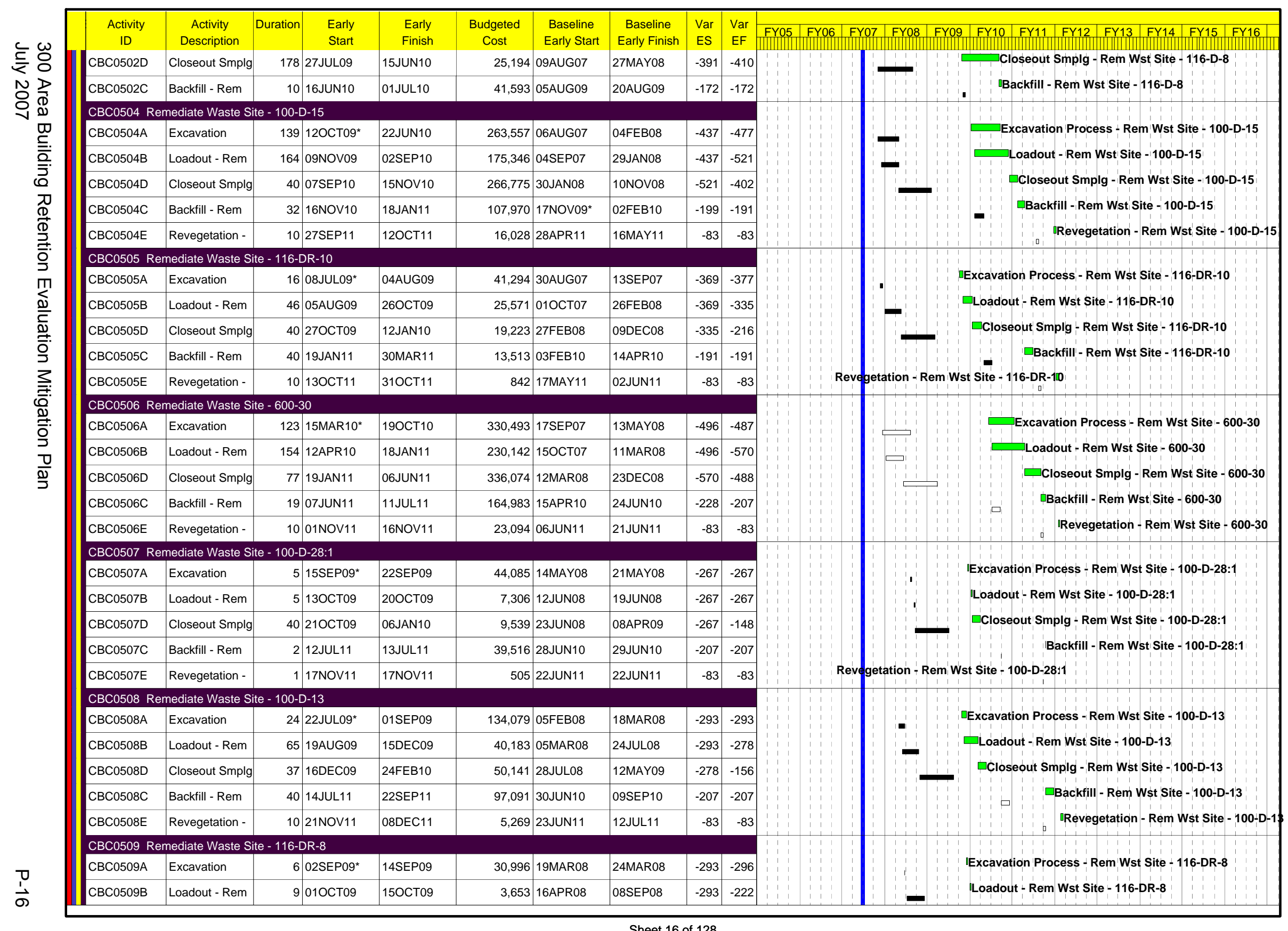




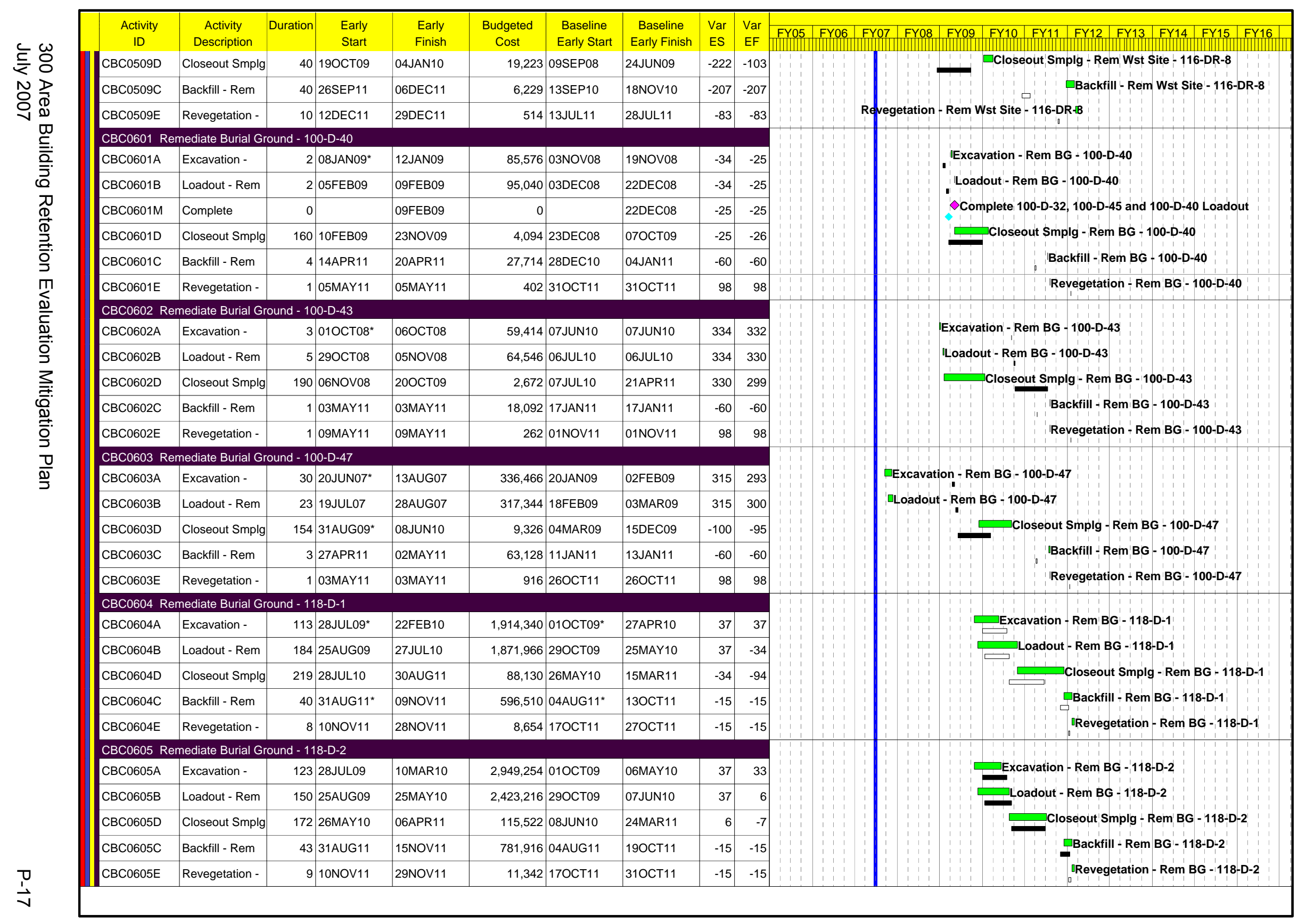




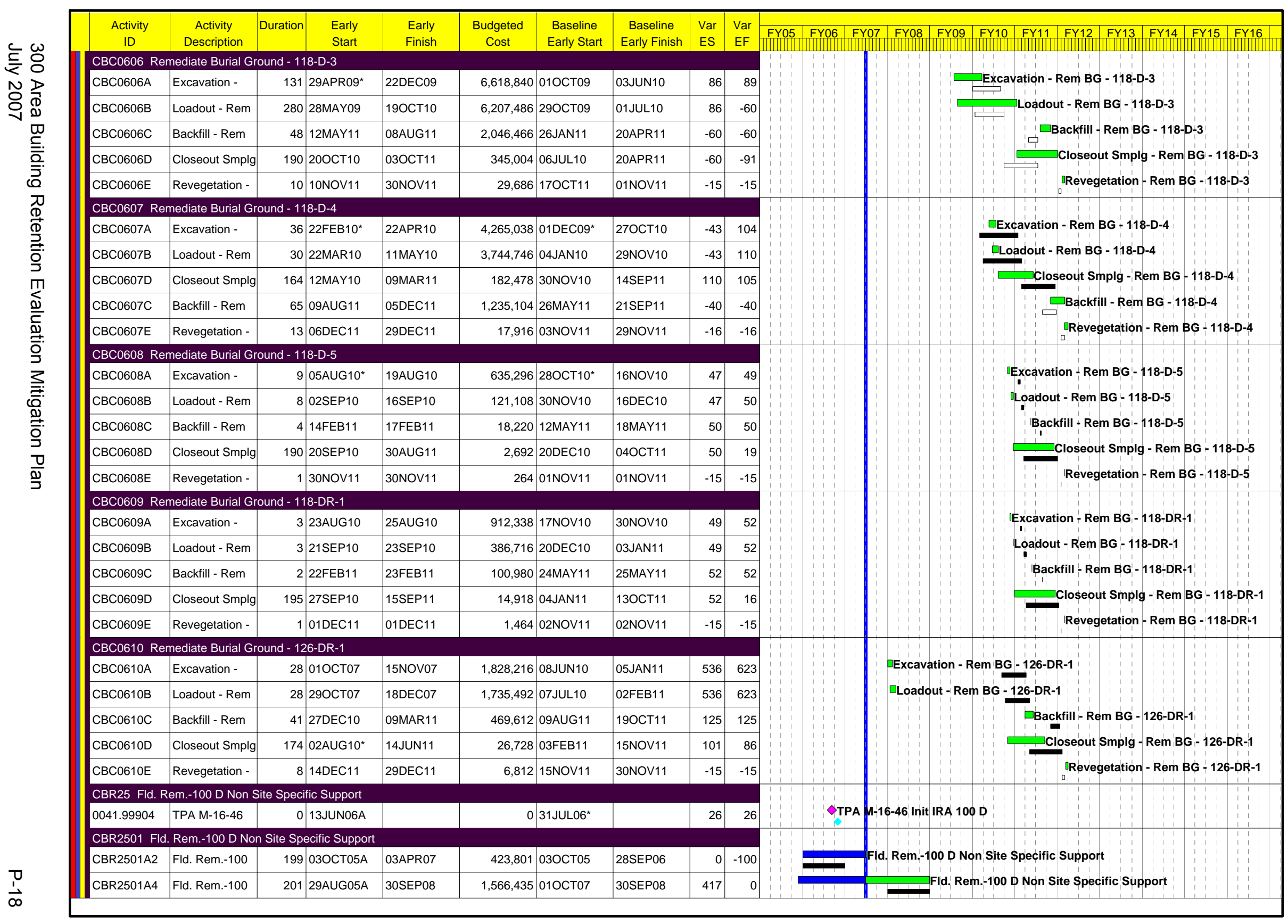




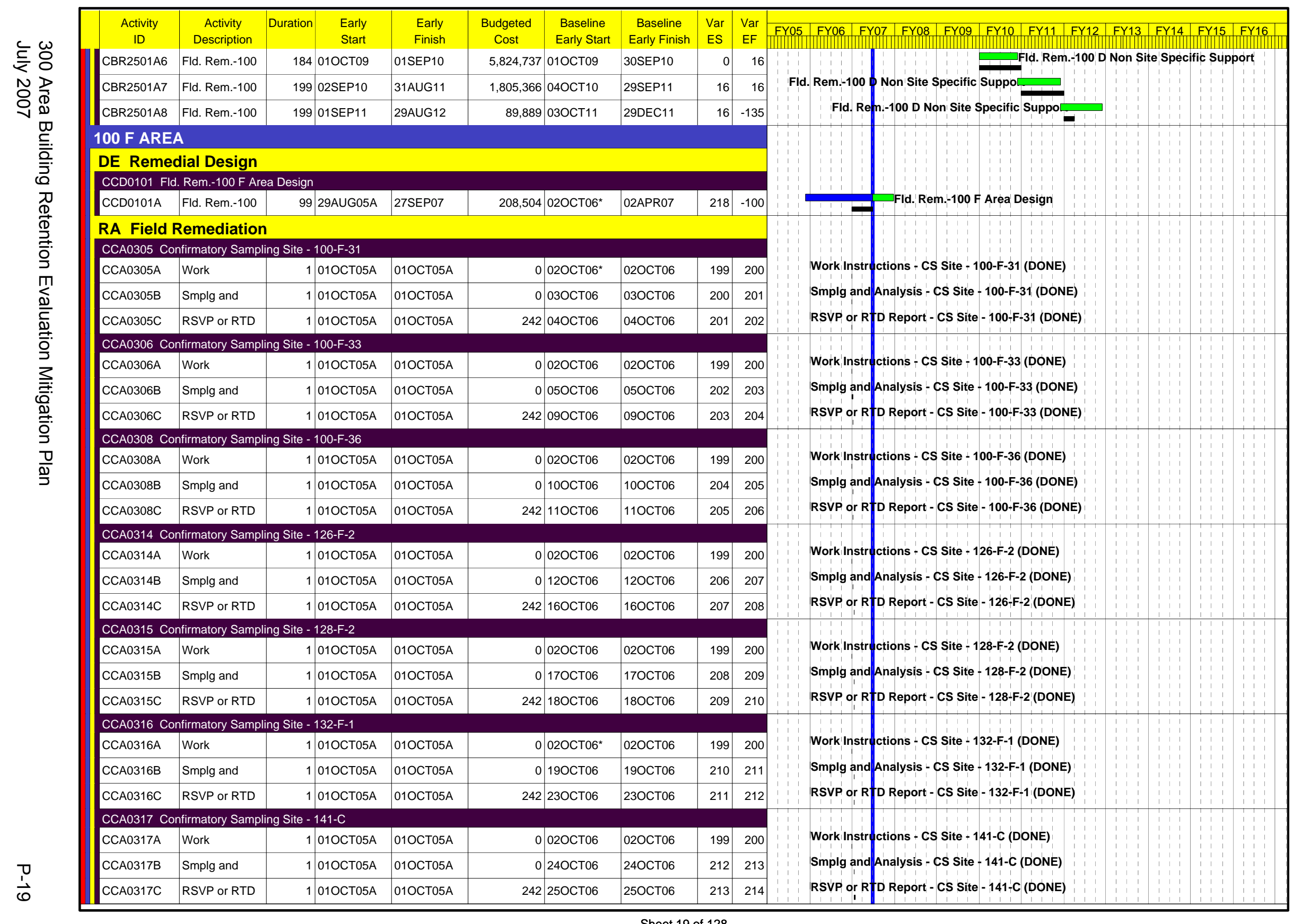




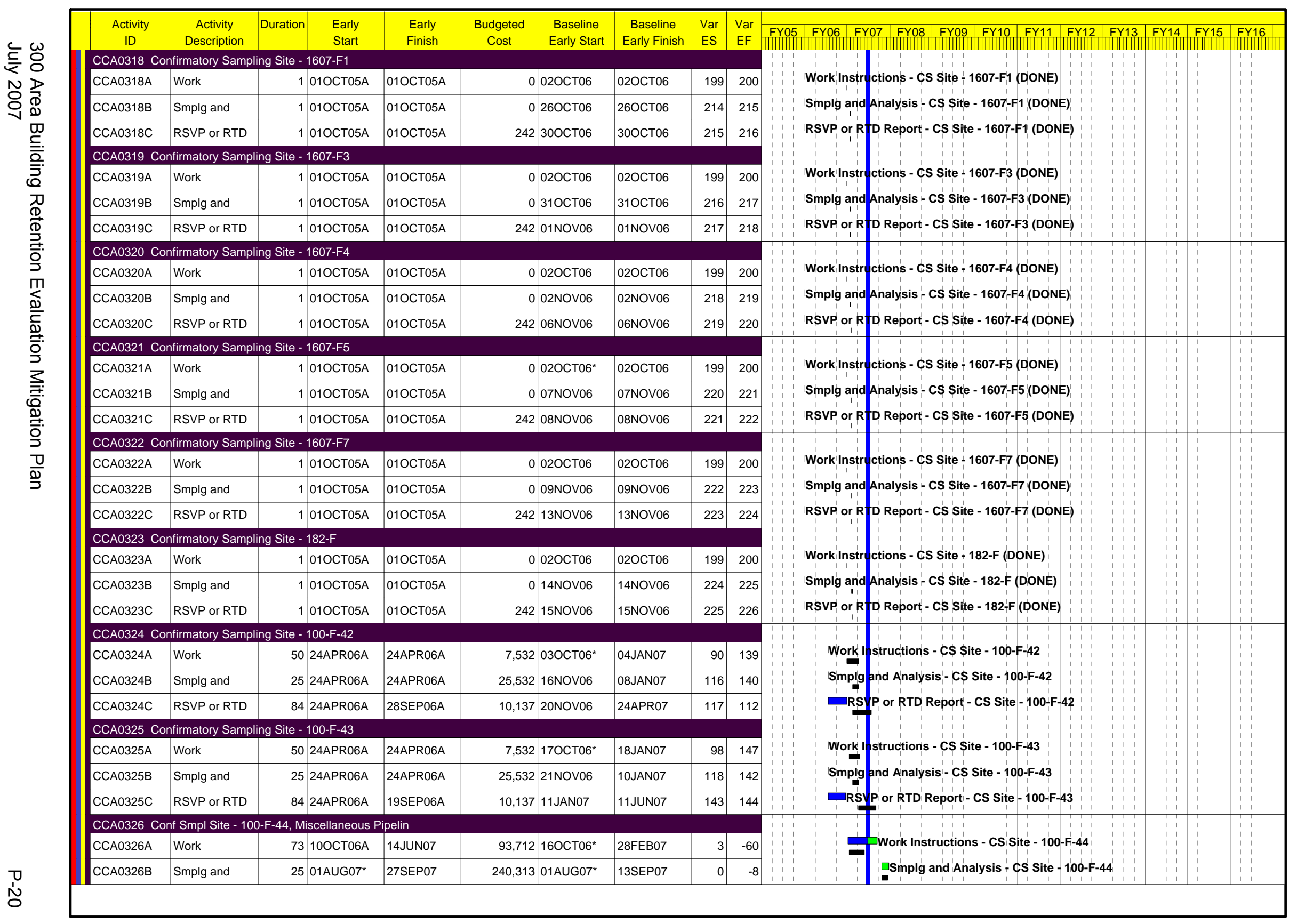




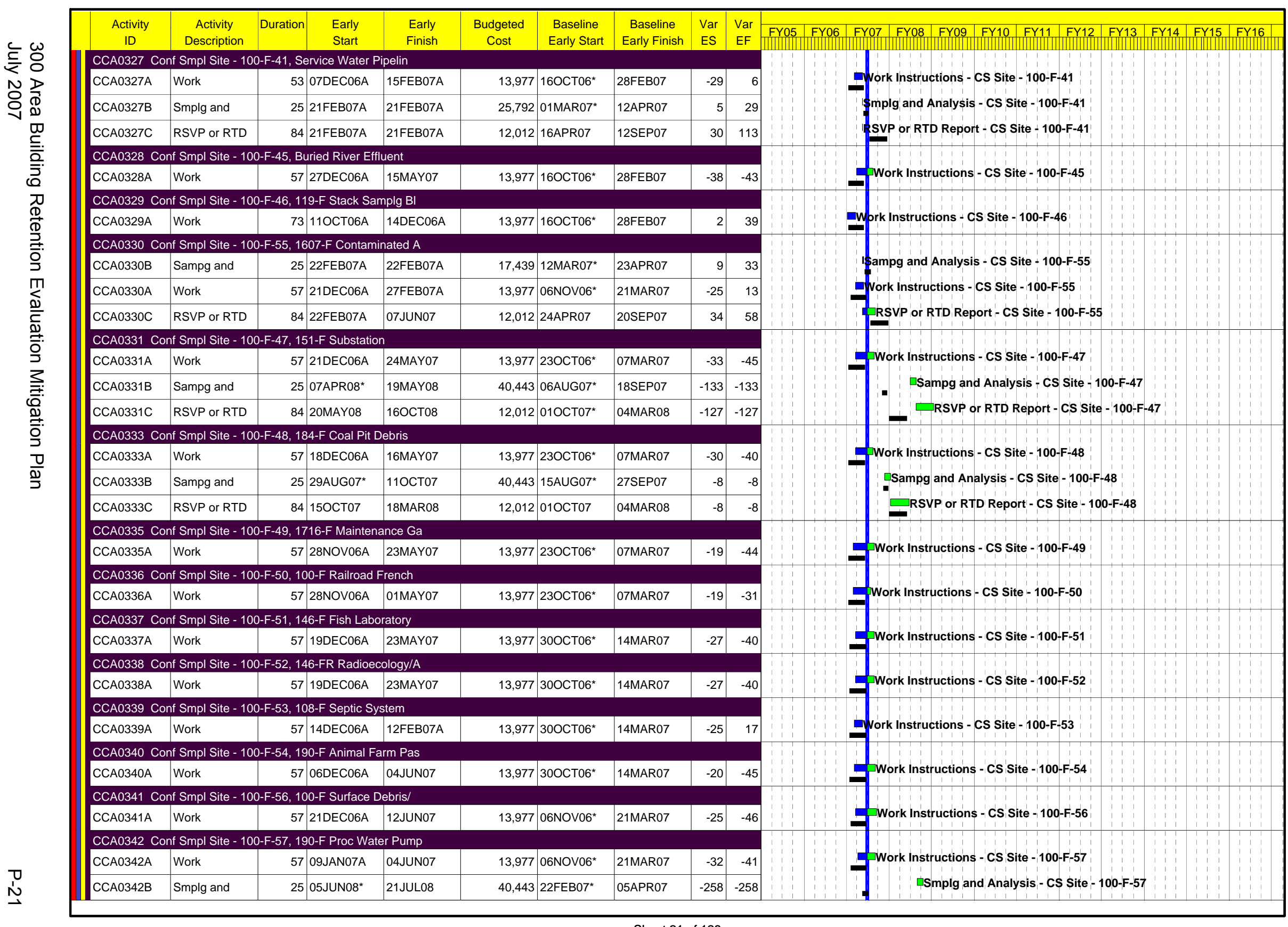




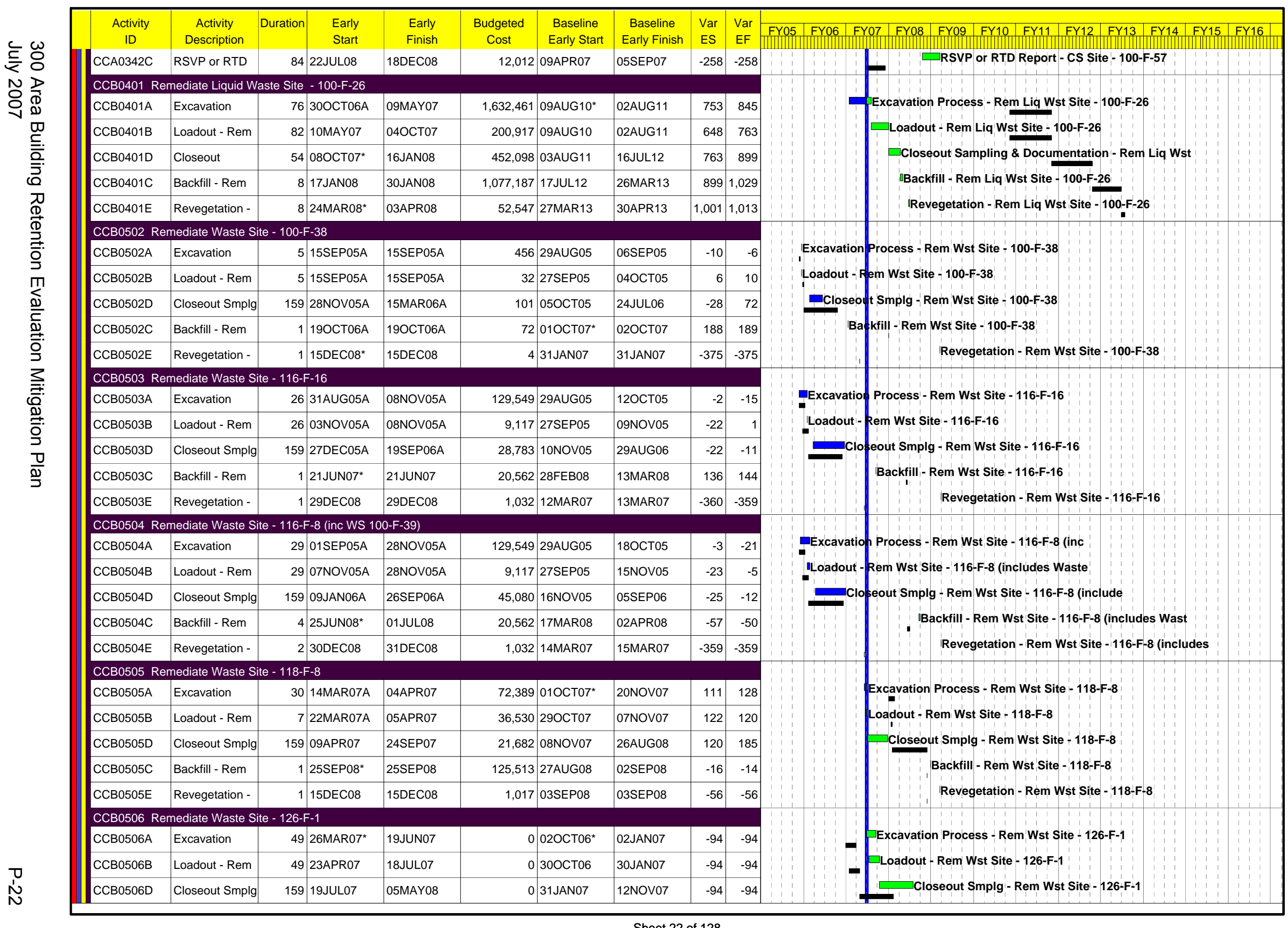




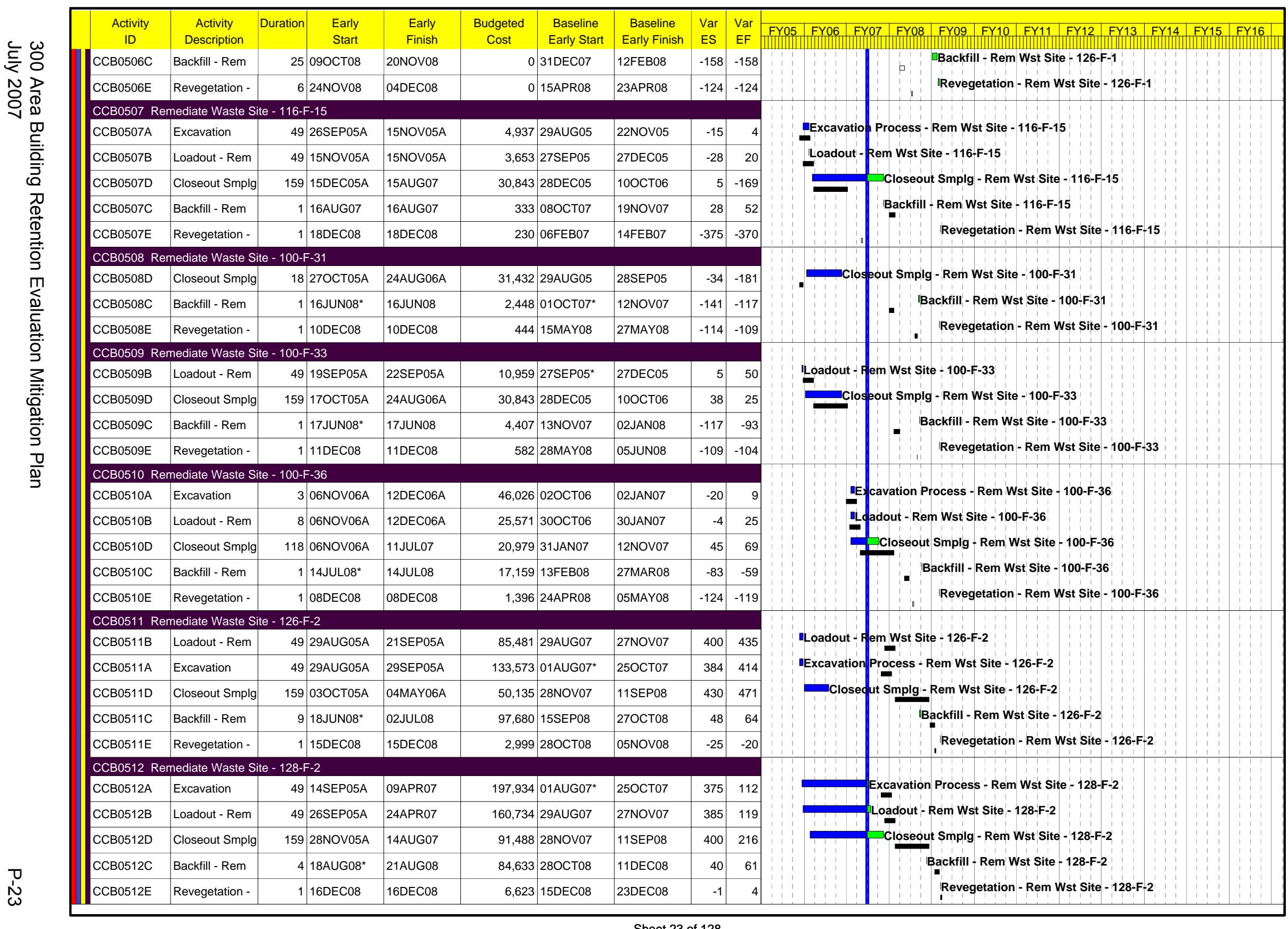




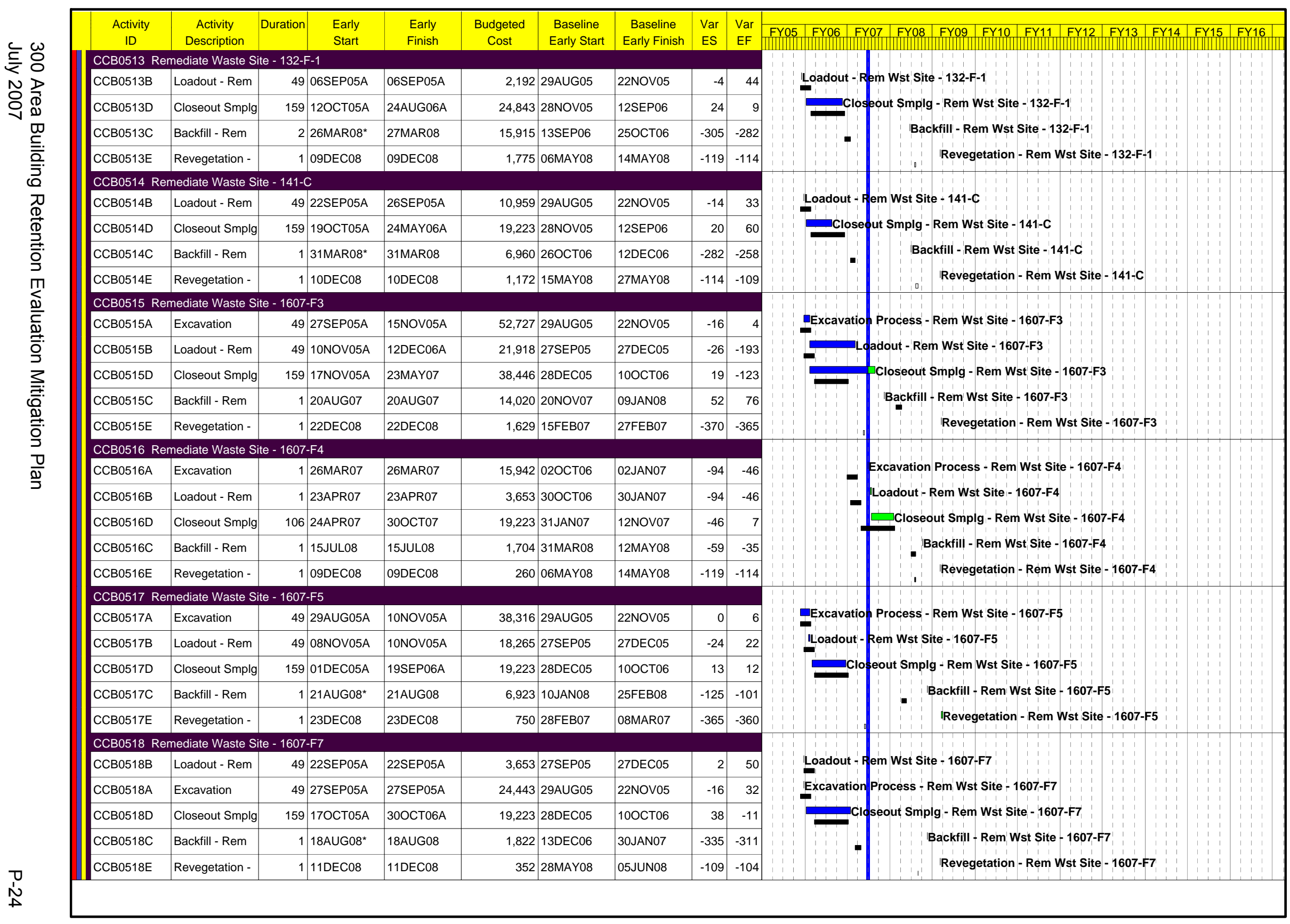




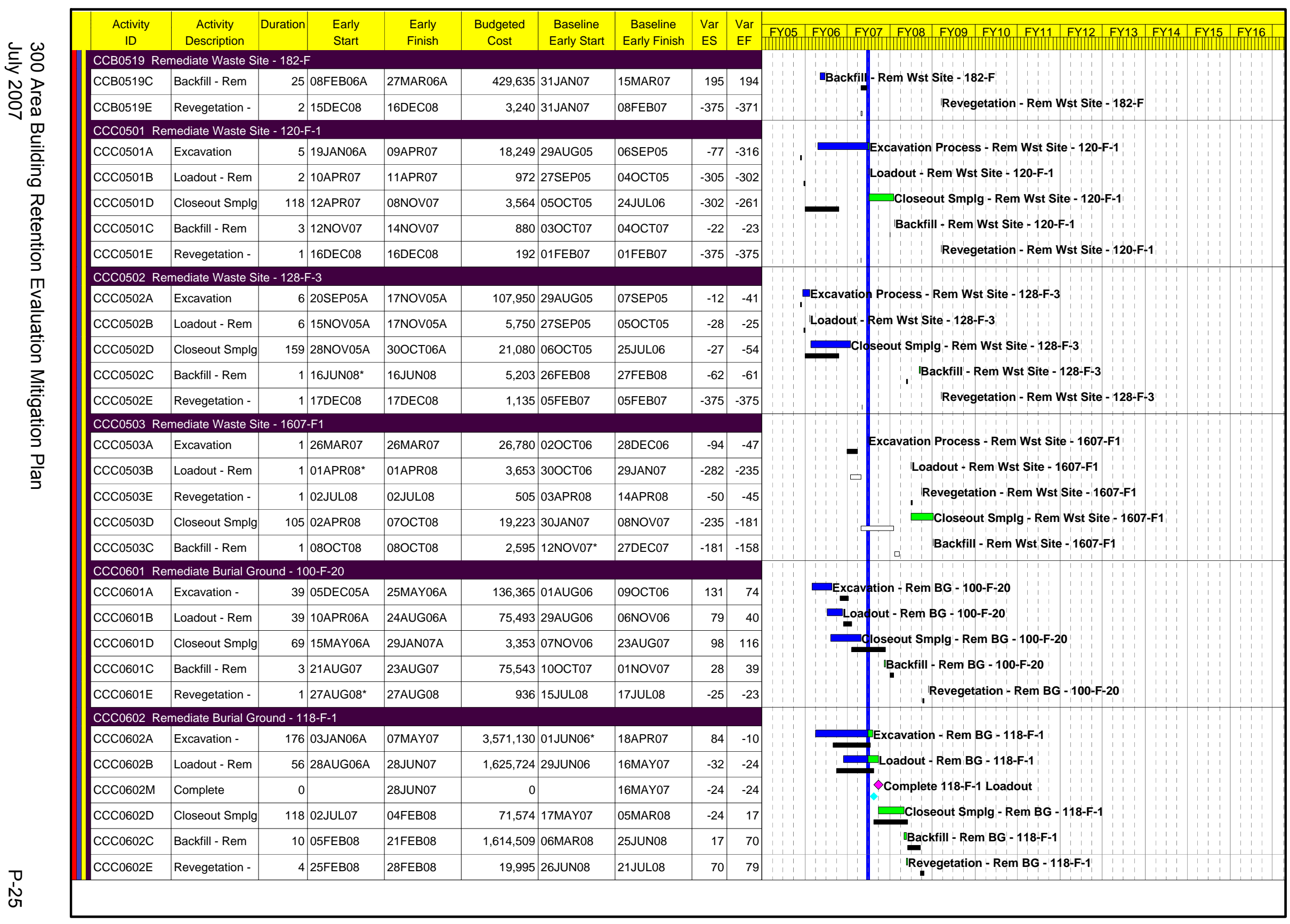




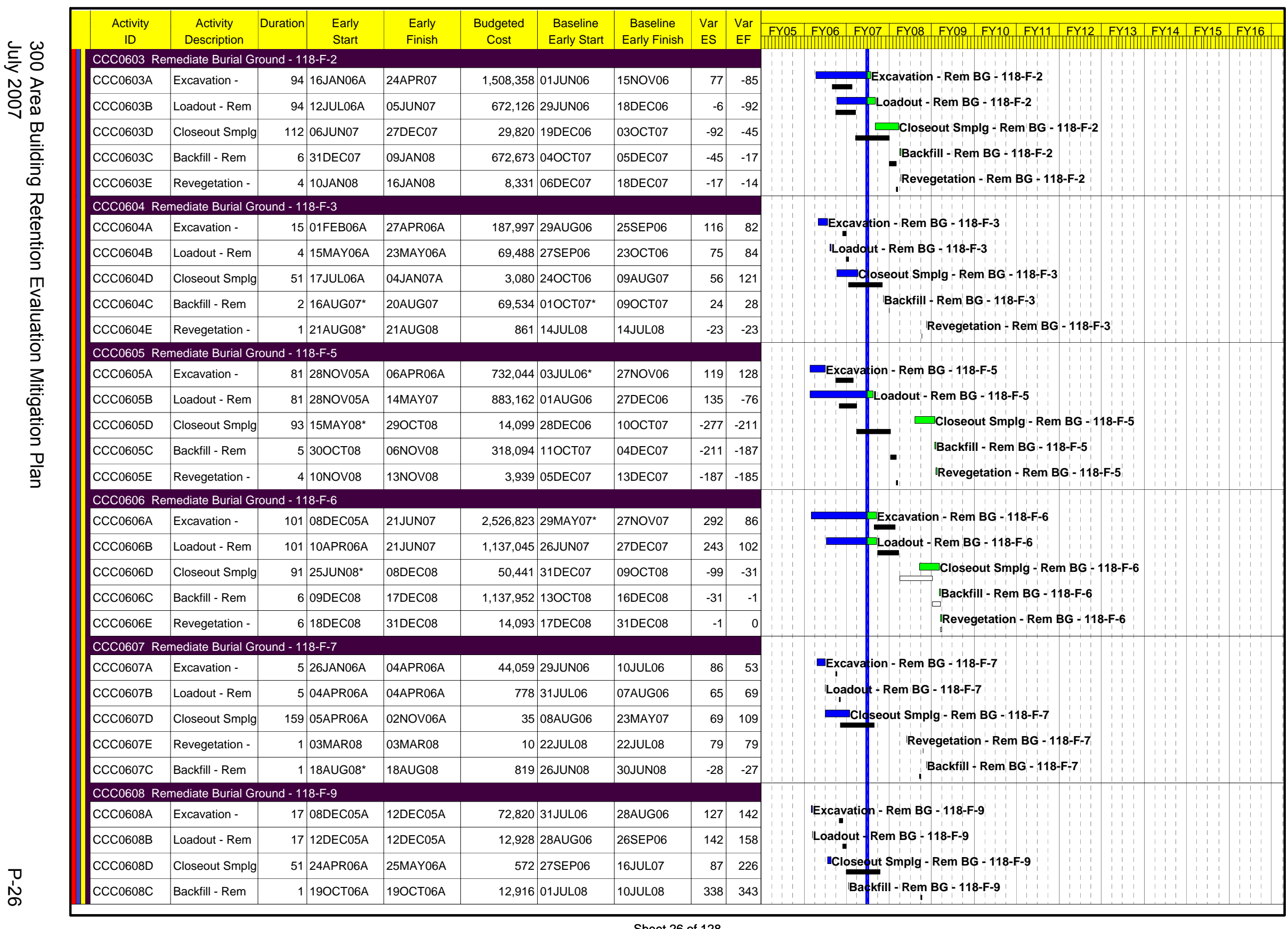




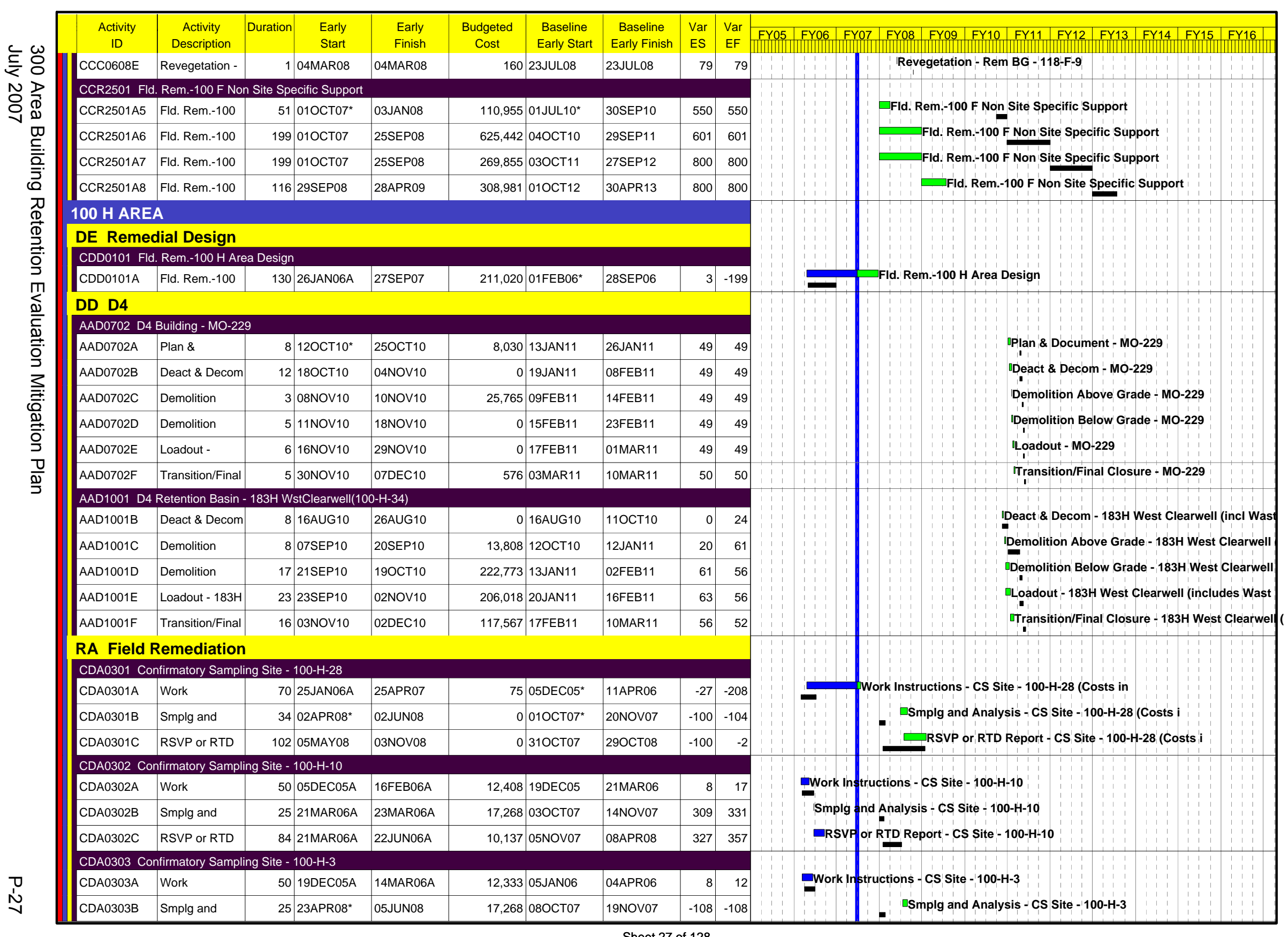




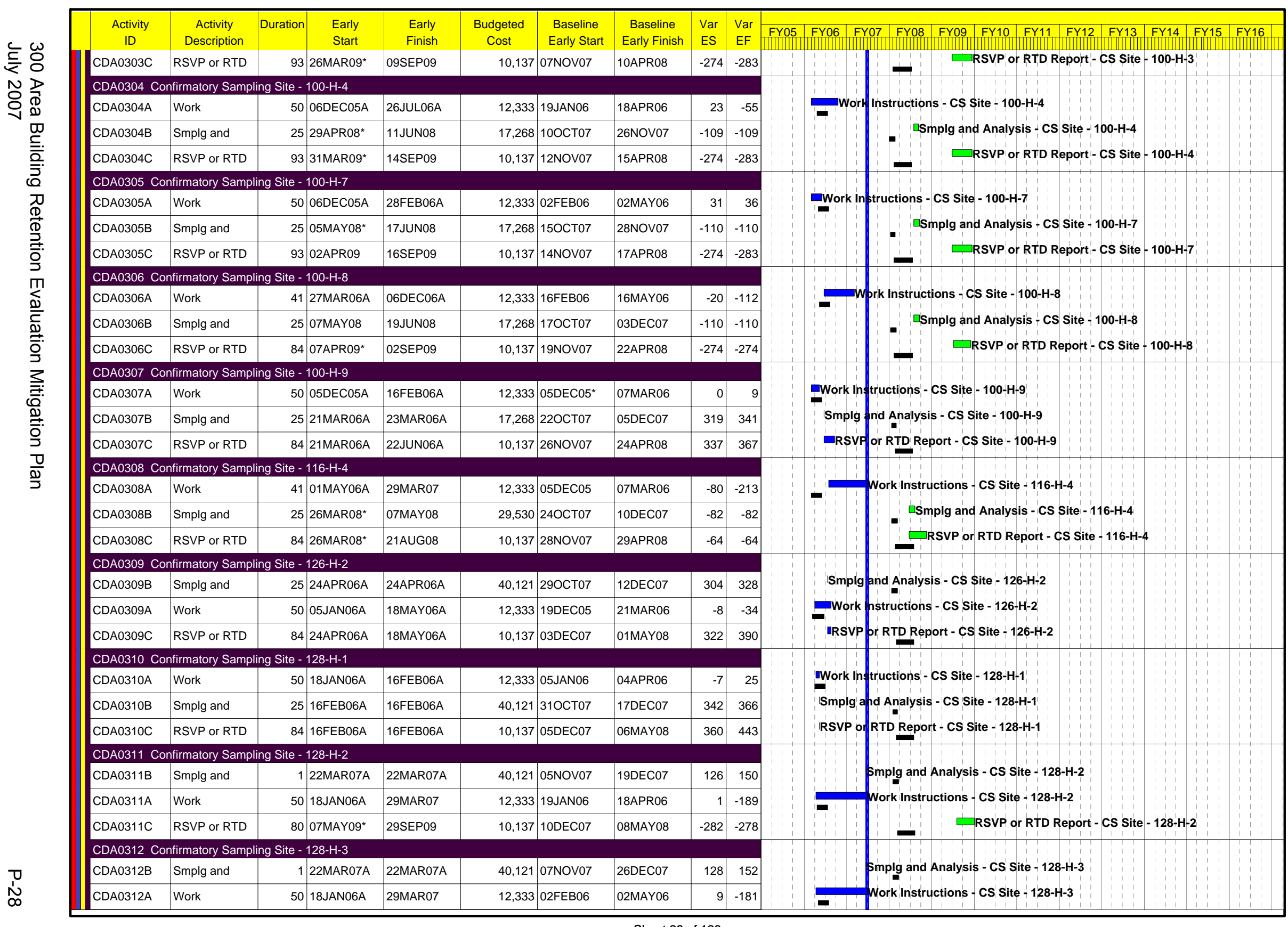




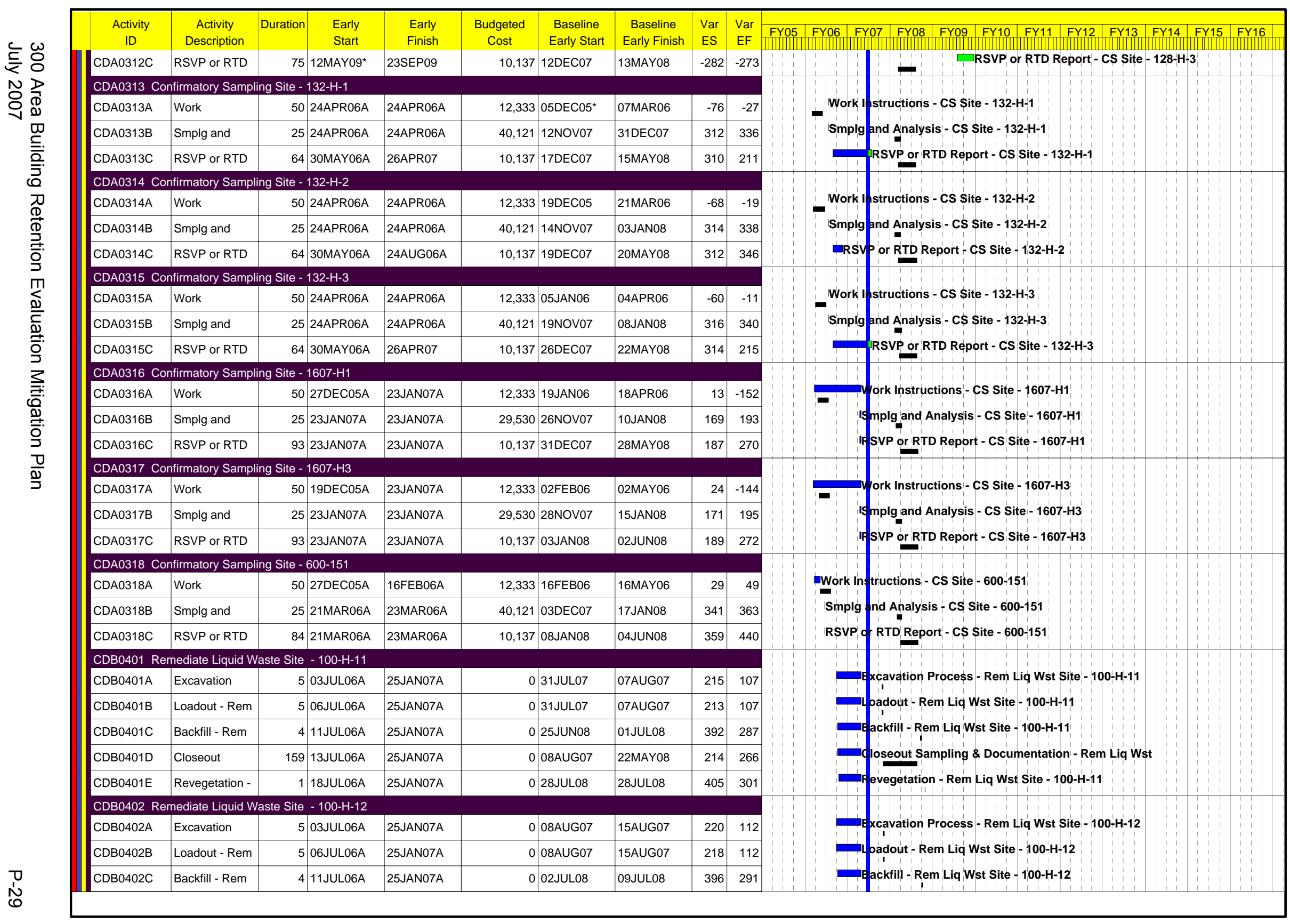




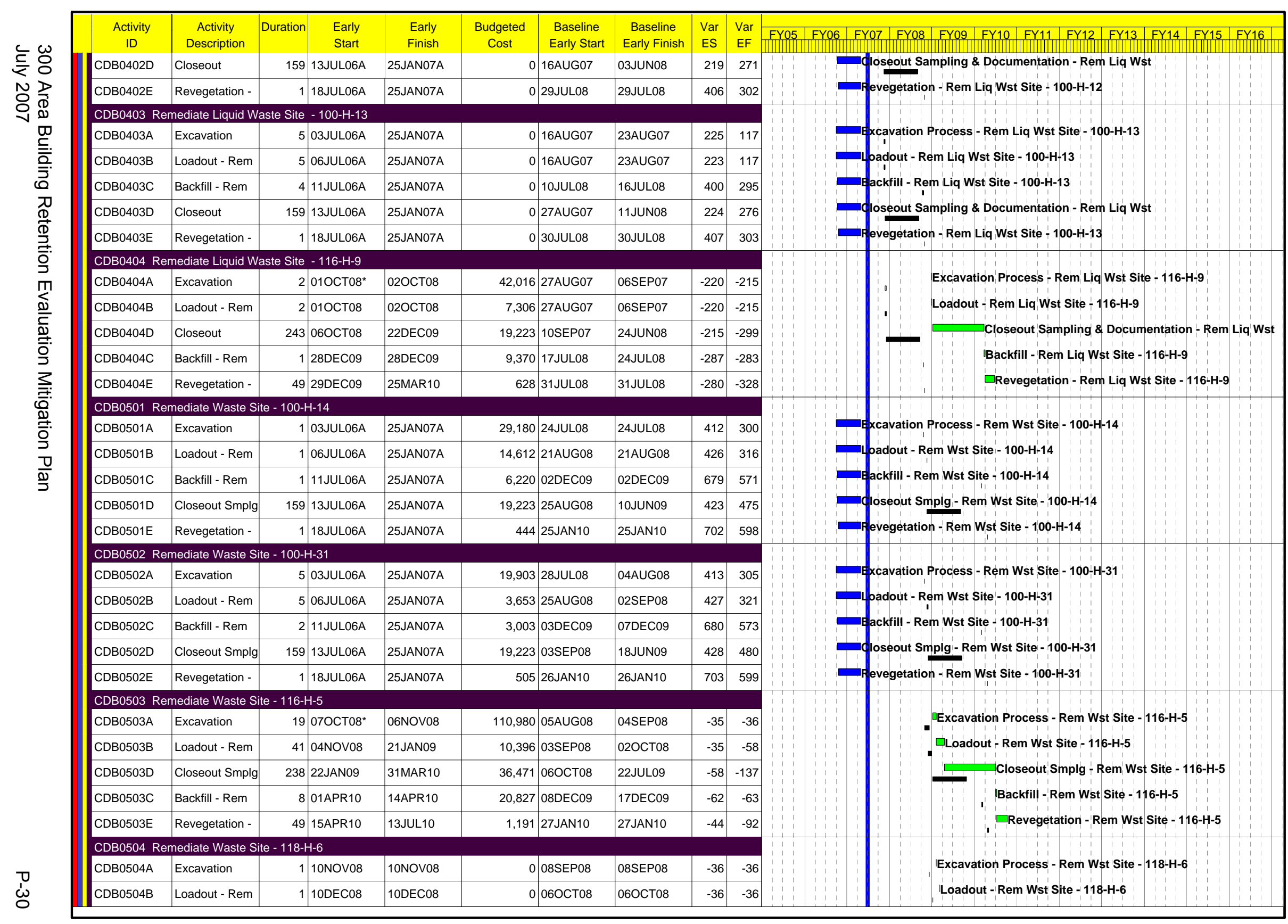




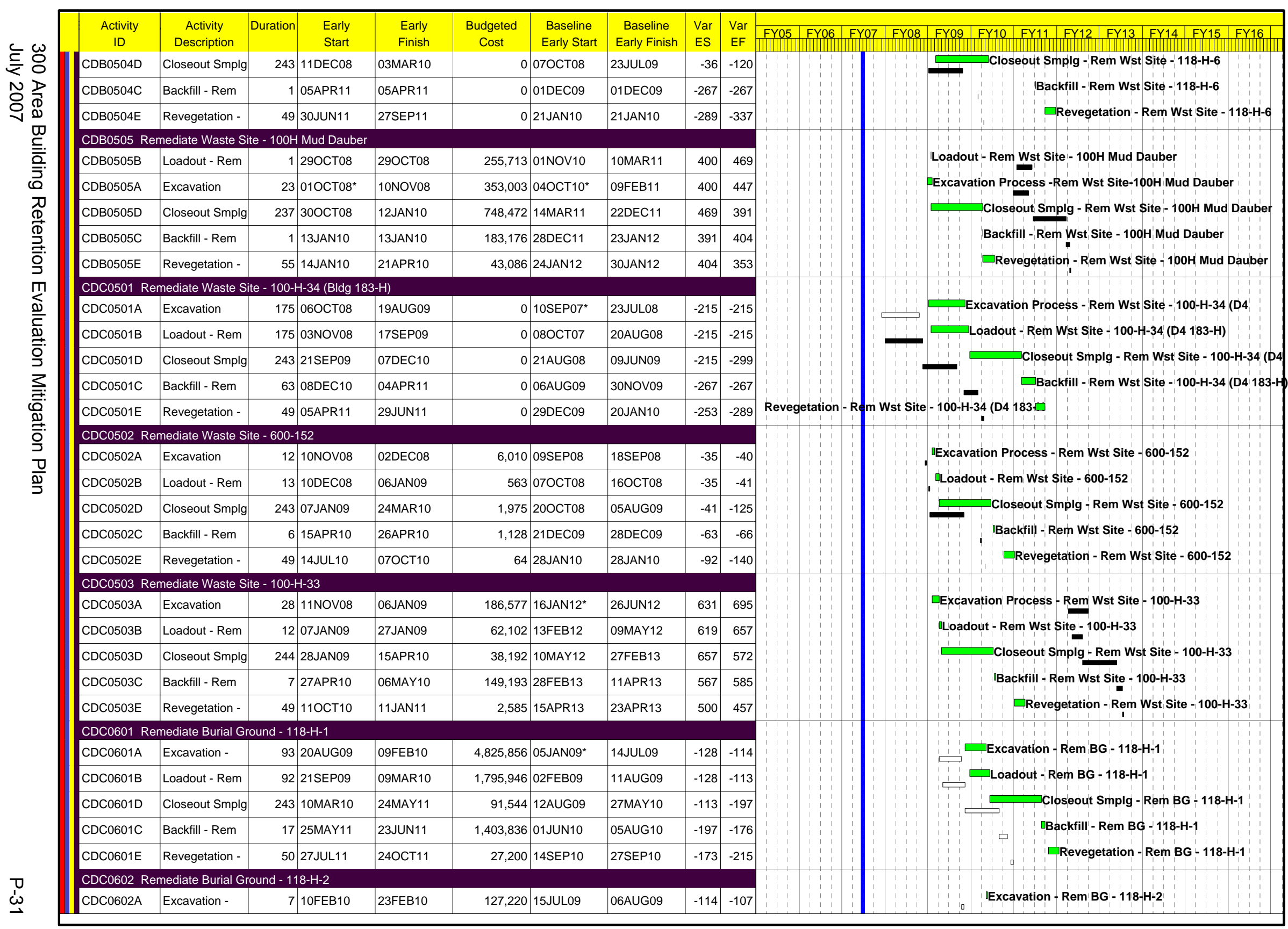




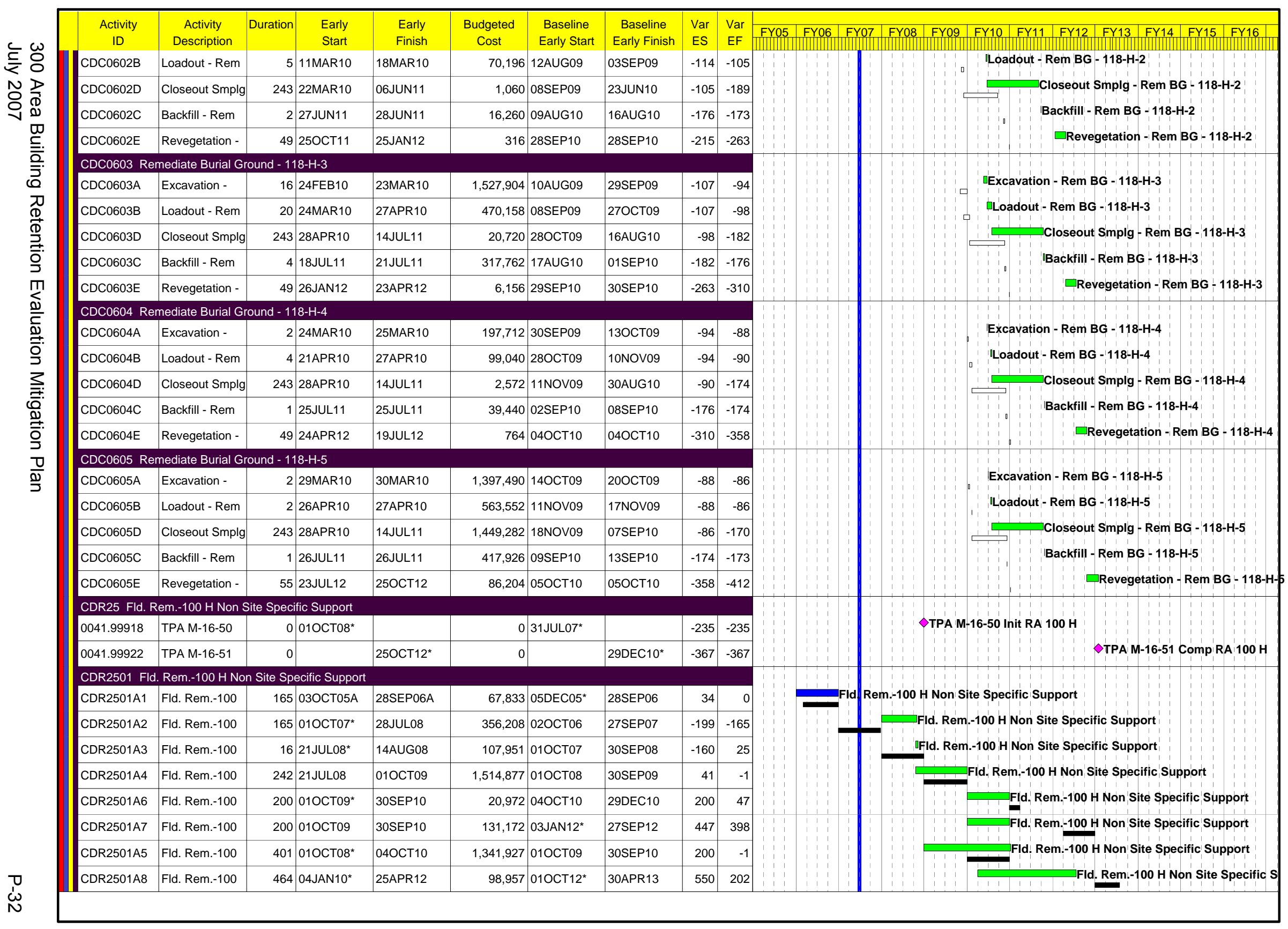




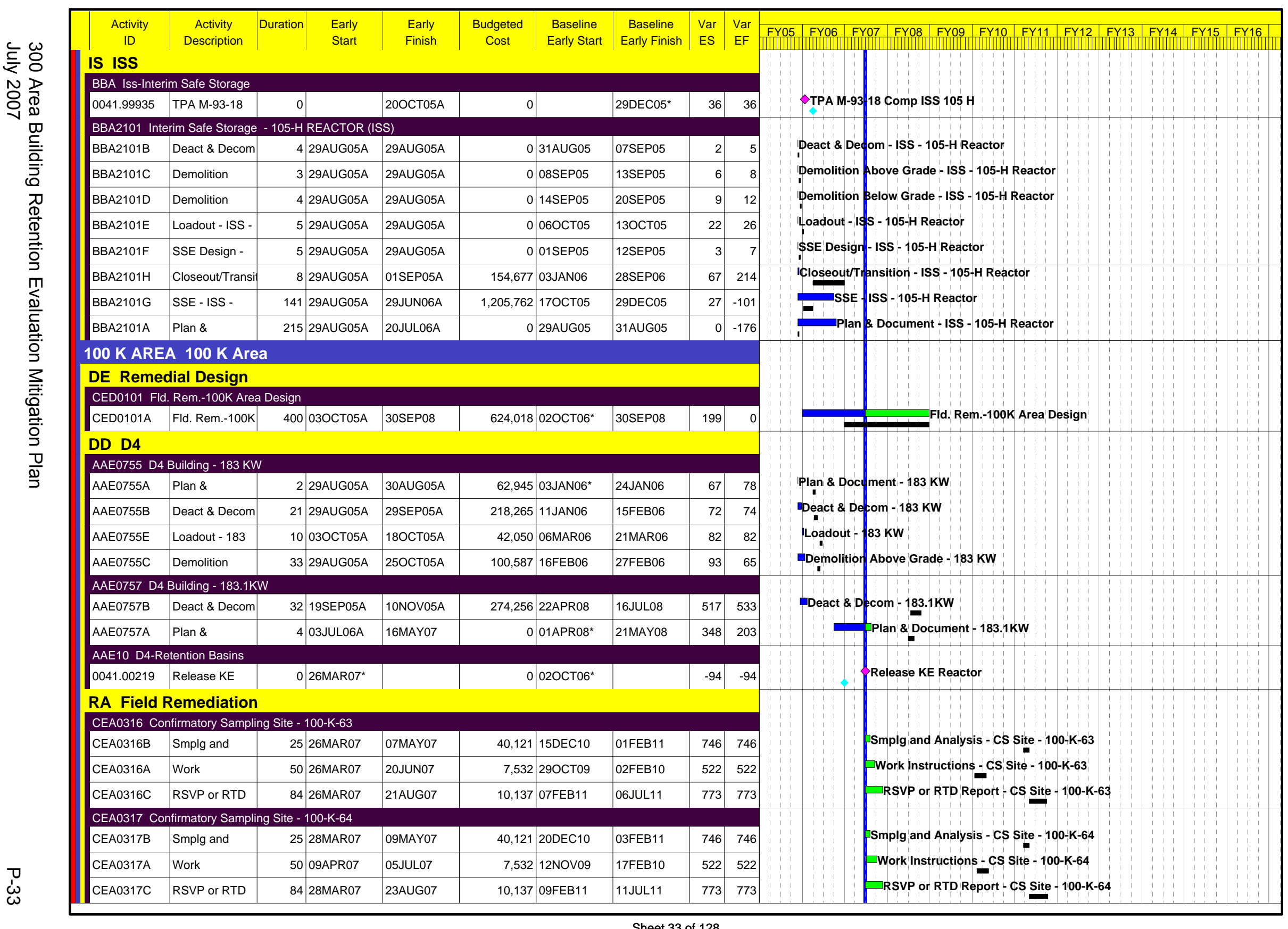




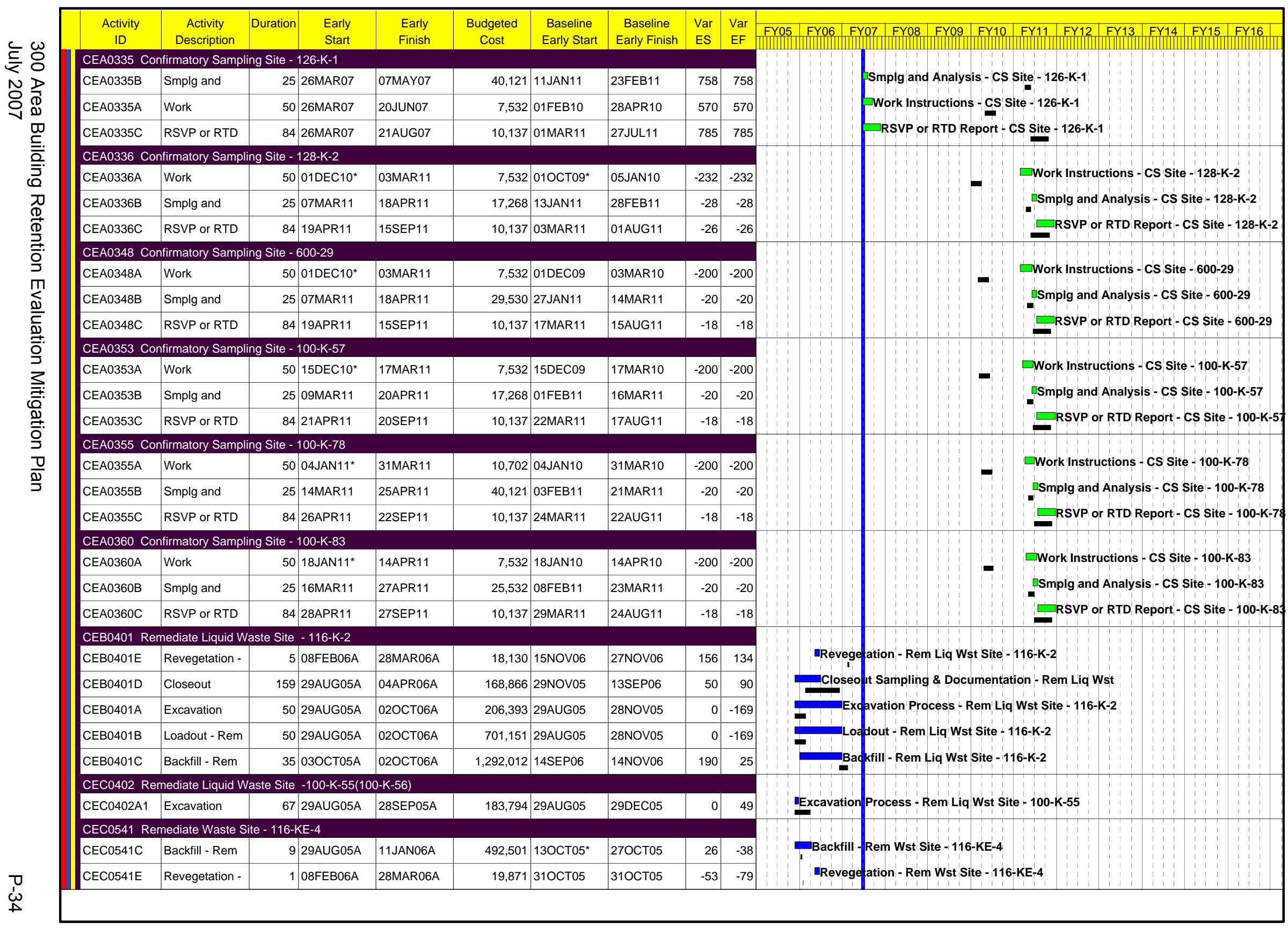




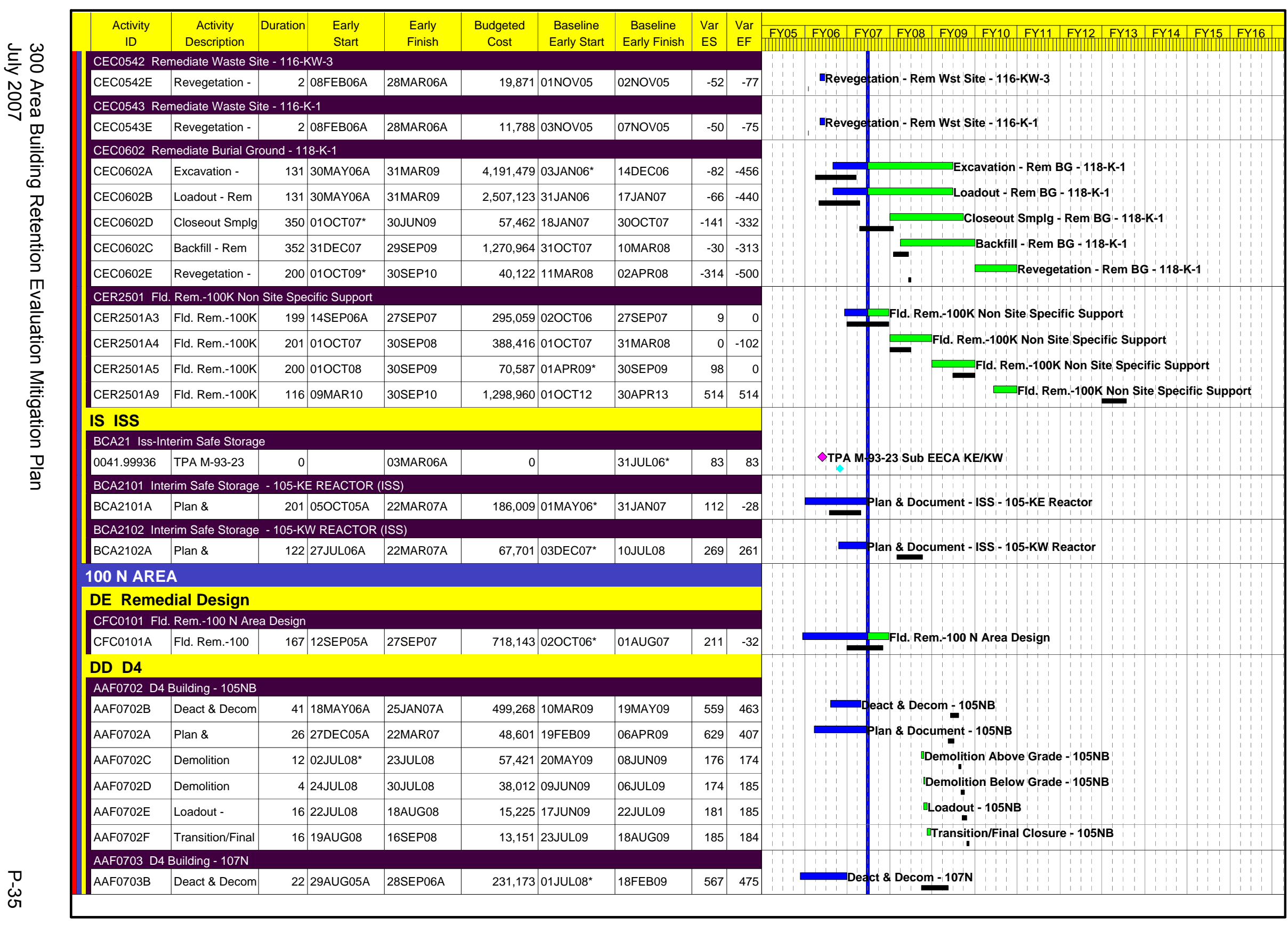




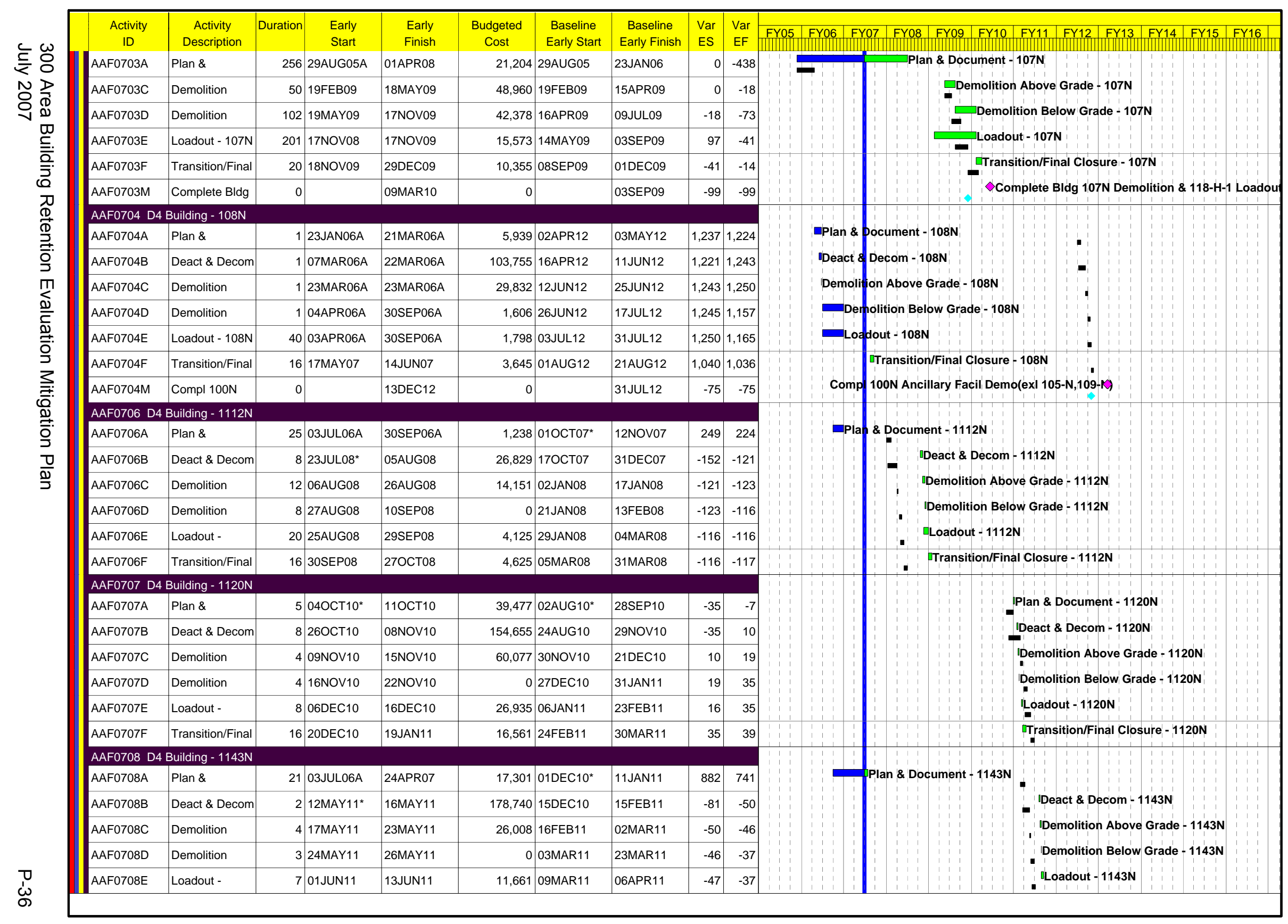




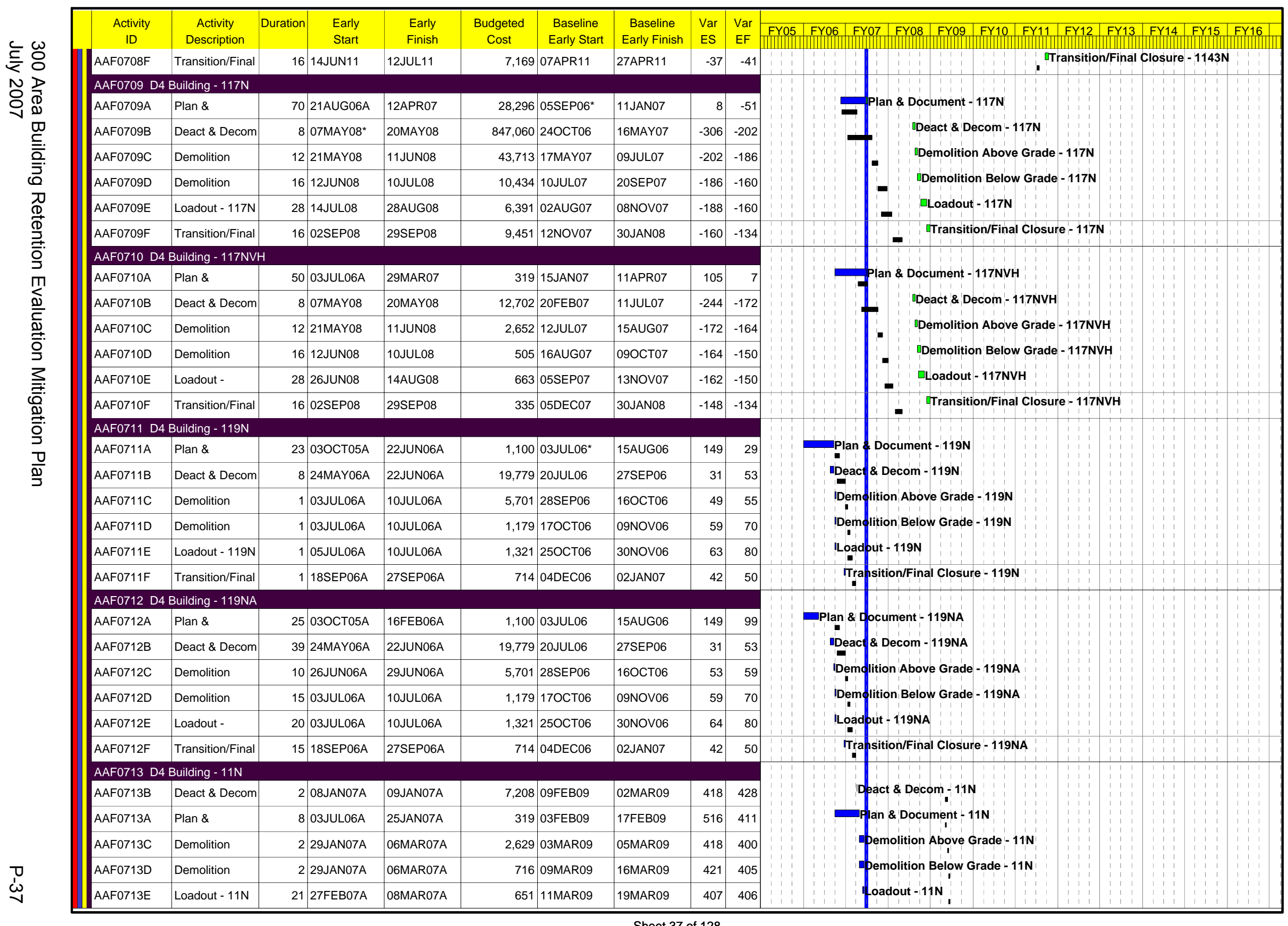




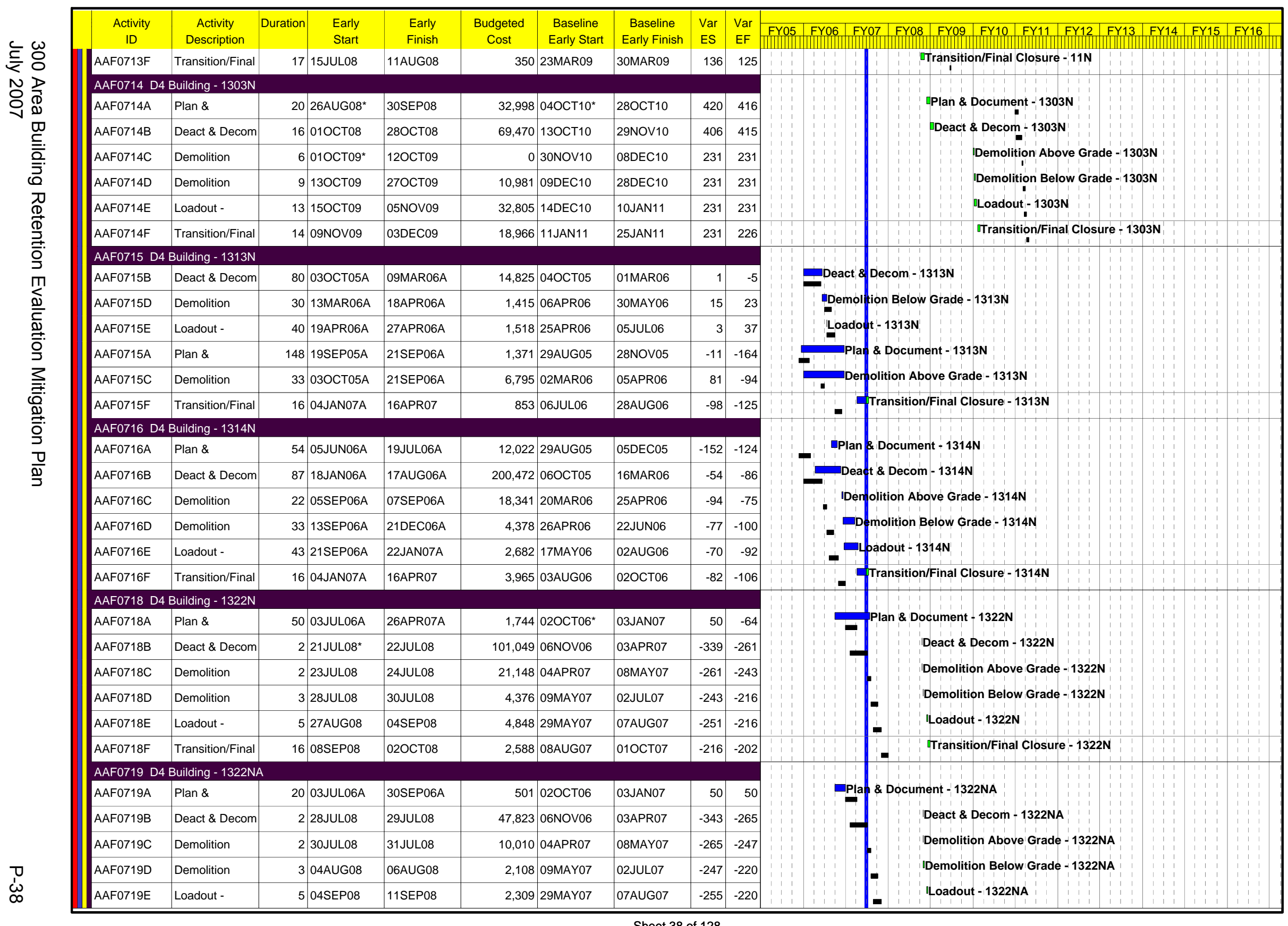




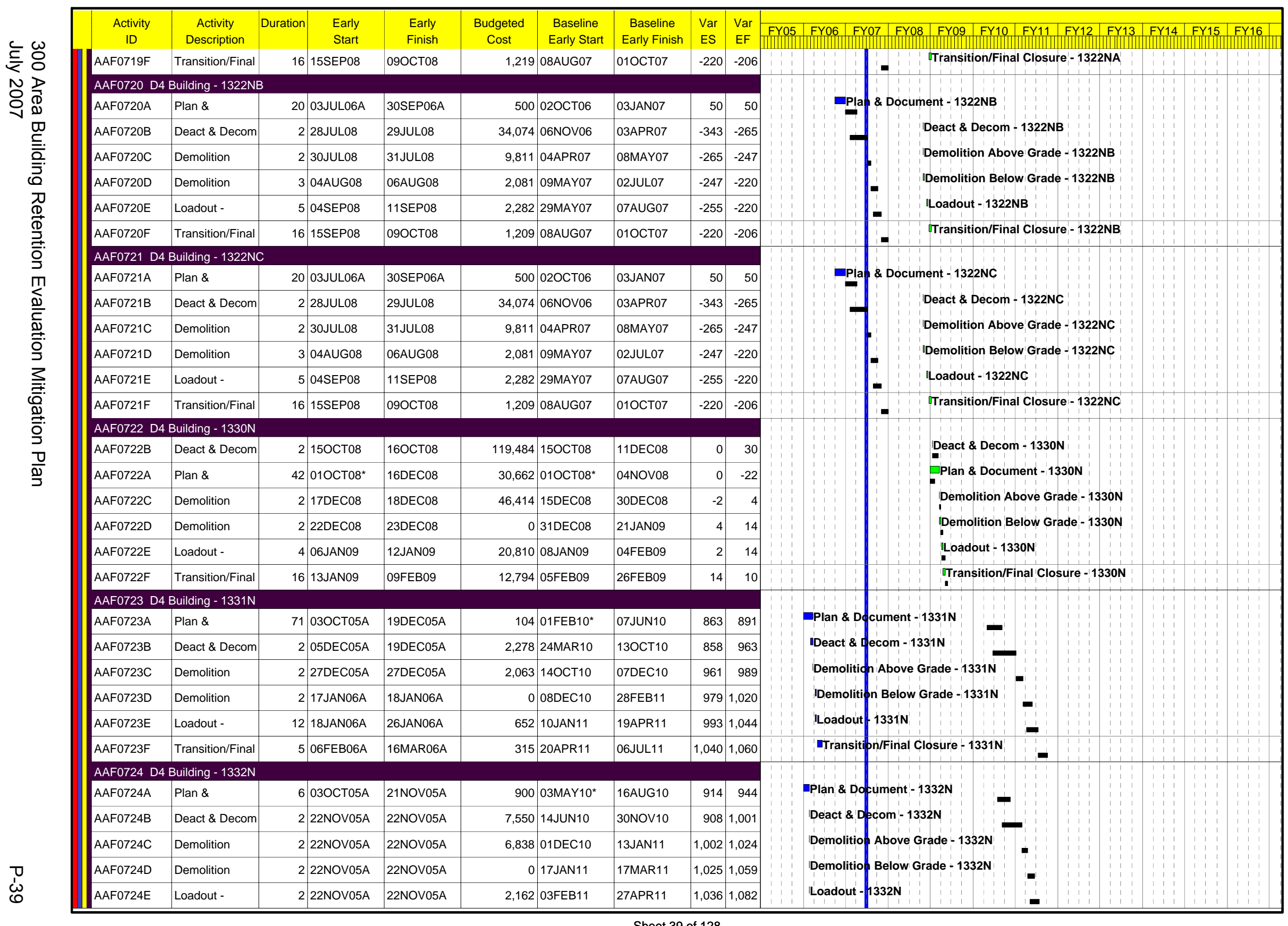




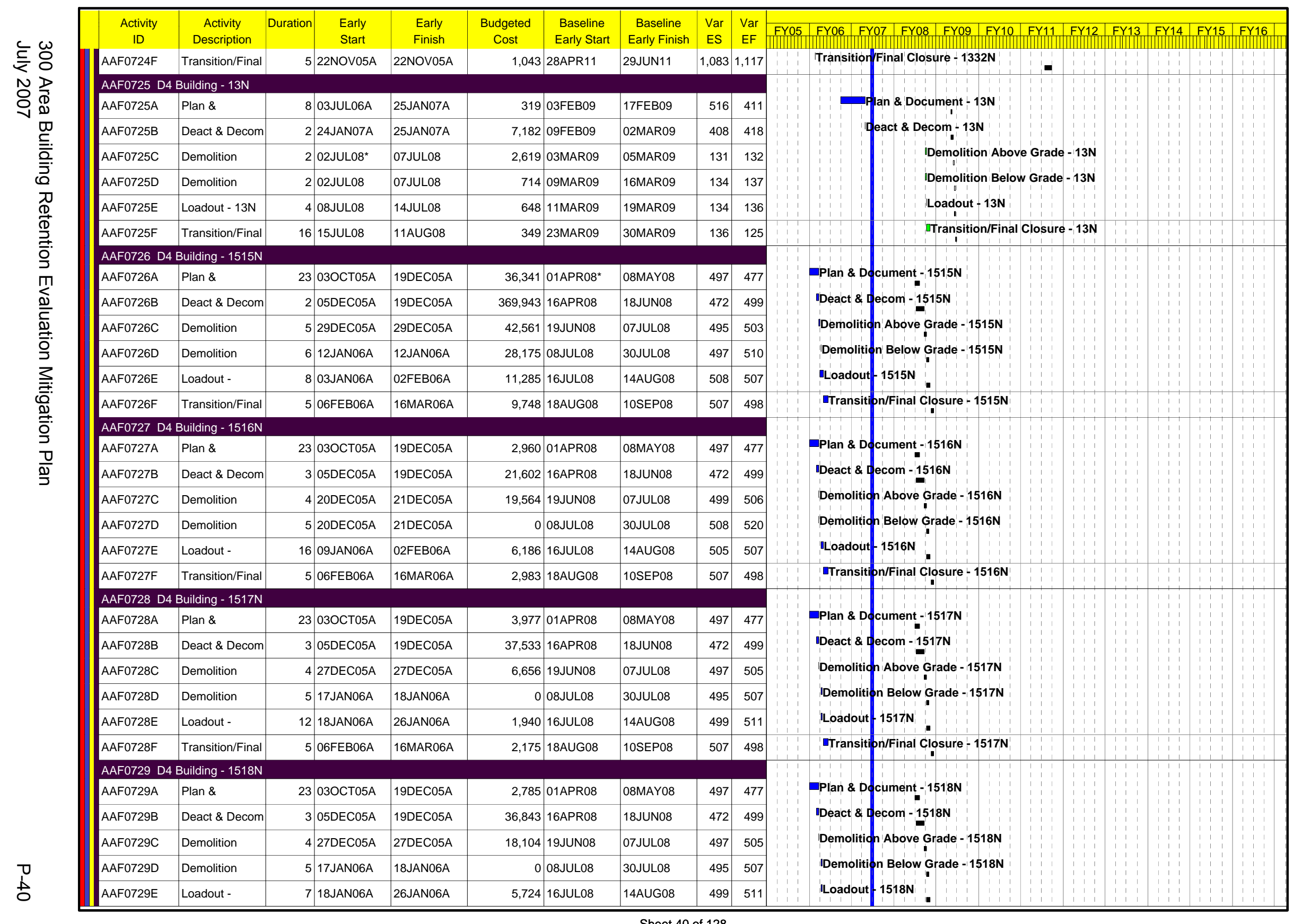




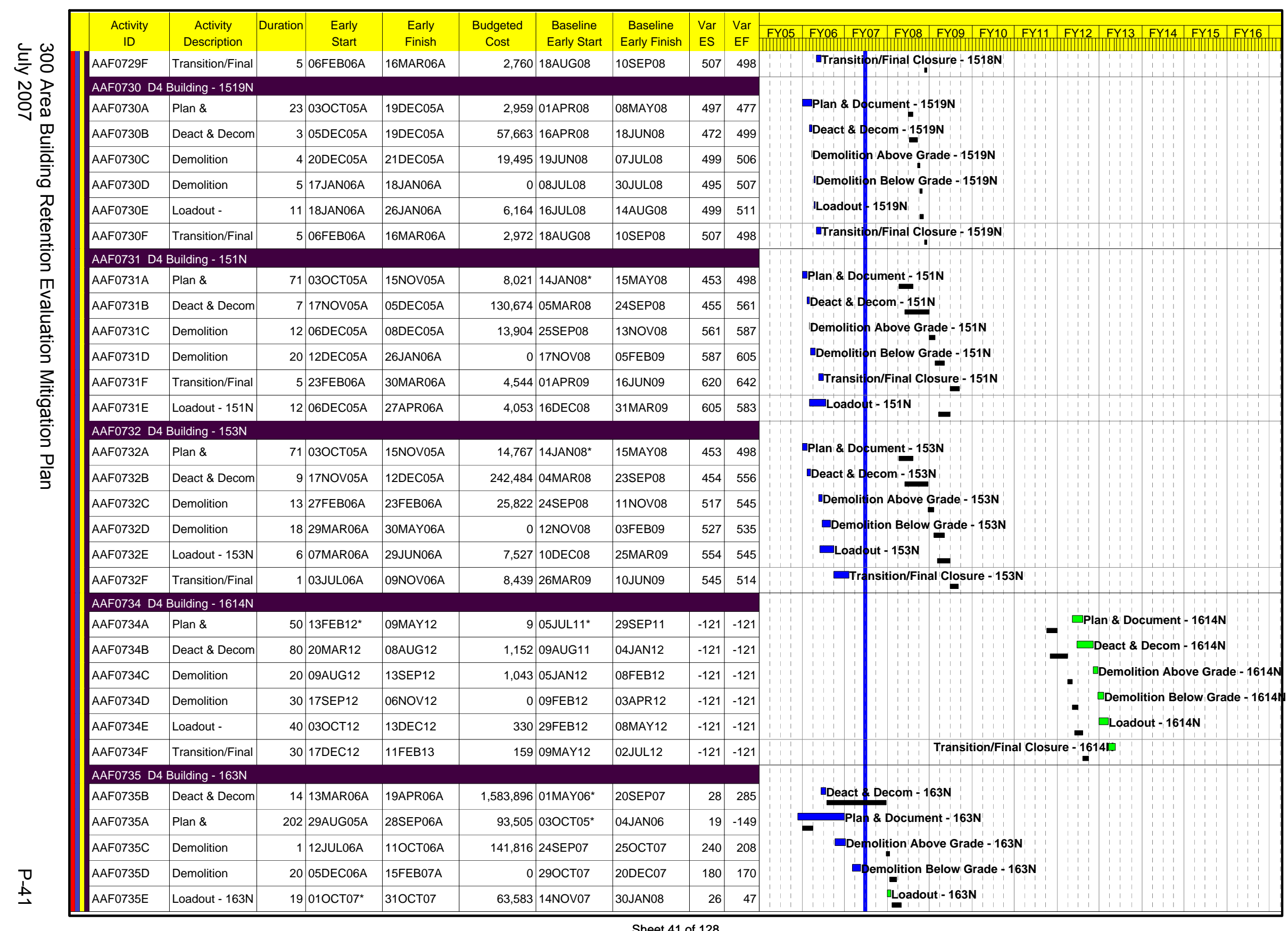




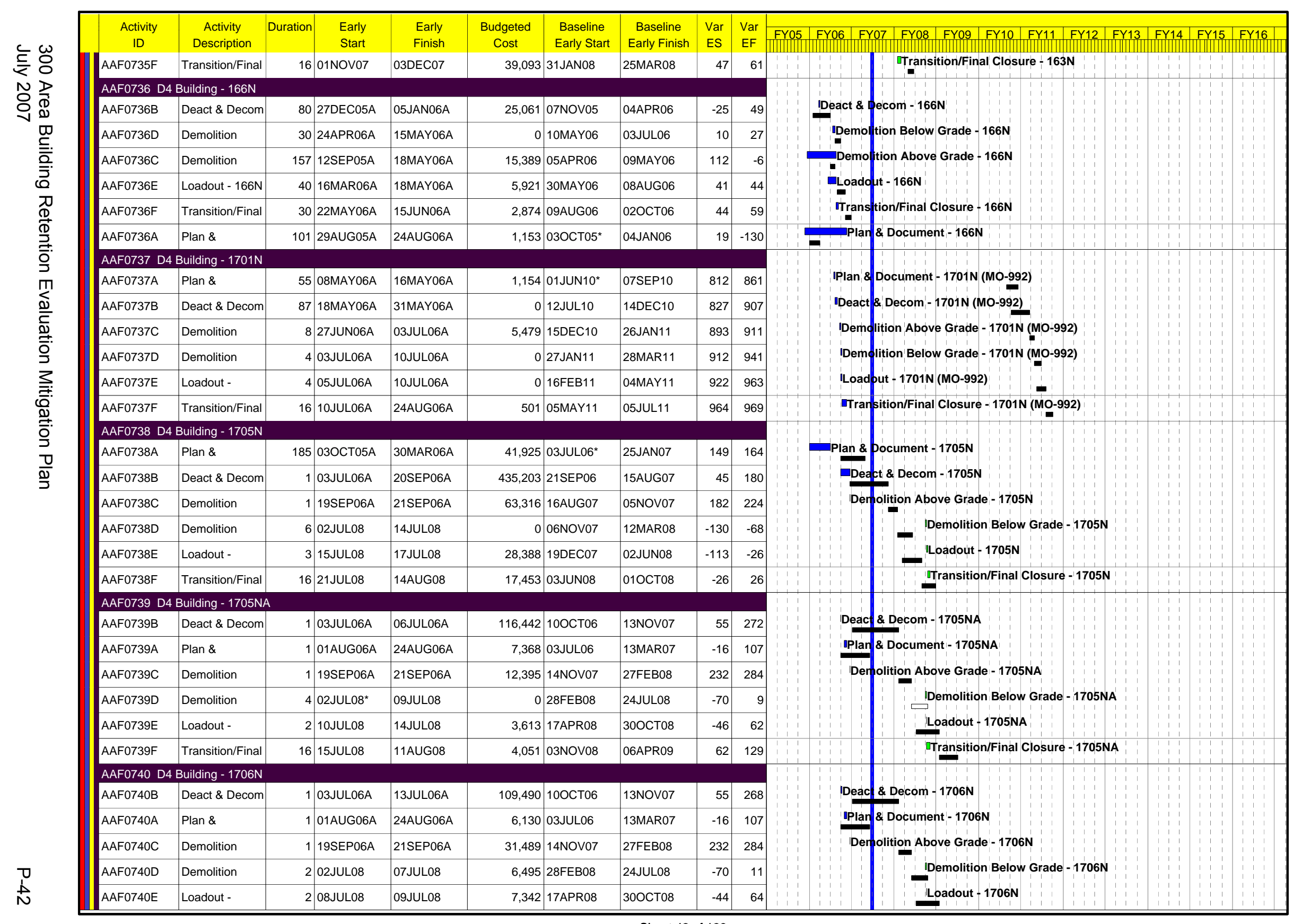




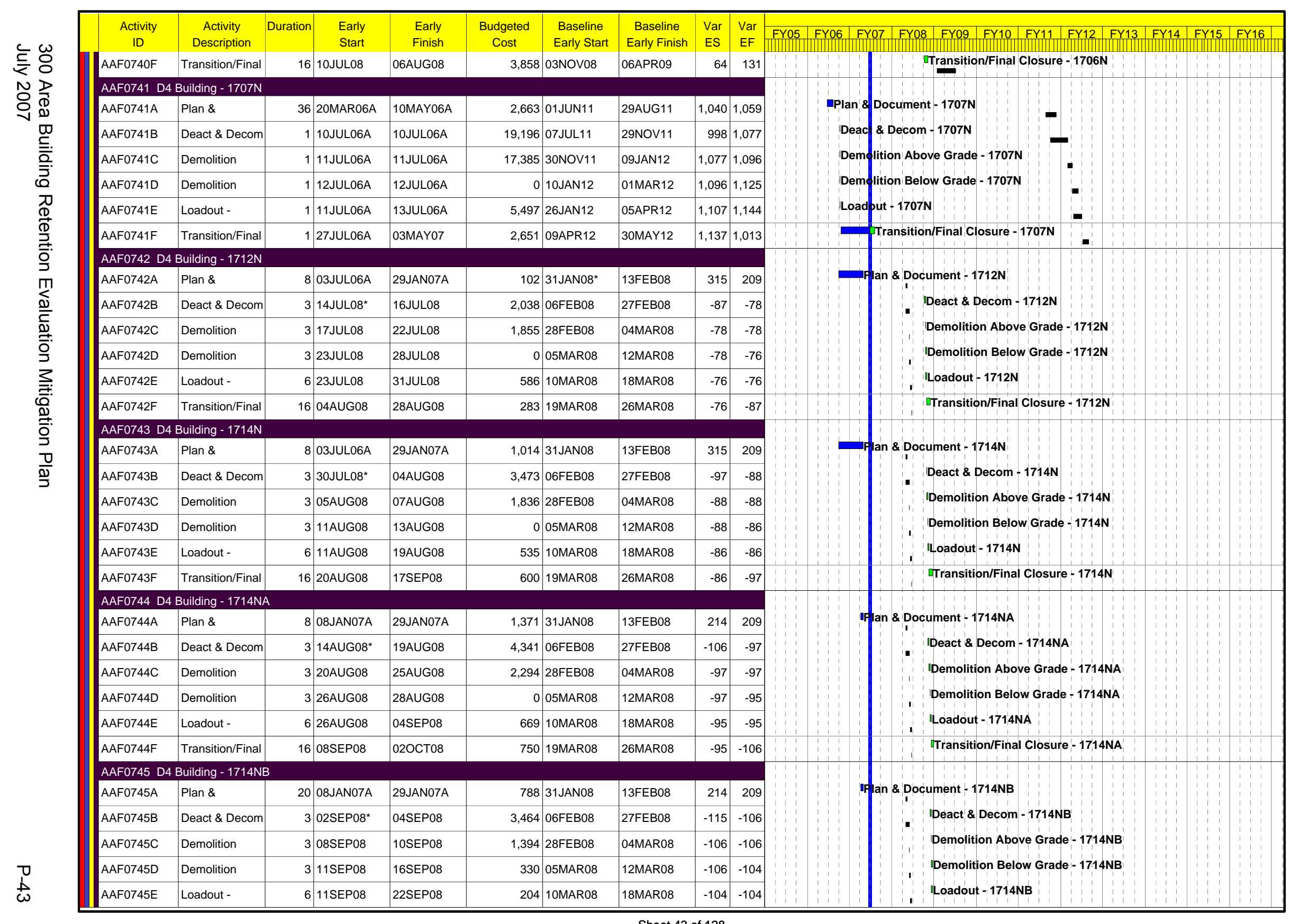




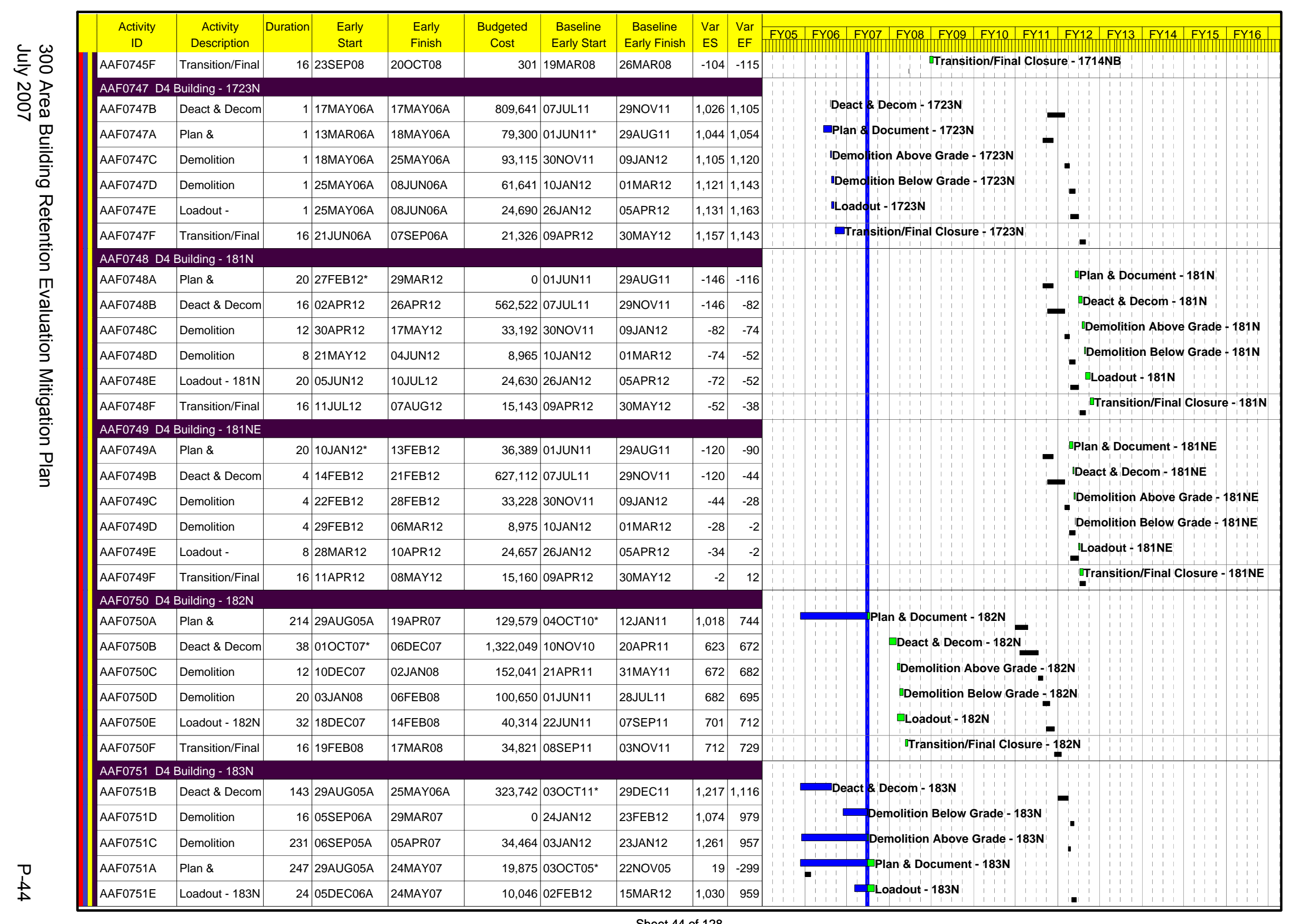




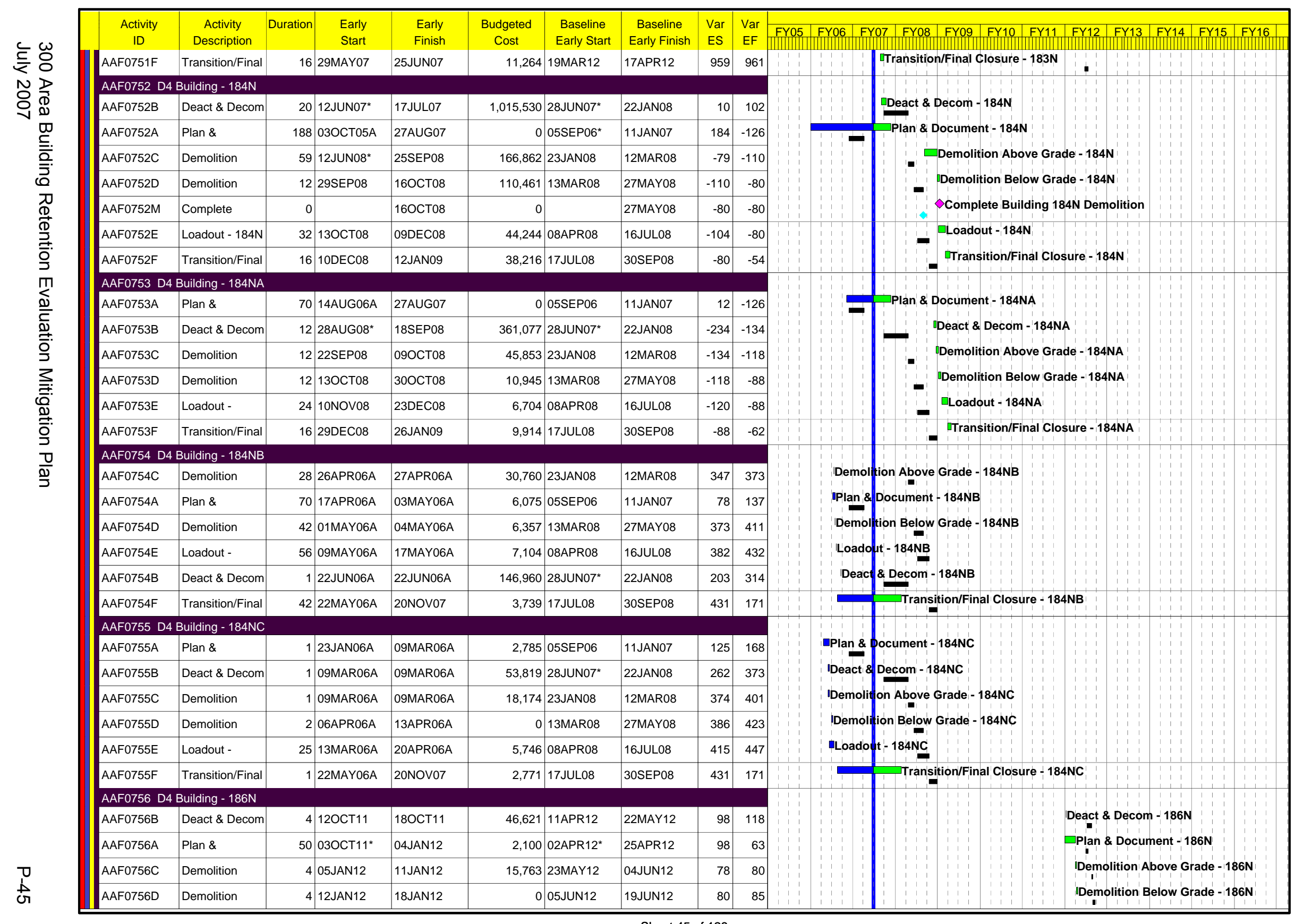




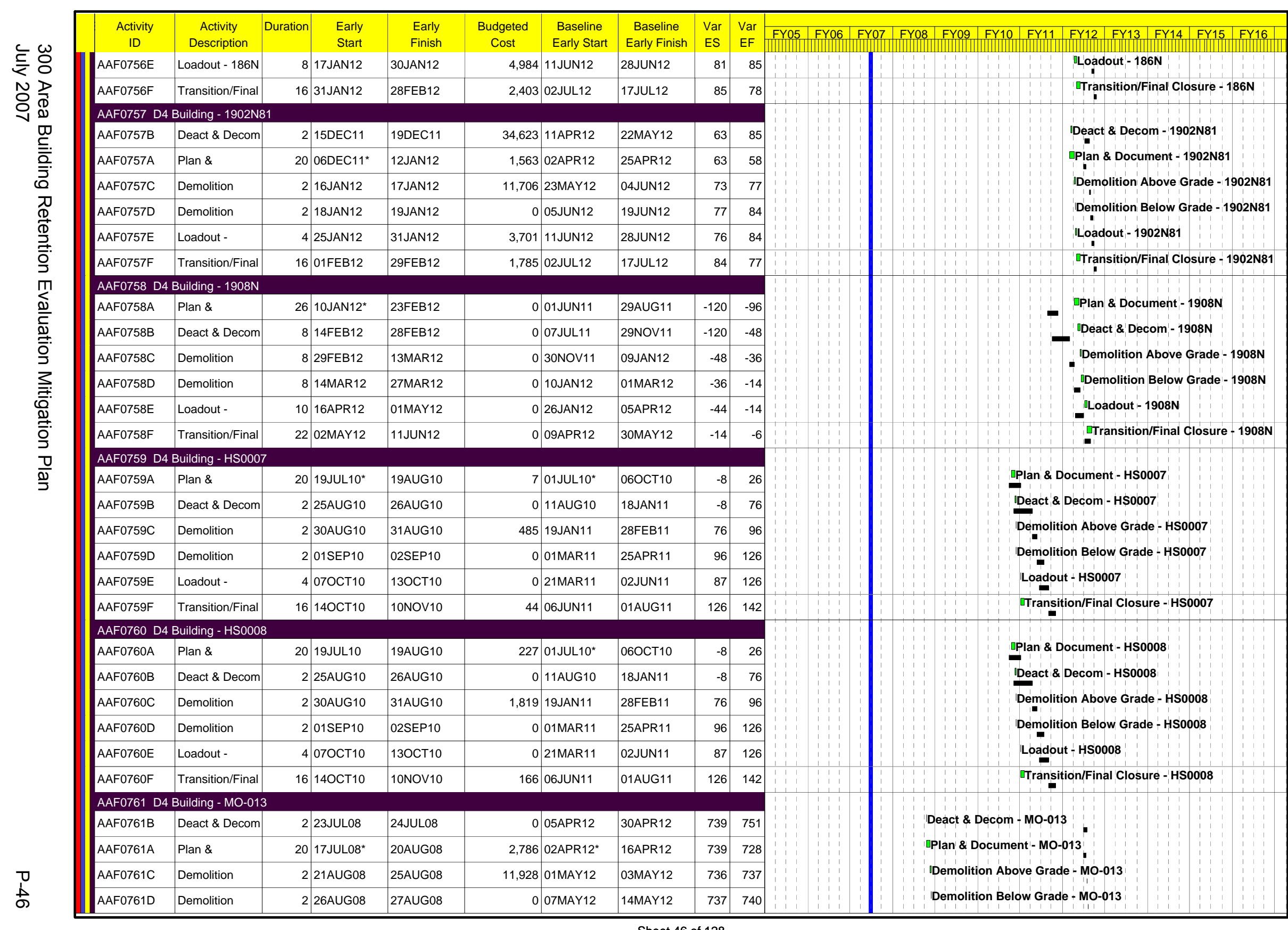




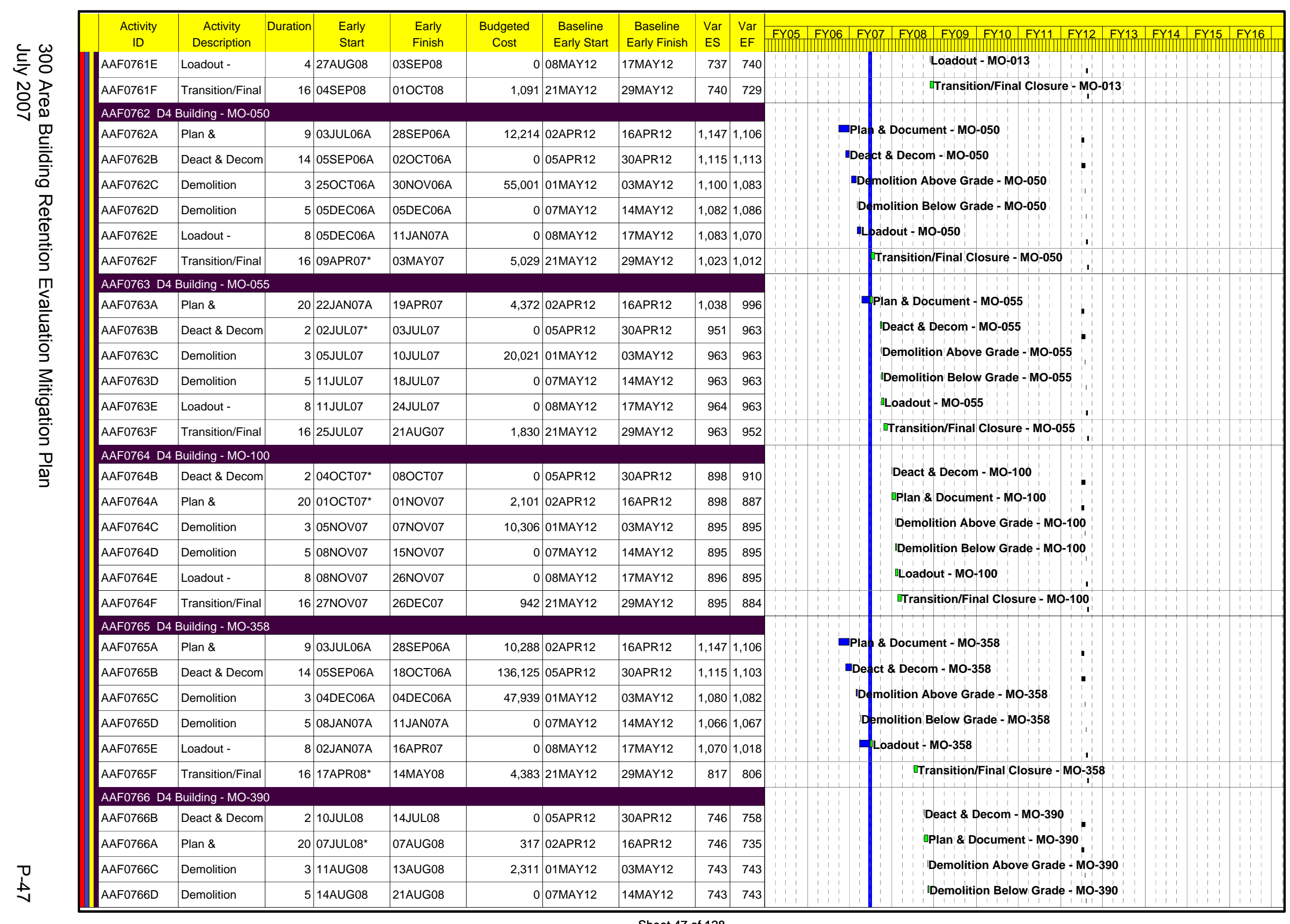




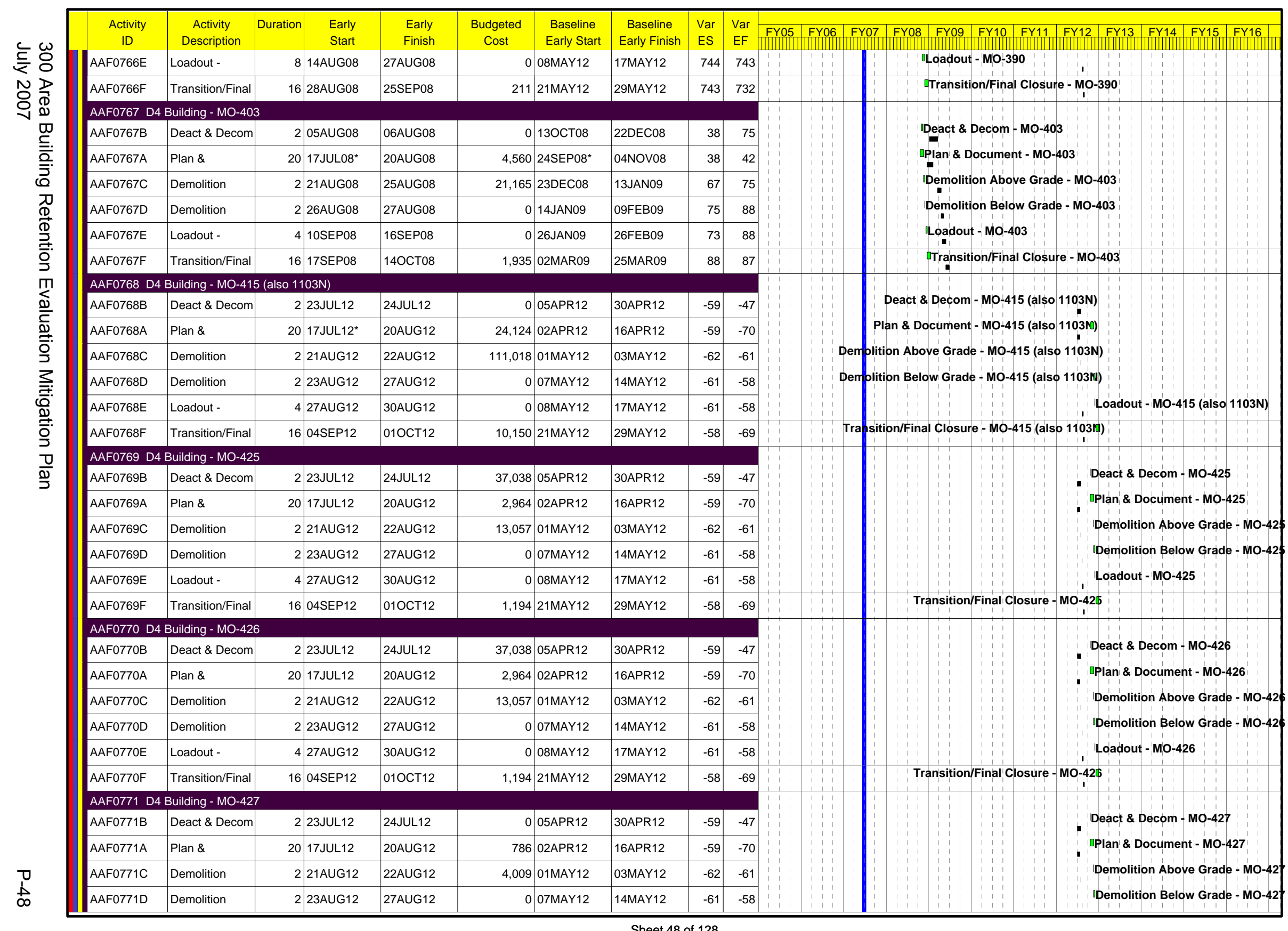




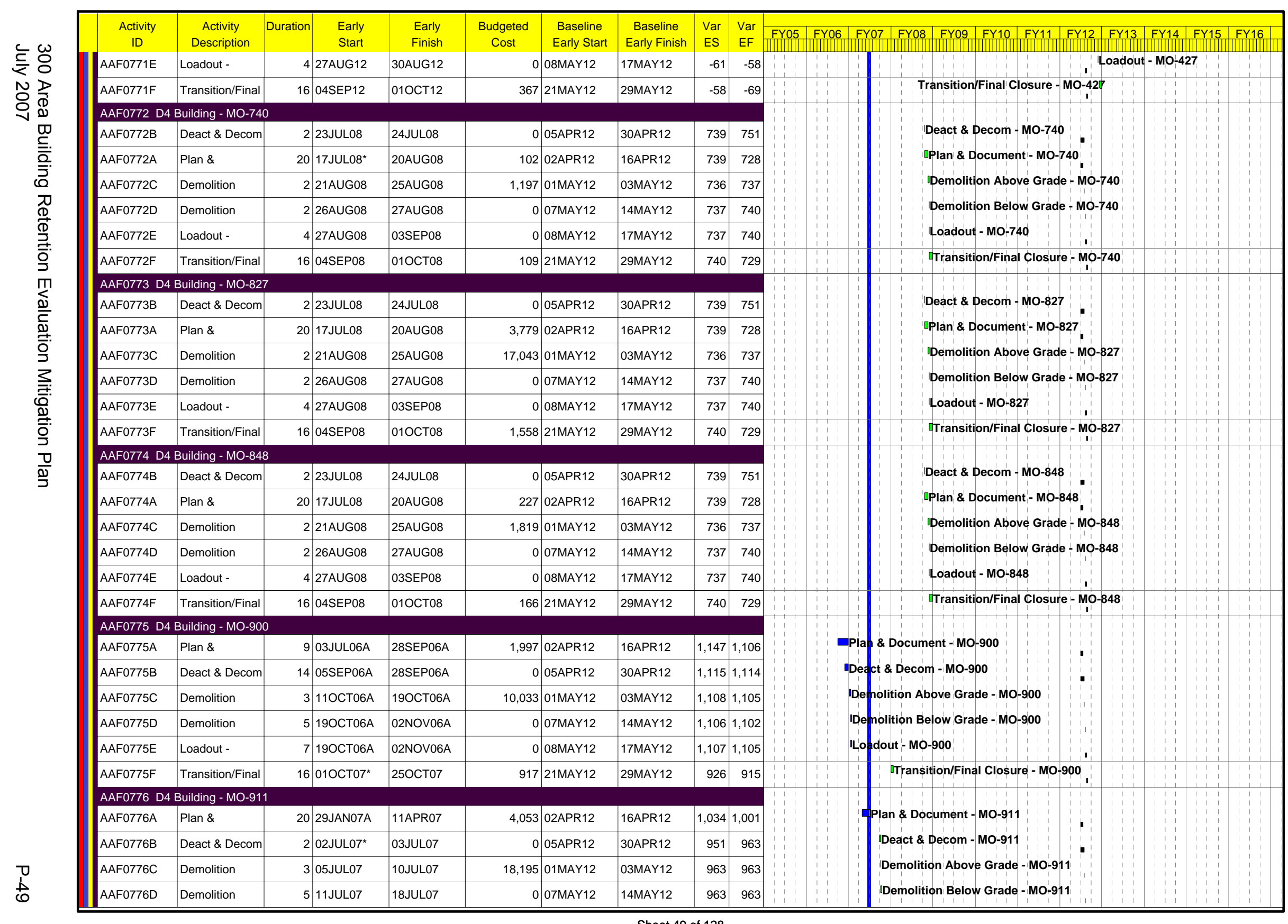




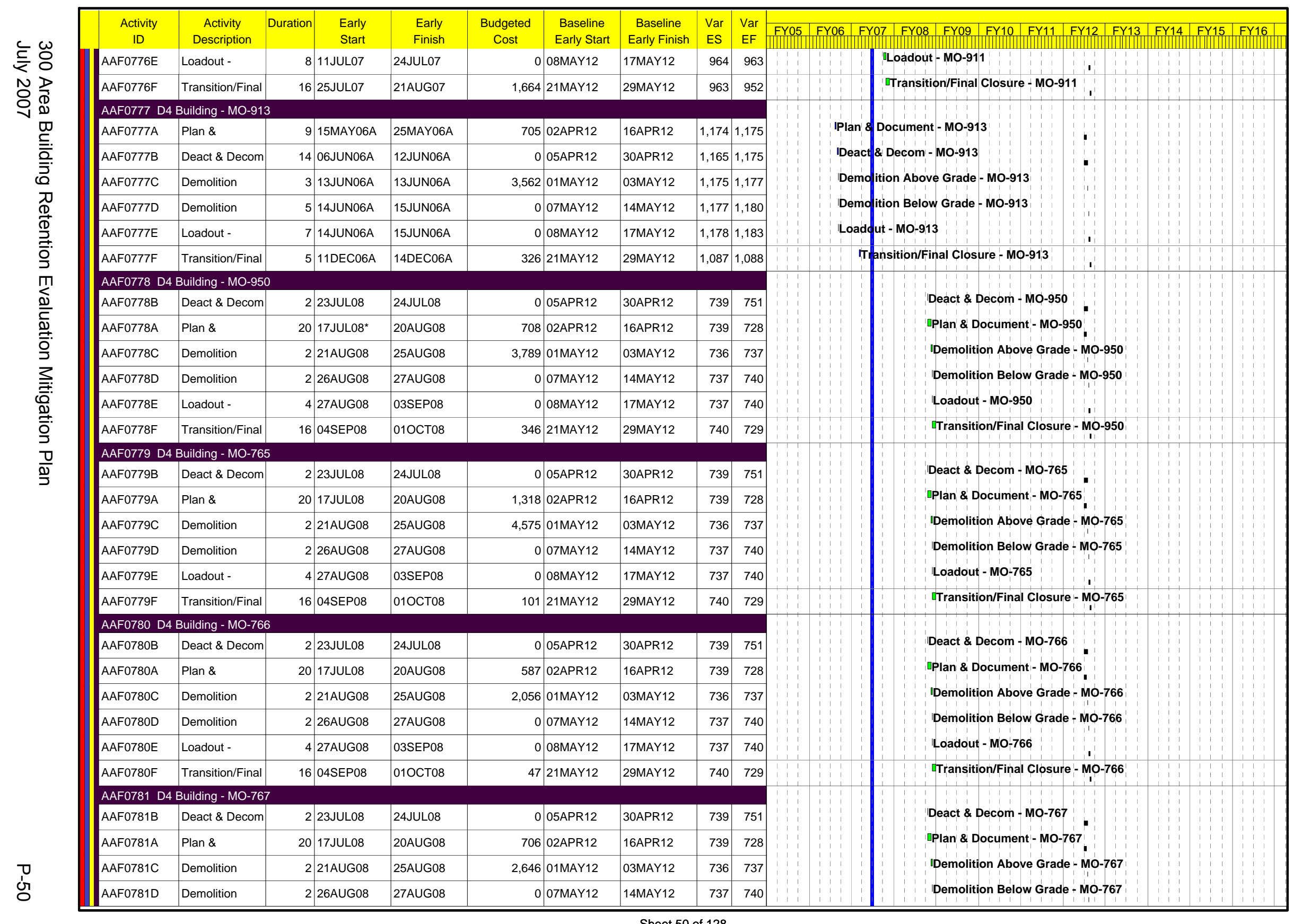




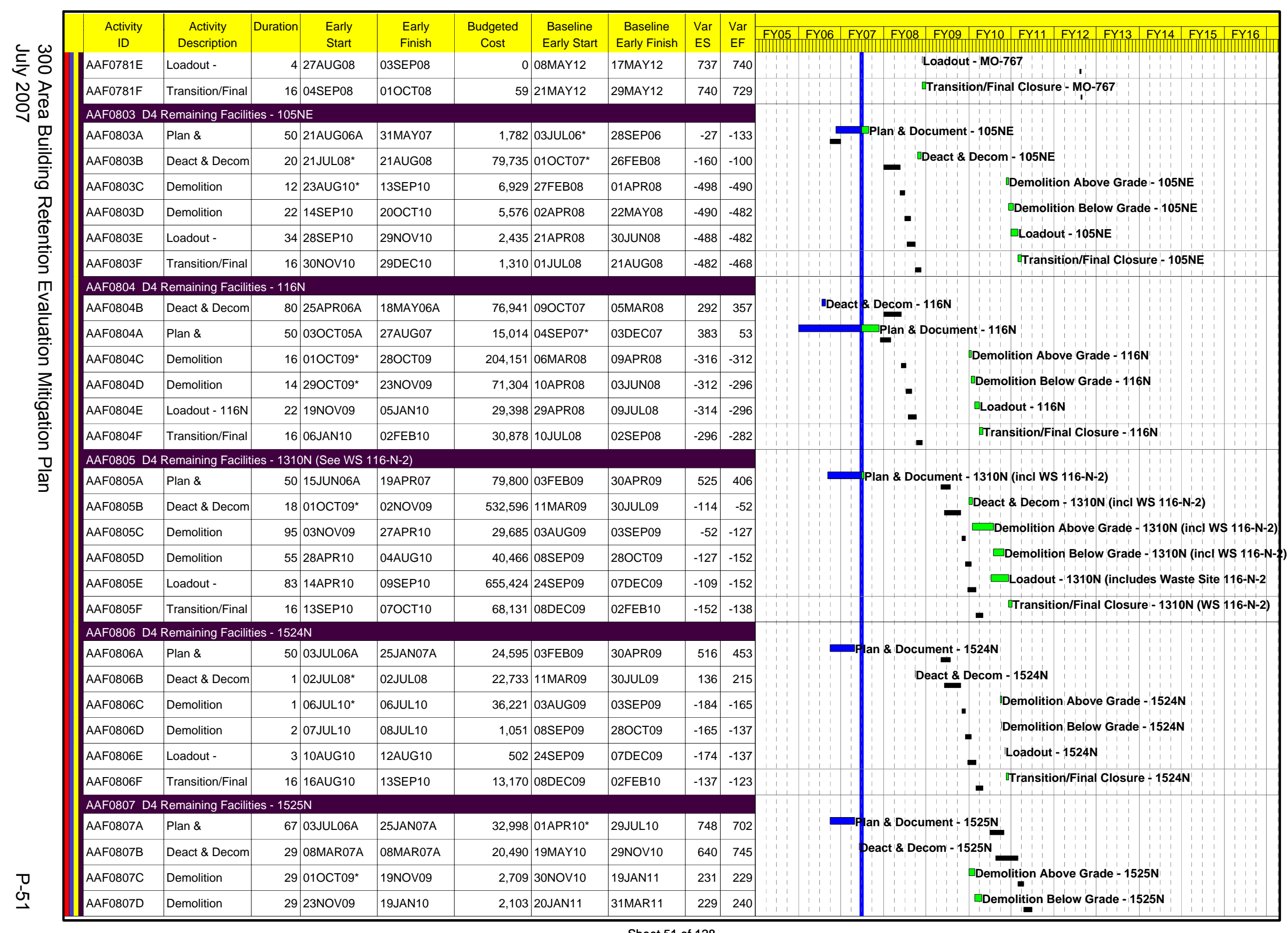




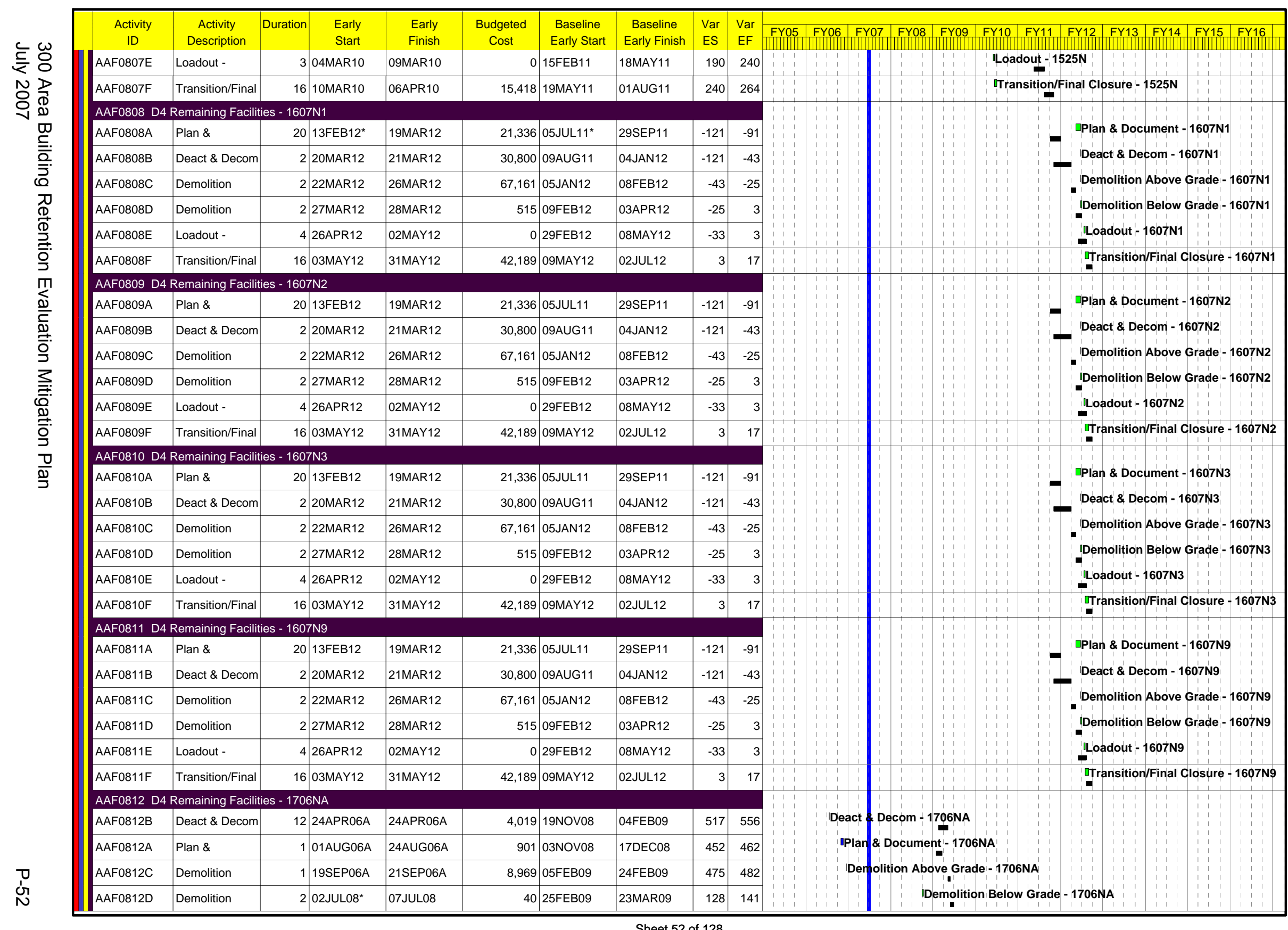




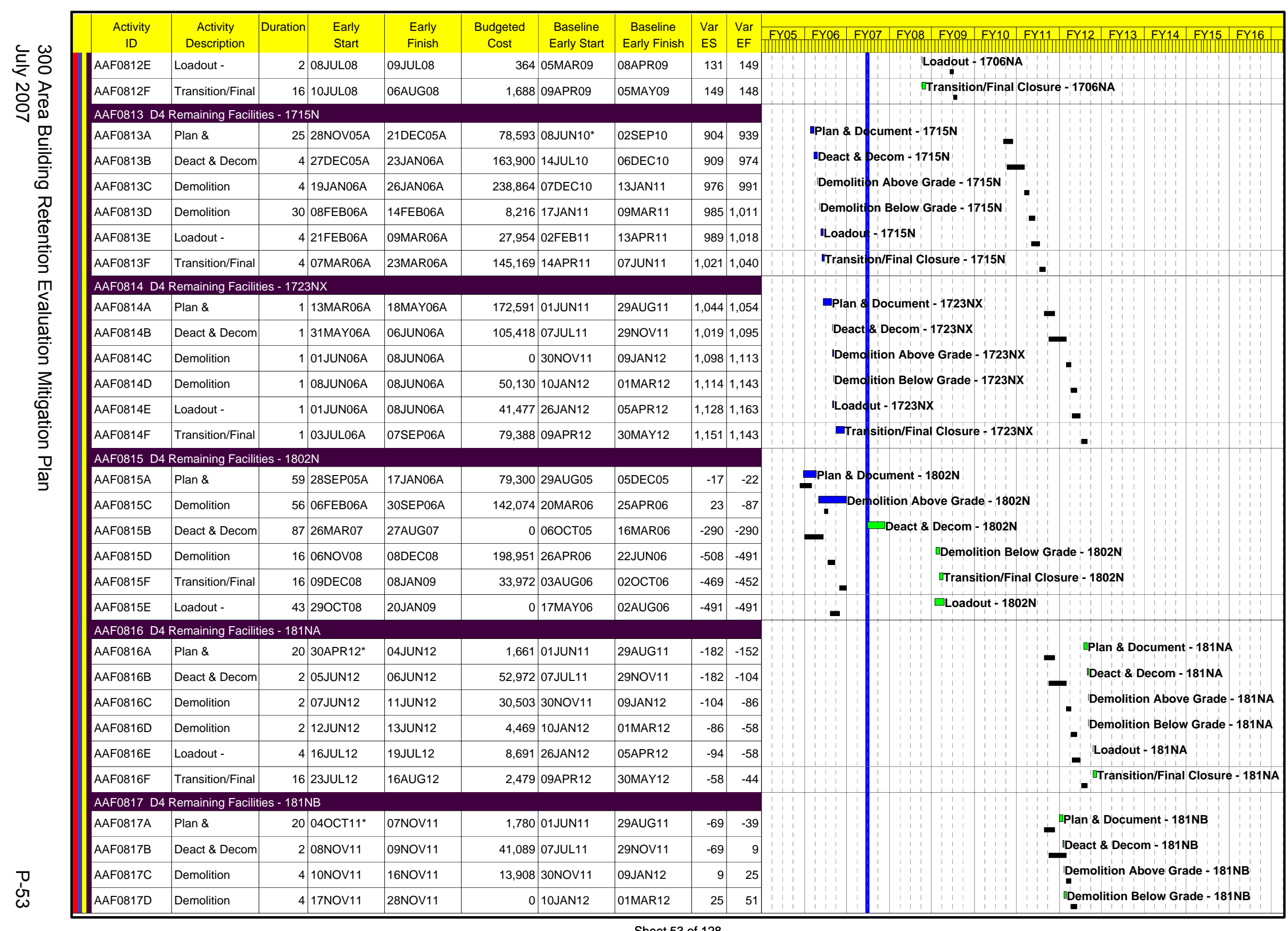




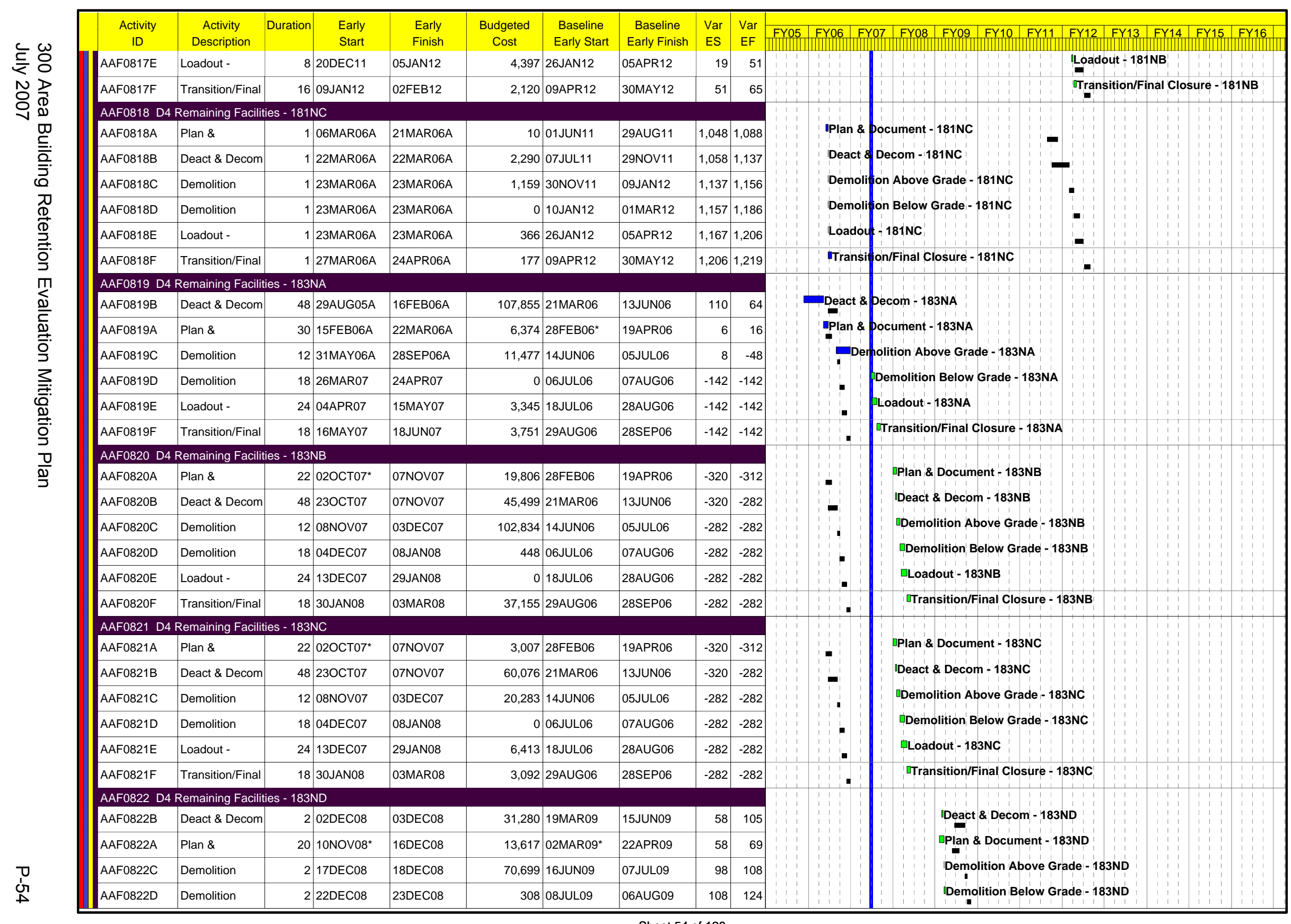




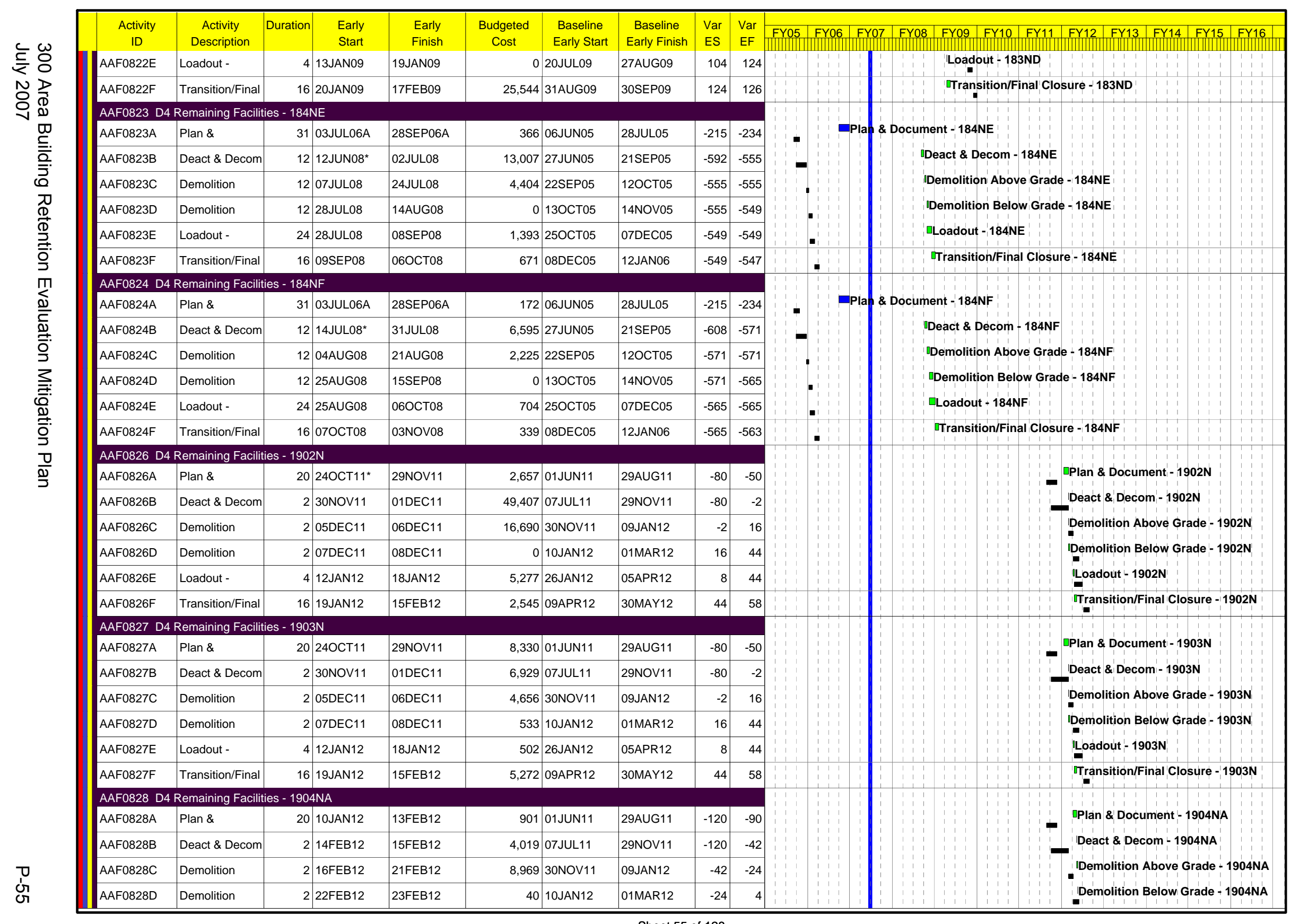




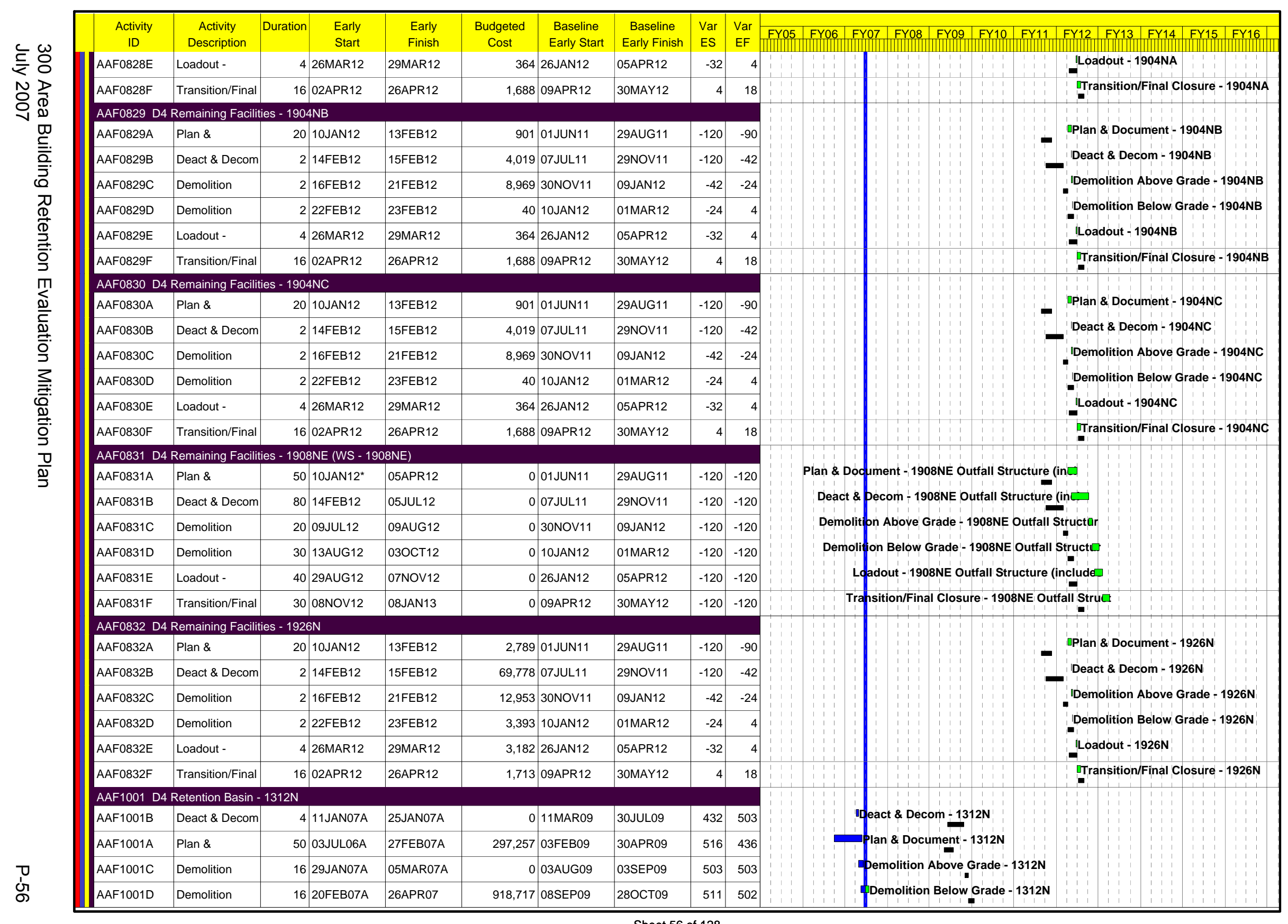




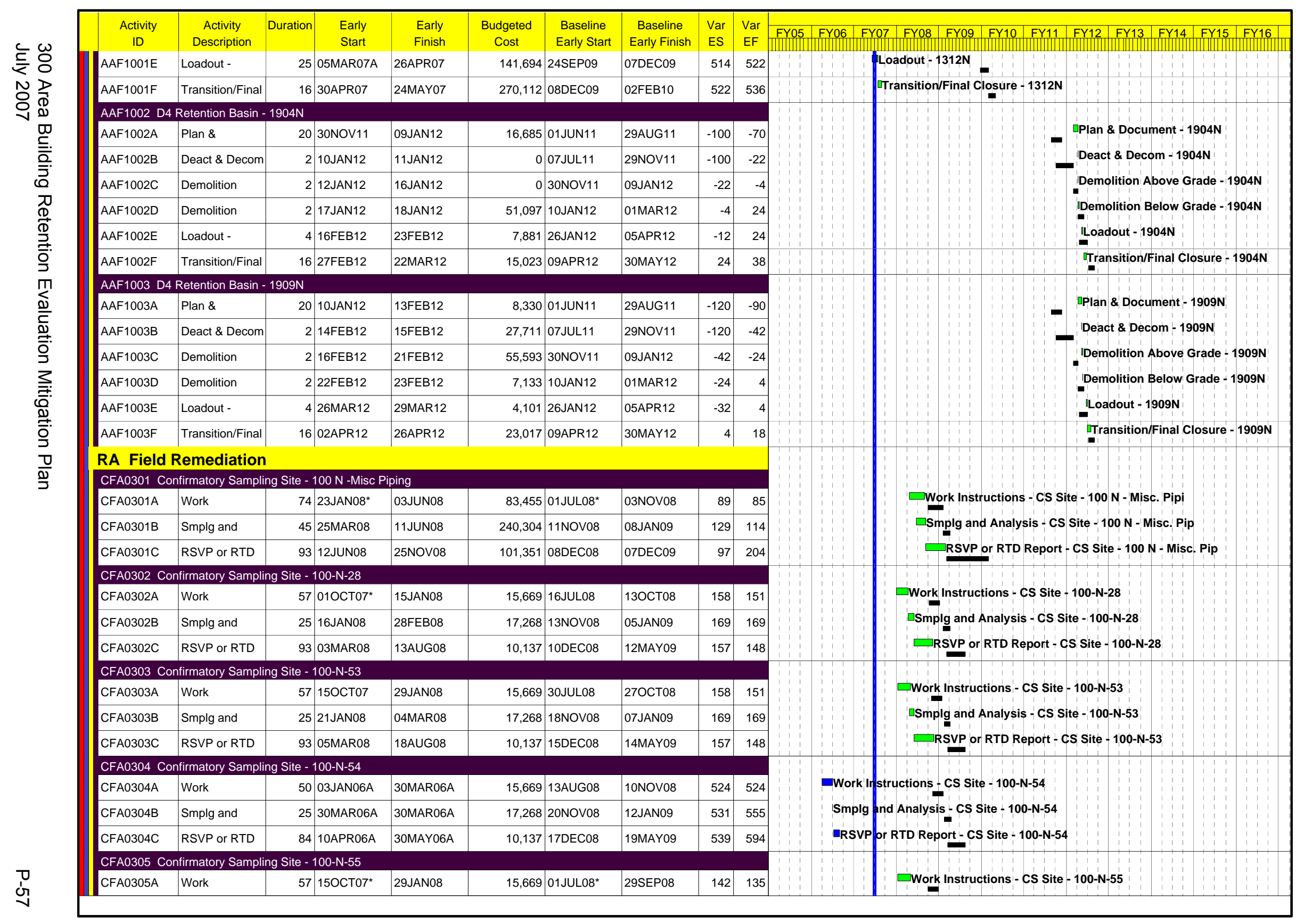




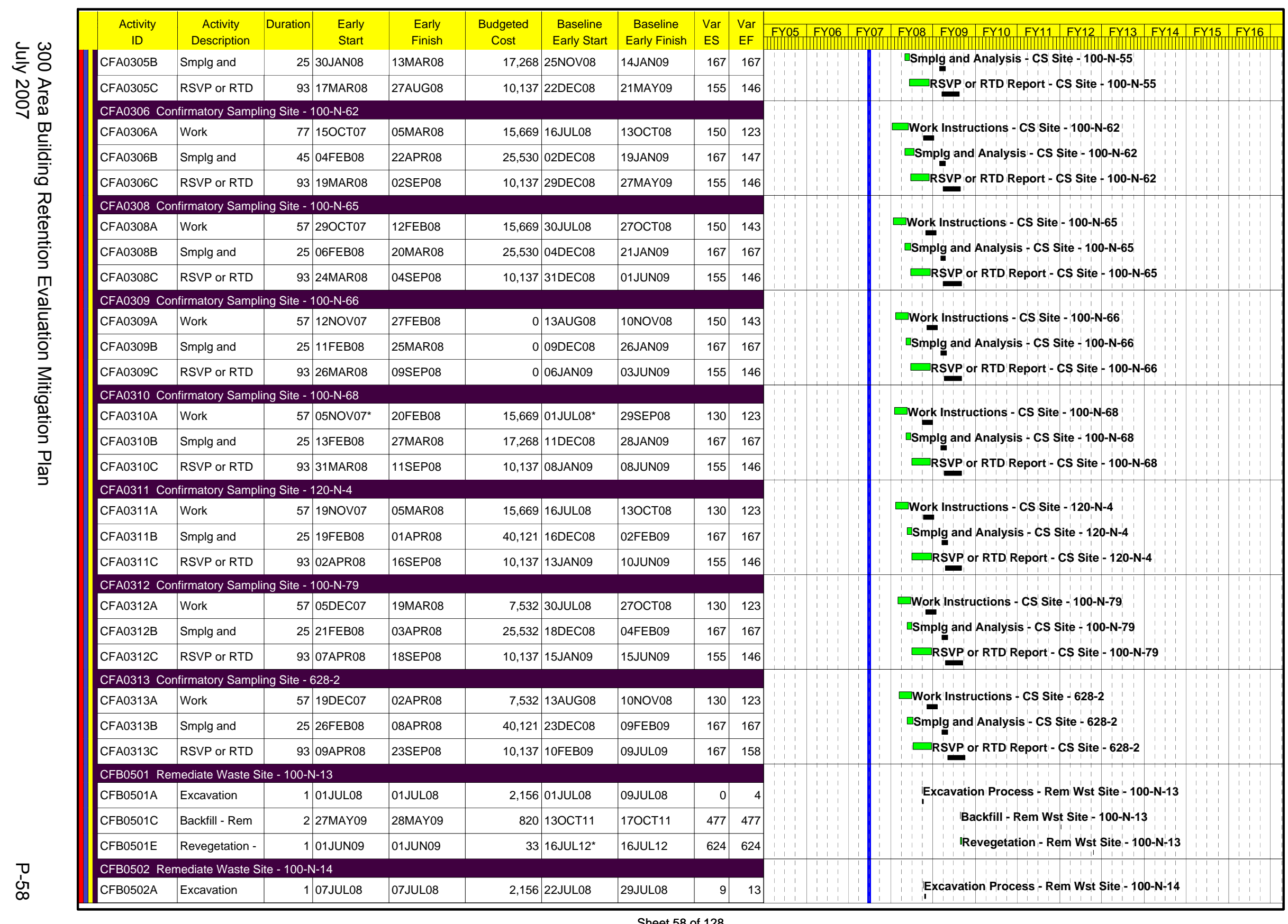




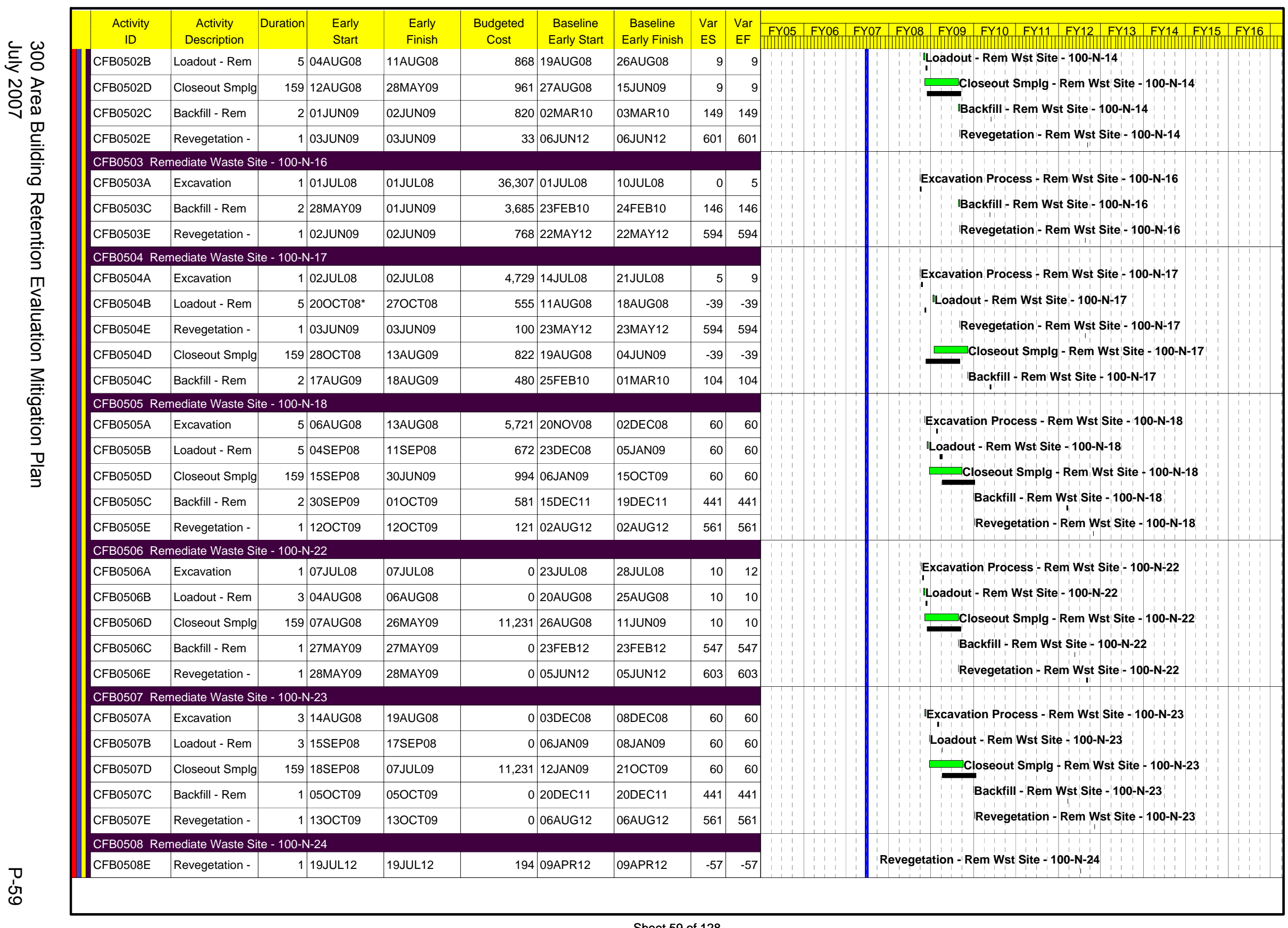




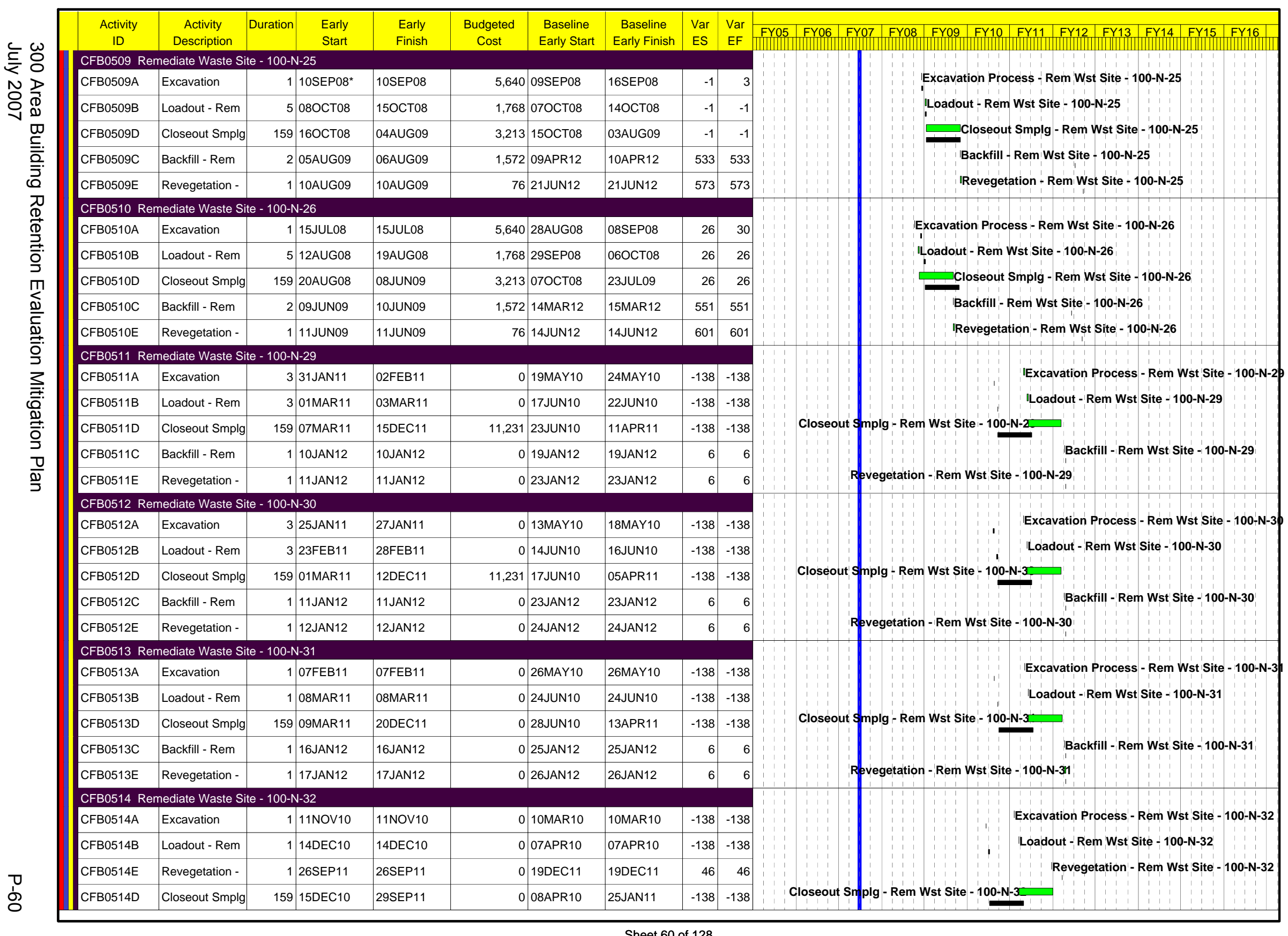




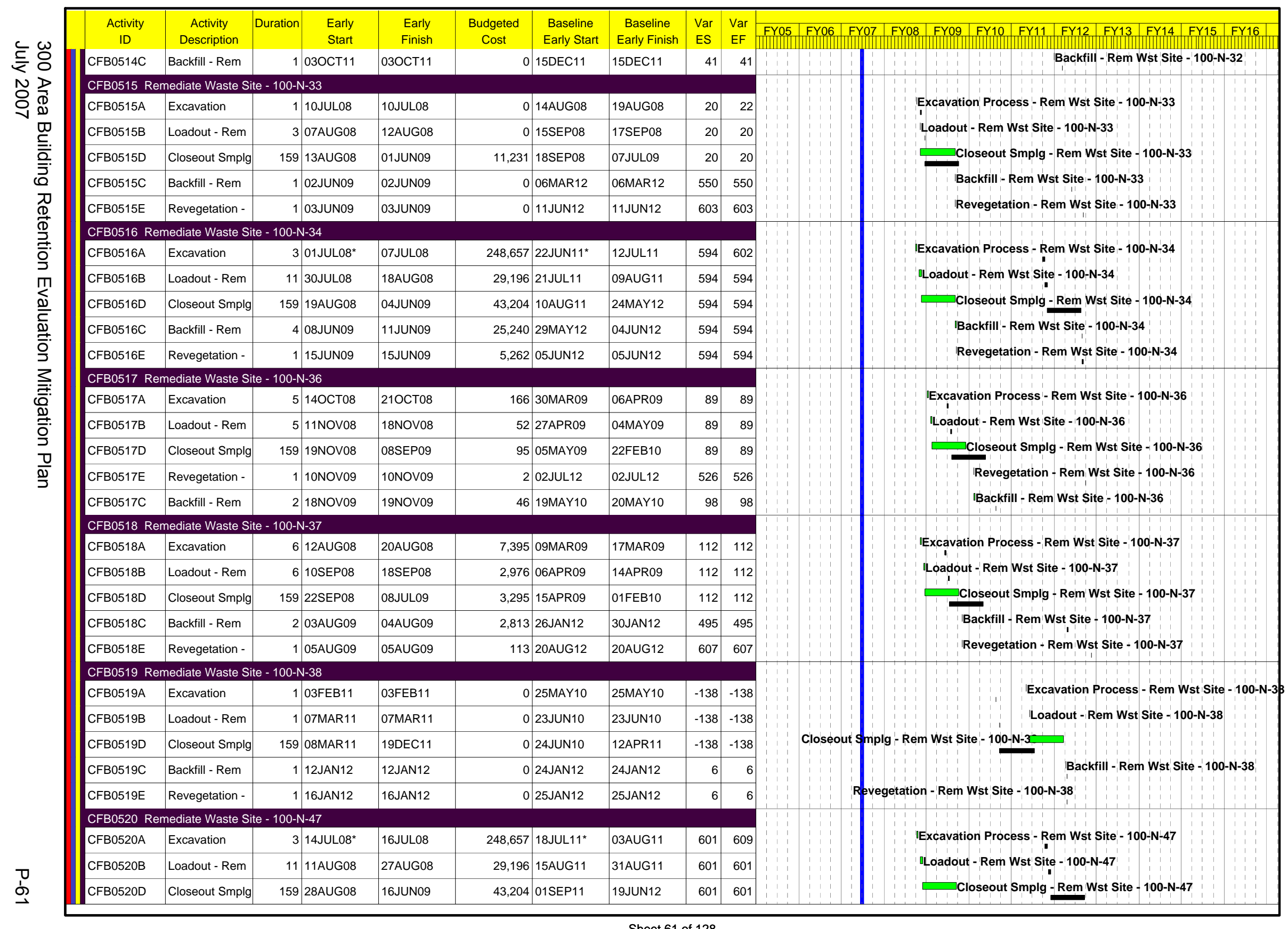




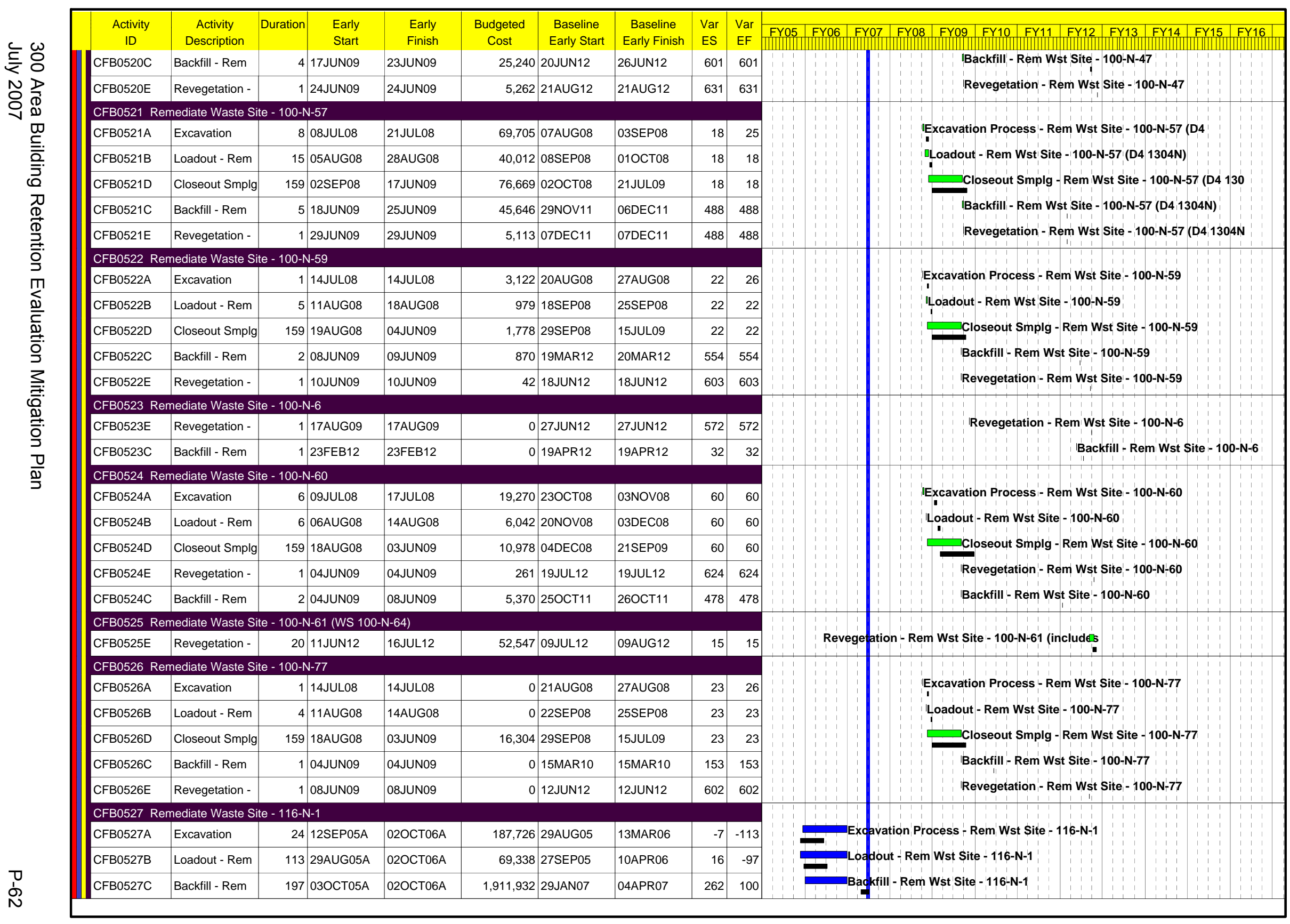




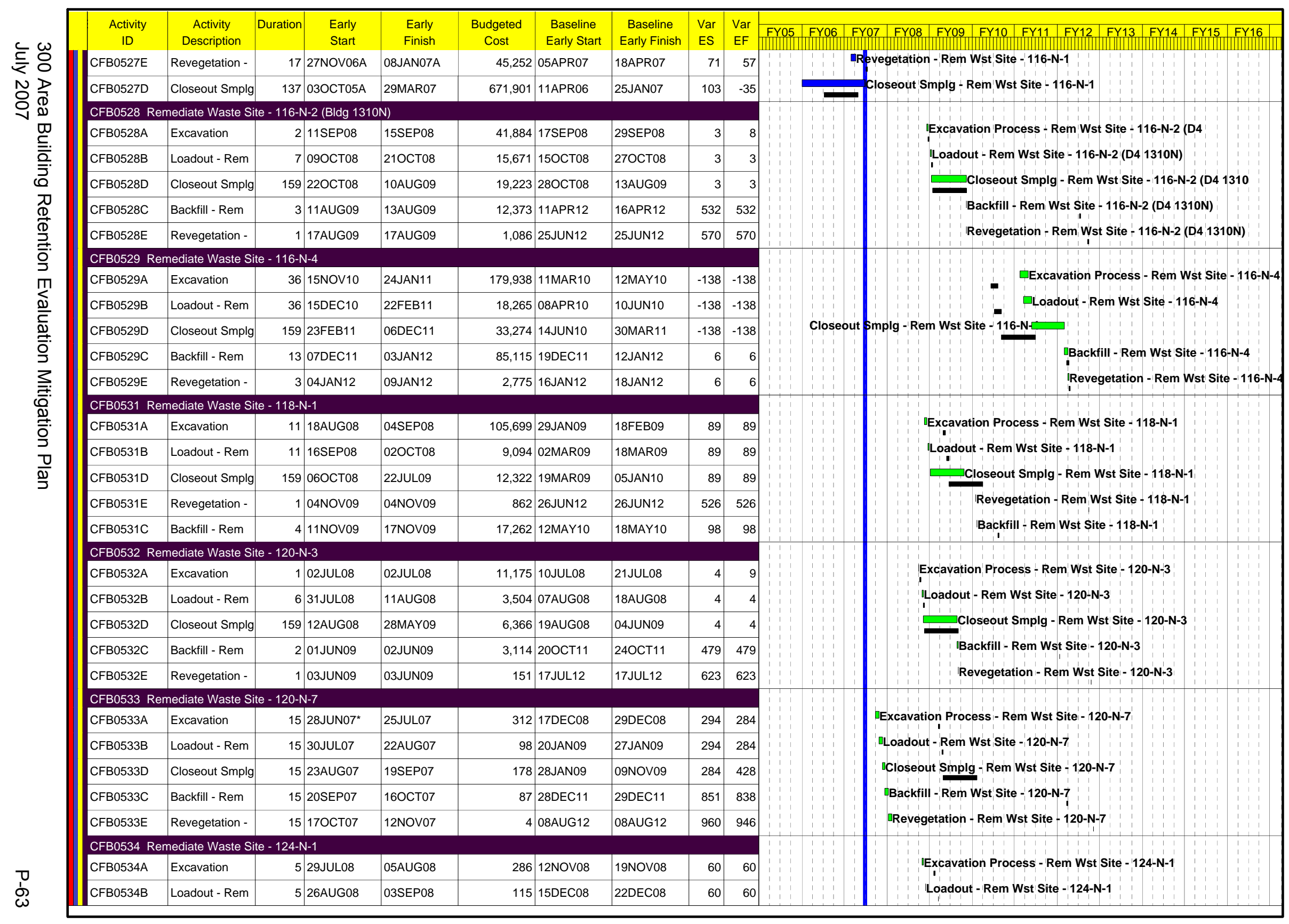




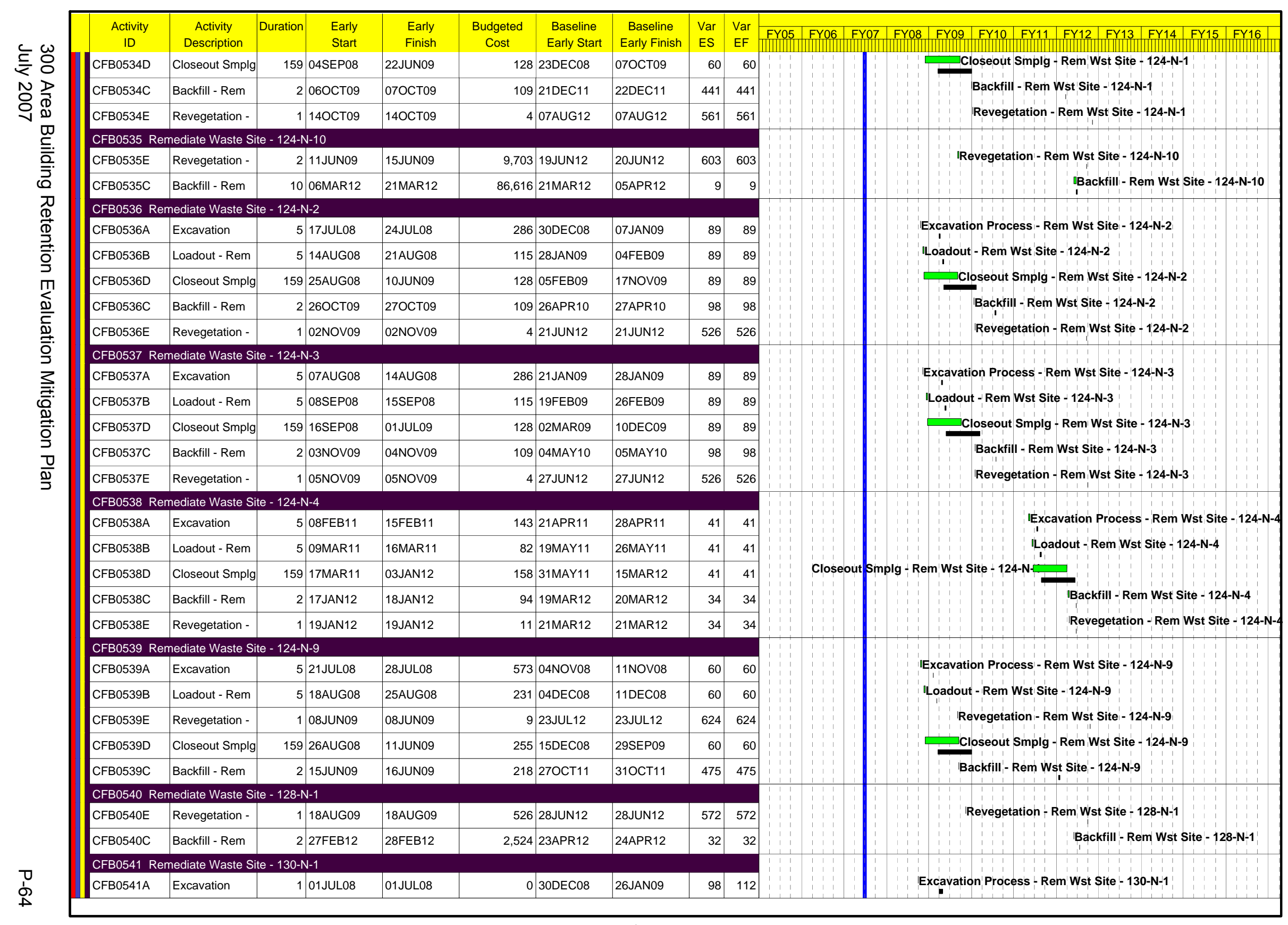




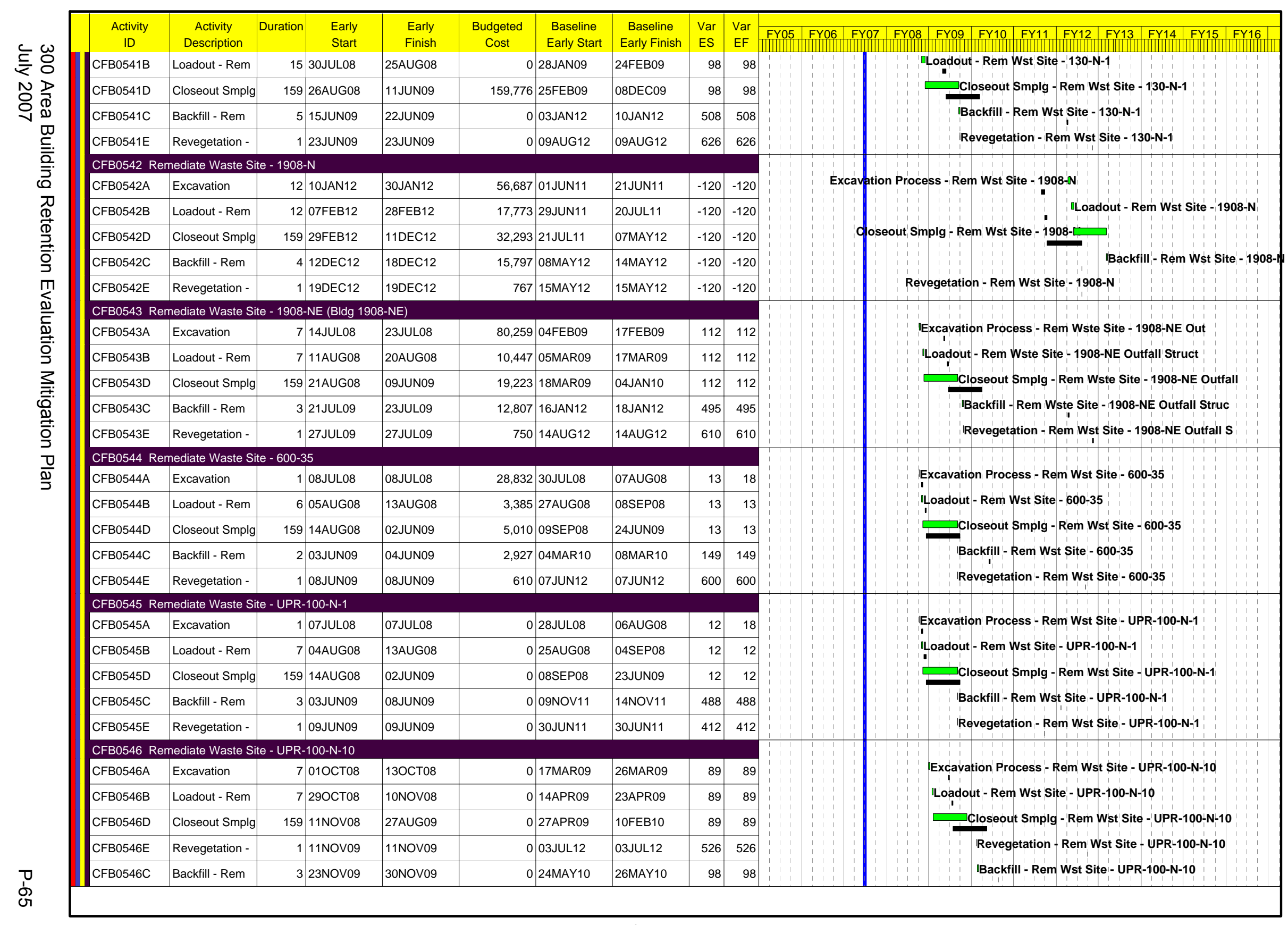




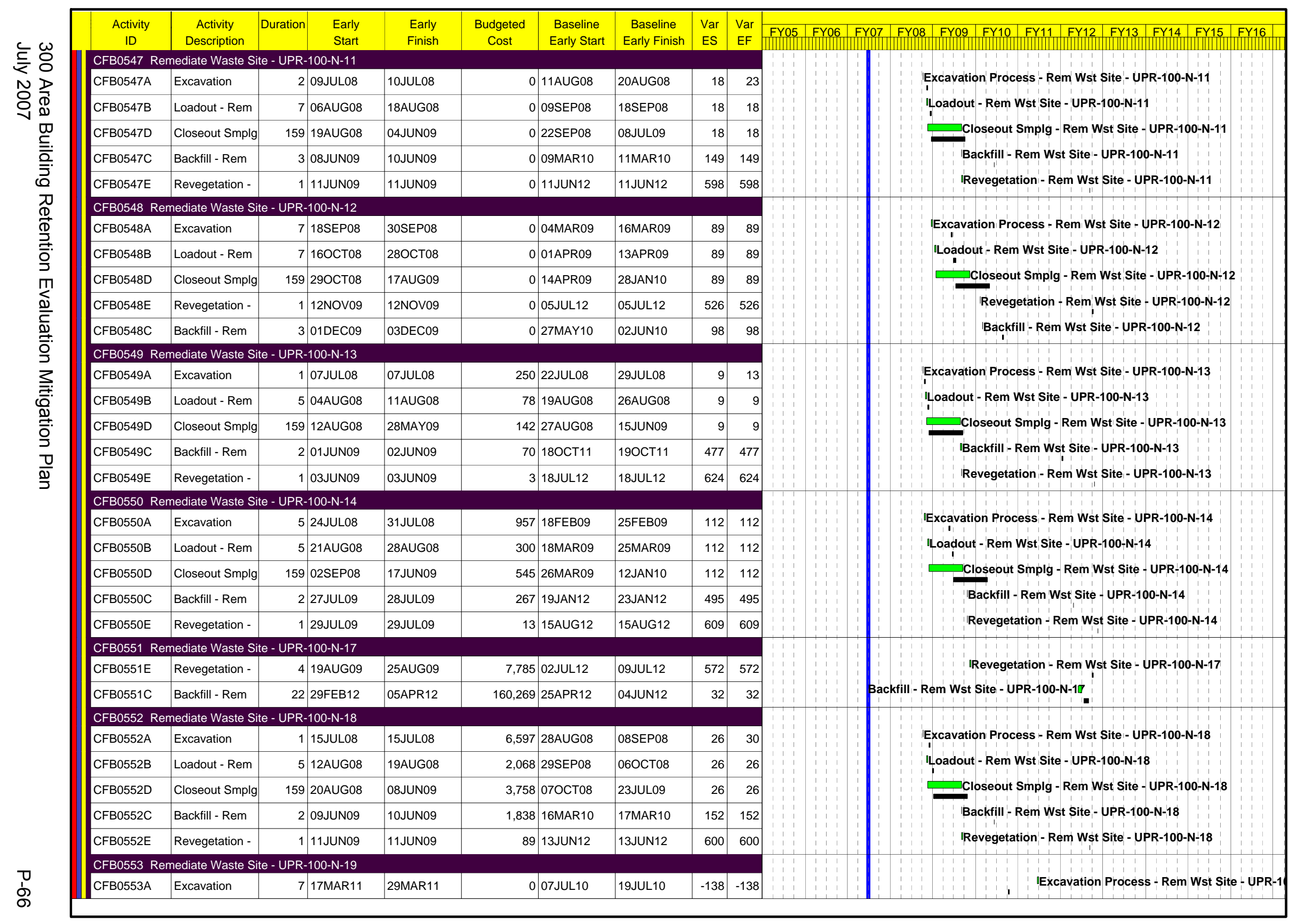




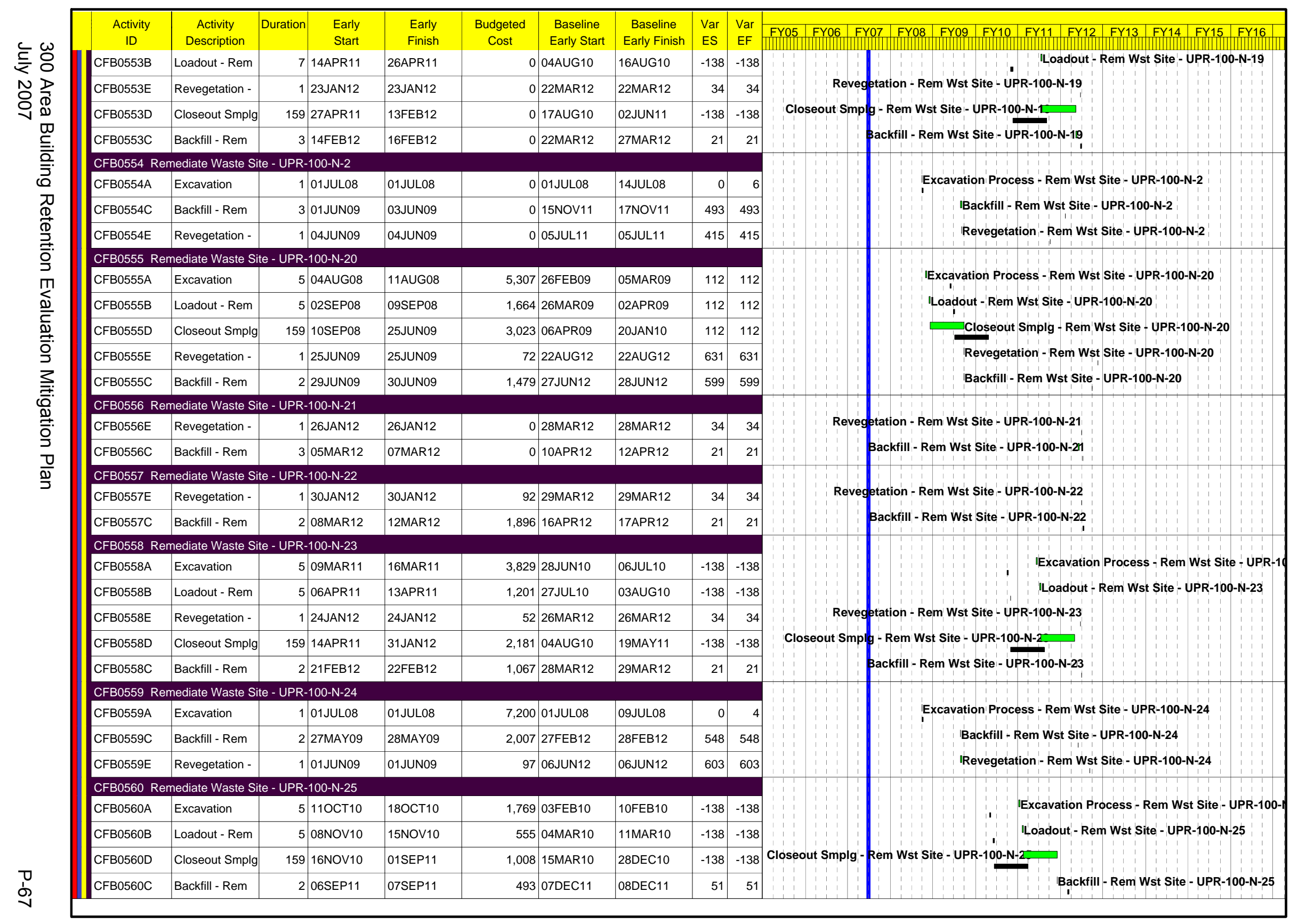




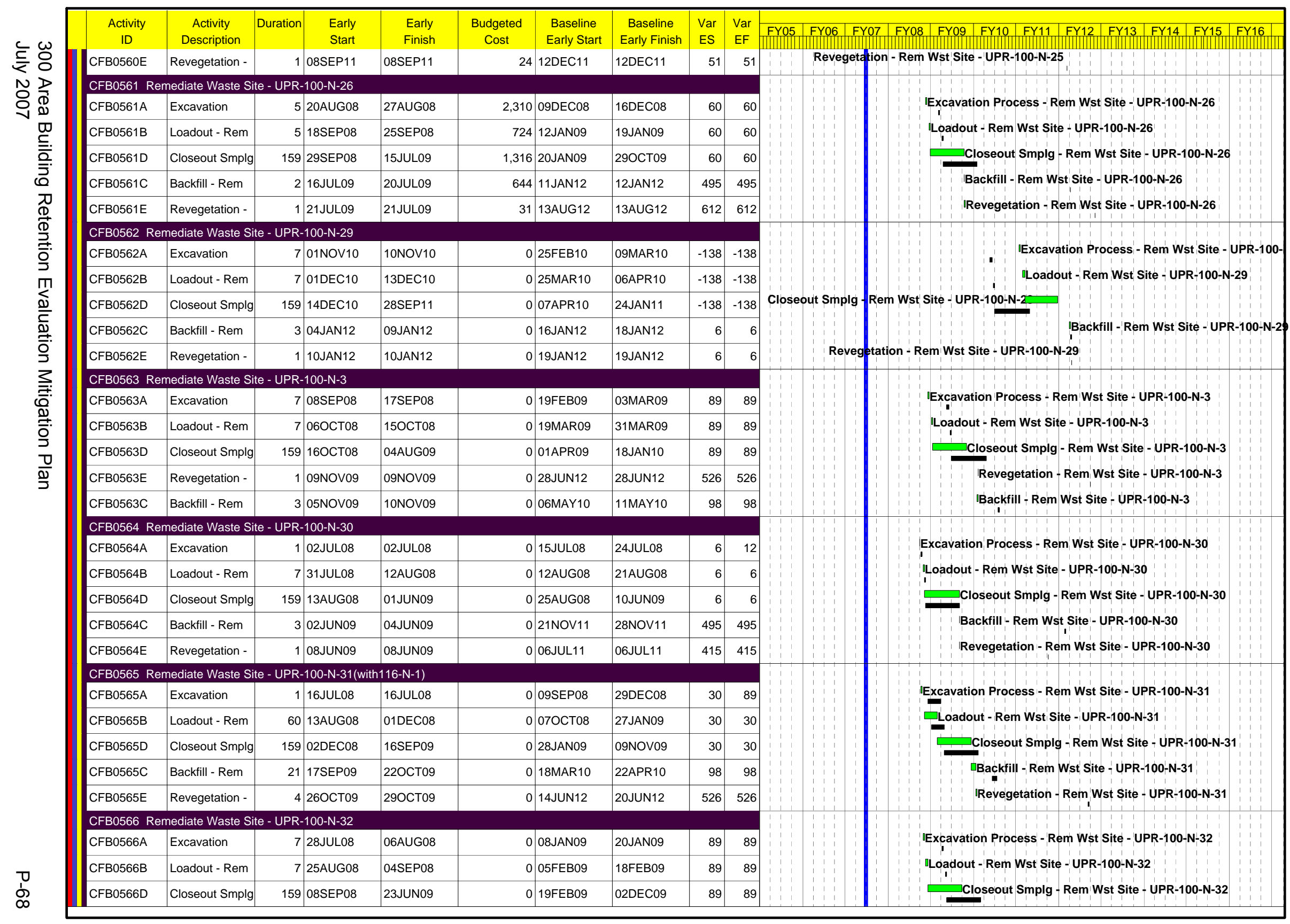




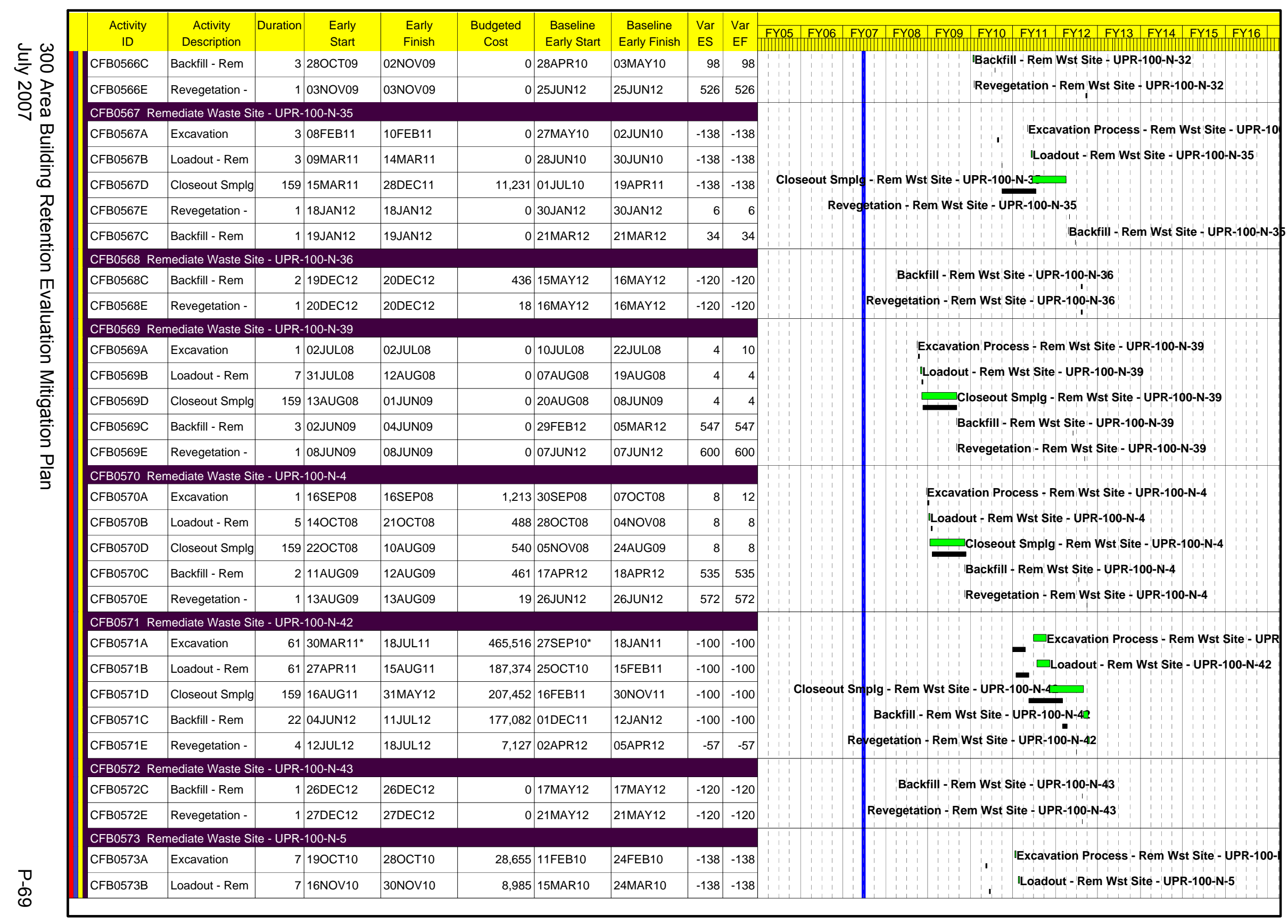




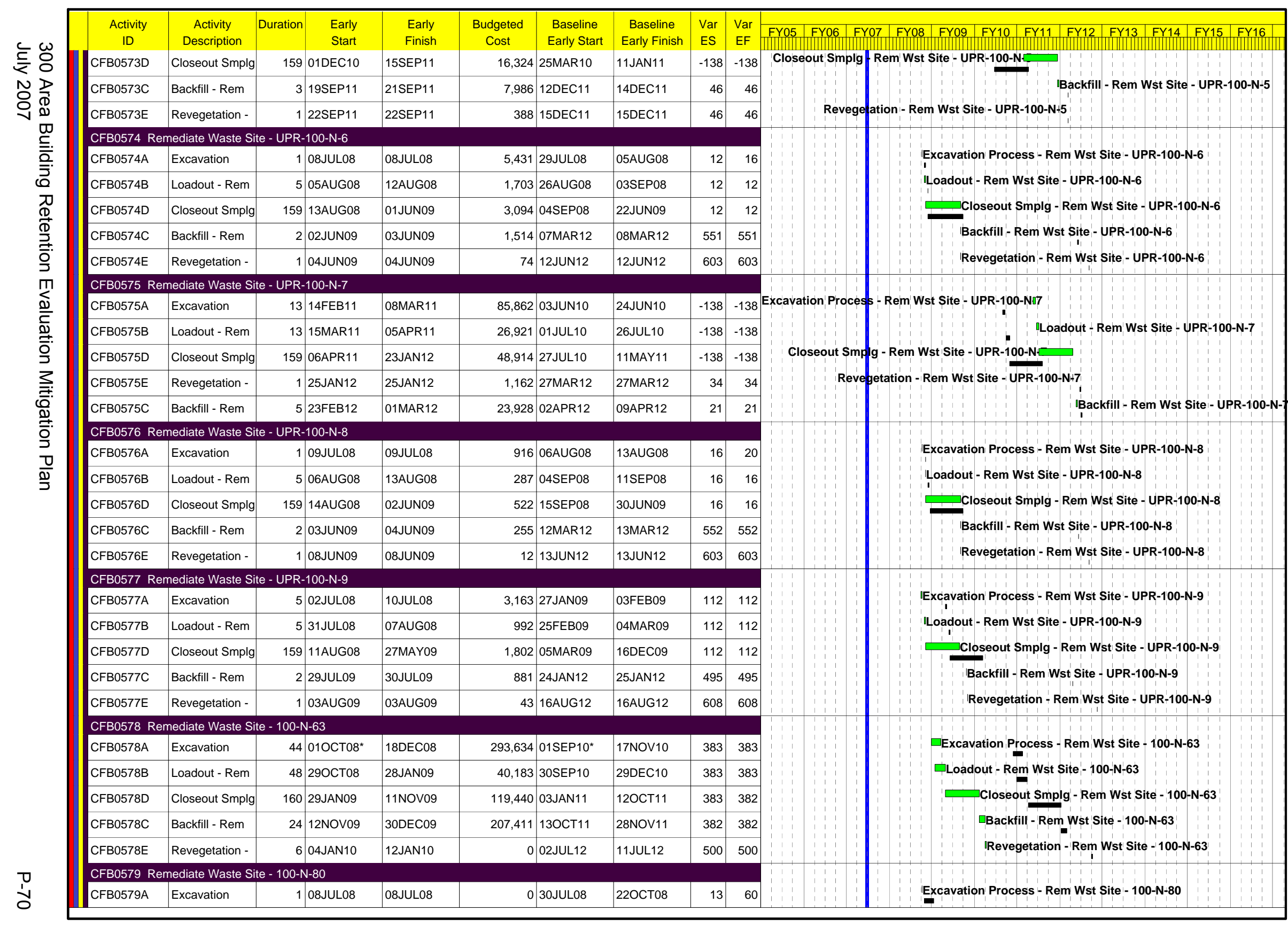




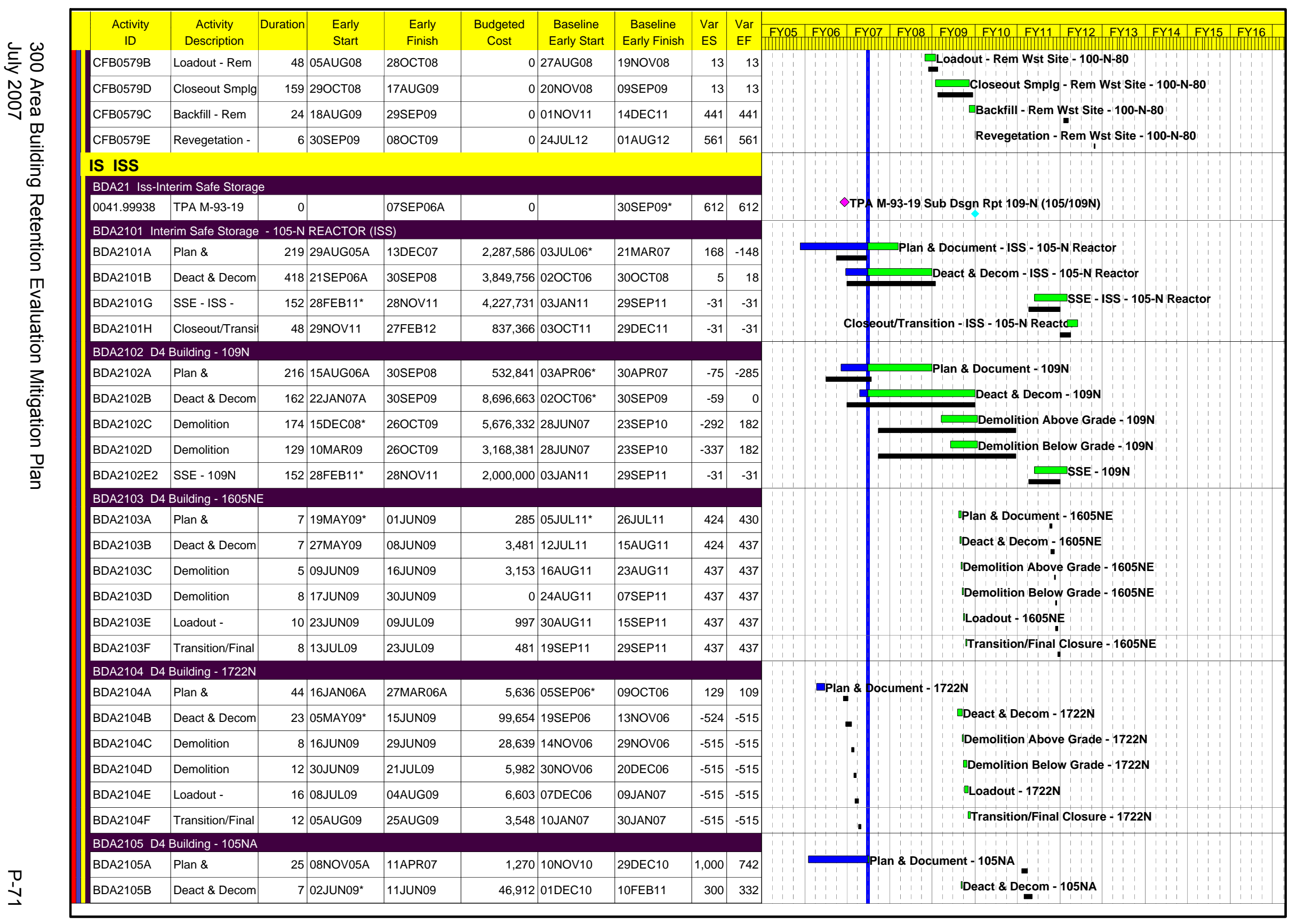




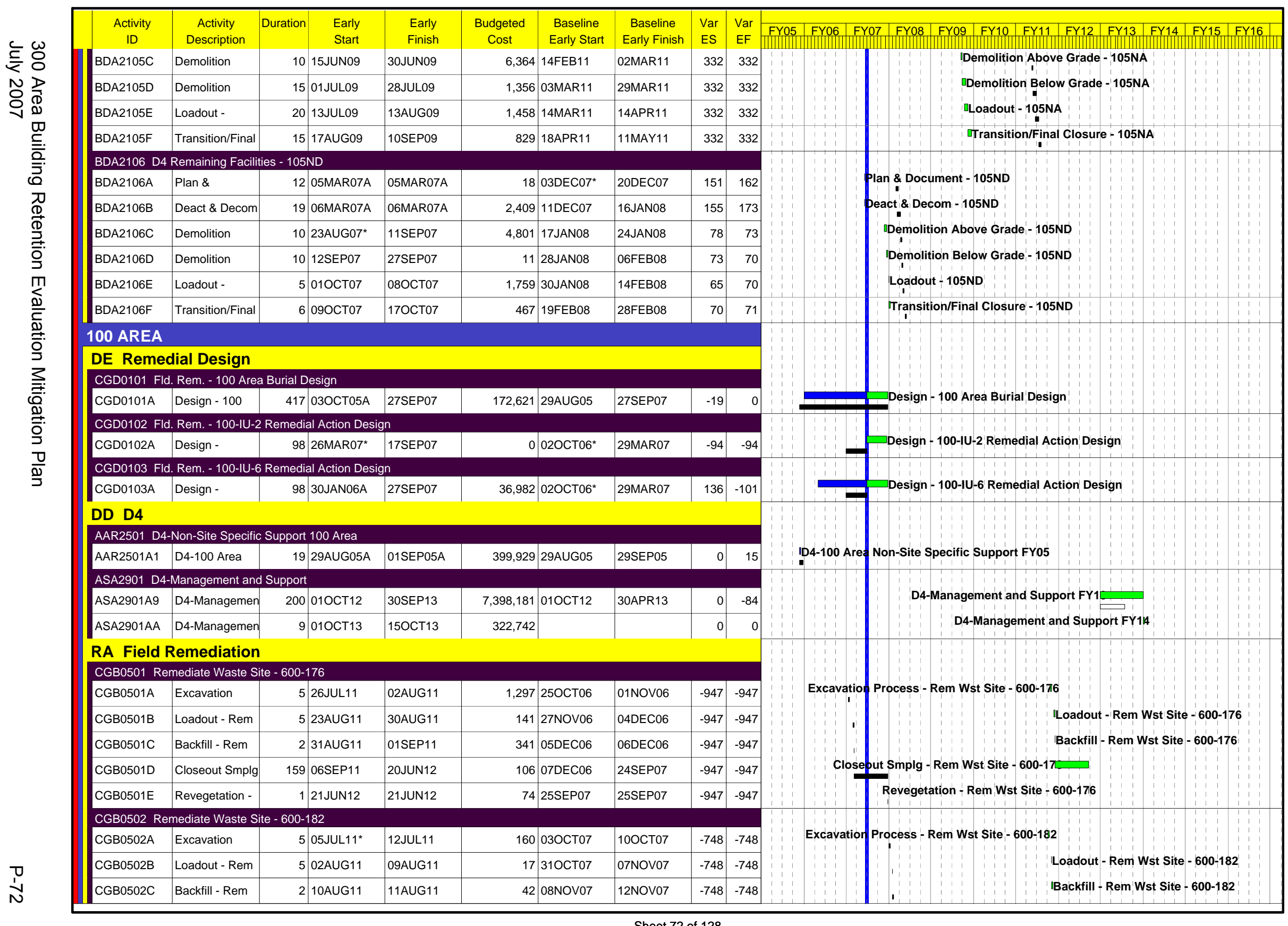




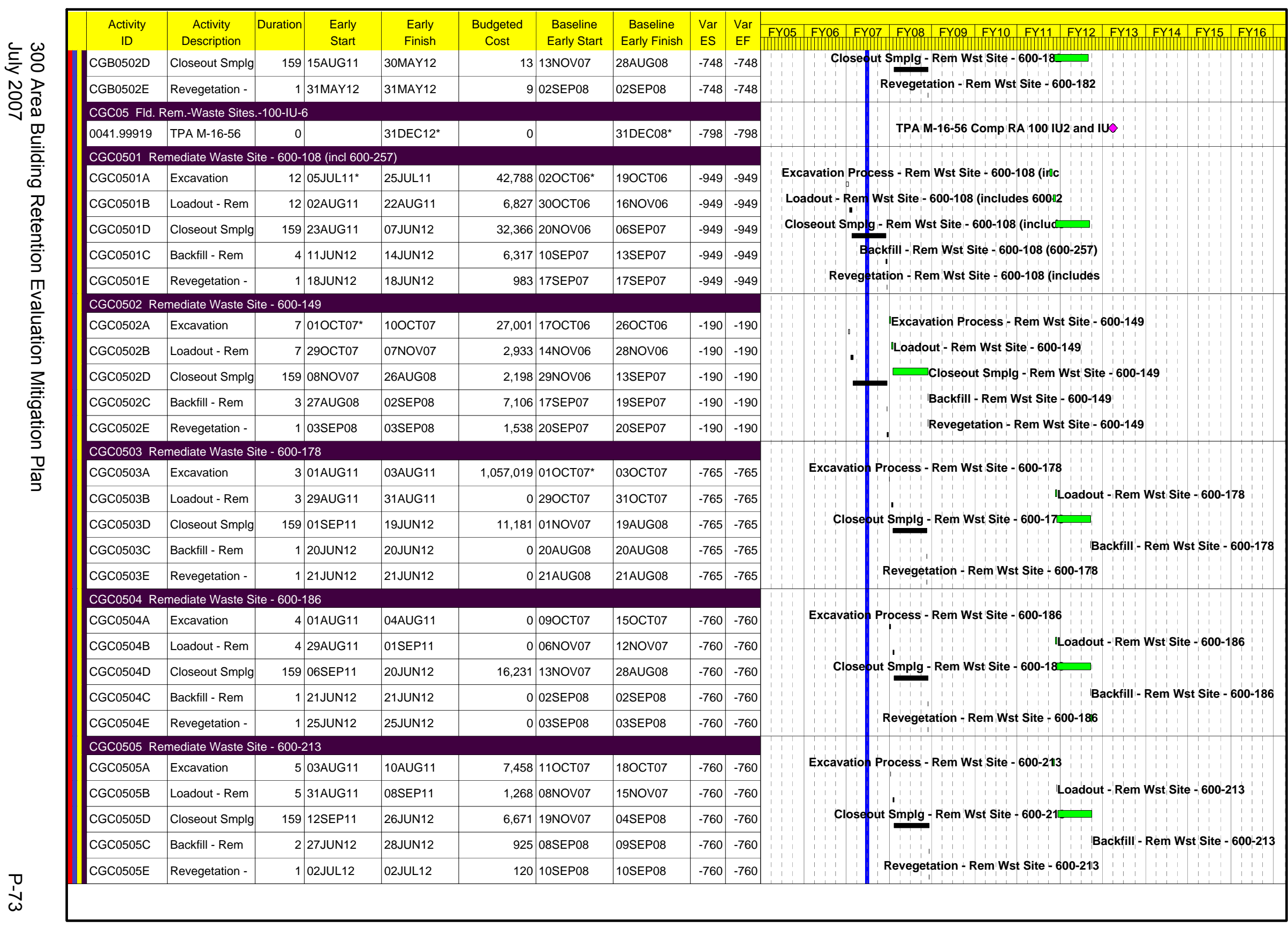




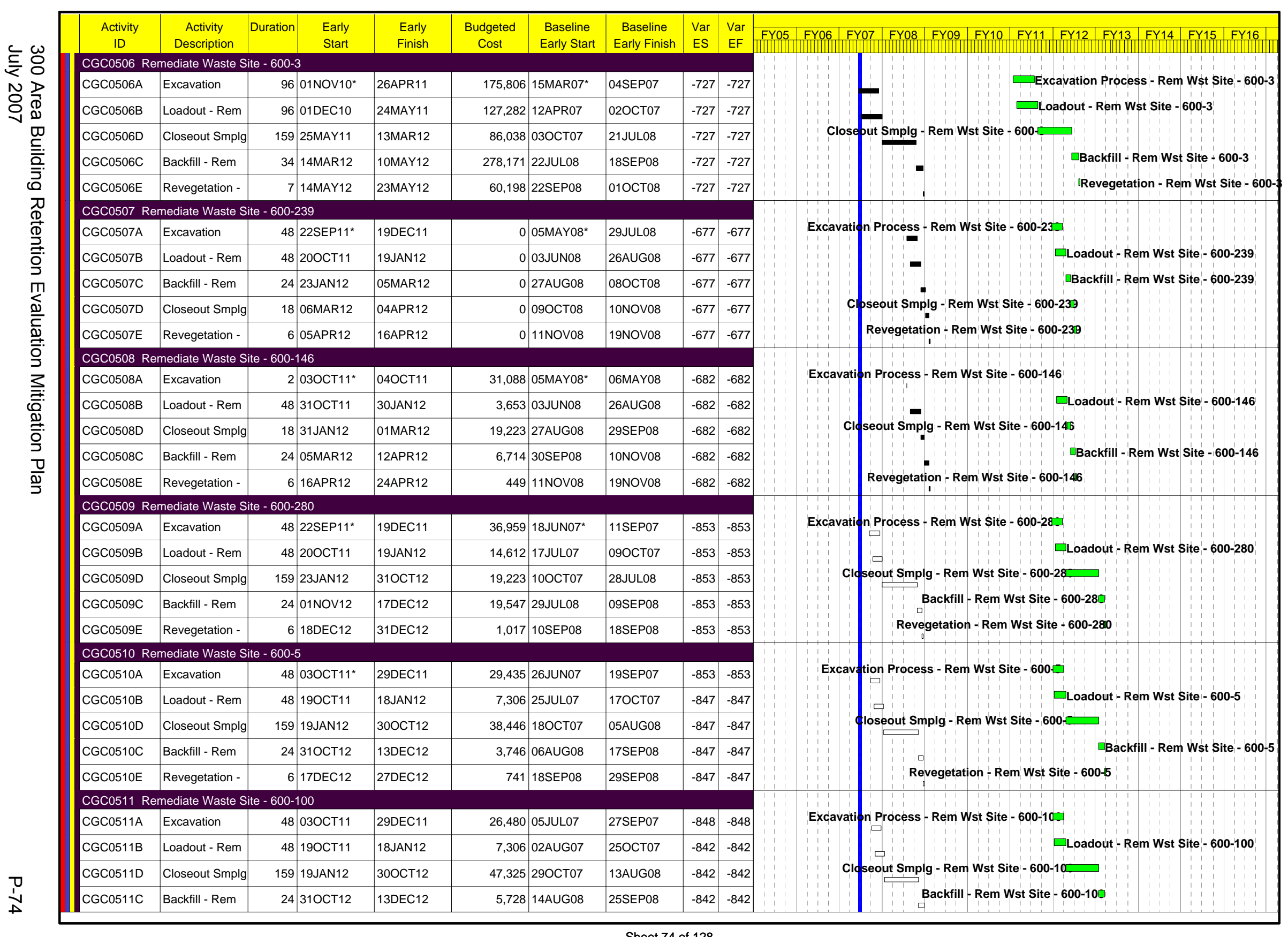




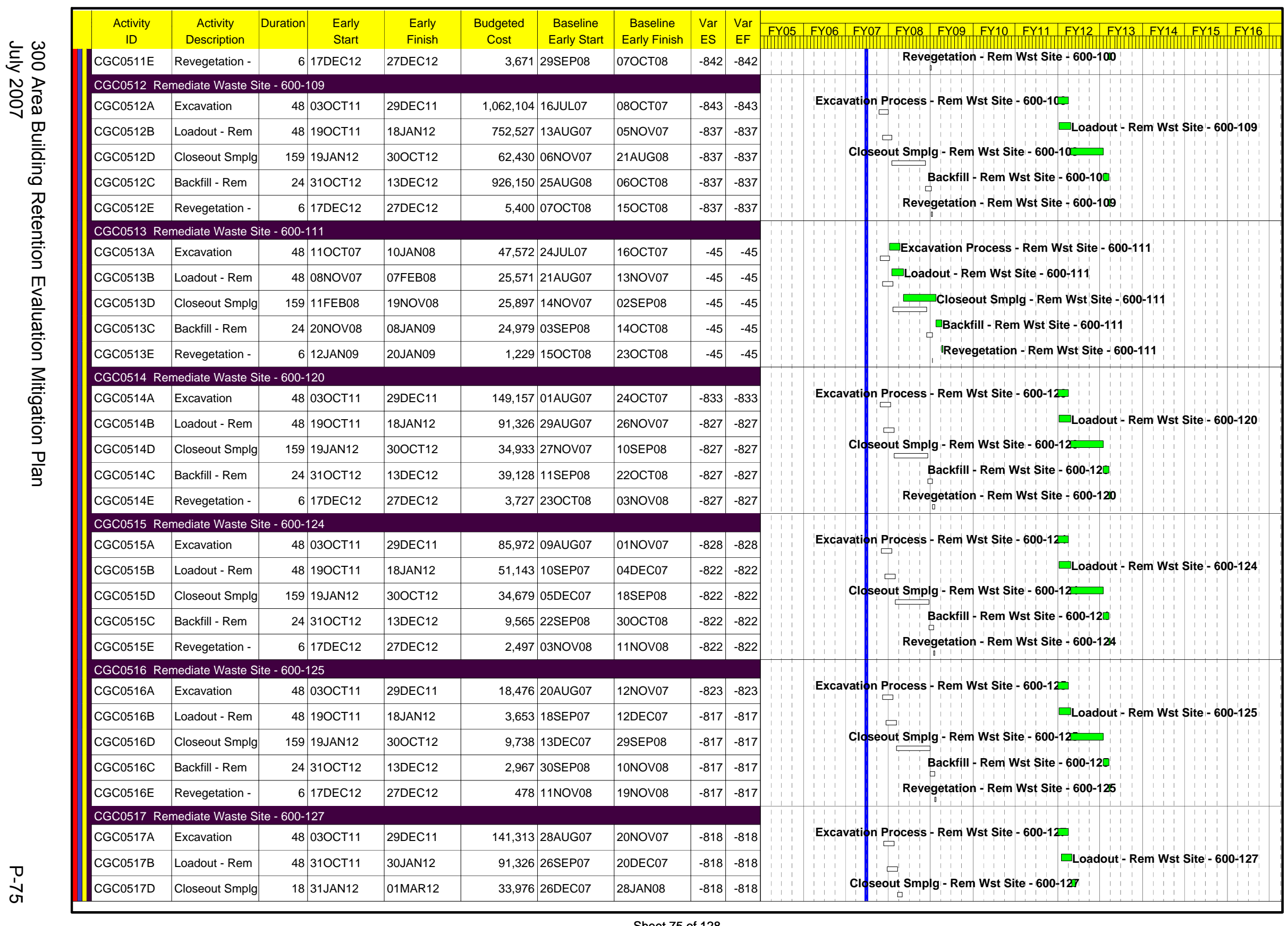




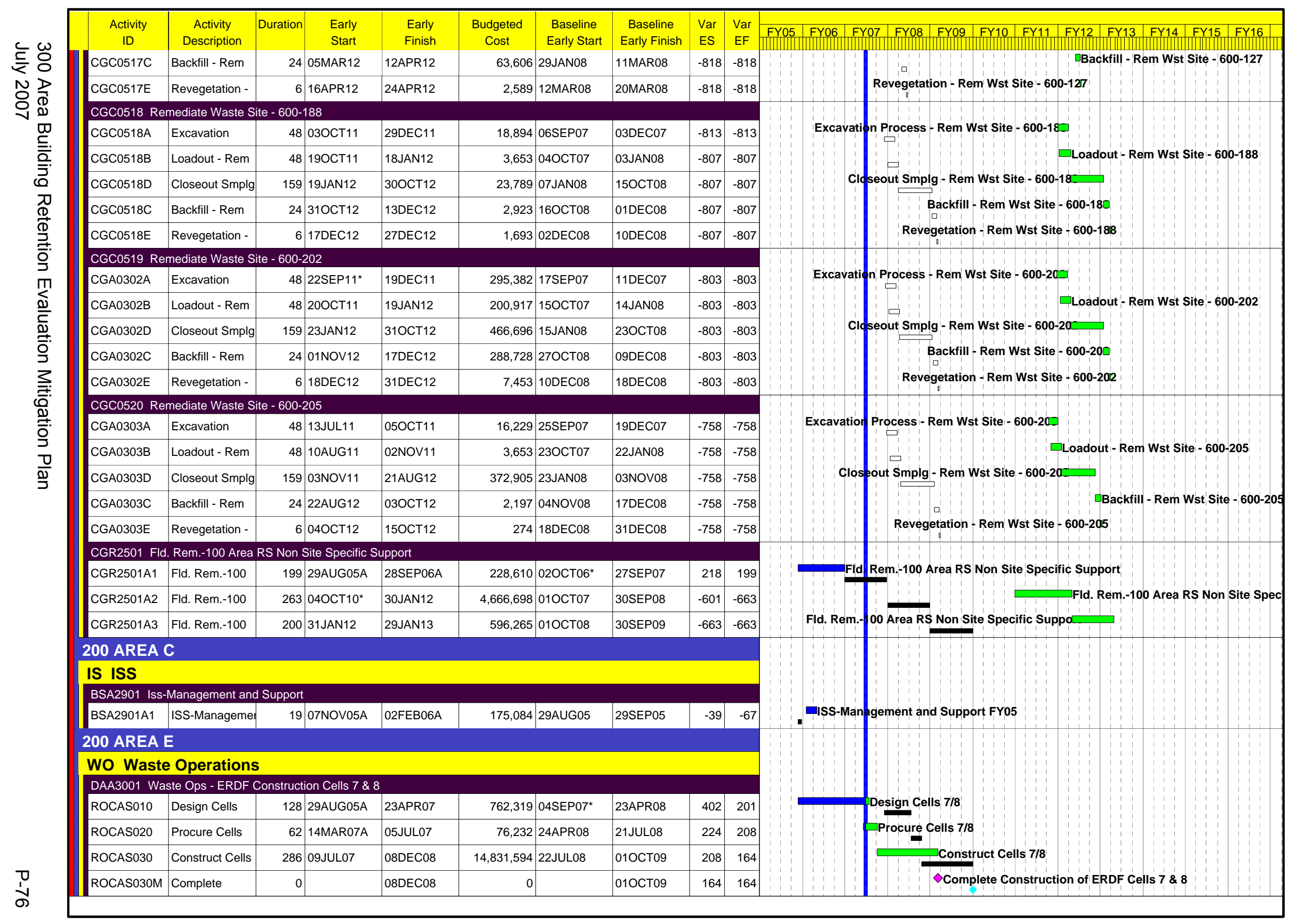




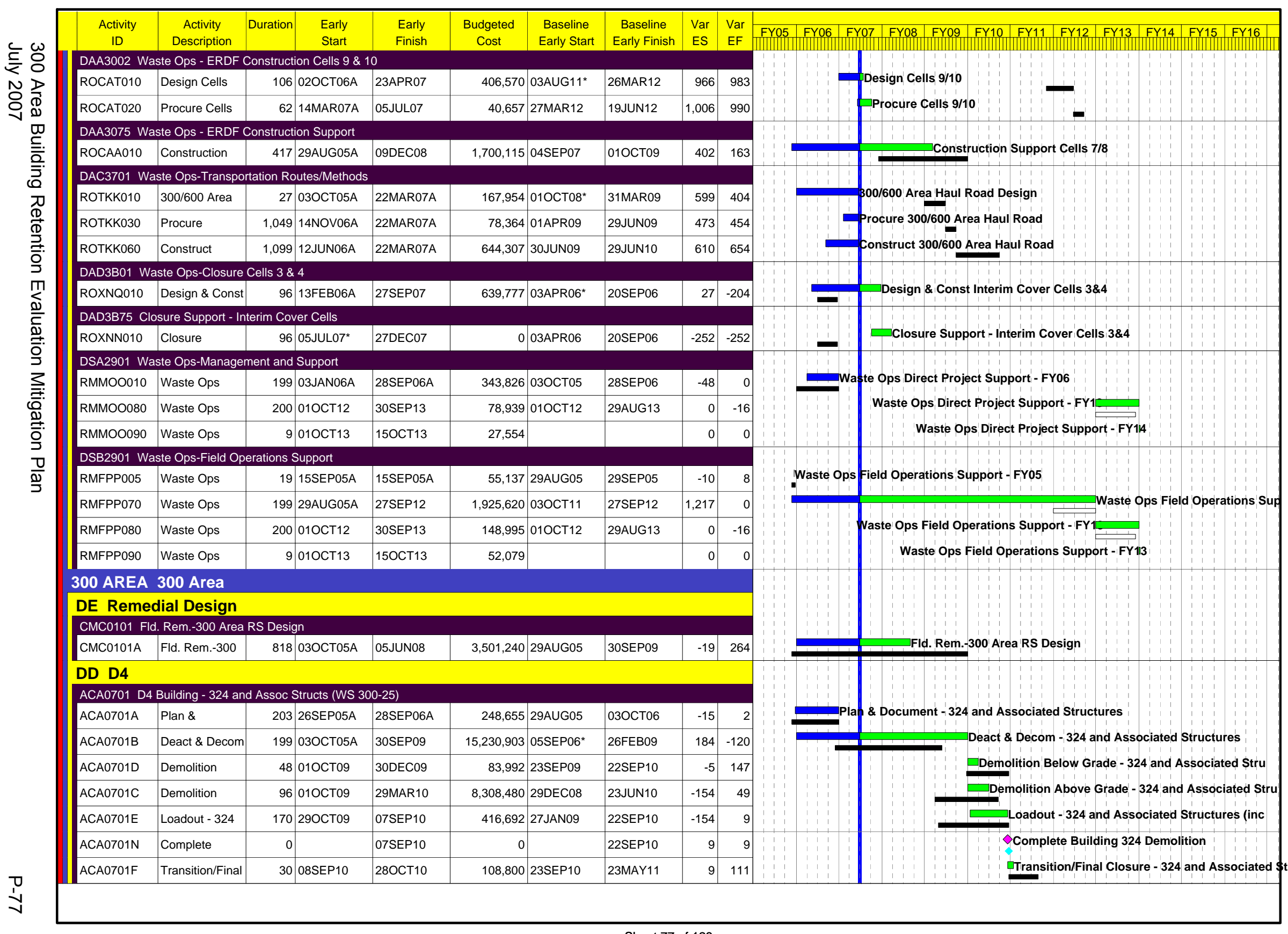




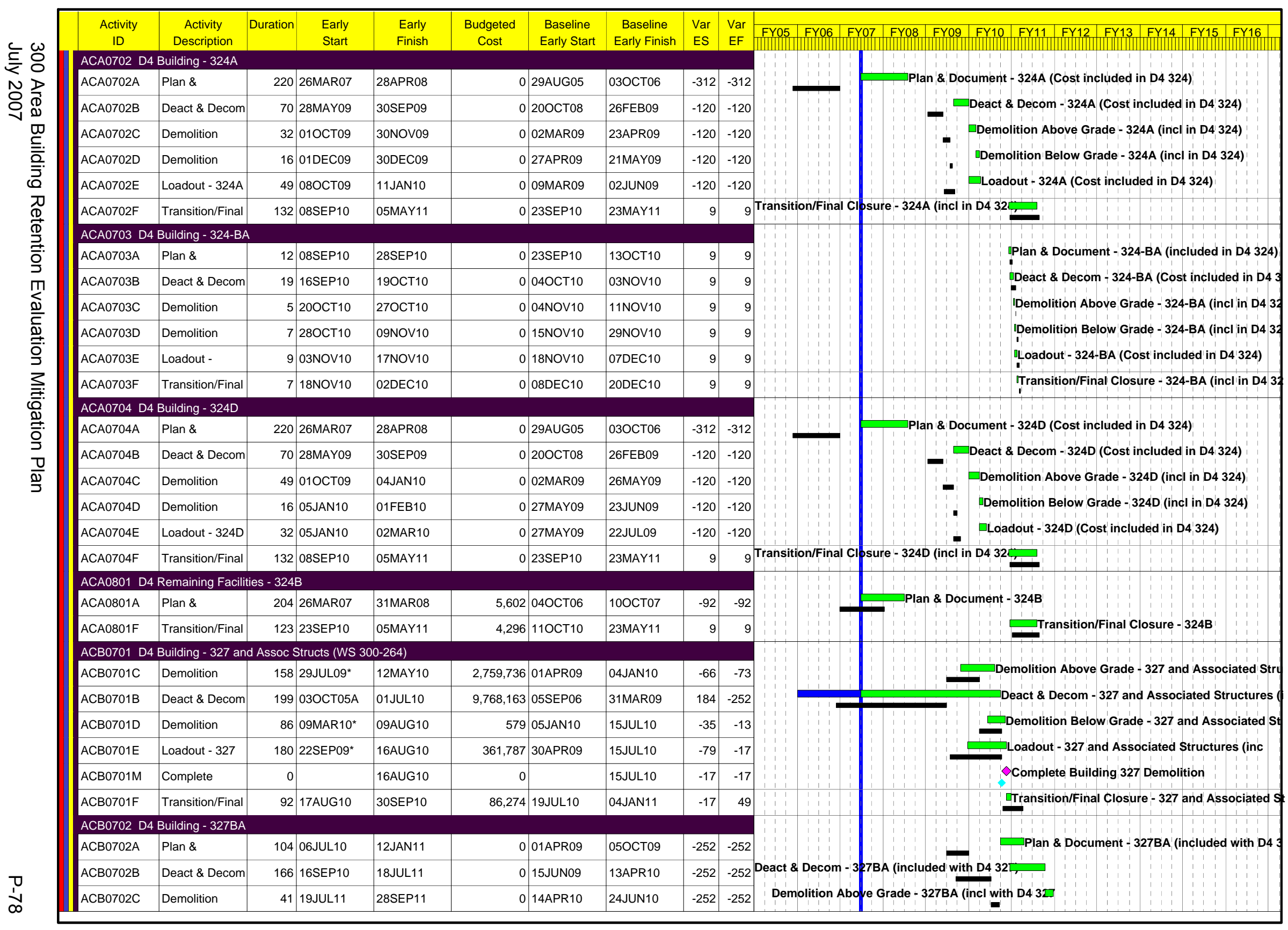




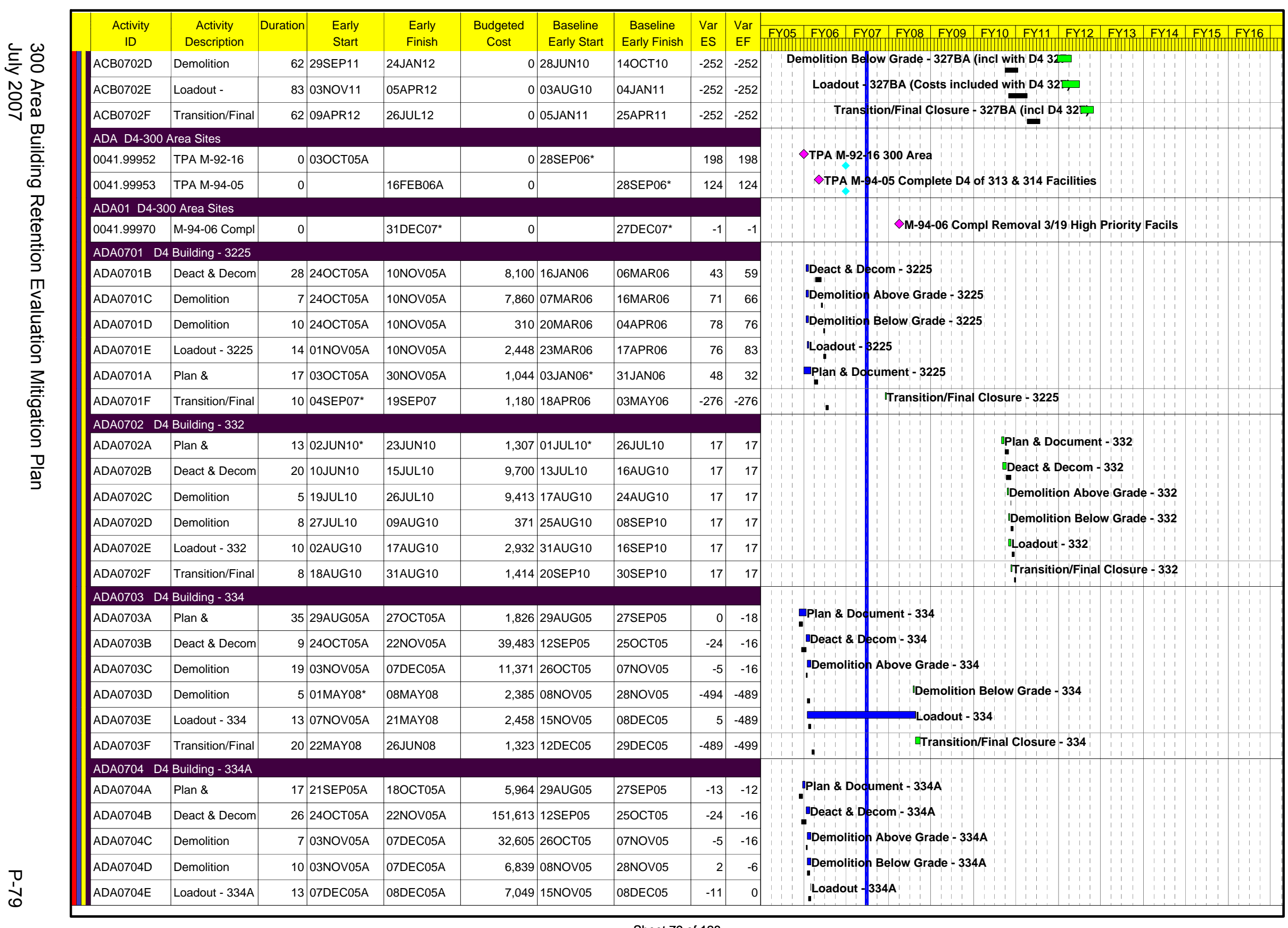




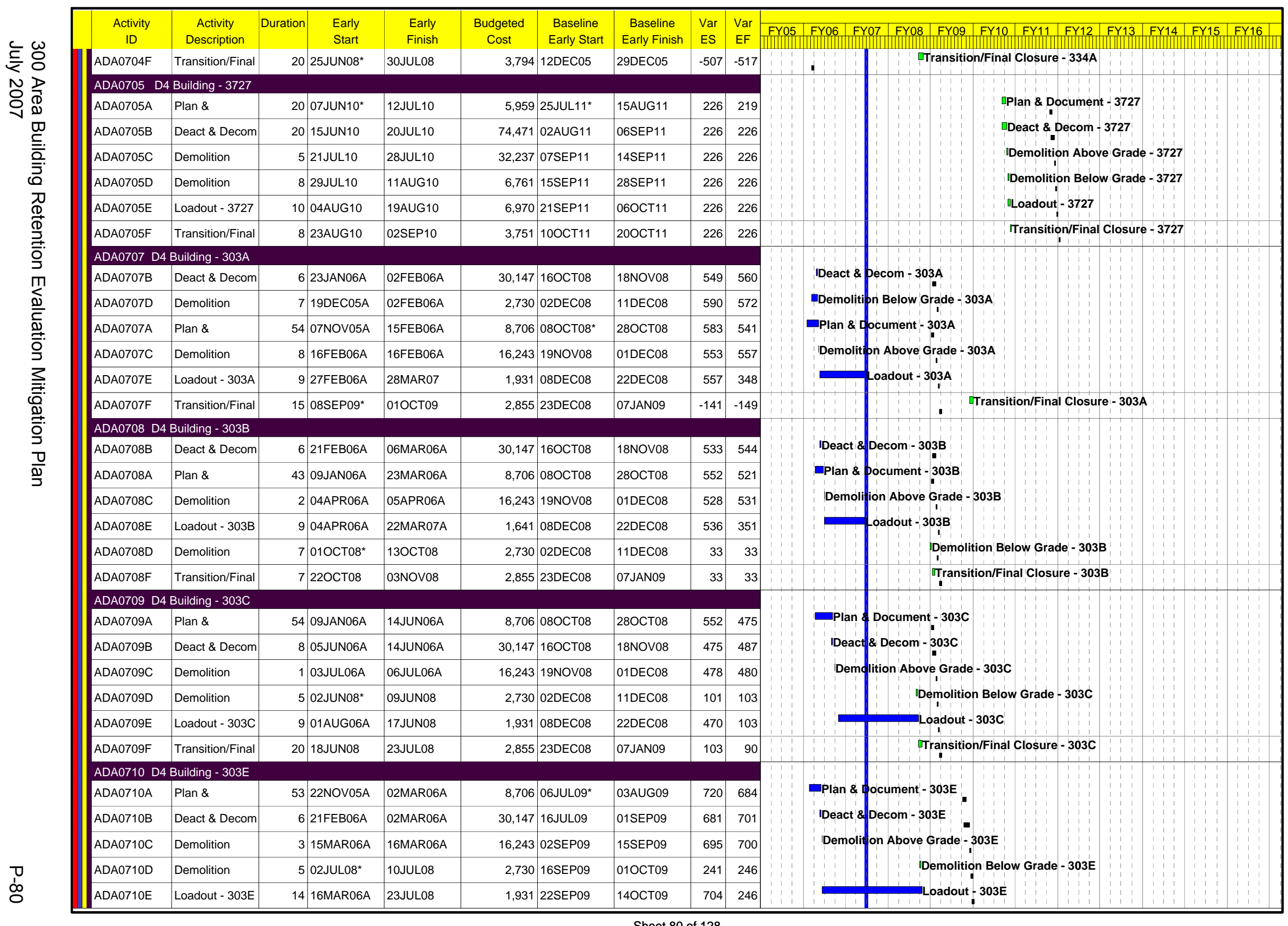




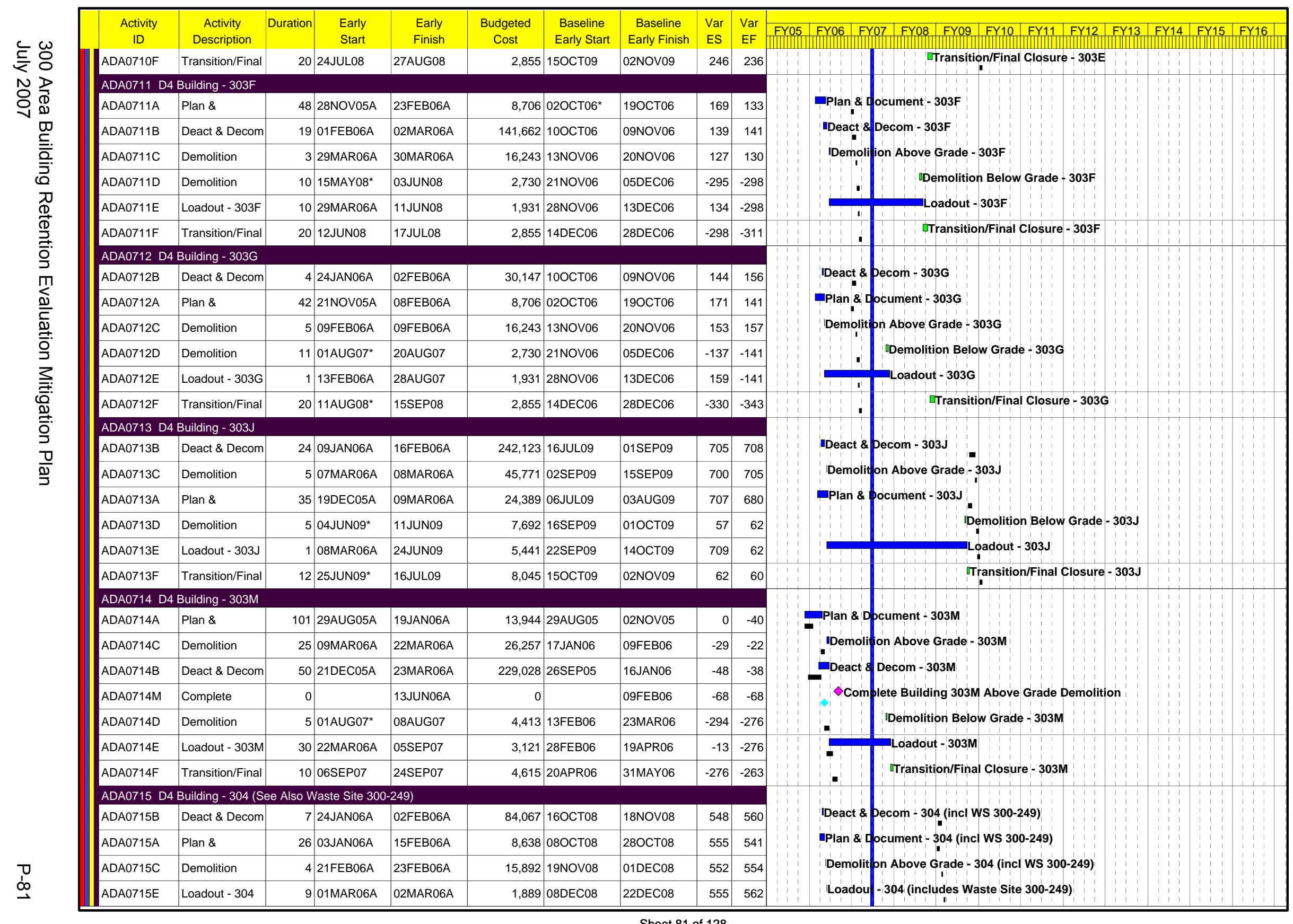




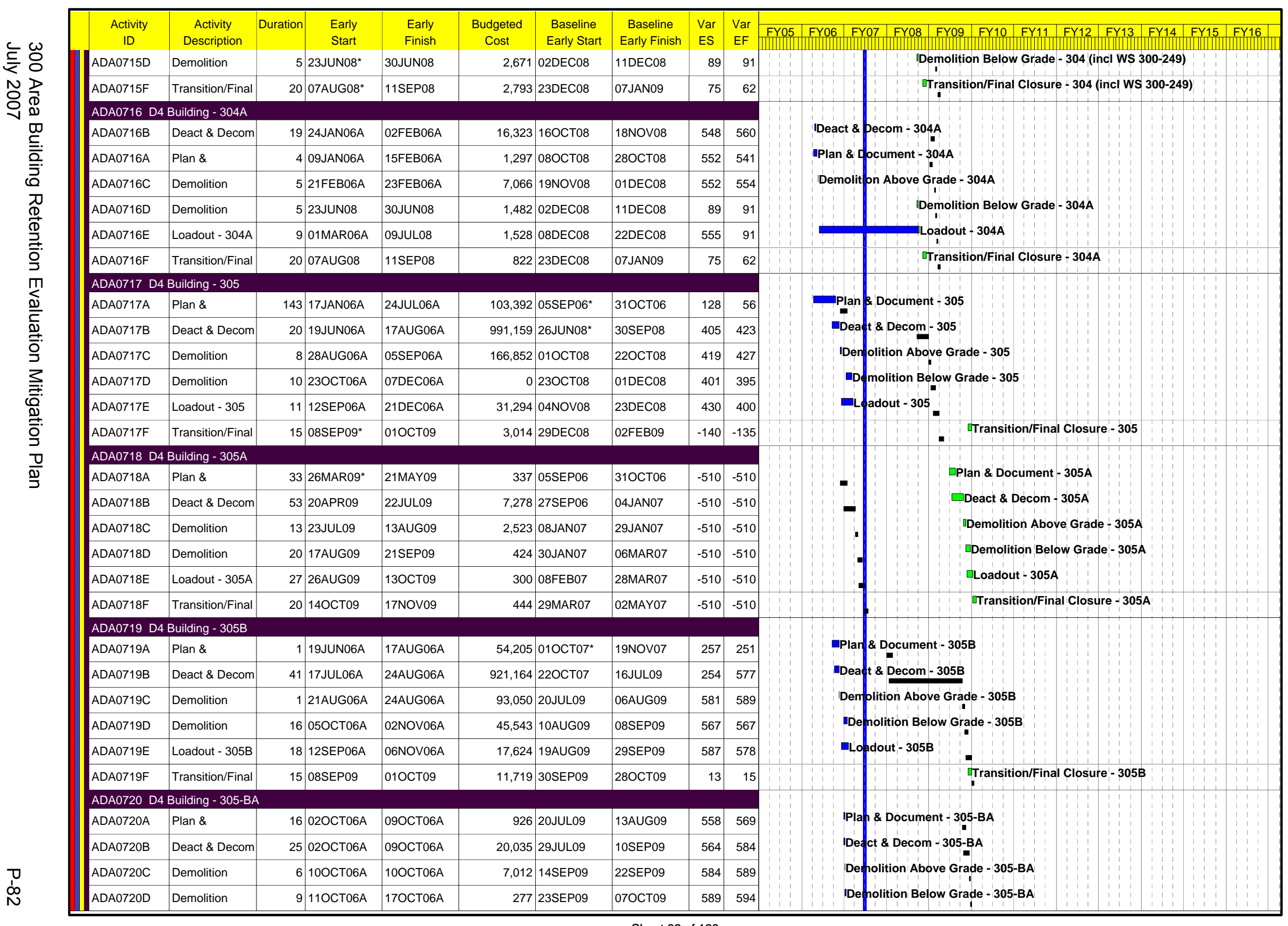




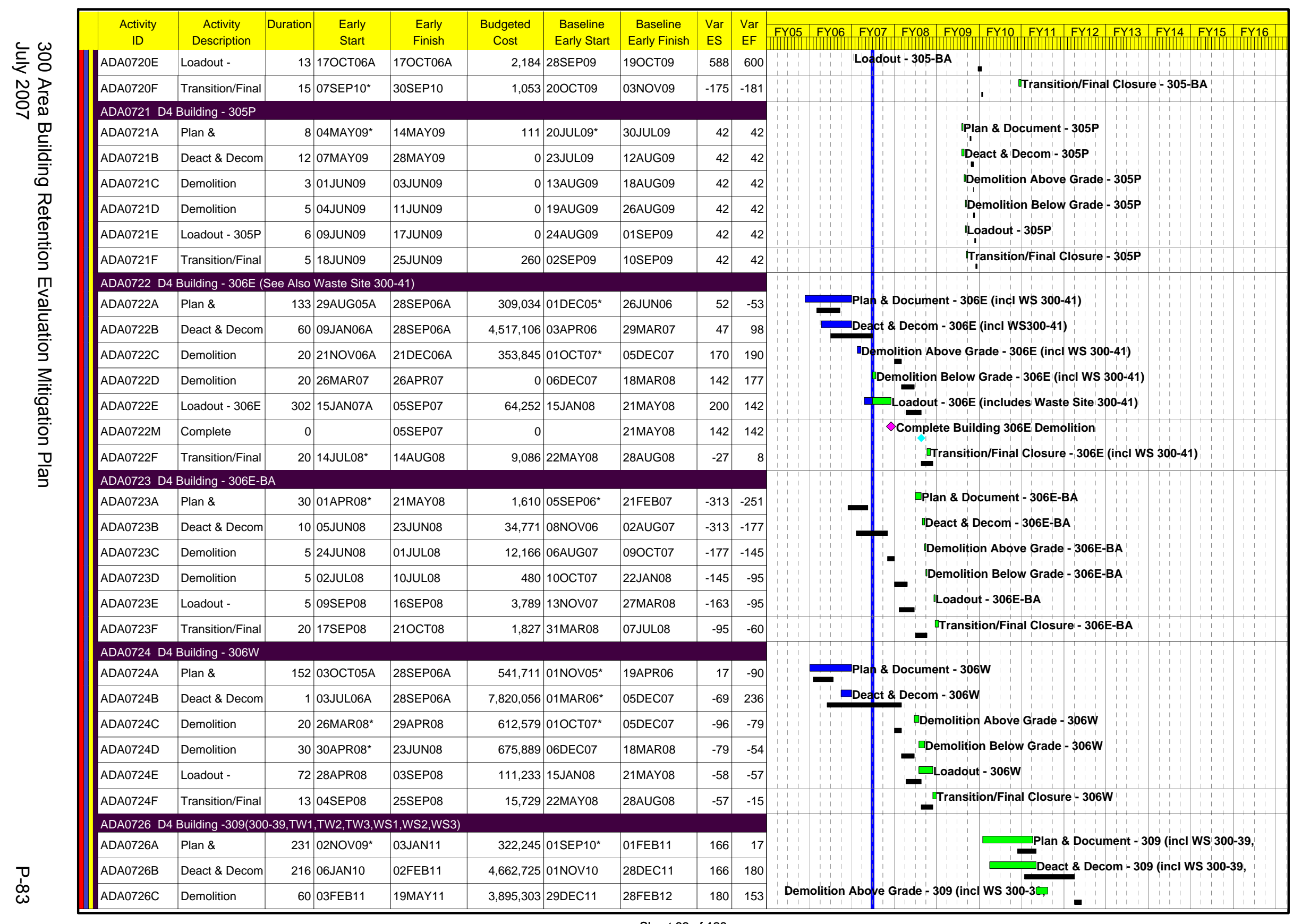




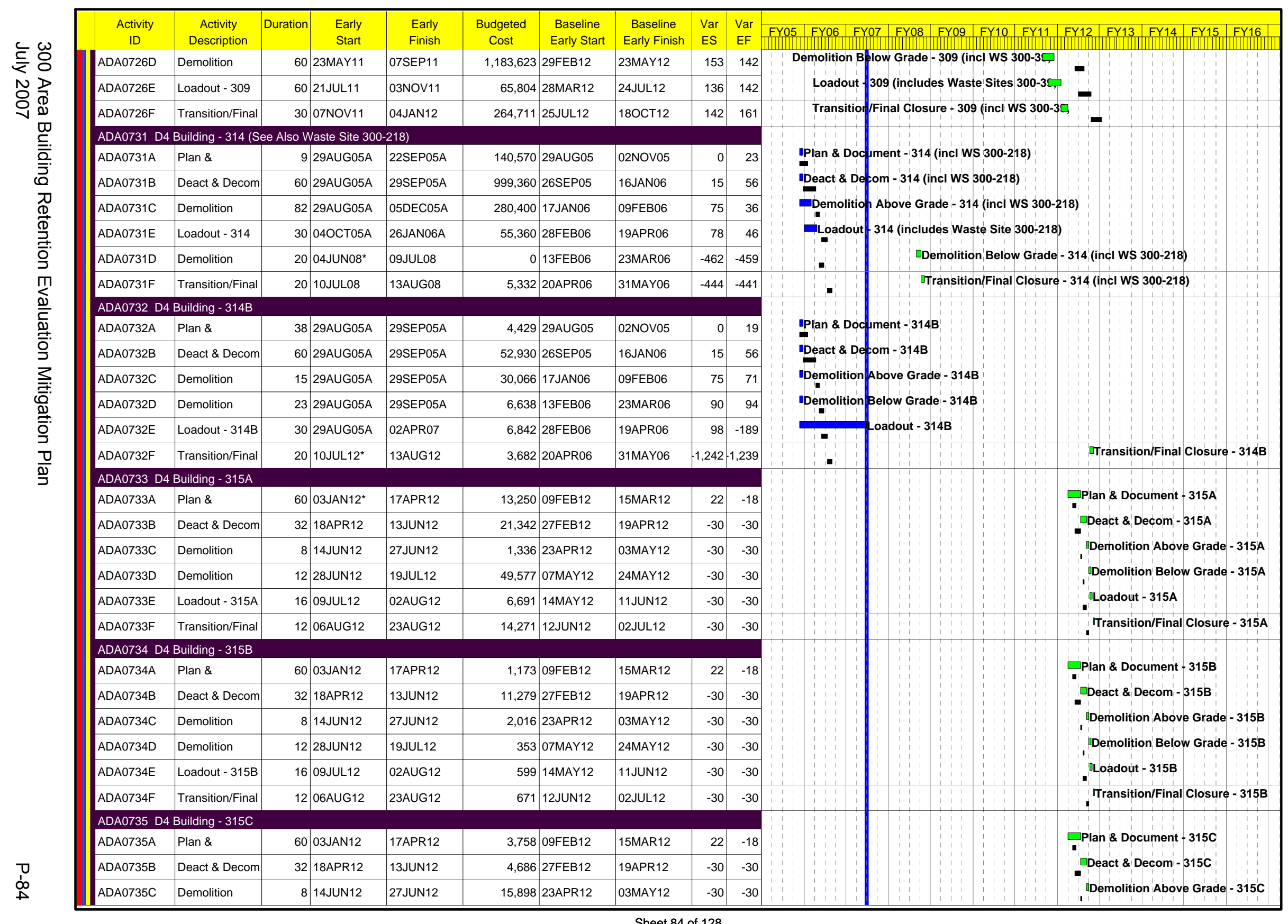




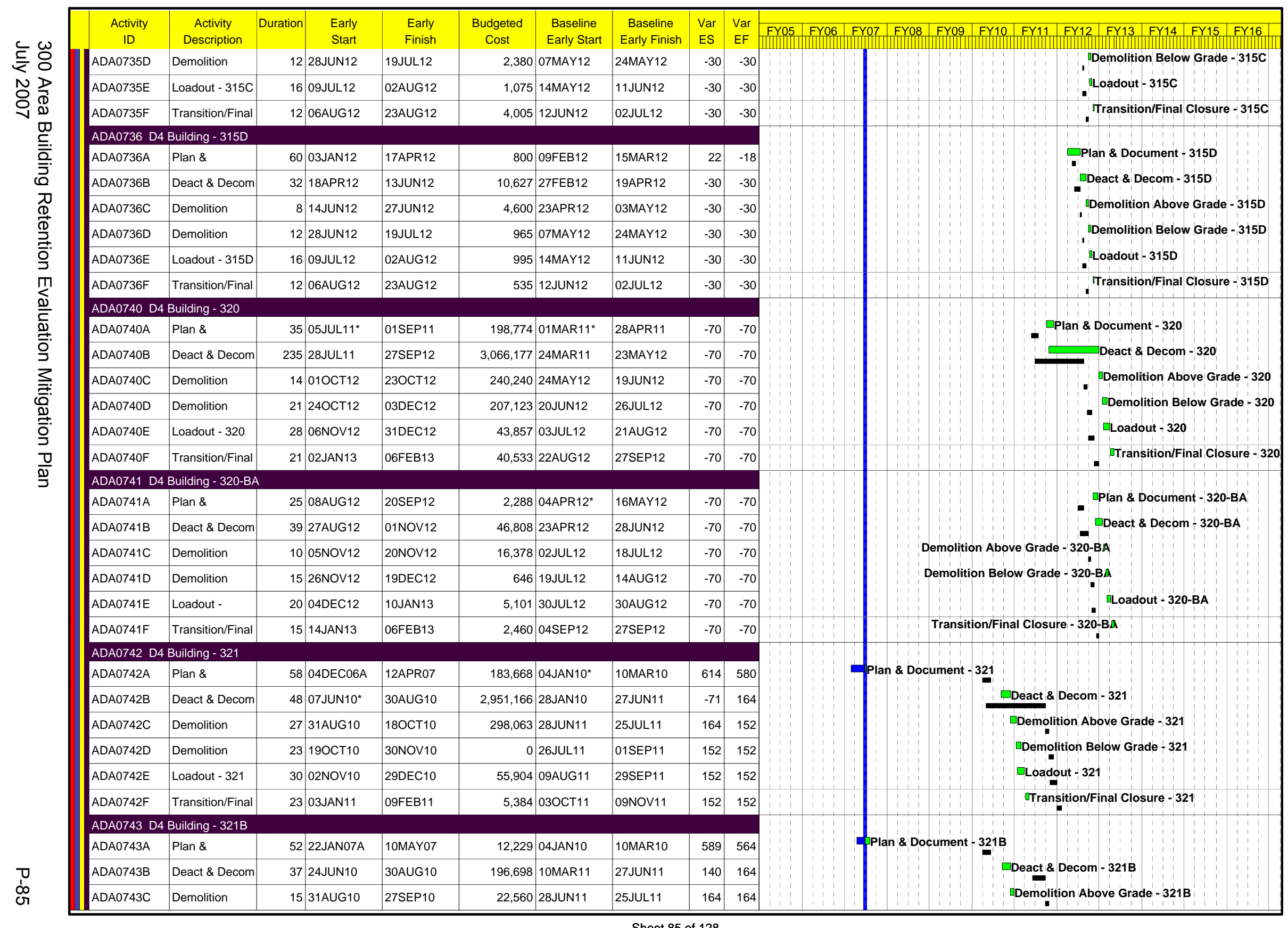




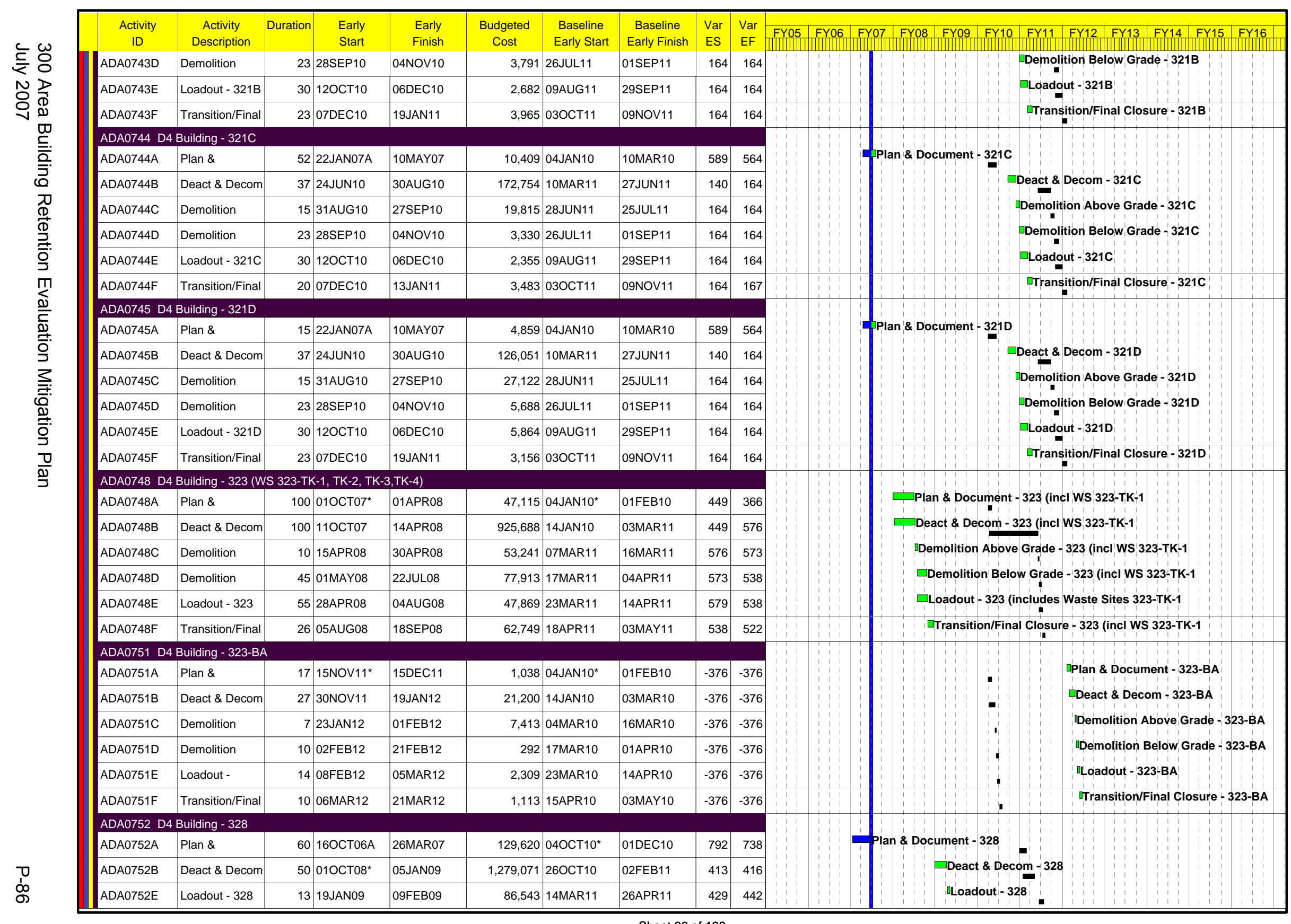




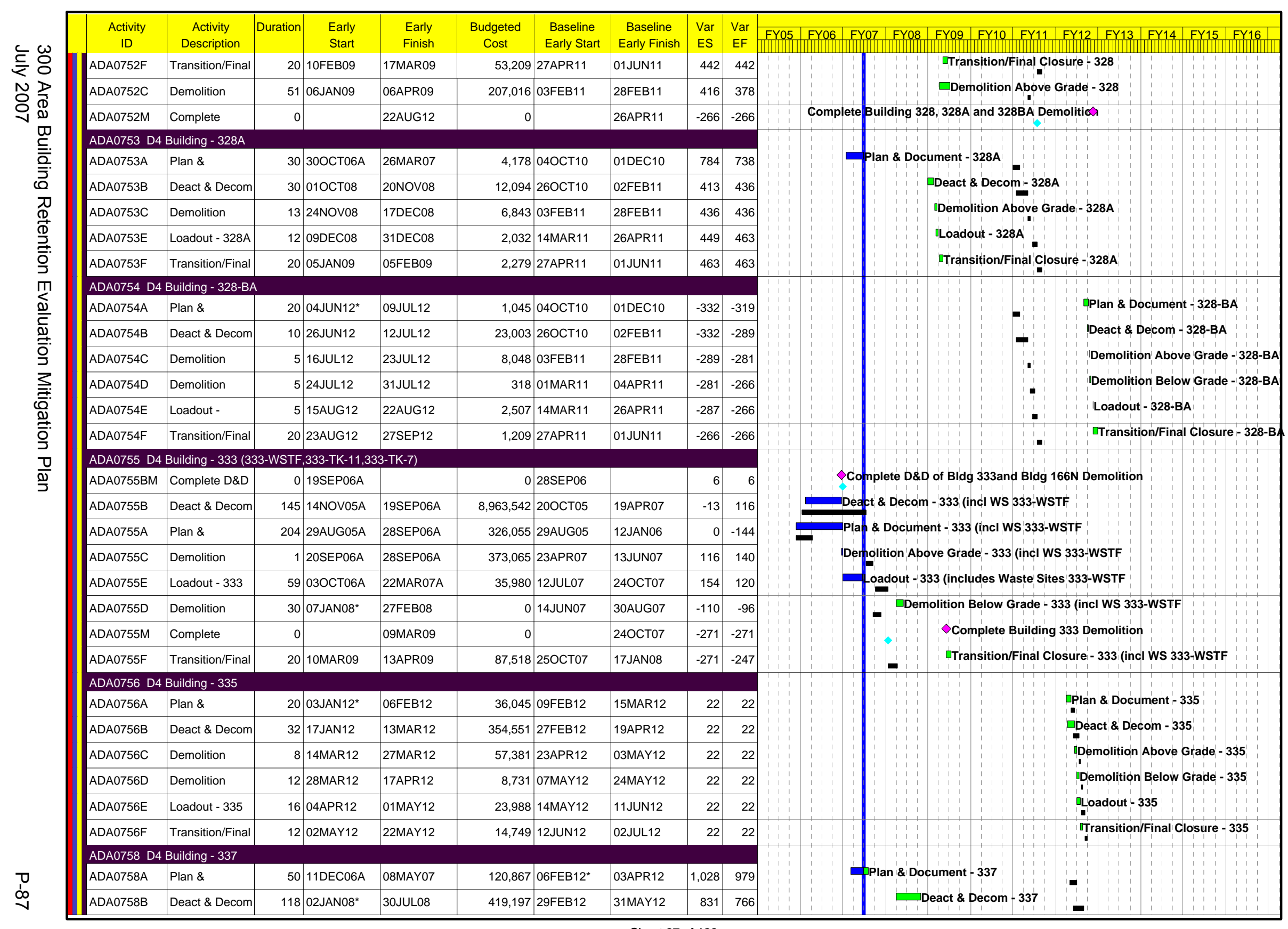




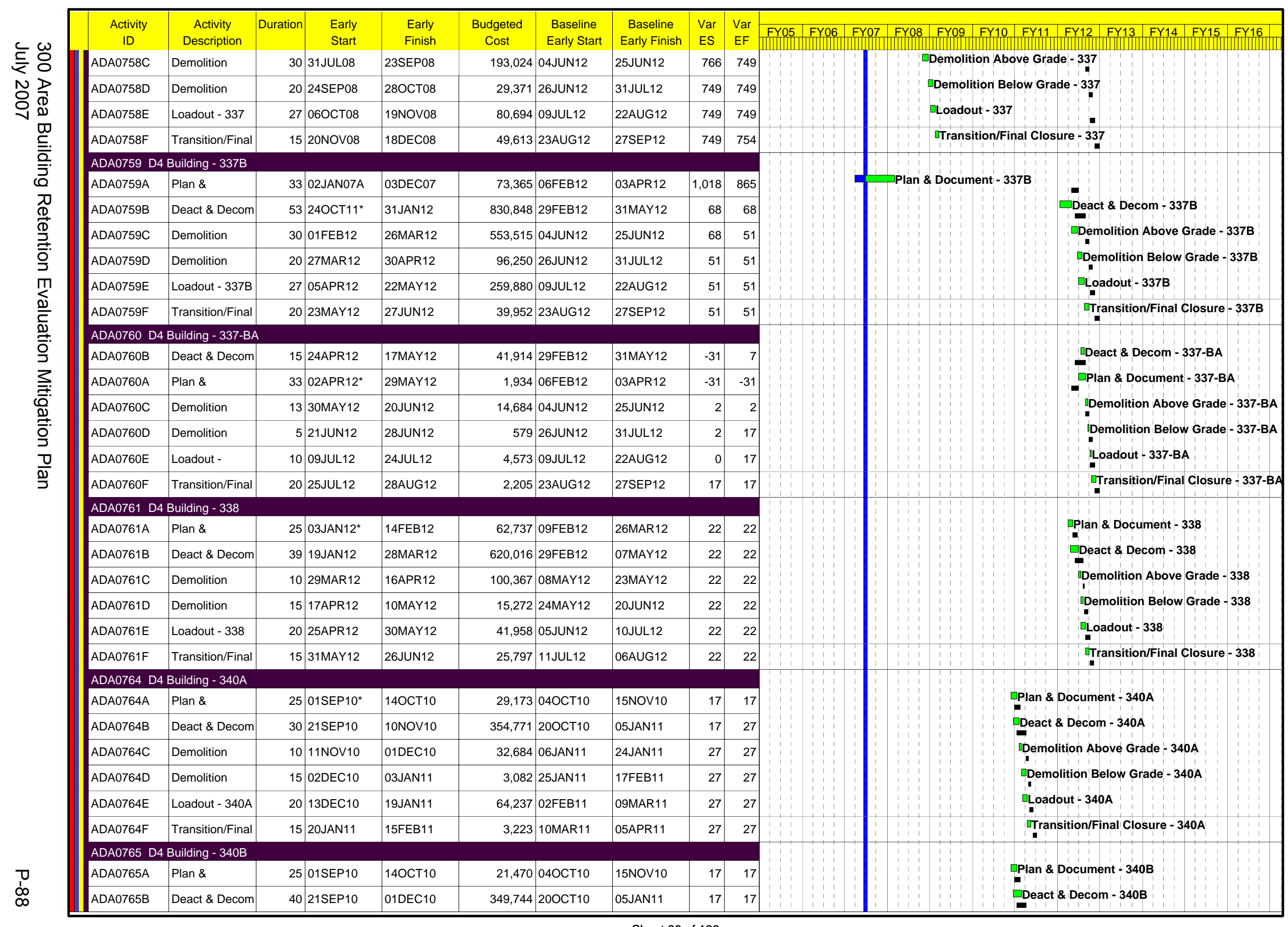




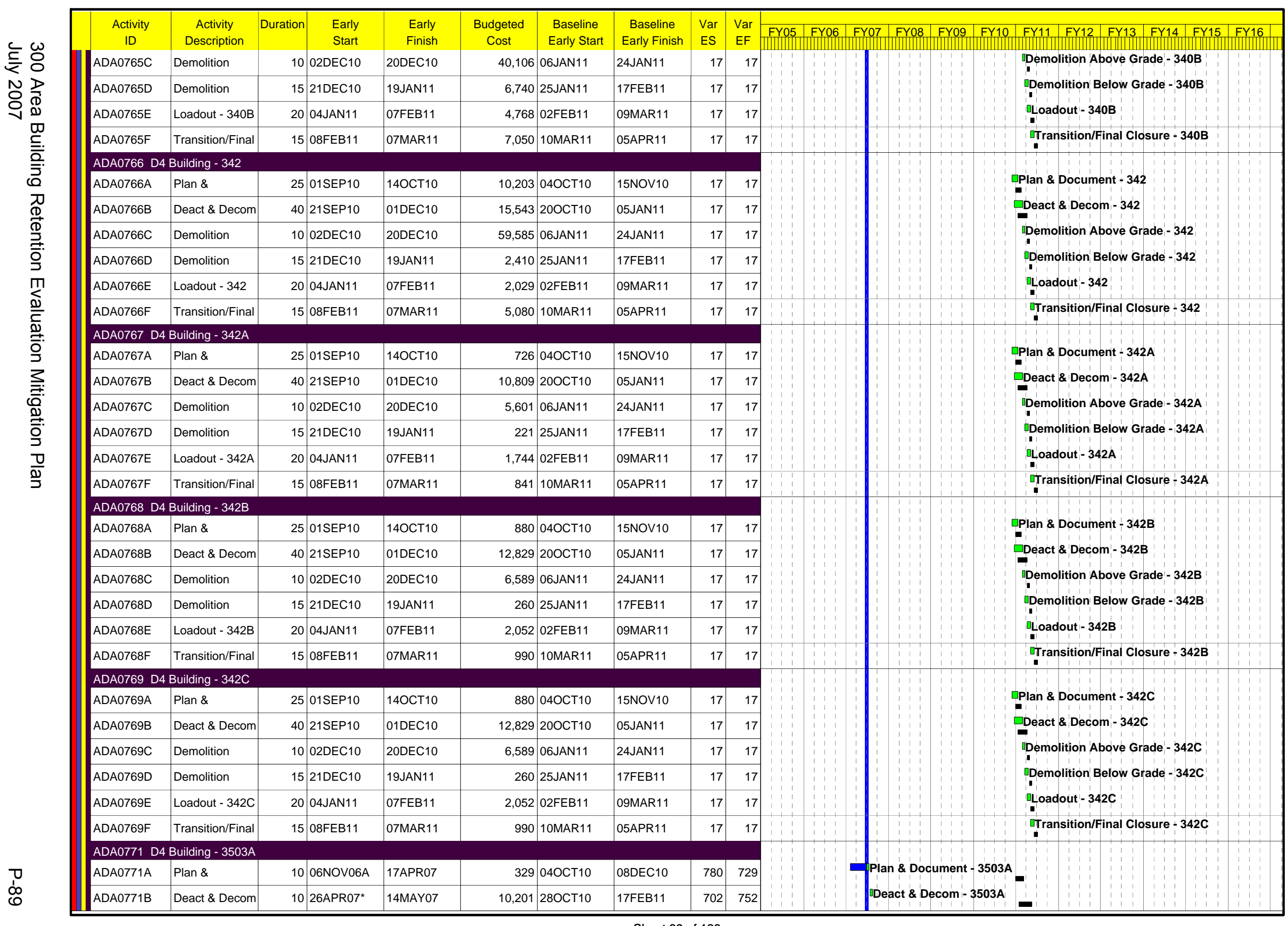




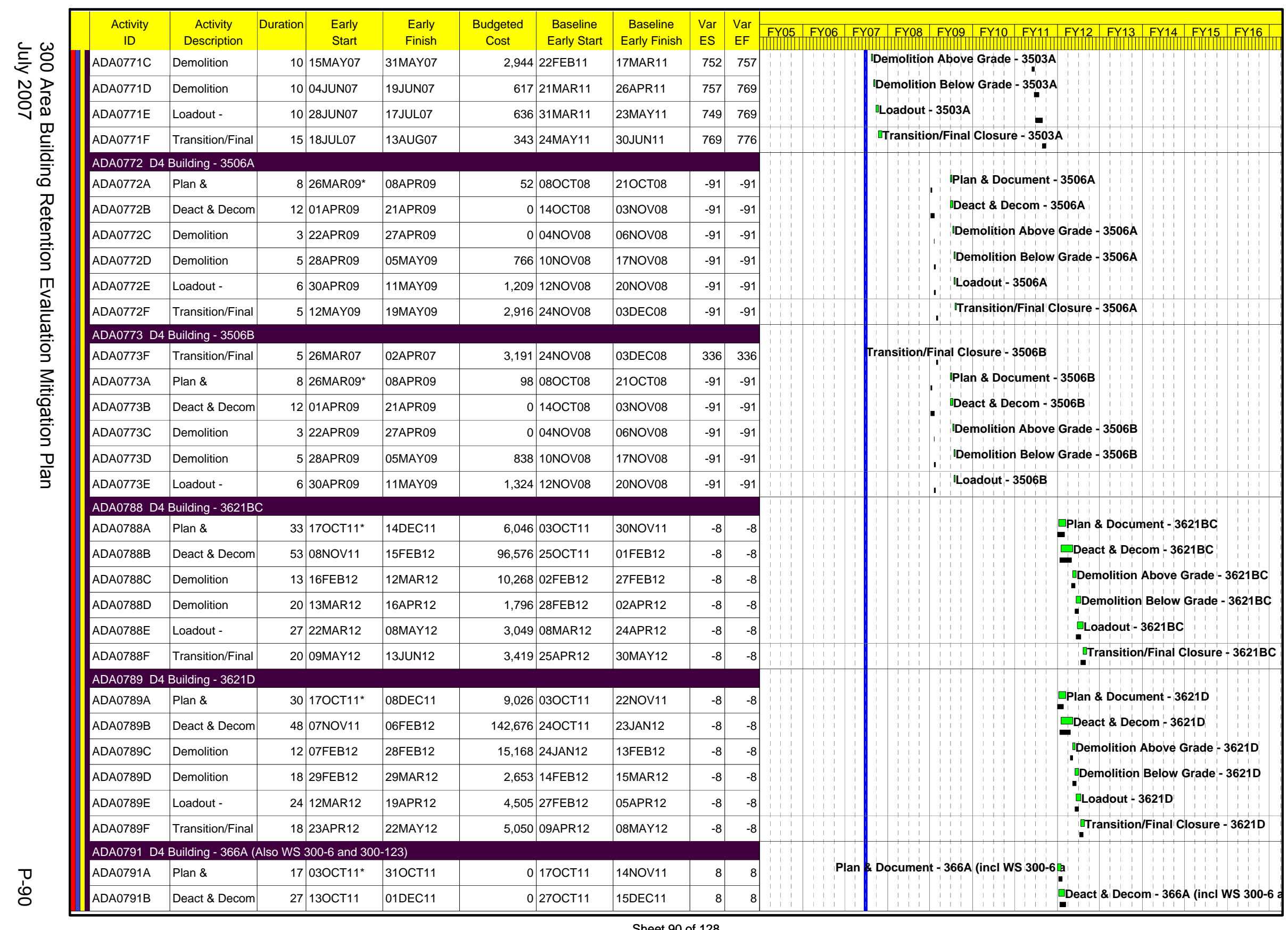




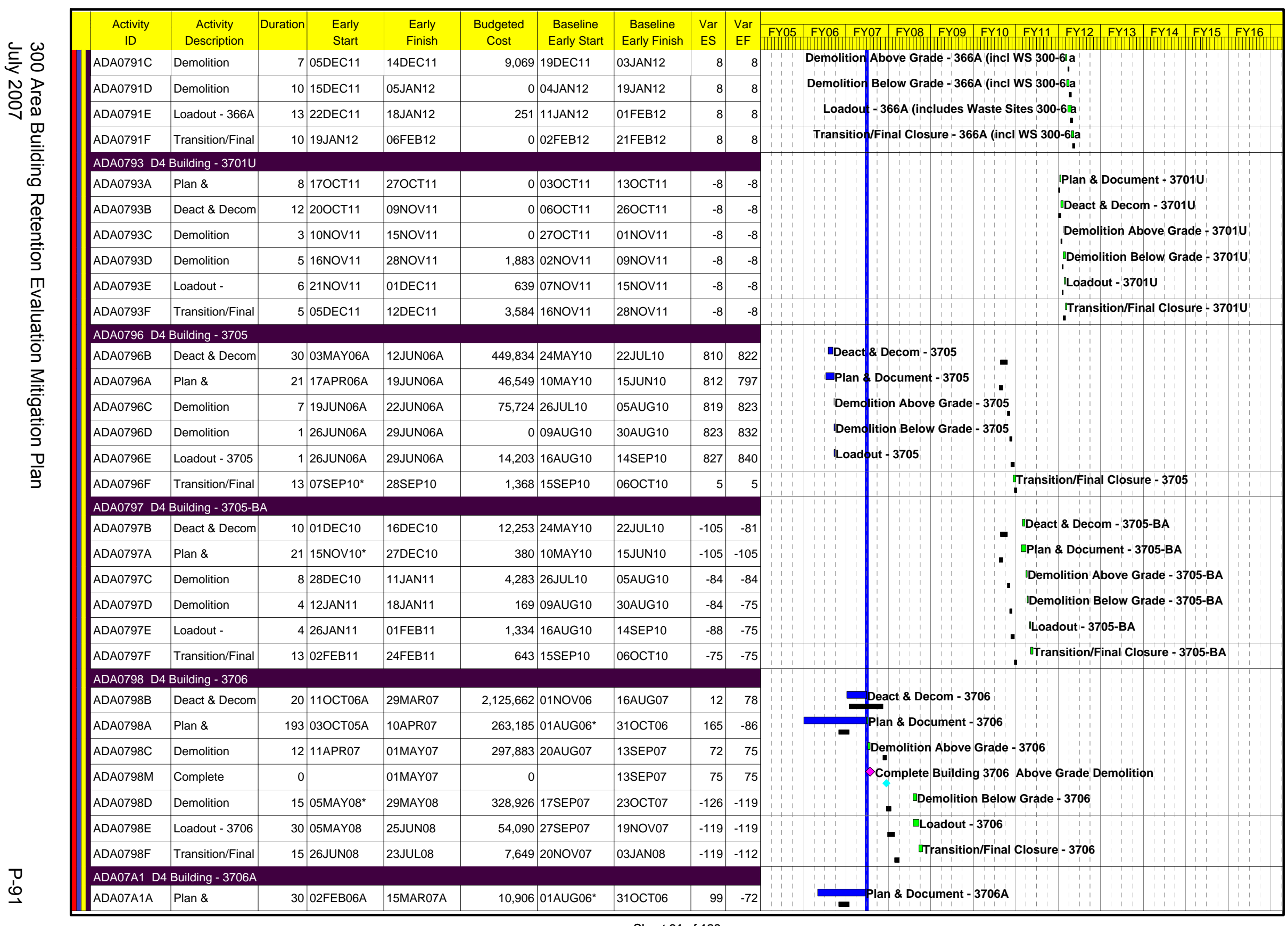




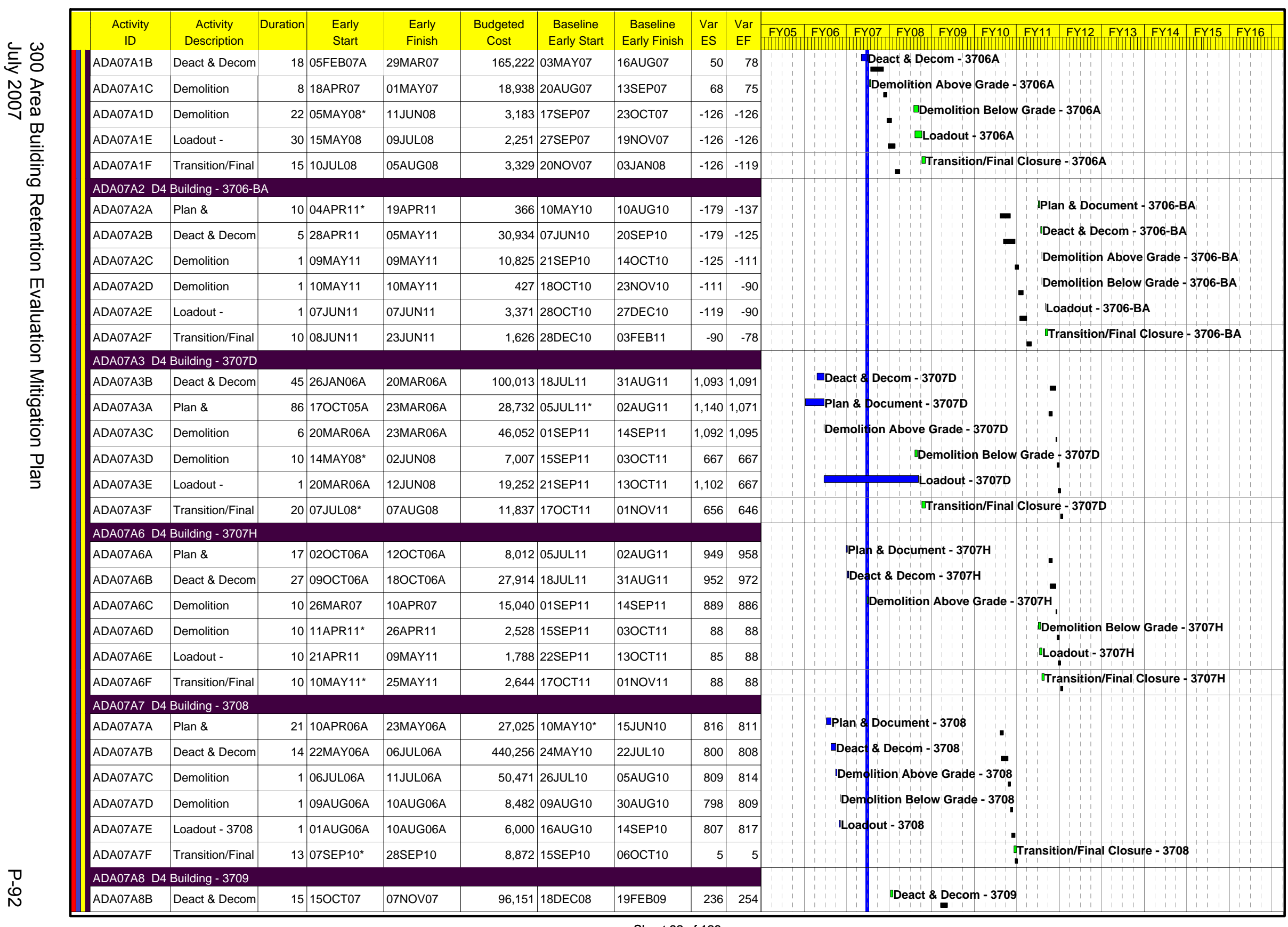




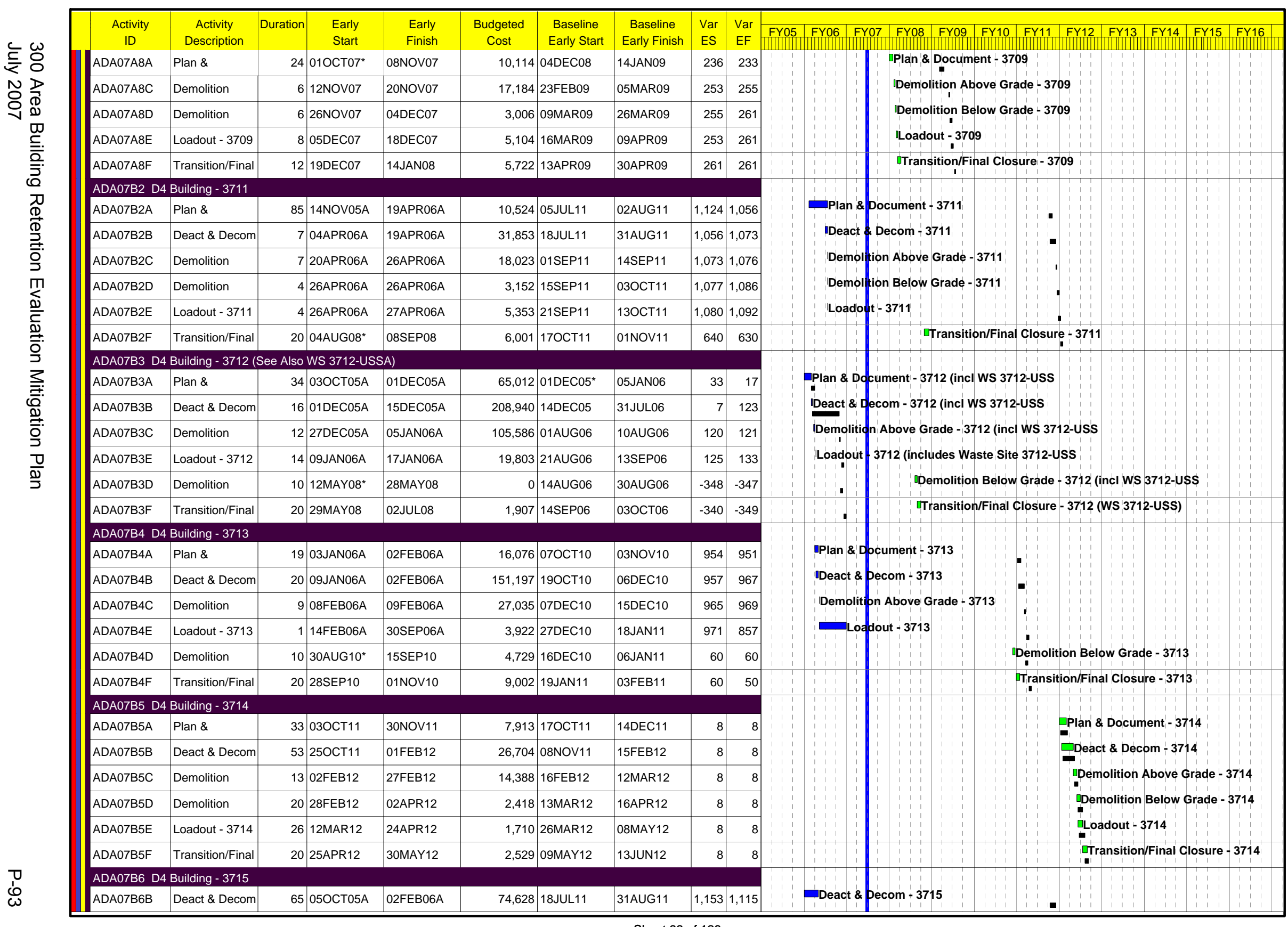




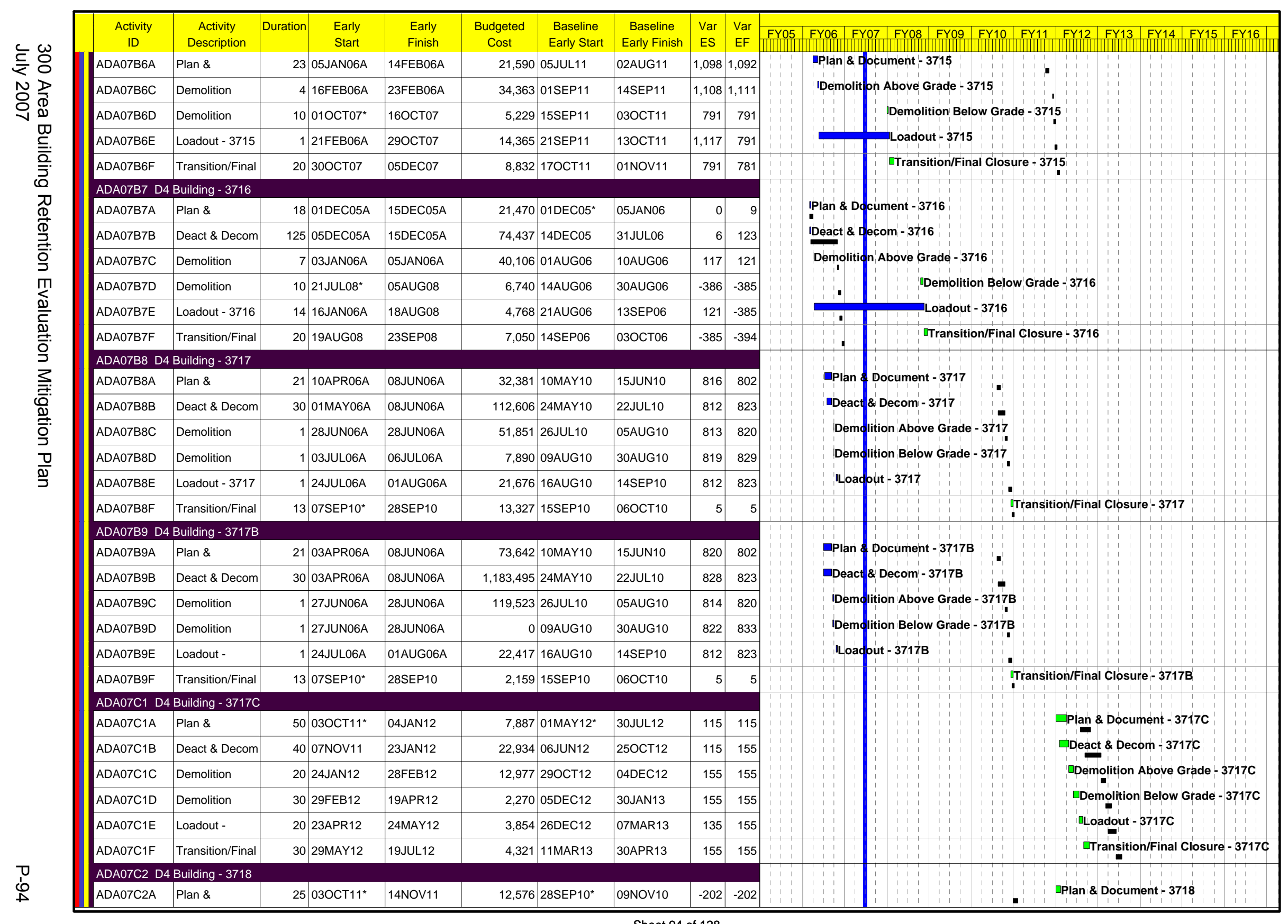




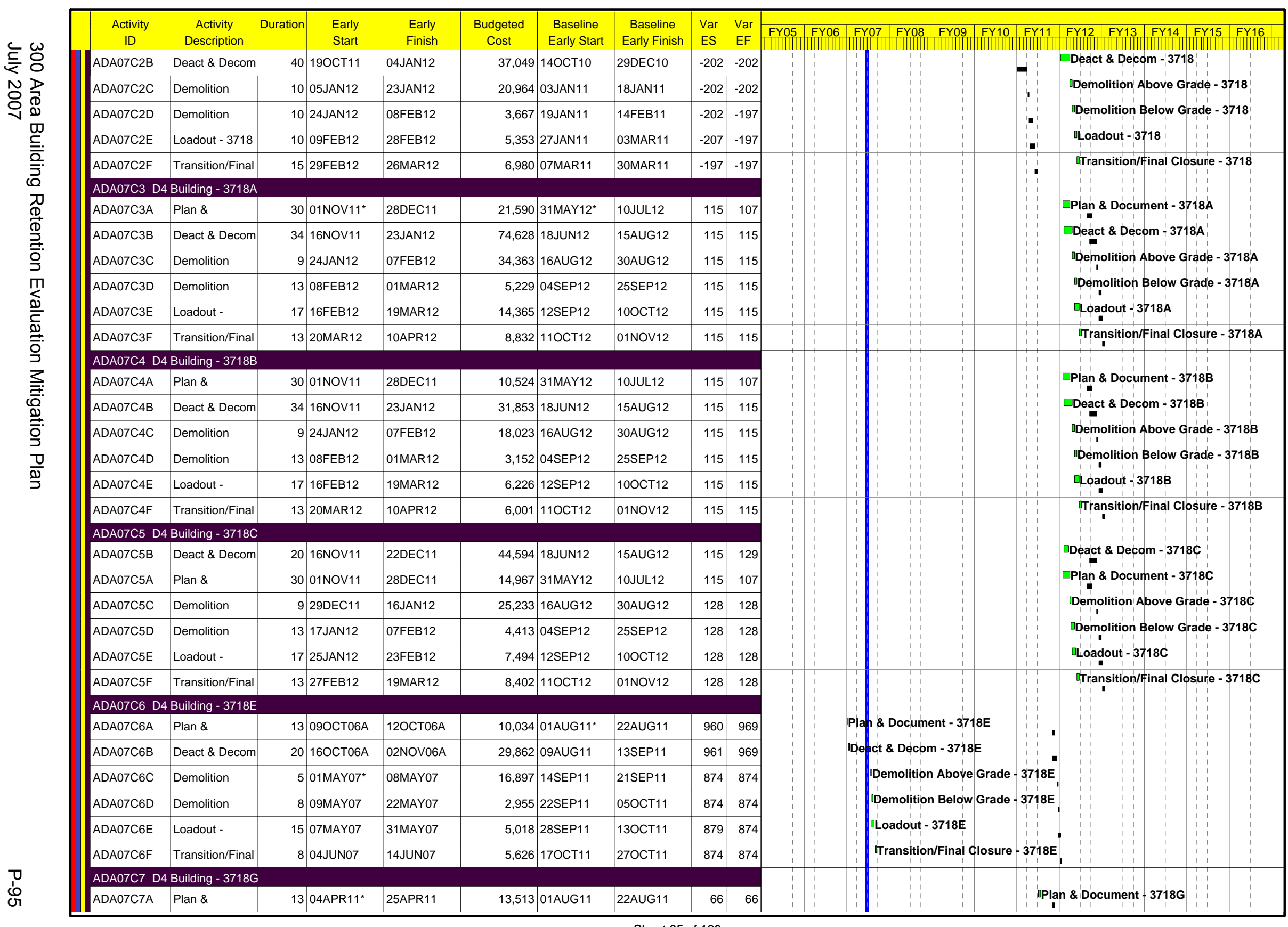




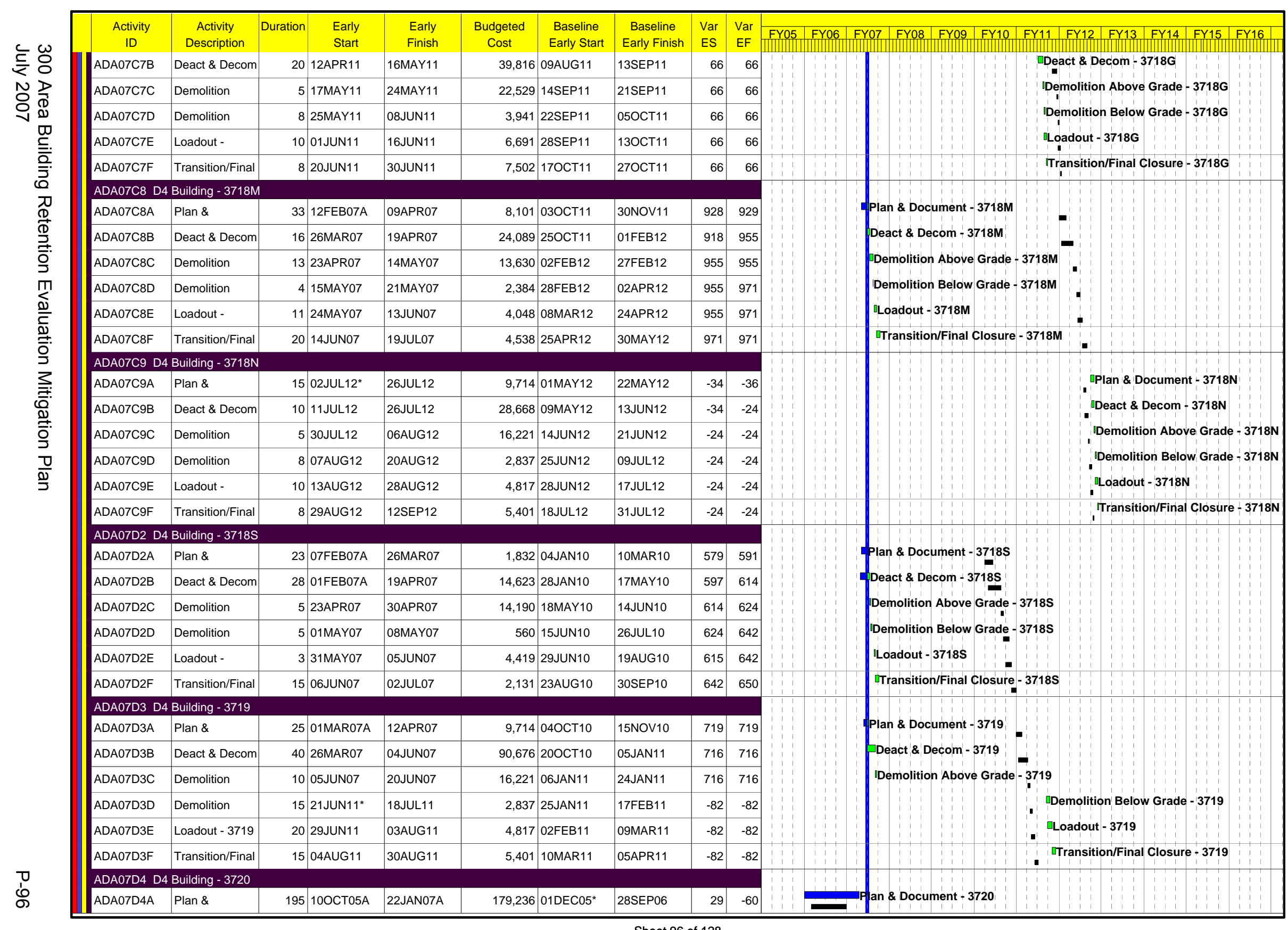




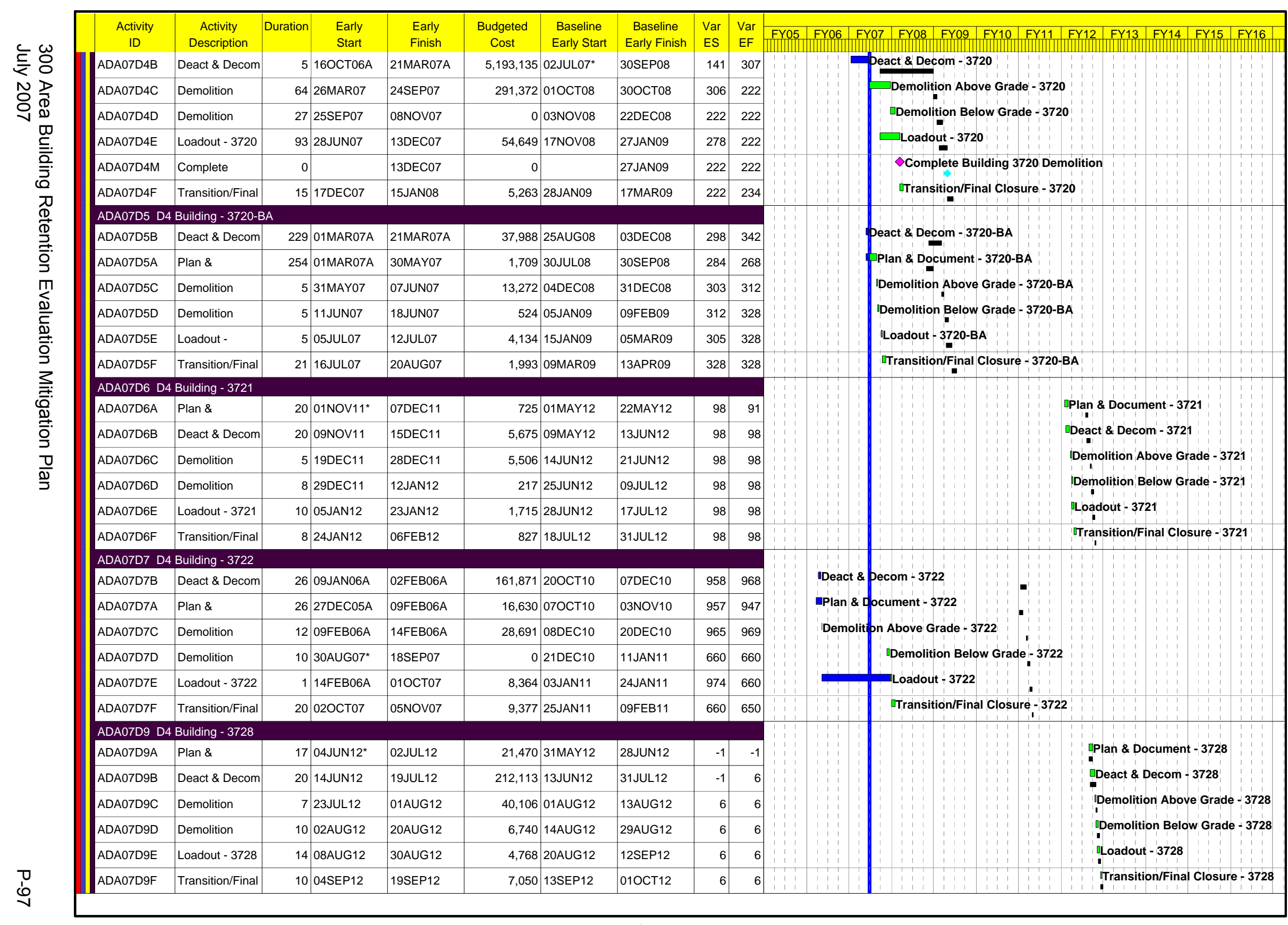




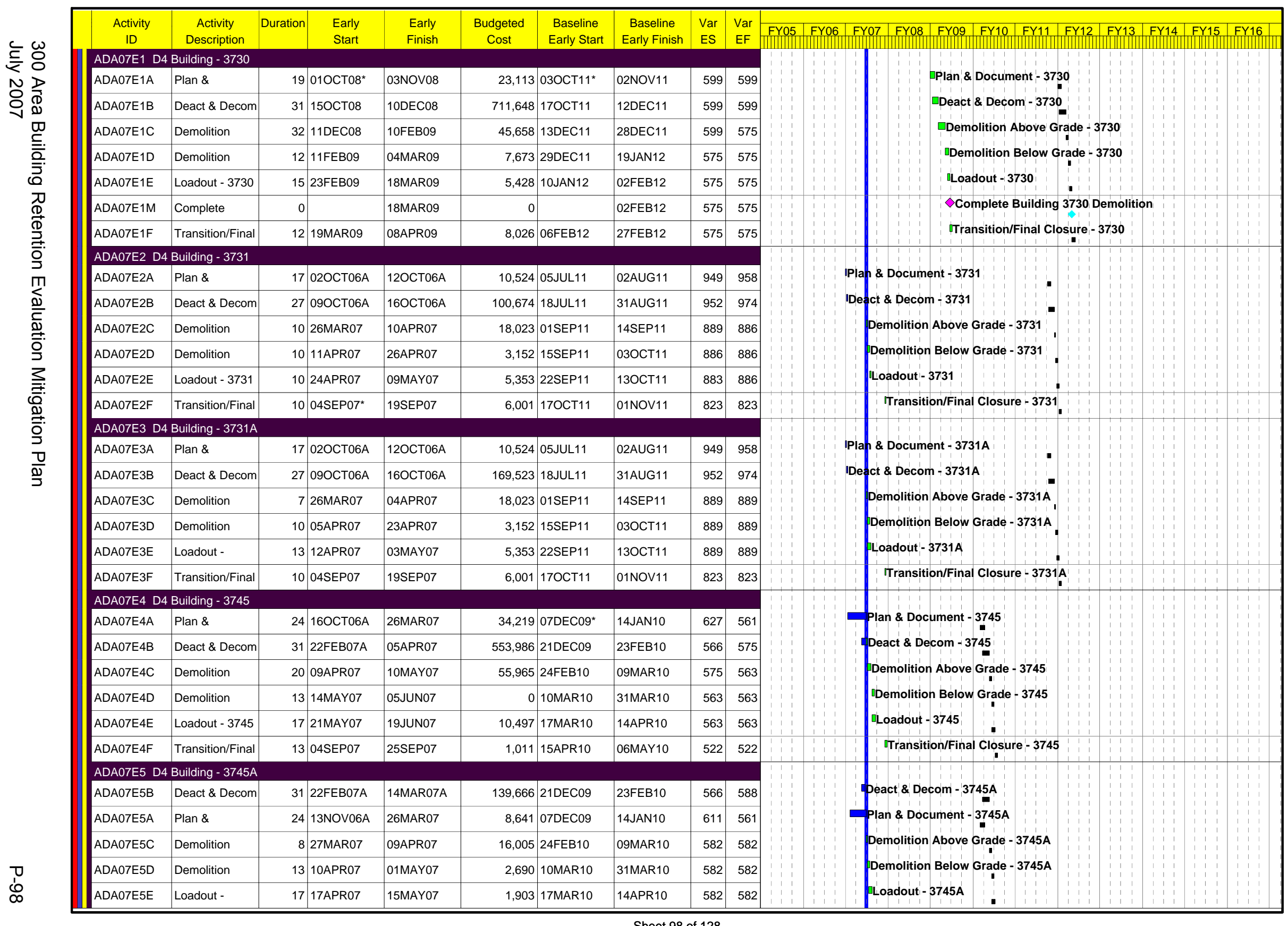




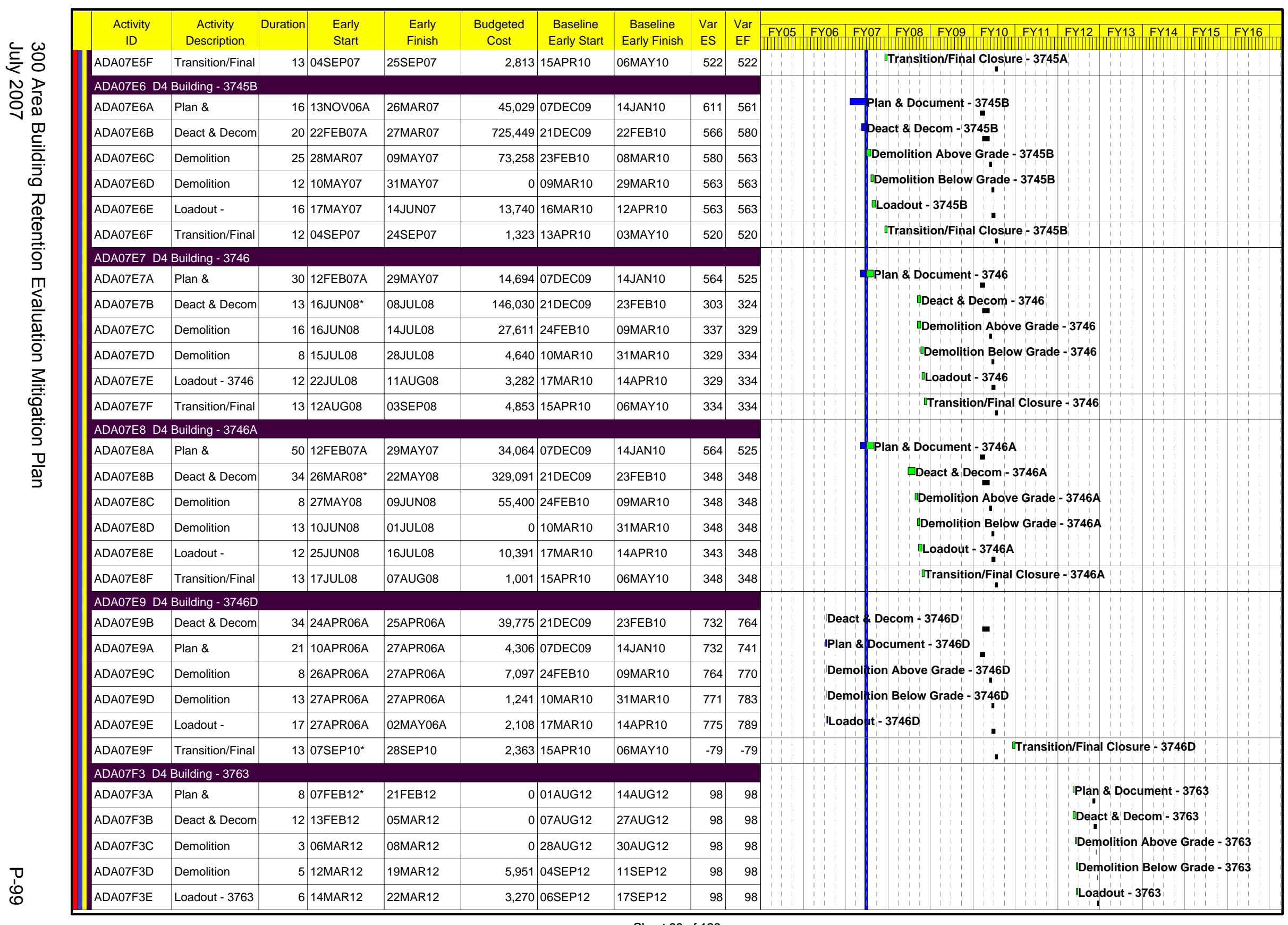




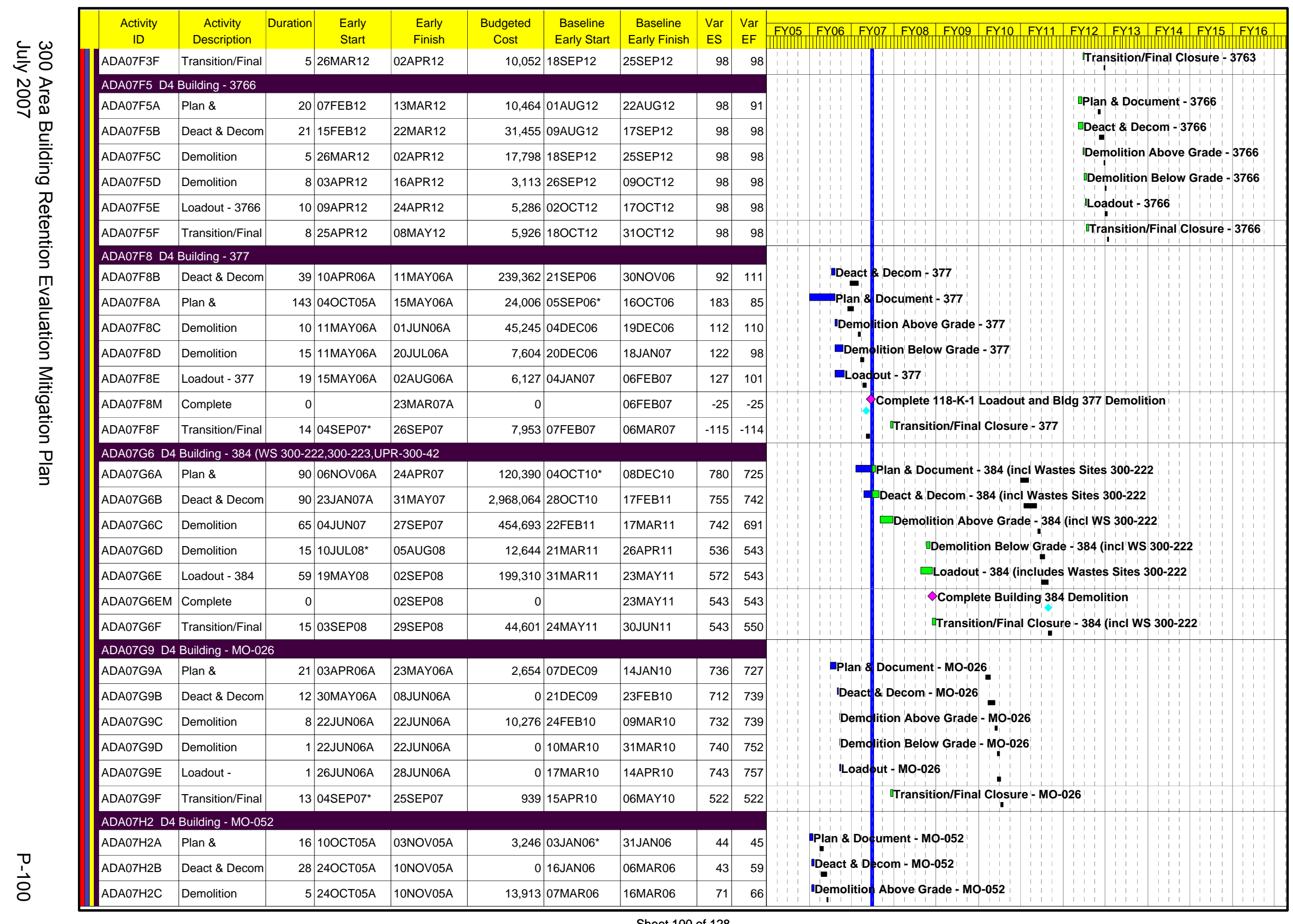




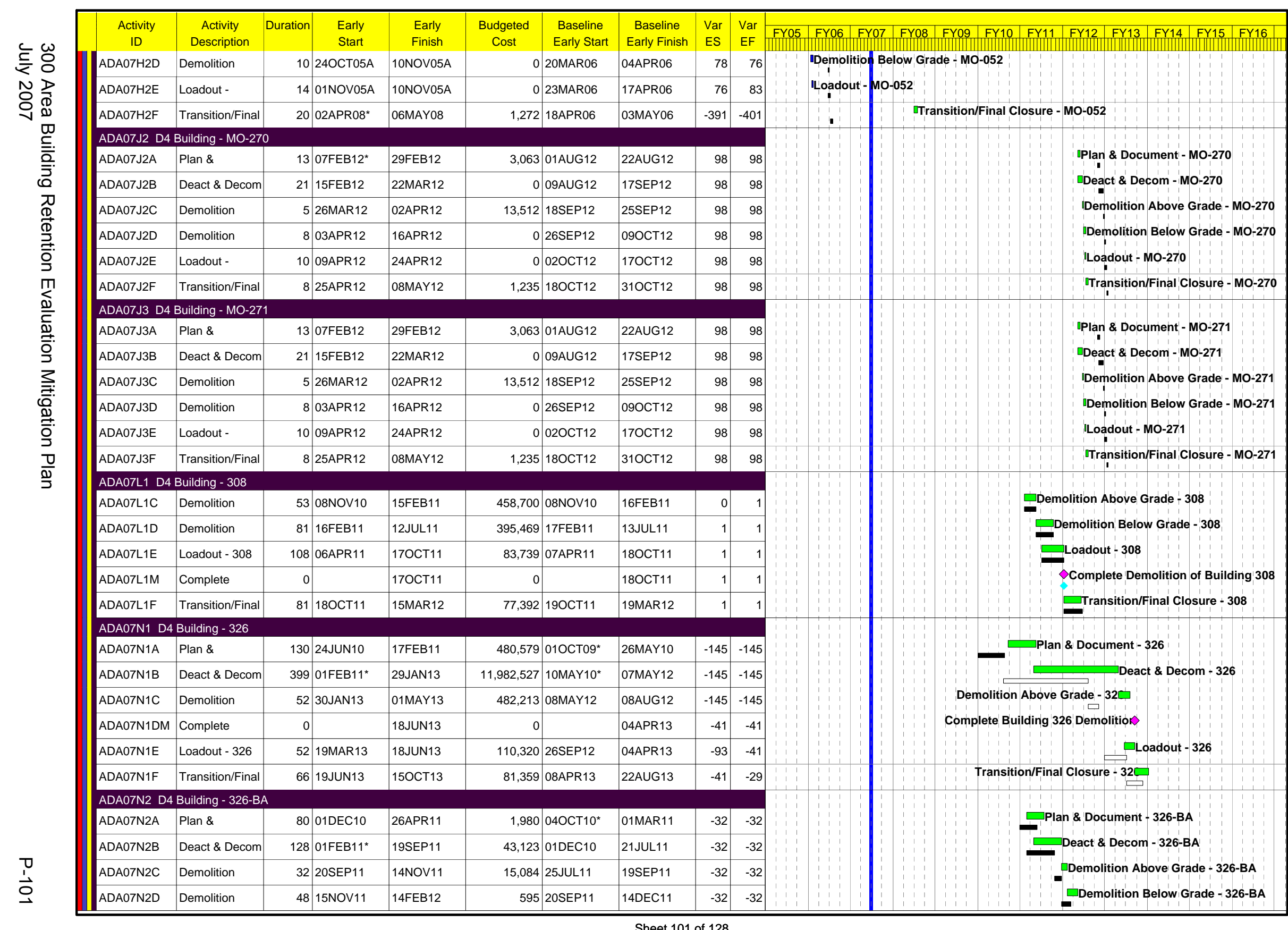




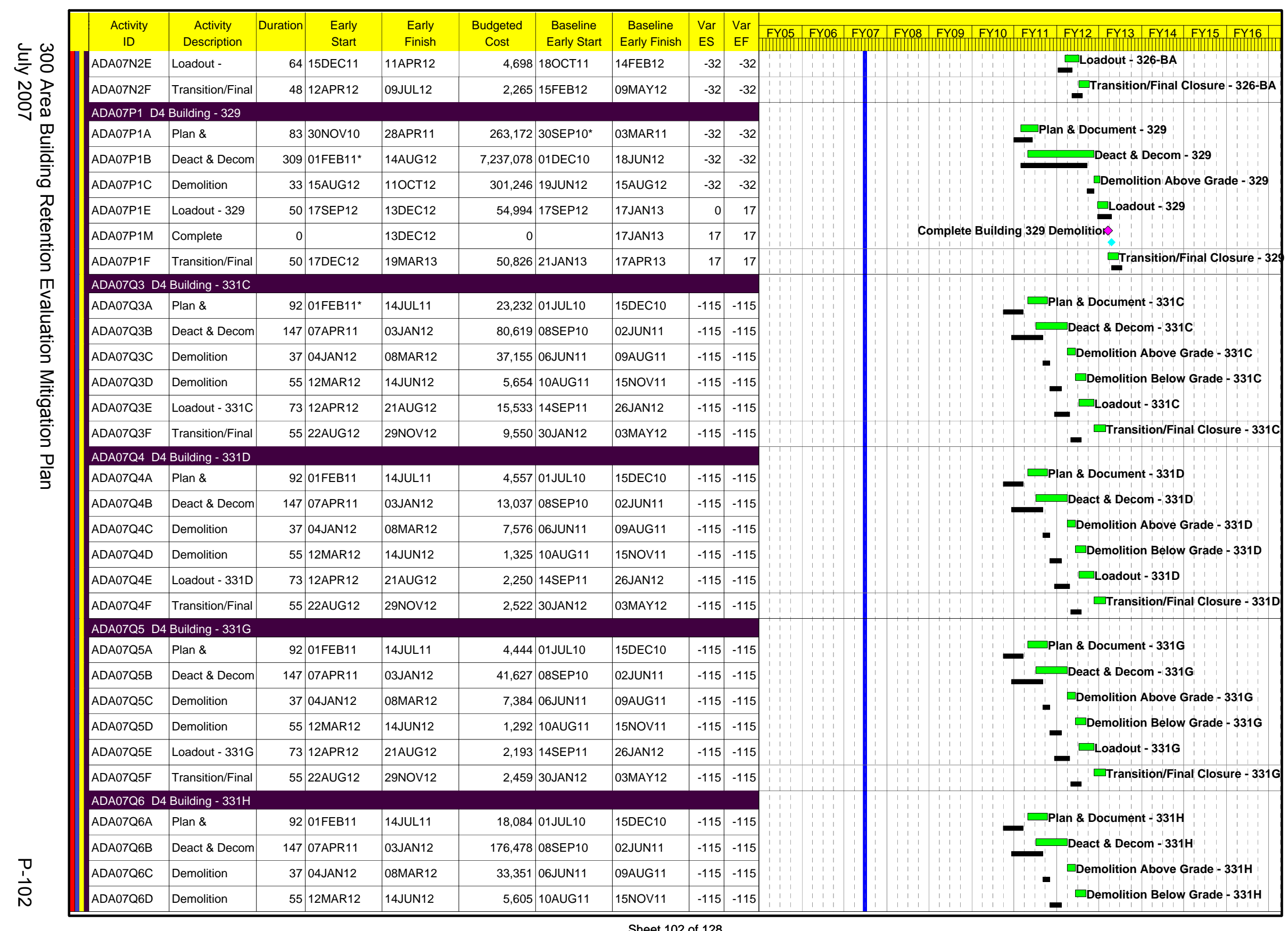




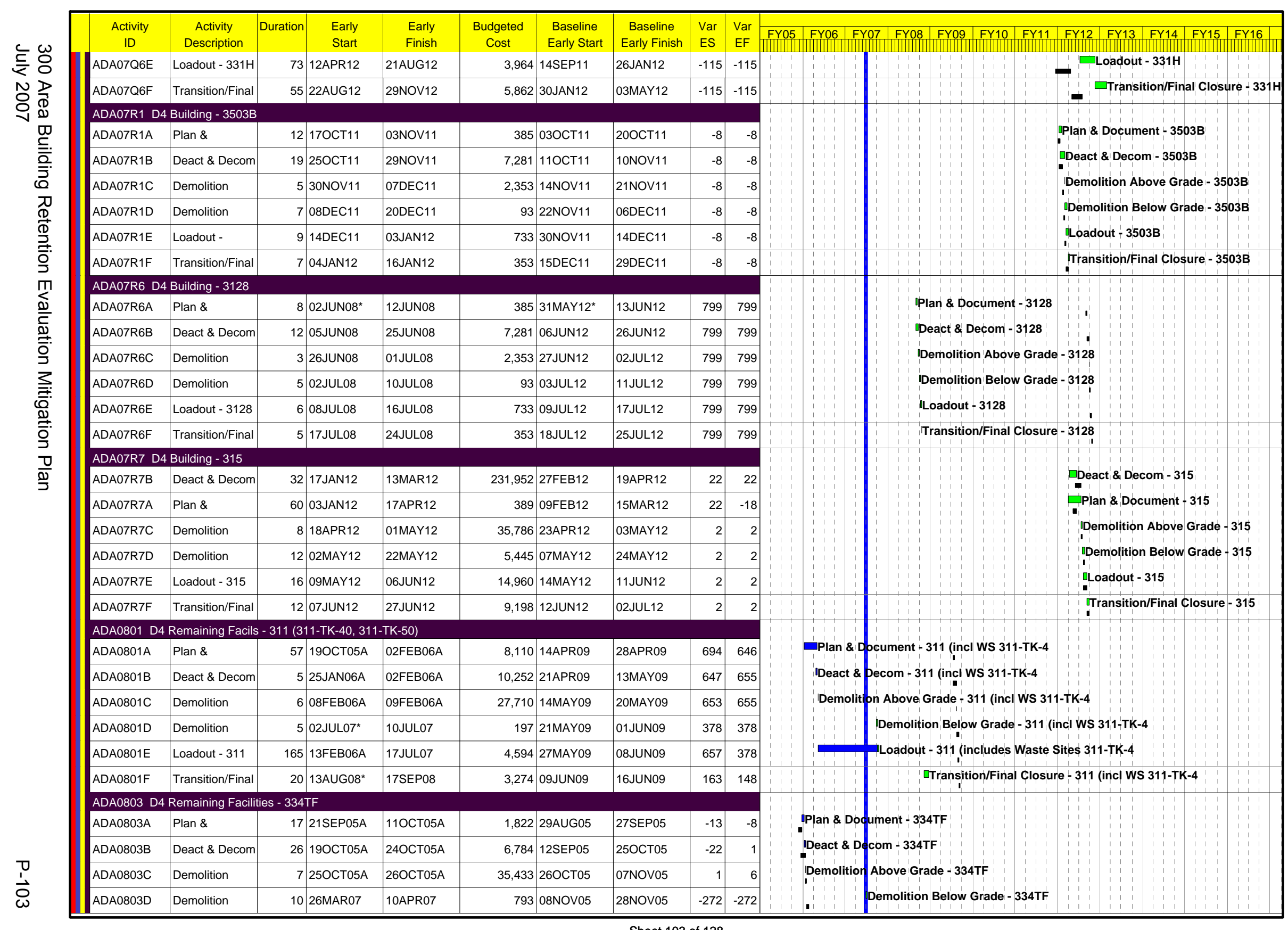




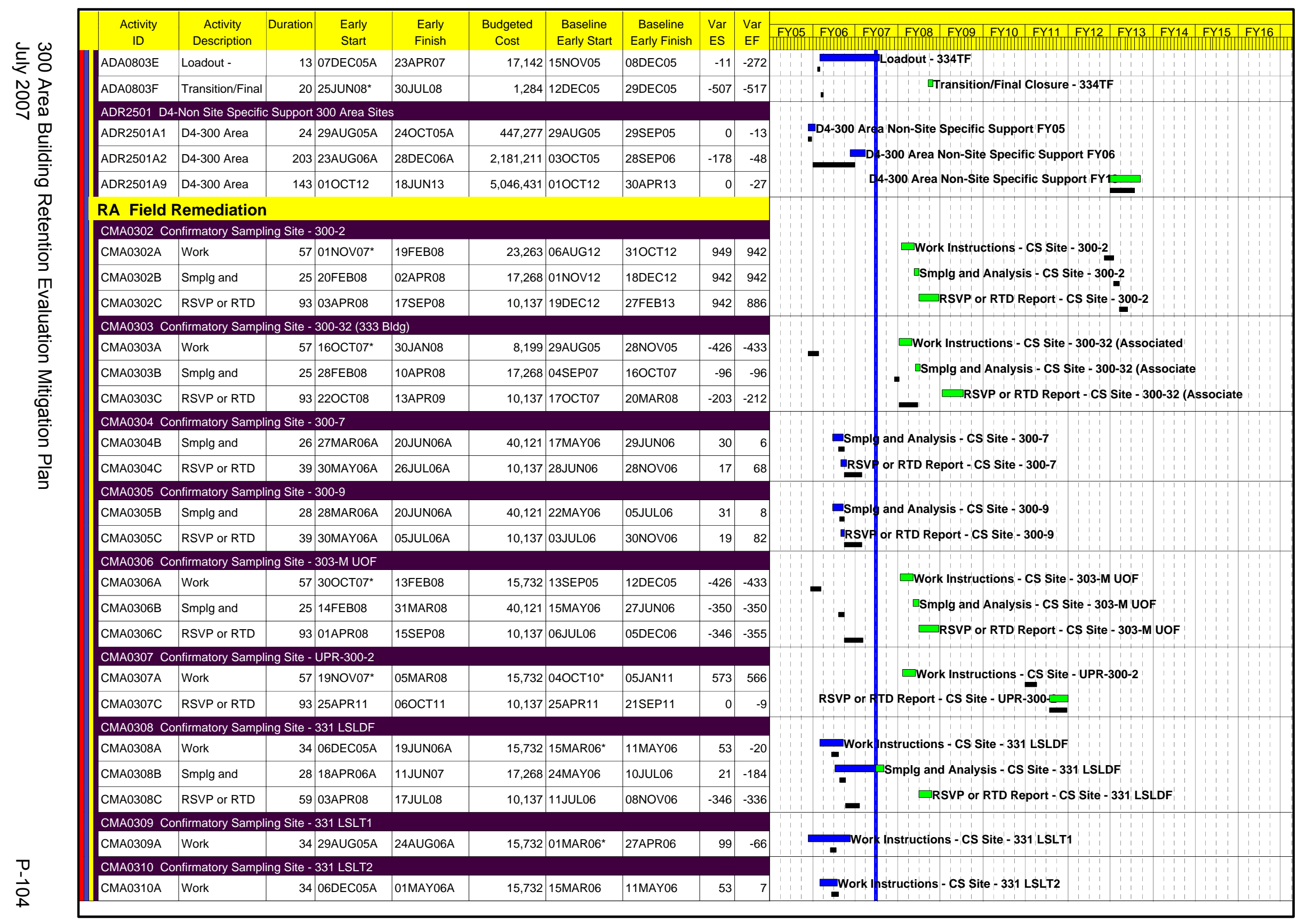




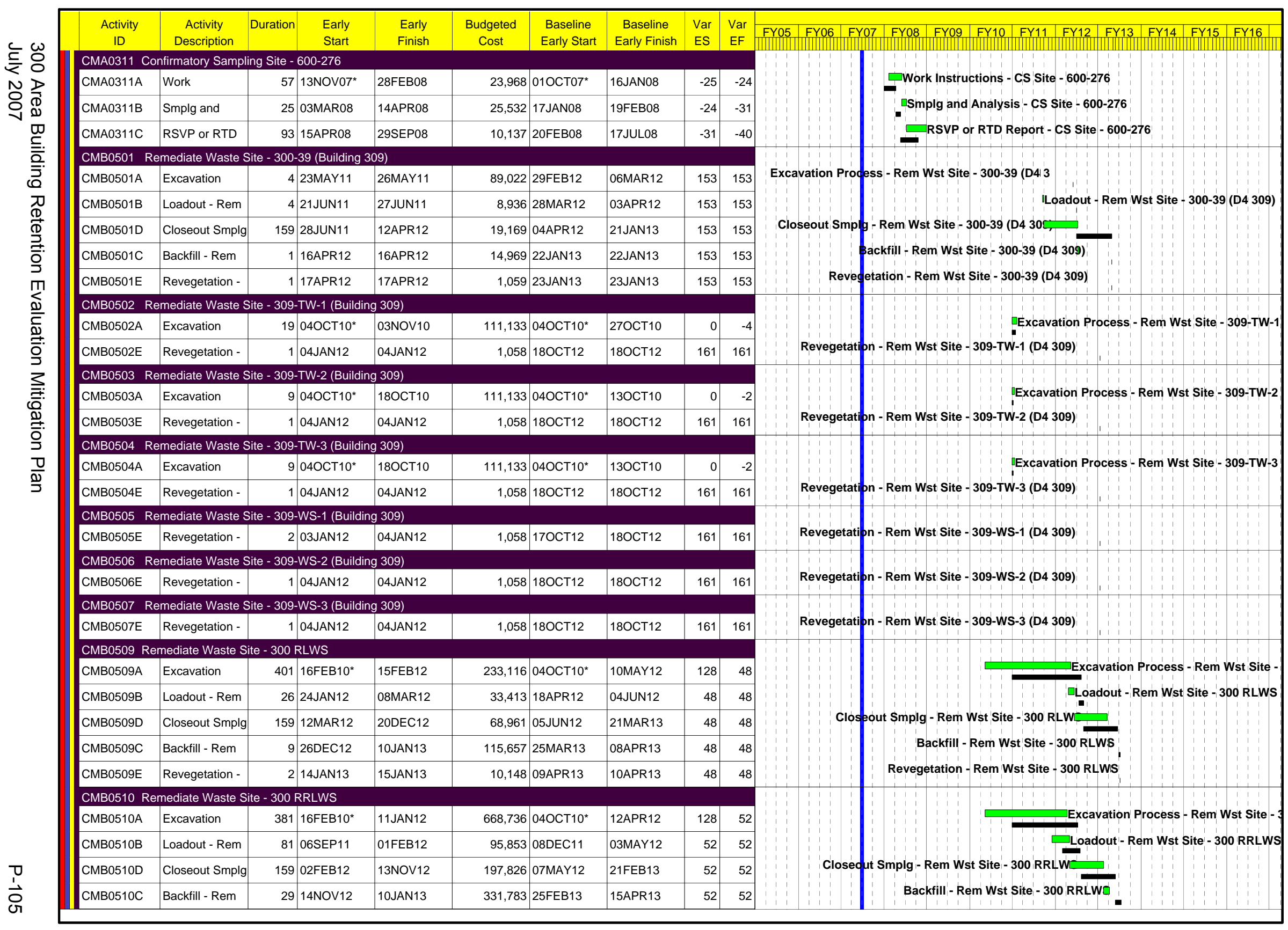




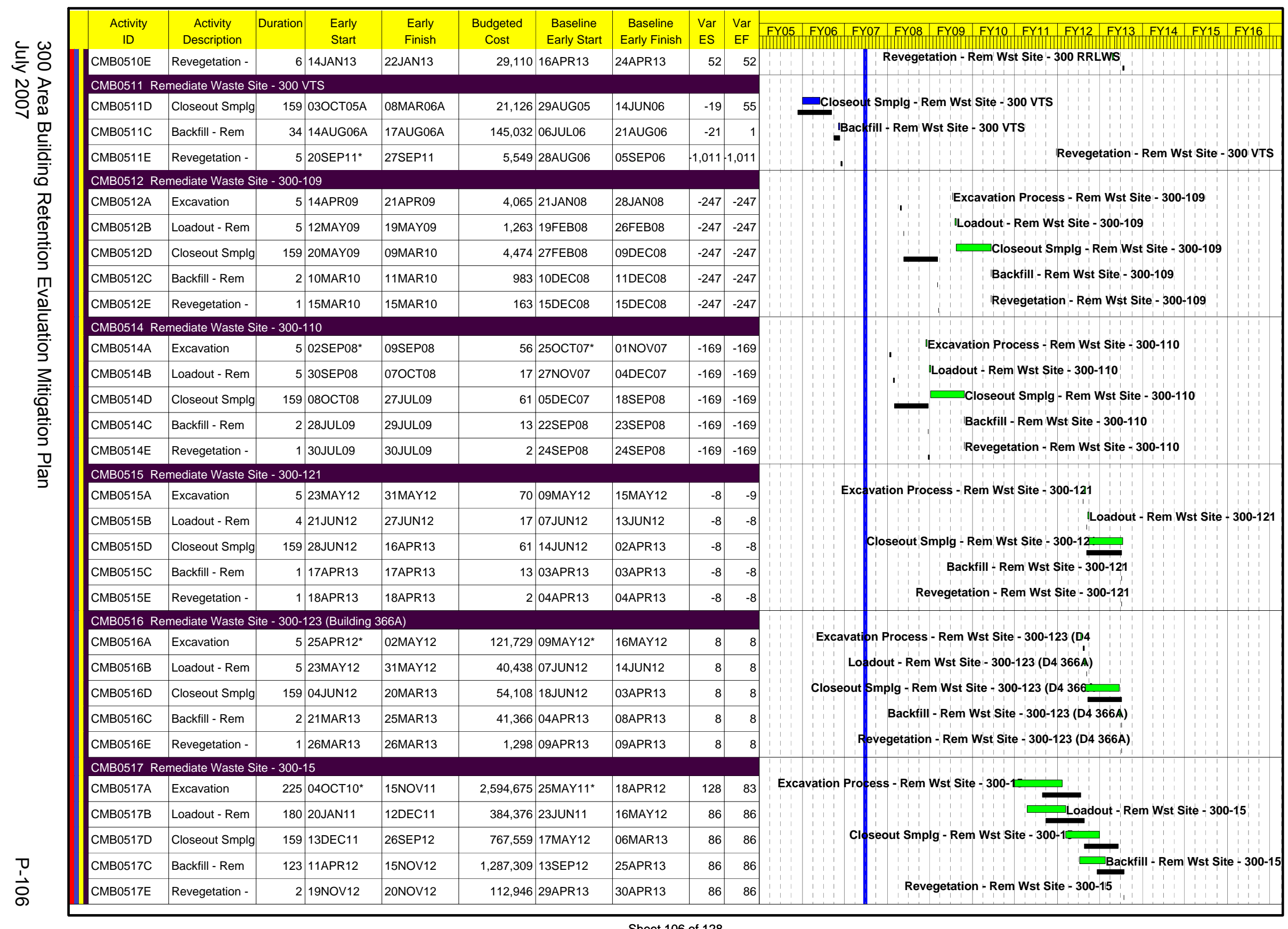




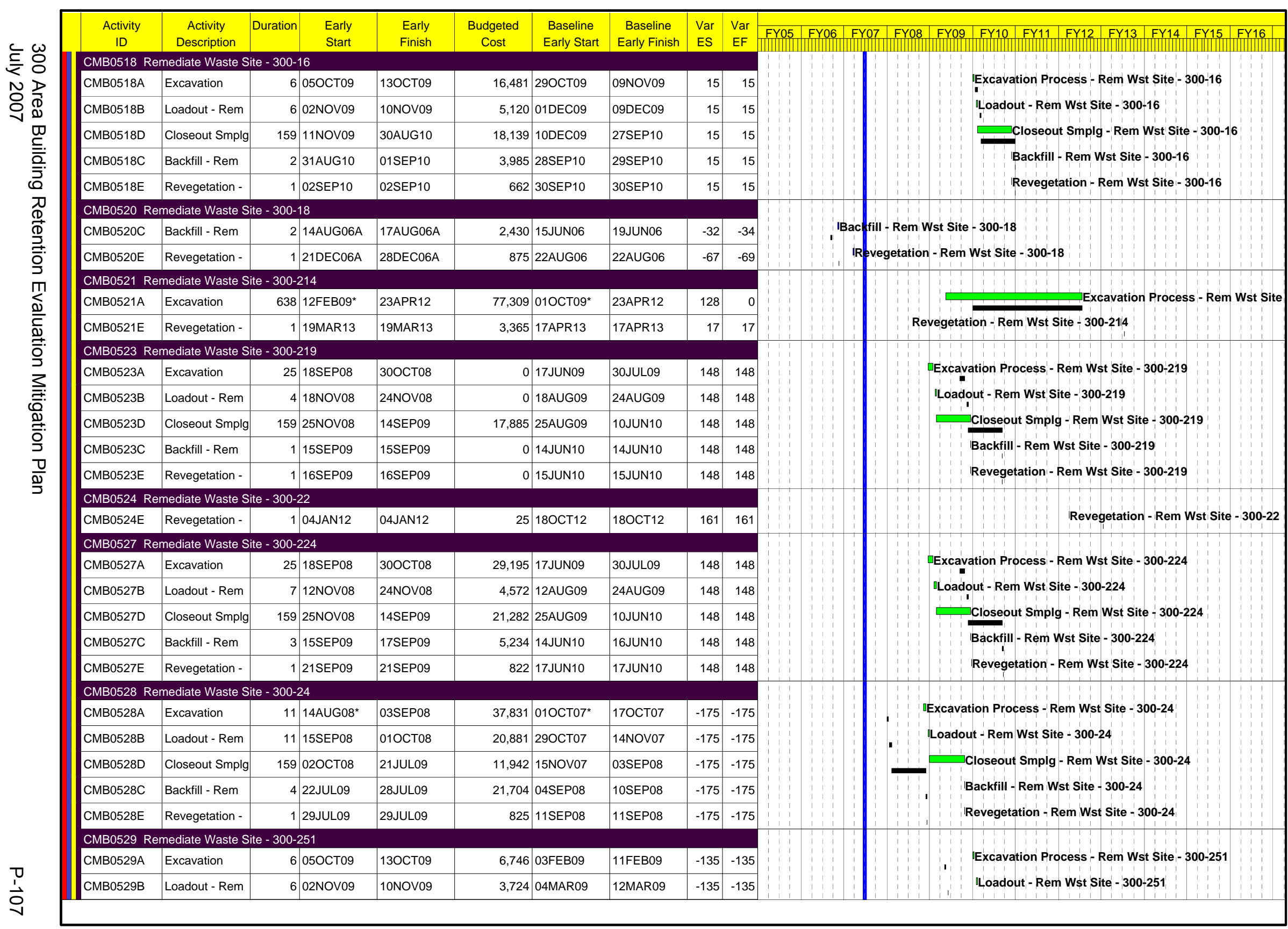




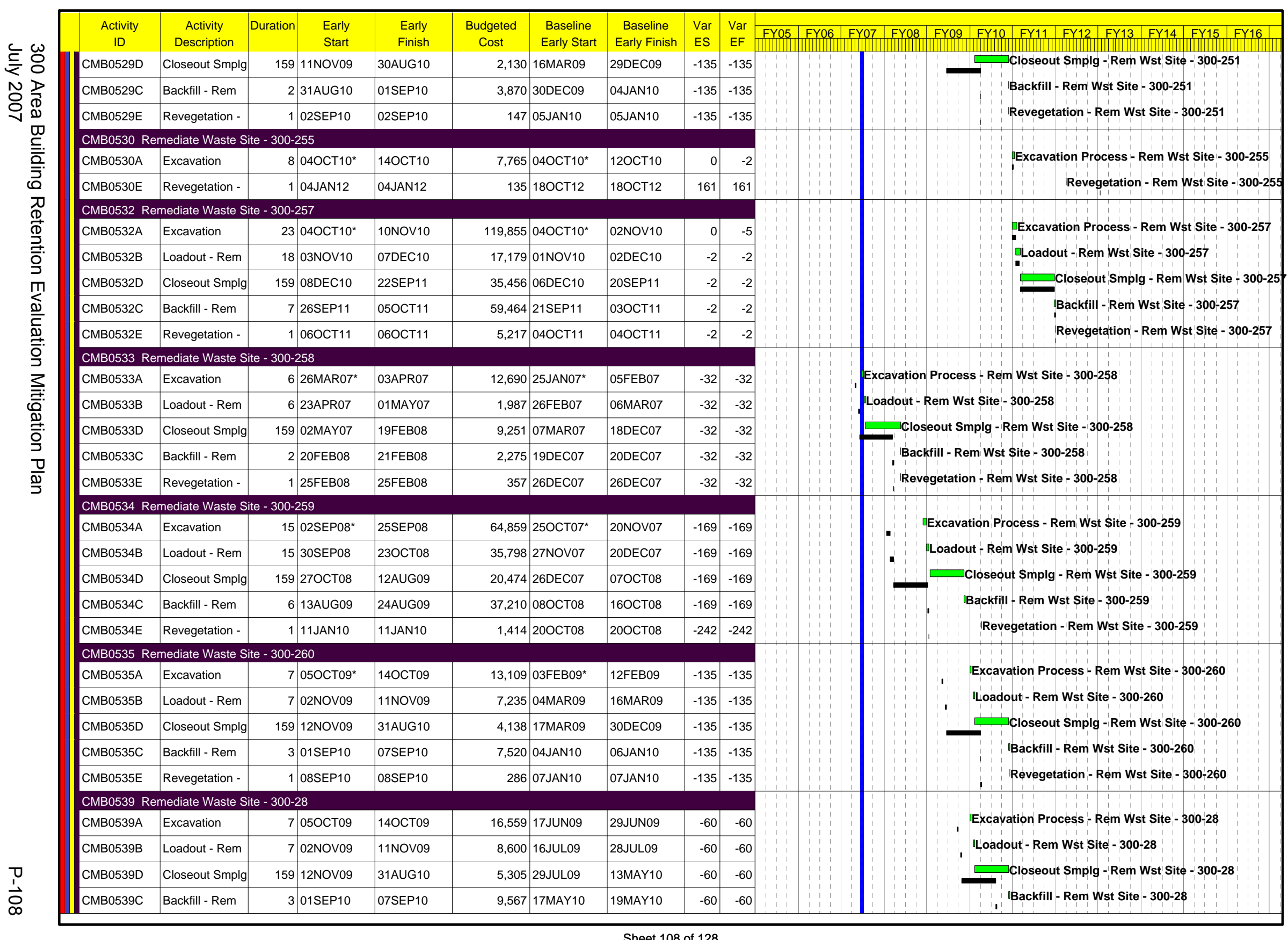




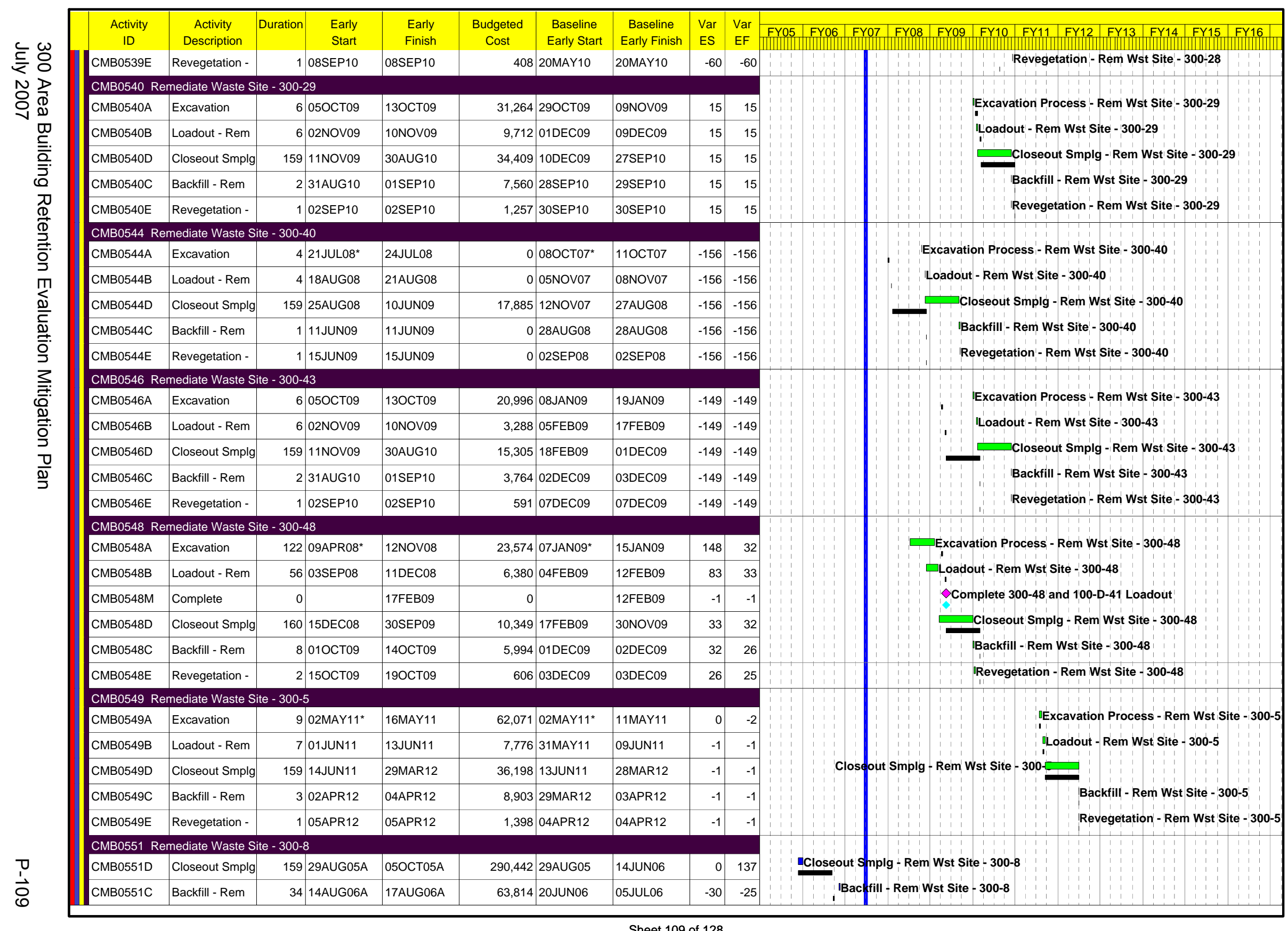




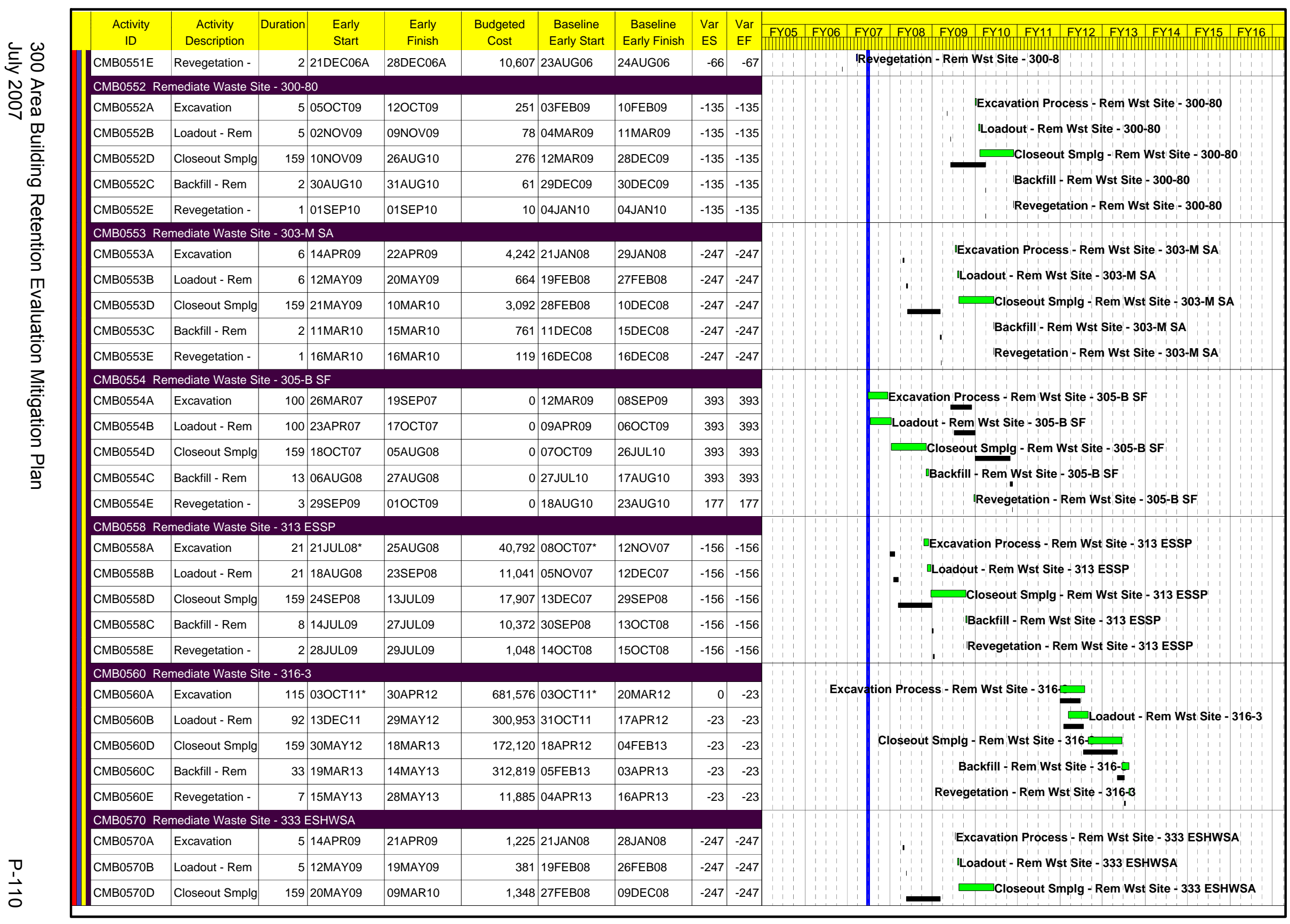




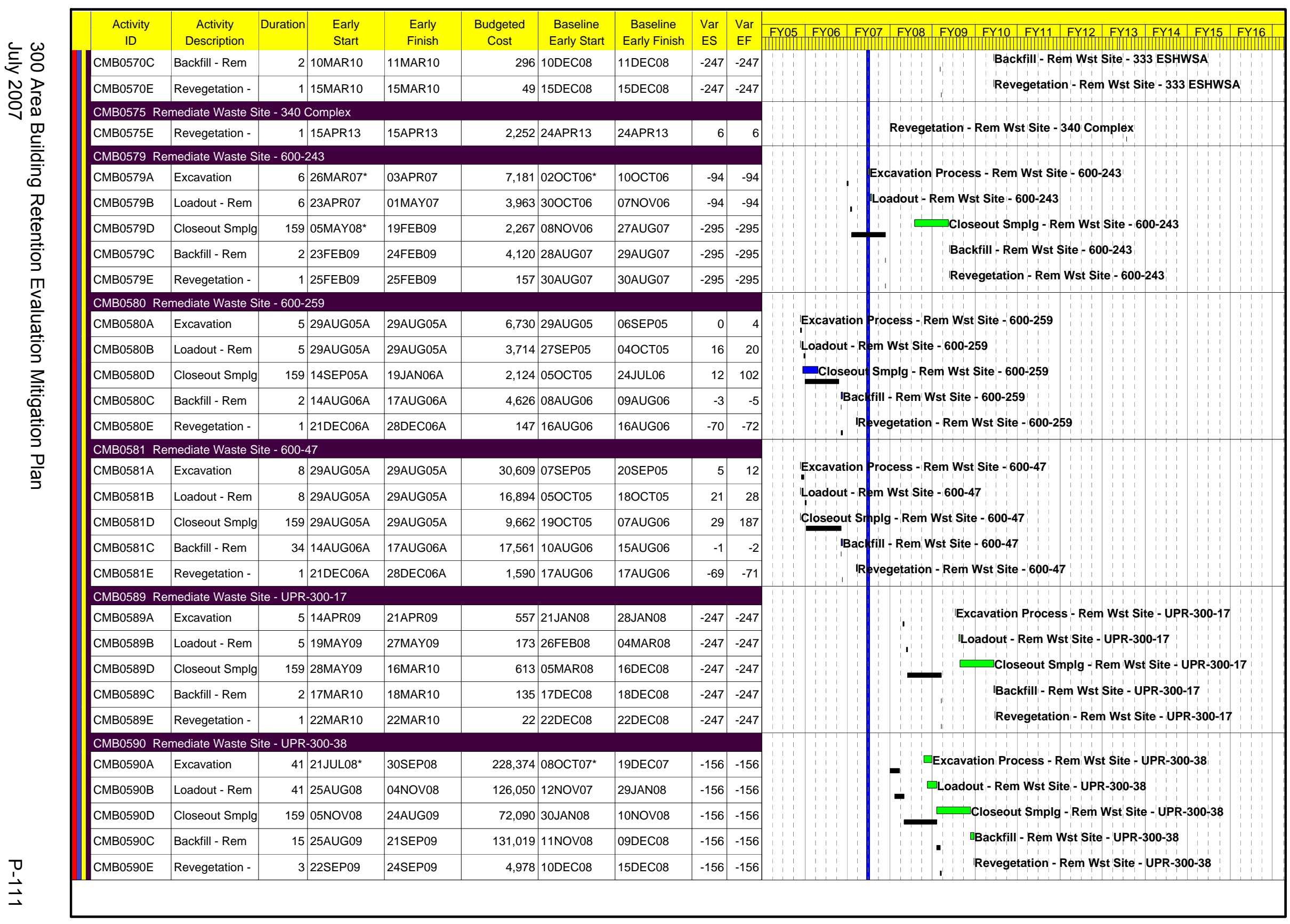




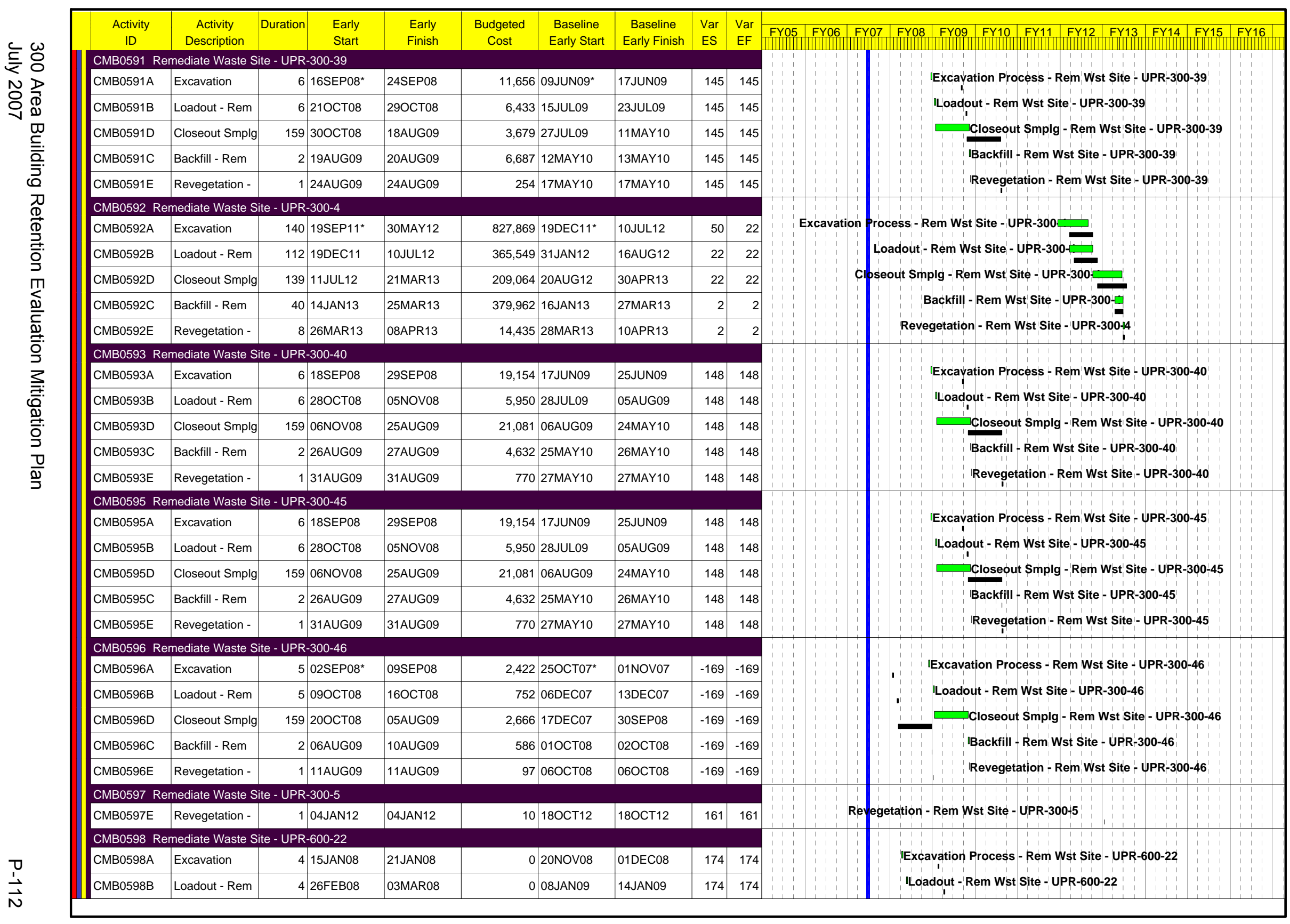




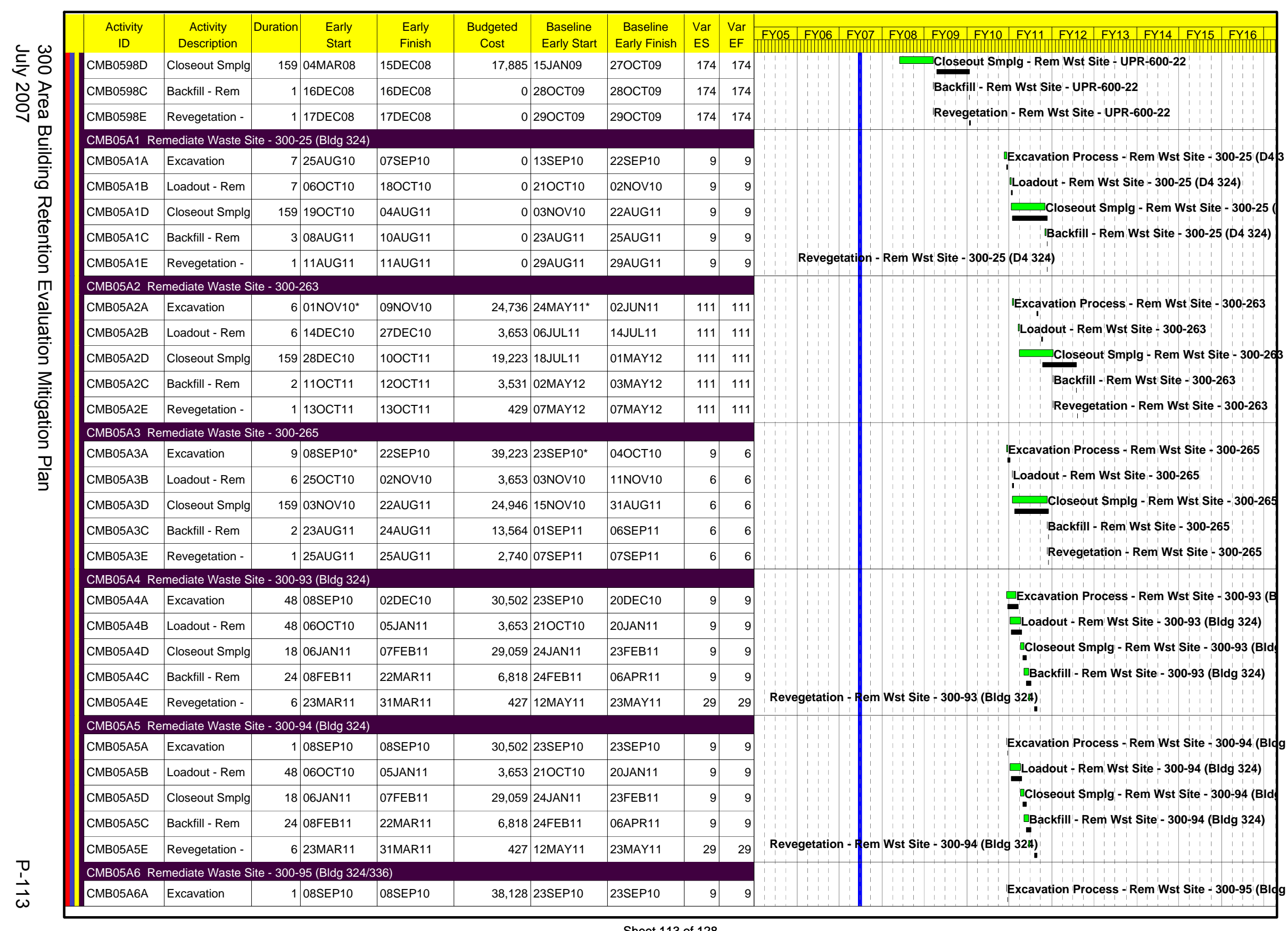




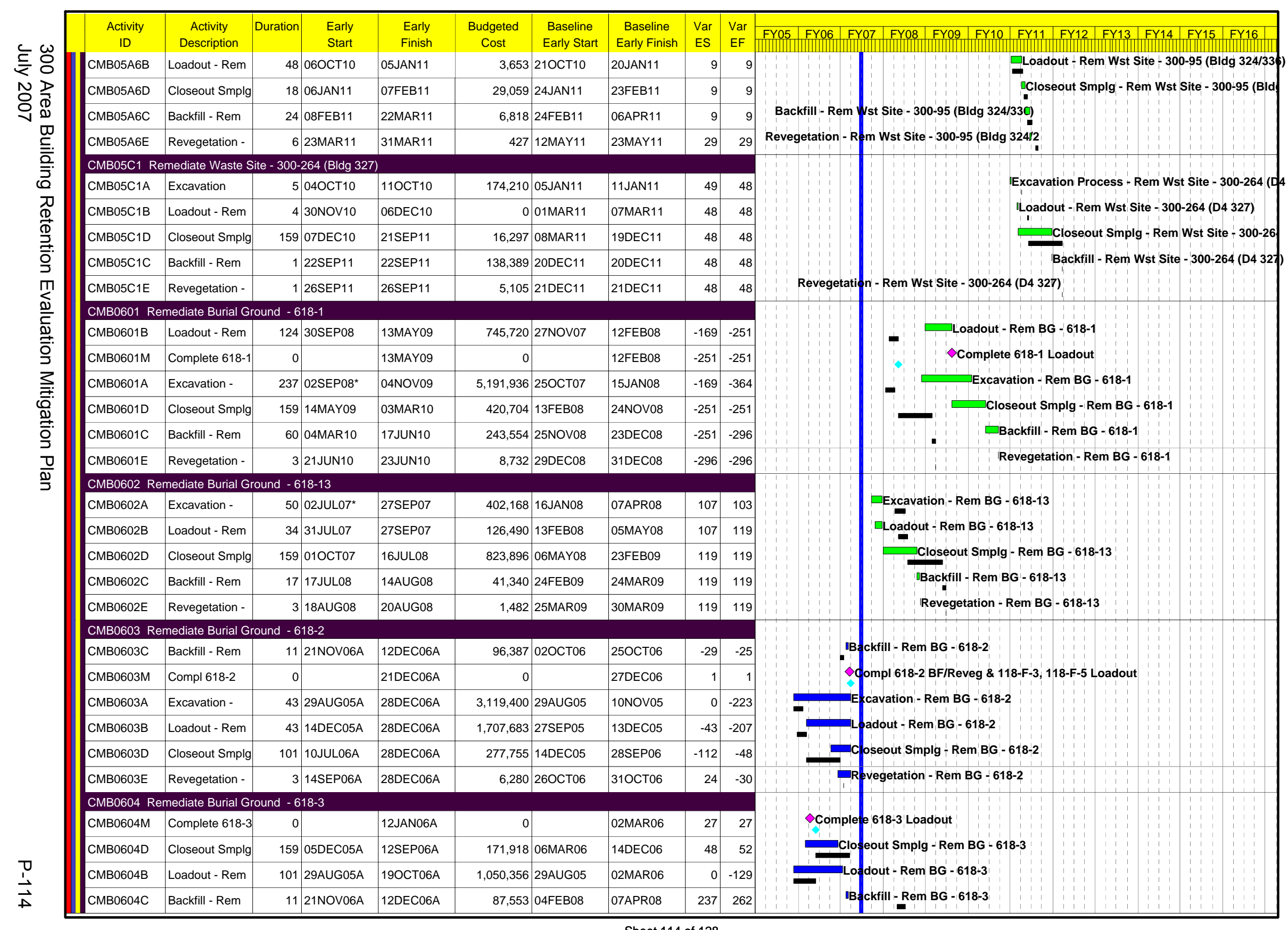




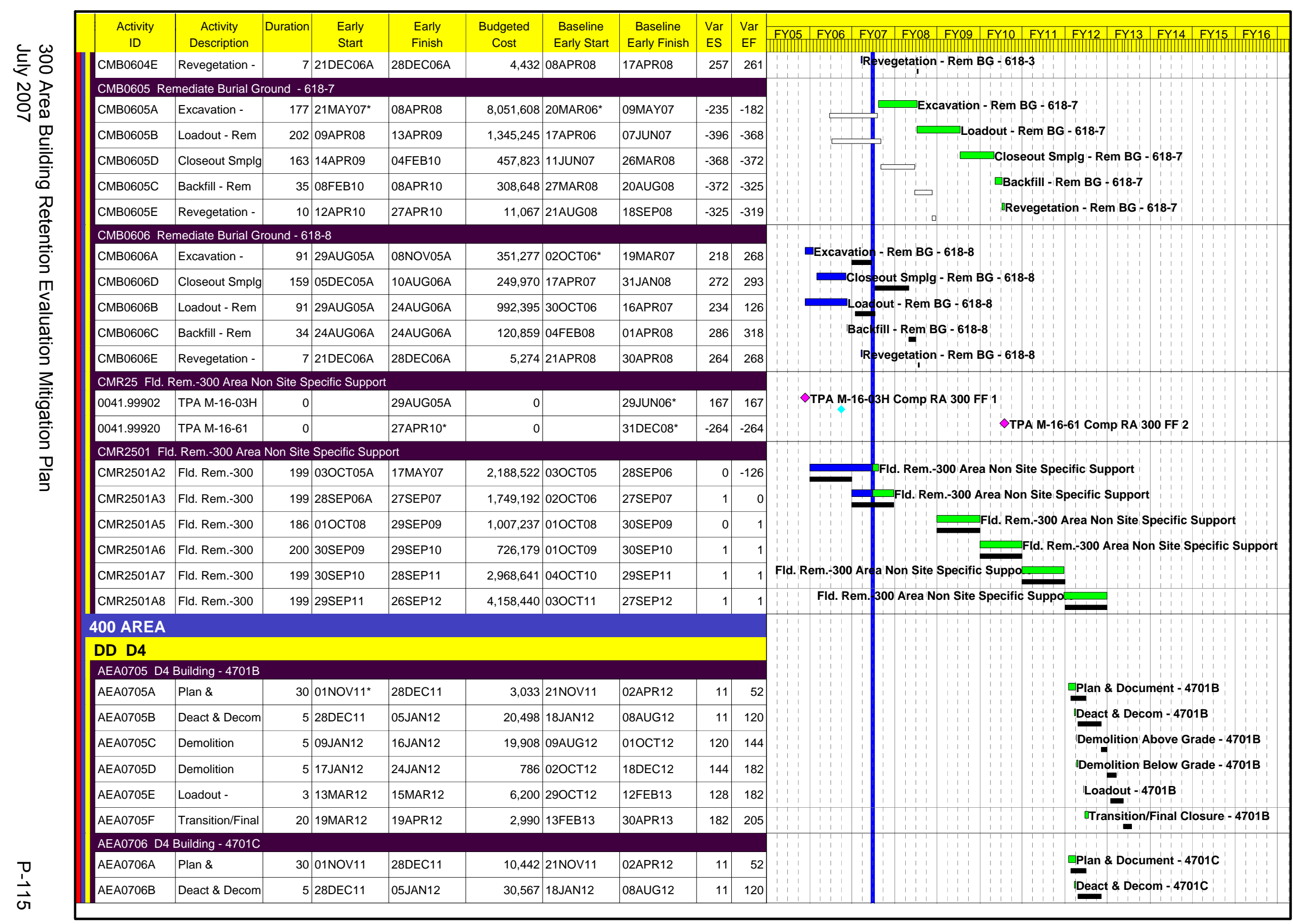




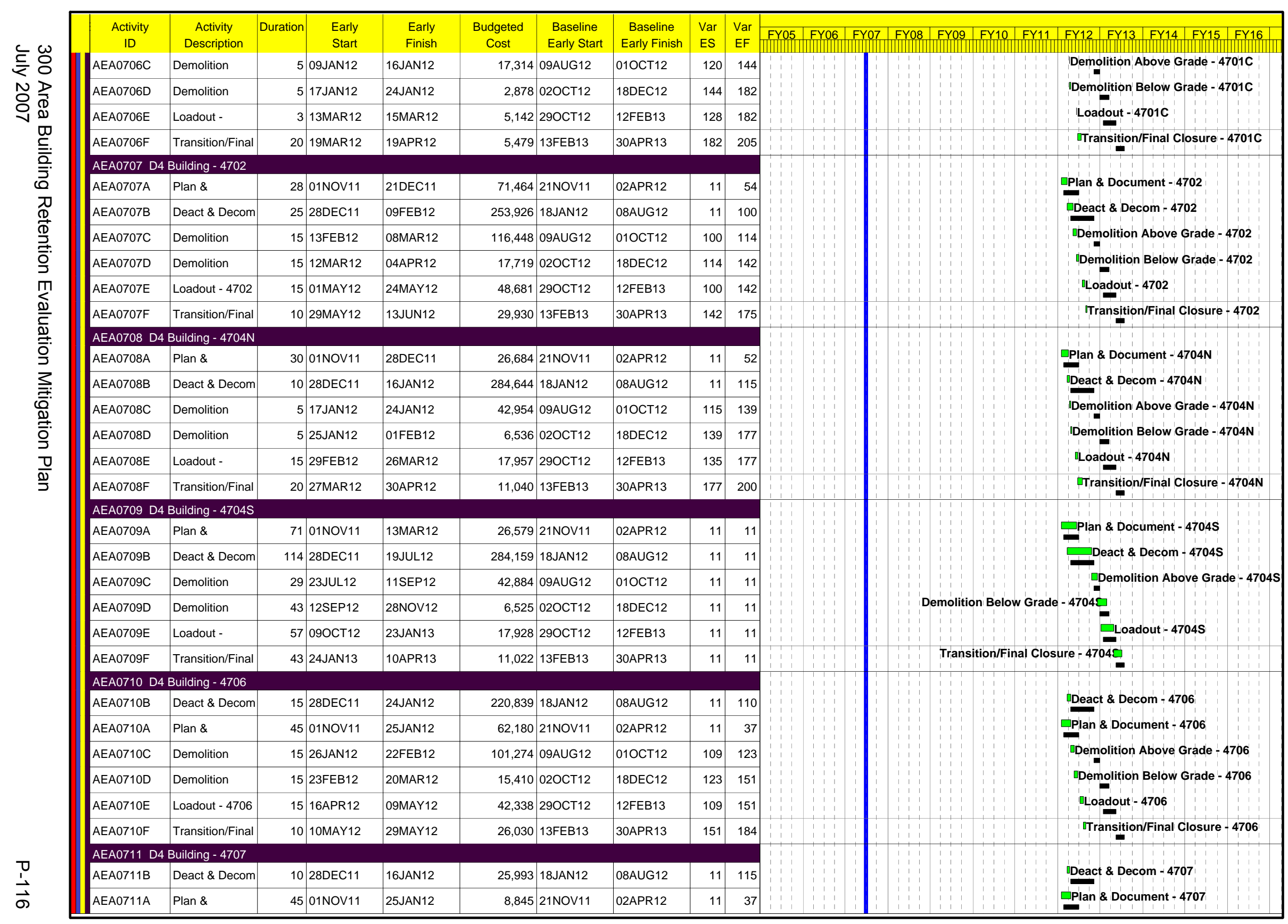




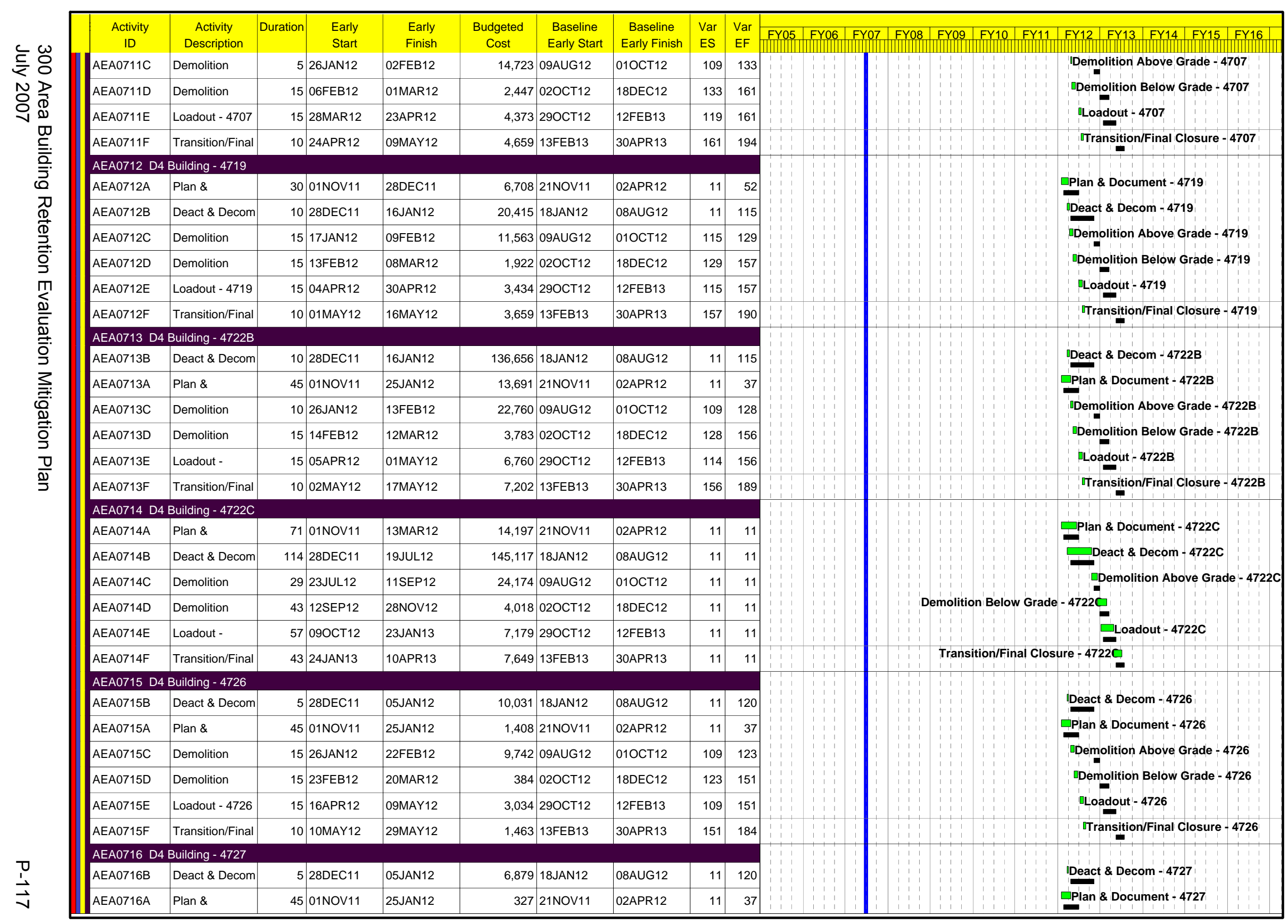




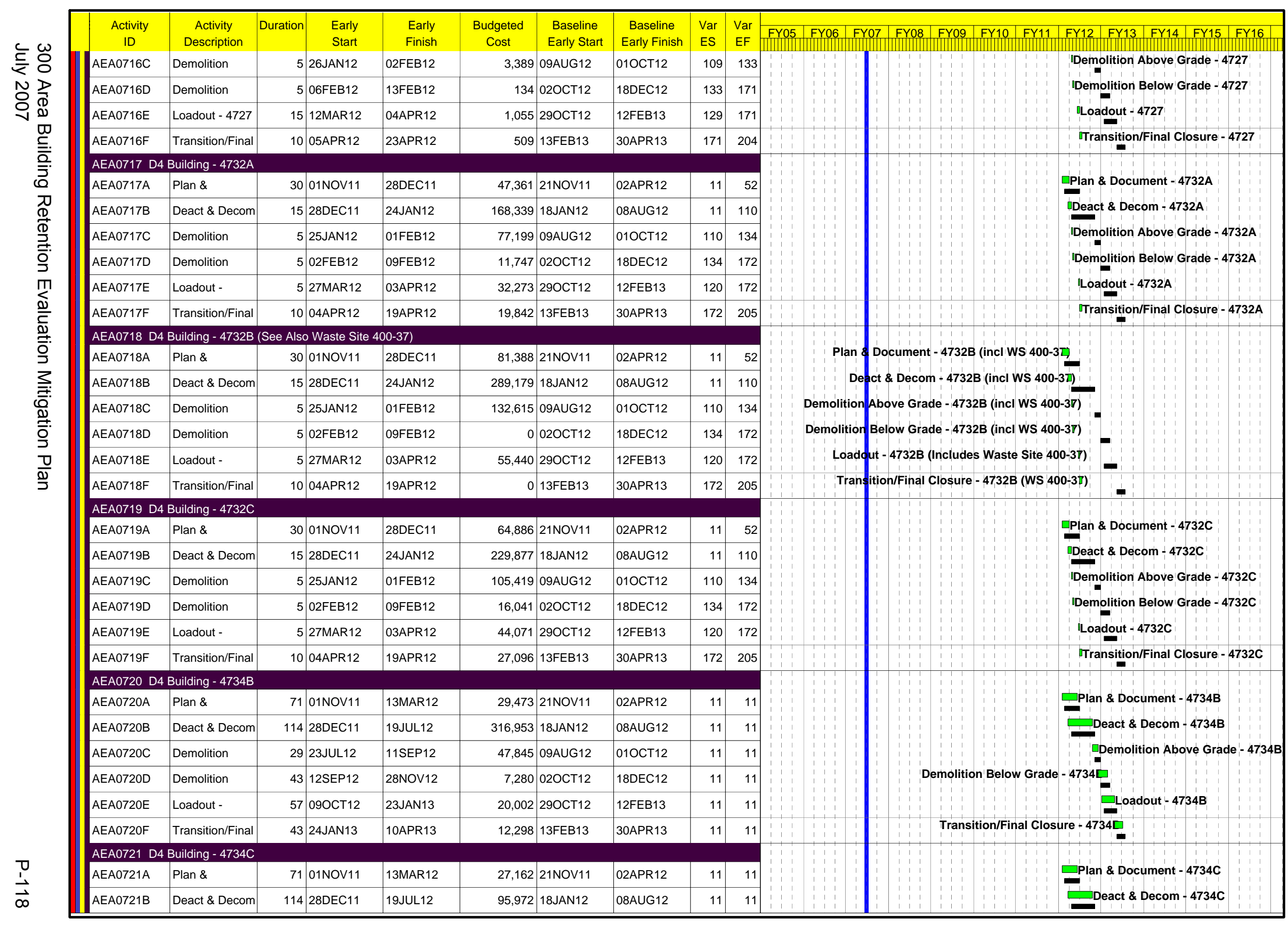




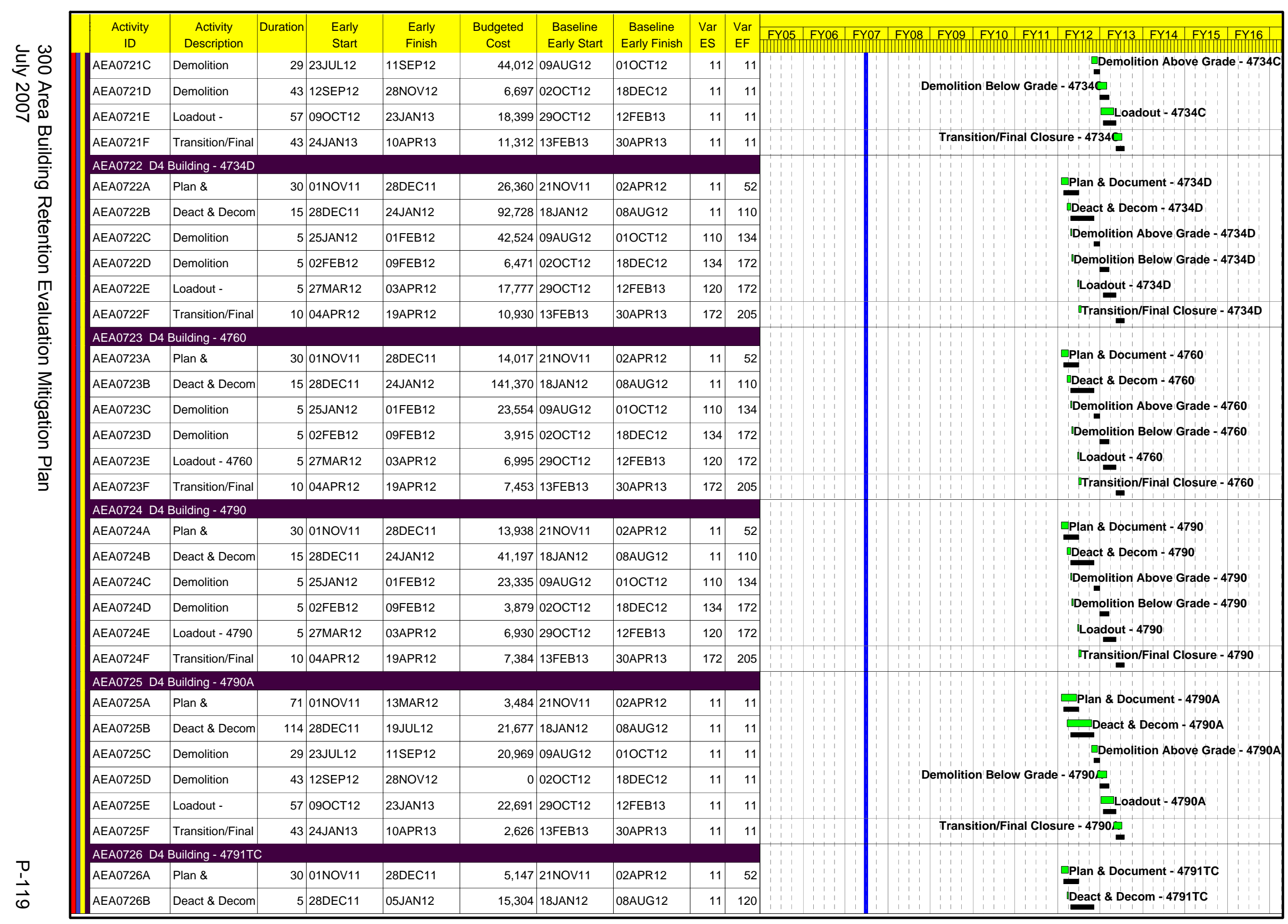




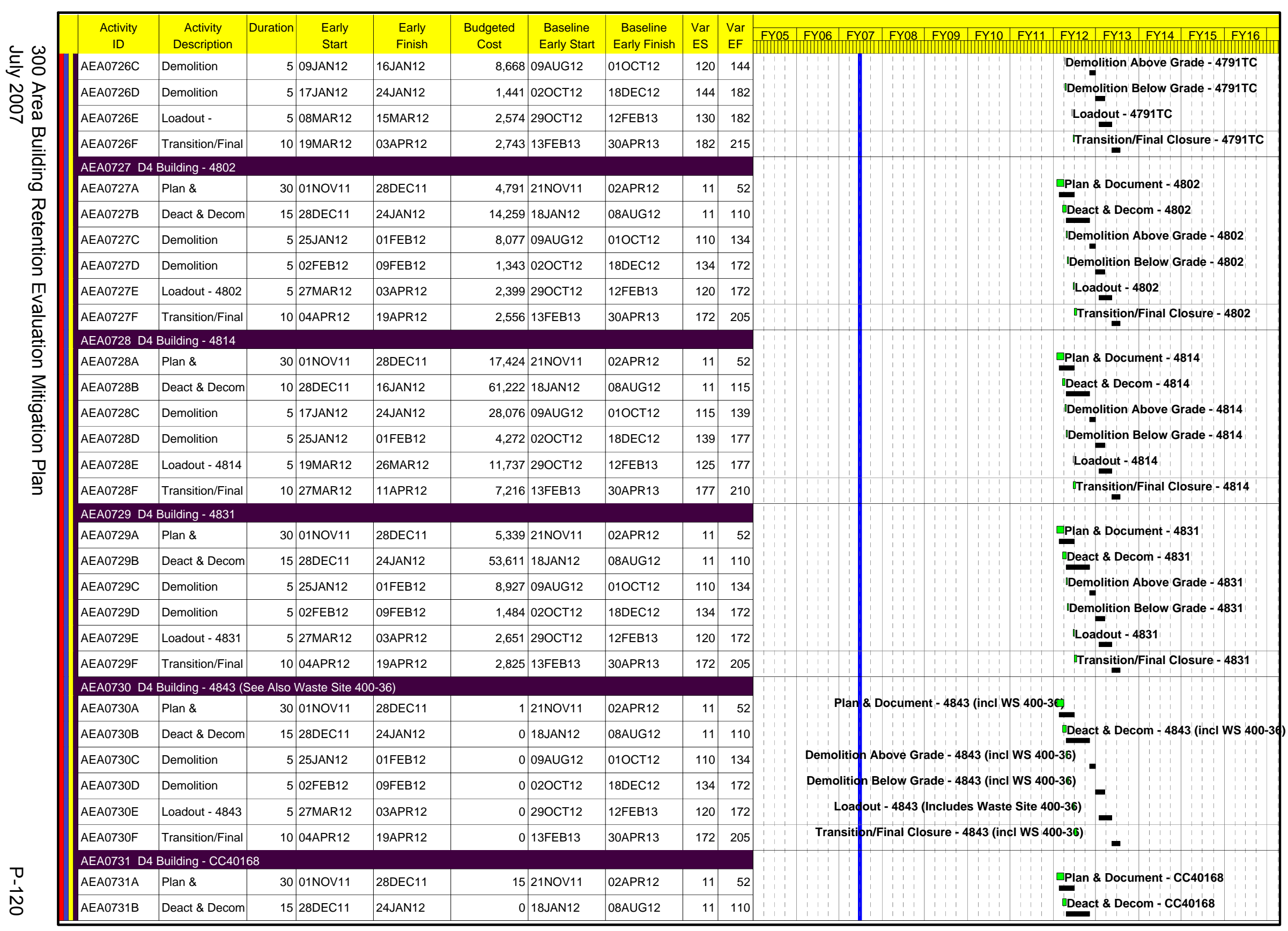




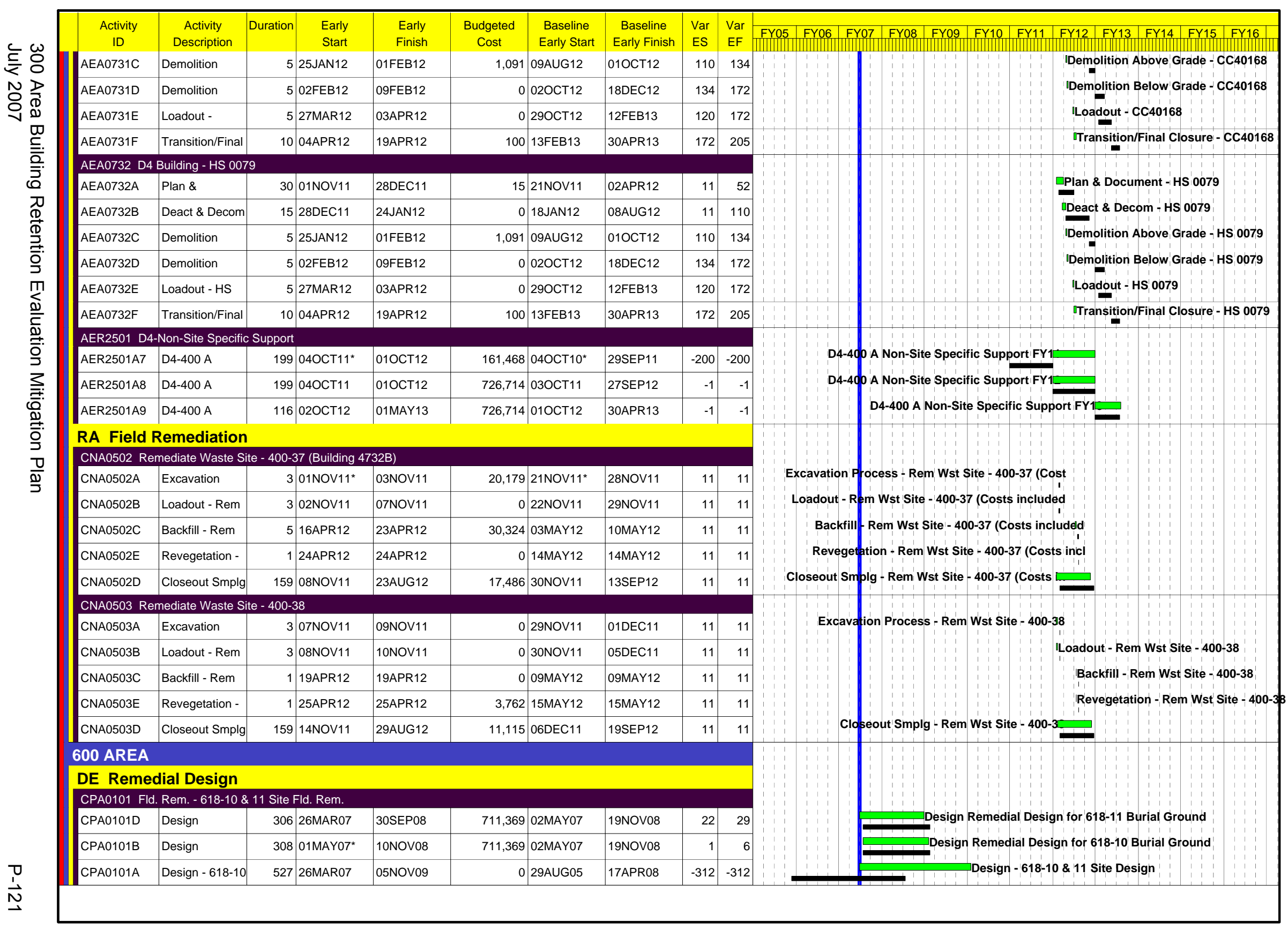




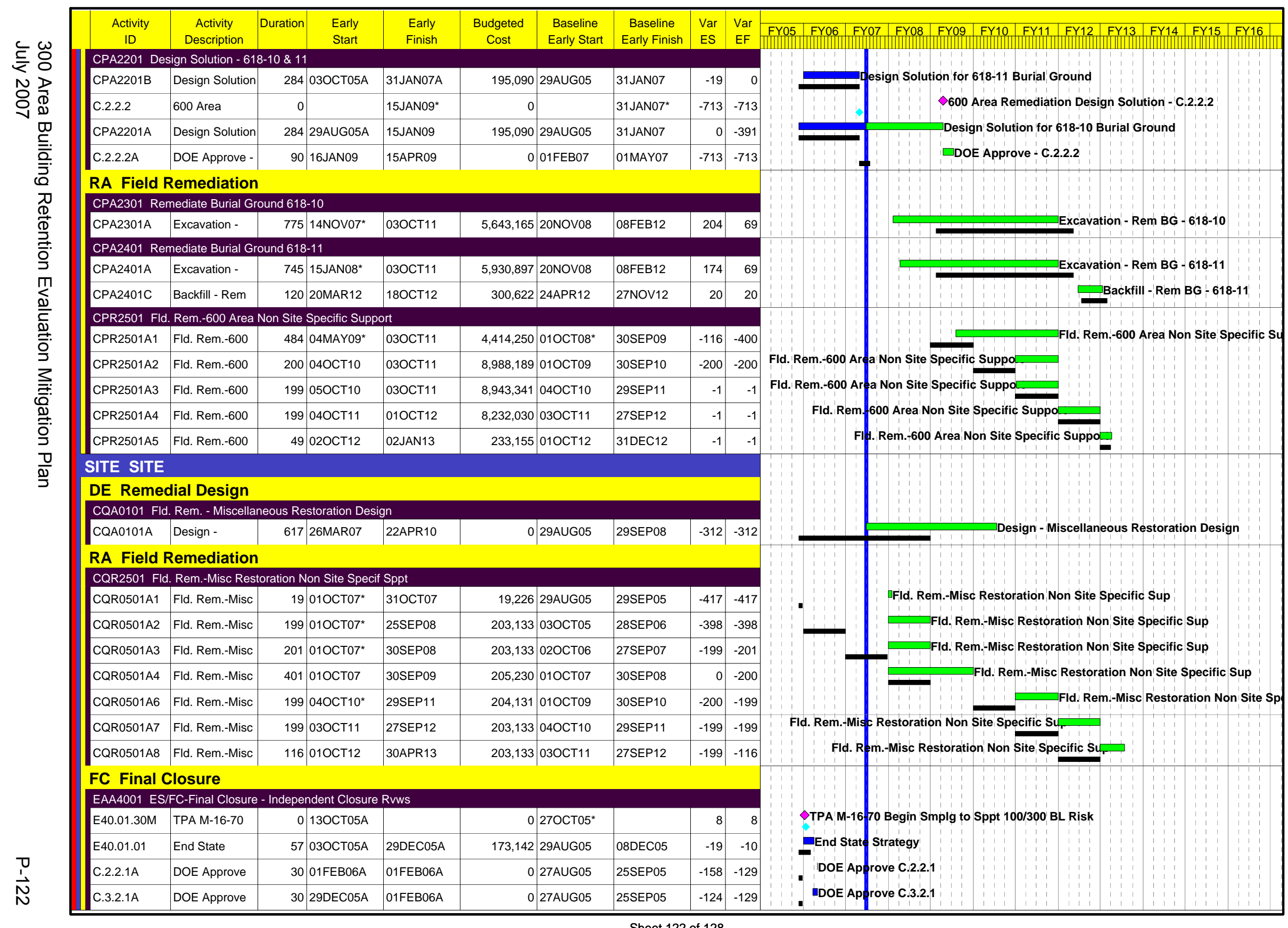




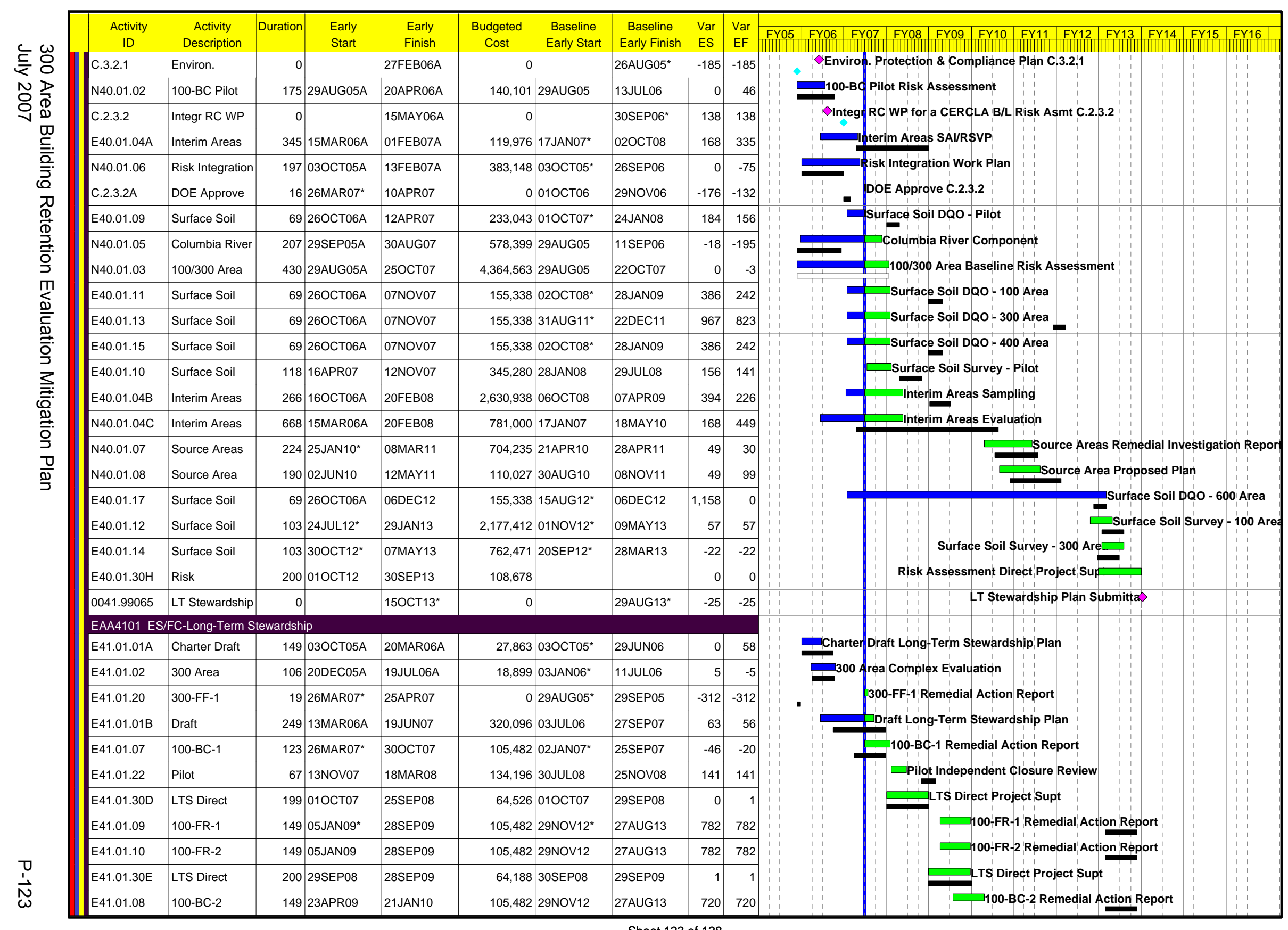




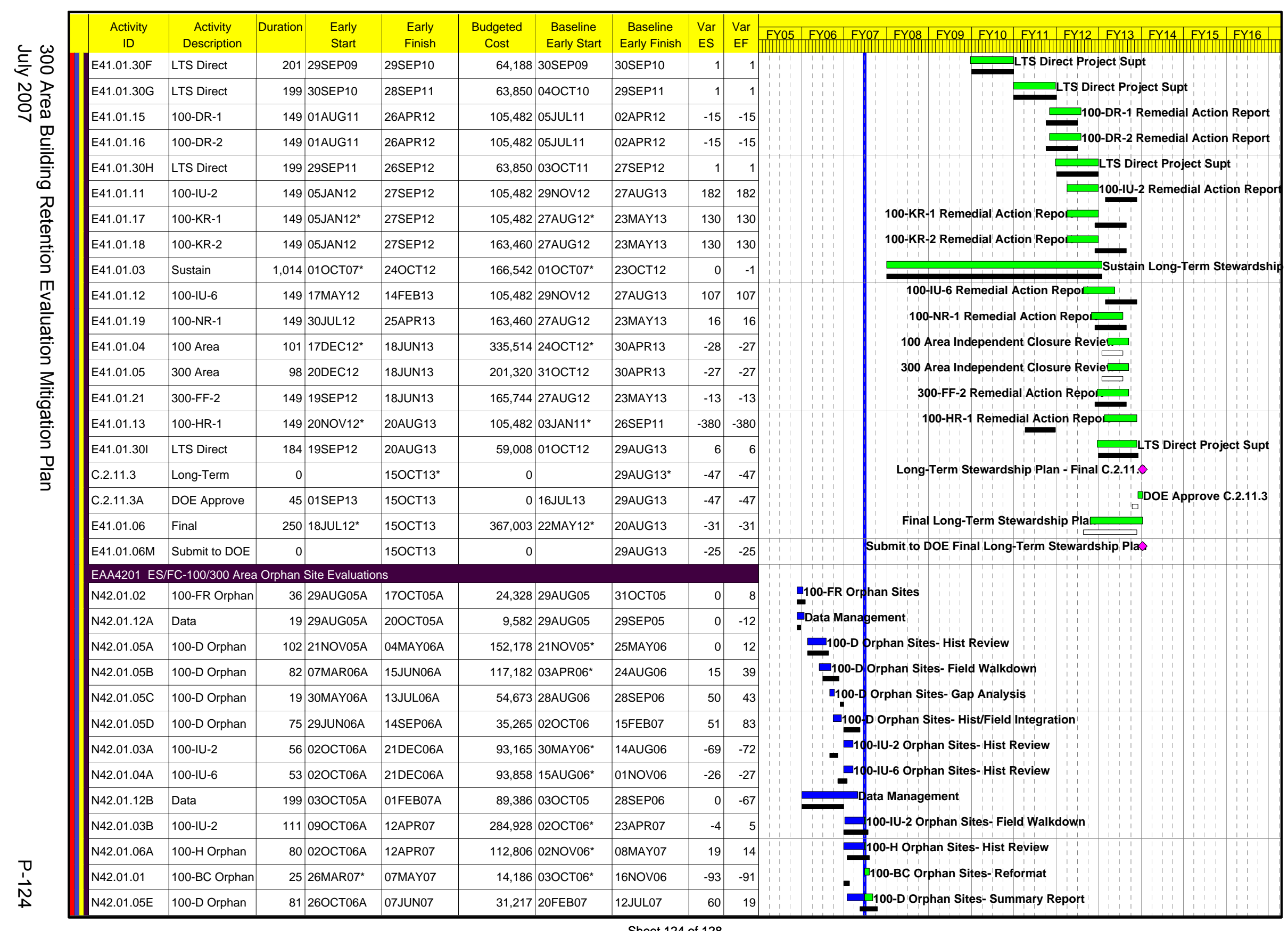




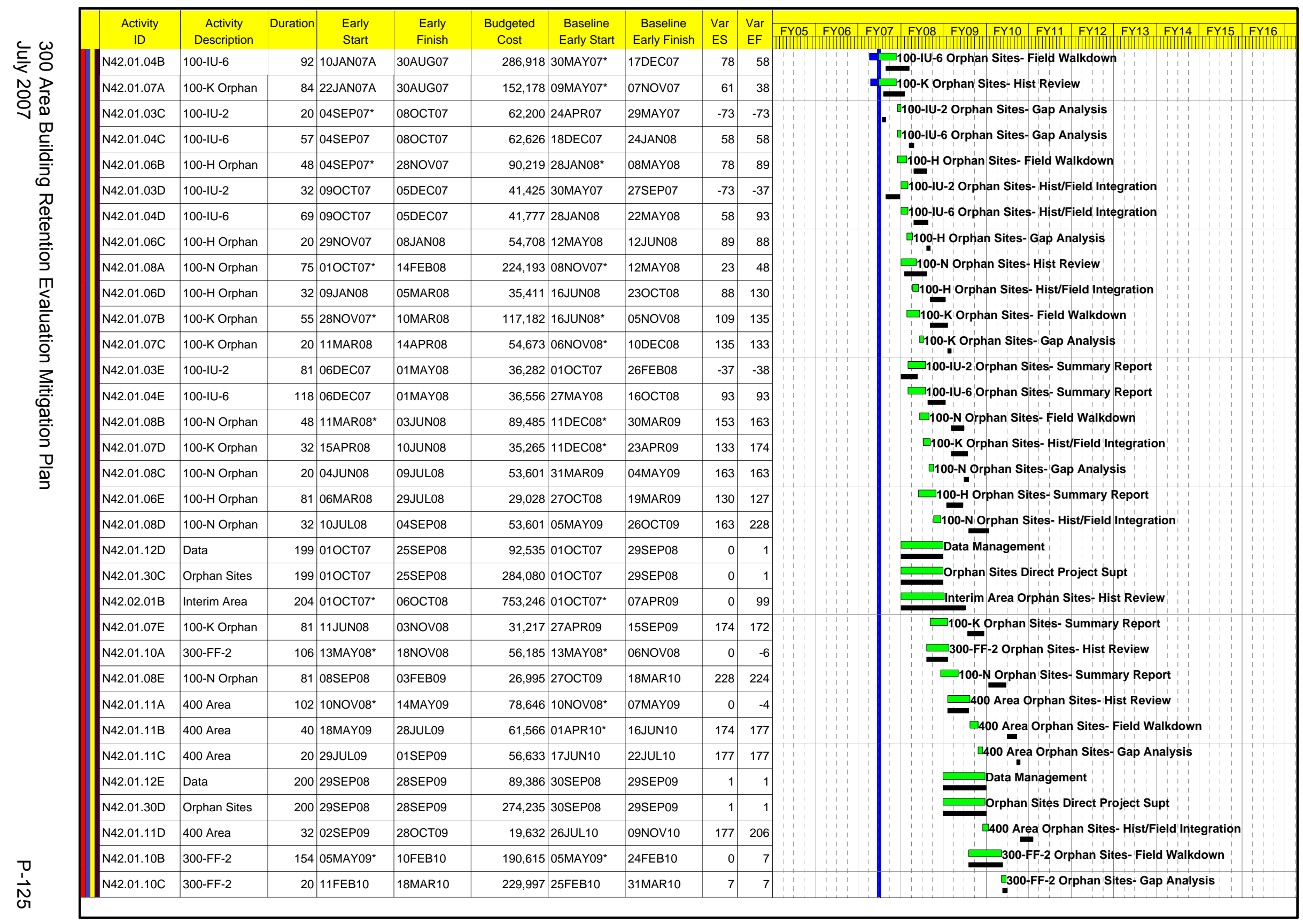




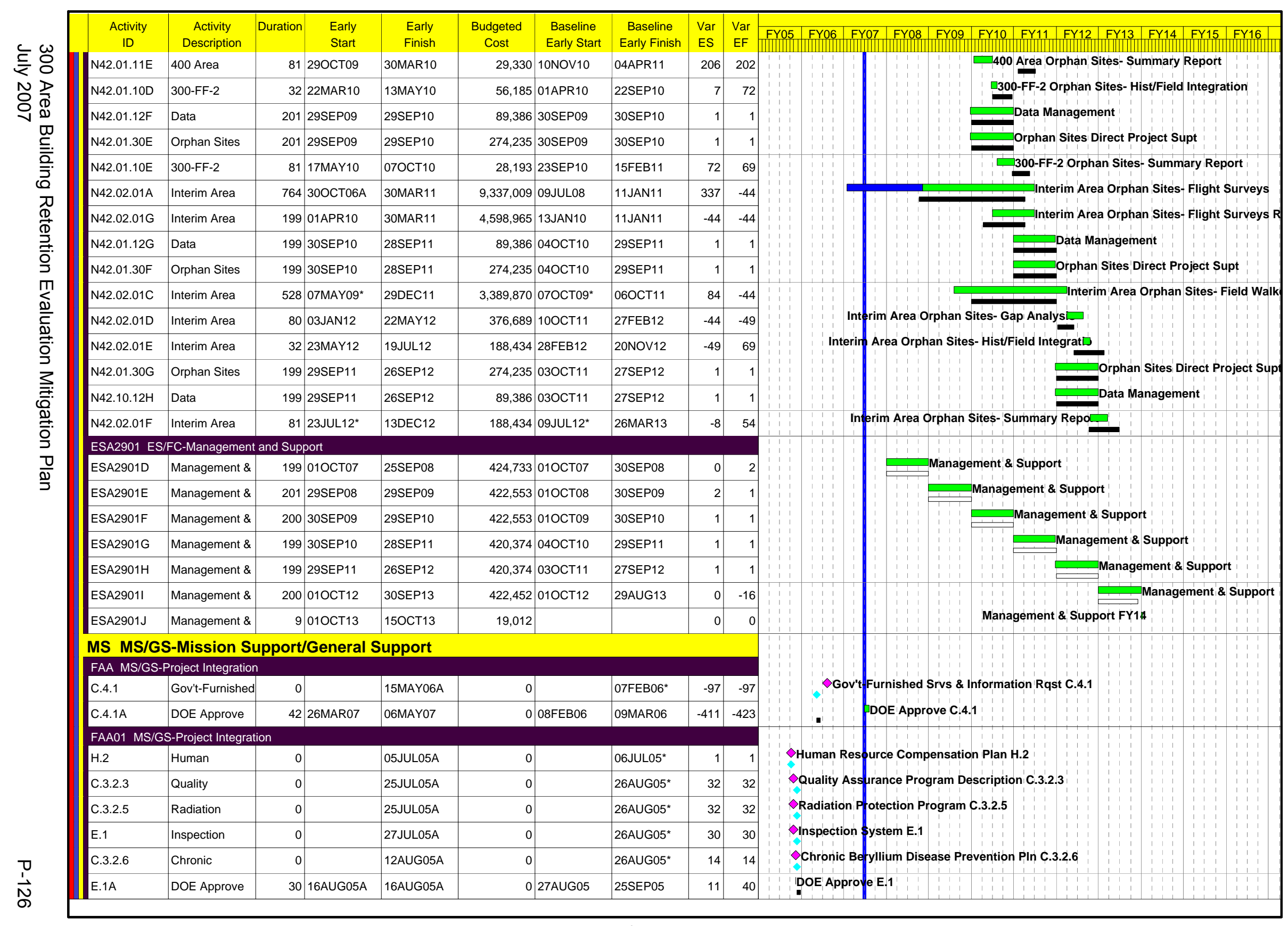




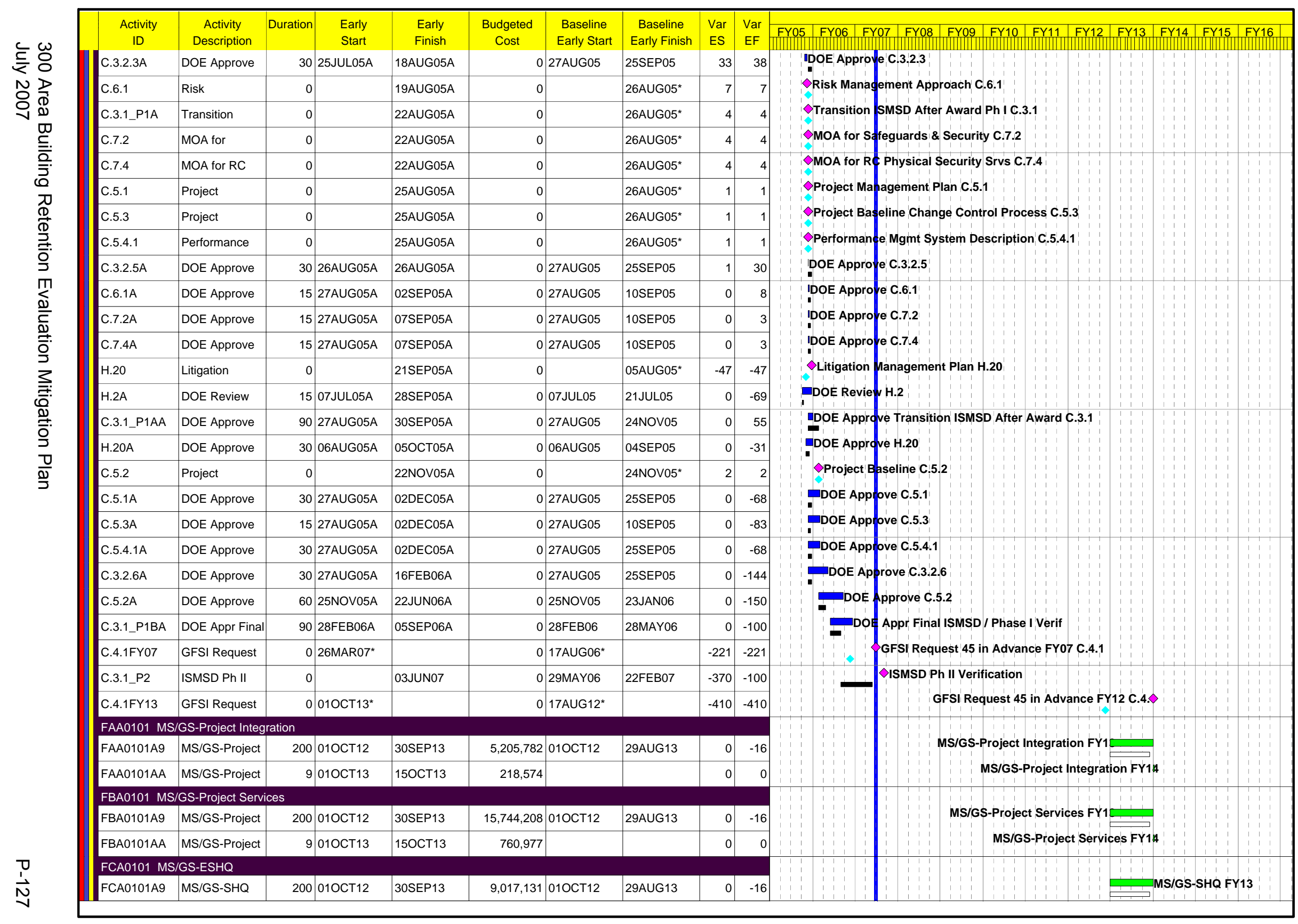




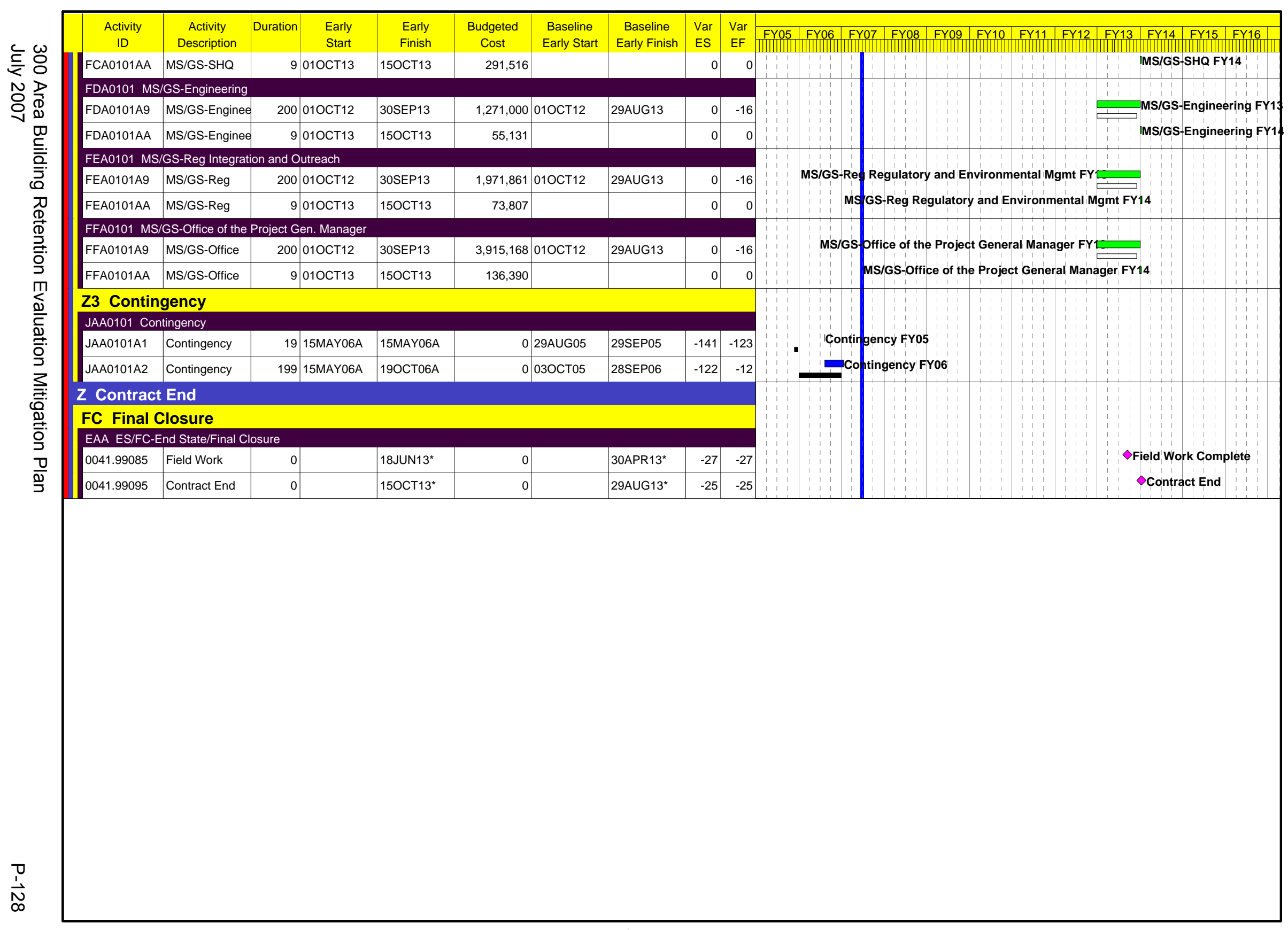




\section{DISTRIBUTION}

U.S. Department of Energy

$\underline{\text { Richland Operations Office }}$

S. L. Charboneau A3-04

J. R. Franco A3-04

R. F. Guercia A3-04

Washington Closure Hanford

M. N. Brosee H4-24

B. C. Covert T2-03

S. E. Dieterle L1-04

R. L. Donahoe X4-08

M. B. Fox H4-24

G. L. Irwin H4-15

W. F. Johnson H4-22

K. L. Kehler L1-04

D. J. McBride (8) H4-15

W. S. Shingler H4-15

C. G. Spencer H4-24

Document Control H4-11

DOE-RL Public Reading Room H2-53

Hanford Technical Library $\quad$ P8-55 
WCH-181

Rev. 0 